PROGRAMA DE DOCTORADO EN PATRIMONIO CULTURAL Y NATURAL. HISTORIA, ARTE Y TERRITORIO

TESIS DOCTORAL:

\title{
REPRESENTACIONES DE MASCULINIDAD Y ASOCIACIONISMO. EL RETRATO DE ARTISTA EN LA PINTURA ESPAÑOLA DEL SIGLO XIX
}

Presentada por María Victoria Alonso Cabezas para optar al grado de

Doctor/a por la Universidad de Valladolid

Dirigida por:

$\mathrm{M}^{\mathrm{a}}$ José Redondo Cantera

Carlos Reyero Hermosilla 
La realización de esta investigación habría sido imposible sin el apoyo de muchas personas que, de una manera o de otra, me han acompañado durante estos años. Sin lugar a dudas, debo agradecer, en primer lugar, a María José Redondo Cantera y Carlos Reyero Hermosilla, directores de la tesis y padres académicos, que han permanecido ahí en los momentos de desaliento con sus consejos, orientaciones y palabras de ánimo. A María José, los numerosos consejos que me acompañarán en mi vida profesional y personal; a Carlos, la confianza que depositó en una alumna desconocida.

También debo mencionar a los compañeros del Departamento de Historia del Arte de la Universidad de Valladolid, tanto profesores como becarios de investigación, el interés que han mostrado, su ayuda, sus palabras de ánimo y las sesiones de terapia. Especial mención merecen Irune Fiz, Javier Castán, Francisco Javier Domínguez Burrieza, Cristina Hernández, Julián Hoyos y Rocío San José. Del mismo modo, otros compañeros de otros departamentos (Diego, Luis, Alberto) han estado ahí cuando les he necesitado, con ideas, palabras de ánimo y café.

En el transcurso de la investigación han sido numerosas las instituciones a las que he debido acudir con regularidad, y sin duda no habría llegado a los resultados obtenidos sin la ayuda facilitada por archiveros, bibliotecarios y personal de museos, cuya amabilidad y orientaciones sirvieron de gran ayuda. Especial mención merecen Esperanza Navarrete y Marina Arroyo, de la Real Academia de Bellas Artes de San Fernando; Fernando Fernández Gómez, de la Real Academia de Bellas Artes de Santa Isabel de Hungría; M ${ }^{a}$ Carmen Zuriaga, de la Real Academia de Bellas Artes de San Carlos, y María Francisca Castilla Crespí, del Museo de Bellas Artes de Valencia. Otros investigadores de diversas instituciones, a los que acudí en busca de orientación e intercambio de ideas, merecen ser mencionados en los agradecimientos; entre ellos, Hannah Williams, María Dolores Caparrós Masegosa y Ester Alba Pagán, así como a las responsables de acogerme en las estancias de investigación, Xesqui Castañer y Johanne Lamoureux.

Finalmente, pero no por ello menos importantes, merecen especial agradecimiento Javier Fernández, quien alimentó mi interés por el estudio de la masculinidad cuando, hace ya años, comentábamos de manera informal el modo en que el género condiciona nuestras vidas; Raphaelle Occhietti, con quien he compartido momentos de estrés doctoral y reflexiones personales hubiese o no un Atlántico de por medio; Pilar Cabezas, que no dudó en acompañarme cámara en mano cuando hiciese falta; Margarita Alonso y Mickael Batton, que a pesar de sus múltiples problemas cotidianos no dudaron en revisar mis textos en inglés. Y cómo no, a Isaac González San José, Fernando Hervás e Isaías Escudero Montón. 
...Quién sabe si esta galería, especie de martirologio ilustrado de soñadores en medio del positivismo al uso, se estudiará algún día con igual afán que las antiguas pinturas, para averiguar los retratos de famosos artistas y peregrinos ingenios. Quizá un Palomino o un Vasari del porvenir descubrirá que aquella testa cuadrada, de barbas rojas, aquella complexión de guerrero medieval, son fiel trasunto del que dio tanta gloria al arte español, del malogrado Casto Plasencia; en aquel personaje de rostro melancólico y suave, que contrasta con lo brioso de su pincel, a Alejandro Ferrant; a Manuel Domínguez en el otro no muy medrado de estatura; que el sujeto de descuidado aderezo y cara de soldado de Flandes es el famoso estatuario Jerónimo Suñol...

BALSA DE LA VeGA, 1895: 595. 


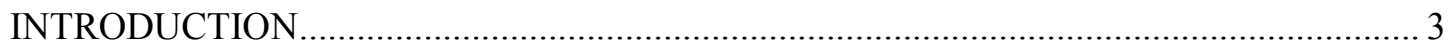

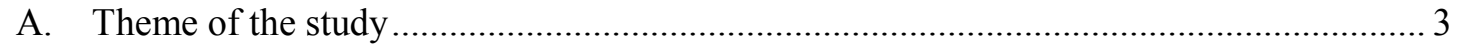

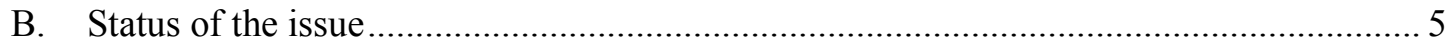

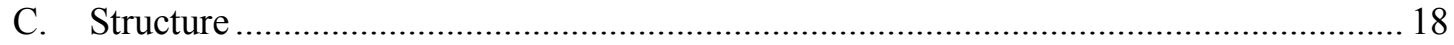

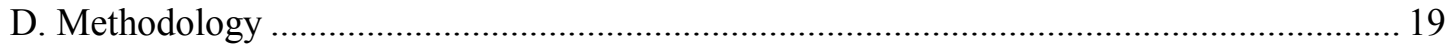

1. LA IDENTIDAD MASCULINA DEL ARTISTA Y EL RETRATO .................................... 21

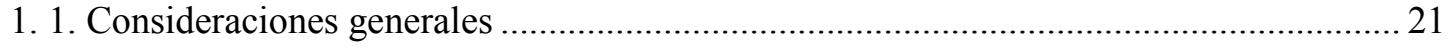

1.2. La formación artística y los aprendizajes de la masculinidad vinculada al artista............ 42

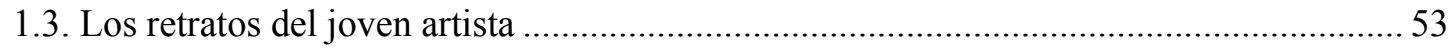

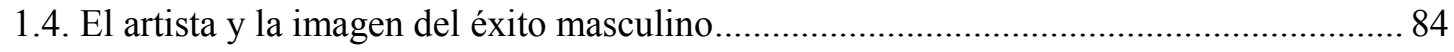

1.5. La inseguridad laboral frente a la imagen del éxito cultural ......................................... 111

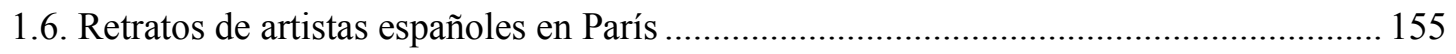

1.7. Presencia de retratos de artista y autorretratos en Exposiciones Nacionales e

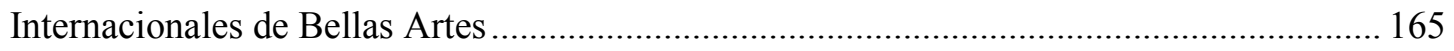

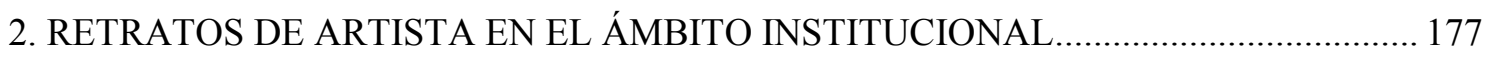

2.1. Las Academias de Bellas Artes y las galerías de retratos ................................................. 177

2.2. Los retratos de la Real Academia de Bellas Artes de San Fernando............................... 193

2.3. Los retratos de la Real Academia de Bellas Artes de San Carlos ................................... 230

2.4. Galería de retratos de la Academia de Bellas Artes de Barcelona .................................. 248

2.5. Galería de retratos de la Real Academia de Bellas Artes de Sevilla ............................... 259

2.6. Retratos de artista en las Exposiciones de las Academias de Bellas Artes ..................... 271

2.7. La galería de retratos de la Academia española en Roma .............................................. 285

2.8. Los retratos de artista en otras instituciones oficiales ...................................................... 296

3. LOS RETRATOS DE ARTISTA EN SOCIEDADES ARTÍSTICAS ................................. 301

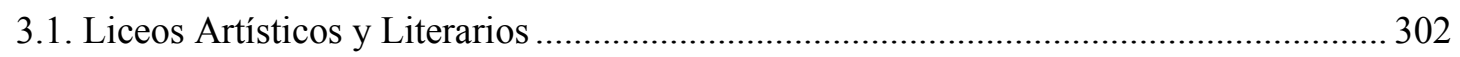

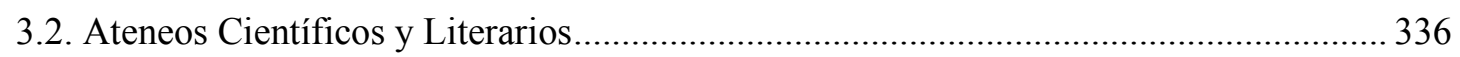

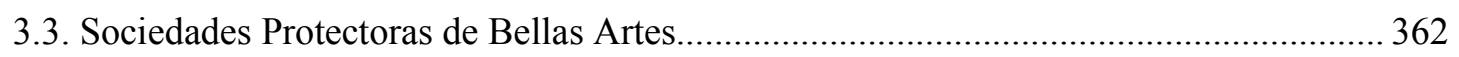

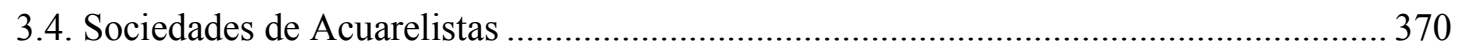

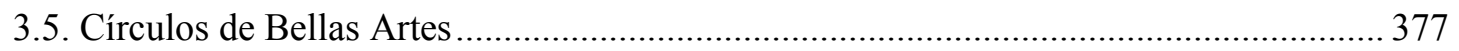

3.6. Artistas españoles y sociedades artísticas en el extranjero............................................ 400

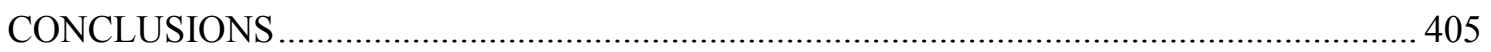

Anexo 1. Retratos de artista expuestos en los salones de París (1820-1879) ........................ 411

Anexo 2. Retratos de artista y autorretratos en los salones de París (1820-1879)................. 412 
Anexo 3. Retratos de artista en las Exposiciones Nacionales de Bellas Artes.....

Anexo 4. Evolución histórica de la Sala de Retratos de la Academia de San Fernando

Anexo 5. Evolución histórica de la galería de retratos de la Academia de San Carlos a través de sus inventarios y catálogos

Anexo 6. Listado de los retratos existentes en la galería de la Academia de Bellas Artes de Santa Isabel de Hungría.

Anexo 7. Relación de pensionados y de retratos existentes en la Academia Española en Roma (1874-1905).....

Anexo 8. Relación de socios artistas documentados en el Liceo Artístico y Literario de Madrid (1837-1849)

Anexo 9. Listado de socios artistas en el Liceo Valenciano (1838-1845).

Anexo 10. Lista de socios de la Sociedad Protectora de Bellas Artes de Sevilla.

Anexo 11. Listado de los socios de la Sociedad de Acuarelistas de Madrid, según las noticias recogidas en la prensa periódica.

Anexo 12. Listado de artistas vinculados al Círculo de Bellas Artes (1880-1892) y presencia de retratos en las exposiciones

Anexo 13. Retratos del friso del Círculo de Bellas Artes y relación de los retratados con la sociedad. 455

Listado de reproducciones. 458

BIBLIOGRAFÍA 464 


\section{INTRODUCTION}

\section{A. Theme of the study}

The project of this $\mathrm{PhD}$ dissertation originates in the consideration on what is it that makes masculine the image we've inherited of men artists, nearly as a product of the question asked by Linda Nochlin (1988) about why there have been no great women artists. The issue was not innocent and it was related to the many questions I asked myself when I first approached, during my MA dissertation, the influence of biographical clichés in the art criticism of the 1960s USA. Some interesting studies on this topic, such as Kris and Kurtz's (1995 [1979]), Wittkower's (1982 [1963]), Esperanza Guillén's (2007), Francisco Calvo Serraller's (1990) or María Bolaño's (1996) offered a hypervirile rhetoric about men artists; this, together with the contemporary questioning about normativity while dealing with the artist's homosexuality and his performative appropriation of both attitudes and an appearance rooted in a masculine myth, feeded my doubts about the origins, evolution and sociocultural components that have encouraged a History of Art seen from an androcentric -even though the term might sound rather obsolete- point of view. Many questions followed: if History is starred by male characters, what are the features, beyond those merely biological that characterise them as such? Can we talk about male artists in a context where their privileged monopoly has overshadowed other stories and female characters, whose role is still a field of research that faces its own difficulties? Even if we could partially answer these questions, what would be the graphic evidence that highlights these experiences that might be considered exclusively masculine?

It was that same year (2013) when Bridget Alsdorf published her study on Fantin Latour's group portraits, in which she exposed the importance of male sociability in the construction of community, artistic identities. Following her example, we considered the hypothesis that the Nineteenth Century was precisely the moment when contemporary gender stereotypes could be better visualized, allowing thus a better approach to some answers about a certain "artistic masculinity". Concurrently, we laid out the hypothesis that the study of male artist's masculine experiences was indissolubly linked to the images he produced of himself and his pairs. This starting point did not seem quite as ambitious as it proved to be later, as the aim was, apparently, clear and simple: the execution of an analysis about artists' portraits, a gender especially exploited during Contemporary Age, that answered the question of which were those male experiences lived in the Nineteenth Century, understanding its similarities and peculiarities from the normative construction of masculinity. Facing such a fascinating issue, we were aware that the topic needed to be delimited, reason why we decided to focus the study only on the peninsular, Spanish geographic frame. The wide range of both chronological and geographical frames was at the same time a need and an obstacle. Need, firstly because of the choice of a full century, as political and military events shaped the concept of man with plural and changing significations during this 
period -sometimes enduring beyond 1900-, that also affected artists; and secondly on the limitation to a geographical frame, because the study of Madrid as a great artistic centre would only offer a partial image that would only downplay the historical, social and cultural reality in other cities. These decisions meant also an evident obstacle, because in their wideness they impede a monographic approach of the study of differences between, for instance, the construction of masculinities during the Liberal Triennium and the First Republic, or between the analysis of the particularities in artists' male identities in the Absolutist Spanish academic schoolrooms compared to Spanish artists' in the Second Empire's Paris. The restraint of our approach is also conditioned by the existence of graphic and documentary sources. That is another reason why geographical limitation also meant an obstacle, as in the need of sustaining our research we had to focus on those cities that were big enough to shelter artistic communities and their institutions and associations, which were created in reflection of the capital and its fashions, and where artistic and documentary sources have been preserved. That led us to discard from our study the analysis of marginal or minor cities.

The aim of this research, previously outlined, is more complex as it is based on three main central ideas, closely linked together: artist's portrait, masculinity and associationism. In the first place, this dissertation was meant to trace a new reading of artist's portraits painted in Nineteenth-Century Spain, understood as an independent artistic gender. There is no place here for exclusively biographical approaches, such as a visual testimony of a certain moment of an artist's life, nor do we intend to analyze the construction of the male identity of one single artist during his full lifetime as a synthesis of the cultural meaning of masculinity in a certain time and place. This kind of approach, whether more specific and apparently less keen to speculation, has the disadvantage of offering only one point of view, and thus just one way of understanding, living and expressing different male and artistic experiences. The inclusion of many artists has the advantage of exposing more experiences and aspirations, maybe very similar to each other, but differently understood depending on the historical moment, the social background of the artist or the behavioural patterns with which he came in contact. In the second place, its gendered reading is focused on the study of masculinity, but its aim is not to defend the main role of male artists in the History of Art, but to understand the mechanisms of inclusion and exclusion in the Nineteenth-Century artistic system; in other words, it is not our intent to simply understand which were those professional or economic aspirations that made the artist only a male figure, as this has been very explicitly explained by the feminist History of Art. Our purpose is to understand how these aspirations influenced the construction of a certain male identity, and how these interpretations of what a male artist has to be are made visible in portraiture. Finally, we cannot understand artist's portraits without their function of social experience; the analysis of portraiture and masculinity in Spanish artists has its starting point in a permanent play of interrelations: those that, in a visible way, contribute to display a certain male appearance; those which, more evidently, reveal affective links, and those which, in a veiled way, express a will of belonging to a group, institution or society. 


\section{B. Status of the issue}

\section{B.1. Artist's portrait in Spain}

This research's object of study is a pictorial gender considered secondary in comparison to History Painting, and usually employed as an anecdotal way to physically and psychologically visualize the artist in monographic studies. The study of self-portraiture has deserved deeper attention since the exhibition held at the Museum of Modern Art in 1943 (MUSEO NACIONAL DE ARTE MODERNO, 1943), whose closest precedent dates from 1907 and the exhibition Autorretratos de Artistas Españoles held in Barcelona; the gap between both exhibitions made that the 1943 one might also be considered as the first accurate study in the twentieth century, while the 1907 exhibition was still a consequence of nineteenth-century fashions. The publication of Juan Antonio Gaya Nuño's Autorretratos de artistas españoles in the mid-twientieth century (GAYA NUÑO, 1950) proved a scientific and methodological progress, followed by Wifredo Rincón García's study in 1991, linked with the exhibition held by the Mapfre Foundation El autorretrato en la pintura española. In the midst of the never-ending theoretic reflections that self-portraiture has nurtured, the analysis made by Julián Gállego in 1978 about Goya's self-portraits is a remarkable contribution; he established three typologies in self-portraiture: figurante, actuante and confidente, to refer to those included in a complex scene, those that show the artist with his work tools and those that focus on the physiognomy and human nature of the self-portrayed artist. Later on, the work of Cid Priego (1985) acknowledges the sociological function of selfportraits as an affective object while respecting their traditional psychological function as a tool of self-knowledge, broadening thus Gállego's typology of the figurante as he also uses it in group portraiture, where emotional, social and professional relationships can be established between the figures. Gerardo Pérez Calero (1994: 289-293) presented this issue too, following the steps taken by Gállego and Cid Priego, and also proposing, though not applying it, a psychoanalytic theory to help understand the psychic relationship between the individual and his representation; nonetheless, he did not go any further than the other previously cited authors, which meant a poor contribution to the theory of self-portraiture. Rafael Argullol analyzed, in the twenty-first century, the self-affirmation of the artist as a subjective myth and as a hero in action, stating how it is usually highlighted "the solitary combat of the artist, with no other element than his opponent, the white canvas, and his palette and brushes as only weapons" (ARGULLOL, 2004: 52). Curiously, the parallelism established by Argullol between self-portraiture and a combat (whether inner of outer) is rooted in an assumption of violent action that shows a male behaviour of the artist, but this is unseen or taken for granted in his text, in a way that it does not seem necessary to explain the gendered connotation underlying in self-portraits. It was in the same year 2004 when Antigüedad Castillo-Olivares published a rather succinct paper concerning self-portraiture in Spanish nineteenth-century, which in spite of dealing with this artistic practice from a delimited chronological and geographical frame does not imply a solid theoretic contribution, seen how she just defended the idea that self-portraiture was employed by Spanish artists as a way of introspection and display of their personality, an approach 
that errs in an excessive dependence to the idea of romantic genius and the assumption of the "inner sight" as a feature of contemporary individualism, not delving into its causes and consequences. Estrella de Diego theorized more recently about the role of self-portrait as biographical material distorted by the idealized image of the self, or by the ideal aspiration of what the self should be (DE DIEGO, 2010), something we will keep in mind in this dissertation, especially while referring to the male ideals that shape, or help to self-shape, the image of the artist. The recent $\mathrm{PhD}$ research developed by Juan Carlos Bejarano Veiga (BEJARANO VEIGA, 2015) about fin-de-siècle selfportraiture in Catalonia has also been of interest for our study, as he lays out how the fin-de-siècle crisis and the legendary construction of the image of the artist affect the way the latter faces his own portrait.

It is curious that the acceptation of the term "artist's portrait" to allude to an independent, pictorial gender separated from self-portraiture is only reached in the late years of the twentieth century, at the same time when the Prado National Museum held an exhibition whose aim was precisely to rethink this kind of images from the portraits kept in its collection. Curated by José Luis Díez, Artistas pintados put in the same place self-portraiture and artist's portrait. In its catalogue, Julián Gállego also made, though without distinguishing both terms, a short allusion to the scarce number of portraits by women artists in the collection -only the one of the miniature painter Teresa Nicolau-, that seems to make a sexual differentiation between artist's portraits pointing out how "male artists" tend to disguise beauty in favour of intelligence and decision" (DÍEZ, 1997: 18). This reference to male values, to which he returns more than once while speaking about "manly shyness", rests as an anomaly in the text as he does not offer explanations to uphold such rotund affirmations, which make us think again about how these male values are universal and the reader and spectator can overunderstand. José Luis Díez is more explicit in his chapter and differentiates between self-portrait and artist's portrait, alluding to a relational and emotional characteristic in the latter which grants its artistic independence, and of which he highlights a certain complicity in the way of treating the sitter, as it is a painting made by and destined to a professional of the arts (DÍEZ, 1997: 39-40), an idea he will maintain later (DÍEZ, 2004: 315, 330). Susan Waldmann made a comparison between artist's portrait and self-portrait too, in this case to state the history of legitimation and social reaffirmation of the Spanish artist during the seventeenthcentury (WALDMANN, 2007), that leads to think that History of Art does not discriminate between them anymore, trying to offer new answers from psychological and sociological perspectives. That was the intention of the exhibition held at the Álava Museum of Fine Arts in 2013, which under the title Artist's portraits and self-portraits tried to give new visibility to the pieces of its collection. Finally, following this new exploration of the sociological aspect of artist's portraits, the Prado Museum dedicated in 2015 one of its rooms to the artist's portraits painted by Federico de Madrazo, offering a little show, eloquently entitled Effigies amicorum, artist's portraits by Federico de Madrazo, with several oils and drawings that permitted a relational approach of this pictorial gender. 
Despite this opening towards new fields of research related to artist's portrait, it is relevant to see how very rarely, if not never, importance has been given by Gender Studies, and particularly towards the study of artist's masculinity in this kind of portraits. Over the last decades, Feminist Studies have dug deeper in the analysis of women artists and the female experiences underlying in these pieces; thus, Girolami Cheney and Russo studied women artists' self-portraits, thinking what could be there that made it different from men's self-portraits, with the conclusion that the first allowed greater creative innovation as it reverses the traditional power patterns (DE GIROLAMI CHENEY, L., CRAIG FAXON, A. and RUSSO, K., 2000). Omar Calabrese, too, gave way to his thoughts concerning gender in self-portraiture, as he tried to explain the differences between women's and men's taking into account their own artistic experience; Calabrese introduces the term "sanction", linked to the professional career and social experience, which implies a kind of recognition from a third party. He thus linked female self-portraiture to private experience and early skill, and male's with mature age and professional approval (CALABRESE, 2006). Calabrese's dichotomy offers, in spite of the interest of his proposal, little explanation about the underlying male experiences that allow that validation. Female experience and women artist's portraiture has also been studied in the Spanish context, as in the recent research by Ros (2015), or crosswise in monographies about women artists. To find studies that deal exclusively with aspects concerning the artist's masculinity applied to portraiture, we need to return, once again, to the English-speaking scientific literature; in 2007 Philip Sohm briefly explored the topic of portraiture in his study about artist's old age, where he included the concept of lost masculinity, an issue picked up by Susan Waller in 2010, and in 2011 Benalp Jensen studied the exclusively male issue of artist and fatherhood through portraiture.

Finally, we must consider that artist's portrait has very recently been considered from the double perspective of Gender Studies and Sociology in the work of Bridget Alsdorf (2013). Her study about Fantin Latour's group portraits connected the concept of male homosociability in Nineteenth century Paris and artistic community, taken from Alain Bonnet's studies about group portraiture (2007); despite including a general idea about artistic masculinity through professional association and brotherhoods, she does not mention it as such, nor does she reveal the sociological and psychological framework underneath them.

In view of this methodological gaps and of the absence of a general context concerning the construction of masculinity between Spanish artists in this period and their relationship to portraiture we have outlined this $\mathrm{PhD}$ research, in the aim of offering an outlook, if not exhaustive about the individual identity of each artist, thorough about the construction of masculinities developed in the Spanish artistic field, about its similarities with and specificities from the nineteenth-century male normativity, and its visualization in artist's portrait. The objective of this research is to analyze the imaginary and the appearances depicted, like the relationship between this and the private, social and institutional uses of the painting; to do so, it is essential to 
approach it from Men's Studies and Sociology, whose contributions to the issue will be itemised in the following sections.

\section{B.2. Men's Studies as theoretical framework}

The theoretical framework sustaining this research is Men's Studies, a branch of Gender Studies initiated in North America in the sixties that had an important second wave in the nineties, especially in the fields of Anthropology and Social Sciences; it was in that period that it extended to Humanities. The aim of Men's Studies consists in a redefinition of gender through different societies and cultures, so that it permits the understanding of behavioural codes and of the structure of power that generates visible and invisible differences between men and women, enriching knowledge about the construction of masculinities and feminities and how it affects men in their individual experiences and in the relationship to their pairs.

The starting point for Men's Studies was then the difficulty of the understanding of what means to be a man inside the so-denominated patriarchal system, in traditional historiography as much as in contemporary society. The problem is not superfluous, for, as Connell observed, it affects directly the own methodology of Men's Studies, and can also be understood as troublesome in our study: how, then, can we study men inside a gendered and masculinised society, from a scientific perspective that has always privileged maleness? Doesn't this mean giving masculinity a new protagonism in a history monopolized by male characters? Or, as Connel literally put into words: "what can be expected from a science of masculinity, being a form of knowledge created by the same power that it intends to study?" (CONNELL, 2005: 6). The study of male identity must not be understood at any moment as a revindication of the privilege, as Harry Brod and Michael Kimmel already stated in 1987 while defending the inclusion of Men's Studies in Feminist theory; the postulate of Brod and Kimmel is still valid, for male crises originated in the incorporation of women to the job market have led some men to a compensatory need to legitimate obsolete manly roles through masculinist reactions and social, physical and academic violence (BOURDIEU, 1998; MESSNER, 2004; SAMBADE, 2011). Judith Halberstam acknowledged in 1998 not only the role of Feminist Studies in the construction of masculinities, but also the importance of the recognition of women's role in the construction of masculine archetypes (HALBERSTAM, 1998: 36).

One of the many problems analyzed by Men's Studies is the incessant invisibility of male experience under the traditional universilization of man as humanity, or of humanity as a neutralized synonym of man. Both Harry Brod and Michael Kimmel dealt with this essential question in order to legitimate this new branch of Gender Studies (BROD, 1987a: 186; KIMMEL, 1993), as the categorization of genders by sexual differentiation left out the possibility that the privileged group, from which women had finally achieved academic empowerment, could have a history of its own based on the meaning and experience of being a man. Michael Kimmel studied the ways in which political and economic spheres bestow privilege to one group or another, establishing an interesting comparison between the invisible structures of power and 
gender inequality (KIMMEL, 2001: 48); the need of differentiation and the relationship among the privileged group, imagined as a sexless, universal entity, and the masculinity or masculinities displayed inside it is one of the questions that academics have tried to answer. It is irrefutable that we cannot understand masculinity if it is not from a sociological or relational perspective, because masculinity, however slippery and changing as it may be, is always built in opposition to something, that is, trying not to be feminine, but also through relationships of identification, opposition and negotiation between men. In a theoretical field in which Feminist Studies connected every male thing with privilege and patriarchy, the shaping of the term "hegemonic masculinity" seemed to be the answer to the query of man in the new discourse. At least, it provided a new way of classification of the social relations of men with his congeners and with a female other, translating this to the sphere of privilege and power, that Carrigan, Connell and Lee summarized as "the way in which specific groups of men occupy positions of power and richness, and the way how they legitimate and reproduce the social relations that are generated in their own domain" (CARRIGAN, CONNELL and LEE, 1987: 591; DONALDSON, 1993).

Donaldson, starting from the same idea that hegemonic masculinity is an artifice to obtain women's subordination, describes it as

A culturally idealized shape, which is at the same time a personal and a collective project, commonsense in relation to the family sustenance and manliness; it is exclusive, anxiogenic, differentiated at an inner and hierarchical level, brutal, and violent; it is pseudonatural, though, contradictory, keen to crisis, rich and supported by society (DONALDSON, 1993: 645).

Through this gramscian idea of hegemony, Connel proposed a way of studying masculinities based on gender relations and hegemonic masculinity, analyzing society as a continuous negotiation of powers of domination and oppresion to understand the legitimization of male privilege not just in a gender order (CARRIGAN, CONNELL and LEE, 1987: 552) but also between men who, at a level of social politics, practise domination over other men, an idea introduced by Joseph Pleck (CARRIGAN, CONNELL and LEE, 1987: 571), or over certain groups of men, as Queer Studies revealed. The apparition of Bourdieu's work about male domination in 1998 contributed to the establishment of a new landmark in the relation between masculinity and power in social frameworks, as he explored the processes of differentiation between men and women, the plays of domination exerted by the first ones and the support by institutions.

Although this idea has progressively been put into context ${ }^{1}$, especially the concept of hegemonic masculinity, nowadays substituted by normative masculinity as it is a role model incarnated by a minority and which constitutes the model or norm to other men (CONNEL and MESSERSCHMIDT, 2005: 832), Connel laid the groundwork of the sociological study of masculinity understanding it as a perpetuation of behaviours and conducts fruit not of sexual identity of the individual but of the expectation of society,

\footnotetext{
${ }^{1}$ Several studies, following Bourdieu's guidelines, have tried to explain or refute the concepts he exposed about masculinity and domination (COLES, 2009; REICH, 2010 and HADAS, 2016).
} 
which constitutes a parallel with the idea of gender performativity analyzed by Judith Butler, and links with the theories exposed by Gilmore in 1990 (GILMORE, 1994) about the cultural construction of masculinity, and by Badinter in 1993 about the construction, from a psychoanalytic point of view, of male identity from identification models and constant proofs of legitimization (BADINTER, 1993). That is how Gilmore and Badinter state a male condition unconnected with the sexed body, as a series of behaviour patterns learnt in an exhortative way, as they were some kind of request imposed by the social group to which one belongs, one of the reasons why Men's Studies have been widely accepted by Anthropology, Psychology and Sociology. It is in function of this male ideal how a normative model of masculinity is defined; this model will match the (changing) expectations of each epoch and culture, and though it does not deny the existence of other masculinities, it will automatically turn them into alternative, subordinate masculinities by the simple fact of not fitting into the ideal ${ }^{2}$. On the other hand, the existence of a normative model and the role theory has led other academics to conceive masculinity not as the real experience of men but as an unrealisable ideal, a quality able to lead men to the anxiety of living through performance, always between the limits of over or underplaying the manly values of the character (BHABBA, 1995), or in a masquerade where no real individual lies behind the role playing (BROD, 1995: 17). It has also led to analyze the man who adapts to the normative model as someone who links individual identity with an ideal of social base, resulting in self-inflicted, negative psychological effects ${ }^{3}$, or even to think of masculinity itself as a state of perpetual crisis (SOLOMON-GODEAU, 1995). Indeed, the concept of masculinity has some connotation of crisis throughout men's lives as it is shaped by comparison with multiple models, easily obsolescent and usually out of reach, that do not adjust to the experience lived by men (CARRIGAN, CONNELL and LEE, 1987: 578). The concept of normative masculinity, however, is useful in our study in order to analyze the expectations that nineteenth-century Spanish men had about themselves and about their male condition, a model of which the artist, as a member of a society, is absolutely conscious and regarding which he negotiates -with different levels of anxiety ${ }^{4}$ - his own male identity.

\footnotetext{
${ }^{2}$ Badinter upgrades the idea of the construction of masculinity and manly behaviour to the level of artifice, considering that, at psychological and sociological levels, the unfitting models tend to be seen as faulty or suitable for "damaged men" (BADINTER, 1993: 18-19).

${ }^{3}$ In their analysis about a sociology of masculinity and the academic debates arisen in the seventies, Carrigan, Connel and Lee mark the male role as the only oppresor of man, as it exerts over him a power similar to the one exerted by patriarchy over women, so that "the real self is crushed, twisted or supressed by the demands of the role" (CARRIGAN, CONNELL and LEE, 1987: 567; CONNELL, 2005: 22).

4 We must point out the issue with the term "anxiety" in its translation to Spanish, as, regarding its connotation with Men's Studies, is usually employed as a literal translation of English that overlaps its meaning of sense of trouble or fear. In Spanish, and especially for the non-academic reader, it may unintentionally raise a connotation of psychological pathology which is not, except in extreme cases, the sense we give it while speaking about the worries originated by the normative imperatives that rule the concept of masculinity. French literature about this issue, on the other hand, does not use this term; Bourdieu (2000: 69) eludes it by using "vulnerability" and a succession of antagonistics that codify virility and non-virile attitudes, whereas Elisabeth Badinter (2012: 631) prefers to employ "pathos" and "suffering" caused by the "illusio viril" at an individual level, of "masculine crisis" (2012: 638) as a social effect (which also appears in the bibliography concerning the changing roles of masculinity in
} 
We must also keep in mind that the construction of masculinity is not exclusively based on the negotiation of powers inside a society or group, but that it depends on economic structures; industrial society and the impositions of the capitalist system, such as labour division, the progressive separation of the domestic sphere from the workplace and the unequal distribution of wealth imply the configuration of different ideals and gendered experiences depending on the belonging to one or another social class, the psychological and affective models displayed at home, the education level, dominant institutions, as much as sociability and the reality of the different spheres of the job market. The intentional treatment of the artistic world as a social group raises its own questions, as it is initially based upon profession as the only common point. Nonetheless, they also share a specialized educative system and institutions that channel the expectations and duties of the male artist, and this means a nexus that brings together, both sociologically and psychologically, a group of individuals, who, beyond romantic mythology, share and face similar job and personal anxieties, and whose attitude towards them will vary according to their interpretation of the ideals of what means to be a man and an artist.

The leap of Men's Studies to Humanities has allowed, since the early nineties, the increase of focus and a comprehension of the historical construction of different structures of power and male experiences (MARTÍN, 2007: 96), and also their visual projection, especially when referring to contemporary art. The valuable contributions from the field of History have been significant, as they have enlarged the theoretical framework, originally limited to the understanding of our contemporary society; Michael Kimmel's and John Tosh's studies allowed a theoretical background to the plurality of masculinities and its evolution in different historical moments and geographical contexts. Tosh suggested to face masculinity as a cultural concept or social status, proved or displayed in specific contexts, but also as the fruit of a subjective identity and the male experiences lived (TOSH, 1994: 184); this way, biographical and epistolary documents were a tool for the historian, who could study specific individuals and understand their different ways of dealing with power structures. Harvey and Shepard questioned themselves in 2005 about the methodologies and the development of Men's Studies in History, coming to the conclusion that the process had consisted in the analysis, on the first place, of patriarchy and gender relationships, followed by the study of the link between masculinity and social and class history, which came to a last phase or third wave consisting in the exploration of subjective experiences and their representation (HARVEY and SHEPARD, 2005: 275), an approach which has had its parallel in France thanks to the contribution of historians such as Alain Corbin or Anne-

contemporary society [BEYNON, 2002: 77]), and "suffering" or "anxiety" only from a freudian, psychoanalitic point of view (2012: 766). Sohn (2009: 133) upgrades this suffering to a higher level when she analyzes the "despair of the subjugated by male domination". We do not mean to downplay the emotional impact that trying to fit into idealized behaviour, especially among the young men Sohn alluded, had in men; nonetheless, both "suffering" and "despair" go much further the component of temporary worry anxiety has. Bearing in mind these reasons about the term, meanings and possible readings and misreadings it could have, we will not use "ansiedad" in our Spanish text, but "preocupación" [worry] while speaking about the consequences in male individuals of the fear of an outof-reach, normative ideal. 
Marie Sohn (2009). In Spain, History has also made interesting contributions in the field of gender relations, beginning with its emergence in the mid-nineties and the VIII Meeting "from the Enlightenment to Romanticism", whose topic was precisely -yet with a limited focus- male identity in the eighteenth and nineteenth centuries (RAMOS SANTANA, 1998). The evolution towards Men's Studies focused on social relations is the product of the twenty-first century and the contributions of Nerea Aresti, and also those focused on the links between power, elite and masculinity in the work of María Zozaya. Though it remains a marginal branch of Gender Studies, the fact that in 2015 the Spanish Association of Research on the History of Women devoted an international workshop to feminities and masculinities on gender historiography makes us think of a broader opening over this last decade to this kind of studies.

\section{B.3. What have Art Historians done with masculinity?}

Rethinking Harvey and Shepard's question about what Historians had done with masculinity, we must also revisit the way Art and Visual Culture Historians have dealt with masculinity. Feminist Studies have had a great impact on the field of Art History and have made great advances recovering the role, work and experiences of women artists; Men's Studies did not have the same chance until, precisely, the nineties and the turn of the century, highly influenced by Queer Studies and by the reception this topic had in History, Literature and Visual Culture, especially in film studies and advertising due to their relevance on the construction of contemporary male archetypes. That does not mean that the Liberation Movements in the sixties did not raise awareness about masculinity, but that the approach was focused on the needs of social reality and did not consider a pressing matter to analyze the problems of male identity in relation with art. Thus, in 1973 conceptual artist June Wayne claimed the emasculation of the artist regarding his social perception and the art market, comparing him to a woman "unable to cope with the real world of money and trade, although the artist, like the woman, waits while others are alleged to cope in his behalf" (WAYNE, 1973: 414); Wayne argued that this emasculation was a consequence of the romantic myth of the artist which, according to her point of view, was perceived from the same angle that puts on the same level sensibility and feminity or homosexuality. In the eighties, masculinity was explored by feminist theoreticians from the bias of the erotic look of men artists, and Marcia Pointon stated how

A crisis of the confidence in traditional art history with its attention to the individual male artist and his intentions accompanied by an increasing commitment to art history as a part of cultural history (...) has resulted in a state of affairs in which the study of the individual male artist seems a less than worthy enterprise. (...) The concept of the male artist as an inalienable, ahistorial, monumental category is repudiated. The male artist is an individual and should not be assumed to be a universal category in history, though he may have become so in historiography. (...) We are in danger of ignoring the evidence that an acknowledgement of the particular existence of the male artist may offer in understanding the meanings of works of art as they operate in our own society and as they functioned in the past (POINTON, 1986: 7). 
This meant the male artist is at the same time subject to and part of the patriarchal order. In spite of her statement, Pointon does not explore the male psyche nor the male identity of the artist, except to analyze Ford Maddox Brown's castration feeling regarding domesticity (POINTON, 1986: 20). Herbert Sussman's contribution to the study of Victorian masculinity permits, on the other hand, a deeper perception of the relations between artistic system, male identity and social groups (SUSSMANN, 1992 and 1995); in his works he states the troubles that normative masculinity generated in British middle class and the behavioural patterns of the romantic artist. Sussman outlines the features of the successful artist as a man closely bound to the trade world, meaning someone productive not just in a creative sphere but also economically, and at the same time a man conscious of his own sexuality. Joseph Kestner discusses the construction of male identities in Victorian painting (KESTNER, 1995), and he clarifies the manly values praised by English society, from the hardworking man to the head of a household, and also other attributes linked to imperialist militarism, heroism and vulnerability in masculinity through the study of artistic institutions and nude painting.

The implementation of Men's Studies applied to art history found a new development in the nineties by taking two different roads; on one hand those which, from a sociological point of view and with the artwork always in mind, try to understand the shaping of male identities and their functioning taking into account the interplay between artists; on the other those which, closer to Visual Culture, focus on the representation of masculinity and its hermeneutics, examining the appearances of men and their different meanings in art history depending on the geographic and social background and its particular concept of normative masculinity.

Among the first ones we find Thomas Crow (1995) and Abigail Solomon-Godeau, who proposed the troubles of the all-male artistic sphere and the social interactions taking place inside it, reshaping the concepts of emulation, rivalry, brotherhood, fraternity and homosociability first discussed by Sedgewick, which contributed to form artists' identities in Revolutionary and Postrevolutionary France and to create a concept of masculinity where the male gaze, eroticism and social interplay have their own place as a reflect of a patriarchal society. Further studies, such as Susan Waller's about virility in French ateliers (WALLER, 2000 and 2002), have contributed to acknowledge how the artistic training spaces are also sexed places, not just regarding the posing model, but also in relation to the interplay between young artists and initiation rites in a hierarchical system.

The second branch of Men's Studies in art history are also prolific during the nineties; Amelia Jones published in 1995 her work on the performative function of the male artist (JONES, 1995), where she discusses how appearances and fashion codes are the visual attributes of an eccentric, male role. Four years later, feminist philosopher Susan Bordo analyzed in The Male Body the changing concept of masculinity in the twentieth century from a cultural bias, assuming that the body and its sexed meanings are submitted to a continuous redefinition by both receivers and consumers, whether male or female (BORDO, 1999). It was in this decade when the comparative study of 
feminity and masculinity in art begun, as can be seen in Gill Perry's and Michael Rossington's work (PERRY and ROSSINGTON, 1994).

The contribution of this blooming theoretical framework and the development of Men's Studies gave way to a process of recovering the male body in the museum, which was meant to raise awareness in non-academic public about his new field of research; this led to new exhibition discourses whose aim was to empower the spectator with an erotic gaze, in order to help him rethink the way he understands masculinities. However controversial due to the exhibited pieces (male nudes), and in spite of the close link between scandal and cultural market, some interesting exhibitions as Nude Men (2012, Viena Leopold Museum), Masculin/Masculin (2013, Musée d'Orsay) or The Male Nude (2014, México) have proliferated since then. Their discourse is more innovative and visually consistent than the first exhibitions dedicated to the male figure, as The Masculine Masquerade in the nineties, but maybe also poorer in the contribution to Men's Studies (PERCHUK and POSNER, 1995).

Men's Studies in Spain in the domain of art history are rare. In 1996 appeared the first monography devoted to male appearance in nineteenth-century visual arts, by Carlos Reyero. He took Feminist Theory as a starting point to explore the image of the sexed male, and argued that the esthetical treatment of man in painting was only possible inside all-male places. In this case, the study of male appearances disregards private experiences; the same happened in the study José Miguel García Cortés devoted to the representation of masculinity and male body. In Hombres de mármol (2004) he discusses the male body as an artifice, producer of changing meanings, trapped by the sociocultural limits that seek to rule and understand the body. Despite this study's focuson the analysis of appearances, some interesting terms highlighted in the discourse reveal the assimilation of a more recent wave of Gender Studies, as he posits that the male individual is always placed in a hierarchical sphere where his body is always subdued. Finally, in 2005 came to light Jesús Martínez Oliva's El desaliento del guerrero, a study about the new masculinities in the last decades of the twentieth century, but also about a male image in crisis, where he explores non normative concepts such as the ill man, androgyny and transgender masculinity. An interesting term he integrates is that of power fantasy, combined with the artist/spectator process of identification in the image analysis when sexual identity is at stake; we argue that it is possible to transfer this idea to nineteenth-century artistic production and to artist's portraits, the latter allowing the construction of the male artist's image as a sexed one, but also as an identification model and as a narcissist reflect of a desired identity. The Spanish framework has also led to exhibitions about male identity, as Héroes caídos (GARCÍA CORTÉS, 2002), and more recently the concept of masculinity in contemporary art and culture has been revisited by young researchers like Héctor Sanz or Elena Sacchetti. The gender approach to masculinity in nineteenth-century Spanish art, and the construction of the male identity of its main characters remain, nonetheless, unexplored. 
Special mention is required to Álvaro Molina's works due to their high influence in our research, as he explores gender relations and Visual Culture. Even if he specializes on Eighteenth-century Studies, Molina introduced the debate about the invisibility of genders (2012) alluding to both Feminist and Men's Studies, as he argues that the exclusion of the other meant a step backwards in the analysis of the social, cultural and visual construction of men and women. His breaking-ground study about the representation of genders in Spanish eighteenth-century constitutes a great contribution to art history, as he explores the construction of both feminity and masculinity during Enlightenment. Albeit interesting in the dual consideration of genders, it is his study of masculinity in the context of political and cultural institutions prevailing in the first half of the nineteenth-century which has meant a greater help in the methodological development of our research.

We must confess that the starting hypothesis tried to answer an ambitious and erroneous question, as it stated the existence of an exclusive concept of masculinity among male artists regarding professional identity. In the course of this research, we channelled it through a sociological bias, which meant that the study of the social interplay of the artist in dissimilar spheres (domestic, institutional, associationism) was unavoidable in order to understand the different frames inside which male identity is reshaped and negotiated, and how this is expressed in artist's portraits, as both memento and social object, or in other words, as a tool to narrate the artist's masculinities regarding the changing, normative concept of man during the nineteenth century.

\section{B.4. Sociability, associationism, institution and the image of the male artist}

Thinking of the artist's portrait as a social object means to consider it as the result of a concrete experience, of an interplay between the artist-author and the artist-sitter, or a relation between the portrait itself, the portrayed individual and the space it was meant for. Likewise, when it has to be rethinked from a male gendered point of view, this implies a need of further analysis about the rituals and social interactions of the artist regarding the social groups inside which he builds his identity, among which he interplays and in front of whom he performs a role with its specific image (ALSDORF, 2013; BONNET, 2007). We must here turn to Simmel's text about the principles of association and sociability, as there is a parallelism with the social function in the construction of male identities:

A man as a whole is, so to speak, like an unshaped complex of contents, powers, potentialities; only in function of his motivations and his relations in a changing existence he assembles into a differentiated, defined structure. Like a political, economic agent, like a member of a family or a profession, he is an ad hoc construction (SIMMEL, 1949: 256).

The slippery nature of Men's Studies is interwoven here with the difficulty of determining which are, precisely, the spaces and groups that constitute not just a relational framework for men's social identity, but also those that have relevance in the shaping of a male identity, and analyze them through the material evidence of the artist's portrait. According to Simmel's statements about the mutable construction of the 
social individual depending on the context (SIMMEL, 1986), we searched which would be those spaces that affect the process of construction of the artist's sexed, professional identity. We will itemise them, as different ways of interplay or social meeting have different implications on male identity, and accordingly they will affect differently the results of our research. On the one hand, we find those involuntary ways of social interplay, given by family or emotional bonds, usually displayed in the domestic sphere, and which match a sociability linked with private experiences. In the artist's instance, we have considered the domestic background as the first place for male identification, following Tosh's works about domesticity, and as object of study, family portraits between artists, in order to explore a primary male identity in the child and adolescent, and also the father-to-son bonds that can be traced both in portraits and in documentary sources. Inside this non-corporative, non-associative kind of social experience, we have included the correlation between male identity and artistic training, taking the academic space as the scene of the young artist, where he learns and masters techniques, but also where he learns and develops male behavioural patterns; this sphere, though very interesting from a theoretical point of view, finds little graphic support.

On the second hand, sociability is characterised by a voluntary relation and the consequent feeling of satisfaction from a friendly meeting; it is the basis of the artist's portrait as artistic practice and as social experience: usually entitled "portrait of a friend", this kind of painting translates the joy of the generally all-male, artist meetings among friends and professional colleagues, and a will to perpetuate or seal their bond by the exchange of portraits as a gift. The increasing of this sociability, frequently highlighted in the study of nineteenth-century portraiture, is also the core of other forms of association and the reality of social relationships in official institutions and societies. However, we must differentiate the social interplay performed in the two last spaces, as they determine the way the artists understood the practice of portraiture inside them, their function and the expectations or male anxieties concealed in them. Following, once again, Simmel's ideas, we can define the institution -meaning the Academies- not just as an association between equals in the quest of a common aim, even if that was its original goal, but as a stage where professional and social expectations of the male artist are at play, while other societies, based on a ludic form of association, or maybe understood as supplement to sooth the seriousness of professional life, take more interest in the pleasure of the meeting and of the activities undertaken inside them. Both are artificial social constructs, where the individual must fit into the group and negotiate his identity in a relational way, adjusting to the behavioural code, emotional control (curiously linking the principles of sociability with male restraints and nineteenthcentury urbanity protocol [GUEREÑA, 2013]), and the common objective of a seemingly democratic group by the dismission of the ego; nonetheless, the inequality among members in the institution makes emulation and rivalry a consequence of the professional sphere, and so they are both unleashed as a hierarchical fight that affects the construction of male identity as it forms part not just of the daily life, but of the projection and assimilation of a personal status and expectations that need a constant negotiation. On the contrary, associations are spaces of sociability where profession is 
not at stake, nor is the social or economic status of the member attacked in any possible way; inside these societies and associations, the social interplay is based on a principle of equality among members because there is no menace to the individual or group identity, reason why emulation and rivalry are taken as an innocent social game that reflects the outer reality. Our hypothesis sustains the idea that the artist's portrait painted in different social interplays translates the plurality of aims and social principles of each sphere; even if they are subject to similar codes of representation, their function inside the social group will vary in the same way as their relevance in the construction or negotiation of the portrayed people's male identity regarding the community.

Accordingly, we have tried to analyze the relation between male hierarchy, masculinity and professional identity by the study of artist's portraits in official institutions and corporations, mainly in the Academies of Fine Arts in nineteenthcentury Spain. We have tried to clarify if there is any possible difference between corporative initiatives, focused on the creation of gallery portraits as a visual history of the institution, and portraiture fruit of sociability at the Academy's exhibitions, for there is scarce use of group portraiture -neither corporative nor due to private initiative- in the Spanish context. In both contexts, we face the same troubles, since in an all-male sphere, portrait is an object of memory and projection of power, but their meanings and those related to the interrelation of pieces vary. Though we have had present Hannah Williams's study of the parisian Académie Royale portraits (WILLIAMS, 2015), which has proved interesting and useful as it explores portraiture as fruit of very specific relationships inside the institution, we have tried to dig deeper in portraiture as a sexed practice, an issue intentionally eluded by Williams. Her reasons were, on the one hand, the gender permeability in French Enlightenment and its institutions, and on the other the indissolubility of masculinity and the male structure of Academy. The marginalization of women from the academic sphere in nineteenth-century Spain, far from fostering just a social approach to the academician world, encourages a gendered, specific analysis of the anxieties, experiences and male troubles inside it, traceable by portraiture.

Concerning artist's portraits in nineteenth-century associationism, we cannot establish the same parameter of male hierarchy, but we can focus on the social structures that link individual identity with community, always bearing in mind that the resultant portrait is the fruit of a pleasant sociability and that it is its aim to strengthen the ties among the members. Here we follow Simmel and the interpretations about associationism and sociability argued by theoreticians like Jean-Louis Guereña (GUEREÑA, 1990 and 2001), Elena Maza Zorrilla, 2002 and 2008), María Zozaya (2010, 2016) and others (VELASCO MORENO, 2000). We have analyzed the most relevant, Madrid-based artistic associations or cultural societies and extended our focus to other cities, in order to explore the social relations displayed inside them, the male behaviours performed by their members regarding their social background or their elitism, their connection to official institutions and to politics. As a terminological clarification, in our text we will indiscriminately use both association and society, even if this might lead to misreadings, as Bridget Alsdorf $(2013: 6,244)$ pointed out, as the 
contemporary connotation of "society" is usually extended to more regulated groups. However, the term "association" does not appear in the sources while referring to the groups established by nineteenth-century artists, using the more formal title of "societies". Insofar, we will employ both terms understood under the same connotation: as groups formed with a delimited aim, regulated and which constitute a space of sociability for a certain public.

We also hypothesized that each society would affect the perception and selfperception of the artist regarding the group, and that his role as a professional of the arts might grant him a distinctive quality in groups that linked culture with bourgeois leisure. In the same terms, we wondered if, in these mixed spaces, the importance of a certain normative masculinity would mark not just the behavioural rules -which are connected to bourgeois etiquette and the eccentricities of bohemian life-, but also the expectations about male artists. Would his transformation into a cultural hero modify the sociological perform of masculinity depending on the function and membership of each society? We have traced a chronological and geographic survey of different associations, such as Liceos Artísticos, Ateneos, Sociedades Protectoras de las Bellas Artes, Sociedades de Acuarelistas and Círculos de Bellas Artes.

The analysis of the limits of portraiture in sociability places would be incomplete if we did not pay attention to its function inside them: do portraits in a certain group create an image of collectivity and social bonds, ignoring individual identity? Or is the latter renegotiated depending on the context and kind of sociability? The query, then, lies within the artist's identity, his commitment -or rejection- of normative masculinity and sociopolitical hierarchy, and his way of showing himself to society. This also arises suspicion, because the image offered by the artist may also be a way of self-validation, and as such, a way of concealing male anxiety channelled through the need of reaffirmation required by masculinity itself.

\section{Structure}

We have chosen a tripartite structure in our dissertation, in order to analyze each of the three main topics regarding artist's portraits. The first section explores the construction of male identity in nineteenth-century Spanish artists, and the way they imagined and lived it through portraiture. We proceeded to a previous theoretical consideration about the normative male code that shaped the artist's identity, paying attention to the way he negotiated his manly role by appropriation or rejection of normativity. The study of the different stages in which this gender construction takes place, according to the periods of life, is supported by the analysis of visual representations of the artist; in this way, we begin our tour of masculinity with the process of male identification in families of artistic background, followed by the construction of masculinities in training spaces, both academic or in ateliers. Continuing our discourse, the link between male identity, profession and the rhetoric of success is explored through the iconography of the artist as a worker and images of success as the epitome of his cursus honorum. Conversely, job anxieties and the negotiation of the real situation of male artists in society and the market place are also examined. 
The second section explores the relation between the male artist, the academic institution and its power structure by the study of the presence of artist's portraits inside official corporations. We have chosen as starting points the portrait galleries existing in four of the main Academies of Fine Arts: San Fernando (Madrid), San Carlos (Valence), San Jordi (Barcelone) and Santa Isabel (Seville). Each one is analyzed separately in order to observe the kind of social, economic and emotional relations that affected the creation of the galleries. We have also paid attention to the presence of portraits at the Academy exhibitions, with the aim of understanding the level of visibility the artist may have intended in his participation with an artist's portrait. A brief comparative study of the Spanish Academy portrait gallery in Rome is included, interesting due to the link of these portraits with a specific stage in artist's life as was the Prix de Rome.

Finally, the third section deals with associationism. Here we explore the social and cultural needs that lead male artists to the creation of artistic societies, and to form part of other all-male societies as a way of inclusion in that kind of social privilege. Some local societies are also explored, in order to understand the export of cultural models from the capital and how portraiture has the added value of sociability between amateurs and artists inside these societies as social groups.

\section{Methodology}

In the course of this research we have approached the existent bibliography about Men's Studies, masculinity and its relation with art history, in order to have a critical background. Because of the origin of this literature, mostly in English as the United States and Great-Britain have made important contributions to this field of knowledge, our theoretical framework is closely linked to its concepts. Bibliographic revision was later focused on the Spanish artistic context, filtering monographies about artists, their collected letters, biographies and memoirs published since the nineteenth century. This work has mostly been done with the resources offered by University Libraries, the Spanish National Library and the Prado Museum's Library.

On a second phase, with the theoretical background settled and an approximative selection of artist's portraits, our research focused on the analysis of primary sources and archive documents at the Archivo de la Real Academia de Bellas Artes de San Fernando and Archivo de la Real Academia de Bellas Artes de San Carlos, Archivo del Museo Nacional del Prado, Archivo de la Casa-Museo Benlliure, Archivo Histórico Nacional, Archives Nationales de France and at the École Nationale Supérieure des Beaux-Arts in Paris; we have also had access to digitalised documents by these institutions and the INHA Library in Paris. We have paid special attention to the academic agreement's record, which provide significant pieces of information about the production and incorporation of portraits both to their galleries or their museums' collections, and to information about social relations between academicians.

We have also consulted newspaper and periodicals libraries to follow the development of the different associations and exhibitions, their artists and portraits. This research has been carried out in the Spanish National Library, Biblioteca Valenciana 
Nicolau Primitiu, Hemeroteca Municipal de Madrid, Hemeroteca Municipal de Valencia, and digitalised newspaper's databases, such as the Biblioteca Virtual de Prensa Histórica, Biblioteca Virtul de Andalucía, Galiciana (Biblioteca Digital de Galicia), Liburuklik (Biblioteca Digital del País Vasco), BiValDi (Biblioteca Valenciana Digital), ARCA (Arxiu Català de Revistes Antigues) and Gallica, and digital resources provided by the BDHAHA database and the INHA.

During the course of doctoral research, we made two research stays. The first one took place in the months of May and June, 2016, under the charge of Professor Xesqui Castañer, at the Universitat de València. The second took place in the months of April, May and June 2017, at the INHA (Institut National d'Histoire de l'Art, Paris), under the charge of the Département des Études et de la Recherche coordinator, Professor Johanne Lamoureux.

This $\mathrm{PhD}$ research has been financed with a FPU Grant from the Ministry of Education and Culture of the Spanish Government (ref. FPU2013/3082), which consisted in a predoctorate fellowship at the Art History Department, Universidad de Valladolid; attendance to seminars has also been possible with the University's financial support, and the support of the Research Group (GIR) IDINTAR of the Art History Department (Universidad de Valladolid). 


\section{LA IDENTIDAD MASCULINA DEL ARTISTA Y EL RETRATO}

\section{1. Consideraciones generales}

\subsubsection{Masculinidad en el siglo XIX}

Las bases de la educación ilustrada y el concepto de masculinidad transmitido en las primeras décadas del siglo XIX ponen de manifiesto que no se trataba de una condición fija y natural, sino de una serie de actitudes y conductas que debían aprenderse en la infancia por asimilación e imitación de modelos ejemplares en el ámbito familiar y educativo. La construcción de una identidad masculina ya hundía sus raíces en la oposición o diferenciación, constituyéndose como lo opuesto a lo femenino. La influencia de Rousseau se deja entrever en los planteamientos que al respecto se hacen en España, tamizados por la moralidad y el catolicismo. El Tratado de las obligaciones del hombre, traducción española del francés realizada en 1795 por Juan de Escoiquiz, expresa en términos educativos y moralizadores algunos de los valores propios del varón, con una orientación pedagógica y escolar; sus sucesivas reimpresiones a lo largo del siglo XIX evidencian que se trató de una obra ampliamente divulgada, y cuyos valores se transmitieron formando parte de la educación moral de la población masculina a lo largo del siglo. En sus páginas se encuentran algunos de los valores que marcan la conducta masculina decimonónica, como la reputación personal, la constancia en el trabajo, la racionalidad en el proceder y el dominio de uno mismo, reprimiendo, según Escoiquiz, las pasiones que escapan del control de la razón, una constante en los manuales de educación y urbanidad que subrayan una pedagogía de la contención emocional en sociedad (MAYORDOMO, 1983; GUEREÑA, 1997; SIMMEL, 1949); igualmente, aconseja acostumbrar a afrontar con valentía y sin abatimientos las adversidades (físicas y morales) puesto que un exceso de delicadeza solo contribuiría a afeminar cuerpo y mente (ESCOIQUIZ, 1828: 56). Del mismo modo, en el discurso educativo se puede observar cómo existe un interés por subrayar la existencia de una serie de jerarquías - a nivel familiar y en el ámbito escolar, como microcosmos que refleja la realidad social y el prototipo de orden burgués- en función de la edad y de los cargos, en el que la interrelación está codificada por estructuras de poder a la que los más inferiores deben someterse y obedecer ${ }^{5}$; el respeto al orden basado en el autodominio y la sociabilidad pacífica se constituye así como una forma de naturalizar la desigualdad de clases y como medio de enseñar al individuo -respecto a sí mismo y a la sociedad - en el respeto, no promoviendo conductas que puedan alterar el sistema social o político establecido (AMPUDIA DE HARO, 2004: 289). El tratado de urbanidad incluido a modo de apéndice en el de Escoiquiz insiste en este concepto de jerarquía, que lejos de ser invisible, impregna tanto a la sociedad como al individuo,

\footnotetext{
5 "Es preciso también que tengamos respeto y reverencia a todos aquellos que son nuestros mayores por su edad, por su clase o por su autoridad (...), presentándonos delante de ellos con modestia, y hablándoles con humildad y sumisión. Aún con más razón debemos hacer esto con nuestros propios superiores, a los cuales además hemos de estar subordinados, ejecutando prontamente cuanto nos manden" (ESCOIQUIZ, 1828: 75).
} 
poniendo de manifiesto que las relaciones entre individuos están marcadas por esta continua visualización y negociación del poder de cada hombre. Es en relación a la urbanidad y a las relaciones sociales en las que el autodominio juega un papel fundamental, que se compara con un "arte de cubrirse de un barniz semejante al que hace desaparecer en nuestros muebles las asperezas o desigualdades del material" (REMENTERÍA Y FICA, 1837: 10), en el que se ocultan los verdaderos sentimientos del hombre, para lo cual es preciso enseñar a "reprimir su carácter y de doblegarlo a los deberes y circunstancias de la sociedad" (REMENTERÍA Y FICA, 1837: 13).

El concepto de privilegio masculino en el siglo XIX está asentado sobre las bases de la superioridad moral, y se visibiliza en el orden social a través de la dominación sobre la mujer (negando la igualdad de derechos) y sobre la institución familiar, la acumulación de capital y el establecimiento de jerarquías. No es de extrañar que los movimientos que buscan la supresión de alguno de estos factores sea considerado un ataque directo al privilegio establecido; de este modo, las opiniones combativas son introducidas en las obras más inverosímiles, como ocurre en La higiene del matrimonio de Pedro Felipe Monlau, en que ataca a partes iguales al comunismo, el fourierismo y en sansimonismo: el primero, porque niega el privilegio económico y la autoridad social derivada de este, afirmando lo natural de la desigualdad entre hombres; al segundo, porque destruye el concepto tradicional de familia y la autoridad paterna -transmisora de unos valores masculinos concretos, pero también el concepto de propiedad patrimonial- al relegar la educación de los hijos a la comunidad o al propio Estado; y al tercero porque además de atacar a la propiedad privada y a la estructura social supone, a través de la defensa de la emancipación de la mujer, acabar con otra forma de dominación, algo que expone de manera muy explícita al preguntar "¿Queréis emancipar a la mujer, esto es otorgarle los mismos derechos, e imponerle sin duda iguales deberes, que al hombre? ¿Queréis darle la misma educación que al hombre, a fin de que sea apta para todas las funciones públicas que son hoy privilegio exclusivo de aquel?"(MONLAU, 1858: 14).

Las ideas de Monlau, ancladas en el conservadurismo, transmiten también algunos de los ideales o supuestos de la masculinidad normativa decimonónica con un fuerte componente moralizador y religioso, estableciendo en la familia los cimientos de la sociedad y en el hombre el papel de jefe y de proveedor $^{7}$, dando al ideal de domesticidad el componente de atributo necesario para la vida correcta del hombre al ser su núcleo afectivo en los momentos de descanso ${ }^{8}$. De esta manera, la misión del

\footnotetext{
${ }^{6}$ Este hermetismo emocional se percibe en otros pasajes de la obra, como al recomendar al hombre "no llevéis a la sociedad vuestras pesadumbres ni desazones. Si estas os entristecen e incomodan, quedaos en vuestra casa con vuestras ideas melancólicas" (p. 41), o "no habléis de vuestra mujer ni niños" (p. 42), a menos de tratarse de reuniones entre iguales, en que es permitida cierta intimidad.

7 "Para ser jefe de familia es necesario tener una profesión o carrera probada, es necesario poder inspirar respeto a la esposa y a los hijos, es indispensable que la inteligencia se encuentre bastante desarrollada, y el corazón con suficiente experiencia del mundo, para dirigirse uno a sí propio y educar y dirigir a la familia, y todo esto no puede reunirse antes de los 25 años en el hombre" (MONLAU, 1858: 28).

8 "Yo creo, con Fodéré, que los hombres dedicados a las profesiones intelectuales pueden y deben casarse; que el amor de una esposa y los cariños de una familia les harán más llevaderos sus arduos trabajos, les alentarán en ellos y amenizarán sus ocios y sus horas de descanso" (MONLAU, 1858: 54).
} 
hombre se corresponde con la de ser el pilar de la sociedad a través de sus distintas organizaciones (familiares, institucionales o políticas), así como su principal defensor y protagonista $^{9}$. La importancia concedida a la familia en la sociedad industrial adquiere especial interés en lo que respecta a la construcción de la identidad sexual del niño a través de dos modelos diferenciados, en que el padre constituye una figura de autoridad para toda la familia, y un prototipo de masculinidad para el niño, en el que se puede percibir una asimilación de la construcción jerárquica del privilegio masculino. Gloria Espigado puso en relación la autoridad paterna con un reflejo directo del poder público (ESPIGADO TOCINO, 1995: 144), lo que hace ver que el proceso de aprendizaje de las conductas masculinas se fundamenta en una comprensión de las escalas y la división de poderes, en el que la sumisión a la autoridad es la base para poder ser un hombre de bien, de igual modo que la sumisión a la autoridad política es la base para ser buen ciudadano. No en vano se ensalzaba en 1820 un modelo de virilidad vinculado con la constancia y la moderación, fortaleza, virtud y sabiduría, y el desempeño de cargos de poder político, a la hora de pedir juicio a los electores en su decisión respecto a los diputados ("A los electores", 1820: 4); y en 1841 se equiparaba directamente edad adulta y ejercicio práctico del privilegio masculino en El Amigo de la niñez, afirmando que en la edad viril, a pesar de ser común a hombres y mujeres "es en la que el hombre empieza a ejercer el imperio y la superioridad sobre todos los vivientes. Entonces hecho miembro de la sociedad, participa de todos sus privilegios, y de todos los deberes que ella impone (...) Esta edad es la de la fuerza y del trabajo" ("Virilidad, vejez", 1841: 7677).

El hecho de que las obligaciones laborales y la huida a espacios de sociabilidad lejos del hogar llevase a muchos padres de familia a descuidar sus obligaciones para con sus hijos fue motivo de especial crítica en la segunda mitad del siglo XIX, viendo en ello los moralistas una de las principales causas de las conductas rebeldes entre los adolescentes, uno de los motivos por los que la imagen del padre involucrado en los ocios familiares se constituye en un tópico recurrente; así sucede, por ejemplo, en el caso de Alejandro Ferrant, a quien en 1890 se define "como perfecto modelo de buenos hijos, como amante apasionado de esas dulzuras con que el brasero brinda a la familia", acudiendo muy raramente a círculos y sociedades, señalando que "pronto abandona aquel lugar de artísticos solaces para dirigirse a su casa (...) casi enojado de tener que contestar a los saludos de sus numerosos amigos y admiradores que le roban así el tiempo que el arte le deja libre, para dedicarse a los goces del santo cariño de la familia" (BALSA DE LA VEGA, 1890: 1).

\footnotetext{
Igualmente, el autor menciona una necesaria continencia, aun dentro del matrimonio, y especialmente en los hombres dedicados a profesiones liberales, estableciendo un paralelismo entre capacidad genésica y trabajo intelectual: "Los literatos, los artistas, los hombres de bufete o que ejercen una profesión liberal, verán consumirse con prodigiosa rapidez su vida si no andan con mesura en entregarse a los transportes del tálamo conyugal" (MONLAU, 1858: 134), señalando que la impotencia y la esterilidad son frecuentes en los hombres de ciencias y de letras (p. 232).

${ }^{9}$ Gloria Espigado recoge cómo la noción de hombre ofrecida por el Diccionario de pedagogía de Mariano Carderera insiste en estas cualidades masculinas, siendo el deber del hombre ser "el sostén y defensa de los intereses generales de la familia toda, de la patria, de la sociedad" (ESPIGADO TOCINO, 1995: 137).
} 
Además de los valores morales vinculados a la masculinidad, existen otros de índole social que Bejarano Veiga resume como "la realización de un trabajo bien hecho, la defensa del capitalismo, poseer un carácter pragmático y utilitario, y una confianza ciega en el progreso, símbolo del status alcanzado y que se debía proteger" (BEJARANO VEIGA, 2015: 289-290). En efecto, el trabajo constituye la base de la sociedad industrial y es el motor económico y social del privilegio, haciendo que todos los hombres tengan una capacidad definida para el consumo ${ }^{10}$, que es el símbolo visible del poder; y los espacios de sociabilidad, en muchas ocasiones exclusivamente masculinos, son el escenario en que se escenifican las relaciones sociales que otorgan significado a las jerarquías y sus símbolos, configurándose por lo tanto la identidad laboral y la identidad social como rasgos que constituyen la identidad masculina del hombre decimonónico fuera del ámbito doméstico.

Nerea Aresti define los cambios en la construcción de la noción contemporánea de masculinidad a través del

progresivo abandono de ideales de corte caballeresco, la construcción de una nueva respetabilidad masculina obrera y burguesa, la importancia del trabajo, del valor moralizante del hogar, del autocontrol, y el giro desde un modelo basado en la reputación ante los otros fundamentado en la interiorización de una identidad subjetiva (ARESTI, 2010: 24),

refiriéndose fundamentalmente al modelo de masculinidad imperante en el primer tercio del siglo XX, en el que se pueden contemplar sin embargo los planteamientos en que se cimenta la forma de entender la normatividad de género a la que se enfrentó el hombre del siglo XIX. El ideal caballeresco permanece vigente a través de la idea del honor y de la conquista de privilegios aristocráticos como exhibición social de poder, mérito o influencia, sin que esto entre en conflicto con la coexistencia de una nueva valoración del trabajo, con sus correspondientes jerarquías; de este modo, el concepto de masculinidad extendido entre la burguesía y la clase obrera está anclado en unos ideales similares, pero se manifiesta de manera diferente en función del nivel cultural, de la educación adquirida y de la importancia dada al tipo de poder a ejercer, desvinculándose los mecanismos del poder político y de la superioridad intelectual del ejercicio práctico de la violencia a través del dominio de las pasiones. El hecho de que la identidad profesional se relacione directamente con un estatus social y con un tipo de poder concreto, como ocurre en las vinculadas con el ejercicio de la medicina, con la legalidad o con las carreras humanísticas, que permiten al hombre decimonónico desempeñar trabajos de alta remuneración económica o puestos en la administración pública, lleva a diferenciar distintos tipos de masculinidad en función de los requisitos de las diferentes prácticas laborales. Esto es especialmente visible en el caso de profesiones directamente asociadas con conductas hipervirilizadas, como es el caso del ejército (cuya presencia en el siglo XIX español es continua, tanto a través de conflictos internos como las

\footnotetext{
${ }^{10}$ La sociedad industrial y el consumo son equiparados con la plenitud y la "virilidad social", ya que "empieza el cuerpo político a adquirir robustez y con el vigor y la actividad riqueza, todos trabajan igualmente, desde el rey o caudillo que los manda hasta el último de los guerreros, y todos disfrutan con igualdad de los goces que se adquieren" (El Nacional, 1836/09/06: 543).
} 
guerras carlistas o en el exterior, desde las campañas en África hasta la guerra de Cuba), en el que se presupone al oficial un grado de compromiso, respeto al código de honor del cuerpo al que pertenece, así como valentía y fuerza, que pueden degenerar en temeridad y brutalidad en casos extremos, o entre las clases obreras, en que el trabajo manual lleva a despliegues de una masculinidad basada en la exhibición de fuerza física.

La continua aspiración a aumentar el estatus social y económico así como una asimilación de los ideales proyectados por la burguesía urbana hacen que la forma de entender la masculinidad decimonónica de distintos cuerpos profesionales haya sido desdibujada por la imposición de un modelo normativo. La irradiación de este a través de los planteamientos ilustrados y de la alta burguesía a otras capas de la sociedad, así como la mutación de esta a lo largo del siglo XIX, implican también la exportación de las prácticas empleadas por esta para la demostración de su privilegio, que adquiere especial importancia a través de la constitución de grupos o sociedades en las que, a pesar de una pretendida república fraternal en la que no existen las clases, este pueda ponerse en juego ya sea en los propios espacios de trabajo como en los destinados al ocio $^{11}$.

Puede establecerse de este modo que existen tres ejes fundamentales en los que el hombre decimonónico aprende y pone en funcionamiento las conductas aprendidas como estrictamente masculinas: por una parte, el familiar, que determina no solo los modelos de identificación del niño sino el rol que este desempeñará cuando establezca su propia familia, así como su forma de entender su oficio; por otra parte, la profesión, en la que influyen el tipo de educación recibida y la relación con los maestros en términos de identificación, pero también las connotaciones asociadas al tipo de labor a desarrollar, las opciones de ascenso y de una proyección económica; y finalmente la integración y promoción social como interrelación con otros individuos, tanto en la práctica cotidiana como a través de espacios dedicados específicamente a ello.

\subsubsection{Masculinidad artística y modelos de dominación}

Ante este modelo de masculinidad decimonónica consolidado en la sociedad española, la pregunta evidente es si puede hablarse de una masculinidad específica del artista como un concepto universal y generalizado. Entendiendo la comunidad artística como un grupo cohesionado a nivel social por compartir unas formas de aprendizaje exclusivas, así como una identidad profesional definida, puede entenderse por masculinidad artística la que se aprende y se despliega en los contextos de formación y en los laborales, así como los que emanan a nivel sociocultural a través de la proliferación de ciertos tópicos -veraces o infundados- relacionados con la vida artística.

Existen dos formas de entender el objeto de este estudio; en primer lugar, y tomando como referente el modelo de masculinidad normativa en el periodo concreto

\footnotetext{
${ }^{11}$ Antonio Alarcón menciona la diferenciación de sexo y de clase ejercida en los núcleos de sociabilidad exclusivamente masculina, vinculando las cuotas de admisión con una forma de elitismo (ALARCÓN GUERRERO, 1995: 303; ZOZAYA, 2015).
} 
que estudiamos, abordaremos la masculinidad del artista a partir de los hábitos y comportamientos más recurrentes, lo que nos permite acercarnos a un modelo ideal de masculinidad artística. No debe olvidarse que, como tal modelo, es una construcción mental respecto a la cual los artistas negocian su identidad, y que por lo tanto no se configura como un patrón de conductas y aspiraciones asumidas por todos los hombres artistas. Del mismo modo, y a pesar de las narraciones transmitidas por la historia tradicional de arte y por las biografías artísticas, ningún artista encarnará a la perfección el papel ideal que se le presupone, ni estará libre de las preocupaciones que le suscitan las imposiciones sociales y culturales respecto a su propio ser-hombre-artista. Así pues, el estudio del contexto social específico del mundo artístico, de sus instituciones, de las relaciones interpersonales y de la recepción contemporánea de los artistas nos permite formular un modelo de masculinidad artística, que podemos considerar como el dominante dentro de un grupo, sin que esto impida que sea un modelo cambiante a lo largo del tiempo y la existencia de otras masculinidades, también en el contexto artístico. En segundo lugar, podemos entender la masculinidad del artista a partir de las experiencias privadas de cada hombre artista, lo que plantea una visión basada en la vivencia y en la asimilación y negociación del individuo respecto a los modelos planteados.

Tomando como punto de partida la afirmación de Connell de que es en el nivel regional o nacional en el que se operan los cambios culturales que dan forma a las masculinidades y que cambian las estructuras normativas (CONNELL, 2005a: 850), podemos afirmar que no solo ambas formas de estudio son válidas, sino que no pueden entenderse la una sin la otra, de tal modo que es imposible realizar un estudio sobre la identidad masculina de un cierto pintor sin analizar el modelo respecto al cual ha moldeado esa identidad, ni es posible entender esta de manera genérica, sin tener presente las experiencias de distintos hombres artista en determinados momentos y lugares. Igualmente, no es posible entenderla sin sus contradicciones ni sus tensiones internas, a pesar de -y debido a- su situación de privilegio frente a otros grupos, $\mathrm{y}$ concretamente frente a la mujer artista. Ante la pregunta de si la masculinidad artística es una forma de masculinidad dominante, la respuesta debe ser rotundamente afirmativa, ya que a través de las instituciones y de los comportamientos socialmente aprendidos impone su poder mediante la exclusión de los otros, sin que esto niegue -lo cual nos lleva a posicionarnos en la línea de pensamiento de Coles (COLES, 2009)- la existencia de otras masculinidades dominantes coexistentes, cada una en distintos grupos, e incluso dominadas estas por un modelo de masculinidad a nivel regional. El sistema artístico decimonónico perpetúa un modelo de masculinidad en el que la mujer es continuamente aislada; la historia feminista del arte ha señalado los mecanismos empleados para hacer efectiva la situación dominante del hombre artista: la exclusividad del acceso al modelo del natural, base del conocimiento artístico; la supresión de los estudios de dibujo para niñas (DE DIEGO, 2009: 265) o las tasas discriminatorias ${ }^{12}$, que

\footnotetext{
${ }^{12}$ En la Escuela de Dibujo de Santiago de Compostela, por ejemplo, las niñas y mujeres debían pagar ocho reales mensuales (más que sus compañeros varones) "en atención a que la sociedad necesita emplear
} 
limitaban el acceso de mujeres de escasos recursos al conocimiento del dibujo destinado a las artes aplicadas -y alejándolas, por lo tanto, de un sector profesional; la creación de un mito del artista romántico plagado de tópicos hipervirilizados, el tratamiento paternalista de la crítica hacia las obras hechas por mujeres artistas o la vinculación de la creatividad con una carrera profesional exclusivamente masculina, con un sistema de méritos codificado por y para hombres, como pone de manifiesto el hecho de que los requisitos para acceder a la oposición a una plaza de enseñanza artística superior fuesen haber sido pensionado en Roma o haber obtenido medalla en Exposiciones Nacionales, algo que, como señala Estrella de Diego, difícilmente podía suceder si fallaba la educación en el dibujo en el caso de las mujeres artista.

Una vez expuestos estos hechos, parece poco legítimo abordar las implicaciones que este sistema jerárquico tiene para el hombre artista, siendo él el principal privilegiado; sin embargo, es preciso analizar no solo los agentes que perpetuaron un sistema de dominación masculina en el campo del arte, sino también la forma en que los artistas se beneficiaron de esta situación y cómo negociaron su situación de poder, especialmente teniendo en cuenta la tradicional imagen de vulnerabilidad transmitida por el relato autobiográfico, por el mito del artista maldito frente al héroe cultural y por el precario equilibrio entre creatividad y comercio. Seguramente uno de los problemas fundamentales que ha tenido que afrontar esta investigación es la existencia de una historia sobre el ascenso social del artista que la recorre de manera paralela, cuyos mecanismos de poder, aunque invisibles, salpican la historia tradicional del arte. Intentar visibilizar la masculinidad del artista corre el peligro de anclarse en esta historia social, especialmente cuando entra en juego en relación a conceptos tan frecuentes y resbaladizos como institución artística, jerarquía y mercado. En efecto, la voluntad de un progresivo reconocimiento social es el motor continuo del hombre artista, pero quizás no tanto para su producción creativa, sino de cara a una acumulación de capital económico y cultural- que le permita acercarse más al arquetipo de masculinidad que mayor poder ejerce en cada época y contexto; la interrelación entre sociedad, poder y masculinidad es tan frecuente que se suele obviar el peso que cada uno de los tres factores tiene de cara a los otros. A su vez, es la voluntad de poder -según el concepto acuñado por Bourdieu (1998: 97) - la que origina un sistema de jerarquías no solo en la institución artística, sino en la forma de relacionarse como órgano mediador entre el poder político y el trabajador en el ámbito del arte, que afecta a las aspiraciones de este y modula su posicionamiento frente a la sociedad y la comunidad artística.

\subsubsection{Voluntad de poder y privilegio masculino}

Jerarquía y privilegio son dos conceptos intrínsecamente ligados, que en el caso del artista alcanza su máximo exponente en la nobleza de la pintura reclamada en el siglo XVII; el ascenso social del artista pasa así por la reclamación efectiva de privilegios relacionados con las formas de dominio aristocrático (MARTÍN GONZÁLEZ, 1991). El tema, estudiado por Waldmann (2007), permite observar que en el ascenso social del

sus fondos en otros objetos de más urgente interés", añadiendo que "el dibujo no es tan necesario a las jóvenes como a los artistas" (Reglamento..., 1838: 26). 
artista existe una voluntad de equiparación con la jerarquía sociopolítica, y que la creación de una imagen cultural del artista se define por la relación respecto a los parámetros de una masculinidad dominante, imponiéndose el artista caballero, virtuoso e intelectual. De este modo, la representación del privilegio del artista está filtrada, en primer lugar, por dos marcadores elitistas como son la erudición y la moral; al mismo tiempo, Waldmann señala también un punto importante que configurará posteriormente el valor primordial de la masculinidad entre burguesía y clase media: el mérito individual. Efectivamente, en las vidas de artista se impone una justificación del acceso del artista -trabajador manual- a los privilegios tradicionalmente otorgados por nobleza de sangre, y en ellas la identidad profesional, codificada en mayor o menor medida a través de la esfera de lo intelectual, y el mérito alcanzado a través de esta constituyen, junto a sus virtudes particulares, un punto clave para considerarlo como figura ejemplar, como sucede en el Libro de descripción de verdaderos retratos de ilustres y memorables varones de Pacheco ${ }^{13}$. La evolución del autorretrato y del retrato de artista, codificado a través de un discurso del mérito en el que cobran importancia honras y títulos de manera paralela a la biografía de $\operatorname{artista}^{14}$, confirma además que este es cómplice del sistema de jerarquías al que ha accedido o aspira a acceder, y que le favorece. La relación con la Corte es, no debe olvidarse, una distinción exclusiva a la que pocos artistas consiguen llegar, y precisamente por su componente elitista y por el privilegio que ofrece - a nivel económico y social- se convierte en el modelo a seguir o aspiración por parte de los artistas.

La noción de privilegio sigue presente en el siglo XVIII, reformulada a través de los cambios sociales y del imaginario de un nuevo cuerpo político basado en el Estado; los planteamientos ilustrados sobre una masculinidad centrada en el dominio de la razón y en el mérito individual favorecen, en principio, al artista, puesto que ya ha articulado su identidad en torno a estos parámetros y encuentra en las clases dominantes no solo un cliente potencial, sino un nuevo admirador de las virtudes encarnadas por el artista. Así, el escultor Felipe de Castro exponía la vinculación entre virtudes intelectuales y un concepto de masculinidad al señalar "que no excluyen las ciencias a ninguno, sea del nacimiento que fuese, porque el ser de honrado nacimiento es fortuna, pero el hacerse hombre de bien y científico es atributo del alma y de ánimo bien dispuesto, y al mismo tiempo bien propio adquirido de uno mismo, por lo que merece más alabanza" (BÉDAT, 1979: 29). Álvaro Molina señaló la vinculación del cuerpo social ilustrado con el cuerpo masculino, analizando el modo en que las prácticas de poder se codifican y multiplican con la dinastía borbónica (MOLINA, 2013: 77). Las nuevas instituciones políticas, abiertas a un número mayor de hombres, se ven reflejadas en la creación de otras instituciones que reproducen el sistema de autoridad; las Academias se convierten en uno de los escenarios institucionalizados respecto a los cuales los artistas, como ciudadanos y como expertos, negociarán su identidad y sus privilegios, no solo a través del papel de estas para la imposición y generalización de un gusto artístico, sino

\footnotetext{
${ }^{13}$ ASENSIO, 1886; CACHO CASAL, 2011.

${ }^{14}$ Sirve de ejemplo el Parnaso español pintoresco laureado, cuyas biografías de artista no solo inciden en la formación y el carácter anecdótico, sino que prestan especial atención a aquellos artistas ilustres vinculados en mayor o menor medida al poder (PALOMINO, 1724).
} 
también como reflejo de la microesfera política y social que constituyen y de la relación de esta con el poder estatal, el aristocrático y el de la monarquía. La extensión del poder del rey sobre la Academia se pone de manifiesto en la elección de los cargos administrativos entre hombres de la corte ${ }^{15}$, así como en la fiscalización de algunas prácticas artísticas fuera del ámbito de la Academia, como el uso de modelo del natural o la tasación de obras de arte (RABASF, 1757: 87) o la prohibición de las cofradías y congregaciones artísticas (RABASF, 1757: 89); al mismo tiempo, a los profesores académicos se les otorga el privilegio y exenciones propias de la hidalguía ${ }^{16}$, y a los discípulos pensionados y a los premiados se les exime de ciertas cargas concejiles ${ }^{17}$, siendo especialmente interesantes las relacionadas con el ejército y el servicio militar como levas, quintas y reclutas (NAVARRETE, 1999: 62), exenciones estas últimas que afectan a preocupaciones propias de la población masculina, y que abordamos en capítulo aparte.

Respecto al carácter masculino de la Academia, este puede entenderse a través de la proyección de la profesionalización de la educación impartida, así como en la distribución de poderes y jerarquías en su seno. La presencia de académicas de mérito en el siglo XVIII ha sido subrayada en varias ocasiones como una forma de paternalismo hacia las artistas, fruto de las relaciones de carácter patriarcal que se desarrollaban en la institución; Álvaro Molina destaca, sin embargo, la presencia de cuatro mujeres que fueron nombradas directoras honorarias como un ejemplo de que algunos títulos, más allá de su carácter honorífico, sí que habrían permitido a las mujeres artista tomar parte activa en la vida académica. El hecho de que las cuatro (Mariana de Silva Bazán y Sarmiento, Mariana Urries y Pignatelli, Mariana de Waldstein y Antonia de Lavauguyon) perteneciesen a la nobleza ${ }^{18}$ indica también que, a pesar de sus méritos, el privilegio aristocrático favorecía a estas figuras excepcionales respecto a otras artistas. La presencia femenina es más difusa en el siglo XIX, relacionada a títulos meritorios y a parentesco con otros académicos, lo que supone que la negociación de poderes que se ejerce dentro del espacio, ya por sí privilegiado, de la Academia manifieste una voluntad de dominio masculino; este hace que la configuración de la identidad del artista, en su voluntad de poder, se vincule a aspiraciones de dominación social y cultural, ya sea a través del ejercicio de una

\footnotetext{
15 “También me reservo la nominación de los consiliarios a proposición igualmente del protector, y es mi voluntad que sean del número de los Grandes, de los Ministros y personas más autorizadas de mi corte" (REAL ACADEMIA DE BELLAS ARTES DE SAN FERNANDO, 1757: 79).

16 “A todos los Académicos Profesores que por otro título no la tengan, concedo el especial privilevio de Nobleza personal con todas las inmunidades, prerrogativas y exenciones que la gozan los Hijos-Dalgo de Sangre de mis reinos, y mando que se les guarden y cumplan en todos los pueblos de mis dominios donde se establecieren, presentando el correspondiente título, o certificación del secretario de ser tal académico" (RABASF, 1757: 95-96).

17 "El conserje, porteros, discípulos pensionados y los que hubieren obtenido un premio serán exentos de levas, quintas, reclutas, alojamientos de tropas, repartimientos, tutelas, curadurías, rondas, guardias, y todas las demás cargas concejiles" (RABASF, 1757: 96).

18 Mariana de Silva Bazán y Sarmiento, duquesa de Huéscar y Arcos; Mariana Urries y Pignatelli, marquesa de Estepa; Mariana de Waldstein, marquesa de Santa Cruz y Antonio de Lavauguyon, princesa de Listenois Beaufremont (MOLINA, 2013: 249).
} 
profesión regulada o del nuevo establecimiento de jerarquías vinculado al sistema educativo.

Para entender la formación de identidades artísticas en el siglo XIX es preciso tener en cuenta que el volumen de cada comunidad artística es variable en cada núcleo de población, multiplicada en las grandes ciudades, donde hay una mayor demanda gracias a la existencia de clases sociales acomodadas, y con una menor autonomía en ciudades pequeñas. Por otra parte, el relato focalizado sobre los artistas se centra en carreras profesionales exitosas que corren paralelas a los hitos marcados por las instituciones, sean estas la corte, la Academia o el sistema público de enseñanza y pensiones, de tal manera que en buena medida desconocemos la historia de los artistas menores, aquellos que o bien fracasaron en su carrera artística o que la desarrollaron al margen de los ámbitos oficiales, e incluso de otros muchos dedicados a otras profesiones artísticas relacionadas con las artes decorativas o las artes y oficios, y a las cuales se presuponen otros patrones de conducta más vinculados con la clase obrera.

\subsubsection{Artistas como hombres hechos a sí mismos}

La influencia del género biográfico en la percepción novelada del artista como héroe cultural no es particularmente sorprendente, ya que remite a la codificación del privilegio masculino a través de la erudición y el mérito. Así ocurría en las tradicionales biografías de artista italianas, de las que Pacheco toma el modelo para su colección de retratos de hombres ilustres; en ella la vinculación de relato y biografía sirve como modelo ejemplificador, puesto que Pacheco se limita a realizar una introducción retórica, mencionar la familia a la que pertenecía cada biografiado (entre los que se cuentan escritores, poetas, artistas, médicos y soldados) y algún topos relativo a su infancia, seguido de una alusión a su educación, sus cualidades personales y hechos virtuosos. Antonio Palomino, familiarizado ya con la retórica del mérito demuestra su intención de perpetuar la memoria de los artistas como "ínclitos varones cuyas hazañas les constituyeron acreedores del inmarcesible laurel de la Fama", y no solo consigna los datos relevantes de cada uno de ellos respecto a su familia y lugar de origen, sino que concede especial importancia a la formación del artista, atendiendo al concepto de escuela como perpetuación de estilos de maestros a discípulos, así como a los viajes de formación y a las obras realizadas ${ }^{19}$. De los datos que ofrece sobre la personalidad de los artistas prevalecen los relacionados con la virtud y la fe, generalmente cualidades unidas, y la aplicación al trabajo, como muestras positivas de comportamiento masculino; como ejemplos de virtud y fe menciona a Gaspar Becerra, Luis de Vargas, Juan Bautista Juanes, Juan de Juni, Gregorio Fernández, Pablo de Roelas, Francisco Sánchez Cotán, Dionís Mantuano y a algunos religiosos dedicados a la pintura, como Fray Nicolás Factor, Francisco Galeas, Luis Pascual Gaudín, el hermano Adriano y Agustín Leonardo. Entre los datos inspirados por otras formas de masculinidad se

\footnotetext{
${ }^{19}$ De las 226 biografías incluidas en la obra, incorpora datos sobre el origen e infancia de 216 artistas; la información sobre sus obras es incorporada en 204 biografías, la relativa a la formación en 153, y la vinculada a sus respectivos títulos y honras únicamente en 48 , ofreciendo así una imagen del carácter exclusivo de las últimas.
} 
destacan también otros vinculados con un carácter dominante basado en la altivez, la afición o la destreza en las $\operatorname{armas}^{20}$ e incluso la violencia ${ }^{21}$.

La relación de Retratos de los españoles ilustres abordada por Álvaro Molina (MOLINA, 2016; MOLINA, 2013: 214-218) fue un proyecto ilustrado que responde al interés biográfico y a la publicación de estampas por entregas, en la que se puede apreciar la influencia europea en la elección de los personajes no en función de su nobleza, sino del mérito individual (MOLINA, 2016: 48), ensalzando así un ideal cívico exclusivamente masculino. La inclusión de un grupo de retratos y biografías de artistas en un cuaderno monográfico publicado en 1797 respondía no a una voluntad de exaltación de la figura del artista, sino al interés patriótico por subrayar el progreso en las artes a través de sus máximos representantes. Sin embargo, la idea del mérito individual ofrece cambios interesantes en la forma de abordar a los artistas presentes en la colección, fruto de un ambiente cultural en el que la negociación jerárquica no dependía exclusivamente de la relación con las esferas cortesanas, sino del trabajo intelectual, la práctica habitual y el trabajo constante, siendo el mejor ejemplo el caso de Velázquez, cuyo retrato, como señala Molina, abandona la iconografía del cortesano para incluir, a través de los útiles de su trabajo, no solo una referencia alegórica a la pintura (MOLINA, 2016: 53), sino una manifestación dignificada de la profesión artística. Los símbolos de la profesión, relacionados con el decoro, se constituyen como una prueba o garantía de la valía del retratado (MOLINA, 2013: 216; WALDMANN, 2008: 102), de los motivos de su condición social y, por lo tanto, justificación de su inclusión en la colección de hombres ilustres como modelos a imitar. En fecha similar se gesta el Diccionario de Ceán Bermúdez, publicado por la Academia de San Fernando en 1800, en el que se propone salvar las lagunas biográficas de Palomino, a quien achaca "la desgracia de dar acogida a las fábulas y cuentecillos que con tanta facilidad se introducen y difunden en el vulgo de los aprendices y maestros" (CEÁN, 2001: 3). A pesar de que Ceán Bermúdez no suele incurrir en tópicos biográficos, sí que se observa, especialmente en las biografías de sus contemporáneos, un interés por manifestar algunos rasgos propios del siglo XVIII, como la afición a las artes por parte de la aristocracia y su transmisión genealógica ${ }^{22}$; otro de los rasgos que marca con especial interés es la voluntad individual del artista por su mejora en el aprendizaje de las artes, la adaptación al sistema meritocrático académico (relación de premios, pensiones y títulos en la institución) y cortesano, apareciendo los conceptos de "estimulación" y

\footnotetext{
${ }^{20}$ Es el caso de algunos pintores como José Antolínez, aficionado a la espada negra, y de Alonso Cano, Fray Juan del Santísimo Sacramento y Juan Cano de Arévalo, cuya destreza con las armas es subrayada por Palomino.

${ }^{21}$ Además de Alonso Cano, se menciona a Francisco Fernández, Francisco de Herrera el Mozo, Juan Carreño, Pedro Atanasio, Juan de Valdés, Juan Cano de Arévalo y Juan Niño de Guevara.

${ }^{22}$ Sirve como ejemplo el del marqués de Montehermoso, José María Aguirre Hortes de Velasco; pero también en el caso de artistas reconocidos, como Antonio González Velázquez y sus hijos Zacarías, Isidro y Cástor (CEÁN, 2001: 222), o los Vergara (CEÁN, 2001, t. V: 191). Llama también la atención la inclusión de varias mujeres artista, generalmente por vínculos familiares o matrimoniales, que merecieron el reconocimiento de la Academia. Sin embargo, de María Loreto Prieto señala con evidente pena cómo su matrimonio, aunque fuese con un grabador, cortó una carrera prometedora como dibujante y grabadora (CEÁN, 2001, t. IV: 124).
} 
“emulación ${ }^{23}$ " entre discípulos y artistas contemporáneos ${ }^{24}$. En este sentido, el celo y la aplicación ${ }^{25}$ del artista se constituyen como los pilares de una carrera profesional dentro de una historia construida en clave masculina, como se pone de manifiesto de manera muy resumida en la biografía de Ramón Bayeu ("La aplicación, la asistencia a la Academia de San Fernando y la dirección de tan buen maestro formaron a un pintor correcto") y otros artistas, desde la fase de aprendizaje como discípulo de la Academia y de maestros particulares, hasta su propia constitución en maestro y transmisor de su saber, basado en ideales ilustrados ${ }^{26}$. La excepción la constituye el relato de Luis Paret y Alcázar, en el que a pesar de la aparente imparcialidad del relato -construido siempre limitando la capacidad de acción del artista- Ceán Bermúdez deja entrever su admiración personal ("muy pocos o ningún pintor nacional tuvo en España en estos días de tan fino gusto instrucción y conocimientos como Paret, y yo que le he tratado de cerca lloraré siempre su muerte y el poco partido que se ha sacado a su habilidad" [CEÁN, 2001, t. IV: 55]), minimizando el papel de la Academia a una breve fase de formación, y otorgando a otro maestro y al trabajo personal del artista la causa de sus méritos en la corte de Carlos III. Del mismo modo, comienza a introducir ciertas notas relacionadas con el trabajo del artista como medio para su sustento -algo que pasa desapercibido por su obviedad en otras biografías- en casos concretos, como el de Antonio Ponz, de cuya estancia en Roma destaca no solo la capacidad de estudio e investigación, sino su continuo trabajo como pintor "pues era el recurso para su manutención y para comprar cuantos libros de artes podía" (CEÁN, 2001, t. IV: 108), o el de Preciado de la Vega, quien en Roma, y bajo la dirección de Sebastián Conca "estuvo siete años manteniéndose a sus expensas hasta que Felipe $\mathrm{V}$ le concedió una pensión de 500 ducados" (CEÁN, 2001, t. IV: 122), e incluso el caso del pintor que, considerado por Ceán como un extravagante por mantenerse voluntariamente ajeno a los cargos y

\footnotetext{
${ }^{23} \mathrm{El}$ término, poco frecuente, aparece vinculado a jóvenes en proceso de aprendizaje, como es el caso del escultor Ignacio Vergara (CEÁN, 2001, t. V: 187) respecto a su primo Francisco Vergara.

${ }^{24}$ Así sucede en la biografía de Manuel Álvarez Cubero, señalando de él haberse ocupado "en trabajar con utilidad, estimulando a los jóvenes con su asistencia y aplicación cuando era alumno, con sus sabios preceptos cuando maestro, y dirigiendo a los discípulos por el buen camino cuando estaba postrado en cama en los últimos años de su vida. Ninguno más inteligente, ni más observante de las reglas del arte, sacrificando muchas veces sus propios intereses a esta observación" (CEÁN, 2001: 23).

${ }^{25}$ Se pone de manifiesto en biografías como la de Francisco Bayeu (CEÁN, 2001: 100) y Ramón Bayeu (CEÁN, 2001: 105), el grabador Gerónimo Antonio Gil (CEÁN, 2001, t.II: 187), Antonio González Ruiz, a quien califica de "celosísimo en la enseñanza de sus discípulos" (CEÁN, 2001, t. II: 212-213), el pintor Antonio González Velázquez (en cuya biografía se vincula ya directamente calidad pictórica y aplicación con los honores académicos) (2001: 221), el escultor Francisco Gutiérrez (p. 246), Bernardo Martínez del Barranco (CEÁN, 2001, t. III: 82), Agustín Navarro ( 2001: 225) y de José Vergara, "no habiendo estado jamás ocioso" (CEÁN, 2001, t. V: 191); alcanza un toque extremo en la biografía de Mengs, de quien dice que "el mucho trabajo, la ninguna diversión, el corto alimento y hallarse sin su familia (...) fue la causa de una gran melancolía y de una consunción que a paso largo le conducían al sepulcro" (2001: 125).

${ }^{26}$ Así, del escultor Juan Pascual de Mena señala que concurrió "con el mayor tesón y celo a la enseñanza de los jóvenes desde los estudios de la junta preparatoria hasta los últimos meses de su vida, que finalizó en Madrid el día 16 de abril de 1784 con gran sentimiento de sus discípulos, que amaba como hijos" (CEÁN, 2001, t. III: 105), y José Vergara dio "repetidas pruebas de su amor a los discípulos, y de la dulzura con que los enseñaba y estimulaba a sus adelantamientos" (CEÁN, 2001, t. V: 192); de Francisco Tramulles que su entierro fue "costeado por sus discípulos, que le amaban tiernamente" (CEÁN, 2001, t. V: 71], y de Ignacio Vergara que su cadáver fue llevado en hombros de sus discípulos (CEÁN, 2001: 189).
} 
honores, forja por sí mismo una carrera mediocre, como señala respecto a Lorenzo Quirós $^{27}$. El carácter de una biografía en términos masculinos matizada ya por la retórica del hombre que se hace a sí mismo aparece en la entrada dedicada al pintor sevillano José de Rubira, quien "no hubo de sujetarse a ningún maestro aunque quedó sin él en la corta edad de trece años, confiado en su gran genio y buenas disposiciones", y a quien "las obligaciones que contrajo con el matrimonio le precisaron a buscar otros medios para vivir que no le suministraban los retratos ni otras pequeñas obras al óleo, al temple, al pastel y de miniatura" (CEÁN, 2001, t. IV: 277), dedicándose finalmente a otros negocios, o en el caso del escultor Carlos Salas, quien habiendo sido pensionado por sus méritos en Roma renunció "con el honrado motivo de tener que asistir y socorrer a sus ancianos padres" (CEÁN, 2001, t. IV: 300), dedicándose para ello a la enseñanza en Zaragoza. Además, es perceptible un tono moralista más allá de las virtudes familiares o masculinas, especialmente vinculada con la relación entre exceso de acumulación de capital y falta de modestia, como sucede en el caso de Matías de Torres, no solo porque "llegó a ser rico, tratándose con un tono y decencia superior a su clase", algo que en su relato queda rápidamente relegado dada su miseria en su vejez, sino especialmente por haber dedicado su carrera a realizar obras exclusivamente comerciales o de fácil salida en el mercado ${ }^{28}$.

El relato del hombre hecho a sí mismo convive a lo largo del siglo XIX con el ideal del genio, en una búsqueda de la proyección social del artista adaptada al modelo burgués de masculinidad. Se reivindica en Europa el carácter libre del genio, que no debe constreñirse a las restricciones de un oficio (SCHOELCHER, 1831: 281) sino dar rienda suelta a su creatividad en biografías marcadas por relatos turbulentos y plagados de obstáculos y contrariedades ${ }^{29}$. El ideal del hombre que supera las adversidades estoicamente y forja su carrera se opone a la del artista que, superado por su sensibilidad, decide apartarse de las normas de la sociedad, y por lo tanto de la adaptación a una masculinidad normativa basada en las leyes de la política y el comercio $^{30}$. Es así como lo señala el autor del artículo "De la position sociale de l'artiste" publicado en 1832 en L'Artiste, manifestando - de manera un tanto idílica- que

\footnotetext{
27 "Por la extravagancia de su genio abandonó la protección sucesiva de los pintores de cámara Corrado y Mengs, que quisieron ocuparle en obras del rey, pero entregado a sus caprichos, apreciaba más la libertad que lo honores y los bienes de fortuna" (CEÁN, 2001, t. IV: 139).

28 "Se ocupaba en pintar al temple arcos y adornos (...), obras siempre apresuradas que dejan más utilidad pecuniaria que buen nombre, sin detenerse en los escrúpulos del dibujo, pero que satisfacen a los ignorantes" (CEÁN, 2001, t. V: 61).

29 "¿A qué precio se les hace pagar la gloria? Lo sabemos, al precio de la miseria, del abandono, de las lágrimas más amargas. La desgracia ha sido tal que hasta nuestros días se ha hecho que se ha convertido en la savia necesaria de su genio, y que, por una triste broma, se ha convertido en algo banal pretender que sean necesarios grandes y profundos sufrimientos para producir grandes obras (...) gemimos ante estos nobles infortunios, los contamos con lágrimas e inagotable dolor; hemos creado, con el fin de explicar estas gloriosas miserias, unas máximas cómodas y banales: que el genio ha nacido para sufrir, que la infelicidad fecunda el genio" (SAINT-C., 1832: 51).

${ }^{30}$ En un artículo publicado en L'Artiste se sugiere que el artista, en su esfera elevada, no desea implicarse en las banalidades del mundo de la política [“¿En qué afectan nuestras tormentas a los artistas, a esos locos sublimes, como los calificamos, que, en su esfera elevada viven su vida aparte, su vida blanda y soñadora, y que temen tocar el suelo de la política tan movediza y volcánica?” (G.L.,1831: 233).
} 
la mayor consecuencia de la Revolución Francesa para el artista reside en la emancipación de la protección de los poderosos:

Ya no sabemos lo que es la protección de un gran señor o de un financiero; ya no hay favores embrutecedores, pensiones o limosnas tiradas al artista por parte de un rico o de un noble que solo piden a las creaciones del arte esparcimiento y diversiones para sus ocios. El artista hoy está situado en medio de toda la sociedad (...). Ya no es lacayo, sino pueblo; no espera su salario más que de su trabajo y de las producciones libres de su genio; su posición social se ha convertido pues en algo más moral, más independiente, más capaz de favorecer los progresos del arte (SAINT-C., 1832: 53).

Es preciso señalar que, a pesar de la idealización del carácter romántico, y aunque no sea el tema predilecto de la biografía romántica francesa, el elogio del mérito en relación con la institución y el arte oficial permanece presente a través de las figuras de poder (el Institut y la École des Beaux-Arts, así como la Académie de France en Roma) contra las cuales esta imagen tópica del artista emancipado pretende rebelarse señalando las constricciones profesionales y masculinas a las que le someten estas y manifestando su desprecio ante la vigencia, especialmente en la esfera social, de un modelo de artista basado en el éxito y la jerarquía (no en vano Gustave Planche la denomina "la aristocracia oficial de los pintores, escultores y arquitectos" [PLANCHE, 1832: 117]), de la cual Heim dejará amplia representación plástica.

En el caso español, la imagen del artista como un hombre fuertemente vinculado a la sociedad a través de las instituciones garantes de su privilegio permanece vigente en las biografías de artistas, a pesar de la introducción de pequeños tópicos, y se ofrecen relatos que afianzan las aspiraciones burguesas de pintores y escultores contemporáneos a través del mérito, el estudio y el trabajo. La forma en que las biografías publicadas en El Artista (1835-1836) inciden en este tema es aún algo velada, pero indiscutiblemente visible en las de artistas contemporáneos, donde se prescinde de algunos tópicos relacionados con la infancia del genio a favor de una personificación del artista como hombre de su sociedad. Sin embargo, ofrece diferencias respecto a otras biografías de contemporáneos publicadas por la revista francesa L'Artiste, en la que es exclusivamente la obra la que constituye el elogio del mérito (H. de V., 1832: 301-302). De este modo, Eugenio de Ochoa no duda en señalar que José Álvarez Cubero nació "de padres honrados y de escasa fortuna", y que es a través de la aplicación y de sus progresos en los estudios académicos como el escultor forja su carrera, adaptándose a los distintos escalones de la jerarquía artística, desde los premios de estudio a la pensión en París, los salones y el éxito en el extranjero, especialmente su vinculación a la Academia de San Lucas; todo ello manteniendo una actitud viril y virtuosa ("el joven español se presentó en la palestra, sin arredrarle la novedad del teatro, ni su calidad de extranjero, ni la falta de protección que pudiera temer en un país extraño y entre gentes desconocidas" [OCHOA, 1836a: 122]). Algo similar ocurre en la biografía que Juan Nicasio Gallego redacta de Vicente López, en que aludiendo al mérito prácticamente en cada párrafo se recrea en narrar los obstáculos que debió superar en su infancia y juventud debido a la desgraciada muerte de su maestro y de su padre, obteniendo 
sucesivos éxitos gracias a su "esmero y continua dedicación" y a la "aplicación incansable y la práctica continua de cincuenta años, en los cuales tal vez no ha pasado un día sin que haya trabajado por lo menos media docena de horas" (GALLEGO, 1836: 280). También "enteramente abandonado y pobre" quedó Juan Antonio de Ribera por las muertes de su padre y la de su maestro Francisco Bayeu, obteniendo sus logros "por su mérito y su buen carácter" (MADRAZO, 1836: 25), sobreviviendo en Roma mediante la realización de copias. Todo "estudio y laboriosidad" era también Isidro González Velázquez, a pesar de algunos tópicos excesivos respecto a las penurias a que su carácter intrépido y estudioso le sometió haciendo mediciones en Italia, quien aun en su ancianidad continuaba trabajando con la misma intensidad que en su juventud (ANÓNIMO, 1836: 2-5). Del mismo modo, de los honores de José Ribelles se dice que fueron granjeados por su laboriosidad y su mérito, "pues bien sabemos que no era intrigante ni adulador" (U. y R., 1836: 38), y que en los giros de la fortuna se vio obligado a salir adelante dedicándose a la pintura de decorados teatrales. Finalmente, la última biografía de un artista contemporáneo incluida en El Artista es la de José de Madrazo, que también incide en el mérito y el trabajo del pintor, aludiendo a sus progresos -manifestando para ello el incremento de la dotación económica de su pensión-, a las dificultades políticas a que se enfrentó en Roma y a sus éxitos pictóricos (CARDERERA, 1836: 306-310). La biografía de Madrazo llama también la atención por la inclusión de una brevísima alusión relativa a la "dulzura de la vida doméstica", que debe vincularse a los ideales de domesticidad y de realización a través de la familia, un rasgo que comenzará a acompañar los relatos biográficos de artistas contemporáneos como virtud masculina a subrayar del artista en cuanto hombre.

Las biografías de artista aparecidas en El Museo Universal mantienen unos esquemas similares, subrayando en primer lugar las adversidades que lastran el mérito artístico, para destacar posteriormente los cargos obtenidos -incluyendo, en ocasiones incluso, la dotación económica como dato a tener en cuenta por el lector. De este modo, en la biografía que Milanés publica de Juan Antonio de Ribera señala las dificultades sobrevenidas tras la invasión napoleónica, encontrando auxilio en Roma en Carlos IV y María Luisa, quienes lo nombraron pintor de cámara

con el sueldo vitalicio de 18000 reales, confirmado después en las capitulaciones con Fernando VII, sueldo que le fue suprimido por ignorarse sin duda la procedencia de esta carga, en el arreglo de la servidumbre de palacio del año 1835 (...) Combatido siempre este artista por las privaciones y las desgracias, le tocó quedar excedente y oscurecido en la reforma de la servidumbre de Palacio hecha en 1835, y en esta posición, verdaderamente triste para un hombre de su mérito y singulares servicios en la real casa, relegó la paleta y los pinceles al olvido (MILANÉS, 1857: 30).

La orfandad de Juan Antonio de Ribera encuentra su equivalente en otra biografía contemporánea, la de Antonio María Esquivel, destacando los orígenes artísticos entre las privaciones de la vida y los trabajos pictóricos realizados para asegurar su subsistencia, algo a lo que se relaciona también lo prolífico de su obra (especialmente la retratística). También huérfano de padre y madre partía el escultor Manuel Vilar como 
pensionado a Roma, "pero le acompañaba un ángel custodio que se llama talento" y con continuos esfuerzos obtuvo éxitos "en el ejercicio de su arte y de los deberes sociales" (ANÓNIMO, 1862: 67). La transmisión paternofilial del saber artístico también es incluida como rasgo destacable en los casos en que procede, como en el de Ribera ("su hijo primogénito don Carlos Luis, bien conocido ya entre los amantes de las bellas artes por sus obras" [MILANÉS, 1857: 30]) o en el de Antonio María Esquivel ("su hijo, digno heredero del nombre de su padre, ha demostrado ya también que es muy capaz de conservar y aun enaltecer su gloria, su crédito y sus laureles" [ANÓNIMO, 1857: 55]). Laboriosos y de vida irreprochable, tales son los calificativos empleados hacia los artistas biografiados por El Museo Universal, como manifiesta el "trabajo asiduo" de Víctor Manzano, cuya plenitud profesional estuvo acompañada de "las dulces emociones que proporcionan el santo cariño de la familia" y "los dulces afectos de la amistad" (ANÓNIMO, 1862: 363).

Las biografías posteriores indican un interés por resaltar la doble imagen del artista como trabajador profesional y esforzado, modesto y laborioso (así se califica, por ejemplo, a Ponciano Ponzano [ANÓNIMO, 1877: 186]), en una exaltación nueva de la profesión artística en su vertiente más manual (en el caso de Casto Plasencia, a quien se describe satisfecho "cubierto de polvo y subido a un andamio" [ANÓNIMO,1876: 307]), tal y como se desprende de la inclusión de las relaciones de formación en el extranjero y los premios en exposiciones y cargos oficiales obtenidos; pero también como hombre consciente de su papel en la sociedad. El artista como hombre completo prolifera en las páginas de La Ilustración Española y Americana, mostrando el premio del mérito no solo en una carrera exitosa, sino en la felicidad de las relaciones públicas y de la vida familiar. Respecto a las primeras, es reseñable el listado de virtudes que se atribuyen al joven Casado del Alisal como apoyo fundamental a su carrera profesional, y que Ricardo Becerro de Bengoa resume en "la fe en el arte, la laboriosidad más absoluta en el trabajo y la formalidad más exquisita en la vida y en la sociedad ${ }^{31}$ ". En términos similares se menciona a los hermanos Benlliure, cuyo mérito artístico "constituye una verdadera leyenda, leyenda del trabajo, de la constancia, de la aplicación, de la virtud", retomando el discurso del hombre que se hace a sí mismo al hablar de unos artistas "que nacidos de humildes y honradísimos padres gozan hoy de envidiable renombre" (IBÁÑEZ, 1891: 402), o del propio José, a quien se atribuye una juventud llena de trabajo, haciendo vida sobria y recogida (ANÓNIMO, 1893: 203). El incidir en la conducta virtuosa permite también hablar de un tipo de dominación silenciosa, basada en la autoridad y en el recto comportamiento, especialmente en lo que respecta al dominio de sí mismo y de las pasiones violentas. No debe extrañar, por lo tanto, que al hablar de Bernardo Rico en relación al Círculo de Bellas Artes de Madrid se le describiese en los siguientes términos

\footnotetext{
${ }^{31}$ A estas virtudes, añade la constancia más absoluta en el trabajo, señalando que "no ha descansado en un espacio de cerca de treinta años, llevando a cabo una obra que sorprende y admira, no solo por lo magistral, sino por lo que como trabajo significa (...) Firme en su puesto, ha permanecido encerrado en su estudio horas y horas y meses enteros, sin dar lugar a las treguas que oxidan y perturban el regular ejercicio de las facultades" (BECERRO DE BENGOA, 1886: 215).
} 
Jamás adoptaba el tono grave, y todo el secreto de la autoridad que ejercía sin que lo notasen, ni pesara sobre nadie, estaba en la sencillez de su conducta, y en que más que presidir y dirigir ejercía la tutela cariñosa de un hermano. Y era en eso tan hábil o tan franco, que pidiendo consejo al parecer, hacía al fin suave y naturalmente lo que era su santa voluntad, que no era otra sino lo más conveniente para el Círculo; de condición enérgica, había aprendido a dominarse, hasta repugnarle todo procedimiento violento y brusco, como si esas desafinaciones hiriesen su temperamento (FERNÁNDEZ BREMÓN, 1894: 354),

añadiendo con especial ahínco su porte varonil y su carácter de cumplido caballero. La falta de aspiraciones profesionales, gran lastre en el hombre mundano, es percibida a medio camino entre el reproche y el respeto por parte de Fernández Bremón en lo que toca a otro artista colaborador de la revista, Alfredo Perea, atribuyéndole unos rasgos impensables en las biografías de la primera mitad del siglo: "era artista de corazón, pero sin ambiciones personales; trabajador lo estrictamente necesario para lo indispensable de la vida, gustaba de conservarse en esa penumbra poética entre la fama y la mediocridad, que permite al artista brillar sin perder su independencia" (FERNÁNDEZ BREMÓN, 1895: 98). La imagen del dibujante se aproxima más a unos patrones de conducta masculina, asociada al trabajo constante pero no brillante, y destinada en exclusiva a "tener asegurada la subsistencia por algunos días, sin pensar en el mañana", a la sociabilidad del café, casino o círculo con el entretenimiento del juego y la conversación sobre "cuadros y óperas y mujeres".

De Eduardo Zamacois se señala su vinculación con el mercado artístico parisino, adornado con "la felicidad doméstica (...) al lado de una amante esposa" y "las caricias de su hijo" (NOMBELA, 1871: 56), un carácter accesorio que figura también en la biografía de José Piquer (FLAVIO, 1871: 453). Los afanes por el estudio y el trabajo son en este momento la forma del artista de manifestar "la virilidad de su imaginación" (ARNAO, 1872: 734), como se expresa en la biografía de Domingo Valdivieso, a la que debe acompañar su correspondiente familiar que encauza a esta no solo en la buena moral burguesa, sino también en el círculo vicioso de necesidades afectivas y económicas masculinas. Es un rasgo que se subraya también en la biografía de Joaquín Domínguez Bécquer, a quien se alaba no solo su buena disposición al hacerse cargo de los hijos de su difunto maestro y primo, sino el cumplimiento de una "sagrada obligación" (ANÓNIMO, 1880: 61). La sutil manera en que se deja entrever la vida personal del artista responde también a los gustos del lector, que no solo desea encontrar la retórica tipificada del artista como genio, sino una vertiente más humana anclada en las vicisitudes de la vida real, incluyéndose datos conmovedores sobre la familia que otorgan mayor patetismo a la pérdida del artista en cuanto profesional y hombre ${ }^{32}$. Así, en la biografía publicada tras la muerte de Ricardo Balaca se busca dar un carácter de fatal premonición a sus últimos trabajos, puesto que en Una alameda de la Real Casa

\footnotetext{
${ }^{32}$ Sirve como excepción el caso de Valentín Carderera, a quien se señala como familia adoptiva a sus protectores, el duque de Villahermosa y los condes de Guaqui, respaldándose en la figura de Carderera como pintor y erudito consagrado a sus estudios, así como en el cultivo de la fe y la religión (N., 1880: 350), o el de Casado del Alisal, que vuelca sus afectos familiares en sus hermanos (BECERRO DE BENGOA, 1886: 215).
} 
de Campo "representó a una joven y apenada viuda que, acompañada de cariñosa madre, paseaban lentamente por la solitaria alameda" y "tomó como modelo a su esposa y a su propia madre para aquellas dos figuras, cuyos semblantes expresan una aflicción profunda que hoy, por desgracia, es triste realidad" (ANÓNIMO, 1880: 181). Francisco Sans y Cabot también gozaba de una vida familiar satisfactoria, como indica que el día de su muerte hubiese comido "a la mesa de su familia", grabándose el patetismo narrativo en el hecho de señalar que se desplomase "en los brazos de su acongojada esposa" (ANÓNIMO, 1881; 299), aunque el paroxismo en este tipo de relato biográfico se alcanza al referir la escena de la muerte de Bernardo Rico (FERNÁNDEZ BREMÓN, 1894: 354). A pesar del gusto por lo truculento, la excusa de la vida familiar es también empleada, más allá de como simple complemento de lo masculino, como una manera de justificar el trabajo asalariado o el no haber llegado a alcanzar la gloria artística; así lo refleja Parada y Santín en la biografía que redacta a la muerte de Luis de Madrazo, recriminando de manera velada la actitud del pintor al ser relegado a un segundo puesto, eclipsado por su hermano Federico:

A ello contribuyó más que nadie con su exagerada modestia el mismo D. Luis, que, admirador de los trabajos de su hermano y por su carencia de vanidad personal, buscaba en la vida del hogar y en la satisfacción de su recta conciencia otros goces, no tan deslumbrantes como los que proporciona la gloria, pero más positivos y duraderos (PARADA Y SANTÍN, 1897: 147).

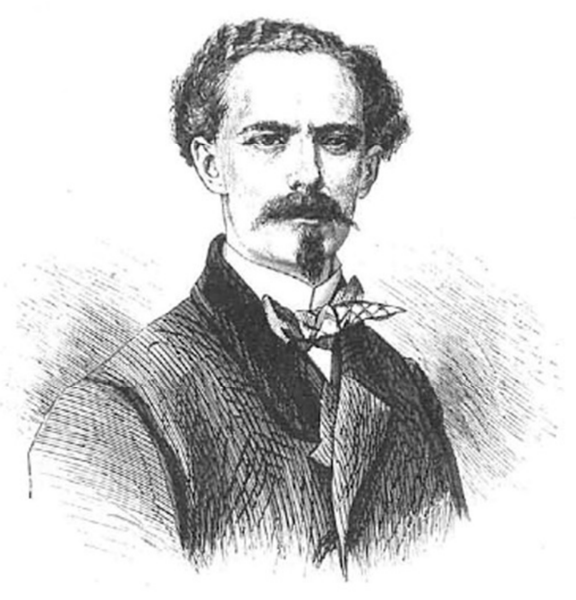

Fig. 1. José Casado del Alisal. El Museo Universal, 25 de noviembre de 1860, p. 381.

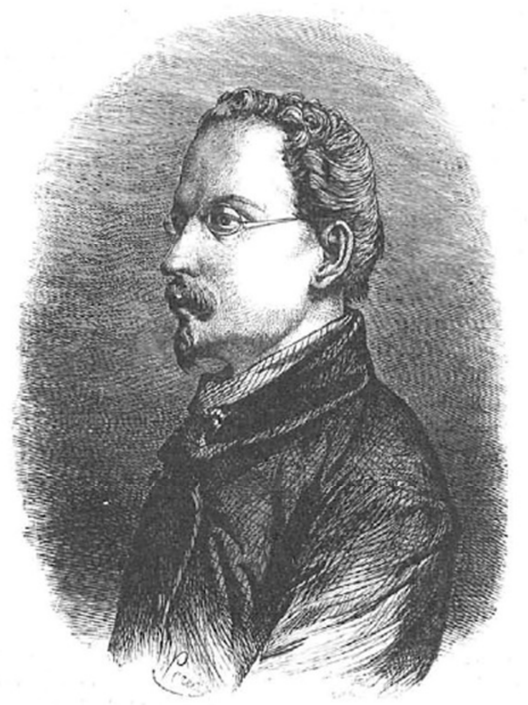

Fig. 2. Federico de Madrazo. El Museo Universal, 29 de julio de 1860, p. 245.

El interés por el éxito profesional del artista se manifiesta en la progresiva inclusión de retratos de artistas vivos en la prensa periódica con motivo de un hito en su carrera; de este modo, frente a los retratos litográficos que acompañaban a todas las biografías aparecidas en El Artista, El Museo Universal incluye no solo los retratos xilografiados de los artistas a los que dedica una nota necrológica, sino también los de los premiados en la Exposición Nacional de 1860, Antonio Gisbert, Francisco Sanz y José Casado del 


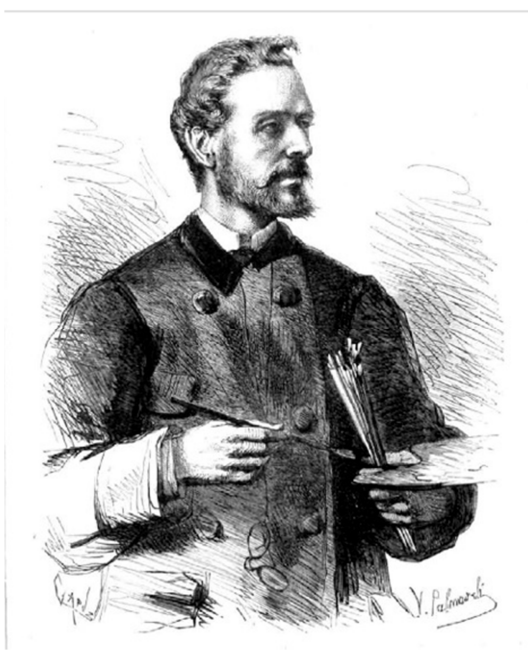

Fig. 3. Eduardo Rosales, La Ilustración Española y Americana, 8 de enero de 1871, p. 1.

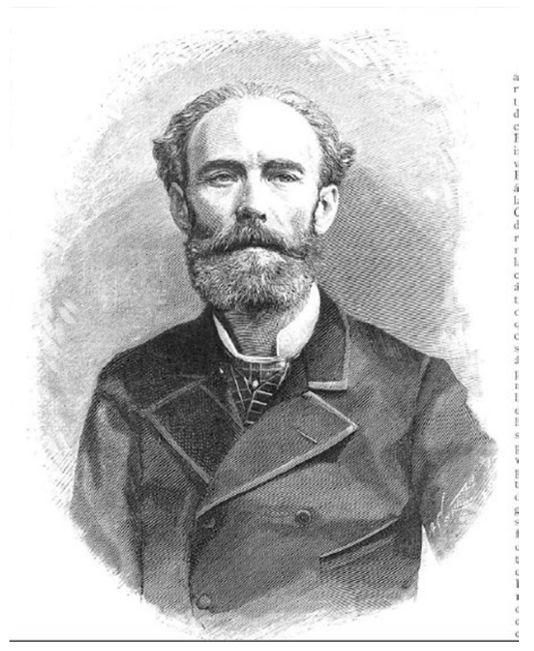

Fig. 4. José Casado del Alisal, La Ilustración Española y Americana, 8 de febrero de 1882, p. 83.

Alisal $^{33}$ [fig. 1], y en1867 los de Benito Mercadé y Vicente Palmaroli ${ }^{34}$, y de Federico de Madrazo [fig. 2] con motivo de su nombramiento como director del Museo de Pintura (ANÓNIMO, 1860: 245).

Del mismo modo, La Ilustración Española y Americana se sumó a la nueva tradición de plasmar a los héroes culturales contemporáneos insertando en enero de 1872 un retrato de Eduardo Rosales diseñado por Palmaroli [fig. 3], con motivo de su controvertido éxito en la Nacional de 1871 con La muerte de Lucrecia; el retrato de Francisco Pradilla, dibujado por Perea, se publicó en 1878, con motivo del éxito alcanzado en la Nacional de ese mismo año (ANÓNIMO,1878: 298); y en relación a la Exposición Universal de París de 1878, incluyó también los retratos de los pintores Martín Rico y Raimundo de Madrazo, dignificados con el honor de aparecer en primera plana como deferencia a las condecoraciones otorgadas por el gobierno de Mac Mahon. En 1882 se publicaba, junto a una reproducción del cuadro La leyenda del rey monje, el retrato de su autor, José Casado del Alisal [fig. 4] (ANÓNIMO, 1880: 83), con motivo de reconocer mediante ambas ilustraciones no solo el éxito obtenido en la Exposición Nacional de 1881, sino el hecho de que el Estado aprobase en 1882 la adquisición de la obra. Una biografía, acompañada de su correspondiente retrato, de Arturo Mélida es insertada en la misma revista, con motivo de su obra del Pabellón Español de la Universal de París de 1889 (ANÓNIMO, 1889: 179), mérito que también es compartido por el pintor Manuel Domínguez por su labor en el comité de la sección española de Bellas Artes (p.226), y por Luis Jiménez Aranda, premiado con medalla y condecorado con la Legión de Honor. En 1891 se incluye el retrato de José Moreno Carbonero, con motivo del éxito alcanzado por el pintor en las exposiciones de Budapest y Berlín en ese año (ANÓNIMO, 1891: 131), y dos años después el de Joaquín Sorolla (ANÓNIMO, 1893: 27) y el de José Benlliure (ANÓNIMO, 1893: 217),

\footnotetext{
${ }^{33}$ Los dos primeros figuran en el número correspondiente al 18 de noviembre de 1860 (373), mientras el de Casado del Alisal se publica en el del 25 de noviembre del mismo año (381).

${ }^{34}$ El retrato de Benito Mercadé se publica el 24 de febrero de 1867 (60), y el de Vicente Palmaroli el 3 de marzo (69).
} 
ambos por sus éxitos en la exposición internacional de Madrid de 1892. Nuevamente aparece un retrato y breve biografía de Joaquín Sorolla en 1895 para celebrar el éxito del artista en la Exposición Nacional (ANÓNIMO, 1895: 162).

Entre los éxitos que hacen del artista una figura de interés público se encuentra también el acceso privilegiado a la institución académica; así pues, se comienzan a incluir también los retratos de los nuevos académicos de San Fernando, como Jerónimo Suñol (ANÓNIMO: 1882, p.385), Ricardo Bellver (ANÓNIMO, 1890: 147) o José Moreno Carbonero, así como de los nuevos profesores ${ }^{35}$ y de los directores de la Academia Española en Roma.

\subsubsection{Otra masculinidad artística: privilegio a través del mercado}

Uno de los conflictos a los que se enfrenta el artista es la negociación de su papel en la sociedad a través de su posición económica, ya que la voluntad de realización de una carrera propia y la apertura del mercado a través de nuevas figuras intermediarias entre público y artista permiten a este una nueva vía de obtener ingresos, en ocasiones elevados, a partir de la venta de su obra. Las críticas hacia una emancipación del artista del sistema institucional oficial se basan no solo en la asimilación de la idea de que el artista se debe a obras elevadas, sino también en el choque de intereses que supone el hecho de que un artista pueda adquirir una posición social y económica privilegiada sin estar sometido a las restricciones profesionales académicas. Se trata, por lo tanto, de una nueva negociación del privilegio del hombre artista fomentada por el sistema económico, con su nueva demanda de obras por parte de una burguesía enriquecida, y también por el carácter elitista de las jerarquías oficiales. Sin embargo, y a pesar de que desde los años treinta del siglo XIX se habían ido haciendo patentes las necesidades de protección económica por parte de los artistas, la relación entre arte y mercado suele pasar desapercibida en el género biográfico, entendiéndose como una preocupación menor del hombre artista -aquella que lo equipara al resto de mortales y que subraya su condición de hombre (masculino), limitado por las necesidades familiares $\mathrm{y}$ profesionales.

Es el caso en el que se aborda, por ejemplo, la dedicación a la pintura de género; ampliamente descalificada esta por la crítica y por los artistas académicos por su fácil carácter comercial -quizás el calificativo de fácil es en el que pensaba Federico de Madrazo al aconsejar a Raimundo no dedicarse a la pintura de género ${ }^{36}$-, constituye una de las fuentes de recursos más explotadas por los artistas a pesar de que los biógrafos aluden en ocasiones a esta ocupación como un compromiso pasajero y necesario para costear obras de más envergadura. Así se emplea en la biografía que La Ilustración Española y Americana publica de Luis Jiménez Aranda en 1889, donde se dice que en

\footnotetext{
${ }^{35}$ Un caso curioso es el de Félix Parra, a quien, habiendo sido nombrado catedrático de dibujo de ornato y decoración en la Academia de San Carlos de Méjico, se le dedica un artículo biográfico y la inclusión de su retrato (AGÜEROS, 1884: 402 y 405).

36 "Me hablas de que entra en tus proyectos hacer pintura de género... no sé qué te diga sobre esto. ¡Hay tanto pintor de género! Yo creo que el género va a cansar pronto a todo el mundo, y además, habiendo hecho estudios serios, creo que debes tener otras miras más elevadas" Carta de 9 de mayo de 1866 (DÍEZ, 1994a: 648).
} 
Roma "la necesidad de ganar algo sometió su pincel al género agradable de majas y casacones, entonces a la moda" (ANÓNIMO, 1889: 354).

El debate sobre la faceta mercantil del arte ya había salido a colación en el debate público español con motivo de las exposiciones y ventas organizadas por las primeras sociedades artísticas, en las que la crítica no veía obras propias del genio. La relación entre arte y economía radica, en primer lugar, en la necesidad individual del artista que pretende ganarse la vida con su trabajo. José Puiggarí señalaba la dicotomía existente entre el idealismo y la realidad social del artista en cuanto hombre en La Ilustración española y americana, afirmando que

Ninguna posición social en el día es más equívoca y comprometida que la del artista. Misionero de ideas sublimes, criado en la esfera de la identidad y obligado a abstraerse del realismo de la vida en busca de inspiración, queda enteramente descaminado y fuera de su centro cuando la generación a quien se consagra, descarriada a su vez por muchos rumbos, no le comprende ni aplaude, y por consiguiente lo le premia. (...) En efecto, el artista, al igual que el poeta, si bien ejerce una misión, no es un apóstol: es un ciudadano, como otro cualquiera; debe vivir de su industria, y ganarse el sustento, ayudado de las gentes con quienes vive (PUIGGARÍ, 1870: 222).

A esto contribuye la realidad socioeconómica que algunos artistas alcanzan en territorio francés, especialmente en el ejemplo ofrecido por Meissonier, cuyos discípulos españoles adquirieron fama por su dedicación al tableautin y por el renombre que este género les reportó, asumiendo también que se vinculaba a unos ingresos económicos notables que les ayudaba a mantener un nivel de vida elevado; de este modo, a partir de los años setenta la imagen del artista español que triunfa en el mercado aparece con relativa frecuencia. Al dar noticia del fallecimiento de Luis Ruipérez se le señala como único discípulo de Meissonier, y que siguiendo su estilo "pintó innumerables cuadros a los que dio siempre fácil salida" (ANÓNIMO, 1867: 366). La noticia biográfica aparecida tras la muerte de Eduardo Zamacois indica, de manera bastante sumaria, el enriquecimiento del artista debido a que "la justa fama que adquirió Zamacois aumentaba el precio de sus trabajos", aunque se percibe cierta incomodidad en el planteamiento de la cuestión por parte del autor, Julio Nombela, quien afirma también que el pintor realizó en seis años "más de cincuenta obras, que adquiridas a gran precio han centuplicado su valor con la muerte del artista" (NOMBELA, 1871: 56). La producción de Galofre también se observó con ironía al tratar de las obras destinadas al comercio, tal y como recoge Pasquino al afirmar que "Galofre, el distinguido acuarelista, ha terminado también sus consabidas veinte acuarelas grandes que pinta todos los veranos en las orillas del golfo de Nápoles y que luego vende en Roma a razón de 1000 liras cada una, es decir, un total de 4000 duros. No es mala renta. ¡Hable usted luego mal del arte!” (PASQUINO, 1882: 1).

El valor económico de la obra de arte es motivo de preocupación al darse el caso de que la especulación en el mercado del arte produjese fortunas dispares, disparándose la desigualdad económica y social entre artistas. El recelo suscitado por el artista adinerado puede percibirse como un miedo ante la injerencia de este y sus mediadores 
en el ámbito del mercado y la economía burguesa, haciendo del artista no ya una simple figura de producción, sino también capaz de negociar su capital. La Ilustración Española y Americana subraya el hito del precio por el que Vanderbilt adquirió en París una obra de José Villegas "en la respetable suma de 150000 pesetas" (WOLFF, 1880: 1), ofreciendo al público un retrato del autor al no poder reproducir la obra "ante el criterio exclusivista de su poseedor, quien a nadie ha permitido sacar fotografías" (ANÓNIMO, 1880: 83). La controversia sobre el elevado precio de la obra, que pareció inconcebible "a algunos croniqueurs del boulevard", se debía, según el autor del artículo, a que no se trataba de una obra de los pintores más cotizados de la capital francesa, como Meissonier o Bonnat. Curiosidad o simple coincidencia, el retrato que Villegas ofrece para ser reproducido en la revista es obra de Mariano Fortuny, estableciéndose así una interesante comparación que parece legitimar las aspiraciones económicas de Villegas, a pesar de que las críticas francesas señalaban que la introducción de Villegas en el mercado parisino se correspondía a una estrategia de "invención de fenómenos extranjeros" directamente inspirada en el caso de Fortuny, no sin antes comparar la relación entre artista y marchante con la de una prostituta y su madame. El precio de la obra es, sin duda, elevado en comparación con los que se adjudicaron a otras de sus obras en ventas; así, en la organizada por Durand-Ruel en 1881 con los bienes de Everard las obras de Villegas alcanzaron precios que oscilaban entre los 1500 y los 10000 francos (1881: 35), respondiendo a las apreciaciones de Albert Wolff sobre la breve duración que tendría que fenómeno Villegas en París.

\subsection{La formación artística y los aprendizajes de la masculinidad vinculada al artista}

\subsubsection{Mito y realidad sobre la infancia y juventud del artista decimonónico}

El hecho de que la infancia del artista como seña inconfundible del temprano despertar del genio tuviese un gran desarrollo en la literatura artística decimonónica no es, en absoluto, sorprendente; Kris y Kurtz vinculaban el recurso a la infancia del artista como una necesidad de explicación causal, mitificada a través de la premonición, por parte de la sociedad ante individuos singulares (KRIS y KURTZ, 1995: 31). La idea desarrollada por la estética romántica de que el genio artístico conserva un espíritu creativo como el de los niños, como señala Esperanza Guillén (2007: 107), alimentó aún más esta estrecha relación entre la infancia del artista y la conversión de su biografía en un mito: de este modo, el artista-niño y sus singulares dotes constituyen tema de interés para la sociedad culta y fuente de inspiración entre pintores dispuestos a señalar la singularidad de la creación pictórica. Esta configuración de una imagen mítica del artista desde su infancia plantea sin embargo una problemática que no puede pasar desapercibida: por una parte, porque deja en segundo plano la posibilidad de un despertar tardío de la vocación artística -ya sea en la juventud o en la madurez del hombre; por otra, revela que el interés por la infancia del artista solo tiene interés en función de su yo futuro, es decir, de su consolidación artística y su proyección como héroe cultural, pasando por alto el paso de ese despertar del genio en potencia al artista creador al obviar el proceso de aprendizaje común a los artistas en los años de su 
infancia y su adolescencia. Thierry Laugée lo plantea de una manera significativa, relacionando esta ausencia en las biografías artísticas de los años de aprendizaje con la idea de que este "no parece revelar ni genio, ni divinidad" (LAUGÉE, 2011: 231); es decir, que los años del aprendizaje artístico equivalen a un rasgo común de esa parte de la humanidad dedicada al arte, convirtiéndose en una etapa pasajera, desindividualizada y carente de interés más allá del establecimiento de un hipotético linaje maestrodiscípulo. Sin embargo, la afirmación de Laugée, planteada desde el punto de vista del genio artístico, permite generar otros interrogantes más relacionados con la práctica artística decimonónica y la construcción de la identidad masculina del artista.

Considerando que el despertar de la vocación artística así como el aprendizaje se producen en los años en los que el niño no solo es ya consciente de la diferencia de género, sino que está configurando su identidad sexual por asimilación y repetición de los modelos que observa en su entorno, se desprende como consecuencia lógica el que, durante su infancia y adolescencia, el joven artista asimila como propias no solo una serie de pautas masculinas vinculadas a su contexto sociocultural, sino también las peculiaridades de la identidad y comportamientos -variables a lo largo del siglo XIXdel hombre artista. La elipsis en el relato biográfico de la formación del artista no es ni puede ser casual en una narrativa construida desde y para la autocomplacencia masculina del héroe -y por lo tanto figura dominante- cultural; no solo abandona el terreno espinoso de la equiparación momentánea del genio con el resto de la humanidad al precisar aprender para desarrollar su hipotético potencial, sino que olvida por completo un momento decisivo de asimilación del patrón de conducta masculina en el que el artista ha ocupado el puesto más bajo de la jerarquía. Para el artista y el erudito que codifican la biografía del personaje singular desde su propia posición de poder no existe nada más revelador de la inseguridad que suponía la fase de formación como momento de consciente asimilación de la escala jerárquica del mundo artístico que la supresión, consciente o inconsciente, de la adolescencia del artista y su sustitución por velados tópicos.

Al plantear la problemática que supone la mitificación de la figura del artista para la interpretación de la construcción de su identidad masculina no debemos, sin embargo, concluir de antemano que por la escasez de relatos verídicos no es posible analizarla en profundidad; por el contrario, no solo el género biográfico ofrece interesantes datos a través de lo que elude en su deseo compensatorio, sino que su cotejo con otras fuentes permite establecer algunos puntos esenciales para la comprensión de la masculinidad del artista en formación. De este modo, las biografías de artista constituyen una fuente interesante para observar los cambios en la forma de abordar las vidas en función del código de masculinidad normativa imperante en cada momento y establecer las particularidades que se atribuyen al hombre artista dentro de la sociedad; los relatos autobiográficos, a pesar de su componente novelesco y de la inconfundible perspectiva de rememoración nostálgica desde la edad madura, tienen el componente añadido de introducir reflexiones o confesiones sobre la vivencia personal de la formación artística; a ellos es preciso vincular la documentación histórica relacionada con las prácticas y comportamientos del joven artista dentro de los entornos de formación, ya fuesen 
estudios particulares, escuelas de dibujo o la propia Academia, que traducen, en ocasiones codificada mediante la inclusión de nuevas prohibiciones en estatutos o en el endurecimiento de los castigos previstos en los reglamentos, la tensión existente entre la asimilación del escalafón más bajo en la jerarquía artística masculina y las vías de escape del joven artista para la reafirmación de su masculinidad; y por último, y fuente principal de nuestro estudio, las evidencias gráficas de cómo esta identidad masculina era interpretada plásticamente tanto por parte de los artistas adultos vinculados al entorno de aprendizaje -familiar, escolar o de taller- del niño o adolescente, como por el propio artista a través del raro ejemplo del autorretrato de juventud.

\subsubsection{Las infancias del artista: biografía y autobiografía en clave masculina}

La publicación en El Artista de algunas biografías de artistas plantea uno de los primeros acercamientos divulgativos en la prensa española de estos como exitosos personajes culturales, así como una voluntad de dar a conocer la imagen del artista a través de su retrato. En estos relatos, la infancia y la formación artística son abordados desde el tópico, no solo en el caso de los artistas del pasado, sino también y significativamente, en el caso de los grandes artistas contemporáneos. De este modo, si en el caso de Velázquez se plantea la formación con Pacheco, se hace desde un punto de vista de total libertad de expresión del genio ${ }^{37}$; en el del escultor José Álvarez Cubero se alude a la práctica artística desde la infancia, equiparándolo a Miguel Ángel, mencionando de pasada el aprendizaje académico (OCHOA, 1836a: 121). La elipsis es total y premeditada en el caso de José de Madrazo, en el que el biógrafo, Valentín Carderera, se excusa de esta manera:

Nada ciertamente interesarían a nuestros lectores las minuciosidades y detalles de todos los pasos de su primera edad, y aun cuando quisiéramos tomarnos este superfluo trabajo, difícil nos sería desempeñarlo por la falta de noticias; además, ¿a qué conduciría el saber que siendo niño llenaba los papeluchos de gurrapatos, que dibujaba monos por todas las paredes, y otras cosas de este jaez? (...) Así pues, contentándonos con decir que estudió en Madrid el dibujo bajo la dirección de don Cosme de Acuña y don Gregorio Ferro, directores entonces de la Real Academia de San Fernando, pasaremos a considerar al artista en la edad en que el talento humano es capaz de obrar a favor de la verdadera gloria; porque un artista de mérito es un ser privilegiado por el cielo, y su misión en el mundo no empieza como la de muchos santos del calendario desde antes de poderse considerar como hombres (CARDERERA, 1836: 306).

Pretextando la falta de noticias, algo inverosímil debido a su directa relación con Madrazo, Valentín Carderera expone la idea de que el artista ha de ser considerado solo en su madurez en relación con los frutos de su trabajo, algo muy vinculado con el concepto del artista como hombre trabajador. Pero la intención de Carderera resulta

\footnotetext{
37 “Dio Velázquez desde sus primeros años notables indicios de su mucho ingenio, sobresaliendo en todos los estudios a que se dedicó, como si para todos hubiera recibido iguales disposiciones de la naturaleza; pero no tardó en dar muestras de su extraordinario talento para la pintura (...) pasó a la escuela de Francisco Pacheco, profesor de un carácter dulce y más instruido en la teoría del arte que en la ejecución. Luego que Pacheco conoció la gran disposición de su discípulo y su inclinación a pintar la naturaleza, le dejó que se dedicase a ella con toda libertad..." (OCHOA, 1836b: 6 y 7).
} 
sospechosa, ya que lejos de ensalzar una infancia y adolescencia en la que el aprendizaje artístico requirieron por parte del pintor un gran esfuerzo, elude, a favor de la reputación social de Madrazo, la realización de tareas serviles como medio de subsistencia $^{38}$ y el análisis detallado de su formación académica. En la biografía de Juan Antonio de Ribera es evidente un concepto algo distinto, ya que Federico de Madrazo incide en las penurias acontecidas durante la etapa de formación del pintor aunque solo menciona de pasada los mentores con los que contó (MADRAZO, 1836: 25). Tampoco en el caso de la biografía de Vicente López se incluyen grandes detalles, señalando el componente familiar con la formación paterna, y de manera desganada su paso por las academias de San Carlos y San Fernando (GALLEGO, 1836: 277); la excepción de la de Isidro Velázquez (ANÓNIMO, 1836: 2) tal vez pueda estar determinada por la procedencia de una familia de artistas de conocida reputación y por las peculiaridades del aprendizaje en la arquitectura, estrictamente reglamentado. En estas biografías, así como en la del último artista contemporáneo publicada, correspondiente a José Ribelles $^{39}$, es preciso notar algunos elementos comunes en estos relatos y los datos deliberadamente olvidados en ellos: por una parte, la importancia de la formación familiar busca dar cabida a una historia genealógica que adapta a los vínculos familiares $\mathrm{y}$ afectivos los profesionales; por otra parte, la enseñanza académica, que apenas es mencionada, se configura exclusivamente a través del logro de los premios en esta, manifestando así el impacto que un sistema de aprendizaje basado en la superación de pruebas tenía para los jóvenes artistas.

No obstante, algunas autobiografías y memorias sí que mencionan elementos de la formación artística que pueden vincularse con la iniciación a la sociabilidad y los comportamientos masculinos del joven artista. Deben mencionarse, en primer lugar, las situaciones que subrayan la pervivencia de un sistema jerárquico en los ámbitos de aprendizaje artístico, en los que puede leerse una muestra de la estratificación social a través del reparto de tareas o de la función destinada a cada tipo de enseñanza artística. El sistema artístico, y especialmente el del aprendizaje, entendido como una escala de méritos al combinarse entre la enseñanza reglamentaria en la Academia y posteriormente en las Escuelas Especiales y el ámbito privado del taller, mantiene a lo largo del siglo un cierto componente gremial que tiene también como resultado el establecimiento de jerarquías basadas en la edad y en la antigüedad entre alumnos y discípulos, especialmente en los talleres privados. Así, prácticas y tareas como el molido de los colores, el limpiado de los pinceles o el aparejamiento de los lienzos, tradicionalmente delegadas en los aprendices ${ }^{40}$, podían ser igualmente asignadas a los

\footnotetext{
${ }^{38}$ Por su parte, Federico de Madrazo recordaba que su padre era propenso a hablar de su formación artística con Gregorio Ferro, quien le había retratado en una de sus obras de altar como uno de los ángeles, mencionando "varias veces me llevó a verlo y siempre que servía esto de motivo para tener el gusto de recordar a su buen maestro" (GONZÁLEZ LÓPEZ y MARTÍ AYXELÁ, 1994: 14).

39 "Aprendió el joven Ribelles los principios del arte, bajo la dirección de su padre, hasta el año de 1799, en que vino a Madrid, y se presentó como uno de los aspirantes a los premios anuales que para los más sobresalientes preparaba la Academia de San Fernando: de los que obtuvo el segundo de primera clase en el arte de la pintura" (U. Y R., 1836: 37).

40 Las biografías decimonónicas de algunos grandes maestros inciden con énfasis en estas tareas secundarias, vinculándose con el mantenimiento de una práctica contemporánea relacionada con el
} 
recién llegados, junto con la realización de cuantos recados se estimasen oportunos. Esta situación, que en el ámbito francés se interiorizó como parte del ritual masculino del taller a través de las tareas o cargas impuestas al rapin o recién llegado por parte de los anciens (WALLER, 2000: 145; LETHÈVE, 1968: 13-14; LEMAISTRE, 1889: 38), debió tener su paralelo en el caso español, a pesar de que sean pocos los datos que conservamos al respecto. Martín Rico enuncia, de pasada, haber entrado de aprendiz en el taller de Castelló, aunque no menciona las tareas que se le adjudicaron al margen de las propias de su formación (RICO, 1906: 8). Sin embargo, otros artistas son más específicos; así, José Benlliure recordaba de su etapa de formación con Francisco Domingo el haber realizado tareas relacionadas con el servicio, vinculándolo a su humilde procedencia social:

No teniendo medios para pagar como discípulo, aunque él me dijo que nada quería, yo le solía servir de mandadero y a veces con buen sol en verano le llevaba el almuerzo de su casa al estudio, siempre de portero, porque como los otros discípulos a más de ser mayores eran señoritos yo comprendía que a mí me tocaba hacerlo antes que me lo mandaran (BONET SOLVES, 1998: 190),

un ejemplo de asimilación de una posición de inferioridad como medio de integración en la jerarquía de taller en el que se observa una predisposición por parte del propio Benlliure que podría vincularse con la que tradicionalmente se atribuye al rol femenino. A pesar de esto, Benlliure no profundiza en las posibles formas de presión que artistas y discípulos pudieron haber ejercido para el desarrollo de estas tareas, ni sobre el tipo de relaciones entre unos y otros.

\subsubsection{La formación artística como fuente de preocupación masculina}

El olvido al que ha sido sometido el aprendizaje artístico como experiencia masculina, vinculada no solo a la formación para el desarrollo de una profesión sino a sus interrelaciones con los patrones de comportamientos adolescentes, hace que las conductas de los artistas en los ámbitos académicos se hayan obviado, supeditando cualquier situación al esquema tradicional de transmisión de saberes maestro-alumno que puede contemplarse en las monografías de artista. Teniendo en cuenta que la formación artística -entendida como aquella con vocación profesional y no como complemento cultural- se produce idealmente durante la adolescencia ${ }^{41}$, no puede

aprendizaje de los rudimentos del oficio y de las jerarquías internas. Así, Tubino afirma sobre Murillo "a la sombra de este maestro adelantó Murillo en la carrera del arte. Su genio apacible, docilidad de carácter y su amable trato, fueron partes para que en poco tiempo se granjease el afecto, tanto del maestro como de sus condiscípulos, hasta el punto de que el primero cifrase particular empeño en su educación; pero sin relevarle por esto del trabajo de moler los colores, limpiar los pinceles, poner la tablilla y aparejar los lienzos, como operaciones que debía saber todo pintor que aspirase a poseer su arte con perfección", (TUBINO, 1866: 25).

${ }^{41}$ En las Academias de Bellas Artes, las indicaciones respecto a la edad de los alumnos son variadas, pero parece mantenerse la constante de que los alumnos accedían una vez cumplidos, de media, los diez años (a diferencia, por ejemplo, de la Escuela de Bellas Artes de París, que fijaba de manera muy clara los límites de edad de sus discípulos entre los quince y treinta años), en los estudios elementales, continuando los destinados al estudio de las Bellas Artes durante la adolescencia, y marcándose el límite -por restricción en los concursos de oposición- a los treinta años. Nada se dice en el caso de la Academia de San Carlos de Valencia, que en 1809 y 1828 mantiene la redacción de los estatutos de 1768 (REAL 
pasarse por alto el paralelismo entre este proceso de aprendizaje y el de configuración de una identidad masculina. Desde los estudios de género, la antropología, la sociología y la historia se ha señalado el conflicto que supone la configuración de una identidad masculina al entenderse como una maniobra de negación, es decir, de constituirse como lo no femenino, desencadenando comportamientos rudos o violentos, el recurso al lenguaje grosero, la búsqueda de la visibilidad mediante actitudes invasivas como el ruido, el humor o las actitudes sexualizadas (BADINTER: 1992, 683; SOHN: 2009). Los centros de enseñanza artística, ya fuesen academias o escuelas de dibujo, constituyeron uno de los centros de sociabilidad masculina (institucionalizada) entre los jóvenes artesanos y artistas desde la Ilustración, en el que las diferencias de edad y de procedencia social anteriormente desarrolladas en los talleres fueron manifestadas a través de tensiones internas entre discípulos y de faltas de comportamiento que, aunque penalizadas por las instituciones como forma de establecer un orden y jerarquía internos, entraban dentro de la normalidad en la formación de una identidad masculina. Junto al modelo del artista aplicado que puede encontrarse en las biografías, los reglamentos de las distintas instituciones, así como una revisión de los expedientes de los alumnos podrían arrojar datos muy interesantes sobre la construcción de masculinidades en los espacios de formación artística. A pesar de que un estudio de la documentación sobre expedientes y castigos impuestos a los distintos alumnos arrojaría datos interesantes sobre las principales faltas de conducta entre los alumnos, el tema

ACADEMIA DE SAN CARLOS, 1828), ni en los estatutos de la Academia de San Fernando de 1845, si bien la admisión en los estudios superiores - previa presentación de certificación de haber superado los elementales bien en los establecimientos de la Academia, en escuelas provinciales o con maestros privados- se haría, en este caso, con posterioridad a las edades especificadas por las academias provinciales (RABASF, 1845; ANÓNIMO, 1871: 606). Tan solo en el reglamento de 1893 se estipula, en el artículo 32, el requisito de haber cumplido doce años para poder ser admitido en la Escuela ("R. D. de 26 de diciembre de 1893...", 1893: 939). En lo que atañe a las escuelas y academias provinciales de dibujo y nobles artes, la edad mínima para el ingreso parece oscilar entre los ocho y doce años. En la convocatoria de apertura de curso para 1818, la Academia de San Luis de Zaragoza especificaba que los aspirantes debían tener la edad de diez años cumplidos (RINCÓN GARCÍA y QUINTO Y DE LOS RÍOS, 1992: 14). El proyecto de reglamento de la Escuela de Diseño de Sevilla de 1807 indicaba que la edad de los discípulos no debía ser inferior a siete años (ACADEMIA DEL ARTE DE SEVILLA, 1807). En otras academias y escuelas de dibujo se observa también que la edad mínima oscila entre los ocho y diez años, como es el caso de la Academia de Bellas Artes de Murcia, dependiente de la Sociedad de Amigos del País, que en su reglamento de 1832 estipulaba que los alumnos debían ser mayores de ocho años (REAL SOCIEDAD ECONÓMICA DE AMIGOS DEL PAÍS DE MURCIA: 1832, 6), mientras que en el reglamento de 1844 se indicaba que los alumnos destinados a la clase de Figura y Modelo debían ser mayores de diez años (REAL SOCIEDAD ECONÓMICA DE AMIGOS DEL PAÍS DE MURCIA, 1844: 6); la escuela de Dibujo de Santiago de Compostela fijaba también en 1837 la edad mínima en diez años (REAL SOCIEDAD ECONÓMICA DE AMIGOS DEL PAÍS DE LA CIUDAD DE SANTIAGO, 1837: 15), mientras que la Academia de Bellas Artes de Vitoria fijaba el mínimo de edad en once años en 1830, y doce en 1855, debido tal vez a los problemas de disciplina que se observaban en las clases (1830: 7), aunque al parecer en las escuelas de dibujo de la Real Sociedad Bascongada de Amigos del País la edad mínima había sido durante el siglo XVIII de catorce años (RUIZ DE AEL, 1992: 163). También lo fue de catorce años en la Academia de Dibujo de Burgos, según el reglamento de 1781, vigente hasta 1856, rebajándose a doce años en 1880 (IBÁÑEZ PÉREZ, 1982: 131-138). El reglamento de la Escuela Especial de Pintura de 1857 estipula que los alumnos que deseasen acceder a los estudios menores debían tener nueve años cumplidos, y los que deseasen pasar a estudios superiores, quince ("Reglamento Provisional...", 1857: 1), mientras que el de 1893 rebaja a doce la edad de ingreso ("Reglamento..." 1893: 939). 
excede los límites de esta investigación ${ }^{42}$; sí que puede observarse que, junto a la obediencia al orden promovida por la moral burguesa, el proceso de aprendizaje artístico está también vinculado de manera indisoluble a la construcción masculina aprendida y repetida en el ámbito familiar y en el educativo -ya fuesen colegios y seminarios o academias y escuelas de dibujo-, que manifiesta la necesidad de reafirmación del joven artista a través de comportamientos aparentemente atípicos. Entre estos se cuentan las faltas de respeto -generalmente a conserjes o modelos- o la rebelión esporádica contra un maestro, tratados en numerosas ocasiones de manera indulgente.

Esta imagen parece chocar con el ideal ilustrado de las propias instituciones académicas. En 1801 las actas de la Academia de San Luis de Zaragoza reflejaban el comportamiento ejemplar por parte de los jóvenes de todas las edades que acudían a los estudios, atribuyéndolo al celo de carácter ilustrado sobre la enseñanza de sus profesores y protectores, quienes se implicaban en tal grado por "asegurar la subordinación, la concurrencia, el silencio y lo demás que corresponde a las costumbres, buena educación y urbanidad" que los que acudían a visitar las aulas se sorprendían del silencio tan profundo que reinaba a pesar de estar "llenas de jóvenes de todas las edades" (REAL ACADEMIA DE BELLAS ARTES DE SAN LUIS, 1801: 34). En efecto, el papel que correspondía al alumno en la enseñanza académica era el de joven sumiso y obediente, exponiéndose a castigos de diferente índole en función de la falta cometida; por otra parte, la fiscalización de la conducta y el progresivo endurecimiento de los reglamentos en las academias y escuelas, a la par que pretendía ejercer control sobre una comunidad estudiantil muy heterogénea, formada por aspirantes a artistas, artesanos y artífices industriales, cuya educación evidenciaba las grandes diferencias de sus correspondientes contextos sociales, prueba también que la realidad distaba de este ideal de buen comportamiento. El continuo -aunque laxo- control por parte de la Academia sobre el comportamiento de los discípulos no solo pretendía asegurar el orden en el desarrollo de los estudios, sino también imponer el sistema de jerarquías del artista académico y, como señala Susan Waller en relación al caso francés, perpetuar la identidad masculina del artista a través de pautas de comportamiento (WALLER, 2000: 138); pero la rebeldía por parte del discípulo se consideró, a excepción de las faltas graves, una forma de reafirmación masculina a través del intento de llamar la atención $\mathrm{y}$, al mismo tiempo, una manera de probar la osadía e inconformismo del joven artista. De este modo, la percepción de algunos comportamientos eran entendidos como una normalidad respecto a la cual se configuraba una identidad masculina entre pares.

En España, a pesar de los desórdenes políticos, el ambiente en las clases era, al menos durante la primera mitad de siglo, heredero de los códigos de comportamiento

\footnotetext{
${ }^{42} \mathrm{La}$ información a la que hemos tenido acceso no es completa, ya que seguramente una revisión de los libros de matrículas y el análisis de expulsiones por comportamientos indebidos podría aportar información más específica sobre la configuración de masculinidades artísticas en el ámbito académico; parece, sin embargo, que las bromas y humillaciones no llegaron al caso generalizado en el ámbito francés, donde el taller era el escenario de peculiares novatadas a modo de pruebas iniciáticas en un espacio plenamente masculinizado, incorporándose posteriormente a la Escuela de Bellas Artes (WALLER, 2000: 135-151; BONNET, 2006: 124-125).
} 
ilustrados. El primer paso para la fiscalización parte de la matriculación del nuevo discípulo, en que era preciso que el alumno menor de edad aportase los datos sobre sus familiares o tutores a fin de notificaciones, lo que supone que la Academia entiendía el poder de la jerarquía familiar sobre el alumno y se servía de él al aplicar como medida de castigo el notificar sus ausencias o faltas de conducta. Las normas usuales de conducta implicaban puntualidad en las clases, respeto a los directores y al resto de discípulos, urbanidad y modestia ${ }^{43}$; el progresivo endurecimiento de los reglamentos parece indicar que el comportamiento de los discípulos, relacionado con el cambio sociocultural en torno a la prolongación de la adolescencia y los comportamientos más rebeldes vinculados a esta, no solo no se adaptaba a las normas básicas establecidas sino que encontraba nuevas formas de dar salida bien a su descontento o bien a la necesidad de reafirmar su pequeño ámbito de poder dentro de la escala jerárquica. Al absentismo en algunos casos comprensible debido a las obligaciones laborales de los discípulos-, que estaba castigado con el aviso a casa e incluso con la expulsión, se sumaron faltas menores como alborotos en corredores y escaleras, así como malos tratos a los empleados de la Academia, ya fueran conserjes, porteros o modelos; o incluso el maltrato o deterioro de los fondos artísticos o muebles de la institución. En el caso de la Academia de San Fernando, los excesos se cometían especialmente en los estudios elementales de la calle Fuencarral ${ }^{44}$ y de la Merced, donde ya en 1821 se daba cuenta de "muchos y escandalosos desórdenes que se cometían en aquel estudio por los discípulos y dependientes ${ }^{45}$, , prosiguiendo los avisos en años posteriores ${ }^{46}$. Esperanza Navarrete señala algunos casos de desobediencia por parte de los discípulos de la Academia hacia sus profesores, como el protagonizado por varios alumnos del Natural ante una suplencia por parte de Luis López, o por los de la clase del Yeso al negarse en 1842 a realizar el ejercicio propuesto por Juan Gálvez, y también los abusos sufridos por los conserjes (NAVARRETE, 1999: 243-244). También Federico de Madrazo relata, con

\footnotetext{
43 Los estatutos de la Academia de San Carlos estipulaban que los directores debían tratar a sus discípulos, independientemente de su clase social, "con todo amor y paciencia, para que atraídos de un amor benigno y cariñoso, se apliquen con fervor, y consigan la instrucción y adelantamientos", previniendo que "en caso de que por inaplicación, inmodestia y otro motivo mereciesen ser tratados con severidad", se les podía reprender e incluso imponer castigos domésticos. Sin embargo, los tenientes directores solo tenían autoridad para reprender (RABASC, 1828: 24 y 28).

${ }^{44}$ En 1829, las actas recogen que "El Subdelegado principal de Policía de la Provincia de Madrid había oficiado con el Sr. Viceprotector sobre algunos desórdenes que cometían en las calles los discípulos de la clase de Fuencarral cuando salían de su estudio por las noches". Junta Ordinaria de 5 de abril de 1829, ARABASF, Secretario general, Libro de actas de juntas ordinarias, generales y públicas (3-88), fol. 225r. En adelante se incluirá únicamente la signatura para elementos consignados bajo la misma localización en archivo.

45 A raíz del despido de un discípulo de este estudio, hijo del maestro bordador Manuel Jiménez, la Academia dejaba constancia del desagrado que le producía enterarse de la noticia de los reiterados desórdenes, "pero habiendo manifestado el Sr. Viceprotector que tenía tomadas eficaces providencias para remediar estos abusos y corregir tales desórdenes, la Junta acordó que se lleven a efecto con todo rigor dichas providencias", Junta Ordinaria de 4 de febrero de 1821, ARABASF (3-88), fol. 50v.

${ }^{46}$ Así, se da cuenta en 1836 de la expulsión de un discípulo por su mal comportamiento: "El Sr. Académico de honor D. León Gil de Palacio, como celador del Estudio de la Merced, participaba haber sido despedido el discípulo José Nuñez por los excesos que había cometido faltando al respeto debido a los Sres. Académicos y profesores, y aprobando la Academia cuanto se había hecho por dicho Sr. D. León, acordó también que no sea admitido tampoco dicho Núñez en los próximos curos, avisándose para ello a los demás estudios de la Academia". Junta Ordinaria de 13 de marzo de 1836, ARABASF (3-89), fol. 164 r.
} 
cierta indulgencia, cuánto hicieron rabiar él y sus compañeros al conserje Alejandro Peña, "hombre de bien a macha martillo, honrado y bondadoso", burlándose, entre otras cosas, de sus tropiezos lingüísticos (GONZÁLEZ y MARTí, 1994: 54).

El reglamento de 1845 de la Academia de San Fernando establecía la reprensión en privado para la primera falta cometida por un alumno, la represión pública para la reincidencia o las faltas graves, y finalmente la expulsión definitiva de las aulas en la tercera falta $^{47}$. Frente a esta normativa en la Academia, las Escuelas de Dibujo dependientes de las Sociedades Económicas señalan también en sus reglamentos las faltas más habituales entre el alumnado; en la de Santiago de Compostela se consideraban faltas leves llegar con retraso, hablar entre los discípulos, cualquier distracción, levantarse del puesto o entrar cubierto en el aula, mientras que las faltas graves consistían en robar o esconder propiedades de otros alumnos, faltar al respeto al profesor y entorpecer al portero o maltratarle física o verbalmente, siendo falta imperdonable "proferir palabras ofensivas a la buena moral", a la religión o contra el gobierno $^{48}$.

Los casos de mal comportamiento no se redujeron al ámbito de la enseñanza oficial, en la que la presencia de alumnos procedentes de clases sociales con una educación menos refinada era habitual, sino también se produjeron casos en los talleres privados de algunos artistas. Quizás el más sorprendente por la envergadura del espacio en que se produjo fue el acontecido en el Real Estudio de Pensionados de Pintura, dirigido por Vicente López; el pintor de cámara, notando falta de aplicación por parte del discípulo Félix Bausac, llamó a este a su casa para recordarle sus obligaciones. Según López, Bausac respondió con "desfachatez, imperio y falta de respeto", hasta tal punto que Bernardo López "viendo insultado a su padre, como buen hijo le ha hecho salir de mi estudio, y el lance hubiera podido ser muy serio" si no se hubiera interpuesto el valenciano (DÍEZ, 1999: 224-225), quien se contentó con despedir al discípulo. A1 parecer, Bausac también acudió a la clase del colorido de la Academia, dirigida por José de Madrazo, y de su paso por esta recuerda Federico tratarse de una persona divertida y ocurrente, si bien bastante desvergonzado (GONZÁLEZ LÓPEZ y MARTÍ AYXELÁ, 1994: 54).

La formación de la Escuela Especial de Pintura, Escultura y Grabado y de las Escuelas Provinciales de Bellas Artes también contemplaba los problemas de comportamiento de los jóvenes artistas, formándose un Consejo de Disciplina; las actas de la Academia de San Fernando dan cuenta de la iniciativa, en la que se instaba a que este consejo estuviese compuesto por el presidente de la Academia, los consiliarios y el director de la Escuela, así como de dos profesores, dos padres de familia y del secretario de la Academia en el caso de Madrid, y en las Escuelas Provinciales del director de la

\footnotetext{
${ }^{47}$ RABASF, 1845: 23. Otros reglamentos de especial interés son los de la Academia de Bellas Artes de Vitoria (1830) y (1855).

${ }^{48}$ REAL SOCIEDAD ECONÓMICA DE AMIGOS DEL PAÍS DE LA CIUDAD DE SANTIAGO, 1838: 15. Por su parte, desde la Academia establecida en Murcia se apelaba a la educación doméstica, observando que esperaba que los padres "acostumbren a sus hijos a guardar moderación, a ser obedientes y agradecidos, y que presten constante aplicación”. SOCIEDAD ECONÓMICA DE AMIGOS DEL PAÍS DE MURCIA, 1832.
} 
Escuela, dos profesores, un miembro del Ayuntamiento y dos padres de familia ${ }^{49}$. Sin duda, esta medida buscaba velar por la buena moral en las Escuelas de Bellas Artes, atendiendo no solo a la presencia del profesorado sino también a los dos referidos padres de familia. No obstante, en el reglamento de la Escuela de 1857 se estipula, en su artículo 21, que el Consejo de disciplina está constituido de manera exclusiva por la junta de profesores "para juzgar a los alumnos que incurriesen en faltas graves y proponer al gobierno la represión o el castigo a que los considere acreedores" ("Reglamento provisional...", 1857: 1), lo que se mantiene en los reglamentos de $1871 \mathrm{y}$ de 1893, negándose además a los alumnos la posibilidad de presentar reclamaciones colectivas $^{50}$.

Además de algunos de estos comportamientos, la Academia era también el espacio en que los jóvenes artistas se adaptaban a un sistema competitivo -profesional y social-, ya fuera mediante la burla hacia los malos dibujantes, algo de lo que Federico de Madrazo da no pocos ejemplos, como los casos de Eustaquio Medina, el propio Bausac o Romualdo Ballesteros (GONZÁLEZ LÓPEZ y MARTÍ AYXELÁ, 1994: 54) y que era una consecuencia directa de la instauración de premios o recompensas en las clases $^{51}$, o mediante el desdén hacia el despliegue de actitudes alternativas consideradas menos masculinas. Así sucede con la influencia de la moral religiosa, según los recuerdos de Martín Rico, en los jóvenes alumnos de Bernardino Montañés como ayudante de Federico de Madrazo, desarrollando algunos de ellos actitudes de aislamiento y excesos místicos frente a las distracciones juveniles, que fueron interpretados como sucesos atípicos y contrarios a los deberes del hombre. No en vano la masculinidad eclesiástica supone uno de los extremos -frente a la hipervirilidad militar- que marcan el siglo XIX, siendo considerada problemática por la feminización de las apariencias, la imposición del celibato forzoso y el voto de castidad (AIRIAU, 2011: 241-254), atributos que se basan en la virtud del autodominio a través de la negación de la sexualidad, si bien la visión negativa hacia el clero estaba relacionada con su desvinculación del sistema de producción económica. Ceferino Araujo da a entender las dificultades a las que el carácter retraído e ideales místicos podrían haber acarreado a Bernardino Montañés, a quien sus compañeros apodaron "el curita", de no haber sido por unas habilidades pictóricas que le ganaron el respeto en las aulas ${ }^{52}$. Otro

\footnotetext{
49 Acta de la Junta Ordinaria de 2 de mayo de 1854, ARABASF (3-91), fol. 239r.

50 "Los alumnos dirigirán sus reclamaciones al director de la Escuela, pero nunca reunidos y colectivamente ni a nombre de otro, sino cada uno de por sí y en representación propia, bajo pena, según los casos, de pérdida de curso o de expulsión de la Escuela, previa consulta, en uno y otro, de la Junta de Profesores" (p. 2).

${ }^{51}$ Martín Rico, sin entrar en demasiados detalles respecto a las tensiones existentes dentro de la clase, menciona la asignatura de Colorido, en su momento a cargo de Federico de Madrazo, como una especialmente propensa a esta competitividad que alimentaba el espíritu de trabajo ("Se trabajaba, verdaderamente, con entusiasmo por amor al estudio, por ver quién hacía la mejor figura en la semana". RICO, 1906: 18-19).

52 "El que figuraba a la cabeza era el zaragozano Bernardino Montañés, a quien con esa justicia y desinterés tan rápidos de la juventud todos consideraban como superior, a pesar de que entre muchachos alocados tenía algunas cualidades que pudieran serle perjudiciales, como su carácter serio y retraído, su modo de vestir, semejante al de un seminarista externo, y sus ideas místicas, que hicieron se le pusiera entre los compañeros el apodo de el Curita. Pero el Curita dibujaba y pintaba mejor que los demás, y era
} 
caso curioso es el de Nogueras, quien siendo discípulo de Bernardo Rico tomó la decisión de ingresar en la Compañía de Jesús, privando con ello de su sueldo a la familia, y del que Martín Rico evoca el choque que esta decisión suponía para una familia de recursos limitados que contaba con el artista como figura masculina $y$ proveedora.

Hay que advertir que el padre, que había sido tipógrafo de la imprenta real, no podía ya trabajar, y además tenía dos hermanos pequeños, y todos se sostenían con lo que ganaba el mayor. Este padre rogó a mi hermano que hablara a su hijo, puesto que tenía mucho respeto y amor hacia su profesor. Efectivamente, mi hermano le echó un sermón que estuvo escuchando con la cabeza baja; le pintó la miseria de la familia, del padre, de los hermanos pequeños...; no contestó ni una palabra; a los dos o tres días vino a recoger sus buriles y sus chismes de trabajar, y no le hemos vuelto a ver (RICO, 1906: 21).

No cabe duda de que algunos comprtamientos extremos no son exclusivos de los jóvenes artistas, puesto que traducen una preocupación generalizada por parte de los adolescentes frente a la autoridad como reafirmación masculina a través de pequeños ejercicios de poder. El carácter específico de la formación artística, sin embargo, sí que produjo conflictos internos relacionados con el aprendizaje progresivo, la superación de las pruebas o distintos pases de estudios ${ }^{53}$, la obtención de premios, recompensas o pensiones, así como el requisito de justificar el buen empleo de los mismos. Frente al estudiado caso francés de sociabilidad y tensiones masculinas originadas en un sistema altamente competitivo (CROW, 2002) y que suponían que para el artista la llegada a la edad viril se retrasase hasta la conclusión de los estudios en Roma y la emancipación definitiva de los maestros ${ }^{54}$, la escasa vigencia que tuvieron en España los premios y pensiones de Roma y París, convocados los primeros de manera esporádica hasta la instalación definitiva de la Academia Española en Roma, no implica que estos no fuesen entendidos como una forma de profesionalización y proyección internacional durante la primera mitad del siglo XIX (REYERO, 1991: 377-396), y que como tal codificasen las expectativas de los jóvenes artistas.

La correcta conciliación entre la formación y las obligaciones laborales para contribuir a la economía familiar fue una de las preocupaciones de numerosos jóvenes artistas que, sin contar con el respaldo de una familia de tradición artística en la que formarse de manera gratuita, debían costearse las clases en talleres particulares. El desarrollo de la formación artística en un margen de edad adecuado también fue una fuente de preocupación entre los jóvenes artistas; se encuentra, por una parte, el caso de los arquitectos, que debían tener veinticinco años para poder solicitar el correspondiente título, siendo frecuente encontrar en las actas de la Academia de San Fernando

querido y respetado de todos, tanto por esto, como porque a pesar de su seriedad era muy afable" (ARAUJO, 1897: 137; REYERO, 2014: 134; HERNÁNDEZ LATAS, 1994: 43).

53 Así, el caso de Martín Rico, quien vio pasar a numerosos compañeros en la clase del antiguo sin realizar avances durante doce años (RICO, 1906: 17).

54 "Diez años en París y cinco años en Roma, ese es el camino a seguir, invariable y cifrado. No toman la toga viril hasta los treinta y cinco años; hasta ese momento están bajo la férula de sus maestros" (PLANCHE, 1832: 61). 
solicitudes, a título individual, de dicha exención para poder ejercer profesionalmente. Por otra, y un caso de significativa importancia, se encuentran las limitaciones de edad para concurrir a las oposiciones a Roma, por similitud con el Prix de Rome francés, excluyendo a los mayores de treinta años; una medida que, orientada a favorecer una estancia en el extranjero como culmen de la formación artística, fue sin embargo fuente de constantes quejas y revisiones al buscar aplicar a hombres en edad madura los reglamentos y obligaciones de envío propios de un simple alumno.

\subsection{Los retratos del joven artista}

\subsubsection{Consolidación de masculinidades artísticas en el ámbito familiar}

La existencia de un sistema de aprendizaje codificado por la Academia no impidió que los vínculos familiares tuviesen un alto peso en la formación artística, y especialmente en la infancia y primera adolescencia, durante la primera mitad del siglo XIX. Cabe plantearse las consecuencias que este primer contacto que aúna lo familiar y lo profesional tuvo para padres e hijos, al participar de un contexto sociocultural muy específico respecto a las ideas de familia, paternidad y diferencia de roles en el ámbito decimonónico español. La figura paterna como iniciadora en la actividad artística es una constante histórica, que siguiendo las ideas sobre construcción de identidad masculina expresadas desde la psicología, la teoría psicoanalítica y la sociología, permitiría contribuir a romper el vínculo materno-filial del niño-artista e iniciar su proceso de identificación con lo masculino, al mismo tiempo que confirma la autoridad paterna no solo en el ámbito doméstico, sino especialmente en el intelectual al configurarse como el transmisor de saberes de aplicación práctica. De este modo, al igual que el niño adquiere progresivamente una identidad masculina por separación de la madre y vinculación con el padre, el padre-artista se configurará en el modelo positivo de identificación del niño-artista, que por lo general establecerá una relación indisoluble entre lo familiar y lo profesional.

Esta relación padre/hijo que tiene lugar bien en el ámbito doméstico o bien en el profesional como un alumno más en el taller puede entenderse de manera distinta en función del modelo de paternidad ejercido. John Tosh, al hablar de la masculinidad entre la clase media victoriana, establecía cuatro tipos de paternidad que se definían como: el padre íntimo, caracterizado por la valoración de la ternura y las relaciones espontáneas con sus hijos; el padre ausente, que no mantenía ninguna implicación doméstica; el padre emocionalmente ausente, es decir, aquel que aunque físicamente presente en la vida cotidiana familiar no volcaba sus afectos o atenciones en ella; y finalmente el padre tiránico, caracterizado por una personalidad autoritaria y represiva como forma de autolegitimación masculina y social ${ }^{55}$ (TOSH, 1999: 93-99). Una primera aproximación podría relacionar a los padres/artistas decimonónicos con el modelo íntimo, alegando una proximidad paternofilial a través de la enseñanza artística; sin embargo, en algunas representaciones plásticas de la primera mitad del siglo XIX se

\footnotetext{
${ }^{55}$ Sobre masculinidad, burguesía y representaciones de la familia, ver: PRAZ, 1971 y HOFFMANN, 1996.
} 
pueden observar matices que permiten hablar de distintos conceptos de paternidad $-\mathrm{y}$, por lo tanto, de modelos de identificación masculina del niño-artista.

Es necesario hacer ciertas precisiones antes de analizar algunos ejemplos; en primer lugar, debe señalarse que al hablar de la identificación hijo/padre no se trata de un modelo exclusivo de construcción de una identidad masculina vinculada al arte, puesto que esta se verá determinada por la interacción -posterior o simultánea- con otros grupos sociales, figuras de autoridad en el ámbito educativo, político y cultural, y especialmente con la interacción entre pares a lo largo de la adolescencia; por lo tanto, la imagen ofrecida en algunos retratos del niño-artista en vinculación con el entorno familiar debe entenderse como una construcción efímera y en continuo cambio, sin necesidad de que la identificación con la profesión del progenitor se prolongue en la adolescencia. En relación con esto, no debe olvidarse que la perspectiva de estas representaciones procede siempre del punto de vista del artista adulto, generalmente el propio padre, quien ofrece una imagen canalizada a través de su propia experiencia masculina estableciendo relaciones afectivas y/o jerárquicas en la composición, y probablemente idealizando la experiencia masculina infantil como prolongación de su propio deseo de identificación. En este sentido tampoco se puede obviar el hecho de que el interés por la representación del vínculo artístico familiar, más allá del mero retrato individual, solo cobraría pleno significado si dispusiésemos de fuentes escritas relacionadas con la experiencia del crecimiento en cada una de las familias artísticas que cotejar con las obras que han llegado hasta nosotros; las noticias, memorias y vivencias de artistas y familiares de artistas ponen de manifiesto que la profesión paterna trascendía los límites de lo estrictamente profesional e impregnaba la vida doméstica, como recordaba Roberto Domingo sobre su padre, Francisco Domingo Marqués $^{56}$, aunque existe un cierto distanciamiento afectivo en lo que respecta a la enseñanza artística. En este sentido, es curioso observar cómo Federico de Madrazo muestra en sus memorias una imagen ausente de su padre, no solo en el ámbito afectivo -desviando la atención hacia su tío Pedro, mentor y compañero durante sus primeros años- sino también en el de la enseñanza artística, mencionando el estudio de los discípulos y las lecciones de principios bajo la dirección de un protegido de José de Madrazo; paralelamente, a pesar de los retratos infantiles de los niños Madrazo, no consta ningún retrato que permita establecer una identificación directa entre José y Federico de Madrazo durante su infancia, a pesar de la importancia que para ambos cobrará la vida familiar en relación con la profesión artística ${ }^{57}$, como manifiesta el

\footnotetext{
56 "Nuestro hogar era la prolongación del estudio; casi se podría decir que toda la casa era el estudio de mi padre", recogido en NÚÑEZ J. PEÑASCO, 1958: 10-11.

${ }^{57}$ Respecto a la vida familiar de los Madrazo son numerosos los retratos producidos por José, ya fuesen composiciones alegóricas o retratos individuales; no obstante, es llamativa la ausencia reiterada del pintor en los retratos, rehusando de algún modo el retrato de familia, lo que puede vincularse a su necesidad de dividir esferas - profesional y familiar- y personificando, debido a sus múltiples ocupaciones, un tipo de paternidad ausente y controladora. Las memorias de Madrazo no transmiten una imagen muy cercana de su padre, y curiosamente una de las anotaciones o mementos para seguir con sus recuerdos de 1826 pone en relación "Papá, nervios, Tupper (...)" con su siguiente apunte, "Mis malos dibujos (Academias de Mengs)", lo que parece indicar que, iniciados sus estudios en la Academia, era ya evidente una cierta preocupación en el joven pintor respecto a una voluntad -adolescente- de identificación y aprobación paterna. Ver: DÍEZ, 1998a; GONZÁLEZ LÓPEZ y MARTÍ AYXELÁ, 1994; DÍEZ, 1994; DÍEZ, 1998 b.
} 
hecho de que Federico aconsejase a su hijo Raimundo que tuviese su estudio y su casa unidos $^{58}$, o sobre los valores civilizadores y masculinos que conviene inculcar a los $\operatorname{hijos}^{59}$.

En su Autorretrato con sus hijos [fig. 5], Antonio María Esquivel opta por un retrato de familia alejado de la típica imagen de reunión de sus miembros en una escena casual o enternecedora, extendida entre la clase media española y ampliamente explotada desde el Romanticismo como recuerdo de los vínculos afectivos y como objeto decorativo, como el caso de los autorretratos familiares del duque de Rivas. En su obra, Esquivel se autorretrata junto a sus dos hijos varones eligiendo como tema el propio acto de pintar; en esta escena metapictórica se pone de relieve una escenificación de la vida familiar de los Esquivel donde la imagen del padre íntimo queda relegada a un puesto secundario.

El tema de la obra ha sido tradicionalmente interpretado como una lección espontánea de dibujo impartida por Esquivel a sus dos hijos, aludiendo así al rol paternal de iniciación en la vida artística de los jóvenes varones, y en oposición a su pendant, el retrato de su mujer y su hija. La figura de Esquivel domina la composición, representándose sentado, vestido con elegante levita negra con botones dorados, apoyando sobre sus piernas cruzadas una tabla sobre la que traza un dibujo con el lápiz que sostiene en su mano derecha. Junto a su butaca aparecen dispuestos, en perfecto orden, los pinceles del pintor, algo que parece sugerir que el dibujo que se encuentra realizando es algo más que un mero entretenimiento pasajero.

Carlos María y Vicente Esquivel asoman en segundo plano, el mayor apoyado en el respaldo de la butaca de su padre, en actitud de contemplar el dibujo que realiza por encima de su hombro izquierdo; el menor sostiene en sus manos un pequeño maniquí articulado coronado con un sombrero de papel, una alusión a la dimensión lúdica que puede tener el arte para un niño pequeño y que José González Bande retomó en El camino de la gloria artística. A pesar de que las tres figuras aparecen captadas, no sin cierta ternura en el tratamiento de ambos niños, un hecho que llama la atención es la ausencia de comunicación entre la figura de Esquivel y sus hijos. La escena solo corresponde a un intimismo moderado en la medida en que la inclusión de los dos niños corresponde a la exigencia propia de un retrato de familia, pero si bien Carlos María mira -con un deje de ensimismamiento- el dibujo y Vicente parece reclamar con su mirada y su gesto la atención del padre, Antonio María Esquivel solo parece tener ojos para sí mismo. Prerrogativa del autorretrato en el espejo o no, el pintor permanece con la vista al frente, cómodo en el ambiente familiar en que se encuentra, pero completamente ausente a esta realidad. Esquivel no alude al espacio en que se desarrolla

\footnotetext{
${ }^{58}$ Carta de 8 de agosto de 1873 (DÍEZ, 1994:739).

59 "Cada día me convenzo más y más en que no hay felicidad cumplida fuera de la familia, y todo lo que tienda a fortificar esta necesidad creo que es conveniente. Tú tienes un niño (que Dios te conserve) que llegará a ser hombre, y cada día te persuadirás más y más de lo necesario que es fomentar ciertos sentimientos únicos civilizadores. No sé si con la prisa me he explicado con claridad, pero ya me entenderás, espero". Carta de 15 de marzo de 1879 (DÍEZ, 1994: 796).
} 


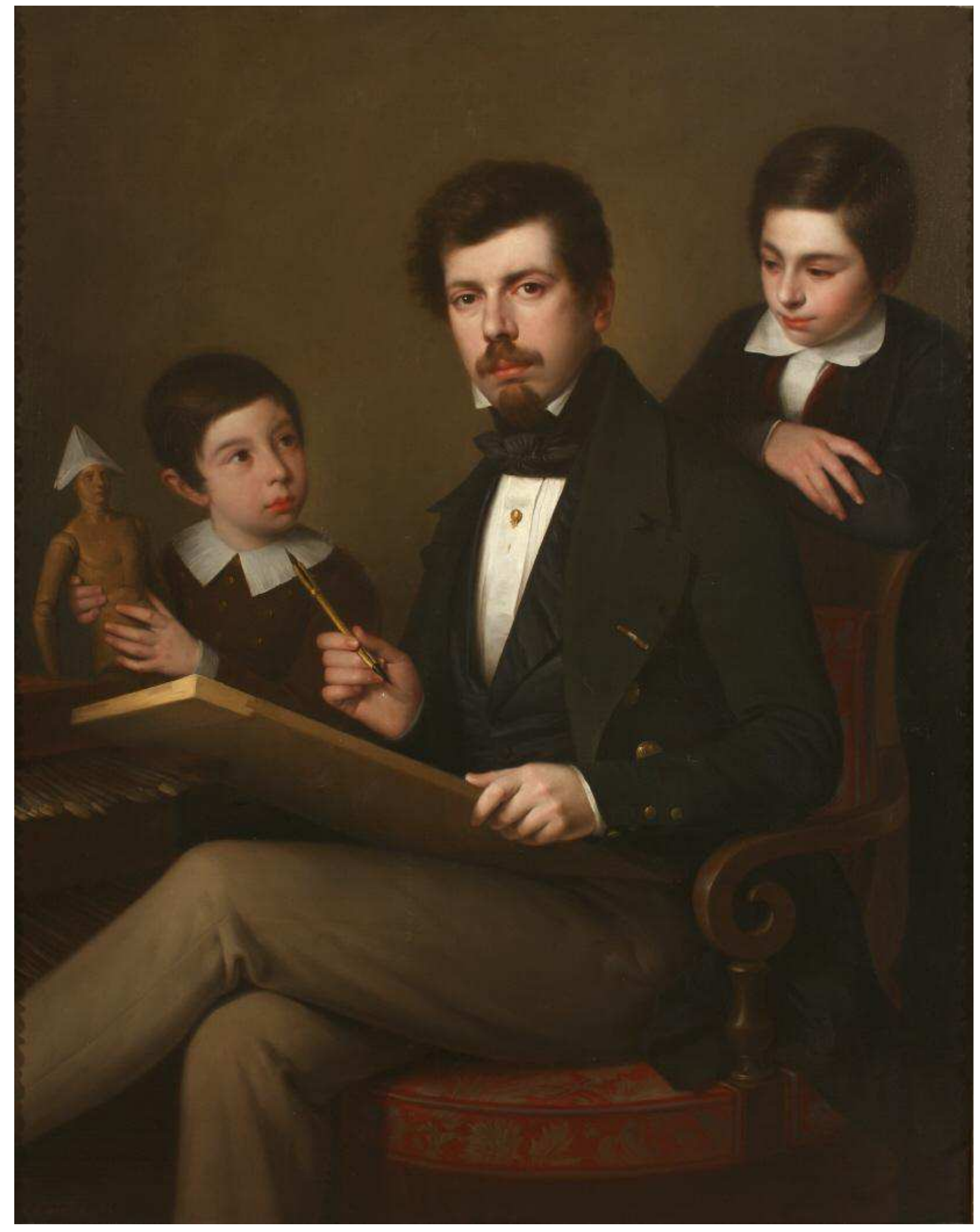

Fig. 5. Antonio María Esquivel, Autorretrato con sus hijos Carlos y Vicente (1843). Museo Nacional del Romanticismo (Madrid) [CE7167]. 


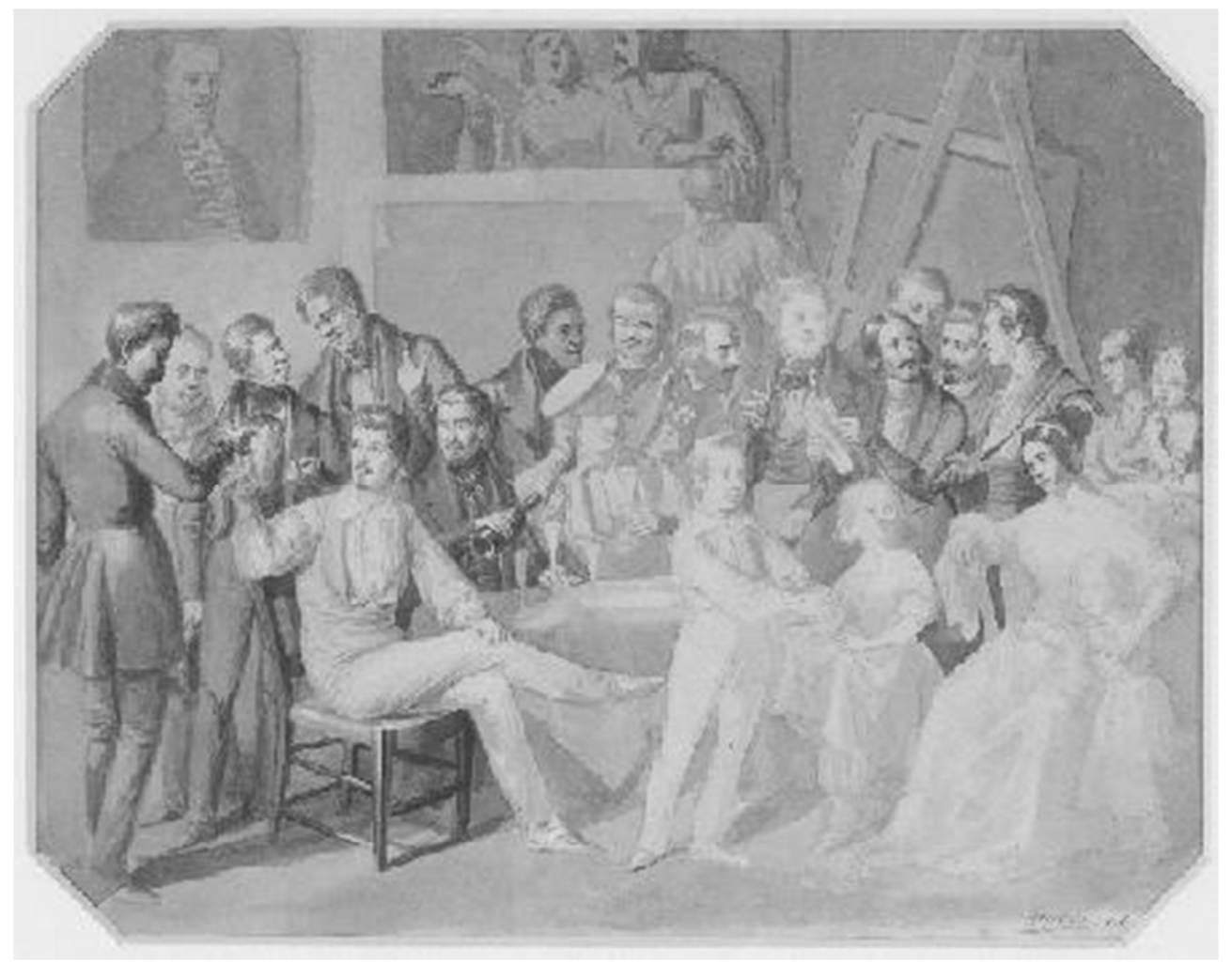

Fig. 6. Antonio María Esquivel, Tertulia en el taller. Museo de Bellas Artes de Sevilla ( ${ }^{\circ}$ inv. 0557D).

la escena: ya sea el interior de su estudio, un espacio doméstico o alguna tertulia privada, tan solo hace de él un fondo neutro, carente de importancia; es en las figuras en las que parece concentrar todos los significados, consciente de las distancias y jerarquías -reales o imaginarias- que está plasmando en el hieratismo de su autorretrato. Lejos de ser la única representación familiar, Antonio María Esquivel manifestó repetidamente interés por retratar separadamente a sus hijos ${ }^{60}$, habiéndolos incluido también anteriormente en el dibujo Tertulia en el taller [fig. 6]. La escena, como Antonio de la Banda describía, es un retrato de grupo en el que Esquivel decide figurar, junto a sus amistades y a su familia, en el interior de su taller. No es la inclusión de los miembros de la familia lo que llama la atención, aun siendo un reflejo perfecto de la importancia y permeabilidad que esta cobraba tanto para la configuración de una identidad masculina como de cara a su proyección social, sino la disposición y roles de cada uno de ellos en comparación con el Autorretrato con sus hijos. En la escena festiva Esquivel recurre a disponer a los personajes alrededor de una mesa, colocando a sus amistades en segundo plano y a sí mismo y su familia en primero. Sin embargo, la composición evidencia dos grupos diferenciados: Esquivel, que permanece sentado en actitud desenfadada, en camisa, brindando con un personaje, se enmarca claramente en la atmósfera masculina de las amistades, mientras en el extremo derecho dos mujeres, una de ellas la esposa del artista, permanecen junto a sus hijos. Ocupando casi el centro

\footnotetext{
${ }^{60}$ Antonio de la Banda y Vargas menciona un retrato de Carlos María en la colección Marañón, y otro de Vicente en una colección particular sevillana (BANDA Y VARGAS, 2002), conociéndose además el retrato de su hija en la colección de la Real Academia de San Fernando (nº inv. 1162).
} 
de la composición, la figura de Carlos María, hijo mayor del pintor, destaca como el único de los varones identificado con una apariencia masculina vistiendo ya pantalón; consta, por lo tanto, que su proceso de desvinculación materna se ha producido, estando su identidad masculina en construcción. Equidistante de su padre y de su madre, la única relación que se produce, a través de un juego de miradas, es sin embargo con su madre; en la representación, ya fuese un boceto para una composición pictórica o un recuerdo destinado a un álbum, Esquivel pone de relieve dos aspectos a tener en cuenta: el primero es su capacidad para realizar un autorretrato prescindiendo del recurso del espejo e interactuando con el resto de personajes; el segundo es, a pesar de la inclusión de la familia en la escena, la distancia afectiva existente entre el padre y el resto de los miembros, siendo especialmente significativa la oposición gestual $-\mathrm{y}$ por lo tanto de miradas- que se da entre sí mismo y la imagen de su hijo, creando un vacío en la composición que no tiene equivalente en el grupo de la derecha al incluir entre Carlos María y su madre la figura de su hermana.

En el Autorretrato con sus hijos ambos niños han entrado en la esfera masculina del padre, pero no lo hacen en igualdad de condiciones: Vicente es representado aún como un niño, que en su corta edad de seis años ${ }^{61}$ aún no entiende los fundamentos del arte de ahí la dimensión lúdica del maniquí, reduciendo a su portador a una imagen infantil-, y sometido a la necesidad de aprobación paterna, como manifiesta la mirada que le dirige. La actitud de Carlos, que a sus trece años se encuentra en los límites de la adolescencia, manifiesta un grado distinto de identificación con la figura paterna: en su forma de contemplar el trabajo que este realiza se deja entrever su interés y una mayor capacidad de comprensión, en oposición a la actitud de su hermano menor. Significativamente, Esquivel no se preocupa en centrar la atención de su hijo en su figura como padre, sino en la obra que se encuentra realizando, dando a entender de este modo que, en lugar de una relación afectiva, como traduce la ausencia de comunicación entre las figuras, los vínculos que comienzan a unir a padre e hijo están más próximos a la transmisión de conocimientos e imitación con intención profesional. Es por esto por lo que Esquivel busca representarse como padre emocionalmente ausente, a favor de una imagen de sí mismo más próxima al autorretrato de artista trabajador concentrado en su trabajo, legitimándose así como un modelo específico de paternidad de tinte burgués.

Son escasas las representaciones familiares entre artistas en las que puede establecerse este proceso de identificación masculino paternofilial vinculado a la formación artística, a pesar de que el retrato de familia fue ampliamente practicado y tuvo una notable presencia en las exposiciones oficiales en el siglo XIX. En este último caso suele traducirse el interés del artista, por transmitir los vínculos emocionales propios -su sentir respecto a su papel como esposo y padre- dentro del espacio doméstico $^{62}$, pero no busca generar una identidad artística de su descendencia,

${ }^{61}$ Tomamos como dato la partida de nacimiento de Vicente Esquivel, publicada por Valverde Madrid (1979: 238).

${ }^{62} \mathrm{El}$ mismo interés de reflejar los goces de la permeabilidad entre vida artística y familiar aparecen en el dibujo, prácticamente contemporáneo, de José Jiménez Aranda titulado "El pintor feliz", en que Pérez 
especialmente si el/los hijos representados pertenecen aún a esa etapa sexualmente indefinida de la primera infancia. El retrato familiar que Ángel María Cortellini presentó a la exposición nacional de 1860, actualmente en paradero desconocido (PUY MORENO,1983: 141) y que solo podemos reconstruir a través de las descripciones ofrecidas por la prensa, puede considerarse ejemplo de este tipo de retrato. A pesar de la ambigüedad del título, que figuraba como Retrato de la esposa del pintor o como La familia de un artista, la descripción ofrecida tanto por el catálogo como por algunas reseñas permite reconstruir la escena: lo que inicialmente es un retrato de su esposa (tal y como recoge Ossorio y Bernard), apareciendo esta en primer plano y destacada mediante el uso de luces y color, se convierte en un retrato familiar que plantea ciertos interrogantes al incluir en el fondo de la composición un autorretrato del artista con su hijo (Catálogo..., 1860: 9). La intención artística de la obra es manifiesta, puesto que el recurso al autorretrato pintando una escena familiar pone de manifiesto no solo el componente afectivo sino que también sugiere la privilegiada permeabilidad de la profesión masculina en el hogar. De la descripción ofrecida por Juan de Dios Mora se desprende que pintor e hijo aparecen vinculados entre sí por su inclusión en un mismo plano y un mismo tratamiento pictórico ${ }^{63}$; sin embargo, otras fuentes incluyen datos que permiten observar cómo padre e hijo mantienen una actitud diferente en la escena: el artista aparece representado con su paleta y pinceles, es decir, identificado a través de su labor profesional delante de un lienzo, recurso que fue considerado negativo por los críticos de El Museo Universal y La Iberia ${ }^{64}$, mientras que prácticamente nada se dice del niño, salvo su carácter gracioso, "dulce, emblema de ternura y de esperanza" (MORA, 1860: 3). El situarse próximo a la figura paterna, pero no vinculado con su actividad pictórica, salvo tal vez como espectador, parece remitir más a la idea de un deseo de identificación infantil, en el que la construcción de una identidad masculina se encuentra aún en una etapa inicial.

La introducción de la figura del hijo como heredero masculino de la profesión artística paterna es tardía en lo que respecta a la representación plástica, si bien en la tradición literaria es un recurso habitual. La reafirmación del artista como padre parece quedar plenamente manifiesta en la plasmación del hijo iniciándose en la actividad artística, como sucede en Chicos dibujando, de Ignacio Pinazo, aunque la exclusión de la figura paterna de la obra parece conferirle un carácter más anecdótico con sentido de ocio artístico. Sin embargo, la pintura de Pinazo ofrece significativas diferencias respecto a otro tipo de representaciones de infancias, supuestamente artísticas, extendidas como tema amable en la pintura de género.

Los niños-artistas de Eduardo Zamacois en La distracción [fig. 7] (Museo de Bellas Ártes de Álava, $\mathrm{n}^{\circ}$ inv. 3043)o de Juan Comba en Idealismo y realidad [fig. 8], obras en las que no puede aludirse al tema familiar, son abordados como usurpadores

Calero ve un autorretrato del artista junto a su esposa y su primogénita (PÉREZ CALERO, 2006: 359 y 366).

63 "Reina allí la dulce intimidad del hogar. En el color hay blandura y gracia. Las figuras del artista y del niño están suavemente rebajadas por oscuro en el fondo, destacándose por claro la figura de la señora, en la que se advierte dulzura de ejecución y belleza de tono (...)" (MORA, 1860: 3).

64 “Exposición...", 1860: 402; PALET Y VILLAVA, 1860: 3. 


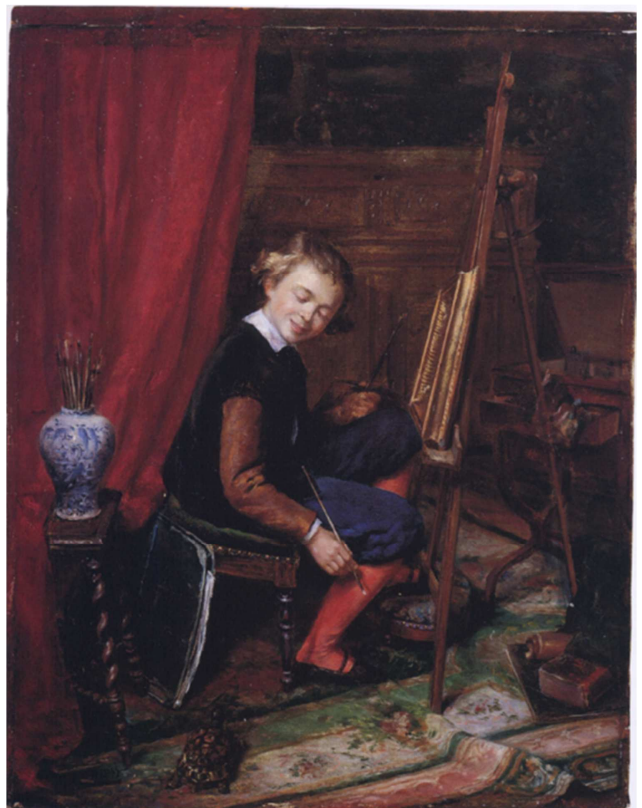

Fig. 7. Eduardo Zamacois, La distracción. Museo de Bellas Artes de Álava ( $\mathrm{n}^{\circ}$ inv. 3043).

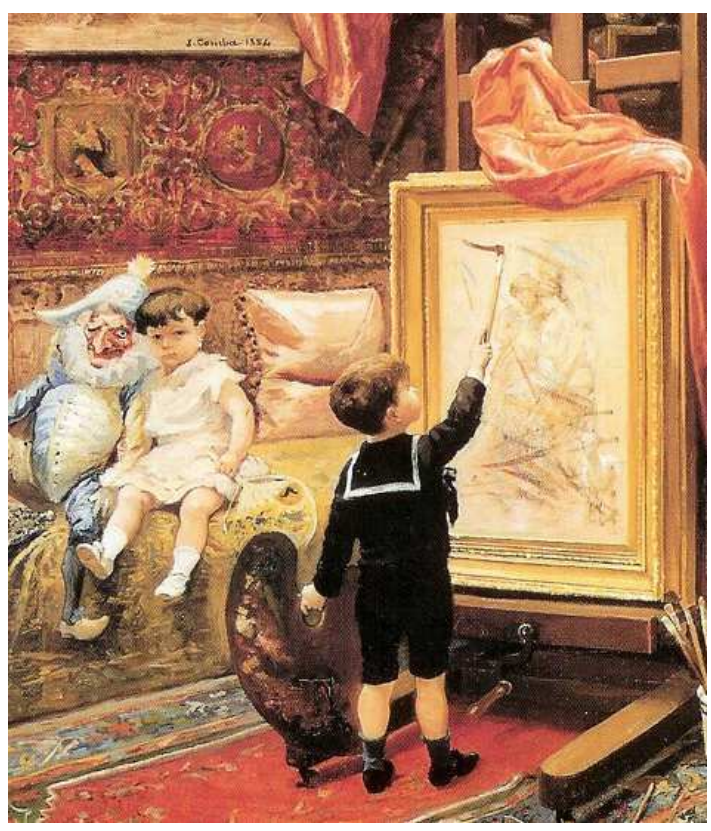

Fig. 8. Juan Comba, Idealismo y realidad (detalle). Colección particular.

del espacio del trabajo del artista, en los que se exageran las características de la infancia (distracción y travesura) enajenándolos así de cualquier posible identificación con el artista -padre o maestro- cuyo espacio ocupan.

Por el contrario, Pinazo representa a sus hijos en un ambiente modesto, convertido en un espacio de trabajo personalizado mediante la silla que sirve para apoyar la tabla en que dibuja; la actitud de concentración de los niños parece remitir, de manera indirecta, a la presencia invisible de una figura autoritaria -el propio Pinazo tras su lienzo- que vigila la escena. La figura ausente del padre-artista puede intuirse también en la pintura, atribuida a Vicente Esquivel, Escena de familia, realizada en la década de los setenta del siglo XIX ${ }^{65}$, en que a través de la representación de un interior burgués se introduce a un momento familiar. En el extremo derecho de la composición, una madre supervisa el trabajo de su hija, quien se distrae para contemplar al pintor; en el izquierdo, en una butaca baja, un niño dibuja en un cuaderno, con una caja de colores a su lado. El pequeño artista, que podría parecer abandonado en su labor creativa, no es, frente a lo que podría parecer, independiente en su labor. La mirada de la niña traiciona la presencia de una cuarta persona tras el lienzo, probablemente una figura paterna que, al igual que hace la madre con la hija, supervisa esporádicamente la labor del hijo. El vínculo que se intuye está subrayado, sin embargo, por esta sensación de distanciamiento que produce la propia actividad artística del progenitor.

\footnotetext{
${ }^{65}$ La única referencia a la obra, no localizada, procede del archivo Ruiz Vernacci, mediante una fotografía de Laurent tomada entre 1872 y 1879 [VN-09295].
} 


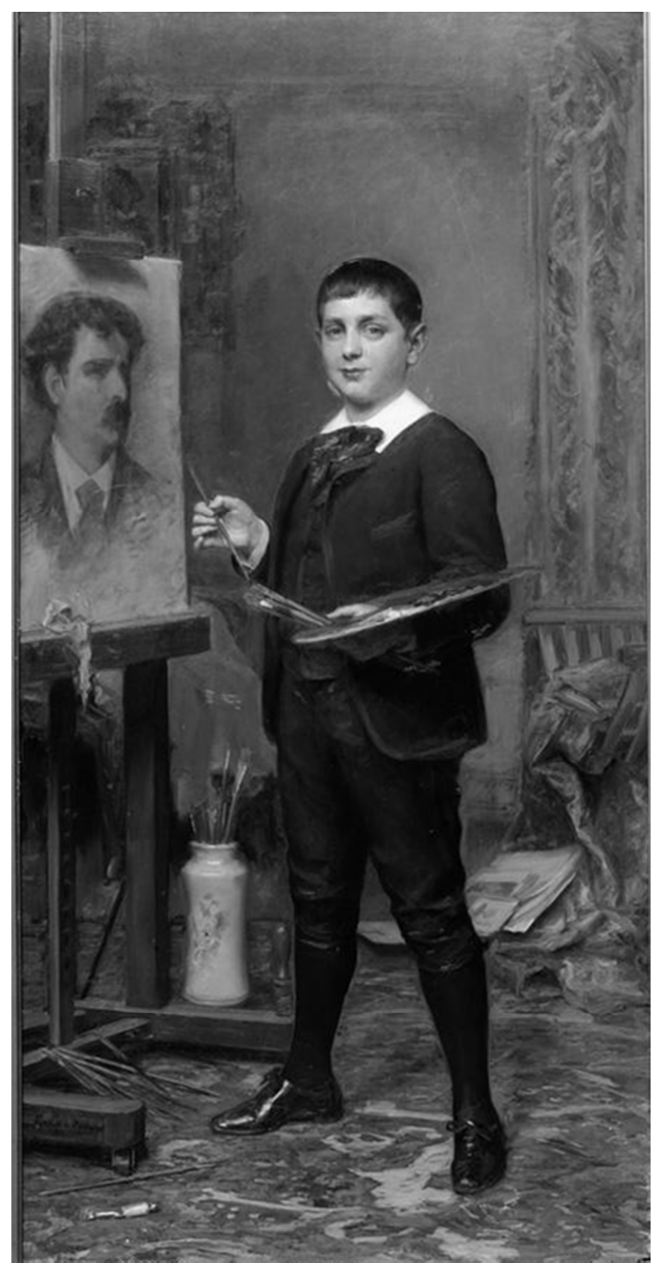

Fig. 9. Ricardo de Madrazo, Retrato de Marianito Fortuny copiando el retrato de su padre. Imagen procedente del Archivo Ruiz Vernacci (VN-07185).

En el retrato que Ricardo de Madrazo realizó en 1884 de su sobrino Mariano Fortuny y Madrazo [fig. 9] se pueden establecer algunos vínculos entre la imagen del artista adolescente y la figura del padre como modelo de identificación. La escena llama la atención por el elevado componente familiar, no solo entre pintor y retratado, sino en la propia actitud del joven Mariano Fortuny, captado realizando el retrato de su padre, fallecido diez años antes. Posando paleta en mano, la imagen ofrecida es la de un preadolescente seguro de sí mismo, con una expresión alegre que desmiente cualquier rasgo patético que el retrato de su difunto padre pudiera aportar a la escena. Un rasgo interesante es el juego de miradas presente entre el retratado y el pintor, ya que el retrato de Mariano Fortuny (padre) adquiere un valor secundario frente a la habitual relación padre-hijo existente en otros retratos de familia, permaneciendo en la obra como objeto para la memoria que legitima la presencia artística del adolescente, pero que difícilmente ofrece un modelo de identificación masculina para este. El hecho de que Marianito Fortuny aparezca representado de cuerpo completo, abandonando el retrato que realiza de su célebre progenitor para posar con la mirada fija en la figura de su tío (invisible para el espectador, que ocupa su lugar) hace que la identificación se traslade, por voluntad del pintor, hacia este mismo, convirtiéndose no solo en una figura cercana en el ámbito familiar sino en su mentor para la configuración de una identidad 
masculina y su condición de artista. Por otra parte, la ubicación del retrato en el caballete, con su cabeza ladeada y mirando hacia su propio hijo, parece subrayar la intención de Madrazo de volcar sobre el joven Fortuny la atención del espectador; con la inclusión del padre en la obra, la relación del pintor con el retratado no constituye una usurpación del rol paterno, sino un desplazamiento del modelo de autoridad sin perder de vista la paternidad a través del retrato dentro del retrato. En el acto de retratar a Marianito retratando a su padre, Ricardo de Madrazo consolida y legitima la identidad artística del pintor adolescente ante el espectador contemporáneo, mientras que su mirada al frente revela ya la traslación del modelo de identificación más allá de la idealizada figura paterna.

El retrato familiar realizado por Joaquín Sorolla en 1901 introduce abiertamente el proceso de identificación del niño con el padre a través del trabajo artístico, pero en él se advierten nuevos cambios respecto a la exclusividad masculina del arte. La obra $L a$ familia [fig. 11] (Ayuntamiento de Valencia) presenta una escena llena de matices, en la que Clotilde y Elena -esposa e hija menor del artista, respectivamente- posan para el pintor, que asoma en el fondo mediante un juego de espejos, mientras que María y el pequeño Joaquín, en segundo plano, permanecen inmersos en la realización de un dibujo. Se ha señalado ya la inspiración de Sorolla en una fotografía para la realización de la obra (VV.AA., 2006: 198), manifestándose algunas de las diferencias fundamentales entre la composición pictórica y su modelo fotográfico [fig. 10]; es importante, sin embargo, subrayar entre estas la significativa diferencia en el tratamiento de la relación entre padre e hijo. El modelo presenta una escena de familia en la que Joaquín Sorolla se incluye en el grupo interactuando con sus miembros: ubicado tras Clotilde, se inclina para comprobar el trabajo que su hijo está realizando al retratar a su hermana menor; en la imagen fotográfica, el pequeño Joaquín es el foco de atención por parte de su padre y su hermana mayor, sirviendo ambos de guía y referencia, mientras su madre y Elena miran al fotógrafo. El posado colectivo permite una lectura de paternidad íntima, transmitiendo el interés del padre por el hijo, y la identificación de este con la figura paterna a través de la práctica artística. El cambio en la pintura, que José Luis Díez relaciona con la influencia velazqueña en el uso del espejo, el gesto de María y la gama tonal (DÍEZ, 2009: 284; DÍAZ PENA, 2011: 192-195), implica también un cambio en la lectura de la relación padre-hijo; en palabras de Díez, "Sorolla se retrata a través de su reflejo en el ejercicio de su profesión de pintor, paleta en mano como Velázquez, además de en su calidad de cabeza de familia, a la que observa y retrata desde el otro lado del espacio del cuadro, que se prolonga a través del espejo", y sus modelos le devuelven la mirada "con la franqueza cotidiana de los ojos que miran al marido y al padre, antes que al pintor". En efecto, la figura de Sorolla cobra un nuevo protagonismo en la ausencia del grupo, al producirse el habitual distanciamiento que impone el juego del autorretrato en familia; sin embargo, esta lejanía afecta especialmente al pequeño Joaquín: sin su padre en el grupo central, está representado en actitud de dibujar, con la mirada fija en su hermana menor que le sirve de modelo. 


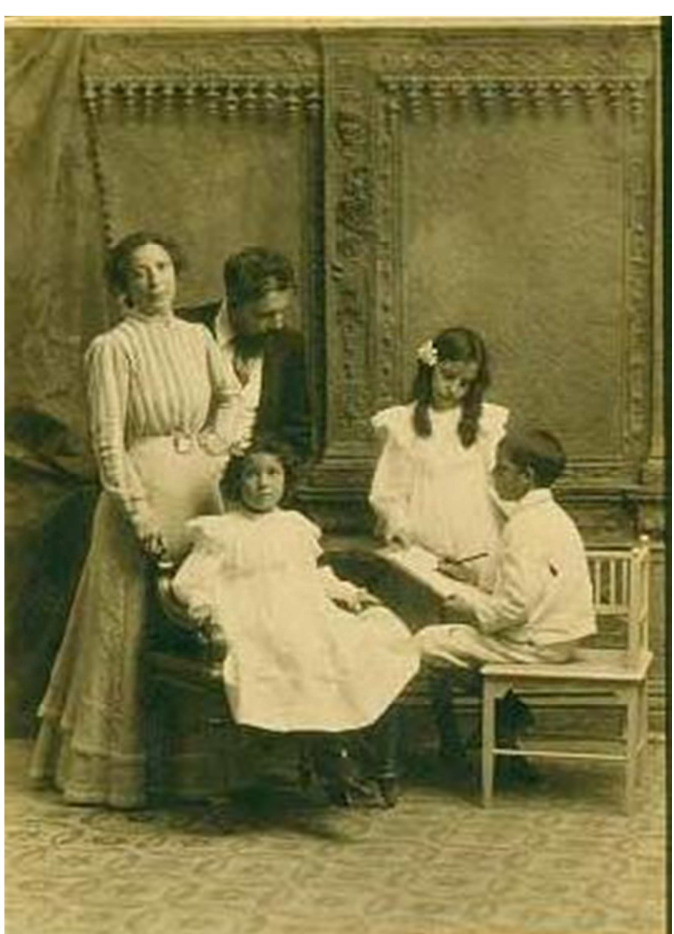

Fig. 10. Antonio González. Joaquín Sorolla, su mujer y sus hijos, fotografia amtigua. Museo Sorolla ( $\mathrm{N}^{\circ}$ Inv. 80242).

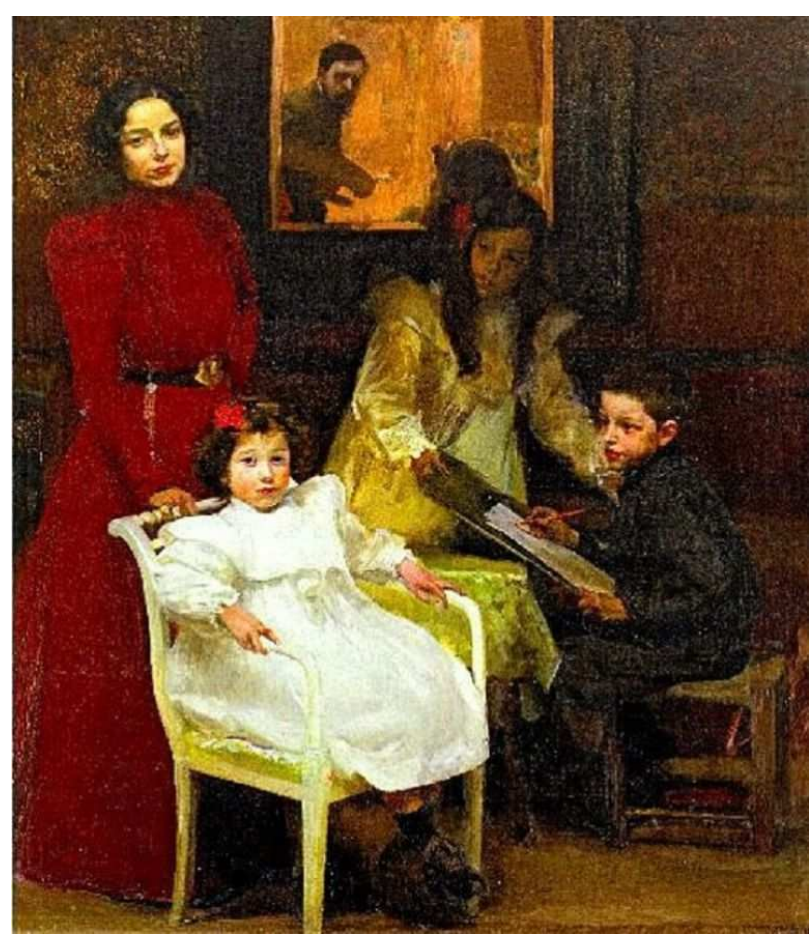

Fig. 11. Joaquín Sorolla, La familia (1901). Ayuntamiento de Valencia.

Mientras Sorolla, en pleno ejercicio pictórico y con los atributos que le corresponden, se presenta como un modelo profesional y, en cierto sentido, desaparece como padre momentáneamente ausente, es María la que orienta al niño en su ejercicio de dibujo, manifestándose como figura sustitutoria, y lo que es más importante, como muestra de que la construcción de una identidad artística no corre necesariamente pareja a la construcción de una identidad masculina en el ámbito de los Sorolla, como demostrarán los numerosos retratos que Joaquín Sorolla realizará de María pintando.

Dos conclusiones pueden extraerse de esta aproximación a la masculinidad del niño-artista en el ámbito familiar: la primera indica que la inclusión del retrato infantil como prolongación de la vida profesional de su progenitor es, además de un interés por manifestar la felicidad del hogar y el estatus social como muestra de poder a través de la fundación de una "dinastía" artística, una forma de evidenciar el triunfo personal al hacer del niño una figura privilegiada que dispone de un modelo de identificación, tanto masculino como profesional, en el propio hogar. No en vano, en los casos analizados el padre, autor de la obra, procede de una familia no vinculada directamente al mundo artístico: recordemos a Esquivel, huérfano de padre tras la batalla de Bailén; Cortellini, cuya familia no consideraba el arte como una opción de vida ${ }^{66}$; los orígenes humildes de Ignacio Pinazo y su infancia y adolescencia vinculado al trabajo artesano, o el caso de Sorolla, huérfano desde su temprana infancia y formado en temas artísticos fuera del ámbito familiar. La segunda conclusión evidencia una difícil conciliación entre las exigencias de la paternidad y las limitaciones a que se ve sometido el retrato de grupo en el caso de la familia del artista, puesto que la inclusión del autorretrato del padre-

\footnotetext{
${ }^{66}$ Respecto a Ángel María Cortellini Ossorio solo manifiesta que su familia intentó disuadirle de los
} estudios artísticos, aunque fue en vano, puesto que entró a la edad de nueve años en la Escuela de Dibujo. 
pintor, al caer en el recurso de la autocontemplación en el espejo, no puede sino generar una sensación de alienación entre los representados. De este modo, existe en las representaciones del siglo XIX una distancia -ya sea real o potenciada por la propia práctica pictórica- entre padre e hijo, y entre hijo y padre, que subraya de manera inconsciente una cierta tensión respecto a la identidad masculina del padre y el modelo de paternidad que encarna, y la identificación que el hijo puede adoptar en relación a esta.

\subsubsection{Artistas adolescentes y jóvenes en el ámbito de la Academia}

Los vínculos familiares en el ámbito académico, especialmente visibles en el siglo XVIII y de forma menos evidente en el XIX a través de la sucesión de varias generaciones de un mismo apellido, señalan un modo de sociabilidad entre artistas en el que la profesión se articula como eje de la vida artística y personal ${ }^{67}$. Las actas de la Academia de San Fernando reflejan de manera velada la interrelación entre vida profesional y familiar, ya sea a través de reprensiones sobre la aplicación de hijos o parientes de los académicos ${ }^{68}$, las solicitudes de títulos a favor de estos ${ }^{69}$, la renuncia a premios para no despertar críticas de favoritismo ${ }^{70}$ o la abstención en las votaciones en que se juzgaba el talento de familiares. La Academia vio también la plasmación de estos vínculos familiares en la presentación en junta de algunos retratos de académicos y discípulos, si bien de forma muy esporádica y coincidiendo con la revaloración de lo familiar en la última década del siglo XVIII y primera del XIX (BENALP JENSEN, 2011). De este modo, la Junta vio expuestos los retratos realizados por Ana María Mengs de su padre, esposo y de su hija mayor, al mismo tiempo que los retratos en miniatura realizados por Salvador Carmona de toda su familia, en agosto de $1790^{71}$; el retrato de la familia del arquitecto académico Alfonso Rodríguez, en mayo de $1805^{72}$, o el retrato familiar presentado por el pensionado Francisco Lacoma Sans ${ }^{73}\left(\mathrm{MNAC}, \mathrm{n}^{\circ}\right.$ inv 042403-000). Finalmente, otra evidencia de la existencia de vínculos familiares en el espacio de la Academia es el desplegado en las exposiciones anuales, mediante el recurso al retrato como legitimación o presentación simbólica ante la comunidad artística, y en la donación de retratos para la creación de galerías en las distintas academias, temas que se estudian de manera específica en otro apartado.

\footnotetext{
${ }^{67}$ Hannah Williams explora los vínculos familiares establecidos en el seno de la Académie Royale en el siglo XVIII, atribuyendo a la Academia el carácter de grupo o espacio social propio, en el que se desarrollan no solo relaciones profesionales y educativas, sino también de carácter personal y familiar (WILLIAMS, 2015).

${ }^{68}$ En junta ordinaria de 5 de febrero de 1775 se indicaba a Antonio Velázquez "previniese a su sobrino se debiere más en la corrección y conclusión de sus diseños" (ARABASF [3-83], fol. 334v.).

${ }^{69}$ En febrero de 1828, la Junta académica se hace eco de la petición de Antonio López Aguado para el nombramiento de su hijo como académico de mérito (Junta Ordinaria de 24 de febrero de 1828, ARABASF [3-88], fol. 191).

${ }^{70}$ En Junta Ordinaria de 13 de marzo de 1836 se da a conocer que en la clase de José de Madrazo, habiendo sido premiado su hijo Pedro, el propio padre solicita se destine a otro alumno (Junta Ordinaria de 13 de marzo de 1836, ARABASF [3-89], fol. 136r).

${ }^{71}$ Junta Ordinaria de 4 de agosto de 1790, ARABASF (3-85), fol. 136v.

72 Junta Ordinaria de 5 de mayo de 1805, ARABASF (3-87), fol. 165r.

73 "Fran ${ }^{\text {co }}$ Lacoma un quadro de familia al olio, retratos de sus Padres y una hermana", Junta Ordinaria de 6 de septiembre de 1807, ARABASF (3-87), fol. 330.
} 
La escasez de retratos del artista en formación en el ámbito académico, más allá de los vínculos familiares, no es un impedimento para intentar profundizar en la configuración de una identidad masculina relacionada con el aprendizaje artístico. Siguiendo este relato progresivo sobre el desarrollo masculino del artista, la iniciación en el aula supone, para el adolescente iniciado en el ámbito familiar, una desvinculación progresiva de la figura paterna, y para el adolescente neófito una primera toma de contacto, constituyéndose en ambos casos el profesorado como una fuente de identificación sustitutiva, más palpable en el caso de la sociabilidad de taller al permitir un mayor desarrollo de lazos interpersonales.

El estudio fuera del ámbito familiar, y especialmente en el caso de los pensionados, puede vincularse con el concepto de iniciación desarrollado por historiadores como Gilmore o Sohn en relación al adolescente estudiante, así como en los estudios antropológicos y sociológicos; al vincular adolescencia con el inicio de la autoconsciencia y la identidad individual, puede entenderse de qué manera los jóvenes artistas, en relación con el sistema meritocrático de la Academia, asimilan el mito masculino del self-made man propio de la sociedad industrial como meta propia, atribuyendo a la profesión artística valores exclusivos en los que construir una identidad personal (CATANO, 1990: 421-436). De este modo, tanto la retórica académica como la reivindicación del yo-creativo heredada del Romanticismo son expresiones masculinas de una idea común, es decir, de la necesidad de construcción individual en diálogo con un sistema de poderes, sea por identificación o por oposición, con el fin de hacerse un hueco en el mercado y en la sociedad, traduciendo no un ideal individual, sino el deseo de un pequeño grupo social -el alumnado artístico- en función de la proyección de un modelo concreto - la profesión artística- y su grado de adaptación a los ideales masculinos de la sociedad. La figura del pensionado de provincias constituye el prototipo por excelencia de la asimilación del mito de la autoconstrucción masculina entre los jóvenes artistas, desvinculándose del hogar para llevar a cabo lo que se espera sea el desarrollo óptimo de las habilidades técnicas en un marco de excelencia -la Academia-, con la intención de iniciar una carrera de éxitos profesionales. El conflicto entre el ideal y la realidad del pensionado, evidenciado por la falta de recursos económicos y por la continua necesidad de probar sus avances ante la institución, es una muestra de la lógica en que se construye la identidad masculina, y concretamente la del joven artista, mediante la continua superación de obstáculos, de lo que dan cuenta las actas de las sesiones académicas al recoger minuciosamente los pases y avances de los pensionados.

Constituidos algunos artistas académicos en figuras carismáticas sinónimo de profesionalidad y éxito, adoptan en la memoria del discípulo la imagen de un nuevo padre al que emular ${ }^{74}$; no obstante, la práctica invisibilidad jerárquica del discípulo en la Academia parece ser correspondida con una negación del vínculo de identificación con el maestro al no producirse retratos mutuos. Significativamente, el retrato de grupo en que se muestra a maestro y discípulos solo comienza a desarrollarse en España a través

\footnotetext{
${ }^{74}$ Ceferino Araujo recuerda a José de Madrazo como una figura paternal (ARAUJO SÁNCHEZ, 2005: 172), y Martín Rico hace una alusión similar respecto a Juan Antonio de Ribera (RICO, 1906: 17).
} 
de la fotografía, como testimonio o recuerdo de una clase o una promoción, sin manifestar una identidad de grupo (BONNET, 2007: 66), mientras que el retrato individual del maestro, a modo de homenaje o agradecimiento, cobra relevancia fuera de la institución académica, especialmente durante la segunda mitad del siglo XIX, debido a la sociabilidad del taller.

Pueden encontrarse varias razones a la elipsis de la imagen del discípulo en la Academia: en primer lugar, está precisamente relacionada con una realidad social en la que la etapa de formación, por ser común a todos los artistas y tener un matiz burocrático mediante la institucionalización de la enseñanza artística, niega la retórica romántica de lo excepcional (LAUGÉE, 2011: 231); en segundo lugar, las relaciones interpersonales establecidas en el aula académica no parecen lo suficientemente sólidas ni sus logros lo suficientemente memorables para que profesores o académicos retratasen a sus discípulos con el fin de conservar su recuerdo dentro de la institución; finalmente, la inseguridad técnica de los jóvenes discípulos, así como una posible idea de traspasar una barrera sobre los méritos que podrían justificar un autorretrato en el ámbito académico. Esta última idea, acorde con la idea de Omar Calabrese sobre la sanción y la escasez de autorretratos masculinos de adolescencia (CALABRESE, 2006: 221-223), puede responder a la escasez de retratos de jóvenes artistas en la Academia. Un caso bastante enigmático tiene lugar en 1805, cuando el pensionado por el consulado de La Coruña Tomás Fernández de Erosa (o Herosa) presentó como pruebas de su adelantamiento un cuadro de invención y un autorretrato ${ }^{75}$, un atrevimiento poco modesto del que la junta no da mayores datos, decretando únicamente que, en vista de las obras, Erosa no adelantaba. Añadía, además, que no había tomado maestro en la Academia para que le dirigiera, algo que tal vez tenía que ver no solo con la calidad pictórica de las obras, sino también con la falta de modestia que podía suponer la presentación de su autorretrato. Sin embargo, la voluntad de Erosa podía deberse a una necesidad de reafirmación, ya que a sus veintiocho años se veía superado en los certámenes por discípulos mucho más jóvenes.

Del mismo modo, a pesar de la realidad académica como espacio social -y asimilado como tal por parte de los artistas-, no constan referencias a la práctica del retrato entre pares entre jóvenes artistas como muestra de sociabilidad o de la práctica cotidiana en la Academia. Tan solo dos noticias de este tipo de retrato parecen adecuarse a esta idea, sin que haya sido posible su localización en los fondos académicos, tratándose de los retratos de José Amaro y José Solano, realizados ambos por su condiscípulo Carlos Blanco y presentados a las exposiciones de la Academia de 1805 y 1806, respectivamente.

\footnotetext{
${ }^{75}$ Junta Ordinaria de 8 de septiembre de 1805, ARABASF (3-87), fol. 201 r.
} 


\subsubsection{Retratos de jóvenes artistas para la emulación}

\subsection{Los retratos de los pensionados a Roma de 1848 en la Academia de Bellas Artes de San Fernando}

Con motivo de las oposiciones para Roma de 1847 se instala en la Academia el primer conjunto de retratos de jóvenes artistas del que tenemos noticia, siendo la fuente el recuerdo de Ceferino Araujo sobre la Sala del Colorido (ARAUJO, 2005: 169), retomado por Fernando J. Martínez Rodríguez en su tesis doctoral (2007: 40-42). Según Araujo, con motivo de los exámenes, los opositores pintaron mutuamente sus respectivos retratos, y se conservaron "con respeto para que sirvieran de emulación y recuerdo de las pensiones". Tomando como referencia los dibujos copiados por Bernardino Montañés, Martínez Rodríguez señala la existencia de seis retratos, es decir, los seis aspirantes por la pintura: Francisco Lameyer, Francisco Sáinz, Carlos Múgica, Luis de Madrazo, Manuel Iglesias y Bernardino Montañés, tal y como constan reflejados en los retratos a lápiz de Montañés, realizados en cuartilla y agrupados de dos en dos.

Cabe la duda de si los seis aspirantes, o tan solo los tres laureados, gozaron finalmente del privilegio de ver su retrato en la Sala del Colorido. Las actas de la Academia no arrojan ninguna luz sobre una iniciativa que, con toda probabilidad, fue propiciada por la experiencia cosmopolita de profesores como Federico de Madrazo y Carlos Luis de Ribera, quienes habrían podido conocer de primera mano esta forma de premiar el mérito en los estudios parisinos ${ }^{76}$. Tampoco los inventarios de la Academia, tanto el manuscrito de 1867 como el de 1884, así como los contemporáneos de pintura y dibujos, dejan constancia de ningún retrato representando ni a los aspirantes ni a los pensionados, por lo que tal vez los retratos permanecieron poco tiempo en este lugar. Los retratos mencionados por Martínez Rodríguez corresponden a la descripción dada por Araujo, quien afirmaba que estaban realizados de perfil, aunque no aportaba más datos sobre la técnica; cabe suponer, en vista de las copias realizadas por Bernardino Montañés, que eran únicamente retratos de busto, y que fueron realizados durante o poco después de las pruebas de oposición.

La noticia de Ceferino Araujo arroja una imagen interesante del ambiente de animación que supuso la reinstauración de las pensiones a París y Roma, que permite dotar a los retratos ubicados en la Sala del Colorido de una relación con un grupo muy concreto. La existencia de tres retratos pictóricos realizados en 1848 representando precisamente a los pensionados podría plantear la hipótesis de que pudieran haber sido pintados con destino a la Academia, aunque corresponden al tipo de retrato de amigo destinado a reconocer el talento y los vínculos entre iguales, y permanecieron (a excepción de uno de ellos) en propiedad de los representados. Se trata de dos retratos pintados por Luis de Madrazo, representando uno a Bernardino Montañés (HERNÁNDEZ LATAS, 1994: 281) y otro a Francisco Sáinz (Museo Nacional del

\footnotetext{
${ }^{76}$ Especialmente Carlos Luis de Ribera, quien ingresó en el taller de Delaroche, pudo haber conocido directamente los retratos de alumnos premiados o distinguidos, destinados a servir de inspiración a los discípulos (HAUPTMAN, 1985: 79-119).
} 
Prado, $n^{\circ}$ inv. P03417), adquirido este último por la Junta de Iconografía Nacional para la Galería de Españoles Ilustres en 1886, y del retrato de Luis de Madrazo realizado por su hermano y maestro Federico, enviado a la Exposición de la Academia de ese mismo año con clara intención de subrayar el éxito alcanzado por el joven artista (Colección Madrazo, Madrid). Frente a este tipo de retrato, habitual entre artistas y que señala una forma de socialización profesional en el extranjero, los retratos que permanecieron hasta fecha indefinida en el aula adquirieron el valor añadido de servir de estímulo a nuevos discípulos, incorporándose así en el discurso francés del retrato de discípulos en el atelier, canalizando un ideal profesional -las pensiones al extranjero- de autoconstrucción masculina a través de la emulación y la identificación directa. De este modo, el sistema de relaciones masculinas en el estudio o en el taller planteado por Crow, Kosofsky o Solomon-Godeau ${ }^{77}$, visibiliza una estructura jerárquica en que se plantea un modelo de fácil identificación para el alumno a través de los logros de sus compañeros, lo que asienta entre los artistas españoles un sistema de competitividad y rivalidades exclusivamente masculino.

Esta experiencia del retrato para la emulación fue puntual, ya que no queda constancia de que posteriormente volviera a repetirse.

\subsection{El retrato de José Utrera Cadenas en la Academia de Bellas Artes de Cádiz}

A pesar de que, como ya se ha señalado, los retratos de jóvenes artistas son escasos en las instituciones oficiales, resulta peculiar el caso del retrato de José Utrera y Cadenas en la Academia de Cádiz como ejemplo atípico para la emulación en una academia provincial. El joven Utrera, discípulo de la academia gaditana y posteriormente de la de San Fernando, falleció en 1848 a los veinte años tras haber alcanzado el éxito en la exposición de 1847 con su obra Guzmán el Bueno. En 1851, la Academia le homenajeaba con la colocación de su retrato, realizado por Santiago González Lago (Museo de Cádiz, no inv. CE20171), en el Salón de Sesiones junto al de Ana Urrutia, artista y académica de mérito formada en Cádiz y fallecida en 1850. En la sesión pública de 17 de agosto de 1851, Alfonso de Castro comenzaba su discurso de distribución de premios a los alumnos aventajados haciendo alusión a ambos retratos como prueba manifiesta de que el genio artístico no tiene sexo ni edad:

Señores: en el acto solemne de distribuir hoy la Academia Provincial de Bellas Artes los premios a aquellos jóvenes que han manifestado más felices disposiciones y mayor aprovechamiento en los estudios del último año, debo llamar la atención, así de los discípulos como de todas las demás personas que me honran escuchando mis palabras, hacia los dos retratos que se ven en el testero de esta sala, en que la Junta celebra sus sesiones. Uno y otro son de artistas que nacieron en la patria de los Balbos y de Columela, si diferentes en sexo, iguales en la afición y en el deseo de adquirir buena y justa fama por medio de los pinceles (...) Ni el sexo ni la edad tienen jurisdicción alguna sobre el ingenio, cuando el ingenio no nace niño,

\footnotetext{
${ }^{77}$ Sobre el concepto de homosociabilidad y fraternidad artística, así como su papel en el manteniemiento o cuestionamiento de masculinidades normativas ver: CROW, 2002; KOSOVKSY-SEDGWICK, 1993; SOLOMON-GODEAU, 1997: 48-50; MOROWITZ y VAUGHAN, 2000.
} 
sino gigante (...) Con el talento pueden alcanzar honrosísima fama y hacer a su autor inmortal entre los hombres los cuadros de un artista que apenas vea asomar en su rostro la flor que más tarde ha de convertirse en espesa barba (ANÓNIMO, 1852: 30).

Sin embargo, el mensaje dirigido a los discípulos de la Academia incide, mediante un lenguaje simbólico, en el atrevimiento de Utrera por acometer, en plena juventud, lo que debía ser una obra de madurez, al afirmar sobre su Guzmán el Bueno "quiso el joven gaditano anticipar el curso de los tiempos: lo que el estudio y el talento habían de hacer en largos años, ejecutó en los abriles de su existencia, y su existencia terminó al terminar Utrera la obra de su vida". La referencia a los retratos, presentes en la entrega de premios, así como el discurso de homenaje hacia Ana Urrutia y José Utrera manifiesta el carácter de emulación que estos podían tener sobre los discípulos, alentando a los jóvenes artistas a continuar el estudio con los ojos puestos en sus dos malogrados compañeros.

La función de estos dos retratos, aparte de servir como estímulo para los jóvenes alumnos de la Academia, es próxima también a la idea de perpetuación del recuerdo vinculada al éxito profesional y al homenaje póstumo en comparación con el espíritu de emulación que alentaba los retratos de los pensionados en la Academia de San Fernando. Los convencionalismos a los que se someten los retratos de Ana Urrutia [fig. 12] y de José Utrera indican, además, que a pesar del discurso igualitario de Alfonso de Castro los discípulos difícilmente encontrarían ambas figuras como fuente de identificación profesional, al emplearse únicamente la iconografía de pintor en el caso del retrato de Utrera, siendo el de Ana Urrutia una muestra de retrato femenino burgués al presentarla sentada, con las manos cruzadas y un abanico cerrado. Llama también la atención que, frente a la sobriedad de los retratos de pensionados en la Academia de San Fernando, en los que la representación de perfil -y probablemente, como ya se ha señalado, de busto- no permite la inclusión de los atributos característicos del pintor, en el caso del joven José Utrera se incorpore a la Academia un retrato juvenil que muestra ya una identidad profesional. La causa debe buscarse en la fuente de la que Santiago González tomó el modelo, siendo un autorretrato del propio Utrera fechado en 1847 [fig. 13] (Museo de Cádiz, $n^{\circ}$ inv. 20433), año de su éxito en la exposición de la Academia de San Fernando y un momento en el que, movido tal vez por la vanidad, el artista se sintió capacitado para asimilar y representarse acorde a la identidad profesional del pintor con sus atributos. Sin lugar a dudas, Utrera estaba familiarizado con esta iconografía, que había podido contemplar en Madrid y de la que es ejemplo su copia del retrato del escultor José Vilches (QUINTERO ATAURI, 1919: 19). 


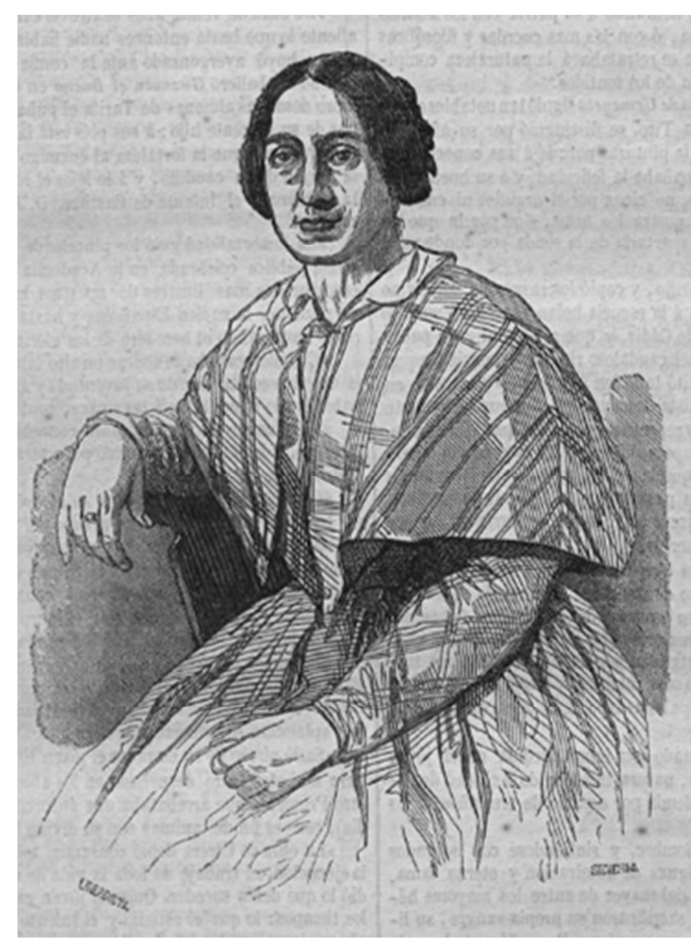

Fig. 12. Ana Urrutia y Urmeneta. Semanario Pintoresco Español, 25 enero de 1852.

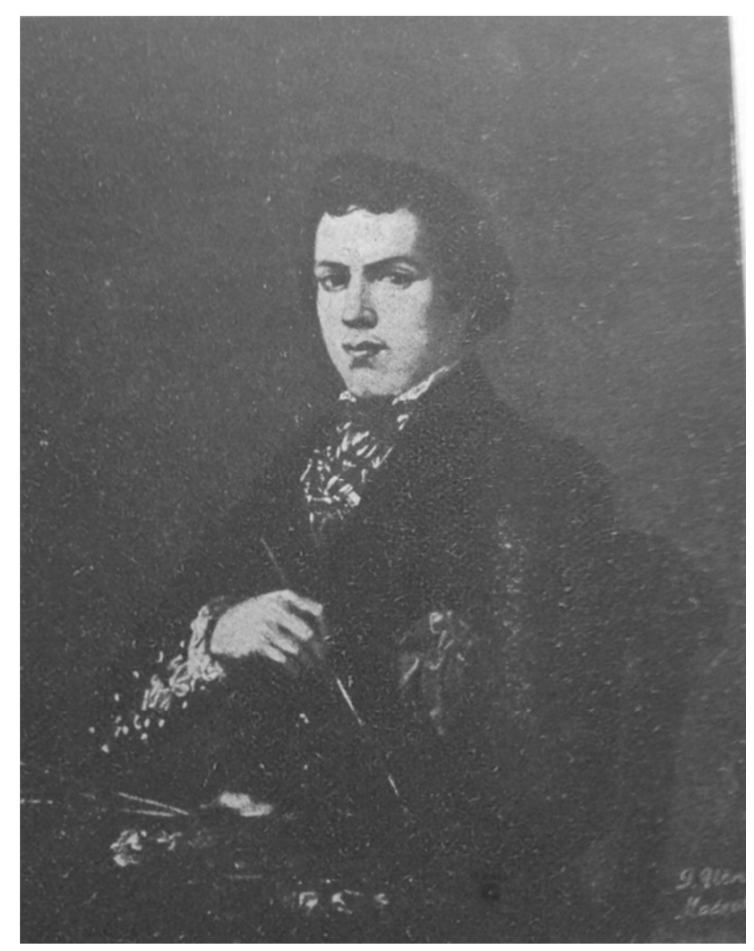

Fig. 13. José Utrera y Cadenas. Autorretrato. Museo de Cádiz ( ${ }^{\circ}$ inv. 20433).

En su autorretrato, Utrera se presenta como un joven elegante, sentado y con la paleta en la mano izquierda, sosteniendo con la derecha un pincel; su escasa edad se adivina en la redondez del rostro y en la sombra de un bigote que asoma sobre el labio superior. Sin embargo, en su pose erguida y en la profunda autocontemplación que manifiesta su mirada fija, se traduce una sensación de orgullo que choca con la habitual inseguridad de los autorretratos juveniles, y que suele subsanarse justificando su presencia en una representación familiar, como el Autorretrato de Francisco Lacoma junto a su tío Antonio (MNAC, $\mathrm{n}^{\mathrm{o}}$ inv. 010443-000), o mediante la inclusión del retrato en una composición histórica ${ }^{78}$.

\subsubsection{Jóvenes artistas en París}

\subsubsection{Masculinidad y la práctica del arte en París}

La meta de completar la formación en París y en Roma suponía, para los artistas españoles, una toma de contacto no solo con otras escuelas sino también con otras jerarquías y espacios masculinos. La propia École des Beaux-Arts ofrece una imagen significativa del proceso de construcción de una masculinidad artística entre los jóvenes franceses, así como de las preocupaciones y los patrones de conducta derivados de la iniciación en la práctica artística. Uno de los puntos que más ha llamado la atención, por su componente de travesura artística y por alimentar con anécdotas las biografías de muchos pintores decimonónicos franceses, es el de las charges y blagues relacionados con la tradición del bizutage o novatada, que Susan Waller (2000) analizó como un rito

\footnotetext{
${ }^{78}$ Otros autorretratos juveniles, en los que no se tiene en cuenta la identidad profesional, son también frecuentes en el siglo XIX, con ejemplos como el supuesto Autorretrato de Antonio María Esquivel de 1824 (MNAC, $\mathrm{n}^{\circ}$ inv. 040910-000), o el de Rafael García Hispaleto de 1850 (en paradero desconocido).
} 
de iniciación profesional y masculina. Al estudio de Waller, que aportó una nueva visión del taller como espacio sexualizado para los jóvenes artistas, se suman también los testimonios contemporáneos a estas prácticas, en los que se explicitan los significados de cada rito. Alexis Lemaistre relata en L'École des Beaux Arts dessinée et racontée par un élève la serie de bromas y humillaciones a las que se sometía al recién llegado, entre las que se incluye un discurso por parte del massier justificando la necesidad de las vejaciones: "la vida del estudiante, como la vida del artista, es una imagen en reducción de la vida (...) Para habituarte, muchacho, a esas pruebas reales te hemos sometido a estas pruebas de broma" (LEMAISTRE, 1889: 20). El componente exclusivamente masculino de estas iniciaciones se desprende de comportamientos en los que existe una violencia moderada y un interés por imponer la jerarquía del taller, que obligaban al recién llegado a desnudarse o a narrar sus experiencias sexuales. Hauptman mencionaba estas pruebas como una forma de canalizar las tensiones del taller debidas a la rivalidad y competitividad tanto de las pruebas de acceso a la Escuela como posteriormente al Prix de Rome (HAUPTMAN, 1985: 88; SEGRÉ, 1998: 133-135), y que en algunos casos generaban tanta inquietud entre los jóvenes artistas que estos elegían maestro en función de la reputación y tono de los recibimientos en su correspondiente taller $^{79}$.

Los pintores españoles en París debieron conocer de cerca las tradiciones y condiciones en las que se desarrollaba el aprendizaje artístico, tanto en el taller como en la École des Beaux Arts; sin embargo, apenas es posible encontrar testimonios que traduzcan el impacto que pudo suponer su entrada e iniciación en el taller. Waller señalaba que, en el caso francés, eran pocos los que mencionaban este tipo de recibimientos en su correspondencia familiar, probablemente para no causar alarma o para no ser reprendidos por su actitud o por el desembolso de dinero para el tradicional refresco de bienvenida con que el nuevo obsequiaba a sus compañeros de taller. No parece plausible suponer que los recién llegados extranjeros fuesen dispensados de este recibimiento ya que suponía un trámite ineludible para la aceptación dentro del grupo, a pesar de no tratarse de competidores serios -y por lo tanto no generar la misma rivalidad- al estar restringido el Prix de Rome a los artistas franceses. A su llegada a París, Carlos Luis de Ribera entró en el taller de Delaroche, considerado por Hauptman como uno de los más feroces en lo que respectaba al recibimiento de los nuevos alumnos (HAUPTMAN, 1985: 86); llama la atención que, poco después de su llegada, su padre se quejase con frecuencia -tal y como traduce la correspondencia de José de Madrazo con su hijo Federico (DÍEZ, 1998b: 227)- de que Carlos Luis apenas le escribía, pudiendo vincular este silencio con una lenta adaptación a la realidad parisina. Al igual que sobre su bizutage, tampoco se conservan noticias sobre su trato con otros

\footnotetext{
${ }^{79}$ Muestra de ello fue, por ejemplo, la decisión final de Hippolyte Flandrin de presentarse al taller de Ingres, que no solo estuvo motivada por la calidad artística de este, sino también por la ausencia del fastidioso recibimiento del nuevo discípulo. Carta a Mr. Flandrin, 14 de abril de 1829: “(...) Sabes que estábamos prácticamente decididos a ir al taller de Hersent; he cambiado de idea y no es por capricho. He aquí los motivos: en primer lugar, en París Ingres es valorado de mayor talento que Hersent; además, su escuela está mucho mejor reglada y es más tranquila. No soporta que se hagan esas malas bromas que hacen con frecuencia que el mejor no pueda quedarse. Así pues, papa, ya ves que hay buenas razones para irse con Ingres" (DELABORDE, 1865: 113).
} 
compañeros de taller, aunque a juicio de Federico de Madrazo la "mala actitud" de Ribera adquirida en París manifestaba pereza y malas compañías ${ }^{80}$.

Otros artistas españoles tuvieron relación con el atelier de Gérôme -formado primero con Delaroche y posteriormente con Gleyre-, y también debieron entrar en contacto con las bromas y charges, más sutiles, heredadas del taller de este último, ya que al parecer Gérôme adoraba las bromas, y disfrutaba con los relatos de "algunas de las cargas, a veces inocentes, que ocurrían en los ateliers" (MOREAU-VAUTHIER, 1906: 8); es el caso del canario Manuel Méndez, José Moreno Carbonero, Rafael Ochoa $^{81}$, Luis Buxos, Leopoldo Roca o Fernando Tirado en la década de los setenta del siglo XIX (REYERO, 1991: 384-395), aunque nuevamente parece que la experiencia no aparece reflejada ni en biografías ni en correspondencia privada.

Lo mismo sucede con los pintores que entraron en el atelier de Gleyre. Las noticias sobre los artistas españoles formados con Gleyre son contradictorias; por una parte, Carlos Reyero ponía de relieve haber encontrado solo dos registros de matrícula en la Escuela de Bellas Artes en los que el alumno español hubiese sido presentado por este maestro, siendo el caso de Antonio Caba, y de Valdeavellano ${ }^{82}$, vinculado el hecho de que Ossorio mencionase al menos otros cuatro nombres distintos con el interés propagandístico de promocionar el mérito de los artistas nacionales a través de relaciones con el mundo artístico francés ${ }^{83}$. Además de estos dos pintores, en el mismo registro de matrícula consta otro español presentado en 1856 por Gleyre, el murciano Luis Ruipérez ${ }^{84}$, más conocido por su filiación particular con Meissonier. En los archivos del Louvre figuran otros pintores españoles, registrados como alumnos de Gleyre: Mariano Baquero, que también consta así en la entrada redactada por Ossorio, Germán Hernández Amores, Leopoldo Gil, Francisco Merino y Nicolás Ojeda ${ }^{85}$.

El atelier más frecuentado por los pintores españoles en París fue el de Léon Cogniet $^{86}$, del cual se han conservado algunos testimonios sobre el respectivo bizoutage

\footnotetext{
80 "Carlos Ribera (...) trabaja muy poco; ya se ve que su padre lo tenía enteramente atado. Ha venido aquí, se ha juntado con españoles hambrones y majaderos y esto le ha bastado y le ha sobrado para perder la afición que tenía al estudio" Carta de Federico de Madrazo a su padre, 21 de octubre de 1837 (DÍEZ, 1994: 37).

${ }^{81}$ Moreau-Vauthier señala entre sus alumnos extranjeros a los españoles Rafael de Ochoa y Antonio de la Gándara (MOREAU-VAUTHIER, 1906: 177).

${ }^{82}$ REYERO, 1991; ANF AJ/52/235, números 3363 (Valdeavellano, 8 de octubre de 1862, fol. 144) y 3377 (Antonio Caba, 31 de marzo de 1863, fol. 145).

${ }^{83}$ Los cinco pintores citados por Reyero, tomando como fuente a Ossorio son el propio Caba, Eduardo García Guerra, Víctor Hernández Amores, Joaquín María Herrer Rodríguez y Nicolás Ruiz de Valdivia.

${ }^{84}$ ANF AJ/52/235, $\mathrm{n}^{\circ} 3003$, fol. 108.

${ }^{85}$ Mariano Baquero figura en 1854, Germán Hernández en 1851 (recogido también en Ossorio y Bernard), Leopoldo Gil en 1847, 1848 y 1851, y Francisco Merino y Nicolás Ojeda en 1855. En la lista de alumnos publicada en el catálogo de exposición Charles Gleyre ou les illusions perdues se incluían además como alumnos de Gleyre a Ferrándiz (utilizando como fuente los datos aportados por Auguste Michelin, discípulo de Gleyre), a los dos mencionados por Reyero, Víctor Hernández y Ruiz de Valdivia, y de manera errónea a Luis Ruipérez (Catálogo..., 1974: 140-149).

${ }_{86}$ Aurelio Blasco, Carlos María Esquivel, Rafael Olavide, Mariano de la Roca, Ramón Rodríguez, Eusebio Valldeperas (REYERO, 1991); en el registro de copistas del Louvre figura como presentado por Cogniet, además de sus alumnos españoles, Pedro de la Roca (ANF AJ/52 [alumnos 1845-1849], *LL 08, fol. 56).
} 
y charges, no solo por parte de artistas franceses sino también, y lo que es más importante, por parte de un pintor español: Raimundo de Madrazo. A través de las memorias publicadas en 1976 por Martine Mialaret pudieron conocerse algunos datos interesantes de la autobiografía de Raimundo, siendo interesante comprobar cómo este dedicó una especial importancia a los datos sobre su iniciación en el mundo artístico parisino en 1862, siguiendo los modelos de las biografías y memorias de artistas publicadas en territorio francés. A juzgar por los testimonios que ofrece, su estancia en el atelier de Cogniet no debió de llegar a durar más que un par de semanas; aunque no parece que le atrajese demasiado el ambiente que describe, lo que encaja con la moral masculina burguesa aprendida en el ámbito familiar, sí que relata, de forma somera y sin entrar en detalles escabrosos, su propio bizutage:

Quise también conocer los célebres ateliers de los que tanto se hablaba en Madrid, y entré en el de Cogniet (...) Antes de comer, me hicieron subir a un taburete (bisutage), y escribí sobre la pared mi nombre y mi edad; me huicieron las preguntas estúpidas y obscenas acostumbradas en tales lugares. Para salir de esta mala situación, fingí hablar mucho menos francés del que sabía, y me dejaron tranquilo (MIALARET, 1975, pp. 303-313).

Algo sorprendente en el relato de Madrazo, a pesar de haber sido escrito a finales de su vida, es la ausencia de preocupación que la entrada en el taller de Cogniet podía suponer, conocedor como era de las famosas charges d'atelier; su actitud resignada y desencanto con esa parte de la vida artística se pone de manifiesto más adelante, al mencionar las consecuencias de la tradicional invitación al vino caliente: "A la hora de la comida, les pagué el vino caliente de bienvenida: siguieron las celebraciones, de las cuales los caballetes y taburetes sufrieron las consecuencias. Todo aquello me decepcionaba un poco" (MIALARET, 1975). Raimundo de Madrazo señala abiertamente que el contenido de las preguntas que se le hicieron fue obsceno, como era la costumbre, una eventualidad de la que no le salvó la fama de su apellido ${ }^{87}$. Su recuerdo del taller de Cogniet coincide punto por punto con el ofrecido por otro pintor, Amédée Besnus, quien subido a la mesa de la modelo -que permanecía sentada, fumando $\mathrm{y}$, debe intuirse, aún desnuda- fue sometido a las mismas preguntas indiscretas $^{88}$, y hace imaginar el tipo de bienvenida que los demás jóvenes españoles vivieron en el taller de este artista.

Otra de las peculiaridades del ambiente y sociabilidad del taller parisino es la generalización del retrato, entendido primeramente como un homenaje al talento y una valoración de la figura del discípulo -mediante la ocupación simbólica del espacio educativo-, y posteriormente como una vía de escape, reflejo del ocio y la camaradería

\footnotetext{
${ }^{87}$ La correspondencia de Raimundo de Madrazo con su padre, conservada en el archivo del Museo del Prado, podría mostrar si el joven artista informó a su familia de su bienvenida en el taller. Lamentablemente, la documentación no ha podido ser consultada (a excepción de la publicada en GUTIÉRREZ MÁRQUEZ y MARTÍNEZ PLAZA, 2017) al estar siendo investigada por el propio Museo.

88 "Me pidieron que me subiese a la mesa de la modelo, que descansaba mientras fumaba un cigarrillo; se llamaba Georgette; y solo entonces comenzaron las preguntas más... indiscretas, a las cuales respondía como mejor podía para acabar lo antes posible, tomando de vez en cuando un tono desenfadado para darme ánimos" (BESNUS, 1898: 86).
} 
masculina, a través del humor en la proliferación de caricaturas. Hauptman consideraba los retratos de los ateliers de Delaroche y de Gleyre (Musée du Petit Palais, $\mathrm{n}^{\circ}$ inv. PPP900), como retratos de grupo (HAUPTMAN, 1985: 88), un concepto rebatido posteriormente por Alain Bonnet (2007: 66-67), vinculados a la existencia de unas estructuras sociales alejadas de una rígida jerarquización, marcadas por la camaradería, hasta el punto de ver en ellos una forma de evasión de las rivalidades a través del premio al talento. Bonnet señalaba, además, un rasgo interesante: estos retratos, eclécticos y colectivos, eran obra de uno o de varios alumnos, pero no de los profesores, tratándose por lo tanto de un producto de la sociabilidad del atelier (BONNET, 2007: 67); lo cual, unido a la idea de que solo algunos alumnos, elegidos por haber sobresalido por su talento, eran incluidos en la tela, indica que no solo de rivalidades se alimentaba el ambiente entre discípulos. De este modo, parece que este tipo de composiciones estaba concebido como una particular galería de retratos, al mismo tiempo pequeños homenajes a los compañeros que coronaban algún éxito y aliciente para el esfuerzo y superación para el resto de discípulos.

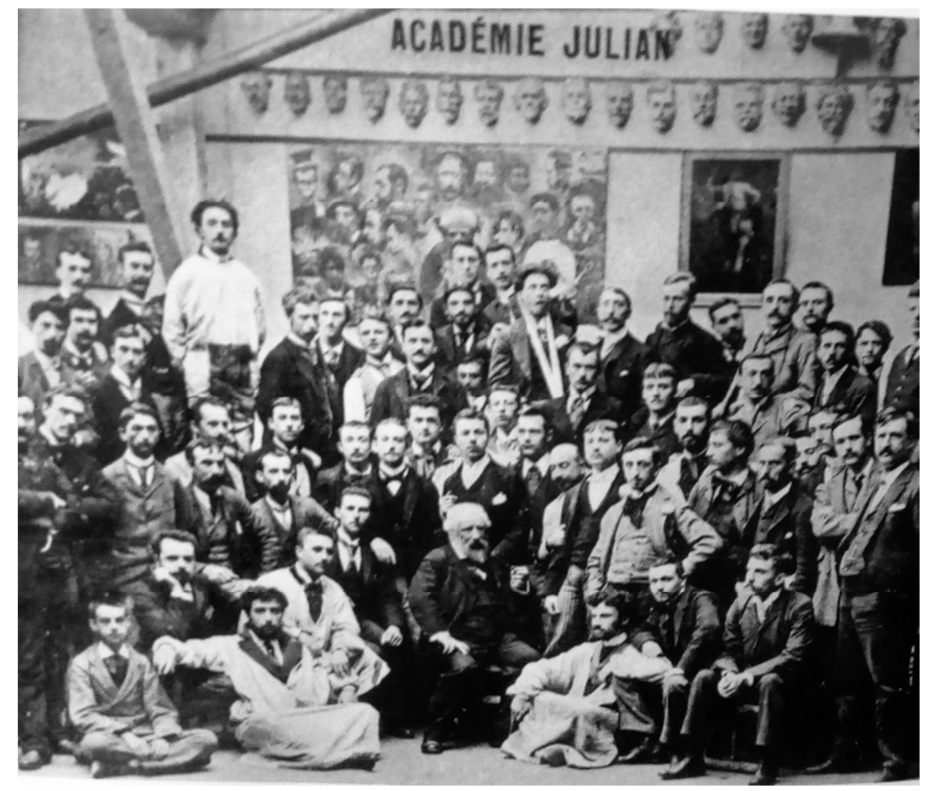

Fig. 14. Bouguereau y Toudouze rodeados por sus alumnos (detalle). Fotografía.

Tras el caso de los retratos en los talleres de Delaroche y Gleyre, la práctica se heredó como tradición a modo de ritos artísticos en las prácticas cotidianas, perviviendo en la Escuela de Bellas Artes en forma de caricaturas, y pasó a otros espacios educativos, como la Académie Julian. Una curiosa fotografía de grupo de los alumnos masculinos de Bouguereau y Toudouze en la Académie Julian [fig. 14] pone de manifiesto el valor especial del retrato. En la imagen, los alumnos posan, junto al maestro, en el propio taller; frente a esta imagen democrática de la fotografía de grupo, en el que todos tienen cabida, destaca en la pared del fondo, junto a algunas academias, un lienzo en el que se han pintado algunos de los rostros de los alumnos, con un estilo desenfadado. Al ser la Académie Julien la introductora de las clases para mujeres artistas, cabe preguntarse si los talleres que les estaban destinados albergaron también una muestra de sociabilidad, en este caso femenina, a través de la práctica del retrato. Camille Debans, haciendo una distinción entre los ateliers masculinos y femeninos, 
señalaba que en los primeros reinaba el humor y que los muros, además de estar cubiertos con las composiciones premiadas, mostraban buenas caricaturas y dibujos de naturaleza satírica; por el contrario, en los destinados a mujeres apenas había alguna caricatura tímida y de escaso valor (DEBANS, 1889: 195 y 204). Catherine Fherer recogía que, según una reseña publicada por un reportero inglés en The Sketch, al menos un retrato de la artista Marie Bashkirtseff era visible en la oficina del propio Julien, junto a otros retratos de sus alumnos favoritos, hechos por sí mismos o por otros compañeros (FEHRER, 1994: 756); por otra parte, Jane R. Becker apuntó que, respecto a las caricaturas de mujeres artistas conservadas, era manifiesta una rivalidad feroz entre las pintoras (BECKER, 1999: 69-107), transformando el retrato -con su componente ideal de homenaje y emulación- en una cruel mofa alejada del humor, aparentemente inofensivo, de las caricaturas de la Escuela de Bellas Artes.

Aunque, como hemos podido comprobar, no existiese una práctica similar en las Escuelas Superiores de Pintura españolas, no debe pasarse por alto la influencia que este tipo de retratos, muestra de una sociabilidad entre artistas en el propio espacio de aprendizaje, tuvo en el posterior desarrollo de retratos en las sociedades artísticas españolas de la segunda mitad del siglo XIX, a las que pertenecieron muchos artistas pensionados -0 que viajaron a sus expensas- en París durante las décadas de 1850 y 1860.

\subsubsection{Un posible retrato de Carlos Luis Ribera en un retrato colectivo}

El retrato anteriormente mencionado correspondiente al atelier de Delaroche [fig. 15], datado entre 1835 y 1843 (año de su cierre), contiene cuarenta y cinco figuras, aunque en el lienzo son evidentes continuos repintes y vacíos de figuras que fueron extraídas de la composición. De todas estas figuras, según Hauptman, tan solo cinco han sido identificadas: Auguste Toulmouche (discípulo de Gleyre), François Nazon, JeanLéon Gérôme, Léon Dussart y el caricaturista Cham (RIBEYRE, 1883: 3).

Carlos Luis de Ribera se cuenta entre los artistas españoles que estuvieron en el taller de Delaroche. Pilar de Miguel Egea ubicaba las fechas de su estancia en París, gracias a la pensión que le fuera concedida en 1832 y que en aquel momento no podía disfrutar debido a su edad, entre 1836 y 1845, pero a pesar de mencionarle como discípulo de Delaroche (MIGUEL EGEA, 1983: 15; 2007: 681) no aclara si durante esos nueve años perteneció o estuvo vinculado de alguna manera al taller, pasando en 1843 al de Gleyre junto al resto de discípulos. Las fuentes francesas son igualmente elusivas, puesto que mencionan a Carlos Luis de Ribera como discípulo de Delaroche, pero no aparece reflejado en las memorias de otros artistas sobre dicho taller. El hecho de que Ribera hubiese obtenido ya reconocimiento por parte de la Academia de San Fernando y su condición de extranjero, que lo excluía de aspirar al Prix de Rome, puede explicar su elusión de los relatos de taller; además, Ribera contaba ya con una clientela española y mantenía contactos, personales y profesionales, con otros artistas franceses y de la colonia española, pudiendo haberse alejado del núcleo social del atelier Delaroche. 


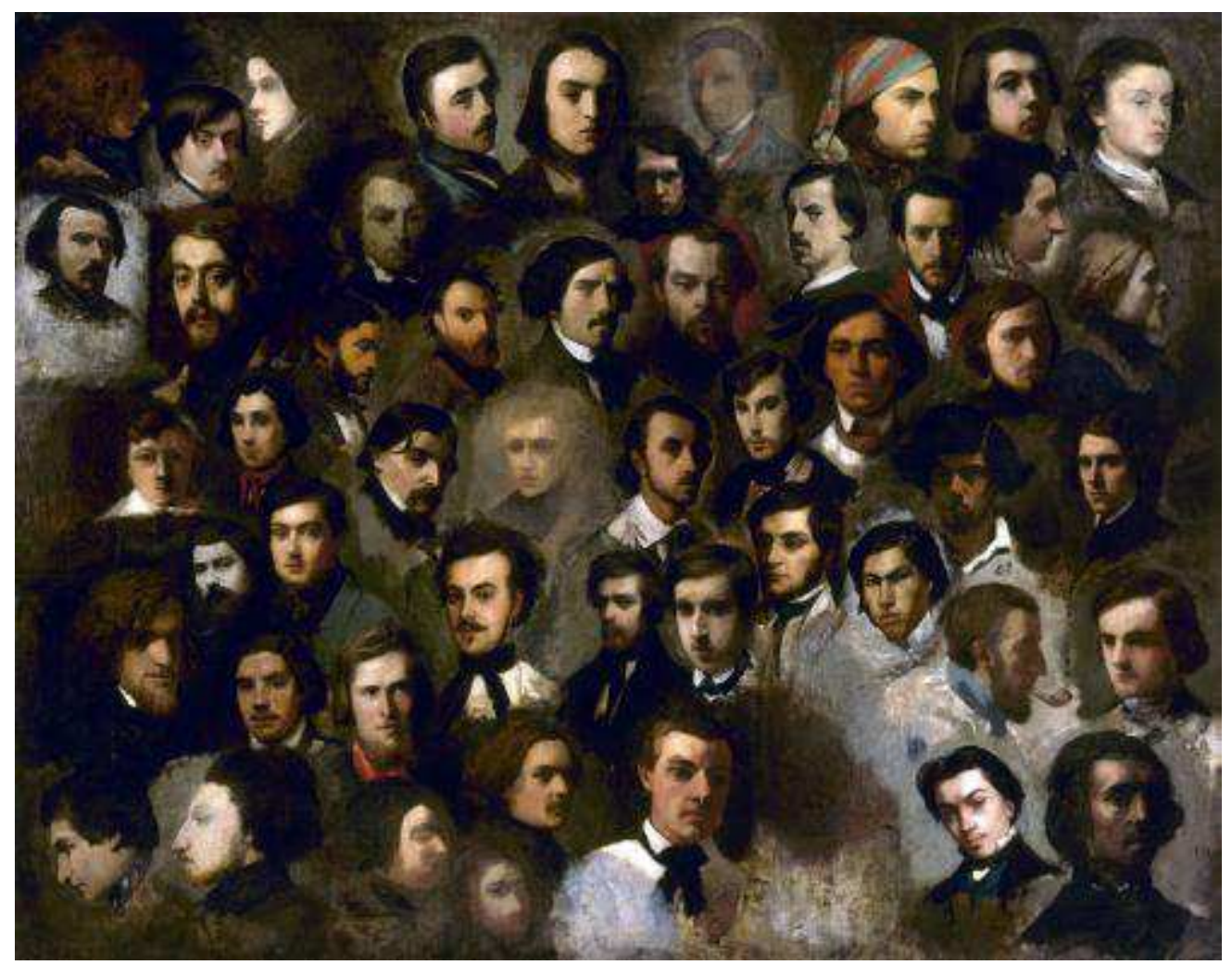

Fig. 15. Varios autores. Retrato de los alumnos del taller de Paul Delaroche, 1835-1843. Musée du PetitPalais, París.

No queda constancia de que en 1843 ingresase en el atelier de Gleyre, y de hecho algunas fuentes francesas contemporáneas no lo consideraban pensionado -en calidad de discípulo- sino un artista expatriado por los problemas políticos y bélicos de su país $^{89}$. La lógica parece apuntar, al menos con las noticias de que disponemos hasta la fecha, que Carlos Luis de Ribera no fue incluido en el retrato de grupo del atelier Delaroche. No obstante, por algunas noticias de Federico de Madrazo parece comprobarse que, en 1839, Carlos Luis de Ribera mantenía aún alguna vinculación con la Escuela y sus talleres ${ }^{90}$; además, una de las figuras en esta composición responde a la fisionomía que Ribera podría presentar hacia finales de 1839.

Los dos retratos que nos han llegado de él durante su estancia parisina, debidos ambos a la mano de Federico de Madrazo, manifiestan un cambio físico notable entre febrero $^{91}$ y septiembre de 1839; la última imagen registrada por Madrazo en el dibujo conservado en el Museo de Prado [fig. 16] ( $\mathrm{n}^{\circ}$ nnv. D05390) muestra a un Ribera que se ha desprendido de su melena romántica y se ha dejado una barba completa, reforzando así una apariencia más madura.

\footnotetext{
89 "Exposition de 1839", Journal des artistes, 7 de abril de 1839, p. 210; "Salon de 1840", Journal des artistes, 8 de marzo de 1840, p. 152; "Salon de 1841", Journal des artistes, p. 181; "Salon de 1845", Journal des artistes, pp. 95 y 188.

${ }^{90}$ En carta de Federico de Madrazo a su padre, 9 de febrero de 1839, dice: "no puedo mandar a V. como había pensado, la explicación o dibujo de cómo está alumbrada esta Academia de dibujo, porque se halla cerrada y no se abre hasta el mes que viene. Carlos, que la conoce, me ha dicho que me hará un dibujito" (DÍEZ, 1994: 193).

${ }^{91}$ En esta fecha aún se encontraba Madrazo pintando el retrato de Ribera (Museo Nacional del Prado, $\mathrm{n}^{\circ}$ inv. P07799), por lo que cabe suponer su fisionomía mantendría los rasgos representados.
} 


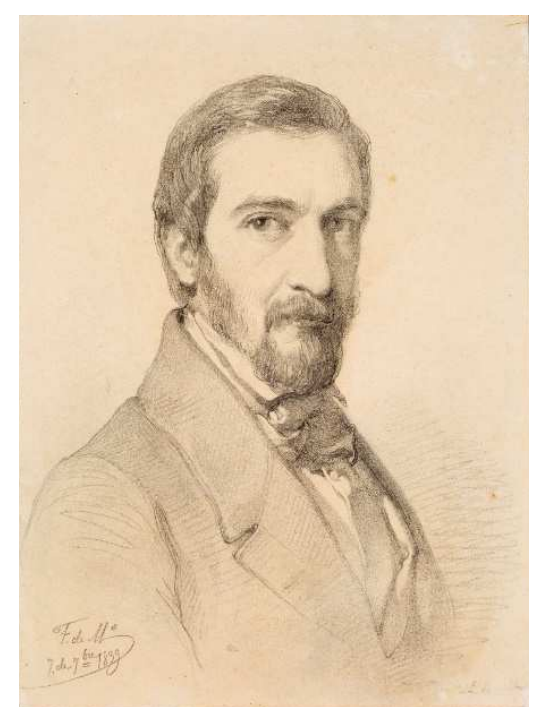

Fig. 16. Federico de Madrazo, Retrato de Carlos Luis de Ribera (detalle). Museo Nacional del Prado ( $\mathrm{n}^{\circ}$ inv. D05390).

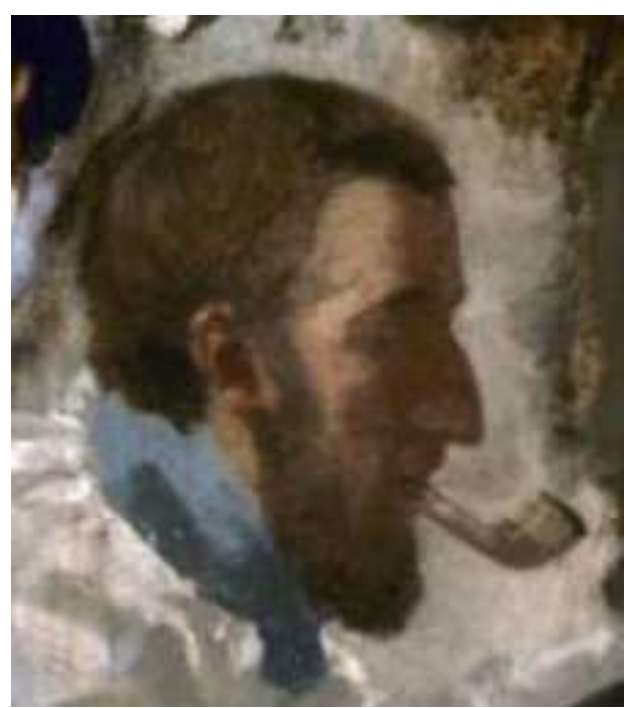

Fig. 17. Retrato de los alumnos del taller de Paul Delaroche (detalle).

La figura representada en el grupo Delaroche [fig. 17], ubicada en la parte inferior derecha, sostiene una pipa en la boca; la nariz aquilina y fina, la forma de la línea del nacimiento del cabello, e incluso el pequeño cerco despoblado en la barba, así como las proporciones faciales se corresponden a la perfección con el retrato de tres cuartos realizado por Madrazo. Tal vez el motivo para rendir homenaje a Ribera se deba a su Don Rodrigo Calderón camino del cadalso, que presentó a la exposición de 1839, y que, a pesar de estar muy mal colocado (DÍEZ, 1994: 200), obtuvo medalla de tercera clase, poniéndose así de manifiesto que, a pesar de su origen extranjero, mantuvo vínculos fraternales con sus compañeros de taller.

\subsubsection{Retratos individuales entre condiscípulos en el ámbito educativo}

A pesar de que los registros de matrícula de la Escuela de Bellas Artes de París dejan constancia de la presencia de artistas españoles entre sus alumnos, son escasas las noticias registradas sobre su relación con otros discípulos y las noticias de las obras realizadas por estos, a excepción de los trabajos premiados de Aurelio Blasco en la asignatura del Natural en 1866 (École Nationale Supérieure des Beaux-Arts ${ }^{92}, \mathrm{n}^{\mathrm{o}}$ inv. FDN 6) o de Roselló en 1867 (ENSBA, no inv. FDN 8). Dados los escasos datos respecto a la sociabilidad de los pensionados en París, restringiéndose en ocasiones a la colonia española, tan solo hemos conseguido recoger un retrato de un artista francés realizado por un español que pueda deberse a los contactos mantenidos en el ámbito educativo y como muestra de una amistad juvenil. El pintor de origen canario Manuel González Méndez realizó su prueba de acceso a la École en 1872, presentado por Gérôme $^{93}$; en 1874, Carriès entró en el taller del escultor Dumont en París para preparar sus pruebas de acceso en la misma ${ }^{94}$.

\footnotetext{
${ }^{92}$ En adelante ENSBA.

93 ANF AJ/52/236, fol. 8.

${ }^{94}$ ANF AJ/52/322, registro de matrícula 583.
} 


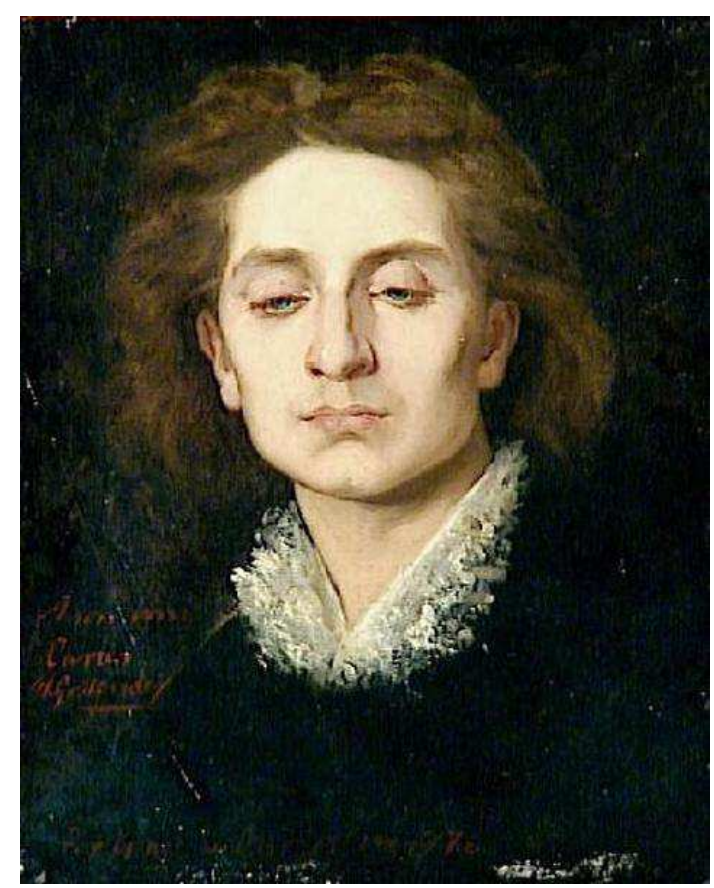

Fig. 18. Retrato del escultor Carriès, Manuel González Méndez. 1876. Musée d'Orsay.

Es probablemente en este contexto en el que González Méndez y Carriès entablan una amistad de juventud, reforzada tal vez por el hecho de que ambos artistas compartían una procedencia humilde y periférica en relación con los grandes centros artísticos, y por la vinculación de ambos con la escultura y las artes decorativas, como manifiesta el hecho de que González Méndez fuese alumno de la École des Arts Décoratifs, obteniendo su primer reconocimiento en ellas su primer reconocimiento aunque decidiendo ese mismo año centrar sus esfuerzos en la pintura (A.P., 1872: 2; ROMILLY, 1904: 8-14). Las biografías de Jean-Joseph Carriès son confusas en lo que atañe a la formación del escultor y su estancia parisina, y en ellas no se menciona a González Méndez; no obstante, el retrato realizado por el pintor canario (Musée d'Orsay, $n^{\circ}$ inv. R.F. 1983-24) [fig. 18], con su dedicatoria "à mon ami Carriès" deja constancia de la relación entre ambos. El contacto entablado durante el año de 1874, en que Carriès accede a la École y González Méndez finaliza sus estudios en la misma, perdurará al menos hasta 1876, año en que ambos participan en el Salon des Artistes Français, en el que Carriès buscó su inspiración en un asunto de temática española. El retrato pintado por González Méndez debió realizarse en el interludio entre 1874 y 1876, año en que Carriès regresa a Lyon con motivo del fallecimiento de su hermana y del inicio de su servicio militar. El busto presenta a un Carriès en plena juventud, con el rostro enmarcado por una melena desenfadada que señala la actitud despreocupada del escultor hacia los convencionalismos sociales y artísticos, aunque mantiene la mirada baja, con un deje de melancolía. Como corresponde al retrato de amigo espontáneo o de carácter íntimo, González no incluye en la obra ninguna referencia a la profesión del retratado; no obstante, la imagen permaneció en posesión del escultor, haciéndose pública como curiosidad de juventud en su biografía de 1895 (ALEXANDRE, 1895: 188). 


\subsubsection{Retratos de la sociabilidad de taller: la imagen del discípulo}

Finalmente, otro núcleo definitivo de sociabilidad importante para la formación del artista era el estudio en el taller de un maestro, de manera complementaria a la enseñanza oficial. Mientras que en el ámbito académico no se encuentran manifestaciones plásticas de un vínculo particular entre profesor y alumno, el espacio más íntimo del taller, al facilitar un intercambio social menos artificial y jerárquico, sí que permite encontrar ejemplos de retratos de discípulos por parte de sus maestros. Estas obras, que pueden englobarse en el tipo de retrato de amigo, suelen caracterizarse por un alejamiento de la tradicional iconografía del artista con sus útiles de trabajo, por lo que suele tratarse de retratos de busto en los que se evidencia una cercanía con el retratado.

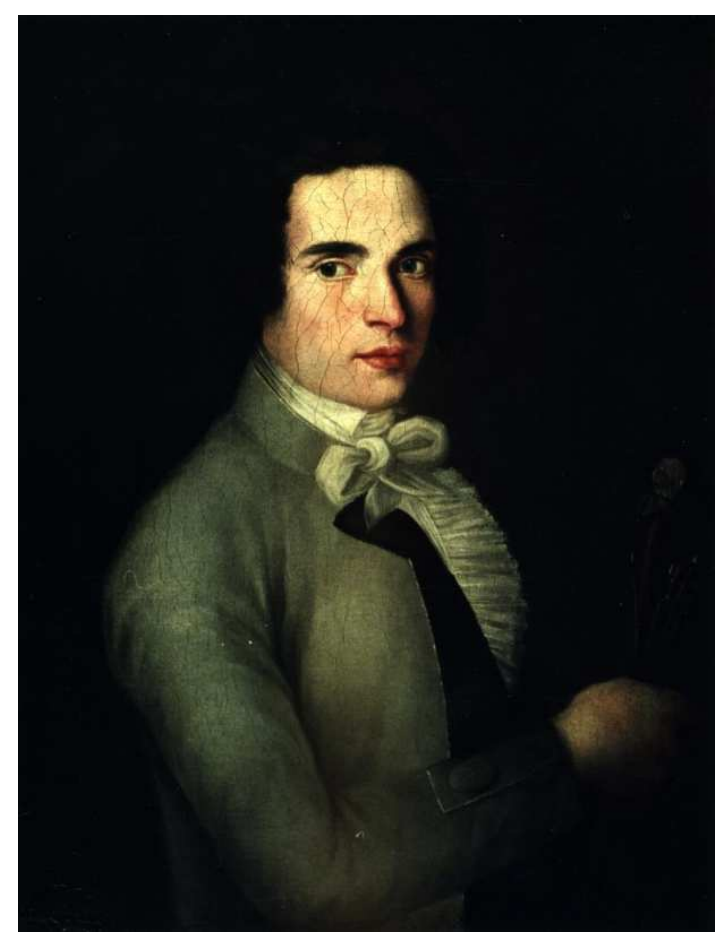

Fig. 19. Agustín Esteve, Joven pintor. Fundación Lázaro Galdiano ( $n^{\circ}$ inv. 2001)

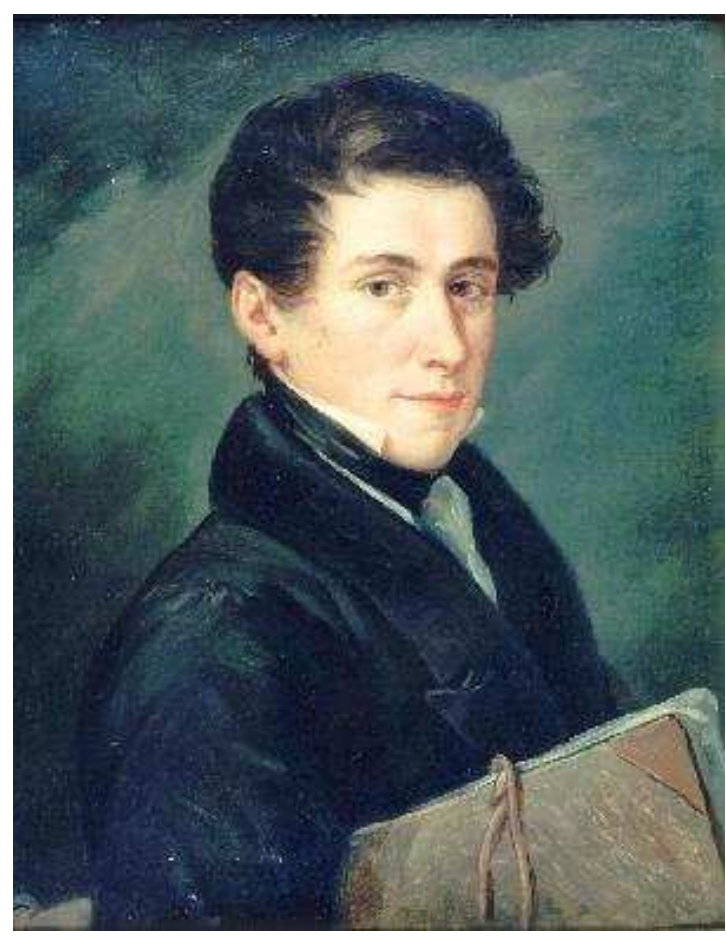

Fig. 20. Anónimo. Retrato del pintor Leonardo Alenza. Fundación Lázaro Galdiano $\left(\mathrm{n}^{\mathrm{o}}\right.$ inv. 07681)

Esta exclusión de la referencia profesional, razón fundamental del vínculo autorretratado, aun justificada a través de la amistad o proximidad, pone de manifiesto una tensión subyacente: el representado, por lo general un muchacho de unos dieciocho años de edad, relativamente imberbe, de facciones aniñadas, posa despojado de los útiles que podrían adjudicarle una cierta autonomía, frente a un artista consagrado que demuestra su superioridad en el propio acto y en la forma de realizar el retrato. Lejos de las representaciones de jóvenes artistas que buscan una autolegitimación a través de su aprendizaje artístico, como podría intuirse en los pinceles que sostiene el Joven pintor de Agustín Esteve [fig. 19] (Fundación Lázaro Galdiano, $n^{\circ}$ inv. 2001) o en la carpeta de dibujos que el supuesto Retrato de Leonardo Alenza [fig. 20] (Fundación Lázaro Galdiano, $\mathrm{n}^{\mathrm{o}}$ inv. 07691) presenta bajo el brazo, estos retratos transmiten una imagen descontextualizada. 
Dos retratos de juventud de Francisco Torrescassana realizados por Martí Alsina manifiestan una evolución en la percepción del joven pintor. El primero de ellos, conservado en el Museo de la Real Academia de San Fernando ( $\mathrm{n}^{\circ}$ inv. 0764) [fig. 21], debió realizarse hacia 1860 (DÍEZ, 1997: 88) a juzgar por la apariencia del representado, que debía de contar algo más de quince años durante la realización del retrato. En la obra, un muchacho devuelve de manera desenfadada la mirada al pintor, envuelto en el halo dulce de su expresión. La suave curvatura de sus facciones, la candidez de la mirada y una sonrisa velada, así como el asomo de una sutil pelusa rubia en su labio superior y en su barbilla ponen de manifiesto la adolescencia de Torrescassana, tal y como supo captarla Martí Alsina. El cambio es notorio en el retrato conservado en el Museo del Prado ( $\mathrm{n}^{\mathrm{o}}$ inv. P04330) [fig. 22], que Fontbona sitúa acertadamente a mediados de la década de 1860 (DÍEZ, 1997: 88), y que sería apropiado fechar en 1864, año en que Torrescassana obtiene una mención honorífica en su primera participación en la Exposición Nacional de Bellas Artes. En el nuevo retrato, Martí Alsina opta por una representación distinta: excluye de la imagen el pincel o lápiz que Torrescassana parecía sostener en su mano derecha de manera anecdótica, y se centra en plasmar un rostro por el que parece haber pasado algo más que el tiempo; en efecto, las facciones, mucho más duras y angulosas, evidencian que el joven pintor ha pasado el umbral de la pubertad, y su bigote se ha convertido en una masa rubia más espesa y definida, pero la expresión dulce ha desaparecido, convertida -en parte gracias a la sombra en que se oculta la parte derecha de su rostro- en una imagen de preocupación y dureza. La mirada penetrante, casi triste, bajo un ceño ligeramente fruncido parece indicar que Martí Alsina no buscaba reflejar una imagen triunfal, sino a un joven en actitud de pensarse y cuestionarse a sí mismo, sujeto a las tensiones y tensiones de la realidad artística.

Un aspecto similar presenta el retrato del pintor Ramón Padró y Pedret (MNAC, $\mathrm{n}^{\circ}$ inv. 010131-000) [fig. 23], retratado a los diecinueve años por Antonio Caba. La obra, firmada y dedicada por "su amigo", podría ser el resultado de una sociabilidad de taller ${ }^{95}$, mostrando al joven pintor con facciones infantiles - un rostro redondeado y claramente imberbe- y una mirada que transmite una sensación de tristeza [fig. 24]. Antonio Caba, diez años mayor que el retratado y recién llegado de París, podría haber canalizado en la obra su propia preocupación laboral, al aislar la figura de cualquier connotación artística y focalizar toda la atención en el rostro de Padró y su expresión melancólica. Una vez más, el inocente retrato de amigo exilia de la representación no solo las manos -rasgo comprensible tratándose de un retrato de amistad y dada la dificultad y coste añadido de su posible inclusión- sino cualquier referencia a la condición de Padró como iniciado en el mundo artístico.

\footnotetext{
${ }^{95}$ Carmen Riu señala que los Padró compartieron su segundo taller, ubicado en la Casa de l'Ardiaca, con Antoni Caba, aunque no especifica las fechas (RIU DE MARTÍN, 2009: 173).
} 


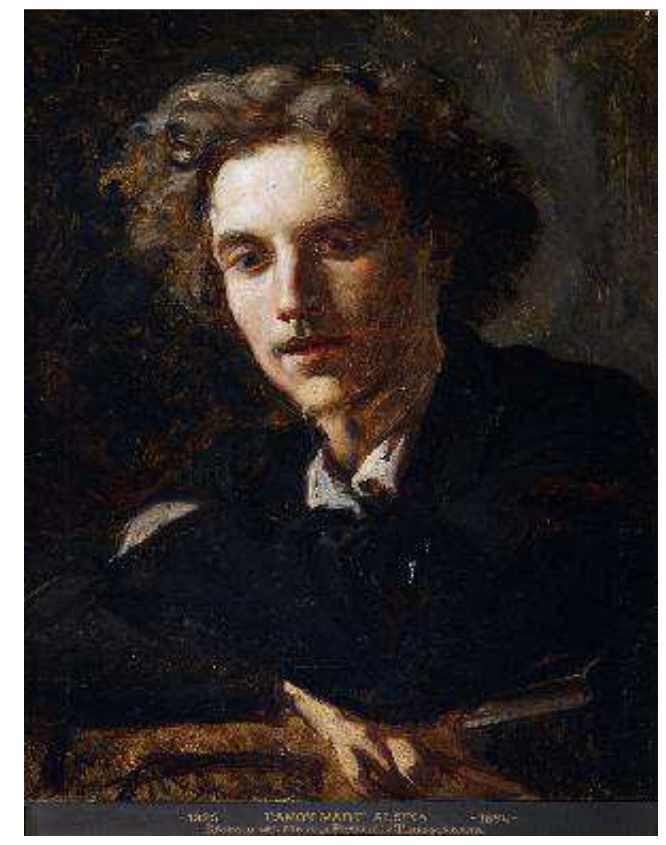

Fig. 21. Antonio Caba, El pintor Francisco Torrescassana, Museo de la Real Academia de San Fernando.

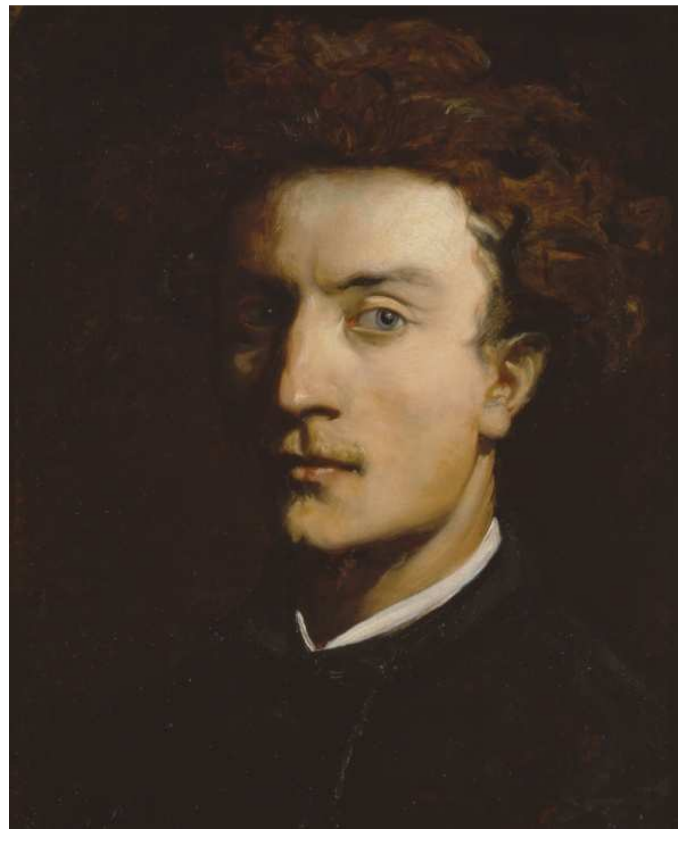

Fig. 22. Antonio Caba. El pintor Francisco Torrescassana, Museo Nacional del Prado.

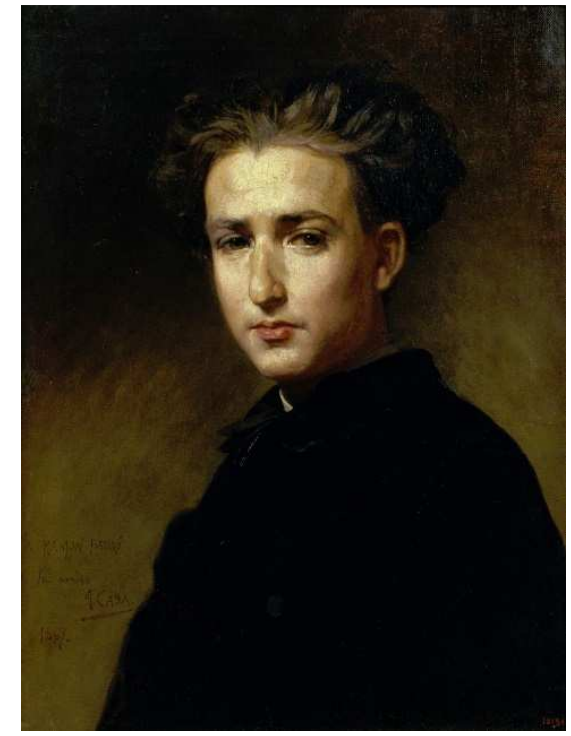

Fig. 23. Antonio Caba, Retrato del pintor Ramón Padró. MNAC ( $\mathrm{n}^{\mathrm{o}}$ inv 010131)
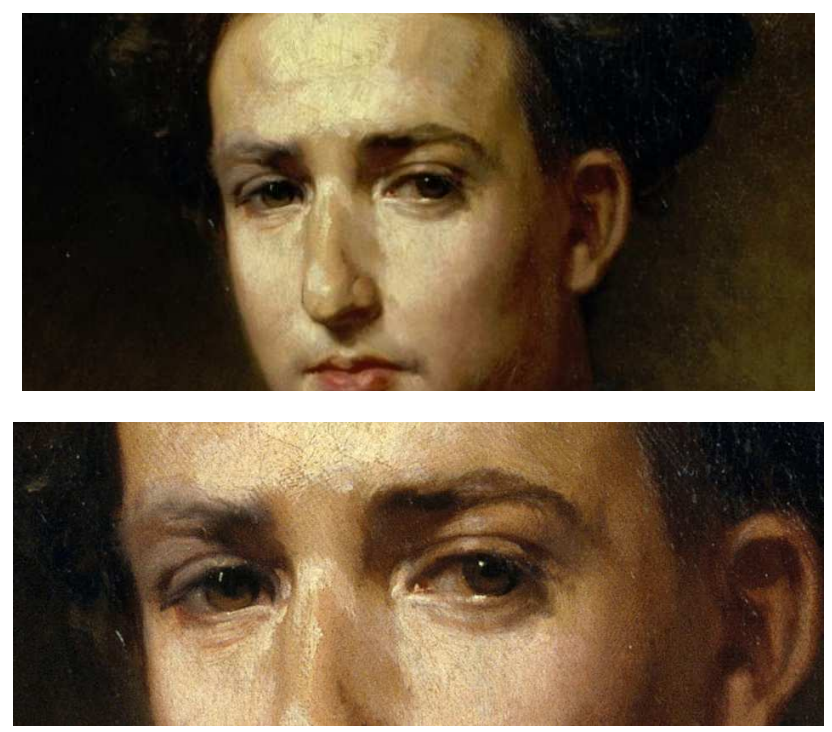

Fig. 24. Antonio Caba, Retrato del pintor Ramón Padró (detalles). 


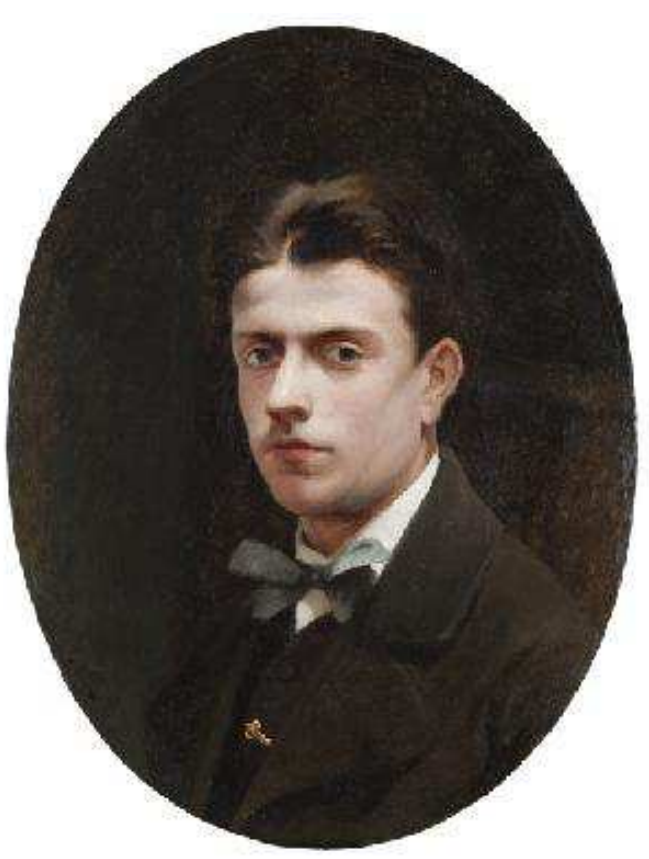

Fig. 25. José Jiménez Aranda, Retrato de José García Ramos. Museo de Bellas Artes de Sevilla ( $\mathrm{n}^{\mathrm{o}}$ inv. 0515P).

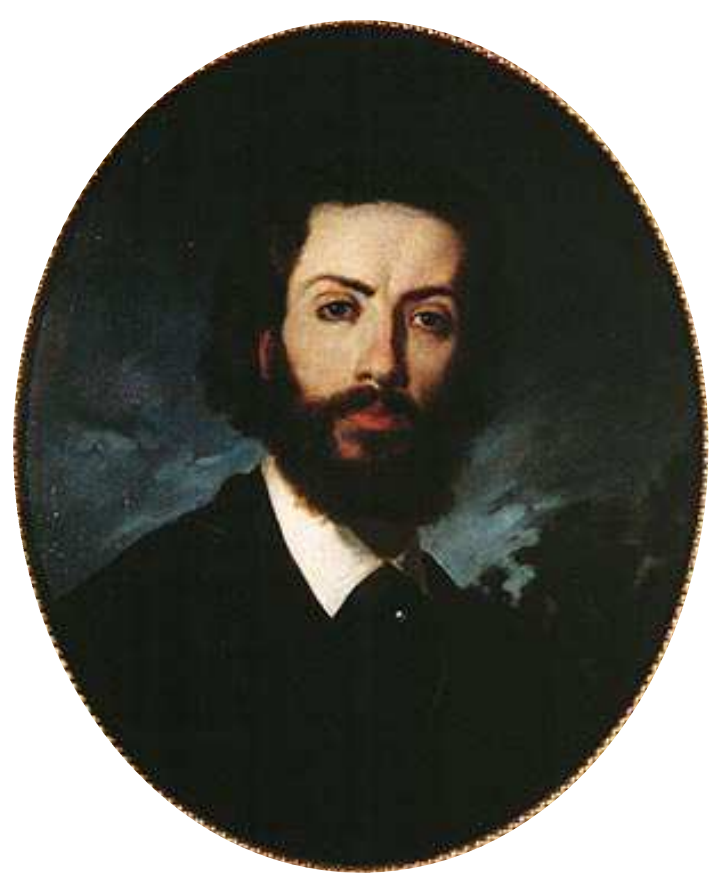

Fig. 26. José Jiménez Aranda, Autorretrato. Museo de Bellas Artes de Sevilla ( $\mathrm{n}^{\circ}$ inv.0516P).

Otro ejemplo, prácticamente contemporáneo, pero con una voluntad distinta es el que José Jiménez Aranda dedica a su discípulo José García Ramos [fig. 25]. La estrecha relación entre Jiménez Aranda y García Ramos puede comprobarse no solo en el hecho de que el pintor realizase también su retrato en el momento en que se encontraba pintando los de los miembros de su familia, sino también en que el discípulo acompañase a Jiménez Aranda y familia en su viaje de formación a Roma (PÉREZ CALERO, 1982: 14 y 24). En 1870, fecha de realización del retrato, García Ramos contaba con tan solo dieciocho años, una edad que se refleja en sus rasgos asimétricos, sintomáticos del cambio corporal en la adolescencia. El detalle de que Jiménez Aranda incorporase en su producción el retrato de su discípulo en su ciclo de retratos familiares no implica, sin embargo, que le dotase de las mismas características que estos; de este modo, su Autorretrato [fig. 26] (Museo de Bellas Artes de Sevilla, $\mathrm{n}^{\circ}$ inv. 516) y el Retrato de su esposa son, aunque ovales al igual que el de García Ramos, mayores en sus dimensiones $(0,62 \times 0,41 \mathrm{~m}$ frente a $0,53 \times 0,42 \mathrm{~m})$. Asimismo, y a pesar de que ambos son retratos de busto que carecen de atributos que los relacione con su profesión, es visible una diferencia jerárquica entre ellos. José Jiménez Aranda opta por representarse en un espacio abierto, plasmando un fondo de paisaje de carácter onírico que, junto con el punto de vista bajo elegido para realzar una imagen de superioridad y la expresión ausente, como de ensoñación -incluso a pesar de la frontalidad de la imagen-, mueve a pensar en una voluntad de representación como hombre maduro y dotado de cierta autoridad y de capacidad creativa. Por el contrario, José García Ramos es representado ante un fondo completamente neutro, cuya oscuridad parece evocar el interior del propio taller del pintor -en el que el retratado es un subordinado; al mismo tiempo, el punto de vista elegido es distinto, y su imagen, por lo tanto, no aparece dignificada. Además, su expresión seria y su mirada directa al retratista no implican el 
componente añadido en el de Jiménez Aranda de la ensoñación creativa, pero tampoco parecen incidir en la expresión melancólica de los retratos anteriormente mencionados, sintomáticos de la crisis masculina de sus autores.

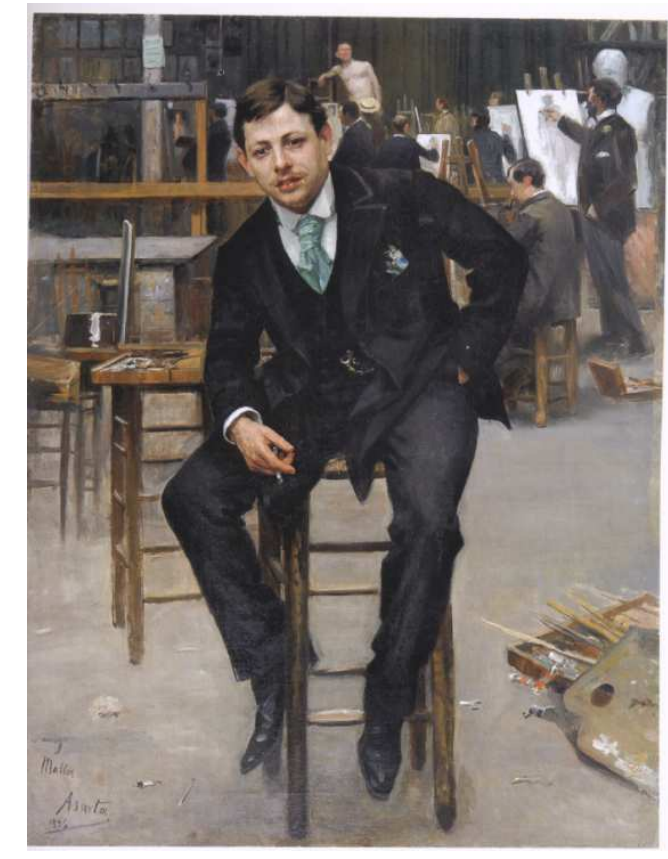

Fig. 27. Inocencio García Asarta, Retrato de un joven artista. Museo de Bellas Artes de Álava ( $n^{\circ}$ inv. 3290)

Incluimos finalmente en este apartado otro retrato de un artista, de identidad desconocida, que marca un cambio respecto al tipo de representación que se espera de un joven artista. En su obra Retrato de un joven artista (Museo de Bellas Artes de Álava, $n^{0}$ inv. 3290) [fig. 27] Inocencio García Asarta emplea como fondo una clase de dibujo, en la que un modelo posa mientras varios artistas, repartidos por la sala, toman sus apuntes. En primer plano presenta a un joven sentado en una banqueta, en una postura relajada: su mano izquierda se encuentra metida en el bolsillo de su elegante traje, mientras el brazo derecho se apoya, con la correspondiente inclinación de espalda, en la pierna derecha. Además de lo llamativo de la postura, que indica una asimilación de una conducta despreocupada, y de una voluntad de ocupación del espacio, el joven artista, cuyo rostro -con un débil asomo de bigote rubio- aparenta entre dieciocho y no más de veintidós años, aparece reflexivo mientras fuma un cigarro que sostiene en su mano. El retrato, que probablemente fue realizado al regreso de García Asarta de su estancia parisina (MUSEO DE BELLAS ARTES DE ÁLAVA, 2013: 66), presenta así a un joven que se ha apropiado de todos los atributos de una apariencia masculina, como su cuidado traje, la actitud desgarbada e incluso el hábito de fumar, junto a la expresión ligeramente abstraída, entrando en perfecta sintonía con el tipo de retrato masculino generalizado a finales del siglo XIX, extendido también entre los artistas. 


\subsection{El artista y la imagen del éxito masculino}

Los estudios existentes sobre el retrato del artista y el autorretrato se han ocupado, de manera concienzuda, en el desarrollo de una iconografía vinculada con el oficio del artista y su mayor o menor vinculación con una voluntad de proyección a través de un cierto poder intelectual o social, es decir, con la conformidad con los estándares ${ }^{96}$ y la normatividad de género; de tal modo, frecuentemente ha servido como apoyo a la historia del ascenso social del artista, o se ha enmarcado de manera monográfica en la visión subjetiva del pintor respecto a sí mismo. En las reflexiones de Julián Gállego al respecto, planteaba que "el pintor que se retrata se verá, dentro de lo posible, guapo, y si no, gallardo, elegante, viril o, cuando menos, inteligente” (DÍEZ, 1997: 14). El hombre que se plasma en el lienzo se ve de este modo asociado a un concepto vago sobre su masculinidad, que debe intuirse en la imagen que proyecta sobre sí mismo; la experiencia de género queda codificada a través de la apariencia física, la vestimenta y el despliegue de una conducta vinculada por imperativo al bando masculino, al estar indisolublemente ligada al concepto del artista-trabajador. Por su relación con el discurso historiográfico tradicional y el carácter de encarnación del privilegio masculino sobre el mundo artístico, el retrato de artista -como hombre maduro- suele ser abordado como curiosidad o un detalle biográfico más. Por otra parte, la limitación a que se somete este tipo de representación en el ámbito español ha contribuido a que su lectura se reduzca a una narración sobre el cursus honorum del artista -entendido como un concepto general-, aplicándole algunas distinciones: por una parte, el tipo de retrato como artista-intelectual, iconografía más extendida a finales del siglo XVIII y en las dos primeras décadas del XIX; por otra, el modelo de artista-trabajador, es decir, exhibiendo una identidad profesional concreta y bien definida, y finalmente como retrato oficial, el tipo tradicionalmente considerado menos interesante por su sumisión a una iconografía generalizada en otros retratos masculinos de la época y vinculada a una imagen de poder y de elitismo social.

Ante este concepto general, una puntualización se hace precisa, y se trata de la importancia de ese cursus honorum en la configuración de la identidad-masculina- del artista, no solo desde el punto de vista profesional, como indica Omar Calabrese, sino también desde una perspectiva psicológica individual. De este modo, un retrato con los atributos de trabajo no se relaciona exclusivamente con una identificación profesional, sino que también puede leerse como una culminación de la experiencia del hombre artista a través de una carrera llena de expectativas -formativas y laborales- que ha moldeado su personalidad. La representación, empleando los convencionalismos de moda en función de cada época, no hace sino responder a una voluntad de expresar de manera triunfal la superación de los obstáculos de la jerarquía artística hasta posicionarse en la cima -es decir, la unión de independencia y éxito-, exhibiendo un estatus que no solo es social o profesional, sino una demostración o reafirmación -como

\footnotetext{
${ }^{96}$ Así lo expone Bejarano Veiga, afirmando que "lo cierto es que el pintor español del siglo XIX no se preocupó en mostrar su diferencia o excepcionalidad respecto al resto de la sociedad, sino que antepuso poder gozar del reconocimiento por el desarrollo de una carrera prestigiosa, según los estándares oficiales" (BEJARANO VEIGA, 2015: 374).
} 
tantas otras que se propone el hombre a lo largo de su existencia- de su propio ser hombre, adecuándose a esa escala de méritos entendidos como masculinos, como el ejercicio de una profesión, la capacidad para obtener ingresos económicos con que sustentar una familia, y la progresiva distinción social basado en sus logros artísticos y sus habilidades relacionales.

\subsubsection{Usos y connotaciones de la iconografía del artista trabajador}

Amelia Jones señalaba en 1995 la importancia de la apariencia del artista como muestra de una vinculación ideológica -simulada o verídica- del individuo respecto al mundo, y hacía para ello un estudio de los atuendos utilizados al caso en los retratos de artista desde el siglo XIX hasta la actualidad (JONES, 1995: 18-32). Sus argumentos respecto a los artistas decimonónicos se centraban en una distinción clara entre el artista burgués o "aristócrata de la cultura", ajustado no solo al decoro oficial sino que lo llevaba al paroxismo en el atildamiento de sus trajes y en el cuidado extremo de cabelleras y barbas, y el artista trabajador, representado en mangas de camisa o en su desgarbado hábito de trabajo. Dos iconografías distintas que parecen corresponder a dos conceptos de masculinidad opuestos y a una voluntad de visibilizar posicionamientos políticos extremos. A pesar de esta idea, como bien señaló la propia Amelia Jones, la existencia de representaciones tan dispares de lo que podría interpretarse como estatus social no es más que una apropiación simbólica de unos atributos, ya sean de la representación de la alta burguesía autocomplaciente y frívola o de los del trabajador que rechaza de manera agresiva a través de su imagen otras pretensiones sociales (JONES, 1995; MUSÉE D’ORSAY, 1989: 8); a través estos atributos el artista negocia la imagen de sí mismo mediante los valores específicos asociados a cada una de ellas. En el primer caso prima la imagen del éxito social y económico a través de una apariencia cuidada y elegante, rayana en ocasiones en el dandismo, que viene a asociarse al deseo de identificación con una sociedad elitista en la que el artista se ha hecho hueco. En el segundo, la imagen del trabajador recurre a la retórica del mérito y a los valores masculinos de la autorrealización a través de la profesión, presuponiéndose un mayor compromiso con la realidad social del artista. En el caso español, la asimilación exclusiva de una u otra iconografía es un recurso relativamente tardío, siendo más habitual la representación oficial -vinculada por lo tanto a una sociedad de tono elegante-, o el recurso intermedio al retrato o autorretrato con los útiles de trabajo aunque con una vestimenta cuidada, imagen que deriva del retrato de artista neoclásico en el que apariencia y atributos remiten al trabajador cívico e intelectual.

Este último es el más habitual que se puede encontrar en los retratos individuales, y que permite, en una sola lectura, vincular una profesión artística con una situación personal que, si no acomodada o equiparable con la élite, parece desahogada y desentendida de las tensiones cotidianas del mercado laboral. De este modo, algunos de los autorretratos neoclásicos de Zacarías González Velázquez en los que aún no recoge una indumentaria institucional, como el de 1802 (Academia de Bellas Artes de San Fernando, $\mathrm{n}^{\mathrm{o}}$ inv. 0704), su retrato de Elías Vallejo (Academia de Bellas Artes de San Fernando, $\mathrm{n}^{\mathrm{o}}$ inv. 0560), o el autorretrato del joven Francisco Lacoma, se adecúan a esta 
representación, donde el uso de una cuidada vestimenta a la moda los sitúa entre los ciudadanos elegantes de la corte madrileña (REYERO, 2010: 495 y 501) tal y como los recoge Antonio Rodríguez en las estampas sobre la moda en la capital a comienzos del siglo XIX (BOZAL, 1982), con el añadido, en absoluto anecdótico, de sus útiles de trabajo. Se evidencia así que en el cambio de siglo también los artistas no solo han asimilado el ideal burgués de la autoconstrucción de su imagen a través del trabajo, sino que han hecho de su oficio un nuevo símbolo de su propio poder, extendiendo esta nueva idea en la representación individual que tanto desarrollo tuvo en el Siglo de las Luces (MOLINA, 2013: 177). La imagen de la modernidad del artista madrileño queda también reflejada, de manera velada al incluirse en una obra de composición, en el doble retrato de José y Juan Aparicio [fig. 28] que el primero incluyó en su Episodio de la fiebre amarilla en Valencia [fig. 29] (Academia Nacional de Medicina de París), que presenta a ambos hermanos con el habitual lápiz de trabajo (AUGÉ, 2007: 15).

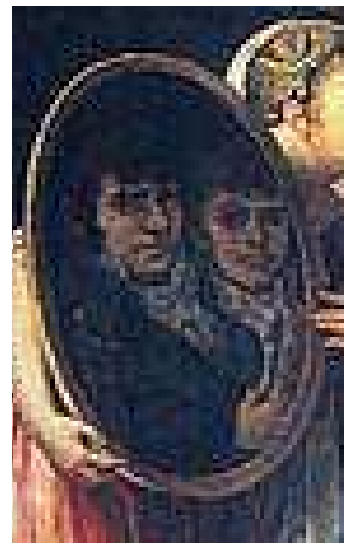

Fig. 28. José Aparicio y su hermano en Episodio de la fiebre amarilla en Valencia (detalle).

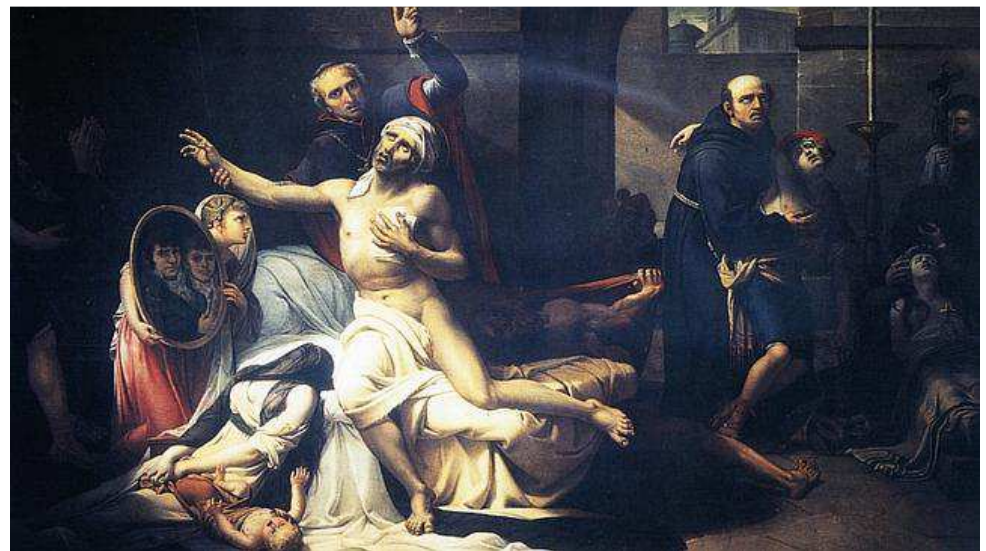

Fig. 29. José Aparicio, Episodio de la fiebre amarilla en Valencia. Academia Nacional de Medicina de París.

Esta forma de retrato de artista se mantiene en el Romanticismo coexistiendo con el retrato, más franco y directo, de busto y sin atributos; Monterroso Montero señalaba al respecto que los artistas españoles rehusaban conscientemente la identificación con el artesano asumiendo el tipo velazqueño de pintor caballero, si bien adecuado a las nuevas modas. La idea de Monterroso, en efecto, concuerda con el tipo de retrato de artista habitual en el Romanticismo español, en que el artista se reviste de un nuevo traje aburguesado sin perder los atributos que lo vinculan no tanto con su profesión sino con la idea de pertenencia a la élite intelectual. De este modo, la imagen que ofrecen de sí mismos se corresponde con una voluntad de poder, es decir, de identificarse social y culturalmente como hombres sin rival, de tal manera que puede considerarse una evolución del autorretrato actuante. El concepto de masculinidad que articula esta representación refleja, por lo tanto, un interés personal por manifestar una situación privilegiada, en la que el dominio de sí mismo se extiende a la imagen de superioridad sobre un otro indefinido -el espectador familiar en el ámbito doméstico, el público amateur en las exposiciones artísticas-, tanto hombres como mujeres, que ni siquiera aparecen en la representación. El retrato configurado de esta forma revela no solo la construcción narcisista de una apariencia dominante sino también la inseguridad subyacente, haciendo de la referencia a los útiles de trabajo no tanto una forma de 
identificación laboral como un pretexto para la reafirmación del ego en relación a las formas de dominio sociocultural masculino. La generalización del retrato elegante también entre los artistas conlleva la evolución de esta idea, ya que en el progresivo abandono de los útiles de trabajo se refuerza la imagen del artista como ciudadano o como hombre de mundo, cuya identidad profesional es anecdótica frente a la imagen de autodominio y poder adquisitivo que desea manifestar. En este sentido, la asimilación del traje de tres piezas no debe entenderse estrictamente como una forma de homogeneidad entre hombres acorde a la nueva imagen urbana, al menos hasta una fecha relativamente tardía. Lejos del encorsetamiento romántico de levitas, pecheras y cuellos almidonados, el traje cotidiano de chaqueta parece transmitir, a partir de los últimos años de la década de los cincuenta y especialmente en la de los sesenta, que se ha producido una democratización artística y que el pintor, consciente de su realidad social, se encuentra libre de la etiqueta vestimentaria en sus retratos. Garb realiza, sin embargo, una lectura interesante respecto a esta generalización de moda urbana al considerarla una vía de escape respecto a la vulnerabilidad psicológica acarreada por la autoconsciencia, permitiendo al hombre decimonónico ampararse en un refugio capaz de generar, aunque fuese de manera ilusoria, una identidad colectiva en lo que respecta a género y clase (GARB, 1997: 63).

La moda romántica en que se retrataron artistas como José de Madrazo en la década de los años cuarenta, o del modo en que los retrató Vicente López -sirvan de ejemplo los casos de los artistas de éxito Carlos Bosch y José Piquer-, se encuentra con mayor frecuencia en aquellos retratos en que el artista opta por dar de sí mismo una imagen de hombre desvinculada - casi por completo- de su identidad profesional, como ocurre en el retrato de Fernando Ferrant Llausás realizado por su hermano (Museo Nacional del Romanticismo, $n^{0}$ inv. CE0144), en el que únicamente el nombre del representado permite vincularlo al ámbito artístico. La elegancia, un cierto dandismo y la voluntad de ofrecer una imagen de hombre de mundo pervivirá no obstante a lo largo del siglo XIX, incorporando en los años cuarenta chisteras próximas a los retratados, como el mencionado Ferrant o Manuel Cabral y Aguado Bejarano en su autorretrato de 1851 [fig. 30] (Museo Nacional del Romanticismo, $n^{\circ}$ inv. CE0053), o en los sombreros que, bajo la excusa de un retrato de exterior o de constituir un adorno exclusivamente masculino, exhiben sin pudor Josep Arrau (MNAC, $\mathrm{n}^{\mathrm{o}}$ inv. 012027-000), Joaquín Vayreda (MNAC, $\mathrm{n}^{\mathrm{o}}$ inv. 010569-000), o Ignacio Pinazo [fig. 31] - en buena parte de sus autorretratos, desde $1872^{97}$.

Frente al desarrollo de un retrato individual carente de atributos, la progresión lógica en la representación del artista como trabajador es precisamente la opuesta, directamente relacionada con la práctica manual del arte, es decir, la del propio artista en traje de faena o en su espacio de trabajo, ya sea ante el caballete o modelando una escultura. En este tipo de retrato la vinculación con el oficio pasa también por una

\footnotetext{
${ }^{97}$ Es el caso de su Autorretrato con sombrero de 1872 (Colección particular); Autorretrato joven con sombrero, de 1895 (Museo Nacional del Prado, $\mathrm{n}^{\circ}$ inv. P04582); el Autorretrato de1900 (MNAC, $\mathrm{n}^{\circ}$ inv. 010025-000) o su Autorretrato de 1901 (Museo Nacional del Prado, no inv. P04572).
} 


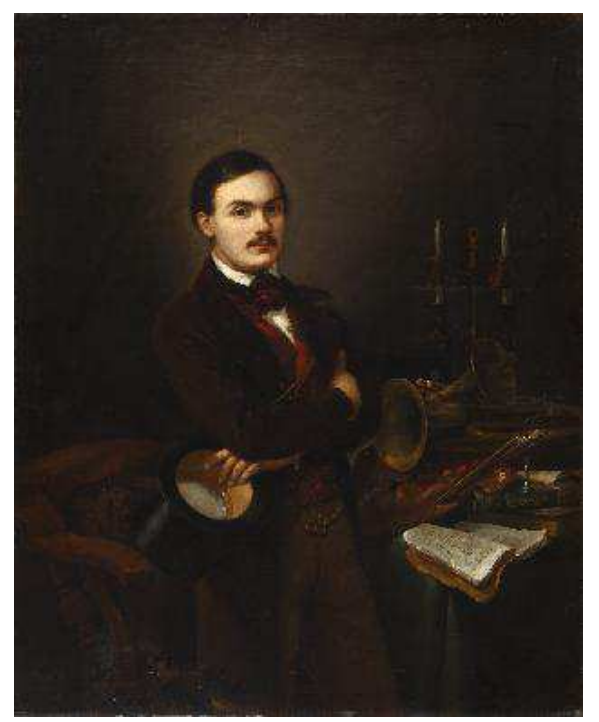

Fig. 30. Manuel Cabral y Aguado Bejarano, Autorretrato. Museo del Romanticismo ( $\mathrm{n}^{\circ}$ inv. 0053).

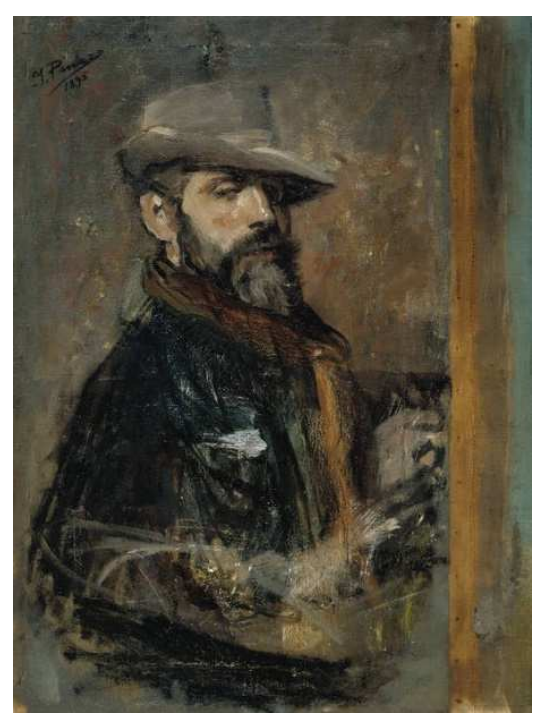

Fig. 31. Ignacio Pinazo Camarlench, Autorretrato joven con sombrero. Museo Nacional del Prado $\left(\mathrm{n}^{\circ}\right.$ inv. P04582).

reivindicación social de la labor más manual del arte, no tanto como una reclamación de lo artesanal en el arte sino como forma de ensalzar los valores masculinos relacionados con el trabajo: el mérito individual, la capacidad creativa y productiva, la autorrealización del hombre artista y la vinculación de este con el poder adquisitivo. Relacionado con el autorretrato actuante, no quiere decir que toda representación del artista trabajando se vincule directamente con su realidad social o con la idea capitalista del trabajador como obrero, ya que la evolución de esta tipología es lenta, y solo alcanza pleno desarrollo en la segunda mitad del siglo al desligarse de la representación del trabajo como vinculación con la élite. Esta forma de representación heredera de la Ilustración se refleja, por ejemplo, en el espacio abstracto y casi regio del retrato que Zacarías González Velázquez realiza, a modo de copia, de su padre para la Academia de San Fernando ( ${ }^{\circ}$ inv. 0694), en el que la escenografía nada aporta, en realidad, al personaje retratado, más allá de una referencia puntual a su obra; se trata, por lo tanto, de un retrato actuante en el que prima la vinculación entre profesión y élite social. Por el contrario, el autorretrato de Federico de Madrazo de 1858 (Madrid, colección particular) introduce ya las notas del nuevo tipo de retrato de artista trabajador; en él tanto la figura del pintor como el propio espacio transmiten una idea concreta de profesión artística y de hombre vinculado a su producción y a su taller, permitiendo observar el cambio que se está produciendo respecto a la imagen del $\operatorname{artista}^{98}$.

El hecho de que Federico de Madrazo optase por representarse de cuerpo completo, paleta y pinceles en mano y en el interior de su estudio, no parece excesivamente inusual si tenemos en cuenta el importante impulso que dio a la representación del artista como trabajador Antonio María Esquivel en época romántica A pesar de que Esquivel se representase, aun en las obras en que aparece pintando, con una indumentaria civil y elegante, al menos dos ejemplos dan testimonio gráfico de su forma de entender la iconografía del artista alejada del decoro oficial o de carácter

\footnotetext{
${ }^{98}$ Sobre los espacios de representación del artista, ver EGEA GARCÍA, 2013.
} 
burgués en dos retratos secundarios en su producción. De este modo, los días 8 y 9 de octubre de 1835 realizó el retrato de su amigo Domingo Gallego y Álvarez [fig. 32] (Biblioteca Nacional, IH/3432), que dibujó y litografió él mismo y que conocemos a través del ejemplar existente en la Biblioteca Nacional y la Iconografía Hispana de Ángel Barcia. En la obra, en la que no se incluye aún ninguna referencia espacial, Esquivel presenta a su amigo con paleta y pinceles en la mano, y ataviado con lo que parece un amplio blusón de trabajo.

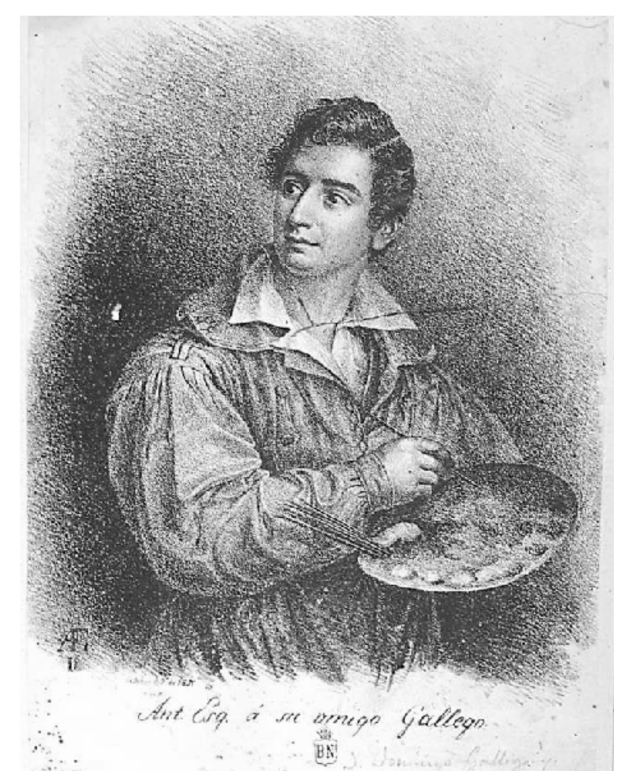

Fig. 32. Antonio María Esquivel. Retrato de Domingo Gallego. BNE (IH/3432)

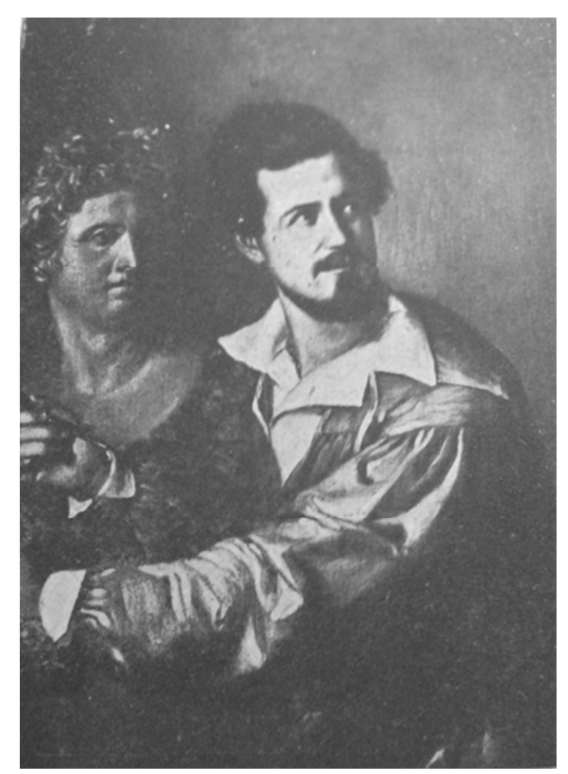

Fig. 33. José Utrera, Retrato de José Vilches. Museo de Cádiz ( ${ }^{\circ}$ inv. 434)

De manera similar retrató al escultor José Vilches, obra que conocemos por la copia realizada por José Utrera [fig. 33] (Museo de Cádiz, $n^{\circ}$ inv. 434), en la que el artista aparece entregado a su trabajo, junto a un busto clásico, y vestido una vez más con una bata o blusón. Curiosamente, esta iconografía no es la habitual en los retratos que Esquivel realiza de otros artistas, puesto que elude la representación de los útiles de trabajo y aún más de la indumentaria de faena, como ponen de relieve sus retratos de José Domínguez Bécquer (Museo de Bellas Artes de Sevilla, no inv. CE0450P) o de José Gutiérrez de la Vega (Museo Nacional del Romanticismo, nº inv. CE1278).

En el autorretrato de Madrazo, de dimensiones muy reducidas, el protagonismo de la figura traduce un evidente interés por manifestar su condición de pintor. Aparece así vestido con un largo gabán de trabajo, de cuyo bolsillo asoma un trapo, ambos impolutos, y en su mano izquierda sostiene paleta y pinceles, apoyándose igualmente con la misma mano en el tiento. Federico de Madrazo manifestó escaso interés por el autorretrato, debido probablemente a su concepto del retrato como objeto social, y tan solo se conoce anteriormente a esta obra su autorretrato juvenil incluido en El Gran Capitán recorriendo el campo de la Batalla de Ceriñola. De este modo, la iconografía parece responder, aunque se tratase, como señala Julián Gállego de un pequeño obsequio al conde de la Unión (DÍEZ, 1997: 50), a una necesidad de autoafirmación basada en la profesión y no en la suma de títulos públicos, acumulada a lo largo de los años, recurriendo así a la escenografía del taller como espacio de creación, a los 
atributos del pintor y a una apariencia elegante aunque directamente relacionada con la labor que desarrolla.

Siguiendo este breve recorrido por la imagen del artista como trabajador a través de su indumentaria y atributos, son los ejemplos de fin de siglo los que más han acaparado la atención al personificar de manera muy clara el proceso de creación artística y el interés por vincularlo a una forma concreta de trabajo manual. La progresiva inclusión de una moda menos envarada, relacionada con el propio trabajo, en el retrato de artista supone la asimilación de nuevos rituales sociales en los que el poder simbólico masculino se establece en relación al estatus del artista trabajador de clase media, y no solo en función del poder -simbólico y capital- de la clase alta, al mismo tiempo que se comienzan a asumir construcciones identitarias próximas a la del obrero, evidenciando así una crítica relativamente autocomplaciente respecto a la inestabilidad económica y laboral del artista, y una necesidad de mostrarse como hombres moldeados a partir de su trabajo. Una transformación social que tampoco pasó desapercibida ante algunos críticos, y que llevaron a comparar directamente no solo el trabajo artístico, sino también el estilo pictórico y sus temas, con una nueva virilidad, de tal modo que Ramón Balsa de la Vega, ante el autorretrato de Vicente Cutanda y el retrato de Arredondo, presentados a la exposición del Círculo de Bellas Artes de Madrid, llegó a afirmar que "supo Cutanda retratar dos temperamentos tan distintos como el de su amigo y el suyo, pero esbozándolos a martillazos como forjan y moldean el hierro los obreros que pinta" (BALSA DE LA VEGA, 1896: 3).

La coexistencia de distintas formas de representación del artista llevaron también a una codificación mixta en que los significados del artista trabajador y la imagen del éxito oficial conviven. Quizás el ejemplo más notorio de esta reinterpretación galante de la imagen del trabajador es el retrato que José Jiménez Aranda realizó de Joaquín Sorolla en 1901, en que el juego de amarillos y pardos de su bata de trabajo desvirtúa cualquier posible humildad trabajadora, como la que se veía en el retrato de Perea [fig. 34], al ensalzarlo, mediante la cinta de la legión de honor en uno de sus ojales, al grado de retrato del triunfo del artista [fig. 35] (Museo Nacional del Prado, $n^{\circ}$ inv. P04354). Los ejemplos son, sin embargo, anteriores, y se relacionan con la voluntad de vincular el éxito en el mundo artístico nacional e internacional con una imagen urbana y trabajadora del artista, heredera de la moda francesa, como pone de manifiesto el retrato que Raimundo de Madrazo realizó de su padre en 1875.

Los retratos de algunos escultores indican no solo esta proximidad del artista con la idea de profesión artística, sino que la imbuyen de una gestualidad embebida de connotaciones masculinas. Así sucede con el retrato de Clarasó realizado por Rusiñol [fig. 36] (colección particular), en que la escena de taller con su medido desorden concuerda con la actitud gallarda del escultor. Clarasó, que se encuentra modelando una escultura en barro, aparece representado como un apuesto adulto, las líneas de su cuerpo enfatizadas mediante su contraposto. La camisa blanca, que focaliza toda la luz del taller, asoma de manera elegante de la bata abierta, jugando con los conceptos de hombre trabajador y de seductor empuñando un palillo de modelar con gesto agresivo. 


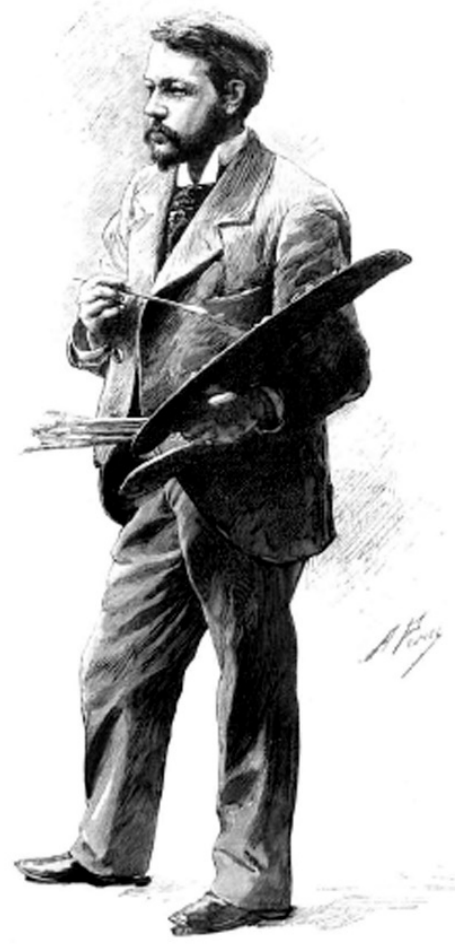

Fig. 34. Alfredo Perea, Retrato de Joaquín Sorolla, publicado en La Ilustración Española y Americana, 22 de septiembre de 1895.

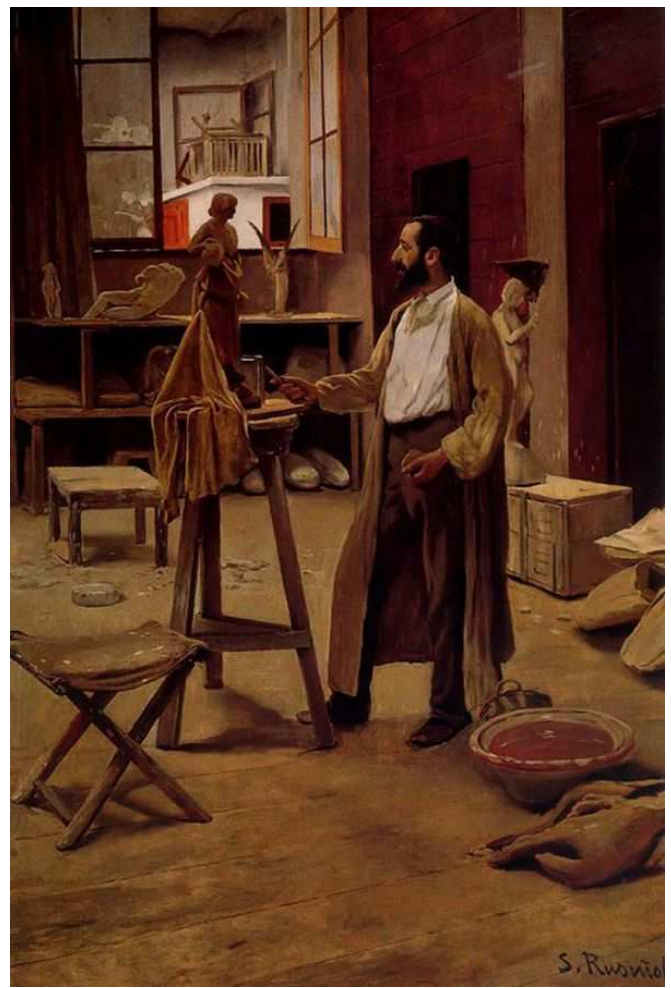

Fig. 36. Santiago Rusiñol, El escultor Clarasó modelando. Colección particular.

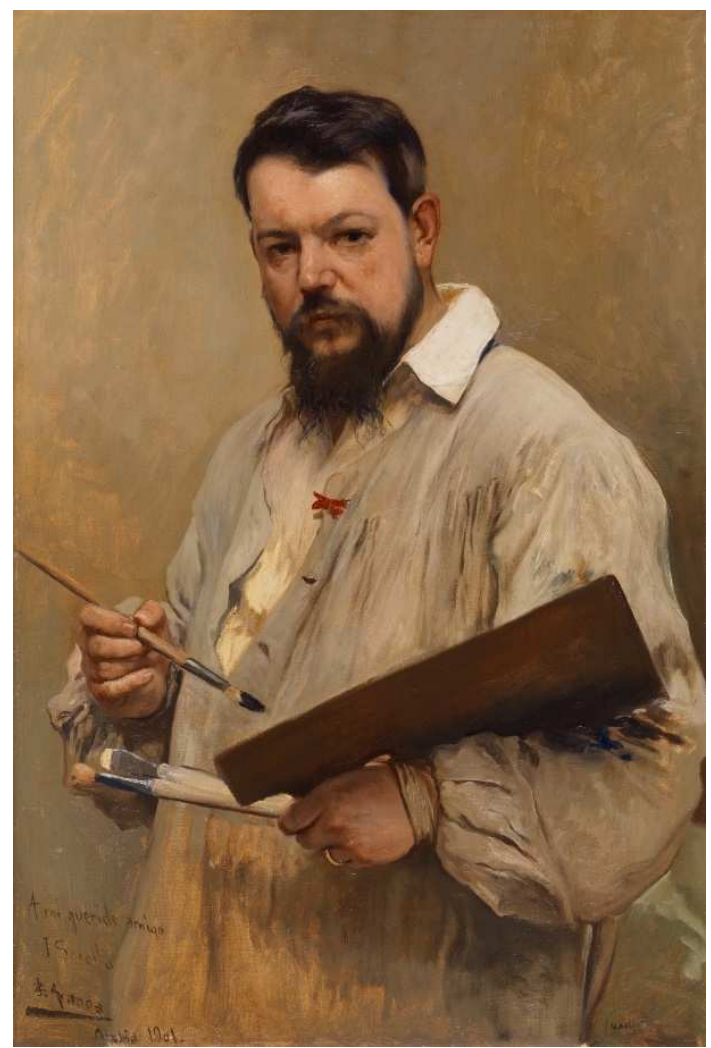

Fig. 35. José Jiménez Aranda, Retrato de Joaquín Sorolla. Museo Nacional del Prado ( ${ }^{\circ}$ inv. P04354).

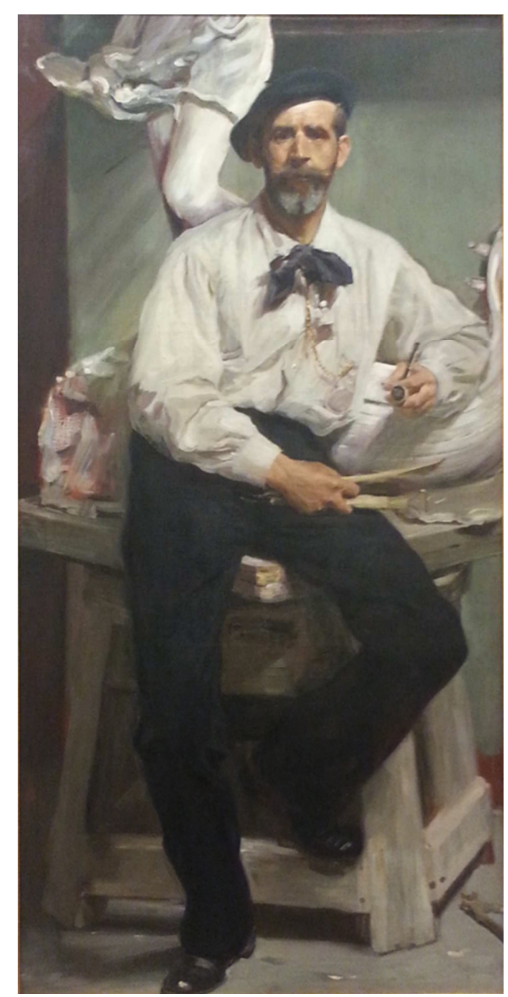

Fig. 37. José Villegas, El escultor Ercole Monti. Museo de Bellas Artes de Sevilla ( $\mathrm{n}^{\circ}$ inv. 684P) 
José Villegas Cordero, al retratar en 1894 a su cuñado el escultor Ercole Monti [fig. 37] (Museo de Bellas Artes de Sevilla, $n^{\circ}$ inv. CE0684P) también juega con la forma de representación para exaltar una imagen masculina; en este caso, opta igualmente por un retrato de cuerpo completo, en que Monti posa, apoyado en una de sus esculturas. El ligero desenfado de su actitud contrasta, sin embargo, con la mirada fija que el escultor dedica al autor de la pintura desde un rostro cuya barba entrecana traiciona madurez, y con la rotundidad de sus manos. Así, el sutil giro del torso permite centrar la atención en el brazo derecho del representado, que se intuye fuerte bajo la blusa ahuecada, y que demuestra resolución en la forma de sostener, apretadas, sus herramientas de modelado. Al igual que sucedía en el retrato de Clarasó, hay también una voluntad de elegancia masculina, perceptible en la indumentaria -no en vano Monti posa en mangas de camisa, con un pañuelo de amplio lazo al cuello, sin vestir bata de trabajo- y en el juego de movimiento, relajado pero lleno de tensión, del cuerpo.

\subsubsection{Retrato del artista como hombre elegante}

En lo que respecta a las apariencias, la contraposición del artista como trabajador es la representación del artista como hombre de mundo, elegante, arrojando de sí mismo una imagen en relación con la buena sociedad. A medio camino entre el burgués y el aristócrata de la cultura mencionados por Amelia Jones, el artista español se presenta siguiendo fielmente la aparentemente sobria moda masculina (GARCÍA ÁLVAREZ, 2017: 153-170; BOEHN, 1929), y dotando a sus melenas y al vello facial una connotación como forma de parecer masculino (REYERO, 2010: 502). Sean autorretratos o retratos de amigo, la completa ausencia de referencias a la profesión artística indica que existe una dicotomía masculina en el artista entre su identidad creativa y su identidad social, buscando por lo tanto un atuendo correspondiente a las normas de elegancia que es sinónimo de una voluntad de pertenencia de clase (BOURDIEU, 1998b). La voluntad de identificación entre retratado-alta sociedad-autor se pone especialmente de manifiesto en las dos últimas décadas del siglo XIX, en que el deseo por lo elegante recupera con fuerza el componente aristocrático del que algunos artistas desean participar, siendo especialmente evidente en la evolución de los retratos realizados por Joaquín Sorolla, siguiendo las modas importadas de Francia y de Estados Unidos (PÉREZ ROJAS, 2000: 110-113; LLORENS, 2006). Además de los ejemplos puntuales mencionados anteriormente, buena parte de los retratos de artistas del siglo XIX corresponden a esta imagen en la que las actitudes y los gestos se configuran no solo como marcas de la personalidad del retratado, sino también como referencias a su masculinidad a través de una alusión a su poder económico y cultural, y como señala Pérez Rojas se emplean como recursos no solo la moda elegante, sino también un despliegue gestual (PÉREZ ROJAS, 2000: 107) que corre paralelo al posado masculino en la fotografía. La importancia de la indumentaria en el caso del artista está indisolublemente vinculada a su entorno de socialización; de este modo, no sorprende la continua alusión a la correcta vestimenta y adorno entre los Madrazo ${ }^{99}$, las

\footnotetext{
${ }^{99}$ Federico de Madrazo escribía a su padre pidiéndole que le mandara a París "mi repetidor de oro y la cadena más sencilla de lo mismo (...) Aquí la gente se paga mucho de eso, y el que tiene una cadena de oro, ya se sabe, tiene más mérito que el que no la lleva, en eso se parecen estos mucho a los ingleses que
} 
descripciones sobre el elegantísimo frac o levita de Jenaro Pérez Villaamil, aparte de las distinciones empleadas en recepciones oficiales; por otra parte, existe una progresiva asimilación de comportamientos masculinos que se incorporan al retrato: en lo que respecta a la gestualidad, el hieratismo da paso a actitudes que transmiten fuerza y seguridad en sí mismo, acompañadas en ocasiones de fondos románticos de paisaje que canalizan las pasiones tradicionalmente negadas al hombre decimonónico; progresivamente se evoluciona también a poses más desenfadadas, en las que frente al autoritarismo se busca resaltar una masculinidad más amena y lúdica, en ocasiones próxima a la idea de la bohemia, buscando plasmar la elegancia del cuerpo y la ocupación masculina del espacio en poses más lánguidas y desenfadadas, donde la gestualidad cobra un nuevo nivel de significado.

El retrato de Rafael Montesinos por Bernardo López (Museo Nacional del Romanticismo, $\mathrm{n}^{\mathrm{o}}$ inv. CE 0080) muestra al pintor como un hombre elegante, tal y como manifiesta su cuidada vestimenta, el peinado y el perfecto arreglo de su poblada perilla; sin embargo, en el suave giro del torso, el cruce de los brazos y la mirada fija se puede leer una seguridad en sí mismo, y un aplomo considerado acorde a una actitud viril. Una imagen que se refleja de manera prácticamente igual en el retrato del pintor Gumersindo Díaz (Museo de Bellas Artes de Sevilla, $n^{\circ}$ inv. CE 0376P), cuya pose estática de brazos cruzados puede implicar un cerramiento sobre sí mismo alusivo igualmente al control sobre las emociones y el dominio personal, imperativo de la masculinidad normativa decimonónica, y que el retratista repite en el retrato del pintor Francisco Tristán (Museo de Bellas Artes de Sevilla, ${ }^{\circ}$ inv. DO 0387P). Este tipo de retrato pervivirá, como demuestra el autorretrato de Ricardo Villodas (Tokio, Colección Suma), como un prototipo masculino.

El posado sentado con las piernas cruzadas es también postura habitual en los retratos masculinos, indicando desenvoltura y comodidad en el ambiente en que se hallan los retratados. Quizás aún incidiendo en el envaramiento y rigidez de carácter, Palmaroli retrata a Ventura Miera [fig. 38] (Museo Nacional del Prado, nº inv. P04534) desde un punto de vista frontal, mostrando del pintor una visión dignificada; la elegancia de su atuendo, que mantiene la capa, la severidad del rostro y la tensión de los dedos entrecruzados sobre la rodilla mueven a pensar que el retratado posa en el estudio de su amigo, incluyéndose en esta ocasión los objetos de trabajo del autor. Miera, desvinculado de la paleta y los pinceles que se mantienen apoyados sobre un pequeño mueble, se presenta como una visita elegante y un hombre de sociedad, lejos del posible desenfado de otros retratos de amigo. Así presenta Raimundo de Madrazo a Benito Soriano [fig. 39] (Museo Nacional del Prado, $n^{\circ}$ inv. P07877), quien evidentemente se encuentra en perfecta armonía con el espacio elegido, que no es otro sino un estudio de artista, en el que destacan los elementos propios de la distensión del trabajo, como el piano del fondo o la guitarra en primer plano. Benito Soriano es presentado en un atuendo elegante, en el que destaca, como rasgo de ostentación burguesa, la cadena de oro de un reloj; ladeado en su butaca, escapa al rígido hieratismo de una postura frontal

juzgan por los adornos exteriores del mérito de las personas”, carta de 8 de diciembre de 1837 (DÍEZ, 1994: 60). 


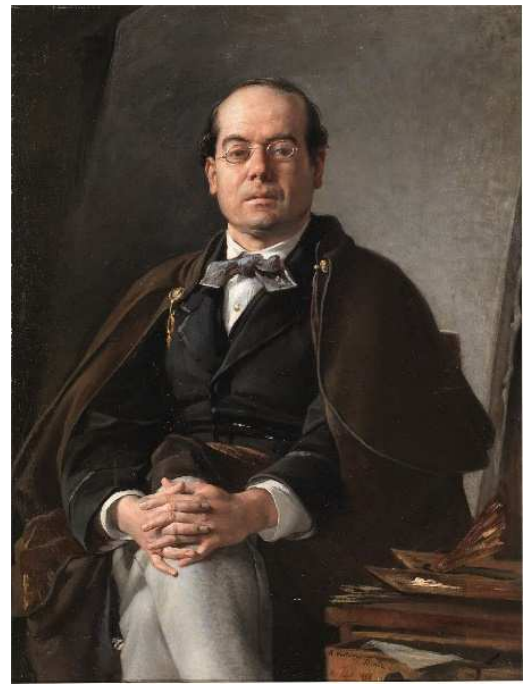

Fig. 38. Vicente Palmaroli, Retrato de Ventura Miera. Museo Nacional del Prado ( ${ }^{\circ}$ inv. P04534).

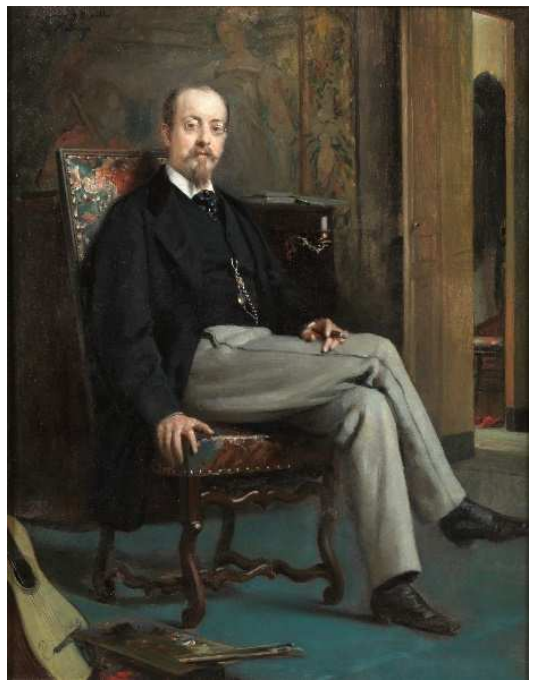

Fig. 39. Raimundo de Madrazo, El pintor Benito Soriano Murillo. Museo Nacional del Prado $\left(\mathrm{n}^{\circ}\right.$ inv. P07877).

y contempla al retratista con seriedad, con las engomadas puntas de su bigote que destacan sobre el papel pintado de la habitación, mientras el puro que sostiene en su mano derecha se consume lentamente.

Igual o mayor comodidad adopta el pintor retratado por Casimiro Sáinz en El descanso. Estudio del pintor, ¿qué pensará? (Museo Nacional del Prado, $\mathrm{n}^{\circ}$ inv. P04636). El artista ha abandonado su obra de composición y se dedica a esbozar, junto a una mujer elegantemente vestida, tal vez una visita; permanece sentado con los pies apoyados en una silla, actitud que contrasta con el recato en que se mantiene la mujer.

Llama la atención, en la década de los sesenta y setenta, la actitud con que Federico de Madrazo plasma a sus amigos artistas; tratándose de retratos de busto, en los que la gestualidad corporal no puede complementar la del rostro, algunos detalles permiten comprobar cómo el pintor transmite un ideal masculino distinto, más próximo a la de la evasión creativa y en el que no faltan las notas de melancolía, alusivas, por otra parte, a la vida interior del genio. Dos factores contribuyen a ello: en primer lugar, la predilección por los rostros girados, en que las miradas se desvían para no enfrentarse a la del pintor, y en segundo, un especial tratamiento en los brillos de los ojos que, con un aspecto vidrioso, evocan una cierta tristeza. Ocurre así en los retratos de Eduardo Rosales [fig. 40] (Museo Nacional del Prado, $\mathrm{n}^{\mathrm{o}}$ inv. P04461) y de Mariano Fortuny [fig. 41] (MNAC, $n^{\circ}$ inv. 045962-000), realizados en 1867, en los que el uso de luces y sombras acompaña a la ausencia de expresión facial, contrastando con la mirada fija que presentaba el retrato de Benito Soriano [fig. 42] (Museo Nacional del Prado, $\mathrm{n}^{\mathbf{o}}$ inv. P07641) realizado en 1855, o con la rotunda presencia de la figura de Carlos de Haes [fig. 43] (Museo Nacional del Prado, $n^{\circ}$ inv. P004464), realizado también en 1867 y con el que comparte el recurso del retrato de algo más de tres cuartos, aunque desviando la mirada. La nostalgia de las figuras puede corresponder con el desaliento de Federico de Madrazo en estas fechas, que alcanza su punto álgido en el retrato de Raimundo de Madrazo (Museo Nacional del Prado, $\mathrm{n}^{\circ}$ inv. P07662), en el que se percibe - no sin una cuidada compostura- la tristeza del joven artista, recién enviudado; no obstante, dota a 


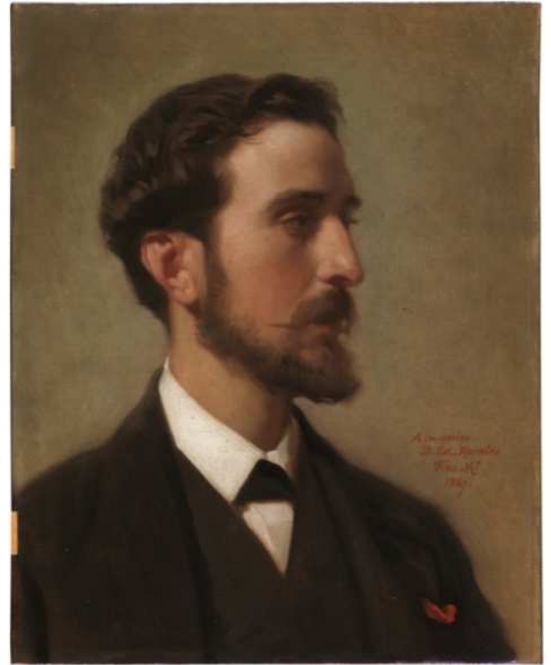

Fig. 40. Federico de Madrazo. El pintor Eduardo Rosales. Museo Nacional del Prado.

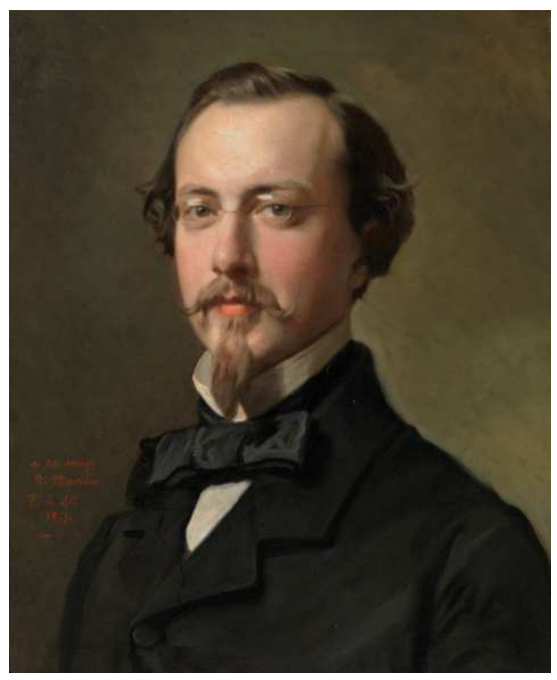

Fig. 42. Federico de Madrazo, El pintor Benito Soriano. Museo Nacional del Prado.

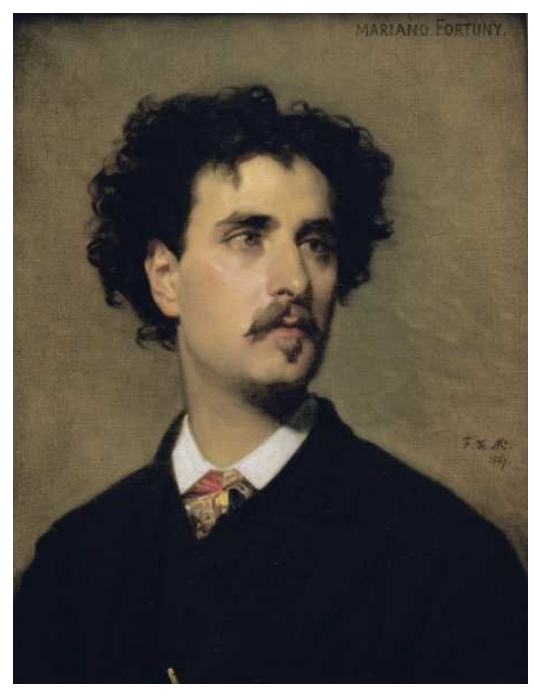

Fig. 41. Federico de Madrazo, Retrato en busto de Mariano Fortuny. Museo Nacional del Prado.

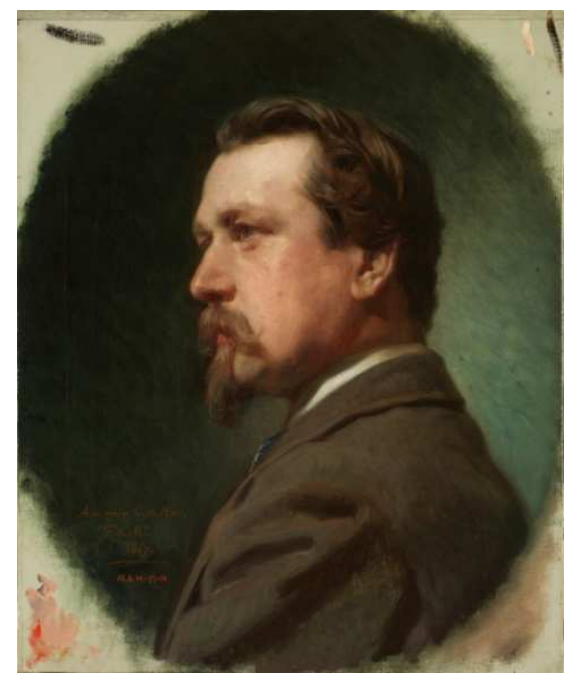

Fig. 43. Federico de Madrazo, El pintor Carlos de Haes. Museo Nacional del Prado.

los efigiados de una cierta gravedad, de un porte de hombre de vida interior y que, pese al sufrimiento, se resigna a no hacer gran ostentación de este.

Entre las poses y gestos elegantemente masculinos que comienzan a proliferar, también entre los artistas, se encuentra el retrato de pie, con elegante atuendo, acompañado de accesorios como bastones o del tabaco. En dos retratos de Miguel Utrillo realizados por Santiago Rusiñol hacia 1890 se evidencia que, a pesar de los rigores de la vida parisina, los artistas españoles se esforzaron por subrayar su virilidad. En el primero del que nos ocupamos [fig. 44] (MNAC, $\mathrm{n}^{\mathrm{o}}$ inv. 011383) el pintor figura de pie, con su traje de abrigo, en un exterior; el largo gabán y el sombrero acentúan la verticalidad de la figura, que contempla fijamente, de manera casi insolente, a su compañero, mientras fuma un grueso cigarro que sostiene a la altura del pecho. En el segundo [fig. 45] (MNAC, $\mathrm{n}^{\mathrm{o}}$ inv. 011384), Utrillo posa de pie, apoyado contra una cancela de Montmartre, con una mano apoyada de manera decidida en su cadera, y acompañado de un bastón. 


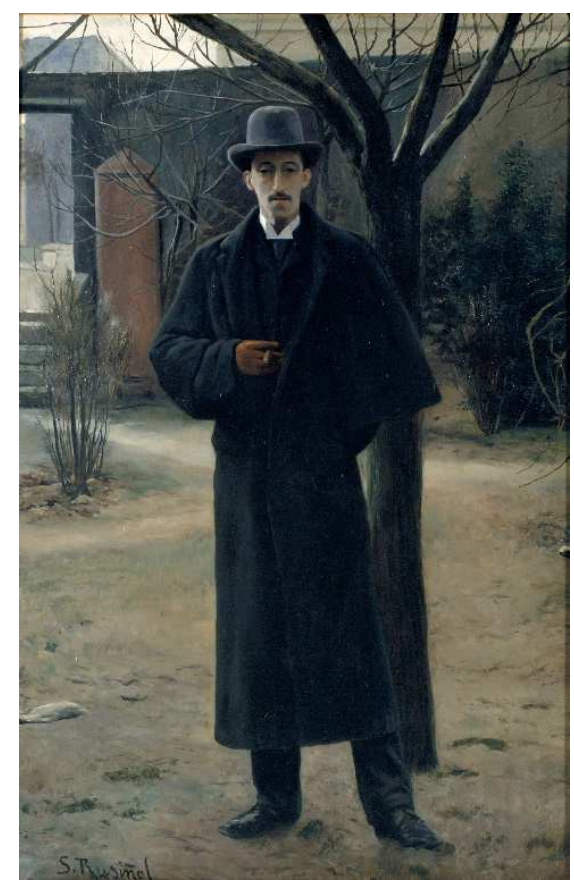

Fig. 44. Santiago Rusiñol, Retrato de Miguel Utrillo. MNAC ( ${ }^{\circ}$ inv. 011383).

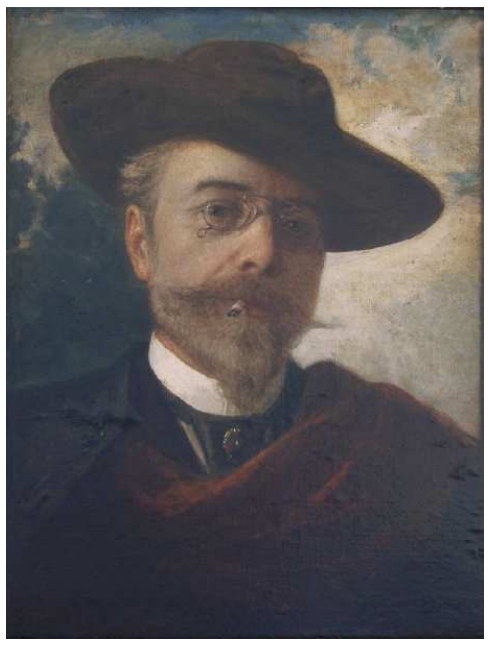

Fig. 46. Dionisio Fierros, Autorretrato del pitillo. Colección particular.

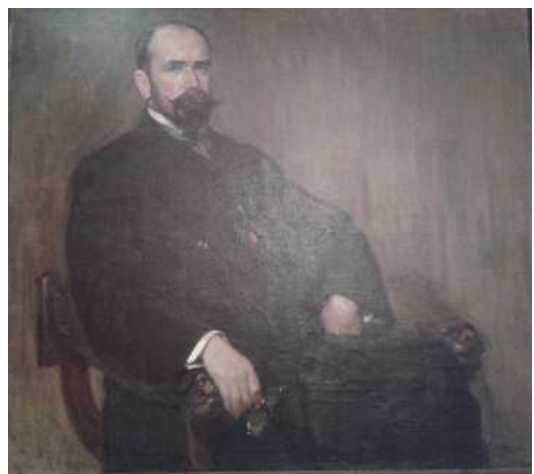

Fig. 48. José Ramón Zaragoza, Retrato de D. José Benlliure. Casa-Museo Benlliure.

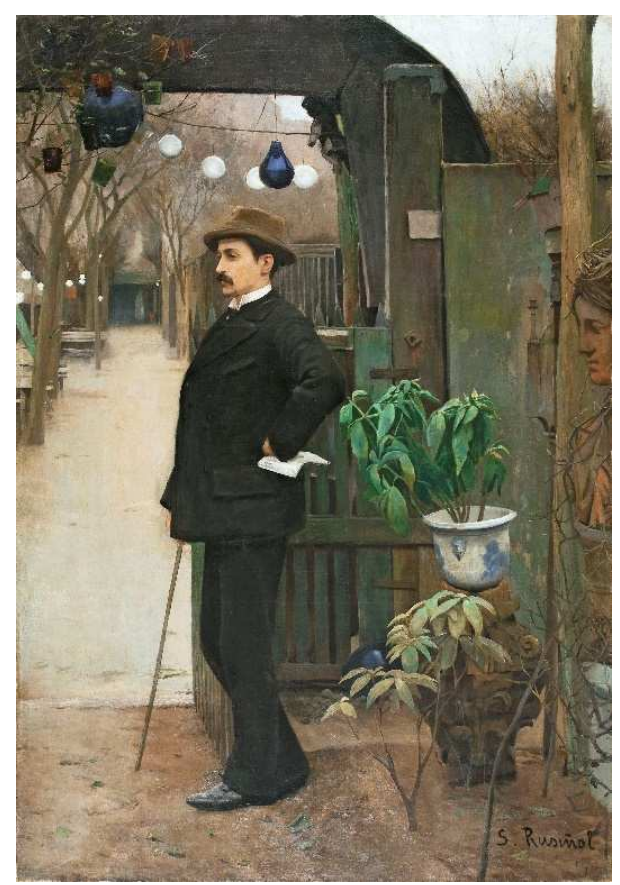

Fig. 45. Santiago Rusiñol, Retrato de Miguel Utrillo. MNAC ( $\mathrm{n}^{\circ}$ inv. 011384).

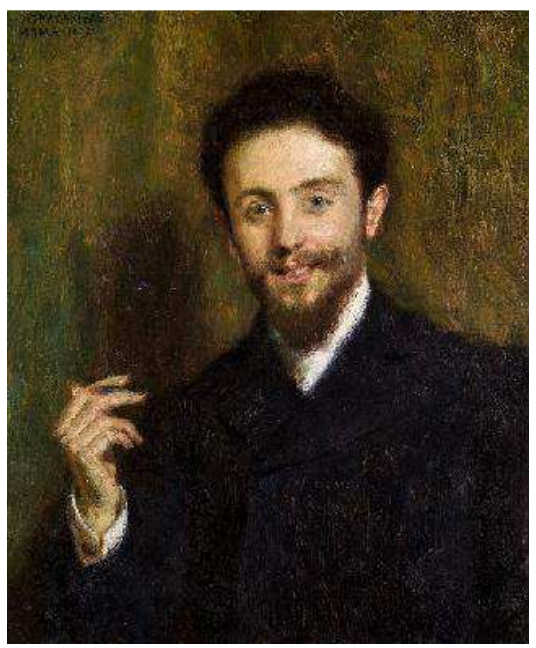

Fig. 47. Gustavo Bacarisas, Autorretrato, Museo de Bellas Artes de Sevilla.

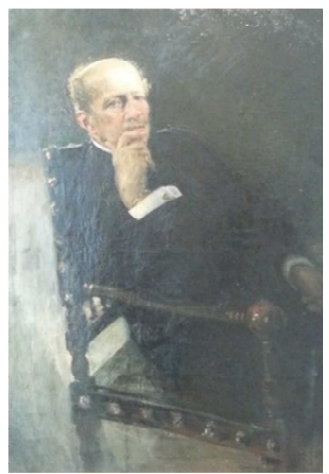

Fig. 49. José Villegas Cordero, Autorretrato. Museo de Bellas Artes de Sevilla. 
La adopción de posturas más desenfadadas es también una consecuencia del cambio de comportamientos masculinos en las últimas décadas del siglo XIX, resaltando una vertiente lúdica y elegante que contrasta con la gravedad que debía observarse en sociedad (REMENTERÍA Y FICA, 1837: 31) y que manifiesta una nueva forma de relacionarse con el espacio ocupándolo sin solemnidad. Frente a la imagen elegante y ligeramente amigable con que Dionisio Fierros se representa en su Autorretrato del pitillo de 1887 [fig. 46], en que la severidad del gesto queda traicionada por la inclinación de la cabeza y el brillo de la mirada, Gustavo Bacarisas ofrece una imagen complementaria en su Autorretrato de 1902 [fig. 47] (Museo de Bellas Artes de Sevilla, $\mathrm{n}^{\circ}$ inv. DJ0322P), en el que la actitud contenida se ha sustituido por una deslumbrante sonrisa, una expresión espontánea que parece mostrar al pintor en amigable charla, como si se encontrase en sociedad, mientras fuma un cigarro acompañante masculino- que humea en su alzada mano derecha.

También en la última década del siglo XIX y extendiéndose en el siglo XX se generaliza un tipo de retrato del artista que pretende potenciar su poder cultural, casi a modo de hombre académico; en él, el artista vuelve a aparecer desvinculado de su profesión, pero dotado de una gravedad en su porte y su gesto que lo vinculan directamente con la élite intelectual y, por lo tanto, con una elevada posición social. Sirven de ejemplo los retratos realizados en 1885 por Luis de Madrazo de algunos de sus familiares, como los de su padre, su hermano Pedro o Federico (Colección Madrazo, Madrid), en que los presenta acomodados en sus correspondientes butacas, con gesto severo, sumidos en sus pensamientos, a semejanza de grandes patriarcas. Correspondiendo con la época de producción y la edad de los representados, hay una tendencia a vincular esta imagen de autoridad con la imagen del erudito, haciendo de la edad madura y de la vejez etapas para un despliegue masculino más basado en la reflexión que en la acción. Gestos que Sorolla repite en otros retratos de comienzos del siglo XX, como el del pintor Antonio Gomar (Museo Nacional del Prado, $\mathrm{n}^{\circ}$ inv. P04653), en el que la severidad es convertida en una actitud más risueña y menos jerárquica, pero que también repitió en los retratos de españoles ilustres para la colección de la Hispanic Society. También José Benlliure fue retratado, en estos términos de dignidad autoritaria, por José Ramón Zaragoza [fig. 48] (Casa-Museo Benlliure, Valencia). El modelo será imitado, de manera tardía, por José Villegas en su Autorretrato de 1917 [fig. 49] (Museo de Bellas Artes de Sevilla, $\mathrm{n}^{\mathbf{0}}$ inv. CE0690P), en el que posa en un sillón frailero, elegantemente vestido y apoyando su cabeza en su mano derecha, en un gesto de profunda reflexión.

Es notorio que, mientras se desarrolla este tipo de retrato en que el artista aparece plasmado como un hombre de poder, los últimos años del siglo XIX y los primeros del $\mathrm{XX}$ ven nacer un tipo de retrato ( $\mathrm{y}$ fundamentalmente de autorretrato) en el que el artista no solo se vincula con su trabajo, sino con una masculinidad casi hipervirilizada a través del recurso a gestos desafiantes, tal y como puede observarse en los presentados a la Exposición de Autorretratos de 1907 (CÍRCULO ARTÍSTICO DE BARCELONA, 1907), donde llaman la atención la expresión chulesca del escultor Miguel Oslé de Medrano [fig. 50], la magnificación de la figura del artista en el Autorretrato de Ramón 
Llissas a partir de un punto de vista extremadamente bajo [fig. 52]; o en el Autorretrato en traje de esgrima de José Benlliure Gil (Casa-Museo Benlliure, Valencia) [fig. 51], en que el joven artista se apropia no solo de la indumentaria deportiva ${ }^{100}$, sino que parece querer lucirla como muestra de un carácter atrevido y decidido. Esta dicotomía ejemplifica la crisis no solo social, sino también masculina, vivida con el cambio de siglo (ARESTI, 2010: 133), y la forma en que los artistas buscaron negociar su identidad: por una parte, los de más edad se acomodan en el principio de la legitimación a través del éxito -primero artístico y luego social-que les permite ofrecer una imagen acorde con la de los intelectuales, encarnando así un papel de privilegiado; por otra parte, los artistas con una carrera menos dilatada o menos exitosa parecen buscar su papel como hombres en clave compensatoria.

\footnotetext{
${ }^{100}$ Este tipo de retrato, que puede incluirse entre los autorretratos elegantes en actividades deportivas, como los retratos en traje de caza (como el Autorretrato ecuestre de Ricardo Balaca), busca además de seguir la imagen del caballero a la moda -a través del deporte y la higiene corporal- extrapolar otros valores masculinos que van más allá de los que definen la profesión artística, entrando en negociación con los de la élite social.
} 


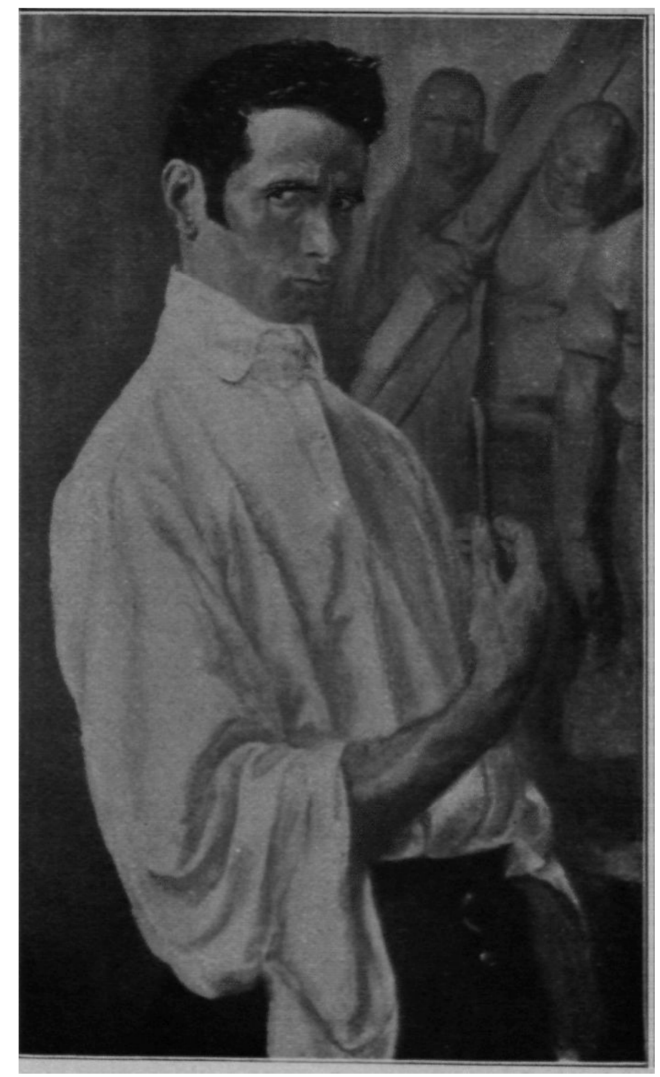

Fig. 50. Miguel Oslé de Medrano, Autorretrato. Exposición de Autorretratos (1907).

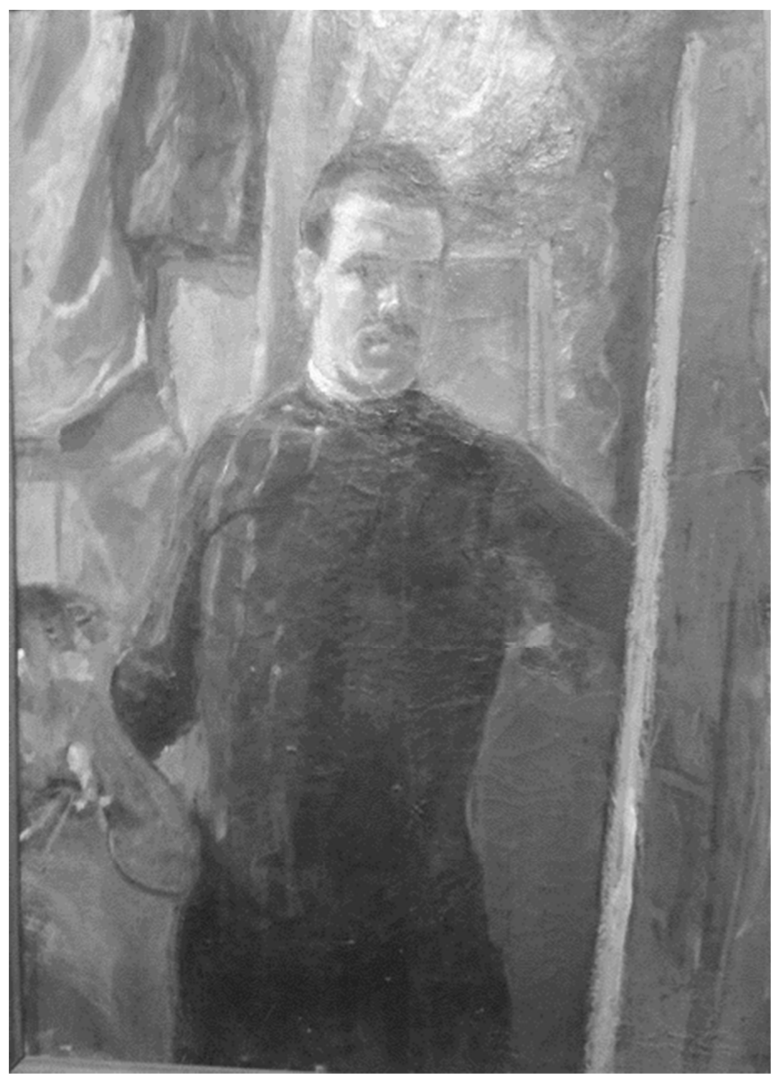

Fig. 51. José Benlliure Ortiz, Autorretrato en traje de esgrima. Casa Museo Benlliure, Valencia.

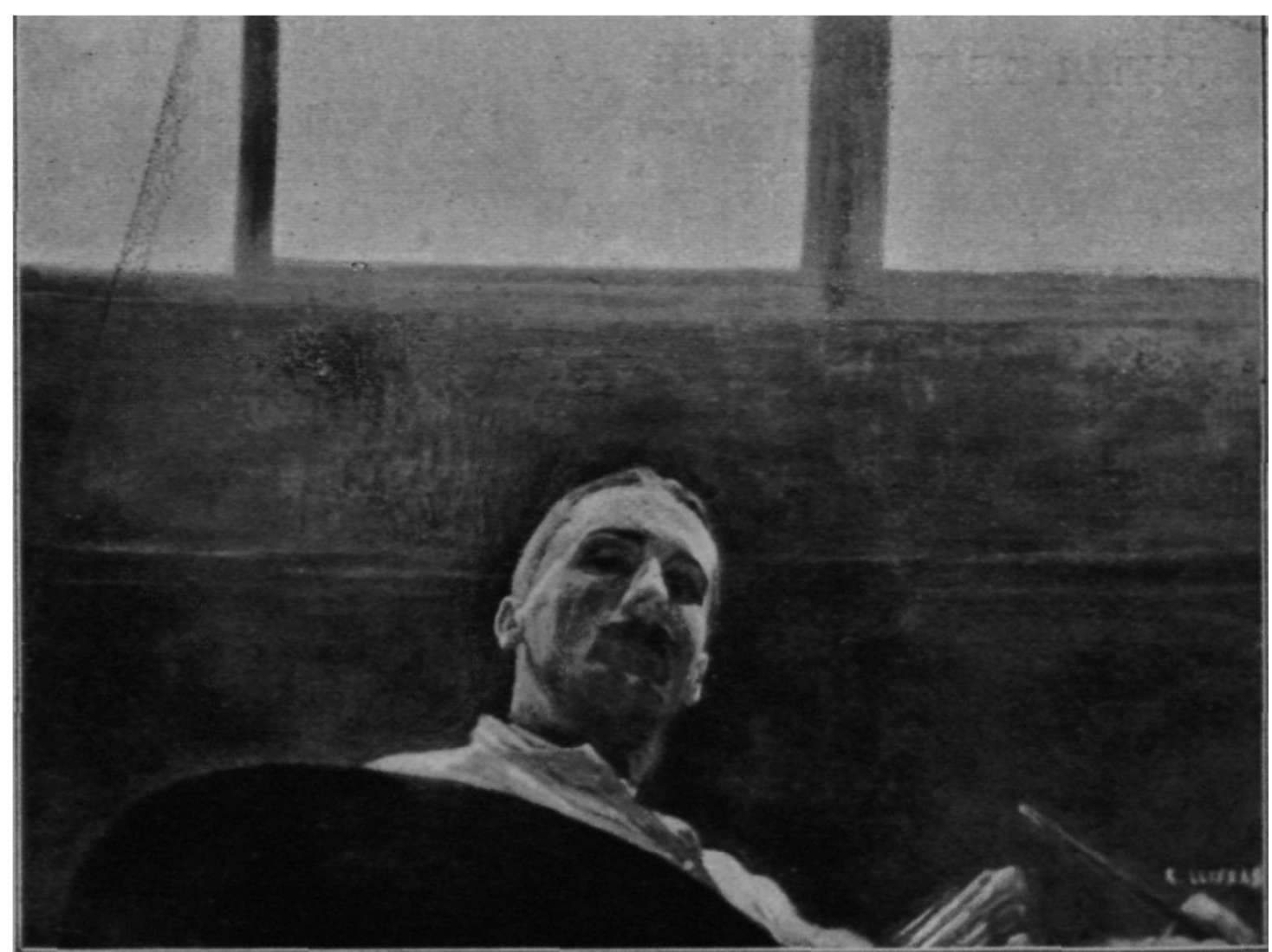

Fig. 52. Ramón Llissas, Autorretrato. Exposición de Autorretratos (1907). 


\subsubsection{Retratos de carácter oficial y la normativización del éxito artístico}

El retrato de artista exhibiendo orgullosamente sus éxitos ha sido considerado como una de las representaciones más habituales (BONNET y JAGOT, 2013: 5) y, en numerosas ocasiones, como carente de interés más allá de constatar el estatus social adquirido, vinculándose irremediablemente al mundo del arte oficial y a los reconocimientos otorgados por este. Así, Wifredo Rincón lo incorpora dentro de la tipología del retrato "convencional del pintor posando", en el que no aparecen atributos de la profesión artística y es difícil saber si se trata de retrato o autorretrato (RINCÓN, 1991: 31); sin embargo, es evidente que este tipo de representación indica una clara voluntad de dignificación y reconocimiento social que trasciende la proporcionada por la mera identidad profesional, en el que el sentimiento de pertenencia a un grupo, élite social o cultural, se vincula directamente con el ejercicio de cierto poder. Relacionado de este modo con las prácticas de la alta sociedad, el retrato de artista que responde a esta iconografía refleja las ambiciones del representado con respecto a la sociedad. Omar Calabrese aborda la idea del autorretrato (extensible por otra parte a este tipo de retrato de artista) como cursus honorum del artista integrado en el mundo oficial en tanto prueba fehaciente de las ambiciones profesionales de este en relación a la sociedad (CALABRESE, 2006: 202). Su análisis de las diferencias entre el autorretrato femenino y el masculino, en el que se ocupa fundamentalmente del momento de la carrera artística en que mujeres y hombres optan por la realización de sus retratos, expone la vinculación entre masculinidad, sociedad y esta tipología, considerándolo una autoafirmación basada en el reconocimiento exterior. A través del término "sanción" estipula el carácter social del reconocimiento profesional masculino, tratándose de un juicio de valor que supone la legitimación del individuo respecto al grupo al haber alcanzado éxitos que conducen a la celebridad ${ }^{101}$.

El retrato del éxito artístico suele ligarse estrechamente a la inclusión de elementos alusivos al mismo, según el funcionamiento del sistema artístico oficial; de este modo, en la primera mitad del siglo XIX - y en algunos ejemplos también de manera tardíacobrará especial dignificación el uniforme, bien de académico o de artista de cámara. La importancia del uniforme de cámara es señalada por Federico de Madrazo como parte de su orgullo profesional juvenil, ya que en 1834 anotaba en su agenda-diario el haber prestado su juramento como pintor de cámara el 29 de enero y añadía, pocos días después, el haber ido a comprar el material necesario para su uniforme de la Real $\mathrm{Casa}^{102}$.

\footnotetext{
101 "Generalmente, los hombres esperan para realizar su autorretrato a esta consagración exterior (por parte de la sociedad, de la Corte, del público o de la crítica) que los situa en el seno de una galería de hombres supuestamente ilustres, a la cual ellos mismos aportarán su contribución (...). De hecho, sanción es un término ambiguo. De manera general, designa el juicio legal o de valor que un tercero -dotado de una autoridad institucional o moral- hace sobre el acto de un sujeto agente. (...) Lo que cuenta, sin embargo, es que la sanción llega siempre al término de una sucesión de pruebas, un recorrido que debe ser admitido, implícitamente, como acabado. Lo cual quiere decir que este mismo recorrido debe constituir de alguna manera un relato reconstruible para aquel que debe juzgarlo (...)" (CALABRESE, 2006: 221-222).

${ }^{102}$ Archivo Museo del Prado, AP17/1.
} 


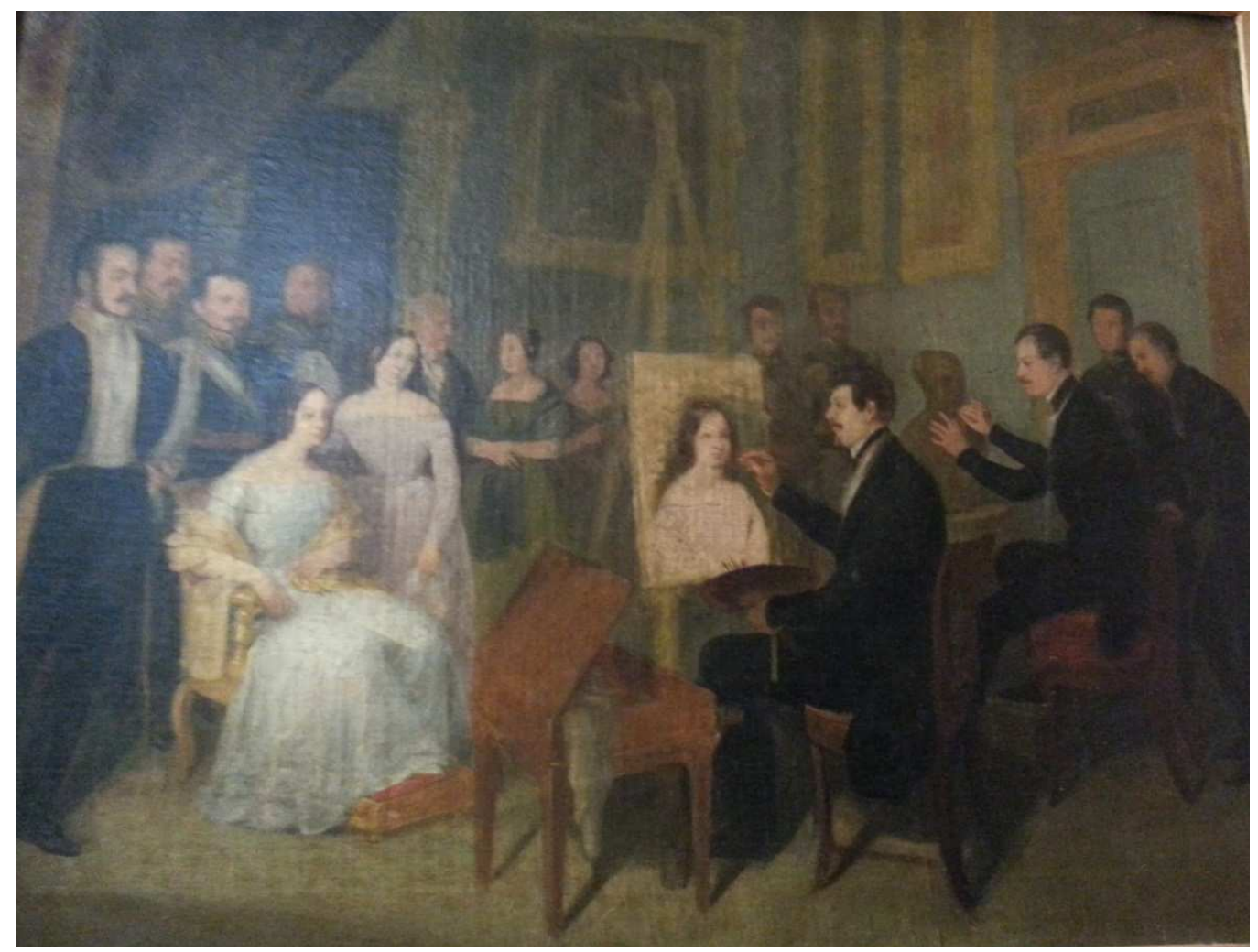

Fig. 53. Antonio María Esquivel, Esquivel en Palacio retrata a Isabel II. Museo de Bellas Artes de Sevilla.

Dado que el uniforme de las Academias de San Fernando y San Carlos es un elemento que analizaremos en el apartado correspondiente a las relaciones entre el individuo y la corporación académica, tan solo incluimos como ejemplo un esbozo probablemente destinado a un retrato de grupo- realizado por Antonio María Esquivel, en el que se evidencia la complacencia del pintor en su labor profesional y su relación con el poder. Se trata de Esquivel en palacio retrata a Isabel II [fig. 53] (Museo de Bellas Artes de Sevilla), una pequeña obra fechada hacia 1846 en la que la reina, acompañada por su séquito, posa ante el pintor y escultor de cámara, cada uno de ellos ocupado en la realización de su obra, y en el que a pesar del carácter abocetado se puede percibir el ribete de un uniforme que adquiere en la escena un papel significativo como exponente de los máximos honores/poderes a los que el artista podía acceder en época isabelina. Llama la atención la escasez de retratos en que el pintor decimonónico se incluye en una escena de personajes de poder; junto al boceto de Esquivel, en el que evidentemente se autocomplacía al incluirse en una escena en la que aparecía la reina, podemos citar otro ejemplo anterior en el que la relación entre artista y monarquía aparece subrayada como rasgo de orgullo profesional. Se trata del Autorretrato de Luis de la Cruz y Ríos (colección particular), en que se presenta sentado en un luminoso estudio junto a un retrato de Fernando VII; en la obra, Luis de la Cruz realiza un curioso juego de dignidades acorde todavía con la ideología del absolutismo, puesto que en el retrato del rey este aparece revestido de todos sus atributos del poder; por el contrario, el pintor opta por presentarse sentado, vestido de manera informal con traje doméstico y zapatillas rojas. La ausencia de un atuendo de etiqueta y de condecoraciones que subrayen su dignidad, rasgo aparentemente de modestia, permite sin embargo establecer 
una relación directa entre el pintor y la realeza al mostrarse como servidor orgulloso de esta, conforme con el sistema de jerarquías en el que Luis de la Cruz se ve incluido.

La progresiva inclusión de condecoraciones manifiesta también la costumbre de ostentación de las clases altas, entre las que los artistas oficiales desean contarse. A pesar, sin embargo, de tratarse de una imposición de la moda como forma de visibilizar no tanto los méritos del individuo como su posición en la élite social, la inclusión en retratos y autorretratos responde a la importancia que estas adquirían no solo de cara a la sociedad, sino a su propia autoconstrucción como individuo que forma parte de los mecanismos del poder (no en vano se requería presentar pruebas de nobleza y limpieza de sangre ${ }^{103}$ ). La evolución de las formas de concesión de las distintas condecoraciones, comenzando por la solicitud personal y por la recomendación hasta el premio por los trabajos artísticos, supone para el artista oficial el reconocimiento por parte del poder institucional a sus méritos y esfuerzos; no en vano las múltiples solicitudes dirigidas a Palacio en busca de reconocimientos y honores hacen hincapié, de manera continua, en el valor de su propio trabajo.

\subsubsection{1. Órdenes de Carlos III e Isabel la Católica}

El privilegio más habitual concedido a los artistas oficiales durante el reinado de Fernando VII es el nombramiento de caballero de la Orden de Carlos III; contar con esta distinción suponía gozar del privilegio real, puesto que como señalaba José de Madrazo en 1828, era preciso acreditar, aparte de los requisitos anteriores, no haberse adherido al régimen constitucional. Así lo declaraba él mismo en relación a la solicitud de la Cruz de Caballero de la orden, afirmando que

Para condecorarme con sus insignias necesito acreditar que he sido de buena vida y costumbres; que no he estado informado de caso grave, y feo; y que en el tiempo del sistema llamado constitucional no me adhería a sus máximas, habiéndome mantenido con el mayor amor a nuestro Soberano (...) para lo cual estoy pronto a señalar seis testigos condecorados que dispongan al tenor de este escrito",104.

De igual modo, Vicente López fue nombrado caballero supernumerario en 1828, para lo cual tuvo que presentar sus correspondientes pruebas de nobleza y de limpieza de sangre ${ }^{105}$, así como "las informaciones de testigos recibidas en Valencia y en esta corte" que acreditaban "que el Sr. Pretendiente es de buena vida y costumbres". Sin embargo, la relación de la orden de Carlos III con el mérito artístico es prácticamente nula, estando vinculada a los artistas relacionados con la propia Corte y con la Casa Real, como manifiesta el hecho de que los condecorados con anterioridad a 1833 fuesen, precisamente, los pintores de cámara.

Con motivo de la subida al trono de Isabel II surge una nueva fiebre de honores con la creación de la Orden de Isabel la Católica, que convivirá con la de Carlos III como

\footnotetext{
103 "Extracto de las pruebas de Nobleza de Don José de Madrazo", Expediente de José de Madrazo. A.H.N., Secretaría de órdenes civiles, Sección Orden de Carlos III, Exp. 1969.

104 "Extracto de las pruebas de Nobleza de Don José de Madrazo", Expediente de José de Madrazo. A.H.N., Secretaría de órdenes civiles, Sección Orden de Carlos III, Exp. 1969.

${ }^{105}$ AHN, Secretaría de órdenes civiles, Estado, Sección Carlos III, Exp. 1986.
} 
muestra de la pertenencia a la sociedad más escogida. En respuesta al Real Decreto de 24 de diciembre de 1838, en que se concedía a Jenaro Pérez Villaamil la Cruz de Caballero de la orden de Isabel la Católica como "prueba del aprecio que me merecen sus talentos artísticos, y que le sirva al mismo tiempo de estímulo para alentar su aplicación”, el pintor se regocijaba, manifestando que era mayor el aprecio que le suponía al haberla obtenido sin solicitarla ${ }^{106}$. Otros artistas, sin embargo, sí que pidieron directamente esta honra, lo que pone de relieve la importancia que las apariencias, el juego de influencias y las pequeñas muestras de poder tuvieron para algunos artistas. Es el caso de José Gutiérrez de la Vega, que alega como mérito en su solicitud "los esfuerzos que constantemente ha hecho por que renazca el buen gusto de la escuela sevillana ${ }^{107}$ ", el de Vicente López, a quien se concede "como recompensa de su distinguido mérito artístico y por la consideración que como Primer Pintor de Cámara de S.M. merece ${ }^{108,}$, o el de Antonio María Esquivel, que redacta una larga solicitud en la que, además del mérito profesional, alega estar en igualdad de condiciones que otros pintores condecorados ${ }^{109}$, una curiosa manifestación de celos profesionales que se repite en $1841^{110}$. Otros méritos expuestos son el triunfo artístico en el extranjero, tomando como ejemplo el caso de la Legión de Honor francesa respecto a los artistas premiados en los salones; así sucede en el caso de Pablo César Gariot, que alude a la medalla de oro obtenida en el Salón parisino de $1843^{111}$ como motivo para solicitar la Cruz de Caballero de Isabel la Católica. Posteriormente se ofrecieron también como recompensa condecoraciones de la orden de Carlos III a los artistas ya premiados en más de una Exposición Nacional de Bellas Artes ${ }^{112}$, como se propuso con Antonio Gisbert en 1864.

Frente a esta obsesión por la exhibición del mérito, cuyo único fin es el reconocimiento y la visibilidad social, y que se traduce en que la apariencia masculina revista un toque más elegante y ostentoso, no debe llamar la atención que, desde la realidad económica de muchos artistas, la solicitud y concesión se realizase con exención de gasto. Jenaro Pérez Villaamil, a quien Valentín Carderera recordaba

\footnotetext{
${ }^{106}$ A.H.N., Secretaría de órdenes civiles, Estado, Sección Isabel la Católica, 6320, Exp. 129.

${ }^{107}$ A.H.N., Secretaría de órdenes civiles, Estado, Sección Isabel la Católica, 6322, Exp. 113.

${ }^{108}$ A.H.N., Secretaría de las órdenes civiles, Estado, Sección Isabel la Católica, 6321, exp. 107.

109 “A V.M. humildemente suplica se digne concederle la Cruz de Isabel la Católica en los mismos términos que la han obtenido sus compañeros D. Genaro Villamil y D. José Gutiérrez, a quienes no se juzga inferior en amor a las artes". A.H.N., Secretaría de órdenes civiles, Estado, Sección Isabel la Católica, 6324, Exp. 64.

110 “'(...) habiendo tenido el honor de haber sido agraciado por S.M. con la Cruz de Caballero de la Real Orden de Isabel la Católica, en premio de sus adelantos en el noble arte de la pintura que profesa y deseando ponerse a nivel de los artistas de su clase suplica a la Regencia se digne concederle la Cruz de Comendador”. A.H.N., Secretaría de órdenes civiles, Estado, Sección Isabel la Católica, 6324, Exp. 64.

${ }^{111}$ A.H.N., Secretaría de órdenes civiles, Estado, Sección Isabel la Católica, 6329, Exp.29.

${ }^{112}$ En el reglamento de 1860 se estipula: "Art. 16. Además de las medallas, concederá el Gobierno las condecoraciones siguientes: La cruz de caballero de la Real y distinguida orden de Carlos III al artista que en dos exposiciones hubiese obtenido la medalla de primera clase; en el caso de que tuviera ya esta condecoración, se le concederá la de comendador ordinario; y si también se hallare condecorado con esta última, tendrá opción a la primera de comendador de número que vaque entre las correspondientes al ministerio de Fomento" ("Reglamento...", 1860: 3). En el de 1862, además, se estipula que se concede la Cruz de Comendador de la Orden de Carlos III "al autor de la obra cuyo mérito exceda al de las que merecieron primera medalla y no sea bastante para obtener el premio de honor" (art. 29), además de la concesión de la cruz de caballero de la orden de Carlos III a "cualquier primera medalla obtenida por segunda vez" (art. 30) (“Reglamento...", 1862: 168).
} 
enamorado de sus distinciones ${ }^{113}$, explicaba detalladamente los problemas económicos que le suponía la concesión de su cruz de caballero de Isabel la Católica:

en el segundo oficio se exige el pago de varios gastos para poder obtener el diploma, y yo me veo en el sensible caso de no poder condecorarme por la absoluta imposibilidad de satisfacer el importe de aquellos, pues con muy pocas obras y cargado de una numerosa familia, apenas bastan mis recursos para subvenir a sus necesidades. Por lo que me atrevo a suplicar a V.E. como tan amante de las artes y de los artistas, se sirva interponer su influjo para que me sea concedido el relevo de los citados gastos ${ }^{114}$.

$\mathrm{Su}$ petición fue atendida en consideración a su aplicación y mérito artísticos. Igualmente, en el momento de la concesión a José Gutiérrez de la Vega, se proponía inicialmente que fuese eximido de todo gasto "menos de los decretados por las Cortes y el depósito en la orden para cuyo pago tengo a bien señalarle medio año de término", algo a lo que el pintor respondió "alegando la estrechez en que se encuentra por falta de trabajo y tener que atender a la subsistencia de una numerosa familia ${ }^{115}$ ". Aunque Antonio María Esquivel sí que satisfizo el pago del depósito en la Orden y de la suma estipulada por las Cortes, en adelante en las solicitudes y concesiones se señalará cuidadosamente el "libre de todo gasto", como sucede en la de Carlos Luis de Ribera ${ }^{116}$ o Miguel Parra ${ }^{117}$, así como en la concesión del uso de placa de Caballero Supernumerario de la Orden de Carlos III de José de Madrazo, la cual aun siendo libre de gasto costó al pintor cien reales de vellón ${ }^{118}$.

José de Madrazo se hizo representar por su hijo Federico en un retrato [fig. 54], lamentablemente no conservado, en el que luce en la solapa la cruz de caballero supernumerario de la orden de Carlos III que le fuera concedida en 1828; la obra, realizada tal vez en 1832 -fecha que José Luis Díez marca ya como dudosa-, incluye la cruz de Comendador de la Orden de Isabel la Católica, que le fue concedida en $1833^{119}$. También Vicente López fue representado por su hijo Bernardo, en la copia de su autorretrato [fig. 55] (Academia de Bellas Artes de San Fernando, $n^{\circ}$ inv. 0740), ostentando en la solapa la condecoración de Caballero Supernumerario de la Orden de Carlos III, que le fue concedida al tiempo que a José de Madrazo, además de la banda de la Orden de Isabel la Católica.

\footnotetext{
${ }^{113}$ Carta de Valentín Carderera a Federico de Madrazo, 15 de octubre de 1845. "Estoy picado por el retrato a Villaamil, no habiéndome querido hacer el mío. Lo que tiene el ser feo, ¡averígüese! El Sr. Comendador Villaamil, como aquí se anunciaba, si fuera un poco más alto sería lo que aquí se llama un buen mozo". Archivo del Museo del Prado (en adelante AMP), AP6/Exp. 62.

114 A.H.N., Secretaría de las órdenes civiles, Estado, Isabel la Católica, 6320, Exp. 129.

115 A.H.N., Secretaría de órdenes civiles, Estado, Isabel la Católica, 6322, Exp. 113.

${ }^{116}$ A.H.N., Secretaría de órdenes civiles, Estado, Isabel la Católica, 6321, Exp. 131.

117 A.H.N., Secretaría de órdenes civiles, Estado, Isabel la Católica, 6323, Exp. 74.

${ }_{118}$ Carta de pago de José de Madrazo. AMP, AP15/exp.22/doc. 43.

119 Así se lo comunica a Federico en carta de 8 de agosto de 1833 [DÍEZ (1998), p. 25], honor que fue aumentado en grado en 1848 (Nombramiento de Caballero Gran Cruz de la Orden de Isabel la Católica a José Madrazo, pintor de cámara. A.H.N., Secretaría de órdenes civiles, Estado, Isabel la Católica, 6335, exp. 13).
} 


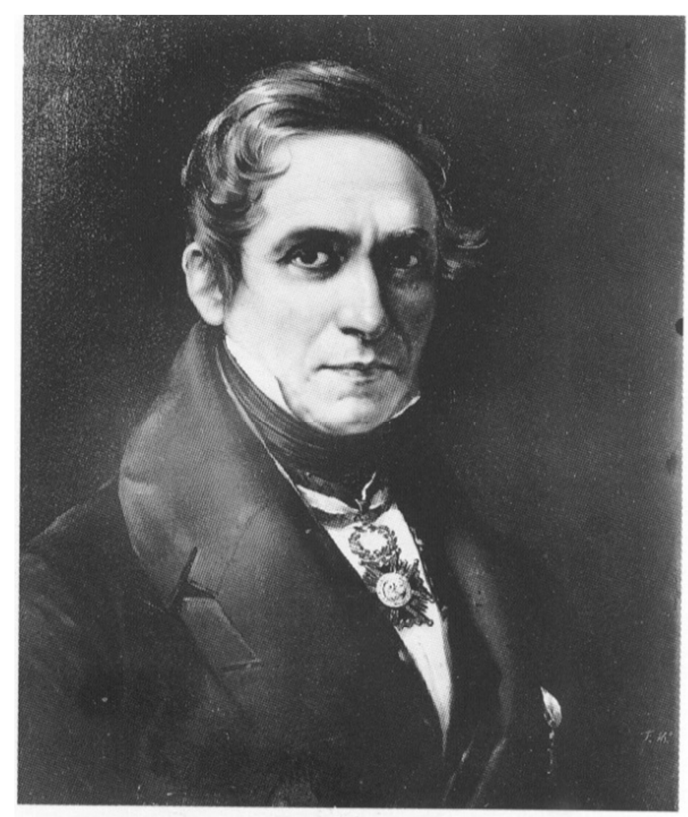

Fig. 54. Federico de Madrazo, Retrato de José de Madrazo. Destruido en 1935. Archivo Moreno ( $\mathrm{n}^{\mathrm{o}}$ inv. 06401C).

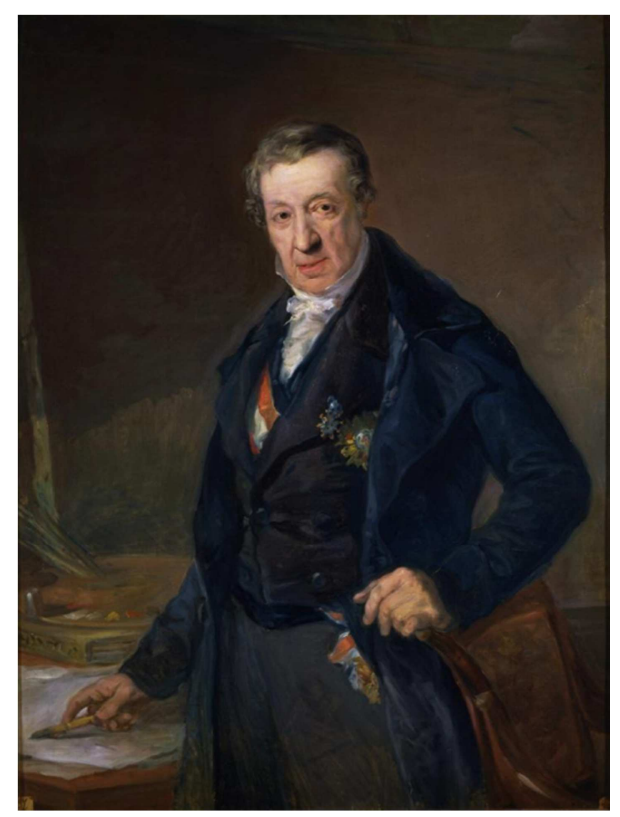

Fig. 55. Bernardo López, Copia del autorretrato de Vicente López, Academia de San Fernando.

La importancia que tanto José de Madrazo como Vicente López adjudicaban a estos honores da también muestra de la rivalidad existente entre ambos; en más de una ocasión el primero recuerda a su hijo Federico la necesidad que se tiene de condecoraciones y honores en la buena sociedad ${ }^{120}$. Sin embargo, Federico mantuvo una actitud opuesta a estos, especialmente a los que se otorgaban de manera indiscriminada o por petición, reafirmándose en esta posición en 1868 estando especialmente descontento con el trato recibido por la Casa Real:

Lo que sé es que nada he pedido ni pediré y que si se me ofrece algo menos que una gran cruz no la recibiré, no por orgullo ni por vanidad ridícula, sino por lo que debo a mi posición actual. Me crucé de caballero de Carlos III al mismo tiempo que Bretón de los Herreros, Vega, Hartzenbusch, Gil y Zárate y otros, de los cuales la mayor parte recibieron hace tiempo la gran cruz de Isabel la Católica. Muchos de los que han sido discípulos míos tienen la cruz de comendadores de Isabel la Católica o de Carlos III. Por consiguiente siendo yo (con mérito o sin mérito) Director del Real Museo, de la Real Academia de San Fernando, individuo del Instituto Imperial de Francia y de la Academia de San Lucas de Roma, etc., etc., oficial de la Legión de Honor y comendador de varias Reales Órdenes extranjeras ( $\sin$ haberlo pedido) ni puedo ni debo recibir menos que una gran cruz. Probablemente no recibiré nada, porque aquí solo se consiguen las cosas que se

\footnotetext{
120 "Yo sé muy bien que tú no ambicionas honores de Cruces, y aun te resistías a que yo pidiese a S.M. la gracia que te ha concedido porque aquella a que aspiras es la sólida y verdadera del saber". Carta de 22 de agosto de 1833 ( DÍEZ, 1998b: 32). "Te remito en esta carta un poco más de una $3^{\text {a }}$ de cinta de Isabel la Católica para que te sirva por dos veces haciendo el lazo, que así se acostumbra a llevar en Francia, y siento que no hubiese pensado yo en esto porque ya que tienes esta decoración debes llevarla, pues en Francia se hace mucho caso y da mucho prestigio". Carta de 29 de septiembre de 1837 (DÍEZ, 1998b: $88)$.
} 
piden y yo estoy decidido a no pedirlas jamás (GONZÁLEZ LÓPEZ y MARTÍ AYXELÁ, 1994: 79).

Al parecer, también Jenaro Pérez Villaamil tuvo en alta estima las condecoraciones que había obtenido, según recoge Ceferino Araujo, y siempre adornaban su elegante atuendo de frac o levita (ARIAS ANGLÉS, 1986: 165), a pesar de su inestable situación económica; sin embargo, en los retratos que le realizó Federico de Madrazo (colección particular) lo presenta como un hombre elegante y orgulloso, debido en gran parte al punto de vista bajo empleado, con un asomo de sonrisa en los labios, aunque sin grandes ostentaciones, luciendo únicamente una pequeña cinta en el ojal de su levita, y sin figurar en su pecho o cuello ninguna condecoración.

Empleada también como rasgo de distinción, es llamativa la inclusión de la cruz de la Orden de Carlos III en el retrato de boda que Vicente López realiza de su discípulo Nicolás Gato de Lema, tanto más cuanto muestra evidente interés por dignificar al artista. En comparación con el retrato que López le realizase anteriormente se saca rápidamente la conclusión de que, en su retrato nupcial, hay una pretensión por mostrar una recién adquirida madurez en el joven, conseguida plásticamente a través del poblado bigote que adorna su rostro, y de manera simbólica aludiendo a su éxito mediante la condecoración.

\subsubsection{La Orden civil de María Victoria}

La institución durante el reinado de Amadeo de Saboya de la Orden civil de María Victoria buscaba paliar en cierto modo la fiebre por las condecoraciones indiscriminadas creando una recompensa destinada específicamente a premiar los méritos científicos, artísticos y literarios; en la justificación para la formación de esta nueva orden civil el ministro de Fomento Manuel Ruiz Zorrilla hacía alusión al carácter militar o nobiliario que habían merecido otras órdenes, vinculándolo a una jerarquía basada no tanto en el mérito como en el poder adquisitivo del aspirante, buscando con la de María Victoria dar reconocimiento al esfuerzo individual y al trabajo constante:

En otros tiempos se creaban órdenes para premiar las glorias militares, y solían ser privilegio de la nobleza y alguna vez del dinero; a esta edad de libertad y de discusión, en que está abierto el campo a todas las inteligencias y en que el mérito individual sobresale y se abre ancho camino hasta los más elevados puestos, corresponde la creación de órdenes civiles que lleven como emblema el ramo de oliva de la paz y los útiles del trabajo; órdenes que puedan considerarse como asociaciones de lo más eminente del país; de los hombres que se hayan distinguido por los tranquilos y benéficos trabajos a favor de la ciencia y del arte; del sabio que investiga, del artista que crea, del pensador y literato que enseñan y mejoran la condición moral; del obrero que ejecuta con paciencia y maestría, y del industrial que aumenta la riqueza pública y favorece los elementos de orden y moralidad, contribuyendo todos por tan diversos medios a la gloria y felicidad de la Nación (RUIZ ZORRILLA, 1871: 133).

Por este motivo, continuaba, "se suprimen toda clase de derechos para evitar que el premio, recayendo en clases hijas del trabajo, sean una carga, y se hace compatible la 
concesión de la cruz de María Victoria con todos los empleos y cargos", lo que implicaba que la expedición del diploma era inicialmente gratuita ${ }^{121}$, aunque la concesión seguía estando sujeta a la posibilidad de petición por parte del interesado o por propuesta del Ministerio ("Decreto...", 1871: 133). La nueva noción respecto al mérito personal vinculado a la identidad profesional y al progreso se refleja en el hecho de que el propio diploma debía hacer constar la razón por la cual se concedía a cada individuo. La distinción para los premiados por la rama de las bellas artes sería de banda o cinta de color rosa, y podían aspirar a tal mérito los artistas catedráticos de número de la enseñanza oficial con más de quince años de antigüedad o los que hubiesen obtenido una medalla en Exposiciones Nacionales de Bellas Artes o Exposiciones Universales que obtuviesen un nuevo mérito por una obra artística ("Reglamento ...", 1871: 253). De este modo, fueron propuestos para la cruz sencilla los pintores que, habiendo presentado obras a la Nacional de 1871, merecían recompensa y no la obtuvieron por haber conseguido en exposiciones anteriores premios más distinguidos: Dióscoro Puebla, Pablo Gonzalvo, Benito Mercadé, Domingo Valdivieso, José Marcelo Contreras, Juan García Martínez, Alejandro Ferrant, Marcos Hiráldez Acosta, Mariano de la Roca, Manuel García Hispaleto, Bernardo Ferrándiz, Francisco Díaz Carreño, José Mirabent, Antonio Pérez Rubio y Francisco Torras (MONTEJO Y ROBLEDO, 1871: 701), concediéndose a los dos primeros ${ }^{122}$ (Gaceta de Madrid, 1872/23/03:868). Se concedió gran cruz a Federico de Madrazo en mayo de 1872 (Gaceta de Madrid, 1872/18/05:484), así como a Carlos Luis de Ribera, Antonio Gisbert y José Casado del Alisal (Gaceta de Madrid, 1872/25/05: 563).

La supresión de la Orden de María Victoria por la Primera República por considerar el reconocimiento de los méritos individuales opuesto a los principios democráticos afectaba a los artistas de manera tangencial, ya que los reconocimientos obtenidos por estos durante el reinado de Amadeo de Saboya se redujeron a los anteriormente citados. Estanislao Figueras afirmaba además que los artistas ya gozaban de otros reconocimientos basados en el mérito, como eran las medallas en las distintas exposiciones, uno de los motivos que fundamentaba la supresión de la orden (FIGUERAS, 1873: 347). Se desconocen retratos de los artistas anteriormente citados que figuren condecorados con algún grado de la orden civil de María Victoria, algo que tal vez puede explicarse por la brevedad de vigencia de la Orden o por el componente político que podía suponer dicha representación.

\subsubsection{La Legión de Honor y el orgullo por el mérito internacional}

El sistema meritocrático francés tuvo en la Legión de Honor uno de los exponentes más reseñables de la exhibición del éxito y la influencia. Henri Delaborde señalaba en 1891 cómo el propio Napoleón dio impulso al reconocimiento social del artista no solo concediendo títulos nobiliarios, sino también al consentir "en nombrar a algunos pintores y escultores caballeros de la Legión de Honor” (DELABORDE, 1891: 223).

\footnotetext{
${ }^{121}$ El Reglamento, sin embargo, estipula que tras la publicación de la concesión el interesado debía abonar cinco pesetas por derechos de expedición del diploma ("Reglamento...", 1871: 253).

122 A Francisco Torras y Armengol le fue concedida en 1873 (Gaceta de Madrid, 1873/29/01: 327).
} 
Esta condecoración se había configurado ya a comienzos de siglo como mérito indispensable en muchos retratos de artistas franceses, figurando en obras románticas como el Retrato de Pierre-Narcisse Guérin (ENSBA, París, no inv. MU 1509); sin embargo, es escasa su repercusión en territorio español hasta los años sesenta del siglo XIX, y su código de etiqueta evidencia una nota más urbana y modesta que la habitual acumulación de cruces y placas, ya que lejos del protocolo de corte se incluye, como nota colorida, en el ojal de la solapa de la chaqueta.

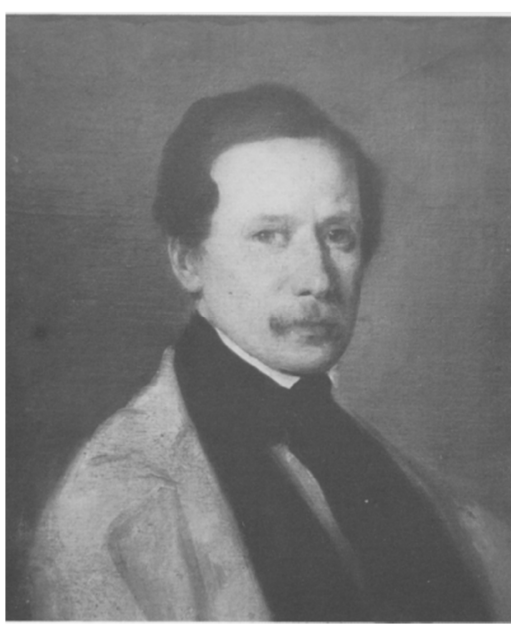

Fig. 56. Federico de Madrazo, Retrato de Jenaro Pérez Villaamil. (MNAM, 1943: $\mathrm{n}^{\circ}$ 256).

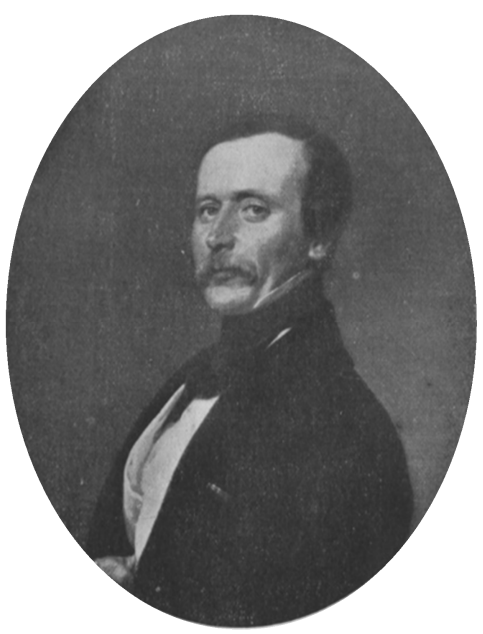

Fig. 57. Federico de Madrazo, Retrato de Jenaro Pérez Villaamil (ARIAS ANGLÉS 1986: 166).

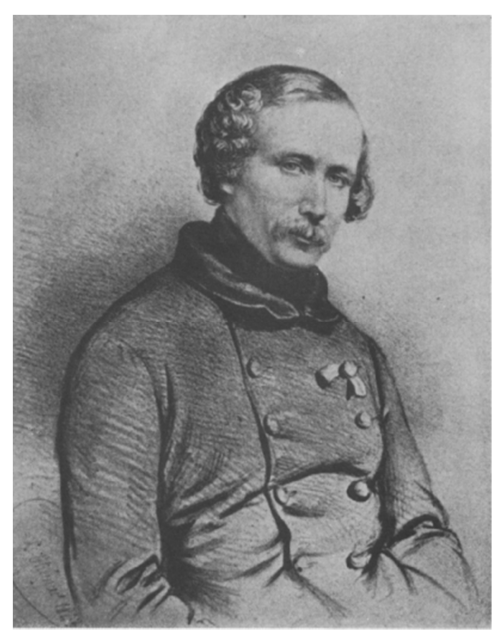

Fig. 58. Louis Ghémar, Retrato de Jenaro Pérez Villaamil, Biblioteca Real de Bélgica.

Curiosamente, frente a los retratos que Federico de Madrazo realizó de Jenaro Pérez Villaamil [figs. 56 y 57], carentes, como hemos visto, de ostentación, el retrato divulgado en la prensa extranjera del pintor sí que le muestra con la Legión de Honor que obtuvo por su medalla en el Salón de París de 1842. Así, en el retrato litográfico que le realiza Louis Ghémar [fig. 58] (Biblioteca Real de Bélgica, gabinete de estampas, S. II 22511) aparece el pintor sentado, con una mirada de complacencia y satisfacción, los extremos de la cinta asomando en el ojal de su chaqueta cerrada. Afianzada entre los artistas franceses como una muestra de reconocimiento público, se generaliza también entre los españoles con el componente añadido de tratarse del más importante reconocimiento extranjero al concederse con motivo de los premios en los salones oficiales parisinos. Siguiendo la costumbre francesa, los artistas españoles la llevarán en la chaqueta de su traje, sin acompañarse de otras distinciones, tal y como figura en los retratos de Eduardo Rosales (como el realizado por Federico de Madrazo, o el envarado retrato póstumo que pintó Sorolla para el Ateneo de Madrid), con su correspondiente escarapela roja por su medalla en la Exposición Universal de París en 1867.

Federico de Madrazo, que no se hizo representar con ninguna condecoración española, a pesar de haberlas recibido y llevado en sociedad, recibió en 1846 la concesión de la cruz de caballero de la Legión de Honor ${ }^{123}$, aunque no consta representado con ella hasta tres décadas más tarde. Es en 1875 cuando aparece retratado por su hijo Raimundo [fig. 59] (Museo de Bellas Artes de Bilbao, $n^{\circ}$ inv. 05/167) en

\footnotetext{
${ }^{123}$ AMP, AP16/exp. 2.
} 
actitud de pintar, y luciendo en la solapa el botón rojo de la Legión, de la que había sido nombrado oficial en $1860^{124}$, una condecoración de la que se sentía especialmente orgulloso y que lució tanto ante la aristocracia española como en el extranjero, quizás con más motivo habiéndose realizado el retrato en París. Debe señalarse la amargura con que se refería el propio Madrazo a la concesión indiscriminada de condecoraciones al dar noticia de una visita a Palacio para realizar los retratos de la Infanta Isabel y del conde de Girgenti el 5 de mayo de 1868:

Llevaba yo en el frac la roseta de oficial de la legión de honor y una placa, la de Gustavo de Suecia. Me preguntó el Infante qué condecoración era aquella y se lo dije; me preguntó después si no tenía yo condecoraciones españolas, y le contesté que tenía la Cruz de Caballero de Carlos III, que me había dado la Reina Gobernadora María Cristina hacia el año 40, y el Infante me manifestó su extrañeza al saber que no tenía yo la de comendador. Ahora bien, ¿no saben estos Sres. quiénes son los que han obtenido grandes cruces en estos últimos años? ¿no lo ven en la Guía de forasteros? (...) ¿No saben que nunca v.g. han sido los médicos más recompensados que los artistas y no ven que ahora hay en España bastantes médicos grandes cruces? ¿No saben que en Francia, en Inglaterra, en Alemania y en Italia han sido nombrados Barones muchos artistas y en Francia grandes oficiales de la Legión de honor y senadores? (GONZÁLEZ LÓPEZ y MARTÍ AYXELÁ, 1994).

Dos artistas españoles fueron condecorados con la Legión de Honor francesa en la Exposición Universal de 1889. El primero de ellos fue el propio Raimundo de Madrazo $^{125}$, quien ya había merecido el nombramiento de oficial en 1878, como revela Federico en su correspondencia ${ }^{126}$; en carta de 23 de julio de 1878 Federico de Madrazo se queja del escaso interés de los jurados españoles por asegurar honores a los pintores españoles, indicando a Raimundo la necesidad de que alguien pidiese por él la cruz de la Legión de Honor, felicitándole en octubre por "la distinción merecidísima que has recibido ${ }^{127,}$.

Influido sin duda por el trato con la alta sociedad francesa y por la alta estima que los artistas franceses tenían en mostrar este rasgo de distinción, aparece retratado en al menos dos ocasiones (en su Autorretrato [fig. 60] [Meadows Museum, $n^{\circ}$ inv. 73.01] y en el retrato que le realizó Joaquín Sorolla [Hispanic Society, Nueva York]) con el mismo distintivo en la solapa de su chaqueta.

\footnotetext{
${ }^{124}$ En 1878 se le concedería la Cruz de Comendador de la Legión de Honor por su participación en el homenaje a Fortuny en la Exposición Universal

${ }^{125}$ Carta de 3 de noviembre de 1889 (DÍEZ, 1994: 910).

126 "Si esos jurados españoles no fuesen unos mentecatos, debieron pedir para ti la cruz de la Legión de Honor, pero no lo harán, ni se les ocurrirá, si no se les dice: yo creo que deberías hacer que alguno, por ejemplo Ponte, indicase algo al que lleve la batuta" (DÍEZ, 1994: 778).

${ }^{127}$ Carta de 23 de octubre de 1878 (DÍEZ, 1994: 781).
} 


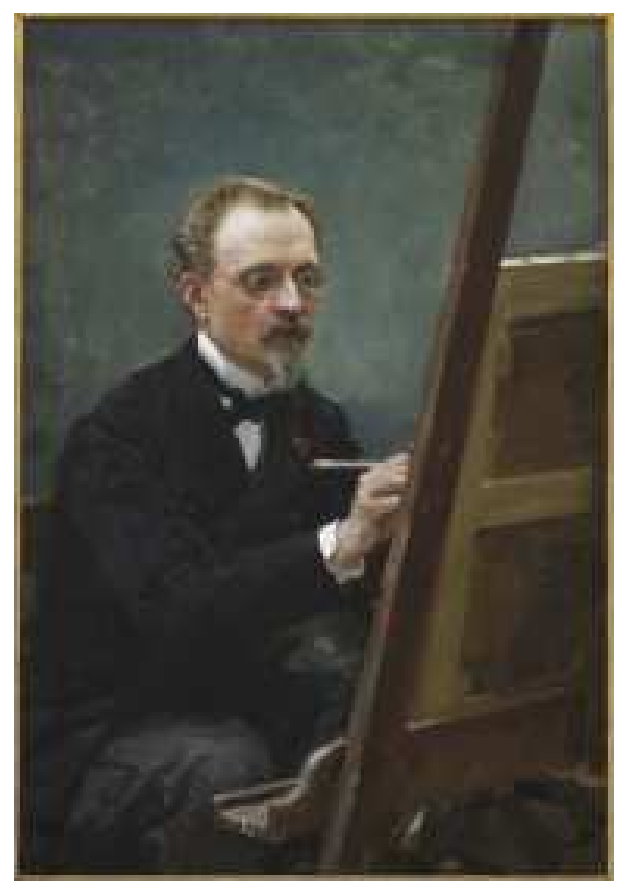

Fig. 59. Raimundo de Madrazo, Federico de Madrazo pintando. Museo de Bellas Artes de Bilbao.

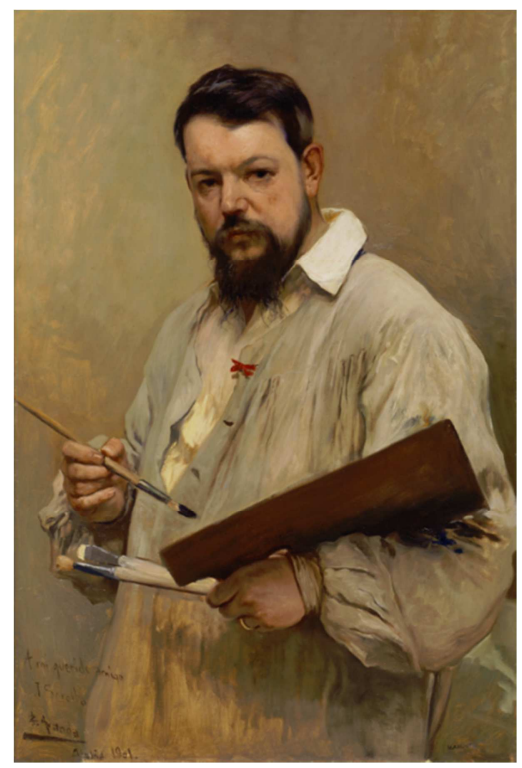

Fig. 61. Joaquín Sorolla, Autorretrato (detalle). Museo Nacional del Prado.

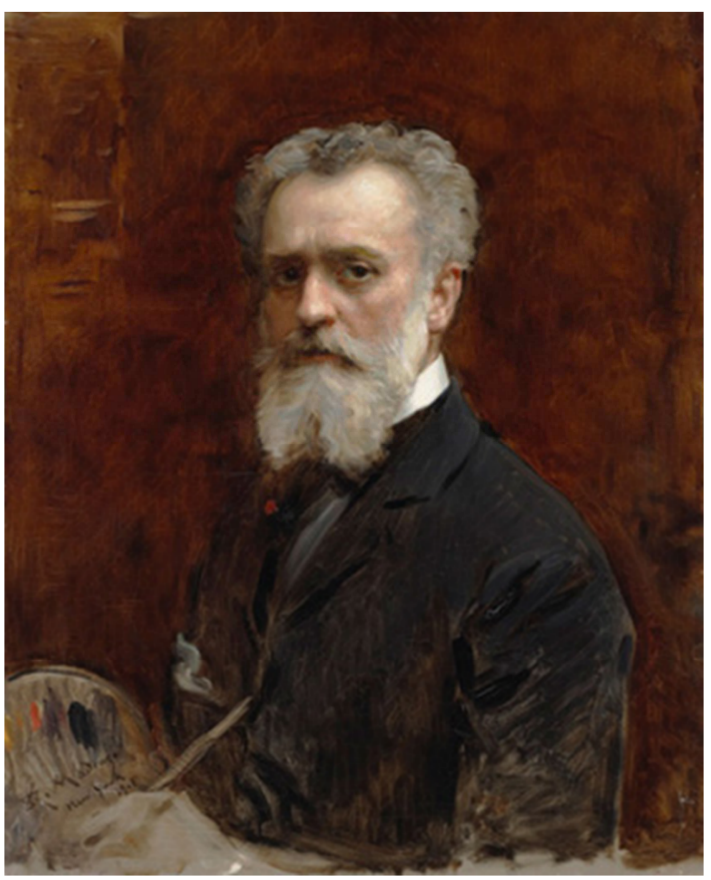

Fig. 60. Raimundo de Madrazo, Autorretrato. Meadows Museum, Dallas.

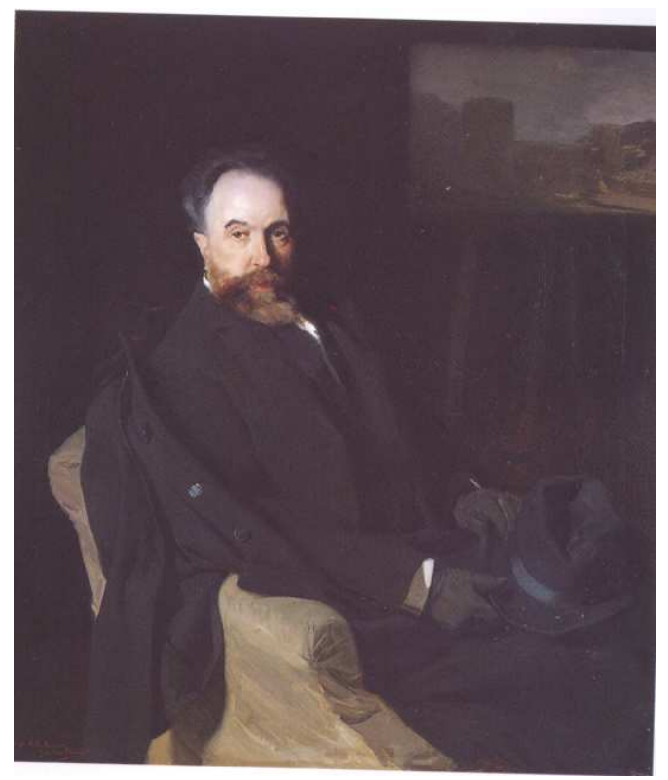

Fig. 62. Joaquín Sorolla, El pintor Aureliano Beruete (detalle). Museo Nacional del Prado.

Las imágenes de Raimundo no pueden desvincularse de la sociedad elegante con la que trató a lo largo de su vida, a pesar de mostrar una imagen del artista envejecido; se trata de representaciones que encajan con la estética de fin de siglo y con el carácter de una masculinidad vinculada a la alta sociedad, como ocurre también con el retrato que Salvador Martínez Cubells realizó del otro español galardonado en la Universal de 1889, el arquitecto Arturo Mélida, para el Ateneo de Madrid.

Otro pintor habituado al trato con la alta sociedad y caballero de la Legión de Honor fue Joaquín Sorolla, para quien la importancia de esta distinción queda de 
manifiesto en los retratos que realiza a comienzos del siglo XX. Su Autorretrato de 1901 [fig. 61] (Museo Nacional del Prado, $n^{\circ}$ inv. P04354) refleja la dualidad entre la identidad laboral, de la que el artista no desea desvincularse, y la imagen del mérito artístico y el reconocimiento social, incluyendo en su bata de trabajo el lazo de la orden francesa, de la que fue nombrado caballero en la Exposición Universal de 1901.

La imagen contrasta con la que ofrece de dos artistas contemporáneos, José Jiménez Aranda y Aureliano de Beruete, a los que plasma desplegando toda su elegancia y vinculados a su imagen pública; el retrato de Aureliano de Beruete [fig. 62] (Museo Nacional del Prado, $\mathrm{n}^{\mathrm{o}}$ inv. P04646) es significativo, ya que además de representar a un artista amigo se trata también de otro laureado en la Universal de 1901. Sin olvidarse de la identidad profesional del artista, a la que alude mediante un paisaje que, colocado sobre un caballete, se aprecia en el fondo de la composición, Sorolla muestra una imagen de Beruete como hombre acomodado y elegante, arropado en su abrigo negro, con los guantes aún puestos y sosteniendo su sombrero; la disposición de la figura, sentada y girada hacia la derecha, hace del botón de la Legión de Honor un punto prácticamente insinuado, que casi pasaría desapercibido de no formar parte de la diagonal que guía la composición. Por el contrario, y lejos de esta elegancia aristocrática, Sorolla opta por representarse con las manos desnudas y sosteniendo los útiles de trabajo, girado hacia la izquierda y haciendo bien visible su propia distinción.

\subsection{La inseguridad laboral frente a la imagen del éxito cultural}

\subsubsection{El artista como trabajador asalariado}

Si uno de los ejes de esta investigación se centra en la importancia de la identidad profesional del artista es debido a que la definición masculina está directamente relacionada con la estructura económica ${ }^{128}$; la estrecha relación existente entre el hombre artista, las relaciones familiares y las aspiraciones a una estabilidad económica puede rastrearse como una preocupación constante por parte de numerosos pintores españoles, dando cuenta de situaciones de precariedad e insatisfacción que, sin duda, afectaron a su propia percepción como hombres. Así se lo manifestaba Manuel Arbós a Federico de Madrazo en una carta, en la que le confesaba: "mi mujer en Roma me pide dinero para vivir y yo le he contestado que empeñe por el pronto algunos cubiertos que

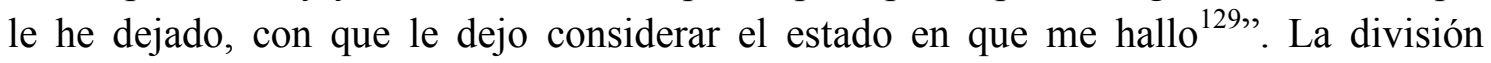
sexual del trabajo, a pesar del desarrollo industrial y de la importancia de la mujer obrera conlleva la percepción de un nuevo estereotipo masculino en la mediana y alta burguesía en que el hombre se constituye como el trabajador y proveedor para sí mismo y para su familia ${ }^{130}$, concentrando el poder capital que le otorga al mismo tiempo

\footnotetext{
${ }^{128}$ BADINTER, 1992: 726-727; CONNELL, 1995: 29; BARON, 2006: 143-160; ARESTI, 2010: 24.

${ }^{129}$ Carta de Manuel Arbós a Federico de Madrazo, fechada en 2 de septiembre de 1862. AMP, AP8/Exp. 14.

${ }^{130}$ Esto no excluye, sin embargo, que las ideas sobre la feminidad en el siglo XIX español no alentasen una cierta participación por parte de la mujer en el negocio de su marido, si bien desde un plano secundario basado en la modestia y en la moralidad católica (ARESTI, 2000: p. 369).
} 
la autoridad social y moral sobre las personas que dependen de él ${ }^{131}$. Este ideal de domesticidad se incorpora paulatinamente en el siglo XIX como fruto del desarrollo capitalista y de la moral burguesa, encontrándose entre sus características la imposición del rol laboral masculino y la separación de esferas: el lugar de trabajo deja de vincularse al propio hogar (TOSH, 1999: 17), si no siempre físicamente sí de manera simbólica, dando lugar por contraste a otro concepto de feminidad. Es en relación a este concepto del hombre como trabajador/proveedor en el que la identidad profesional conlleva una inseguridad o crisis masculina, señalada por Tosh de la siguiente forma:

Para el hombre de clase media el trabajo constituía asociaciones profundamente contradictorias: por un lado, el orgullo de ascender en la escala del éxito, de proveer para su familia y adquirir la estima de sus pares; por otro, el resentimiento por el tiempo y el duro trabajo requeridos, el miedo al fallo en las manos impersonales del mercado, y revulsión hacia la moral del mundo de los negocios (TOSH, 1999: 34).

Una afirmación que, por otra parte, ha sido retomada ampliamente en estudios sociológicos contemporáneos sobre el impacto del mercado laboral en la construcción de masculinidades, con un componente de crisis añadido a la pérdida de privilegio por el acceso de la mujer al ámbito laboral (BADINTER, 1992: 642).

En el mundo artístico la preocupación laboral del hombre artista puede percibirse a distintos niveles, siendo la causa fundamental de la creación romántica de una retórica del artista maldito o incomprendido cuya base no es otra que la inseguridad o rechazo respecto al sistema laboral y el precario equilibrio de la personalidad artística en el mercado económico, como señalan las idealistas palabras de Pedro de Madrazo en 1836:

Mientras dure la nobleza de las bellas artes no deben los artistas someterse a los favores de los que en la pobreza de sus almas sienten la prosperidad de aquellas agitarse encerrada en sus bolsillos, como la felicidad de un artesano justamente valuada por el precio de sus obras. Repito que la protección que a las bellas artes se debe es de justicia, y que no es lícito al potentado el considerarse como árbitro poseedor y disponedor del genio del artista (MADRAZO, [P.], 1836: 51).

La dependencia de encargos -más o menos puntuales- llevó también al artista a la necesidad de incluirse en el orden económico del trabajo asalariado, lo que se traduce en el codiciado acceso a puestos relacionados con las instituciones públicas -el amparo laboral como pintor de cámara- o educativas -en las Academias de Bellas Artes y escuelas de dibujo. La relación institución/trabajo artístico/salario no fue siempre satisfactoria; en el ámbito de Palacio el goce de sueldo no se vio igualmente reconocido, puesto que algunos pintores de cámara debieron esperar a que su nombramiento se viese respaldado por el goce efectivo de sueldo, como sucedió en el caso de Federico de Madrazo: José de Madrazo se alegraba en comunicar a su hijo Federico su nombramiento como pintor de cámara supernumerario "con opción al goce de sueldo en

\footnotetext{
${ }^{131}$ Estrella de Diego recoge algunas de las preocupaciones (masculinas) de pensadores españoles del siglo XIX ante la posibilidad de que la mujer se emancipase del espacio doméstico para perseguir una carrera laboral o científica (DE DIEGO, 2009: 169-170, 183).
} 
la primera vacante que quede" (DÍEZ, 1998a: 25), algo que el pintor recordará, no sin amargura, en sus memorias. El hecho de que en 1832 Manuel Álvarez Bouquel solicitase auxilio económico a la Academia de San Fernando recordando la pensión vitalicia que el rey había concedido a su difunto padre muestra la precariedad en el mantenimiento familiar ${ }^{132}$. También son conocidas las dificultades que los artistas empleados en la Academia tuvieron en la reclamación de sus salarios. Esperanza Navarrete señala la inexistencia de una asignación fija para los artistas profesores al menos hasta 1817 (NAVARRETE, 1999: 63) a raíz de una petición de aumentar los escasos salarios de los miembros de la Academia elevada al infante Carlos María Isidro de Borbón ${ }^{133}$, y aun así los problemas posteriores con los salarios fueron continua fuente de preocupación para los mismos.

Es el caso de Asensio Juliá, quien en 1821 se vio necesitado de solicitar a la Academia un certificado de los sueldos que se le debían ante una reclamación de su casero $^{134}$. Juliá había entrado en 1818 a trabajar como profesor de dibujo en las escuelas menores (GIL SALINAS, 1991: 60; GIL SALINAS, 1986: 81), pero las actas de la Academia reflejan que sus necesidades económicas eran acuciantes; en 1825 solicitó un aumento salarial como director de la sala de adorno del Estudio de la Merced, atendiendo al sueldo que había cobrado anteriormente Juan Gálvez ${ }^{135}$. Ante la última imagen conocida de Asensio Juliá, su retrato de 1814 por Goya (Sterling and Francine Clark Inst.), en que se nos presenta la imagen del colaborador del artista a sus cincuenta y cuatro años, vestido pulcramente a la moda burguesa y con un llamativo sombrero de copa, se plantean dudas sobre el estatus económico de Juliá en este momento, en que según Gil Salinas y Alba Pagán se encontraba adaptado en el círculo de artistas valencianos afincados en Madrid y trabajando realizando copias en el taller de Goya (ALBA PAGÁN, 2004: 60). El posicionamiento político de Juliá durante la Guerra de Independencia y su trabajo, próximo al de Goya, pintando composiciones bélicas sobre la brutalidad ejercida en el territorio español y retratos de los héroes del momento, pudo haber influido en su economía, aunque parece más posible que se debiese a su trabajo como dibujante y a su simpatía con los tipos populares, así como su posicionamiento liberal en 1821 y su negativa a solicitar una carta de depuración en $1824^{136}$, tuvieron malas consecuencias para la mermada economía de un artista ya anciano. También causa política tuvo la solicitud del pintor Francisco Mena, que había sido ayudante

\footnotetext{
${ }^{132}$ Junta Particular de 16 de diciembre de 1832, ARABASF, Secretario general, Libro de actas de sesiones particulares (3-127), f. 62. En adelante se empleará únicamente la signatura para elementos procedentes de la misma sección de archivo.

${ }_{133}$ Junta Particular de 20 de septiembre de 1816, ARABASF (3-127), f. 124r.

${ }^{134}$ Sesión Ordinaria de 2 de diciembre de 1821, ARABASF (3-88), fol. $70 \mathrm{v}$.

${ }_{135}$ Asensio Juliá, que percibía 3000 reales anuales, solicitaba se aumentase a 6000 , consiguiendo únicamente un aumento de 1500 reales (Sesión Ordinaria de 20 de febrero de 1825, ARABASF (3-88), fol. 120), y rectificándose posteriormente a un total de 5000 reales anuales "como dotación del director propietario que es o fuese de la sala de adorno de la Merced supuesta su purificación y las demás circunstancias de buena conducta y sanos principios prevenidos por reales órdenes y acuerdos de la Academia" (Sesión Ordinaria de 20 de marzo de 1825, ARABASF [3-88], fol. 122).

${ }^{136}$ Ester Alba Pagán señala que probablemente Juliá se retirase en 1823 debido a las consecuencias de la depuración política; sin embargo, los datos de las actas de la Academia de San Fernando señalan que continuaba en activo en 1825, nuevamente descontento con el salario que le había sido asignado (ALBA PAGÁN, 2004: 141).
} 
suplente en los estudios de la Academia, de ser colocado en alguna plaza vacante que quedase en los mismos debido a las penurias sufridas tras haber pasado dos años en prisión acusado de conspiración ${ }^{137}$.

Otros profesores se vieron también en problemas económicos; de este modo, los suplentes de los estudios de la Academia, Carlos Blanco y Antonio Delgado, solicitaron a la misma no ya un aumento, sino una gratificación por su asistencia diaria, con el resultado de que la Academia estimó que esta asistencia no era precisa y desestimaba por tanto la petición, acordando sin embargo darles un aguinaldo navideño ${ }^{138}$. La situación económica de Carlos Blanco le llevó, algunos años más tarde y continuando en su empleo como profesor de pintura en el estudio de la calle Fuencarral, a solicitar el título de académico de mérito siendo eximido de toda prueba, alegando no poder soportar los gastos $^{139}$, e incluso a solicitar el título de pintor de cámara ${ }^{140}$. Una situación que no mejoró en 1826, año en que se produce una queja por parte de los profesores de la Academia, que reclamaban se igualase su sueldo al del resto de dependientes para poder así cobrar los atrasos que se les adeudaban ${ }^{141}$.

Tal vez fuese la necesidad de un sueldo fijo lo que movió a Antonio María Esquivel a saltarse los protocolos establecidos y solicitar directamente a Palacio en 1833 la concesión del nombramiento de director de pintura de la Escuela de Sevilla, a lo que la Academia de San Fernando, enterada del caso, respondió negativamente por tratarse de una solicitud improcedente "no habiendo muerto el director de la dicha escuela D. José Cortés", y avisando de que en caso de producirse una vacante "habría tal vez otros opositores cuyo particular mérito tiene ya reconocido la Academia ${ }^{142 \%}$.

El problema del salario fue también el que inclinó la balanza en 1834 para cubrir la plaza de director del estudio de la calle Fuencarral; ante la duda entre los dos profesores candidatos, Juan Antonio de Ribera y José de Madrazo, la Academia optó por el primero, a pesar de la mayor antigüedad de Madrazo, por haber desempeñado el cargo de teniente en las salas del natural y del yeso sin retribución alguna, mientras se alegaba que Madrazo gozaba de mayor consideración por su cargo en la clase del colorido " $\mathrm{y}$ por el mayor sueldo que por ella disfruta del Gobierno ${ }^{143}$ ". El ascenso de José de Madrazo a director de la Academia también generó dudas sobre si este debía cobrar nuevo sueldo siendo al tiempo profesor de colorido. La nueva plaza suponía un sueldo de 6000 reales, y la secretaría de la Academia comunicaba sus reticencias sobre "si la contaduría del Ministerio se los abonaría en nómina, en razón de gozar de otros 1500 más como Director del Colorido", ante lo cual el propio Ministerio se pronunciaba manifestando no haber incompatibilidad en el cobro de ambos sueldos ${ }^{144}$. Además, Madrazo fue incluido en nómina en 1841 como director de la sala del natural,

\footnotetext{
137 Sesión Ordinaria de 20 de abril de 1826, ARABASF (3-88), fol. 143.

${ }^{138}$ Sesión Ordinaria de 27 de noviembre de 1825, ARABASF (3-88), fol. 137r. y v.

139 Sesión Ordinaria de 21 de julio de 1833, ARABASF (3-89), fol. 81v.

140 Sesión Ordinaria de 25 de agosto de 1833, ARABASF (3-89), fol. 85v.

${ }^{141}$ Sesión Ordinaria de 16 de julio de 1826, ARABASF (3-88), fol. 149r.

${ }^{142}$ Sesión Ordinaria de 10 de octubre de 1833, ARABASF (3-89), fol. 68v,.

${ }^{143}$ Sesión Ordinaria de 12 de octubre de 1834, ARABASF (3-89), fol. 115 r. y v.

${ }^{144}$ Sesión Ordinaria de 9 de diciembre de 1838, ARABASF (3-89), fol. 245 v.
} 
obteniendo una nueva dotación de 6000 reales $^{145}$. Por otra parte, los retrasos en los pagos motivaron quejas en otras instituciones, como en el caso de la Academia de Nobles Artes de Cádiz, donde Manuel Fernández Cruzado reclamó respecto a la irregularidad que afectaba al cobro de los salarios, siendo curiosa la elección semántica en su protesta: para él, el artista y el trabajador vinculado a la Escuela eran trabajadores de pleno derecho y no "simples autómatas" o "infelices criados" (BANDA Y VARGAS, 1983: 13).

En 1843 los grabadores Félix Sagán y Rafael Esteve hicieron llegar al Ministerio de su descontento respecto a su consideración y sueldo; la solicitud no era una novedad, puesto que en 1816 los directores de grabado Manuel Salvador Carmona y Félix Sagán solicitaron al infante Carlos María se igualase su consideración y sueldo al de otros profesores. Entre sus peticiones se encontraba el derecho a sentarse inmediatamente al lado de los tenientes directores, que sus prerrogativas fueran las mismas que las de los directores de arquitectura, escultura y pintura, y que se les igualase el sueldo al que gozaban los mismos directores ${ }^{146}$. Si bien la Academia se mostró tajante respecto a lo primero, haciendo notar que el grabado no se contaba entre las tres nobles artes sino como dependiente de estas, aunque accedía a subir la retribución de los directores de grabado "proponiendo que además de la dotación que actualmente disfrutan se aumente aquella hasta la de teniente, siempre que tengan discípulos ${ }^{147}$, .

La reforma de los estudios en 1845 estableció una plantilla de profesores artistas, si bien los desajustes salariales continuaron siendo una fuente de descontento. En 1846, para cubrir la plaza de teniente director del estudio de la calle Fuencarral vacante tras la muerte de Bartolomé Montalvo, José Castelaro y Perea se presentó -con el respaldo de la Academia - a la misma, proponiendo al Gobierno "el aumento de quinientos reales sobre los tres mil que gozaba, dándose de menos al último de los ayudantes que hubiera de nombrarse ${ }^{148}$,, a lo que accedió la Junta de Gobierno. Sin embargo, los atrasos producidos en el pago de las nóminas y la disminución de algunos sueldos causaron notable intranquilidad entre los profesores, especialmente cuando al hacer las consultas pertinentes recibieron por respuesta un recordatorio de la reciente ley de presupuestos de 20 de marzo de 1846, que prohibía abonos por cuenta de atrasos, instándoles a esperar a que se resolviese el expediente gubernamental ${ }^{149}$. Las noticias posteriores no aclaran si los profesores de las escuelas dependientes de la Academia cobraron sus atrasos; en el caso de José San Martín, ayudante en el estudio de la Trinidad, se le pagaron en 1849 tres mensualidades que se le adeudaban, pero únicamente con motivo de ayudar a "atender los gastos que le ocasionaba la grave y dilatada enfermedad que

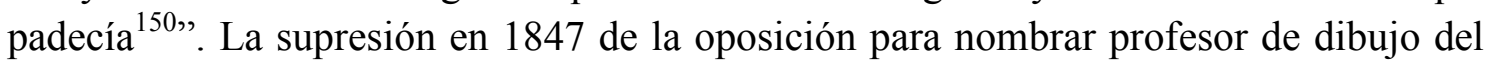

\footnotetext{
145 Sesión Ordinaria de 25 de abril de 1841, ARABASF (3-90), fol. 51v.

${ }^{146}$ Junta Particular de 9 de agosto de 1816, ARABASF (3-127), fol. 117r.

${ }^{147}$ Sesión Ordinaria de 18 de mayo de 1842, ARABASF (3-90), fols. 88v. y 89r.

${ }^{148}$ Sesión Ordinaria de 6 de septiembre de 1846, ARABASF (3-90), fol. $218 \mathrm{r}$.

149 "Que las reclamaciones de los profesores y empleados, que cobraban en las nóminas de la Academia por concepto de atrasos, esperen el resultado del expediente general que se sigue sobre este asunto" Sesión Ordinaria de 12 de julio de 1846, ARABASF (3-90), fol. 210r.

${ }^{150}$ Sesión Ordinaria de 11 de noviembre de 1849, ARABASF (3-91), fol. 37 r. y v.
} 
natural, favoreciendo a la pretensión de Juan Antonio de Ribera ${ }^{151}$ a la misma da idea igualmente del caos al que se enfrentaban los artistas para satisfacer sus aspiraciones laborales, y de las desigualdades económicas existentes entre los distintos profesores. No se produce un aumento de los sueldos hasta 1854, sumándose 3000 reales anuales a los sueldos previos de los directores de cada una de las tres nobles artes, 3000 al catedrático de Anatomía Pictórica, 1000 a los ayudantes y 400 a los "mozos de oficio dependientes de los estudios ${ }^{152}$ ". El proyecto para proveer plazas vacantes de profesores elaborado por la Academia de San Fernando precisaba la necesidad de que estos fuesen académicos de la misma o algunos de sus discípulos más adelantados, "cobrando 6000 reales anuales con la obligación de desempeñar la clase que la Academia les confíe aumentando a los 6000 reales hasta cubrir la dotación que tenga la clase que se les asigne $^{153}$ ". En el caso de los grabadores en hueco y en dulce habría que esperar hasta 1855 para que se realizase una propuesta de aumento de sueldo en comparación al resto de profesores, solicitándose así que fuera de 12000 reales $^{154}$, aunque no parece que se tomasen medidas al respecto.

El profesor de perspectiva y paisaje de la Academia de Sevilla, Manuel Barrón, elevó en 1855 una solicitud de aumento de sueldo, ya que los 6000 reales anuales que cobraba no se ajustaban al salario establecido para las cátedras de estudios superiores (8000 reales), ocasión que los profesores y académicos aprovecharon para elevar a su vez una solicitud al gobierno recordando la precaria situación de algunos profesores de los estudios superiores de pintura en Madrid, señalando en concreto a los profesores agregados, a los de perspectiva y a los de grabado en dulce y en hueco, enseñanzas "todas las cuales gozan solo la escasa dotación de seis mil reales ${ }^{155}$ ". La remuneración debe entenderse escasa, en comparación con los 18000 reales anuales que se concedieron a Fernando Ferrant como profesor de dibujo de paisaje en la Academia y en la Escuela de Caminos y Minas ${ }^{156}$, o en comparación con los profesores ayudantes (o agregados) de la Escuela Especial de Arquitectura, que percibían sus correspondientes 8000 reales $^{157}$. Sin embargo, los sueldos siguieron sin actualizarse el año siguiente, como se desprende de la solicitud realizada por Francisco Mena, profesor ayudante en el estudio de Santa Catalina, quien acogiéndose a lo resuelto por la Academia demandaba que su sueldo de 4000 reales viese el incremento de los 2000 restantes, estando en ello conforme la Academia de San Fernando y resolviendo que la misma medida se aplicase al sueldo de otro profesor ayudante de los estudios menores ${ }^{158}$.

La existencia de interinos no remunerados parece señalar que, a pesar de los incrementos salariales y buenos propósitos de la Academia, la realidad de algunos trabajadores era bastante precaria; en su solicitud de la Cátedra de Perspectiva, que

\footnotetext{
${ }^{151}$ R.O. de 2 de junio de 1847. Sesión Ordinaria de 4 de julio de 1847, ARABASF (3-90), fol. 245r. y v.

${ }^{152}$ Sesión Ordinaria de 5 de febrero de 1854, Libro de actas..., ARABASF, fol. 240v. y $241 \mathrm{r}$.

${ }^{153}$ Sesión Ordinaria de 9 de julio de 1854, ARABASF (3-91), fol. 272r.

154 Sesión Ordinaria de 11 de marzo de 1855, ARABASF (3-92), fol. 10v.

155 Sesión Ordinaria de 28 de agosto de 1855, ARABASF (3-92), fol. 47r.

${ }^{156}$ R.O. de 10 de agosto de 1855 ("Ministerio de Fomento", 1855: 1; Sesión Ordinaria de 28 de agosto de 1855, ARABASF [3-92], fol. 44r.).

${ }_{157}^{157}$ Sesión Ordinaria de 4 de septiembre de 1853, ARABASF (3-91), fol. 209r.

${ }^{158}$ Sesión Ordinaria de 7 de diciembre de 1856, ARABASF (3-92), fol. 103r.
} 
había desempeñado su padre hasta su fallecimiento, Patricio Rodríguez expone haber enseñado en ella de manera gratuita durante catorce años, y haber realizado la pertinente oposición $^{159}$; del mismo modo, Ginés Noguera exponía estar desempeñando la clase de antiguo y de ropajes de manera gratuita en la Academia de Granada, motivo por el cual solicitaba el título y categoría -y presumiblemente también el salario correspondientede profesor de los estudios superiores ${ }^{160}$.

En el informe de modificaciones de sueldos realizado por Paris, Coromina y Rodríguez en 1856 se exponía la conveniencia de que solo hubiese tres directores y tres tenientes directores por cada arte, cambiando la denominación de los profesores de los estudios menores, proponiendo los siguientes sueldos: de 18000 reales para los directores y tenientes directores, de 12000 para los profesores de estudios superiores o de estudios comunes a varias artes, de 8000 para los directores en los estudios menores (con la opción a 1000 reales más el de mayor antigüedad), de 6000 los de aritmética y geometría, y de 4000 los profesores de estudios elementales. A pesar de este informe, la Academia de San Fernando se desvinculó de los asuntos correspondientes a las Escuelas Especiales y su personal, dejando a estas depender directamente del Ministerio de Fomento, que en el Real Decreto aprobado en 7 de octubre de 1857 por Claudio Moyano relativo al reglamento provisional de la Escuela Superior de Pintura, Escultura y Grabado, señalaba las plazas del personal de la misma y su dotación. Las tareas administrativas del director de la escuela, en caso de recaer sobre un profesor, serían remuneradas con una dotación anual de 30000 reales, y las de secretario, que sería siempre un profesor, con un aumento de 2000 reales sobre el sueldo estipulado a su plaza docente. El de cada uno de los siete profesores numerarios correspondía a 16000 reales, con la consideración de catedráticos de enseñanza superior, y el de cada uno de los seis supernumerarios a 8000 reales, al igual que sucedía con los profesores de estudios elementales de mayor antigüedad, mientras los de recién incorporación solo percibían 6000 reales. Las diferencias existentes en los estudios superiores entre profesores numerarios y supernumerarios dependían fundamentalmente del éxito de la carrera artística en el caso de los primeros, al ser plazas provistas por el Gobierno a partir de una terna elegida por el Consejo de Instrucción Pública y de la Real Academia de San Fernando, mientras que las de profesor supernumerario serían provistas por oposición, por terna o entre los artistas que hubiesen gozado de una pensión en Roma alcanzada por oposición ("Reglamento provisional...", 1857: 1 y 2). El decreto de 5 de mayo de 1871 establecía un aumento de sueldo para los profesores de las Escuelas especiales de 500 pesetas por razón de antigüedad cada cinco años, estableciendo el sueldo de los once profesores de número en 4000 pesetas al suprimir la clase de supernumerarios y cambiando el sistema de oposición para las vacantes en la Escuela de Pintura, Escultura y Grabado ${ }^{161}$; las plazas de ayudante, de las que nada se menciona en

\footnotetext{
${ }^{159}$ Sesión Ordinaria de 7 de enero de 1855, ARABASF (3-92), fol. 2v.

${ }^{160}$ Sesión Ordinaria de 19 de julio de 1855, ARABASF 3-92), fol. 43r.

161 "En la de Pintura, Escultura y Grabado, de cada tres vacantes una [se proveerá] por oposición, otra por concurso entre los artistas a cuya especialidad corresponda la vacante, que hayan obtenido premios en Exposición nacional o universal, y la tercera también por concurso entre los Profesores que han
} 
el decreto ni en el reglamento de la Escuela, aparecen nuevamente en 1881, con una dotación de 2000 pesetas ("Dirección general...", 1881: 434; "Dirección general...", 1886: 845). La modificación del reglamento en 1893 introdujo escasos cambios en los salarios de los profesores artistas, sumándose 500 pesetas más al sueldo de los profesores catedráticos en razón de residencia; respecto a los profesores auxiliares, tan solo gozarían un aumento de sueldo en el caso de desempeñar una cátedra vacante, teniendo opción a disfrutar de dos tercios del sueldo de profesor catedrático, si bien vuelve a incorporarse la figura del auxiliar no remunerado ("Reglamento...", 1893: 938).

La percepción hacia otros trabajos artísticos asalariados reviste no menos dificultades económicas, pero en ocasiones sí que una mayor percepción crítica al no estar vinculada a la enseñanza. La vinculación de las artes gráficas con el mundo del comercio dio pie a que la percepción de algunos artistas, inicialmente dedicados a la pintura, entrañase una supuesta pérdida de masculinidad y de libertad creativa al renunciar en cierto modo a la aspiración al privilegio social y cultural del arte oficial para enfocar su trabajo hacia la subsistencia económica, lo cual lo aleja, en cierta medida, de la posibilidad de adquirir rápidamente una posición de privilegio en el mercado. Al hablar en 1894 de Daniel Urrabieta, Morin reflexiona sobre el papel eminentemente económico que tiene la ilustración, comparando al artista que se dedica a ella con un esclavo de su voluntad de recibir un beneficio inmediato, siendo dependiente de un editor que dé el beneplácito a sus trabajos. Entre los problemas que reviste el arte de la ilustración, que Morin vincula directamente con las estructuras del trabajo de la sociedad industrial, se encuentra precisamente la descalificación del arte como objeto y producto de la élite cultural, estando ahora vinculado con la clase media y sus necesidades económicas. Sin embargo, su reflexión es aplicable al arte de consumo, y pone de manifiesto el problema al que se encuentra expuesto el artista o pintor no asalariado, ya que la venta de obra, salvo en encargos puntuales, es incierta, y el mercado económico contemporáneo demasiado invasivo para pretender que el desembolso esporádico de una cantidad en concepto de venta sea una forma de vida adecuada a los requisitos e imposiciones -especialmente familiares- que recaen sobre en artista como hombre:

La venta de una pintura es incierta; ¿cómo tener el coraje de comerse su pan en seco mientras espera los mil quinientos o dos mil francos que tanto se harán esperar, cuando basta con pasarse un día y una noche para satisfacer al editor apurado y obtener de él el pan de cada día? (MORIN, 1894: 96)

De este modo, la incapacidad del artista por negociar su realidad económica y su papel de proveedor puede suponer, para el artista decimonónico, una fuente de preocupación laboral y personal que revela las raíces de una crisis masculina. 


\subsubsection{Preocupación laboral y ámbito familiar}

El acceso a puestos públicos, tanto en establecimientos de enseñanza superior como de enseñanza media, refleja las aspiraciones de numerosos artistas que además del acceso a la élite cultural buscaban paliar los posibles efectos socialmente adversos de una actitud masculina atípica cumpliendo fielmente con la imagen de ciudadano, hombre de bien, buen esposo y proveedor familiar inculcados desde la infancia. La asimilación de los valores de domesticidad son especialmente visibles en las memorias de Federico de Madrazo respecto a su infancia, plasmando una imagen de su padre como patriarca de una familia que aún no se ajusta al prototipo nuclear de familia burguesa; la preocupación de José de Madrazo por su rol de proveedor es reflejada tempranamente y de manera indirecta a través del relato de viaje de George Ticknor, en que el americano reflexiona sobre el "pobre Madrazo" quien, a su regreso a España en 1818 abandonaba la estabilidad económica encontrada en Italia ${ }^{162}$ a cambio de la incertidumbre en su propia patria. El caso de José de Madrazo es paradigmático al reflejar cómo la carrera laboral exitosa se torna progresivamente en una obsesión melancólica al monopolizar sus atenciones, tal y como recogía Tosh respecto a las crisis masculinas del hombre trabajador. El aumento de obligaciones laborales como pintor de cámara, profesor de la Reina, profesor de la Academia y director del Museo Real se transmite a través de la correspondencia de José de Madrazo como un progresivo desencanto que será frecuente en otros artistas; de este modo, frente al orgullo por el lugar alcanzado en la sociedad como artista reputado y orgulloso de sus méritos que refleja en su Autorretrato, se destila una preocupación propia del hombre trabajador continuamente ausente del hogar, melancólico respecto al consuelo que podría ofrecerle la vida familiar -sentimiento evocado en su correspondencia y mitigado a través del retrato de los miembros de la familia ${ }^{163}$-, y que se acentúa con la aproximación de la vejez.

El Autorretrato de Antonio María Esquivel con su esposa de 1827 [fig. 63] (en paradero desconocido) puede enmarcarse también dentro del reconocimiento por parte del autor de su nuevo rol masculino. La imagen del matrimonio en un interior es altamente elocuente, ya que el retrato de Antonia Rivas domina la composición y la presenta elegantemente vestida y en actitud relajada, mientras el joven pintor, que se asoma en el extremo derecho ataviado de manera más sencilla y con largas patillas a la moda, aparece parapetado tras su mesa en pleno trabajo. En el retrato Esquivel asume un papel aparentemente secundario por el protagonismo de su esposa; el tratamiento de la escena, sin embargo, es interesante al presentarse el pintor no solo en contemplación de su mujer y de sí mismo, sino revestido de la supuesta independencia y poder -quizá

\footnotetext{
162 “(...) nunca perdimos nuesta alegría y buen humor, aunque el pobre Madrazo, que había salido de su país siendo muy joven y había vivido fuera de él durante diecisieta años, a veces sentía que se le encogía el corazón al pensar que había abandonado unos ingresos de tres o cuatro mil al año para volver y reinstalarse aquí por segunda vez", recogido en DU GUÉ TRAPIER, 1932: 18.

${ }^{163}$ De este modo, en su relato melancólico José de Madrazo (en el que expresa el profundo dolor de verse privado de sus hijos) solicita continuamente a Federico su pronto regreso a Madrid, así como la realización de los retratos de sus hijos, de su esposa e incluso el del propio Federico "para colocarle en mi despacho" (DÍEZ, 1998a: 167, 132-133, 16, 208).
} 
no tanto económico como visual- que le otorga el trabajo, en este caso dentro del espacio doméstico, y que constituirá una parte central de sus posteriores representaciones familiares. En la biografía que El Museo de las Familias le dedica se destaca, no sin cierto toque moralista, en el carácter de proveedor de Esquivel con respecto a su recién creada familia, vinculando su producción rápida vinculada al comercio con un afán de mejorar su situación económica ${ }^{164}$, mientras que la nota necrológica publicada por El Museo Universal señala su matrimonio y vida familiar como un lastre en su carrera artística debido, precisamente, a la necesidad de velar por la subsistencia de sus allegados ${ }^{165}$, algo que tampoco pasa desapercibido en las noticias recogidas en 1839 con motivo de la ceguera del pintor, al que se denomina sin más ambages "desgraciado padre de familia" (ANÓNIMO, 1839: 4).

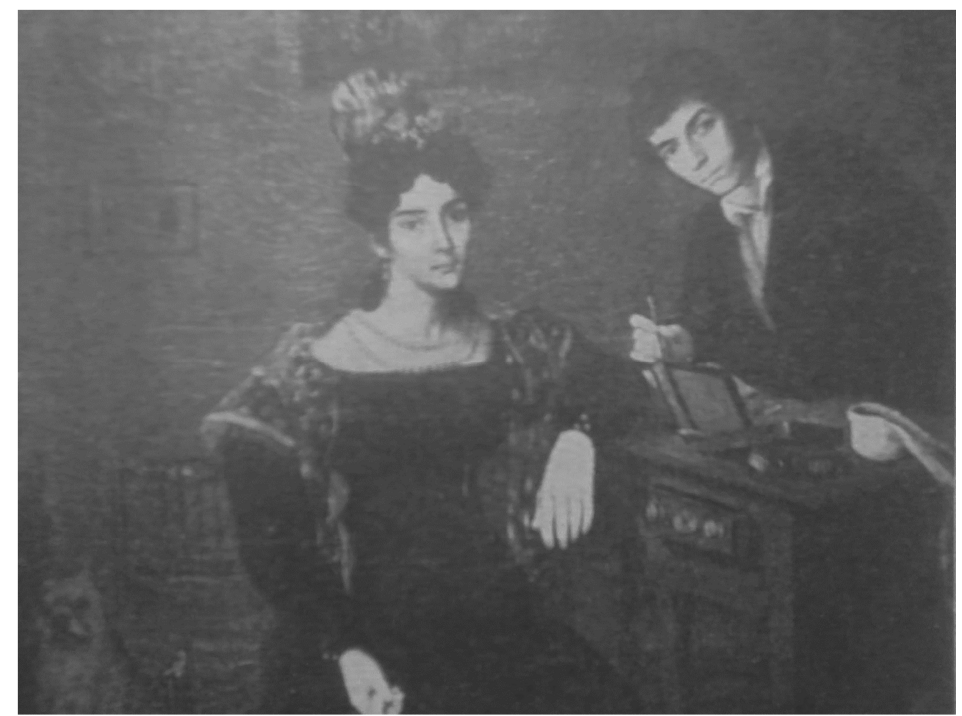

Fig. 63. Antonio M. Esquivel, Autorretrato con su esposa (detalle). Paradero desconocido.

No deja de ser curioso el caso de Federico de Madrazo, quien realizando los trámites para su enlace matrimonial con Luisa Garreta a sus veintiún años y hablando de las asignaciones y dotes correspondientes, se muestra ofendido por el tratamiento con que su futura suegra opina sobre su profesión, "que es el único y mejor considerado caudal del hombre", y añade no sin cierta vanidad que además de la asignación que le destine su padre él mismo dispone de "el dinero que he ganado desde mi venida de París, que son unos dos mil doscientos cincuenta duros poco más o menos ${ }^{166 "}$. Los

\footnotetext{
164 “A la edad de 21 años casó con doña Antonia Rivas, señora de bellísimo trato y de distinguida familia; siguió algunos años más viviendo en Sevilla y pintando prófuga y rápidamente cuadros que vendía a los chalanes de Sevilla y a los particulares, y continuó de este modo algunos años, hasta que intentó trasladarse a Madrid en compañía de su amigo don José Gutiérrez; pero no hallándose con recursos para emprender este viaje, y no queriendo por otra parte dejar a su familia aislada y sin medios, desistió por entonces de este proyecto" (VILLANUEVA, 1844: 92).

165 "A su vuelta continuó su vida artística, en la cual en breve se habría puesto al nivel de los pintores más eminentes, si habiéndose casado a los veintiún años no hubiera tenido muchas veces que posponer el estudio a trabajos poco instructivos, pero que le facilitaban los medios de subsistencia de que carecía" (ANÓNIMO, 1857: 54).

166 "Por lo tocante a la propuesta en cierto modo ofensiva de tu Mamá sobre lo que Papá tenga a bien asignarme, te debo advertir que es muy de extrañar su conducta y su consideración hacia mi profesión, que es el único y mejor considerado caudal del hombre (...) De todos modos ya le diré a Papá lo que
} 
recursos económicos de Federico de Madrazo no fueron un gran problema para el comienzo de su vida familiar, de tal modo que pasó a París y a Roma con una pensión de 12000 reales anuales que, según sus propias palabras, tardaron en pagarle incluso tras su regreso a España (GONZÁLEZ LÓPEZy MARTÍ AYXELÁ, 1994: 65). Los cargos públicos de Federico de Madrazo minaron, como ocurrió en el caso de su padre, su orgullo profesional, algo de lo que deja constancia en varias ocasiones en sus memorias, siendo quizás la que sigue la nota más expresiva de esta amargura:

Todo fue un sueño -sueño la pintura mural, sueño las grandes composiciones, los cuadros de altar sueño... y sin embargo quería seguir soñando, engañándome, porque la esperanza es lo último que se pierde. Se me figuraba siempre poder llegar a conseguir algo de lo que tanto deseaba. Pero la realidad, la triste realidad para mí, han sido los prosaicos retratos con su acompañamiento de bordados, bandas y cruces, las ridículas modas, la realidad para mí han sido los repetidos y abundantes disgustos de todos los géneros ${ }^{167}$ (GONZÁLEZ LÓPEZ y MARTí AYXELÁ, 1994: 69).

El planteamiento sobre sus preocupaciones económicas se alejan del aparente optimismo con que otros artistas, y quizá él mismo, podrían percibir lo que sin duda era una carrera exitosa. Su sueldo inicial como profesor en la Escuela de Pintura debía compaginarse con la realización de retratos para sacar adelante a su numerosa familia; el goce de sueldo como pintor de cámara, que comenzó a disfrutar en 1850, le suponía escasos beneficios por la cantidad de obras que debía realizar, tal y como hizo conocer al ministro de Hacienda a quien comunicaba que "resultará ineludible retribuir mis obras de artista porque de lo contrario habrá que reconocer que el empleo de Pintor de Cámara era un verdadero castigo" (GONZÁLEZ LÓPEZ y MARTÍ AYXELÁ, 1994: 85). Incluso en su madurez y ancianidad el desencanto hacia el mundo artístico y las tareas en la capital, en la Academia y en la Escuela son manifiestas; de este modo, en el año 1858 -fecha de su Autorretrato de cuerpo entero- comunicaba a su hermano Luis que, de no ser por sus hijos y el resto de la familia, no le importaría quedarse en Sevilla "para vivir tranquilo y trabajar tranquilamente ${ }^{168,}$. Diez años después, habiendo perdido gran parte de sus anteriores recursos económicos, Madrazo vinculaba su labor de retratista como la fuente de ingresos a la que hubo de recurrir para mantener a su familia ("Y he pasado el tiempo haciendo retratos por precisión habiéndose aumentado mi familia y mis gastos" [DÍEZ, 1994: 66]), y con la que contaba poder seguir ganándose la vida ("No tengo pues hoy más esperanza, a pesar de mis 62 años, que quiera Dios conservarme mi cansada y disminuida vista, para poder seguir pintando retratos, con lo cual he podido hasta ahora, no sin algunos trabajos hacer frente a mis muchas obligaciones" (DÍEZ, 1994: 101). Las preocupaciones económicas de Madrazo también quedan reflejadas en las continuas llamadas de atención sobre la necesidad de ahorrar

piensa darme (...) y, además de esto, llevaré el dinero que he ganado desde mi venida de París”. Carta de Federico de Madrazo a Luisa Garreta, sin fecha (DÍEZ, 1994: 535).

${ }^{167}$ Señala también su intención en 1866 de renunciar a su sobresueldo como director del Museo, “y eso que no tengo casa y estudio, como me correspondía como primer pintor de Cámara... y eso que trabajo para la Reina y para el Rey sin presentar jamás cuenta alguna y sin recibir siquiera el menor regalo, la menor caja de cigarrillos” (GONZÁLEZ LÓPEZy MARTÍ AYXELÁ, 1994: 71).

${ }^{168}$ Carta de Federico a Luis de Madrazo, 16 de noviembre de 1858 (DÍEZ, 1994: 531). 
que realiza a su hijo Raimundo, afirmando que es una obligación el no tener deudas algo que enlaza con una masculinidad anclada en el privilegio económico, como demuestra el hecho de afirmar "nunca he tenido deudas y me sabe muy mal no pagar las cuentas a su presentación", al aludir a su precaria situación económica en 1868 tras perder sus ingresos e intentar socorrer económicamente a su familia:

Comprenderás los inmensos sacrificios que he hecho y seguiré haciendo hasta donde me sea posible (...) Podré economizar más porque he reducido mucho mis gastos a lo puramente preciso y todavía si van mal dadas, o peor dadas para mí, tomaré un cuarto pequeño y barato y buscaré un estudio que me cueste poco y gastaré mucho menos en alquiler de casa. Porque para mí lo primero de todo es no gastar más de lo que se puede (DÍEZ, 1994: 670-671).

También obligación del hombre consciente de las necesidades de la vida real es el trabajar constantemente "y hacer capital para la vejez", a pesar de envidiar el hecho de que ni Raimundo de Fortuny dependiesen de empleos:

Te recordaré lo que todo artista de talento y de cabeza debe tener siempre presente, y también se lo recuerdo a Mariano. Y es que es preciso no perder de la memoria la fábula de la cigarra y la hormiga. Cuando uno es joven, debe trabajar y hacer capital para la vejez (...) Francamente, te aseguro que tengo una gran satisfacción cuando pienso que tú y Mariano estáis en Europa y que no dependéis de un empleo, y que trabajáis para los europeos (DÍEZ, 1994: 675).

Federico de Madrazo, que asimiló como valores propios los de una masculinidad normativa impuesta por la burguesía de los años treinta, se encontró también constreñido por otras de las caras oscuras de esta imagen de privilegio y seguridad; además de los reveses laborales y económicos, la vida familiar y sus posibles escándalos actuaron sobre su ánimo, que debía mantener sereno a su pesar ante otras personas. A Raimundo de Madrazo le confesaba los inconvenientes del autodominio y de la ocultación de las emociones ante la sociedad en relación a la situación de su hija Isabel, indicando "no sé cómo he de hacerme delante de las gentes el hombre tranquilo, o el contento, teniendo el dardo clavado en el corazón" (DÍEZ, 1994: 808), y cómo le costaba "gran trabajo y gran pena el aparentar con las gentes y con la mayor parte de la familia que estoy sereno, o alegre, cuando tengo tanta tristeza por el motivo que sabes $^{169 ", ~(D I ́ E Z, ~ 1994: ~ 811) . ~}$

Jenaro Pérez Villaamil, quien tanto empeño ponía en las apariencias, vivió a su vez una profunda crisis durante su estancia en Bélgica entre 1842 y 1843 que volcó en su diario, tal y como da a conocer Arias Anglés. La preocupación por la inestabilidad laboral, sus dificultades económicas y la sensación de estar faltando a su deber como esposo y padre son manifiestas en algunas de sus anotaciones; así, el 28 de diciembre de 1842 comparaba sus sufrimientos con los de Rousseau, pensando en su mujer e hijo y sintiéndose incapaz de afrontar las dificultades, especialmente económicas, especialmente tras recibir noticias de esta en que le transmite la poca esperanza laboral

\footnotetext{
${ }^{169}$ Federico se refiere a una situación comprometida atendiendo a la moral burguesa debido a la relación y embarazo de su hija Isabel, que afectaba al buen nombre de la familia; Federico acabaría resolviendo este problema consultando con el doctor Esquerdo e ingresando a Isabel en el manicomio.
} 
que ofrece Madrid ("temo que llegue el caso de no tener ni esperanzas de ganar con qué vivir"). En marzo de 1843 la crisis es manifiesta, confesando estar "desesperado con la idea del porvenir que me espera, y a mi mujer y a mi hijo" (ARIAS ANGLÉS, 1986: 83). Su acceso a la Cátedra de Paisaje en la Escuela Especial de Pintura contribuyó a paliar esta angustia personal, si bien sus ingresos no le permitieron dejar grandes bienes a su familia ${ }^{170}$; poco después de su muerte, El Clamor público se hacía eco de una noticia publicada por El Parlamento, según la cual "la joven viuda y el tierno hijo del malogrado pintor Villaamil (...) se está muriendo de hambre", señalando el desconocimiento de que fuese tanta la desgracia de la familia de un artista cuyos gastos se atribuyen a sus viajes artísticos y a su generosidad con sus amigos ("Sería un escándalo", 1855: 3); poco después la prensa volvía a hacerse eco del caso, manifestando el estupor de que a un huérfano de ocho o diez años le fuese negado conseguir una pensión del gobierno ${ }^{171}$.

Bejarano Veiga, al reflexionar sobre el individualismo del artista en el fin de siglo, vinculaba la marginación de este no solo respecto a la sociedad y los valores normativos impuestos, sino que plantea un tipo de alienación respecto del yo que puede leerse en clave masculina, relacionándose precisamente con las imposiciones de la vida familiar y el problema de conciliarla con una profesión inestable. En su opinión, la búsqueda de la libertad individual enlaza con el rechazo voluntario de establecer una familia y, por lo tanto, con la intención de no contraer deberes más que respecto a sí mismos (BEJARANO VEIGA, 2015: 352). Frente a esta toma de conciencia del sacrificio a favor de la vida artística, la posición que hemos podido comprobar como más frecuente entre los artistas decimonónicos españoles es la vinculada a una normatividad de corte burgués, en que la soltería es contemplada como un estado atípico (sirva como ejemplo el de Carlos Luis de Ribera, que únicamente contrajo nupcias hacia el final de su vida) y no deseable, y en el que como hemos expuesto la práctica profesional queda vinculada a las obligaciones familiares, amparando así las reclamaciones de proteccionismo oficial en las mismas exigencias que la moralidad y la sociedad imponían a los artistas.

La obra de José González Bande El camino de la gloria artística [fig. 64] presentado a la Exposición Nacional de 1856 canaliza pictóricamente la crítica sobre la situación de muchos artistas contemporáneos; sin limitarse a ofrecer una imagen del artista enfermo y condenado a la pobreza, recurre a la familia del mismo para mostrar a un padre de familia incapaz de satisfacer las necesidades de su esposa y de sus dos niños.

\footnotetext{
170 "A pesar de sus honoríficos títulos, ha muerto como mueren casi todos los artistas en España, es decir, pobre. La gloria de su nombre es la herencia que lega a su desconsolada familia" ("Fallecimiento", 1854:3).

${ }^{171}$ En 1854, Leporello alababa a la reina dando la noticia de que se proponía "honrar su memoria [de Pérez Villaamil] señalando una pensión a la viuda y al hijo, que asegure la subsistencia de ambos y ofrezca al pobre huérfano medios de concluir su educación (LEPORELLO, 1854: 4), aunque las noticias posteriores parecen señalar que dicha pensión no fue adjudicada (ALFONSO, 1855: 4; "Cartas madrileñas", 1855: 4).
} 


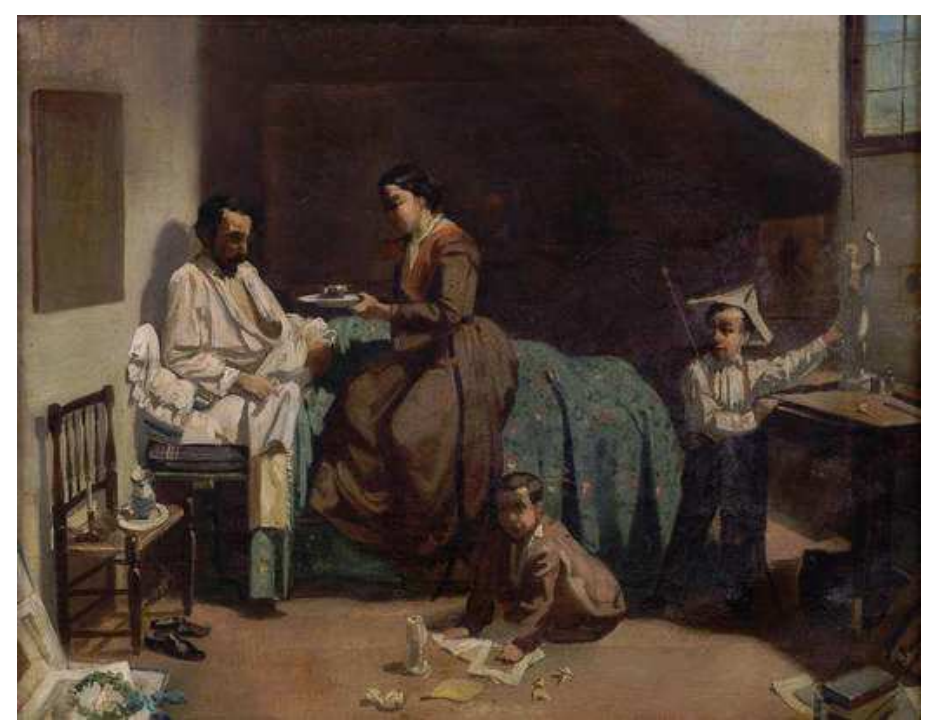

Fig. 64. José González Bande. El camino de la gloria artística (boceto). Museo Nacional del Prado.

El artista representado permanece tumbado en la cama, en una situación de plena vulnerabilidad, con gesto compungido e incapaz de levantar la mirada para encontrarse con la de su mujer; la imagen de González Bande, incluida en un retrato que cuelga, medio despegado, en la pared del fondo, parece reflexionar sobre las promesas ideales que ofrece el mundo artístico en contraposición con una realidad social basada en la inestabilidad, y plantea el abismo existente entre el concepto romántico del artista incomprendido y los imperativos masculinos entendidos como fallo o derrota ante los ideales impuestos por el sistema artístico.

Ante la proliferación de pintores y participantes en las Exposiciones Nacionales de Bellas Artes, Cruzada Villaamil reflexiona en 1867 sobre la calidad del arte y los artistas, instando a los componentes de los jurados a no aceptar cualquier obra, ya que esto influye negativamente en los propios artistas, "haciéndoles concebir esperanzas imposibles de que algún día puedan mantener una familia con la profesión del arte" (GUTIÉRREZ BURÓN, 1987: 567). Finalmente, las recomendaciones y premios en las exposiciones, meta de la profesión artística que comienza, eran también el objeto de quienes, contando con pocos recursos, deseaban llamar la atención sobre su propia necesidad, algunos de ellos "viejos que necesitaban ponerse en condiciones de optar a una cátedra para dar de comer a su familia” (GUTIÉRREZ BURÓN, 1987: 400).

\subsubsection{Preocupaciones y temores de los pensionados en Roma}

Las cargas familiares del artista son también de interés en el caso de los artistas pensionados, quienes partían al extranjero en compañía de su familia o bien contraían matrimonio (con sus correspondientes cargas) durante la etapa de sus pensiones, dando lugar a un contrapunto a la imagen del artista como joven despreocupado y sumido en la vida bohemia de las colonias parisina o romana. La conciliación de formación artística y vida familiar supuso un problema de interés público en el caso francés, en el que se planteó continuamente la duda de si los enviados a Roma debían ser "jóvenes llamados 
a desarrollar allí las disposiciones reconocidas por la prueba de los concursos o un medio de perfeccionamiento dado a hombres de un talento hecho y caracterizado ${ }^{172,}$.

La idea de que las obligaciones de los pensionados en Roma no se correspondían con las de un hombre que, a su edad, debía estar libre de imposiciones externas caló en los escritos de Vernet, quien señalaba además la dificultad de pretender imponer una autoridad a hombres ya maduros. La puntualización de Vernet no aludía exclusivamente a los compromisos artísticos de los pensionados, sino que se desprende de ella una matización interesante sobre el concepto mismo de masculinidad en relación, por una parte, con las obligaciones del hombre en edad viril, y por otra con su misma imagen de autoridad respecto a los propios pensionados. La aplicación de la normativa no se adecuaba a la madurez de los artistas enviados, ya que obligaba a convivir durante cinco años bajo el mismo techo a hombres que podían llegar a cumplir los treinta y cinco en la Villa Médicis, alejándolos de las obligaciones familiares contraídas o de la oportunidad de contraerlas al vivir en un edificio aislado, y restringiendo la práctica libre de obras de composición, lo que perjudicaba a la creación de una reputación artística y a la posterior inserción laboral del pensionado. Este, sometido a la autoridad del director y limitado al juicio emitido por la Academia, se veía posicionado en un estado indefinido entre el de alumno aventajado y el de artista consolidado, dañando en parte su orgullo masculino. Los miedos del pensionado en Roma no pasaban desapercibidos para los académicos y artistas conoceedores de la realidad del mercado, al emplear las siguientes palabras:

Es preciso decir que hay algo de aterrador para un hombre que abandona Francia a la edad de treinta años y que no debe volver hasta cinco años después, al decirse que, durante ese tiempo, todos los favores podrán haber sido acaparados, todas las avenidas ocupadas por aquellos de sus compañeros de estudio que, menos perseverantes o menos hábiles, no habían podido obtener de sus maestros las notas más brillantes de satisfacción. A raíz de esto el Grand Prix puede convertirse en una fuente de decepción y de odio. Hemos podido comprobar que aquellos mismos a quienes la esperanza del Grand Prix había sostenido en sus estudios ya no mantenían la misma perseverancia ni el mismo talento en los envíos de sus últimos años. Hemos visto a los alumnos dispersar en Roma su atención hacia trabajos más fáciles y supuestamente más lucrativos. Este decaimiento en la actividad de los artistas y este desvío de sus deberes más imperiosos deben atribuirse en gran medida a la inquietud que embarga a los alumnos en el momento que se preparan para volver sin la esperanza de una posición fija y de un trabajo asegurado (LAPAUZE, 1924: 271-272).

A esta inseguridad se unía el problema del matrimonio y de la vida familiar del pensionado, que llevó a un largo debate sobre el estado civil que debían tener los aspirantes al Prix de Rome, siendo el detonante la exención concedida en 1833 a

\footnotetext{
172 "Este establecimiento me parece falseado en su principio, ya que la edad de los señores pensionados del Rey, tal y como han sido desde hace tiempo enviados a Roma, no está relacionada con los deberes que se les impone (...) Si la Academia de Roma es considerada como una escuela, los alumnos deberían llegar por debajo de la edad de veinticuatro años y ser sometidos a la autoridad de un director tanto en lo que respecta a sus estudios como en lo que concierne al orden y la moralidad del establecimiento; si, por el contrario, continuamos enviando hombres en edad madura, no será preciso ni un director, ni un reglamento" (LAPAUZE, 1924: 212).
} 
Baltard, pensionado por la arquitectura, de vivir en la Villa Médici y de comer con sus compañeros por estar casado, al tiempo que disfrutaba al completo su pensión (no hay que olvidar que a los pensionados en la Villa se les descontaba de su asignación el importe del alojamiento y manutención), lo que llevó a otros artistas a seguir su ejemplo. El hecho de que Vernet sugiriese bajar el límite de edad no se correspondía únicamente con la necesidad de aceptar alumnos con capacidad de aprender, sino también a la búsqueda de una solución a la situación de los pensionados casados; Vernet afirmaba que "sería una especie de crueldad exigir a hombres que llegan a Roma generalmente con más de treinta años que esperen hasta el final de su pensión para contraer unos vínculos que podrían haberse convertido para ellos en una necesidad imperiosa" (LAPAUZE, 1924: 216) al mismo tiempo que señalaba que permitir el matrimonio de los pensionados pondría fin a la propia institución al estar pensada para generar un clima de fraternidad y convivencia artística. Entre los argumentos que respaldaban la propuesta del director se encontraba el de que la modesta retribución de la pensión - una vez descontados los gastos de manutención y el pago a los modelos- no permitía a un artista cumplir debidamente con la obligación masculina -y señalada como tal por el código civil-de mantener a los miembros de su nuevo hogar, y esto les llevaba a aceptar encargos extraoficiales que perjudicaban a la calidad de los envíos o causaban prolongadas demoras en estos. El informe final redactado por Quatremère de Quincy manifestaba su repulsa ante la propuesta de Vernet de prohibir admitir pensionados casados, señalando que sería ilegal "derogar al código civil por una medida legislativa que pondría a cierta clase de ciudadanos, entre los veinte y los treinta y cinco años, en una especie de celibato forzado por la prohibición del matrimonio" (LAPAUZE, 1924: 220). El debate, que lamentablemente no queda recogido en las actas de la Academia, opuso a la comunidad artística entre los partidarios de imponer un nuevo requisito de soltería a los aspirantes ${ }^{173}$ y los que veían en esta medida una restricción excesiva, traduciendo opiniones distintas sobre la masculinidad del artista, su vinculación con las obligaciones de este como hombre y cómo estas podían afectar al rendimiento, a las actitudes y al propio desarrollo laboral. A pesar de la opinión recogida por Quatremère de Quincy como resolución definitiva oponiéndose a la propuesta de Vernet, en el reglamento de concurso al Grand Prix de 1846 figura ya, recogida en el artículo cinco, la prohibición de concurrir a hombres casados, un enunciado que permanece inalterado hasta $1935^{174}$, en que se introduce una medida transitoria que permite concurrir, como caso excepcional, a artistas casados después de haber sido objeto de críticas que comparaban el estado de los artistas con el de los seminaristas ${ }^{175}$.

\footnotetext{
${ }^{173}$ Es el caso del propio Vernet, que afirma que los reglamentos están ideados pensando en una persona sin compromisos familiares, y que por lo tanto "si los reglamentos están hechos para solteros, únicamente los solteros son los que deben ser admitidos a concurso ya que el resultado de estos es someterlas a las exigencias de los mismos reglamentos (...) ¿Acaso es forzarlos al celibato el excluirlos de un establecimiento en el que se encontrarían desplazados?"(LAPAUZE, 1924: 223).

${ }^{174}$ ACADÉMIE DES BEAUX ARTS, 1854: art. 5; ACADÉMIE DES BEAUX ARTS, 1933(ANF, $\mathrm{AJ} / 52 / 438)$.

${ }^{175}$ El artículo reflexiona sobre los problemas que la soltería de los pensionados les acarreaba, afirmando que era la causa de que muchos artistas de talento abandonasen su pensión (BALBY, 1913:1). En 1928 el
} 
Al contrario que en el caso francés, en que la prohibición de matrimonio a los artistas imponía un celibato forzoso y un retraso de la formación de una familia, en España la vida familiar no era un impedimento legal para que los artistas disfrutasen de sus pensiones, aunque en 1817 se decretase que los pensionados fuera del reino tendrían prohibido el contraer matrimonio sin la licencia del rey ${ }^{176}$. Esta medida, destinada a fijar el tiempo de estancia de los pensionados y la cuantía de las ayudas, contribuía sin duda a controlar las necesidades de los artistas en el extranjero en función de sus obligaciones, después de que algunos pensionados como José de Mazdrazo, José Álvarez Cubero o Ramón Barba llevasen diecisiete años fuera del reino; por este motivo, la Academia estimó la necesidad de devolverlos a España, de tal manera que las cantidades invertidas en su formación en el extranjero revirtiesen en un beneficio para la nación. Ferrer del Río cita el matrimonio de José de Madrazo (contraído en 1809) como el motivo del inevitable aumento de obligaciones del artista, cuya pensión fue suprimida un año antes con motivo de la guerra, y siendo la causa de que se dedicase a realizar retratos (FERRER DEL RÍO, 1859:13-14). Aunque se tienen menos datos al respecto, la situación de otros pensionados fue similar, ya que José Álvarez Cubero contrajo matrimonio en 1804 con Isabel Bouquel, y Juan Antonio de Ribera lo hizo, probablemente durante su etapa parisina, con Emilia Fievée.

La relación entre las obligaciones familiares y su compaginación con los estudios de pensionado se mantuvo como una preocupación, ya que estas les acarreaban gastos imprevistos y motivaba en muchos casos el desarrollo de una carrera paralela a los trabajos de envío, y que en ocasiones conllevaba también prolongar la residencia en territorio extranjero ante las escasas esperanzas profesionales que ofrecía España; por este motivo, las pensiones en Roma fueron el objeto de críticas y quejas en el ámbito español, fundamentalmente respecto a su dotación económica. En 1836, Eugenio de Ochoa publicaba en El Artista un artículo reivindicativo en el que llamaba la atención sobre los pensionados en Roma (OCHOA, 1836c: 181-183) ${ }^{177}$, alarmado por la existencia de un puesto de director de pensionados con una dotación económica excesiva, mientras los artistas españoles en Roma se encontraban con que los pagos de sus escasas pensiones no llegaban a tiempo, y además no eran suficientes para cubrir sus gastos. "Los 6000 reales que reciben serían tal vez suficientes si vivieran juntos en una Academia donde tuvieran habitación y estudio, pero no en manera alguna faltándoles este requisito", señalaba Ochoa en una nota a pie de página, señalando lo perjudicial que era para los artistas y las artes la falta de una Academia en Roma a similitud de las de otras naciones, donde los pensionados pudieran vivir en comunidad. A su vez, Ochoa culpa al gobierno de estar incumpliendo el contrato pactado con los pensionados, puesto que la cantidad a percibir por los últimos no debía considerarse un sueldo ni una

debate continuaba abierto, ya que tras la autorización de matrimonio a los pensionados, el requisito de soltería para aspirar al Grand Prix seguía vigente en los reglamentos (“Le futur reglèment...", 1928: 1).

${ }^{176}$ Junta Ordinaria de 2 de febrero de 1817, ARABASF 3-87), f. 616v.

177 mismo año se había publicado ya una nota, al parecer remitida desde Roma, en que se avisaba de la situación de los pensionados españoles "pues habiendo hecho todos los estudios elementales de su arte y algunas copias con muy feliz resultado, se ven en la dura necesidad de no poder emprender los estudios que son consiguientes a los que ya han seguido, ni servirse del natural para hacer algo de invención. Necesitarían para ello taller a propósito y aumento de pensión (...)” (ANÓNIMO, 1836: 132). 
limosna, sino un libramiento a cambio de las muestras de adelantamiento en los estudios, algo que los artistas en Roma habían cumplido con rigor. Las dificultades económicas eran, según Ochoa, el motivo por el cual los pensionados no podían dedicarse a realizar grandes obras ${ }^{178}$, ya que a falta de fondos carecían de recursos materiales y se veían precisados a aceptar trabajos secundarios para conseguir fondos para su manutención y material ${ }^{179}$.

Federico de Madrazo partió en 1837 a disfrutar su pensión cuando ya había iniciado su vida familiar, lo que también implicaba que las preocupaciones por mantener a esta fuesen continuas ${ }^{180}$; a su llegada a París con su esposa e hija indicaba a su padre su intención de vivir de la manera más económica posible, para lo cual contaba con sumar a su pensión lo obtenido de la venta de dibujos. Consciente de sus ingresos, pero también de la necesidad de proveer ciertas comodidades a su familia, escribía:

Yo siempre tengo presente el dinero con el que puedo contar, por lo que no tenga V. cuidado de que me exceda en mis facultades. Puedo asegurarle a V. que no he tomado más cosas que las necesarias. V. sabe todo lo que se necesita en una casa. Es verdad que aquí no venimos para quedarnos siempre. Esta reflexión sería buena si Perico y yo estuviéramos solos, pero con Luisa, la mayor parte del tiempo lo pasaré, como es natural, en casa, no conviene tampoco que esté sin ninguna comodidad (DÍEZ, 1994: 42).

Esto le llevó, lógicamente, a realizar otras obras de encargo, pero también a solicitar en repetidas ocasiones ayuda económica a su padre. Las perspectivas laborales preocuparon a Federico de Madrazo aun a pesar de sus éxitos, y así se lo comunicaba a su padre desde Roma en 1841 al anunciarle que aún no regresaba a España:

se ha de considerar cómo están las cosas de España para que los artistas se puedan esperar obras de lucimiento, pues eso de emplear uno su vida en hacer solamente retratos es muy poco risueño, no porque no se gane quizás más de ese modo, pero por lo árido que es este trabajo y aun perjudicial el abuso para los pintores de historia (DÍEZ, 1994: 359).

\footnotetext{
${ }^{178}$ El director de pensionados Antonio Solá respaldaba en 1848 su preocupación por las penurias económicas de los pensionados, rememorando "Estas noticias le podrán servir a usted caso que el Gobierno pensase pagar las pensiones con los referidos fondos, cosa que traería a los pensionados grandes disgustos y privaciones, como sucedió la vez pasada, que el Sr. Aparici no hizo ningún caso de las Reales Órdenes del Gobierno, ni el Gobierno se empeñó en tomar resoluciones enérgicas contra su encargado, y quien lo pagamos fueron los pensionados y su director, reduciendo a los primeros a la más vergonzosa miseria e imposibilidad de estudios". Carta de Antonio Solá a José de Madrazo, 4 de agosto de 1848. AMP, AP6/Exp. 77.

179 "Por más aplicación y disposiciones que se tengan ¿cómo han de emprender grandes obras si carecen de los recursos materiales para llevarlas a cabo? (...) Pues bien, lo repetimos, y lo diremos cien veces si es preciso, aunque se nos tache de machacones: ¿cómo han de enviar a la academia nuestros pensionados buenos cuadros, buenos bajorrelieves si no tienen dinero para pagar estudio, modelo, colores? ... mas diremos, ¿si se ven precisados a dar lecciones de dibujo para no carecer de lo absolutamente necesario para satisfacer las necesidades de la vida?" (OCHOA, 1836c: 182).

${ }^{180}$ En su carta de 18 de octubre de 1837 a José de Madrazo, escribe "Dauzats me ha presentado en casa de Mr. [en blanco] que compra cuadritos y dibujos a estos pintores, y no los paga mal. Estas noches largas de invierno haré dibujos y se los venderé. Con una docena que haga tendré bastante para pagar el alquiler de la casa" (DÍEZ, 1994: 35).
} 
La ausencia de pensiones hasta 1848 dio lugar a situaciones de precariedad entre los artistas que buscaron ampliar su formación y currículum en el extranjero. En 1842 se publicaba un artículo bajo el título Situación de los artistas españoles en Roma, en que se aludía al estado de desprotección al que estos se veían abocados tras la disolución de la colonia existente en Roma en 1840, formada por los escultores Solá, Ponzano, Vilar, Amella y Vermel, por los pintores Jiménez, Arbós, Luis y Fernando Ferrant, Espalter, Milá, Clavé, Cerdá, Lorenzale, Galofre, Madrazo y por el grabador Alcaide ("Situación de los artistas...", 1842: 1-2). Las causas, según el autor, radicaban en no tener pensión ni comisiones, culpando de lo primero al Gobierno y de lo segundo al hecho de que los poderosos españoles que visitaban Roma no se preocupasen de interesarse por los artistas españoles, ni de visitar sus estudios, ni de encargarles o comprarles obra alguna. Una comunicación de Julián de Villalba señalaba cómo la mayor parte de los artistas españoles en Roma en ese momento eran catalanes, algunos antiguos pensionados, otros que aún gozaban de alguna ayuda, $\mathrm{y}$ otros dedicados al estudio por afición o a sus expensas (VILLALBA, 1840: 4).

Ante la convocatoria de una nueva oposición para Roma por Real Decreto, los redactores de El Renacimiento acogieron la noticia con regocijo, ya que estimaban sorprendente el abandono gubernamental hacia los jóvenes artistas: los pensionados en Roma podrían tener una Academia "si no tan espléndidamente organizada como la de Francia, a lo menos dotada con todo decoro" ("Real Decreto", 1847: 102). Que no fuesen desatendidos y pudieran "presentarse con decoro" era la aspiración también de Velaz de Medrano (1847: 3); sin embargo, fue El Renacimiento el que acogió con mayor preocupación la necesidad de que el Gobierno asegurase la labor de protección sobre los pensionados al retreso a España: “¿Y luego? Luego vuelven a España llenos de saber, entusiasmo y de esperanzas, y su saber (el saber tan laboriosamente adquirido en Roma) les es absolutamente inútil; su entusiasmo se va a donde se van todas las ilusiones juveniles, y a sus dulces esperanzas sucede una tristísima realidad" (R., 1847: 107-109, 115-116 y 123-125). La preocupación subyacente tras estas palabras, sin duda relacionada con el buen aprovechamiento de los fondos públicos, afectaba también a la percepción de los artistas y a la construcción de su porvenir, ya que la desazón era una constante compartida con los pensionados franceses; el escritor de El Heraldo lo dejaba patente en su escrito sobre el regreso de los pensionados en 1852, en el que si bien realiza un enfoque político en el que carga la culpa sobre el gobierno puede intuirse la crisis masculina derivada de la precariedad laboral al terminar las pensiones:

Termina el plazo de sus pensiones y regresarán a su patria... ¿a qué? A hacer probablemente los pintores, retratos, los escultores figuras de yeso para monumentos de una semana de vida, los arquitectos casas para los especuladores. ¡Hermoso porvenir! Y para esto, ¡tantos estudios, tanta fe, tantos insomnios! (...) Acaban los pocos años de pensión, y el joven pintor, o estatuario, o arquitecto, que vuelve de Roma, de Nápoles, de Florencia, de París, con el corazón lleno de esperanzas y la inteligencia llena de ideas, se encuentra trasplantado a un país que le repudia. (...) ¡Qué triste desencanto! (“Pensionados españoles...”, 1852: 1). 
Consecuencia lógica era que los artistas "adolescentes" que partían a Roma volviesen sin haber desarrollado plenamente la virilidad de su talento, es decir, la capacidad de haber creado un estilo propio y novedoso adaptado a la pintura de composición. Todo ello apunta que la instauración de un sistema académico reflejo del francés no acababa de amoldarse a las escasas necesidades del sistema artístico español, ya que daba lugar a un progresivo aumento de estudiantes y discípulos con poca proyección de futuro laboral, lo que se sumaba a las preocupaciones generalizadas entre los jóvenes artistas por sus futuros y las de los pensionados que debían abandonar, en el momento de regresar a la realidad, sus esperanzas frente a las obligaciones profesionales y del mercado artístico (GALOFRE, 1853: 3). Este problema también fue analizado por Eugenio de Ochoa, quien consideraba que el Estado no debía velar por los artistas realizando encargos, ni siquiera a los antiguos pensionados, ya que estos dependían de las clases adineradas, de sus intereses artísticos y culturales (OCHOA, 1867: 3-4).

Fue en el contexto de la instalación de la Academia Española en Roma cuando surgieron las críticas fundamentadas, precisamente, en la necesidad de encauzar la enseñanza de manera científica de modo que no se malograsen "talentos lozanos, cuyos medros limita la miseria" (TUBINO, 1873: s.p.). La definitiva instalación de la Academia se correspondió con la prolongación de un sistema de enseñanza en el que el artista pensionado continuó manteniendo un estatus de alumno al que era preciso proteger y enseñar. La flexibilidad del reglamento original de la Academia en Roma suscitó dudas sobre la capacidad de velar por el comportamiento y cumplimiento de las obligaciones de los pensionados:

Desde el momento en que los pensionados no contraen el deber de vivir al lado del Director mientras gozan de su pensión, no se explica cómo se impone a este la obligación de informar cada tres meses acerca del comportamiento de aquellos y del curso de sus tareas (...) De donde resulta que el Director no tiene nada que dirigir, que sus funciones son puramente económicas, y de inspección o vigilancia a corto plazo (“El arte...”, 1874: 474-495).

El modelo a seguir, sin lugar a dudas, era la Academia Francesa en Roma, donde el establecimiento no servía exclusivamente como fraternidad artística, sino que en él el director se constituía en figura de autoridad -tanto artística como moral- para los pensionados. Frente al ejemplo francés, donde todos los pensionados eran de igual categoría, la diferenciación española entre pensionados de número y de mérito estuvo condenada a generar diferencias entre los artistas en formación y los artistas consagrados. De la misma manera, las lagunas en el reglamento español favorecían abusos y la ejecución de trabajos lucrativos, por lo que llegó a considerarse que la libertad que se les ofrecía era perjudicial, frente a la pretendida misión de la Academia de formar a hombres jóvenes y convertirlos en hombres menesterosos y de provecho; el término medio entre el libre albedrío reinante y la rigurosa vigilancia que convierte "a los pensionados en párvulos que no pueden dar un paso sin la venia del pedagogo" (CASTELAR, 1875:1) aniquilando con ello su masculinidad era difícil de alcanzar. Se tomó el modelo francés, que restringía la edad para opositar a un máximo de treinta 
años, algo que causó cierto malestar, especialmente cuando la convocatoria se veía aplazada de un año a otro dejando a los candidatos en el límite de edad sin posibilidad de presentarse. Aunque no se previó la prohibición de matrimonio, ni las pensiones gubernamentales ni las de las Diputaciones estaban lo suficientemente dotadas como para asegurar la estabilidad económica de la nueva familia. Al respecto señalaba Luis Alfonso, con tono crítico, el tipo de vida y aprovechamiento que un pensionado podría hacer con su escasa pensión, y aun más en el caso de tener obligaciones familiares: "poco tono podrán darse los pensionados en país extranjero, con algunas familias (si las tienen) y con 6000 realazos" (L.A., 1877: 2).

La apertura definitiva de la sede de la Academia también se correspondía con el modelo francés y suscitó dudas respecto a si alentaba un tipo de vida basada en la fraternidad artística y si esto afectaba a la vida familiar. La inauguración del edificio de la Academia en 1881 refleja la existencia de un espacio altamente confortable para los pensionados, que contaban con estudio propio, habitación, comedor y sala de billar, además de criados (UN ESPAÑOL EN ROMA, 1881: 95-98). Casado Alcalde menciona una supuesta exigencia de soltería a los pensionados en el artículo 26 del reglamento de 1873, si bien no aparece en ninguno de los reglamentos anteriores a 1913, lo que parece indicar que, efectivamente, los pensionados en Roma durante el siglo XIX tuvieron libertad para contraer matrimonio y formar una familia. Esto queda corroborado por el reglamento interno de 1880 , en el que se recoge la posibilidad de que el pensionado casado conciliase su estancia en Roma con su vida familiar viviendo fuera de la Academia; en efecto, la rígida moralidad del reglamento, que prohibía que los modelos (masculinos y femeninos) pululasen por el edificio, y especialmente la presencia femenina una vez entrada la noche, no podía ver con buenos ojos la distracción que supondría la presencia de la familia del pensionado en la propia Academia. Así, el artículo tercero recoge que

Ninguna persona extraña podrá pernoctar en el edificio de la Academia, siendo personales el derecho y obligación de residir en él. Si alguno de los pensionados estuviere casado y su familia residiera en Roma, podrá vivir con ella fuera de la Academia, previa autorización del Director (BRU ROMO, 1971: 351).

Esta permisividad relativa, ya que según Casado Alcalde el vivir fuera de la Academia excluía de poder gozar de la subvención de casa y estudio (algo que a su vez llevaba aparejado la necesidad de realizar trabajos lucrativos), contrasta con el cambio acontecido en el reglamento de 1913, en que el artículo 26 recoge la necesidad de acreditar a los pensionados el "no ser casados, y si durante la pensión contrajeren matrimonio perderan el beneficio de aquella" (CASADO ALCALDE, 1987: 53), vinculándose a una normalización de la vida familiar como parte de la identidad masculina en la que el artista se veía directamente atacado. Bru señalaba que esta modificación partía del antiguo director, José Benlliure, y Casado Alcalde la ubica en el proyecto de reforma redactado por Eduardo Chicharro y destinado a reforzar la autoridad del director, haciendo de la soltería un medio para mantener la disciplina en la Academia (CASADO ALCALDE, 1987: 85-86). La reformulación del reglamento en el siglo XX indica un cambio interesante respecto al concepto de masculinidad del artista, 
a quien se obliga a "sacrificar su sensibilidad de artista enamorado y el concepto que tenga como hombre para convertirse en un ridículo Casto José, o a no dejar modelo tranquilo". De esta manera, las desigualdades existentes entre los pensionados necesariamente solteros- y el director, que tenía reservado el derecho de vivir con su familia en la Academia, eran consideradas como una inmoralidad que atentaba no solo contra el propio concepto de masculinidad, sino también porque movía a los artistas a mantener relaciones premaritales, amantes e hijos que no podía reconocer legalmente (POMPEY, 1917; BRU ROMO, 1971: 382-384).

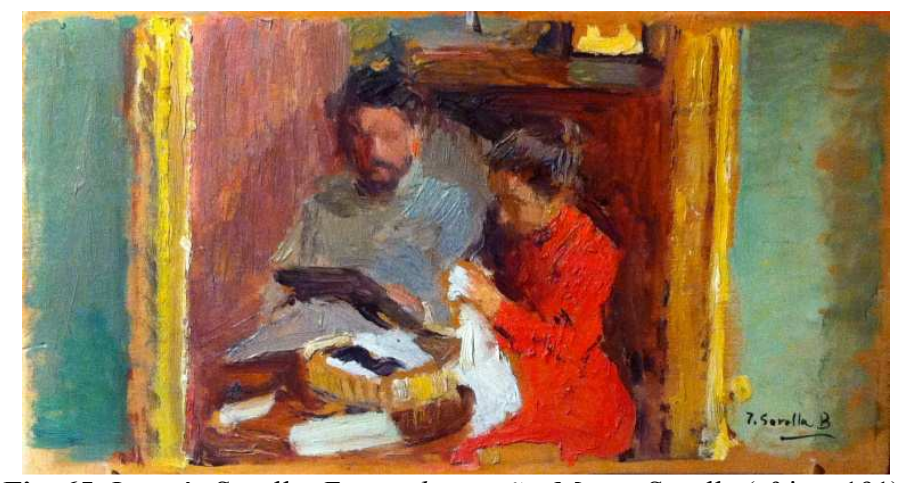

Fig. 65. Joaquín Sorolla, Escena hogareña. Museo Sorolla (nº inv. 191).

Entre los pensionados - por el Gobierno o por Diputaciones Provinciales- españoles que optaron por iniciar su vida familiar se encuentran, entre otros, José Benlliure, quien durante su etapa de pensionado contrae matrimonio y firma su contrato con Colnaghi (BONET SOLVES, 1998) ${ }^{181}$, o Joaquín Sorolla, quien recoge en un retrato abocetado su efigie y la de Clotilde. Bajo el evocador título de Escena hogareña [fig. 65] (Museo Sorolla, $\mathrm{n}^{\circ}$ inv. 00191), la joven pareja aparece representada en Asís, transmitiendo los roles diferenciados que cada uno asume en un momento familiar: Clotilde aparece sentada ante una mesa, con un cesto de costura ante ella, mientras se afana en coser una prenda; Sorolla, por su parte, se autorretrata en esta escena doméstica, partícipe y ajeno al mismo tiempo al contemplarla a través de un espejo, entregado en la tarea de pintar en una tabla que sostiene sobre su rodilla.

\subsubsection{El artista y la vida militar}

1.5.4.1. Academias, privilegios militares y preocupación masculina (17571825)

Un caso que afecta también a los artistas españoles y al concepto de masculinidad es la vinculación entre masculinidad, compromiso social y vida militar, especialmente teniendo en cuenta lo convulso de la situación política española en el siglo XIX y sus correspondientes conflictos bélicos. Los primeros reglamentos de la Academia incluían entre los privilegios concedidos a los académicos algunas exenciones de índole militar, si bien buena parte de los artistas ajenos a la institución quedaron al margen de estas prerrogativas. Las peculiaridades del sistema militar español, basado en un sistema de quintas y reemplazos, hacen que su relación con el mundo artístico y la influencia que tuvo en la experiencia masculina de algunos artistas pueda pasar desapercibida. Sirve

${ }^{181}$ Archivo Casa-Museo Benlliure (26MEM013, fol. 8). 
como ejemplo de caso contrario el sistema francés, en que la existencia de un servicio militar obligatorio sí que ha dejado testimonio de la construcción de una conciencia bélica y patriótica entre los artistas, que se pone de relieve no solo en las prácticas hipervirilizadas en el taller (desde la práctica de esgrima en los descansos reflejada por Vernet al festejo patriótico pintado por Ferrándiz), sino en la preocupación que el cumplimiento de este deber refleja en el caso de jóvenes artistas o en las tensiones surgidas en momentos de conflicto a través de la llamada a las armas entre los pintores. Las actas de la Académie de París reflejan algunos casos en que las obligaciones militares afectaron a las aspiraciones laborales de jóvenes artistas, que no dudaron en solicitar la intercesión de la institución para poder prorrogar sus permisos de exención temporal, generalmente con la intención de no verse privados de concurrir a las pruebas del Prix de Rome. Sucede así con Guignet, aspirante por la pintura en 1837, quien expone que "la prórroga que había obtenido para ser eximido del servicio temporal había expirado y que, si no obtenía su prolongación, debería renunciar a la oportunidad del concurso", solicitando por intercesión de Blondel que se escribiese al ministro de Guerra para que se le concediese una prórroga extraordinaria hasta, al menos, el fallo de las pruebas (BOUVIER y MASSOUNIE, 2003: 168). El 17 de octubre de 1840 se informaba de que el segundo premiado de 1838 Duval había sido llamado al servicio militar, solicitándose que se hiciesen las gestiones oportunas para que se le concediese una dispensa temporal o una exención definitiva (MASSOUNIE, 2007: 117); en esta ocasión, el ministro de Guerra concedió prórrogas de tres meses a los pensionados Roux, Bénouville y al propio Duval, aunque reconocía que el estado actual de la nación no le permitía expedirles la exención definitiva recogida por el artículo 14 de la ley de 21 de mayo de 1832 (MASSOUNIE, 2007: 171). Posteriormente se concedió otra por seis meses más a Roux (MASSOUNIE, 2007: 171). También se intercedió por otros alumnos de la Escuela de Bellas Artes, como Barrias, a quien se autorizó una prórroga en 1843 que, pese a que inicialmente no podía ser renovada, se extendió otros cuatro meses en 1844 (MASSOUNIE, 2007: 475 y 489). Los alumnos admitidos en los concursos definitivos gozaban de mayores privilegios en lo que respecta a exenciones militares frente a sus compañeros, como manifiesta el hecho de que la Academia optase en sesión de 6 de mayo de 1848 por no interceder a favor del estudiante de arquitectura Révoil, ya que gozaba de una prórroga hasta el 15 de junio y no había sido admitido a concurso (BELLAMY-BROWN, 2008: 315), pero sí que lo hizo en 3 de junio del mismo año a favor de Maniglier, admitido en la segunda prueba definitiva de escultura (BELLAMY-BROWN, 2008: 325).

En el caso español, la institución académica está también relacionada con una cierta garantía ante la preocupación de los artistas frente a las peculiaridades del sistema militar, ya que el reemplazo por quintas implicaba que, en principio, todo ciudadano soltero y sin cargas familiares mayor de dieciocho años era elegible para entrar en el sorteo. Así sucede, al menos, a partir de 1757, momento en que los estatutos de la Academia de San Fernando garantizan el privilegio de exención de quintas a los alumnos que hubiesen sido premiados, lo que implicó que para los jóvenes artistas existía una posibilidad de escapar, eso sí a través de la aplicación, de un servicio militar 
que oscilaba entre los ocho y doce años de duración y marcado por rigores $\mathrm{e}$ incomodidades, o de la opción de endeudarse para redimir su suerte en metálico. El temor de los jóvenes artistas puede observarse en los oficios remitidos a la propia academia, solicitando algunos la intercesión de la institución para poder continuar sus estudios artísticos y poder optar así en el futuro al premio que garantizaba una exención militar. Es el caso de Enrique Berzosa en 1768, quien habiendo sido incluido en las quintas de Arévalo se veía privado de seguir su profesión "y de oponerse a los premios que S.M. se digna conceder a los que por su habilidad se tracen merecedores de su real agrado $^{182,}$, cuya solicitud es denegada por no adecuarse a lo fijado en los estatutos, o de otros discípulos como Alfonso Regalado en $1762^{183}$, Ramón Manuel Rodríguez en $1779^{184}$, o Julián de San Martín en $1786^{185}$. El privilegio gozado por los artistas de la corte fue extendido a los de la Academia de San Carlos de Valencia en 1774, institución que veló especialmente por garantizar las correspondientes exenciones a sus alumnos para que no viesen truncada su carrera profesional. Así, en 1795 se quejaban ante la Academia de San Fernando de que la correspondiente exención no se había observado en lo que respectaba a los discípulos, y señalaban

la necesidad de que se observen estas excepciones para el preciso estímulo de los discípulos y fomento de las nobles artes, y los perjuicios que de lo contrario se seguirían precisamente, pues en vista de lo largo de su carrera, motivo por el cual han de estudiar los discípulos muchos años antes que puedan ganar en sus respectivas facultades lo que necesitan para su subsistencia, se ven precisados a mantenerse solteros hasta edad madura permaneciendo entre tanto expuestos del sorteo en las quintas, y a perder en un momento todas las esperanzas que habían adquirido con tan largos estudios ${ }^{186}$.

Otras instituciones buscaron gozar de privilegios similares, como la Sociedad Económica de Amigos del País de Segovia, que solicitó exención de servicio militar a los profesores de sus escuelas de dibujo "para que así pongan mayor cuidado y desvelo con los discípulos, y sean más rápidos los progresos de aquel Cuerpo ${ }^{187 \%}$. La Escuela de Nobles Artes de Granada hacía una solicitud similar en 1806, aplicada a los discípulos premiados, indicando que los premios de aplicación solo otorgaban a estos "las cortas cantidad[es] que se les da ya en dinero o ya en medallas y un corto honor a los que consiguen estos, tan pequeño que si después los llaman para los sorteos de nada les aprovecha $^{188 ",}$, haciendo que muchos de ellos abandonasen los estudios. La dirección de la Escuela consideraba que conseguir una exención del sorteo de quintas serviría de estímulo para los jóvenes artistas. Sin embargo, la solicitud de esta escuela fue

\footnotetext{
182 Oficio remitido a la Academia de San Fernando en 6 de marzo de 1768; ARABASF, Le-1-12-1.

${ }^{183}$ Oficio remitido a la Academia de San Fernando en 25 de enero de 1762; ARABASF, Le-1-12-1.

${ }^{184}$ Expediente de D. Ramón Manuel Rodríguez; ARABASF, Le-1-12-1.

${ }^{185}$ ARABASF, Le-1-12-1.

186 "La Real Academia de San Carlos de Valencia sobre que conforme al artículo 34 de los estatutos de esta de San Fernando se declarase exentos de quintas a sus discípulos pensionados, a los premiados en concursos generales, al conserje y demás dependientes de ella", ARABASF, Le-1-12-1.

187 "La Sociedad económica de Segovia sobre que se declarasen exentos de quintas a los profesores y ayudantes asalariados de las escuelas de dibujo de aquella ciudad", ARABASF, Le-1-12-1.

188 "La Escuela de Nobles Artes de Granada pide exención de sorteo de quintas para sus discípulos premiados", ARABASF, Le-1-12-26.
} 
desestimada por el rey, alegando que de concederse "se debería conceder igual gracia a las demás escuelas de Nobles Artes del reino ${ }^{189}$ ", lo que pone de relieve la desigualdad entre artistas según su relación con las instituciones de patrocinio real.

Durante la Guerra de Independencia la Academia de San Carlos de Valencia también debatió al respecto, buscando proteger los privilegios de los artistas, tanto de los académicos como de sus discípulos. Felipe Garín recoge algunas noticias interesantes, como la aprobación del discípulo Antonio Rubio como arquitecto "por haberle tocado la suerte de soldado en el presente reemplazo $\mathrm{y}$, debiendo inmediatamente marchar a su destino, le interesa hacerlo de arquitecto, cuya graduación le sería de mucho mérito" (GARÍN, 1945: 167). Un oficio de los académicos Cloostermans y Sempere, junto al discípulo Llácer, alude igualmente a la exención de quintas; según recoge Garín, en la junta extraordinaria de 9 de junio de 1810 la academia respaldaba esta petición, solicitando que se declarase "exento de sorteo o que se dispense la misma gracia que a la Universidad Literaria a favor de los Académicos y discípulos premiados en concurso general", solicitud que finalmente fue denegada (GARÍN, 1945: 170).

Las solicitudes de exención a la Academia de San Fernando en el siglo XIX no son muy abundantes, debido sin duda al carácter aleatorio del sistema de quintas; aun así, se conservan interesantes datos al respecto que reflejan que el servicio militar siguió constituyendo una preocupación entre los discípulos y artistas que deseaban mantener su privilegio. Es el caso de Carlos Blanco, pensionado por la pintura en Madrid, de cuya aplicación se da cuenta en su solicitud de exención de quintas en 1806, afirmando que

ahora cuando empezaba a conocer las dificultades del Arte, se halla con la novedad de haber salido Miliciano en su patria, queriéndosele obligar a dejar la carrera a que se ha dedicado malogrando así su conato y los auxilios que se le han suministrado de orden de S.M. ${ }^{190}$,

y solicitando se le expidiese un certificado para solucionar esta situación. En el certificado de concesión se explicita que por su condición de pensionado y los premios obtenidos se le consideraba gozar de exenciones y privilegios marcados en los estatutos. En relación a las quintas celebradas en Burgos en 1817, la Academia de San Fernando conserva también la solicitud de Hilario Palomar de que su hijo Venancio, discípulo de dibujo y pintura de la Escuela del Consulado y de la Real Academia, fuese eximido de la suerte que le había tocado de soldado miliciano, alegando los méritos y premios obtenidos por este, de los que suplicaba certificado a la propia academia y a Mariano Maella, con el único fin de que pudiese seguir concurriendo a sus estudios para perfeccionarse en su arte ${ }^{191}$.

\footnotetext{
${ }^{189}$ ARABASF, Le-1-12-26. Acordado en Junta Particular de 1 de junio de 1806.

190 "Dn. Carlos Blanco, pensionado por S.M. por la pintura, solicita un certificado para libertarse del sorteo de milicias. Pide el mismo en 1807 que S.M. le declarase exento", ARABASF, Le-1-12-26.

191 "Venancio Palomar, discípulo de la Academia, habiéndole tocado la suerte de soldado de milicias solicita se le permita permanecer en Madrid a continuar sus estudios", ARABASF, Le-1-12-26.
} 
Tan solo un año después, Vicente Peleguer, académico de mérito de la Academia de San Carlos y discípulo de la de San Fernando, solicitaba ser exento del sorteo a celebrarse en Valencia; en su expediente se da cuenta de que había sido soldado en la anterior campaña, consiguiendo licencia mediante redención en metálico. En respuesta a la consulta elevada por la Academia de San Fernando se indicaban las características especiales del reemplazo de ese año, que habían movido al Estado a incluir en él "clases privilegiadas y exentas hasta ahora de este servicio por leyes del reino ${ }^{192,}$, entre las que constan los pensionados de la academia, con la única excepción de los directores, no pudiéndose así dar la correspondiente exención a Peleguer, aunque indicaba que si le cupiese la suerte de soldado cabría la posibilidad de elevar una nueva solicitud que, atendiendo a los méritos del grabador, harían que fuese relevado del servicio militar por gracia excepcional. El cambio operado en el reemplazo del ejército vuelve a manifestarse en una nueva petición realizada en 1819. En esta ocasión la Academia de Nobles Artes de Valladolid intercedía a favor de su discípulo José Hernández Sánchez, premiado en los años precedentes y nombrado pensionado en Madrid en 1817 -traslado que finalmente no fue efectivo-, rogando a la de San Fernando se le dispensase de la suerte de soldado que le había tocado en el reemplazo del ejército en Valladolid en 1819. En la respuesta de la Academia consta el cambio operado en el sistema de reemplazos por adición a la ordenanza de 1817, según la cual solo quedaban exentos

en el artículo $5^{\circ}$ los directores y subdirectores, (esto es tenientes directores) de las Academias de nobles artes, y por consiguiente no lo quedan ni los académicos de mérito ni los discípulos pensionados y premiados, ni los dependientes de este Real cuerpo que lo estaban antes en virtud del Estat[uto, artículo] $34^{193}$.

Sin noticias de que esta nueva orden se derogara en años posteriores, el Gobierno liberal parece cambiar notablemente la situación al realizar su proyecto para la Milicia Nacional, en la que inicialmente el alistamiento era obligatorio. La situación en 1821 preocupó a algunos artistas, ya que en ese mismo año son los propios directores y tenientes de la enseñanza de la Academia -y más concretamente aquellos vinculados al bando realista- los que solicitan exención del servicio de la milicia nacional, a la que sigue la especificación de "legal y forzosa". Vicente López, Custodio Moreno, Juan Miguel de Inclán y Valdés firman el 19 de febrero de 1821 un escrito dirigido a la Academia, señalando cómo habían sido requeridos en sus respectivos domicilios para ser incluidos en el censo de la Milicia, y la necesidad de que la institución dirigiese al ayuntamiento un listado de aquellos que por las prerrogativas concedidas estuviesen exentos de dicho servicio, de manera que el trámite fuese más rápido y extensivo a todos los individuos que se viesen en la correspondiente situación ${ }^{194}$; sin embargo, la Academia acordó en junta particular de 12 de marzo de ese mismo año denegar la solicitud, señalando que

\footnotetext{
192 "Dn. Vicente Peleguer, académico de mérito de la de Valencia y discípulo de esta solicita la exención del sorteo de quintas", ARABASF, Le-1-12-26.

193 "Dn. José Hernández Sánchez", ARABASF, Le-1-12-26.

194 "Los Directores y Tenientes de la enseñanza pública en la Academia solicitan la exención del servicio de la Milicia Nacional legal y forzosa", ARABASF, Le-1-12-26.
} 
con conocimiento de las ideas del Gobierno sobre este asunto acordó se suspenda por ahora tomar resolución en él, y que en particular cada individuo acuda a la autoridad competente a exponer las excepciones, que según Reglamento crea corresponderle $^{195}$.

En el margen de la solicitud se especificada el acuerdo tomado de negarse a presentar una solicitud como corporación por creerlo más prudente al estar informada de que se pretendía que el alistamiento en dicha Milicia fuese exclusivamente de voluntarios $^{196}$. Efectivamente, la Milicia Nacional pasó a estar compuesta exclusivamente de voluntarios ese mismo mes de marzo, siendo efectiva en junio, decretándose que los exceptuados contribuyesen con una cuota de cinco reales mensuales, motivo por el cual la solicitud de los profesores de la Academia no suscitó nuevas consultas a la Junta de Gobierno.

La última solicitud que consta en el archivo de la Academia de San Fernando relacionada con el reemplazo en el ejército y servicio militar data de 1825; se trata de un discípulo de arquitectura, Mariano Sánchez, a quien correspondió suerte de soldado en la quinta de ese año por su localidad natal. En ella, su padre consultaba a la Academia, en su intento de poner un sustituto que sirviese su suerte en el ejército, por lo que la institución procedió a realizar consultas sobre el aprovechamiento del discípulo en sus salas. En Junta Ordinaria de 14 de agosto se informaba de que la secretaría había facilitado al secretario del Consejo de Guerra los datos relativos al discípulo, sin que constase ya en este caso ningún tipo de mediación por parte de la institución con respecto a sus alumnos ${ }^{197}$.

Las leyes de reemplazos publicadas con posterioridad indican cómo los anteriores privilegios, en lo que respecta a los concedidos a los artistas mediante las Academias, pierden validez, ya que se incluye en los servicios de quintas a todos los hombres españoles, solteros y viudos sin hijos, entre los 18 y 25 años de edad, con un listado de excepciones en los que la inutilidad física y el mantenimiento - en los casos en que el recluta figurase como única fuente de ingresos- de miembros de la familia corren paralelos al ejercicio del privilegio de clase a través de la redención en metálico ${ }^{198}$ o del

\footnotetext{
195 Junta Particular de 12 de marzo de 1821, ARABASF (3-127), fol. 214r.

196 "La Academia informada de que se trata por el Gobierno de establecer dicha Milicia bajo otro pie y de que solo se alisten en ella voluntarios, creyó prudente por ahora suspender toda mediación sin perjuicio de que en particular solicite y represente cada individuo a la autoridad competente las excepciones legales que puedan comprenderle con presentación de los títulos o documentos de que se apoyen". Respuesta de la Junta a los señores Vicente López, Juan Miguel Inclán y D. Custodio Moreno, ARABASF, Le-1-12-26. Sobre el proceso de alistamiento en la Milicia Nacional y las dificultades encontradas para formar un batallón de milicianos forzosos frente a los voluntarios, ver PÉREZ GARZÓN, 1978: 145 y ss.

197 Junta Ordinaria de 14 de agosto de 1825, ARABASF (3-88), ff. 130v. y 131r.

${ }^{198}$ Las cantidades a librar varían a lo largo del siglo; en 1842 se habla de 60 reales (Gaceta de Madrid, 1842: 4), 6000 reales en 1851 (Gaceta de Madrid, 1851: 1); en la ley de 29 de noviembre de 1859 aumenta a 8000 reales, coincidiendo con la Guerra de África, y volviendo a la cuota de 6000 reales en 1869 ("Decreto...", 1869: 1). El proyecto de ley sobre el reemplazo del ejército presentado en las cortes en 1870 planteaba la supresión de la redención en metálico (Gaceta de Madrid, 1870: 1), mantenida sin embargo en la ley definitiva tras varios debates (Gaceta de Madrid, 1870: 1); a partir de la Ley de reclutamiento y reemplazo de 1878 la cantidad prefijada para la exención son 2000 pesetas [Gaceta de Madrid, 10 de septiembre de 1878, p. 726], y de 1500 en 1882 (Gaceta de Madrid, 1882: 175); en 1885
} 
pago a sustitutos, lo cual ponía de manifiesto la desigualdad social existente y que llevó en 1855 a un auténtico movimiento público a favor de la supresión de las quintas. El condicionamiento del servicio militar obligaba a los jóvenes en esa franja de edad a cumplir con la ley y estar sometidos al censo de sus respectivas localidades; la fiscalización de la juventud masculina implicaba la imposibilidad de acceder a ningún empleo o cargo público sin acreditar su alistamiento y certificación correspondiente ${ }^{199}$, en ciertos sectores del mundo obrero o de las compañías de ferrocarriles ${ }^{200}$, o de salir al extranjero sin poseer certificado de alistamiento o del pago por adelantado de la cuota de exención a partir de $1870^{201}$. Únicamente a partir de 1878 se incluye un dato de interés respecto a la posibilidad de redención, "cuando el mozo que la verifique acredite

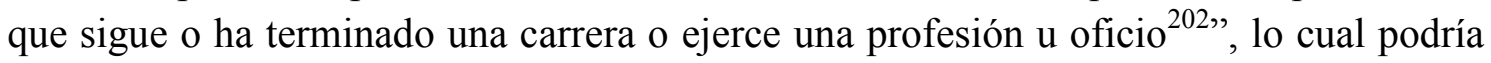
haber beneficiado a clases sociales más desfavorecidas y a jóvenes artistas de no ser porque estaba igualmente sujeta al pago previo de cuota de redención.

En el caso de los artistas, son escasas las noticias existentes al respecto; entre los pertenecientes a familias con una fuerte economía es posible que se produjesen redenciones en metálico en el caso de salir declarados soldados por sorteo en quintas, como seguramente sucedió en el caso de José Gutiérrez de la Vega (hijo) y de Luis de Madrazo en la quinta del distrito de la Aduana en 1844 ("Distrito de Quintas...", 1845: s.p.). Así parece constar también en la biografía publicada en La Ilustración Española y Americana a la muerte de este último, en la que al mencionar su respeto al deber en la juventud, se señala que gracias a los trabajos realizados "cuando su padre trató de librarlo del servicio militar, había ganado lo bastante para redimirse él con el producto de su trabajo" (PARADA Y SANTÍN, 1897: 149). En una carta de Eduardo Rosales a su hermano recogida por Pardo Canalís y fechada en 1854 se menciona someramente el tema, ya que al hacer una alabanza de la libertad y del apoyo a Espartero da cuenta de la situación altamente militarizada en la capital y da a entender con cierta preocupación que la participación en milicia sería forzosa. En un intento de tranquilizar a su hermano, le dice que

en cuanto a lo de las quintas te doy mi palabra de ponerte en la caja todo el dinero que gane para ver si juntando tú también un poquillo te podemos dejar solamente

se distinguen dos cuotas para la redención del servicio militar, siendo de 1500 pesetas para el servicio en la Península, y de 2000 para Ultramar (Gaceta de Madrid, 1885: 122).

${ }^{199}$ Capítulo XVI de la ley re reemplazos de 1838 (Gaceta de Madrid, 1838/02/01: 2).

${ }^{200}$ El artículo 32 de la ley de reemplazo de 1885 incluye en esta medida los cargos del Estado, provincia, municipio o elección popular; los funcionarios, obreros y dependientes de compañías de ferrocarriles, empresas o sociedades autorizadas por el Estado, el municipio o la provincia; así como capataces, destajistas, jornaleros o empleados de obras gestionadas por el estado, provincia o municipio.

${ }^{201}$ En la ley de reclutamiento de 1878 ya aparece recogido que "para evitar que los mozos sujetos al reemplazo eludan su responsabilidad saliendo fuera del Reino, no se dará cédula personal con este destino a los que estén en la edad de 15 a 35 años cumplidos, si no acreditan hallarse libres de toda responsabilidad, o no aseguran estar a las resultas de la que pueda corresponderles, consignando al efecto en depósito la cantidad de 2000 pesetas en metálico" (Gaceta de Madrid, 1878/10/09: 720); se recoge igualmente en la ley de reemplazo de 1882 , y en la de 1885 se especifica que el pago de esta cantidad garantiza las mismas condiciones que la redención en metálico.

${ }^{202}$ Gaceta de Madrid, 1878/10/09: 726. En la ley de 1882 se estipula que los redimidos de este modo ingresarán como reclutas en depósito, "para acudir a las armas solo en caso de guerra, y a las asambleas de instrucción que practiquen los demás reclutas de su reemplazo" (Gaceta de Madrid, 1882/10/02: 589). 
en el grado de miliciano. Las quintas ya no serán todos los años y solamente la mitad de hombres. ¡Viva la libertad! (PARDO CANALÍS, 1974: 357).

También Mariano Fortuny se vio preocupado por la alteración que supuso para sus planes artísticos el estar incluido en las quintas en el momento de ser pensionado en Roma, de lo que deja constancia el acta de la junta general de 7 de febrero de 1858 de la Academia de Sant Jordi. En ella se da cuenta de la situación del joven artista, que aún no había podido emprender su viaje no solo por motivos familiares, sino por la necesidad también de "buscar una fianza para obtener pasaporte", según las leyes relativas al servicio militar ${ }^{203}$.

Otro ejemplo del que se conserva testimonio es el de José Benlliure, quien en sus memorias da noticia del espíritu bélico en torno a la Gloriosa en su familia; su padre tomó parte en la Milicia Nacional valenciana, "con la idea de defender lo que tanto se había prometido de que sus hijos no harían más el servicio militar, o lo harían todos pobres y ricos ${ }^{204}$ ". Sin embargo, pese a los ideales democráticos de Juan Antonio Benlliure (padre), que respondían al malestar social ${ }^{205}$ y a al debate público respecto a la supresión de las quintas, la pervivencia de estas supuso que José Benlliure fuese incluido en el sorteo de reemplazo de 1875, donde obtuvo en el sorteo el número 117 por el distrito de Serranos; la existencia del certificado de exención del servicio militar permite observar la resolución final por parte de la familia Benlliure, redimiendo la suerte del joven pintor mediante el pago en metálico ${ }^{206}$.

\subsubsection{Retratos de artista relacionados con la vida militar}

La relación entre los artistas españoles y el ejército depende, por una parte, de los ideales políticos que llevan a algunos a enrolarse de manera voluntaria en cuerpos armados, como la Milicia Nacional, atendiendo a la llamada generalizada a la población masculina de defender la patria. Además de los artistas recogidos por María del Carmen Simón Palmer como pertenecientes a la Milicia, entre los que se encuentran nombres como Sabino Medina, Francisco Bellver o Jenaro Pérez Villaamil ${ }^{207}$, se conoce la relación de otros con mayor o menor vinculación con este cuerpo ciudadano, como sucede en el caso de José Madrazo - requerido para formar parte de una comisión para la formación y alistamiento de la milicia urbana de Madrid en 1834, cargo que rehusó bajo el pretexto de tener sus horas ocupadas en otros encargos al servicio de la Corona ${ }^{208}$ - y de Pablo Cabrera ("Milicia urbana...", 1834: 284), así como de Pedro Kuntz; en la lista

\footnotetext{
203 Junta General de 7 de febrero de 1858, Llibre de l'actes... (1856-1871), p. 39.

204 "Memorias de mi vida artística", Archivo Casa-Museo José Benlliure, C26Mem008, fol. 2.

${ }^{205}$ Sobre el panorama social y masculinidad en el sistema de quintas en el último tercio del siglo XIX, ver MOLINA LUQUE, 1996.

${ }^{206}$ Archivo Casa-Museo José Benlliure, C26Cer001.

${ }^{207}$ Los artistas que recoge tomando como fuente la documentación del Archivo Municipal de Madrid son: Juan Marcos Bausac (pintor y escultor) en 1836; Francisco Bellver (escultor) en 1841; Antonio Cabral Bejarano (profesor de pintura) en 1836; Fulgencio Llorens (profesor de pintura), en 1836; Antonio Maffei (pintor) de 1836 a 1854; Sabino Medina (escultor) en 1839; Jenaro Pérez Villaamil (pintor) entre 1835 y 1838; Patricio Rodríguez (pintor de historia) en 1839 y Ramón Soldevila (retratista) en 1856. SIMÓN PALMER, 1974: 319-339.

${ }^{208}$ Archivo Museo del Prado, AP15/Exp. 22/Doc. 22.
} 
de alistados en la Guardia Nacional de 1836 figuran los artistas Federico de Madrazo (junto a su cuñado Eugenio Ochoa), Vicente Arbiol, Mariano Roca y Ricardo Bucelli ("Lista de los individuos...", 1836: s.p.). Llama la atención la hoja de servicios de Jenaro Pérez Villaamil, quien al solicitar dimisión del cargo de teniente en 1835 retiró la misma, dudando de las implicaciones que podía tener para su honor ya que podía ponerse en cuestión su valentía. De este modo señala que permanecía en su cargo de teniente "para que no se creyera que en circunstancias difíciles se separaba de la suerte de los demás" (SIMÓN PALMER, 1974: 337-338). La revolución de 1854 y los disturbios producidos en Madrid dieron un nuevo empuje por parte de los progresistas a la Milicia, algo que debió inquietar a buena parte de la población, de lo que da cuenta Eduardo Rosales en una carta dirigida a su hermano en la que, al relatar la situación en la capital, le comenta "cuando nos veamos me huele que tú serás miliciano y yo id. ${ }^{209}$ ", (PARDO CANALÍS, 1974: 355). En los llamamientos realizados por el Ayuntamiento de Madrid a los ciudadanos para alistarse en la Milicia Nacional durante el bienio progresista se pueden encontrar los nombres de otros artistas, como Ricardo Llopis (“Ayuntamiento constitucional...", 1855: 1), los hermanos Nicolás y Carlos Gato de Lema ("Ayuntamiento constitucional...", 1855: 1), Antonio María y Carlos María Esquivel (“Ayuntamiento constitucional...”, 1855: 1).

Las primeras vinculaciones entre retratos de artista y ámbito militar se encuentran en relación a la Guerra de Independencia, y los valores que se desprenden de estas representaciones aluden a una masculinidad ciudadana y comprometida con la causa política, en que la imagen del profesional intelectual es compatible con la del hombre de acción. Dos retratos de artista conservados en Cádiz manifiestan esta voluntad de vincular la profesión artística con el patriotismo y el mundo militar, en ambos casos como voluntarios en la Guerra de la Independencia. Se trata, en primer lugar, del retrato del pintor Manuel Montano [fig. 66] (Museo de Cádiz, no inv. CE20292), vecino de El Puerto de Santa María, y pensionado, según Ossorio, en la Academia de Bellas Artes de Cádiz. Pemán y Pemartín (1964: 209) y Quintero Atauri (1919: s.p.) señalan como rasgo definitorio el hecho de que el retratado aparezca vestido con el uniforme de voluntarios distinguidos de Cádiz en la Guerra de Independencia. La representación envarada y rígida, potenciada por la gruesa corbata y por la inclusión forzada de la paleta en posición frontal, adquiere su connotación militar exclusivamente a través de la representación del uniforme, ya que el resto de atributos (desde las patillas y la corbata almidonada al lienzo y paleta) lo vincularían con una masculinidad civil que busca potenciar la identidad profesional. La levita azul, con cuello y solapas amarillas, aportan un nuevo dato sobre la imagen que Montano quiso ofrecer de sí mismo. La pulcritud del propio uniforme, sin embargo, parece entrar en conflicto con algunas de las noticias sobre el aludido, quien siendo Regidor del Ayuntamiento de la mencionada población gaditana en 1813 hubo de quejarse ante las Cortes por la afrenta que supuso que dos compañeros regidores criticasen la vestimenta, al parecer descuidada y pobre, con que

\footnotetext{
${ }^{209}$ En la misma carta, en la que Rosales da noticias de los sucesos sin dar cuenta de haber tomado parte en ninguno de ellos, indica a su hermano que "algunos amigos se han batido, ya te escribiré los que han sido".
} 
este se presentaba en actos públicos. La respuesta de las cortes hacía patente que salvo que el reglamento interior del Ayuntamiento dictase obligación de etiqueta, nada podía hacerse contra la voluntad individual de un ciudadano, señalando que "la decencia del traje no puede por ahora extenderse a más que a la honestidad" (El Duende..., 1813: 352). Con su representación en uniforme, paleta en mano y ante una obra esbozada, Manuel Montano deja firme constancia de su vinculación política y militar, de lo que es también testimonio su reclamación de devolución de una multa por importe de quinientos ducados por adhesión al sistema constitucional, concedida durante el Trienio liberal (Colección de los decretos ..., 1822: 4).

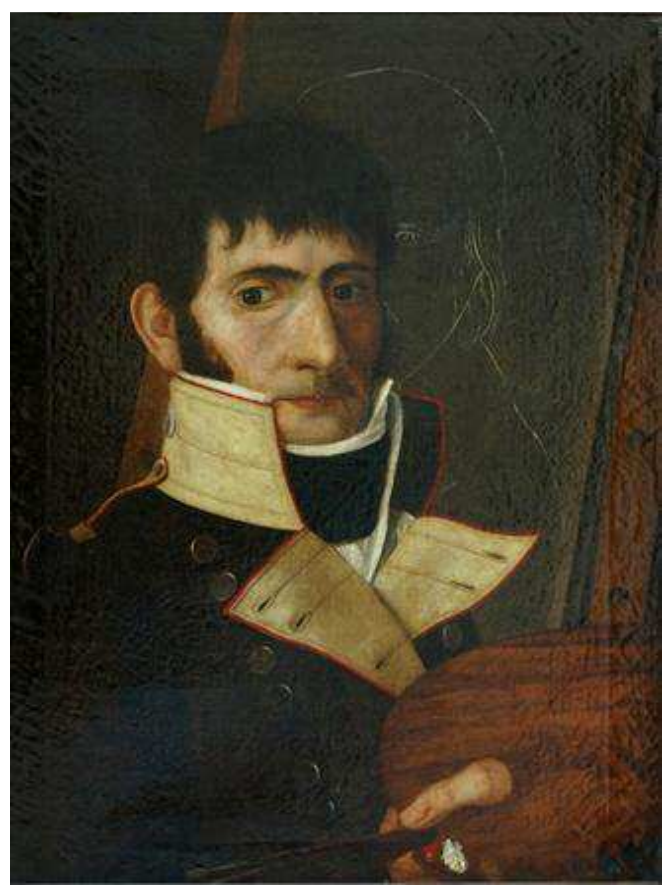

Fig. 66. Manuel Montano, Autorretrato. Museo de Cádiz.

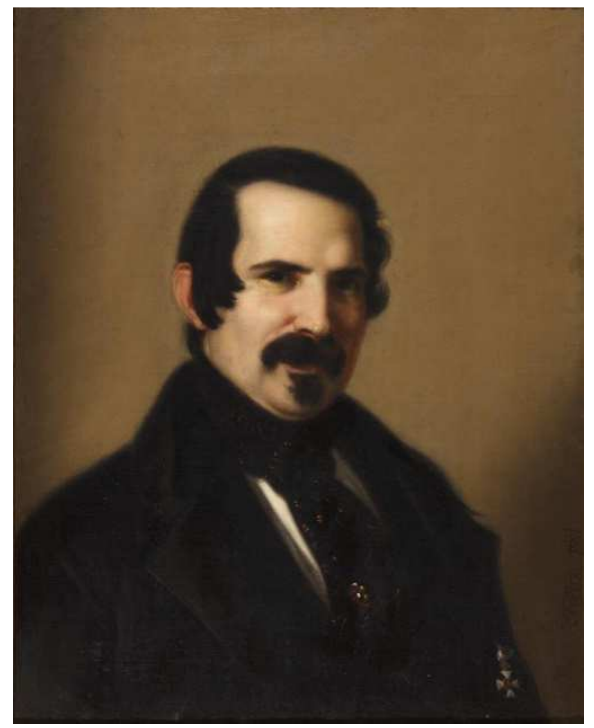

Fig. 68. Joaquín Manuel Fernández Cruzado, Autorretrato. Museo Nacional del Romanticismo.

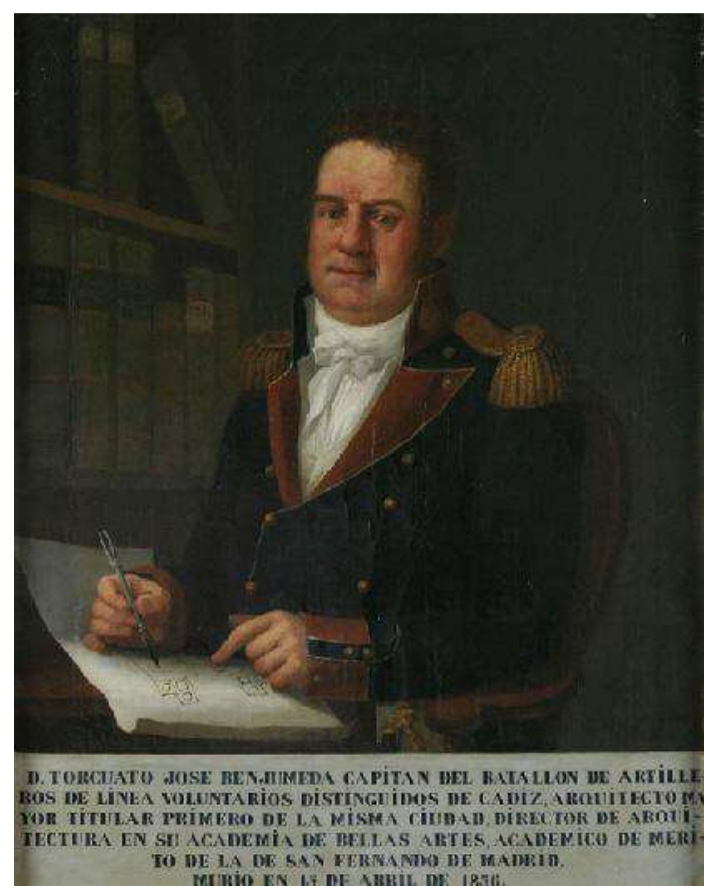

Fig. 67. Juan Rodríguez Jiménez, Retrato de Torcuato José Benjumea. Museo de Cádiz.

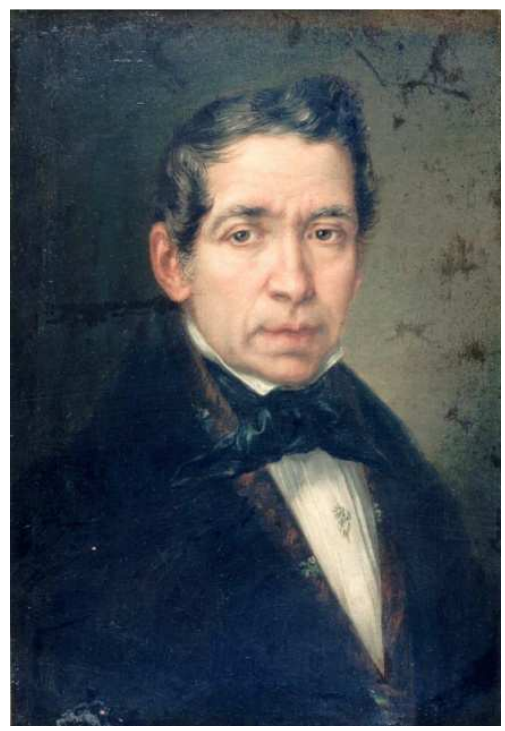

Fig. 69. Vicente Castelló, Autorretrato. Museo Lázaro Galdiano. 
El retrato del arquitecto Torcuato José Benjumeda ${ }^{210}$ [fig. 67] (Museo de Cádiz, ${ }^{\circ}$ inv. DO20198) es también una muestra de la manera de aunar la identidad profesional artística con el desempeño de tareas militares; aparece representado siguiendo un esquema tradicional, sentado a una mesa sobra la que traza un plano, vestido con el uniforme de capitán de artilleros de Voluntarios Distinguidos de Cádiz, reconocible por las solapas y mangas rojas de su casaca azul, así como por sus ostentosos galones. La obra, firmada por Juan Rodríguez Jiménez, se acompaña de una inscripción con los títulos del efigiado, subrayando su papel como capitán del batallón de artilleros, como arquitecto mayor de Cádiz y como director de arquitectura en la Academia de Bellas Artes de la ciudad. Este retrato permaneció en la familia del artista hasta después de su muerte, lo que indica que existía una gran identificación con la imagen representada de este como hombre de armas y trabajador al servicio de la patria.

Las alusiones directas a la participación de los artistas en el servicio militar o en acciones bélicas son mucho menores de lo que podría esperarse, incluso en el género biográfico. Ossorio y Bernard tan solo cita a cuatro artistas que participaron en la Guerra de la Independencia, entre ellos Tomás Sixto y Bácaro -pintor gaditano-, Buenaventura Planella, Vicente Castelló y Amat, y Joaquín Manuel Fernández Cruzado, quizás del que refiere más datos afirmando que

cuando en 1808 una parte de los vecinos de Madrid tomaron las armas, que esgrimieron gloriosamente en defensa de la religión y del trono, Fernández fue uno de ellos, y sostuvo en unión de un gran número de artilleros la puerta de Fuencarral, batiéndose tan admirablemente que llegó a quedar sin más que la mitad de sus compañeros. A consecuencia de sus hechos de armas, fue creado subteniente de infantería por nombramiento de la Junta de Molina de Aragón, expedido en 20 de enero de 1809, grado que se le ratificó por Real Despacho de 14 de marzo de 1810. En el castillo de Santa Catalina, del Puerto de Santa María, sostuvo una larga defensa, y asistió posteriormente a las acciones de Daroca y Cariñena, ocurridas el 14 y 16 de julio (...) mereciendo por su comportamiento ser recomendado al Gobierno para que premiase sus méritos. En 22 de noviembre de 1819 se le hizo efectivo el grado de capitán, que disfrutaba hacía tres años, y en 1823 cayó prisionero del ejército francés al dispersarse la división en la que servía, permaneciendo en el depósito de Granada mientras duró la guerra. Restablecido el gobierno del rey, pasó a Cádiz con licencia indefinida, obteniendo en 1830 la Cruz de San Hermenegildo, que completó las distinciones que anteriormente había recibido por acciones de guerra.

En el Autorretrato que conserva el Museo del Romanticismo [fig. 68] ( $\mathrm{n}^{\mathrm{o}}$ inv. 45), Joaquín Manuel Fernández Cruzado se representa de busto, vestido a la moda burguesa con chaqueta negra y corbata de seda al cuello, luciendo en la solapa la Cruz de San Hermenegildo, lo que manifiesta una particular identificación con su carrera militar, a la que se dedicó desde 1808 hasta $1830^{211}$ y que refleja detalladamente en el memorial presentado por el artista a la Junta de la Academia de Cádiz en 1826 al solicitar la

\footnotetext{
${ }^{210}$ Según Pemán y Pemartín (1964: 208), fue realizada en 1813, y donada por el hijo del retratado.

${ }^{211}$ Entre los datos biográficos aportados, recibió licencia indefinida en febrero de 1824, la ilimitada en 1829, y posteriormente el retiro a petición suya (QUINTERO ATAURI, 1910: 13).
} 
vacante como profesor dejada por su padre (REAL ACADEMIA PROVINCIAL DE BELLAS ARTES DE CÁDIZ, 1983: 11), así como en la correspondencia mantenida con la Academia en 1809 solicitando, entre expresivas manifestaciones de patriotismo, una certificación de sus estudios para el desempeño de su nuevo destino en el ejército (QUINTERO ATAURI, 1910: 9). Las penurias de su vida militar durante la Guerra de la Independencia le llevaron a solicitar auxilio económico a la Academia de Cádiz en al menos dos ocasiones, señalando cómo se veía abatido al hacer "una vida selvática en los campamentos envuelto en polvo, lodo y a toda intemperie, siéndole lo más triste el no ver cuándo darán una paga para reponer su indecente uniforme" (QUINTERO ATAURI, 1910: 14). La inclusión por lo tanto de la Cruz de San Hermenegildo distinción solicitada y concedida como premio a la constancia militar tras un servicio de veinticinco años- manifiesta una voluntad por parte del artista de visibilizar en la esfera social la vinculación no solo a una carrera militar, sino también a ciertos valores masculinos de sacrificio, valentía y heroísmo, estrechamente relacionados con esta.

En el caso de Vicente Castelló son pocos los datos que revelen su pasado militar; en la entrada que Boix le dedica, se menciona que Carlos IV lo eximió del servicio militar, pero que durante la Guerra de la Independencia "tomó las armas en defensa de la patria" (BOIX, 1877: 28). Sin embargo, ni su Autorretrato de 1832 ni el Autorretrato conservado en el Museo Lázaro Galdiano [fig. 69] y realizado hacia 1840 se incluye ninguna alusión a su pasado militar ni a su identidad profesional, adecuándose al tipo de autorretrato confidente. Es preciso señalar también que, aunque José de Madrazo se encontraba en Roma durante la invasión napoleónica, su patriotismo fue repetidamente ensalzado al haber sido encarcelado junto a otros pensionados en Roma por negarse a reconocer a José Bonaparte como nuevo monarca español. En 1820 se le concedió una cédula con permiso para usar el distintivo del Sufrimiento por la Patria, que generalmente se otorgaba a los militares que habían sido prisioneros durante la Guerra de la Independencia ${ }^{212}$, y que consistía en una medalla que debía colgarse del ojal de la chaqueta, mediante una cinta amarilla con los extremos verdes; sin embargo, tampoco se conoce ninguna representación del pintor en la que incluyese dicho distintivo.

Otros artistas, como Luis de la Cruz y Ríos, tampoco ocultaron en su vida pública su compromiso político y militar; de él es sabido que, alistado en el ejército de los Cien Mil Hijos de San Luis, fue recompensado con el Escudo de la Fidelidad (REYERO, 2008: 413), distinción concedida por Fernando VII a los defensores de la causa del soberano por Real Decreto de 14 de diciembre de 1823. La exhibición de este escudo, que debía ir bordado en el lado izquierdo del uniforme, constituía una demostración pública de afección al bando realista, tanto más cuanto en 1824 solo se concedía mediante despacho real y a aquellos individuos purificados que pudiesen demostrar no haber pertenecido a la Milicia Nacional. Sin embargo, ninguno de los retratos conocidos

${ }^{212}$ AMP, AP15/Exp.22/Doc. 2. 


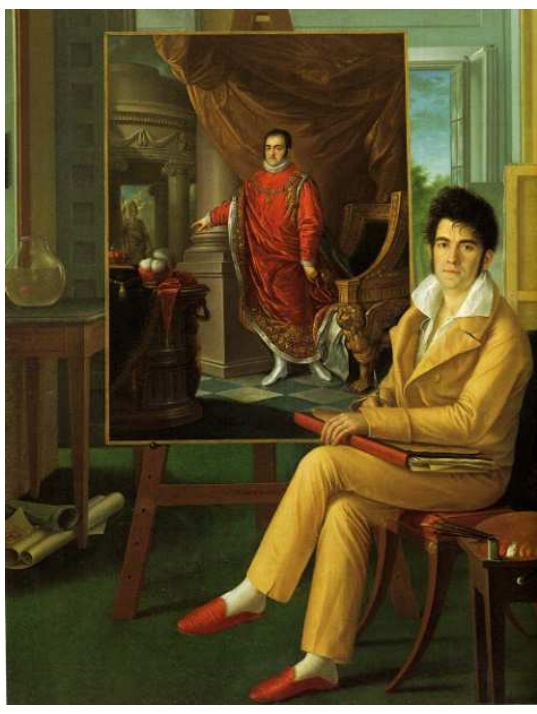

Fig. 70. Luis de la Cruz y Ríos, Autorretrato. Colección particular.

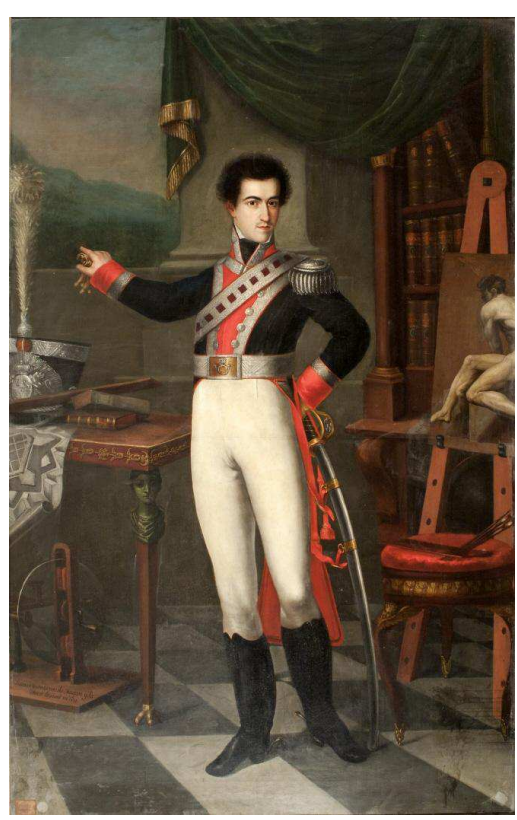

Fig. 72. Juan Nepomuceno Magán, Autorretrato. Museo de la Academia de San Fernando ( ${ }^{\circ}$ inv. $331)$.

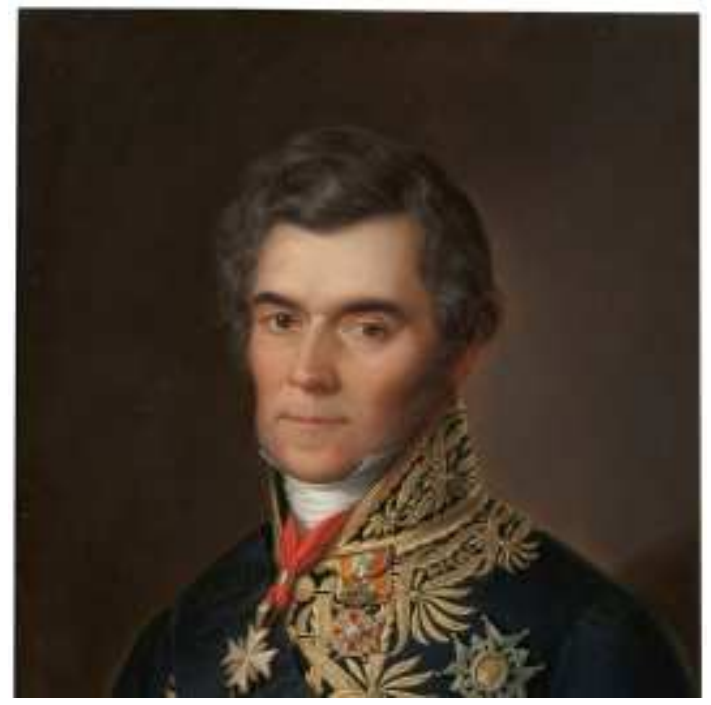

Fig. 71. Luis de la Cruz y Ríos, Autorretrato. Museo Nacional del Prado.

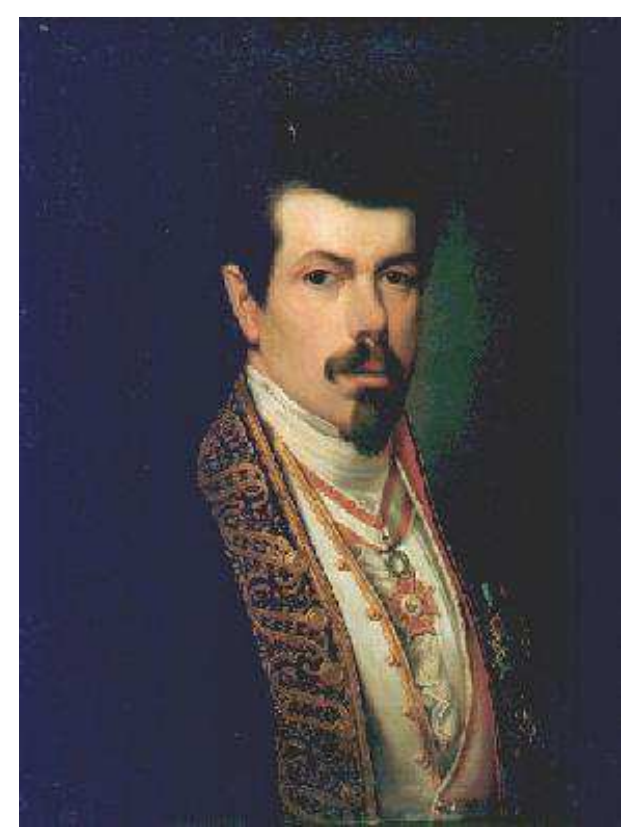

Fig. 73. Antonio María Esquivel, Autorretrato (copia). Museo de Bellas Artes de Córdoba.

de Luis de la Cruz presenta este distintivo militar; en el Autorretrato de 1825 [fig. 70], la relación del pintor con el trono se verifica a través de la inclusión del retrato de Fernando VII con el hábito del Toisón de Oro y en la casaca del uniforme de pintor de cámara que descansa en el respaldo de su silla. En el Autorretrato del Prado [fig. 71] fechado por Díez hacia 1830, la imagen presentada es la de un servidor de palacio, luciendo uniforme y las condecoraciones de las órdenes de la Espuela de Oro, Carlos III e Isabel la Católica (DÍEZ, 1997: 72); por este motivo, debe fecharse a partir de 1833, momento en el que, al ver aproximarse la muerte de Fernando VII y la jura de la princesa Isabel como heredera, Luis de la Cruz solicita ser nombrado Caballero de la Orden de Isabel la Católica, alegando para ello su apego al trono en $1814^{213}$, aunque

${ }^{213}$ A.H.N., Secretaría de órdenes civiles, Estado, Isabel la Católica, 6318, Exp. 116, fol. 42-48. 
dejó de lado su vinculación al bando realista durante el Trienio Liberal ante los nuevos cambios políticos.

En la Academia de San Fernando se conserva un retrato fechado en 1821, es decir en pleno Trienio Liberal, en el que la vinculación con el mundo militar (más sorprendentemente con el bando realista) y el ámbito artístico son explícitamente subrayados. Se trata del Autorretrato de Juan Nepomuceno Magán [fig. 72] (Academia de Bellas Artes de San Fernando, ${ }^{\circ}$ inv. 0331), académico de honor desde 1825, legado a su temprana muerte en $1827^{214}$. En el retrato, de cuerpo entero, Magán se representa vestido de uniforme de gala de la Guardia Real, con casaca azul, pechera roja y ribetes plateados, cruzado el pecho con banda plateada y cuarteada, y con sable al cinto, señalando con gesto decidido el campo abierto que se puede ver a través de una ventana. A su izquierda, el morrión y el plano de una fortificación aluden claramente a su actividad militar, mientras a la derecha se distingue un caballete en el que reposa un lienzo con una academia a medio pintar. La paleta y los pinceles descansan en una silla, aludiendo a la afición por las artes del joven. El carácter explícito de la identidad militar solo es comprensible juzgada desde el compromiso político indisolublemente unido a la profesión de Magán, otorgando al estudio artístico un papel secundario frente a su ocupación prioritaria: la carrera de las armas. En efecto, Magán no consta como discípulo de la Academia, aunque sí de los estudios de la Sociedad Económica de Amigos del País (Gaceta..., 1815), y las noticias que de él se tienen lo vinculan desde edad temprana al cuerpo de la Guardia Real. Esto, unido a que su nombramiento como académico de honor solo se realizó por mediación del infante Carlos María ${ }^{215}$, indica que lejos de ser un inconveniente, la representación orgullosa de su afiliación política no era otra cosa que una consecuencia de su identidad profesional. Por ello, Magán no duda en presentarse orgulloso de su apariencia gallarda, recreándose en el detallismo de su uniforme; la inclusión del desnudo y la alusión a la práctica de la pintura mueve a pensar en la voluntad de Magán por relacionarse con la élite aristocrática y militar, en la que el cultivo de la sensibilidad constituía un rasgo de distinción.

Antonio María Esquivel también estuvo vinculado a los sucesos políticos y militares desencadenados en España con motivo de la llegada de los Cien Mil Hijos de San Luis. El carácter informativo de la entrada que le dedica Ossorio y Bernard a este episodio contrasta con la magnificación heroica de Guerrero Lovillo; según el primero, Esquivel se apartó de la pintura debido al ejercicio de las armas, sin especificar los motivos que le llevaron a ello, y lo ubica efectivamente en el sitio de Cádiz y en la defensa del Trocadero. Guerrero Lovillo traza una biografía narrativa de carácter romántico en la que se lee claramente un vínculo de emulación paterna en la toma de las armas por parte de Esquivel, relacionando esto con el carácter liberal y la virtud de la defensa de la patria que habían llevado a su padre a morir en la batalla de Bailén ${ }^{216}$. Sin

\footnotetext{
${ }^{214}$ Junta Particular de 27 de agosto de 1827, ARABASF (3-127), fol. 297r.

${ }^{215}$ Junta Particular de 14 de junio de 1825, ARABASF (3-127), fol. 260v.

${ }^{216}$ La prosa del autor, marcada por una forma de entender la masculinidad anclada en la mentalidad heroica de mediados del siglo XX, no deja lugar a segundas lecturas, escribiendo cómo "revivía en sus venas ahora la sangre del caído en Bailén" (GUERRERO LOVILLO, 1957: 14). La biografía publicada en El Arte en España lleva el tópico romántico más lejos, enlazándolo con la primera infancia, afirmando
} 
embargo, la biografía de Guerrero Lovillo aporta datos interesantes sobre su paso por la defensa de Cádiz, que se encargó a los Nacionales de Sevilla, en cuya milicia sirvió Esquivel "en la $7^{a}$ compañía primero, y luego en la de granaderos que mandaba el famoso D. Manuel Cortina"; el dato parece tomado de la biografía publicada en El Museo de las Familias, en que se menciona a un Esquivel presente

en todas las acciones y escaramuzas a que dio lugar este célebre sitio, y en todas ellas se distinguió por su caballerosidad y valor, mereciendo por estos hechos que el gobierno le agraciase en 1840 con la cruz y placa del sitio de Cádiz. Su capitán don Manuel Cortina le distinguió y apreció cual se merecía por su pundonor como soldado, por sus buenas prendas y talento (VILLANUEVA, 1844: 91$)^{217}$.

El hecho de que Esquivel sintiese orgullo hacia los valores que había defendido en su juventud en su breve actuación militar queda de manifiesto en su solicitud de que le fuese concedida la Cruz de Comendador de la orden de Isabel la Católica en 1841 -de la que ya era caballero ${ }^{218}$-, exponiendo entre sus títulos el haber sido "condecorado con el grado de subteniente por el sitio de Cádiz ${ }^{219}$ ". El hecho de que este dato fuese añadido en su solicitud de 1841 -ya que en la de 1839 no hacía ninguna referencia a su pasado militar- hace pensar que fue motivado, precisamente, por la concesión de la placa de distinción de Cádiz, junto al resto de milicianos nacionales que participaron en 1823 en la defensa de la ciudad, por decreto provisional de 15 de febrero de 1841 modificado por Circular el 19 de marzo de ese mismo año (VELASCO DUEÑAS, 1843: 219). Atendiendo a la fecha en que Antonio María Esquivel firma esta segunda solicitud -6 de mayo de 1841-, es muy probable que hiciese gala del nuevo honor concedido con carácter meramente práctico para eximirse del pago de la Cruz de Comendador de Isabel la Católica, relegando el orgullo militar a un segundo plano. Este distintivo, que debía llevarse al pecho, es el que Díez señaló en el Autorretrato de Antonio María Esquivel de la Fundación Lázaro Galdiano [fig. 73], bajo las cruces de las órdenes de Isabel la Católica y de Carlos III. Es preciso hacer notar, sin embargo, que a pesar de la importancia concedida a esta distinción en biografías contemporáneas y posteriores, nada parece indicar que Esquivel se manifestase especialmente identificado o vinculado con su pasado militar, ya que este es eludido en todos sus autorretratos previos. La inclusión en el de 1847 parece corresponder únicamente a las exigencias de etiqueta y al carácter formal de la obra, vinculado a una necesidad de visibilizar el nuevo estatus social adquirido más que a una muestra de orgullo por una virilidad militar. Corrobora esta hipótesis el hecho de que la placa pase prácticamente desapercibida al aparecer en una zona sumida en sombra, en la que solo sus contornos son fácilmente distinguibles.

También se ha señalado la vinculación de Jenaro Pérez Villaamil con el ejército, señalándose frecuentemente en paralelismo al caso de Antonio María Esquivel al

que había heredado "el belicoso genio de su padre, y su corazón joven y entusiasta vacilaba entre la gloria que le ofrecía la vida aventurera del soldado y la más tranquila y no menos cierta del artista" [S.N., 1868: 40).

${ }^{217}$ También las noticias incluidas por Manuel Fernández señalan que Esquivel destacó por sus méritos militares (FERNÁNDEZ Y GONZÁLEZ, 1857: 1).

${ }^{218}$ La Cruz de Comendador le había sido concedida en octubre de 1840 (“Junta provisional...”, 1840: 1).

${ }^{219}$ A.H.N., Secretaría de Órdenes Civiles, Estado, Isabel la Católica, 6324, Exp. 64, f.8. 
encontrarse ambos en Cádiz en 1823 (GUERRERO LOVILLO, 1957: 14; REYERO, 2008: 414). Ninguna noticia parece apuntar a que fuese condecorado con la Placa de Distinción de Cádiz, y Ossorio menciona su presencia en la ciudad como prisionero de guerra, "herido en un combate contra las tropas del General Lauristo", cuando era ayudante del Estado Mayor del Ejército. Arias Anglés, tomando como fuente las descripciones ofrecidas por Ceferino Araujo, menciona el especial apego que Pérez Villaamil tenía hacia su Cruz de la Orden de San Fernando, "que había ganado de joven siendo militar" (ARIAS ANGLÉS, 1986: 165). Nuevamente, ninguno de los retratos conocidos del artista lo presenta con dicho distintivo representativo de su orgullo por su pasado militar.

Las representaciónes de artistas vinculadas al ámbito militar se hacen cada vez menos frecuentes, apuntando a una progresiva preponderancia de la imagen civil y del hombre de buen tono alejado de las ideas políticas y culturales encarnadas por el soldado en los años centrales del siglo con motivo de las guerras carlistas, que podía relacionarse con una masculinidad violenta y carente de autocontrol, a pesar de que en la escena El pintor carlista y su familia Valeriano Domínguez Bécquer solamente incidiese en la amabilidad propia de una escena doméstica burguesa.

1.5.4.3. Españoles en París: la guerra francoprusiana y la Comuna (18701871)

La relación entre los artistas españoles, el concepto de masculinidad heroica y el conflicto bélico internacional alcanza su máximo exponente fuera de España, en el ambiente exaltado parisino de la guerra francoprusiana. El clima militar nacional alcanzado con la Guerra de África dotó a los españoles de un nuevo espíritu patriótico que, acompañado a su vez por el clima político de la revolución de 1868, dio lugar a un nuevo sentido de visibilización masculina en el ámbito público. La propuesta elevada a las cortes por el ministro de Guerra sobre los reemplazos del ejército suscitaba un nuevo concepto de participación masculina en la vida militar, al hacerla obligatoria sin opción de redención, para lo cual tomaba como ejemplo el que

en otras potencias militares de Europa y naciones modelos de pueblos libres y de instituciones democráticas han impuesto la obligación del servicio militar a todos los ciudadanos, sin que puedan librarse de él por dinero, así como la necesidad de mantener y elevar el espíritu militar suprimiendo los premios y remuneraciones pecuniarias (“Documento parlamentario...", 1870: 1).

De este modo, se pretendía hacer que el servicio militar fuese obligatorio para todos los españoles mayores de 20 años, que debían permanecer cuatro años en servicio activo; esto se fundaba en un principio democrático dada la escasez de hombres debida a las campañas en Cuba. A pesar de que el proyecto de ley no llegó a aplicarse con el rigor que se planteaba en principio, no cabe duda de que el espíritu militarizado afectó a la forma de entender los valores masculinos, especialmente al vincularse al de otras potencias europeas $\mathrm{y}$, aunque no se señale directamente, con el ideal francés del 
compromiso político de los ciudadanos ${ }^{220}$. El concepto de ciudadanía francesa que vincula directamente virilidad y protección de la patria tuvo un hondo calado entre algunos de los artistas más comprometidos con la causa bélica francoprusiana, como fue el caso de Meissonier, de Manet o de Regnault. A pesar del clima que reinó en los años posteriores a la guerra, en que el arte buscó fundamentalmente dedicarse a temas amables para contribuir a la recuperación nacional (BOIME, 1995), la participación activa o la huida de la guerra fue un motivo de reproche continuo entre los ciudadanos franceses y que tocó también directamente a algunos artistas españoles. A pesar de que la producción de retratos relacionados con esta tribulación masculina no tuvo reflejo en el caso español, sí que contribuyó a reforzar una imagen concreta de masculinidad en los círculos artísticos parisinos, tanto entre aquellos que huyeron del país, como es el caso de Eduardo Zamacois y de Martín Rico, como entre los que se quedaron, como Ignacio León y Escosura, Raimundo de Madrazo o Daniel Vierge.

Respecto al primero, en las memorias de Raimundo de Madrazo este afirma que durante el sitio de París los artistas que permanecieron en la ciudad solían reunirse bien en casa de Goupil, o en la de Vibert, "el cual testimoniaba un gran desprecio por Zamacois desde su regreso a España". Jean-Georges Vibert, pintor acuarelista, mantuvo una estrecha relación, tanto de amistad como artística, con Eduardo Zamacois ("Le Salon", 1870: 4), como pone de manifiesto el hecho de que ambos poseyesen obras del otro (en el catálogo de la venta Zamacois de 1872 figuran acuarelas de Vibert, y en el de la venta Vibert consta una obra de género, titulada Les deux ennemis, realizada a medias por ambos artistas [Mobilier artistique..., 1887: 17]); el repentino desprecio hacia el español venía motivado directamente por la huida de Zamacois de la guerra, algo que, como el propio Raimundo de Madrazo señalaba, "no tenía nada de particular tratándose de un extranjero". Sin embargo, el hecho de que Zamacois hubiese completado su formación y hubiese alcanzado sus éxitos artísticos en París lo equiparaba, a efectos prácticos, con la situación de muchos artistas nacionales, entre ellos del propio Vibert, quien participó activamente en la guerra, tal y como el mismo artista se encargó de manifestar en varias ocasiones. Así, en su autobiografía publicada en 1902, recogía haberse separado del arte para ir al campo de batalla, de donde volvió "herido, enfermo y desalentado" (VIBERT, 1902: 237); las noticias biográficas posteriores se encargaron de magnificar su participación, otorgándole el papel heroico de defensor de la patria al vincular su nombramiento de Caballero de la Legión de Honor con sus heridas en Malmaison, como recogen la Revue Illustrée (PICTOR, 1894: 128) o la Revue Universelle (1902: 39). Sin embargo, la documentación relacionada con esta distinción permite afirmar que "la bravura en el ataque de la Malmaison" es una excusa para mitificar a Vibert y que la condecoración le fue concedida con anterioridad al estallido

\footnotetext{
220 “Aún no se ha penetrado el Gobierno de que la fuerza necesaria a mantener el derecho, por el Estado formulado, debe prestarla todo ciudadano; es una carga que imponen a este los deberes sociales, y como tal, no ha de mirarse nunca, según algunos erradamente piensan, como fin o vocación de la vida" ("Triste realidad", 1870: 1). Igual idea, proclive al nuevo sistema basado en el servicio militar obligatorio, aparece en "Quintas", 1870: 1.
} 
de la guerra francoprusiana, por decreto del 18 de junio de $1870^{221}$ ante una petición formulada en 1868, que no pudo reclamar hasta $1882^{222}$.

La recepción de la noticia de la muerte de Zamacois fue tardía debido al corte de las comunicaciones de París con el exterior durante el Sitio; se conoció entre los artistas a través de Goupil, y fue publicada en febrero ofreciéndose datos verídicos sobre la causa ("Les on-dit...", 1871: 2). Sin embargo, algunas fuentes francesas reinterpretaron posteriormente las causas de su fallecimiento y las relacionaron directamente con la guerra, tal vez porque la noticia ofrecida por Le Rappel no citaba el lugar de la muerte de Zamacois; se estableció la causa únicamente en una angina, ya que eran numerosas las muertes por neumonía en los campamentos militares, como fue el caso de Giraud, para el cual Gautier reclamó el mismo grado de reconocimiento heroico que a los muertos en el campo de batalla ${ }^{223}$. Charles Dolivet (1872: 90) incluye a Zamacois entre la lista de artistas-soldados fallecidos en combate, al hablar del Salón de 1872, junto a Regnault y Giraud hijo, afirmando que los tres llevaban inscrito en sus pechos el nombre "de valientes soldados muertos en el campo de honor", sin dar cuenta de que Zamacois falleció en Madrid tras haber huido de la guerra, tal vez pensando que, si lo expresaba en estos términos, podía ser interpretado como una afrenta al honor del malogrado pintor. Francis Wey, al hablar en su Chronique du Siège de Paris de la relación entre los artistas y la guerra, mencionaba a aquellos que habían participado en ella y sobrevivido, y también a los que "ya sea por sus fatigas, sus golpes o por los sufrimientos del exilio" habían perdido su vida, estableciendo términos de igualdad entre la muerte heroica de Regnault y Zamacois (WEY, 1871: 417). Théophile Gautier redactó un largo artículo sobre la muerte de Victor Giraud en la que mencionaba las notables pérdidas para el arte que había supuesto la guerra, excluyendo el nombre de Zamacois no solo por no haber fallecido por consecuencia de esta, sino también por no ajustarse al modelo de honor militar masculino en el que la huida y la deserción son pecado capital. Para Gautier, la muerte de Zamacois pasa desapercibida porque no se encuadra dentro de los elogios que realiza al artista-ciudadano, es decir, al hombre entregado al deber contraído con la patria (GAUTIER, 1871: 124).

Las noticias españolas sobre la muerte de Zamacois únicamente informan de las circunstancias que habían obligado al artista a regresar a Madrid, donde -casualidad o no- se encontraba pintando una obra sobre otra ciudad sitiada, sin ver en su salida de París deshonra alguna al haber actuado pensando en su familia (NOMBELA, 1871: 56; PALACIO, 1871: 30). Sin embargo, en los Recuerdos de mi vida Martín Rico reivindica un carácter masculino y militarizado por parte de su amigo Zamacois en el apartado que dedica a la situación en París en 1870. Relata que Zamacois "tenía el carácter muy exaltado, fue a la embajada española a decir que estaba dispuesto a coger un fusil y quedarse durante el sitio" (RICO, 1906: 61), siendo el embajador quien le convenció

\footnotetext{
${ }^{221}$ ANF LH/2705/46, fol. 7.

${ }^{222}$ ANF LH/2705/46 fol. 10.

223 "Si no han tenido el honor de sucumbir como soldados en el campo de batalla, no han perdido su vida menos que estos, oscuros mártires del deber. Aunque su sangre no haya corrido, aunque su fallecimiento sea puesto bajo culpa de la bronquitis o de la neumonía, la patria debe reconocerles el mismo interés de sacrificio" (GAUTIER, 1871: 124).
} 
para desistir en su propuesta. Curiosamente Martín Rico, que abandonó París igual que Zamacois, no expresa sus propios motivos para volver a España, ni si en algún momento tuvo intención de permanecer en París, declinando toda responsabilidad al acogerse a lo publicado en un bando que recomendaba salir de la ciudad a todos los "extranjeros y bocas inútiles" (RICO, 1906: 61). Sin embargo, el bando publicado en el Journal Officiel de l'Empire Français el 26 de agosto de 1870 solo apelaba a las personas inútiles en caso de sitio, es decir, de aquellas sin medio de subsistencia y maleantes; en lo que concierne a los extranjeros, la medida de Trochu de 28 de agosto de 1870 solo era efectiva para los extranjeros no naturalizados franceses y procedentes de naciones en guerra con Francia. El hecho de que Rico permaneciese en París tras finalizar su pensión y de que estableciese negocios con Reitingler y Goupil permite afirmar que en 1870 no se encontraba ni en situación de desamparo económico, ni podía pasar por espía prusiano, ni tenía contraídas obligaciones militares con el Estado francés al no afectarle, como extranjero, el llamamiento y reclutamiento en la Guardia Nacional. Tal vez en sus palabras se esconde un cierto temor al reproche que se le podría haber hecho desde los círculos parisinos por no haber permanecido en la ciudad, declinando la responsabilidad en la política francesa y en la voluntad de Zamacois de volver a España. También la eventualidad de que tanto Zamacois como Rico estuvieran casados sí que podría haber sido la causa definitiva de la huida de la guerra ${ }^{224}$. En el caso de Zamacois fue su viuda la que reconcilió el honor perdido del pintor español con la familia Vibert y con el mercado artístico francés ${ }^{225}$, de modo que su fama quedó prácticamente intacta tras la muestra póstuma de sus obras en la Exposición Universal de 1878 (ÉNAULT, 1878: 88). Sin embargo, el hecho de que los pintores Meissonier (GRÉARD, 1897) y Vibert ni siquiera lo mencionen en sus memorias, a pesar de abordar la guerra francoprusiana en varias ocasiones, hace pensar que tal vez su regreso a España no fue perdonado por los dos artistas de activa vida militar.

El caso de Raimundo de Madrazo es el opuesto, ya que al haber decidido permanecer en París, su actitud no solo fue ensalzada por los artistas franceses, sino que constituyó una parte especialmente importante del relato que el propio pintor quiso dejar de sí mismo. En sus memorias el pintor resalta únicamente dos momentos de su vida: sus inicios artísticos en el ámbito parisino y los acontecimientos de la guerra francoprusiana, lo que evidencia, en ambos casos, una voluntad de vincularse directamente a las formas de vida francesas y a los hitos puntuales que marcaron la normatividad masculina entre sus artistas. Su voluntad de permanecer en París aparece reflejada a medio camino entre la actitud del ciudadano comprometido y la del extranjero involucrado en la ciudad que había visto su proyección artística. Su decisión no fue entendida por Federico de Madrazo, quien recomendó a su hijo abandonar la capital francesa, como ya habían hecho Zamacois y Rico, recordándole los perjuicios que el permanecer allí podía acarrearle. El primero de ellos era, indudablemente, la

\footnotetext{
${ }^{224}$ Zamacois contrajo matrimonio en 1865 con una joven apellidada Perrin (L'indicateur..., 1865: 2), y Martín Rico en 1869, según se desprende de una carta de Fortuny a W. Stewart (DAVILIER, 1875: 53).

${ }^{225}$ A su regreso de París la viuda de Zamacois fue acogida por los Berne-Bellecoeur y por los Vibert, quienes además le ayudaron con la organización de la venta Zamacois de 1872 ( Notes et souvenirs..., 1895: 81-82).
} 
pérdida de tiempo para continuar su carrera artística, motivo por el cual le recomendaba retirarse a Londres o a San Sebastián, donde podría continuar trabajando los meses que durase la guerra (cartas de 18 de agosto y 3 de septiembre de 1870 [DÍEZ, 1994):684 y 689]. Otro, quizás más preocupante, era la posibilidad de que Raimundo fuese increpado por parte de los franceses por no enrolarse en el ejército, viendo así comprometido su honor al ser acusado de cobardía:

Por consiguiente, si salías de París todo se reducía a que pasases un mes o poco más fuera de disgustos y quizá de compromisos; digo de compromisos porque por más que seas pacífico y que no te metas con nadie, podrías ser insultado en la calle el día menos pensado, pues viéndote joven y suelto te dirán, o te podrán decir, que por qué no estás en el ejército y si dices que no eres francés ya comprendes lo mal que puede sonar ser extranjero a cierta clase de gentes (DÍEZ, 1994: 684-685).

Profundizando en esta preocupación, Federico de Madrazo volvería a escribir a su hijo el 12 de septiembre, recordándole que no tenía ninguna necesidad ni obligación de someterse a las mismas pruebas masculinas que sus compañeros franceses, y que abandonar París constituía una decisión basada en la prudencia y no en la cobardía:

Que los franceses que conoces y que son quizá causa de que no te hayas venido cuando Rico, Sans, Zamacois... se queden en París y llamen cagones a los que se van, lo comprendo, por lo mismo que son franceses; pero tú que eres extranjero no sé la necesidad que tenías de pasar por esa triste prueba... ni tu honor te llama a combatir al enemigo ni ha de criticarse el que uno deje la ciudad en que vive en esos casos excepcionales y cuando la prudencia y el buen sentido y la práctica constante lo exigen (DÍEZ, 1994: 692).

Tras haber estado la ciudad sumida en la confusión durante el mes de agosto de 1870, fueron numerosas las personas que decidieron ponerse a salvo de los posibles peligros y huyeron a otras regiones o al extranjero, una cuestión igualmente viva entre los artistas franceses y extranjeros instalados en París en un momento en que la exaltación patriótica causaban al mismo tiempo fascinación y temor. Raimundo de Madrazo contempla la partida de Rico y Zamacois una vez enfriados los ánimos sobre la posibilidad de victoria de los franceses, y señala con orgullo en sus memorias que, al ser interpelado por un Gérôme que acaba de tomar la decisión de partir y que le preguntaba por qué no se marchaba, le respondió con cierta parquedad fanfarrona "porque quiero quedarme" (MIALARET, 1975: 311). Su resolución parece encajar con el discurso sobre el honor y la cobardía, y la exaltación de un modelo de masculinidad militaroviril, siendo especialmente apreciada por sus compañeros franceses, y en concreto por Vibert. Para Raimundo de Madrazo abandonar la ciudad era prácticamente comparable en deshonra a una deserción, al anteponer el bienestar propio al bien común, algo sobre lo que después reflexionó al escribir que "las deserciones son fatales, y después la vida continúa y no se vuelve a pensar en ello" (MIALARET: 1975: 311), a pesar de que en el momento son consideradas como una decisión capaz de hundir el honor y reputación de una persona. Esto último encaja con los pensamientos de Manet, quien indicaba a su esposa que 
Muchos hombres incluso se han marchado, pero creo que lo pagarán a su regreso (...) En la reunión de Belleville se ha proclamado los nombres de las personas ausentes y se ha propuesto pegar sus nombres por París y confiscar sus bienes en beneficio de la nación (MANET, 1996: 41-42),

o con el hecho de que, según las memorias de Madrazo, el pintor Saintin pidiese al español que llevase sus maletas a la estación al decidir partir de la ciudad, temeroso de ser acusado de cobarde ${ }^{226}$.

La decisión también despertó reacciones entre los colegas españoles de Raimundo de Madrazo, ya que a pesar de que Federico intentó presionar a su hijo indicándole que "aquí todos los que me preguntan por ti me dicen que has hecho muy mal en no salir de París” (DÍEZ, 1994: 692), Martín Rico lo recordaba con gran admiración al señalar cómo al optar por permanecer en la ciudad Raimundo aceptaba las consecuencias y los horrores del sitio, prefiriendo la opción de "portarse como un valiente" (RICO, 1906: 62). Al parecer, también Mariano Fortuny admiraba la actitud del joven Madrazo, quizás más por desafinidad política con la forma en que España entendía la guerra francoprusiana que por interés por la causa o por involucrarse en el conflicto. Así, en una carta a Raimundo le dice

Entiendo lo que la situación tiene de triste; pero preferiría mil veces estar en tu lugar que encontrarme en España, donde soy testigo de la parcialidad hacia Prusia y de la malevolencia hacia los franceses (DAVILLIER, 1875: 64).

Sin embargo, la relación entre compromiso político, actitud viril y la actividad militar no parece excesivamente arraigada entre los pintores españoles, ni en el propio Madrazo, quien en la distancia temporal de sus memorias observa el ridículo de la fiebre patriótica entre los franceses, de la que al parecer él no llegó a contagiarse. Así relata que, al ser cuestionado por parte de sus compañeros sobre cuál sería su actividad durante la guerra y sitio, le animaron a enrolarse en el Batallón de los Amigos de Francia, única y exclusivamente porque el uniforme era muy bonito. La proliferación de uniformes militares ${ }^{227}$ tampoco sedujo a Madrazo, que la veía de manera crítica como una recreación en las apariencias y en la pretensión de una gallardía que abandonaba al hombre en los momentos más importantes, ejemplo de lo cual es su ridiculización del supuesto heroísmo de Vibert ${ }^{228}$, o del miedo de Goupil ${ }^{229}$.

El relato de Raimundo sobre su vida cotidiana durante el sitio está plagada de lagunas en lo que respecta a retratar la miseria y las situaciones dramáticas que se

\footnotetext{
226 "Saintin vio a su tío y decidió marcharse, y como le preocupaba que le vieran partir, me pidió que llevase su maleta a la estación: todo el mundo creía que era yo el que se marchaba" (MIALARET, 1975: 311).

${ }^{227}$ El orgullo que se traduce en la carta de Manet a su esposa al decirle "ojalá pudieras verme en mi capote de uniforme de artillero" refleja que, evidentemente, muchos artistas franceses entendían el uniforme militar como una nueva forma de despliegue masculino (MILNER, 2000: 93).

${ }^{228}$ Así, señala que al primero que vio "pavonearse en el uniforme de Amigos de Francia, el día de la batalla de Champigny lo vi de civil", y que la herida de Vibert no tenía "nada de glorioso (era en el trasero)", y que Vibert no volvería a salir a combatir (MIALARET, 1975: 311).

229 "Quería que me fuese a vivir a su casa con la intención de ser protegido por la bandera española. $\mathrm{Ni}$ hablar" (MIALARET, 1975: 312).
} 
sucedieron en París; sin embargo, su opinión sobre los franceses, especialmente sobre los vinculados al mundo del arte, entra en conflicto con el concepto de heroísmo que aparece en las biografías de artistas franceses publicadas a finales del siglo XIX y comienzos del XX, en un intento de reflejar la cobardía subyacente en muchas de sus actitudes. También concede atención a algunas mujeres de la familia Vibert que permanecieron en París, a pesar de que el punto de vista generalizado tras el decreto de Trochu fue que las mujeres eran prescindibles en una plaza en sitio, una opinión compartida también por Manet ${ }^{230}$ y visto de manera extrema por Madrazo. Las mujeres Vibert son descritas como más exaltadas y más patriotas que los hombres, algo que, lejos de suponer un halago o un comentario admirativo, recae en un estereotipo de género, al recriminar la facilidad con que se emocionaban, no solo como un rasgo propio del carácter femenino, sino también como consecuencia de su alejamiento de la realidad militar, lo que sentencia con un contundente "ellas no van al frente" (MIALARET, 1975: 310). La labor de Madrazo durante el sitio se limitó a participar en el proyecto de la Lotería de la Ópera y su vinculación con el servicio de ambulancias. En el primer caso, consta entre los miembros del comité artístico junto a Meissonier, Baudry, Charles Garnier, Corot, Lenepveu, Pils y Henri Regnault ("Loterie Nationale", 1870: 2), quienes registraron las obras que se recibían como donación y cedieron obra de su mano; también se conservan datos de su participación en la lotería de 1871. Respecto a su pertenencia al cuerpo de ambulancias, Raimundo no busca presentarlo como un hecho heroico, sino que lo atribuye a la necesidad de salir de la ciudad, lo que lleva a entender que tomó parte en las salidas extramuros.

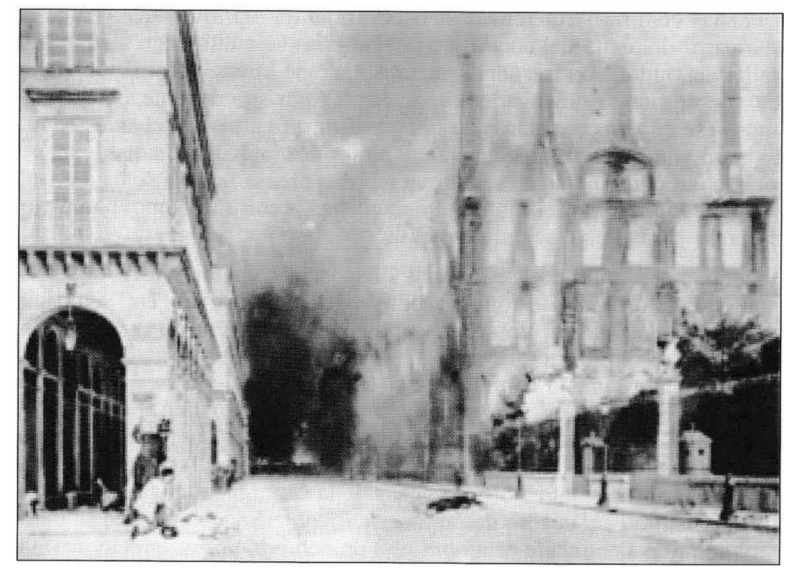

Fig. 74. Ignacio León y Escosura, La calle Rivoli la mañana del 25 de mayo de 1871. Paradero desconocido (ALZAGA, 2011:371).

Tan solo una obra realizada por Ignacio León y Escosura en esta época introduce una nota visual respecto a los artistas españoles en París durante el sitio y la Comuna. Se trata de La Calle Rivoli la mañana del 25 de mayo de 1871 [fig. 74], que Octave Lacroix señala en 1872 en la exposición internacional de Londres y que describe como una imagen de la calle

\footnotetext{
230 “Te equivocas al reprocharte no haberte quedado. De hecho, las mujeres no harían más que entorpecer a los hombres (...) además, muy pocas mujeres se han quedado”. Carta a Suzanne Manet de 15 de septiembre de 1870 (MANET, 1996: 41).
} 
Desierta y desolada, llena del humo del incendio; el lamentable espectáculo de la guerra civil. Un cadáver se encuentra tirado en la calzada, y, a la derecha, dos burgueses asustados esperan el momento de cruzar la calle sin peligro (LACROIX, 1872: 6).

La escena, en efecto, muestra una vista del Palacio de las Tullerías incendiado, mientras dos personajes se refugian tras la famosa arcada de la calle; sin embargo, más que dos burgueses asustados, las actitudes que demuestran son significativas: uno de ellos parece estar tomando apuntes de la escena, mientras que el otro pertenece al cuerpo de ambulancias. Otra reseña más tardía relacionaba al dibujante de la escena con el propio León Escosura, haciendo de él un autorretrato heroico en un momento histórico y turbulento. Les Annales politiques et littéraires publicaba en 1904 una reproducción de la obra, señalando que

Cerca de esta inocente víctima de la guerra civil, dos hombres, escondidos detrás de uno de los pilares de las arcadas, miran atentamente hacia la barricada y siguen la aproximación de los soldados. Uno de ellos, rodilla en tierra, toma rápidamente apuntes en un cuaderno. Es el propio Sr. Escosura, el autor del cuadro que reproducimos, y a cuya audaz curiosidad debemos esta imagen de gran interés histórico y de un aspecto tan desgarrador (Les Annales..., 1904: 199).

Según recoge Amaya Alzaga, Escosura permaneció en París durante la guerra francoprusiana, donde contempló los grandes acontecimientos "gracias a su amistad con un médico de las ambulancias, en cuya compañía marchaba, tomando los apuntes necesarios para el trabajo que meditaba" (ALZAGA RUIZ, 2011: 295); Ossorio y Bernard, quien usó como fuente a Manuel Murguía, ayudó a transmitir una nueva imagen del artista español como valiente cronista del momento al mencionar la obra, en la que se autorretrata junto al doctor Koene, exponiéndose a grandes riesgos. De esta manera, Escosura "empezó su cuadro bajo las balas de las barricadas y entre el tumulto del combate", aprovechando la escena para mostrarse "oculto tras uno de los pilares de las arcadas, a la derecha de las Tullerías". Se adecuó de este modo al modelo de masculinidad extendido entre los artistas parisinos mediante la exaltación de la valentía y el trabajo artístico del natural por encima de la seguridad personal (ALZAGA RUIZ, 2011: 295). El tema de la obra otorgó nueva notoriedad al pintor; la pintura fue adquirida por el marchante Avery, lo que contribuyó también a proyectar una imagen de Escosura acorde con la situación política y con las nuevas expectativas que la sociedad tenía en los artistas como testigos del cambio social.

Algo similar sucedió en el caso de Daniel Urrabieta Vierge, en su caso vinculado al artista como reportero intrépido, aunque este último tiene como modelo la figura paterna, involucrada, según Le Monde Illustré (1880: 16), en el espíritu militar español (MARTHOLD, 1906: 3$)^{231}$. Tanto Vicente Urrabieta como Daniel Urrabieta Vierge participaron con sus dibujos sobre el frente y la defensa de París en la prensa francesa del momento; el primero lo hizo en L'Illustration, con obras como la Llegada de los heridos transportados por los barcos-ómnibus del Sena (1871:183) y el segundo en Le

\footnotetext{
${ }^{231}$ La nota biográfica incluida a la muerte del dibujante sitúa a Vicente Urrabieta como miliciano en Madrid en los años cincuenta, por lo que fue condecorado con la Cruz de San Fernando en 1856.
} 
Monde Illustré, donde dejó constancia de su condición de testigo de distintos acontecimientos, tal y como sucede en el Fusilamiento de la calle de la Paz el 22 de marzo (1871: 196), firmado por Urrabieta, o Los desastres de París (1871: 73), Escenas del bombardeo (1871: 73) o La suspensión de las armas (1871: 294) de Vierge. Es fundamentalmente durante la Comuna cuando Escosura y Vierge desarrollan su actividad pictórica frente a la interpretación de las posturas adoptadas por Madrazo, Rico y Zamacois, cuyo posicionamiento pasó desapercibido durante la guerra francoprusiana. A pesar de que las biografías publicadas sobre Daniel Urrabieta Vierge destacan su coraje al permanecer en la ciudad ${ }^{232}$, un hecho que le facilitó la aceptación entre los franceses (MARTHOLD, 1906: 27), es cierto que no contribuyó al conflicto armado ni como soldado ni como reportero en el frente, como pone de manifiesto el hecho de que sus escenas de la guerra sean reproducciones de dibujos de otros artistas, como Régamey o Harant. Su papel de dibujante en la Comuna es, sin embargo, fundamental en las biografías de Urrabieta Vierge como forma de destacar su desprecio ante los riesgos, lo que ofrece una imagen masculina que enfatiza el hecho de que las adversidades no le afectan (MARTHOLD, 1906: 42; BERGERAC, 1911: 125; WELLS, 1904: 209), y que revierte en una nueva interpretación del artista de la historia contemporánea de ojo imparcial.

\subsection{Retratos de artistas españoles en París}

El análisis al que ha sido sometida la representación del artista en el ámbito parisino, abordada recientemente con un recorrido bastante completo por Carlos Reyero (2014), y de manera más somera por González y Martí (1989) o en alusiones puntuales en monografías o catálogos de exposiciones (DÍEZ, 1997; RINCÓN, 1991), suele hacer hincapié en la vinculación entre este y la gestación de una imagen a medio camino entre la bohemia y el casticismo español, especialmente entre los artistas que visitan París a partir de la década de los sesenta. La interrelación entre París y la bohemia artística, aplicada a los artistas españoles, suele vincularse, en primer lugar, a que la estancia parisina era una etapa de formación juvenil, en la que se adaptaban a la tradicional despreocupación y fogosidad de su edad, y las características de la vida en la capital francesa. Efectivamente, buena parte de los artistas que a lo largo del siglo XIX viajaron a París lo hicieron en su juventud y como parte de su aprendizaje artístico; el estudio del registro de copistas del Louvre, en el que, entre los datos personales se registraba la edad del artista, demuestra que de los cuarenta y tres artistas españoles que solicitaron permisos entre 1834 y 1870, treinta y uno se encontraban en el rango de edad entre los veinte y treinta años, correspondiéndose también con la edad de los que frecuentaban

\footnotetext{
${ }^{232}$ Marthold inicia el relato del carácter militaroviril de Daniel Urrabieta desde su infancia, vinculándola directamente en el despertar artístico en una anécdota con soldados de plomo que utiliza para dibujar, precisamente, un soldado (MARTHOLD, 1906: 9; MOUREY, 1911: 161; MORIN, 1894: 108); Bergerac (1898: 1-2; 1911: 119) incluso señala cómo "a la primera bomba que cayó en París" Vierge corrió a su encuentro, relacionando su determinación de no regresar a España durante la guerra, ofreciéndose a trabajar en la prensa, resuelto a compartir los males de la ciudad y a captar la actualidad; es en relación a la posibilidad de obtener un trabajo por lo que tanto Bergerac como Wells razonan la decisión de quedarse en París, precisando este último que "estaba a punto de regresar a Madrid cuando se le abrió una plaza entre el personal de Le Monde Illustré" (WELLS, 1904: 209) la fama de Vierge en relación con la guerra llegó también a oídos americanos (ROBINS PENNELL, 1920: 199).
} 
bien la Escuela de Bellas Artes o los talleres particulares parisinos ${ }^{233}$, una edad a medio camino entre la juventud y la madurez. No obstante, también debe tenerse presente la existencia de otros artistas españoles en París, especialmente de aquellos formados en España y que se afincaron en la capital francesa con posterioridad, y que por lo tanto no aparecen consignados en el análisis de datos del registro del Louvre.

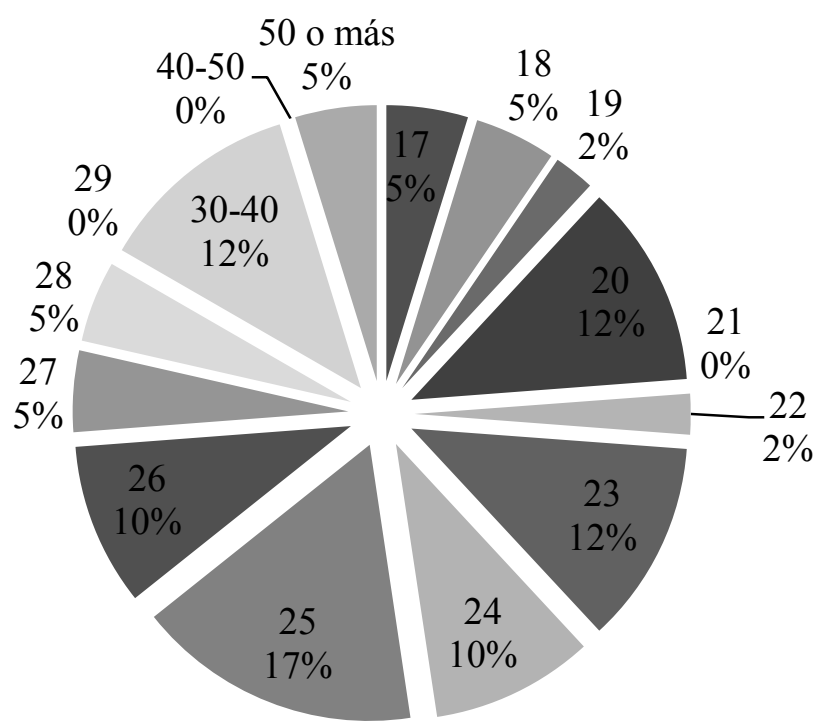

Tabla 1. Rango de edad de los copistas españoles en el Louvre (1834-1870)

Una vez constituida París como capital del cosmopolitismo europeo y de la moda artística, es evidente que la imagen que los españoles -relacionados o no con la colonia española en París- quisieron dejar de sí mismos en sus retratos se adecúa con la del hombre de mundo, es decir, como elegante y habituado a los usos de la sociedad culta extranjera. Entre los retratos de artistas españoles (y autorretratos) que se produjeron en París pueden distinguirse entre los de amistad, los relacionados con el éxito artístico, y los vinculados con la bohemia.

\subsubsection{Retratos de amistad}

Si los artistas españoles afincados en París no fueron numerosos en las dos primeras décadas del siglo XIX, Federico de Madrazo dejó constancia en la tercera de buena parte de sus compatriotas, la mayoría de ellos jóvenes artistas pensionados en París, entre julio y septiembre de 1839, antes de partir a Roma. Formó con ellos un álbum privado (DÍEZ, 1994b: 80) de especial valor sentimental para el pintor, en que queda de manifiesto el valor social y sentimental del retrato que probablemente José de Madrazo le había inculcado, y que Reyero (2014) señala acertadamente en la correspondencia entre padre e hijo al encargarle realizar el retrato de Ingres en 1833. No en vano el patriarca de los Madrazo realizó durante su estancia en Roma numerosos retratos, al

${ }^{233}$ El registro de copistas del Louvre, en el que entre los datos personales se registraba la edad del interesado, demuestra que de los 43 artistas españoles que constan haber solicitado permisos entre 1834 y 1870, 31 se encontraban precisamente en ese rango de edad, siendo la más común entre los artistas que acuden con intención formativa a París. Tan solo cinco se encuentran en el rango entre los 15 y los 20 , otros cinco en el de 30-40, y dos son artistas maduros mayores de 50 años [ANF 20150282/201-203]. 
dibujo, al aguafuerte y pintados, de algunos de sus compañeros españoles y de otros artistas afincados en la Ciudad Eterna, como el alemán Reinhardt ${ }^{234}$. Entre los retratos realizados por Federico de Madrazo en París figuran los del escultor José Siro (Museo Nacional del Prado, $\mathrm{n}^{\circ}$ inv. D5376), el pintor Carlos Luis de Ribera [fig. 75] (realizado el 7 de septiembre [Museo Nacional del Prado, $\mathrm{n}^{\circ}$ inv. D5390]) y el del grabador Calixto Ortega [fig. 76] (9 de septiembre [Museo Nacional del Prado, $\mathrm{n}^{\circ}$ inv. D5375]), a quienes retrata a lápiz, de busto, prestando especial atención a sus rostros y mostrando de ellos una imagen de jóvenes elegantes y de cuidado aspecto, con melena y romántica perilla, a excepción de Carlos Luis, cuyo porte erguido, cabello corto y la barba cerrada indican una mayor madurez.

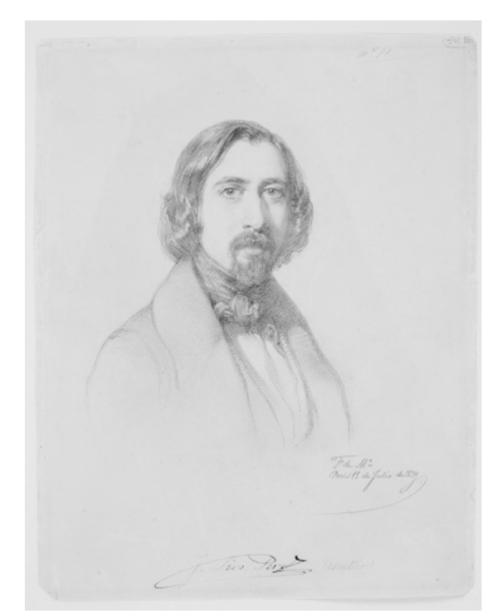

Fig. 75. Federico de Madrazo. Retrato de José Siro. Museo del Prado.

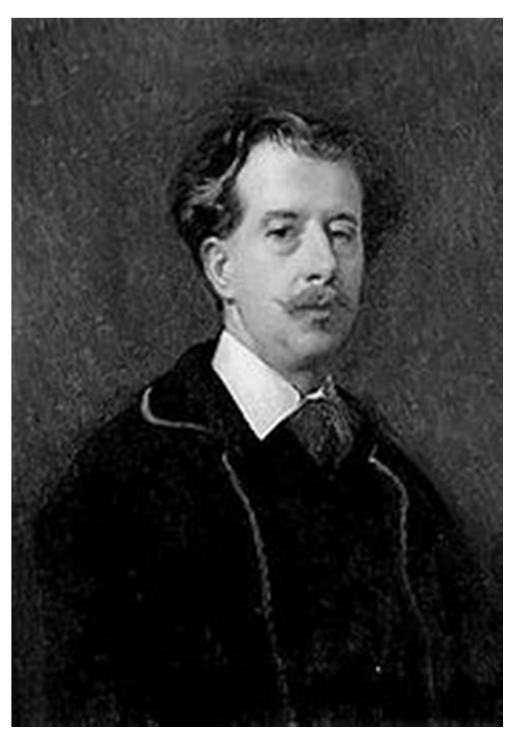

Fig. 77. Raimundo de Madrazo. Retrato de Francisco Lameyer (MARTÍNEZ RODRÍGUEZ, 2007:113).

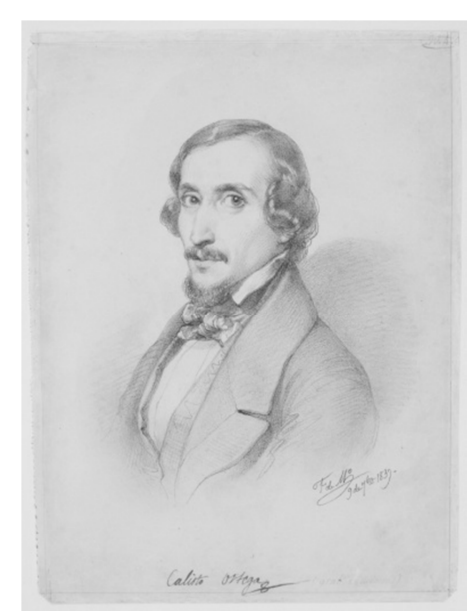

Fig. 76. Federico de Madrazo. Retrato de Calixto Ortega. Museo del Prado.

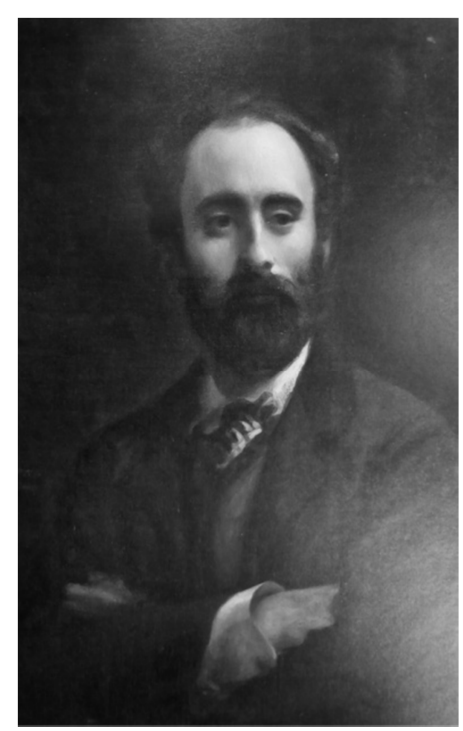

Fig. 78. Raimundo de Madrazo. Retrato de Martín Rico. Museo de Bellas Artes de la Habana.

\footnotetext{
${ }^{234}$ El inventario de José Madrazo recoge, entre otros, el retrato en busto del grabador Luigi Fabri (1809), el de Bonelli y Reinhart (1812); consta que además realizó los de Teodoro Mur, Miguel Cabañas, Ramón Barba y Antonio Solá (DÍEZ, 1998a: 392 y 400; SOLACHE VILLELA, 2007: 84-96).
} 
También Raimundo de Madrazo retrataría, casi treinta años más tarde, a otros de sus compañeros en París: a Francisco Lameyer [fig. 77] (MARTÍNEZ RODRÍGUEZ, 2007: 113), a Eduardo Zamacois en 1864 y Martín Rico en 1866 [fig. 78] (Museo Nacional de Bellas Artes de La Habana, $n^{\circ}$ inv. 93-444), que permiten entender la forma en que Madrazo entendía su propia posición de artista como hombre serio y elegante, lejos de la informalidad que se presupone de la colonia española en París ${ }^{235}$. La sensación que transmite el retrato de Rico es la de un hombre seguro de sí mismo, como denotan sus brazos cruzados y su porte erguido, casi hermético, y que cuida su apariencia sin abandonarse a la etiqueta del París elegante; de él solo se intuye su profesión artística en el carácter introspectivo de la mirada perdida, que denota una vida interior creativa, y en la vestimenta al mismo tiempo moderna y modesta del trabajador cosmopolita. La dignidad que presentan tanto Rico como Lameyer, a pesar de la frialdad de color que se ha señalado como impropia de un retrato de amigo (LAGUNA ENRIQUE, 2013: 898-899; BARÓN, 2011: 260-262), en los retratos pintados por su hijo debió de disgustar a Federico de Madrazo al compararlo con la imagen que ofrecía el retrato que Léon Bonnat realizó de Raimundo en la misma fecha; así se lo comunicaba en carta de 10 de diciembre de 1866, en que comentaba que, a pesar de tratarse de un esbozo, no dejaba de ser "una pintura triste" que daba una pobre imagen de Raimundo: “qqué necesidad había de representarte enfermizo y sucio?" (DÍEZ, 1994a: 656). Así, el retrato pintado por Bonnat se alejaba de la tradicional imagen del pintor español como moderno elegante, y por lo tanto de la muestra de un interés por la corrección y el afán de superioridad que caracterizaba a los artistas de buena sociedad, algo que al parecer Raimundo de Madrazo había olvidado, tal y como le reprocha su padre en varias ocasiones ${ }^{236}$.

\subsubsection{Retratos de éxito}

Sin embargo, más allá de esta imagen del joven pensionado, el desarrollo de carreras artísticas en el extranjero contribuyó a crear una imagen del éxito del artista basada bien en la ostentación económica, relacionada con una trayectoria prolífica en el mercado, bien en la bohemia y el reflejo de la vida mundana. Entre las imágenes del éxito cultural del artista español puede encontrarse el Autorretrato en el estudio de Antonio Gisbert (REYERO, 2014), en el que la figura del artista como estudioso solitario en su espacio de trabajo queda resignificada por el espacio que le rodea, donde

\footnotetext{
${ }^{235}$ Federico de Madrazo prevenía a su hijo sobre los artistas españoles en París en sus cartas de 1862 y 1863, calificándolos de "pilletes". Así, en enero de 1862 le dice que su hermana Carlota le ha dicho "que los artistas de allí son unos pilletes, lo cual no es nuevo para nosotros; creo que debes tener pocas relaciones con ellos y solo llevarte bien de dientes para fuera" (DÍEZ, 1994a: 587), precaución que reitera en julio de 1863 en los mismos términos (DÍEZ, 1994a: 620).

${ }^{236}$ En 1867 Federico de Madrazo le acusa de no estar pensando en su carrera artística ni en su futuro profesional, de lo que se desprende un continuo cuestionamiento de las capacidades de Raimundo para abordar las obligaciones masculinas según las entiende Federico. "Es necesario" le dice "que vayas pensando seriamente pues, ya tienes edad para ello, en que se necesita orden y método para vivir a la moderna sobre todo, y que de lo contrario pueden seguirse muchos perjuicios" (DÍEZ, 1994: 660).
} 


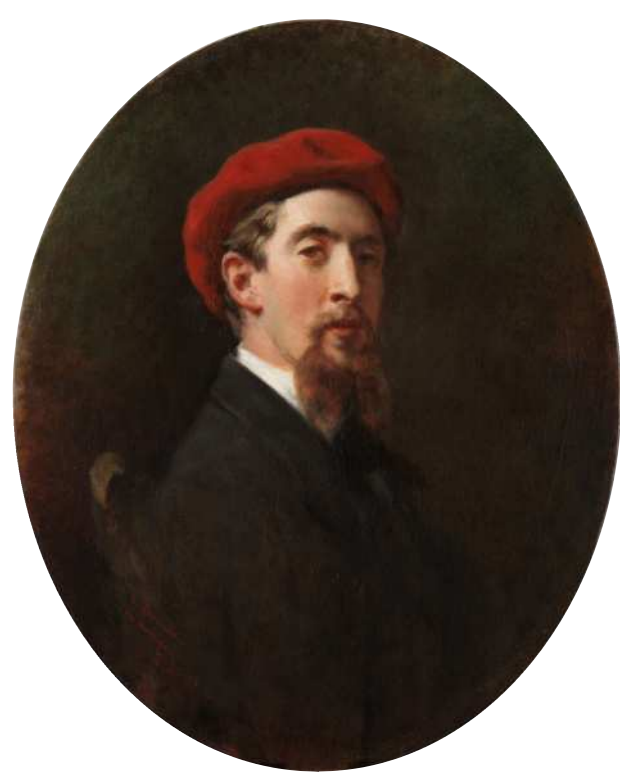

Fig. 79. Raimundo de Madrazo, Retrato de Eduardo Zamacois. Museo Nacional del Prado.

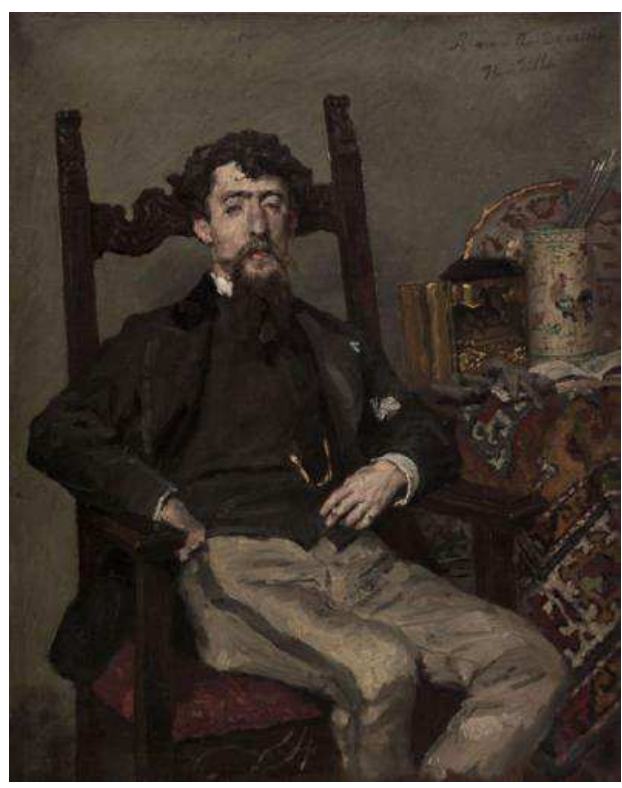

Fig. 80. Henri Pille. Retrato de Eduardo Zamacois. Musée du Petit-Palais, París.

se presentan alusiones a la pintura italiana, a la música, y a la experiencia acumulada del artista a través de unas carpetas de dibujos que acumulan bocetos y apuntes.

Ejemplo del primer caso es Eduardo Zamacois, quien habiéndose formado con Meissonier alcanzó rápidamente el reconocimiento por parte de la crítica francesa y un notable éxito económico, especialmente por su vinculación estilística con la pintura de casacón y el origen del fortunysmo (REYERO, 1990:219-230). De los artistas españoles con los que Zamacois mantuvo relación - personal o profesional ${ }^{237}$, , destacan sus íntimos amigos Raimundo de Madrazo y Mariano Fortuny. Raimundo de Madrazo realizó en 1864 un retrato de busto prolongado de su amigo Zamacois [fig. 79] (Museo Nacional del Prado, $\mathrm{n}^{\circ}$ inv. P08105) en el que lo presenta en actitud majestuosa a pesar de su juventud, sentado, con una larga perilla y tocado con una boina roja, adivinándose una expresión de curiosidad. La imagen contrasta con la elegida, seis años después, por el francés Henri Pille [fig. 80] (Musée du Petit-Palais, $n^{\circ}$ inv. PP651), que evidencia también el cambio producido en el artista. Frente a la imagen viva y galante ofrecida por Raimundo de Madrazo, Pille muestra ya a un artista maduro, representado casi de cuerpo entero.

Pille opta por una imagen dignificada del profesional como hombre elegante, incluyendo en la composición un bodegón en el que destaca un jarro decorado con un fallo, en el que reposan varios pinceles. Bray señala acertadamente de este retrato el carácter de visita que reviste la presencia de Zamacois (BRAY. 2004: 148), cuyo guante descansa sobre un libro, alejándose así de los autorretratos del pintor bilbaíno en que se muestra trabajando en los que Reyero identifica una imagen deliberadamente bohemia (REYERO, 2014: 137).

\footnotetext{
${ }^{237}$ El catálogo de la venta Zamacois pone de manifiesto que el artista tuvo relación no solo con Fortuny y Madrazo, sino también con Rico, Palmaroli, Merino y Sans, y con los franceses Pille y Vibert (PETIT, 1872).
} 
La deliberada adopción por parte de Zamacois de una pose de caballero distinguido hace patente un interés por subrayar su masculinidad, en una imagen de burgués intelectual plenamente integrado en la élite de la sociabilidad artística, frente a la que ofrecía de sí mismo en su autorretrato de 1862 El autor y sus amigos (Museo Nacional del Prado, $\mathrm{n}^{\circ}$ inv. P07591), en que optó por mostrarse, de acuerdo a su situación social en el momento, como un trabajador que precisa protección, es decir, dependiente económicamente de su trabajo para otras personas. Frente a la interrelación existente en esta obra, en que es evidente una clara diferencia social entre los visitantes y el propio artista, y que por lo tanto pone de manifiesto cómo se veía Zamacois respecto a su papel masculino en la esfera parisina ${ }^{238}$, la imagen ofrecida por Pille evidencia la nueva escala a la que ha accedido el artista, afianzando su éxito en el elegante ambiente cultural parisino. Así lo revela también el que fuera incluido en la composición de Ignacio León y Escosura, Gérôme visitando el estudio de un discípulo ("The exhibition...", 1874; ALZAGA RUIZ, 2011: 312), presumiblemente el del propio artista, donde Zamacois es incluido en el grupo de la derecha.

Francisco Domingo también se asentó en París, si bien en alejado del bullicioso centro de la ciudad, donde pronto fue conocido por su pintura de género y tipos populares. En los retratos que realiza de sí mismo en su etapa parisina se presenta de perfil y en actitud de pintar -rasgo que se intuye en el autorretrato de 1883 (Academia de Bellas Artes de San Fernando, $\mathrm{n}^{\circ}$ inv. 0777), a pesar de ser de busto, en el avance de su brazo derecho y que queda patente en el de 1884 (Museo Nacional del Prado, $\mathrm{n}^{\circ}$ inv. P04492), en que figura ya con paleta y pinceles, y ante un lienzo de grandes proporciones. Jesús Gutiérrez Burón lo considera un retrato mundano (DÍEZ, 1997: 144), y Carlos Reyero (2014: 141) una imagen al mismo tiempo elegante y descuidada en comparación con la mayor etiqueta que presenta el de 1883; su traje cuidado y sobrio, el acicalamiento de la barba y el peinado negligé de sus rizos permite vincularlo efectivamente a la imagen de un artista que desea dejar constancia de sus buenas relaciones con la sociedad elegante, pero que reivindica su condición profesional no solo a través de los atributos, sino de su actitud corporal, de tal modo que su mirada rehúye la del espectador y abandona también la superficie del lienzo para mirar más allá a un modelo que no se incluye en el retrato. La exclusión del modelo indica una voluntad de protagonismo fuera de lo anecdótico, una forma de subrayar su autoridad en una representación del artista ausente; el carácter escenográfico del retrato queda de manifiesto en la representación parcial de los rasgos del pintor y en la ubicación de la figura fuera del eje central del lienzo, que es el lugar que ocupan su mano izquierda y su paleta. La inclinación de la paleta y de los pinceles, así como la mirada del artista conducen al gran espacio vacío en la parte izquierda de la composición, donde se deja intuir que algo está captando la atención del pintor, algo que le da significado como profesional al estar destinado al lienzo que se encuentra pintando, pero cuya inclusión restaría protagonismo e importancia al propio artista.

\footnotetext{
${ }^{238}$ Carlos Reyero señalaba, entre las principales diferencias entre el pintor y sus visitantes, una clara diferencia de edad y de indumentaria, poniendo de relieve que estos pertenecen a una clase social más elevada, afirmando que el pintor aparece en cierta actitud de sumisión (DÍEZ, 1997: 94); aun así, observa también que la vestimenta del artista lo presenta como un moderno cosmopolita (REYERO, 2014: 137).
} 
Entre las imágenes del artista español como muestra del éxito y de la vida cultural francesa incluimos finalmente dos retratos realizados por el francés Jacques Émile Blanche de Rafael de Ochoa [fig. 81] y de Ignacio Zuloaga [fig. 82]. El primero, naturalizado francés, se formó en la Escuela de Bellas Artes y con su primo Raimundo de Madrazo; pintor poco conocido, perteneció activamente al mundo artístico y literario parisino. En el retrato de busto que le realiza Blanche (Museo de Bellas Artes de Rouen, $\mathrm{n}^{\mathrm{o}}$ inv. 1924.1.15) en 1890 lo presenta, efectivamente, como un hombre distinguido perteneciente a la alta sociedad, vestido con elegante traje de chaqueta y camisa y corbata blanca, sobre la que destaca un llamativo alfiler ${ }^{239}$. Por el contrario, la imagen que ofreció de Zuloaga entre 1900 y 1904 se corresponde más claramente con la iconografía del pintor: lo presenta de cuerpo entero, vestido con traje, capa y sombrero, pintando al aire libre en un inmenso lienzo del que solo ofrece el envés. Como ya observaron Gronkowski (1927: 14) y Laffon (1981: $\mathrm{n}^{\mathrm{o}}$ 50), existe un vivo interés por adscribir la imagen de Zuloaga con la tradición pictórica española, y concretamente con la del siglo XVII, recurriendo a una tonalidad más parda y al modo de retrato actuante, que recuerda los modelos de pintor-caballero elegidos por Velázquez, mientras que en el fondo de tormenta se busca enlazar con la propia técnica de Zuloaga y la influencia directa de El Greco.

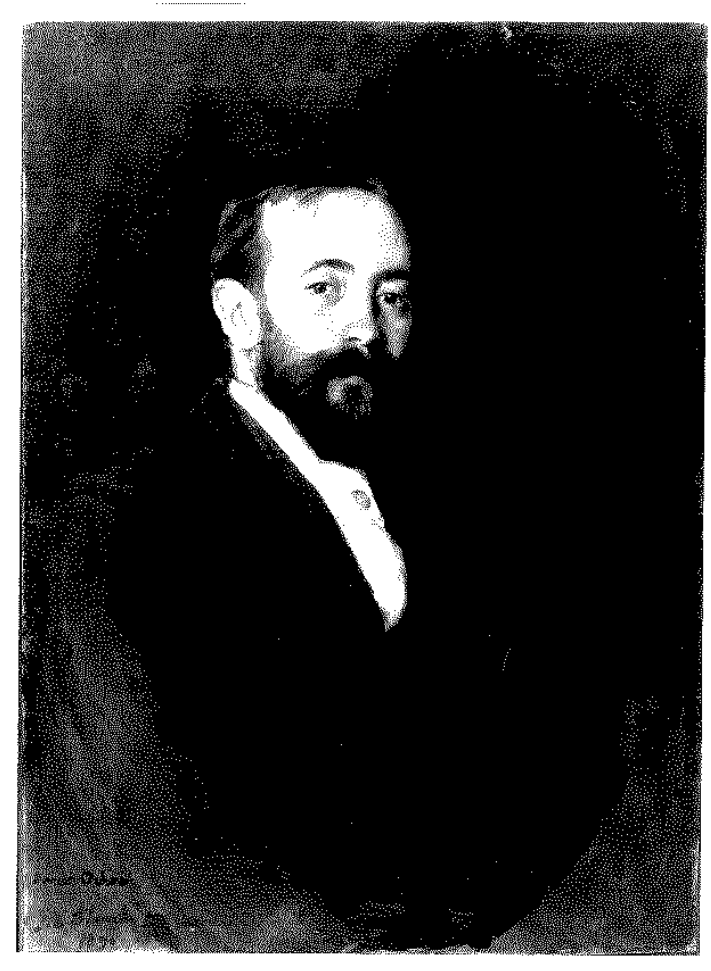

Fig. 81. J.E. Blanche, Retrato de Rafael de Ochoa, Museo de Bellas Artes de Rouen.

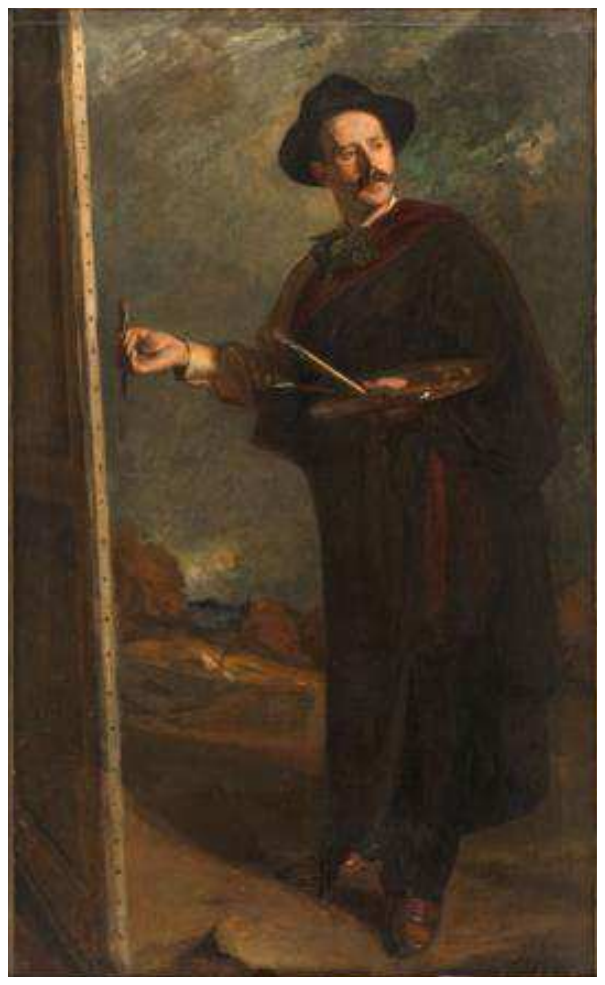

Fig. 82. J.E. Blanche, Retrato de Ignacio Zuloaga, Musée du Petit-Palais, París.

\footnotetext{
${ }^{239}$ Agradecemos a Mme. Ikram Achi, secretaria del Departamento de conservación y fototeca del Museo de Bellas Artes de Rouen habernos facilitado documentación y reproducción fotográfica del retrato de Rafael de Ochoa.
} 


\subsubsection{Retratos de artista vinculados a la bohemia}

\subsubsection{Daniel Urrabieta Vierge}

La imagen contemporánea del dibujante Daniel Urrabieta Vierge en París ofrece también una muestra interesante del éxito de un artista español, figura ampliamente mitificada debido a su origen y a las peculiaridades de su biografía ${ }^{240}$, aunque sin duda fue su decisión de permanecer en la ciudad durante la guerra franco-prusiana, así como su milagrosa recuperación tras la enfermedad que lo mantuvo paralizado, lo que más admiró a los parisinos. Sus biógrafos y conocidos se encargaron de transmitir, gráfica y verbalmente, la apariencia física de Vierge, caracterizándola de una belleza puramente masculina, en palabras de Elizabeth Robins (ROBINS PENNELL, 1920: 199), quien señaló una perfecta armonía entre el personaje y su vestimenta pintoresca (propia del artista bohemio) en su juventud, y lamentaba que al final de su carrera hubiera terminado aburguesándose.

Era realmente una criatura bella, aunque dudo si calificarlo de hermoso, por sugerir algo afeminado, ya que efectivamente no había nada afeminado en Vierge. Tenía todos los rasgos esenciales que constituyen la belleza masculina: una altura espléndida, una figura espléndida, una espléndida cabeza, rasgos finos y regulares, ojos brillantes y grandes, el rico color del español. Su barba era poblada y corta, su bigote espeso, su cabello, dividido a la mitad, razonablemente largo. Y su traje no le hacía menos pintoresco. Habría sido imposible verlo en traje negro y cuello almidonado. No llevaba abrigo, y su camisa ligera de franela estaba sujeta a su cintura por un cinturón mostrando la esplendidez de su figura y que destacaba el pañuelo de seda gris azulado que ataba flojamente alrededor de su cuello (...) No había el más mínimo tinte teatral en Vierge, o la más mínima huella de autoconsciencia: su indumentaria le pertenecía y era tan parte de él como las rayas lo son del tigre (...) Vierge cambió tanto en su apariencia como en su fortuna, y ojalá no lo hubiera hecho, puesto que se había dejado en una negligencia no menos fácil de perdonar en el hombre bello que en la mujer hermosa. Se volvió gordo y encorvado, llevaba unos pantalones anchos, una camisa amplia y descuidada, un sombrero viejo y cuello alto, doblaba la parte posterior de sus pantuflas y, lo peor de todo, había cortado su barba y cabello, eliminando el antiguo pintoresquismo para convertirse solo en el buen burgués que va a juego con la casa (ROBINS PENNELL, 1920: 200-201).

La imagen de Urrabieta que él mismo transmite en su Autorretrato [fig. 83] (Musée du Petit-Palais de París, $n^{0}$ inv. PPD292) busca transmitir la apariencia de un hombre con especial confianza en sí mismo; su indumentaria parece recordar a la mencionada por Robins, pasando desapercibida camisa y gorro en su tratamiento meramente esbozado frente a la potencia con que destaca no solo las facciones, sino también los juegos de sombras de su melena y de su hirsuta barba.

\footnotetext{
${ }^{240}$ Las biografías de Daniel Vierge están plagadas de anécdotas hipervirilizadas sobre su comportamiento durante el sitio de París o su gallardía en la forma de afrontar su hemiplejía (BAYARD, 1898: 299-307; MARTHOLD, 1906).
} 


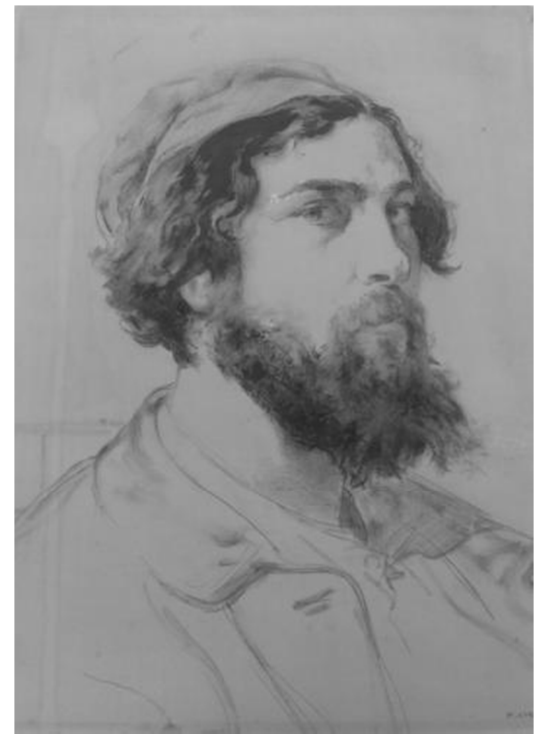

Fig. 83. Daniel Urrabieta, Autorretrato. Musée du Petit Palais, París.

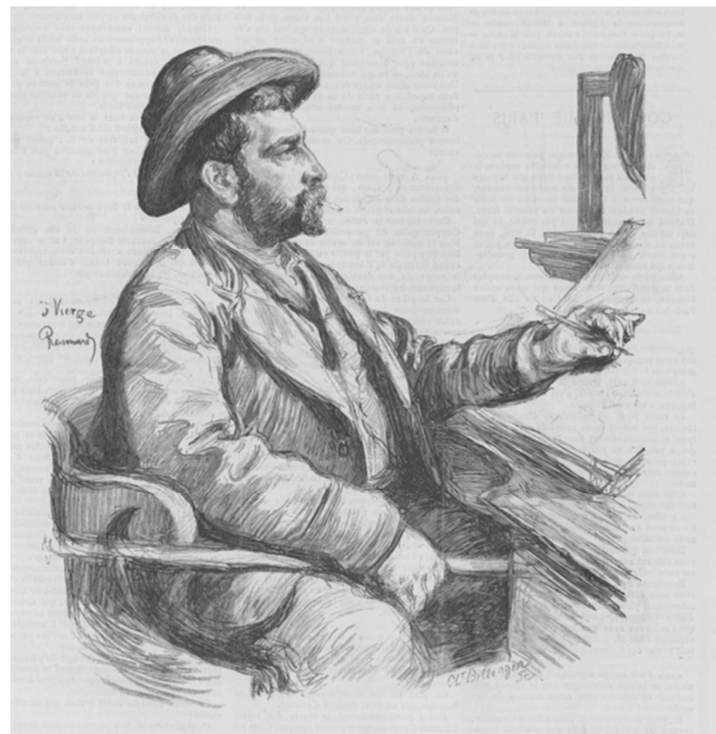

Fig. 84. Paul Renouard, Retrato de Urrabieta Vierge, Le Monde Illustré.

Uno de los retratos que conocemos de Vierge, realizado por Paul Renouard en 1889 y publicado en la portada de Le Monde Illustré [fig. 84] (1889: 1; La ilustración española..., 1890: 355) presenta al artista vestido sencillamente con un traje poco ostentoso, con su sombrero y un bastón -acompañante indispensable tras su enfermedad-, sentado a la mesa de trabajo donde se afana en realizar un dibujo con la mano izquierda mientras fuma tranquilamente un cigarro. Además de esta imagen de trabajador, Vierge luce en la solapa de su chaqueta la Legión de Honor que le fue concedida en la Exposición Universal ese mismo año; el retrato, tal y como traduce el pie de página, es una obra conmemorativa del mérito alcanzado entre los artistas franceses y del homenaje que le dedicaron los ilustradores de París el 5 de diciembre. El artista volvió a retratarse en 1890, esta vez con la mano izquierda, según testimonio de Martín Rico, quien lo remitió para que fuese publicado en La Ilustración Española y Americana junto a la carta con una breve biografía del dibujante, en la que afirma que el retrato "es uno de sus últimos dibujos, y en él se ve la mejoría de la cruel enfermedad que le aquejaba" (RICO, 1890: 355). El retrato ofrece una imagen de la visión que el propio Urrabieta tenía de sí mismo y contrasta con la que había realizado en su juventud; el artista, ahora en edad madura, aparece despojado de sus largas barbas y melena, que lo vinculaban con una personalidad bohemia, demostrando en las canas que coronan su sien derecha cierto orgullo por su aspecto físico. También la indumentaria ha cambiado, puesto que se presenta con una camisa abotonada al cuello, una chaqueta abierta y un pañuelo que reposa sobre sus hombros, con lo que se adecúa a la imagen de artista relacionado con la burguesía y la alta sociedad.

1.6.3.2. Pintores españoles en la colección Nos peintres dessinés par eux mêmes: Luis Falero y Antonio Casanova.

La colección francesa Nos peintres dessinés par eux mêmes, publicada por Bélina en 1883 pretendía constituirse como un repertorio de glorias artísticas contemporáneas 
que incluye las biografías y retratos de 150 pintores conocidos en territorio francés, veinticinco de los cuales eran extranjeros pero considerados "franceses por el talento, todos perfeccionados al contacto de la bella escuela francesa, y todos orgullosos de tener su residencia en París, capital de las artes" (BÉLINA, 1883: 7-8). Entre ellos se incluyó a dos artistas de origen español: Luis Ricardo Falero y Antonio Casanova, acompañados por sus respectivos autorretratos.

Falero, de origen granadino e instalado en París, es considerado por Belina como un prototipo del caballero español velazqueño, caracterizado por su barba puntiaguda y su bigote de extremos retorcidos. La imagen que ofrece su autorretrato [fig. 85] es la de un joven que se autocontempla, con el ceño fruncido y una mirada profunda; la camisa abierta, sin rasgos de la pulcritud propia de la etiqueta oficial, y el tratamiento despreocupado de su cabello se alejan de las imágenes de otros pintores incluidos en la compliación (especialmente de los vinculados al Instituto), habitualmente plasmados en busto o de medio cuerpo, con traje de chaqueta y en ocasiones pañuelo al cuello. Embebido de un cierto halo de misterio, el Falero que se presenta ante el público francés busca potenciar el lado creativo y trabajador de un artista "que pudo vivir de manera independiente desde los diecisiete años” (BÉLINA, 1883: 77).

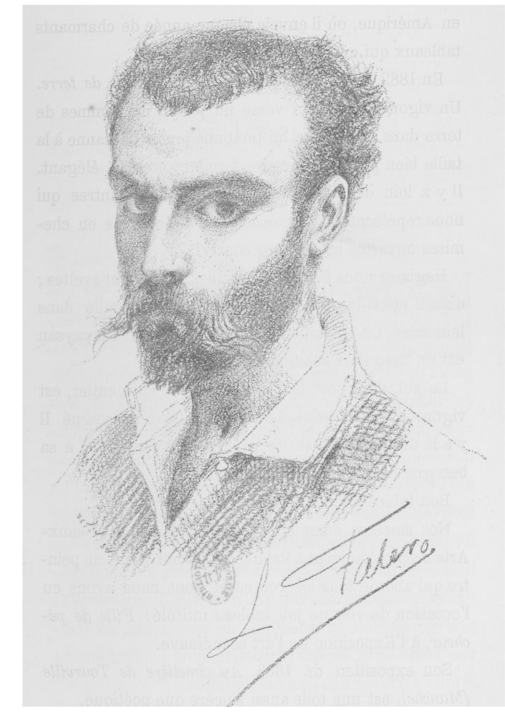

Fig. 85. Luis Ricardo Falero, Autorretrato (BÉLINA, 1883).

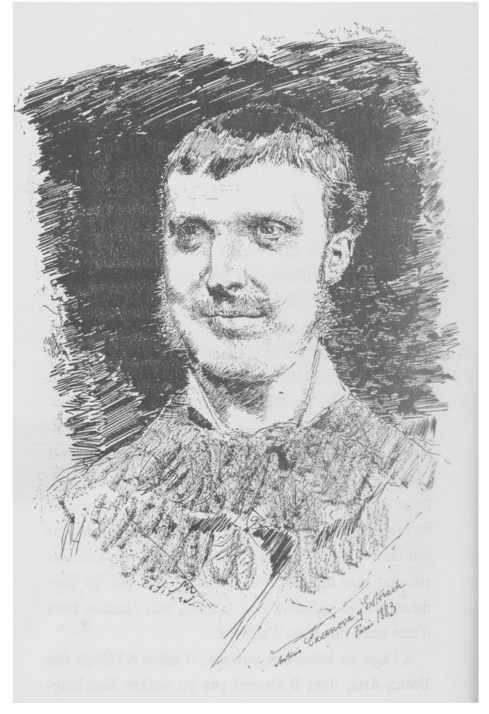

Fig. 86. Antonio Casanova, Autorretrato (BÉLINA, 1883).

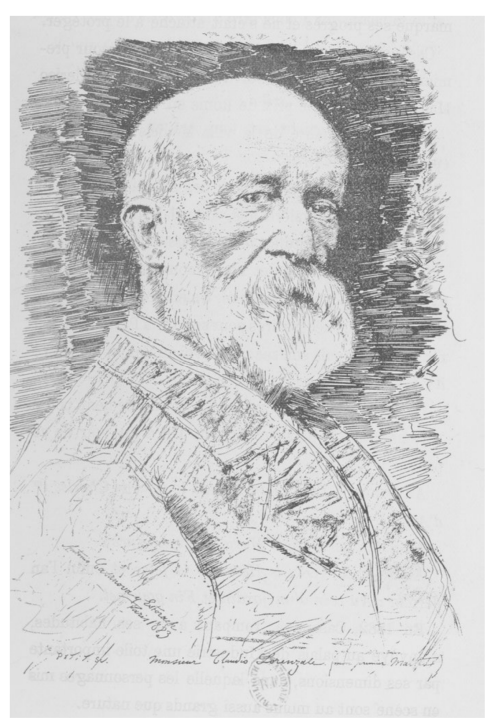

Fig. 87. Antonio Casanova, Claudio Lorenzale (BÉLINA, 1883).

También interesante por su adaptación al modelo biográfico francés es el caso de Antonio Salvador Casanova y Estorach, que en el mismo año de la publicación de Nos peintres dessinés... obuvo una segunda medalla de segunda clase en la Exposición Nacional de Bellas Artes. La biografía de Casanova generaliza las etapas de formación en la Escuela de Bellas Artes -obviando que se trataba de las de Barcelona y Madrid-, señalando que pasó por las clases de dos grandes maestros, Claudio Lorenzale y Federico de Madrazo. En clave humorística se añadía que había obtenido el Prix de Rome, una honrosa manera de denominar la pensión concedida por la Diputación de Barcelona. El retrato de Casanova [fig. 86] introduce datos poco significativos sobre su condición de artista: se representa de busto, con el pelo corto, patillas y bigote, y tan 
solo el pañuelo de lazo que anuda al cuello puede aludir a su vida bohemia. Sin embargo, fue voluntad de Casanova incorporar junto a su retrato el de su maestro en Barcelona, Claudio Lorenzale, que aparece representado en página aparte [fig. 87], compartiendo el tratamiento del fondo, aunque con un interés mayor por la captación realista de sus facciones. El retrato, dibujado por el propio Casanova, incluye un pequeño pie en el que se lee "Monsieur Claudio Lorenzale, mon premier maître", lo cual constituye, tal y como recoge Bélina (1883: 216), un homenaje a su venerado profesor.

\subsection{Presencia de retratos de artista y autorretratos en Exposiciones Nacionales e Internacionales de Bellas Artes}

La fiebre del retrato de artista o del autorretrato en las exposiciones públicas fue una constante a lo largo del siglo XIX, ya que permitía, por una parte, servir como una presentación simbólica del retratado ante la sociedad -especialmente la artística-, y revelar la fisionomía de un autor presente con varias obras en la misma; por otra parte, podía poner de manifiesto la existencia de un vínculo social y amistoso entre artistas, que dejaban de este modo constancia de su relación; y finalmente, constituía un escaparate de las habilidades retratísticas del autor. Un capricho al que no solo se dedicaron los artistas consagrados, sino que cada vez fue más empleado por pintores de segunda clase. Sin duda, la influencia de los Salones parisinos fue decisiva como escaparate para los retratos de artista, presentes ya en el siglo XVIII; así, las noticias ofrecidas por los catálogos de los mismos permiten observar que en el de 1822 se presentaron nada menos que veinte retratos, entre aficionados y artistas oficiales, veintiuno en el de 1824 , ascendiendo a treinta y dos en 1833 y a cuarenta en 1848. La cifra se multiplicó notablemente cuando, además de los veintidós retratos presentes en el salón de 1859, François-Heim incluyó los sesenta y cuatro retratos que había realizado de los miembros del Institut.

Del mismo modo se puede constatar que, siendo la mayoría de los expositores hombres ya que el máximo de retratos de mujeres artistas se alcanza en 1865 con un total de cinco retratos ${ }^{241}$, es a partir de 1830 cuando el número de autorretratos comienza a aumentar, con un gran protagonismo en 1841 (un total de ocho autorretratos frente a los diez retratos de artista incluidos en el salón), y en 1847 (dieciocho de veintitrés retratos de artista), si bien se continúan enviando retratos de amigo y de otros artistas de manera regular. Llama también la atención en los Salones parisinos la presencia, si bien moderada, de retratos de grupo, entre los que se encuentran retratos familiares del artista (Retrato del artista y su familia, Le Courcelle; Retrato del pintor y su familia, Carpentier; Retrato de la autora y su hijo, Mme. Archinard; Retrato del autor y de su hermano, Eugène Duval), escenas de taller (Interior del taller de alumnos de Gros, Massé; Interior de un taller de pintura, Le Carpentier; Interior del taller de alumnos de Cogniet durante el descanso, Mlle. Biet; Interior de taller: retratos de los señores E.B- y J.D., Émile Berthelemy) y grupos vinculados con la sociabilidad

\footnotetext{
${ }^{241}$ Ver Anexos 1 y 2.
} 


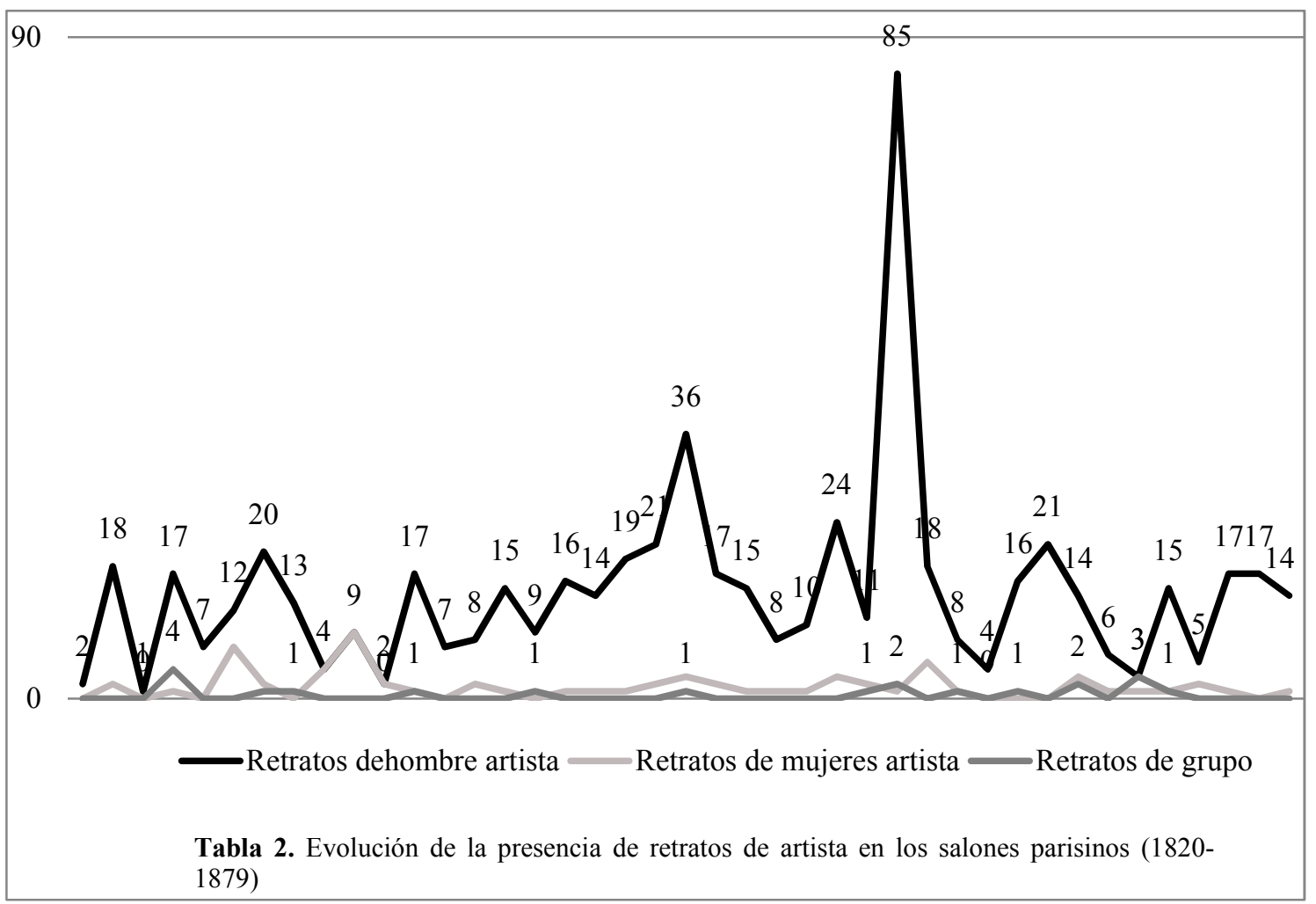

artística (Una reunión de artistas, Antony Serres; Homenaje a Delacroix, FantinLatour; Le Toast, Fantin-Latour; Un taller en les Batignoles, Fantin-Latour).

Otro de los rasgos característicos que diferenciarán la presencia de retratos de artista en los Salones parisinos y en las Exposiciones Nacionales de Bellas Artes es la vinculación con el éxito y el talento, ya que si bien en los primeros es notorio el incremento de retratos de aficionados y de pintores principiantes, también es altamente reseñable la visibilidad que tiene la jerarquía artística, de tal modo que se pueden encontrar dos retratos de directores de la Academia de Francia en Roma junto a numerosos retratos de artistas (pintores, escultores y arquitectos) vinculados al Institut, así como algunos profesores de las Escuelas de Bellas Artes, tanto de la capital como de provincias.

La presencia de retratos de artistas españoles en las Exposiciones Nacionales es, significativamente, muy limitada, y suele correr pareja a una voluntad de proyección personal o a una intención de subrayar vínculos familiares. Frente a lo ocurrido en las exposiciones en la Academia, para cuyo estudio remitimos al apartado correspondiente, se observa un progresivo desinterés por el retrato de artista o autorretrato por parte de los pintores con una carrera ya consolidada, ya que a partir de la exposición de 1862 suelen ser los pintores de provincias los que envíen sus efigies bajo el título "retrato del autor". Debe señalarse, por otra parte, que estas conclusiones se obtienen tras el análisis de unas fuentes escasas en noticias, puesto que los catálogos de las respectivas exposiciones solo destacan los autorretratos con el anterior lema, señalando los demás únicamente como "retrato" o "retrato de" seguido las iniciales, lo que sin duda dificulta la identificación de las obras. Las reseñas y críticas de las distintas exposiciones ofrecen algunos datos de interés, aunque por lo general suelen mencionar de pasada, si no 
obviar, los retratos presentados a las exposiciones por ser el género más abundante y considerado de escaso interés para el público.

\subsubsection{Retratos de artista en las Exposiciones Nacionales de Bellas Artes (1856- $\underline{1900)}$}

La creación de las Exposiciones Nacionales de Bellas Artes supuso para algunos artistas el escenario en el que era posible manifestar no solo orgullo profesional (o vanidad de aficionado) a través del autorretrato, sino también vínculos familiares y homenajes, lazos de amistad y, en algunos casos, un cierto deje de crítica social. De las obras presentadas a la primera exposición en 1856, cuatro constan como autorretratos y dos como obras de composición con posibles autorretratos. Llama la atención que, de los primeros, dos correspondan a miembros de una misma familia; los retratos de Antonio María Esquivel y de su hijo Carlos María parecen formar un grupo homogéneo subrayando, mediante la presencia de sus autorretratos, el talento familiar. Acostumbrado el público a la participación de Antonio María Esquivel como artista consagrado en las exposiciones de la Academia y del Liceo, no llamaron excesivamente la atención sus envíos a la Exposición Nacional de este año. A pesar de que el crítico de La España (1856/29/05: 2) consideraba el autorretrato del pintor como una de las mejores obras presentadas por Esquivel en esta exposición -aun cuando no se trataba de las mejores salidas de su pincel-, opinión respaldada por el crítico de La Esperanza (1856/03/06: 4), son muy escasas las referencias que se hicieron a la obra. El "Dómine Lúcas" (1856: 4) señalaba al respecto que "no hay cabeza mejor pintada en toda la exposición; (...) por lo que hace a la ejecución, tiene un relieve y un juego de color que parece hallarse recortada sobre el fondo del lienzo". La obra presentada fue, sin lugar a dudas el Autorretrato (Museo Nacional del Prado, $\mathrm{n}^{\circ}$ inv. P04297) [fig. 88] fechado en este mismo año, en el que se ofrece una imagen completamente distinta de la que había buscado en las exposiciones de la Academia de San Fernando. Lejos de la imagen de artista oficial, Esquivel se presenta con un sencillo traje a la moda burguesa, sin elementos de ostentación; el tratamiento de la cabeza, en que destacan los volúmenes gracias a la soltura de la pincelada con que trabaja el cabello, genera contraste con la expresión del rostro. El pintor tiene un gesto serio, rozando la tristeza, con una sombra de preocupación que se refleja en la arruga de su ceño. El cambio en el atuendo y la profundidad emocional pueden relacionarse directamente con el nuevo papel con el que Esquivel desea asociarse de cara al público de la exposición. De este modo, a pesar de que en el catálogo de la exposición se subrayasen sus méritos particulares como académico y profesor, la imagen de Esquivel busca una mayor aproximación a la realidad social del artista comprometido. Debe recordarse que Esquivel había contribuido a la fundación de la Sociedad Protectora de Bellas Artes, que ese mismo año de 1856 comenzaba a ser seguida por la prensa, lanzando al pintor a una nueva situación pública como principal gestor -ante la burguesía y aristocracia- en la búsqueda de fondos y animador de las actividades creativas. Se trata, de este modo, de un retrato en el que la proyección social del hombre otorga un valor añadido a la identidad profesional -ausente en la obra, pero que en el espacio expositivo era evidente por su vinculación con el resto de pinturas presentadas. 


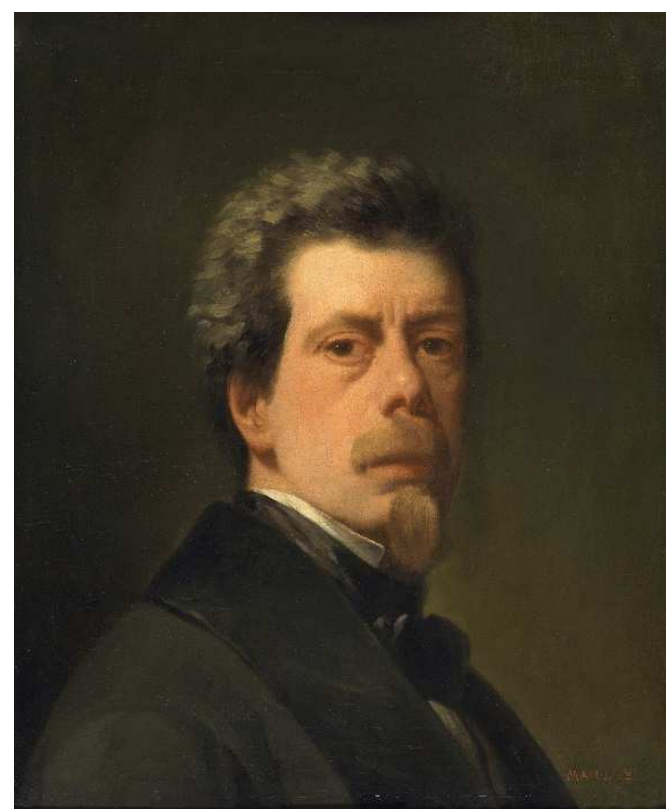

Fig. 88. Antonio María Esquivel, Autorretrato. Museo Nacional del Prado.

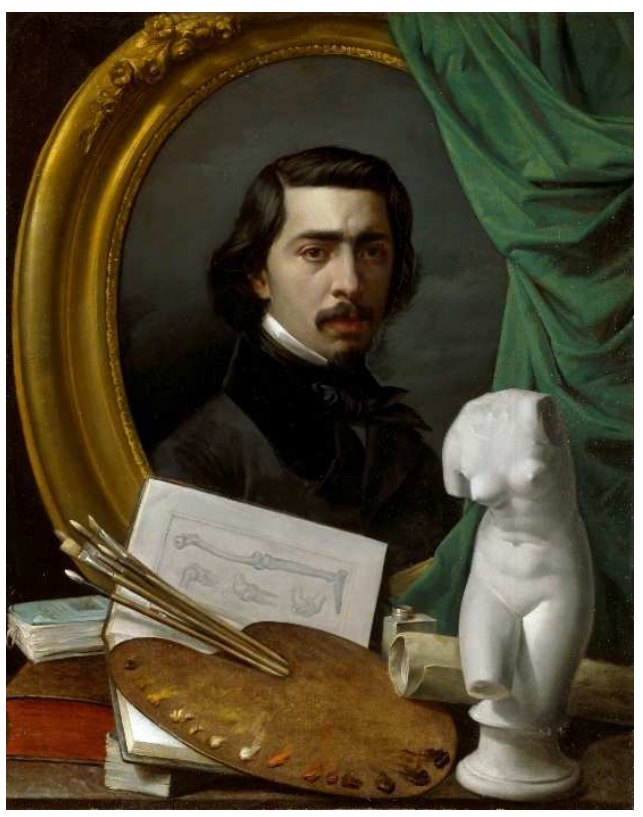

Fig. 89. Carlos María Esquivel, Autorretrato. Museo Nacional del Prado.

El Autorretrato de Carlos María Esquivel (Museo Nacional del Prado, $\mathrm{n}^{\circ}$ inv. P04306) [fig. 89] responde, sin embargo, a necesidades diferentes. En su voluntad de legitimarse como artista a pesar de su juventud, el pintor no dudó en incluir en su retrato un bodegón que, al uso de las estampas de artistas ilustres, combina elementos de la teoría y la práctica de las artes. José Luis Díez interpreta la composición como una alegoría de la pintura, en la que Esquivel encarna el componente humano de la creación artística (DÍEZ, 1997: 84). A pesar de lo correcto de esta lectura iconográfica, también es preciso aludir a la apropiación a la que recurre, en la que subyace la clara idea de una inseguridad juvenil y profesional; de este modo, podrían vincularse los tratados no solo con la teoría artística, sino con la etapa de estudio en la que el joven artista aún se incluye, no sin su correspondiente ansia de fama. En este sentido, destaca el hecho de que Carlos María envió su autorretrato junto a una obra de composición, La prisión de Guatimocín, que obtuvo una segunda medalla; la voluntad de dar a conocer al autor, es decir, al pintor detrás de otras obras, pudo haber motivado la complejidad del autorretrato y el juego de trampantojos, y sin lugar a dudas corresponde a una necesidad de identificación profesional. En las lecturas realizadas sobre este retrato tampoco ha pasado desapercibida la vinculación paternofilial, no solo en la inclusión del tratado de anatomía pictórica, sino también en el parecido físico, por lo que ha llegado a considerarse un homenaje; no obstante, las diferencias existentes en el tratamiento del rostro y de su expresividad indican también que el autorretrato de Carlos María, con la mirada ensoñada, se enmarca no solo en la tradición romántica del artista creador, sino también en la aspiración juvenil del porvenir artístico, sin el componente de proyección social visible en el retrato de su padre. Así debió de interpretarse también por el público asistente a la exposición, que encontró en el catálogo la somera descripción de la trayectoria artística del efigiado exclusivamente como discípulo (de su padre y de Léon Cogniet [Catálogo..., 1856: 12]). La crítica acogió el retrato como una muestra de su evolución artística incompleta, tal y como se desprende de la crítica publicada en El 
Clamor Público que incluía a Esquivel entre los “jóvenes que aunque todavía no gozan de la consideración de maestros, la lograrán en breve" (C.H., 1856: 3). También figura en el catálogo, con el número 42, un retrato realizado por Carlos María Esquivel de V. E. que, según la prensa contemporánea, se trataba de su hermano Vicente Esquivel, lo cual introduciría una nueva lectura, en clave familiar, de la presencia de los tres Esquivel en la primera Exposición Nacional.

Un tercer autorretrato fue el presentado por el pintor valenciano Antonio Gómez Cros, que ostentaba el título de pintor honorario de Cámara, junto a otras cinco obras de distintos géneros; el diario La Época (1856/03/05: 3) anunciaba con adelanto las obras que Gómez Cros presentaría a la exposición, incluyendo entre ellas "el retrato del autor pintado por sí mismo", lo que pone de manifiesto que la inclusión del autorretrato no fue una elección aleatoria o carente de premeditación. Al tratarse de un artista de reconocido prestigio, como demuestra el haber expuesto La batalla de Pavía, obra encargada por y propiedad de la Reina, parece que el presentar su autorretrato confirma una voluntad de reconocimiento público. El hecho de que sus obras no estuviesen muy bien colocadas en la exposición, tal y como recoge La España (1856/29/05: 2) subrayando el golpe que habría supuesto para el autor, hace comprensible que muchas reseñas no se ocupen de su retrato, puesto que, tal y como señala La Zarzuela (GANTE, 1856: 148), este estaba colocado a bastante altura. Las noticias aportadas por el catálogo lo definen como un retrato en óvalo, de media figura y tamaño natural (Catálogo..., 1856: 15); por su parte, Gil Salinas (1992: 174), tomando como fuente la exposición retrospectiva dedicada al artista en 1953, lo describe representado "tocado con un gorro de petite point al estilo de Teófilo Gautier", una imagen más próxima a la del artista consciente del carácter excepcional del genio que a la del trabajador vinculado al ámbito oficial.

Entre los retratos de artista presentados a la Exposición Nacional de 1856 figura, casi de pasada, el Autorretrato de Louis Debras, pintor francés afincado en Madrid, que apenas es mencionado en las noticias de la época (GANTE, 1856: 141); al igual que a Carlos María Esquivel, se consideró a Debras un artista no consagrado (C.H., 1856: 3). A pesar de esto, su obra obtuvo mención honorífica. Finalmente, consta un último retrato presentado por un artista que firmó bajo la inicial V., de quien el catálogo regía la voluntad de permanecer en el anonimato; con el número 209 se encontraba la obra bajo el título Familia de cinco personas, cuya descripción precisa "parecen ser una madre y sus cuatro hijos; el mayor, oficial de artillería, al lado de un caballete con la paleta de pintar en la mano".

En la exposición de 1858 tan solo se presentan tres retratos de artista, correspondientes todos ellos a principiantes. El que más llamó la atención de la crítica fue el retrato que Eduardo Balaca realizó de su hermano Ricardo, por tratarse de la efigie de un pintor adolescente que concurría a su vez a la exposición con dos obras de composición (un Episodio de la batalla de las Navas de Tolosa y Josué deteniendo al sol). Se trata, en este caso, de una presentación en sociedad del pintor, que participaba, según Ossorio (1971), en su primera exposición y de una llamada de atención, 
evidentemente propagandística sobre su corta edad ${ }^{242}$, al mismo tiempo que señalaba la importancia de los vínculos familiares, al encargarse de la realización del retrato su hermano mayor.

Sin embargo, los otros dos retratos presentados -autorretratos en ambos casos- no parece que llamasen la atención de la crítica. El primero de ellos representaba al pintor José Díez, de quien el catálogo informaba ser natural de Sevilla y discípulo de la Academia de San Fernando (Catálogo..., 1858: 6); este pintor, según Ossorio, no volvió a concurrir en otras exposiciones, lo que mueve a pensar que se tratase probablemente de un artista aficionado o un principiante cuya carrera no siguió adelante. Más fortuna tuvo Vicente Izquierdo, discípulo de las academias de San Fernando y de San Carlos de Valencia, que concurrió por primera vez a una Exposición Nacional en 1858 con su autorretrato y continuó posteriormente su carrera artística, si bien su obra no llamó la atención. La vinculación entre su carrera profesional, su identidad y su proyección pública debió ser de especial importancia para este pintor, ya que en 1864, afianzado como profesor de dibujo (La Época, 1864/05/12: 4), presentó nuevamente un Autorretrato acompañando su obra Murillo pintando la Concepción.

La exposición nacional de 1860 tan solo contó con un autorretrato, obra igualmente de un pintor secundario en el panorama peninsular; se trata de Juan Mestre Bosch, pintor mallorquín reconocido en su ciudad -no en vano figura como ganador de varias medallas en exposiciones provinciales (Catálogo..., 1860: 46), miembro del comité de Bellas Artes de la Exposición Agrícola de Palma de Mallorca y dibujante oficial durante la visita de Isabel II a las islas (La Corona, 1860: 2; El Mallorquín, 1860: 3). En la reseña de La Iberia se mencionaba el desconocimiento que hasta ese momento había tenido la corte de Juan Mestre, quien concurrió a la exposición con "cuatro retratos que no obstante su pésima colocación demuestran las buenas facultades de su autor", y aludía al autorretrato del pintor elogiando algunas de sus cualidades técnicas, como "buen empaste, textura y brillantez en el colorido, expresión y vida" (PALET Y VILLAVA, 1860: 3). El envío evidencia no solo su voluntad de dar a conocer su trabajo en Madrid, sino también un elevado orgullo personal. Más dificultades de interpretación tiene un posible autorretrato incluido en un retrato de grupo de carácter familiar, obra de Angel María Cortellini. En el catálogo de la Exposición figuró con el número 43, bajo el título Retrato de la esposa del pintor en el estudio del mismo y seguido de una breve descripción en la que se indicaba que, pese a que efectivamente la mujer del pintor dominaba la escena, también se incluían en el fondo el retrato del pintor junto a su hijo. La noticia que aportan las críticas de El Universal y La Iberia (1860/02/11: 3) permiten corroborar que Cortellini se autorretrató siguiendo el modelo velazqueño, parapetado tras un lienzo, subrayando no solo el componente familiar de la escena, sino también unos valores profesionales que compartía ante el público.

Otra de las obras remitidas a la Exposición Nacional de 1860, y que difícilmente podemos considerar un retrato de grupo al uso (REYERO, 2014: 135), es la enviada

\footnotetext{
${ }^{242}$ Así, el Mundo Pintoresco prestaba alguna atención "a un niño que promete un genio, si el puff de los periódicos no lo agosta en flor" (“Esposición...”, 1858: 243; ALARCÓN, 1858:3).
} 
desde París por Bernardo Ferrándiz, y que representa El estudio donde concurren los artistas españoles en París, en el acto de llegar la nueva de la toma de Tetuán por las tropas españolas (Museo Nacional de Cerámica y Artes Decorativas, Valencia), que obtuvo mención honorífica de segunda clase. Carmen Gracia señalaba respecto a esta obra que era un autorretrato del pintor, en reunión con sus amigos, en el taller de Lenoir (GRACIA, 1986: 123), a pesar de que las reducidas dimensiones de la tabla no han facilitado hasta la fecha la identificación de los personajes. Se trata de una imagen de festejo - poco habitual en los retratos de artista- de marcado componente político, en la que llama la atención la intención de Ferrándiz, ya que la presencia de esta peculiar escena en la Exposición Nacional parece querer transmitir, como señala Reyero, que los jóvenes artistas españoles en París eran hombres comprometidos con la política de su tiempo a pesar de permanecer lejos de su patria y de no haber tomado parte activa en los acontecimientos bélicos. El tema militar evidentemente no podía faltar en esta Exposición Nacional como síntoma de exaltación patriótica; la batalla de Castillejos fue abordada por el joven pintor Ricardo Balaca, quien a pesar de sus quince años -o quizás fruto de estos- no dudó, como señalan las críticas, en afrontar un tema de historia contemporánea vinculándose así con la realidad política española al ensalzar la figura del general Prim (Jóvenes aprovechados”, 1860: 3). Por otra parte, el tema de la Guerra de África fue explotado por Ramón Rodríguez (Los heridos de la guerra de África) y por Carlos María Esquivel (Un asistente presenta el equipaje de un oficial muerto en África a su familia [G., 1860: 1]). Sin embargo, no cabe duda de que por su tema, especialmente significativo respecto al panorama contemporáneo, refleja la necesidad del pintor de dejar constancia de una forma concreta de masculinidad. El punto de vista de Ferrándiz de artista español fuera de su patria, potenciado por otra de sus obras enviadas (el estudio de un Modelo de París [“Esposición de nobles...", 1860: 4]), indica el deseo directo del artista por presentarse no solo como intérprete de los hechos contemporáneos, sino como hombre que los vive desde su realidad personal y social.

El tema del artista parece más frecuente en la exposición de 1862 (Catálogo..., 1862), pero tratado exclusivamente desde la pintura de género, ya que no constan retratos de $\operatorname{artista}^{243}$. El tema de estudios y talleres de pintor fue representado por el sevillano José Díaz Valera, Domingo Gallego y Tony de Vergue ${ }^{244}$. Otros de carácter anecdótico fueron abordados por José María Estrada (Un pintor disgustado de su cuadro, en el acto de romperlo) e Ignacio León y Escosura (La vida del artista).

En la Exposición de 1864 constan algunos retratos de artista, como el escultórico de Cecilio Pla realizado por Agapito Vallmitjana y el busto del pintor Valdivieso; por otra parte, el pintor Léon Bonnat pudo haber presentado dos retratos de compañeros artistas. Se trata, en el primer caso, del "retrato de Casado", presente en la sala quinta ("Lista de los cuadros...", 1864: 3) y que debemos identificar con José Casado del Alisal, del que

\footnotetext{
${ }^{243}$ Por los someros títulos del catálogo, en que tan solo figura "retrato", no puede saberse si se trataba de retratos de artista o autorretratos (de estos últimos, tan solo figura uno, debido a doña Matilve Álvarez del Valle).

${ }^{244}$ José Díez presentó El taller de un pintor ( ${ }^{\circ} 51$ del catálogo), Gallego Estudio de un pintor ( $\mathrm{n}^{\circ} 81$ del catálogo), Tony de Vergue Un estudio de pintor $\left(\mathrm{n}^{\circ} 261\right)$.
} 
daba noticia Alisa Luxenberg (DÍEZ, 1997: 100); y, en el segundo, de un retrato de Araujo del que da noticia La Esperanza (DOMENECH, 1865:3), de los que únicamente se dice "El retrato del Sr. Casado pintado por D. Léon Bonnat es muy bueno, y nos agradaría más aún si tuviese mayor grandiosidad en sus líneas. No nos pasa lo propio con el del Sr. Araujo, del mismo autor". Luxenberg relaciona estos dos retratos con los retratos de amigo que habituaba a realizar Bonnat, afirmando tratarse de una muestra de agradecimiento por su participación -al menos en el caso de Araujo- en la exposición de Bayona. Sabemos que Bonnat estuvo en Madrid en octubre de 1864, donde sus antiguos condiscípulos le realizaron una cena homenaje (La Correspondencia..., 1864/09/10: 3), momento que probablemente aprovechase para realizar el retrato de Araujo. Cabe pensar que el retrato de Casado del Alisal respondería al mismo estilo franco y ligeramente desdibujado que se observa en el de Araujo, ofreciendo una imagen íntima y cercana de los dos pintores españoles.

La ausencia de retratos de artista fue también notable en la Exposición de 1866, en la que de un total de cuarenta y tres retratos presentados, tan solo dos parecen corresponder a este subgénero; se trata, por una parte, del autorretrato del francés Célestin Allard-Cambray, que pasó completamente desapercibido ante la crítica y la prensa; y por otra del autorretrato de Mariano Roca y Delgado (Catálogo..., 1867: $\mathrm{n}^{\circ} 10$ y 358). Avalado por sus anteriores éxitos artísticos, el sevillano figura como discípulo de Cogniet en París, galardonado en la sección de pintura de historia en 1858 y en la de pintura de animales en las Exposiciones Nacionales de 1860 y 1862 . El retrato es incluido bien como obra de género o como boceto, titulándose Un estudio, retrato del autor. Consta además un retrato de artista más, si bien en el catálogo figura exclusivamente como "Un retrato"; se trata de un Autorretrato de Francisco Domingo Marqués pintado en 1865 (Museo Nacional del Prado, $\mathrm{n}^{\circ}$ inv. P04489) que presentó junto al Retrato de su madre, quizás más por interés en demostrar su habilidad técnica en varios géneros distintos que por orgullo personal, en el que se muestra como un joven enigmático, casi enfermizo, en un juego de claroscuros.

La Exposición de 1876 vio nuevamente temas relacionados con el arte y la vida del artista entre sus obras. Joaquín Espalter y Manuel Cabral presentaron representaciones de estudios de artista, y Zenón Herrero, una Escena de la vida artística (Catálogo..., 1876: 14). Del mismo modo, Agustín Rigalt presentó la obra titulada El pintor en el momento de concebir la idea de la obra que ha de ejecutar (Catálogo..., 1876: 20), y Casimiro Sainz la anteriormente mencionada El descanso, estudio del pintor, ¿qué pensará? (Catálogo..., 1876: 37), en el que se ha especulado sobre la identidad del artista representado, con la hipótesis planteada por Arturo Caballero de que se tratase de Eduardo Pelayo (DÍEZ, 1997: 142-143). Tan solo consta una noticia de un retrato de artista, que consiste en el Autorretrato de José Galofre, poniendo de manifiesto el escaso interés de los artistas españoles por dar a conocer su imagen ante el público.

En 1881, dada la dimensión de la Exposición General de Bellas Artes, algunos pintores extranjeros incluyeron rertatos de artistas junto a las obras de los españoles. Entre los primeros se cuentan el Retrato del escultor Simoes de Almeida, obra del 
portugués José Ferreira Chaves y Cinco retratos de pintores alemanes realizados al aguafuerte por Ernest Forgberg. Tampoco existe un gran interés entre los artistas españoles por presentar retratos de amigo o autorretratos en esta exposición, ya que tan solo constan dos autorretratos: el de Ignacio León y Escosura, que figuraba en el catálogo como propiedad de la Universidad de Oviedo y el de la pintora Joaquina Serrano, sobrina y discípula de Espalter. La presencia de retratos de aficionados volvió a hacerse patente en la Nacional de 1884, en la que constan los autorretratos de Diego Casals y Vázquez (Catálogo..., 1884: 33), Matilde Lorenzo (Catálogo..., 1884: 78), Enrique Lozano y José María Soler (Catálogo..., 1884: 132), de los que no nos han llegado más noticias. Junto a ellos figuró el Retrato de Marianito Fortuny realizado por Ricardo de Madrazo -si bien algunas fuentes lo atribuían a Raimundo-, y un retrato del pintor Aureliano Beruete, del mismo autor, con los números 413 y 414 del catálogo respectivamente. Si el retrato del joven Fortuny llamó la atención por su gusto delicado, son escasas las referencias al de Beruete, quien estaba además presente en la misma sala mediante una obra representando La puerta de Bisagra de Toledo.

La tendencia a la baja en el género hace que las noticias de retratos de artista sean prácticamente nulas en la última década del siglo XIX. El español afincado en París Arturo Decirle, discípulo de la Escuela de Bellas Artes de dicha ciudad, presentó a la Nacional de 1887 una obra que bien podría ser un autorretrato o un retrato de amigo; titulada Pensando en el estudio, se trataba de un dibujo a carboncillo del que no se tienen más datos que los aportados por el catálogo. Otro artista concurrió a la misma con un autrretrato de grandes dimensiones; se trataba del gaditano, ya en edad madura (A.M., 1887: 227), Manuel Sala Julién, pintor y decorador de escasa proyección. Ricardo de Madrazo retomó la temática fortunyana al presentar a la Exposición de 1890 la obra El último cuadro de Fortuny, acto que fue considerado por la crítica un acto de homenaje y cariño a su cuñado, al que ubica en su taller, sentado de espaldas y trabajando en La Playa de Portici. Así se expresaba Augusto Comas, señalando

Ricardo de Madrazo, que todo se lo debe a Fortuny, ha hecho bien en rendir un tributo de admiración y de cariño al que le guió en los comienzos de su carrera. El último cuadro de Mariano Fortuny representa al gran artista delante del caballete donde está La Playa de Portici. El fondo del cuadro es el estudio de Fortuny, y todas las preciosidades artísticas que logró reunir aparecer allí dispersas por todas partes. En primer término, sobre una silla el magnífico casco que a su muerte fue vendido en 12000 francos, y la espada morisca que él mismo damasquinó. En un rincón el jarrón árabe, y en la paredes, cubiertas de tapices, armas, platos y acuarelas. Mariano Fortuny, delante de La Playa de Portici, apoyada la cabeza en la mano derecha, contempla triste y pensativo su última obra. Tal vez se siente ya herido de muerte y se despide con dolor de su ocupación favorita (...) / El cuadro de Ricardo Madrazo, propiedad del marqués de Comillas, está bien pensado, y la ejecución es muy esmerada. En mi humilde opinión la obra ha ganado mucho al quitar la Musa que estaba cerca de Fortuny, que es como figuró en la pasada Exposición de Barcelona (COMAS Y BLANCO, 1890). 


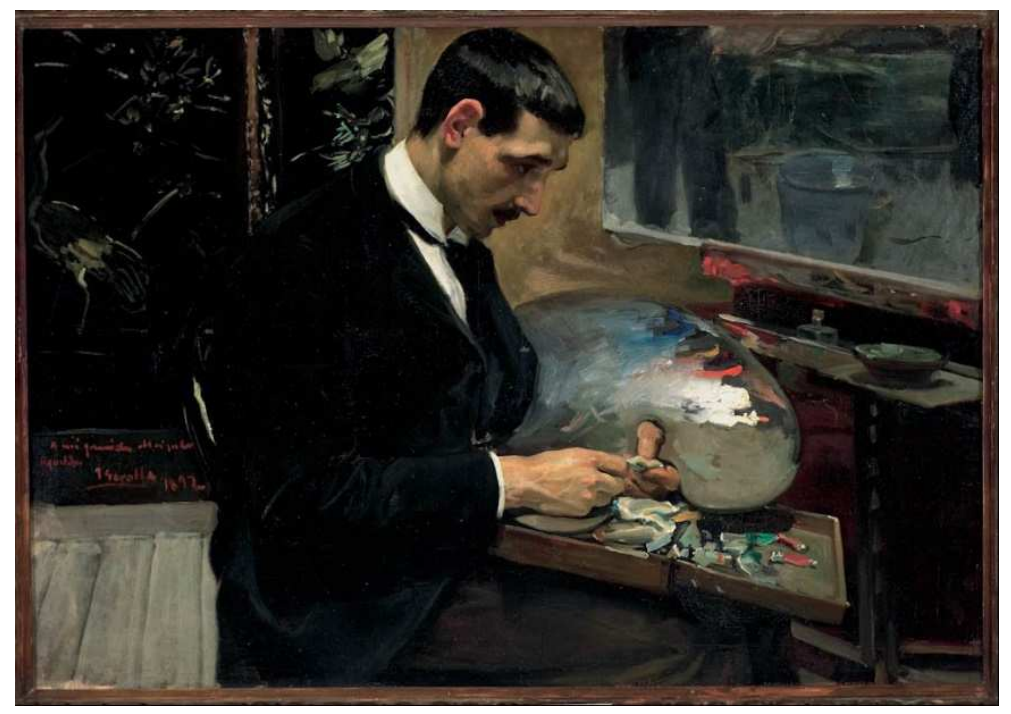

Fig. 90. Joaquín Sorolla. Retrato de Agustín Otermín. Colección Banco Santander.

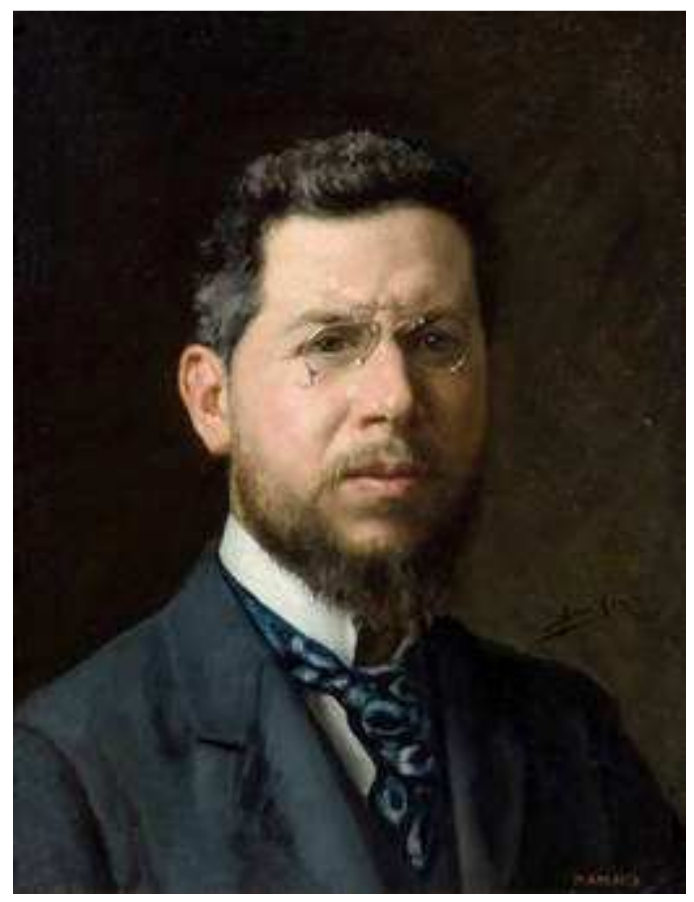

Fig. 91. José Díaz Molina, Autorretrato. Museo Nacional del Prado.

Entre las obras presentadas por Joaquín Sorolla a la Exposición Nacional de 1892 se encontraba el Retrato de Agustín Otermín (Colección Banco Santander) [fig. 90], en que presentó al asturiano en un lienzo de atípico formato horizontal, sentado ante un lienzo en el momento de disponer los colores en su paleta. Otermín era en aquel momento discípulo del valenciano y acudía regularmente al taller de este a recibir lecciones del maestro, una relación a medio camino entre la amistad y la jerarquía que queda presente en la obra; por una parte, el testimonio de afecto de Sorolla a Otermín se hace patente no solo en la dedicatoria (“A mi querido discípulo Agustín”). Sin embargo, la aparente cercanía del retrato evidencia también las diferencias existentes entre el autor y el retratado: a pesar de la dignidad de su traje de chaqueta, del gesto reflexivo y serio con 
que manipula un tubo de pintura, Agustín es representado desde un punto de vista alto y aprisionado por los límites del lienzo. La atmósfera del taller, que podría ensalzar la labor del discípulo, traiciona por otra parte un distanciamiento por parte de Sorolla, quien en su tratamiento pictórico de la obra es minucioso, a excepción del lienzo en el que trabaja su discípulo. En el acto de mostrarlo no solo entregado al trabajo, sino a un trabajo inacabado, del que ni siquiera muestra su totalidad, se intuye una relación jerárquica probablemente inconsciente, que sin embargo no entra en conflicto con la función de retrato psicológico de la obra.

En la Exposición Nacional de 1897 se presentó una curiosa obra realizada por el asturiano, y aún poco conocido, Joaquín González Ibaseta, que se menciona en La Correspondencia de España haciendo una somera descripción de la obra. Titulada "Mis amigos", podría tratarse de un retrato de grupo en la que el pintor realizó

una colección de retratos muy parecidos, bien agrupados, buenos todos y algunos superiores, de jóvenes artistas y literatos que concurren al Círculo de Bellas Artes. Es el lienzo representación viva de una peña de caballeros muy simpáticos, famosa ya por alguna de sus ocurrencias y digna de perpetuarse en lienzos para ejemplo de las primohermandades presentes y futuras (“Exposición Nacional...”, 1897: 1).

La obra figuró con el número 484 en el catálogo de obras, obteniendo una mención honorífica; de ella se ocuparon dos críticas jocosas (Gedeón diputado..., 1897: 4), aunque apenas se hizo referencia en las reseñas de la exposición.

El último autorretrato que hemos podido rastrear en las Exposiciones Nacionales del siglo XIX corresponde al del pintor José Díaz Molina (Museo Nacional del Prado, $\mathrm{n}^{\mathrm{o}}$ inv. P04282), premiado con mención (GUTIÉRREZ BURÓN, 1987: 1077) [fig. 91], en el que el artista emplea una aproximación confidente para presentarse de busto, con gesto serio y mirada perdida tras sus lentes.

\subsubsection{Retratos de artistas españoles en los Salones parisinos}

La revisión de los catálogos de los distintos salones parisinos ofrece una conclusión llamativa, ya que al igual que ocurriese con las Exposiciones Nacionales de Bellas artes, fueron muy pocos los artistas españoles que optaron por remitir sus autorretratos o retratos de sus colegas. Aparte de la noticia de un retrato de "M. L..., Pintor del Rey de España”, pintor cuya identidad nos es desconocida, presentado al Salón de 1837 por Carnevali, los primeros pintores españoles en presentar retratos al Salón optaron por representar bien a conocidos miembros de la élite artística parisina, como hizo Federico de Madrazo en su Retrato de Adrien Dauzats (Salón de 1840), o de su propio entorno, como Joaquín Espalter con el Retrato de su esposa (Salón de 1855). Hasta 1868 no figura el primer autorretrato de un artista español, tratándose del de Juan Antonio González; los datos ofrecidos por el catálogo lo presentan como nacido en Chiclana y alumno de Pils y de Rodríguez, con dirección en la Rue de Seine, 12. Se trataba del primer salón en el que participaba el pintor y aguafortista (BIBLIOTHÈQUE NATIONALE, s.a., 261] con dos pinturas, un Idilio y su propio Autorretrato. Al parecer, este rasgo de vanidad por parte del artista no fue el único acontecido a lo largo 
de su carrera, ya que asentado en París y participante asiduo en las exposiciones, tuvo en 1882 un desencuentro con el personal de seguridad al considerar que una de sus obras no estaba bien situada (Courrier de l'art, 1882: 220).

El mejicano José Calderón, alumno de Pelegrín Clavé, presentó su Autorretrato dibujado en 1869, mismo año en que el José Cecilio Montes ${ }^{245}$ concurría con el retrato del pintor gaditano Ramón Rodríguez Barcaza, quien había obtenido en el salón de 1867 una medalla de oro por su composición La Junta de Cádiz en 1810. Se trataba, además, de una muestra de consideración y respeto, pues el retratado era su propio maestro; el valor de la obra parece residir fundamentalmente en su carácter de homenaje por parte del discípulo, ya que no llamó la atención de la prensa parisina ni de la española.

En 1885 consta, en el Salón de la Sociedad de Artistas Franceses, el retrato de Francisco Domingo realizado por su discípulo, Federico Olaria. Las pocas noticias conservadas respecto al pintor, de origen valenciano ${ }^{246}$, hacen pensar que fue hijo de Fernando Olaria, pintor y discípulo igualmente de Domingo ("Nécrologie", 1898: 3); las obras presentadas fueron, precisamente, los retratos de Francisco Domingo y su esposa, sin duda como agradecimiento público al artista. En 1888 el mismo Olaria presentaría una obra que, según su título, El joven Olaria vuelto a la vida por el doctor M..., podríamos considerar bien un autorretrato, bien un retrato realizado por su padre (SALON DES ARTISTES FRANÇAIS, 1888: 277).

\footnotetext{
${ }^{245}$ Consta nacido en Tenerife, alumno de Ramón Rodríguez y con domicilio en el número 40 de la Rue Fontaine.

${ }^{246}$ Así consta en la noticia relativa al pintor incluida en los catálogos de los salones, como el de 1887 de la Sociedad de Amigos de las Artes de Le Havre (p. 50).
} 


\section{RETRATOS DE ARTISTA EN EL ÁMBITO INSTITUCIONAL}

\subsection{Las Academias de Bellas Artes y las galerías de retratos}

Las Academias de Bellas Artes, como focos centralizadores de las artes y las enseñanzas artísticas, constituyen el núcleo primordial para el estudio del desarrollo de las artes en los siglos XVIII y XIX, pero también del entramado relacional entre sus miembros mediante las estructuras de poder existentes en la institución y de las identidades masculinas construidas en este entorno. La historia tradicional de la Academia suele invisivilizar cuestiones de género especialmente relevantes, puesto que al tratarse de una institución predominantemente masculina su vida cotidiana y sus luchas por el poder se interpretan desde un enfoque exclusivamente social, sin atender a las masculinidades configuradas en ella, de tal modo que se aísla el concepto de identidad laboral y se vincula a la producción artística sin asumir el peso de la institución en la asimilación de la noción de hombre artista que se hace a sí mismo (KIMMEL, 1993: 28). Las historias de instituciones organizadas, controladas y gobernadas por hombres, tal y como subraya Kimmel, universalizan la experiencia masculina y niegan el papel que esta tiene en la negociación entre individuo y sociedad (CONNEL, 1995: 29). La institución artística es, por lo tanto, un núcleo en el que la identidad masculina del artista respecto a la corporación y la sociedad está en continua redefinición. El concepto ilustrado de "academia", anclado como señala Pevsner en el modelo centralizado y absolutista francés (PEVSNER, 1982: 71), supone considerarla de antemano como una extensión más del poder regio (MOLINA, 2013: 88), delegado en hombres que basan su identidad masculina en nociones inconscientemente asumidas relacionadas con las jerarquías sociales, y que buscan transformar el estatus social del artista para vincularlo con la élite y el privilegio; sin embargo, y aun a pesar de que los estudios de género han profundizado en el exclusivismo masculino de las academias a través del estudio y rescate de las biografías y obras de mujeres artistas, no es común encontrar discursos que analicen de qué manera el monopolio ejercido por la Academia sobre las artes afectó a la definición masculina de la identidad profesional del artista.

Partiendo de la idea de que la identidad masculina del artista está indisociablemente unida a una identidad profesional que permite establecer una diferenciación respecto a otras masculinidades que, bien por privilegio de clase en el siglo XVIII y comienzos del XIX, bien por la progresiva codificación de un elitismo cultural, entran en escena en el ámbito académico y con las que el artista tendrá que negociar su puesto en la estructura de poderes de la academia, podemos entender esta como un espacio homosocial de especial interés debido a: 1) su papel respecto a la emancipación del artista de la estructura gremial y a la nueva dignificación intelectual de los artífices; 2) el monopolio de la academia sobre la enseñanza, cualificación y producción artística; y 3) la manera en que su administración es reflejo de las estructuras sociales imperantes en cada momento, proporcionando modelos con los que el artista buscará identificarse o contra los que rebelarse en la configuración de su identidad. 
Las diferencias de clase y los conflictos por el poder forman parte esencial de la historia de las Academias, a modo de un relato de progresivas inclusiones y exclusiones; mientras los estudios feministas han centrado su atención en la revisión de las causas que motivaron el papel secundario de las mujeres en las Academias, concluyendo la premeditada necesidad de alejar a la mujer de una profesionalización artística con que se enfocó la enseñanza de las artes hacia el denominado sexo débil, aún se acaba de comenzar a profundizar en el impacto que el proceso social y emocional que la enseñanza artística y la profesionalización de las artes ejercieron en el hombre artista, siendo inmediatamente visible el hecho de que lejos de ser fraternidades idealizadas, el proceso de autoconstrucción - profesional y masculina- del artista está relacionado con tensiones e inseguridades (CROW, 1995; WALLER, 2000; BARRELL, HALLET y MONKS (eds.), 2013). En el largo transcurso desde mediados del siglo XVIII hasta finales del XIX, las Academias de Bellas Artes serán un instrumento de la monarquía o del gobierno para el control de la educación artística y la gestión del patrimonio, constituyendo no solo una institución monopolizadora de la actividad cultural, sino también un escenario en el que se ponen continuamente en juego las aspiraciones profesionales de los propios artistas. En esa búsqueda de una identidad individual y una reivindicación profesional en clave masculina dentro del cuerpo colectivo formado por la institución, las galerías de retratos pueden ofrecer una lectura visual de esta construcción identitaria y de las interrelaciones del artista con el mundo académico.

\subsubsection{Las galerías de retratos como relato de una identidad colectiva}

Entender la academia como corporación -ese Cuerpo con mayúscula que se reitera en las actas y en la historia de la institución- conlleva asumir su carácter colectivo; en él, al estar compuesto por una pluralidad de m0iembros, la identidad del individuo solo se entiende como parte del grupo, del mismo modo que el grupo no tiene sentido salvo como unión de sus individuos. La Academia como asociación de miembros unidos por unos objetivos artísticos y culturales comunes cobra una dimensión social en la que los procesos dialécticos de exclusión/inclusión y de visualización de la diferencia-de clase y de género- marcan las pautas de un sistema de jerarquías mantenido hasta mediado el siglo XIX. En la configuración de su identidad colectiva, que precisa para su desarrollo de condiciones oportunas como cierta estabilidad ideológica y continuidad en el tiempo, la creación de una historia común no solo se visibiliza mediante la producción de la documentación relativa al gobierno y cotidianeidad de la corporación, sino también a través de las obras artísticas vinculadas a ella.

Es en este ámbito en el que cobra un significado especial el retrato, ya que mediante la creación de galerías de retratos se puede poner de manifiesto esa imagen de la academia como grupo de individuos; sin embargo, y teniendo siempre presente que las galerías son imágenes muy parciales de la totalidad de la institución académica, analizar quiénes figuran en ellas y su relación con la institución, así como respecto a las iconografías empleadas, permite observar cómo el retrato se eleva como una prueba de ese consenso continuo entre la identidad individual y la colectiva, y como tal una muestra de las distintas negociaciones entre el hombre artista individual, con todas las 
peculiaridades de su psicología y personalidad, y el hombre académico como proceso social. Las galerías de retratos se convierten así en espacios autónomos, eminentemente masculinos, con un cierto aire sacralizado, destinadas a perpetuar la historia del conjunto a través de los miembros que la componen, y susceptibles de perder su significado una vez aisladas de su espacio -social y físico- original.

Conscientes del valor del retrato para la institución, algunas de las academias más importantes de Europa se interesaron por configurar galerías de retratos que dignificasen su historia a través de las efigies de sus miembros; dos de ellas serán de especial importancia en cuanto a su influencia en el ámbito español: la de San Lucas de Roma y la de la Académie Royale de París (WILLIAMS, 2015). La principal peculiaridad de esta última frente a otras galerías académicas radica en el componente relacional y ritual del propio retrato como experiencia, por una parte para los efigiados, ya que ser elegido como modelo implicaba un reconocimiento solo accesible en la más alta jerarquía académica, y por otra para los pintores, ya que los retratos constituían precisamente las obras de recepción en la institución. Dadas las particularidades de la Académie Royale y la temprana cronología de su Sala de los Retratos, Williams (2015: 306) pone de relieve el valor antropológico de los retratos como serie; en efecto, es esta idea de conjunto la que aporta cohesión y estructura visualmente el grupo social constituido por la Academia, hasta tal punto que no plantea la necesidad del retrato de grupo para plasmar físicamente una identidad corporativa ni para evocar las relaciones sociales entre los miembros que la componen.

Esta sensación parece también desprenderse de otra de las galerías académicas de retratos más temprana, la de la Academia de San Lucas de Roma, que mantiene una cierta continuidad en los siglos XVII y XVIII. Según sus estatutos, los académicos debían remitir a la corporación una obra y su propio retrato, algo que en 1789 recordaba el secretario Antonio Maron para poder formar una serie de todos los profesores de la Academia, y cuyo cumplimiento no se observó de manera estricta por parte de muchos de ellos (INCISA DELLA ROCCHETTA, 1979: 15). El modelo de la Academia Real de París fue esencialmente el seguido en las academias españolas (PEVSNER, 1989: 219), si bien cabe preguntarse si fue su Sala de los Retratos la que determinó el modelo de las galerías de retratos, o si, como parece más verosímil, fue la galería de retratos de San Lucas, con la que los artistas españoles tendrían mayor relación, la que estructuró modelos similares en España (CHOCARRO, 2006: 264).

Como se observará en el estudio de las iniciativas surgidas en el seno de la de San Fernando en el siglo XVIII, no se alude a un modelo a imitar, aunque no es verosímil creer que sus promotores desconocieran las iniciativas llevadas a cabo en otras academias europeas. El caso de la Académie Royale de París es especialmente interesante, a pesar de ser escasos los datos que relacionen directamente a artistas españoles con la práctica del retrato. Sin embargo, un artista que estuvo vinculado a la de París y posteriormente de manera activa a la de San Fernando de Madrid sí que pasó por el rito iniciático académico del retrato como obra de recepción. Es el caso de Manuel Salvador Carmona, quien para ser nombrado académico de mérito realizó en 


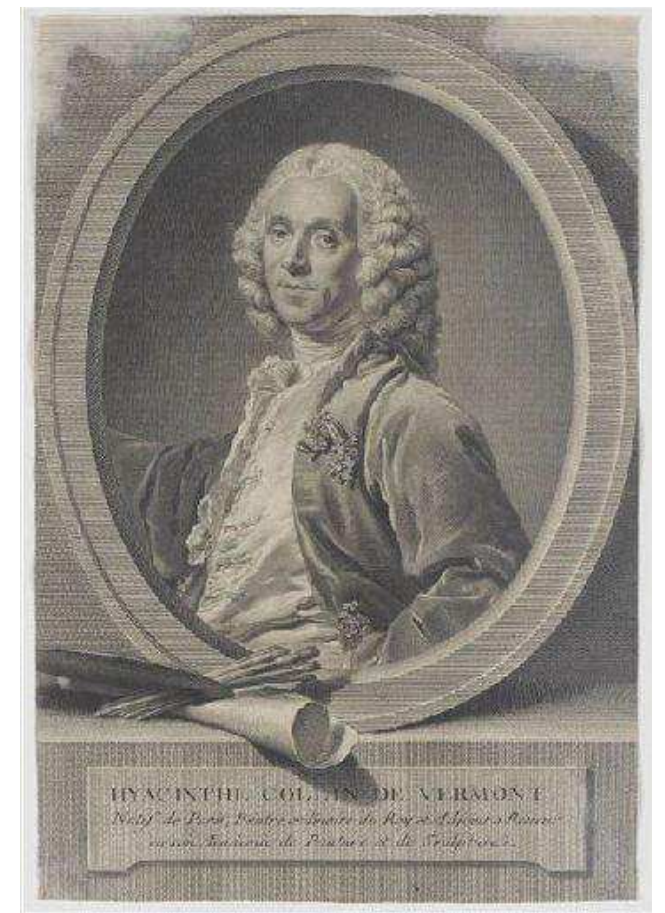

Fig. 92. Manuel Salvador Carmona, Retrato de Hyacinthe Colin de Vermont, 1761. Museo Magnin, Dijon.

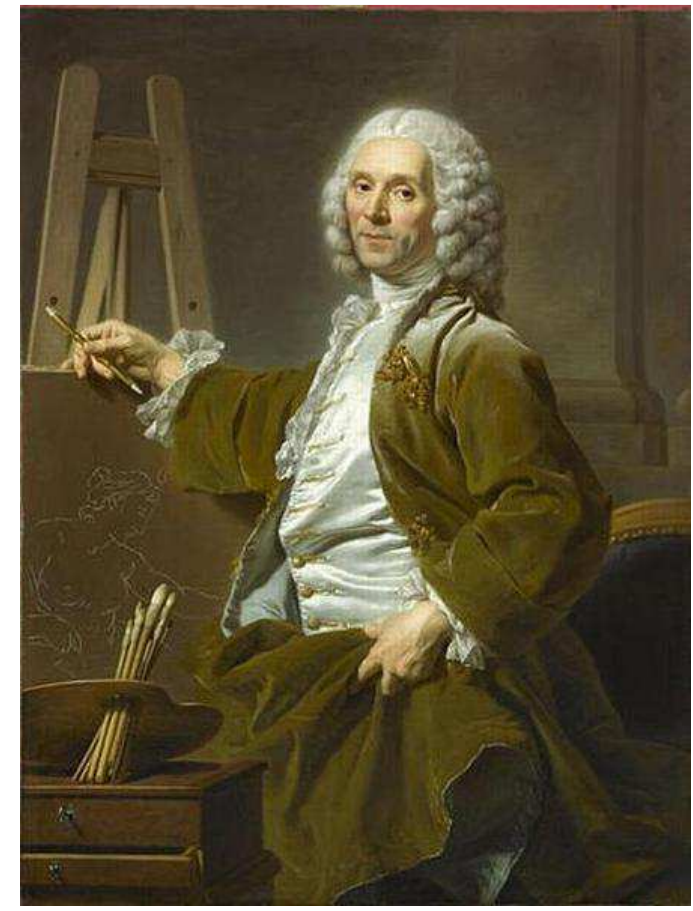

Fig. 93. Alexandre Roslin, Retrato de Hyacinthe Colin de Vermont, 1753. Museo Nacional de Versalles.

1761 dos retratos grabados, uno de ellos representando al pintor Colin de Vermont [fig. 92], tomado de un original de Roslin [fig. 93], y otro de Boucher. Significativamente, las obras no fueron destinadas a la Sala de los Retratos de la Academia Real, sino a la Grande Salle, destinada a acoger, de manera general, las obras de recepción; el hecho de que el modelo en el que Carmona se inspiró para realizar el retrato de Colin de Vermont estuviese ubicado en la Sala de los Retratos indica, por otra parte, que el español entró en contacto directo con los significados jerárquicos del retrato dentro de la institución (DÉZALLIER D'ARGENVILLE, 1781: 39; BLANCO, 1997: 279). Tampoco en el siglo XIX, momento de máximo desarrollo de las galerías de retratos en las academias españolas, se aludirá a posibles modelos de otras corporaciones extranjeras; sin embargo, los artistas españoles sí que pudieron haber tenido contacto directo con estas: por una parte, la galería de la Académie Royale, que tras el cierre de esta se había instalado en 1798 en Versalles como parte del museo de la Escuela Francesa, recuperó parte de su significado inicial cuando, en 1820, cincuenta de los retratos pasaron a la Escuela de Bellas Artes de París, inaccesibles al público hasta el traslado y apertura de la colección en el Museo del Louvre en 1890, pero sí a los artistas que mantuvieron relación estrictamente administrativa o docente, puesto que se destinaron a la Sala de Juntas (WILLIAMS, 2015: 305). Otra parte de los retratos de la Académie permanecieron en la colección de Versalles, de más fácil acceso para el estudiante o viajero que la Sala de Juntas de la Escuela.

Mucho más certero es el contacto que tuvieron los artistas españoles con la galería de la Academia de San Lucas desde fecha muy anterior, ya que la corporación romana gozaba de la más alta consideración y reconocimiento entre los artistas en los siglos 


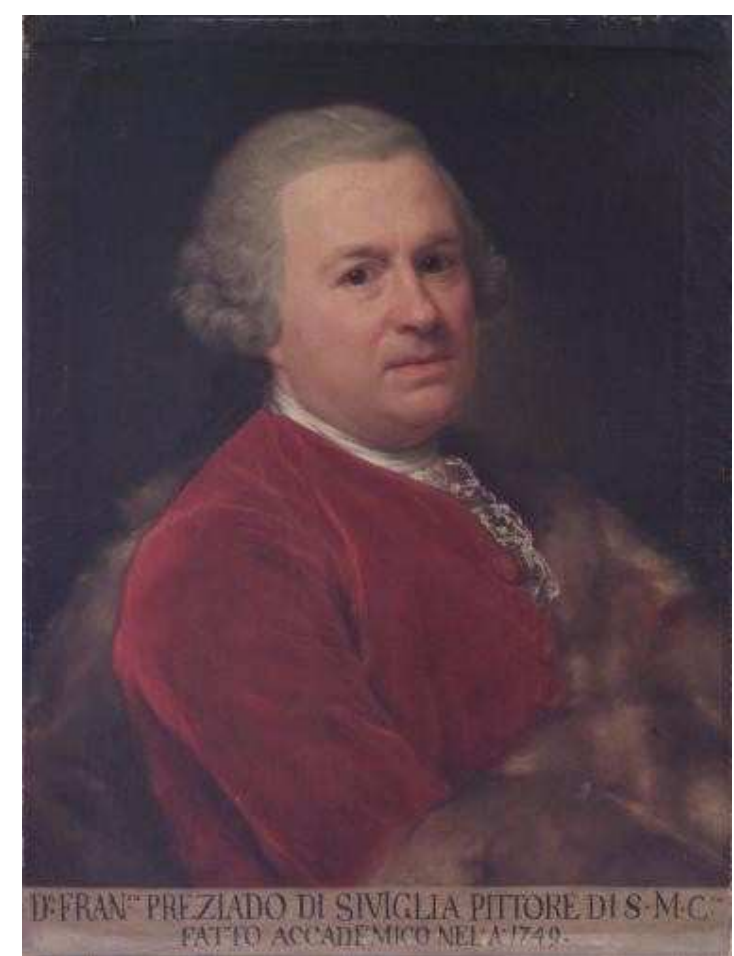

Fig. 94. Anton von Maron, Retrato de Francisco Preciado de la Vega, 1767. Academia de San Lucas (inv. 451)

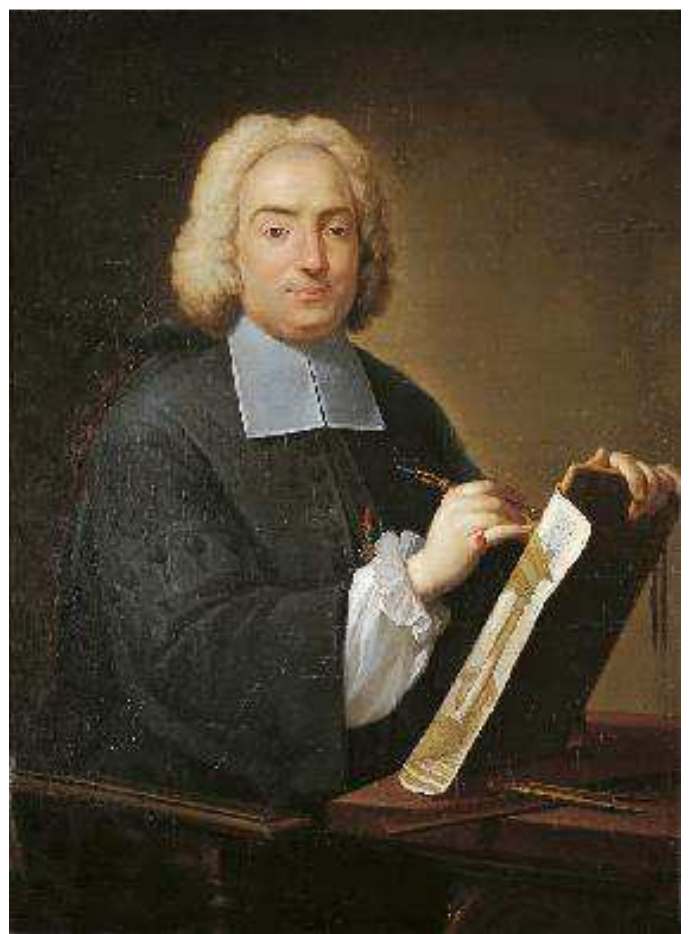

Fig. 96. Copia del retrato de Filippo Juvarra, Academia de San Fernando ( ${ }^{\circ}$ inv. 0566)

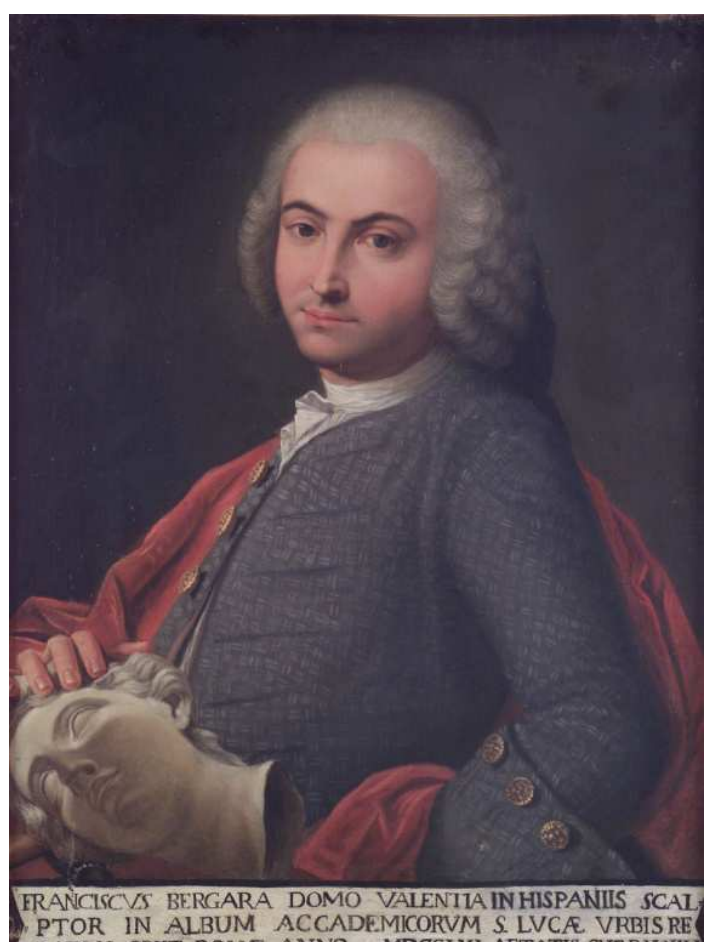

PTOR IN ALBUM ACCADEMICORVM $S$. LVCA VRBISRE

Fig. 95. Anónimo. Retrato de Francisco Vergara,

1761. Academia de San Lucas (inv. 463)

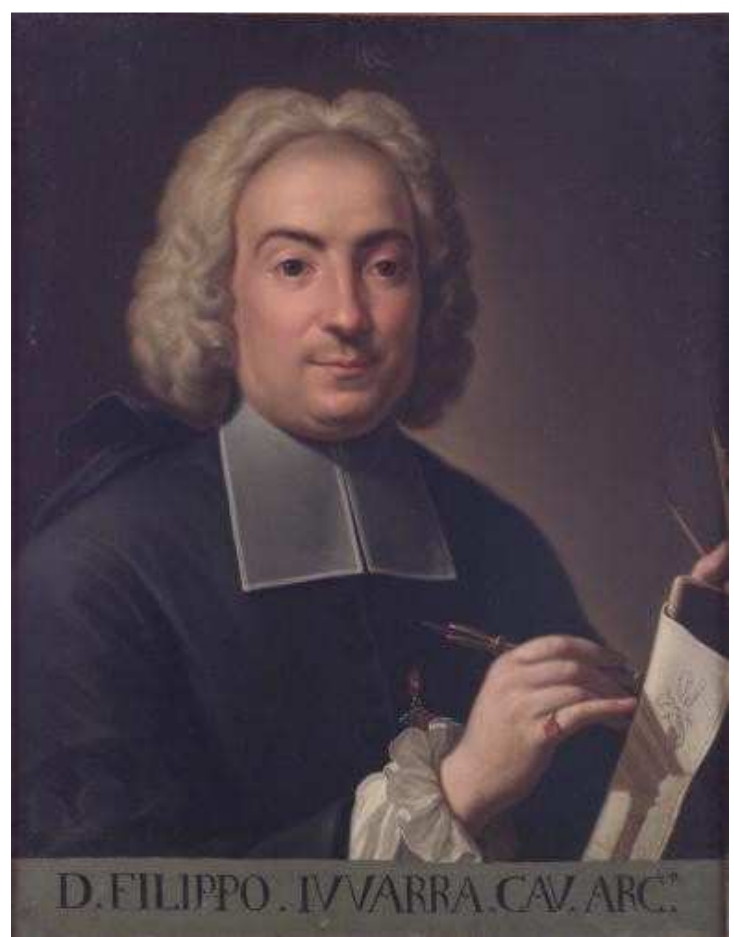

Fig. 97. Agostino Masucci (atrib.), Retrato de Filippo Juvarra, Academia de San Lucas (inv. 452). 
XVIII y XIX. No en vano José de Madrazo escribía a su hijo Federico sobre la alta honra de pertenecer a aquella institución:

Me alegraría que hubieses convidado a Cammuccini y a todos los demás profesores de esa Academia de San Lucas, conviniéndote tenerlos propicios para que te

admitan en ella de Académico de Mérito, distinción que debes apreciar mucho por ser, entre las Academias de Bellas Artes la más distinguida de todas, contando en su catálogo los profesores más célebres de toda Europa, tanto antiguos como modernos (DÍEZ, 1998b: 451) ${ }^{247}$.

Según los estatutos de la corporación, los académicos debían remitir a la institución una obra de composición y un autorretrato, una norma que no siempre era cumplida ya que en 1798 el secretario Antonio Maron precisaba la necesidad de que se llevase a cabo para poder formar una serie de todos los profesores de la Academia. De los artistas españoles que enviaron allí sus retratos o autorretratos se desprende la conclusión de que tan solo se dio cumplimiento en aquellos casos de especial vinculación con la corporación. En el siglo XVIII lo hicieron el pintor Francisco Preciado de la Vega (académico desde 1749), que envió su retrato hacia 1767 [fig. 94], y el escultor valenciano Francisco Vergara en 1761 [fig. 95], una experiencia que sin duda pudo influir en el concepto que tendría la futura galería académica de la de San Carlos.

Otros factores indican la relación entre los pintores españoles y la relación con la academia romana, vinculados a su galería de retratos, quizás el más relevante la copia exacta que se conserva en la Academia de San Fernando del retrato de Filippo Juvara [fig. 96], tomada del original -realizado por Agostino Masucci- de la de San Lucas [fig. 97].

También el escultor Antonio Solá, que se vinculó activamente a la de San Lucas, de la que fue académico y príncipe, remitió dos retratos. El primero de ellos es un retrato pictórico, realizado por Rafael Tejeo, que ingresó en 1831 con destino a específico a la galería de retratos (INCISA DELLA ROCCHETTA, 1979: 73); el segundo fue un autorretrato de busto, realizado en mármol, que fue legado por disposición testamentaria en 1861. Consta la voluntad de otros artistas vinculados a la corporación romana de remitir su autorretrato, sin que finalmente llegaran a hacerlo, como sucedió en el caso de José de Madrazo (DÍEZ, 1998a: 328-331), así como la vinculación más reciente de otros artistas. De este modo, conocemos que en 1906 el secretario del consejo de la Academia de San Lucas escribió a José Benlliure solicitando su autorretrato e indicándole las precisiones técnicas a observar:

Ilustre colega; en calidad de secretario del consejo de esta Real Academia y en conformidad del artículo 9 capítulo VI de los estatutos, debo solicitar la atención de ud. Sobre la observación del artículo 7, capítulo XI, en el cual se ordena a los académicos de mérito el envío de su propio retato para la galería de esta Academia. Este retrato, en caso de ser pintado sobre tela al óleo tendrá la dimensión de 0,62 m

${ }^{247}$ Carta de José a Federico de Madrazo, 22 de marzo de 1841. 
de altura por 0,50 de ancho; en caso de ser un busto de mármol o de bronce, deberá ser de tamaño natural ${ }^{248}$.

Además de señalar la obligación, el secretario añadía también la muestra de orgullo personal que suponía la presentación del autorretrato y su valor como contribución a la historia del arte, si bien Benlliure no correspondió a dicha solicitud hasta 1912, tal y como refleja la carta enviada por el presidente de la Academia para comunicarle el agradecimiento de la corporación y la colocación del retrato ${ }^{249}$.

El componente ideológico de estas galerías es fundamental al configurse a partir de series de retratos, diferenciándose notablemente del retrato de grupo; en la galería, la construcción de una identidad común se realiza de manera imaginaria, vinculando las representaciones de los individuos -a veces ni siquiera unificadas por dimensiones o iconografías- a la propia historia de la institución, es decir, con la intención de perpetuar la imagen de esta, posibilitando la incorporación de nuevos miembros a un relato en continuo crecimiento; el resultado es, por lo tanto, una construcción simbólica, en la que se puede sumar a las relaciones sociales de miembros contemporáneos una relación virtual a modo de linaje. El retrato de grupo, por su parte, permite visualizar las relaciones personales entre un número definido de participantes, plasmando mediante una escena -real o imaginaria- el carácter efímero de una circunstancia puntual que expresa, no obstante, una identidad colectiva -cerrada-por sí misma. En el caso español la representación de la Academia como comunidad artística no encontró su debida expresión plástica mediante el retrato de grupo, tal vez por la marcada influencia francesa y por el hecho de que en el país vecino este género solo cobrase sentido como manifestación de una sociabilidad basada en la necesidad de generar una identidad cultural no institucional durante la Revolución; el clima político tampoco fue excesivamente proclive al desarrollo de este tipo de escenas corporativas, ya que la pervivencia de las estructuras absolutistas y el ambiente bélico de la primera mitad del siglo influyeron en el papel centralizador de la Academia, que solo se vio contrarrestada con un movimiento asociacionista artístico de cierta envergadura a finales de los años treinta. La singularidad del panorama académico inglés es reseñable en este sentido, debido a la sólida identidad profesional de una institución reservada en exclusiva a los artistas; en ella, a la voluntad de perpetuar la efigie del artista dentro del espacio de la Academia -sirva como ejemplo el caso de Sir Joshua Reynolds, quien durante su presidencia en la Royal Academy realizó y ubicó su autorretrato en la Sala de Juntasvenía aparejado un interés por plasmar visualmente la unión de los artistas -de carácter asociativo- mediante interesantes retratos de grupo, entre los que se cuentan el temprano lienzo Clase del natural en la Academia de St Martin's Lane (Royal Academy, Londres, $\mathrm{n}^{\circ}$ inv. 03/621), que utiliza el tema de la Academia nocturna para

\footnotetext{
${ }^{248}$ Carta del secretario del consejo de la Academia de San Lucas a José Benlliure, 30 de junio de 1906. Archivo Casa-Museo Benlliure (Valencia), C20ACC017.

249 "Al mismo tiempo, le doy las más sentidas gracias en nombre de la Academia por la donación de su autorretrato, que acaba de ser presentado en la ordenanza general del día 8 de diciembre y que será adecuadamente colocado en nuestra sede con los retratos de los demás académicos". Carta del Presidente de la Academia de San Lucas a José Benlliure, 11 de diciembre de 1912. Archivo Casa-Museo Benlliure (Valencia), C20ACC028.
} 
presentar un retrato colectivo en el que se ha identificado a varios de los fundadores de la Royal Academy, como George Michael Moser, John Alexander Gress o John Hamilton Mortimer (FENTON, 2006: 62); el conocido retrato de Zoffany Los Académicos de la Real Academia (1771), o el de carácter mucho más institucional realizado por Henry Singleton Los Reales Académicos en asamblea general, de 1795 (Royal Academy, Londres, $\mathrm{n}^{\mathbf{o}}$ inv. 03/1310). Este último presenta una imagen plenamente corporativa, ubicando a la totalidad de los académicos -incluidas Mary Moser y Angelica Kauffman- en la Sala de Juntas de su sede en Somerset House, plasmando entre los detalles decorativos los monumentales retratos de Jorge III y de la reina Carlota, que presiden simbólicamente la asamblea, y el autorretrato de Reynolds. También en otros países algunos artistas se interesaron por esa representación colectiva de la Academia como espacio de estudio artístico para incorporar retratos, como Martin Ferdinand Quadal en La Sala de Natural de la Academia de Viena (1787), o el más tardío La clase de Joseph François en la Academia de Bruselas (1825), en que Célestin François se excusa con el tema de la clase para representar, en primer plano, a los profesores de la Academia (BONNET, 2007: 78).

Dentro del panorama español parece evidente que algunas representaciones de grupo relacionadas con la realidad y la aspiración artística a comienzos del siglo XVIII, como El taller de escultura de Valsaín y Academia de dibujo, de Michel Ange Houasse (CHOCARRO, 2006: 254), no tuvieron una gran influencia en la retratística asociada a la posterior fundación de la Academia de San Fernando. La obra Academia de dibujo, al presentar a varios artistas ubicados en semicírculo frente a un modelo colocado de espaldas al espectador plantea la posibilidad de que sea un retrato de grupo; aunque la escena se sitúe en un escenario ficticio (LUNA, 1981: 203), el hecho de que las miradas de algunos de los participantes de la escena, hipotéticamente inicialmente dirigidas al modelo, estén destinadas al propio pintor podría corroborar esta hipótesis, si bien se aleja de cualquier posible lectura sobre identidad de grupo o corporativa.

Solo consta la noticia de una iniciativa de un retrato de grupo vinculado a la Academia de San Fernando con intención de plasmar esa identidad artística colectiva, que no parece que llegase a ver la luz. Se trata de un supuesto cuadro de La Academia de San Fernando en un día de sesión de los artistas más notables, un proyecto que formaba parte de una tentativa por parte del pintor sevillano Antonio María Esquivel de pintar varios retratos de grupo, y del que daba noticia El Español en $1846^{250}$ :

No se limita a esto solo el proyecto del Sr. Esquivel, sino que también se extenderá a pintar otras escenas donde figuren otra clase de notabilidades, entre las que se encontrará el palacio real en un día de besamanos, la Academia de San Fernando en un día de sesión de los artistas más notables, el Congreso de los Diputados y el teatro en el momento de ensayarse una función. Nosotros damos nuestro parabién al Sr. Esquivel por esta feliz idea, en virtud de la que se legará a la posteridad una colección de cuadros de costumbres, tan importante para el estudio que se haga en el futuro de la época presente como para conservar el recuerdo vivo de los personajes célebres de nuestro tiempo (El Español, 1846: 4).

${ }^{250}$ Díez sitúa la noticia en El Clamor Público (DÍEZ, 2004: 325). 
Otros periódicos del momento, como El Tiempo (1846: s.p.), no recogen con el mismo grado de detallismo la iniciativa de Esquivel, limitándose a anunciar que

Concluida esta obra [Los poetas contemporáneos] emprenderá el señor Esquivel otras varias de igual género: la primera de ellas que lo será también de la colección, representará la procesión del Jueves Santo en la galería del real palacio con los retratos de S.M., los de su augusta familia y los de todas las personas de la real comitiva. En seguida retratará el salón del Congreso y el del Senado con sus individuos reunidos en sesión; y por último ejecutará otros varios cuadros que comprendan todas las notabilidades políticas, literarias y sociales de la época actual, formando una magnífica colección que será inapreciable a la vuelta de algunos años, y coronará la justa reputación del célebre artista autor de tan feliz pensamiento.

El hecho de que Antonio María Esquivel diese un nuevo empuje al retrato de grupo puede deberse a la influencia de la pintura inglesa, aunque también es relevante el hecho de que el pintor fuese parte de la activa sociabilidad cultural al margen del ámbito académico llegando a establecer dos importantes sociedades artísticas: el Liceo Artístico y Literario, que fue objeto de uno de sus retratos de grupo, y la Sociedad Protectora de Bellas Artes. No queda constancia de que esta obra llegase a realizarse, ni de que se haya conservado ningún boceto al respecto, por lo que solo cabe imaginar qué imagen podría haber dado Esquivel de la Academia de San Fernando, y qué entendió el redactor por "una sesión de los artistas más notables", ¿se trataría de un retrato de grupo de los artistas que formaban parte del cuerpo profesional de la Academia, tal y como imaginaba Pardo Canalís (1971: 381) ${ }^{251}$ ? ¿O tal vez era una necesidad de mostrar otra imagen de la Academia, más contemporánea y viva, de una clase en la academia al estilo de otras obras europeas?

Una vez asumido el carácter específico de las galerías como suma de retratos, es preciso al abordar su análisis abandonar la idea de que, al estar compuestas por retratos individuales, estos constituyen únicamente una celebración individual de la personalidad $^{252}$. A pesar de construirse de manera paulatina -casi perezosa en algunos casos en las academias españolas-, no se trata de honrar en exclusiva a individuos aislados, a la manera de una galería de hombres ilustres: la existencia de una voluntad de historiar la institución, y en este caso una institución artística, a través de sus miembros impregna esa configuración de una identidad corporativa de interrogantes extremadamente sugerentes, que afectan también a la propia percepción que el artista decimonónico tenía de sí mismo dentro de la Academia. De este modo, las galerías

\footnotetext{
251 "Presumible es que, en tal supuesto y presididos por las figura patriarcal de Don Vicente López, no hubieran dejado de concurrir con el propio Esquivel -acaso, con sus hijos, jóvenes artistas-, Federico de Madrazo y sus hermanos, Alenza, Elbo, Gutiérrez de la Vega, Eugenio Lucas, Pérez Villaamil, Tomás, Elías, Piquer, Ponzano, Medina, Bellver, Juan Antonio y Carlos Luis de Ribera, Custodio Moreno, López Aguado, Isidro González Velázquez, Pascual y Colomer, Tejeo, Espalter, Van Halen, Bernardo y Luis López, Ferrant, Carderera y algunos más. Es decir, la playa mayor de los artistas románticos, amigos y compañeros todos de los literatos de su tiempo" (PARDO CANALÍS, 1971: 381).

${ }^{252}$ La lectura que realiza Alain Bonnet de las galerías de retratos apunta, casi exclusivamente, al valor de documento histórico que constituyen como conjunto, señalando la imposibilidad de interrelación, o de una lectura de las relaciones sociales entre los efigiados (BONNET, 2007: 15-17).
} 
estudiadas ponen de manifiesto las diferentes formas de asumir la jerarquía interna de la Academia y sus relaciones con el poder, ya fuese supeditándose directamente a la autoridad real y postergando la representación de presidentes y consiliarios en el caso de la de San Fernando, o testimoniando las relaciones con los gobiernos municipales en las academias provinciales. En la amalgama de significados que podemos intuir de unas galerías que en la actualidad están, en su mayoría, dispersas y desactivadas, cobra importancia la relación entre efigiado y artista: si ambos pertenecían a la corporación y si el retrato derivaba, por lo tanto, de las relaciones sociales dentro de este grupo; si eran resultado de los vínculos familiares entre académicos -un rasgo propio del mundo artístico gremial pero que se mantiene muy presente en el siglo XIX español. Se plantea también la importancia de las distintas iconografías en la construcción de la identidad del individuo, ya que el retrato de artista mantendrá una inicial importancia al reivindicarse como muestra del ejercicio de una profesión, generalizándose posteriormente un retrato de tipo burgués y elegante, en el que la profesión se desdibuja a favor de una imagen relacionada con la posición social y la pertenencia a la élite cultural, recurriendo en algunos casos a la identidad corporativa al hacer uso de distintivos comunes, como uniformes o medallas.

En la Academia de Bellas Artes de San Fernando el uso de uniforme estaba vinculado a la relación de la institución con el poder real, de tal modo que ante los privilegios que gozaban los miembros de la Real Academia Española, la Real Academia de la Historia y el Gabinete de Historia Natural, se elevó en 1800 por parte de los directores, tenientes y empleados de la Academia la súplica de ser igualmente reconocidos como criados de $\mathrm{Su}$ Majestad, atendiendo al título de Real Academia de que gozaba la institución. La solicitud, en que se recogía la necesidad de tener un "uniforme o traje reglado para que de este modo fuesen conocidos y respetados debidamente (...) y ellos mismos más estimulados al cumplimiento de sus obligaciones $^{253}$ ", fue analizada en junta particular de 2 de marzo de 1800, y elevada tanto al rey como al marqués de Santa Cruz para que sirviese de respaldo favorable a la petición, acordándose que en la redacción se expresase la solicitud de "uniforme o traje reglado según sus clases". Dicho privilegio fue concedido el 26 de mayo 1800, mediante una Real Orden que equiparaba las prerrogativas de la de San Fernando a las de la Real Academia Española, pero sin precisar nada respecto al uso de uniforme ${ }^{254}$, poniéndose en contacto la primera con la Española para conocer en detalle en qué consistían las prerrogativas concedidas ${ }^{255}$. La contestación por parte de esta no satisfizo la curiosidad de los académicos de San Fernando, ya que en ella "no se expresaba nada sobre uniformes, que era una de las gracias que pretendían los directores y dependientes con la de criados de S.M. ${ }^{256 "}$ se resolvió volver a elevar en octubre del mismo año una solicitud al rey, renovando en este caso la petición de poder usar un uniforme particular de la corporación, expresándose en los siguientes términos:

\footnotetext{
253 Junta Particular de 2 de marzo de 1800, ARABASF (3-125), fol. 147 r. y v.

${ }^{254}$ Sesión Ordinaria de 1 de junio de 1800, ARABASF (3-86), fol. $140 \mathrm{r}$.

255 Junta Particular de 1 de junio de 1800, ARABAS (3-125)F, fol. 153r.

${ }^{256}$ Junta Particular de 7 de septiembre de 1800, ARABASF (3-125), fol. 159r.
} 
Estimulados de la benignidad con que V.E. los atiende, vuelven a molestar su atención, suplicando a V.E. se digne elevar segunda vez al Trono sus deseos de que la gracia que les ha concedido S.M. se extienda y declare a usar de Uniforme que sea particular del Cuerpo: con lo qual serán los Profesores y Dependientes mas estimados y respetados del publico en estos Estudios, resultando de esta distinción que los suplicantes esperan conseguir de la protección de V.E. mas decoro a este $\mathrm{R}^{1}$ Cuerpo, y un eficaz estímulo para los Jovenes dedicados al estudio de las Nobles $\operatorname{Artes}(\ldots)^{257}$.

La solicitud iba firmada por los directores y tenientes directores de las distintas enseñanzas Pedro Arnal, Manuel Martín Rodríguez, Juan Adán, Gregorio Ferro, Alfonso Giraldo y Bergaz, Guillermo Casanova, Antonio Navas, Magín Vallespinosa, Julián de San Martín, Antonio Aguado, Manuel Salvador Carmona, Francisco Javier Ramos y José Camarón y Meliá, así como por el vicesecretario Silvestre Pérez, el bibliotecario Juan Pascual Colomer y el conserje Francisco Durán.

No parece que esta segunda solicitud tuviese éxito, y los empleados de la Academia parecen abandonan la cuestión del uniforme hasta 1816; seguramente la influencia del ingreso del infante Carlos María Isidro como consiliario y Jefe Principal de la institución, que motiva una reorganización del plan de enseñanzas y de las colecciones artísticas, dio pie a un nuevo interés por el decoro y la ostentación de los privilegios académicos por su vinculación al poder regio. El nombramiento del infante se produce en noviembre de 1815, y la toma de posesión en enero de 1816, mismo mes en que se retoma el asunto de los uniformes. Así queda recogido en el acta de la junta particular de 26 de enero, en que el Viceprotector indica la necesidad de "que se vuelva a solicitar de S.M. (...) que a consecuencia de ser considerada la Acad como casa real según el capítulo 34 de sus estatutos, se solicite del Rey Nuestro Señor la gracia de uniforme de casa $\mathrm{R}^{1}$ para sus individuos ${ }^{258,}$.

Debido a las nuevas relaciones entre la Academia y la Casa Real, no extraña que en esta ocasión la solicitud sí que fuera atendida, declarándose por Real Orden de 13 de febrero de 1816 la prerrogativa de uso de uniforme, tal y como se comunicó a los miembros académicos en Junta Particular de 26 de febrero ${ }^{259}$. Ante las dudas de si esta medida era aplicable a todos los académicos o exclusivamente a los dependientes de la Academia, fue preciso elevar una nueva consulta a través del Viceprotector, mientras se remitían los modelos de uniforme, que fueron aprobados por Real orden de 17 de marzo $^{260}$. La decisión definitiva fue que únicamente los empleados de la Academia, es decir, "los de dentro de la Casa" ${ }^{261}$ ", gozasen del privilegio del uniforme, estando restringido así a los directores, tenientes directores, bibliotecario, conserje, porteros y

\footnotetext{
${ }^{257}$ ARABASF, Le-1-12-22.

258 Junta Particular de 26 de enero de 1816, ARABASF (3-127), fol. 91v.

259 "Cuarto. Que S.M. había declarado que los individuos de esta Academia puedan usar el uniforme de Casa Real correspondiente a sus respectivas clases como uno de los honores concedidos a este $\mathrm{R}^{1}$ Cuerpo en el artículo 34 de sus estatutos, y según se observa con los dependientes del Gabinete de Historia natural". Junta Particular de 26 de febrero de 1816, ARABASF (3-127), fol. 94r.

${ }^{260}$ ARABASF, Le-1-12-22.

${ }^{261}$ Junta Particular de 5 de abril de 1816, ARABASF (3-127), 1816, fol. 97r.
} 
mozo de limpieza. Nada indica que existiese problema alguno con el uniforme de los directores y tenientes directores; sin embargo, Juan Pascual Colomer expresó su deseo de que su uniforme, en calidad de bibliotecario, fuese distinto al de porteros y conserje, algo que la Academia entendió debido a la diferencia existente entre ambas clases de empleo, siendo aprobados los modelos en el mes de junio ${ }^{262}$; el conserje y porteros, por su parte, agradecieron el privilegio de poder vestir uniforme de Casa Real, pero solicitaban que fuesen costeados por la Academia ${ }^{263}$.

En lo que respecta a otras academias, conocemos también el caso de la de San Carlos de Valencia, que en 1825 remitió una instancia al rey, firmada por los profesores, solicitando que se les concediese la gracia de llevar uniforme, para lo cual incorporaron el modelo. El ministro de Estado remitió la solicitud a la Academia de San Fernando para que emitiese un informe, lo cual hizo en junta de 16 de octubre de 1825, según refleja el acta de la sesión:

La Academia se enteró de los términos y razones en que fundaban los interesados esta solicitud, de los antecedentes que hubo para conceder esta gracia a los Sres. Profesores de nombramiento Real de esta de San Fernando y de otros que obraban en el archivo, y finalmente de una exposición del Sr. Viceprotector recomendando dicha solicitud por el estímulo que producirá en un cuerpo artístico que no solo ha formado pintores tan recomendables, sino que ha contribuido a mejorar los artefactos en una de las provincias más industriosas del reino. Notándose que había variedad de dictámenes en la conferencia se procedió a la votación y resultó por 17 votos contra lo que se informase apoyando la pretensión de los profesores y secretario de la Academia de Valencia ${ }^{264}$.

\subsubsection{Los artistas en las Academias de Bellas Artes en España}

La instauración del sistema académico en España alteró la identidad artística mediante el establecimiento de un nuevo método educativo, el control de la producción de obras de arte y un concepto de profesionalización basado no solo en el dominio de la práctica artística, sino también en la dignificación intelectual, promoviendo entre sus miembros el desarrollo de capacidades de adaptación al orden social interno, habilidades para la administración, la transmisión de conocimientos y la urbanidad en el trato exigida a la buena sociedad, es decir, cualidades y virtudes de una masculinidad asociada a la aristocracia y a la jerarquía. La inicial estructura académica, analizada por Bédat y Navarrete pone de manifiesto la existencia de una estructura jerárquica en la que el artista debía buscar su lugar en relación a los demás miembros de la institución. En el caso de la Academia de San Fernando, una doble estructura diferenciaba las tareas administrativas y representativas desempeñadas por los consiliarios de las propiamente artísticas, articulándose en torno a dos pirámides; la jerarquía entre los artistas estuvo compuesta, hasta la reforma de los estatutos de 1846, por los académicos de mérito en su escalón más bajo, tratándose en muchas ocasiones de aficionados a las bellas artes,

\footnotetext{
262 Junta Particular de 19 de junio de 1816, ARABASF (3-127), fol. 109v. y 110r; oficio a mayordomía mayor del Rey, ARABASF, Le 1-12-22.

263 Junta Particular de 11 de mayo de 1818, ARABASF (3-127), fol. 104v. y 105r.

${ }^{264}$ Junta Ordinaria de 16 de octubre de 1825, ARABASF (3-88), fol. 131v.
} 
pero también de artistas de talento. El hecho de que el título de académico de mérito fuese codiciado como forma de distinción social y profesional en el siglo XIX queda recogido en las continuas solicitudes dirigidas a la Academia; en este sentido, es llamativo cómo Federico de Madrazo relata a su padre la aspiración secreta de Esteve de ser reconocido académico de mérito sin solicitarlo, aludiendo sin duda a la necesidad personal del artista por ver coronado su talento ${ }^{265}$. Formando el cuerpo de profesores se encontraban los tenientes directores, los directores de las respectivas artes, y un director general (NAVARRETE, 1999: 61). La relación entre profesores y consiliarios no estuvo exenta de grandes diferencias en funciones y privilegios, y por lo tanto fue objeto de grandes tensiones, ya que frente al cuerpo profesional, que exigía la demostración de un saber, los cargos administrativos no fueron ocupados por artistas sino por aristócratas con mayor o menor interés por las bellas artes, que por lo elevado de su número y las prerrogativas derivadas de su condición social llegaron a suponer un lastre para el desarrollo artístico y cultural de la corporación ${ }^{266}$. La situación de vulnerabilidad laboral de los profesores se puso de manifiesto en los recortes, demoras e incluso suspensiones de sus sueldos, en la injerencia de los consiliarios en materias de carácter artístico o en las desiguales votaciones que estos, en mayoría de número, ejercían para perjudicar a los académicos profesores (BÉDAT, 1989: 159; NAVARRETE, 1999: 63). La vida de los académicos profesores estaba estrechamente vinculada con la institución, aunque no constituyese esta su ocupación principal, al ser los encargados de las enseñanzas artísticas, rivalizando entre sí y siendo conscientes de las diferencias que entrañaban sus respectivos cargos. A pesar de esto, la academia se constituyó a través de las figuras de los profesores y hasta mediados del siglo XIX como uno de los referentes profesionales para los discípulos, ya que, a similitud de lo expuesto por Albert Boime (1986: 4) en relación al sistema académico francés ${ }^{267}$, el acceso al grado de académico de mérito estaba al alcance de muchos artistas aplicados, permitiendo esto conseguir no solo los honores de pertenecer a la institución sino también la posibilidad de ocupar alguna vacante en las enseñanzas artísticas. Del mismo modo, el carácter ritual y jerárquico que teñía la vida académica, con sus ostentosas entregas de premios en las que intervenían el rey y grandes hombres de estado, unido al despliegue institucional y al orgullo profesional de muchos de sus miembros, contribuyó a afianzar una imagen del artista académico como miembro de la élite cultural hasta 1850. La imagen del académico como guardián y súbdito de la norma académica, denostada por los partidarios de la libertad creativa individual como Goya, queda más manifiesta en el papel que los

\footnotetext{
265 “El Sr. Esteve (...) regalará un ejemplar a la Academia de San Fernando; se conoce que desea mucho que esta Academia le nombre académico de mérito, sin solicitarlo. Tiene en esto bastante empeño oculto en su aparente modestia. Lo que es él bien merece ser académico, en verdad". Carta de Federico a José de Madrazo, 8 de junio de 1839 (DÍEZ, 1994: 234).

${ }^{266}$ En palabras de José Caveda, "confundido el precepto con el consejo y no bien enlazadas sus partes componentes, primero revelan el amor al Arte que los ha dictado, que el conocimiento profundo de los medios más a propósito para organizar cumplidamente el cuerpo encargado de la enseñanza. Ora confunden la Academia con la escuela, ora dan a la una y a la otra atribuciones mal avenidas con su carácter respectivo". CAVEDA, 1867: 38.

${ }^{267}$ Boime señala que entre las diferencias del sistema académico en los siglos XVII-XVIII y el instaurado en el XIX el hecho de que en el primero la oportunidad de ser nombrado académico estaba al alcance de todos, lo que estimulaba a los estudiantes, mientras que el sistema decimonónico, al tener un número fijo de plazas, se convirtió en un cuerpo cerrado y exclusivo.
} 
artistas cobran en la academia a partir de esta fecha. La crítica de Galofre (1851: 164) contra la academia en El artista en Europa subrayaba el hecho de que esta institución pedagógica se hubiese convertido en un escenario para "ceremonias sociales donde se reparten pueriles dignidades", donde entra en juego un nuevo componente social en el que la academia es el escenario de artistas sumisos (WALLER, 2000: 146) y obsoletos, frente al concepto moderno de artista que se hace a sí mismo, es decir, entre la masculinidad vinculada al antiguo régimen frente al nuevo concepto burgués. Es preciso entender sin embargo que el papel de las academias en la primera mitad del siglo XIX, por su vinculación con un ritual ceremonioso y su política de premios, así como la honra del título ${ }^{268}$, supuso para los artistas el principal escenario social en el que desplegar su vanidad y orgullo profesional.

La reforma de los Estatutos de 1846 limitó en gran medida la estructura interna de la Academia: por una parte, la sección administrativa se vio desprovista de la obsoleta figura del protector, cambiándose también la de viceprotector por un presidente, y el número de consiliarios, anteriormente ilimitado, se vio reducido a seis; por otra parte, el número de académicos se redujo a sesenta, dividiéndose por secciones: de este modo, dieciséis profesores lo serían por la sección de pintura (doce de historia y cuatro de paisaje y costumbres), ocho por la de escultura, dieciséis por la de arquitectura, y cuatro por el grabado, a los que se sumaría un total de dieciséis académicos no profesores. Al desaparecer las categorías de académicos de mérito y de honor se buscaba potenciar la profesionalización de la Academia, limitando de este modo el acceso a la corporación de individuos más interesados por los honores del título que por la afición o el mérito en las artes, y que no participaban de manera activa en la vida académica (NAVARRETE, 1999: 61). Y esto supuso, al mismo tiempo, una revalorización del propio título de académico, ya que no solo estaba vinculado a una relación efectiva con las artes, sino que requería pruebas fehacientes de una carrera consolidada, transformándose en una corporación aún más elitista, y con una media de edad mucho más envejecida. El cambio en la estructura académica estaba también relacionado con el inicio de la separación de la enseñanza artística de la institución; sin embargo, en un primer momento el desarrollo de las Escuelas de Bellas Artes no está plenamente desvinculado de la Academia, ya que aún dependían de estas. Al mismo tiempo, y aunque el acceso al cuerpo docente de las escuelas de bellas artes no estaba limitado al personal académico, sino que se realizaba por oposición a la que podía presentarse cualquier profesional acreditado, ser nombrado profesor de la Escuela de Bellas Artes suponía ser considerado de inmediato individuo nato de la Academia.

En la segunda mitad del siglo XIX la Academia siguió teniendo parte de su anterior atractivo como corporación en la que una reducida élite artística ostentaba su poder, generalmente como órgano consultivo en materias de bellas artes y conservación del

\footnotetext{
${ }^{268}$ La confusión en la correlación de los grados académicos jugó una mala pasada en el caso de José Álvarez Bouquel, la Academia de San Fernando recibió una queja por parte de la de San Lucas, al haberse publicado en la biografía de este que era académico de mérito, cuando solo lo era de honor, subrayando que "la clase de honor es muy inferior a la de mérito, que es la distinción principal que solo se confiere a los catedráticos y profesores de no común consideración residentes en Roma o que han hecho allí larga permanencia” (Junta Ordinaria de 5 de mayo de 1829, ARABASF (3-88), fol. 227 v.).
} 
patrimonio; sin embargo, el desarrollo de las enseñanzas en las Escuelas de Bellas Artes, de una nueva sociabilidad artística y la desvinculación de la institución respecto a la práctica de las artes restaron en buena medida interés a su influencia en las aspiraciones del artista, de manera que en la construcción de la identidad profesional de los pintores y escultores la Academia perdió su inicial significado como fuente de emulación y de identificación. Estos cambios se vieron mejor reflejados con la reforma de los estatutos de 1864 que, además de eliminar de manera definitiva la figura del consiliario, dio lugar a una Academia destinada a tareas intelectuales, y que limitaba aún más el número de sus miembros a treinta y seis académicos.

La vinculación de las academias con el poder oficial es patente con la publicación del Real Decreto de 1849, en el que se establecía que los presidentes de las corporaciones provinciales serían elegidos por el gobierno, aunque podían ser presididas por el jefe político cuando este lo considerase oportuno, un elemento jerárquico que no pasa desapercibido en las galerías de retratos, en las que se observa a partir de este momento un creciente interés por los retratos de presidentes (especialmente notable en el caso de Valencia) frente a los de artistas académicos. Del mismo modo, el reconocimiento de las Academias Provinciales de Bellas Artes también dio lugar a la iniciativa, en muchos casos caída en el olvido, de iniciar sus correspondientes galerías. Es el caso, por ejemplo, de la de Cádiz, de la Academia granadina, en cuyo seno se da cuenta de la celebración de un acto, público y solemne, en 1854 para colocar en la Sala de Juntas el retrato de Francisco Pérez de Herrasti, primer presidente de la Academia ${ }^{269}$, o de la Academia de la Purísima Concepción de Valladolid, que a pesar de haber sido considerada academia de primera clase no inició una galería de retratos de directores hasta la presidencia de José Fernández Sierra, cuyo retrato data de 1855, consolidándose plenamente como galería al ubicarse en el salón oficial de actos a partir de 1873 con las obras realizadas por Martí y Monsó (URREA, 1998: 35).

Es preciso hacer algunas consideraciones generales respecto a los retratos en las galerías académicas españolas. En primer lugar, los retratos que formaron parte de estas series fueron, fundamentalmente, imágenes para la memoria, e ingresaron en sus respectivas corporaciones únicamente tras la muerte del académico; se observa aquí una diferencia respecto al caso francés, y también respecto al romano, en el que no era infrecuente que algunos retratos se incorporasen en vida del donante para mayor gloria del artista. En el propio territorio español también se observan diferencias en los modos de entender las galerías de retratos, y podría extrañar a primera vista comprobar cómo la academia más antigua y de vital importancia por su carácter central, la de San Fernando,

${ }^{269}$ El acta de la sesión que acompañaba a esta noticia aparecida en la revista Las Bellas Artes explicaba que la realización de este retrato del difunto primer presidente se había acordado en la propia Academia, ofreciéndose para ello el director de pintura Ginés Nogueras y Fernández. Los gastos de esta iniciativa correrían por parte de la propia Academia; no obstante, al llegar la noticia a la familia del difunto, ofreció poner por su parte el retrato para aliviar económicamente a la corporación, a lo cual esta, en agradecimiento, correspondió celebrando un acto para la colocación del retrato ("Revista de Academias", 1854: 98). Sin embargo, son escasas las noticias de otros retratos en dicha academia, constando únicamente un retrato del director de pintura Fernando Marín en 1818, y otro del pintor Ginés Noguera entre 1875 y 1879 (SANTOS MORENO, 1997: 41-42, y 93). 
alberga la colección de retratos más ecléctica y de más difícil lectura, al haberse configurado de manera paulatina mediante la incorporación esporádica de retratos por legado testamentario de los académicos o de sus descendientes. Por el contrario, la Academia de San Carlos parece tomar conciencia desde época temprana del significado de su galería, comisionando la tarea de realizar los retratos de los académicos a sus propios profesores.

Esto no debe llevar al equívoco precipitado de considerar los retratos de la de San Fernando como obras externas a la corporación, ya que una aproximación a su contexto de producción mostrará cómo un retrato, inicialmente no destinado a la galería sino al uso privado bien del autor o del retratado, es fruto de una relación de sociabilidad vinculada al ámbito académico; otros casos, no menos desdeñables en número, manifiestan una voluntad de perpetuar un linaje familiar dentro de la Academia, un rasgo que lejos de resultar anacrónico parece una característica intrínseca de la corporación durante el siglo XIX de la que son muestra, entre otros muchos, los Álvarez, González Velázquez, Madrazos, López y Ferrant. Tampoco el caso valenciano debe tomarse a la ligera, ya que si bien antes señalábamos la posible influencia que la vinculación de Francisco Vergara y la galería de la Academia de San Lucas pudo ejercer en sus parientes Ignacio y José Vergara, fundadores de la de San Carlos, y aun tratándose en su mayoría de retratos póstumos, manifiestan la importancia de las relaciones interpersonales en el ámbito educativo académico. También fruto de la sociabilidad académica fueron los retratos ofrecidos como prueba para la admisión en el grado de académico de mérito, especialmente a finales del siglo XVIII y comienzos del XIX. En este sentido, también es notorio el hecho de que el autorretrato apenas tenga cabida en las galerías de retratos españolas en el siglo XIX, independientemente del orgullo que el artista pudiera sentir de su pertenencia a la corporación, aunque sí tuvo una mayor proyección en las exposiciones públicas organizadas por estas instituciones.

La representación del artista en las galerías académicas es interesante, ya que las imágenes elegidas, especialmente en la primera mitad del siglo XIX, acentúan la identidad profesional mediante la inclusión de los útiles de trabajo o de alguna de sus obras; este rasgo, aparentemente irrelevante en cuanto repetición del modelo neoclásico de retrato de artista, es más significativo en contraste con los retratos de otros académicos, y permite una lectura en clave social en la que parecen potenciarse las diferencias entre la idea de jerarquía y la de mérito personal, sin incurrir, por el propio carácter elitista de la corporación, en la iconografía del artista trabajador o de clase media en el desempeño mecánico de su arte.

Nos hemos centrado en las problemáticas de las galerías de retratos en las academias de bellas artes españolas a partir de cuatro ejemplos, representativos cada uno de distintas motivaciones, a través del estudio de fuentes documentales y de la propia colección pictórica: la madrileña de San Fernando, que a través de su Sala de Retratos y de distintas iniciativas construye una imagen particular y sesgada de la institución; la Academia de Bellas Artes de San Carlos de Valencia, que configura en la primera mitad del siglo XIX una galería claramente diferenciada; la Academia de Sant 
Jordi de Barcelona, cuya galería de retratos es heredera de las relaciones de poder de la Escuela de Dibujo; y finalmente la Academia de Bellas Artes de Santa Isabel de Sevilla, en la que los artistas del pasado cobran especial significado para construir un linaje simbólico para la institución decimonónica. A través de estos cuatro casos se estudian las distintas formas de configuración tanto de la identidad profesional como de una identidad colectiva, analizando el papel que los artistas -y los retratos de artistatuvieron en ellas. Para ello, se ha prestado atención a las características y peculiaridades presentes en cada una de ellas respecto a la formación de la galería, a los retratos que las componen y su relación con los espacios que ocuparon.

\subsection{Los retratos de la Real Academia de Bellas Artes de San Fernando}

Al hablar del papel del artista en la historia de la Real Academia de Bellas Artes de San Fernando suele indicarse, casi a modo de lamentación, que lejos de las costumbres establecidas en otras academias europeas, con París y Roma como referencia, en la madrileña no arraigó la tradición de establecer una galería de retratos que reivindicase la figura del artista dentro de la institución. En su estudio del autorretrato en España Wifredo Rincón afirma que

es lamentable que la Real Academia de Bellas Artes de San Fernando no impusiera a los individuos de número, como lo hiciera la romana de San Lucas, el ritual del autorretrato. Hubiera sido esta una obligación, con toda seguridad, gratamente aceptada por los artistas, que nos hubiera permitido tener una importantísima galería iconográfica de los artistas académicos de la primera Academia de Bellas Artes de España (RINCÓN GARCÍA, 1991: 22),

una idea que mantiene en páginas subsiguientes, haciendo notar las diferencias respecto a otras academias, como la de San Carlos. No obstante, al recorrer la historia de la institución y de sus colecciones se pone de manifiesto la existencia de una temprana preocupación por la creación de una identidad colectiva y una historia propia a través del uso del retrato. Por otra parte, y frente a lo propuesto por Rincón, la imposición de legar autorretratos al modo romano había supuesto en el joven sistema artístico español una falta de modestia y recato, ya que es evidente la preferencia a un reconocimiento del mérito personal por parte de terceros - constituidos en figuras de autoridad-, lo que también explica que el proceso de construcción identitaria de la institución académica española fuese un proceso lento. En este sentido, Williams señala cómo la toma de conciencia de una comunidad académica como una entidad autodefinida requiere, por lo general, asumir un devenir histórico previo, indicando que la identidad corporativa solo puede desarrollarse a través del retrato como legitimación de un colectivo cuando existe un autoconocimiento de los individuos que lo conforman, de sus relaciones personales y laborales, y cuando estos factores, una vez combinados en el transcurso de los años, permiten hablar de una historia común (WILLIAMS, 2015:17). En la galería de retratos, la obra es la encargada de reflejar e ir construyendo, mediante sucesivas incorporaciones, una historia del pasado que refuerza la identidad colectiva en su relación no solo con los otros retratos, sino con los individuos de la comunidad que interactúan a diario con ellos y que dotan al conjunto de un significado propio. En el 
caso de la Academia de Bellas Artes de San Fernando la propia designación de galería resulta chocante por la inexistencia de rasgos comunes entre los retratos y la escasa trascendencia que estos parecen tener en lo reflejado por las historias tradicionales de la institución; no se trata, por lo general, de piezas de recepción, como en el caso de París, ni de una exigencia establecida por la propia corporación como ocurría en Roma, sino de donaciones de carácter particular en los que se denota una voluntad de vincular la identidad individual del artista con la de la Academia. Sin embargo, la propia corporación manifestó en varias ocasiones la necesidad de formar una galería de retratos de académicos, idea que fue retomada en varias ocasiones y que dio lugar a un espacio, al mismo tiempo dignificado y ecléctico, dentro de las colecciones artísticas de la academia.

\subsubsection{Las tentativas de crear una galería de retratos (1752-1808)}

En 1754, con apenas diez años de historia a las espaldas desde los intentos de la Junta Preparatoria de establecer una Academia, concurren varios acontecimientos que motivan la iniciativa de comenzar una galería de retratos vinculados a la historia de la corporación. El fallecimiento de su primer protector, José de Carvajal y Lancaster, desencadenó el deseo de acreditar el reconocimiento a sus desvelos, y lejos de considerarlo un hito puntual, las actas recogen la voluntad de crear a partir de ese momento una galería de retratos de los monarcas y de los protectores de la Academia. El acta de la junta celebrada el 6 de junio de 1754 recoge la decisión tomada:

Con deseo de acreditar la Academia el reconocimiento que conserva a su difunto Protector, el Excmo. Sr. D. Joseph de Carvajal y Lancaster determinó que se haga en pintura y escultura el retrato de S. E. Con este motivo se hizo presente que la primera obligación de la Academia es contribuir por cuantos medios pueda a eternizar la memoria de nuestro augusto monarca y sus sucesores con la de los Excmos. Protectores que la gobiernan. En fuerza de esta justa consideración se resolvió por unánime consentimiento, y se le dio fuerza de acta, que de hoy en adelante sea cargo preciso de la Academia hacer por medio de los Directores, u otros Individuos, que nombre el Sor. Vicepor. los Retratos en esta forma: en un lienzo de nueve pies de alto, y seis de ancho se pintará de cuerpo entero el del Rey $\mathrm{N}^{\mathrm{o}}$. Sor. y los de sus sucesores. Y su busto al natural se esculpirá en mármol. Los retratos de los Sres. Protectores serán el de pintura, de medio cuerpo en un lienzo de cuatro pies de alto, $y$ tres de ancho; y el de escultura, la cabeza al natural en una medalla de mármol ${ }^{270}$.

El deseo de eternizar la memoria del gobierno efectivo de la corporación, anclado en la ideología absolutista, no se extiende a la de los artistas que la componen, cuyo papel está reducido a la producción, estrictamente codificada, de las imágenes que configurarán su historia, dejando incluso una laguna sobre si esta tarea deben realizarla los Directores -como la lógica jerárquica indicaría-, u otro individuo de la Academia. Resulta difícil aventurar cómo interpretaron los artistas de la Academia esta iniciativa, aunque la premura con que Andrés de la Calleja y Felipe de Castro, a pesar de la

\footnotetext{
${ }^{270}$ Junta Ordinaria de 6 de junio de 1754, ARABASF (3-81), fol. 21v.
} 
defensa de la situación del artista en la Academia por parte de este último (BÉDAT, 1979: 31), realizaron los retratos inaugurales parece manifestar su conformidad con la idea de honrar la memoria de los monarcas y protectores que, como cabeza visible de la academia, detentaban el mayor poder en la institución. Significativa en cuanto a la voluntad de generar una galería es la especificación que se hace en la misma acta, indicando que "todas estas piezas en su clase deben ser de figura y tamaño uniforme para formar una serie que sea en lo sucesivo no solo un digno monumento de la piedad de Nros. Soberanos, y del celo de sus Ministros ${ }^{271}$, sino es también una gloriosa demostración de la gratitud de la Academia ${ }^{272}$ ". Independientemente del destino de los retratos, que no se especifica en las actas, se subrayaba la necesidad de que tanto el retrato de José de Carvajal como el de Fernando VI estuvieran concluidos antes de la distribución pública de los premios anuales con la intención de que formasen parte del despliegue monumental, cargado de connotaciones políticas y propagandísticas de la institución, de la ceremonia académica. Ambos retratos, del que interesa particularmente el pintado por Andrés de la Calleja de José de Carvajal [fig. 98], representando precisamente en el acto de entregar una medalla, constan como adorno en dicha entrega de premios tal y como recoge Ceán Bermúdez:

Para repartir los premios de la oposición del año siguiente [1854] se dispuso el teatro en el seminario de nobles, donde se celebró el 22 de diciembre, y presidió el señor D. Ricardo Wal, secretario de Estado. La academia dio entonces una prueba de su gratitud al rey y a su ministro, su fundador y su primer protector, presentando al público un busto de $\mathrm{S}$. M. y una medalla con el retrato del señor Carvajal, ya difunto, que trabajó en mármol Olivieri, otro retrato del mismo ministro, pintado por D. Andrés de la Calleja, y acordó que D. Antonio González Ruiz pintase el de S.M ${ }^{273}$.

A pesar de este primer impulso de codificar una galería de retratos institucional, no queda constancia de que esta iniciativa siguiera adelante, ya que ni en las actas ni en las colecciones de la academia se da noticia de nuevos retratos de protectores. Antonio González Ruiz realizó ese mismo año para la Academia el retrato de Fernando VI en la composición alegórica Fernando VI como protector de las Artes y las Ciencias [fig. 99], cuyas grandes dimensiones evidencian el abandono de las restricciones impuestas para los retratos de los protectores. No debe pasar desapercibido el papel de Antonio González Ruiz en la configuración inicial de una identidad académica, ya que en 1746 cumplió con el encargo de la Academia de representar la Junta Preparatoria en su Alegoría de la fundación de la Academia y de su mano constan algunos de los retratos de la colección de académicos, relacionados sin embargo con su relación con los

\footnotetext{
271 De este modo, son los soberanos y sus ministros, atendiendo al modelo de masculinidad de los hombres de estado y la aristocracia, culta y vinculada al poder político, los únicos dignos de merecer, al menos en un principio, tal dignificación dentro de la institución.

${ }^{272}$ Junta Ordinaria de 6 de junio de 1754, ARABASF (3-81), fol. 21v.

${ }^{273}$ Acta de la Sesión Pública de 22 de diciembre de 1754, ARABASF (3-81); CEÁN BERMÚDEZ, 2001: $257-258$.
} 


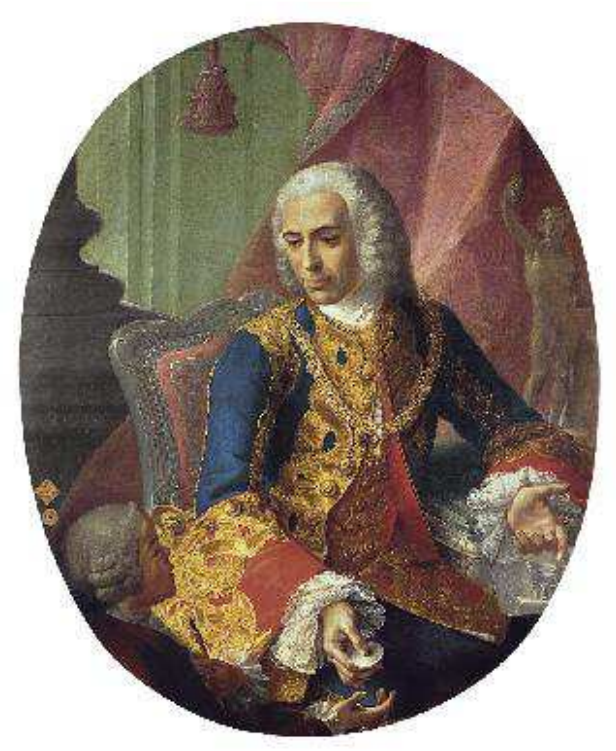

Fig. 98. Andrés de la Calleja, Retrato de Don José de Carvajal y Lancaster. Academia de San Fernando (inv. 0722).

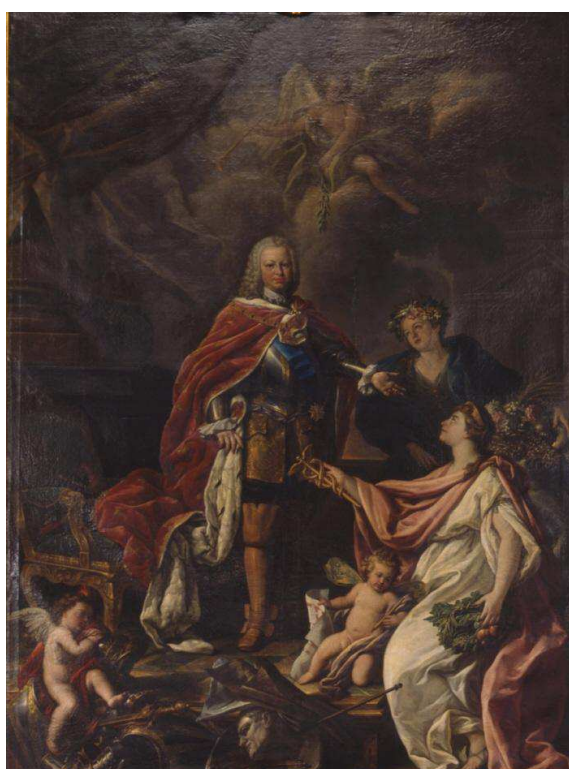

Fig. 99. Antonio González Ruiz, Fernando VI como protector de las artes y las ciencias. Academia de San Fernando (inv. 0683).

retratados (su suegro Juan Bernabé Palomino y el secretario Ignacio Hermosilla) y no con la iniciativa de una galería de retratos ${ }^{274}$.

Mayor importancia reviste la propuesta de 1774, realizada por el consiliario Vicente Osorio Moscoso, conde de Aguilar, por la implicación que tiene respecto a la visibilidad del artista dentro de la Academia a través de su retrato. En Junta Ordinaria de seis de marzo, el conde de Aguilar planteó la conveniencia de "que todos los profesores hiciesen sus retratos, y se presentasen a la Academia así para el más propio adorno de ella, como para perpetuar por este medio la memoria de todos ${ }^{275}$ ". No cabe duda de que se trataba de dar una mayor dignificación a los profesores de las bellas artes dentro de la Academia, pero es posible que también influyera sobre esta propuesta el hecho de que en las dos décadas precedentes se hubieran realizado, de manera esporádica y siguiendo más una tradición extranjera que ninguna norma española, donaciones de retratos de artistas a la Academia. Los dos casos más significativos corresponden, curiosamente, a mujeres artistas, y para más detalle extranjeras, que deseaban ser admitidas como académicas de mérito. El primer caso conocido es el de Faraona Olivieri, que presentó -acorde a la tradición de la Academia Real parisina- no uno, sino dos retratos originales realizados al pastel, representando uno al arquitecto francés, y director honorario de la Academia de San Fernando, Jaime Marquet, y otro de una mujer que hasta fecha muy posterior no fue considerado un autorretrato de la $\operatorname{artista~}^{276}$; al señalarse en las actas la

\footnotetext{
${ }^{274}$ Sí que podría estar vinculado, sin embargo, el retrato que realizó del grabador Francisco Tomás Prieto (BNE, IH 7470), cuya similitud con el propio autorretrató de Antonio González Ruiz no pasa desapercibida (GACTO, 2012: 1154).

275 Junta Ordinaria de 6 de marzo de 1774, ARABASF (3-83), fol. 261r y 261v.

${ }^{276}$ En el acta se dice que aseguraron "algunos profesores que el otro es igualmente semejante a una mujer que sirvió de original", sin aventurar la identidad de la representada. En los inventarios históricos de la Academia de San Fernando aparece como un "retrato de mujer" hasta que en 1824 se identifica como autorretrato de Faraona Olivieri. Junta Ordinaria de 18 de diciembre de 1759, ARABASF (3-82), fol. 68v.
} 
identidad de Marquet, artista ya distinguido en la Academia, pero no la de Faraona Olivieri se pasaban igualmente por alto el vínculo afectivo existente entre ambos retratados $^{277}$ y la posibilidad de legitimación de una mujer artista a través de un autorretrato en una institución aún demasiado joven para haber tomado plena consciencia de la necesidad de construir su identidad a través del retrato. El segundo es el de la también parisina María Josefa Carrión, que en 1761 presentaba el retrato a pastel del Director de Arquitectura Diego de Villanueva ${ }^{278}$.

Con estos antecedentes, en los que retratos de académicos, y más concretamente, de académicos profesores, se convirtieron en piezas de recepción, no es de extrañar que el conde de Aguilar echase en falta una iniciativa propia por parte de los artistas de la Academia de legar su efigie para perpetuar su memoria, tanto la individual como la colectiva. Más curiosa aún fue la resolución tomada por la Junta, que "oyó con mucho gusto esta proposición y acordó, no solo que se ejecute así, sino que también los Sres. Consiliarios, y demás individuos de todas las clases de la Academia procuren que se hagan y se pongan en la Academia sus retratos, y los que se puedan hacer o adquirir de los Sres. difuntos ${ }^{279}$,, en la que cabe entender cómo se transmite, de manera velada, un conflicto dentro de la propia institución. Sin duda, la propuesta de visibilizar a los artistas de la corporación podía interpretarse como un reconocimiento a su labor intelectual y profesional en la institución, pero también como un excesivo afán de protagonismo, sobre todo teniendo en cuenta que la iniciativa de crear una galería de retratos de protectores había caído en el olvido. El acuerdo final pactado pretendía no afectar al orgullo de ninguno de los académicos, fueran estos profesores o consiliarios; de este modo, se votó que se realizasen los retratos de todos ellos, profesores y consiliarios, aunque sin designar en este caso la tarea a los propios profesores, sino apelando a las donaciones y a la iniciativa privada. Este hecho, aparentemente intrascendente, puede deberse precisamente a la incomodidad y tensiones existentes entre consiliarios y profesores, dando libertad a todos ellos para hacer o mandar hacer sus retratos por artistas ajenos a la corporación, aunque esto chocase con la lógica de utilizar los recursos artísticos de la propia institución. Tampoco queda constancia de que se estipulasen unas dimensiones ni pautas fijas para configurar una serie coherente, debido a esta libertad, nada comprometedora, de la autoría de los retratos, o quizás con la intención de ofrecer mayores facilidades para donar a la Academia retratos ya realizados. Todo parece apuntar que fue esta propuesta, caracterizada por una escasez absoluta de premisas y que podía desembocar, como efectivamente hizo, en una colección ecléctica de retratos, unida a la tradición extranjera de presentar un retrato para la recepción como académico de mérito, la que dio lugar a la creación de una muy reducida colección de retratos que no alcanzaría una gran trascendencia dentro de la academia hasta finales del siglo XIX y comienzos del XX.

\footnotetext{
${ }^{277}$ El arquitecto Jaime Marquet y la pintora Faraona Olivieri estaban casados. Las dimensiones de ambos retratos son prácticamente idénticas $(0,55 \times 0,46 \mathrm{~m})$, lo cual, junto al hecho de que fueron presentados al mismo tiempo, hace pensar que la propia Olivieri planteó estos retratos como pendants para la Academia. Para más información sobre Faraona Olivieri, ver SMITH, 2006: 56.

${ }^{278}$ Junta Ordinaria de 20 de diciembre de 1761, ARABASF (3-82), fol. 189v.

${ }^{279}$ Junta Ordinaria de 6 de noviembre de 1774. ARABASF (3-83), fol. 261v.
} 


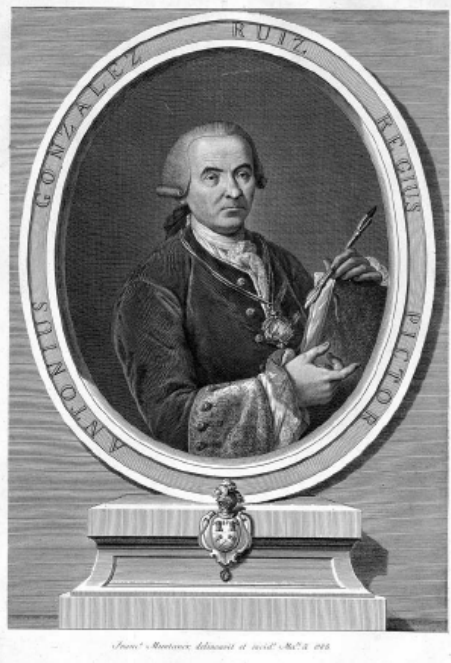

Fig. 100. Francisco Muntaner, Retrato de Antonio González Ruiz. BNE (IH/4009G).

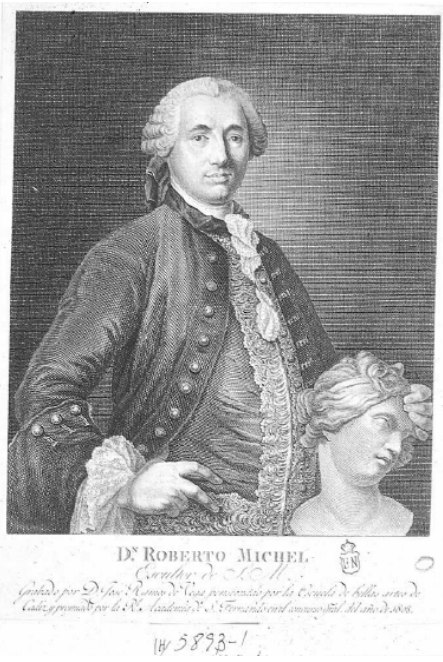

Fig. 102. José Ramos, Retrato de Roberto Michel, 1808. BNE (IH/5893/1).

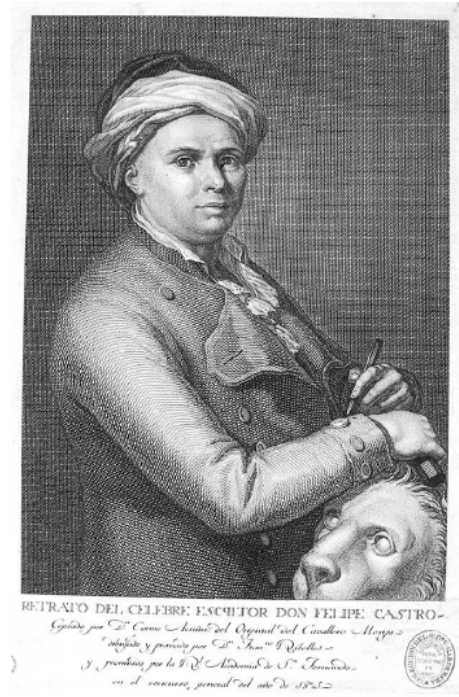

Fig. 101. Francisco Ribelles, Retrato de Felipe de Castro. BNE (IH/1959/1).

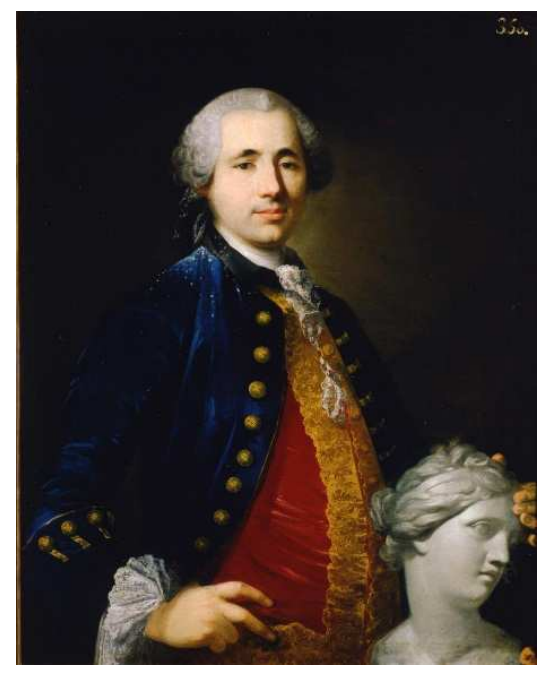

Fig. 103. Retrato de Roberto Michel, s. XVIII.

Museo Academia de San Fernando ( $\mathrm{n}^{\mathrm{o}}$ inv. 0715).

Una última tentativa es la vinculada a la enseñanza del grabado de láminas y los premios para el concurso anual, iniciada de manera tardía en 1806. La iniciativa tenía por fin formar una galería de Artistas Nacionales, en concreto de profesores de la Academia ya difuntos, tal y como transmite el acta de la Junta Ordinaria de 13 de diciembre de 1807 al hacer la elección de temas, lo que demuestra una voluntad de configurar un corpus de retratos cohesionados ya no solo por una identidad artística, sino también por su estricta vinculación al cuerpo académico ${ }^{280}$ :

De palabra expuse que bajo estos datos se escogieron en el concurso anterior asuntos nuevos tomados de la Historia Nacional en pintura, escultura y ambos

\footnotetext{
280 Álvaro Molina señala como primera inclusión de retratos de artistas del pasado como grupo independiente la colección Retratos de los españoles ilustres, publicada en 1797, en la que protagonizaron un cuaderno monográfico en la duodécima entrega (MOLINA, 2013: 215-6); apunta, además, al cambio iconográfico introducido al subrayar la profesión artística por encima de la condición cortesana (MOLINA, 2016: 54).
} 
grabados, y en el de láminas el retrato de D. Felipe de Castro con el objeto que, haciendo honor la Academia a sus Profesores beneméritos ya difuntos, se vaya formando una Galería de Artistas Nacionales ${ }^{281}$.

Esta propuesta se desliga así de las surgidas en la Real Academia de Bellas Artes de Viena, a cargo de Jacob Merz (1984: 47-55), o de los retratos de académicos dibujados por George Dance en la Royal Academy de Londres entre 1793 y 1796, en los que el retrato está relacionado con los académicos en activo y que manifiestan un vínculo real entre el autor y los retratados. A pesar de ser frecuente en las academias que los alumnos de grabado realizasen como ejercicios copias de retratos de artistas del pasado $^{282}$, en la de San Fernando también se encuentran con anterioridad a 1806, aunque de manera esporádica, algunos retratos de artistas contemporáneos vinculados a la Academia y realizados al grabado, como el de Francisco Bayeu por el académico de mérito José Vázquez, y presentado en febrero de $1804^{283}$, o el de Antonio González Ruiz por Francisco Muntaner [fig. 100], que ya constaba en el inventario de 1804. En relación a la iniciativa -especificada como tal únicamente a partir de 1806-, solo queda constancia de que en 1805 se eligió el retrato del escultor Felipe de Castro [fig. 101] (GACTO, 2012: 1155), fallecido en 1775, resultando premiado el discípulo Francisco Ribelles, y que se propuso para el concurso de 1808 el retrato del también escultor Roberto Michel $^{284}(\dagger 1786$ ) [fig. 102], tomándose como modelo la obra legada por el hermano del escultor, Pedro Michel, a la Academia [fig. 103]. Todo parece apuntar que tras los sucesos de 1808 la galería de grabados de artistas nacionales vinculados a la Academia cayó en el olvido.

Si bien la colección de retratos de la Academia de San Fernando comenzó a formarse a partir de donaciones particulares, vinculadas en algunos casos, como el de Faraona Olivieri y María Josefa Carrón, a la tradición del morceau de réception de la academia francesa, el hecho de que la madrileña no especificase una temática para las obras que debían presentarse para la recepción como académico de honor y/o de mérito ajenos a la propia formación académica conllevó que el número de retratos presentados fuese considerablemente reducido. Encontramos de manera esporádica noticias sobre el ingreso de este tipo de obras en las dos últimas décadas del siglo XVIII, con toda probabilidad atendiendo a aquella idea expresada por el conde de Aguilar de formar una galería que eternizase la memoria de sus miembros. Así, a los ya citados representando a Jaime Marquet, Faraona Olivieri y Diego de Villanueva, se fueron uniendo otros retratos de relevantes académicos: Bernardo Martínez del Barranco, que consta como discípulo de la Academia, de Mengs y Corrado Giaquinto, presentó en 1774 (meses

\footnotetext{
281 Junta Ordinaria de 13 de diciembre de 1807, ARABASF (3-87), fol. 351.

${ }^{282}$ En la Academia constaban dibujos preparatorios y grabados de algunos retratos como el de Murillo por Manuel Alegre en 1790, dos retratos de 1793 de Ventura Rodríguez realizados por Blas Amatller y por Manuel Esquivel, y uno de Juan Bernabé Palomino dibujado y grabado por Tomás López Enguídanos.

283 "El Académico de mérito Dn. Josef Vázquez presentó con un memorial una prueba de la estampa que acaba de grabar y representa el retrato del difunto Dn. Francisco Bayeu, con su marco y cristal, y pedía que la Academia se sirviese colocarlo en sus Salas. La Junta admitió este obsequio del Académico Vázquez y acordó que se le diesen las debidas gracias”. Junta Particular de 8 de febrero de 1804, ARABASF (3-126), fol. 50r.

${ }^{284}$ Junta Ordinaria de 13 de diciembre de 1807, ARABASF (3-87), fol. 355.
} 
después de la propuesta del conde de Aguilar), junto a otras obras, los de los consiliarios marqués de Sarria (Museo de la Academia de Bellas Artes de San Fernando, $\mathrm{n}^{\mathrm{o}}$ inv. 0141) y del propio conde de Aguilar ${ }^{285}$, solicitando el grado que la Academia conviniese adjudicarle ${ }^{286}$.

Ana María Mengs presentó en la junta pública de 4 de agosto $1790^{287}$ el retrato de su esposo Manuel Salvador Carmona, junto a otros retratos familiares de los que nos ocuparemos al abordar las relaciones familiares en el seno de la Academia, siendo esta obra la que pasaría a la colección de pinturas, como puede comprobarse en el inventario de la Academia de 1796-1805 (Museo de la Academia de San Fernando, no inv 0868).

Seis años más tarde, en 1796, las actas de la Academia dejan constancia de la donación por parte de la viuda de Ignacio de Hermosilla (Museo de la Academia de San Fernando, $\mathrm{n}^{\circ}$ inv. 0009) del retrato de su difunto marido en señal de gratitud a la corporación $^{288}$. Esta obra, como ya se ha señalado realizada por el académico Antonio González Ruiz hacia 1760 (PAREDES GIRALDO, 1992: 303 Y 312; PÉREZ SÁNCHEZ, 1977: 41), y procedente como la mayoría de las obras de esta colección del ámbito privado del retratado, configuraba para los miembros de la Academia una pintura llena de significados relevantes respecto a su propia historia institucional, sellando mediante la efigie de un particular los vínculos afectivos entre dos académicos, pues además de recordar la importancia de Hermosilla como secretario dentro de la corporación evocaba la historia de triunfo académico del propio pintor Antonio González Ruiz, quien en la fecha de realización de este retrato acababa de recibir la medalla de oro de manos del entonces secretario de la Academia.

Otra artista, María Lucía Gilabert, ya académica de honor y de mérito por la pintura, entregó a la Academia su retrato en 1799 "a fin de que después se quedara en la Academia ${ }^{289, ", ~ y ~ a u n q u e ~ s i e m p r e ~ f u e ~ c o n s i d e r a d o ~ a u t o r r e t r a t o ~ c u r i o s a m e n t e ~ n o ~ m e r e c i o ́, ~}$ como veremos, la misma atención que otros retratos de artista. Desconocemos la fecha exacta de ingreso del retrato del grabador Juan Bernabé Palomino realizado por Antonio González Ruiz en 1741, que figura en el inventario manuscrito de 1796-1805, aunque es probable que ya perteneciese a la colección con anterioridad al paso de siglo.

Suscita algunas dudas la presentación en junio de 1804 de un retrato de Mengs por parte de un pensionado ${ }^{290}$, ya que en el inventario coetáneo elaborado por la Academia ya figura una copia del Autorretrato de Mengs realizado por Carlos Espinosa en Roma

\footnotetext{
${ }^{285}$ A pesar de haber sido el promotor de la creación de una galería de retratos, no hay constancia de que el retrato del conde de Aguilar presentado por Bernardo Martínez del Barranco fuese legado a la Academia para tal fin, como tampoco ninguna efigie suya por otro artista, como queda de manifiesto en los inventarios históricos de la Academia.

${ }^{286}$ Junta Ordinaria de 6 de noviembre de 1774, ARABASF (3-83), fol. 307r.

287 "Hubo varias obras que diferentes señoras habían hecho y presentado, con el fin de que se expusiesen en este día para prueba de su aplicación y amor (...) tres retratos del natural pintados de pastel por la Sra. $\mathrm{D}^{\mathrm{a}}$. Ana María Mengs, y eran el de su padre, el de su marido el Sr. Dn. Manuel Carmona y el de su hija mayor". Junta pública de 4 de agosto de 1790, ARABASF (3-85), fol. 136.

${ }^{288}$ Junta Ordinaria de 10 de enero de 1796, ARABASF (3-86), fol. 84v.

${ }^{289}$ Junta Ordinaria de 4 de agosto de 1799, ARABASF (3-86), fol. 127v.

${ }^{290}$ Junta Ordinaria de 3 de junio de 1804, ARABASF (3-87), fol. 89r.
} 
hacia 1784. El hecho de que en el acta de la junta correspondiente no figure el apellido del pensionado correspondiente -al que se alude únicamente como Carlos- podría conducir a vincular estas dos obras como la misma; no obstante, parece más adecuado pensar que, como señala Jordán de Urríes, la copia del retrato de la colección de Nicolás de Azara ingresase en la Academia en torno a 1788 (JORDÁN DE URRÍES, 2012: 217), cuando Carlos Espinosa aún se encontraba en Roma como pensionado, y que la obra presentada en 1804 fuese una copia realizada como ejercicio por el discípulo Carlos Blanco $^{291}$, carente como tal del interés necesario para incorporarse a la colección artística de la corporación.

El último retrato del que tenemos constancia que ingresase en este momento es el del escultor Roberto Michel, correspondiendo a la propuesta de realizar su retrato para la prueba de grabado del certamen de 1808. El hermano del difunto artista, y también académico, Pedro Michel, procedió a la donación en 3 de enero de 1808 de un retrato al óleo que pudiese servir de modelo, cediéndolo a la academia "para que haga el uso que mejor le parezca ${ }^{292 "}$. La Academia recibió la obra con intención no solo de que sirviese de modelo para el ejercicio de los alumnos de grabado de láminas, sino para "añadir a sus preciosidades el retrato de un Profesor tan benemérito de la misma y de las artes ${ }^{293}$,, indicando de esta manera su beneplácito al contar con el retrato de un miembro destacado de su historia.

A partir de estos datos podemos comprobar cómo a comienzos del siglo XIX el conjunto de retratos de académicos era bastante reducido, pues el total apenas llegaba a la decena, incluyendo los anteriormente citados y el del protector José de Carvajal y Lancaster. A pesar de las posibles tensiones existentes entre consiliarios y profesores, no parece que finalmente los retratos que se incorporaron fuesen ajenos a la corporación; aun así, la escasa presencia de retratos de consiliarios parece bastante elocuente, pues únicamente queda noticia de tres, de los cuales tan solo uno fue finalmente recogido en los inventarios históricos de las colecciones académicas y, según reflejan las actas, fueron todos realizados por artistas vinculados a la Academia o aspirantes al grado de académico de mérito. Respecto a los retratos de artista, fueron en su mayoría ofrecidos como obras de recepción y, con la excepción del retrato de Roberto Michel, en el que se observa un mayor desarrollo de la iconografía del artista escultor, son todos retratos de busto en los que no se hace ninguna alusión a la profesión artística. Finalmente, merece la pena señalar que es en este periodo ilustrado en el que ingresan retratos de mujeres artista, debiendo esperar al siglo XX para que tal suceso volviera a repetirse, codificándose la galería como el espacio para una historia, en clave masculina, de la institución.

\footnotetext{
${ }^{291}$ Carlos Blanco figura reiteradamente en las actas de 1804 y 1805 como uno de los pensionados en la Academia de San Fernando cuyas obras se someten al examen de la junta.

${ }^{292}$ Junta Ordinaria de 3 de enero de 1808. ARABASF (3-87), fols. 356v. y 357r.

${ }^{293} \mathrm{Id}$.
} 


\subsubsection{Los retratos de la Academia de San Fernando (1808-1881)}

La Guerra de Independencia conllevó en buena medida una paralización de las actividades académicas y también el ingreso del último retrato de artista contemporáneo en una larga temporada: el del arquitecto Juan de Villanueva realizado por Goya, legado a la Academia en su testamento en $1811^{294}$. A partir de este momento, las incorporaciones de retratos de artista vinculados a la historia de la Academia serán esporádicas, a pesar de que en 1816, con motivo de la incorporación del infante Carlos María Isidro de Borbón como jefe de la institución, se recordó

la falta de observancia de otro acuerdo del año de 1754 respecto a los retratos de los Reyes y de los Protectores, cuya falta era muy notable en la Academia; la cual considerando cuán decoroso la [sic] sería formar una Sala con estas obras de estudio, de sus propios individuos de mérito, cuya serie formaría la historia artística del establecimiento ${ }^{295}$;

que aludía especialmente a la falta de rigor en la presentación de obras de recepción (no necesariamente retratos) por parte de los académicos. El acta de la misma sesión recoge la propuesta de reordenar los fondos artísticos de la Academia, mencionándose por primera vez un espacio destinado exclusivamente a los retratos, a pesar de que la propuesta de continuar con una colección de retratos de reyes, protectores y artistas no encontró la respuesta que se esperaba.

Los inventarios realizados entre 1817 y 1829 aportan datos interesantes para conocer la historia de esta colección; así, por el de 1819 conocemos la existencia de un retrato de Teodoro Ardemans (RABASF, 1919: $n^{\circ}$ 201; RABASF, 1821: $\mathrm{n}^{\circ}$ 202), supuestamente copia realizada por Ginés Aguirre, del que se tiene la última noticia en el inventario de 1821; el de 1824 aclara sin embargo que se trataba en realidad del retrato de Filippo Juvarra ya mencionado, y que aún se conserva en la Academia (Museo de la Academia de San Fernando, $n^{\circ}$ inv. 0566) $)^{296}$.

La presencia de Goya, de carácter obligado, fue posible gracias al interés de Javier Goya y de Rosario Weiss. El primeró donó el Autorretrato (Museo de la Academia de San Fernando, $n^{\circ}$ inv. $n^{\circ}$ inv. 0669) ${ }^{297}$ de su padre de 1815, y la segunda gestionó, por necesidad económica, la venta de una copia realizada de su mano del retrato de Goya por Vicente López ${ }^{298}$. Pero aparte de la incorporación -muy tardía- en el inventario de 1840 del retrato de Ventura Rodríguez, copia realizada en 1794 por Zacarías González Velázquez de la obra de Goya [fig. 104], solo tenemos noticia en este momento de la presencia de unos pocos retratos de académicos más, como los de los secretarios Antonio Ponz y José Munárriz, y el del viceprotector Manuel Fernández Varela.

\footnotetext{
${ }^{294}$ Junta Preparatoria de 24 de noviembre de 1811. ARABASF (3-126), fol. 404v.

295 Junta Particular de 11 de mayo de 1816, ARABASF (3-127), fol. 102v. y 103r.

${ }^{296}$ Considerado copia del existente en la galería de la Academia de San Lucas, realizado por Agostino Masucci.

297 Esperanza Navarrete (1999: 374) aclara que, aunque la obra figura como donación, se trataba en realidad de una negociación entre el hijo de Goya y la Academia, tras reclamar este los atrasos debidos a su padre por la realización de un retrato de Fernando VII para la Academia.

${ }^{298}$ Junta Ordinaria de 12 de octubre de 1834. ARABASF (3-89), fol. 116 r. y v.
} 


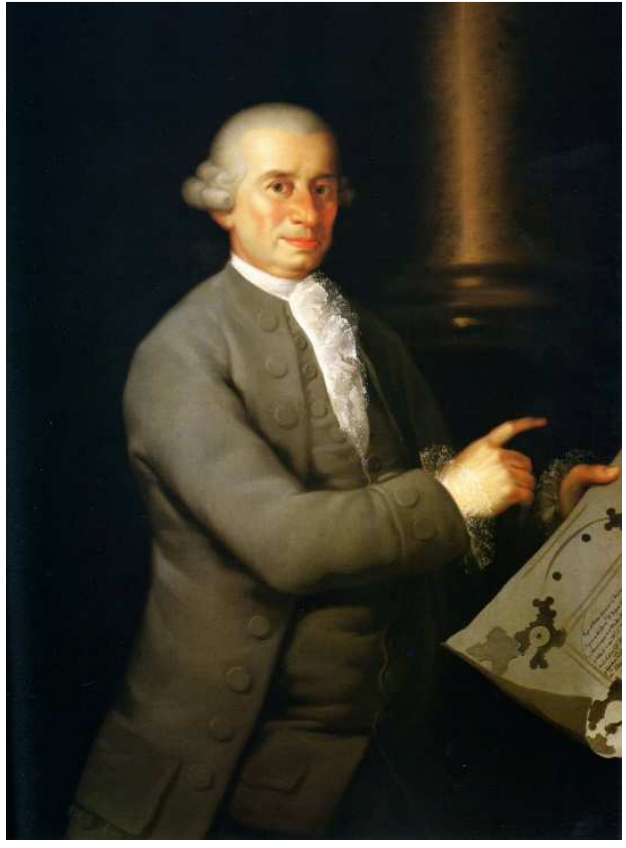

Fig. 104. Zacarías González Velázquez, Retrato de Ventura Rodriguez (copia del original de Goya). Museo de la Academia de San Fernando (nº inv. 0539).

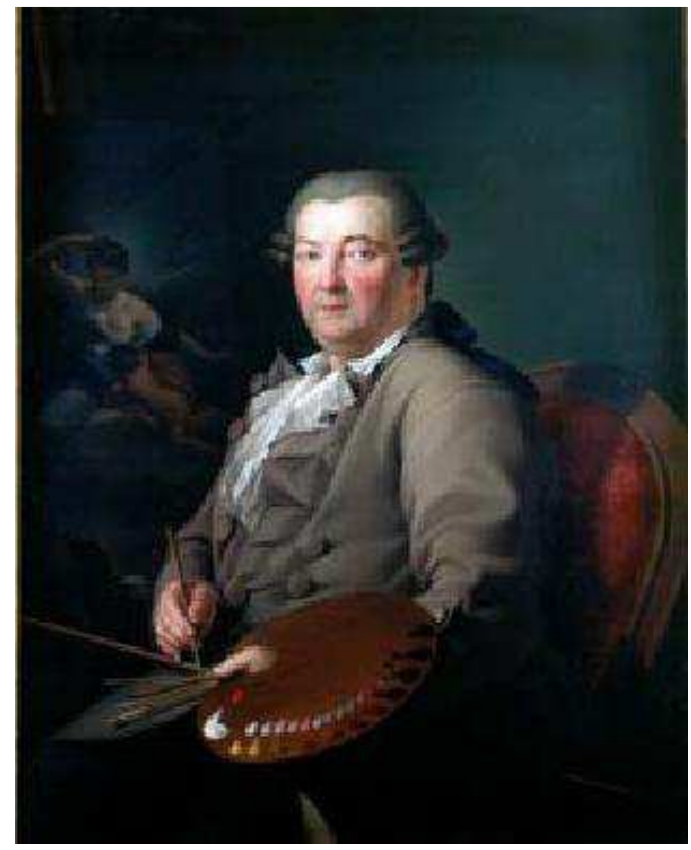

Fig. 105. Zacarías González Velázquez, Retrato de Antonio González Velázquez. Museo de la Academia de San Fernando ( ${ }^{\circ}$ inv. 0694).

Hubo que esperar a 1827 para que Zacarías González Velázquez entregase la obra reglamentaria correspondiente a su ingreso como académico de mérito -obligación que, según se desprende de nuevo en las actas de este año, varios académicos habían olvidado-, que consistió en un retrato de su padre, el pintor y antiguo director de la Academia Antonio González Velázquez ${ }^{299}$ [fig. 105]. Es interesante observar que, dentro del hermetismo propio de las actas, se subraya la conformidad de la junta respecto a este retrato no solo por su ejecución, sino también "por lo que representa", pudiendo entenderse en esto que el retrato suponía una doble prueba de amor filial, en cuanto a la que hacía el pintor como homenaje a su padre y a la que demostraba a la Academia al ceder una efigie de uno de sus ilustres profesores, y como tal, padre espiritual dentro de la institución. Pocos años después se recibe otra donación de un retrato que puede tener una lectura de homenaje filial, si bien la de San Fernando obvió cualquier posible significado de la obra al relegarla en sus colecciones. El autorretrato de José Vergara (Museo de la Academia de San Fernando, $n^{\circ}$ inv. 0716), que ingresa en 1831 por donación del hijo de este ${ }^{300}$, Antonio María Vergara, no parece en efecto despertar gran entusiasmo en la corporación, quizás al remitirse en el mismo envío otras obras del artista; fuera cual fuese el motivo, el retrato pasó desapercibido en el seno de la academia, pues a pesar de que en el acta de la sesión en que se da cuenta del regalo se señala su identidad aparece mencionado en el inventario de 1840 simplemente como "Un retrato de un secretario de la Academia de Valencia ejecutado por él mismo";

299 "El director de pintura Dn. Zacarías Velázquez en cumplimto. de lo que tenía ofrecido desde su admisión de Académico de mérito presentaba a la $\mathrm{Acad}^{\mathrm{a}}$. el retrato que había hecho de su Padre Dn. Ant ${ }^{\mathrm{o}}$. Gonz. Velázquez pintor de cámara de S.M. y Director de este $\mathrm{R}^{1}$. Cuerpo; y la Acad ${ }^{\mathrm{a}}$. acordando se contestase el recibo expresando haber parecido bien dho. retrato por lo que representa y por su desempeño". Junta Ordinaria de 9 de septiembre de 1827, ARABASF (3-88), f. 178r.

300 Junta Ordinaria de 21 de agosto de 1831, ARABASF (3-89), fol. 16v. 
además, a pesar de incorporarse a las colecciones no parece que formase parte de la galería de retratos, probablemente por considerarse un retrato al margen de la historia de la institución madrileña.

Observando las obras que ingresan en la colección en estos últimos años, y especialmente las que lo hacen en el intermedio entre los inventarios de 1829 y 1840 , se pone de manifiesto que, frente al notorio auge del retrato -tanto de carácter oficial como al retrato de artista-, inmerso en esta época ya en la modernidad del Romanticismo, los retratos que engrosan paulatinamente la colección de la Academia están bañados en su gran mayoría de un carácter obsoleto y encorsetado, y, salvo algunas excepciones, su calidad apenas sobrepasa la mediocridad. Parece desprenderse la idea de que la Academia de San Fernando no tuvo entre sus propósitos el encargar obras de calidad para perpetuar la memoria de sus miembros más relevantes, limitándose a aceptar las dispares muestras de agradecimiento - y vanidad- de los familiares de algunos de sus académicos, y propiciando con ello la configuración de una colección de retratos desganada y ecléctica. Los propios artistas tampoco buscaron perpetuar su imagen en la galería académica, a pesar de que en este momento la institución se encontraba en un momento de expansión y aglutinaba en su seno a numerosos artistas de prestigio.

Esta idea parece chocar con el interés suscitado por la recopilación de los datos biográficos y títulos de los académicos, de la que se tiene una primera noticia en 1831, momento en que el secretario Martín Fernández de Navarrete remitió una circular solicitando información a distintos miembros de la corporación. El archivo de la Academia conserva las sucintas respuestas de José Bueno, Pascual de Liñán, José de Imaz, Pedro García González, Damián Campeny, Antonio Celles, Roch, Manuel Esquivel de Sotomayor, Alejo Andrade y Francisco Elías. El destino de estos datos, al parecer, era elaborar una lista de los miembros de la Academia -tanto residentes en la corte como en otras provincias- y sus respectivos méritos, para hacerlos constar en las actas. Sería sin embargo erróneo creer que los artistas académicos se desvincularon de la práctica del retrato dentro de la propia institución, más vinculado a la promoción de la identidad laboral y la imagen del éxito mediante obras fruto de la sociabilidad entre artistas, ya que precisamente es en este momento entre 1817 y 1851 cuando los retratos de artistas académicos tuvieron un importante papel en las exposiciones públicas de la institución, cuyo estudio abordaremos en capítulo aparte.

Con el cambio de mentalidad observado a finales de los años cincuenta y comienzos de los sesenta en el seno de la corporación se apuesta por un mayor espíritu de fraternidad entre sus miembros, propiciado por una reducción considerable en su número, y al mismo tiempo por una mayor afinidad profesional. De manera contemporánea a las primeras sociedades de socorros mutuos, las actas comienzan a recoger reiteradas peticiones de sufragio por las almas de los académicos fallecidos, y se empieza a tomar conciencia de la necesidad de la institución de formar comisiones representativas en los funerales; pero también se procede a recuperar su memoria individual y colectiva. En relación a la primera, se planteará repetidamente la necesidad de recopilar noticias biográficas de los académicos tras su muerte, una tarea de la que 
estaba encargado el secretario y que pareció encontrar numerosos obstáculos por parte de los familiares de los fallecidos. Una de las noticias más tempranas encontradas al respecto en las actas data de 1862, proponiéndose que los académicos facilitasen en vida una noticia biográfica ("su carrera, servicios y obras") al secretario; entre la correspondencia conservada en el archivo de la Academia de San Fernando se encuentran, sin embargo, referencias anteriores sobre la solicitud por parte de la Academia de noticias biográficas de algunos académicos, como de Manuel López Cepero (carta fechada en febrero de 1859) o de Juan Antonio de Ribera (carta fechada en 12 de junio de 1860$)^{301}$. No obstante, esta cuestión fue retomada en 1870 tras la muerte de Aníbal Álvarez Bouquel, demostrando que la mayoría de los académicos faltaban a este compromiso ${ }^{302}$. Por otra parte, con el mismo interés de vincular identidad personal y colectiva, podemos fechar en 1863 el resurgir de la sala de retratos dentro de la vida académica, ya que es en esta fecha cuando el presidente Federico de Madrazo "hizo presente lo conveniente que podría ser para la historia de la Academia el formar una colección de retratos de todos sus individuos ${ }^{303}$ ". En su propuesta, Madrazo aludía a las facilidades que la fotografía otorgaba para la realización de los retratos, y la Academia respondió con una aceptación unánime, decretando la necesidad de que se realizasen los retratos de los académicos vivos, pero también de los que ya habían fallecido, invitando a los miembros de la corporación a que remitiesen, de forma paralela, sus retratos y sus noticias biográficas, encargando nuevamente al secretario la obtención de los de los académicos fallecidos a través de sus familias. No en vano los estatutos de la Academia de 1865 recogen como una de las funciones de la misma el reunir y coleccionar retratos y biografías de artistas y de escritores de artes, siendo tarea del secretario el recopilar y escribir las noticias biográficas de los académicos que fallecen (RABASF, 1865: 25).

La idea de Madrazo podía derivar de una nueva preocupación por la pervivencia de la memoria de los artistas y académicos en la corporación tras el reciente fallecimiento de su padre, o verse influida por las iniciativas realizadas en el ámbito parisino (especialmente la de Chennevières $[18 \mathrm{XX}]$ con la publicación de sus Portraits inédits d'artistes français y la de trasladar los retratos de la Académie como galería institucional al Louvre; sin embargo, no puede descartarse que estuviese vinculada con la propia existencia de la sala de retratos y de su presencia, aparentemente desapercibida, entre las colecciones artísticas de la Academia. Es comprensible que, vista la escasa relación que la sala mantenía con la vida contemporánea de la misma al estar reducida a retratos obsoletos, Madrazo se viese en la necesidad de llamar la atención sobre la importancia del retrato en la configuración de una identidad e historia común; en este sentido, no es coincidencia que en estos momentos se produzca una búsqueda de cohesión académica, viendo la luz la obra de Caveda Memorias para la historia de la Real Academia de San Fernando y el Diccionario biográfico de Ossorio y Bernard, o que sea también es en estas mismas fechas cuando se gesta una nueva

\footnotetext{
301 ARABASF, 1-47-2.

302 Junta Ordinaria de 16 de febrero de 1862, ARABASF (3-93), fol. 5v y 6r.

${ }^{303}$ Junta Ordinaria de 9 de febrero de 1863, ARABASF (3-93), fol. 53r.
} 


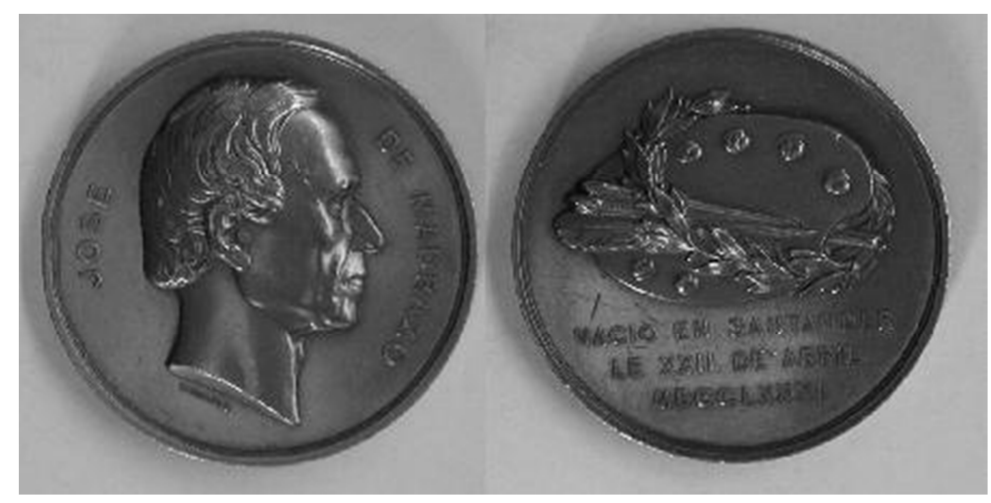

Fig. 106. Eduardo Fernández Pescador, Medalla retrato de José de Madrazo. Museo Lázaro Galdiano ( $\mathrm{n}^{\circ}$ inv. 6906).

reforma de los estatutos (efectiva en 1864) que estipulaba, entre otros cambios, una nueva reducción del número de académicos dando lugar a un cuerpo aún más selecto y, por lo tanto, a un círculo social más restringido. Tampoco puede obviarse que en la misma junta en que Federico de Madrazo realizó su propuesta se diese la noticia de la donación del retrato del marqués de Casteldosrius, "digno individuo que fue de esta Academia, ejecutado por el distinguido pintor de cámara e individuo también de este cuerpo, D. Vicente López ${ }^{304,}$, en el que podría haber entrado en juego la rivalidad artística; algunos años después la academia recogía la noticia de que Federico de Madrazo había repartido entre los académicos una medalla con el retrato grabado de su padre [fig. 106], José de Madrazo, ejecutada por Eduardo Fernández Pescador:

Leí una comunicación con la que nuestro digno director el Excmo. Sr. D. Federico de Madrazo remitía para distribuir a los señores académicos treinta y tres ejemplares de la medalla retrato de su Sr. Padre el Excmo. Sr. D. José de Madrazo, director general que fue muchos años de las enseñanzas artísticas de la Academia, cuya medalla había sido ejecutada con singular acierto por nuestro académico de número el Sr. D. Eduardo Fernández Pescador, el cual había hecho a dicho Sr. Director D. Federico el obsequio de un número considerable de ejemplares de la misma. La academia recibió con el mayor aprecio y gratitud este fino donativo que recuerda además y proyecta en ella la memoria del digno y venerable artista que por tantos años perteneció a su seno ${ }^{305}$.

La sala de retratos cobró durante esta década de 1860 a 1870 un mayor protagonismo en los debates de la junta, viendo aumentar las obras que la formaron, si bien en una proporción bastante menor de lo que auguraba la propuesta de Federico de Madrazo. En 1864, tras el fallecimiento de la viuda de Isidro González Velázquez, se legaba por disposición testamentaria el retrato del arquitecto realizado por Vicente López $^{306}$, constando inmediatamente que se colocase en su correspondiente galería.

Apenas un año más tarde, la galería de retratos volvió a ser un tema de discusión cuando el académico Teodoro Ponte de la Hoz propuso la colocación en esta de los

\footnotetext{
${ }^{304}$ Junta Ordinaria de 9 de febrero de 1863, ARABASF (3-93), fol. 52v.

305 Junta Ordinaria, 10 de enero de 1870, ARABASF (3-95), f. 51.

${ }^{306}$ Sesión Ordinaria de 7 de septiembre de 1864, ARABASF (3-93), fol. 164.
} 
retratos de los dos últimos presidentes fallecidos "como muestra de aprecio y cariño 307 ". Amador de los Ríos, que secundó rápidamente la idea, vinculó esta propuesta con la que se venía llevando a cabo en la Real Academia de la Historia, en la que el ritual decretaba que, a la muerte de un presidente, su asiento se dejase vacío en señal de luto y cubierto de crespones negros, colocándose inmediatamente el retrato del finado en un lugar de honor. En la misma junta, Pedro de Madrazo señaló que la galería de retratos, como muestra de la historia de la corporación y honra de perpetuación de su memoria, no debía conformarse únicamente con estos dos retratos, sino con los de todos los presidentes que habían ocupado el cargo desde la reforma de 1846; la nula alusión a la vinculación entre los presidentes y la práctica artística, o a retratos de otros artistas, lleva a relacionar esta iniciativa con el carácter institucional del cargo de presidente. Para ello se estimaba que el medio más fácil para llevar a cabo esta galería era "dirigir una atenta y expresiva invitación a las familias de los presidentes finados, las cuales acaso facilitasen los retratos sin que la Academia tuviese que hacer dispendio $\operatorname{alguno}^{308}$,

Aunque esta tarea no parece que llegase a llevarse a cabo, probablemente por sumarse a los encargos del secretario de la Academia, sí que parece claro que en estos momentos la función de la sala de retratos estaba clara e indiscutiblemente asociada a la identidad académica, y consta que algunos retratos fueron rechazados por no ajustarse a esta premisa: así ocurrió en 1866 al presentarse el retrato de Joaquín Álvarez del Prado, quien no parecía tener vinculación alguna con la academia, llegando ésta a considerar necesario precisar que "se proponía admitir y conservar en su galería de retratos solo aquellos que pudiesen ser útiles para el arte o para su historia, ya por la celebridad de los personajes que representasen ya por el mérito de su ejecución ya por el nombre distinguido de sus autores; y que este acuerdo sirviese de norma para casos semejantes $^{309,}$. A pesar de esta afirmación, los retratos que continúan engrosando la colección son alabados, precisamente, por su calidad de tratarse de efigies de académicos y no tanto de artistas. Es en ese año cuando se ofrece a la Academia la cesión del autorretrato del primer director de pintura, Antonio González Ruiz, con destino a la galería de retratos ${ }^{310}$; la importancia del personaje representado, académico y profesor en la corporación madrileña cuya memoria había pervivido en la academia a través de la estampa realizada por Muntaner, alimenta el interés de la institución, que inicia los trámites para su adquisición (caso excepcional entre los retratos de la colección), que sería efectiva en $1868^{311}$.

En el proyecto manuscrito de inventario y nueva numeración de las obras de la Academia acometido por Valentín Carderera y por Gato de Lema en mayo de 1867 [fig. 107] se desglosa el orden de colocación y numeración de cada una de ellas, se marca en

\footnotetext{
${ }^{307}$ Sesión Ordinaria de 9 de octubre de 1865, ARABASF (3-93), fol. 239 r.

${ }^{308} \mathrm{Id}$.

${ }^{309}$ Sesión Ordinaria de 2 de enero de 1866, ARABASF (3-94), fol. 2 r.

${ }^{310}$ Sesión Ordinaria de 4 de junio de 1866, ARABASF (3-94), fol. 46r.

${ }^{311}$ Sesión Ordinaria de 1 de junio de 1868, ARABASF (3-94), fol. $213 \mathrm{v}$.
} 


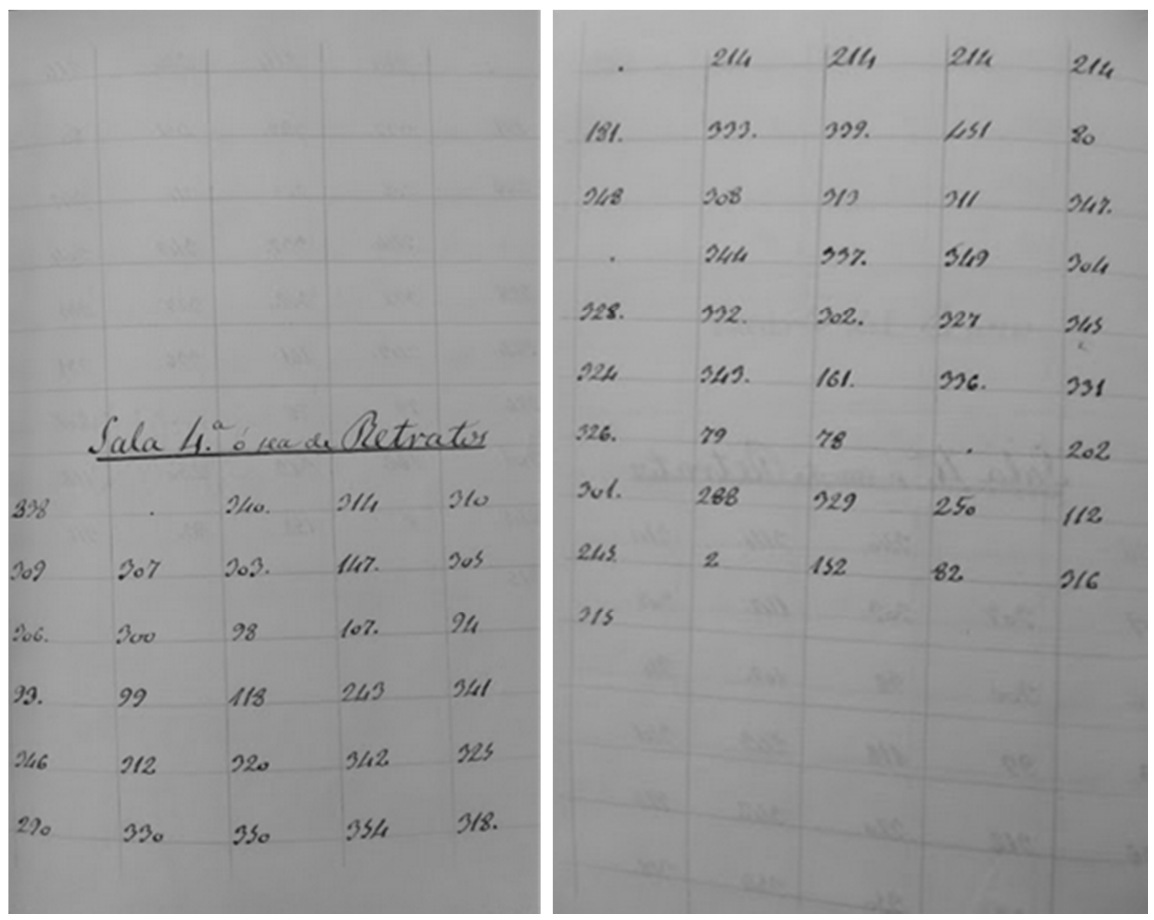

Fig. 107. Inventario manuscrito de 1867. Ordenación y numeración de las obras conservadas en la Sala de Retratos. ARABASF, leg4-90-1.

tinta negra el número anterior de inventario y en lápiz rojo la nueva asignación, y se incorpora asimismo una serie de cuartillas a modo de ficha de cada una ${ }^{312}$.

Curiosamente, en lo que respecta a la sala de retratos no se observa ninguna modificación respecto a la numeración, ni información detallada de cada obra; sin embargo, el documento no carece de interés ya que permite conocer la posible disposición de las obras en la sala, así como el número total de retratos, que ascendía a setenta y dos, es decir, diecisiete más respecto al inventario inmediatamente anterior (1840). En lo que respecta a la disposición, existen dos versiones diferentes que pueden indicar un cambio o reordenación de las obras en 1867: la reproducida anteriormente corresponde a la versión definitiva, tal y como la comisión encargada hizo llegar a la Academia en forma de cuadernillo manuscrito, aunque en cuartilla suelta figura otra lista de las obras [fig. 108], probablemente un borrador, en la que, si tomamos como referencia las especificaciones incluidas en las relativas a otras salas, estas aparecerían ordenadas según otra disposición, mantenida en 1862, 1865 y 1867.

Fue precisamente Valentín Carderera, consciente del valor icónico del retrato y del papel alcanzado por la sala en estos momentos, quien realizaría la generosa donación del autorretrato juvenil de Maella, gesto que fue interpretado como un regalo destinado a aumentar "la galería de retratos de los artistas célebres" y al mismo tiempo a estimular a otros académicos a que continuasen "aumentando siempre que les sea posible el

\footnotetext{
${ }^{312}$ Inventario y nueva numeración de las obras de la Academia, realizado por una comisión integrada por Valentín Carderera y Gato de Lema; ARABASF, leg. 4-90-1.
} 

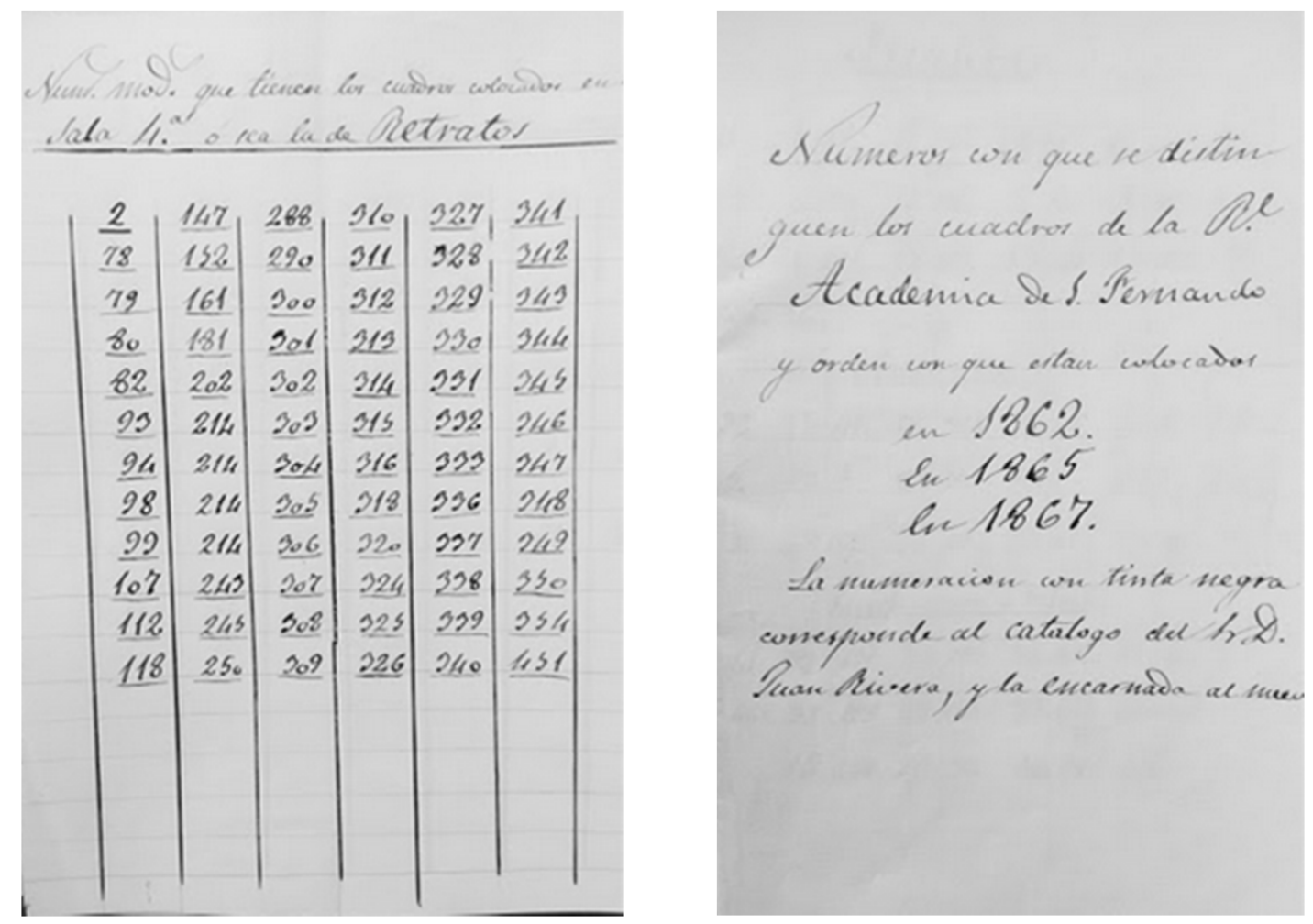

Fig. 108. Cuartillas sueltas, inventario manuscrito de 1867. ARABASF, leg4-90-1.

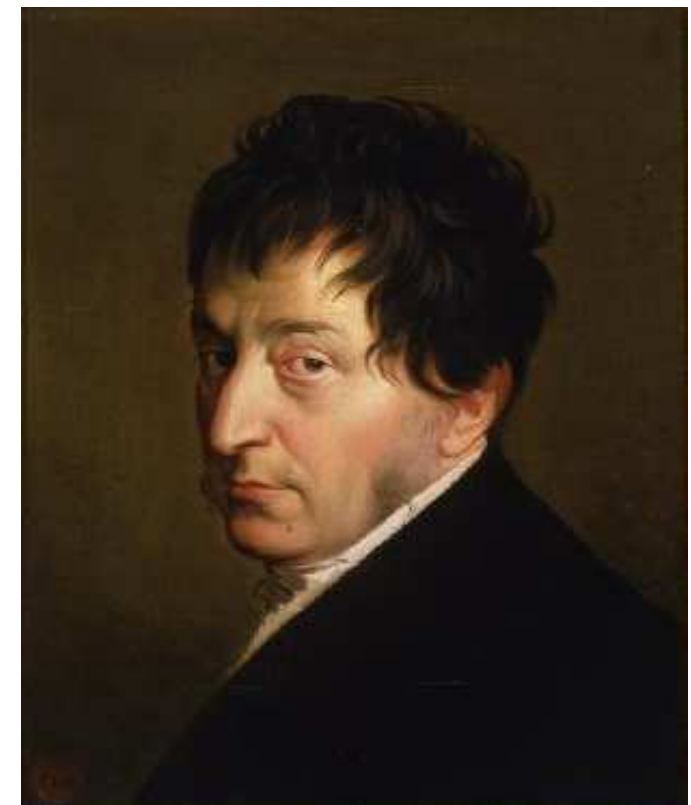

Fig. 109. Zacarías González Velázquez, Autorretrato. Museo de la Academia de San Fernando ( $\mathrm{n}^{\circ}$ inv. 0042).

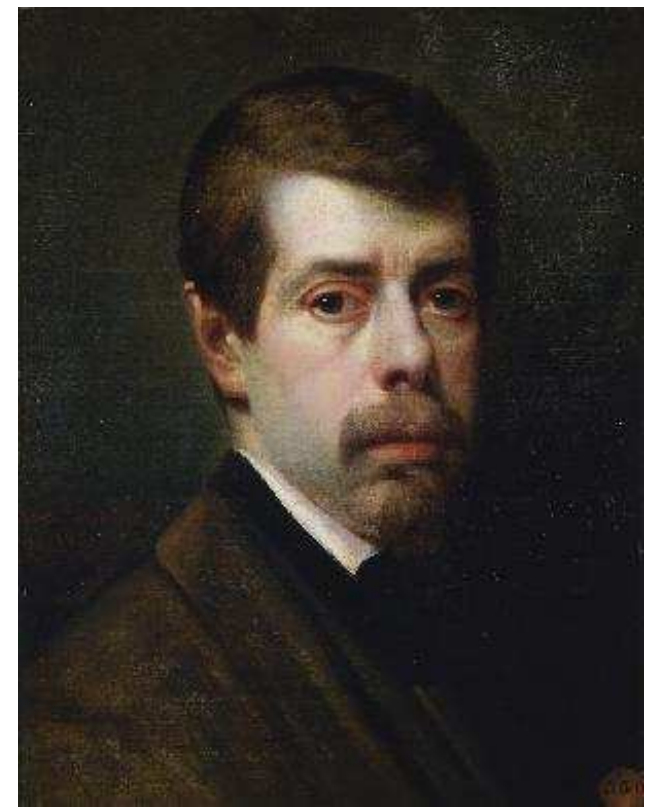

Fig. 110. Carlos Gato de Lema, Retrato de Antonio María Esquivel. Museo de la Academia de San Fernando ( $\mathrm{n}^{\mathrm{o}}$ inv. 0763). 
caudal de la expresada galería ${ }^{313,}$. No debe pasarse por alto que la donación se produjo en el mismo año en que estaba realizando el inventario de las colecciones de la Academia, y que sin duda la sala de retratos debió de influir en su decisión de desprenderse de una obra tan significativa.

Siguiendo su ejemplo, Vicente Poleró donó un año después el Autorretrato de Zacarías González Velázquez (Museo de la Academia de San Fernando, nº inv. 0042) [fig. 109]; aunque el destino del retrato no queda claro en las actas, debemos pensar que el protagonismo de la galería de retratos, la relevancia del personaje representado respecto a la historia de la Academia y el hecho de que en 1884 figurase ubicado en la sala sexta, apuntan a que fue colgado inmediatamente en la sala de retratos de la institución. Movidos por este interés, y quizás teniendo en mente el eco de la propuesta de Pedro de Madrazo, varios académicos donaron retratos de artistas de comienzos de siglo, no observándose el mismo interés por otros de su historia más reciente, siendo quizás la excepción Nicolás Gato de Lema, académico de la sección de pintura desde 1859, quien regaló en 1871 (catorce años después de la muerte del representado), el retrato que su difunto hermano Carlos había hecho del profesor de la Academia Antonio María Esquivel en 1850 [fig. 110], como forma de perpetuar al mismo tiempo la memoria del efigiado, cuya relevancia para la Academia era notoria, y la del autor, cuya prematura muerte había truncado la que podía haber sido una prometedora carrera en la institución. Así lo recoge el acta de la sesión de 27 de marzo de 1871, en que se da noticia del ofrecimiento del retrato "del individuo que fue de la misma y profesor de sus escuelas D. Antonio María Esquivel (...) pintado por el difunto hermano del donante D. Carlos Gato de Lema, que falleció a la temprana edad de veinte años siendo ya un aventajado discípulo de la Academia ${ }^{314,}$.

La década posterior supone para la sala de retratos cierto abandono, ya que únicamente ingresan dos retratos pictóricos: por una parte, el donado por Bernardo López representando a su padre -copia de su autorretrato-, y el del político y académico José Canga Argüelles ${ }^{315}$. La donación de Bernardo López es especialmente reseñable; producida en 1874 como legado testamentario, no se redujo a una muestra de admiración filial a través del lienzo destinado a perpetuar la memoria de Vicente López en la Academia, sino que, siguiendo tal vez la propuesta de Madrazo, también destinó a este efecto dos retratos escultóricos, representando uno a su padre y otro su propia efigie (AZCUE BREA, 1994) ${ }^{316}$. De este modo, su presencia en la Academia estaría irrevocablemente unida al recuerdo del vínculo familiar, ya fuese a través de la pintura, obra del hijo que retrata a su padre, o a través de la escultura en la convivencia de los dos bustos de mármol, obras a su vez del escultor José Piquer. La copia del autorretrato de Vicente López pasaría, tal y como consta en el inventario de pintura de 1884, a la Sala de Retratos.

\footnotetext{
${ }^{313}$ Junta General de 8 de abril de 1867, ARABASF (3-94), fol. 120r.

${ }^{314}$ Sesión Ordinaria de 27 de marzo de 1871, ARABASF (3-95), fol. 207.

315 Sesión Ordinaria de 27 de junio de 1877, ARABASF (3-96), p. 655.

${ }^{316}$ Sesión Ordinaria de 28 de septiembre de 1874, ARABASF (3-96), p. 129.
} 
El progresivo abandono de la idea de una galería corporativa no provocó excesiva extrañeza entre los académicos, ya que las iniciativas citadas pasaron rápidamente desapercibidas entre el caudal de información y asuntos a tratar por la Aademia. En 1877 Francisco María Tubino, tal vez desconociendo las propuestas anteriores -algo, por otra parte, perfectamente comprensible ya que Tubino acababa de ingresar en la Academia y el carácter ecléctico de la sala de retratos no correspondía con la idea que un foráneo podía tener de una "galería de retratos de académicos"-volvía a llamar la atención sobre este asunto; así, en sesión ordinaria de 22 de octubre proponía que la Academia formase una galería de retratos de los académicos difuntos, a lo que se le respondió escuetamente y no sin cierto reproche, tal y como recoge el acta, ya que "no hubo necesidad de tomar acuerdo, pues ya estaba tomado tiempo ha, y solo falta darle cumplimiento, lo que se procurará ir haciendo con la cooperación de las familias de los académicos $^{317}$ ". Esta llamada de atención cobra interés meses después, tras la muerte de José Amador de los Ríos, puesto que la importancia del fallecido dentro y fuera de la corporación, de la que era académico de número desde 1859 y censor desde 1868, espoleó a la Academia a solicitar a sus familiares su retrato. En junio de 1878 su viuda, agradecida por los esfuerzos de la Academia en honrar la memoria de su esposo, ofreció el retrato que de él había realizado Federico de Madrazo. Este hecho pareció de especial relevancia a los académicos, convirtiendo el retrato de uno de sus miembros en un objeto doblemente simbólico al estar realizado no solo por un artista notorio, sino por el mismo presidente de la Academia $^{318}$ e iniciador de la propuesta de dignificación de sus miembros. Así, el retrato de José Amador de los Ríos se colgaba en la sala de retratos, poco tiempo después de la colocación en la misma del busto de Fortuny realizado en bronce por el escultor francés Épinay ${ }^{319}$, pero el problema de la escasa identificación de la sala de retratos con el espíritu contemporáneo de la Academia seguía estando tan presente como la dificultad de recopilación de noticias biográficas de los académicos fallecidos: ante una propuesta del marqués de Monistrol de obtener las biografías completas de los académicos fallecidos se observa ya cierto desencanto por parte de los presentes en la sesión, ya que pareció bien esta idea, pero se creyó tan difícil poderla llevar a cabo que no pudo tomarse ningún acuerdo sobre esto ${ }^{320}$. . Finalmente, tan solo consta noticia del ingreso de un nuevo retrato, esta vez un busto escultórico, con anterioridad a la iniciativa de 1881 . Se trata de la donación realizada por el académico Carlos Nicoli, elegido correspondiente en Ferrara en 1878, precisamente con motivo de este nombramiento. La obra remitida por el escultor consistió en el retrato de un académico de la de San Fernando, aún vivo y en activo en el seno de la institución madrileña: el escultor Sabino Medina ${ }^{321}$.

\footnotetext{
${ }^{317}$ Sesión Ordinaria de 22 de octubre de 1877, ARABASF(3-97), p. 33.

318 “Acordó (...) se manifestase el aprecio que la Academia hace de tan precioso donativo en el doble concepto de recordar las facciones de su ilustre miembro y de ser ejecutado por el esclarecido artista que la preside". Sesión Ordinaria de 18 de junio de 1878, ARABASF (3-97), p. 198.

${ }^{319}$ Sesión Ordinaria de 7 de enero de 1878, ARABASF (3-97), p. 98.

${ }^{320}$ Sesión Ordinaria de 3 de marzo de 1879, ARABASF (3-97), p. 318.

${ }^{321}$ Sesión Ordinaria, 24 de noviembre de 1879, ARABASF (3-97), p. 422.
} 


\subsubsection{Una galería de retratos de académicos difuntos (1881-1900)}

La muerte del pintor Francisco Sans Cabot, académico de número desde 1874, reavivó el debate sobre una galería de retratos de académicos. Tras la aceptación de la oferta hecha por su viuda de un retrato en busto para la Academia, el asunto volvió a ser abordado con cierta seriedad y una nueva connotación, ya que desde ese momento se concibe como una galería de retratos de académicos fallecidos, lo que incide en el valor de la obra como objeto para la memoria. Serían esta vez Pedro de Madrazo, Francisco Asenjo Barbieri y Francisco María Tubino los encargados de señalar la necesidad de reunir una colección de retratos "de los señores académicos fallecidos desde la instalación de la Academia ${ }^{322 " ; ~ y a ~ f u e s e ~ p o r ~ l a ~ u n i o ́ n ~ d e ~ v a r i o s ~ a c a d e ́ m i c o s ~ e n ~ e s t a ~}$ petición o porque la propuesta llevaba demasiado tiempo -casi dos décadas-surgiendo repetidamente en las sesiones sin que nada se hiciese al respecto, parece que esta vez hubo una mayor disposición a llevar a cabo esta iniciativa. Federico de Madrazo ofreció el retrato de su padre, José de Madrazo $^{323}$, consciente sin duda de que su presencia en la galería no era únicamente un tributo a su figura artística, sino también el debido homenaje rendido por la Academia mediante las iniciativas respaldadas, precisamente, por dos de sus hijos. El ofrecimiento de Madrazo, que quizás consistía en el Autorretrato de José que había pintado con destino a la Academia de San Lucas, o en el realizado por el joven Federico en 1835, no llegó a trascender, ya que nunca llegó a llevarse a cabo tal donación y ningún retrato pictórico del patriarca fue incorporado a la colección de la Academia. En la misma sesión se recordó también la conveniencia de reunir las biografías de los académicos fallecidos. En lo que respecta a los retratos, se tomó como medida inicial el nombramiento de una comisión destinada a formar esta galería, compuesta por Carlos Luis de Ribera, Francisco María Tubino, Francisco de Cubas y Rafael Hernando, cuyo trabajo es, por el momento, desconocido, y de la que no se vuelve a tener noticias en las actas. Tal vez se debió a su actividad el ingreso del retrato del secretario Don Eugenio de la Cámara (Museo de la Academia de San Fernando, $\mathrm{n}^{\mathrm{o}}$ inv. 0593), fallecido en 1883; a pesar de la inexistencia de datos sobre la fecha de incorporación a la colección de la Academia, consta ya recogido en el inventario de pintura de 1884 , por lo que se podría fechar en el mismo año de su muerte. Es posible que, debido a la falta de espacio en la sala de retratos, fuese destinado a un lugar de carácter más privado, puesto que se colgó en el despacho del bibliotecario en lugar de hacerlo en las dependencias destinadas a secretaría, lo que honraba su memoria a los desvelos en sus años de servicio en la Academia.

\footnotetext{
322 Sesión Ordinaria de 6 de junio de 1881, ARABASF (3-98), p. 114.

${ }^{323}$ Tal vez, como señala Díez (1997: 76) el propio autorretrato que José de Madrazo había pintado con destino a la Academia de San Luca y que nunca llegó a remitir (Museo del Prado, nº inv. 4470).
} 


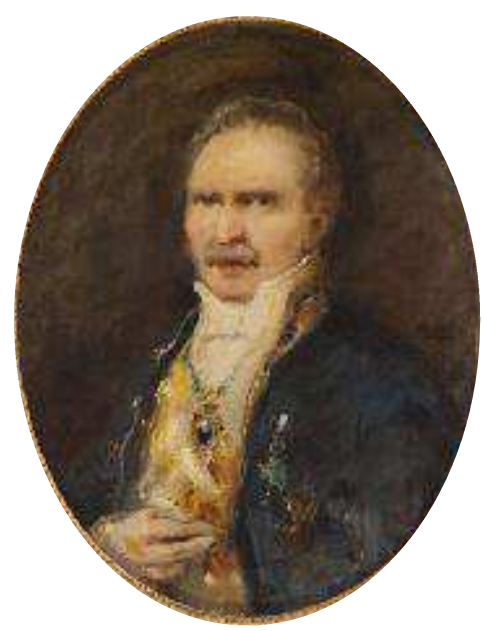

Fig. 111. Alejandro Ferrant, Valentín Carderera. Museo de la Academia de San Fernando ( ${ }^{\circ}$ inv. 0567).

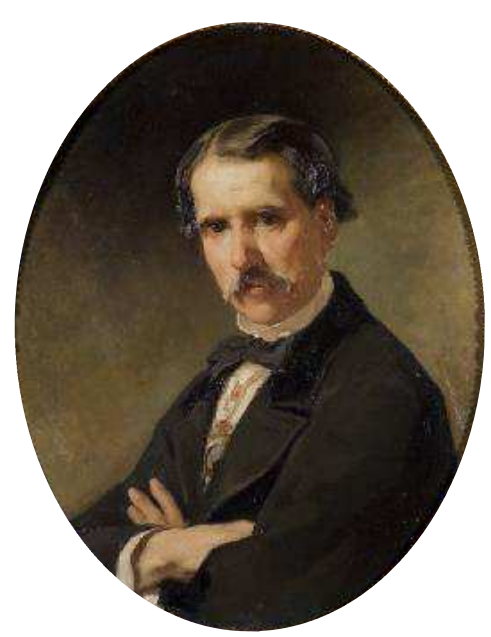

Fig. 112. Alejandro Ferrant, Retrato de Luis Ferrant. Museo de la Academia de San Fernando $\left(n^{\circ}\right.$ inv. 0561).

En 1887, dos años después de su recepción como académico de número (título que le fue concedido en 1880 en la vacante dejada por la muerte de Valentín Carderera), Alejandro Ferrant Fischermans remitió como donativo a la Academia dos retratos especialmente relevantes por la identidad de los representados y su vinculación con el donante: el propio Valentín Carderera (Museo de la Academia de San Fernando, $\mathrm{n}^{\circ}$ inv. 0567) [fig. 111] y Luis Ferrant Llausás (Museo de la Academia de San Fernando, $n^{\circ}$ inv. 0561) [fig. 112]. Es indiscutible la importancia que tuvo para la Academia el primero, a la que estuvo plenamente vinculado desde su nombramiento como académico de mérito en 1832 hasta su fallecimiento en 1880, haciendo que la presencia de su retrato en la corporación fuese prácticamente imprescindible; teniendo en cuenta que era su vacante la que ocupaba el pintor, el retrato cobra un significado prácticamente ritual en su destino a la Academia. También Luis Ferrant tuvo una estrecha relación con la de San Fernando, de la que fue académico desde 1844; no obstante, la distancia temporal entre su fallecimiento -acontecido en 1868- y la presentación de este retrato parece indicar una motivación personal por parte de Alejandro Ferrant: en primer lugar, por los vínculos de parentesco y afectivos existentes entre ambos, siendo el retratado no solo tío de Alejandro Ferrant, sino también su padrastro y mentor; y en segundo, porque el retrato presentado, realizado por el propio donante, es una copia de otro que el propio Alejandro había pintado en fecha próxima a la muerte de su tío, y que había presentado como sentido homenaje en la Exposición Nacional de 1868 (Museo Nacional del Romanticismo, $\mathrm{n}^{\circ}$ inv. 7122). El hecho de que la Academia aceptase con mucho aprecio estos dos retratos "de los individuos que fueron de esta Corporación" puede vincularse también a la implicación iconográfica de estos dos retratos respecto a la identidad colectiva de la Academia ya que, no en vano, se trataba de los primeros de los que se incluían en su colección en presentar a los efigiados con la medalla corporativa. Este rasgo distintivo, que podía vincularse desde hacía tiempo con la dignificación del individuo mediante la pertenencia -visualmente testimoniada- a la Academia, no era ni desconocido ni inusual, tanto para los propios académicos como para el observador ajeno a la corporación. Rasgo identificador de la comunidad académica y del éxito profesional del retratado, la imagen así dignificada supone algo más que una 
representación abstracta de la fisionomía y personalidad, ya que alude directamente a las vinculaciones con el grupo al que pertenecen el efigiado, el pintor y el receptor final de la obra. Para el público no académico, sin embargo, esta dignificación cobra múltiples sentidos: por una parte, su contemplación aislada -como en el retrato de Luis Ferrant en la Nacional de Bellas Artes de 1868, en el que ya aparece representado con la medalla- se vincula a la biografía y al cursus honorum del efigiado, como muestra de una identidad profesional públicamente reconocida. Sin embargo, en la contemplación como grupo planteada por Alejandro Ferrant a través de los dos retratos con distinción corporativa, se despiertan ya connotaciones más complejas al hacerse patente un vínculo de identidad común del que los retratos de académicos existentes en la de San Fernando habían carecido hasta ese momento.

La representación intencional del individuo como perteneciente a una comunidad parece haber calado, en cierta medida, en la Academia, a pesar de que el problema de los retratos de los académicos continuaba siendo una cuestión muy relajada. Así, el retrato del artista y secretario general José María Avrial, pintado en $1888^{324}$, se recrea destacando - con un vivo acento sobre la chaqueta negra- la medalla corporativa como único complemento a la severa fisonomía representada. Esta imagen del artista como académico, incorporada de manera tardía, siguió conviviendo con los retratos de los que se desprendían los descendientes de los artistas y académicos, muchos de ellos realizados en la primera mitad del siglo XIX: Francisco Bellver y Collazo legó a la Academia a su muerte en 1890 el retrato de su padre, Francisco Bellver, pintado por José Ribelles $^{325}$, con una estética propia de comienzos de siglo y en el que, como corresponde a su temprana fecha de ejecución, no aparece ninguna alusión plástica a la identidad -artística o académica- del representado; la corporación mandó que se colocase inmediatamente en la galería. El mismo matiz obsoleto en cuanto a estilo se aprecia en el ingreso ese mismo año del retrato de José Piquer, realizado por Vicente López y legado por su viuda, Emilia Lull, pasando inmediatamente a la sala de retratos, e incluso en fecha tan tardía como 1900, con la incorporación del retrato del escultor Francisco Elías realizado por Zacarías González Velázquez. En 1890 ingresa también el retrato en miniatura de Juan Nicasio Gallego, que interesó a la Academia por recordar "la fisionomía del que dignamente ocupó la presidencia de la misma durante el año 1851 a $1859^{326 \% " . ~ A p e n a s ~ u n ~ a n ̃ o ~ d e s p u e ́ s ~ s e ~ i n c o r p o r o ́ ~ e l ~ r e t r a t o ~ e s c u l t o ́ r i c o ~ d e ~ o t r o ~}$ académico contemporáneo fallecido, José Casado de Alisal, donado por la viuda del autor, Medardo Sanmartí ${ }^{327}$, al tiempo que recibía el donativo de una fotografía del artista Meissonier, recientemente fallecido, que la Academia mandó colocar en un marco $^{328}$. Del mismo modo, en 1892 Rodrigo Amador de los Ríos, académico de la sección de pintura desde 1890, dona a la misma el retrato de su abuelo, Joaquín Fernández Villalta (Museo de la Academia de San Fernando, $n^{\circ}$ inv. 0519), pintado por

\footnotetext{
${ }^{324} \mathrm{Su}$ fecha de ingreso no aparece recogida en las actas, aunque cabe pensar que sería en fecha próxima al fallecimiento del retratado, en 1891.

${ }^{325}$ Sesión Ordinaria de 12 de enero de 1891, ARABASF (3-100), p. 313.

${ }^{326}$ Sesión Ordinaria de 9 de diciembre de 1891, ARABASF (3-100), p. 295.

${ }^{327}$ Sesión Ordinaria de 27 de julio de 1891, ARABASF (3-100), p. 295.

${ }^{328}$ Sesión Ordinaria de 28 de septiembre de 1891, ARABASF (3-100), p. 473.
} 
su padre, el que fuera también académico, José Amador de los Ríos “en el año 1843 cuando alternaba en el manejo de la pluma y los pinceles", y se destinó a la Sala de Retratos $^{329}$.

La última década del siglo XIX supone para la Academia un momento de especial reflexión sobre lo que supone ser miembro de la corporación, los vínculos afectivos entre estos y una preocupación por la perpetuación de su memoria a través de la biografía y el retrato. Son varios los motivos que se plantean para esta introspección, siendo quizás el más relevante el hecho de que la media de edad entre los académicos fuese en este momento especialmente elevada, llegando a encadenarse numerosos fallecimientos en muy poco tiempo, siendo evidente una preocupación por la perpetuación de la memoria. Esta etapa de marcado pesimismo, debido a la relevancia de muchos de los académicos fallecidos -entre los que se cuentan José María Avrial, Benito Soriano Murillo, Germán Hernández Amores, Federico de Madrazo, Carlos de Haes, Vicente Palmaroli, Emilio Sala o Pedro de Madrazo-, se ve reflejada en las propias actas, donde el habitual hermetismo dando cuenta de la muerte de un académico se transforma en un completo despliegue de emotividad, interviniendo muchos de los presentes en el elogio del compañero fallecido y en una plasmación de los vínculos pasados y presentes- que los unían, suspendiéndose a continuación la sesión como señal de luto. Por otra parte, la continua llegada a la Academia para su examen y aprobación de retratos de personajes ilustres con destino a Calcografía Nacional o al Museo Nacional de Pintura hacía que la idea de memoria estuviese especialmente presente. Con estas razones es comprensible que la Academia propusiese en este momento que debía ser tarea de los académicos electos realizar una necrología del académico fallecido cuya vacante cubrían, pero también que el problema del retrato volviese a salir a la luz.

En pleno duelo por la muerte del pintor Germán Hernández Amores, el académico de número Salvador Martínez Cubells (recién ingresado en 1891 en la vacante de Benito Soriano) expuso ante los académicos "que era a su juicio lamentable el que en esta Academia, compuesta en parte de pintores, no se vieran los retratos si no ya de todos los Sers. individuos que a ella han pertenecido y pertenecen, al menos los de todos los que han sido directores de ella ${ }^{330}$ ". La observación de Martínez Cubells es interesante, ya que a este pintor valenciano no solo le extrañaba el hecho de que la Academia de San Fernando no contase con una galería de académicos, sino que se atrevía a juzgar este hecho como "lamentable", teniendo sin duda en mente el ejemplo de la Academia de San Carlos, en la que se había formado y que, siendo una institución con una historia algo menos dilatada que la de la Corte, sí que contaba con una galería de retratos de académicos en la que la propia institución se había volcado durante el siglo XIX. El valenciano no se limitó a realizar esta crítica, puesto que invitó a los académicos de la sección de pintura a la nada desdeñable tarea de "formar una Galería de retratos de todos los directores que ha tenido la Academia desde su fundación", propuesta que fue acogida con aplausos por parte de los académicos, que recomendaron a la sección de

\footnotetext{
${ }^{329}$ Sesión Ordinaria de 19 de diciembre de 1892, ARABASF (3-101), p. 140.

${ }^{330}$ Sesión Ordinaria de 23 de mayo de 1894, ARABASF (3-101), p. 526.
} 
pintura comenzar cuanto antes. En la misma sesión, aprovechando el interés y entusiasmo que había suscitado la idea de la galería de retratos, la Academia aprovechó para invitar al académico correspondiente Esteban Aparicio a realizar y donar un retrato de su difunto padre, José Aparicio. Este correspondió a la invitación realizada, y en junio de 1895 se da noticia de la donación "de un busto vaciado en yeso, retrato de su Sr. Padre D. José Aparicio, profesor que fue de los estudios a cargo de esta corporación, obra del escultor Sr. Salvatierra ${ }^{331}$.

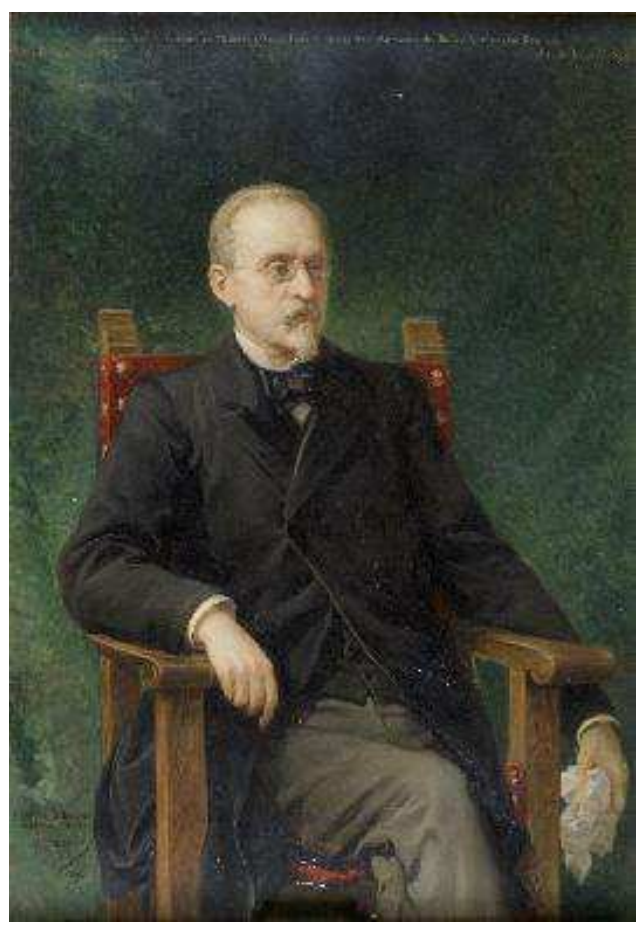

Fig. 113. Salvador Martínez Cubells, Don Federico de Madrazo. Museo de la Academia de San Fernando ( $\mathrm{n}^{\mathrm{o}}$ inv. 0564).

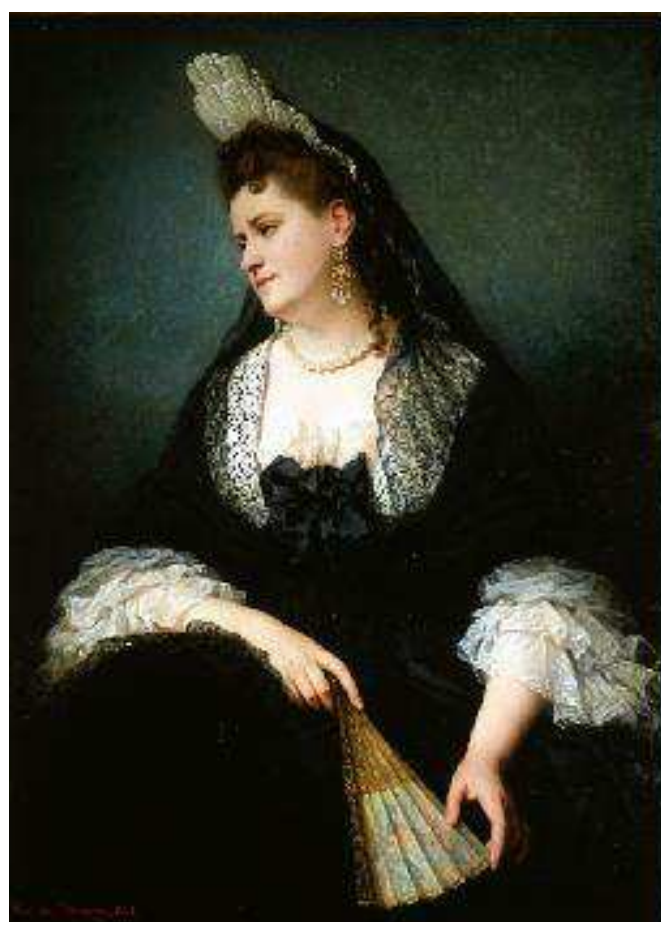

Fig. 114. Henriette Brown, Retrato de Alejandrina Gressler (Madame Anselma). Museo de la Academia de San Fernando ( $\mathrm{n}^{\mathrm{o}}$ inv. 0220).

Fue precisamente Salvador Martínez Cubells quien, cumpliendo su palabra y haciendo honor a su propuesta de crear una galería pictórica de retratos de académicos, remitió en 1896 un retrato de Federico de Madrazo pintado por su mano, copia de un original de Luis de Madrazo [fig. 113]. La obra, en cuya parte superior se incluyó una leyenda con los datos del retratado, muestra a Federico de Madrazo en edad avanzada, sentado en actitud contemplativa y la mirada perdida, sumido en lo que parece ser profunda reflexión intelectual. Como único rasgo alusivo a su identidad artística sostiene en su mano izquierda un paño. En la sesión en que se da cuenta de esta noticia, el director Pedro de Madrazo insiste en la conveniencia de seguir el ejemplo de Martínez Cubells, animando a los académicos profesores de la sección de pintura a dedicar algún tiempo "a hacer el retrato de otros de los actuales Sres. Académicos ${ }^{332,}$, implicando ya en este caso una interacción entre los académicos que posan y los que retratan. La exhortación de Madrazo fue respaldada por el académico Sr. de la Rada y Delgado, quien proponía que también la sección de escultura debía involucrarse en la perpetuación de la memoria de otros individuos presentando sus bustos, enlazando

\footnotetext{
${ }^{331}$ Sesión Ordinaria de 24 de junio de 1895, ARABASF (3-102), p. 196.

${ }^{332}$ Sesión Ordinaria de 8 de junio de 1896, ARABASF (3-102), p. 407.
} 
precisamente con la repercusión que la escultura había alcanzado en la configuración de la Sala de Retratos en las últimas décadas. Así, académicos de las secciones de pintura y escultura podían iniciar una nueva etapa en la Sala de Retratos, proveyendo a la corporación de las efigies de sus consocios, ofreciendo al mismo tiempo una imagen de la vida social de la misma. A pesar de la buena voluntad de Rada, secundada por Riaño, y del nuevo ofrecimiento de Martínez Cubells de "ejecutar los retratos de algunos Sres. académicos si se le proporcionaban datos", la galería mantuvo su carácter ecléctico debido al ingreso de obras procedentes de donaciones puntuales. Esto se puede observar en las escasas noticias existentes sobre el ingreso de retratos antes de 1900: en 1897, Alejandrina de Gessler, académica correspondiente, informaba de su voluntad de legar en su testamento a la Academia su retrato, realizado por la artista Henriette Browne ${ }^{333}$ [fig. 114] -aunque su ingreso no se verificó hasta su fallecimiento (acontecido en 1907)-, y en febrero de 1900 se daba cuenta de la donación realizada por Antonio Ruiz García de Salces (que sería poco después nombrado académico correspondiente en Sevilla) del retrato de su padre, fallecido en 1899. El acta recoge la comunicación del autor,

hijo del censor que fue de esta corporación en la que manifestaba que [ilegible] a cuyas tareas prestó aquel su incansable colaboración, se atreve a ofrecerle el retrato de su señor padre D. Antonio Ruiz de Salces, que a ejecutado con tal objeto, deseando honrar la memoria de este y al propio tiempo dar una prueba de consideración y respeto al Ilustre Cuerpo Académico ${ }^{334}$.

\subsubsection{La galería en la transición al siglo XX}

Podría creerse que la iniciativa de Martínez Cubells estuvo vinculada a la creación de la galería de retratos de la Escuela de Bellas Artes de París al estar enterado de las novedades museísticas extranjeras debido a su cargo de presidente del Museo Nacional de Pintura. El caso parisino resulta curioso ya que, tras la apertura en 1888 de la Sala de Retratos de Académicos en la sala Denon del Louvre, planteaba el debate de cómo establecer un equilibrio entre aquella identidad institucional vinculada al Antiguo Régimen y la necesidad de los artistas y académicos de dar continuidad a la misma en la corporación. La política de ingreso en el Louvre no consentía la presencia de obras de artistas vivos, algo que parece que también influyó en España durante la primera fase de la Galería de Españoles Ilustres en el Museo Nacional; el debate sobre la necesidad de una perspectiva histórica para juzgar los honores de pertenecer a la galería de retratos del Louvre, esgrimido entre Chennevières y Castagnary (defensor de la presencia de retratos de artistas vivos), se correspondía veladamente con un debate sobre la vanidad del artista contemporáneo y su deseo de ser incluido en las grandes filas de la historia del arte, algo impropio a la buena etiqueta ${ }^{335}$, lo que influyó en que finalmente solo incorporase dos retratos de artistas contemporáneos, fallecidos con posterioridad a 1870: Courbet y Ricard. Sin embargo, el deseo de crear una colección de retratos

\footnotetext{
${ }^{333}$ Sesión Ordinaria de 2 de noviembre de 1897, ARABASF (3-103), p. 54.

${ }^{334}$ Sesión Ordinaria de 26 de febrero de 1900, ARABASF (3-103), p. 608.

335 Sobre la Sala Denon y su vinculación con los retratos de académicos ver: WILLIAMS, 2015: 307; CHENNEVIÈRES-POINTEL, 1883; LAFENESTRE, 1888.
} 
permaneció en el espíritu corporativo con la imagen siempre presente de la Galería de los Uffizi, de tal manera que la propia École des Beaux Arts favoreció la creación de una galería. El papel de Henri Jouin, secretario de la misma, fue fundamental no solo para la promoción de la iniciativa, sino también para su constitución definitiva a partir de 1891, curiosamente el mismo año en que volvió a salir a la luz el tema de una galería de retratos de Académicos en la de San Fernando. Sin embargo, la propuesta de Martínez Cubells se elabora con anterioridad a la de la École, ya que en esta última los debates sobre su establecimiento se realizan en dos sesiones celebradas en julio y octubre de 1891, lo que manifiesta el carácter local y la dimensión institucional que tenía la galería planteada por Cubells. No fue hasta 1893 cuando, haciendo acopio de los retratos donados a lo largo del siglo a la institución y de los solicitados a los miembros del profesorado a través de una circular ${ }^{336}$, Jouin publicó un primer catálogo sobre la colección formada en la escuela parisina (JOUIN, 1893). Los retratos de los vivos, con una evidente voluntad ecléctica de no constituirse como galería exclusivamente pictórica $^{337}$, destinados a la Sala de Juntas o del Consejo, reformulaban así de nuevo la existencia de una identidad común en el seno de la institución ${ }^{338}$. Curiosamente, la mayoría de las obras incorporadas entre 1891 y 1920 se correspondían con retratos escultóricos, y no incluía la imagen de ninguno de los miembros correspondientes extranjeros, como Federico de Madrazo o Arturo Mélida.

El paralelismo entre la Academia de San Fernando y la galería de la Escuela de Bellas Artes de París no debe buscarse en el origen de las iniciativas, sino en un movimiento de sus fondos pictóricos que dio nuevo protagonismo a los retratos de académicos. Al igual que en su correspondiente parisina, la Academia de San Fernando también se vio despojada de algunas de sus obras, aunque en su caso no se trató de los retratos corporativos sino de algunas obras maestras depositadas en la institución y reclamadas por el gobierno por Real Decreto en septiembre de 1901. Sí que se puede observar que frente a la anterior incorporación de retratos en la Academia, especialmente durante la última década del siglo XIX, el tránsito al XX supone una cierta apatía al respecto, reflejo de una crisis social y económica que llevaba a muchos familiares y descendientes de artistas a vender sus obras -retratos incluidos-al Estado, en lugar de donarlas altruistamente a corporaciones. En los primeros años del siglo XX se incorporaron algunos nuevos retratos de académicos, lo cual manifiesta que la voluntad de memoria, aunque a través de escasos ejemplos, continuó vigente, pero no fue hasta la segunda década del siglo cuando se empezaron a concebir novedades respecto a la forma de entender la colección de retratos de la Academia de San Fernando. Entre las primeras incorporaciones realizadas constan el retrato al óleo de Francisco Elías, remitido por el albacea testamentario de la hija del retratado en

\footnotetext{
336 ANF AJ/52/451.

337 Jouin estableció como rasgo diferenciador de la nueva galería el que no fuesen exclusivamente pictóricos, ya que "El Louvre y Florencia, en sus salas de retratos, no encierran más que pinturas. ¿Por qué? Acojamos el busto, la estatuilla, el medallón, la medalla, el dibujo, la miniatura, la estampa" (JOUIN, 1893: 4).

${ }^{338}$ Algo similar se desprende de su historia de la Institución a partir de los miembros de su cuerpo educativo (JOUIN, 1894).
} 
septiembre de $1900^{339}$, y los bustos de los académicos Francisco Pérez del Valle ${ }^{340}$ legado por sus hijos como recuerdo del escultor- en 1901; de Juan Facundo Riaño ${ }^{341}$ donado en 1901 por el autor de la obra, y académico, Ricardo Bellver-; de Esteban de Ágreda $^{342}$ en 1906 y el busto del pintor y académico Manuel Domínguez ${ }^{343}$, realizado por Mariano Benlliure y donado por la familia del retratado en 1907. Sin embargo, todos ellos comparten el rasgo de ser donaciones relacionadas con la perpetuación de la memoria de los efigiados, ya fallecidos, en la corporación y en ningún momento se especifica el destino de los mismos.

Las incorporaciones posteriores permiten entender un nuevo impulso del retrato de académicos tras un periodo de crisis para la institución, marcado en primer lugar por el traslado de sus obras maestras al Museo Nacional de Pinturas en 1901 y seguido por el elevado número de fallecimientos entre sus miembros, lo que provocó una renovación continua en los asientos de la Academia. Al respecto se quejaría el marqués de Villa Alta, quien señalaó en 1903 que ante esta situación no se daban las suficientes muestras de alegría o duelo relacionadas con las recepciones y el fallecimiento de los académicos, algo que iba unido a la pérdida de la costumbre de que los académicos profesores legasen una obra como recuerdo de su talento, más allá del tradicional discurso de recepción ${ }^{344}$. En estas fechas, en las que los mayores homenajes que se podían rendir consistían en la dedicación de una placa conmemorativa (PITA ANDRADE, 1991: 273296), bien en la propia sede de la Academia (es el caso de José Piquer) o bien en el edificio de nacimiento, la Academia parece perder progresivamente el interés por los retratos de académicos. De este modo, con motivo de la Exposición Nacional de Retratos de 1902, la Academia participa por indicación del Ministerio de Instrucción Pública y Bellas Artes y, a pesar de haber sido invitada a enviar obras procedentes de su pinacoteca en las sesiones ordinarias, con especial énfasis sobre la voluntad de concurrir con bustos escultóricos y dibujos, así como sobre destinarlos a una sala exclusiva para la institución ${ }^{345}$. Tal y como se propuso, la Academia remitió un número escaso de retratos pictóricos; a pesar de las numerosas obras existentes en la colección entre las que podría haber elegido, todos los retratos enviados finalmente se corresponden con académicos o dependientes de la misma. Mediante un autorretrato de Goya y los retratos del secretario Munárriz, José Piquer, Alejandro de la Peña y Francisco Bellver (EXPOSICIÓN NACIONAL DE RETRATOS, 1902: $\mathrm{n}^{\circ}$ 637) la Academia no solo pretendía reivindicar la importancia de los propios miembros de la institución a través de su historia, sino también de los ilustres artistas presentes en sus colecciones, tras el varapalo sufrido por el traslado de obras de 1901, que fue entendido por la Corporación como un primer paso dado por el Gobierno para desprestigiar y aniquilar a la de San Fernando $^{346}$. También es en esta primera década del siglo XX cuando la Academia de

\footnotetext{
${ }^{339}$ Sesión Ordinaria de 26 de septiembre de 1900, ARABASF (3-104), p. 75.

${ }^{340}$ Sesión Ordinaria de 6 de mayo de 1901, ARABASF (3-104), p. 247.

${ }^{341}$ Sesión Ordinaria de 21 de octubre de 1901, ARABASF (3-104), p. 335.

${ }^{342}$ Sesión Ordinaria de 5 de diciembre de 1906, ARABASF (3-106).

${ }^{343}$ Sesión Ordinaria de 16 de diciembre de 1907, ARABASF (3-106), p. 272.

344 Sesión Ordinaria de 12 de octubre de 1903, ARABASF (3-105), pp. 121-122.

${ }^{345}$ Sesión Ordinaria de 7 de abril de 1902, ARABASF (3-104), pp. 479-480.

${ }^{346}$ Sesión Ordinaria de 30 de septiembre de 1901, ARABASF (3-104), p. 309.
} 
San Fernando, como órgano consultivo, ve desfilar entre las obras sobre las que se le solicita informe numerosos retratos de artista, destinados en su mayoría al Museo de Arte Moderno; es el caso del autorretrato del pintor José Díaz Molina, de los dos de Balaca, o incluso el retrato del académico Germán Hernández Amores realizado por Casto Plasencia, obras ante las que se mantiene objetiva, declarando su valía en sus informes y realizando la tasación pertinente, pero sin que estas obras despierten ningún interés particular por la propia colección de la Academia.

Es en 1911 cuando se produce la primera donación del retrato un académico en activo, el de Amós Salvador y Rodrigáñez, académico de número por la sección de escultura desde 1898, realizado por el pintor José Moreno Carbonero (quien tomó posesión como académico de número en el mismo año que el retratado) y que fue donado "para perpetuar su memoria entre los bienhechores de esta docta

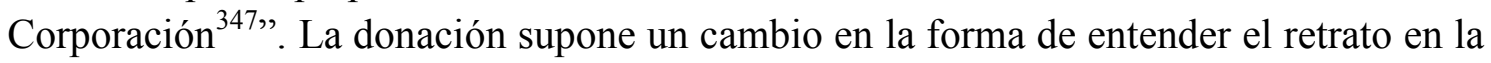
Academia de San Fernando, vinculado a un homenaje en vida del que son testigos tanto el retratado como el pintor, con la presencia además de ambos en la sesión en la que se da noticia del ingreso de la obra. Amós Salvador reconoció así ante el resto de académicos el gesto de José Moreno Carbonero, donante de la obra, agradeciendo "la alta honra de que ahora es objeto con motivo del valioso e importante donativo del Sr. Moreno Carbonero". El resto de académicos, movidos por las palabras de Mariano Benlliure a favor de una mayor presencia de artistas -y de sus obras- en la Academia, no dudaron en señalar que el ejemplo dado por Moreno Carbonero debía repetirse, sin anular la solemnidad de la ceremonia de recepción de académicos y su consabido discurso, ante lo cual se plantea la posibilidad de que los artistas puedieran ser recibidos mediante la presentación de una obra de arte, a la que serían respondidos con un discurso de elogio ${ }^{348}$. Con esta voluntad de autoproyección en la institución, que asume las prácticas realizadas en otras corporaciones, la presencia de artistas vivos y de sus retratos en la Academia comienza a ser frecuente a partir de este momento. En 1917 Francisco Domingo Marqués se acoge al reglamento y remite, de acuerdo con el párrafo segundo del artículo noventa y uno, una obra original que no es otra que su propio Autorretrato $^{349}$, rasgo que indica el cambio en la forma de entender la ya obsoleta idea de modestia en el ámbito académico. José Garnelo realizó en 1920 la donación de un retrato, en este caso de un académico difunto: el de Rodrigo Amador de los Ríos ${ }^{350}$, con lo que continuaba la representación dinástica de esta familia en la Academia. El fallecimiento de José Villegas también es respondido con la rápida llegada de su propio Autorretrato $^{351}$; apenas transcurren diez días entre el triste suceso y la recepción de la propia obra, donada por la viuda del pintor. Se incorporaría también una nueva pintura, realizada por José Garnelo con anterioridad a 1929, consistente en el retrato del arquitecto y académico Manuel Aníbal Álvarez, que figura en el Catálogo de ese año, lo cual permitió dar un nuevo impulso a la formación de una colección de retratos de la

\footnotetext{
${ }^{347}$ Sesión Ordinaria de 11 de diciembre de 1911, ARABASF (3-107), pp. 348-349.

${ }^{348}$ Sesión Ordinaria de 11 de diciembre de 1911, ARABASF (3-107), p. 350.

${ }^{349}$ Sesión Ordinaria de 28 de mayo de 1917, ARABASF (3-108), p. 549.

${ }^{350}$ Sesión Ordinaria de 6 de diciembre de 1920, ARABASF (3-110), p. 141.

${ }^{351}$ Sesión Ordinaria de 21 de noviembre de 1921, ARABASF (3-110), p. 371.
} 
mano del académico y arqueólogo José Ramón Mélida. Conocedor este último de otras corporaciones, y especialmente de la Real Academia de la Historia, de la que era miembro, hizo notar en 1928 esta necesidad "de formar la colección completa de directores como hacen otras corporaciones análogas 352 ", y propuso conseguir el de Elías Martín $^{353}$. Con ello se abrió entre los años 30 y 60 del siglo XX una nueva etapa través de la presencia de nuevos retratos, muchos de ellos ubicados en un espacio privilegiado de la Institución.

\subsubsection{La Sala de Retratos de la Academia}

Mencionado ya el problema que supone para la configuración de una historia $-\mathrm{y}$ una identidad- de la Academia de San Fernando el eclecticismo con que se forma su colección de retratos, es necesario detenerse en los espacios a los que estos estuvieron destinados, ya que directa o indirectamente condicionaron su percepción como objetos para la memoria, pero también sus relaciones con el ideal de comunidad o con conceptos como la jerarquía en la vida cotidiana de la academia. Destinar una galería de retratos a un espacio concreto significa moverse en los límites de la metonimia, ya que el abandonar una idea de dispersión de los retratos -que únicamente favorece una percepción del retratado como identidad individual o en relación con la colección pictórica de la Academia- permite hablar de un conjunto en el que la identidad individual no puede aislarse de las connotaciones que le aporta la relación colectiva de las obras. Del mismo modo, la identidad colectiva generada solo adquiere pleno significado en la unión de sus partes o en el conjunto de identidades individuales representadas con posterioridad a su ejecución pictórica ya que, en el caso madrileño, fueron escasos los retratos realizados específicamente para formar conjunto. La idea de pertenencia a la Academia que se desprende del conjunto - ese ser en una comunidadradica en gran medida en la dignificación de la efigie más allá de sí misma, es decir, en la percepción del grupo, pero también conlleva otros significados secundarios: pertenecen por igual a la institución el retratado y el académico o discípulo que lo contempla, pero existe una distancia temporal y jerárquica entre ambos; el retratado pertenece como imagen para la memoria, es decir, como recuerdo del honor, de una carrera profesional exitosa y de su vínculo - real o tal y como era percibido por el retratado o el donante- con la Academia, mientras que en su relación con el retrato colgado el académico o discípulo pertenecen en potencia. Ambos se encuentran en inferioridad con respecto al efigiado, y entienden la galería como una representación de un linaje espiritual, un conjunto de rostros en los que identificar el respeto artístico y la emulación.

No son muchos los datos que tenemos respecto a la ubicación de estos retratos con anterioridad a 1817, año en que se realiza el primero de los catálogos con una clasificación de las obras atendiendo a su ubicación en el edificio de la Academia, tras la reubicación de las colecciones en 1816. La propuesta inicial de crear una serie de monarcas y viceprotectores, unida a la precisión de que las primeras obras estuviesen

\footnotetext{
${ }^{352}$ Sesión Ordinaria de 17 de diciembre de 1928, ARABASF (3-112), p. 574.

${ }^{353}$ Sesión Ordinaria de 28 de enero de 1929, ARABASF (3-112), p. 608.
} 
concluidas el día de la distribución de premios, evidencia una clara intención de que las obras formasen parte de ese escenario ritual en la Casa de la Panadería, pero se desconoce la ubicación que merecieron en ella los primeros retratos que ingresaron en la Academia: ante el ofrecimiento de Faraona Olivieri de su autorretrato y del retrato de Jaime Marquet únicamente se especifica que serían colocados "desde luego en

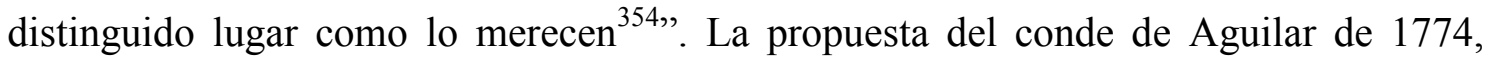
vinculada a la creación de una galería de retratos, tiene lugar un año después de la adquisición de la sede definitiva en el palacio de Goyeneche; aunque no queda de manifiesto en la propuesta, es posible que se tuviese en mente destinar un espacio concreto a dicha galería ${ }^{355}$, ya que si la previsión del conde de Aguilar era correcta y todos los académicos cedían sus retratos, esta crecería rápidamente y dotaría al espacio que la albergase de un carácter corporativo propio. Tal vez tuviese en mente la Sala de los Retratos de la Académie Royale de París, que había concentrado la historia de la institución a través de los retratos de sus académicos y había alcanzado la apabullante suma de noventa y dos obras ${ }^{356}$.

No obstante, los planos realizados en 1773 por Villanueva para la distribución de espacios de la Academia no contemplaban un lugar de honor específico para los retratos, unido al hecho de que la iniciativa del conde de Aguilar tuvo una pobre respuesta en el caso de la Academia de San Fernando, pudo motivar que estos quedasen relegados a un espacio secundario hasta la redistribución realizada en 1816. La distribución de las pinturas y esculturas en el inventario de 1817 pone de manifiesto la diferenciación, casi jerárquica, de los espacios y las obras destinadas a ellos en función de su uso, tal y como recogió el secretario Pedro Franco. Merece la pena destacar la completa ausencia de retratos de artista o de académicos en las tres salas de mayor relevancia para la vida académica: así, en el cuerpo principal del edificio, la Sala de Juntas, la antesala o el Salón de Funciones estuvieron decorados con obras maestras de Murillo y Velázquez, retratos de la monarquía y pinturas de temática religiosa; de este modo, no eran los retratos de sus miembros los que recibían a los académicos antes de acceder a la Sala de Juntas, ni los que presidían, como ocurriría en otras academias, las propias reuniones de la Junta, ni las paredes del salón de Actos en las solemnes entregas de premios a los alumnos. Consideradas las demás como salas o dependencias menores, acogieron de manera diferenciada el resto de obras, destinándose una de ellas a la colección de retratos. En un escrito redactado por Pedro Franco el 11 de mayo de 1816 se señalaba que

La Sala de Juntas como la principal debe adornarse con toda magnificencia posible por medio de las mejores pinturas y los bustos de Reyes en bronce y mármol que

\footnotetext{
${ }^{354}$ Junta Ordinaria de 18 de diciembre de 1759, ARABASF (3-82), fol. 69r.

355 La alusión de que estos retratos fomentarían el mejor adorno de la Academia, como el conde de Aguilar formula en su propuesta, está muy vinculada a un tema anteriormente tratado en las juntas sobre el adorno del nuevo edificio de la Academia, para lo cual se estaba gestionando el traslado de las pinturas del Colegio Imperial. Junta Particular de 6 de marzo de 1774, ARABASF (3-122), fol. 187r.

${ }^{356}$ En su análisis de esta Sala de los Retratos, Williams (2015: 147) señala la importancia de aislar este espacio de otros - tanto dependencias académicas como salas de exposición- para poder configurar una experiencia visual de la identidad colectiva, dotándolo de un carácter ritual.
} 
posee la Academia [...] En las demás salas y piezas menores de la casa se pondrán con división de clases todo cuanto hay en la Academia, según corresponde, a saber en una las pinturas de mayor mérito, en otra la colección de retratos, en otra las obras selectas de profesores que sean o hayan sido individuos de la Academia (AZCUE BREA, 1994:. 18; NAVARRETE, 1999: 337).

La información que ofrecen los inventarios es que esta colección se encontraba en la sala sexta, denominada precisamente Sala de Retratos. Siguiendo el orden lógico establecido en los distintos inventarios y la identificación de algunos de los espacios realizada por Juan José Martín González (1992: 165-210; 1991: 517-532), todo parece indicar que esta sala estuvo ubicada en uno de los lados del Oratorio, en el espacio que Hermosilla dedicó a librería en su plano, y su acceso, aparentemente enrevesado, requería recorrer la Sala Larga y la sala del pasillo [fig. 115].

Resulta interesante esta hipótesis ya que podría significar una valoración especial del propio cuerpo académico al constituirse el oratorio como un eje central a cuyos lados, en un orden simétrico, las dos salas colindantes albergarían piezas con un significado especial. Así, una de ellas -denominada sala sexta o sala de retratos-, se convertiría en el espacio destinado a albergar, de manera exclusiva, la galería de retratos de la Academia, mientras la otra, en perfecta simetría, se destinaría a las obras realizadas por los propios académicos. Esta hipótesis parece confirmada por la propuesta realizada en Junta Particular respecto a dos obligaciones que la Academia había contraído en 1754, y que en 1816 se hacía recordar a sus miembros: por una parte, la entrega obligatoria de obras de composición para la admisión como académicos de mérito, y por otra, la configuración de una colección de retratos, inicialmente de reyes y protectores. El ideal de simetría aparece ya reflejado en la propuesta de reordenación de las colecciones artísticas de 1816, buscándose decorar "sus salas con orden y simetría, colocando en las principales las pinturas de mayor mérito, en una la colocación de retratos, en otra las obras selectas de profesores que hayan sido de la Academia ${ }^{357}$,.

El devenir de la Academia y la escasez de retratos de académicos y de artistas pudo haber condicionado el que en esta sala conviviesen, manteniendo al menos una unidad respecto a la temática, los retratos de académicos anteriormente citados con otros retratos históricos, fundamentalmente de la monarquía. Martín González menciona de pasada la Sala de Retratos, diciendo que en ella "figuraban efigies de personajes regios de las casas de Austria y Borbón” (MARTÍN GONZÁLEZ, 1991: 525), a pesar de que estadísticamente la sala estuvo durante el siglo XIX compuesta en un tercio por retratos regios, otro por retratos de académicos y un último tercio de retratos bien sin identificar o procedentes de otros ámbitos, a excepción de la última década del siglo, en que los retratos de académicos constituyen en buena medida las obras de la sala, materializando en parte esa ansiada galería corporativa.

No debe sorprender la presencia de retratos de la monarquía en esta sala, en primer lugar porque en una academia de patronato regio era obligada, lo que además permitía establecer en la disposición de las obras una relación directa entre los protectores de las

${ }^{357}$ Junta Particular de 11 de mayo de 1816, ARABASF (3-126), fol. 103r. 
artes desde el Siglo de Oro a la actualidad, mientras que los artistas y académicos vinculados a la institución contaban con una historia relativamente corta. Parece respaldar esta idea el hecho de que, hasta 1821, convivieron con los retratos dos representaciones -copias de la escuela italiana- del origen de la pintura (inventario de $1819, \mathrm{n}^{\mathrm{o}} 1877$ 194; inventario de $1821, \mathrm{n}^{\mathrm{o}} 188$ y 194$)$.

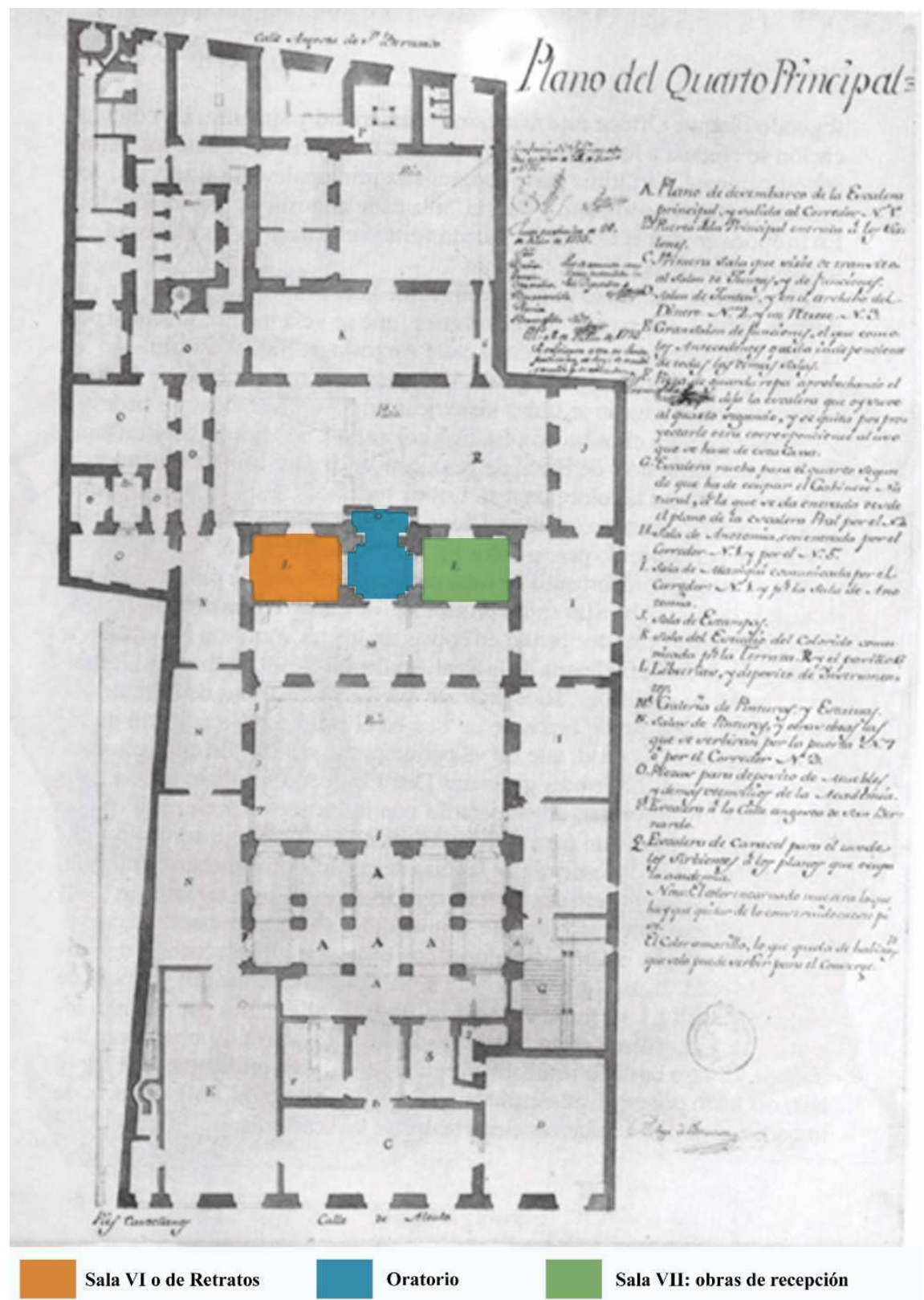

Fig. 115. Ubicación en plano de los espacios dignificados, según el plano del edificio de la Academia proyectado por Villanueva (MARTín GONZÁLEZ, 1991).

$Y$ en segundo lugar porque la iniciativa original de la sala estaba orientada hacia la exhibición de una colección de retratos del poder, en este caso de reyes y protectores, a pesar de que la propuesta de una galería contemporánea se vio frustrada por una recopilación de antiguos retratos procedentes de la colección académica (ver anexo 4). Más problemático resulta analizar el incremento de retratos pictóricos durante la 
segunda mitad de siglo, debido a las escasas noticias aportadas por las actas y a los infructuosos intentos de realizar una catalogación de las obras existentes en la Academia, ya que existe un lapso de cuarenta y cuatro años desde el inventario de 1840 hasta la redacción de otro, actualizado, en 1884 (ya que el manuscrito de 1867 no introduce datos nuevos), durante el cual ingresan nuevos retratos vinculados a la corporación. La siguiente tabla [tabla 3] ofrece una idea de la proporción de retratos de académicos según la información recopilada en inventarios y catálogos:

Obras en sala

Retratos de académicos*

*De los cuales son de $\stackrel{\infty}{\infty} \stackrel{\infty}{\infty}$

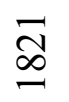

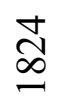

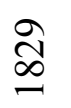

40

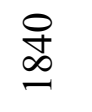

55

19

14

$10 \quad 10 \quad 12$

15

14 $\underset{\infty}{\infty} \quad \stackrel{\infty}{\infty}$

$72 \quad 77$

artista

\begin{abstract}
Retratos de la monarquía
\end{abstract}
Retratos de personajes

53

3

3

3

16

21 desconocidos

Otros*

*De los cuales no son
$8 \quad 10$

4

$5 \quad 5$

retratos

Tabla 3. Relación de las obras existentes en la Sala de Retratos según los inventarios de la Academia

Es interesante señalar que, a pesar de que el criterio para la incorporación de retratos a esta sala de retratos no siempre fue el mismo, obedeció a cierta lógica hasta, al menos, 1840; de este modo, encontramos que otros retratos que no están vinculados a la historia de la Academia o a la protección de las artes se ubican en la Sala Larga, e incluso que algunos de los retratos presentados como obras de recepción fueron destinados en un primer momento a la sala séptima, destinada a las obras de académicos y profesores. Así ocurrió, inexplicablemente, con el autorretrato de Lucía Gilabert, que se menciona ubicado en la sala del oratorio hasta el inventario de 1829, y con el retrato de Antonio González Ruiz, aunque en este caso la identidad del retratado, su iconografía directamente relacionada con la profesión artística y su vinculación con la Academia motivaron su rápido traslado a la Sala de Retratos ${ }^{358}$. De manera similar, es curiosa la presencia que tuvo Goya en esta sala, ya que en 1829 -y por consiguiente justo después de su incorporación a la colección- ya aparece colocado su Autorretrato en la sala de retratos; no obstante, la copia realizada por Rosario Weiss del retrato de Goya, en la que la iconografía tiene más relevancia como muestra de la identidad profesional del artista, fue relegada a la biblioteca, donde aparece colocado en el catálogo de 1840. En la posterior reubicación de las obras, el Autorretrato de Goya se

\footnotetext{
358 Como obra de recepción, fue destinada a la Sala Séptima, donde aparece ubicada en 1829. No obstante, en el catálogo de 1840 se menciona ya en la sala de retratos.
} 
destinó, como imagen del genio creativo, a acompañar a las obras que del aragonés poseía la Academia, de modo que la obra de Weiss obtuvo el honor de pasar a la Sala de Retratos. También es preciso apuntar una cierta dispersión de los retratos de académicos, y en su mayoría de artista, que manifiesta el catálogo de 1884; a pesar de que la sala de retratos había ganado en identidad profesional y corporativa con la incorporación de los retratos de Antonio González Ruiz, el de Goya por Rosario Weiss, Vicente López, Zacarías (Museo de la Academia de San Fernando, nº inv. 0042) e Isidro González Velázquez, Antonio María Esquivel y Maella, y de los del académico Pedro Franco y el benefactor Manuel García de la Prada, es llamativa la presencia de dos retratos de artista en el Cuarto del maniquí. Se trataba de un autorretrato de Zacarías González Velázquez (Museo de la Academia de San Fernando, $\mathrm{n}^{\circ}$ inv. 0704) y del retrato de Joaquín Espalter.

Respecto al autorretrato de Zacarías González Velázquez, sabemos que ingresó por donación del pintor Vicente Poleró en $1868^{359}$, aunque no consta en el acta de la comunicación oficial de esta información el lugar al que fue destinado. El de Joaquín Espalter (Museo de la Academia de San Fernando, no inv. 0339), académico y profesor de la Escuela de Pintura, ingresó el mismo año de su fallecimiento (1880) por donación de su viuda, hecho que no queda reflejado tampoco en las actas de la academia. La presencia de estas dos obras en una sala que seguía siendo utilizada con fines didácticos puede ser debida a motivos de escasa relevancia, como la falta de espacio en otras salas, o la existencia de otro retrato en el caso de Zacarías; sin embargo, es interesante en cuanto al valor que pudieron tener como imágenes para la memoria de dos importantes profesores de pintura, especialmente en el caso de Joaquín Espalter, ya que su presencia tras su reciente fallecimiento podía aún despertar vínculos de identificación con los alumnos que pasaban por la sala. Además de estas dos obras existentes en el Cuarto del maniquí, cuatro retratos anteriormente ubicados en la Sala de Retratos fueron destinados al denominado Cuarto de Susana: el del marqués de Sarriá, el de Ignacio de Hermosilla, el Autorretrato de Lucía Gilabert y una obra, mencionada someramente como "retrato de pintor", que podría tratarse del autorretrato de José Vergara ${ }^{360}$, donado a la Academia en 1831 pero que no consta en los catálogos bajo esta identificación.

A pesar de esta leve dispersión, debida probablemente a la falta de espacio, es muy notorio el papel que adquiere la Sala de Retratos en las dos últimas décadas del siglo XIX. Además, a los retratos pictóricos se añadió un número considerable de bustos de académicos que dotaron al espacio de un carácter mucho más identitario de lo que cabría imaginar si únicamente se hubieran albergado las obras de pintura. El inventario de 1897, del que aporta numerosas noticias Leticia Azcue Brea, ofrece una imagen bastante significativa de la configuración de la Sala de Retratos, en la que la presencia de los académicos queda dignificada a modo de galería de retratos de hombres ilustres. Entre los bustos que apoyaban el significado de la sala se encontraban el de Goya, realizado por Cayetano Merchi, y adquirido por el Estado para la Academia en 1858; en

\footnotetext{
359 Junta Ordinaria de 30 de marzo de 1868, ARABASF (3-94), fol. 199r.

${ }^{360}$ Las dimensiones de la obra mencionada en el catálogo de 1884 coinciden con las del Autorretrato de José Vergara.
} 
1874 se incorporaron los de Vicente y Bernardo López, por Piquer, el de Narciso Pascual Colomer, y el de Mariano Fortuny por Prosper d'Epinay; en 1878 el del Director de Escultura Sabino Medina, realizado por Nicoli y Manfredi; en 1881 el de Francisco Sans y Cabot, por Vallmitjana; en 1891 los de Casado del Alisal por Medardo Sanmartí y Francisco Bellver por Ricardo Bellver; y el del pintor José Aparicio, cedido por su hijo Esteban Aparicio y realizado por Valeriano Salvatierra que se incorpora en 1895 (AZCUE BREA, 1994).

Quizá el aspecto más llamativo de la colección de retratos de la Academia de San Fernando fue, precisamente, las implicaciones que tiene el hecho de que mereciese un espacio dignificado dentro del destinado a la exposición de los fondos artísticos de la corporación. Por una parte, anulaba la relación con los espacios representativos del poder dentro de la Academia, ya que al no estar ubicados ni en la Sala de Juntas ni en el Salón de Actos no presidían -ni física ni simbólicamente- los acontecimientos más relevantes de la historia de la corporación; las juntas, como reunión de sus miembros y órgano de gobierno, no se desarrollaban en compañía de las efigies de los académicos del siglo anterior, sino bajo la suntuosidad de algunas de las obras de arte más valiosas y la omnipresencia de la monarquía. Es evidente que la ausencia de retratos de académicos en la Sala de Juntas puede sorprender, en primer lugar porque no parece configurarse como una galería representativa del poder institucional; pero también porque parece negar ese carácter de historia común propio de una galería de retratos, al no permitir que los académicos se reuniesen bajo la memoria de sus antepasados en el cargo. Respecto a la primera afirmación, la desvinculación del retrato de los académicos de los de los monarcas parece no concordar con esa imagen de los primeros como detentores de una función pública al servicio del Estado; sin embargo, dada la historia de la academia y las continuas rivalidades entre consiliarios y profesores, es posible que se buscase precisamente evitar un conflicto permanente entre las jerarquías e identidades profesionales que cohabitaban en la institución. Por otra parte, la ubicación de la Sala de Retratos al margen de las salas destinadas al gobierno de la academia permitía el acceso a estos a todos aquellos que no pertenecieran a la exclusiva élite artística: las colecciones, de carácter público, podían ser recorridas por académicos, profesores y especialmente por los alumnos, que verían en este espacio propio una dignificación de la profesión artística, en el que se reflejaban los vínculos familiares y una imagen en continua construcción de la historia de la corporación, y también por un público que podía vincular ese espacio separado con la idea de una galería de retratos.

Es en el siglo XX cuando el carácter especial de la Sala de Retratos permite una nueva relación con la institución; la realización de una reubicación de las colecciones permitió aglutinar en la Sala de Juntas muchos de los retratos de académicos, dotándola así de un nuevo significado corporativo. Es difícil asegurar la fecha exacta en que se produce este paso de los retratos a la sala más significativa de la vida académica. Una primera aproximación a la historia de la corporación casi parece sugerir que fue motivado por el traslado de obras al Museo Nacional de Pinturas en 1901. En efecto, algunas de las obras más significativas habían ocupado hasta ese momento un lugar privilegiado en la Sala de Juntas, como ocurre con la Santa Isabel de Murillo; sin 
embargo, las noticias de 1901 y 1902 informan de que la sala mantuvo, quizás como recuerdo de la actitud del Gobierno hacia la Academia, sus paredes sin decorar. En la sesión celebrada inmediatamente después de la salida de las obras, el académico Zubiaurre hizo notar el nuevo estado de la sala al observar "que al entrar los Sres. Académicos en el Salón de Sesiones habrán visto con dolor las llagas o heridas abiertas en su galería pictórica con la realizada traslación de sus más preciadas joyas de $\operatorname{arte}^{361}$ ".

Más curiosa es, sin embargo, la intervención en una sesión ordinaria en 1902 realizada por Bretón, "quien preguntó (...) qué razón existe para que permanezcan desnudas en el salón de sesiones los lugares que ocupaban los cuadros de Santa Isabel y los Medios Puntos", un comentario aparentemente inocente que despertó susceptibles respuestas por parte de sus compañeros académicos. El secretario recoge en acta que fue respondido por el académico Sr. Monasterio, si bien no indica las explicaciones dadas por este, y nuevamente Bretón insiste en "la conveniencia de proceder a una nueva colocación de cuadros ${ }^{362} \%$. La tajante respuesta de Avilés demuestra que el tema era aún duro para el orgullo de los académicos, indicando lo pertinente de dejar por el momento la sala como se encontraba, consintiendo en la necesidad de una nueva colocación de los cuadros más adelante y sin apresuramientos. Sin que exista otra documentación al respecto, en 1903 se deja entrever que la Sala de Sesiones ha cambiado de emplazamiento; así se desprende en la sesión celebrada el 23 de noviembre, donde se decide ubicar una lápida en memoria de Piquer sobre la entrada de la antigua sala de sesiones, y hablando de la instalación eléctrica de la actual Sala de Sesiones ${ }^{363}$. Y a pesar de que en varias ocasiones se habla de la necesidad de realizar obras en la Academia y de catalogar las obras artísticas de esta para ello, algo que queda especialmente plasmado en 1909 con la configuración de una comisión al efecto compuesta por Avilés, Menéndez Pidal, Sentenach, Marinas, Mélida y Landecho, no es hasta 1928 cuando Herrero procede finalmente a la realización de un catálogo de las pinturas de la Academia, en el que efectivamente se puede comprobar que la Sala de Juntas es el espacio designado para albergar la mayor parte de los retratos de académicos. Según este catálogo (RABASF, 1929: 77-89), los retratos que cuelgan en otros espacios de la Academia (un total de diecisiete obras) es significativamente menor que el de los ubicados en el espacio más representativo de la Academia, respondiendo más a la ordenación museográfica y a la interrelación de los retratos con otras obras que a una voluntad de dotarlos directamente de connotaciones institucionales, como sucede, por ejemplo en la Sala de Vicente López. Otros retratos son destinados a espacios administrativos, figurando en el antesalón de actos los de Zacarías González Velázquez y el de Antonio María Esquivel, en el antedespacho el de Francisco Bellver y Llop, y en la anteSala de Juntas los de Antonio Ponz, Antonio González Ruiz y Madame Anselma, o en el despacho del secretario, que cuenta con los autorretratos de las artistas María Luisa Gilabert y Faraona Olivieri.

\footnotetext{
${ }^{361}$ Sesión Ordinaria de 16 de diciembre de 1901, ARABASF (3-104), p. 385.

362 Sesión Ordinaria de 10 de marzo de 1902, ARABASF(3-104), p. 460.

${ }^{363}$ Sesión Ordinaria de 23 de noviembre de 1903, ARABASF (3-105), p. 157.
} 
La Sala de Juntas aglutina en este momento un total de cuarenta obras, todas ellas retratos significativos para la corporación y su historia; seis son retratos de personajes de la realeza, representando al rey San Fernando, Felipe V, Carlos III, Carlos IV, Napoleón I e Isabel II, y nada menos que veinticuatro son retratos de académicos, una cifra nada desdeñable teniendo en cuenta el total de obras en la sala y el hecho de que algunas de las más recientes incorporaciones estén presentes entre las obras, incluyéndose de este modo el de Rodrigo Amador de los Ríos, los autorretratos de Villegas y de Francisco Domingo, así como los retratos de Amós Salvador Rodrigáñez y Manuel Aníbal Álvarez; las cifras son bastante elocuentes [tablas 4 y 5], ya que en el último catálogo del siglo XIX (1884) el total de retratos de artista y académicos en la sala sexta (o de retratos) era tan solo de 24 , siendo significativo el aumento que se ha producido hasta la tercera década del siglo XX.

Antesalón de actos

Antedespacho

AnteSala de Juntas

Sala de Juntas

Capilla

Despacho del secretario

Sala de Vicente López

Sala de doña Bárbara de Braganza

Tabla 4. Número de retratos (en pintura) de artista y académicos en el Catálogo de 1929 por distribución

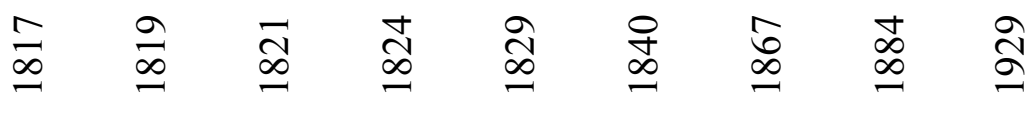

Sala de Retratos

$11 \quad 13$

13

14

15

19

27

*total en sala

139

$/ 41$

$/ 41$

137

$/ 40$

155

72

$/ 77$

Sala de Juntas

*total en sala

$\begin{array}{lllll}1 & 1 & 2 & 3 & 2\end{array}$

Otras dependencias

1

Tabla 5. Comparativa del núm distribuidos históricamente.

En el estudio preliminar de los Retratos de la Academia de San Fernando de 1930, el académico Herrero, autor del catálogo de 1929 y director de la Junta de Iconografía Nacional exponía las dificultades que la etapa contemporánea suponía para el retrato, y especialmente para el retrato masculino, por la igualdad de trajes, gestos e incluso por los convencionalismos sociales del momento, estimando que únicamente en el recogimiento solitario de la vida cultural puede el hombre -aludiendo especialmente al 
artista- ser hombre ${ }^{364}$, y renegando de la vida social (en la que incluye el espíritu colectivo, asociaciones, trusts, sindicatos y corporaciones) como restricción para su expresión pura. La publicación de la Junta de Iconografía Nacional permite no solo hacer un recorrido por las colecciones pictóricas de la Academia elaborando una galería de españoles ilustres - con especial atención a las obras de Velázquez y Goya-, sino que también es un alegato por parte de la propia Academia reivindicando su identidad corporativa, dando a conocer a sus individuos a través de cuarenta y seis retratos de los mismos procedentes de sus fondos.

\subsection{Los retratos de la Real Academia de Bellas Artes de San Carlos}

El caso valenciano, como se señaló anteriormente, llama la atención por su numerosa y codificada galería de retratos. Tras la breve vida de la Academia de Santa Bárbara, en cuya lista de miembros ya era posible contemplar el apoyo más selecto por parte de la población valenciana (GARÍN, 1945; ALDANA FERNÁNDEZ, 2001), quedó constituida y reconocida la Academia de Bellas Artes de San Carlos en 1768 tomando como referencia la institución madrileña, ya que se guiaba por sus estatutos y sus miembros adquirían privilegios similares a los otorgados por la de San Fernando. La valenciana, ligada a las autoridades de la ciudad -ya que tanto los presidentes, vicepresidentes y consiliarios eran elegidos entre los regidores de la misma (CATALÁGORGUES, 1990: 6), relacionándose por este motivo con la aristocracia y la alta burguesía local- se tomó muy en serio la necesidad de configurar una identidad corporativa mediante una galería de retratos, ya que a finales del siglo XVIII ya contaba con varias efigies de académicos fallecidos y colgadas en lugar de honor que llevaron posteriormente a un tipo de representación estrictamente codificado. Las diferencias que se puede observar respecto a la Academia de San Fernando, puesto que se configura como la primera galería académica autónoma y con carácter de serie, sorprenden al ponerse de manifiesto cómo una institución mucho más joven destina mayores esfuerzos a la dignificación de sus miembros, algo que podría encontrar su explicación al tratarse de una corporación más pequeña, anclada en una sociedad más vinculada a la burguesía comercial que al complejo mundo aristocrático de la capital. Sin embargo, el hecho de que la mayor parte de los retratos fuesen incorporados como obras de recepción para el grado de académico de mérito parece también relacionarse con una familiarización con las prácticas académicas extranjeras, y al mismo tiempo con una conciencia muy clara de la institución y de la importancia de la identidad de sus miembros. De este modo, encontramos una galería en la que las tensiones entre consiliarios y académicos se resuelven, probablemente de manera inconsciente, mediante la creación de dos series diferenciadas, cuyos orígenes no constan en las actas $\mathrm{y}$ en las que se ponen de manifiesto distintas formas de entender la jerarquía académica -sea por el poder institucional en el caso de consiliarios o presidentes, sea por el protagonismo de los profesores como piezas fundamentales en el mecanismo de la corporación-, visibilizadas también mediante la iconografía propia de cada uno.

\footnotetext{
364 "Por eso el hombre que se oculta para dar rienda suelta al llanto y esquiva las miradas ajenas cuando sella con un beso los labios de la mujer querida, solo en horas de recogimiento profundo abre por completo su espíritu a las supremas impresiones de la belleza" (HERRERO, 1930: 20).
} 


\subsubsection{Inicio de dos galerías de retratos: Presidentes y Profesores (1768-1821)}

Una lectura del primer inventario manuscrito de la Academia de San Carlos, realizado entre 1797 y 1830, parece transmitir una idea bastante clara: se estaba realizando una galería de retratos, en la cual los presidentes tenían un protagonismo especial. Según la noticia que se ofrece sobre algunos de estos retratos, es posible comprobar que fueron presentados como obras de recepción para obtener el título de académico de mérito: así consta de los del presidente Joaquín Obregón y Pareja, realizado por Vicente López y nombrado por la presentación de dicha obra académico de mérito en $1793^{365}$; del de Francisco Andrés de Azpiroz, realizado por José Camarón y Boronat en $1798^{366}$ en el momento en que el retratado era presidente, que valió al artista el mismo título, así como el del vicepresidente Antonio Pascual, pintado por Luis Planes y Domingo ${ }^{367}$ y el del consiliario Manuel Giner, por Vicente Velázquez ${ }^{368}$. En fecha más tardía se incorpora, sin que conste su encargo, el retrato del presidente Jorge Palacios, realizado por Vicente López ${ }^{369}$.

Junto a esta galería presidencial, que vincula estrechamente la historia de la institución con la jerarquía política y cultural de la sociedad valenciana del siglo XIX, las actas de las juntas ordinarias introducen la idea de una galería de profesores, que de manera paralela se vincula con la propia historia de la Academia, si bien presentan características propias tanto a nivel iconográfico como en sus usos y significados. Es preciso aclarar que esta segunda galería, destinada a subrayar el carácter profesional y la identidad artística de los encargados de la docencia académica, no tuvo un origen tan claro en cuanto a su función a pesar del desarrollo independiente que cobra durante el primer tercio del siglo XIX.

Como se ha podido comprobar respecto al ingreso de retratos de presidentes, 1798 es un año clave, también en el inicio de la galería de retratos de artistas. En este sentido, las dos primeras obras que ingresan en la Academia como retratos de profesores tienen un carácter especial al tratarse de los fundadores de la misma, Ignacio

\footnotetext{
365 "Dn Joaquín de Pareja y Obregón, corregidor dos veces de esta ciudad, y como tal Presidente de esta academia, pintado por Dn Vicente López, discípulo de la misma Academia, y su pensionado que ha sido en Madrid, y con motivo de haber presentado dho retrato se le creó Académico de mérito", ARABASC, Inventario manuscrito, 1797-1830; DÍEZ, 1999: 72.

366 "72. Un retrato de tres y cuatro palmos con marco dorado y remate de talla del Sor Dn Franco Andrés de Azpiroz actual Presidente, obra de Dn Manuel Camarón y Meliá, por la cual se le creó Académico de mérito en su clase de Pintura el año 1798", ARABASC, Inventario manuscrito, 1797-1830.

367 "73. Otro retrato en todo igual al antecedente qe lo es del Sor Dn Antonio Pasqual, actual VicePresidente como Consiliario mas antigo, obra de D: Luis Planes y Domingo, por la que se le creó en 1798 Académico de mérito en su clase", ARABASC, Inventario manuscrito, 1797-1830.

368 " 81 . Un cuadro de tres y cuatro palmos con marco cortado y remate de talla que representa el retrato del Sr Manuel Giner consiliario de la Academia por el qual fue creado Académico de Mérito Dn Vicente Velázquez cuyo asunto se le dio (ilegible) y creado académico en 28 sept. de dho año", ARABASC, Inventario manuscrito, 1797-1830.

369 "92. Un cuadro con marco dorado y remate igual a los compañeros retrato de Dn Jorge Palacios Presidente que fue de esta Academia pintado por Dn Vte López", ARABASC, Inventario manuscrito, 1797-1830.
} 
y José Vergara ${ }^{370}$. Al analizar estos retratos, David Gimilo (2003: 76) señaló la posibilidad de que hubiesen sido realizados con el objetivo expreso de iniciar una galería académica, al compartir dimensiones e iconografía. En efecto, ambos retratos, realizados por el pintor José Vergara, adoptan los convencionalismos retratísticos del siglo XVIII, presentándose de medio cuerpo con una cuidada y elegante vestimenta con chalecos bordados en oro, en un significativo segundo plano entre los útiles propios de su oficio, presentados en primer plano, y un fondo de cortinaje. Esta representación al uso del artista se vincula más con el carácter intelectual, tomando como modelo la iconografía del artista-filósofo, a través de la ausencia de interacción con sus herramientas de trabajo. De este modo, rehuyendo el carácter manual o mecánico de las artes, el escultor Ignacio Vergara reposa su mano izquierda sobre un busto clásico, alusivo a los modelos estéticos que debe seguir la creación artística, mientras con su diestra señala con un elocuente gesto sus útiles de trabajo: un lápiz de carbón, que subraya la importancia del dibujo en la formación artística, y una regla y un compás como instrumentos para alcanzar la medida y proporción, eludiendo cualquier referencia a herramientas de carácter mecánico en la escultura, como podrían haber sido mazas o cinceles. Por su parte, José Vergara se representa tras una mesa en la que reposan un lápiz, incidiendo en la importancia del dibujo, y la paleta y pinceles; no obstante, su lenguaje corporal es más hermético que en el retrato de su hermano, adoptando una pose amanerada que ha sido calificada de "símbolo de ostentación" (GIMILIO, 2005: 184), introduciendo la mano derecha en el chaleco y reposando la izquierda en la cadera. Ambos retratos fueron presentados a la Academia a modo de pruebas de gratitud y para memoria de los dos $\operatorname{artistas}^{371}$, y se colocaron con solemnidad en la Sala de Juntas.

También se destinó a la Sala de Juntas otro retrato de artista en el año 1798: el retrato del arquitecto Vicente Gascó, realizado por el pintor José Zapata y presentado por este último a la Academia en ese mismo año, en que es nombrado académico de mérito. En él se observa ya cierta evolución estilística; con una estética más sombría en la que predominan los tonos oscuros tanto en la vestimenta como en el fondo, Zapata presenta a Vicente Gascó sentado en el que podría ser uno de los codiciados asientos académicos, forrado en seda carmesí, con una expresión inquisitiva en su rostro mientras sostiene en su mano izquierda un compás y apoya con la derecha en su pierna un grueso volumen de De Architectura de Vitrubio, tal y como se lee en el tejuelo. El cambio respecto a los retratos de Ignacio y José Vergara es evidente no solo en el uso de los colores: se ha abandonado esa rigidez del retrato de pie y prácticamente frontal, apostando por una pose que pretende una mayor naturalidad en la presentación de los elementos -nuevamente de carácter intelectual- del oficio, e incluyendo cierta introspección psicológica en ese rostro que, presentado de tres cuartos y ligeramente inclinado, dirige una mirada sesgada al hipotético espectador. A pesar de que Gascó se jubiló en 1801, su vinculación profesional con la Academia fue especialmente estrecha; de este modo, la propia institución dejó constancia en 1804, al referir la muerte de

\footnotetext{
${ }^{370}$ En la Junta Pública de 6 de diciembre de 1798, el académico de honor Nicolás Rodríguez de Laso incluyó en su dilatado discurso una lista completa de las obras del escultor Ignacio Vergara, probablemente a modo de homenaje (GARÍN, 1945: 125).

${ }^{371}$ Inventario manuscrito 1797-1830, ARABASC (160)., no 75 y 76.
} 
Gascó, de la presencia de su retrato en la Sala de Juntas como objeto para mantener la memoria del arquitecto: "esta Academia no puede mostrarse insensible a la pérdida de uno de sus individuos que tanto la ilustró por espacio de 37 años. Pero él vive todavía y sería indeleble en ella su memoria aun cuando no tuviese la buena suerte de conservar su retrato en la Sala de Juntas, en cuya execución fue feliz el pincel de D. Joseph Zapata $^{372, "}$. Curiosamente, el fuerte impulso de la galería de retratos en 1798 encuentra, en el caso de los artistas, la incorporación simultánea de las tres nobles artes (escultura, pintura y arquitectura), en el espacio simbólico y administrativo de la corporación. Una de las dudas a la hora de analizar la galería de retratos de artistas en la Academia valenciana radica, precisamente, en los motivos que fundamentan la presencia de ciertos artistas; la vinculación de muchos de los representados con el cargo de director general es significativa, a pesar de la existencia de lapsos temporales. En efecto, tanto los hermanos Vergara como Vicente Gascó ostentaron dicho cargo en los primeros años de la Academia, y de los veinte artistas en quienes recayó la dirección general entre 1770 y 1840, doce de ellos verían su retrato incorporado en la galería. En la tabla siguiente [tabla 6] se incluye una relación de los directores generales y sus correspondientes retratos:

Director entre Retrato

\begin{tabular}{lll} 
Cristóbal Valero & $1770-1772$ & $\bullet$ \\
Ignacio Vergara & $1773-1775$ & $\bullet$ \\
Vicente Gascó & $1776-1778$ & $\bullet$ \\
José Vergara & $1779-1781$ & $\bullet$ \\
& $1787-1790$ & $\bullet$ \\
José Esteve & $1781-1784$ \\
Antonio Gilabert & $1784-1787$ \\
José Puchol & $1790-1793$ \\
Joaquín Martínez & $1793-1796$ \\
José Camarón & $1797-1799$ \\
Francisco Bru & $1800-1802$ \\
Vicente Marzo & $1802-1805$ \\
& $1812-1814$ \\
\hline Luis Antonio Planes & $1805-1808$ \\
& $1815-1817$ \\
Francisco Alberola & $1809-1812$ \\
\hline
\end{tabular}

${ }^{372}$ Inventario manuscrito 1797-1849, ARABASC (147), nº 74; RABASC, 1805: 12. 


$\begin{array}{ll}\text { José Gil } & 1817-1820 \\ \text { Manuel Blasco } & 1821-1823 \\ \text { Miguel Parra } & 1824-1826 \\ \text { Vicente López } & 1827-1829 \\ \text { Cristóbal Sales } & 1830-1832 \\ \text { Francisco Grau } & 1833-1835 \\ \text { José Cloostermans } & 1836-1839\end{array}$

Entre los artistas que ostentaron el cargo en el siglo XVIII y que no vieron su retrato incluido en la galería destacan el escultor José Puchol, cuya carrera en la Academia destaca por los progresivos méritos alcanzados dentro de esta (aprobado escultor en 1768, académico de mérito en 1769, teniente en 1771 y director en 1776), o el pintor y escultor Francisco Bru, de quien Alcahalí señala haber desempeñado todos los cargos (ALCAHALÍ, 1897: 77). La evolución de la colección de retratos de profesores indica que, junto al carácter honorífico de las imágenes para la memoria en el siglo XVIII, con su respectivo componente ritual como obras de recepción, en el siglo XIX evoluciona hacia una reflexión sobre la identidad corporativa.

Siguiendo la tradición inaugurada en 1798, un nuevo retrato acrecienta esta galería de profesores en 1805, con la donación realizada por Josefa Vilella, viuda del escultor José Esteve, director de dicha disciplina en la Academia de San Carlos entre 1781 y 1784 y fallecido en 1802. El acta relativa a la Junta Ordinaria de 2 de agosto de 1805 especifica que se trata de un retrato pintado por su primo Agustín Esteve "de tamaño igual a otros que tiene la Academia" (GARÍN, 1945: 152). Este dato llama ya la atención sobre la relevancia cobrada por la formación de su galería de retratos, como proyección de los méritos y medio de subrayar la importancia adquirida en el seno de la institución académica; el inventario manuscrito realizado entre 1797 y 1830 recoge este Retrato de José Esteve [fig. 116] señalando, como es habitual en la sucesión de retratos, esa uniformidad propia de una galería al tratarse de "Un retrato de tres y cuatro palmos igual a los demás de la sala con marco cortado y remate q. representa a Dn. Josef Esteve

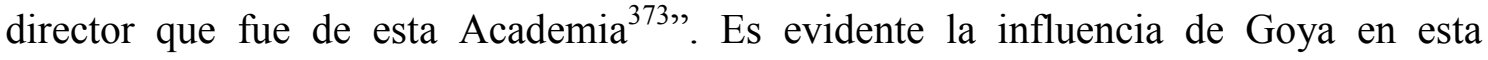
representación; en ella las alusiones a la profesión son abandonadas a favor del creciente protagonismo del mérito a través de la apariencia física: el rostro sereno, en actitud de cortés distracción de la cuartilla que sostiene en la mano, destaca enmarcado en la peluca sobre el fondo oscuro; el artista aparece sentado con una pierna cruzada sobre otra, en actitud relajada, siendo el único indicativo de su condición el uniforme de escultor de cámara que luce. Agustín Esteve se recrea en la plasmación de la vestimenta cuidando los detalles de los bordados en oro sobre la casaca oscura y el chaleco rojo. La obra aparece firmada, al estilo goyesco, en la cuartilla que sostiene el escultor, en la que

${ }^{373}$ Inventario manuscrito 1797-1830, ARABASC (160), $\mathrm{n}^{\mathrm{o}} 97$. 


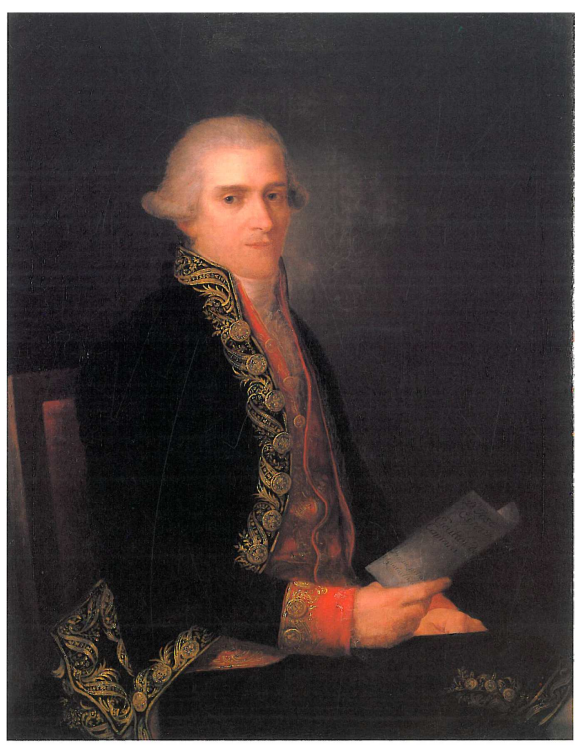

Fig. 116. Agustín Esteve, El escultor José Esteve. Museo de Bellas Artes de Valencia $\left(\mathrm{n}^{\circ}\right.$ inv. 1003).

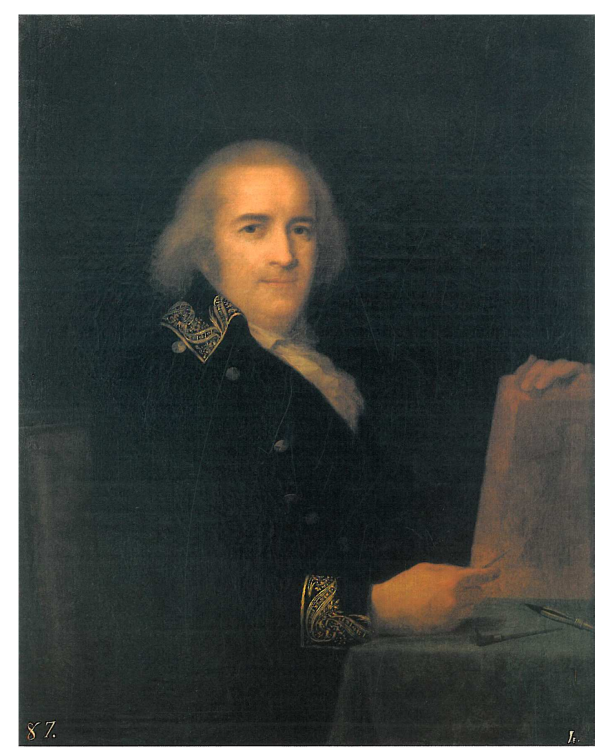

Fig. 117. Agustín Esteve, Retrato de Fernando Selma. Museo de Bellas Artes de Valencia $\left(\mathrm{n}^{\circ}\right.$ inv. 1001).

se puede leer "D. José Esteve escultor de cámara por su primo Agustín Esteve", lo que puede fechar el retrato en torno a 1790, año en que obtiene dicho título.

El grabado, una de las enseñanzas características de la Academia de San Carlos, estaría representado en fechas algo posteriores, mediante el Retrato del grabador Fernando Selma [fig. 117], realizado también por Agustín Esteve y donado por él a la Academia $^{374}$. El artista aparece representado sentado a la mesa de trabajo, vestido con uniforme de grabador de cámara; sostiene con la mano izquierda una de sus obras (el Retrato de Carlos IV [ESPINÓS, 2009:179]), mientras la derecha reposa sobre la mesa, sosteniendo un buril, junto a un lápiz de carbón. Según recogen las actas este retrato, que se ajusta a las medidas habituales, fue donado por el propio Agustín Esteve en 1800 como agradecimiento tras ser nombrado grabador de cámara y académico de mérito en la de San Carlos (El mon de Goya..., 1992: 60); la elección del retratado no es superflua, ya que, al igual que el autor, se trata de un artista valenciano que ha triunfado en Madrid y ha alcanzado el mérito de ser grabador de cámara.

Otro importante retrato de grabador será el de Manuel Monfort, realizado por Vicente López en fecha incierta, ya que tradicionalmente se había asumido que era obra de 1794, aunque José Luis Díez lo fechaba en 1802 debido al estilo personal ya desarrollado (DÍEZ, 1999: 159), y donado por su sobrino a la Academia en 1807. La obra, de carácter oficial, presenta ya al grabador vestido con uniforme de casaca azul oscura con bocamangas rojas y chaleco rojo, bordados ambos en oro. Aparece sentado ante un escritorio, sosteniendo con una mano un libro por cuyo tejuelo sabemos se trata de los estatutos de la Academia, mientras que con la mano izquierda sujeta un legajo de reales órdenes. El propio Díez señaló la posibilidad de que se tratase de un retrato póstumo, atendiendo a la inexpresividad del rostro y al aspecto mortuorio del rictus de nariz y labios. De este modo, atendiendo a la iconografía con que aparece representado,

\footnotetext{
${ }^{374}$ Libro de actas, 1801-1812, ARABASC; Inventario manuscrito 1797-1830, ARABASC (160), $\mathrm{n}^{\circ} 87$.
} 
cabría pensar en la posibilidad de que la pintura estuviese destinada desde un principio a formar parte de una galería de retratos, ya que se ajusta a las dimensiones de las obras pertenecientes a esta, aunque en el inventario manuscrito de 1797-1830 no aparece señalado como parte de la galería.

En 1817 ingresa en esta galería de profesores el Retrato del escultor Francisco Alberola, realizado por el pintor Vicente Rodes. A juzgar por las dimensiones, el cuadro no fue ideado originalmente para esta galería; tanto Salvador Aldana (2001: 128) como Ester Alba Pagán (ALBA, 2004: 1977) han relacionado la fecha de realización con la de su ingreso en la Academia, teniendo en cuenta que fue Vicente Rodes quien donó la obra, lo que le valió el nombramiento de académico supernumerario ese mismo año. Resulta curioso, no obstante, que esta obra no conste en los inventarios de la Academia hasta la tardía fecha de 1863. Rodes elige en este retrato continuar con una imagen tradicional del escultor como intelectual; así, Alberola, representado ya en su madurez, aparece vestido a la moda con una levita oscura de alto cuello, siendo su rostro de gesto severo el elemento principal al destacar sobre un fondo neutro, al igual que su mano derecha, que señala nuevamente un busto clásico apoyado en una mesa sobre la que reposa un lápiz.

\subsubsection{Miguel Parra y la continuación de la galería (1821-1850)}

El inicio del Trienio Liberal supone en el ámbito de la Academia de San Carlos un nuevo interés por el retrato vinculado a las nuevas corrientes estéticas y a una mayor profundidad psicológica. Frente a la tradición de la realización de un retrato como obra de recepción vinculada al título de académico de mérito, o a las donaciones particulares, la actividad en la doble galería de retratos es centralizada desde este momento por la propia Academia, que deriva sus encargos en el director de pintura Miguel Parra. En lo que respecta a la galería de retratos de presidentes, se percibe por parte del propio Parra un interés por vincularse al poder. Así, los libros de actas de la Academia recogen cómo en 1821 el propio Miguel Parra se dirige a la Junta en un oficio expresando el interés del pintor por presentar un retrato del primer presidente de la Academia, el Conde de Almodóvar, "con el objeto de que se sirviera el Cuerpo colocarlo en la colección que posee $^{375, ", ~ o b r a ~[f i g . ~ 118] ~ q u e ~ P a s c u a l ~ G a r n e i r a ~ f e c h a ~ e n ~ t o r n o ~ a ~} 1819$ (PASCUAL GARNEIRA, 1995: 82). No debió parecer desafortunada esta idea a la Academia, ya que meses más tarde el mismo pintor presentaba, esta vez encargado por la propia corporación, el retrato del presidente Francisco Plasencia ${ }^{376}$. Quedó establecido un tipo de retrato de medio cuerpo, con unas dimensiones fijas y presentado en marco dorado; a partir de este momento la responsabilidad de configurar la galería presidencial recayó en exclusividad en el director de pintura, de manera que Miguel Parra realizó en 1825 el

\footnotetext{
375 Junta Ordinaria de 13 de abril de 1821, Libro de Actas de la Real Academia de San Carlos, 18211827, ARABASC.

${ }^{376}$ Junta Ordinaria en 30 de septiembre de 1821, Libro de Actas de la Real Academia de San Carlos, 1821-1827, ARABASC.
} 
retrato del presidente Felipe de Saint-Marco ${ }^{377}$ y Luis Alejandro de Bassecourt ${ }^{378}$, en 1828 el de José María de Carvajal ${ }^{379}$ y el del también presidente José O’Donell ${ }^{380}$, y en 1830 los del presidente Francisco Longa y el vicepresidente Nicolás Mánez ${ }^{381}$. De todos ellos, llama la atención el de Francisco Longa y Anchía [fig. 119], al que Miguel Parra representa alejado del encorsetamiento del retrato oficial -vinculado a honores políticos y cargos militares-, y opta por presentarlo con el uniforme de la Academia, sosteniendo en su mano izquierda un tomo de la Práctica de la pintura de Palomino, y ejecutando con su diestra un dibujo al lápiz sobre la mesa en que apoya el brazo. La asimilación de Longa con la imagen oficial del artista académico es significativa en la producción de Parra, manifestando la influencia que la imagen corporativa de la Academia cobra en los años veinte del siglo XIX, y que se manifiesta especialmente en la progresiva incorporación del uniforme aprobado para la de San Carlos a partir de 1825.

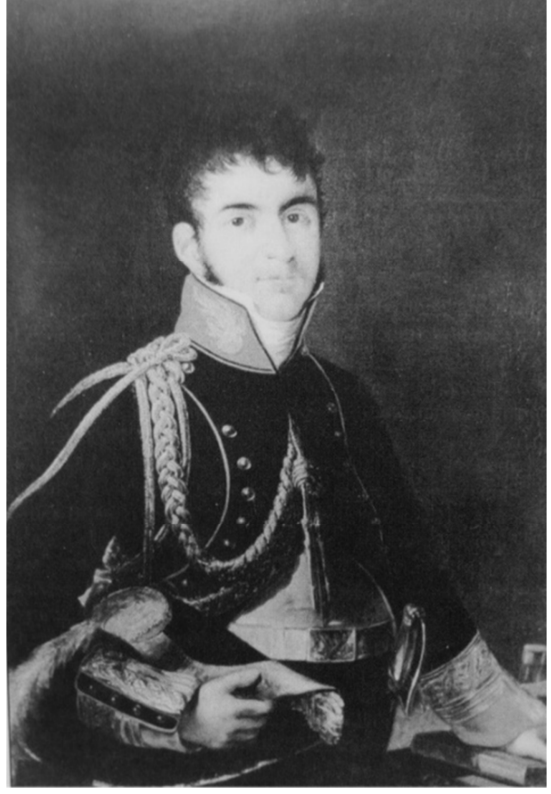

Fig. 118. Miguel Parra, Retrato del Conde de Almodóvar. Academia de San Carlos.

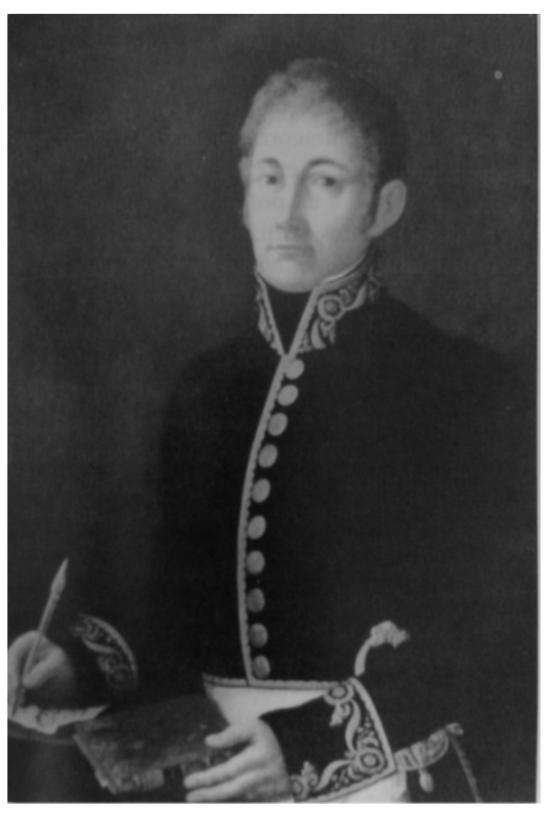

Fig. 119. Miguel Parra, Retrato de Francisco Longa y Anchía. Academia de San Carlos.

\footnotetext{
377 “180. El retrato del Exmo Señor Dn Felipe de Saint-Marco Presidente que fue de esta Rl Academia, de medio cuerpo con marco dorado, igual a los demás señores Presidentes, pintado por el Director General Dn Miguel Parra. Valencia 12 de febrero de 1825”, ARABASC, Inventario manuscrito, 1797-1830.

378 "181. El retrato del Exmo Sor Dn Luis Alejandro de Bassecourt Presidente que fue de esta R1 Academia, de medio cuerpo con marco dorado, igual a los de los demás señores Presidentes, pintado por el Director General Dn Miguel Parra", ARABASC, Inventario manuscrito, 1797-1830.

379 "Se vio y pareció muy bien por la similitud y pintado el Retrato del Exmo. Señor Don Josef María de Carvajal Presidente que fue de la $\mathrm{R}^{1}$ Academia, que por deliberación de la Junta Particular ha hecho el Director $\mathrm{D}^{\mathrm{n}}$ Miguel Parra para continuar la colección de retratos de los Sres. Presidentes", Junta Ordinaria de 13 de abril de 1828, Libro de actas de la Real Academia de San Carlos 1828-1845, ARABASC.

${ }^{380}$ El acta de la Junta Ordinaria celebrada el 7 de septiembre de 1828 daba cuenta de la colocación de dos retratos pintados por Miguel Parra, uno de Fernando VII " $\mathrm{q}^{\mathrm{e}}$ fue muy aplaudido por los SS. concurrentes; igualmente mereció la unánime aprobación el Retrato del Exmo. $\mathrm{S}^{\mathrm{r}} \mathrm{D}^{\mathrm{n}}$ Josef O-Donell, Presidente que fue de la $\mathrm{R}^{1}$ Academia, que se colocará siguiendo la serie de los SS. Presidentes", Libro de actas de la Real Academia de San Carlos, 1828-1845, ARABASC.

381 “196. Retrato del Exmo Sr Dn Fco Longa Presidente de esta $\mathrm{R}^{1} \mathrm{Acad}^{\mathrm{a}}$ con marco dorado de igual magnitud que los demás Sres Presidentes, pintado por el Director D ${ }^{\mathrm{n}}$ Miguel Parra" y "197. Retrato de medio cuerpo del Sr Dn Nicolás Maner, Vice-Presidente de la misma magnitud del anterior y executado por el expresado Dn Miguel Parra”, ARABASC, Inventario manuscrito, 1797-1830.
} 


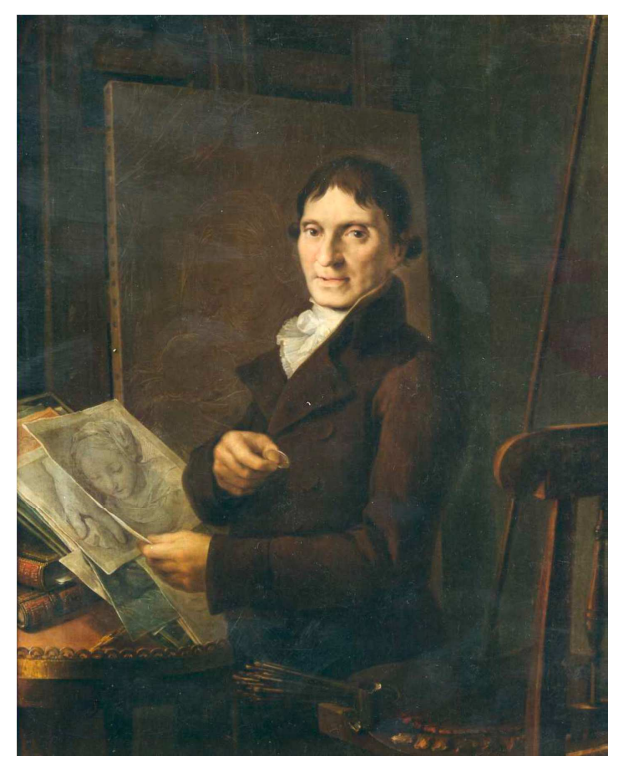

Fig. 120. Miguel Parra, El pintor Luis Antonio Planes. Museo de Bellas Artes de Valencia ( ${ }^{\circ}$ inv. 1012).

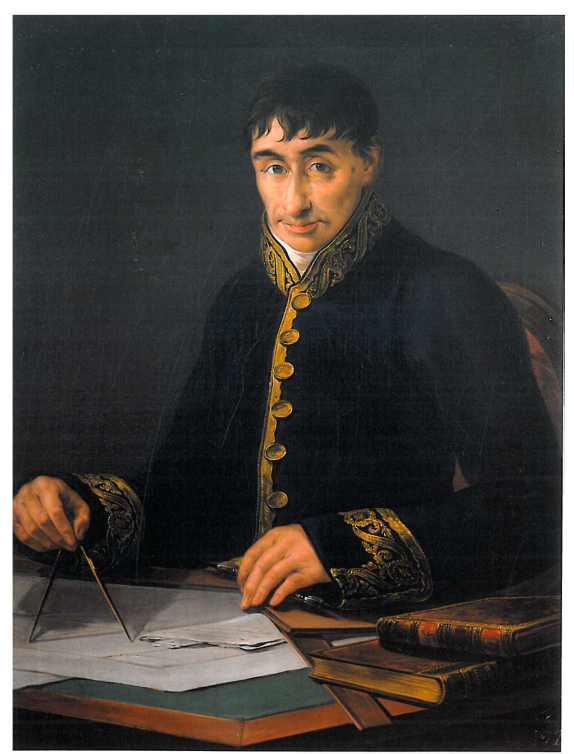

Fig. 121. Mguel Parra, El arquitecto Vicente Marzo. Museo de Bellas Artes de Valencia $\left(\mathrm{n}^{\circ}\right.$ inv. 1013).

La continuación de la galería de profesores también alcanza un desarrollo notable con la actividad de Miguel Parra. Tras el fallecimiento de Luis Antonio Planes, acontecido en 1821, su sobrino Fernando Ximeno donó a la Academia una colección de dibujos del pintor, que fue aceptada en Junta Ordinaria de 13 de enero de 1822 esta decidió aceptar dicha colección. Agradecida, la Academia aprobó además costear la realización "del retrato de dicho Profesor y se coloque en la Sala de Juntas ${ }^{382,}$, y designó para ello al director de pintura Miguel Parra, con el objetivo "de manifestar a $\mathrm{D}^{\mathrm{n}}$ Fernando Ximeno así el debido aprecio de su generosidad, como la digna memoria" de Luis Antonio Planes.

Los resultados no se hicieron esperar, ya que en la junta de 3 de marzo de 1822 se presentó el retrato [fig. 120] "cuya obra mereció la aprobación de todos los señores

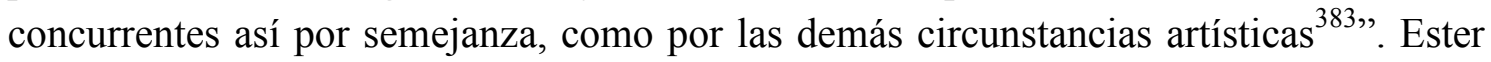
Alba Pagán (2004: 1760 y 1793) ha señalado ese vínculo simbólico entre discípulo y maestro al haber ocupado Miguel Parra la vacante como director de pintura dejada tras el fallecimiento de Luis Antonio Planes. Al tratarse de un retrato póstumo, Parra lo habría realizado bien de memoria, bien basándose en algún retrato o dibujo existente; no obstante, se aleja de la rigidez académica de los retratos realizados a principios de siglo, y se aproxima a una imagen de artista trabajador. De este modo, aparece retratado de medio cuerpo en su espacio de trabajo - probablemente su estudio o el aula de la Academia-, en un descanso en la revisión de estampas o dibujos, como manifiesta la lente que ha bajado del rostro, junto a un lienzo esbozado. En primer plano, reposando sobre una silla, se encuentran una paleta con los colores dispuestos y los pinceles. Un análisis detenido de este retrato plantea la duda sobre las implicaciones iconográficas de esta imagen del artista, ya que podría tratarse, como indica Ester Alba Pagán, de una

\footnotetext{
${ }^{382}$ Junta Ordinaria de 13 de enero de 1822, Libro de actas 1821-1827, ARABASC.

383 Junta Ordinaria de 3 de marzo de 1822, Libro de actas 1821-1827, ARABASC.
} 
representación del artista trabajador y del propio proceso artístico, en la que los dibujos que sostiene serían los bocetos preparatorios para el lienzo que está realizando. No obstante, una hipótesis paralela podría indicar que se trata de una representación del artista como profesor o docente académico, ya que además del dibujo que sostiene, que se corresponde con el esbozo en el lienzo, los que se pueden observar apoyados en la carpeta se corresponden con estudios de manos y rostros, lo que podría indicar que se encuentra revisando los trabajos de los alumnos de la clase de principios. Además, junto a ellos se pueden ver dos libros, en cuyos tejuelos se lee "Tratado de Escultura" y "Práctica de la Pintura", aludiendo al carácter más teórico de las artes y de su enseñanza.

En 1828 se incorporaba el Retrato del arquitecto Vicente Marzo [fig. 121], realizado también por Miguel Parra y donado por el hijo del retratado, quien al hacer entrega de la obra indicaba ya directamente su deseo de que "se colocase en la

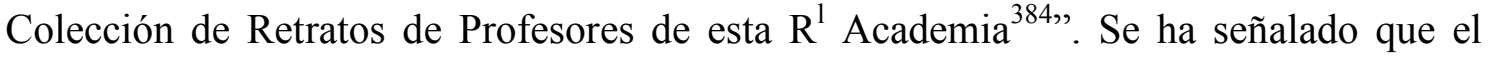
retrato pudo haber sido realizado en torno a 1820 (ALBA, 2004:1791-1792; L'Acadèmia de Santa Bárbara..., 2004: 354), momento en que el representado contaría unos cincuenta años, lo que parece encajar con la fisionomía. Está retratado de medio cuerpo, sentado a su mesa de trabajo y ataviado con el uniforme de la Academia, lo que podría posponer la realización del retrato a 1825; al igual que sucedía anteriormente, Miguel Parra ha representado al arquitecto sorprendido en su trabajo, levantando hacia el espectador la mirada del plano sobre el que realiza mediciones con un compás. Con su mano izquierda, en la que sostiene un lápiz, señala sutilmente una cuartilla cuya escritura nos resulta ilegible, si bien podría tratarse de un breve texto identificando al arquitecto si tenemos en cuenta la costumbre de introducir los datos y méritos del retratado en otros retratos académicos. En el extremo de la mesa reposan, uno sobre otro, dos volúmenes, probablemente relacionados con las matemáticas y la arquitectura. El uso de la iconografía del artista como académico, así como las dimensiones de la obra, señalan que el retrato, a pesar de estar realizado con anterioridad y de haberse conservado hasta 1828 en propiedad de la familia para uso privado, podría haber sido concebido con destino a esta "colección de retratos de profesores" con la que el hijo de Vicente Marzo parecía familiarizado.

Las noticias sobre el Retrato de Benito Espinós [fig. 122], realizado por José Romá, son menos claras, aunque no deja de obedecer a ese carácter de homenaje del discípulo al maestro que ya se observaba en el retrato de Luis Antonio Planes, y que será habitual en el período de 1825 a 1835. La trayectoria de José Romá en la Academia de San Carlos, en la que fue nombrado académico de mérito por la pintura de flores y ornato en 1817 , y por la pintura en 1826, culmina con el desempeño del cargo de director de pintura de flores y ornato en 1828. Dicha enseñanza había sido instaurada por Real Orden de Carlos III de 30 de enero de 1784, destinada al aprendizaje de ornato destinado a la industria sedera. La plaza de director fue adjudicada a Benito Espinós "por estar S. M. informado de su particular mérito y de que desempeñará la confianza

${ }^{384}$ Junta Ordinaria de 13 de abril de 1828, Libro de actas 1828-1845, ARABASC. 
que hace de su habilidad, notorio celo y aplicación" (GARÍN, 1945: 87). La misma ordenanza señalaba que el cargo consistía exclusivamente en la enseñanza de este ramo, debiendo ser desempeñada siempre que fuera posible por un pintor; para evitar tensiones o desigualdades entre artistas académicos, Carlos III se cuidó en señalar que "este director será, y se entenderá de la clase de pintura, y su sueldo, voto, asiento y demás prerrogativas serán en todo iguales a las que gozan los demás directores de su clase" (GARÍN, 1945: 87). Puede entenderse el retrato de Espinós como fruto de esta igualdad en la consideración dentro de la esfera académica, además de como homenaje individual y del posible carácter de herencia simbólica. El retratado había desempeñado este cargo hasta 1815, cuando fue jubilado por enfermedad, falleciendo tres años más tarde. Estos rasgos de la enfermedad quedan plasmados en el retrato, donde el pintor aparece sosteniendo su paleta y un pincel, junto a un cuadro de flores, revelando la mitad derecha de su rostro un estado de parálisis, por lo que se ha relacionado la fecha de realización hacia 1815 y la de ingreso en la Academia en 1826, año en que fue nombrado académico de mérito en la especialidad de pintura. No obstante, no se han encontrado las pruebas documentales respecto a estas fechas y la pintura no aparece incluida en los inventarios hasta 1867, por lo que cabría pensar que tal vez no hubiese formado parte de esta galería de profesores. Algo similar pudo haber ocurrido con otro retrato de un profesor (retrato de José Zapata, por José Dolz ${ }^{385}$ ) del que solo tenemos noticia, presentado en la Junta Ordinaria de 7 de noviembre de 1830 junto a un cuadro de temática religiosa, para obtener el título de académico supernumerario ${ }^{386}$. Dicha obra tampoco consta en los inventarios, y cabe suponer que se trataba de un retrato directo del pintor Zapata, que en la fecha de realización del retrato aún vivía, ya que en el memorial dirigido a la Academia se especificaba haberse pintado en la propia ciudad de Valencia.

En 1830 se incorpora a la galería un retrato pintado, precisamente, por José Zapata. Se trata del realizado al arquitecto Cristóbal Sales [fig. 123], probablemente con el motivo de haber sido nombrado académico de mérito de la Real Academia de San Luis de Zaragoza. En la Junta Ordinaria de 26 de septiembre de 1830 se da noticia de dos retratos de Cristóbal Sales, uno realizado por Miguel Parra con destino a la Academia de San Luis $^{387}$, y otro, cuya autoría no se cita en el acta ni se especifica en los

\footnotetext{
${ }^{385}$ En las actas manuscritas este nombre resulta difícilmente legible como Josef Dolz, y podría tratarse, con algunas reservas, del mismo José Dolz que cita en su tesis doctoral Ester Alba Pagán, ya que menciona las dos obras (Retrato de José Zapata y La Presentación de Jesús en el templo) a que se refiere el acta de la junta.

386 "Se dio cuenta de un memorial de Josef Dolz a fin de acreditar su aplicación acompañaba con cuadros pintados al óleo de la presentación de Jesús en el templo y a más el retrato que ha hecho en esta ciudad de su maestro $\mathrm{D}^{\mathrm{n}}$ Josef Zapata, esperando de la $\mathrm{R}^{1}$ Academia se sirviera (...) concederle el título de Académico supernumerario", Junta Ordinaria de 7 de noviembre de 1830, Libro de actas 1828-1845, ARABASC.

387 "Habiéndose dado cuenta de un oficio del Director $\mathrm{D}^{\mathrm{n}}$ Cristóbal Sales participando haberle nombrado Académico de mérito de la $\mathrm{R}^{1}$ Academia de $\mathrm{S}^{\mathrm{n}}$ Luis, y que se pintase su retrato para colocarlo en una Sala (...) Seguidamente se vio el retrato mencionado, que por encargo de la citada Academia de $\mathrm{S}^{\mathrm{n}}$ Luis ha pintado el Director de esta de $\mathrm{S}^{\mathrm{n}}$ Carlos $\mathrm{D}^{\mathrm{n}}$ Miguel Parra". Junta Ordinaria de 26 de septiembre de 1830, Libro de actas 1828-1845, ARABASC.
} 
inventarios hasta 1867 (RABASC, 1867: 53) ${ }^{388}$, donado por la esposa e hijos del propio Sales con la intención de que se destinase a la galería de profesores ${ }^{389}$. Ester Alba Pagán (ALBA, 2004: 2159) ha señalado que la obra de la Academia de San Carlos, actualmente conservada en el Museo de Bellas Artes de Valencia, es en realidad la realizada por Miguel Parra, sin ofrecer un razonamiento que respalde tal afirmación, ni una explicación sobre el paradero de este segundo retrato donado por la familia. Sabemos que el encargo del retrato de Cristóbal Sales a la Academia de San Carlos, tal y como recoge Jesús Pedro Llorente (1991: 409), fue una idea del pintor Narciso Lalana, precisando que debía ser un retrato de medio cuerpo pintado al óleo, y que Miguel Parra, tras el envío de la obra, solicitó por él 1500 reales de vellón que no parece constasen en ningún acuerdo y que la Academia de San Luis acordó pagar cuando tuviese fondos. Según la información recogida por Jesús Pedro Llorente de este acuerdo de pago, en junta de 5 septiembre de 1830, este incluía el retrato, así como su conducción y embalaje. El hecho de que el retrato realizado por Miguel Parra fuese presentado en la junta de 26 de septiembre de ese año en la Academia de San Carlos parece indicar que aún no había sido enviado a la de San Luis, aunque desconocemos si realmente llegó a producirse posteriormente.

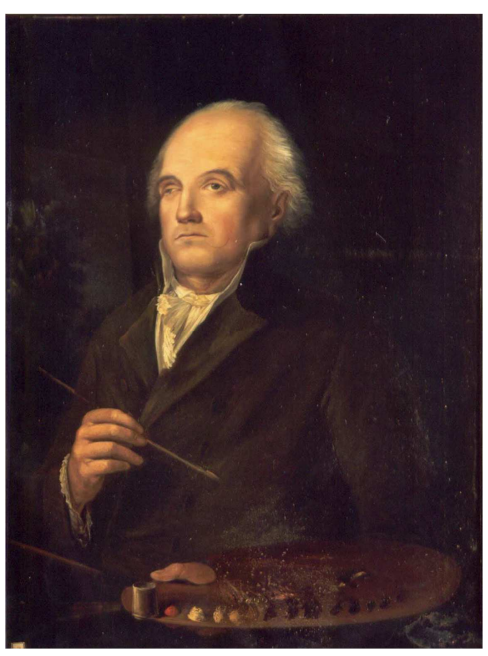

Fig. 122. José Romá, Retrato de Benito Espinós. Museo de Bellas Artes de Valencia ( ${ }^{\circ}$ inv. 1014).

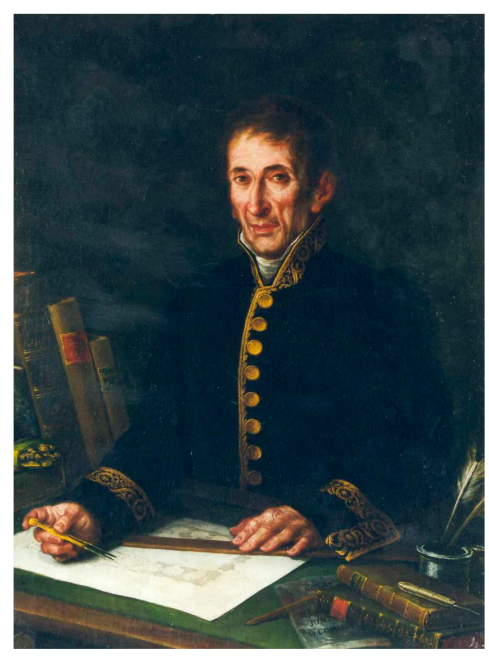

Fig. 123. José Zapata, El arquitecto Cristóbal Sales. Museo de Bellas Artes de Valencia ( $n^{\circ}$ inv. 1000).

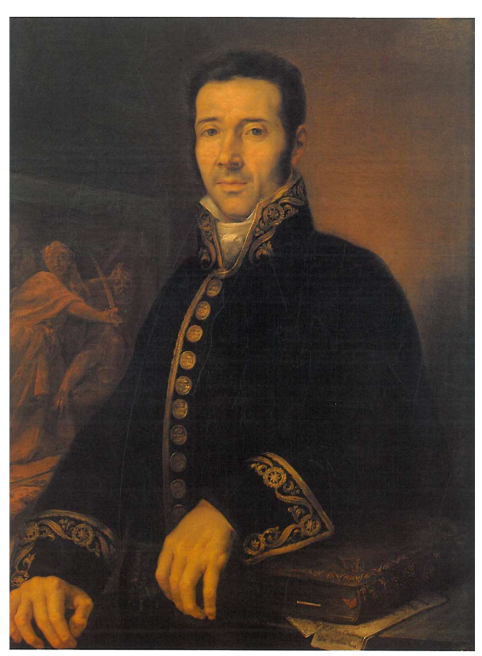

Fig. 124. Vicente Castelló, El escultor José Cloosterman. Museo de Bellas Artes de Valencia ( $\mathrm{n}^{\circ}$ inv. 1017).

El Retrato del escultor José Cloosterman [fig. 124] también responde a esa identidad corporativa, ya que aparece representado con el uniforme académico, de medio cuerpo, con el brazo izquierdo en un grueso libro que descansa sobre una mesa. Según las formas habituales de representación de los escultores, aparece al fondo una de sus obras. La identificación del retratado es posible gracias a la inscripción añadida en

\footnotetext{
388 Probablemente sea de esta fuente de donde se toma como referencia para los posteriores catálogos (GARÍN, 1955: n 1000). Las noticias biográficas sobre José Zapata que dan cuenta de esta obra como suya (OSSORIO, 1975:797; ALCAHALÍ, 1897: 332).

389 Sobre esto, queda recogido en la misma acta que la esposa e hijos de Cristóbal Sales manifestaron “deseaban se colocase entre los retratos de los Profesores el del dicho esposo y padre, de que hacían donativo a favor de la Academia. La Junta lo aceptó con complacencia, atendiendo al mérito del (...) Director, acordando se les diesen las debidas gracias", Junta Ordinaria de 26 de septiembre de 1830, Libro de actas 1828-1845, ARABASC.
} 
la propia obra, en una cuartilla ubicada en la mesa, donde, como ya señaló Alfonso Pérez Sánchez (1990: 19), puede leerse " $\mathrm{S}^{\mathrm{r}} \mathrm{D}^{\mathrm{n}}$ José Clostermans Dir" de Escultura". Esta información ha llevado igualmente a fechar la obra en 1830, momento en que sucede a Felipe Andreu como director de escultura (ALBA, 2004: 737-738), disciplina a la que pertenece el libro que le acompaña. Se observa en este retrato de Clostermans, a pesar de la rigidez propia de un retrato de carácter institucional, una mayor aproximación hacia planteamientos románticos, no solo en la evolución de la moda como puede verse en el uso de las patillas o la cerrada corbata blanca-, sino también y especialmente en la obra que destaca en segundo plano, que por su temática (Judith cortando la cabeza de Holofernes) y dinamismo se aleja de las representaciones habituales de bustos clásicos.

Otro de los retratos que ingresarán en esta galería de profesores es el realizado por José Navarro del pintor José Camarón Boronat, que había sido su maestro entre 1796 y 1799 y que había fallecido en 1803. Navarro debió buscar retratos o grabados en los que basar su obra, como evidencia la vestimenta propia de principios de siglo y el aparente estatismo del rostro, ya que debió realizarla con posterioridad a 1830. En Junta Ordinaria de 5 de noviembre de 1837 se leía "un memorial de D. José Navarro, Académico de mérito en la clase de flores y ornatos (...) al cual acompañó un retrato pintado al óleo de las dimensiones de los demás profesores que existen colocados en esta Academia y es Don José Camarón Boronat Director de Pintura de la misma ${ }^{390,}$, solicitando que por esa obra le fuese concedido el título de académico de mérito en pintura. Navarro se aleja de la forma de representación habitual del artista, bien con sus útiles de trabajo, bien como académico, ya que en este retrato de medio cuerpo busca más un reflejo de la personalidad; por este motivo, otorga especial interés al rostro y a las manos, con una una moneda en una de ellas ${ }^{391}$.

\subsubsection{La galería de retratos en el último tercio del siglo XIX}

El abandono en que cae la galería de retratos tras 1849 es notorio. La causa, que no aparece explícitamente reflejada en la historia de la institución, debe buscarse en la transformación de las enseñanzas artísticas y de la propia Academia a partir de este año. En el último tercio del siglo XIX la galería de presidentes continúa su ampliación, con cambios estilísticos notables, como es el uso de un formato de busto prolongado, en un marco dorado ovalado que permite una mayor aproximación a los representados; del mismo modo, el realismo en la plasmación de las facciones otorga mayor profundidad psicológica a una serie de presidentes que, salvo contadas excepciones, aparecen caracterizados de manera uniforme con elegante frac, camisa blanca, y, al cuello, la medalla de la corporación académica de San Carlos, nuevo rasgo corporativo cuyo uso fue concedido por Isabel II en 1854.

Ferrán Salvador (1963, 45-63), en su artículo sobre las galerías presidenciales valencianas, recorre esta última fase de configuración de la galería de retratos de la Academia de San Carlos posterior a la reforma de 1849, al igual que Felipe Garín

\footnotetext{
${ }^{390}$ Junta Ordinaria de 5 de noviembre de 1837, Libro de actas 1828-1845, ARABASC.

${ }^{391}$ Ester Alba Pagán (2004: 1549) considera que sostiene un reloj de bolsillo.
} 
(1955) en su catálogo del Museo de Bellas Artes de. El primer presiente de esta nueva etapa académica, José Joaquín Agulló Ramón de Sentís, conde de Ripalda, ostentó su cargo desde 1850 hasta 1868; no obstante, su retrato, realizado por Salustiano Asenjo, no ingresó en la Academia hasta 1898, veintiún años después de su fallecimiento. Como una de las excepciones antes mencionadas, aparece representado haciendo gala de otros atributos como el uniforme de la Real Maestranza de Caballería de Valencia, al que se superpone la medalla de la Academia, tal y como sucedería en el retrato de otro presidente procedente de la aristocracia, don Miguel Galiano y Talens, marqués de Montortal y presidente entre 1885 y 1895, también retratado, en esta ocasión por Carlos Giner, con uniforme de maestrante y medalla de académico. Otro miembro de la nobleza ocupó la presidencia de la Academia en 1868 (a pesar de renunciar al cargo debido a la Revolución ese mismo año), don Vicente Noguera y Sotolongo, marqués de Cáceres, quien, al igual que su predecesor, aparece retratado con indicativos de su dignidad aristocrática, siendo esta vez las bandas superpuestas de las órdenes de Carlos III e Isabel la Católica, con sus correspondientes cruces. Vicente Borrás, autor del retrato, lo presentó no obstante con uniforme y medalla académica. El catedrático Vicente Boix, presidente de la Academia de San Carlos entre 1874 y 1880, sí que aparece retratado, en esta ocasión por el pintor José Bergón, siguiendo la iconografía anteriormente citada, con la peculiaridad de no lucir la medalla de académico. Gonzalo Salvá presenta a Juan Dorda Villarroya, presidente entre 1880 y 1885, en el retrato que le realiza con frac, pajarita y medalla académica. El último presidente de la corporación en el siglo XIX fue el marqués de Tremolar, en el intervalo de 1895 a 1900, si bien su retrato no fue realizado hasta 1907 por Julio Cebrián Mezquita. No obstante, la serie presidencial se prolonga prácticamente sin alteraciones hasta los años treinta del siglo XX, manteniendo una iconografía decimonónica con los presidentes Eduardo Attard retrato realizado en 1915 por Eduardo Soler-, el arquitecto Joaquín María Belda, por Carlos Giner, o incluso en el retrato de Juan Dorda y Morera, que alcanza un aspecto especialmente anacrónico, en el que aparece retratado por Julio Peris Brell con traje de académico. Es quizás el retrato de José Benlliure el que aporta una ruptura con los modelos anteriores: el pintor, presidente de la Academia entre 1930 y 1937, aparece retratado por su hermano, Juan Antonio, de medio cuerpo, con un gesto adusto, vestido con sencilla chaqueta, sosteniendo en su mano izquierda la paleta y los pinceles. A pesar de mantener las dimensiones propias de los demás retratos de la galería, el cuadro fue pintado en 1928, con anterioridad a su nombramiento, y no ingresó en la Academia hasta 1950.

Una consulta de los inventarios y de los fondos del Museo de Bellas Artes de la Academia nos informa de que, a pesar de que se dio cierta continuidad a la galería de presidentes hasta el siglo $\mathrm{XX}$, la de retratos de profesores no tuvo la misma suerte, ya que fue abandonada a partir de la reforma de las enseñanzas artísticas de 1849 , lo que corresponde a una invisibilización del artista en el ámbito académico que traduce una estructura más jerarquizada, en la que prima el papel representativo o burocrático de la presidencia y un código masculino asociado con la élite social. En fecha desconocida se incorpora a la galería el retrato de don Juan Plaza, artista y matemático, realizado por 
José Zapata, en el que aparece representado con uniforme académico, sentado en un escritorio, mientras hojea un libro o un cuaderno de dibujos. En la mesa descansa otro libro, unas láminas y una pluma. Se ha señalado el avance técnico de esta obra como una influencia de la pintura de Vicente López, ya que está trabajado con largas pinceladas que construyen los volúmenes mediante manchas de color (ALBA, 2004: 2166; ALDANA FERNÁNDEZ, 1960: 69-83). No aparece mencionado en los inventarios de la Academia de 1797, 1842 o 1867, por lo que es posible que el retrato, cuyas características y dimensiones concuerdan con las del resto de obras, fuese pensado para esta galería de profesores y no llegase a incorporarse a esta hasta fecha muy tardía.

No es hasta finales del siglo XIX y especialmente a comienzos del XX cuando la Academia vuelve a interesarse por los retratos de artistas, al ocuparse de la adquisición de efigies de los vinculados con la institución, aunque realizados al margen de este carácter de galería institucional, y por dar visibilidad tanto a estos como a los recibidos por donaciones particulares, que pasaron a formar parte de los fondos del museo con una intención inicial de iconografía valenciana que no llegó a consolidarse. Prueba de ello es el acta de donación de dos retratos en 1926, con la mediación del consiliario José Benlliure -familiarizado con galerías de retratos existentes en corporaciones nacionales e internacionales, como la Academia de San Lucas o la Accademia Properziana ${ }^{392}$, en la que se especifica que el ingreso en el museo del Retrato de Constantino Gómez y del Autorretrato de Vicente March se debe al interés por "aumentar la colección de autorretratos y retratos de artistas valencianos ${ }^{393}$ ". Así, en los años veinte del siglo pasado ingresaron también el Retrato del pintor Ramón Stolz Segui ${ }^{394}$, el Autorretrato de Bartolomé Mongrell ${ }^{395}$, el Retrato de Juan Peiró ${ }^{396}$ y el Autorretrato de Joaquín Agrasot $^{397}$, ampliándose la colección con el Autorretrato de Cecilio Pla ${ }^{398}$ en 1930, el Autorretrato de Ignacio Pinazo ${ }^{399}$ en 1935 o el de Javier Juste ${ }^{400}$ en 1940.

\footnotetext{
${ }^{392}$ En junio de 1906 el secretario del Consejo de la Academia de San Luca escribía a José Benlliure solicitando su retrato para la galería de la misma, donación que no se verificó hasta 1912 antes del regreso del pintor a España [Archivo Casa-Museo José Benlliure, C20Acc017 y C20Acc028]. Por otra parte, la Accademia Properziana le nombró socio académico en agosto de 1893 [Archivo Casa-Museo José Benlliure, C20Acc029], pidiéndole un retrato fotográfico para la colección de retratos de socios [Archivo Casa-Museo José Benlliure, C20Acc030], a lo que Benlliure correspondió remitiendo cuatro fotografías de sus obras.

${ }^{393}$ Acta de donación, ARABASC, legajo 166, julio de1926, $\mathrm{n}^{\circ} 32$.

${ }^{394}$ Realizado por Juan José Zapater Rodríguez, ingresa por donación familiar en 1921. Museo de Bellas Artes de Valencia ( $\mathrm{n}^{\circ}$ inv. 1271).

${ }^{395}$ Donación a la Academia por el autor en 1921. Museo de Bellas Artes de Valencia (n ${ }^{\circ}$ inv. 1303).

${ }^{396}$ Realizado por Francisco Domingo, donado a la Academia en 1926 por la viuda del hijo del retratado. Museo de Bellas Artes de Valencia ( $\mathrm{n}^{\circ}$ inv. 59).

${ }^{397}$ Realizado en 1887 y donado en 1919 por su viuda e hijo. Museo de Bellas Artes de Valencia $\left(\mathrm{n}^{\mathrm{o}}\right.$ inv. 1353).

${ }^{398}$ Donación del autor a la Academia en 1930. Museo de Bellas Artes de Valencia ( $\mathrm{n}^{\circ}$ inv. 39).

399 Donación por parte de los hijos del autor a la Academia de San Carlos. Museo de Bellas Artes de Valencia ( $\mathrm{n}^{\circ}$ inv. 727.)

${ }^{400}$ Donación a la Academia en 1941. Museo de Bellas Artes de Valencia (n ${ }^{\circ}$ inv. 1311).
} 


\subsubsection{Los espacios de la galería de retratos}

El estudio de la galería de la Academia de Bellas Artes de San Carlos quedaría incompleto si no realizásemos un breve recorrido por el movimiento de estas obras y la importancia que tuvieron como imágenes corporativas. El hecho de que la galería se iniciase en la Sala de Juntas es de por sí muy significativo, ya que evidencia un carácter exclusivo y privado, al que únicamente tenían acceso los propios miembros de la Academia. Felipe Garín señalaba, al referirse a de los retratos de los hermanos Vergara, que figuraron "en los estrados de San Carlos, al nivel mismo que el de Carlos III, al que solo ceden en la preferencia de presidirles" (GARÍN, 1945: 120). De esta manera, como sucede con otros espacios académicos, profesionales y de marcado carácter masculino (pues en el caso de la de San Carlos es reseñable la completa ausencia de retratos de académicas en los inventarios), la historia de la institución queda reflejada en la colocación de las efigies de sus miembros más significativos, por lo que todo acto institucional fue presidido por los retratos de los monarcas, de los presidentes de la Academia y de algunos de sus más notables profesores, confiriendo una identidad propia a un espacio de reunión. La revisión de las actas nos permite comprobar cómo el acto de presentación y colgado de un retrato de un académico estaba revestido de una especial solemnidad, debido en parte a que la mayor parte de estos retratos se incorporó a título póstumo, lo que motivó que quedasen imagen para el recuerdo dentro la corporación de la que fueron miembros activos. En 1808 la colección de retratos de la Sala de Juntas se veía aumentada con el retrato de Fernando VII pintado por Luis Planes $^{401}$, y permanecía inalterable la colocación de los mismos en 1814 , como se desprende de las noticias de la visita de Fernando VII y de los infantes don Carlos y don Antonio.

Es preciso, no obstante, señalar tres movimientos importantes de estas obras en el siglo XIX fuera de la Sala de Juntas, que dotan de significado tanto a los nuevos espacios como a los propios retratos. Los dos primeros se corresponden con una interrelación entre la Academia y el espacio público valenciano durante la celebración de los festejos regios de 1814, relacionados con la visita de Fernando VII, y de 1833, con motivo del nombramiento como heredera de Isabel II, los días 24 y 26 de julio de 1833. Respecto al primero, podemos señalar cómo la Academia de San Carlos optó por trasladar todos o la mayor parte de los retratos de artista existentes en la corporación a la propia fachada, tal y como recoge el cronista Juan Facundo Sidro Vilarroig (1814:46): "a la parte de fuera de la puerta sobre hermosos tapices se hacía ostentación de los retratos de los célebres artistas y profesores valencianos que han ilustrado en todos tiempos las nobles artes, y señaladamente los que pusieron en planta esta Real Academia”. En lo concerniente a la segunda, ya Ester Alba Pagán (2004: 388-390), tomando como referencia las descripciones del ornato de los distintos edificios públicos

\footnotetext{
401 "La Real Academia podría tratar de colocar en la Sala de Juntas el retrato de nuestro augusto soberano el Sr. D. Fernando VII; esta justa propuesta fue unánimemente aprobada, y el Director General D. Luis Antonio Planes ofreció pintarle gratuitamente, cuyo ofrecimiento fue admitido con estimación". Junta de 14 de agosto de 1808 (GARÍN, 1945: 161).
} 
reseñados en el Diario de Valencia ${ }^{402}$, realizó una breve síntesis de la decoración que la Academia organizó en su fachada, en la que los retratos cobraron una especial importancia. La fachada de la sede académica, ubicada en las proximidades de la Universidad Literaria, fue decorada con sedas y damascos, con un pabellón central de raso en cuyo interior se desplegó la galería de retratos reales, cuyo centro era ocupado por Fernando VII, flanqueado por Fernando VI, María Bárbara de Portugal, Carlos III y Carlos IV. Bajo estos retratos se situó un óvalo con las armas de la Casa Real y los atributos de las bellas artes, a cuyos lados figuraban los retratos de los fundadores de la Academia: Ignacio y José Vergara. El resto de la fachada, fuera de este pabellón honorífico, se decoró precisamente con obras procedentes de la galería de retratos, colocados según un orden jerárquico: una hilera superior mostraba a los presidentes y académicos de honor de San Carlos, manifestando de este modo la relación entre la Academia y la ciudad, que constituía la principal patrocinadora de la corporación; bajo ellos aparecían distribuidos los retratos de los profesores de la Academia: Cristóbal Valero, Luis Antonio Planes, José Esteve, Vicente Gascó, Manuel Monfort y Fernando Selma, junto al retrato de Mariano Ferrer realizado por Goya. Por debajo de esta galería aparecían retratos de valencianos ilustres. Se trataba de este modo de trazar una historia de la corporación desde sus orígenes, en la que quedaba patente la supeditación a la protección real, pero en la que también se subrayaba la importancia de sus miembros a través de las dos galerías diferenciadas de presidentes y profesores. De este modo, la galería de retratos entraba en diálogo con la ciudad a través de un discurso que combinaba la ostentación propia de una corporación de carácter restringido y la historia cultural valenciana, de la que la institución se declaraba guardiana y protectora, lo que elevaba socialmente a sus miembros -especialmente a los contemporáneos mediante la exaltación de sus antepasados simbólicos- ante la mirada de los valencianos.

Otro movimiento de estas galerías de retratos puede rastrearse posteriormente, con un carácter temporal más estable al tratarse de una redistribución de los retratos dentro del propio edificio de la Academia. Los motivos para esta nueva colocación pueden encontrarse en el ingreso masivo de obras producido en la Academia tras la desamortización de Mendizábal, ya que esta nueva ubicación de las colecciones aparece reflejada en el inventario de 1842 y no vuelve a observarse en los posteriores. En este momento, los retratos de presidentes aparecen ubicados en el recibidor de la Academia, de manera que ofrecían una imagen institucional del poder civil a todo aquel que accediese al edificio. Es posible que en 1850, tras el cambio de local de la Academia ("Valencia", 1850: 2) y el acondicionamiento del antiguo convento del Carmen como museo provincial (ALBA PAGÁN, 2007: 83), volviese a quedar espacio en la Sala de Juntas, que al igual que la de San Fernando en ese período había acogido algunas de las obras artísticas de mayor importancia, para volver a instalar en ella la galería de retratos.

402 “Continúan las fiestas públicas en celebridad de la jura de la Serma. Sra. Doña María Isabel Luisa, Princesa heredera de la corona de España. Descripción del ornato de la Real casa de la Academia de Nobles Artes de S. Carlos, y de la fachada de la Subdelegación de Policía”, Diario de Valencia, 29 de julio de 1833, p. 165. 
Conocemos la distribución que en este relativamente corto período de tiempo tuvieron los retratos de la Academia dentro de ésta, que se dispersaron por distintas dependencias. Los más representativos como imagen del poder de la Academia fueron ubicados en el recibidor, donde el visitante podía tener una primera impresión de las autoridades que habían formado parte de la directiva académica: aparecían allí los de Floridablanca, Antonio Pascual, Francisco Javier de Azpiroz, Urbina, José O-Donell, Longa, el conde de Almodóvar, Santocildes, Nicolás Manes, Jorge Palacios, Joaquín Obregón y Pareja, y Avilés, acompañados por tres retratos de distintas dimensiones de distintos valencianos ilustres (Jaime Falcó, el beato Nicolás Factor y un "retrato de valenciano ilustre"). En el Archivo de la Academia se colocaron el de Mariano Liñán realizado por Pou, el de Borrull por Zapata, el de Cristóbal Valero, Felipe Castro y el de Mariano Ferrer de Goya, junto a copias al pastel del retrato de Sánchez Coello, por Vicente María Vergara, del de Mengs por Esteve, o del de Rubens por Juan Bautista $\mathrm{Gil}^{403}$.

Resulta especialmente interesante conocer la ubicación de los retratos de los distintos profesores, ya que tendrían una presencia muy especial en las propias aulas de la Academia, de manera que, al permanecer a la vista constante del alumnado, podían mover a emulación mediante la contemplación de los méritos de los grandes artistas vinculados a la Academia. En la sala de Arquitectura se colocaron precisamente los retratos de los arquitectos Cristóbal Sales, Vicente Gascó y Vicente Marzo, así como el del marqués de la Romana, que por su iconografía vincula mediante un plano y un compás los conocimientos de arquitectura y poliorcética con el ámbito militar, la virtud cívica y la promoción social. En la sala del Natural se pusieron los retratos de José Camarón, Bernardo Selma, José e Ignacio Vergara, José Esteve, Manuel Monfort y Luis Planes; la presencia de grabadores, escultores y pintores en el mismo aula, lejos de llamar la atención, permite una lectura clara por parte del discípulo, ya que el nexo común está directamente relacionado con el espacio que retratados y observador ocupan: la práctica y dominio del dibujo del natural. Las salas del yeso y de flores no contaron con ningún retrato, mientras que en la de principios se colocó el retrato "de un escultor francés ${ }^{404,}$, que en realidad era el Retrato del escultor de cámara Domingo Olivieri, donado a la Academia por Tomás Bayarri, y que ya constaba en los inventarios de la misma de 1797-1830.

En el último inventario realizado en el siglo XIX, en 1867, aparecen nuevamente aglutinados todos los retratos en un espacio denominado directamente galería de retratos, con la excepción del retrato de Benito Espinós (Catálogo de los cuadros..., 1867: $\mathrm{n}^{\mathrm{o}}$ 425), que aparecía en el cuarto primero junto al salón de sesiones, y el de Antonio Pascual (Catálogo de los cuadros...,1867: 936), que se ubicaba en la quinta galería. La recolocación de los retratos en su espacio original subraya nuevamente el

\footnotetext{
${ }^{403}$ La autoría de esta copia no aparece documentada en el inventario manuscrito, pero aparece reflejada en las actas de la Academia como obra del discípulo Juan Bautista Gil, que la presentó para ser nombrado académico de mérito. Junta Ordinaria de 17 de junio de 1832, Libro de Actas de la Real Academia de San Carlos, 1828-1845, ARABASC.

${ }^{404}$ Inventario manuscrito, 1842, ARABASC (146), Sala de principios, sin número.
} 
carácter corporativo e institucional al vincular a los protagonistas de su historia con los hechos contemporáneos y la vida administrativa de la academia. Tan solo un cambio más consta reflejado en la consulta de inventarios y catálogos, y probablemente ya en el siglo XX, puesto que según el catálogo de Garín Ortiz de Taranco las galerías de retratos fueron distribuidas en dos espacios, el Salón de Actos y Salón de la Presidencia, con anterioridad al depósito permanente de las obras de la Academia en el Museo de Bellas Artes de Valencia ${ }^{405}$. Se destinaron al Salón de Actos los retratos de los presidentes anteriores a la reforma de 1849 y la galería de profesores, por lo que los del Salón de la Presidencia se configuraron como una variante de la galería de presidentes posteriores a 1850, ya que compartían entre sí los rasgos formales anteriormente analizados, como el formato en óvalo.

Del estudio de la colección de retratos de la Academia de San Carlos se desprende rápidamente una conclusión interesante, que radica en su temprana configuración y en la clara diferenciación existente, tanto a nivel conceptual como iconográfico, entre los retratos de corregidores/presidentes y los de profesores. De este modo, mientras los primeros encarnan la imagen del poder oficial y aparecen revestidos de atributos que subrayan su posición social, como uniformes militares y condecoraciones, el retrato de artista hereda el concepto ilustrado del decoro al acompañarse de atributos que vinculan al efigiado con su mérito y valía, y enlazar con la imagen del artista filósofo, lo que hace evolucionar hasta una representación más evidente de la profesión, en que se subraya no solo la especialización del artista sino sus cualidades singulares y su mérito dentro del rango social académico. La generalización del uso del uniforme académico como distintivo corporativo a partir de 1825 tiene escasa vigencia, y encuentra su sustituto en la medalla corporativa que se incluye en los retratos de presidentes en la segunda mitad del siglo XIX, generando así un espíritu de cohesión y de identidad de grupo entre los retratados y el personal académico del momento. Es especialmente significativo el hecho de que la imagen del artista que se codifica en la galería de San Carlos eluda voluntariamente la representación del éxito oficial a través de retratos condecorados, de manera que en la mente de sus artífices, y especialmente en las de Luis Antonio Planes y Miguel Parra, la autenticidad reside en la representación de hombres vinculados a su oficio, en su vertiente intelectual y en la práctica, en lugar de estarlo al mundo de la alta sociedad y de las apariencias.

\subsection{Galería de retratos de la Academia de Bellas Artes de Barcelona}

La formación de la Academia de Bellas Artes de Barcelona fue un proceso largo y complejo, en el que entraban en conflicto los ideales de la formación artística superior y el estudio del dibujo aplicado a las artes y oficios (RUIZ ORTEGA, 1999), acorde con los intereses de la burguesía comercial. Bajo la protección de la Junta de Comercio de Barcelona se consolida su antecedente directo, la Escuela de Dibujo de La Lonja, que combinó ambas enseñanzas con la aspiración constante de convertirse en academia. En

\footnotetext{
405 En la Guía-catálogo de 1955 se advierte de que estas dependencias, a diferencia de las del Museo, eran propias de la Academia de San Carlos y que, por lo general, no estaban abiertas al público, aunque se podía solicitar su visita.
} 
ella se desarrollaron dos galerías de retratos, relacionadas con las vicisitudes históricas de la corporación: así, durante el periodo previo a su reconocimiento oficial como academia provincial de bellas artes, se formaría una, de carácter oficial y corporativo estrechamente vinculado con la propia Junta de Comercio, en la que se encontrarían los retratos de los Intendentes del Principado, con la que convivirán los retratos de algunos de los directores de la Escuela. Por otra parte, tras ser reconocida como Academia en 1849, comparte con otras corporaciones académicas un interés por generar una identidad propia a través de la galería de presidentes, si bien la incorporación de retratos de artista será más esporádica.

\subsubsection{Retratos de artista procedentes de la Escuela de Dibujo}

Además de en el estudio realizado por Francesc Fontbona y Victoria Durá (1999) de las colecciones pictóricas de la Academia de Sant Jordi, Fernández Pardo señala en el suyo (2000: 19) una evidente diferenciación entre los retratos oficiales de los intendentes de la Junta y los retratos de los directores de la Escuela de Dibujo. Respondiendo a finalidades muy distintas, los retratos de intendentes -cargo que como señala Fontbona conllevaba la presidencia de la Junta de Comercio de Barcelona (FONTBONA, 1993: 168)- fueron destinados, junto a los retratos de otros personajes influyentes en el ámbito comercial barcelonés, a la sala de Presidencia del edificio de La Lonja, en cuyo segundo piso se ubicó la Escuela de Dibujo. Iniciada en los años ochenta del siglo XVIII ${ }^{406}$ y perviviendo hasta los años 30 del siglo $\mathrm{XIX}^{407}$, su carácter es completamente independiente al de una galería vinculada a una corporación artística: los representados, vinculados al poder militar y económico catalán, aparecen de medio cuerpo, uniformados y en una actitud por lo general hierática, haciendo gala de cuantas condecoraciones les han sido concedidas por sus méritos. Como excepción por las alusiones incluidas a la protección de la Escuela de Dibujo, llama la atención el retrato del Intendente Juan Felipe de Castaños y Urioste [fig. 125], copia realizada por Mariano Illa de un original de Mengs, en 1787: en este retrato, el intendente sostiene en su mano derecha un libro abierto, en cuyas páginas se puede leer "Estatuto de la Academia de Dibujo y Gravado", lo que señala como hito importante durante el desempeño de su cargo (1763-1776) la creación de la Escuela (1775). Estos retratos fueron encargos de la propia Junta de Comercio, y mantienen tanto unas dimensiones muy similares como una coherencia iconográfica.

\footnotetext{
${ }^{406}$ Los primeros retratos de los que tenemos constancia en los fondos de la Academia de Sant Jordi son los de los intendentes Juan Felipe de Castaños y Urioste (copia de Mariano Illa de un original de Mengs) y el del intendente Manuel de Terán (por Pedro Pablo Montaña), que ingresaron en 1787.

${ }^{407}$ Los últimos retratos de intendentes que constan en los inventarios son los de Antonio de Barata (por Vicente Rodes) y Manuel de Fidalgo, obra también de Vicente Rodes, ambos fechados hacia 1834. También en 1834 se pinta el retrato de Manuel María Gutiérrez, por Esquivel, obra que fue incluida en la galería de la Junta.
} 


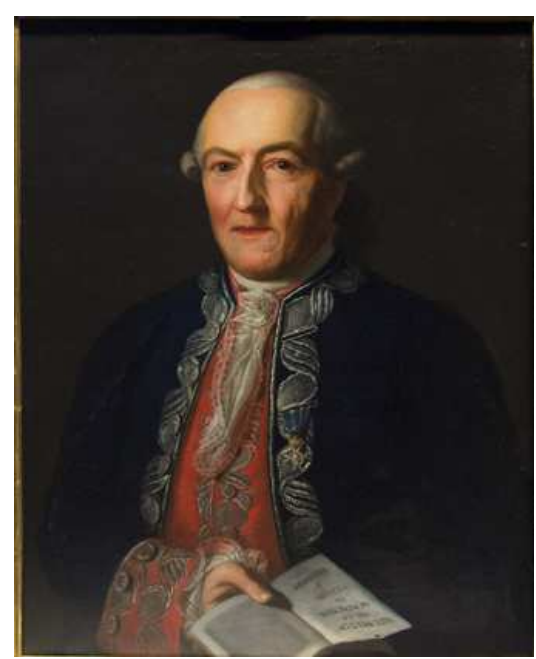

Fig. 125. Mariano Illa, Retrato del Intendente Juan Felipe de Castaños. Academia Catalana de Bellas Artes de Sant Jordi (nº inv. 228).

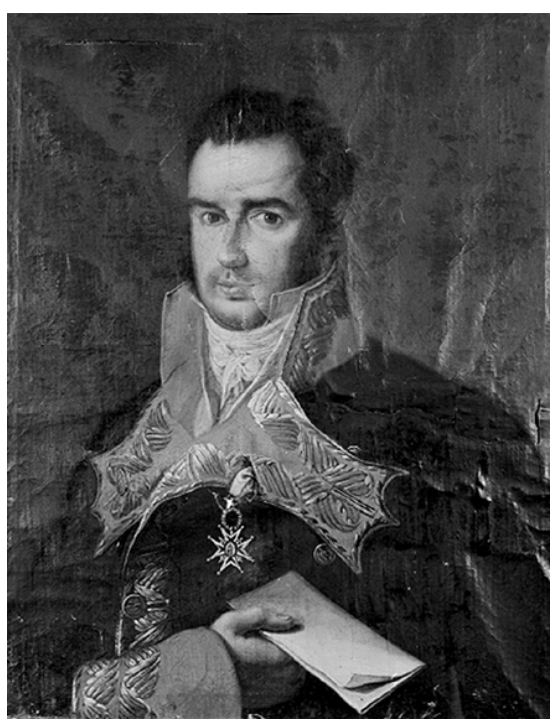

Fig. 127. José Rodríguez Pusat, Retrato del Intendente Juan Bautista Erro y Azpiroz. Academia Catalana de Bellas Artes de Sant Jordi ( $\mathrm{n}^{\mathrm{o}}$ inv. 232).

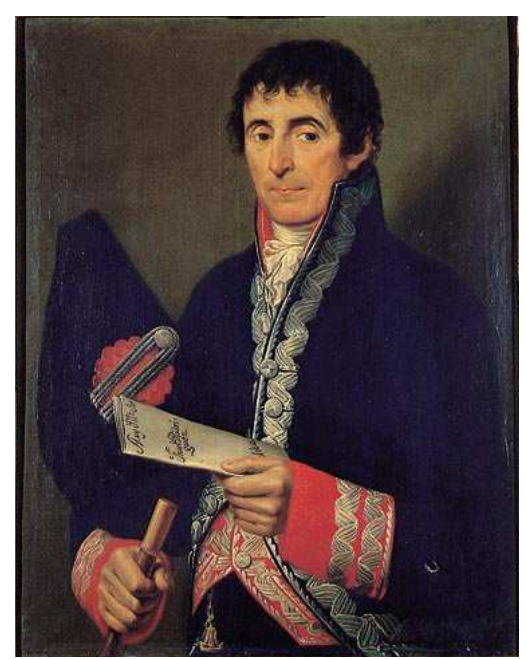

Fig. 126. José Rodríguez Pusat, Retrato del Intendente José de Ansa. Academia Catalana de Bellas Artes de Sant Jordi ( $\mathrm{n}^{\circ}$ inv. 233).

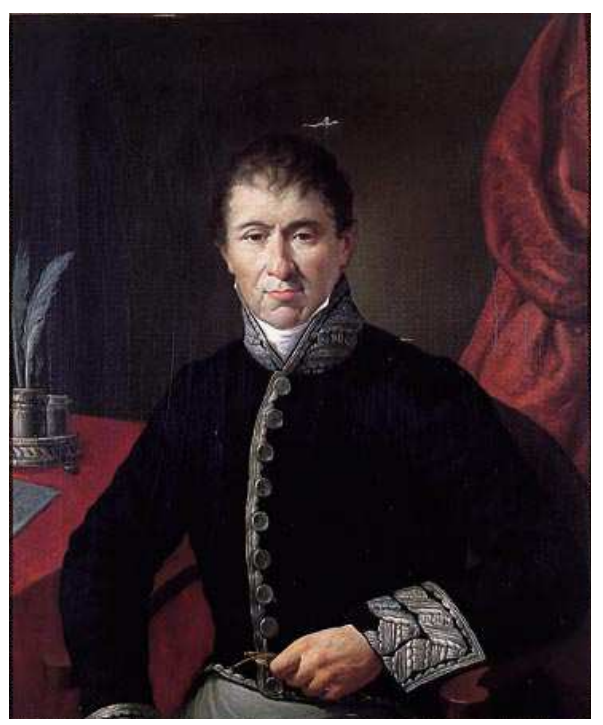

Fig. 128. Vicente Rodes, Retrato del Intendente Antonio Barata. Academia Catalana de Bellas Artes de Sant Jordi ( $\mathrm{n}^{\circ}$ inv. 237).

No obstante, los retratos de artista, que fueron encargados por la propia Junta de Comercio, tienen un carácter distinto al emplear una iconografía que vincula a aquel con la actividad intelectual y aludir directamente a una profesión altamente dignificada. Si seguimos el Catálogo del Museo de la Junta de Comercio elaborado en $1847^{408}$, encontramos hasta cuatro retratos que podrían haber formado parte de una galería inicial de retratos de directores. El primer retrato del que se tiene constancia es el pintado para recordar la figura de Pedro Pascual Moles en 1797 [fig. 129], año de su fallecimiento, para cuya realización Juan Giralt copió un retrato ya existente realizado por Vicente

${ }^{408}$ La similitud en las proporciones de las obras y su agrupación en el catálogo, con los números correlativos 254, 255, 256 y 257 hacen pensar que fueron encargados como parte de una galería de retratos de directores de la Escuela de Nobles Artes de la Junta de Comercio (Catálogo de las obras..., 1847). 


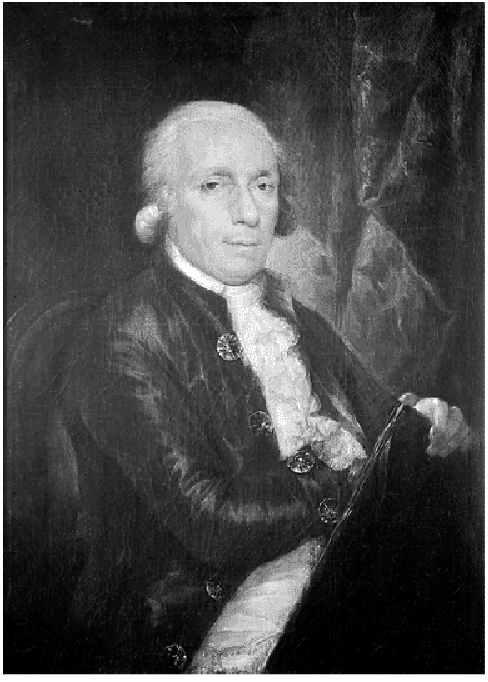

Fig. 129. Juan Giralt, Retrato de Pedro Pascual Moles. Academia Catalana de Bellas Artes de Sant Jordi ( $\mathrm{n}^{\mathrm{0}}$ inv. 258).

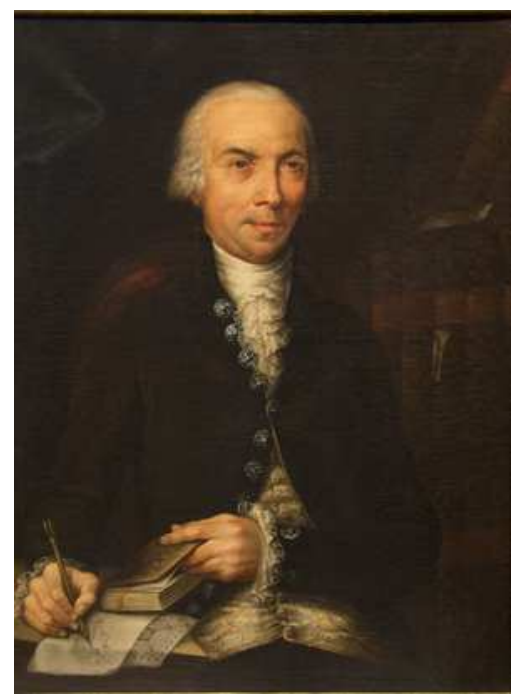

Fig. 131. Juan Giralt, Retrato de Pedro Pablo Montaña. Academia Catalana de Bellas Artes de Sant Jordi ( $\mathrm{n}^{\circ}$ inv. 257).

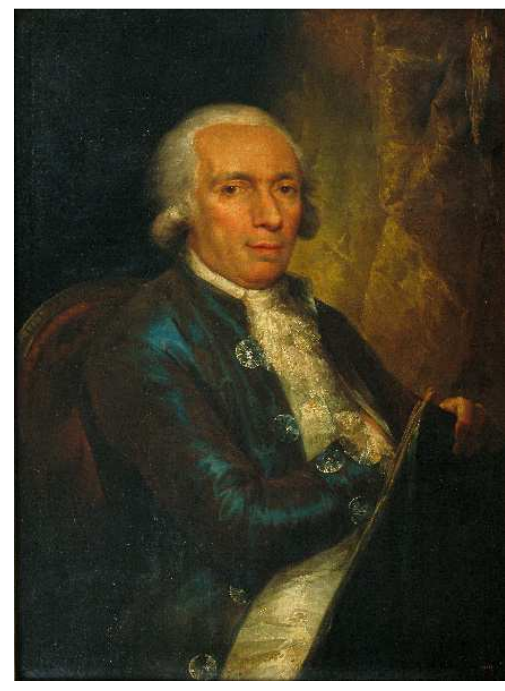

Fig. 130. Vicente López, Retrato de Pedro Pascual Moles. MNAC ( ${ }^{\circ}$ inv. 40088).

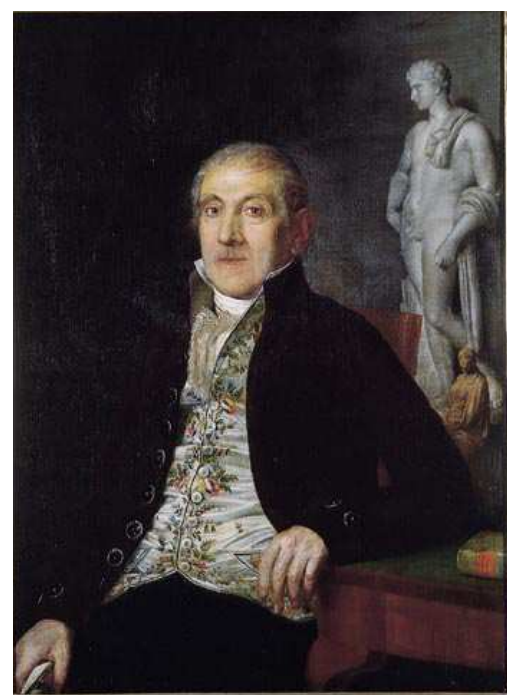

Fig. 132. Ramón Planella, Retrato de Jaime Folch. Academia Catalana de Bellas Artes de Sant Jordi ( $\mathrm{n}^{\mathrm{o}}$ inv. 260).

López [fig. 130]. Esta imagen, sujeta al convencionalismo del retrato del artista como elegante intelectual con una posición social acomodada, que presenta similitudes con los retratos académicos valencianos, no parece introducir ningún rasgo distintivo del retratado como primer director de la Escuela de Dibujo. Solo la carpeta que sostiene con una de sus manos alude a la actividad artística; no obstante, dentro del contexto de producción y atendiendo a los retratos existentes en ese momento en la corporación, encarna una diferencia importante.

También fue Juan Giralt el encargado de realizar el retrato del siguiente director de la Escuela de Dibujo: Pedro Pablo Montaña [fig. 131]. En esta ocasión Montaña aparece igualmente representado según los cánones dieciochescos, de medio cuerpo y sentado, como ocurría en los retratos académicos valencianos, sosteniendo un libro en la mano izquierda y con la derecha esbozando el dibujo de una cabeza. A pesar de que se ha fechado la obra hacia 1800, el hieratismo de la figura y la impasibilidad del rostro, 
completamente ajeno a la acción que ejecuta y al propio hecho de estar siendo retratado -en especial teniendo en cuenta que el retrato lo realiza su propio yerno, lo que podría haber otorgado una cierta familiaridad al trato de los rasgos faciales que sin embargo no aparece reflejada en la obra ${ }^{409}$, hacen pensar que pudiera haber sido ejecutado tras su muerte.

Otro de los retratos recogidos en el Catálogo de 1847 es el Jaime Folch [fig. 132], ejecutado por Ramón Planella y que se ha fechado hacia 1815, tomando probablemente como fecha la de su reinstauración en la Escuela barcelonesa tras la vuelta a España de Fernando VII. En la obra se hace evidente la asimilación del tipo de retrato de escultor según la moda neoclásica (DÍEZ, 1997: 44), que incluía al artista en primer plano y ubiba al fondo una de sus obras representativas. Folch aparece representado de medio cuerpo, sentado junto a una mesa sobre la que apoya el codo, sosteniendo en la mano derecha algunos instrumentos artísticos. Además, el libro de Historia de los dioses que aparece sobre la mesa y las dos esculturas, de factura clasicista, que se recortan sobre el fondo aluden directamente al estilo artístico practicado por el escultor. El último de los retratos que podemos mencionar en el grupo de directores de la Escuela de Nobles Artes es el Autorretrato de Francisco Rodríguez [fig. 133], obra que tradicionalmente se ha venido fechando en 1805 y que, atendiendo al estilo y fisionomía del retratado, otros autores como Fernández Pardo (2000: 108) sitúan en una cronología más tardía, algo que parece respaldar el hecho de que Rodríguez no fue director hasta 1821 .

Francisco Rodríguez i Pusat, de cuya mano son al menos seis de los retratos de Intendentes de la Presidencia de la Junta de Comercio ${ }^{410}$, se presenta siguiendo el modelo de autorretrato en el espejo, en actitud de pintar un retrato oficial. Su gesto desenvuelto, con las piernas cruzadas y el pincel apoyado en el lienzo, así como su vestimenta - que ha abandonado los chalecos de seda bordados y las casacas por una levita cerrada y una alta corbata-, transmiten una espontaneidad que se aleja del retrato oficial de artista a favor de una imagen más íntima, en la que la propia práctica pictórica forma parte de la identidad del representado.

De este modo se observa una similitud con el caso valenciano, en el propósito de crear dos galerías diferenciadas, si bien también existe una divergencia notable que es, precisamente, la dignificación de la galería de intendentes frente a los retratos de artistas. La primera, de carácter representativo, es ennoblecida por el espacio que ocupa y por su progresivo desarrollo, poniendo de manifiesto el interés de la institución por

\footnotetext{
${ }^{409}$ El hecho de que Giralt conociese la obra de Vicente López al haber copiado con bastante acierto el retrato de Moles, en el que sí hay profundidad psicológica y contacto visual entre retratista y retratado, hace más llamativo el hieratismo del retrato de Montaña.

${ }^{410}$ Constan de su mano los de José de Ansa (1816), Francisco de Oteiza (1816), Juan Bautista de Erro y Azpiroz (1820), el de Vicenç de Frigola (ca. 1825), el de Domènec María de Barrafón i Vinyals (1830) y el de Pedro de Alcántara Díaz de Labandero (ca. 1833) (Catálogo ..., 1847).
} 


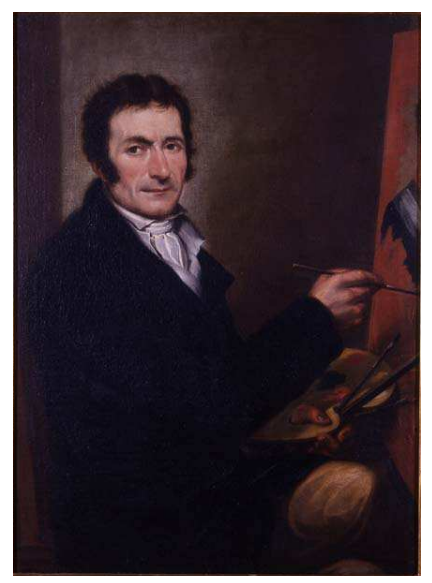

Fig. 133. Francisco Rodríguez Pusat, Autorretrato. Academia Catalana de Bellas Artes de Sant Jordi ( $\mathrm{n}^{\mathrm{o}}$ inv. 259).

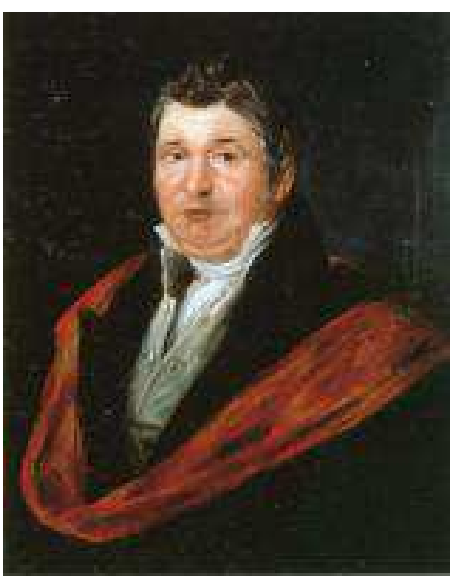

Fig. 134. Ferrán Ferrant Llausás, Retrato de Antoni Celles. Academia Catalana de Bellas Artes de Sant Jordi ( $\mathrm{n}^{\mathrm{o}}$ inv. 240).

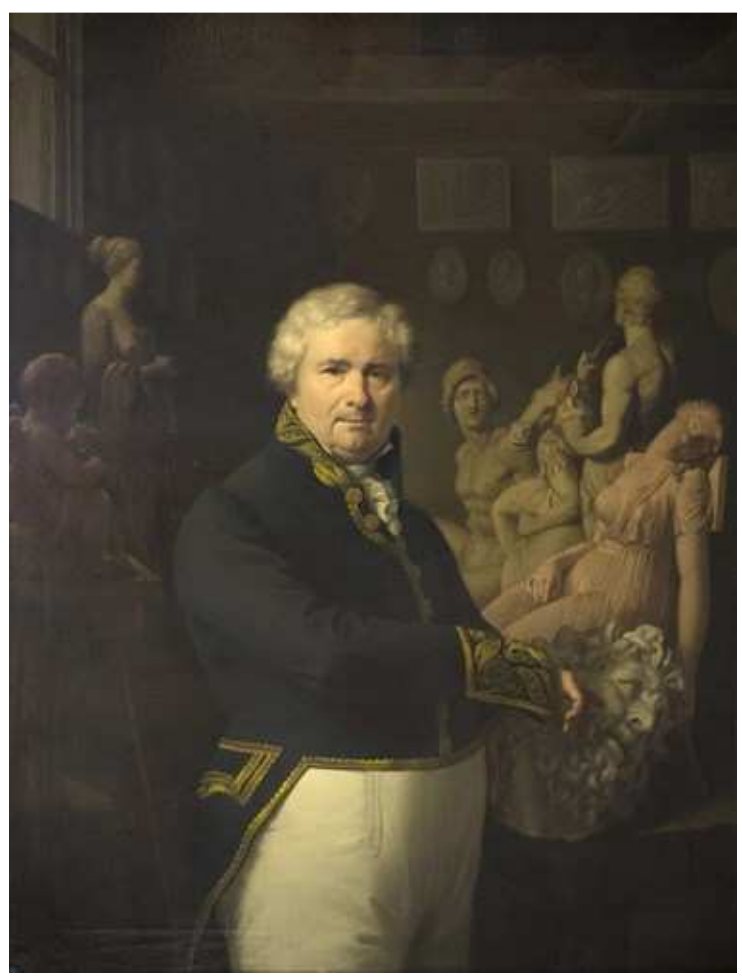

Fig. 135. Vicente Rodés, Retrato de Damián Campeny. Academia Catalana de Bellas Artes de Sant Jordi ( $n^{\circ}$ inv. 222).

configurar una imagen del poder que no está asociada al mundo artístico, tal y como corresponde, por otra parte, a una corporación como la Lonja de Comercio. Su carácter tangencial como protectora de las artes queda patente en el encargo de obras a algunos de sus artistas y profesores, subordinados a una jerarquía administrativa de la que no participan. Es ahí donde se observa también la diferencia entre una imagen masculina vinculada al poder institucional y la masculinidad anclada en el privilegio intelectual que se observa en el retrato de artista, desvinculándose de la ostentación aristocrática a favor de una imagen en transición hacia la idea del artista como hombre burgués vinculado a su trabajo creativo. A pesar de que desconocemos la ubicación inicial de estos retratos, que dudosamente habría sido la sala de Presidencia de la Junta de Comercio, el catálogo de 1847 los sitúa en la Sala de Cabezas y Figuras de la Escuela de 
Dibujo de la Junta de Comercio; esta ubicación pudo deberse a la incorporación de obras artísticas tras la desamortización, siendo este caso similar al acontecido en la Academia de Bellas Artes de San Carlos.

Además de estas cuatro pinturas, el Catálogo de 1847 da noticia de otros dos retratos de directores que, no obstante, no se adecúan a las características de los anteriores. Uno de ellos es el del primer director de la enseñanza de arquitectura, instaurada en 1817, Antonio Celles [fig. 134], realizado por Ferrán Ferrant Llausás, y que ingresó en el Museo hacia 1835 o 1836. Las dimensiones del lienzo, mucho menores a las de los retratos de la galería de directores ${ }^{411}$, parecen indicar que su función inicial no era figurar en esta. La imagen de busto prolongado tampoco parece acorde con las formas habituales de representación de otros profesores, por lo que se trata de una imagen de carácter más cercano, sin alusión alguna al oficio o a su vinculación con la corporación. Bassegoda i Nonell (1999: 25; 1973: 59) intentó aclarar la incógnita de la procedencia de este retrato, asegurando que el propio Celles cedió a la Junta de Comercio esta pintura para que figurase en su clase de arquitectura.

Pero es el que representa a Damián Campeny [fig. 135] el que, por su monumentalidad y por la iconografía empleada, más llama la atención dentro de los retratos de artista en esta etapa de la corporación barcelonesa. Atendiendo a las dimensiones fijadas para las obras destinadas a la galería de directores de la escuela, el de Campeny excede, con gran diferencia, tanto estas como las de los retratos de Intendentes, lo que indica claramente que no se trataba de un cuadro destinado a la Lonja sino a la celebración de la identidad profesional. Su autor, Vicente Rodés, hizo uso de un lenguaje codificado en estos términos vinculados también al reconocimiento social, pues presenta al escultor, de edad avanzada, en una sala de escultura ${ }^{412}$, vestido con uniforme académico ${ }^{413}$ y señalando -como ya ocurriera en el retrato de Alberolauna cabeza -en este caso la de su obra Laocoonte. En segundo término llaman la atención del espectador algunas de las producciones escultóricas de Campeny, como su Lucrecia moribunda o Aquiles herido. José Luis Díez (1997: 46 y 47), al señalar las similitudes con el retrato del escultor Antonio Solá, subraya la calidad de la obra vinculando el uniforme y la producción escultórica representada con una imagen del cursus honorum del artista. En efecto, estas dos características parecen manifestar una voluntad de primar el reconocimiento como artista en una institución oficial, algo que también fue común en la Academia de San Carlos, en lugar de su condición de director de la enseñanza de escultura, de la que se encargaría en Barcelona desde 1819. A pesar de que la obra resalta la vanidad masculina de la identidad y el éxito profesional, no parece que el retrato estuviese destinado a ser propiedad de Campeny, ya que ingresó en el Museo de la Junta de Comercio por donación de Rodes, en 1838, cuando el escultor aún vivía. En el retrato de Campeny, frente a las obras que anteriormente se habían

\footnotetext{
${ }^{411}$ El retrato de Antoni Celles mide 68 x $54 \mathrm{~cm}$, frente a los 90 × $61 \mathrm{~cm}$ que se venían observando en los retratos de la galería de directores.

412 Prescindiendo de los fondos neutros habituales en este tipo de retratos, en esta ocasión se ha representado una sala tenuemente iluminada por altas ventanas, en la que esculturas y relieves conviven para dar una imagen de la obra del representado.

${ }^{413}$ Vicente Rodes era académico de mérito por la escultura en las de San Carlos y San Fernando.
} 
incorporado como representaciones de los directores de la Escuela, se pone de manifiesto una voluntad de emancipar la figura del artista con respecto al ámbito institucional de la propia Junta de Comercio. Si en el retrato de Rodríguez Pusat aún quedaban vestigios de la realidad social y masculina del artista como subordinado de una clase superior, incluso en el seno de la propia institución, encargada de realizarle encargos, Rodes opta por una imagen dignificada del éxito autónomo del escultor. A pesar de que la representación de la producción de Campeny se vincula directamente con la enseñanza académica y el gusto oficial, el gesto decidido del escultor, su porte erguido y su mirada desafiante, así como la representación de su taller y de su indumentaria oficial marcan un cambio respecto al resto de retratos de la Junta de Comercio, donde el éxito no se basa en la pertenencia a una élite cultural dependiente de la burguesía comercial barcelonesa, sino con otras formas del poder influidas por la Academia de San Fernando y los gustos de la corte madrileña.

\subsubsection{Retratos de artista en el ámbito de la Academia de Bellas Artes}

Cabe plantearse si el nuevo reconocimiento como Academia Provincial de Bellas Artes supone una asimilación de esa identidad corporativa que no se observa en la anterior galería de retratos, pero que sí existía en la Academia de San Carlos. Respecto a la voluntad de crear una galería de presidentes de la Academia, no parece que fuese una necesidad acuciante a juzgar por las obras ingresadas en esta. A pesar de que las actas de 1856 recogen la donación de un retrato realizado por Miguel Campomar del entonces presidente ${ }^{414}$, el marqués de Alfarrás, una obra de corte romántico que sigue el tipo de representación oficial de hombre civil -con traje de etiqueta y una condecoración al cuello- en el que la vinculación con el arte y la Academia se expresa mediante un plano $\mathrm{y}$ un juego de escribanía ubicados en el escritorio de trabajo que figura en segundo plano, la voluntad de configurar una galería de presidentes, es decir, que expresase una identidad corporativa, no se rastrea en las actas hasta 1884. Francesc Fontbona (2000: 25) consideró que este Retrato del marqués de Alfarrás abría la iniciativa de la galería de presidentes; no obstante, la existencia de un segundo retrato del mismo, realizado por Antonio Caba [fig. 136] en el que sí se evidencian rasgos propios del retrato corporativo, como el uso de la medalla académica, parece desmontar esta idea, que queda corroborada por las propias actas de la Academia. En 1884 se inicia el pensamiento de retomar las galerías de retratos, concretamente tras la muerte del que fue primer presidente de la Academia, ya que, como se puede comprobar, son escasas las incorporaciones de retratos vinculados a la Academia que ingresan en esta en el intervalo de 1850 a 1884, que además fueron destinados, con la excepción del retrato de Vicente Rodes y del del conserje José Antonio Noguera ${ }^{415}$, al Museo de Pinturas. Así queda de manifiesto en el acta de la junta celebrada el 10 de febrero de 1884, donde se recoge:

\footnotetext{
${ }^{414}$ Junta General de 6 de abril de 1856, Llibre d'actes de la Reial Acadèmia Catalana de Belles Arts de Sant Jordi, del 5 de gener de 1856 al 2 de desembre de 1871. RABASJ.

${ }^{415}$ El retrato de José Antonio Noguera ingresa en 1853 por legado testamentario, acordando la Academia que se colocase "en una de las salas del establecimiento". Junta de gobierno de 12 de junio de 1853, Libro de actas 1850-1855, RABASJ, p. 133.
} 
Los infrascritos, que no pueden menos de aplaudir por lo oportuna y justa de tal demostración, creen, sin embargo, que debería hacerse algo más, tomando pie la Academia de este triste acontecimiento para que se pintara el retrato al óleo del Señor Marqués, abriendo con él la galería de los Presidentes de la Corporación, tal como la tiene de los Señores Intendentes que presidieron la antigua Junta de Comercio y de los Señores Directores que han sido de las Escuelas dependientes de la misma ${ }^{416}$.

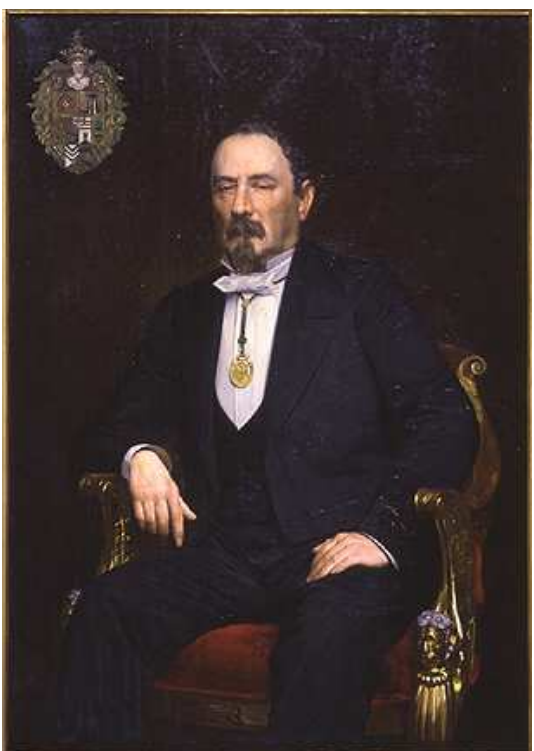

Fig. 136. Antonio Caba, Retrato del marqués de Alfarrás, Academia Catalana de Bellas Artes de Sant Jordi (n $n^{\circ}$ inv. 200).

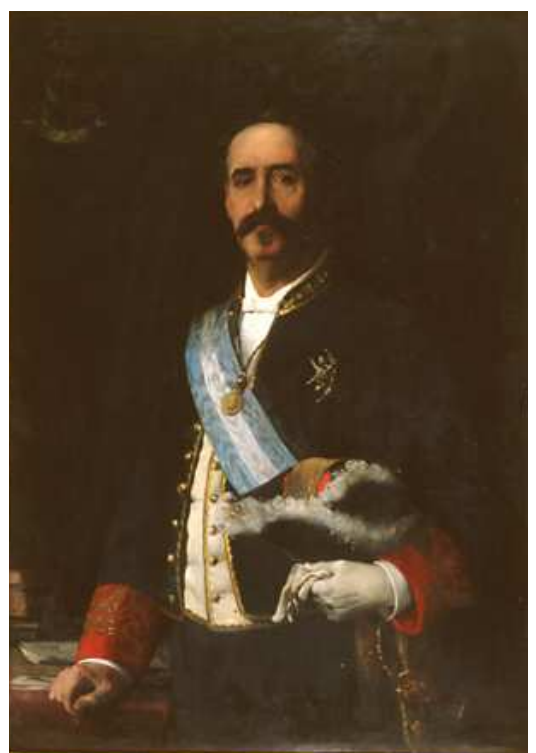

Fig. 137. Luis Franco Salinas, Retrato del marqués de Sentmenat. Academia Catalana de Bellas Artes de Sant Jordi (nº inv. 186).

En 1892 se incorpora el retrato del segundo presidente (1877-1892), el marqués de Sentmenat y Ciutadilla [fig. 137], pintado por Luis Franco Salinas, que retoma un lenguaje oficial en el que se recupera la identidad académica a través de la medalla. Por otra parte, la colección se incrementó mediante donaciones particulares, desvinculándose así de la idea original de una galería de directores en el ámbito administrativo de la Academia. Por legado testamentario ingresa en 1868 el Retrato de Manuel Vilar pintado por Federico de Madrazo $^{417}$ y, en 1872, el Autorretrato de José Arrau (actualmente en depósito en el MNAC de Barcelona), junto a otras dos obras, "para colocarlas perpetuamente en su galería, que es el punto donde empezó sus

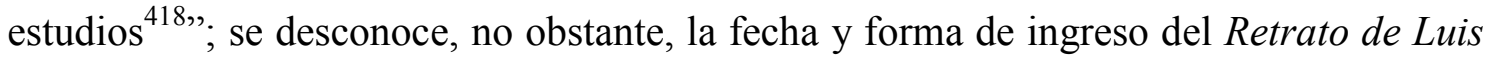
Rigalt. En 1863 se adquirió el Autorretrato de Francisco Lacoma y Sans (actualmente en depósito en el MNAC de Barcelona). También se encargaron en 1865 los retratos de dos pintores aficionados, si bien se debía más a su papel como funcionarios: Eugenio Ochoa y Teodoro Ponte. Además, las obras se encargaron a Federico de Madrazo y a Martí Alsina, constando en las actas la finalidad añadida "de contar con dos buenas

\footnotetext{
${ }^{416}$ Junta General de 10 de febrero de 1884, Llibre d'actes de la Reial Acadèmia Catalana de Belles Arts de Sant Jordi. Del 18 de gener de 1872 al 13 de desembre de 1885, RABASJ.

417 Junta General de 15 de noviembre de 1868 , Llibre d'actes..., RABASJ.

418 Junta general de 22 de febrero de 1872, Llibre d'actes..., RABASJ.
} 
obras más para el Museo contemporáneo de Pinturas ${ }^{419}$ ". Frente a las obras destinadas al Museo de Pinturas, tan solo consta un retrato de artista destinado en este momento a la Academia, tratándose del ya mencionado de Vicente Rodes en la Academia [fig. 138].

El debido homenaje a Rodes, cuya vinculación con la Academia había sido muy fructífera y cuyo suicidio a comienzos de 1858 impactó a la corporación barcelonesa, exigía que su imagen perviviera en esta. La historia de este retrato, recogida en las actas, permite afirmar además que esta obra suponía igualmente el cierre de la galería de retratos de directores que había caracterizado a la anterior etapa al haber sido Rodes profesor y director general de la Escuela de Dibujo. Se solicitó a la hija de Rodes un retrato para sacar una copia y colocarlo en el salón de pinturas de la Academia ${ }^{420}$, con el fin de "recordar constantemente las virtudes y demás apreciables cualidades que tanto caracterizaron al último Director general de las Escuelas ${ }^{421}$ ". La realización de la obra corrió a cargo de Jaime Batllé, y fue presentada en octubre de ese año ${ }^{422}$; a pesar de que en las actas no figura indicación alguna respecto al formato que debía tener el retrato, Batllé se adapta a las dimensiones de los retratos de la galería de directores, y se basó para su ejecución en dos retratos al daguerrotipo. Rodes es representado de medio cuerpo, sosteniendo en su mano izquierda un lápiz y con la derecha un libro que apoya en su regazo, mientras a su espalda se puede ver un dibujo al carbón colocado en el caballete; un tipo de representación del artista como trabajador similar al presente en el autorretrato de Rodríguez Pusat. Se trata de la última obra que ingresa en la Academia como retrato de director, ya que la idea de una galería de retratos de artistas fue completamente abandonada hasta los años noventa del siglo.

\subsubsection{Otros retratos de artista en el ámbito de la Academia: Claudio Lorenzale}

El 12 de abril de 1891, una fecha ya muy alejada de la inicial constitución de la galería de retratos de la Escuela de Dibujo, la Academia pronunció una sesión necrológica en memoria de tres importantes figuras del panorama cultural barcelonés: el filólogo Manuel Milà i Fontanals, el pintor y profesor en la Escuela de Bellas Artes, Pablo Milà i Fontanals, y el pintor Claudio Lorenzale ("Sesión necrológica", 1891: 2). La Academia, además, organizó una exposición con las pinturas y dibujos de Lorenzale como reconocimiento a la labor desarrollada como profesor en la misma (YXART, 1891: 274; La ilustraciò..., 1891: 114).

En 1891 se fecha, precisamente, un retrato de Claudio Lorenzale pintado por Antonio Caba, dos años después del fallecimiento del pintor nazareno, y que probablemente fuese realizado en relación con esta sesión necrológica, acorde con las que habían generalizado en Barcelona instituciones como el Ateneo Barcelonés o el

\footnotetext{
${ }^{419}$ Junta de Gobierno de 17 de marzo de 1865. Llibre d'actes..., RABASJ.

${ }^{420}$ Junta General de 7 de marzo de 1858, Llibre d'actes de la Reial Acadèmia Catalana de Belles Arts de Sant Jordi, del 5 de gener de 1856 al 2 de desembre de 1871, RABASJ.

${ }^{421}$ Junta General de 7 de febrero de 1858, Llibre d'actes de la Reial Acadèmia Catalana de Belles Arts de Sant Jordi, del 5 de gener de 1856 al 2 de desembre de 1871, RABASJ.

422 Junta General de 24 de octubre de 1858, Llibre d'actes de la Reial Acadèmia Catalana de Belles Arts de Sant Jordi, del 5 de gener de 1856 al 2 de desembre de 1871, RABASJ.
} 


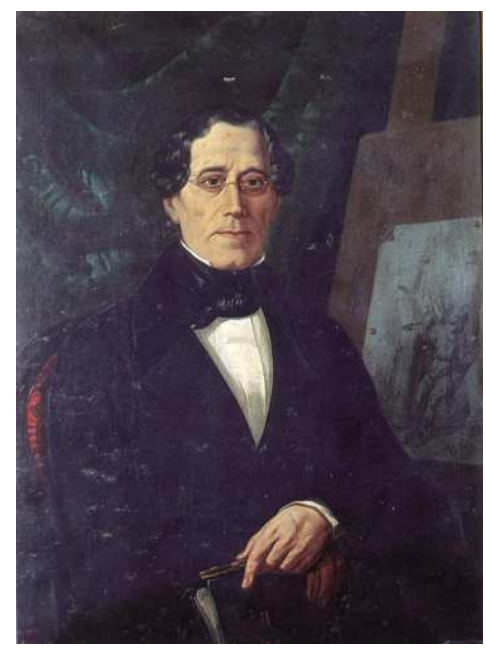

Fig. 138. Jaime Batllé, Retrato de Vicente Rodes. Academia Catalana de Bellas Artes de Sant Jordi (n ${ }^{\circ}$ inv. 261).

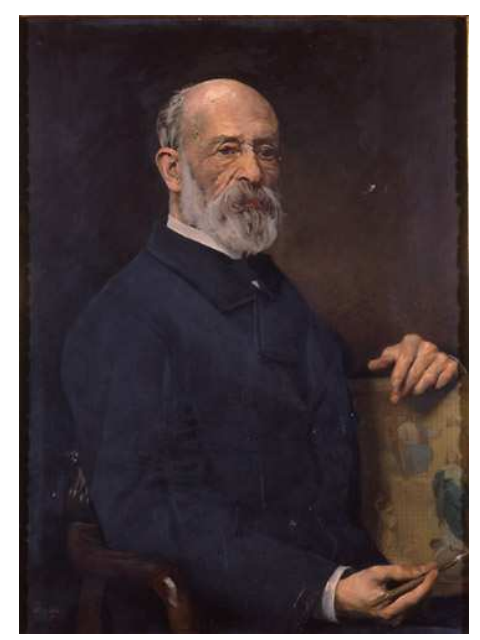

Fig. 139. Antonio Caba, Retrato de Claudio Lorenzale. Academia Catalana de Bellas Artes de Sant Jordi ( $\mathrm{n}^{\mathrm{o}}$ inv. 248).

Círculo Artístico, en las que el retrato del homenajeado cobraba una gran importancia. A pesar de que en las reseñas sobre la sesión de la Academia no constan datos que señalen la presencia de este retrato presidiéndola, este pudo haber sido incluido en la exposición retrospectiva de la obra de Lorenzale que se realizó en ese momento, a similitud de lo que ocurrió en otras exposiciones conmemorativas contemporáneas. El retrato de Lorenzale existente en la Academia [fig. 139] toma como modelo el pintado por el mismo Caba para el Círculo Artístico 1889, si bien se adecúa a las dimensiones de los retratos de otros académicos (como los de Rodes o Rodríguez Pusat) y al tipo de representación. Las diferencias del retrato de la Academia con el de 1889 son significativas, ya que mientras el realizado para el Círculo Artístico presenta a Lorenzale de busto prolongado, sin ningún elemento que distraiga o añada información a la representación fisionómica, a modo de efigie solemne para la memoria, el realizado para la Academia muestra al pintor de medio cuerpo, sentado con una postura erguida y elegante, mientras sostiene con su mano izquierda el boceto -con una cuadrícula plenamente visible- de una obra religiosa que enseña al espectador; en la derecha sostiene un pincel con el que señala la composición. A pesar de este gesto, que alude a las facetas profesionales del artista como pintor y como profesor, ya que parece estar haciendo una indicación o explicación sobre su obra, la composición tiene el inconveniente de la rigidez y falta de verosimilitud propia de los retratos póstumos; el rostro, carente de expresividad a pesar de su perfecto tratamiento técnico, no parece tener ninguna relación con las manos y la obra que muestran. Es significativa la elección de una imagen profesional del artista al estilo de las anteriormente realizadas para la Academia, especialmente en comparación con los retratos de los presidentes marqués de Alfarrás y marqués de Sentmenat, lo que pone de relieve la pervivencia de una serie de valores diferenciados en los distintos miembros de la Academia: la imagen institucional y corporativa es exclusiva de los presidentes, que comparten así una identidad de grupo. Por el contrario, los retratos de artistas producidos en y para la Academia en el siglo XIX evidencian una necesidad de construcción identitaria 
individual a través del trabajo, ajustándose a unos códigos representativos de clase anclados en el mito de la autorrealización masculina.

Algo similar ocurre, ya en 1907, cuando la Academia encargue el retrato de Antonio Caba. La obra, que ingresa el 7 de noviembre de ese año, fue realizada por Arcadi Mas y Fondevila respetando las dimensiones e iconografía del retrato de Lorenzale. La idea de una cierta continuidad tipológica, próxima a la noción de galería, fue asumida por la Academia al optar por ponerle un marco "igual o similar al de Lorenzale".

\subsection{Galería de retratos de la Real Academia de Bellas Artes de Sevilla}

Al contrario de lo ocurrido en las Academias de San Carlos y de Sant Jordi, en la institución sevillana sí que se evidencia un especial interés por configurar una galería de retratos en la segunda mitad del siglo XIX. La principal causa debe buscarse en el ascenso de la Escuela de Nobles Artes de Sevilla a Academia en 1843, implicando para la corporación un cambio muy significativo en lo que refiere a la identidad institucional, que ostentó como agradecimiento y homenaje a su bienhechora, Isabel II, el título de Academia de Nobles Artes de Santa Isabel. Por otra parte, una de las particularidades más interesantes de la academia sevillana reside en su interés por configurar su identidad como legítima heredera de la tradición pictórica sevillana del Siglo de Oro, de ahí que uno de los homenajes imprescindibles fuese el realizado a Bartolomé Esteban Murillo, considerado fundador de la primera academia de pintura en Sevilla y, por lo tanto, antecesor de la corporación, motivo por el cual se promovió desde 1846 la erección de un monumento en su honor, acordándose que su ubicación idónea sería en la plaza del Museo de Pinturas (MURO OREJÓN, 1961: 62). En relación con esta identidad histórica de la corporación académica sería especialmente importante la configuración de una galería de retratos de algunos de sus personajes más ilustres, pensamiento que no se lleva a la práctica hasta después de la entrada en vigor del Real Decreto de 31 de octubre de 1849, y que se inició precisamente con la vista puesta en el pasado.

La presencia de artistas del pasado aparece también en otras colecciones académicas; no debe olvidarse que en la de San Carlos figuran copias de retratos de grandes maestros como obras presentadas para acceder al título de académico de mérito (es el caso de las copias de los retratos de Mengs, Sánchez Coello, Rubens y Gregorio Fernández), del mismo modo que en la de Sant Jordi se observan algunas copias de retratos de artistas célebres realizadas por Rómulo Batllé (Tiziano, Van Dyck, Da Vinci y Perugino) y por Pedro Pablo Montaña (Murillo y Velázquez). Sin embargo, su función en la Academia es distinta a la que tendrán en la sevillana, al formar parte en esta de la configuración de la identidad corporativa a través de una genealogía de antepasados ilustres. El hecho de que otras instituciones y colecciones sevillanas, como la de la Biblioteca Colombina o la de los duques de Montpensier, contasen con numerosos retratos de hombres ilustres puede haber influido en la decisión tomada por la Academia de Santa Isabel. 
La propuesta inicial, debida al entonces consiliario Miguel de Carvajal, era una clara reivindicación de la identidad artística de la Academia fundamentada en su componente regional, haciendo de los grandes artistas sevillanos del pasado los cimientos de una Escuela Sevillana de la que la Corporación se hacía heredera y defensora. Así, siguiendo las noticias recogidas por Antonio Muro Orejón, sabemos que esta iniciativa, recogida en el acta de 31 de enero de 1851, buscaba precisamente enlazar esta identidad entre el arte del pasado y el presente mediante la colocación en la Sala de Juntas de la Academia los retratos de los más ilustres artistas sevillanos, que serían encargados a los pintores de la institución. Conocemos que ese mismo verano de 1851 Eduardo Cano estaba realizando en Madrid el retrato del pintor cordobés Pablo de Céspedes [fig. 140], que sería remitido a la Academia apenas seis meses después ${ }^{423}$, iniciando la galería de retratos con unas características específicas que serían respetadas por otros pintores. El lienzo, de formato rectangular, simula un medallón enmarcando un retrato de busto, en cuyo borde se puede leer el nombre y fecha de la muerte del pintor; para completar la composición, un trofeo alegórico se instala al pie del retrato, con una acumulación en el extremo inferior izquierdo de los atributos propios de la profesión artística (entre otros una paleta con pinceles, un compás, un busto clásico y una maza, que cobija la firma del pintor) y, en el derecho, los correspondientes a la labor intelectual, entre los que se encuentran varios libros, un tintero con sus correspondientes plumas, y una lira. Una rama de laurel corona la parte superior del lienzo, adoptando una iconografía basada en la tradición de las estampas de hombres ilustres.

Durante el año de 1852 consta que se llevaron a cabo los retratos de Velázquez y Francisco Pacheco [figs. 141 y 142], ya que en el resumen de la actividad anual realizado en la entrega de premios de ese curso se da noticia de las donaciones recibidas por la Academia. El de Velázquez fue ejecutado por el pintor José Roldán, “cumpliendo su oferta", y el de Pacheco fue pintado "en virtud de la autorización que se le concediera" por el joven Francisco Cabral Bejarano (RABASI, 1853: 10 ${ }^{424}$ ). El modelo, sin variaciones, repite los esquemas de retrato en busto, con carácter de documento histórico, acompañados de los correspondientes atributos de la teoría y práctica de la pintura, equiparados en el caso de Velázquez, distribuidos unos y otros a cada lado de un eje central imaginario, pero con un evidente predominio de la teoría en el caso de Pacheco, donde este eje central, aparentemente roto por el protagonismo de los tratados, puede releerse como una nueva dicotomía entre la labor del artista como teórico (tintero y libro abierto) y como pintor (volúmenes cerrados y paleta).

\footnotetext{
${ }^{423}$ Gerardo Pérez Calero recoge en su monografía sobre Eduardo Cano que en la sesión de 14 de julio de 1851 la Academia había recibido un oficio del pintor sevillano, en el que comunicaba estar "pronto a pintar el retrato de Pablo de Céspedes, con sujeción al pensamiento acordado por la Sección de Pintura", y que en la sesión de 6 de diciembre de 1851 se consignaba haber recibido el retrato pintado al óleo, con el beneplácito de los académicos (PEREZ CALERO,1979: 16).

${ }^{424}$ En la misma fuente consta que las molduras para adorno de tres de los retratos de la Sala de Juntas fueron donados por el académico Francisco Javier de la Borbolla y por otro académico cuyo nombre no se especifica.
} 


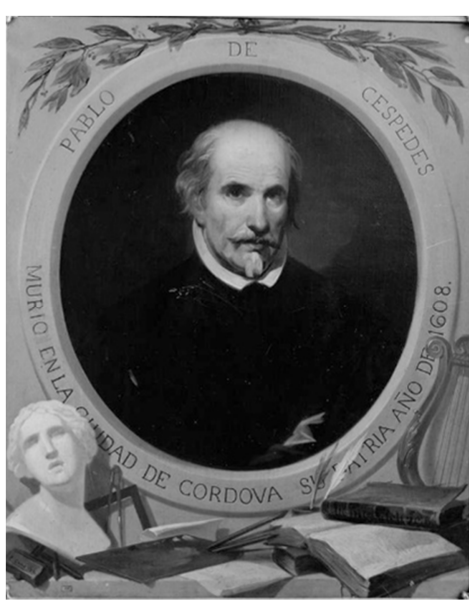

Fig. 140. Eduardo Cano, Retrato de Pablo de Céspedes. Archivo RuizVernacci $\quad\left(\mathrm{n}^{\mathrm{o}}\right.$ inv. VN28294).

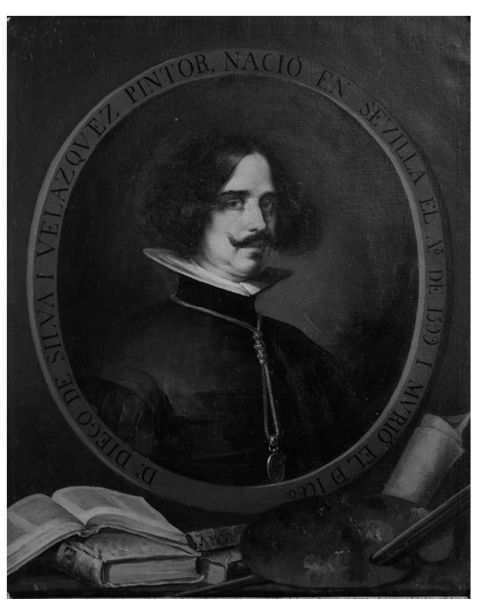

Fig. 141. José Roldan, Retrato de Velázquez. Archivo Ruiz Vernacci ( $\mathrm{n}^{\mathrm{o}}$ inv. VN-28299).

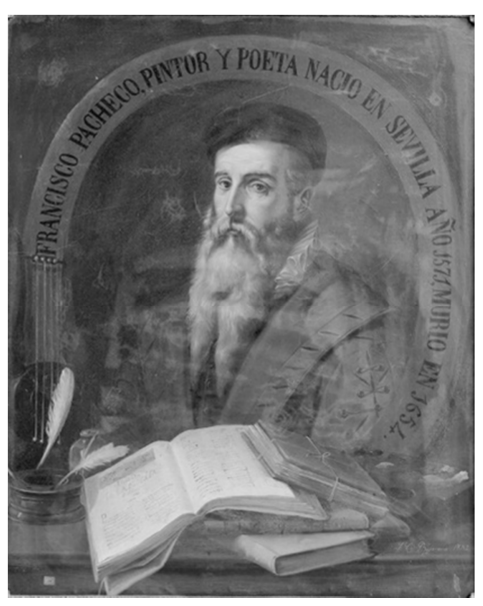

Fig. 142. Francisco Cabral, Retrato de Pacheco. Archivo Ruiz Vernacci ( $\mathrm{n}^{\mathrm{o}}$ inv. VN28296).

Antonio Muro Orejón (1967: 96 y 97), probablemente tomando como referencia las actas de la academia ${ }^{425}$, fecha también en 1852 los retratos de Murillo y Herrera el Viejo, pintados por Antonio Cabral Bejarano, el de Alonso Cano, por José de Escacena, así como el de Valdés Leal, por Manuel Cabral, y ubica, por el contrario, el de Velázquez por Roldán en 1857.

El Retrato de Bartolomé Esteban Murillo [fig. 143], que figurará como obra de Francisco Cabral y Aguado en los catálogos del Museo Provincial (GESTOSO, 1912: ${ }^{\circ}$ 320; HERNÁNDEZ DÍAZ, 1967: 25), se sujeta al modo de representación establecido para la galería, sin establecer grandes particularidades que señalen al fundador de la Academia sevillana ${ }^{426}$ : su retrato figura sobre un trofeo que combina, por una parte, una inmaculada paleta con sus respectivos pinceles, coronada con laurel, y por otra, alusiones a la teoría pictórica mediante dos tratados, decorado a su vez el marco con hojas de acanto. Como rasgo significativo, este retrato se encuentra coronado por un ouroboros que rescata el emblema como alusión a la inmortalidad del genio. Tampoco la representación de Alonso Cano por José Escacena [fig. 144] se libra de las restricciones que impone una galería de artistas ilustres, recurriendo a los elementos habituales para configurar la imagen del hombre como pintor, escultor y arquitecto, a lo que se añade un detallado busto infantil. Sí que presentan algunos cambios interesantes los retratos de Francisco de Herrera el Viejo y de Juan de Valdés Leal [figs. 145 y 146], significativos no en tanto a la efigie sino en cuanto a los atributos de que se acompañan, puesto que los los medallones se dotan de mayor movimiento y ornato (llegando a insinuar el de Valdés Leal el arranque de un caduceo en la parte superior) y de alusiones mucho más llamativas respecto a la práctica del arte: las paletas adquieren un nuevo protagonismo al impregnarse de vivos colores debidamente dispuestos y con sus correspondientes mezclas en el centro, y los pinceles con una variedad muy detallada, se

\footnotetext{
${ }^{425}$ Muro Orejón no acompaña estas afirmaciones de ninguna referencia documental que lo acredite, y la imposibilidad de consultar, por nuestra parte, el material del Archivo de la Academia, nos lleva a plantearlo con sus correspondientes reservas.

${ }^{426}$ Este retrato fue colocado en lugar de honor en el testero del salón de sesiones de la Academia durante los festejos del segundo centenario de la muerte del artista ("Bartolomé Esteban Murillo", 1882: 1 y 2).
} 


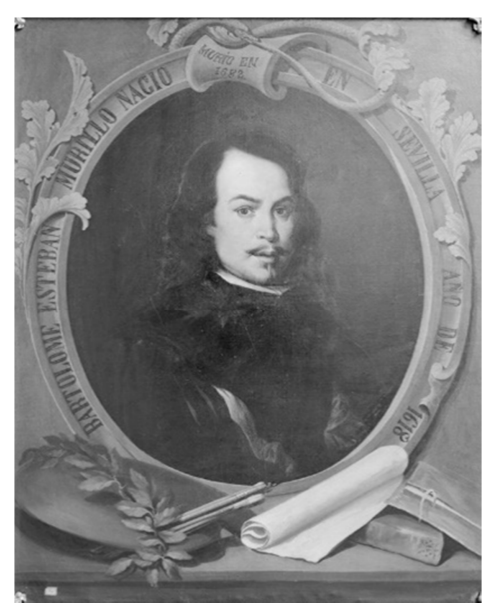

Fig. 143. Francisco Cabral, Retrato de Murillo. Archivo Ruiz Vernacci ( $n^{\circ}$ inv. VN-28297).

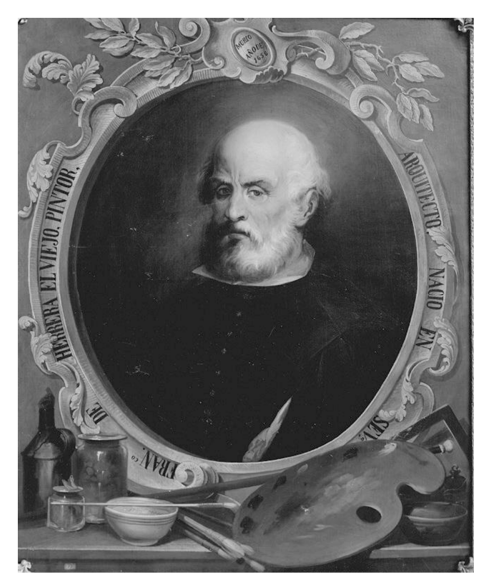

Fig. 145. Francisco Cabral, Retrato de Francisco de Herrera el Viejo. Archivo Ruiz Vernacci ( $\mathrm{n}^{\circ}$ inv. VN-28293).

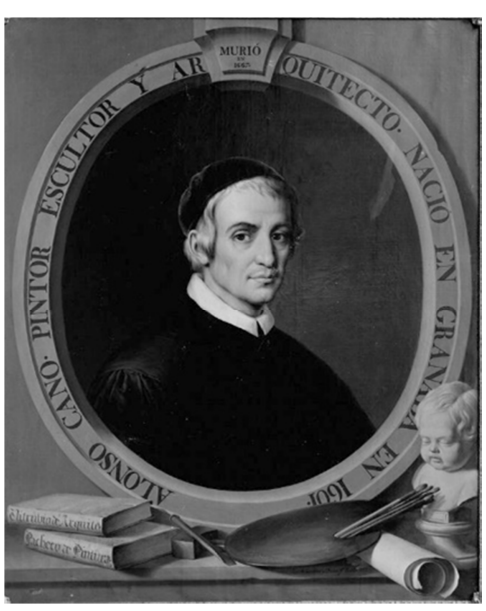

Fig. 144. José Escacena, Retrato de Alonso Cano. Archivo Ruiz Vernacci ( ${ }^{\circ}$ inv. VN-28292).

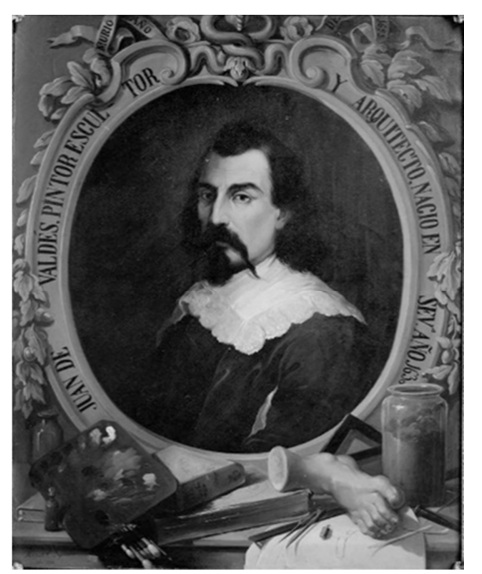

Fig. 146. Manuel Cabral, Retrato de Juan de Valdés Leal. Archivo Ruiz Vernacci ( $\mathrm{n}^{\mathrm{o}}$ inv. VN28300).

acompañan ahora de frascos de pigmento y aceite, señalando una idea de la pintura más próxima a los autores de los retratos que a la de los propios retratados.

Respecto a las efigies de los artistas, pueden hacerse pocas apreciaciones respecto a su vinculación con una masculinidad artística decimonónica, más allá del carácter de este como caballero erudito y cristiano. Consta el interés por ofrecer una imagen histórica verídica a través de la documentación o inspiración en retratos o estampas existentes, atendiendo a la mayor fidelidad posible en cuanto a los rostros y vestimenta; de hecho, se descartó la realización del retrato de Luis de Vargas, encargado a Joaquín Domínguez Bécquer, debido a que este no encontró imagen en la que inspirarse ${ }^{427}$. Finalmente, con destino a esta galería de retratos de artistas del pasado se realiza, ya de manera tardía en 1867 y con cierto carácter aislado, el retrato del escultor Martínez Montañés, en el que Joaquín Domínguez Bécquer prescinde de la representación de atributos para ubicar una sencilla leyenda, lo que enlaza con otros retratos de especial interés para nuestro estudio. Debemos señalar que además de todos estos retratos

${ }^{427}$ Acta de 1 de julio de 1853. Recogido en MURO OREJÓN, A. (1967), p. 97. 
mencionados, que se conservan en la actualidad ${ }^{428}$, Muro Orejón (1967: 73) señala otros tres: el de Zurbarán y Roelas, al parecer pintados por Romero, y el del escultor Pedro Roldán, que habría realizado José Roldán, cuyo paradero actual desconocemos y que en caso de haberse realizado podemos suponer perdidos en el siglo XIX o comienzos del XX, ya que no constan en el catálogo de 1912.

Ya se ha señalado el carácter excepcional de esta galería respecto a otras colecciones académicas en España, que enlaza con la necesidad de historiar la identidad contemporánea a través de las artes y los artistas del pasado, de tal modo que la historia de una Escuela de Nobles Artes relativamente modesta se dignifique enlazando, al convertirse en Academia, con la tradición artística sevillana y, con ella, el estatus social de sus miembros, que busca unas raíces no en la administración local o en el poder político coetáneo, sino en figuras que reivindican la autonomía del artista. La preocupación por ofrecer una imagen corporativa a través de su historia reciente se pone de manifiesto cuando la de Santa Isabel acuerda, tras la muerte en 1858 de su primer presidente (MURO OREJÓN, 1967: 73), configurar también una galería paralela de carácter institucional. Se inicia así una nueva imagen de la Academia mediante los retratos póstumos de los hombres que, ajenos a la práctica artística, ejercieron la presidencia. La peculiaridad de esta iniciativa reside en tratarse de una serie de imágenes del poder que sorprende por su carácter marcadamente diferenciado respecto a la galería de antepasados ilustres existente en la misma Academia, pero también por la falta de constancia que se observó en su realización.

Es probable que para la realización del primer retrato, el del presidente Manuel López-Cepero [fig. 147], Francisco Cabral Bejarano tomase como referencia el que se había realizado a finales del siglo XVIII del director de la Escuela de Bellas Artes, Francisco de Bruna y Ahumada [fig. 148] (GESTOSO, 1912: n 318; HERNÁNDEZ DÍAZ, 1967: 25), conservado en la Academia: se trataría de retratos de medio cuerpo,

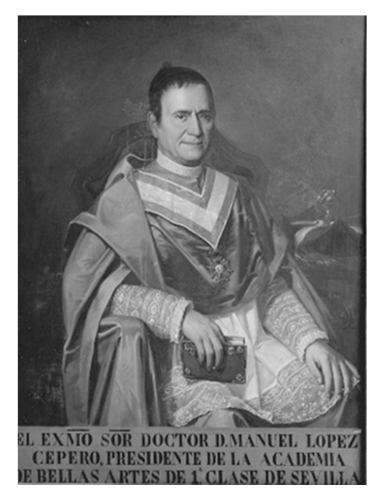

Fig. 147. Francisco Cabral, Retrato de Manuel López-Cepero. Archivo Ruiz Vernacci ( ${ }^{\circ}$ inv. VN-28298).

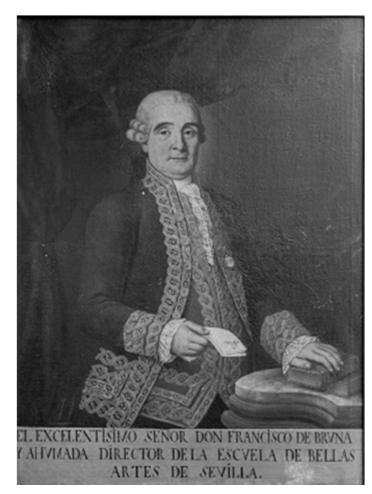

Fig. 148. Anónimo. Retrato de Francisco de Bruna y Ahumada. Archivo Ruiz Vernacci ( ${ }^{\circ}$ inv. VN28295)

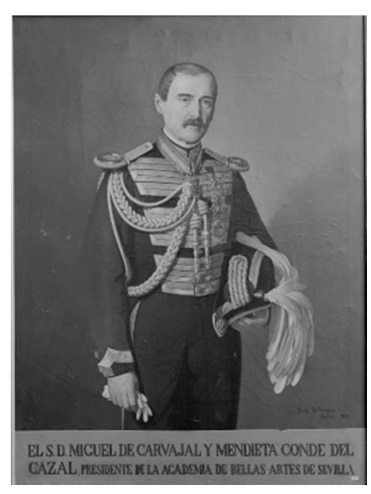

Fig. 149. Joaquín Domínguez, Retrato de Miguel de Carvajal. Archivo Ruiz Vernacci (n1 inv. VN28290).

\footnotetext{
${ }^{428}$ Agradecemos al secretario general de la Academia de Bellas Artes de Santa Isabel de Hungría, el Sr. D. Fernando Fernández Gómez, el habernos facilitado un listado detallado de los retratos que se conservan en la actualidad, procedentes de esta galería de retratos, ubicados actualmente en el Salón de Actos y Sala de Juntas de la Academia. No obstante, para el conocimiento directo de las obras ha sido preciso recurrir a las fotografías conservadas en el archivo Ruiz Vernacci.
} 
de carácter oficial, acompañados de una leyenda al pie especificando el nombre y cargo; en este caso, las obras superan las dimensiones de los retratos de artistas del pasado y se prescinde de la representación a través del medallón para revestirlo de una mayor solemnidad y veracidad, y, por lo tanto, de una mayor autoridad en su presencia en la sala. En junio de 1858 el retrato al óleo era incorporado a la galería de la Sala de Juntas (RABASI, 1858: 7): el deán de la catedral fue representado sentado, luciendo vestiduras eclesiásticas como correspondía a su cargo y dignidad, y luciendo sobre el pecho la cruz de comendador de la orden de Isabel la Católica. Llama la atención que, a pesar de haberse tomado la resolución de proseguir la galería presidencial, el retrato del segundo presidente, don Manuel Cano Manrique, no fuese realizado hasta 1967 por el pintor Juan Rodríguez Jaldón $^{429}$. En este sentido cabe destacar que se realizó, y curiosamente aún en vida y durante su propia presidencia ${ }^{430}$, el retrato de su sucesor en el cargo, D. Miguel de Carvajal y Mendieta [fig. 149], del que se ocupó el pintor Joaquín Domínguez Bécquer en 1872 representándolo de medio cuerpo y vestido con el traje de maestrante de Sevilla, institución nobiliaria y militar de la que Carvajal ostentaba el título de Teniente de Hermano Mayor (GESTOSO, 1912: $n^{\circ} 313$ ). No debe pasarse por alto la dicotomía existente a partir de este momento en la Sala de Juntas al oponerse dos modelos de masculinidad tan dispares, como son la autoritaria eclesiástica de López Cepero y la militar de Carvajal, frente a las imágenes intelectuales de los artistas del pasado, y la civil contemporánea del buen burgués presente en los retratos que se analizan a continuación. La presencia de su retrato en vida obedece, sin duda, a un homenaje por parte de la Corporación ante la personalidad de Carvajal, cuya relevancia en el panorama público era notoria al ostentar varios cargos políticos, entre ellos el de presidente de la Diputación de Sevilla. Sin embargo, no pueden ofrecerse datos sobre su forma de ingreso ni las relaciones con el autor de la obra, al no haber sido posible consultar las actas ni la documentación existente en la Academia.

El retrato de don Andrés Lasso de la Vega, conde de Casa Galindo, no fue pintado hasta 1902, dos años después de su muerte, a pesar de que su presidencia, iniciada en 1882, había finalizado en 1893; en esta ocasión el autor fue Gonzalo Bilbao, quien optó también por una imagen oficial, tomada de fotografía, igualmente vestido con el traje de maestrante de Sevilla, aunque se opta por volver al formato original en óvalo y a la representación de busto prolongado (MURO OREJÓN, 1961: 91; GESTOSO, 1912: nº 312). No se realizó, al parecer, el retrato de José María Asensio, presidente entre los

\footnotetext{
${ }^{429}$ Tomamos la fecha de 1966-1967 como la de realización del retrato ya que, en su monografía sobre la Academia sevillana Antonio Muro Orejón se lamenta de que aún no se hubiese llevado a cabo, a pesar de haberse encargado en 1933 al Sr. Martínez Martín (MURO OREJÓN,1961: 91); sin embargo, el catálogo de Hernández Díaz de 1967 sí que lo recoge entre las obras existentes en la Academia (HERNÁNDEZ DÍAZ, 1967: 25). Del mismo modo, sabemos que el autor, Juan Rodríguez Jaldón, falleció en ese mismo año.

${ }^{430}$ D. Miguel de Carvajal y Mendieta fue presidente de la Academia desde1860 hasta 1882.
} 
años 1893 y $1894^{431}$, y el de su sucesor en el cargo, don Manuel Gómez-Imaz, tampoco fue realizado hasta la década de $1970^{432}$.

$\mathrm{Si}$ en 1858 se iniciaba esta inconstante galería de retratos de presidentes, caracterizada por ofrecer una imagen -masculina, hermética y completamente desvinculada de la representación del artista- del poder dentro de la institución, ocurría también otro suceso importante relacionado con la identidad artística de la Academia sevillana, ya que Valeriano Domínguez Bécquer presentó el primer retrato, aunque póstumo, de un artista contemporáneo para figurar en la Sala de Juntas o de sesiones como parte de esta galería académica (RABASI, 1858: 7). Antonio Muro Orejón hizo una clasificación de estos retratos en tres grupos, abordando de manera separada una galería de retratos de presidentes, otra de retratos de grandes maestros, y por último otra, bajo la consideración de "otros retratos", alusiva a académicos de excepcional mérito. Resulta tal vez muy ambicioso considerar esta última como una galería aislada al estar compuesta únicamente por cinco retratos que, a nivel formal, comparten rasgos con las dos galerías anteriormente estudiadas; del mismo modo, esta calificación de retratos de académicos resulta acertada aunque inexacta, al tratarse en todos los casos de retratos de algunos de los pintores más significativos que formaron parte activa en la vida de la Academia.

El retrato presentado por Valeriano consistía en una efigie de su padre, el pintor José Domínguez Bécquer [fig. 150], fallecido en Sevilla a la temprana edad de treinta y seis años en 1841. Según Muro Orejón, fue la propia corporación la que encargó el retrato en 1853 (en pleno furor de la creación de la galería de grandes maestros sevillanos), al pintor y académico Joaquín Domínguez Bécquer y, por lo tanto, con anterioridad a la galería de presidentes. Probablemente por este motivo la efigie presentada por Valeriano Domínguez Bécquer ofrece similitudes con los retratos pintados para la galería de artistas ilustres, al repetir el trampantojo de un medallón, pero no incluye ningún elemento relativo al arte; a pesar de esto, la indumentaria moderna, con elegante traje de chaqueta y levita, y una gran corbata de lazo al cuello, marcan una ruptura evidente con los otros retratos de artista, subrayando una contemporaneidad casi caduca ya que, en el fondo, no deja de ser un retrato de rasgos románticos, uno de los motivos por los que podría considerarse que el retrato de José Domínguez Bécquer podría incluirse en esa galería históricaa y simbólica de los artistas sevillanos. Pero por otra parte, la ausencia de atributos vinculados con el arte y la inclusión al pie de una escueta leyenda con los datos del $\operatorname{artista}^{433}$, que recuerda la aparecida en el retrato de López Cepero -presentado, es necesario repetirlo, en el mismo

\footnotetext{
${ }^{431}$ Muro Orejón señala que fue encargado a Rico Cejudo, sin que en 1967 se hubiese realizado; tampoco consta entre la relación de retratos conservados por la Academia facilitada por el actual secretario general de la misma.

${ }^{432}$ Encargado en 1933 a Lafita Díaz, según Muro Orejón, en 1967 aún no se había realizado, y tampoco consta en el catálogo del museo provincial de Hernández Díaz de 1967. Según la información aportada por la Academia de Bellas Artes de Santa Isabel de Hungría, fue realizado por Miguel Ángel del Pino Sardá en fecha anterior a 1973, aunque Pérez Calero no menciona ninguna de sus obras tras 1956 -en su mayoría retratos de encargo (PEREZ CALERO, 2013: 781).

${ }^{433}$ En ella se lee: "D. José Domínguez Bécquer e Insausti. Pintor / sevillano. Nació el 22 de enero de 1805 y murió en / 26 de enero de $1841 "$ ".
} 
año que el de Domínguez Bécquer-, parece convertirlo en un híbrido a medio camino entre las dos galerías: un pintor, pero que no comparte la iconografía de los grandes artistas del pasado; y al mismo tiempo un contemporáneo que merece ser dignificado en calidad de hombre artista.

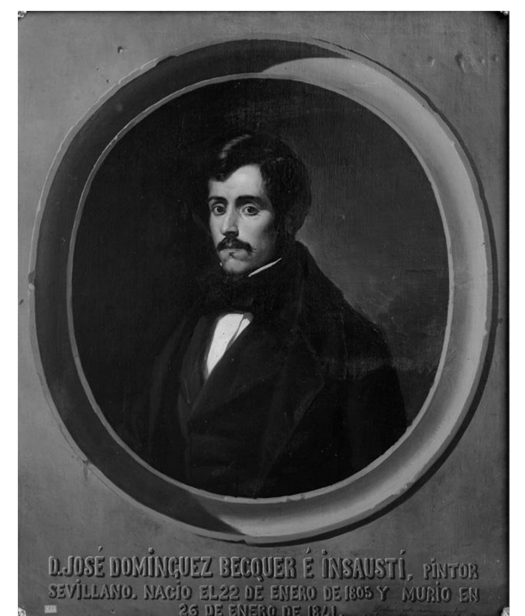

Fig. 150. Valeriano Domínguez, Retrato de José Domínguez Bécquer. Archivo Ruiz Vernacci $\left(n^{\circ}\right.$ inv. VN-28304).

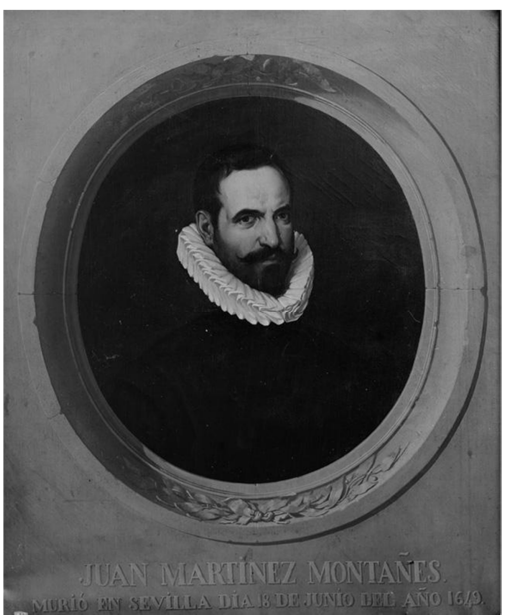

Fig. 151. Joaquín Domínguez, Retrato de Martínez Montañés. Archivo Ruiz Vernacci ( $\mathrm{n}^{\mathrm{o}}$ inv. VN28303).

Resulta curiosa la elección de Domínguez Bécquer como inaugurador de esta "tercera vía" en la galería de retratos, ya que si de pintores sevillanos, contemporáneos e ilustres se trataba, Antonio María Esquivel y José Gutiérrez de la Vega sumaban honores dignos de ser reconocidos: alumnos de la Escuela de Nobles Artes, pintores de éxito reconocido a nivel nacional que sumaban a los muchos honores concedidos el de ser pintores de cámara, y cuyo estilo pictórico estaba directamente relacionado con la escuela sevillana del Siglo de Oro hasta tal punto de ser considerados los Murillos de la España moderna. No obstante, carecían de dos requisitos importantes para ser considerados para la galería: por una parte, su relación con la Academia de Santa Isabel no era la más apropiada, ya que Esquivel se había consagrado como director de Anatomía Pictórica en la Academia de San Fernando, y José Gutiérrez, a pesar de haber sido nombrado director de pintura de la de Santa Isabel, había eludido sus responsabilidades como tal; por la otra, en las fechas en que se encarga el retrato de Domínguez Bécquer Esquivel y Gutiérrez de la Vega tenían el fatal inconveniente de estar aún vivos. La primera de las razones es especialmente significativa ya que los artistas elegidos desde este momento para formar parte de la galería debían ajustarse a la intención de crear una identidad colectiva de la academia, habiendo sido destacados miembros de ella. La presencia del retrato de Domínguez Bécquer puede deberse, por una parte, a la relación de José Domínguez Bécquer con la Escuela de Nobles Artes de Sevilla, de la que fue teniente de pintura desde 1835 hasta su muerte, aunque esto no parece motivo suficientemente sólido como para que la institución, una vez constituida como Academia, decidiese realizar su retrato; por otra parte, puede responder a esa idea de homenaje a título póstumo, relacionado tal vez con el tipo de pintura, especialmente vinculada a las temáticas costumbristas y el ámbito sevillano, que había otorgado más renombre al retratado. 
La estética de este retrato pudo haber condicionado la del Retrato de Martínez Montañés [fig. 151], al tratarse de la obra más próxima en el tiempo, aunque se tratase de un retrato de un artista del pasado; este, a su vez, condicionó el del pintor y académico Antonio Cabral Bejarano [fig. 152]. Realizado en $1872^{434}$, casi doce años después de la muerte del artista, encontramos nuevamente como autor del retrato al hijo del retratado, en este caso Manuel Cabral. Adaptándose al modelo establecido por el retrato de José Domínguez Bécquer, Manuel Cabral presenta a su padre dentro del consabido medallón, con una leyenda en la que se exponen los méritos del efigiado ${ }^{435}$. La relación de Cabral Bejarano con la Academia fue mucho más intensa que la de Domínguez Bécquer, ya que fue académico numerario e introdujo, debido a su papel como primer director de la Escuela de Bellas Artes, importantes mejoras, como la adquisición de una estatua anatómica y modelos de pies y manos para las clases de Anatomía Pictórica y del Antiguo, de estampas para la de Grabado, la construcción de una bancada en forma de anfiteatro para la del Natural o el cambio del sistema de iluminación para esta y la del Antiguo (RABASI, 1853: 6 y 7). Parece evidente que Manuel Cabral tuvo presente un modelo para la realización de este retrato póstumo, tal vez el propio autorretrato que Antonio Cabral realizó en 1851 que se conserva en el Museo de Bellas Artes de Sevilla ( $\mathrm{n}^{\circ}$ inv. $\mathrm{n}^{\circ}$ inventario DJ1479P ); no obstante, la imagen que ofrece es ya plenamente la de un retrato oficial, en el que, vestido de etiqueta, luce orgulloso al cuello la cruz de comendador de Isabel la Católica que le fue concedida en 1844. Al mismo tiempo, luce un elemento que introduce claramente una identidad corporativa: la medalla distintiva de académico de Santa Isabel, que comenzó a utilizarse en 1858. Merece la pena cotejar este retrato con otra obra, tal vez un autorretrato del propio Antonio Cabral [fig. 153], por las similitudes y diferencias que ofrecen entre sí, y que conocemos a través de una fotografía del archivo Moreno ${ }^{436}$. En este retrato de busto, la figura del pintor, ataviada de etiqueta con corbata negra y luciendo al cuello la cruz de comendador de Isabel la Católica, ha sido deliberadamente incluida en un medallón siguiendo la iconografía murillesca tan en boga en la Academia de Santa Isabel, ubicando al pie de este la paleta con los colores dispuestos y sus correspondientes pinceles, un frasco de disolvente y un libro.

\footnotetext{
${ }^{434} \mathrm{El}$ encargo de este retrato parece remontarse a la sesión de 21 de noviembre de 1871, en la que se rindió homenaje a Eduardo Cano, de la que Muro Orejón no da noticia, pero que sí recoge Pérez Calero (PÉREZ CALERO, 1979: 31). Una breve nota en el periódico La Convicción recoge esta iniciativa: "La Academia de Bellas Artes de Sevilla ha resuelto colocar entre los retratos de sus miembros beneméritos que decoran el salón de sesiones, el de don Antonio Cabral Bejarano, pintor notable y a quien se debe, en unión de Manuel López Cepero, la creación del magnífico museo de pinturas..." (“Crónica local”, 1871: 7379).

${ }^{435}$ Más extensa que la de Domínguez Bécquer, en la de Antonio Cabral se lee: "Don Antonio Cabral Bejarano, académico de mérito de la de nobles ar/tes de San Fernando, pintor de Cámara del Museo Naval de Madrid, uno / de los fundadores del museo provincial de Sevilla y catedrático y /director de su Escuela de Bellas Artes. / Nació 1779 Murió 1861".

${ }^{436}$ Catalogado como un autorretrato de Manuel Cabral, no parece ofrecer dudas respecto a la identidad del representado, Antonio Cabral Bejarano.
} 


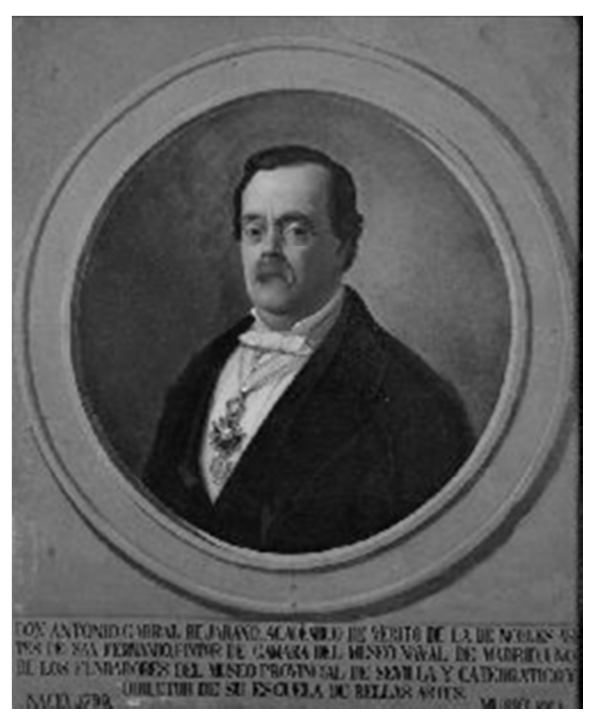

Fig. 152. Manuel Cabral, Retrato de Antonio Cabral Bejarano. Archivo Ruiz Vernacci $\left(\mathrm{n}^{\mathrm{o}}\right.$ inv. VN-28301).

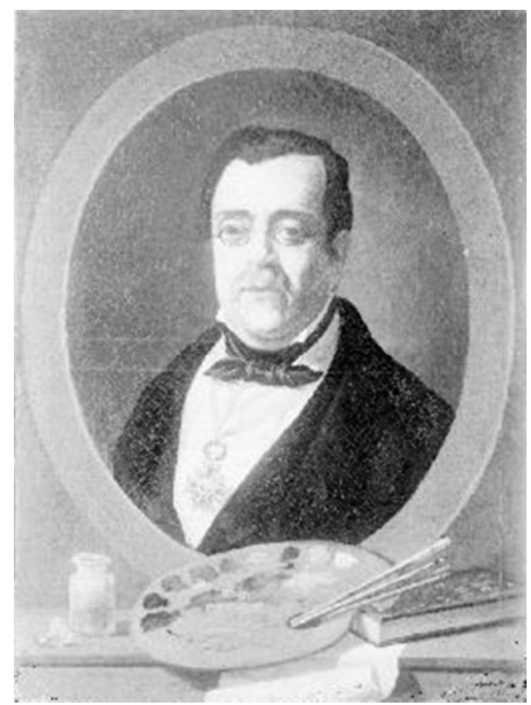

Fig. 153. Antonio Cabral Bejarano, Autorretrato. Archivo Moreno ( $\mathrm{n}^{\circ}$ inv. 08195B).

En esta representación en la que se vincula directamente la imagen del éxito o reconocimiento social de la profesión con los atributos de esta, la ausencia de la medalla corporativa puede ser señal de que o bien el retrato no estaba destinado al ámbito académico, o bien de que su fecha de producción fue anterior a la concesión del privilegio de uso de estas a las academias, por lo que pudo haberse pintado entre 18501855 siguiendo los códigos al uso en la representación académica. Si seguimos esta última hipótesis, parece imposible que Manuel Cabral no conociese esta obra, ya que la similitud en la disposición de la figura y la vestimenta es mucho más evidente que la que se puede observar en el autorretrato del Museo de Bellas Artes de Sevilla, pudiendo afirmarse que Manuel Cabral parece copiar literalmente la figura, aunque reemplace la corbata negra por otra blanca, y añada la medalla corporativa. Parece así significativo que, más acorde con los nuevos usos en el retrato del artista como hombre de éxito y en relación al modelo introducido por el retrato de José Domínguez Bécquer y a las imágenes del poder reflejadas por los retratos de presidentes, Manuel Cabral prescindiese de los útiles que señalaban la condición de artista del efigiado a favor de una imagen que incide en la representación plástica de los méritos y la identidad corporativa.

Aún pasarían muchos años hasta que otro retrato de un director de la Escuela, en concreto el de Manuel Barrón ${ }^{437}$ [fig. 154], fuese destinado a la galería de la Academia. Así, seis años después de su muerte, se incorporaba en 1890 una nueva efigie realizada por Manuel Cabral que seguía fielmente el estilo empleado en el retrato de su padre: el pintor Manuel Barrón aparece representado como un hombre moderno, elegante y exitoso, luciendo al cuello la cruz de la orden de Carlos III y la medalla de la Academia sevillana de Bellas Artes, lo que incide una vez más en la identidad corporativa y no en

\footnotetext{
${ }^{437}$ Manuel Barrón fue director de la Escuela de Bellas Artes entre 1872 y 1884. No obstante, sus dos predecesores, José Romero (director entre 1869 y 1871) y Claudio Boutelou (director en los años 18711872 y 1884), no merecieron el honor de figurar en la galería.
} 
la profesión artística, de la que deja constancia la leyenda al pie ${ }^{438}$. Parece evidente que Cabral empleó como modelo algún retrato o fotografía existente, ya que el representado no aparenta más de cincuenta años.

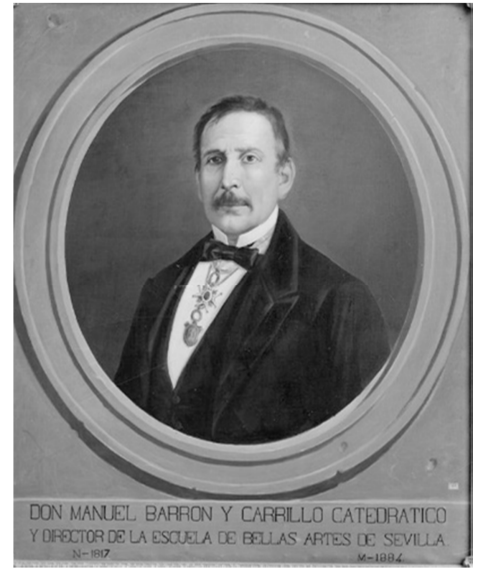

Fig. 154. Manuel Cabral, Retrato de Manuel Barrón. Archivo Ruiz Vernacci (VN-28302).

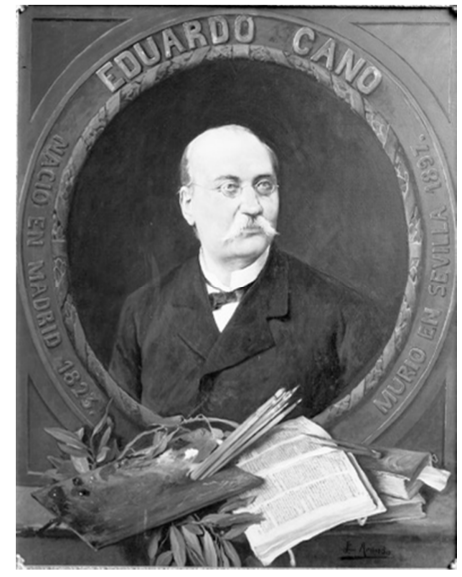

Fig. 155. José Jiménez Aranda, Retrato de Eduardo Cano. Archivo Ruiz Vernacci (VN-28291).

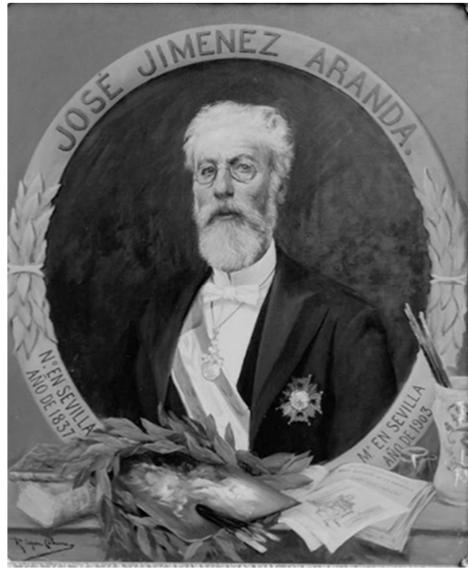

Fig. 156. Ricardo López, Retrato de José Jiménez Aranda. Archivo Ruiz Vernacci (VN-28288).

Finalmente, conocemos otros dos retratos de artistas sevillanos estrechamente relacionados con la Academia, realizados uno en 1897 y otro ya en 1903 con el objeto específico de formar parte de esta galería, y en los que paradójicamente se recuperan los elementos distintivos de su profesión, teniendo sin duda en cuenta el fuerte impacto que tuvieron en la pintura sevillana e incluso en el panorama nacional. El primero de ellos es el del pintor Eduardo Cano [fig. 155], cuyo fallecimiento causó profundo sentimiento en la Academia; esta, en la sesión de 8 de abril de 1897, tan solo una semana después, aceptó la propuesta del académico don Manuel Gómez Imaz de que se realizase un retrato de Cano para colocarlo en la galería:

Siendo el Sr. Don Eduardo Cano el maestro insigne de tantos distinguidos artistas, hoy honra de esta Escuela, [se propuso] se hiciera por uno de ellos, Académico de la Sección de Pintura, el retrato de dicho Sr. en iguales proporciones de los que están colocados en la Sala de Juntas, como justo recuerdo en honor de su inolvidable reputación (PÉREZ CALERO, 1979: 51).

Se ofreció a pintarlo uno de sus discípulos, y su sucesor en la cátedra de composición y colorido, el reputado pintor José Jiménez Aranda, quien tomó como referencia una fotografía ${ }^{439}$. Haciendo uso del formato habitual de moldura o medallón fingido, aprovechó esta para formar una decorativa corona vegetal e incluir los datos de nacimiento y muerte del artista. Lejos del carácter oficial de los retratos pintados por Manuel Cabral, la figura de Eduardo Cano se muestra plasmada con una elegancia sobria, con chaqueta cerrada y sin ostentar ninguna condecoración o reconocimiento, aunque su gesto -quizás por estar tomado de fotografía- es el más esquivo y hermético de la galería: su mirada permanece completamente ajena al hipotético espectador, en

\footnotetext{
${ }^{438}$ En el retrato se lee: "Don Manuel Barrón y Carrillo Catedrático / y director de la Escuela de Bellas Artes de Sevilla / N-1817 M-1884".

${ }^{439}$ Esta fotografía fue reproducida, mediante grabado, en La Ilustración Española y Americana de 30 de abril de 1897 , p. 269, acompañando un artículo de José Cascales y Muñoz.
} 
plena ensoñación; la ligera inclinación de la cabeza parece indicar que el pintor, hombre creativo, busca inspiración en temas elevados, lejos de las banalidades terrenales: una falsa ilusión fruto de la descontextualización de la fuente original, en que aparece de medio cuerpo, posando apoyado en el mueble decorativo del estudio fotográfico. Es llamativa también la ausencia de elementos que lo vinculen, al menos simbólicamente, a la corporación académica; la ausencia de medalla puede deberse a la renuncia en 1887 de Eduardo Cano a su título de académico de número, que ostentaba desde 1850, para dejar libre esa vacante ya que, como profesor, contaba con el título de académico nato y podía seguir igualmente vinculado a la Academia (MURO OREJÓN, 1961: 78).

Elegido académico de número en 1892 y tras haber desarrollado una importante labor docente en la escuela de Bellas Artes, el fallecimiento en 1903 de José Jiménez Aranda supuso también una pérdida importante para la Academia de Bellas Artes de Santa Isabel. Se encargó de pintar su retrato su discípulo y yerno, Ricardo López Cabrera, quien optó una vez más por una imagen híbrida entre la representación del éxito y las alusiones a la profesión artística [fig. 156]. Lejos de la espontaneidad de los autorretratos de Jiménez Aranda, se aprecia una mayor proximidad al retrato realizado por Joaquín Sorolla (Museo Sorolla, $\mathrm{n}^{\circ}$ inv. 01431); va vestido de etiqueta, con la banda y cruz de la orden de Isabel la Católica, y lleva al cuello la medalla de académico. Al pie del medallón aparecen la paleta y los pinceles del pintor, rodeados por una corona de laurel. A su lado, un ejemplar del Quijote alude a uno de los trabajos de ilustración más ambiciosos del pintor, que se encargó de realizar, junto a otros artistas, las láminas para la edición del llamado "Quijote del Centenario"; sobre el libro abierto descansa el dibujo a la aguada de la primera de estas láminas, que representa al ingenioso hidalgo en plena ensoñación -una ensoñación compartida por el propio Jiménez Aranda, quien aparece, como sucedía con Eduardo Cano, con una mirada perdida y reflexiva que genera una sensación de melancólico aislamiento, y en una actitud completamente opuesta a la mirada inquisitiva y reflexiva sobre la propia imagen del autorretrato que presidió en 1903 la exposición conmemorativa celebrada en la Casa-Lonja de Sevilla ${ }^{40}$ y la exposición Jiménez Aranda en Madrid (L.Z., 1903: 3; "Fiesta artística...”, 1903: 2). En el extremo derecho hace su aparición un vaso de cerámica pintada, en el que reposan algunos pinceles, un elemento que será retomado por otro retrato de artista, en este caso artista-presidente, en 1934, en el autorretrato ejecutado por Gonzalo Bilbao (RINCÓN, 1991: 116) con clara intención de figurar en la galería académica ${ }^{441}$.

A falta de una aproximación a las fuentes documentales sobre estos retratos que permitan elaborar un análisis más profundo de las relaciones interpersonales en la Academia de Santa Isabel, pueden extraerse algunas conclusiones de las propias obras. Respaldamos la idea de Muro Orejón sobre una galería tripartita, como se desprende de

\footnotetext{
${ }^{440}$ Publicado en la portada de La Ilustración Española y Americana de 22 de mayo de 1903, se convirtió en la imagen representativa del pintor por tratarse de un autorretrato pintado en sus últimos meses de vida, reproduciéndose en la portada de la revista barcelonesa La Ilustración Artística de 1 de junio de 1903, .

${ }^{441}$ Siguiendo el tipo de representación diferenciada del artista como hombre de reconocido mérito a nivel social, aparece vestido de etiqueta con la banda de la orden de Alfonso XII cruzada al pecho, destacando al pie los instrumentos de su arte.
} 
la existencia de retratos de artistas del pasado, presidentes y artistas contemporáneos. Sin embargo, no debe olvidarse que tan solo dos retratos presidenciales fueron realizados en el siglo XIX, frente a la rotunda presencia de ocho artistas del pasado y de cinco de contemporáneos. Además, pese a la magnificencia de los retratos presidenciales, tanto por sus mayores dimensiones como por su cuidada iconografía del poder, tal y como requería el decoro institucional, las imágenes ofrecidas son las de dos tipos de masculinidad relacionadas con el privilegio tradicional (el clero y la aristocracia militar), de modo que las de los artistas aparecen como las únicas imágenes de hombres contemporáneos relacionados con la vida civil y las realidades (y aspiraciones) de la burguesía artística, y, por lo tanto, como los retratos de más fácil identificación para el académico que las observase. Tampoco puede obviarse la importancia de los vínculos paternofiliales en los retratos de artistas contemporáneos, dos en relación familiar directa, otra en relación política, y dos en clave simbólica al tratarse de una relación discípulo-maestro, algo que recuerda, si bien en modo lejano, a la situación en la Academia de San Fernando y a la perpetuación de la memoria con carácter dinástico dentro de la propia institución.

\subsection{Retratos de artista en las Exposiciones de las Academias de Bellas Artes}

\subsubsection{Academia de Bellas Artes de San Fernando}

Al analizar las características de las exposiciones de la Academia de San Fernando, Esperanza Navarrete (1999: 298) señala la escasa implicación mostrada por los propios académicos en hacer figurar sus obras junto a las de los alumnos y aficionados; sin embargo, en las obras presentadas por algunos académicos e incluso por los discípulos se pone de relieve un mayor interés por el retrato de artista del que se había manifestado en la Sala de Retratos. Es preciso tener en cuenta que, aparte de como escaparate festivo, la exposición de la Academia era en muchas ocasiones el escenario para desplegar ideales políticos y avances estéticos en la pintura de historia, así como las vanidades - políticas y sociales- mediante el retrato; a pesar de que este fue el género predominante, el número de retratos de artista es bastante reducido, y más aún los de artistas vinculados a la corporación académica entre 1794 y 1851; su presencia en las exposiciones, sin embargo, puede entenderse como un rasgo significativo de la construcción de la identidad profesional de los artistas y de la sociabilidad académica. Otros dos rasgos llaman la atención en las exposiciones de la Academia respecto al retrato de artista: el primero, que fueron escenario para la muestra de autorretratos, aunque en muchas ocasiones debidos a pintores aficionados: se recogen, entre otros, un Autorretrato realizado por José Alonso del Rivero en la exposición de 1801, otro de Joaquín Gallardo en la de 1806, uno en miniatura de José Morel en la de 1807, un Autorretrato de José de la Revilla en la de 1829 (El Correo, 1829: 1), los tres presentados por José María Dusmet, Guillermo de Lima y José Peñarredonda en la de 1841 (PARDO CANALÍS, 1975; NAVARRETE, 1999: 486), o el del pintor Ugalde en 1851 (J. L., 1851: 7). Y el segundo aspecto a destacar, que en ellas queda de manifiesto el escaso papel que tuvieron las mujeres, ya que no queda constancia de ningún retrato 
ni autorretrato de académicas de mérito en las exposiciones, lo que revela la realidad androcéntrico de la corporación.

Nos hemos centrado en aquellos retratos y autorretratos en los que es posible establecer una relación entre autor, modelo y la propia institución en la que se exhibe; es decir, en la representación de académicos por otros colegas de la corporación, y en los que se ponen de manifiesto no solo vínculos profesionales y sociales, sino también un interés por configurar una imagen exitosa, al mismo tiempo del individuo y de la corporación, a través del retrato. Para esta tarea son un útil punto de partida los trabajos de Enrique Pardo Canalís (1966: 37-61; 1975: 71-92) sobre las exposiciones de 1841 y 1842 en los que a partir de documentación del Archivo de la Academia y de una revisión de la prensa periódica, se ofrece un corpus informativo bastante amplio sobre las obras presentadas a estas dos exposiciones; también de excepcional utilidad y una fuente rica en documentación es el trabajo de Esperanza Navarrete sobre la Academia, en el que dedica un capítulo completo a las exposiciones públicas que analiza el conjunto expositivo, los autores presentes y los géneros más representativos, incluyendo como apéndices documentales las listas elaboradas por el conserje a la recepción de obras para la exposición, aunque no se encuentran las de todos $\operatorname{los}$ años ${ }^{442}$; en las biografías, artículos y estudios monográficos sobre distintos artistas académicos se ha podido completar alguna información respecto a los retratos presentados o a las motivaciones subyacentes tras estos; finalmente, otra de las fuentes empleadas es la prensa periódica y las reseñas y críticas de las exposiciones de la Academia, que aportan en más de una ocasión noticias interesantes sobre retratos incluidos en las mismas. No obstante, es preciso hacer una aclaración respecto a esta última fuente, ya que al estar sujeta a la subjetividad del redactor, y en ocasiones a su propia memoria tras la visita a la exposición, podemos encontrar cómo una obra de interés para nuestro estudio aparece citada únicamente en una crítica, por lo cual es preciso tratar esta información con cierta cautela. Del mismo modo, los datos aportados por estas reseñas no suelen aludir a la vinculación de los retratados con la institución académica, ni a ninguna razón particular -un nombramiento dentro de la corporación, un ascenso en su graduación o incluso el logro de méritos u honores al margen de la academia por uno de sus miembros-, que pudiera motivar su presencia en una exposición concreta, lo que los coloca siempre al nivel de los otros muchos retratos que figuraban en el escaparate académico en el mes de septiembre. Ha sido preciso cotejar estos datos con las propias obras, de algunas de las cuales no ha quedado constancia gráfica o documental más allá de la exposición en la que fueron presentados, y también con el cursus honorum de los retratados a través de fuentes biográficas y documentales, especialmente la relación general de académicos, lo que permite a su vez arrojar luz sobre la veracidad de las noticias y sobre la función que dichas obras cumplieron dentro de la propia institución.

Iniciaremos este estudio con una revisión de los retratos relacionados con el éxito profesional, que constituyen el cuerpo más numeroso, para mencionar posteriormente algunos casos excepcionales en los que la relación con la Academia es más inusual.

\footnotetext{
${ }^{442}$ Las listas halladas y reflejadas por Esperanza Navarrete son las de las exposiciones de 1801-1808, $1812,1812,1819,1834$ y $1840-1844$.
} 
Pocas son las noticias relativas a las exposiciones celebradas antes de 1800 . Destaca entre ellas la certeza de que Francisco de Goya presentó en la de 1795 el retrato sin concluir de su cuñado, el académico Francisco Bayeu, con motivo de su muerte, lo que constituye quizás el primer homenaje a un artista y miembro de la corporación que se realizaba en una exposición pública.

En 1802, el pintor Zacarías González Velázquez presentó un Autorretrato a la exposición de la Academia, con una clara voluntad de dejar testimonio de su éxito profesional en la institución en la que se había formado y de la que era en ese momento profesor ayudante. Berta Núñez (1998: 39; 2000: 40) se basa en el nombramiento de Zacarías González como pintor de cámara en julio de 1802 para relacionar esta obra con el Autorretrato de la Academia de San Fernando ( $\mathrm{n}^{\mathrm{o}}$ inv. 0704) y señala la coincidencia de que el artista valenciano Juan Francisco Folch de Cardona también presentase dos retratos del pintor en la misma exposición, que aparecen recogidos en la lista de obras para la misma elaborada por el conserje (NAVARRETE, 1999: 467). Curiosamente, en el autorretrato presentado por Zacarías González Velázquez no hay rasgos que lo identifiquen como pintor de cámara: no viste ningún tipo de uniforme, sino un sencillo chaquetón oscuro, y sostiene en su mano derecha un lápiz que alude a su profesión. La imagen que transmite al público, a sus colegas académicos y a sus discípulos es la de un hombre maduro y elgante, con plena confianza en sí mismo y en su capacidad de abordar su propia imagen sin incurrir en una falta de modestia o de decoro. Tampoco el retrato que Núñez Vernis atribuye a Folch (a su vez también pintor de cámara y académico de mérito), reducido a busto, se observa señal alguna de la nueva condición profesional de González Velázquez. A pesar de esto, es evidente que la presencia de tres retratos representando a Zacarías González Velázquez, uno de ellos autorretrato, no responde a simple casualidad sino que constata una celebración pública del pintor en la institución de la que era académico de mérito desde 1790 y en la que alcanzaría nuevos honores a partir de 1807.

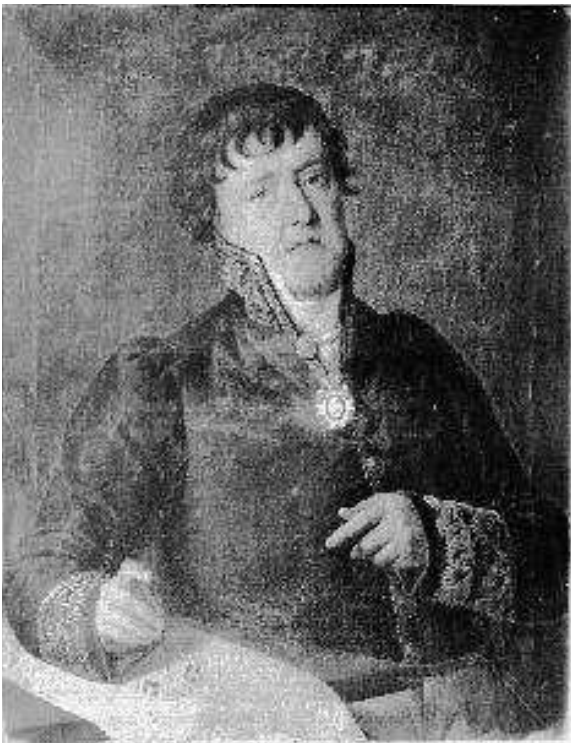

Fig. 157. Retrato de Juan Miguel de Inclán. Archivo Moreno ( ${ }^{\circ}$ inv. 04487B).

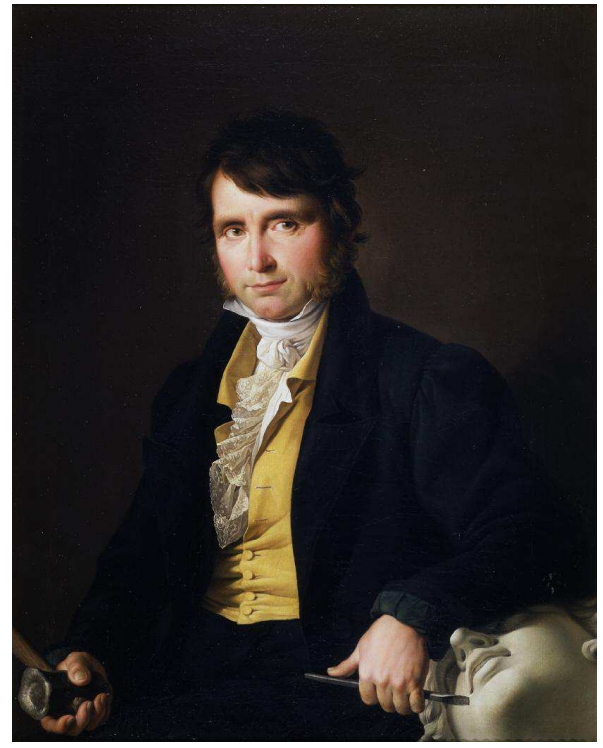

Fig. 158. Zacarías González Velázquez, Retrato del escultor Francisco Elías. Museo de la Academia de San Fernando ( ${ }^{\circ}$ inv. 0560). 
También de Zacarías González Velázquez serían otros dos retratos que merece la pena señalar, si bien mucho más tardíos, ya que ambos fueron presentados en la exposición de 1829 y de los que da noticia El Correo ("Real Academia...", 1829: 1). Se trata, en primer lugar, de un Retrato del arquitecto Juan Miguel Inclán, que figuraba en la exposición junto al de su esposa; pocas son las dudas que ofrece la relación entre González Velázquez e Inclán, ya que el segundo no solo era académico de mérito desde 1814 y teniente director de arquitectura desde 1822, sino que además en 1827 había sido nombrado vicesecretario de la institución, al mismo tiempo que González Velázquez acababa de ser nombrado director general; no obstante, no constan más noticias sobre este retrato que la aparecida en El Correo, ya que tampoco Núñez alude a él en su catálogo razonado de la obra del pintor, por lo que podría ser dudosa su atribución. Podría tratarse del retrato del arquitecto que se conservó en el Instituto Jovellanos de Gijón hasta su desaparición en 1936 [fig. 157], ya que a nivel estilístico se corresponde con otros retratos de artista realizados por González Velázquez, como el del escultor Pedro Hermoso. El otro retrato era el del escultor Francisco Elías Vallejo [fig. 158], quien además de escultor de cámara ostentaba el puesto de teniente director en la Academia desde 1818. No parece tampoco coincidencia el hecho de que, en el mismo momento en que es nombrado director general de la corporación, Zacarías González decida exponer los retratos de dos de sus compañeros académicos, conociendo la importancia que para este pintor tuvo el retrato de sus amigos y colegas profesionales $^{443}$, a los que suele plasmar de manera natural y elegante, prestando especial atención a los detalles de sus vestimentas e incorporando, sobre todo en el caso de los retratos de escultores, las herramientas de su oficio siempre en la mano no solo en alusión a su identidad laboral, sino también dignificando la práctica de su arte. Tampoco puede pasar desapercibido el hecho de que, en un momento de la institución académica en que la Sala de Retratos llevaba diez años instalada aunque con escasas incorporaciones recientes, Zacarías González llevase al terreno público de la exposición la imagen de dos artistas tan estrechamente vinculados a la Academia, teniendo en cuenta que dos años antes había hecho entrega a la corporación del retrato de su padre. El de Francisco Elías y el de Juan Miguel de Inclán ofrecen dos imágenes distintas del artista vinculados a su identidad profesional, puesto que el primero, con una apariencia cuidada y elegante, es presentado con atuendo civil y acompañado de un busto clásico, mientras el segundo viste uniforme académico, subrayándose así su vinculación con la institución.

Los retratos de artistas académicos escasean en los años posteriores, siendo preciso esperar hasta la exposición de 1835: una de las obras que más llamó la atención de la crítica, por la propia calidad técnica así como por la juventud de su autor, fue el cuadro de Federico de Madrazo El Gran Capitán recorriendo el campo de la batalla de Ceriñola, en el que el pintor incluyó su autorretrato. José Luis Díez ha señalado la influencia que tienen en la composición La rendición de Breda y el Entierro del conde

\footnotetext{
${ }^{443}$ El mismo Zacarías González Velázquez realizó también un retrato del escultor Pedro Hermoso, fechado hacia 1813 o 1816, quien además de académico en la de San Fernando (nombrado teniente director de escultura en 1816) era escultor de cámara (NÚÑEZ VERNIS, 1998: 45).
} 
de Orgaz (DÍEZ, 1997: 163-167); la inspiración en la obra velazqueña puede explicar la localización del retrato en el extremo derecho de la composición, aunque también permite aventurar una identificación de Federico de Madrazo con el maestro del Barroco y un evidente orgullo profesional a pesar, o quizás subrayando, su propia juventud.

También se expuso un Autorretrato del pintor sevillano Antonio María Esquivel, si seguimos la reseña aparecida en El Artista $^{444}$, al parecer manifestando el interés del pintor, académico de mérito desde 1832, por acompañar las obras de composición ${ }^{445}$ con su propia efigie; podría tratarse, según Guerrero Lovillo (1957: 17; PANTORBA, 1959: 156), de un autorretrato bajo la apariencia de un alquimista, obra citada por Ossorio como Alquimista en su entrada sobre el pintor sevillano y que retoma Antonio de la Banda y Vargas (2002: 95), quien la menciona ya entre un tipo de "figuras quasi retratos" siendo "la del Alquimista que, expuesto en la Academia de San Fernando en 1835, pasa por ser su autorretrato"; sin embargo, algunas fuentes contemporáneas mencionan directamente la obra como un autorretrato "de gran semejanza, buen colorido y efecto", como ocurre en la crítica aparecida en El Eco del Comercio ("Esposición de cuadros...", 1835: 2). Dadas estas noticias, y al no haber conseguido localizar la obra, parece sorprendente el hecho de que, en la primera exposición en la que tenemos constancia de la participación de Esquivel, este optase por concurrir con un retrato en el que su identidad profesional, en la que acababa de conquistar el primer hito importante, quedase completamente al margen al disfrazarse de alquimista, a pesar de que su fisionomía, como hemos podido comprobar, era perfectamente reconocible.

Sin llamar especialmente la atención de la crítica, en la exposición de 1839 fueron presentados los retratos cruzados de los pensionados en París Federico de Madrazo y Carlos Luis de Ribera [figs. 159 y 160]; ambos retratos fueron enviados por los artistas acompañando sus obras de composición, dando así visibilidad y poniendo rostro a los autores de las obras. En ellos no queda rastro de la identidad académica, siendo la imagen que se ofrece la de dos jóvenes artistas, elegantes y cosmopolitas. En la misma exposición, según recoge El Correo Nacional, José Gutiérrez de la Vega, académico de mérito desde 1832, presentó un retrato del pintor Adriano Ferrán ${ }^{446}$, quien había sido nombrado ese mismo año académico de mérito por la miniatura; la obra, sin embargo, no ha podido ser localizada.

\footnotetext{
${ }^{444}$ En una primera noticia se indica "El Sr. Esquivel ha presentado en esta misma sala tres cuadros. David vencedor de Goliat, una escena familiar de traviesos muchachos ensayando cierta operación médica en un pobre perro, y su retrato según tenemos entendido. Al mismo pertenece una Virgen del Rosario rodeada de ángeles, cuadro de gran tamaño colocado en una de las salas retiradas" ("Esposicion pública...", 1835: 155) y se reitera la presencia de su autorretrato en el siguiente artículo dedicado a la exposición ("los tres cuadros del Sr. Esquivel, y su retrato, no dejan de merecer elogios..." ("Esposición pública...", 1835: 165).

${ }^{445}$ Entre las otras obras de su mano que figuran en la mayoría de las críticas se encuentran Niños jugando con un perro, La Virgen del Rosario y un David vencedor de Goliat ("Esposición de la real academia...", 1835: 4.)

446 "El Sr. Gutiérrez, con su estilo de Murillo, ha presentado un nacimiento y el retrato del Sr. Ferrán. En ambas producciones hay dulzura, suavidad y desvanecimiento, prendas notables de aquel gran maestro..."(D., 1839: 4).
} 


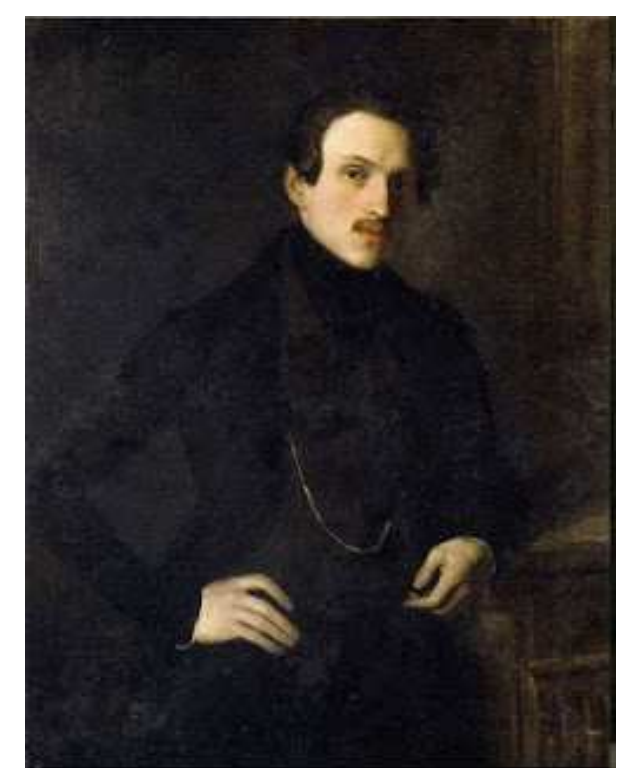

Fig. 159. Carlos Luis de Ribera, Retrato de Federico de Madrazo. Hispanic Society.

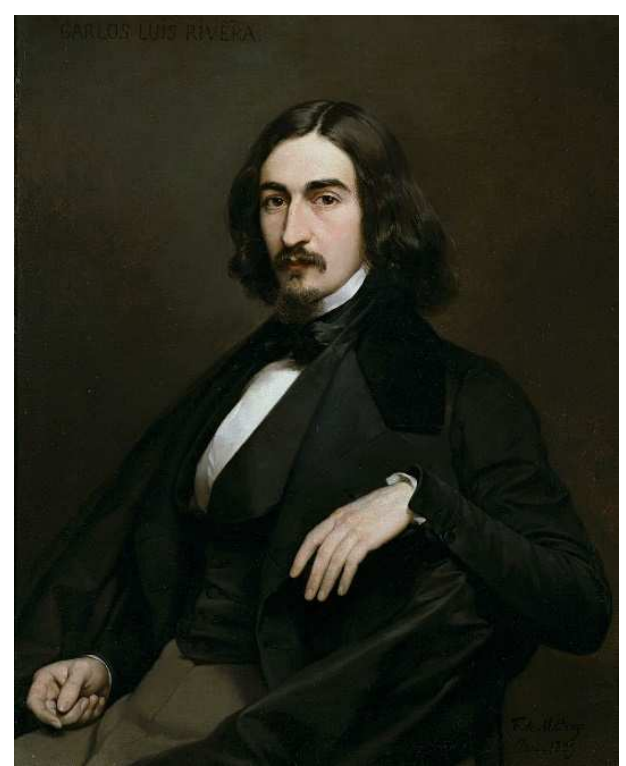

Fig. 160. Federico de Madrazo, El pintor Carlos Luis de Ribera. Museo Nacional del Prado ( $\mathrm{n}^{\circ}$ inv. P007799).

El nombramiento de académico de mérito, en este caso por la arquitectura, es también el motivo por el que se incluye en la exposición de 1841 el Retrato de Carlos Bosch Romañá (Museo de Bellas Artes de Valencia) realizado por Vicente López el año anterior (DÍEZ, 1999: 120), en el que plasma al arquitecto como un hombre elegante, que luce en el ojal de la chaqueta la escarapela de una condecoración, y sosteniendo en sus manos atributos relacionados con su profesión: un compás y un alzado de un templete chinesco. Curiosamente, el académico Antonio María Esquivel publicó en $E l$ Eco del Comercio una crítica sobre la exposición de ese año considerando que, como profesor de la Academia, era la persona más idónea para realizar juicios:

Solo hay de D. Vicente López un retrato; y aunque seguramente un retrato y aun de tan corto tamaño no es suficiente para juzgar a un artista, son tales sus obras, que la menor es suficiente para poner de manifiesto su elevado mérito, aun cuando no conocieran todos antemano a tan distinguido profesor. La cabeza está llena de vida, perfectamente modelada y con mucho efecto; las manos tanto como la cabeza están muy bien dibujadas, y tocado con mucha gracia todo el cuadro: el colorido es de esa escuela suya particular (ESQUIVEL, 1841: 1-2).

En ella, como se puede observar, menciona el retrato de Carlos Bosch de pasada, sin identificar siquiera al retratado, haciendo una apreciación del estilo del pintor valenciano, algo que resulta chocante debido a la indudable relación, aunque fuese meramente institucional, que ambos artistas debían tener.

La exposición de 1842 recogió, al menos, dos retratos de individuos relacionados con la Academia. El primero es un retrato en busto de Federico de Madrazo realizado por el escultor Ponciano Ponzano, académico de mérito de la de San Fernando desde 1839, del que da cuenta la detallada crítica aparecida en La Iberia musical y literaria (ROMERO, 1842: s.p.). Ambos artistas habían coincidido en Roma, de lo que dan testimonio los retratos del escultor realizados por Madrazo; sobre este retrato decía el crítico que era"un busto de Federico de Madrazo, ejecutado al parecer en cera por 
Ponciano, y que no puede pedirse más semejanza". Podría parecer que la exposición de 1842 fue, en cierto modo, una celebración de la familia Madrazo, pues además de este retrato de Federico, José de Madrazo presentó el retrato de su hija; sin ir más lejos, el segundo retrato confirmado de un académico en la de 1842 fue el de Pedro de Madrazo, realizado por su propio hermano Federico. El motivo no hay que buscarlo muy lejos, ya que más allá de los vínculos familiares, Pedro de Madrazo había sido elegido ese mismo año académico de honor; teniendo en cuenta la importancia que tanto José como Federico habían concedido a dejar constancia de su presencia en las exposiciones (hasta tal punto que en una carta fechada en septiembre de 1837 José escribía a Federico expresando su voluntad de "que no faltase nunca obra de los Madrazo en la exposición a fin que las gentes no se olviden ni tomen otros en la opinión el puesto que nos corresponde" [DÍEZ, 1998b: 87]), no es de extrañar que deseasen subrayar la incorporación de un nuevo miembro de la familia a la institución, ya que, aunque se tratase de un nombramiento honorífico y desvinculado de la práctica artística, dejaba constancia de su relación con la élite intelectual, algo que quedaría plenamente ratificado con su inclusión posteriormente en la obra de Esquivel Los poetas contemporáneos.

Según la crítica aparecida en El Español, Federico de Madrazo remitió a la exposición de 1845 su retrato de Jenaro Pérez Villaamil (M., 1845: 1-3), quien había recibido en el mes de febrero de ese mismo año los honores y graduación de director de pintura. De la obra se decía, muy escuetamente, que "además de la excelencia del parecido, está tocado con toda la ligereza y profunda inteligencia de los recursos artísticos que hemos admirado en otras de sus composiciones de este género". La obra, firmada y fechada con la afectuosa dedicatoria "A su amigo G. P. Villaamil, pintor, F. de Madrazo 1845" (ARIAS ANGLÉS, 1986: 82), podría ser un testimonio de reconocimiento por parte de Federico a su compañero académico, a quien la institución había desestimado su solicitud de ser nombrado teniente director por ser académico de mérito por el paisaje y no por la historia, como decretaban los estatutos. Ante esta situación, que Villaamil entendió como una clara injusticia que jerarquizaba de manera obsoleta los géneros artísticos, Federico de Madrazo salió en su defensa, afirmando que los motivos alegados por la Academia respondían, en realidad, a que aún no se había instaurado una cátedra de paisaje en la misma. Fue por mediación de la reina como en 1845 se concedían a Villaamil los honores que solicitaba, y poco después se le asignaba la cátedra de Paisaje recién instaurada por el nuevo plan de estudios. Arias Anglés (1986: 165) menciona dos retratos realizados por Madrazo a Villaamil; el presentado a la exposición de 1845 muestra al artista de busto prolongado, elegantemente vestido y luciendo en la solapa la roseta de una condecoración. La elección de un punto de vista bajo parece elevar aún más la distinción del artista, cuya mirada rehúye la del pintor/espectador; una leve sonrisa esbozada bajo el poblado bigote, que no traiciona la seriedad del conjunto, puede interpretarse en el contexto de la exposición y en el ámbito académico como una imagen triunfal del artista que ponía fin a la anterior animadversión por parte de la Academia contra el paisajista y el género que practicaba. 
En la misma exposición, y tal vez como homenaje, ya que el retratado había fallecido el año anterior, se presentó un busto escultórico del académico Martín Fernández de Navarrete, realizado por Francisco Pérez del Valle ${ }^{447}$, quien había recibido en 1844 los honores y graduación de director de escultura. La obra, firmada y fechada en un lateral ese mismo año de 1845, fue posteriormente ofrecida por otro académico, Pascual y Colomer, a la propia corporación para su galería (AZCUE BREA, 1994: 410-411).

No tenemos noticias de que ningún retrato de artista vinculado a la Academia fuese presentado a la exposición de 1846, ya que las críticas de dicha muestra se centraron en subrayar la baja calidad de las obras presentadas, y únicamente prestaron una especial atención a la obra de Antonio María Esquivel Los poetas contemporáneos. No obstante, si anteriormente mencionábamos el autorretrato de Federico de Madrazo en su composición El Gran Capitán recorriendo el campo de la batalla de Ceriñola [figs. 161 y 162], podemos considerar el autorretrato de Esquivel incluido en Los poetas contemporáneos [figs. 163 y 164] como una nueva manifestación ante la Academia de la identidad -profesional y cultural- de uno de sus miembros. Llamativo tanto por el escaso arraigo del retrato de grupo en el arte español como por la identidad de sus componentes, no cabe duda de que constituye una muestra de la élite cultural y literaria del momento, presidida por los retratos de Espronceda y del duque de Rivas. Al analizar esta obra, a Pardo Canalís (1971: 368-369) le llamaba la atención la amplitud del espacio en que se desarrolla la escena, afirmando del conjunto que "refleja un bienestar, una posición acomodada, diferente, sin duda, de la que en 1842 conociera el corresponsal de La Presse, de París, cuando aseguraba que el estudio de Esquivel era de extremada sencillez, «reduciéndose todo su adorno a algunos bocetos, varias copias de Murillo y de Velázquez, una cajetilla de cigarros y tres sillas para los amigos»"; la obra en conjunto no deja de testimoniar, con abundante dosis de vanidad, el importante ascenso social que el propio Esquivel había alcanzado en la corte, y no debe sorprender que la obra fuese iniciada tras ser nombrado pintor de cámara el 19 de diciembre de 1843.

El pretexto de una velada literaria en el estudio del pintor permitía a Esquivel incluirse en la composición, optando por ubicar su autorretrato en el centro de esta y traicionando así el supuesto protagonismo de Zorrilla, cuya figura, a pesar de atraer la mirada de los presentes, se fusiona con la amalgama de retratos llamando menos la atención que la cabeza del pintor, claramente destacada sobre el fondo. La voluntad de distinguirse en el grupo es manifiesta, ya que Esquivel se presenta como el único pintor, paleta y pincel en mano, en un momento en que abandona el cuadro en el que está trabajando para escuchar a Zorrilla; una imagen, por otra parte, muy lejana del autorretrato de Federico de Madrazo en El Gran Capitán, cuyo rostro semioculto en un extremo de la composición parece un gesto muy humilde en comparación con el protagonismo de Esquivel.

\footnotetext{
447 "El escultor D. Francisco Pérez ha presentado tres bustos, uno de los cuales es el del difunto señor D. Martín Fernández de Navarrete, sacado, según creemos, del vaciado que se hizo después de su muerte". (M., 1845: 1-3).
} 


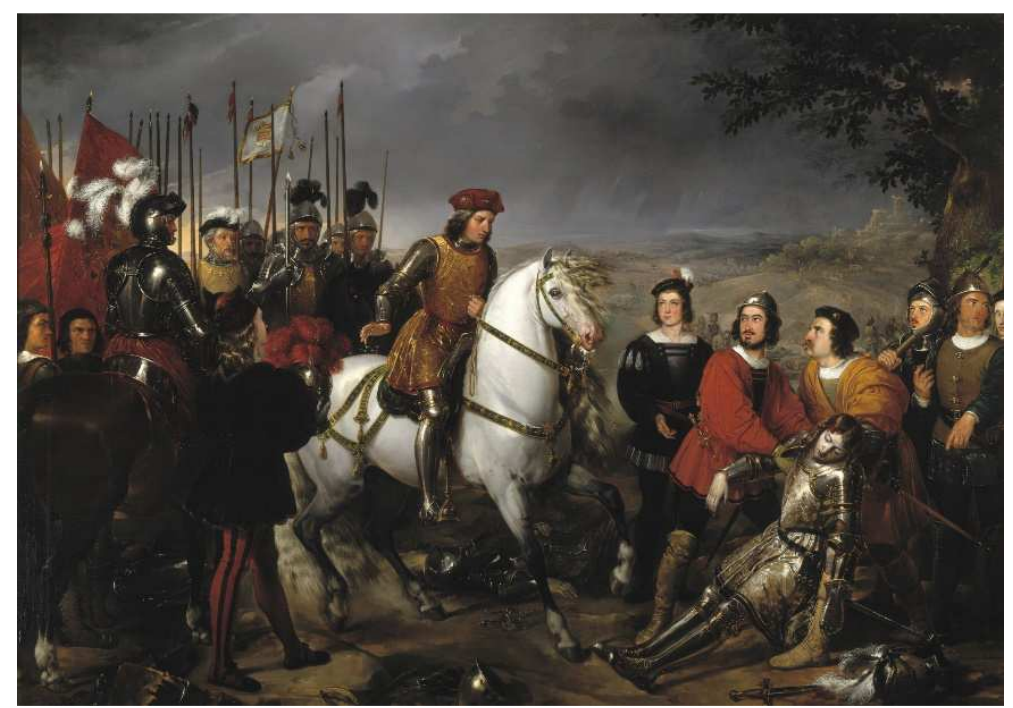

Fig. 161. Federico de Madrazo, El Gran Capitán recorriendo el campo de la batalla de Ceriñola. Museo Nacional del Prado ( $\mathrm{n}^{\circ}$ inv. P008706).

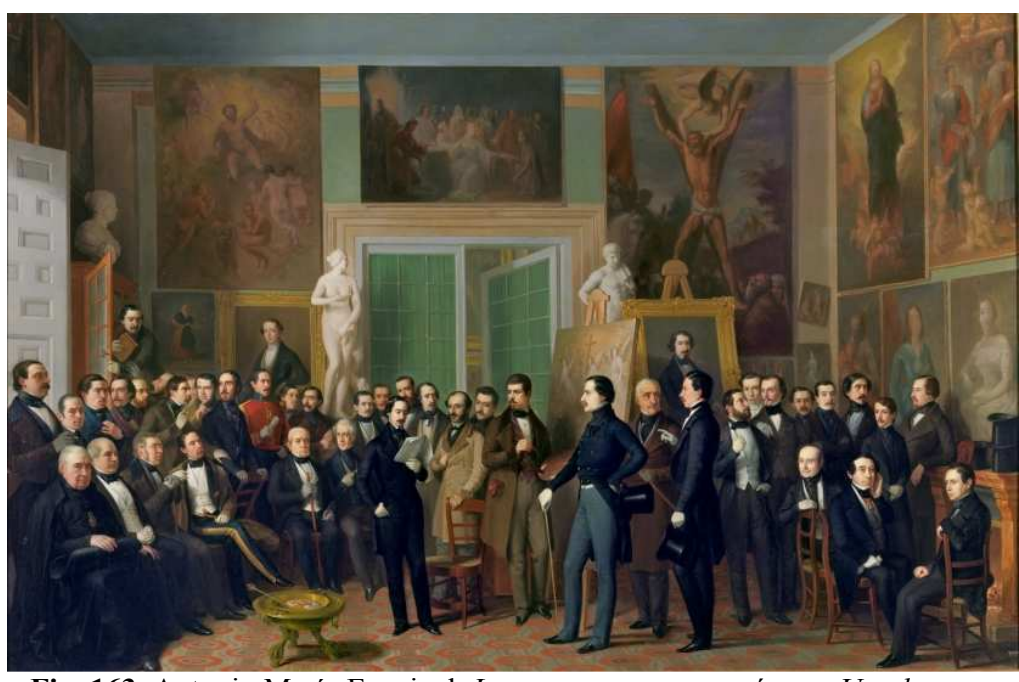

Fig. 163. Antonio María Esquivel, Los poetas contemporáneos. Una lectura de Zorrilla en el estudio del pintor. Museo Nacional del Prado ( $\mathrm{n}^{\mathrm{o}}$ inv. P004299).

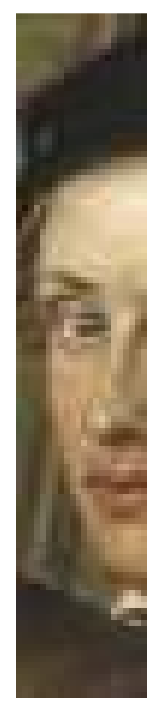

Fig. 162. Federico de Madrazo. El Gran Capitán... (detalle).

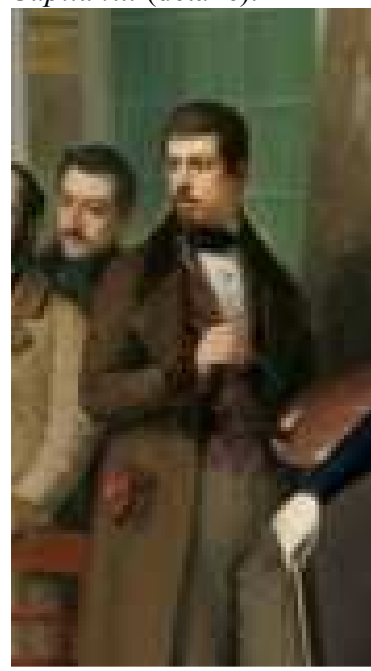

Fig. 164. Antonio María Esquivel, Los poetas contemporáneos (detalle).

Las críticas contemporáneas recogen la negativa reacción de algunos espectadores ante lo que comprensiblemente consideraban un acto de vanidad del propio pintor. José Martínez Villergas (1846: 1), en su satírica composición poética en la que arremetía contra la obra, se limitaba a decir del pintor que "muy bien está Esquivel con la paleta / y fama le ha de dar de autor polígrafo / por las cifras que osado nos espeta", en la que se puede leer una fina ironía alusiva a las aspiraciones del sevillano mediante una producción más basada en la cantidad que en la calidad ${ }^{448}$. Sin embargo, más afilado se mostraba contra la representación de Esquivel el autor de la crítica aparecida en El Espectador el 18 de octubre al escribir:

extrañamos cómo, a qué y por qué el comité mixto-anómalo-literario se ha reunido en el taller de un artista para oír la lectura de un drama (o lo que fuere), y qué papel

\footnotetext{
${ }^{448}$ Una opinión sobre el pintor que compartían, entre otros, los Madrazo, en cuya correspondencia se burlan de la rapidez de ejecución y del número excesivo de obras que realizaba en el Liceo.
} 
representa allí el señor Esquivel, con paleta, tiento y pinceles delante del caballete. Si significa el acto de hacer los retratos, no es el taller del retratista el sitio donde reunirse debieran, ni el punto donde él mismo se ha colocado el más a propósito para pintar la escena. Por esto creemos que el ridículo de esta cosa rara pesa sobre las personas del comité de lectura; y en cuanto al señor Esquivel, pudiera haber evitado alternar con algunos personajes que figuran en semejante escena (B., 1846; 2).

Estas afirmaciones, que culminan un largo texto en el que se critica la notoriedad que algunos medios otorgan al pintor sevillano y se expone una extensísima lista de los fallos de que adolece la producción pictórica de Esquivel, plasman algunas ideas erróneas sobre la composición; en efecto, el crítico no atina a entender el motivo de la escena ni el papel que Esquivel juega en ella, puesto que la tertulia en el taller del artista - cuando Madrid contaba ya con sociedades literarias y artísticas de notable reputaciónno parece responder ni a una lectura verosímil ni al propio acto del retrato. Voluntariamente o por descuido, el crítico no parece haber reparado en que la obra en la que se encuentra trabajando Esquivel es un asunto religioso ${ }^{449}$, y que su voluntad de incluirse en la escena no representa su labor como retratista, sino como pintor de composición. En su colocación central, no pretende testimoniarse a sí mismo como pintor de la escena $-\mathrm{y}$ por tanto, ajeno a ella-, sino como parte integrante del grupo, motivo por el cual se vuelve para escuchar al dramaturgo, y, al mismo tiempo, estableciendo rasgos claramente diferenciadores relacionados con la actividad creativa: solo Zorrilla, con su texto en la mano, y Esquivel, representado en su identidad de artista, rompen con la representación, casi seriada, del resto de literatos como burgueses. Sin duda, el protagonismo de Esquivel fue uno de los puntos centrales de la crítica de la obra, ya que en la aparecida en El Español ("Esposición de pinturas", 1846: 3-4), además de fallos como la distracción reinante entre los retratados, las actitudes innobles entre personas de la alta sociedad y la incorrección del dibujo, se subrayaba como un error más la colocación del pintor en un lugar tan visible, acusando - de manera velada pero muy evidente- al autor de la obra de falta de modestia, para lo cual se sirvió del ejemplo de Las Meninas: si Velázquez, gran pintor consciente de su identidad artística y social, se había contentado "con colocarse en el fondo donde apenas se ve", ¿qué razón podía motivar el protagonismo de Esquivel más que una completa ausencia de humildad?

Por otra parte, la representación de la élite literaria no tiene nada que ver con la Academia donde se exhibió la obra; del mismo modo que algunos de los representados fueron o seguían siendo miembros del Liceo Artístico y Literario ${ }^{450}$, muchos de ellos también pertenecía a la Academia como académicos de honor en el momento de

\footnotetext{
449 Valverde Madrid (1997: 407-432) identifica la escena que se encuentra pintando como una composición mitológica; no obstante, la imagen muestra inequívocamente un asunto religioso.

${ }^{450}$ Entre ellos, el duque de Rivas, Zorrilla, el fundador del Liceo José Fernández de la Vega, Ventura de la Vega, el propio Esquivel, Bretón de los Herreros, José María Díaz, Patricio de la Escosura, Carlos García Doncel, Antonio Gil de Zárate, Isidoro Gil y Baus, Juan Eugenio Hartzenbusch, Tomás Rodríguez Rubí, Luis Olona y Luis Valladares.
} 
realización de la obra ${ }^{451}$, o académicos de número en el de su exhibición; pero si bien tanto el Liceo como la Academia fueron núcleos de sociabilidad frecuentados por Esquivel, no se manifiesta ninguna voluntad de subrayar la pertenencia a ninguno de ellos. El protagonismo del ambiente pictórico del taller ${ }^{452}$ y del propio pintor revelan en la voluntad de este por diferenciarse del grupo, convirtiéndose en el anfitrión de la escena y, por lo tanto, parte indispensable de la sociedad culta, evidenciando a través del espacio y de su autorretrato el estatus alcanzado en Madrid tras la acumulación de honores sucesivos, como el de pintor de cámara en 1843 y el honor y grado de director de pintura en la Academia en 1844. Algo que, como se puede observar en la tradición biográfica esquivelina, lleva de nuevo al lugar común del artista como hombre que se ha hecho a sí mismo.

Más allá de la compleja representación de esta escena, en la exposición de 1847, celebrada en el Museo de la Trinidad y monopolizada por Guzmán el Bueno, obra del joven gaditano José Utrera, el propio Esquivel presentó un nuevo autorretrato [fig. 165] en el que hacía gala de manera mucho más visible y fácil de interpretar de su categoría artística: así, se presentó ante el público de la Academia -y fundamentalmente ante sus colegas artistas y los críticos que no habían entendido su presencia en Los poetas contemporáneos- vestido con uniforme de pintor de cámara ("Esposició de pinturas", 1847: 2). No sorprende que el pintor, ratificado como académico de número en 1846 tras la renovación de los estatutos, se presentase ahora caracterizado con el uniforme, símbolo de su éxito social y profesional en la corte, teniendo en cuenta las duras críticas recibidas en la exposición del año anterior. En este retrato firmado el mismo 1846, y que sin duda es, como señala José Luis Díez (1997: 82), el más oficial que realizó en toda su carrera, Esquivel se pinta haciendo gala de todos sus honores: además del uniforme de pintor de cámara, con su vistoso bordado en oro, pende de su cuello la encomienda de la orden de Isabel la Católica, y mostrando al pecho la placa de la misma orden, la cruz de la orden de Carlos III y la placa del Sitio de Cádiz.

Los dos últimos retratos de académicos de los que tenemos noticia fueron presentados en la exposición de 1848. El primero fue un Retrato de Luis de Madrazo [fig. 166], realizado por su hermano Federico (GARCÍA QUEVEDO, 1848: 3-4; VELAZ DE MEDRANO, 1848a: 3), con toda probabilidad como celebración del hecho de que

\footnotetext{
${ }^{451}$ Es el caso de Juan Nicasio Gallego (nombrado consiliario en 1843), de Antonio Gil de Zárate (académico de honor en 1845), del conde de Toreno, de Mariano Roca de Togores (académico de honor en 1835), del duque de Rivas (académico de honor en 1834), de Francisco Martínez de la Rosa, que había sido su protector, Manuel José Quintana (académico de honor desde 1814), el duque de Frías (consiliario desde 1815) o Pedro de Madrazo (académico de honor en 1842).

${ }^{452}$ La representación del espacio contrasta con la descripción ofrecida en 1844 por Roger de Beauvoir, quien afirmaba que "su taller, situado en la calle del Caballero de Gracia, es de los más sencillos; algunos bocetos, copas de Murillo y de Velázquez, una caja de cigarros y tres sillas para los amigos, eso es todo" (BEAUVOIR, 1844: 214).
} 


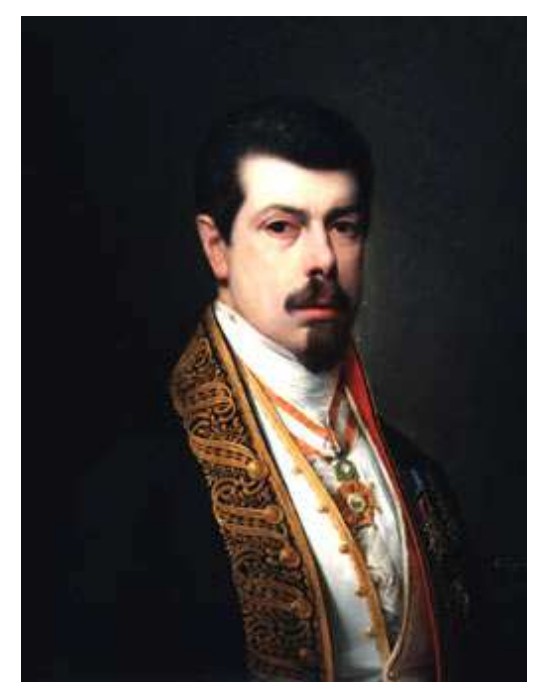

Fig. 165. Antonio María Esquivel, Autorretrato. Museo Lázaro Galdiano ( $\mathrm{n}^{\circ}$ inv. 07983).

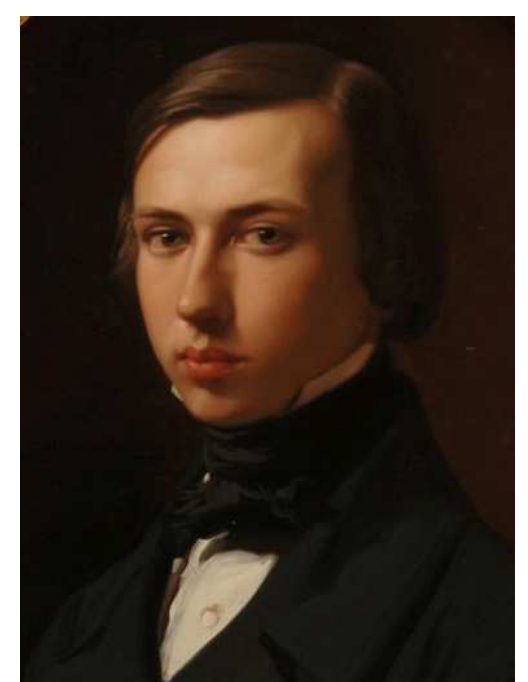

Fig. 166. Federico de Madrazo, Retrato de Luis de Madrazo (detalle). Colección Madrazo ( ${ }^{\circ}$ inv. Madrazo-12).

el joven pintor había sido galardonado ese mismo año con la pensión para pasar a Roma, y también para dejar constancia de la presencia de un nuevo Madrazo vinculado al éxito artístico. Además de las alabanzas respecto a la ejecución técnica, ninguna crítica pasó por alto ni la identidad del retratado ni su relación con el éxito académico manifestado por la pensión en Roma. El otro retrato presentado fue el de Fernando Ferrant, realizado por su hermano Luis (VELAZ DE MEDRANO, 1848b: 3), que probablemente se trate de la obra actualmente conservada en el Museo del Romanticismo ( $\mathrm{n}^{\mathrm{o}}$ inv. 0146). Al ser ambos académicos de la corporación madrileña, la presencia de este retrato en la exposición de 1848 parece responder -aunque fuese presentado junto al de su esposa Natalia de Boris- al éxito alcanzado por el paisajista, quien ese mismo año de 1848 había tomado posesión de su plaza como académico de número en la sección de pintura, para la que había sido nombrado en 1846. Como culmen de esta sucesión de honores, la prensa recogía cómo en ese mismo mes de octubre, y estando la exposición aún abierta, la reina había resuelto nombrar a Fernando Ferrant pintor de cámara.

Además de estos retratos que reflejan esa mezcla de orgullo personal y profesional en el ámbito académico, es preciso mencionar algunos casos excepcionales. De especial interés son las noticias de los retratos expuestos por el discípulo Carlos Blanco, quién además de presentar en la exposición de 1804 el ya mencionado Retrato de Mengs, llevó a las de 1805 y 1806 dos retratos de los que no conservamos ningún dato. Se trata de dos retratos de condiscípulos, apareciendo uno recogido con el título de Retrato del discípulo José Amaro (NAVARRETE, 1999: 468) y el otro como Retrato del joven José Solano (NAVARRETE, 1999: 470), que parecen testimoniar un aspecto de la sociabilidad entre los alumnos de la Academia, aunque hemos de suponerlos obras de escaso mérito artístico. Relacionado con el ámbito académico como trabajador de esta, llama también la atención el retrato "de un empleado de la Academia" en la exposición de 1842, realizado por Leonardo Alenza y calificado por un crítico como el único de sus retratos concluido y correcto. Se trata del retrato del conserje Alejandro de la Peña 
(Museo de la Academia de San Fernando, n inv. 0736), que ingresó en la colección de la Academia por donación de la viuda de este en 1852.

Finalmente, cabe hacer alusión a los retratos de artista no académicos en las exposiciones de la Academia de San Fernando, ya que es altamente significativo el hecho de que, salvo los autorretratos de aficionados anteriormente citados, apenas podemos encontrar referencias a este tipo de obras; un ejemplo es el posible retrato de Cecilio Corro por Antonio María Esquivel, del que da noticia una crítica aparecida en la Revista de teatros, que habría formado parte de la exposición de $1843^{453}$. Son escasos los datos relacionados con este retrato, ya que en la lista del conserje correspondiente a la exposición solo se mencionan como obras de Esquivel un Crucifijo, una Purísima Concepción y un retrato sin identificar, mientras que la obra que nos ocupa, mencionada por Ossorio y Bernard, no es recogida en los estudios realizados sobre el pintor ${ }^{454}$. Del mismo modo, y a pesar de la relación que Esquivel y Corro pudieron tener en otros escenarios artísticos como en el Liceo madrileño, no es posible vincular este retrato, en caso de que la identificación del crítico fuera correcta, con un motivo de peso para su aparición en la exposición pública de la corporación ${ }^{455}$. Del mismo modo, se podría mencionar el retrato escultórico de Carlos Luis de Ribera que figuró en la exposición de 1844; sin embargo, este busto, realizado en 1843, figuraba como obra donada a la Academia ese mismo año por su autor, José Siro Pérez, y al tratarse de una obra de amistad, su presencia en la exposición fue interpretada por la crítica como un recuerdo del pintor ausente ${ }^{456}$.

Vistos estos datos, puede afirmarse que los retratos de artista presentados en las exposiciones públicas de la Academia estuvieron fuertemente vinculados con la propia identidad de la institución: en el escenario propiciado por esta, sus miembros buscaron reafirmar su propia imagen como artistas, celebrando sus propios éxitos laborales y los de sus colegas académicos. En esta autoafirmación, de carácter exclusivamente masculino, se pone de manifiesto la necesidad de mostrar al hombre artista como profesional y como hombre de éxito; en las exposiciones de la Academia de San Fernando, el retrato del artista académico cobra especial significado dentro de la estructura jerárquica y la vida cotidiana de la institución, traduciendo visualmente el sistema meritocrático artístico a través de estas efigies. Los vínculos familiares, especialmente notorios en el caso de los Madrazo, cobran una mayor relevancia en las

\footnotetext{
453 "En el entresuelo se ven tres cuadros del señor don Antonio Esquivel, uno es un buen retrato de su amigo el artista don Cecilio Corro"; ("Exposición de la Academia ....", 1843: 2).

${ }^{454}$ Bernardino de Pantorba lo cita, tomando la referencia de Ossorio pero sin aportar ningún dato al respecto; por su parte, Guerrero Lovillo ni siquiera lo menciona.

${ }_{455} \mathrm{Sin}$ embargo, puede que este retrato, y su presentación pública, correspondiesen a una manifestación de gratitud del pintor sevillano a su compañero liceísta Corro, que había formado parte del jurado en el certamen de los Juegos Florales del Liceo en 1842. En este certamen pictórico Esquivel fue el artista galardonado, lo que despertó críticas airadas del pintor Antonio Gómez Cros; este hizo públicas duras observaciones a su compañero, a las que Cecilio Corro hubo de responder en los periódicos defendiendo la decisión del jurado y veladamente al propio Esquivel (CORRO, 1842: 3).

456 "Don José Siro Pérez ha presentado el retrato de su amigo el distinguido y joven pintor D. Carlos Luis Ribera (...) El busto de D. Carlos Ribera nos ha producido una agradable fascinación: hemos hallado en él el retrato físico y sicológico de nuestro esclarecido artista ausente de España ha tantos años..." (MADRAZO, 1844: 332).
} 
últimas exposiciones de la Academia y revela las tensiones existentes en la institución y en el ámbito artístico en la manifestación de poder que subyace en estas muestras de afecto.

\subsubsection{Academia de Bellas Artes de San Carlos}

Al margen del papel de la galería de retratos como imagen simbólica de la institución, las exposiciones realizadas en el marco de la Academia de Bellas Artes no parecen haber contado con una gran presencia de retratos de artista, al tiempo que estos tienen poca vinculación con la propia Academia, pues si bien los representados habían sido alumnos de la institución, los retratos parecen responder más bien al nuevo espíritu de sociabilidad. La escasez de iniciativas expositivas en la Academia hizo que, con las excepciones de las muestras relacionadas con las obras que los pintores valencianos remitían a otras exposiciones, la institución valenciana no se presentase como escenario propicio para los jóvenes artistas de sus propias aulas. Así, en la exhibición de las obras de artistas valencianos con destino a la Exposición Aragonesa de 1868 en el salón principal del Museo, encontramos únicamente una referencia a un retrato de artista: se trataba de un autorretrato de Manuel Benso, que la crítica calificaba de "brioso" en comparación con otros que se habían visto del mismo autor en los escaparates valencianos ("Los artistas valencianos", 1868: 3; ROIG CONDOMINA, 1994: 222). Las escasas noticias biográficas sobre el pintor tampoco permiten establecer la relación del artista -y de este retrato- con la propia Academia; tal vez Benso, que en 1867 había sido premiado en la Exposición Regional valenciana con una medalla de cobre (“Exposición regional...", 1867: 319), buscaba dar a conocer su imagen ante el público de su ciudad y el zaragozano un año después de este pequeño éxito, lo que sin duda constituye un acto de autoafirmación.

Por otra parte, en la exposición organizada por la Academia en 1871 sí que hubo una mayor concurrencia de retratos de artistas, y llama la atención el hecho de que la mayor parte de ellos fueron autorretratos. Emilio Sala Francés, entonces en plena juventud, pues contaba veintiún años, presentó su autorretrato y un retrato del pintor Antonio Cortina, de los que la crítica decía: "su retrato, por ejemplo, no está en iguales condiciones de dibujo a las de color y ambiente; el del joven pintor Cortina, aunque no lo modele tanto como el anterior, ni tenga tanto ambiente, es una cabeza magnífica a la que no corresponde lo restante del lienzo, en especial las ropas, que son algo flojas" (ROIG CONDOMINA, 1994: 273 y 275). Curiosamente, también Emilio Sala y Antonio Cortina habían sido premiados en la Exposición Regional de 1867, en este caso con medallas de plata. Otros esforzados y jóvenes discípulos también estuvieron presentes: la reseña aparecida en Las Provincias el 25 de julio señalaba la presencia de un autorretrato de Ignacio Pinazo (ROIG CONDOMINA, 1994: 260) y un autorretrato de José Miralles, discípulo de Francisco Domingo; entre los menos destacados por la crítica se encontraban un autorretrato de Ramón Alorda a la acuarela, y un autorretrato de Juan Puerto que fue calificado de incorrecto y descuidado (ROIG CONDOMINA, 1994: 275). 


\subsection{La galería de retratos de la Academia española en Roma}

\subsubsection{El precedente de la galería de pensionados en la Villa Médici}

En diciembre de 1863, La Revue des Deux Mondes publicaba un artículo de Beulé, secretario perpetuo de l'Académie des Beaux-Arts, consagrado a realizar una breve historia de la Academia de Francia en Roma durante el siglo XIX como medio de legitimar sus críticas contra la reforma del Prix de Rome (BEULÉ, 1863: 23). A pesar de realizar un breve recorrido por las influyentes personalidades artísticas que pasaron por la Academia de Francia desde su traslado a la villa Médicis, de mencionar el carácter marcadamente masculino y ritual del Prix de Rome como hito en la carrera profesional de pintores, escultores, arquitectos, grabadores y músicos, e incluso tras destacar la importancia del espíritu de fraternidad durante los cinco años que había marcado la estancia en Roma por parte de $\operatorname{estos}^{457}$, parece olvidar uno de los símbolos más representativos de esta convivencia artística en el extranjero: la galería de retratos de pensionados. Este olvido, motivado sin duda por el interés reivindicativo del texto, puede esconder además el desconocimiento por parte del público ajeno a la Academia de Francia de esta galería, reservada a la experiencia privada de los pensionados en Roma. De este modo, Paul Baudry comunicaba sus impresiones sobre esta galería en una de las cartas destinadas a su familia, indicando cómo

Alrededor de nosotros, desde la parte baja de la pared hasta el techo, se encuentran los retratos de todos aquellos que nos han precedido. No hay nada tan curioso como estos quinientos o seiscientos retratos, algunos de los cuales llevan el nombre de algunos conocidos y admirados en el mundo, como el gran pintor Ingres, Cogniet, David d'Angers, el gran escultor, Berlioz, Halévy, Cortot, Pradier y un montón más, rodeados ahora de admiradores (FOSSIER, 2006: 453-454).

También Henri Regnault, recién llegado a Roma, escribía a su familia en 1861 sobre la vida cotidiana en la Academia de Francia, indicando la ubicación de la galería de retratos al hablar de las comidas: "todos comemos juntos en un gran comedor donde están colgados los retratos de todos los pensionados pintores, escultores, grabadores, arquitectos y músicos desde el comienzo de siglo hasta nuestros días" ${ }^{\text {}}{ }^{2}$.

Parece subrayar esta hipótesis el hecho de que, hasta 1884, las noticias relacionadas con la galería deban rastrearse únicamente a través de la correspondencia privada de algunos de los pensionados. La galería de retratos fue rescatada con la intención de divulgar su existencia, y dentro del interés por los panteones de celebridades y de artistas franceses, en 1884 por Henry Jouin, quien publicó el primer estudio y catálogo de retratos en las páginas de Nouvelles archives de l'art français. Jouin, que se encontraba recopilando datos para una historia del arte francés en Italia, confiaba a esta galería de retratos un lugar lo suficientemente destacado como para publicar esta reseña con anterioridad a la aparición del libro. De la somera descripción que hacía del

\footnotetext{
457 "Todo se verá interrumpido. La moralidad del trabajo común, la dignidad, el desinterés, esta nobleza de corazón de la que uno se impregnaba en Roma durante cinco años de contemplación, de buenos ejemplos, de consejos respetados, de generosa fraternidad, y que nos llevábamos de vuelta a París para el resto de nuestra vida. Todo eso se desaparecerá" (BEULÉ, 1863: 21).

${ }^{458}$ Carta a su abuela, fechada el 10 de abril de 1861 (DUPARC, 1872: 75).
} 
conjunto de obras puede extraerse una visión general de la galería, configurada de manera ordenada y regular:

Estos retratos, de los cuales desgraciadamente una parte no están firmados, fueron pintados sobre lienzo, con la excepción de los de David d'Angers y de Henri Regnault. Están colgados en seis u ocho filas alrededor del refectorio de los pensionados, y todos los personajes están representados en busto (JOUIN, 1884: 58).

La lista de retratos incluida por Jouin ascendía a un cómputo total de 309 retratos realizados hasta, aproximadamente, la promoción de 1879; en ellas incluye el nombre del retratado, la modalidad de su pensión y año en que la consiguió, y en los casos en que el retrato estuviese firmado, el autor de la obra. El carácter meramente documental de los apuntes de Jouin se pone de manifiesto en la ausencia de posibles atribuciones en los retratos no firmados, encontrando un total de 103 retratos - una significativa tercera parte de la galería- cuyo autor es, según Jouin, desconocido. La manera en que se aproxima a esta galería, lejos de imparcialidades, transmite una intención marcadamente nacionalista; el núcleo de la Villa Médicis constituye, para él, la colección más auténtica de retratos de artistas decimonónicos franceses, en oposición a aquellas galerías institucionales (como la de la antigua Académie Royale) dispersas en el momento en distintas colecciones: sin aludir a la importancia del Prix de Rome para la configuración de una reputación artística de los retratados, ni al carácter identitario transmitido por el conjunto de efigies, Jouin solo se lamenta del acceso restringido a la colección de retratos. Para él, "sería deseable que estuviesen reunidos en galerías claras, amplias, de fácil acceso" (JOUIN, 1884: 59). El interés de Jouin por la galería de retratos se mantuvo vivo en la década posterior, así como su voluntad por darla a conocer al público. El 23 de julio de 1891 dirigía una carta a Guillaume, en ese momento director de la Academia de Francia en Roma, transmitiéndole su deseo de escribr algunas páginas sobre los retratos de pensionados conservados en la Villa Médicis en L'Artiste, incorporando algunos retratos grabados de fotografía. Los elegidos serían Regnault, Bizet, Carpeaux, Baudry, Bouguereau, Garnier, Flandrin, Cabanel, Lefebvre, Massé, Berlioz y el propio director, Guillaume. Un estudio actualizado de la galería de retratos fue el publicado por Brunel en 1979 (BRUNEL, 1979), que amplía las noticias ofrecidas por Jouin e incluye nuevas atribuciones. El análisis de la evolución de la galería de retratos de la Villa Médici demuestra cómo la vida de los pensionados franceses en Roma se encontraba sujeta a las experiencias masculinas heredadas previamente en el atelier.

La omnipresencia de los retratos de pensionados en el refectorio o comedor indica, sin lugar a dudas, una relación cotidiana con lo que supuestamente constituía un elemento de carácter social al mismo tiempo que con voluntad de crear una imagen institucional. Del mismo modo, la forma en que la realización de los retratos fue variando con el tiempo es también un testimonio de los cambios en las relaciones sociales dentro de la Villa Médici y un reflejo directo de la transformación en las estructuras de poderes dentro de los talleres artísticos en París. De este modo, se puede observar cómo en un primer momento las tareas de realización de los retratos correspondían a los recién llegados, siguiendo un sistema jerárquico basado en la edad y 
la experiencia, y cambiaron paulatinamente a una valoración de la fraternidad artística entre los pensionados de una misma promoción para introducir, posteriormente, el carácter de individualismo e independencia del autorretrato.

Henri Jouin (1884: 59), al elaborar la lista de los retratos de pensionados, aludía al hecho de que estos fueron pintados durante su estancia en la Villa Médicis; así, proporcionaba el año de entrada en esta, "fecha que permite, pues, fijar aproximadamente la época a la que se remonta el retrato, ya que este fue ejecutado (salvo raras excepciones), durante la estancia de los artistas en la Academia de Francia". A pesar de que la fecha exacta de origen de la galería es desconocido, Jouin presenta como primer retrato el del escultor Jean-Pierre Cortot, premiado en 1809; sin embargo, el elevado número de pensionados ausentes en la galería da noticia del carácter aún embrionario de esta, ya que hasta 1815 no se encuentra el retrato de todos los pensionados de la promoción ${ }^{459}$.

Una de las características de esta primera etapa de la galería de retratos es la relación entre efigiado y autor [tablas 7 y 8] hasta aproximadamente 1830, los retratos fueron realizados por pintores pertenecientes a una promoción más reciente, dándose en ocasiones algunos realizados entre los compañeros de pensión de una misma promoción, siendo significativo el caso de 1821.

$\begin{array}{lcll}\text { Retratado } & \text { Promoción } & \text { Autor } & \text { Promoción } \\ \text { Palière } & 1812 & \text { Forestier } & 1813 \\ \text { Forestier } & 1813 & \text { Vinchon } & 1814 \\ \text { Vinchon } & 1814 & \text { Alaux } & 1815 \\ \text { Roll } & 1814 & \text { Cogniet } & 1817 \\ \text { Alaux } & 1815 & \text { Cogniet } & 1817 \\ \text { Ramey } & 1815 & \text { Coutan } & 1820 \\ \text { Thomas } & 1816 & \text { Cogniet } & 1817 \\ \text { Coiny } & 1816 & \text { Hesse } & 1818 \\ \text { Nanteuil } & 1817 & \text { Court } & 1821 \\ \text { Hesse } & 1818 & \text { Bouchot } & 1823 \\ \text { Dubois } & 1819 & \text { Bouchot } & 1823 \\ \text { Jaley } & 1827 & \text { Flandrin } & 1833 \\ \text { Oudiné } & 1831 & \text { Flandrin } & 1833\end{array}$

Tabla 7. Artistas retratados por autores pertenecientes a promociones posteriores (18121830)

Una posible explicación para que los retratos fuesen realizados por los recién llegados puede relacionarse con las tareas y ocupaciones de los propios pensionados, teniendo mayor disponibilidad los primeros al estar los veteranos ocupados -en

\footnotetext{
${ }^{459}$ Cotejando la lista de retratos de Jouin con la de pensionados de la Academia de Francia, puede observarse que únicamente consta un retrato de 1809, y que el del escultor David, pensionado en 1811, no fue realizado hasta fecha posterior; en 1812 y 1813 las exclusiones de pensionados retratados son limitadas: no se realizan las efigies del escultor Rude ni del arquitecto Suys en 1812, ni las del arquitecto Caristie y el grabador Brandt en 1813; entre los pensionados en la promoción de 1814 se olvida también realizar el retrato del arquitecto Landon y del grabador en dulce Forster.
} 
ocasiones a contrarreloj- en la finalización de la obra de envío. Sin embargo, otra posible lectura de esta práctica inicial es una lectura en clave ritual, como iniciación de los nuevos pensionados en la vida de la Villa Médicis, traduciendo en buena medida la tensión masculina de los talleres parisinos en los que se habían formado, continuando así con un cierto discurso jerárquico algo desdibujado, en el que pervivían elementos como las cargas de bienvenida. En fecha temprana Ingres describía a los demás pensionados como hombres de poca madurez, llamándolos escolares "a veces sin educación y algunos muy ruidosos y vocingleros ${ }^{460}$,, mientras que Henri Regnault deja constancia, en su correspondencia con su padre, de cómo la novatada a los nuevos pensionados se había transformado en 1868, lejos de las antiguas prácticas de subordinación del atelier parisino dirigidas a inculcar una jerarquía cerrada y de costumbres hipervirilizadas ${ }^{461}$.

$\begin{array}{lclc}\text { Retratado } & \text { Promoción } & \text { Autor } & \text { Promoción } \\ \text { Petitot } & 1814 & \text { Vinchon } & 1814 \\ \text { Benoist } & 1815 & \text { Alaux } & 1815 \\ \text { Halévy } & 1819 & & \\ \text { Massin- } & 1819 & \text { Dubois } & 1819 \\ \text { Turina } & & & \\ \text { Leborne } & 1820 & \text { Coutan } & 1820 \\ \text { Blouet } & 1821 & & \\ \text { Rifaut } & 1821 & \text { Court } & 1821 \\ \text { Lemaire } & 1821 & & \\ \begin{array}{l}\text { Dumont } \\ \text { Tabla 8. Artistas retratados por compañeros de pensión de la misma promoción } \\ (1812-1830)\end{array} & \end{array}$

La correspondencia de algunos pensionados permite ver cómo, en efecto, los recién llegados a la Villa Médicis contaban entre sus tareas la realización de algún retrato. A su llegada a la Academia, Flandrin comunicaba a su padre las primeras actividades que le ocuparon, entre las que se cuenta un retrato que debía quedarse en la misma, representando a un pensionado escultor que, habiendo agotado su estancia en Roma, regresaba a París. Curiosamente, es la única referencia a un retrato de pensionado - especificando la identidad del representado (Jaley)- mencionada por Flandrin en su correspondencia ${ }^{462}$, ya que en ningún momento hace alusiones a la galería de retratos.

Las novedades que se comienzan a introducir hacia 1820 señalan un cambio progresivo en la manera de afrontar el retrato para la galería, y probablemente una sociabilidad más basada en la fraternidad artística que en la lucha de poderes. Ese mismo año, el pintor Paul-Amable Coutan, discípulo de Gros, realiza el retrato de su

\footnotetext{
${ }^{460}$ Carta a Julie Forestier de 2 de enero de 1807 (DARAGON, 1909: 137 y 144).

461 "Como Bénard no avisó de su llegada, no pudimos hacerle las novatadas habituales, muy inocentes por otra parte. Normalmente consisten en la instalación de la mayor miseria, ya sea en las habitaciones, que desamueblamos a tal efecto, o en la forma de vivir " carta de 12 de febrero de 1868 (DUPARC,1872: 127128).

${ }^{462}$ Carta del 30 de enero de 1833 a Mr. y Mme. Flandrin (DELABORDE, 1865: 194).
} 
compañero de pensión, el compositor Leborne, y un año después, Joseph-Désiré Court realiza los retratos de al menos tres de sus compañeros de pensión. Aunque son escasas las noticias aportadas por Jouin respecto a la autoría de los retratos realizados entre 1820 y 1837, sabemos por la documentación y biografías de Hippolyte Flandrin que este realizó, además del retrato de Jaley, el del escultor Jean-Baptiste-Joseph Debay (Grand Prix en 1829), el del grabador Oudiné (Grand Prix en 1831) y el de su compañero de pensión, Ambroise Flandrin.

La práctica de retratar a los compañeros de la misma promoción se convirtió en tradición a partir de finales de la década de 1830, con dos modalidades en función de los usos sociales de cada momento: por una parte se encuentran aquellos casos en que el artista, probablemente por modestia o humildad, aborda las efigies de los demás pensionados, pero no la propia, algo que pudo haber sido la costumbre durante la década de 1830 y que se retoma en 1870 [tabla 9], en la que es un pintor de promociones posteriores quien realiza su retrato; por otra se encuentran los casos en que el pintor transmite la imagen completa de toda su promoción, incluyendo en ocasiones su propio autorretrato.

$\begin{array}{ll}\text { Hébert (1839) } & \text { Delaunay (1856) } \\ \text { Biennourry (1842) } & \text { Ulmann (1859) } \\ \text { Barrias (1844) } & \text { Michel (1860) } \\ \text { Cabanel (1845) } & \text { Lefebvre (1861) } \\ \text { Lenepveu (1847) } & \text { Layrault (1863) } \\ \text { Boulanger (1849) } & \text { Maillard (1864) } \\ \text { Baudry (1850) } & \text { Machard (1865) } \\ \text { Bouguereau (1850) } & \text { Blanc (1867) } \\ \begin{array}{ll}\text { Giacomotty (1853) } & \text { Toudouze (1871) } \\ \text { Tabla 9. Autorretratos en la galería de la Academia } \\ \text { de Francia en Roma }\end{array}\end{array}$

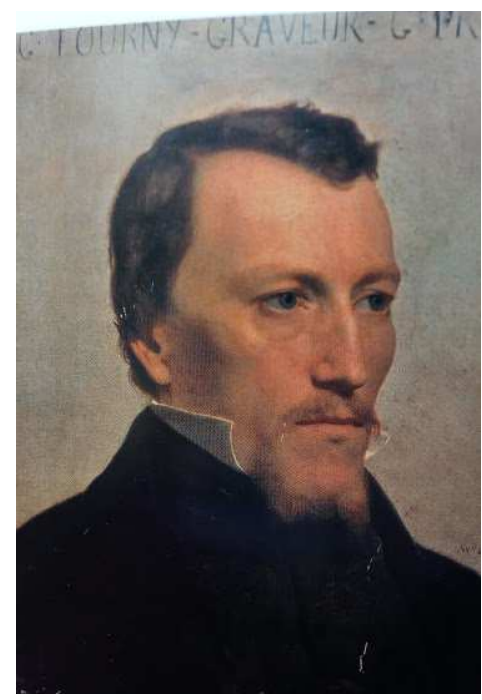

Fig. 167. William Bouguereau, Retrato del grabador Tourny. Villa Médici.

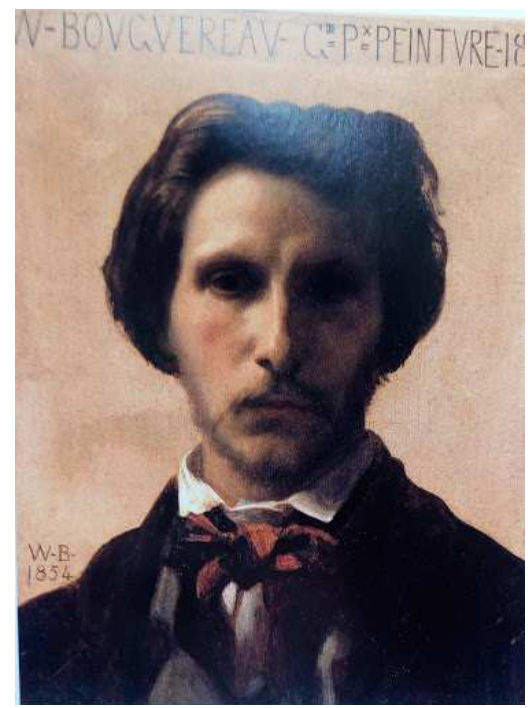

Fig. 168. William Bouguereau, Autorretrato, 1854. Villa Médici. 
En los años cincuenta la realización de los retratos (y autorretrato) estaba ya configurada como una tradición, entendida en algunos casos como una imposición, tal y como deja entrever Baudry en su correspondencia: "el pintor está en la obligación de realizar, en su quinto año, los retratos (...), de este modo, yo tendré que hacer cinco, contando el mío" (FOSSIER, 2006: 365-366). Jouin atribuía, en un artículo consagrado al difunto pintor Jules-Elie Delonay en 1891, un elevado componente de camaradería al acto de pintar los retratos de los demás pensionados (JOUIN, 1891: 241-243), señalando ya la elevada actividad producida durante los años cincuenta. Sin embargo, el hecho de que la realización de los retratos se pospusiese hasta el último momento de pensión del pintor, como señalaba Baudry y como queda corroborado por la afirmación que realiza el director de la Academia, Lenepveu, a propósito del pintor Jules-Louis Machard ${ }^{463}$, quien realizó también su propio autorretrato (FOSSIER, 2006: 154), parece sumar a ese carácter de fraternidad artística un componente de homenaje y despedida.

El origen de esta práctica puede ubicarse en 1838, momento en que Isidore Pils se encargó de retratar a sus compañeros Nicolas Vilain, Uchard, Victor Pollet, CharlesVictor Normand y Georges Bousquet, mientras su propio retrato era realizado por un artista desconocido; lo mismo sucedería en 1839, en que los retratos de Théodore Gruyère, Hector-Martin Leguel, André Vauthier y de Charles Gounod fueron realizados por Hébert, quien se encargó asimismo de realizar su autorretrato. En 1840, PierreNicolas Brissert retrató a sus compañeros Ballu, Saint-Eve y Bazin, dejando el suyo propio a la mano de Barrias, quien, sin lugar a dudas, debió realizarlo durante el último año de pensión de Brissert. Sería también un artista de una promoción posterior, Biennourry, quien realizaría el del pintor Auguste Lebouy, quien pudo haber sido el autor de los retratos de la promoción de 1841 y que Jouin señala como autoría desconocida (Lanoue, Diéboldt, Godde, Paccard y Maillard). Pocas diferencias hay en la siguiente promoción, en la que el propio Biennourry pinta, junto a su retrato, los de Cavelier, Titeux y Roger, completándose dos años después por Barrias con el del grabador Delemer. Félix Barrias sumó su retrato al de sus compañeros de pensión de 1844 (Lequesne, Desbuisson, Aubert y Félix Massé). Dos pintores, además del premio de pintura de paisaje Jean-Achille Benouville, se dieron cita en la promoción de 1845 , pero no recurrieron a retratos cruzados; Alexandre Cabanel, que obtuvo segundo premio en el Prix de Rome, optó por autorretratarse, en 1851, encargándose también de realizar algún retrato de los pensionados de la siguiente promoción. El retrato de Léon Benouville, primer premio, no corresponde a un autorretrato ni a un retrato realizado por Cabanel, sino a uno surgido de una particular fraternidad, al mismo tiempo artística y familiar: los pintores y hermanos Benouville optaron por realizar sus retratos cruzados [figs. 169 y 170] para la galería de pensionados de la Villa Médici.

\footnotetext{
463 “Este Machard, siempre igual! Anuncia su partida, que será a principios de noviembre, a lo que hay que sumar quince días para hacer los retratos de los de su promoción” (FOSSIER, 2006: 102).
} 


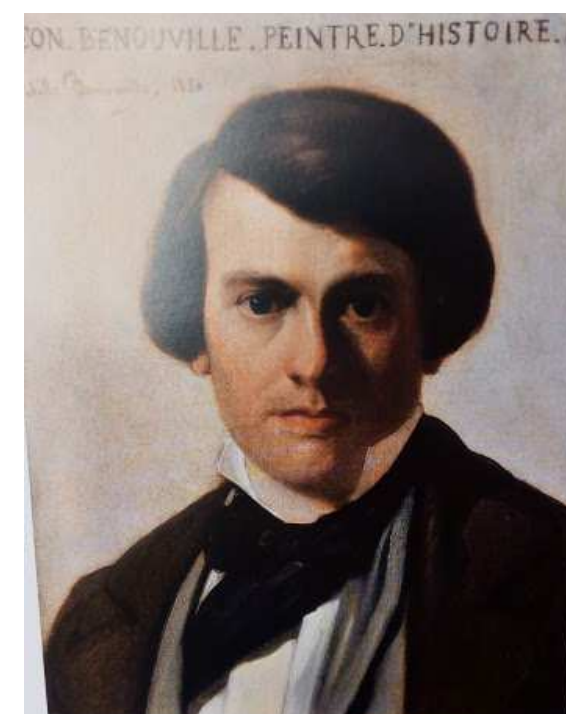

Fig. 169. Achille Bénouville, Retrato de Léon Bénouville, Villa Médici.

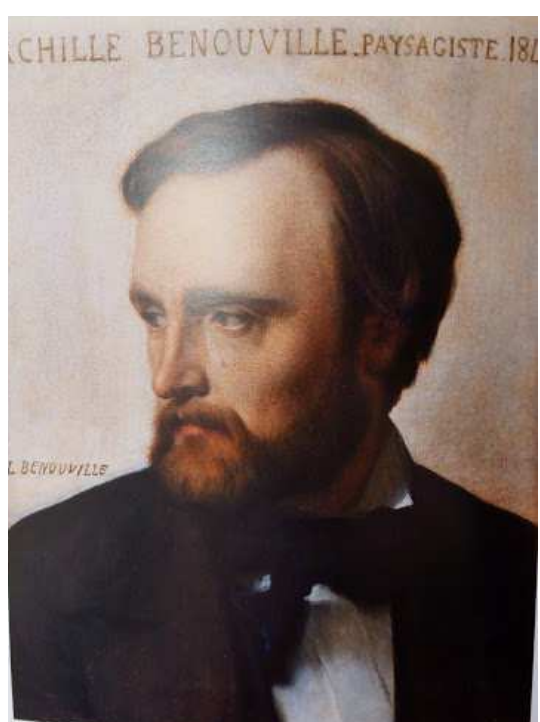

Fig. 170. Léon Bénouville, Retrato de Achille Bénouville, Villa Médici.

A partir de esta fecha este tipo de retrato y de sociabilidad fraternal se hace más frecuente, viéndose cómo ya los pensionados en 1847 compartieron el pincel de JulesEugène Lenepveu, quien se autorretrató también para figurar en la misma galería; la práctica del autorretrato se pone especialmente de manifiesto en pintores que no encontraron sucesor inmediato al no haber pensionados más jóvenes por la pintura, lo que indica que el autorretrato, lejos de ser una muestra de vanidad personal, traduce una necesidad fruto de la realidad en la Academia, como sucede en los casos de Boulanger, Paul Baudry y William Bouguerau.

\subsubsection{La galería de pensionados españoles}

En su estudio sobre la Academia Española de Bellas Artes en Roma, Margarita Bru Romo (1971: 178) recogía la noticia de que "al inaugurarse el edificio de la Academia, los pensionados habían empezado a formar una colección de retratos con la idea de reunir los de todos los artistas que pertenecieron a este Instituto", una colección que los pensionados de la promoción de 1895 buscaron completar al encontrarla incompleta. Casado Alcalde (1987: 241-249) profundizó en las motivaciones de la creación de esta galería, aportando un catálogo de los retratos y una breve consideración como serie icónica de la institución. De este modo, recoge la correspondencia mantenida entre los pensionados y el Ministerio, mediante la cual los artistas pusieron en conocimiento del último la existencia de una galería de retratos, de la cual proporcionaron un listado con las treinta y una obras existentes hasta el momento. El objetivo de esta comunicación era solicitar que la colección de retratos fuese conservada por el Estado para impedir su dispersión, lo que manifiesta la voluntad expresa de que no se perdiese su significado de identidad de grupo y de objeto para la memoria.

Según esta relación, los primeros retratos conocidos son los que representan a Jaime Morera, pensionado de la sección de pintura, retratado por su compañero Casto Plasencia; al propio Casto Plasencia, por Maximino Peña; un autorretrato del pintor Francisco Pradilla (REYERO, 1992: 78), y un retrato, realizado por este último, del pensionado de escultura Ricardo Bellver. A la segunda promoción, de 1878 a 1881, 
pertenecen las efigies de dos pensionados de escultura, Manuel Oms y Medardo Sanmartí, realizados por los pensionados de pintura Eugenio Oliva y Manuel Ramírez Ibáñez respectivamente. Los dos pintores se encargaron también de retratar al pensionado por el grabado, Melesio Figueroa, al de arquitectura Manuel Zabala, y al de música Cleto Zabala. Sin embargo, la labor de estos dos pintores continuaría animando la galería de retratos, pues realizaron también el del escultor Torcuato Taso, los suyos propios y el del músico Tomás Bretón. El último retrato debido a la mano de Oliva sería el del músico Felipe Espino.

La llegada de nuevas promociones de pensionados dio continuidad a la galería: el pintor José Moreno Carbonero retrató a su compañero de escultura Antonio Moltó; Ulpiano Checa realizó los de los pintores Hermenegildo Estevan, Eduardo Barrón y González, el escultor Juan Vancell y el músico Emilio Serrano; Eugenio Álvarez Dumont los del escultor Agustín Querol y los músicos Miguel Santonja y José Sáinz; José Garnelo pintó los retratos del grabador Aquilino Cuervo, el escultor Antonio Parera y el pintor Santiago Regidor. Finalmente, los pensionados en 1895 César Álvarez Dumont y Ángel Andrade retrataron a sus compañeros Fernando Carnicer y Ezequiel Ruiz el primero, y Emilio Tuesta el segundo, además de incorporar sus respectivos autorretratos.

Además de estas pinturas, que aparecen en la lista de 1896, Casado Alcalde daba noticia de doce más, de las cuales cuatro quedaron sin identificar; de las ocho restantes, tres fueron realizadas en el siglo XIX, como parece desprenderse del hecho de que tanto los retratados como los autores fueron pensionados de la Academia durante la última década del siglo. Así, los pensionados entre 1895 y 1899 dejaron las efigies del pintor Joaquín Bárbara (autorretrato) y del músico Emilio Tuesta (por Ángel Andrade), y se incorporó el del arquitecto Juan Moserrat (autorretrato), pensionado entre 1879 y 1882.

Casado Alcalde (1987: 245) lee esta galería como una serie icónica, en que la historia de la institución se legitima a través de los miembros que la han compuesto; no obstante, el hecho de que los primeros retratos comenzasen a realizarse inmediatamente en la primera generación de pensionados evidencia que, además de la sociabilidad entre artistas propia de las estancias en Roma y París, que habitualmente se traducía en el retrato de amigo, existe un interés por parte de algunos de los artistas en dejar constancia del paso por la recién creada institución mediante el retrato. Plantea dudas, sin embargo, el origen de la galería en un sentido estrictamente corporativo; el hecho de que la primera promoción de pensionados no dispusiese de un local a propósito tanto para habitación como para desarrollo de su actividad no solo dificultaba el sentimiento de pertenencia a una Academia cuya existencia era bastante abstracta ${ }^{464}$, sino que

\footnotetext{
${ }^{464}$ Margarita Brú, al analizar el proceso de construcción de un edificio para la Academia Española en Roma, afirma que "el espíritu de corporación, la disciplina y el sentido de la responsabilidad conjunta que se esperaba que informase en la institución creada en Roma no podría lograrse hasta reunir en un local a todos los pensionados" (BRU ROMO, 1971: 24). Por el contrario, Wifredo Rincón recoge un testimonio del Cónsul Administrador de los Reales Establecimientos Españoles en Roma, en el que este refiere con nostalgia la vida de los primeros pensionados en relación a su genio artístico, y en el que califica la nueva vida en el Palacio de San Pietro como "una rémora, pues empequeñece y coarta las aspiraciones y necesidades del genio. (...) Los pensionados deberían vivir en la libertad e independencia que exige el
} 
conllevaba un tipo de sociabilidad más próximo al de la unión de compatriotas en la colonia de artistas españoles en Roma. Los pensionados vieron establecida su vivienda entre el Palacio de la Legación y un piso alquilado ${ }^{465}$, pero la convivencia no acababa de resolver el conflicto de una identidad común; cabe preguntarse si el inicio de la galería, que no fue efectivo hasta 1881, podía responder a esa necesidad de establecer un sentimiento corporativo entre los jóvenes artistas que buscaban así dignificar su estatus y diferenciarse de los otros artistas de la colonia española, y también qué papel jugó el retrato de amigo en la galería.

Al ser la fecha clave para el inicio de la galería la misma de la inauguración del edificio de la Academia y coincidir con la etapa de pensión de Eugenio Oliva y Manuel Ramírez, los cuatro retratos de los pensionados de la primera promoción pueden despejar algunas incógnitas respecto a la motivación subyacente en la constitución de la galería: en primer lugar, porque uno de los retratos, fruto de la amistad entre dos artistas, ni siquiera fue pintado por un pensionado de la Academia en esos años de 1874 a 1877. Se trata del retrato de Casto Plasencia, realizado por el pintor Maximino Peña, de cuya presencia en Roma no se tiene constancia hasta 1885 como pensionado de la Diputación Provincial de Soria. Peña conoció a Casto Plasencia en Madrid, pues acudió a su estudio para completar la formación que recibía en la Escuela Superior de Pintura y le acompañó en la Colonia de Muros de Nalón en Asturias en el verano de 1884. Allí debió de realizar un retrato de su maestro, expuesto ese verano en Soria, de cuya fotografía no se desprendió nunca (CERRILLO RUBIO, 1993: 34), por lo que tal vez fue uno de los modelos que el pintor emplease para realizar el retrato de su maestro para la Academia Española. En segundo lugar, otra de las pinturas es una copia de otro retrato (la obra original fue realizada en 1875 por Casto Plasencia y se conserva en el Museo de Arte Jaime Morera de Lérida), llevado a cabo con posterioridad para la Academia en los años de 1890-1893 por el pensionado Santiago Regidor, representando al joven pintor Jaime Morera. Todo parece apuntar a que el retrato realizado por Casto Plasencia era un retrato de amistad, tal y como se desprende de la dedicatoria con la que el pintor acompaña la firma (REYERO, 1992: 84; CASADO ALCALDE, 1987: 871); las dimensiones de este lienzo se corresponden, sin embargo, con las que se observan en todos los cuadros de la galería. Finalmente, los dos retratos restantes de pensionados de la primera promoción corresponden a la mano de Francisco Pradilla, tratándose de uno del escultor Ricardo Bellver y de un autorretrato.

La bibliografía existente, a partir de la noticia de Casado Alcalde, sitúa este autorretrato como el más antiguo de la colección, y lo fecha, con ciertas reservas, en 1874, momento de iniciar su pensión (CASADO ALCALDE, 1897: 617; LORENTE, 1988: 209; REYERO, 1992: 78), mientras que Wifredo Rincón (2016: 755) pospone su realización tres años, en el momento de finalizarla; resulta difícil datar la pintura, ya que

genio, con un reglamento imperceptible; pero la vida claustral, el edificio fijo y espléndido, donde hay hasta mesas de billar y cocinero, pinche y jardinero, no puede producir más que antagonismos y pereza", (RINCÓN GARCÍA, 1987: 26).

${ }^{465} \mathrm{La}$ residencia estaba ubicada en la Via de la Croce, 34 (BRU ROMO,1971: 24; RODRÍGUEZ RODRÍGUEZ, 2014: 90). 
la imagen de Pradilla, seria y hermética, reproduce una fisonomía muy próxima a la de sus autorretratos de la década de los ochenta, en concreto al regalado al doctor Huertas, datado en 1887. Su aspecto severo y reflexivo, similar al que presenta en el retrato de amistad realizado en 1874 por su compañero de pensión, Alejandro Ferrant (Museo Nacional del Prado, $n^{\circ}$ inv. P04315), parece chocar con los veintiséis años que el artista contaba al pasar a Roma; podría aventurarse la hipótesis de que el retrato no fuese realizado hasta años después, hacia 1881, coincidiendo con su breve paso por la Academia como director y con la iniciativa de los nuevos pensionados. Desde la finalización de su pensión en 1877, Pradilla continuó viviendo en Roma y manteniendo relación con la Academia, acudiendo a algunas de las clases; como director de esta estuvo apenas seis meses, de octubre de 1881 hasta su dimisión en abril de 1882, momento en que los pensionados Eugenio Oliva y Manuel Ramírez se encuentran realizando los retratos de sus compañeros de pensión para iniciar la galería (CASADO ALCALDE, 1987: 703).

A pesar de que la realización de estos retratos para la galería de la Academia denota ya un vivo interés por generar una imagen de la corporación, la existencia de importantes lagunas entre las pinturas de la primera generación es significativa: de los doce pensionados en Roma de la primera promoción, tan solo se hicieron cuatro retratos; son notables las ausencias de los tres pensionados por la arquitectura (Miguel Aguado de la Sierra, Manuel Aníbal Álvarez y Ramiro Amador de los Ríos), del escultor Juan Figueras y del grabador Vicente Moreno, del único pensionado por la música (Ruperto Chapí), y de dos pensionados de pintura: Baldomero Galofre y el de mérito, Alejandro Ferrant. Puede resultar comprensible la ausencia de Galofre, ya que fue destituido de su pensión en su segundo año por dedicarse a trabajos de especulación, lo que motivó que el paisajista sintiese herida su reputación artística y su honra personal (CASADO ALCALDE, 1987: 1141).

Es el empuje de Manuel Ramírez y Eugenio Oliva el que hace arrancar la galería de retratos de la Academia Española en Roma. La inauguración de la sede definitiva de esta se vincula con el nacimiento de un carácter corporativo. Significativamente, a estos dos pintores se debió la realización de diez retratos de pensionados, que deben fecharse todos ellos entre 1881 (fecha en que finalizan su pensión Sanmartí, Figueroa, y Manuel y Cleto Zabala) y 1882, en que llega a su término la de los dos pintores, cuyos sucesores se sumaron a la tradición de continuar la galería. La labor de estos dos artistas no buscó únicamente efigiar a otros pintores, sino que la iniciativa contaba con incluir a todos los pensionados, incluyendo a músicos y grabadores; significativamente se fecha en este momento el único retrato de un pensionado por la arquitectura, ya que no se observa entre las promociones posteriores ningún interés por retratar a los compañeros de este arte. Se configura así una cierta identidad institucional, ya que las obras de la galería están imbuidas también del valor del retrato como experiencia social de los jóvenes académicos, puesto que son un privilegio exclusivo de y entre los pensionados, y ningún director de la Academia, a excepción de José Benlliure, figuró en ella. De este modo, el retrato estaba dotado de un significado de orgullo profesional y consagraba mediante la efigie a los jóvenes artistas españoles como promesa de su porvenir laboral. Este rasgo 
de juventud es significativo ya que, según el reglamento, no podían haber cumplido treinta años en el momento de opositar ${ }^{466}$ ni ser mayores de 40 en el caso de optar a una pensión de mérito, lo cual ofrece una imagen novedosa con respecto a otras galerías de retratos de académicos en España, en que la edad de los efigiados era, como se ha podido comprobar, mucho más elevada y vinculada con la madurez y el éxito consagrado. Se presenta también como una galería configurada al estilo de una serie, con una coherencia en las dimensiones y en el tipo de retratos (de busto) de jóvenes artistas que, en su mayoría, debían contar al ser retratados entre 20 y 30 años ${ }^{467}$.

\begin{tabular}{lcccccccccc} 
& \multicolumn{2}{c}{ Pintura } & \multicolumn{2}{c}{ Escultura } & \multicolumn{2}{c}{ Arquitectura } & \multicolumn{2}{c}{ Grabado } & \multicolumn{2}{c}{ Música } \\
& P. N. & P.M. & P.N. & P.M. & P.N. & P.M. & P.N. & P.M. & P.N. & P.M. \\
Total & 23 & 8 & 12 & 7 & 7 & 3 & 6 & & 10 & 5 \\
\multirow{2}{*}{ Retratos } & 14 & 3 & 8 & 4 & 2 & 0 & 3 & 5 & 3 \\
\hline
\end{tabular}

Tabla 10. Comparativa del número de retratos realizados en la Academia Española en Roma frente al número total de pensionados por disciplina y categoría (1874-1905).

Dado que el último retrato que se incorpora corresponde a la promoción de 1904, el análisis de las cifras es significativo (anexo 7). De un número total de ochenta pensionados constan 42 retratos, entre los cuales las ausencias más notables son las de los arquitectos [tabla 10], puesto que, de un total de nueve entre pensionados de número y de mérito tan solo se llegaron a realizar dos retratos. La proporción es más estable en el resto de disciplinas; en el caso de la pintura, de un total de treinta y un pensionados quedaron diecisiete retratos; doce del total de diecinueve escultores, tres de los seis pensionados por el grabado, y ocho de los quince por la música. Efectivamente, si puede llamar la atención la ausencia de retratos de artistas consagrados, como Alejandro Ferrant, Emilio Sala o Salvador Viniegra, la explicación se encontraría en el conjunto de obras realizadas: la relación de retratos de pensionados de mérito es inferior a la de pensionados de número, sin duda porque su edad, obligaciones familiares y economía más desahogada les llevaron a vivir fuera del espacio fraternal de la Academia.

\footnotetext{
${ }^{466}$ Art. 26, cap. II, tít. $3^{\circ}$ del reglamento de 1873; art. 30, cap. II, tít. $3^{\circ}$ del reglamento de 1877; art. 27 del reglamento de 1894 (BRU ROMO, 1971: 256, 277 y 301). Este requisito se aplica a los pensionados de número; sin embargo, al abordar la manera de proveer las plazas de pensionados de mérito en el reglamento de 1873 no se menciona edad, sino únicamente ser artistas de reconocido prestigio por sus obras, o haber sido galardonados con primeros o segundos premios en exposiciones nacionales (BRU ROMO, M. (1971), p. 261), mientras que en el de 1877 se estipula que no podrán ser mayores de cuarenta años, o excepcionalmente cuarenta y cinco en el caso de haber sido premiado con dos medallas de primera clase (art. 49, cap. III, tít. $3^{\circ}$ ) (BRU ROMO, 1971: 283).

${ }^{467}$ Los más jóvenes en el momento de opositar entre los representados en la galería fueron Jaime Morera y Antonio Parera, con 20 años; excedían los treinta años reglamentarios el pensionado de mérito, Manuel Oms, con 32, el grabador Melesio Figueroa con 36, el pintor Hermenegildo Esteban con 31, el escultor Juan Vancell con 37.
} 


\subsection{Los retratos de artista en otras instituciones oficiales}

\subsubsection{El proyecto de un Museo Iconográfico}

Inmaculada Rodríguez Moya (2013: 271-296), al trazar la historia de la Junta de Iconografía Nacional, la vincula indisociablemente con el concepto de privilegio asociado a la élite política e intelectual en que se fundamentan las colecciones de retratos de hombres ilustres y lo asocia a una nueva necesidad de exaltación patriótica a través de las glorias nacionales en el siglo XIX. La iniciativa del conde de Toreno, ministro de Fomento, de impulsar desde el gobierno la creación de una colección nacional de retratos de españoles ilustres partía no solo de los ejemplos extranjeros de la National Portrait Gallery de Londres o de los retratos existentes en el Palacio de Versalles, sino también de la empresa de Luis de Baviera y su Walhalla, así como otras galerías de retratos, mencionando en su exposición el caso de la Galería los Uffizi de Florencia. Aludiendo a las colecciones de retratos existentes en algunas potentes instituciones tradicionales, monopolizadoras del concepto y uso de privilegio, como el clero y las universidades, Francisco Queipo de Llano omite las iniciativas de matiz privado dedicadas a ensalzar a miembros ilustres, generalmente de la élite política y cultural, no solo en colecciones particulares sino también en conocidas sociedades, como el Ateneo de Madrid, cuya galería de retratos adquiere verdadero impulso tan solo un año antes de que el proyecto de Museo Iconográfico fuese presentado a las Cortes. En este, el conde de Toreno se apoyaba en la centralización de las artes para solicitar un nuevo Museo constituido a modo de "galería de retratos de cuantos personajes hayan contribuido a la gloria y renombre de España, sea cual fuere su patria y sexo" (Gaceta de Madrid, 1876: 445), que sirviera de utilidad pública al constituirse como documento histórico y moral ${ }^{468}$. Por real decreto de 13 de agosto de 1876 se ordena la formación de una junta que

reuniendo en el local que oportunamente se determine todos aquellos retratos, bustos, medallas y demás documentos iconográficos que sean en la actualidad propiedad del Estado, y procurando la adquisición de originales o copias de verdadero mérito que puedan servir para aumentar la riqueza existente, forme una colección nacional de retratos de personajes ilustres ${ }^{469}$,

y dando lugar de este modo a una primera Junta de Iconografía Nacional, cuyos miembros fueron designados el 14 de agosto de 1876, de los que cabe destacar, entre numerosos aristócratas vinculados al gobierno, el papel de Valentín Carderera y Pedro de Madrazo, conocidos ambos por su relación con el mundo del arte, la historia, el

\footnotetext{
${ }^{468}$ Así lo manifiesta el conde de Toreno, al hablar de aquellos españoles "cuya gloria se refleja sobre nuestra patria, como una de esas inapreciables fuerzas morales de que disponen los pueblos de viejos y nobles blasones, y que sirven de estímulo poderoso para que su porvenir corresponda a lo que exige lo ilustre de su pasado" (Gaceta de Madrid, 1876/15/08: 445).

${ }^{469} \mathrm{La}$ R. O. de 14 de agosto, recogida por Rodríguez Moya, nombra como miembros de la Junta a Manuel García Barzanallana, José Álvarez de Toledo, Enrique Ramírez de Saavedra, Francisco de Borja de Bazán y Silva, Leopoldo Augusto de Cueto, Valentín Carderera, Hipólito de Queralt, Pedro de Madrazo, José Gómez de Arteche, Manuel Cañete, Vicente Palmaroli, Francisco Asenjo Barbieri y Gregorio Cruzada Villaamil (RODRÍGUEZ MOYA, 2013: 276).
} 
coleccionismo, así como su interés por el desarrollo de otras galerías de retratos, como se ha visto en el caso de la de la Academia de San Fernando.

La prensa recibió la iniciativa con tibieza, ya que si bien el redactor de El siglo futuro aseguraba que la colección de retratos iría encabezada por los ministros españoles y que daría lugar a una galería tan numerosa "que no bastará el ministerio de Fomento para contener la colección si ha de ser completada" ("Revista política...", 1876: 2), en la Revista de archivos, bibliotecas y museos se hacía notar el peligro de que la galería de retratos cayese en el olvido por "la impremeditación de un exaltado y no muy cuerdo patriotismo", recordando el caso del panteón nacional (C., 1876: 270). La escasa documentación conservada respecto a la actividad de la Junta de Iconografía Nacional apenas permite reconstruir sus primeros años, en que los retratos fueron destinados al Museo Nacional de Pinturas. Para ello fue preciso realizar obras en el establecimiento a lo largo del año 1877 y comienzos de $1878^{470}$, tal y como transmite la prensa del momento; en abril de 1877 el ministro de Fomento y el presidente de la Junta, el marqués de Barzanallana, acudieron al museo para analizar las obras que debían llevarse a cabo para la instalación del Museo Iconográfico (Diario oficial de avisos, 1877: 3). El lugar destinado a esta colección se encontraba en la segunda planta, y el acondicionamiento de la sala aún no estaba concluido en el momento de la inauguración de las nuevas salas de pintura española e italiana en octubre de ese mismo año ( $L a$ Iberia, 1877: 2), ni en febrero de 1878, momento en que se da noticia de que las obras de ampliación para la instalación del Iconográfico "adelantan notablemente 471 ". Mientras tanto, la Junta de Iconografía realizó a partir de marzo de 1877 un llamamiento a los gobernadores y Diputaciones Provinciales solicitando información sobre posibles retratos de españoles ilustres ("Noticias", 1877: 140), documento que conocemos por el existente en la Real Academia de Bellas Artes de San Fernando, en el que se especifica el carácter eminentemente patriótico de la galería a formar, en la que se incluirían "monarcas, sabios, filósofos, poetas, santos, estadistas, guerreros, artistas; todos aquellos que con la virtud, el valor, el ingenio y la inspiración han dado lustre a nuestra patria”. Además, la Junta de Iconografía indicaba que la información que se fuese recabando de diputaciones, sociedades y particulares sería debidamente analizada por la comisión organizadora del Museo iconográfico, acordando "cuáles de estos monumentos convenga trasladar a Madrid ya adquiriendo, si es posible, sus originales,

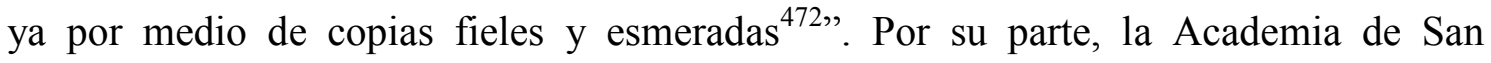
Fernando acordó en sesión ordinaria de 2 de abril responder a esta solicitud "en términos muy cumplidos ${ }^{473}$ " y en 7 del mismo mes se redactaba el borrador de su respuesta a la Junta de Iconografía Nacional, en el que se indicaba que "cooperarán con el mayor gusto e interés a los laudables fines que esa ilustrada Comisión se ha

\footnotetext{
${ }^{470}$ Obras de instalación de un Museo Iconográfico en el Museo Nacional de Pintura y Escultura, Archivo del Museo del Prado, caja 418, leg. 34.21, exp. 2.

${ }^{471}$ La Correspondencia de España, 1878/25/02: 2. Ya en octubre de 1877 se daba noticia de la entrega de algunos retratos para la colección, señalándose que las obras aún no estaban concluidas (La Iberia, 1877/10/10:3).

472 ARABASF, LE-2-40-3.

${ }^{473}$ Libro de actas ... 1877, fol. 593.
} 
propuesto, empleando para ello todos los medios que quepan dentro de su esfera natural de acción y de las prescripciones de sus estatutos ${ }^{474,}$, aunque no consta la correspondencia que posteriormente pudiera mantener con esta.

El Museo Nacional de Pinturas, encargado de albergar el Museo Iconográfico, dio paso también a una serie de medidas necesarias; en primer lugar, las mencionadas obras de acondicionamiento para la nueva sala en el espacio conocido como salas de las Floras, proyecto que fue aprobado por la Sección de Arquitectura de la Academia de San Fernando, y por la institución en conjunto el 27 de junio de $1877^{475}$; en segundo lugar, realizó un primer listado de las obras depositadas por orden de la Dirección General de Instrucción Pública de 27 de junio de $1877^{476}$, en el que se puede observar que la relación de retratos de artista es mínima en la serie de españoles ilustres, compuesta únicamente por ocho de las noventa y siete obras recogidas ${ }^{477}$.

Los cuatro primeros que figuran son copias de retratos ya existentes, todos ellos grandes artistas del pasado: con los números 3 y 4 constan dos obras realizadas por Eduardo Cano, el retrato de Velázquez y el de Martínez Montañés, ambos con las mismas dimensiones $(0,84 \times 0,68 \mathrm{~m})$ por los que se pagaron 250 pesetas cada uno. No se tienen datos del paradero del primero, a pesar de constar entre los retratos solicitados en depósito por la Real Academia de la Historia en 1912 (GONZÁLEZ ZYMLA y DE FRUTOS, 2002: 46-47). Aunque había un retrato de Martínez Montañés en el Museo Nacional de Pintura (inicialmente considerado un retrato de escultor desconocido [MADRAZO, 1843: 18], y posteriormente de Alonso Cano), la obra remitida por Eduardo Cano de la Peña, propiedad del Museo del Prado ( $n^{\circ}$ inv. P03408) en depósito en la Real Academia de la Historia, es una fiel copia del retrato realizado por Francisco Varela existente en Sevilla (GONZÁLEZ ZYMLA, 2003: 54-56). José Martí y Monsó llevó a cabo la copia del retrato del escultor Gregorio Fernández ${ }^{478}$, según original de Diego Valentín Díaz, que figura en el inventario bajo el número 10, y fue adquirido por la Junta por 150 pesetas. Estos tres retratos de artista constan en la relación de retratos con destino al Museo Iconográfico publicada en La Iberia y en El Siglo futuro en octubre de 1877, junto a la copia del retrato del arquitecto Juan Guas (Museo Nacional del Prado, $\mathrm{n}^{\mathrm{o}}$ inv. P03455), firmada por Matías Moreno González, que reproduce el de

\footnotetext{
${ }^{474}$ Borrador de carta dirigida al presidente de la Comisión iconográfica de españoles ilustres, de 7 de abril de 1877. ARABASF, LE-2-40-3.

${ }^{475}$ ARABASF (3-97), p. 653. Ver, además: Inventarios topográficos de las salas que ocupan el Museo Iconográfico, colección de dibujos, colección Pastrana, dos de febrero de 1897, Archivo del Museo del Prado, caja 998, legajo 31.02, expediente 1.

${ }^{476}$ Nota de todos los objetos de arte adquiridos por el Estado con destino al Museo Iconográfico y que se custodian en el de Pintura y Escultura en virtud de la orden de la Dirección General de Instrucción Pública de 27 de junio de 1877, Archivo del Museo del Prado, caja 1367, legajo 114.01, expediente $\mathrm{n}^{\circ} 4$.

${ }^{477}$ Para una breve historia del Museo Iconográfico y de las obras contenidas en él remito al trabajo de Inmaculada Rodríguez Moya, que da noticia de algunos de los retratos que se van incorporando. No da noticia, sin embargo, de la iniciativa de incluir un retrato de Jerónimo de la Gándara, de los de El Empecinado, Martínez de la Rosa, Malaspina y Van der Gotten en 1881 (El Liberal, 1881/10/07: 3), o del de Eulogio Florentino Sanz en 1883 (R.O. de 24 de noviembre de 1883). En 1897, el número total de obras en el Museo Iconográfico era de ciento dos, sin que se observe ingreso de retratos de artistas.

${ }^{478}$ Museo Nacional del Prado ( $\mathrm{n}^{\circ}$ inv. P03418); depositado en la Real Academia de la Historia ( $\mathrm{n}^{\mathrm{o}}$ inv. 1702). En el dorso figura una etiqueta de la Junta de Iconografía Nacional, en que consta la procedencia, autoría y adquisición por Real Orden de 14 de diciembre de 1877 (GONZÁLEZ ZYMLA, 2003: 148).
} 
la capilla funeraria del artista en la parroquia de los Santos Justo y Pastor de Toledo, con su estética medieval y caracterizado como orante. Finalmente, entre los que en el momento se consideraron retratos de artistas del pasado incluidos en la lista de 1877 se encuentra una copia del retrato de Alonso Sánchez Coello, realizada por Salvador Martínez Cubells y adquirida por 155 pesetas, actualmente considerada un retrato de Fernando de Aragón (Museo Nacional del Prado, $n^{\circ}$ inv. P03462) según un original del pintor belga Roland de Mois. El equívoco podría deberse a la existencia en el Museo de Pinturas de Valencia de una pintura, incluida en la galería de retratos, considerada autorretrato de Alonso Sánchez Coello, que figura en el catálogo de 1867 inventariada como tal bajo el número 789 (RABASC, 1867: 50), y que había pertenecido a la Academia de San Carlos por duplicado - uno, considerado original, en la Sala de Juntas y otro, copia al pastel por Vicente María Vergara, destinado al Archivo- sin dudas respecto al sujeto representado (RABASF, 1842: $\mathrm{n}^{\circ} 57$ ).

Tan solo dos son retratos de artistas contemporáneos, si bien ambos fallecidos en el momento de la constitución del Museo Iconográfico. El primero es un autorretrato de Luis de la Cruz, actualmente conservado en el Museo del Prado [fig. 171] ( $\mathrm{n}^{\circ}$ inv. P 03410), asignado con destino al Iconográfico en 1883 sin que conste procedencia ni precio, y el segundo del Retrato del pintor Francisco Sáinz (Museo Nacional del Prado, $\mathrm{n}^{\mathrm{o}}$ inv. P03417) [fig. 172], realizado por Luis de Madrazo y adquirido por 750 pesetas en 1886 (GONZÁLEZ ZYMLA, 2003: 140).

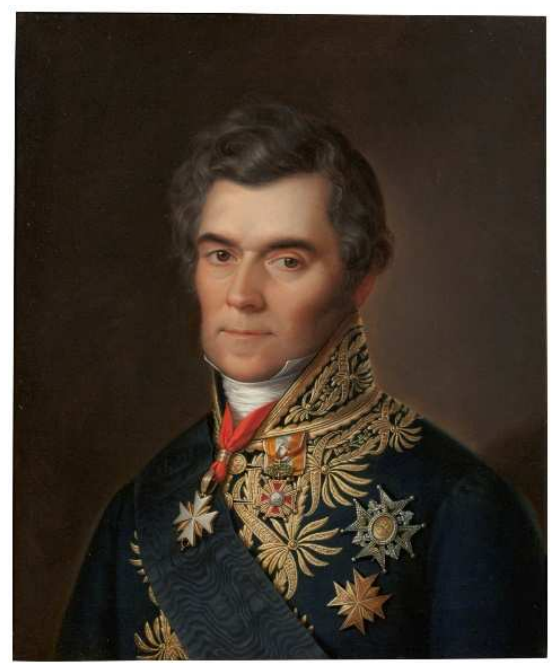

Fig. 171. Luis de la Cruz, Autorretrato. Museo Nacional del Prado.

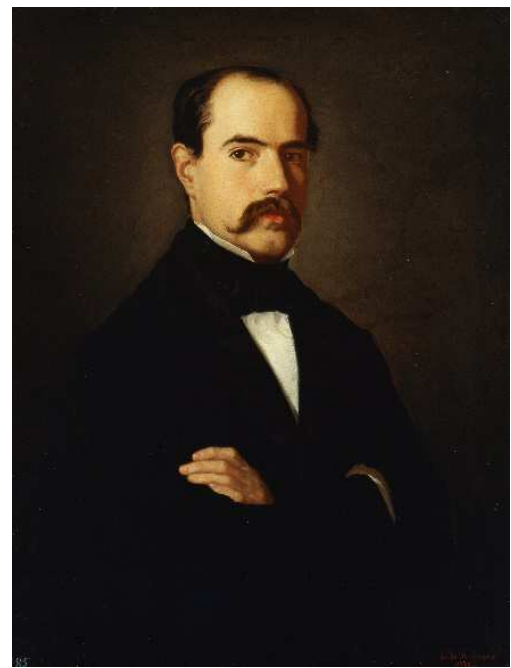

Fig. 172. Luis de Madrazo, Retrato del pintor Francisco Sáinz. Museo Nacional del Prado.

Aparte de estos retratos, y del busto de Damián Forment en yeso realizado por Antonio Palau, no constan más artistas en el Museo Iconográfico, ni una gran movilización por parte de estos por incluir a sus compañeros de profesión entre los españoles ilustres. Tan solo una iniciativa, en mayo de 1877, rogaba al Estado la realización de un homenaje a un artista contemporáneo con la adquisición y colocación de su retrato en la galería. Miguel Martínez Ginesta (1877: 4) dirigía así la atención hacia la prensa, solicitando que se asociase 
para honrar la memoria del distinguido arquitecto D. Jerónimo de la Gándara, recomendando (...) que el Excmo. Sr. Ministro de Fomento, dando una prueba más de su celo e ilustración, ordene colocar el retrato del ilustre arquitecto Gándara en la galería de hombres célebres mandada formar recientemente.

Como se desprende del catálogo de obras del Museo Iconográfico, dicho retrato no fue incorporado, no habiendo tampoco constancia de nuevas iniciativas para honrar la memoria de otros artistas contemporáneos. El inventario topográfico muestra también la escasa relación entre los retratos de artista, esto es, una ausencia de interés por aglutinarlos como un conjunto autónomo dentro de la colección; los retratos de Velázquez y de Martínez Montañés figuraron próximos entre sí (grupo B, números 6 y 8 respectivamente), mientras que los consignados bajo el grupo $\mathrm{D}$, entre los que se encuentran los de Sánchez Coello, Alonso Cano, Luis de la Cruz y Gregorio Fernández (números 4, 8, 9 y 19), aparecen muy próximos entre sí a pesar de la disparidad de representaciones. 


\section{LOS RETRATOS DE ARTISTA EN SOCIEDADES ARTÍSTICAS}

La evolución de las formas de sociabilidad artística y su progresiva institucionalización en sociedades o asociaciones autónomas supone un punto de especial interés para entender el modo en que los artistas decimonónicos españoles asumieron otras posibilidades de cohesión e interrelación en las que las aspiraciones profesionales, la puesta en práctica de una creatividad lúdica y la búsqueda de un entretenimiento provechoso enlazan con la demanda de las distintas clases sociales y las necesidades del individuo masculino. El Curioso Parlante alababa y criticaba a un tiempo el espíritu de asociación como forma de relación humana que impregnaba la sociedad contemporánea. A similitud de lo expuesto posteriormente por Simmel, Mesonero Romanos afirmaba que

esta es la cualidad primordial, el humor dominante de nuestra época; y asi como otras se han refundido y representado, digámoslo asi, en un solo hombre, esta se multiplica y subdivide por millonésimas partes, atomos imperceptibles, entre todos los seres contemporáneos; de suerte que no parece sino que todos nacimos faltos de alguna cosa, y que nos buscamos é incorporamos por instinto, para formar entre todos un juicio completo, ó una verdadera y sólida voluntad. De aquí tantas asociaciones políticas, científicas y literarias; de aqui tantas discusiones y controversias; tantas obras enciclopédicas; tantas compañias de seguros mutuos (EL CURIOSO PARLANTE, 1839: 411-413).

En este asociarse entre los hombres, destinado a la unión en pro de un objetivo común, se encontraba también un mal contemporáneo que se vinculaba estrechamente con valores masculinos en el abandono de las obligaciones domésticas por el entretenimiento o la conversación en círculos y casinos, o la dispersión de la juventud de su aprendizaje laboral en su afán por introducirse en la sociedad masculina. Al aludir en nuestra introducción a un asociacionismo artístico que difiere de los usos institucionales referíamos a un componente lúdico, al tratarse precisamente de núcleos de encuentro social al margen de la práctica profesional; a pesar de que algunas de las sociedades que estudiamos son conocidas por su vinculación con el fomento de las artes y el entretenimiento burgués, creemos preciso hacer una serie de consideraciones previas. En primer lugar, nos hemos centrado en un tipo de asociacionismo artístico en el que la práctica creativa constituye un pilar fundamental, prescindiendo de otras que, aun vinculadas con la práctica artística, están más enfocadas a la educación y al progreso, especialmente aplicados a la artesanía, las manufacturas y el mundo obrero, como puede suceder en sociedades como el Fomento de las Artes; esta primera restricción es significativa, ya que el estudio se ocupa de sociedades que concentran y canalizan el privilegio social y masculino en el siglo XIX, ya sea de manera consciente (en el caso del Liceo y del Ateneo), o por la evolución de las necesidades económicas y culturales, como ocurre en las Sociedades Protectoras de Bellas Artes. Consecuencia también de esta elección es la presencia indiscriminada de artistas de prestigio, 
discípulos y numerosos amateurs y diletantes; en el análisis de la práctica del retrato en las sociedades artísticas no puede discriminarse a los segundos a favor de los primeros, ya que este es fruto de unas relaciones sociales que no están basadas en el nivel de conocimientos o profesionalización. Tan solo con la aparición de sociedades enfocadas directamente a la práctica artística, como es el caso de Sociedades de Acuarelistas y de Círculos de Bellas Artes, se puede observar una mayoría de profesionales del arte en las listas de socios. El estudio de sociedades como Liceos y Ateneos, en los que los artistas se encuentran en clara minoría frente a otras profesiones, es igualmente necesario para analizar las formas de socialización de los primeros y del tipo de imagen que buscaron dejar de sí mismos ante otros hombres. Para su estudio, se han analizado fuentes documentales y hemerográficas, procurando reconstruir las listas de socios artistas en aquellos casos en que fuese posible, así como los retratos que se produjeron dentro de estas asociaciones. Se ha optado por desglosar tipológicamente las distintas sociedades que se han estudiado, haciendo un recorrido cronológico y geográfico de Liceos, Ateneos, Sociedades Protectoras de Bellas Artes, Sociedades de Acuarelistas y Círculos de Bellas Artes.

\subsection{Liceos Artísticos y Literarios}

\subsubsection{El Liceo Artístico y Literario de Madrid (1837-1851)}

Tras las experiencias de sociabilidad en cafés y tertulias, la constitución de núcleos estrictamente relacionados con las artes en Madrid recibió, con el Parnasillo, un carácter diferenciador no solo por los miembros que lo formaban, sino también por las necesidades que lo alentaban. El punto de reunión de los jóvenes precursores del Romanticismo español era el café El Príncipe, contiguo al teatro del mismo nombre (BONET CORREA, 2012: 28 y 219); según Mesonero Romanos, el espacio elegido por jóvenes poetas, literatos, artistas y aficionados, lejos de ajustarse a las comodidades y boato de otros cafés más lujosos, era un "miserable tugurio, sombrío y desierto", pero que ofrecía la ventaja de brindar autonomía e independencia respecto a los que acudían a otros cafés, descritos como lechuguinos insípidos o militares "más o menos indefinidos o indefinibles" (MESONERO ROMANOS, 1994: 408). Estos jóvenes, que aparecen como fieles y activos defensores del liberalismo, encarnaban las filas militantes del Romanticismo poético y artístico, pero también un tipo concreto de masculinidad peculiarizada por el ingenio, la excentricidad, el humor y el ruido, loi que se ajusta en cierto modo al tipo de conducta, con marcada voluntad de llamar la atención, que Sohn (2009) atribuye a la construcción de una masculinidad juvenil. Los artistas que se vincularon al Parnasillo, de los que Mesonero subraya su estrecha relación también con la Academia de San Fernando, fueron en efecto nombres conocidos en el posterior panorama romántico, y participaron en una tertulia caracterizada por la algazara, el animado debate político y "los desenfadados diálogos, punzantes epigramas y galas ingeniosas del buen decir", pero también los precursores del asociacionismo artístico español:

Seguía después la cohorte artística de los adscritos a la Academia de San Fernando, la cual era capitaneada por el entusiasta arquitecto de la villa, Mariátegui, cuya 
obesidad haríale pasar por bombo, si su prosopopeya y coram vobis no le dispensaran el carácter de tambor mayor. En esta legión figuraban los pintores Madrazo, Rivera, Texeo, Carderera, Jimeno, Camarón, Villaamil, Esquivel, Mendoza, Maea y Gutiérrez de la Vega; los arquitectos Colomer y Aníbal Álvarez; los ingenieros Areytio y Echevarría, los grabadores Peleguer, Castelló, Ortega, y los impresores Burgos, Sancha, y el editor Delgado (MESONERO ROMANOS, 1994: 410).

La fundación del Liceo Artístico y Literario, enmarcado en pleno proceso de creación de sociedades en el ambiente liberal de 1835, en el que vieron la luz otras sociedades lúdicas o literarias y científicas, como el Casino (1836) y el Ateneo (1835), se verificó en 1837 como una iniciativa de José Fernández de la Vega, quien no dudaba en vincular la nueva sociedad con la revolución política e ideológica del gobierno liberal en el artículo publicado en la revista del Liceo (SIMÓN DÍAZ, 1947: 12). Su idea de un Liceo, que procedía según él de una tertulia privada en su casa, no solo profundizaba en el ideal de una fraternidad entre las artes, sino que buscaba constituirse como "un campo, en el que el poeta y el artista puedan conquistar una corona" y una república meritocrática en la que se confundían "el sabio con el estudioso, la jerarquía del nacimiento y de la fortuna con la del ingenio" (SIMÓN DÍAZ, 1947: 12). Este concepto que ha aparecido en varios puntos de la investigación pone de manifiesto la asimilación de un nuevo concepto de masculinidad asociado a la revolución burguesa; en la república de las artes y el sistema de fraternidad meritocrática el artista encarna el nuevo ideal del hombre que se hace a sí mismo. La nueva sociabilidad derivada de sociedades burguesas equipara de manera idealizada las distintas jerarquías sociales existentes en el momento (por una parte, procedente del aún sistema aristocrático; por otra, la jerarquía de la fortuna y el poder económico; y finalmente la jerarquía intelectual, vinculada al conocimiento y la práctica artística). Fernández de la Vega legitima al artista como personaje clave en la sociedad, haciendo recaer sobre él la misión de enseñar sus respectivos conocimientos en las cátedras, de orientar el gusto y entretener en las exposiciones públicas, y permitiéndole al mismo tiempo tener un espacio en el que entrar en contacto con la alta sociedad como mecenas potencial. Es la misma idea del artista como hombre de bien y personaje elevado por y para el bien de la sociedad la que rige el concepto de Liceo defendido por Patricio de la Escosura; para él, el liceísta entra en la categoría de hombre entusiasta, con todas sus implicaciones morales y políticas, que obedece "a los impulsos de su corazón, sin contar con más recursos que los propios", y que es capaz de sacrificar intereses y placeres para consagrarse al bien público, ejemplificando estas virtudes masculinas en el fundador de la sociedad. Virtudes que, por otra parte, el propio Fernández de la Vega aducía en algunos de sus textos, refiriéndose a sí mismo como un emprendedor carente de bienes de fortuna, de consideración social, de influencias y de un nombre de "valía para regir una sociedad tan ilustre" (SIMÓN DÍAZ, 1947: 17). Sin embargo, su empresa habría resultado más ardua aún "para otro que contase con menor número entre los hombres de ingenio, aun cuando para lograrlo recurriese al prestigio de una cuna elevada o a la seducción de los bienes materiales" (SIMÓN DÍAZ, 1947: 18). 
La reacción de los artistas en el seno del Liceo no parecía sin embargo tan proclive a esa imagen de la democracia social sino de una república artística dominada por sus artífices; en plena consciencia de su inferioridad social, y seguramente como reacción ante esta, no faltan las expresiones de dignificación y diferenciación del artista. Para Patricio de la Escosura, la labor de las artes es precisamente la de civilizar la especie humana, y el Liceo, destinado a la juventud, la de difundir los conocimientos en artes y letras para contribuir a esta misión civilizadora, así como hacer renacer la escuela española (SIMÓN DÍAZ, 1947: 11). Del mismo modo, Antonio María Esquivel se pronunciaba, si bien de manera más velada, aludiendo al genio como la principal cualidad del artista, es decir, como rasgo diferenciador de su privilegio, además de valorar al mismo tiempo en el papel de la educación para cultivarlo y para adoctrinar a la sociedad (SIMÓN DÍAZ, 1947: 139-143). El ejercicio del privilegio basado en las cualidades intelectuales y artísticas pretendido por los liceístas venía secundado por la voluntad de constituirse en un espacio formativo a la par que social, donde los artistas tuviesen "una arena en que probar sus fuerzas" si no temían la lucha; el hecho de que se buscase establecer un espacio privilegiado donde artistas y escritores pudieran darse a conocer y rivalizar en emulación subraya el componente masculino del Liceo como herramienta de sociabilidad para construir o reproducir la rivalidad profesional, llevada a un terreno neutral de amenidad y de competencia extraprofesional. No es de extrañar que, debido a la rápida afluencia de miembros, muchos de ellos aficionados procedentes de la alta sociedad, y el peligro de que una reunión de afán cultural y profesional quedase rebajada, como finalmente ocurrió, a una finalidad lúdica, los artistas y literatos deseasen subrayar su importancia y necesidad dentro del Liceo y renegociaran su identidad a través del privilegio intelectual frente al poder social y aconómico.

El recuerdo de Mesonero Romanos de la primera reunión, en casa de Fernández de la Vega, en la que cita una docena de personas entre escritores y pintores, ofrece ese carácter íntimo e interdisciplinar. En él da noticia de una tertulia en la que se leyeron poesías de Zorrilla, mientras que Esquivel, Villaamil, Elbo y Camarón se ocuparon de realizar dibujos (MESONERO ROMANOS, 1994: 499). El aumento progresivo de miembros movió finalmente a la creación de la sociedad y, sin duda, la necesidad de capital y de expansión sus fines impulsaron a los socios fundadores a ampliar los límites de la misma: de este modo, a pesar de que su objetivo primordial era el fomento y prosperidad de las bellas artes, se admitió a miembros de la burguesía comercial, como los banqueros Gaspar Remisa y José Salamanca, y de la aristocracia. En su investigación sobre el Liceo Artístico y Literario, Aránzazu Pérez Sánchez analizaba las condiciones de acceso y la diversa procedencia de los socios, y ponía de manifiesto cómo el carácter de república de las artes estaba mucho más condicionado de lo que aparentaba por requisitos más vinculados a una sociedad elitista (PÉREZ SÁNCHEZ, 2005: 61). La condición principal de acceso era ser profesor de bellas artes, escritor o aficionado a las artes y las letras, y las cuotas impuestas a los socios en 1838 ascendían a 100 reales en concepto de ingreso y a 20 mensuales, lo que aumentó a 160 de entrada en 1840 , y a 246 en 1845. Estos progresivos incrementos dan cuenta de la procedencia social y capacidad adquisitiva de los liceístas. Otro rasgo importante a señalar radica en 
la diferenciación de sus miembros ya que, si en el proyecto de 1838 se abogaba por socios de mérito, entendiendo por estos a escritores y artistas, y socios aficionados, la denominación que se instaurará finalmente será, por una parte, la de socios facultativos o adictos de mérito, $y$, por otra, la de no facultativos o adictos internos; los primeros serían profesores que contribuyesen, con su talento, trabajos y desvelos, al desarrollo de actividades en su correspondiente sección, es decir, constituyéndose en los productores de conocimientos, obras o sesiones, y los segundos los aficionados que consumían el capital producido por los primeros. Los socios facultativos, exentos del pago de las cuotas mensuales debido por una parte a su contribución en el esplendor del Liceo y por otra a las posibles dificultades económicas relacionadas con la profesión, quedaron obligados a abonarlas en 1840, tras la reforma del reglamento, algo que pudo dar pie al progresivo abandono en que quedó la sección de Bellas Artes entre 1840 y 1845, fecha esta última en la que quedaron nuevamente exentos. Del mismo modo, los socios facultativos debían, para ingresar en la sociedad, presentar el aval de tres socios; a este requisito, sugerente por la importancia de los vínculos familiares y de amistad en el Liceo, se unía la demostración práctica en el caso de tratarse de los no reconocidos como profesores (ya fuesen aficionados o discípulos) que aspirasen a ingresar en la Sección de Pintura, mediante la presentación de obra en las exposiciones o la participación en las sesiones de competencia. Durante estas, tan solo los facultativos tenían derecho al uso de caballete, de modo que se crearon distinciones entre los artistas profesores, entregados a pinturas y caprichos al óleo, los aficionados que dibujaban o realizaban copias en las mesas de trabajo, y aquellos que, atraídos por el espectáculo creativo, se limitaban a mirar y admirar las habilidades de los maestros ${ }^{479}$ (PÉREZ SÁNCHEZ, 2005: 238-239).

Frente a lo ocurrido en el casino, el Liceo no se constituyó como un espacio exclusivamente masculino; en el catálogo de socios de 1838 ya aparecen, consignadas en una lista aparte, las señoras socias, destacando Rosario Weis (LICEO ARTÍSTICO Y LITERARIO, 1841: s.p.). La proporción era, sin embargo, bastante desigual. Si atendemos a los datos ofrecidos por el Catálogo de socios de 1841, la sección de pintura estaba formada por un total de 65 socios, de los cuales el 75,4\% eran hombres. De los socios artistas (anexo 8) cuyos datos hemos podido recopilar, de un total de ciento trece tan solo diecinueve fueron mujeres que participaron en sesiones y en exposiciones. Algunas de ellas, a pesar de su dedicación al arte, fueron tenidas por sus contemporáneos como aficionadas ilustres. No obstante, a pesar del carácter mixto de profesionales y aficionados reinante tanto en las sesiones como en las exposiciones que traduce Mesonero Romanos ${ }^{480}$, el protagonismo cobrado por los artistas en el desarrollo

\footnotetext{
${ }^{479}$ En la inauguración de la nueva sede del Liceo en el Palacio de Villahermosa, la reina gobernadora acudió a honrar la celebración, pasando "a visitar la salas que servían de estudio de los artistas, a donde se hallaban estos ocupados en sus respectivos trabajos, disponiendo S.M. que continuasen en ellos, y deteniéndose con una complacencia singular delante de cada uno para verle pintar o modelar. Pasando de allí a los salones de Exposición, manifestó repetidas veces a los artistas su inteligencia y agrado..." ("Liceo Artístico y Literario...", 1839: 7).

${ }^{480}$ En sus memorias, recoge "(...) Allí, en los otros departamentos, los célebres pintores de cámara López y Madrazo, y sus hijos; Esquivel, Gutiérrez de la Vega, Villaamil, Elbo, Jimeno, Tejeo, cruzaban
} 
de otras labores, como el desempeño de las cátedras o la decoración de la sede del Liceo pone de manifiesto el concepto masculino que se vinculaba a la profesionalización de las artes, lo que revela así una extensión más de su privilegio dentro de la sociedad liceísta. Valentín Carderera, Antonio María Esquivel, Juan Drument, Jenaro Pérez Villaamil, Justo María Velasco, José Gutiérrez de la Vega, José Elbo, Alejandro Ferrán, Vicente Camarón, Francisco Mendoza, Francisco Prats, Antonio Maea y Ramón Gil fueron algunos de los artistas que, siendo socios del liceo, colaboraron en las enseñanzas de algunas de las cátedras, propiciando la creación de un nuevo espacio de aprendizaje del que Patricio de la Escosura llegaría a considerar imprescindible tras el cambio de los planes de estudio de enseñanzas artísticas ${ }^{481}$.

Sobre el papel de los artistas en el Liceo, entendido como espacio social, es reseñable el hecho de que su pretendido privilegio inicial desapareciese rápidamente con el auge de secciones que contribuían con mayor eficacia a satisfacer las necesidades de consumo de ocio cultural por parte de la burguesía, como efectivamente hicieron la de música y la de declamación. José de Madrazo, poco afín a la sociedad liceísta, veía a sus socios, especialmente a los pintores, como peones y culpables de la transformación del arte en un espectáculo para ignorantes; el discurso retórico de la defensa de las artes y la república de sus artífices solo había conseguido, a su juicio, "ofuscar con una idea

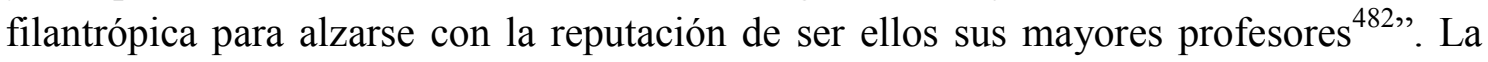
consecuencia de la defensa del privilegio por parte de un número contado de artistas, así como de la estética practicada, había resultado, nuevamente según su opinión, en la práctica del charlatanismo artístico y de una pintura basada en la rapidez y en la espontaneidad, es decir, en obras creadas en las sesiones bajo la necesidad de demostrar ante el resto de asistentes el genio artístico de los nuevos maestros frente a los aficionados y discípulos ${ }^{483}$. Su aguda visión respecto a la realidad del Liceo y de los artistas dentro de él se pone de manifiesto cuando, aún en 1838, lo califica como una academia de música, "lo que llevan muy a mal los necios y presuntuosos pintores que se ven arrinconados sin que nadie mire lo que hacen aunque pinten un cuadro cada noche ${ }^{484,}$. Madrazo, representante del privilegio artístico en las esferas institucionales oficiales, defiende su postura al verse amenazado por el éxito social del Liceo. Cuando en 1839 da noticia de haber acudido al concierto celebrado en el Liceo, al cual asistió la reina, deja constancia de su posición al subrayar que no entró "en las demás piezas del Liceo donde se hallaban todos los artistas al lado de sus caballetes o haciendo que trabajaban ${ }^{485}$ ", aunque meses después es nombrado socio y presidente de la sección de pintura. Su posterior implicación en las tareas del Liceo, de las que con frecuencia hace

sus pinceles con aficionados ilustres, como los duques de Gor y de Rivas y las señoritas Weis y Menchaca..." (MESONERO ROMANOS, 1994:501-502).

481 “(...) Tienen, empero, las secciones de bellas artes la doble satisfacción de haber podido conservar abiertas sus cátedras, con no poca utilidad de sus alumnos, entre los cuales hay muchos que han necesitado de los conocimientos adquiridos en el Liceo para cumplir con una parte de lo que se ordena en los nuevos planes de estudio aprobados por el gobierno para las escuelas de bellas artes...", El Tiempo, 1845/14/11: 3-4.

${ }^{482}$ Carta de José a Federico de Madrazo, diciembre de 1837 (DÍEZ, 1998b: 121).

${ }^{483}$ Carta de José a Federico de Madrazo, 2 de febrero de 1838 (DÍEZ, 1998b: 151-152).

${ }^{484}$ Carta de José a Federico de Madrazo, 9 de junio de 1838 (DÍEZ, 1998b: 200).

${ }^{485}$ Carta de José a Federico de Madrazo, 5 de enero de 1839 (DÍEZ, 1998b: 291). 
alusión en su correspondencia junto a los nombres de las notabilidades sociales que concurren, reclama su papel privilegiado como renovador de la vida artística en la sociedad madrileña ${ }^{486}$. De la inicial república de las artes de 1837 a la sociedad burguesa de 1841 se desprende una idea del fracaso de los ideales de los primeros liceístas; sin embargo, la labor de estos en la defensa de su pequeño territorio de privilegio se trasluce en la práctica de las relaciones sociales y en una estética propia, en lo que colabora el retrato como reivindicación de una identidad común.

\subsubsection{Los retratos en el Liceo: presidentes}

Al ocuparse de la contribución de los artistas a la decoración del local, Aránzazu Pérez Sánchez da noticia de algunas de las obras cedidas por estos a la institución; sin embargo, las que más interesan en nuestro estudio son los retratos producidos en el seno del Liceo o estrechamente vinculados a él, ya que manifiestan las relaciones existentes entre consocios. Sin lugar a dudas, el primero del que tenemos constancia es el de su fundador, José Fernández de la Vega, realizado por Antonio María Esquivel; una obra que, tras ser presentada a la exposición de 1837, permaneció en la sociedad formando parte de la decoración permanente del salón de sesiones:

En 22 de marzo último se constituyó este Instituto y aprobó las bases que le han de regir en lo sucesivo, a petición de su Conservador D. José Fernández de la Vega, el cual en la Junta General celebrada en 24 del mismo fue electo presidente después que el Liceo determinó que, en muestra de su aprecio se le declarase Fundador del mismo, haciendo que este título constase en los archivos del Establecimiento, y que se colocase su retrato en el salón de sesiones (...) D. José Fernández de la Vega, después de manifestar que el honor que el Liceo le dispensaba era para él la mayor recompensa que pudieran alcanzar sus esfuerzos en beneficio del Instituto, suplicó se le admitiese benévolamente la dimisión del cargo que se le confiaba, por creerle superior a sus fuerzas (SIMÓN DÍAZ, 1947: 199).

De este retrato, actualmente en paradero desconocido, nos queda la descripción de Pérez Sánchez (2005: 49), quien lo ubicaba en el Museo Arqueológico Nacional y destacaba en él "un característico aire romántico de ensoñación", y las publicadas en las reseñas de las exposiciones del Liceo (SIMÓN DÍAZ, 1947: 94-98). Tan solo conservamos una imagen del salón de sesiones del Liceo, mediante un grabado publicado el 23 de diciembre de 1843 en El Laberinto, con motivo de la celebración de la mayoría de edad de Isabel II; sin embargo, en aquella ocasión la sala se decoró específicamente con los retratos de los reyes de España coronados antes de su mayoría de edad, y la calidad del grabado no permite distinguir si el retrato de Fernández de la Vega permaneció allí durante la ceremonia. Sin embargo, sí que se conservan dos negativos en el Archivo Moreno que reproducen dos retratos distintos de Fernández de la Vega, al parecer realizados ambos por Antonio María Esquivel [figs. 173 y 174]. El primero de ellos, firmado y fechado en 1833, figuraba en la colección Espantaleón; el segundo, igualmente firmado, y fechado en 1836, perteneció a la colección Céspedes, y probablemente ofrece la imagen más afín al retrato presentado al Liceo, en el caso de

${ }^{486}$ Cartas de 18 de marzo de 1840 y 29 de enero de 1841 (DÍEZ, 1998b: 406 y 444). 


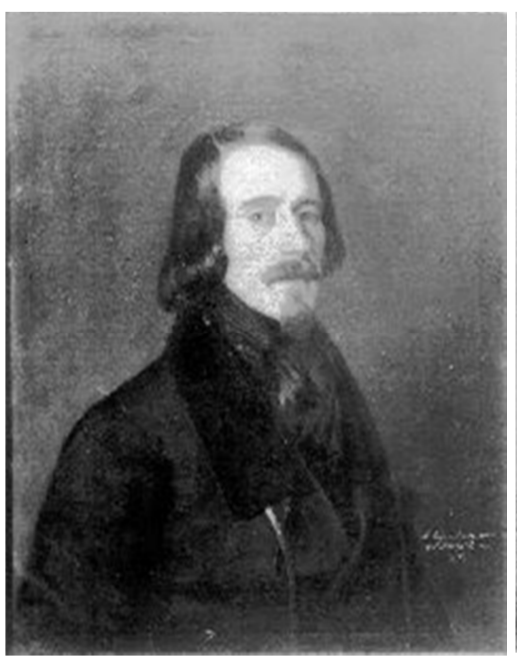

Fig. 173. Antonio María Esquivel, Retrato de José Fernández de la Vega, 1833. Archivo Moreno (inv. 02664B).

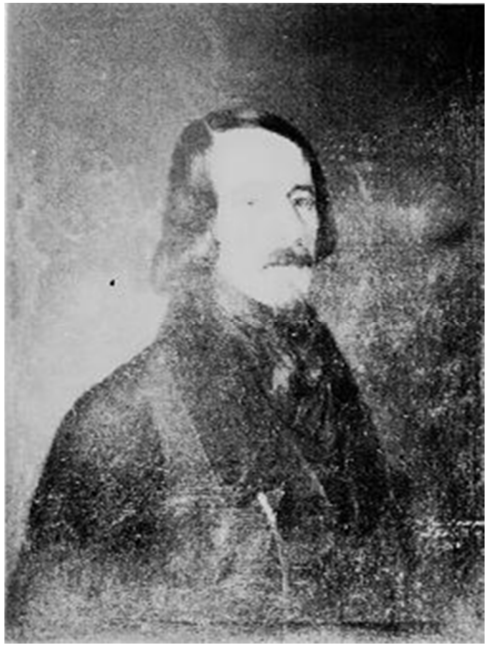

Fig. 174. Antonio María Esquivel, Retrato de José Fernández de la Vega, 1836. Archivo Moreno (inv. 09374B).

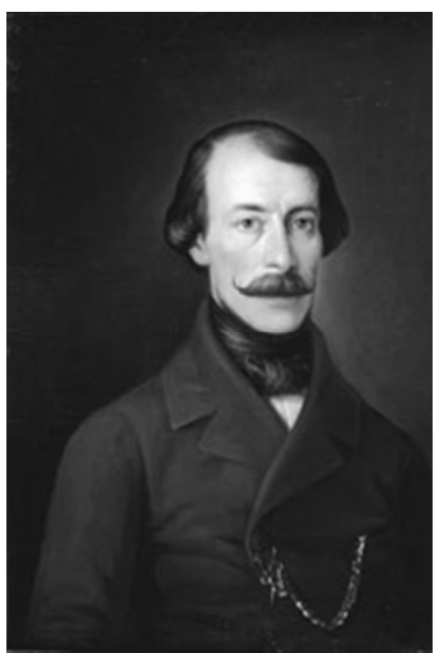

Fig. 175. Carlos María Esquivel, Retrato de José Gutiérrez de la Vega, 1848. Museo Lázaro Galdiano (inv. 09399).

que no sea la misma obra. La relación entre Esquivel y Fernández de la Vega se remonta a la fundación del Liceo y a sus tertulias iniciales, ya que Mesonero Romanos da cuenta de la presencia de Esquivel en la sesión inaugural del 22 de mayo de 1837 en la casa del presidente del Liceo. La relación se mantuvo con posterioridad, incluso tras la destitución camuflada en dimisión de Fernández de la Vega y la reforma de los estatutos del Liceo, tal y como se desprende del hecho de que su retrato fuese incluido en la composición de Los poetas contemporáneos, o de que su hijo Carlos María también realizase un retrato en busto del que fuera presidente del Liceo [fig. 175], obra actualmente conservada en el Museo Lázaro Galdiano como Retrato de caballero desconocido.

Aránzazu Pérez Sánchez también da cuenta del Retrato de Gaspar de Remisa (Museo Nacional del Romanticismo, $\mathrm{n}^{\mathrm{o}}$ inv. 0051), obra de Vicente López, como parte de la decoración del Liceo; el banquero, que ofreció importante respaldo económico a la sociedad, asumió la presidencia del Liceo tras la dimisión de Fernández de la Vega en 1838, y nuevamente en 1844 y 1845. Dada su coincidencia con la fecha de realización del retrato y la relación establecida en la sociedad entre Remisa y López, Pérez Sánchez (2005: 150) aventuraba la posibilidad de que el retrato presentase al banquero en la propia sala presidencial del Liceo, hipótesis que, aunque muy sugerente, no parece corresponder con el espíritu de decadencia artística existente en la asociación en esa fecha; tampoco José Luis Díez (1999: 366), al hablar de este retrato, lo vincula con el Liceo, sino que lo identifica correctamente como un retrato de aparato en el espacio doméstico privado del banquero. La calidad de la obra, la representación del poder a través del estatus socioeconómico y la inclusión de un animal de compañía lo identifican, efectivamente, con una obra de encargo y de iniciativa privada; aunque sabemos que Vicente López también estuvo muy vinculado al Liceo, la ausencia de fuentes documentales y de precedentes gráficos nos lleva a descartar la hipótesis de Pérez Sánchez. 
A pesar del carácter progresivamente institucionalizado y elitista de la sociedad, no ha trascendido hasta el momento noticia alguna de que el Liceo se propusiese realizar una galería de retratos de sus presidentes ni de sus juntas directivas, lo que indica que la identidad de la sociedad como grupo cohesionado no llegó a consolidarse de manera plástica en la breve existencia del Liceo.

\subsubsection{Retratos de liceístas en sesiones y exposiciones}

Respecto a otros retratos entre liceístas, son escasas las noticias y más aún los testimonios pictóricos conservados, si bien el espacio del Liceo ofreció el marco ideal no solo para la sociabilidad entre artistas y el intercambio de ideas, como señalara Patricio de la Escosura, sino también para el retrato directo de consocios. Lamentablemente, la parquedad con que la prensa recogía las sesiones semanales del Liceo no permite más que aventurar cuáles fueron las ocupaciones de los pintores durante las mismas, en las que el retrato debió de tener, sin duda, un protagonismo especial. La mayoría de noticias sobre estos retratos proceden de fuentes hemerográficas (reseñas y críticas), ya que fueron presentados a las exposiciones organizadas por la sociedad. La primera muestra de retratos fruto de la sociabilidad consta ya en la primera exposición del Liceo; se trata del realizado por Calixto Ortega en 1837 del poeta José Zorrilla, ya que si atendemos a las noticias dadas por Mesonero Romanos, ambos frecuentaban la sociedad desde su fundación. La obra, que tal vez se produjese en una de las primeras sesiones del Liceo (de la que queda constancia de la participación activa de Zorrilla declamando versos), figuró en la exposición celebrada en la casa de José Fernández de la Vega en 1837; de ella dijo la crítica que era "el retrato de uno de nuestros más distinguidos poetas", "que posee en extremo la parte del parecido aunque algo frío de colorido", al tiempo que recomendaba al autor que no olvidase el dibujo y se atuviese al natural en el tratamiento de las ropas (FERRÁN, 1837: 6). José Gutiérrez de la Vega presentó a la misma exposición un retrato del escritor Ventura de la Vega y de su esposa, la cantante Manuela Oreiro (PÉREZ SÁNCHEZ, 2005: 426), cuya vinculación con el Liceo y el ámbito cultural es innegable, además de una obra desconocida recogida como "Improvisación en el Liceo. Retrato", sin duda fruto de las sesiones realizadas en la casa de Fernández de la Vega, al igual que la obra "Improvisación en el Liceo. Retrato de joven", pintada por Antonio María Esquivel y que figuró en la misma exposición. Sin embargo, entre las obras mostradas en la exposición de 1838, según recogen las noticias en la prensa periódica y el listado realizado por José Fernández de la Vega ${ }^{487}$, no se incluyó ningún retrato de artista.

En la exposición de 1839, Antonio Cavanna presentó el retrato de Puig; con toda probabilidad se trataba de Lázaro María Puig, miembro de la sección de música, el mismo que en la solemne recepción de María Cristina en el Liceo entonase un aria del Otelo (SIMÓN DÍAZ, 1947: 58; “Liceo Artístico...", 1838: 80). En noviembre de 1838 Lázaro Puig cantó nuevamente en el Liceo, en esta ocasión la romanza de Iradier; conocido en el panorama artístico bajo el nombre de Flavio (El Guardia Nacional,

\footnotetext{
${ }^{487}$ Nota de los pintores que han concurrido con sus obras a la exposición del Liceo, Archivo del Museo del Prado, caja 1341, leg. 11.200, exp. 4.
} 
1841: 2), consta su actividad a partir de 1841 en Londres y París ("Crónica nacional", 1843: 181). Tras alcanzar el éxito en el extranjero, actuó nuevamente en el Liceo madrileño en 1844, participando en el concierto benéfico por los damnificados en el incendio de Granada. En esta ocasión, Puig escogió cantar la Lucía de Lammermoor (La Posdata, 1844: 3), siendo con toda probabilidad el momento elegido por el liceísta Cosme Algarra para realizar el retrato del tenor [fig. 176].

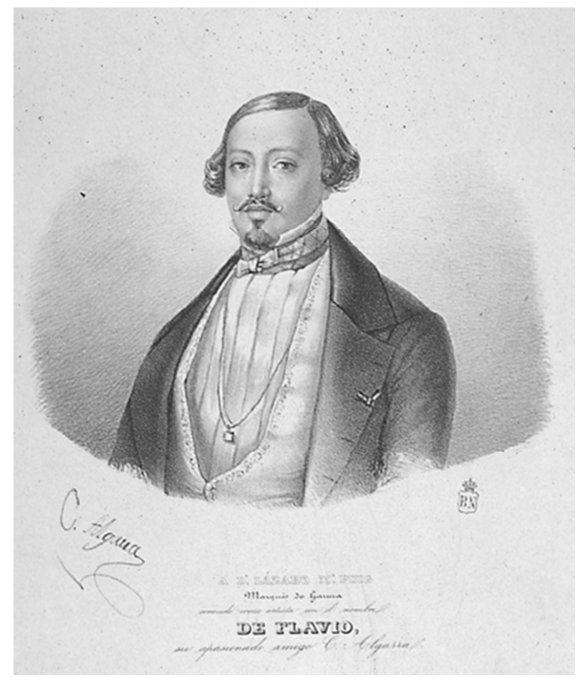

Fig. 176. Cosme Algarra, Retrato de Lázaro Puig, 1844. Iconografía Hispana, 7504-1.

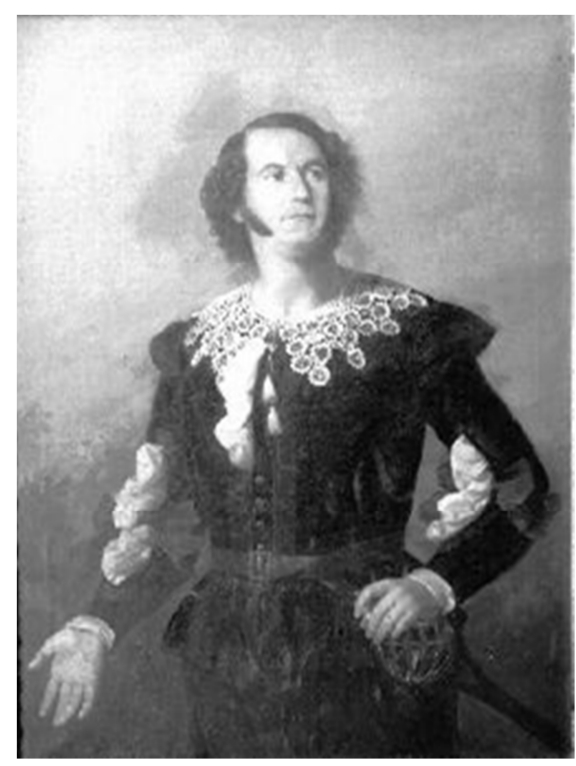

Fig. 178. Antonio María Esquivel, Retrato de Rubini, 1841. Archivo Moreno (inv. 0761B).

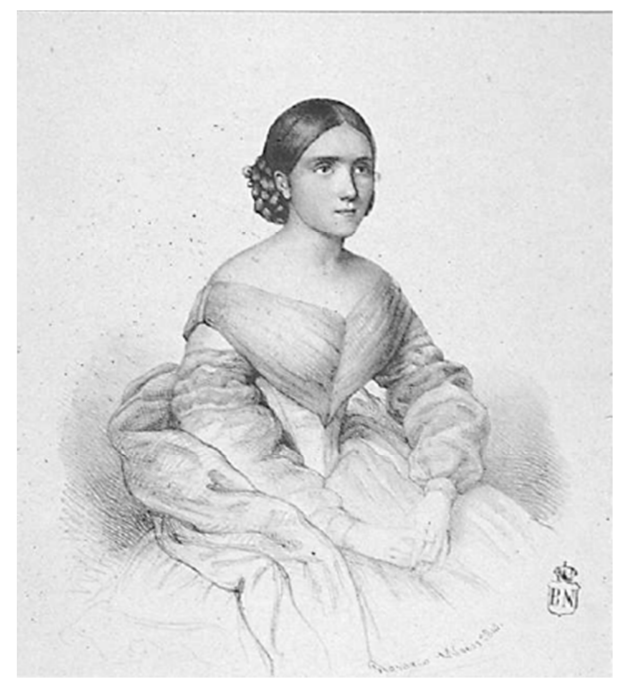

Fig. 177. Rosario Weiss, Retrato de Manuela Oreiro, 1841. Iconografía Hispana, 6668.

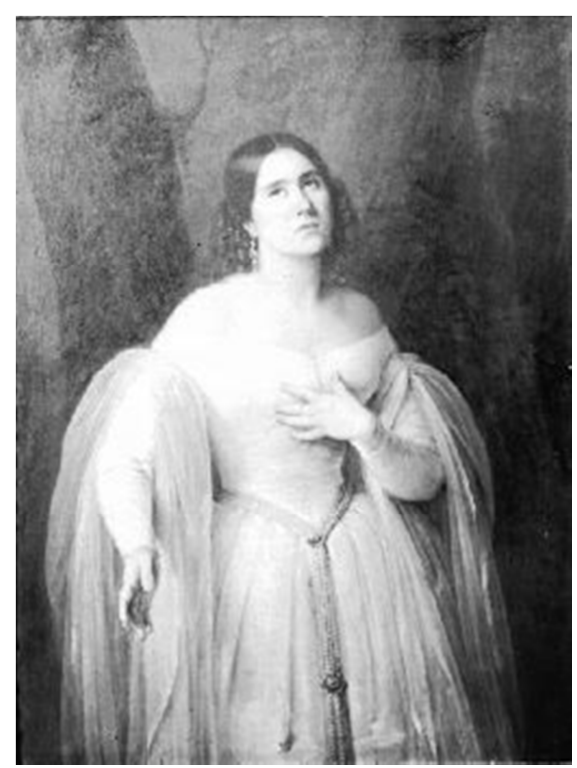

Fig. 179. Antonio María Esquivel, Retrato de Manuela Oreiro, 1841. Archivo Moreno (inv. 0760B).

El auge de las secciones de música y declamación, y tal vez una cierta desilusión por parte de la de pintura ${ }^{488}$, se refleja en que las noticias sobre la actividad de la

488 En 1841, la sección contaba con 65 socios, de los cuales, además del 24,6\% de mujeres (lamentablemente, por ser consideradas aficionadas, el cómputo es negativo), un $24,6 \%$ del total de socios -de ambos sexos- aparecen consignados como ausentes, un 4,6\% como externos, contando además con un corresponsal (Carlos Luis de Rivera). Entre los miembros activos, constan José María Avrial, José 
sección sean progresivamente más esporádicas, hasta el punto de que en el anuncio para la realización de la exposición de 1841 la junta gubernativa casi parece estar recordando a los socios sus deberes respecto al establecimiento ${ }^{489}$. Precisamente en 1841 aparece la noticia de que el Liceo ha mandado realizar los retratos de dos socios de la sección de música (la señora de Vega y de Rubini) para que formasen parte de la colección de la sociedad $^{490}$, sin dejar constancia, como hacía el Semanario Pintoresco Español, de que con motivo de las funciones filarmónicas celebradas a beneficio del establecimiento se habían puesto a la venta, precisamente en la portería del Liceo, los retratos del propio Rubini y de la señora Oreiro [Lema] de Vega, realizados en litografía por Rosario Weiss [fig. 177] ("Estudios filarmónicos", 1841: 395-396). Los retratos al óleo de ambos cantantes habían sido pintados por Antonio María Esquivel [figs. 178 y 179] por encargo de la Junta directiva del propio Liceo, y ambos aparecen caracterizados como los personajes de la ópera Lucía de Lamermoor (PÉREZ SÁNCHEZ, 2005: 252). El Liceo, que ya se había transformado en una sociedad elegante, vio también inmortalizada un año después a Paulina García, quien en 1842 protagonizó varias funciones en los salones que le habían sido cedidos; las noticias de Paulina García, que monopolizan la atención de la prensa y eclipsan la exposición de pintura y bellas artes que se estaba celebrando en el mismo momento, se ven plasmadas en el retrato realizado por Antonio María Esquivel con ocasión de la función a beneficio del Liceo que decidió celebrar la cantante. La obra figuró en la exposición de la Academia de San Fernando de 1842, junto a los retratos de los actores Julián Romea y Matilde Díez, el del propio secretario del Liceo, Pérez Vento, y el de Santiago Alonso Cordero (ÁLVAREZ LOPERA, 1996: 289).

El desinterés de la prensa hirió sin duda el orgullo de los pocos socios que presentaron sus obras en la exposición de pintura de 1842. Francisco de Paula VanHalen reaccionó criticando a los redactores de El Pasatiempo por desmerecer las obras de grandes pintores españoles como Vicente López, José Elbo, Antonio María Esquivel, Camarón o Bejarano. En su alegato, Van-Halen se justificaba asegurando que la

Brugada, Vicente Camarón, Antonio Gómez Cros, Vicente López, José Madrazo, Calixto Ortega, Genaro Pérez Villaamil, Cayetano Palmaroli y Benito Sáez. Algunos de los ausentes eran de especial relevancia por su actividad, como Valentín Carderera, Antonio María Esquivel, Adriano y Augusto Ferrán o Rafael Tejeo. En 1846 el total de socios en la sección de bellas artes era de 66, de los que únicamente 6 de ellos eran mujeres, otros 6 fueron considerados "socios honorables" (Rafael Esteve, Juan Gálvez, Vicente López, José de Madrazo, Juan Antonio de Ribera y Rafael Tejeo), y los 44 restantes constituían una mezcla de artistas reconocidos (Vicente Camarón, Cecilio Corro, Vicente Castelló, Carderera, Francisco Elías -padre e hijo-, Bernardo López, Luis y Federico de Madrazo, Jenaro Pérez Villaamil, José Piquer y Carlos Luis de Ribera entre ellos) y aficionados ilustres.

489 "Debiéndose celebrar a mediados del corriente mes la distribución de premios que este cuerpo tiene prometidos, y habiendo de tener lugar al mismo tiempo la exposición de obras artísticas que previenen los acuerdos de la junta delegada, se avisa a los señores pintores, escultores, grabadores y arquitectos que gusten presentar sus trabajos que los depositen en la secretaría de este establecimiento, donde se les dará recibo hasta el 15 del corriente. La junta gubernativa al poner esto en conocimiento de los artistas, no duda que contribuirán por su parte a dar lustre a este establecimiento y aumentar la gloria de cada uno en particular y de las artes en general" ("Liceo artístico y literario de Madrid", 1841: 2).

490 "Este establecimiento según tenemos entendido, ha mandado sacar los retratos al óleo de la señora de Vega y de Rubini, como una señal de distinción por el gran mérito que estos dos artistas han desplegado en las últimas funciones filarmónicas, y como un grato recuerdo del placer con que han sido oídos por el público madrileño. Ambos cuadros serán una propiedad del Liceo" (“Liceo de Madrid”, 1841: 4). 
exposición, aunque de pocas obras, era "de las más lucidas que ha dado el Liceo, y el artista que haya tomado parte en ella puede vanagloriarse de haber dejado bien puesto el nombre que con sus desvelos se ha granjeado" (VAN-HALEN, 1842: 4). Parece claro, sin embargo, que la decadencia del Liceo, de cuya sección de pintura no queda más reflejo que la mención de las decoraciones del teatro, era ya manifiesta tanto entre sus miembros como para quienes lo veían desde fuera, que reclamaban "menos boato y más fomento para las artes y las letras ${ }^{491}$,.

Hasta el año de 1844 no volvemos a encontrar retratos de liceístas en las exposiciones, en las que destacan por una parte las miniaturas de Cecilio Corro, que representan, entre otros, a Villalta, Navarrete y Vega, y por otra los retratos familiares de Antonio María Esquivel.

La exposición más notable del Liceo fue la de 1846, en la que, quizás para dar un nuevo brillo a la sociedad, se incluyeron por iniciativa del presidente de la sección, Vicente Camarón, obras de artistas desde mediados del siglo anterior hasta la actualidad. Aunque fue una de las exposiciones más numerosas de la sociedad, fueron pocos los retratos de liceístas que se presentaron. A pesar de que Federico de Madrazo envió el retrato de su hermano, el público y la crítica no dieron gran importancia a este hecho, ya que lo vincularon al éxito que ya había cosechado con él anteriormente cuando lo remitió a la exposición de la Academia de Bellas Artes de San Fernando. Antonio María Esquivel presentó el retrato de su hijo Carlos María, que fue especialmente alabado por la crítica $^{492}$; mayor confusión produce la presencia de un supuesto retrato de Joaquín Espalter pintado por Esquivel, del que da noticia Ossorio a partir una crítica publicada por Manuel Cañete, pero que no figura en la mayoría de las reseñas, puesto que se trataba en realidad, como aclara Aránzazu Pérez Sánchez (2005: 402), de un retrato de Manuel Soler y Espalter realizado por Joaquín Espalter. Finalmente $^{493}$, otro retrato de liceísta expuesto por otro socio era el de Vicente Escofet, miembro de la sección de Bellas Artes, realizado por Vicente López. Al mencionar la obra, Velaz de Medrano (1846b: 3) citaba también el retrato de la señora de Escofet pintada por su marido, aludiendo a las similitudes técnicas del segundo respecto al maestro valenciano. Es notorio cómo, a pesar del éxito de la exposición, la vinculación de las obras con el propio Liceo y especialmente los retratos, es prácticamente inexistente, pues solo constan dos retratos más liceístas: se trata, en primer lugar, del retrato a lápiz de Ramón Mesonero Romanos dibujado por la artista y también socia de la institución hasta su temprana muerte en 1843, Rosario Weiss (Iconografía Hispana, ${ }^{\circ}$ 5884-1). De la obra decía El Heraldo que se trataba de un retrato "muy parecido, ejecutado con la acostumbrada delicadeza que se admiraba en esta artista, cuya

\footnotetext{
491 "Liceo artístico y literario", 1842: 4. También Pérez Sánchez (2005: 240) menciona el progresivo abandono de esta sección, hasta el punto de limitar en 1845 las sesiones de competencia a presentaciones de cuadros y dibujos que sirviesen de entretenimiento en las sesiones literarias o musicales.

${ }^{492}$ El crítico de El Tiempo afirmaba no "haber visto nada que nos guste más en su género" (G. de G., 1846: 4). No obstante, en El Heraldo se afirmaba que se hallaban expuestos los retratos de ambos hijos de Esquivel ("Exposición del Liceo", 1846).

${ }^{493}$ Excluimos de esta relación el retrato de Juan José Camarón, realizado por Asensio Juliá (VELAZ DE MEDRANO, 1846a: 3; PÉREZ SÁNCHEZ, 2005: 218), que figuró en la exposición, por tratarse (dada la cronología del autor y del representado) de una obra sin ninguna relación con el Liceo.
} 
temprana muerte, como la del joven Alenza, ha sido una dolorosa pérdida para las artes españolas" (“Exposición de obras...”, 1846: 3). También el escultor Vilches presentó un retrato en busto de Antonio María Esquivel, según recogen varias noticias; de él se destacaba su parecido, pues se trataba de "un trabajo perfecto, es imposible imitar con más verdad la naturaleza" (G. de G., 1846: 4; VELAZ DE MEDRANO, 1846b: 3). Al parecer, el escultor Vilches ya debía ser miembro en 1845, año en que figura realizando una exposición en los salones del Liceo, de la que da noticia la revista literaria de $E l$ Español (1845/10/11: 16).

La escasez de retratos de artistas y liceístas parece evidenciar el progresivo estado de abandono en el que habían caído las artes en el Liceo; en ese mismo año de 1846, Antonio María Esquivel estaba ultimando la obra de Los poetas contemporáneos, que presentaría apenas un par de meses más tarde en la exposición de la Academia de San Fernando. Pese a que algunos de los retratados eran liceístas, no parece que Esquivel se preocupase por presentarla o exponerla en el Liceo; curiosamente, Esquivel no figura en la lista de socios de la sección de Bellas Artes publicada en el Boletín del Liceo (“Catálogo de los señores...", 1846: s.p.), algo que lleva a plantear si las relaciones del pintor con la sociedad se habían enfriado con el paso de los años y el devenir, marcadamente burgués y poco proclive a las artes, del Liceo.

Esta situación llegó a su punto crítico en la penúltima exposición del Liceo, celebrada en 1848 tras la restitución de la sociedad, al haberse convertido en un escaparate de la obra de principiantes y aficionados, y con la que muchos pintores habían dejado de sentirse identificados. A excepción del retrato del escultor Piquer, de Vicente López (cuya relación con la sociedad seguía siendo bastante sólida ${ }^{494}$ ), tan solo constan noticias de tres posibles retratos de artistas vinculados al Liceo, casos todos ellos que deben tratarse con la debida cautela dada la imposibilidad de contrastarlos con fuentes gráficas. Uno de los casos es un Autorretrato presentado por Manuel Ojeda, al que sin duda Velaz de Medrano situaba entre los muchos malos retratos existentes en la exposición, al subrayar los fallos que presentaban sus tres obras $\mathrm{y}$, en concreto, su propio autorretrato $^{495}$. Sin embargo, la crítica de Cañete (1848: 1-2) no consideraba esta obra un autorretrato, sino un retrato de Juan Reigon. Velaz de Medrano (1848c: 4) vuelve a mencionar otro supuesto autorretrato, en este caso de Carlos María Esquivel, únicamente para subrayar su juventud e inexperiencia pictórica a pesar del gran número de obras presentadas; de este modo, se refiere al artista como "joven de pocos años, como parece ser, a juzgar por su retrato de cuerpo entero que ha expuesto", pasando a señalar lo mucho que le quedaba por estudiar y aprender, para finalmente concluir que el hijo de don Antonio "no pasa de ser un principiante". No obstante, esta obra no es

\footnotetext{
494 Al parecer, en 1849 Vicente López era presidente de la sección de pintura. En estas fechas se proyectaba realizar en su honor una sesión artística y literaria que revitalizase la actividad del Liceo ( $L a$ Patria, 1849/03/05: 4).

495 "Don Manuel Ojeda ha expuesto tres retratos, el de una señora, el de su señor padre y el suyo propio. Indudablemente que el mejor de los tres es el segundo. Se ve más detenimiento y cuidado que en los otros dos (...) Aconsejamos al Sr. Ojeda que dibuje mucho y observe los buenos modelos. Las manos de su propio retrato parecen hinchadas, particularmente la derecha, y se notan además otras varias imperfecciones" (VELAZ DE MEDRANO, 1848c: 4).
} 
mencionada en ninguna de las críticas restantes y tampoco ha podido ser localizada. Otro retrato que nos suscita algunas dudas es el del liceísta Mariano Martín, presentado por Algarra; la relación entre ambos personajes parece clara, ya que el primero era socio de la sección de música y fue director de la parte musical en la sesión regia del Liceo celebrada el 19 de junio, en la que Algarra participó como cantante (El Heraldo, 1848/18/06: 4). La posibilidad de que pudiera tratarse del pintor Cosme Algarra no parece descartada, puesto que ya se conocen sus retratos del tenor Puig y de Baltasar Saldoni, quienes aparecen citados en sesiones del Liceo; es escasa la atención que prestan a este pintor tanto Cañete como Velaz de Medrano en sus críticas, ya que en ellas el segundo respalda la autoría de Algarra (VELAZ DE MEDRANO, 1848c: 4), mientras el primero se limita a citar al autor entre otros expositores, sin dar cuenta de las obras que presentó (CAÑETE, 1848: 2).

El nivel de descontento de varios pintores con el Liceo queda patente en las grandes ausencias en esta exposición, justificadas por las quejas de algunos por no haber recibido invitación oficial del Liceo para presentar su obra. Es el caso de Federico de Madrazo, quien no solo expresaba su desagrado por la conducta del Liceo, que le había desanimado a no presentar nada en la exposición, ya que no se le había hecho "la más leve invitación verbal" (MADRAZO, 1848: 4), sino que se mostraba además ofendido por los comentarios aparecidos en las críticas, entre ellos el de haber sido el único artista de renombre que no había concurrido a la exposición, así como la degradante afirmación de que Carlos Luis de Ribera había presentado una obra y la había retirado antes de la inauguración, faltando a su palabra. El descontento de Federico de Madrazo evidencia un honor herido, ya que le respondía dando "las gracias por haberse acordado de mí", pero manifestaba que "en el mismo estado se hallaban también los Sres. Ribera, Tejeo, Espalter, Carderera, D. Luis Ferrant, Camarón y otros que tenían tanto derecho como yo a ser nombrados". Respecto a la acusación contra Carlos Luis de Ribera, Madrazo se erigió en paladín y defensor de su honor, explicando el origen de la confusión y acusando a los anónimos redactores de cobardía, al tiempo que lamentaba no conocer sus nombres "para poderlos sonrojar en público diciéndoles que faltan a la verdad descaradamente".

En enero de 1849 se celebró una poco concurrida exposición de pinturas, de la cual lo más notable fueron los dibujos al lápiz de varios conocidos literatos presentados por Cecilio Corro, a la cual Carlos María Esquivel podría haber presentado un retrato de dicho pintor y liceísta (PÉREZ SÁNCHEZ, 2005: 414; "Exposición del Liceo", 1849: $3)$.

\subsubsection{Sociabilidad y familia: algunos retratos del artista familiar en el Liceo}

Un aspecto frecuente en el fenómeno de socialización decimonónica es, como señala María Zozaya (2015: 106), la importancia de los vínculos familiares y el parentesco en un mismo espacio o sociedad, por lo que se da el caso de que en las listas de socios sea habitual encontrar a varios miembros de una misma familia. En el caso del Liceo, debido a su escasa duración en el tiempo, no es posible establecer ese carácter de endogamia que la investigadora identifica en el Casino madrileño; los vínculos de 
parentesco entre liceístas son difíciles de rastrear debido a la escasez de listas de socios, puesto que solo conservamos las relativas a los años 1838, 1841, 1842 y 1846 y, por otra parte, a que la costumbre del Liceo de extender billetes de convite no permite identificar la relación existente con los convidados, presuponiendo en la mayoría de los casos que se trataría de esposas, hermanas y familiares. Así lo decretaban los estatutos de 1838, determinando que "todo socio facultativo tiene derecho por su sola retribución mensual, a un billete para su esposa, madre, hija o hermana; pero si presenta una señora que no se halle en estos casos, pagará por ella la cuota mensual establecida para las demás"; los socios no facultativos que deseasen presentar una señora, debían pagar su correspondiente cuota de entrada y mensual. En este sentido, Pedro de Madrazo también da noticia del componente familiar de las sesiones del Liceo al hablar de la sesión de Rubini en 1841, señalando cómo José de Madrazo había "tomado dos suscripciones (veinticuatro duretes) y le ha regalado otra a Daguerre, de modo que teniendo él también su billete como miembro de la junta gubernativa" podrían "perfectamente oírle todos los de la casa ${ }^{496 "}$. Uno de los rasgos característicos del Liceo es su carácter mixto, ya que en los sucesivos estatutos se reconocen los derechos de las mujeres a ser socias (tanto facultativas como no facultativas) de las respectivas secciones ${ }^{497}$; la pertenencia al Liceo aseguraba el reconocimiento de un estatus social basado en el gusto artístico, aunque la relación entre capital y cultura quedaba plenamente manifestado cuando se hacía extensiva a varios miembros de una familia, ya fuesen matrimonios ${ }^{498}$, hermanos $^{499}$ o padres e hijos, una apreciación a la que no fueron insensibles los pintores más vinculados con la alta sociedad, como Vicente López, a quien en alguna ocasión acompañó su hijo Bernardo; José de Madrazo, que aparece como socio junto a sus hijos Federico, Pedro y Luis; José Gutiérrez de la Vega y su hijo, o Antonio y Carlos María Esquivel. La proyección de los ideales morales de la burguesía respecto a la familia se reflejan fielmente en el Liceo, que entre otras funciones se había propuesto la de propagar la enseñanza artística, por lo que es frecuente encontrar a los hijos de los socios inscritos en las cátedras ofertadas por la sociedad; del mismo modo, la representación de los vínculos familiares también tuvo cierta acogida en las exposiciones, probablemente como una trascendencia al ámbito público de un aspecto de la vida íntima estrechamente relacionado con la vida social ${ }^{500}$.

Al ser el Liceo uno de los importantes escaparates de la sociabilidad burguesa madrileña merece la pena prestar atención a la importancia que algunos artistas concedieron a proyectar una imagen de sí mismos como hombres familiares, de tal manera que pudiera ser percibida trascendiendo la barrera tradicional de la

\footnotetext{
${ }^{496}$ Carta de José a Federico de Madrazo, 19 de noviembre de 1841 (DÍEZ, 1998b: 486).

${ }^{497}$ Los estatutos de 1838 y 1840 reconocían en su capítulo primero, artículo noveno, que "las señoras artistas pueden ser admitidas como facultativas en cualquiera de las secciones, sometiéndose a lo que prevengan los respectivos reglamentos". Para un análisis del papel de la mujer en los liceos, ver EZAMA GIL, 2015: 32-43; PÉREZ SÁNCHEZ, 2005: 111-113; LICEO ARTÍSTICO Y LITERARIO, 1840.

${ }^{498}$ Puede señalarse el caso de Ventura de la Vega y Manuela Oreiro de Lema.

${ }^{499}$ Engracia y Francisca Carrasco, Jenaro y Juan Pérez Villaamil.

${ }^{500}$ Aránzazu Pérez Sánchez menciona, sin entrar en un análisis detallado ni de las obras ni de sus implicaciones sociales, los distintos grados de parentesco que ofrecen algunas de las presentadas en el Liceo (PÉREZ SÁNCHEZ, 2005: 219).
} 
representación profesional. No se trataba, pues, de señalar al artista reconocido por sus méritos, ya que el espacio ideal para tal tipo de representación era, como hemos visto, la Academia, ni tampoco como destacado profesor, a pesar de la búsqueda de notabilidad manifestada en los dos primeros años de la sociedad; para sus contertulios, consocios y, probablemente, discípulos en las cátedras, la imagen del artista que abogaba por la vertiente familiar tenía matices propios de carácter sociocultural. Aunque la expresión de los vínculos afectivos podría asociarse a la necesidad de buscar el lado humano o íntimo del artista relacionado con el culto a la celebridad, en realidad la proyección familiar responde más a un carácter de presentación en sociedad -y preciso es recordarlo, en buena y alta sociedad- del artista y sus allegados, en un espacio en el que se siente, o aspira a sentirse, entre iguales.

No parece una coincidencia que, mientras en las exposiciones de la Academia hacía gala de su importante carrera artística y de los méritos obtenidos por su trabajo, Antonio María Esquivel optase por introducir poco a poco su dimensión familiar en las exposiciones del Liceo. Mientras en las primeras celebradas (1837 y 1838) sus retratos estaban vinculados con la sociabilidad artística en el ámbito del Liceo, 1844 marca un cambio significativo, pues expuso dos retratos familiares de grupo: su Autorretrato con sus hijos (Museo Nacional del Romanticismo, $\mathrm{n}^{\circ}$ inv. 07167), y otro, que hacía pareja, en el que representó a su esposa con su hija. Resulta curiosa la inclusión de este último, ya que la hija del matrimonio Esquivel, a la que el pintor retrató en al menos tres ocasiones, había fallecido siendo niña en 1840, hecho que Guerrero Lovillo (1957: 44) señala como una forma de "destacar el drama íntimo de una familia del ochocientos". La separación habitual de roles del retrato familiar decimonónico es manifiesta en estos dos retratos: en la escena femenina, en que madre e hija aparecen abrazadas, se plasma abiertamente la afectividad familiar, sin introducir detalles que distraigan la atención; la masculina, por el contrario, ofrece una composición más compleja, en la que el pintor adquiere un gran protagonismo. La elección de una muestra del espacio íntimo del artista hace del retrato, ubicado en las paredes del Liceo, una obra con múltiples lecturas, desde la proyección de una apariencia familiar hasta las posibilidades propagandísticas para la captación de clientes. El orgullo familiar de Esquivel no queda plasmado únicamente en mostrarse como modelo a seguir para sus hijos en cuanto hombre, sino también en la profesión artística, en cuyo proceso de iniciación se encuentran los dos niños, introducidos de esta manera en el ámbito social del Liceo.

La intención de Esquivel al presentar en la exposición de 1846 un nuevo retrato, en este caso de su hijo mayor, podría vincularse nuevamente a esta relación entre sociedad y mundo familiar. La obra, que según Pérez Sánchez (2005: 411) era el retrato conservado en la colección Gregorio Marañón, podría estar vinculada con los comienzos artísticos de Carlos María quien, aunque no aparece recogido como participante en exposiciones del Liceo hasta 1848, podría haberse dado a conocer ya ese año en la sociedad a través de sus sesiones y cátedras, por lo que podría tratarse el retrato de una presentación en sociedad del primogénito del artista. 
Un tipo de modelo diferente puede observarse en otros retratos familiares individuales; en ellos, los vínculos pueden ser especialmente evidentes, como el hecho de que Federico de Madrazo presentase el retrato de su hermano Pedro, o tal vez quedar más desdibujados entre el conjunto de obras de la exposición, aunque sin duda para sus autores y para los espectadores liceístas podían tener significados relevantes sobre la vida social de los representados. Uno de los casos es el de los retratos presentados por otro artista muy involucrado en el Liceo, Antonio Gómez Cros, en la exposición de 1848. Gómez participó con los retratos de su madre y su hermana, según recoge Pérez Sánchez; cabe preguntarse, dadas las rivalidades que se habían producido entre este pintor y Antonio María Esquivel, si la presentación de estos retratos respondía a una voluntad de mostrar ante otros liceístas unos retratos que manifestasen también su ascenso social, a través de las representaciones de su familia, tras su nombramiento como pintor de cámara en 1846. Sin embargo, frente a la costumbre de Esquivel, Gómez Cros no presentó su propio retrato, algo que tal vez podría interpretarse como una muestra de humildad y modestia.

\subsubsection{Reunión literaria. Reparto de premios en el Liceo}

Se ha venido fechando en el mismo año de 1846 el boceto de un retrato colectivo conservado en el Museo Nacional del Romanticismo ( $\mathrm{n}^{\mathrm{o}}$ inv. 0208) con el título Reunión literaria. Reparto de premios en el Liceo [fig. 180]; obra de la que no dan noticia ni Ossorio, ni Guerrero Lovillo ni Antonio de la Banda y que, por su carácter abocetado y la falta de identificación de los representados, rara vez se pone en relación con los retratos colectivos acabados realizados por Esquivel ${ }^{501}$. Si bien en la bibliografía el cuadro de Los poetas contemporáneos suele vincularse con el espíritu del Liceo, parece bastante significativo el hecho de que, aunque algunos de sus miembros sí que tuviesen relación con el mismo ${ }^{502}$, la tertulia literaria no se desarrolle en esta sociedad sino en el estudio del pintor $^{503}$. Por el contrario, Reunión literaria sí que parece corresponder con una representación del Liceo, y Aránzazu Pérez Sánchez (2005: 147) menciona la obra como testimonio gráfico del interior del Palacio de Villahermosa, sede del Liceo, y de su decoración. Sin embargo, es también un valioso documento sobre la sociabilidad entre artistas en el establecimiento. De acuerdo con la forma de Esquivel de componer los retratos de grupo, la obra presenta la nada desdeñable cantidad de cuarenta y cuatro figuras -el mismo número que el cuadro de Los poetas-, dispuestas en un improvisado semicírculo formado por las sillas de la tertulia. La atención de los

\footnotetext{
501 En su estudio sobre el cuadro Los poetas contemporáneos, José Valverde (1997: 407-432) no menciona esta obra; sí que lo hace José Luis Díez (1994b: 197; 2007: 154), señalando que responde a un mismo concepto compositivo y temático.

502 De los cuarenta y cuatro personajes representados, tan solo catorce pertenecían al Liceo en sus primeros años, según la lista de socios publicada en la revista del Liceo. Igualmente interesante es el hecho de que la obra de Esquivel fuese expuesta, en exclusiva, en la Academia, ya que no queda constancia de que fuese presentada a las del Liceo.

503 Aparte del análisis de los motivos realizado en el apartado de las exposiciones de la Academia de San Fernando, es manifiesto el hecho de que el estudio de Esquivel se había convertido en una tertulia privada de especial interés entre la sociedad madrileña. Así lo recoge Luis Villanueva en su biografía del pintor: "Su casa es la reunión de los hombres más eminentes del estado, de los literatos de más nombradía, que pasan muchas horas al lado de nuestro artista admirando sus obras" (VILLANUEVA, 1844: 93).
} 
personajes se encuentra dividida entre dos focos, uno en el extremo derecho, donde la irrupción de una pareja en la sala distrae momentáneamente de la lectura en voz alta que se encontraba haciendo una dama, y otro en el extremo izquierdo, donde varios personajes, cuchicheando entre sí, se giran al frente, hacia el pintor de la obra.

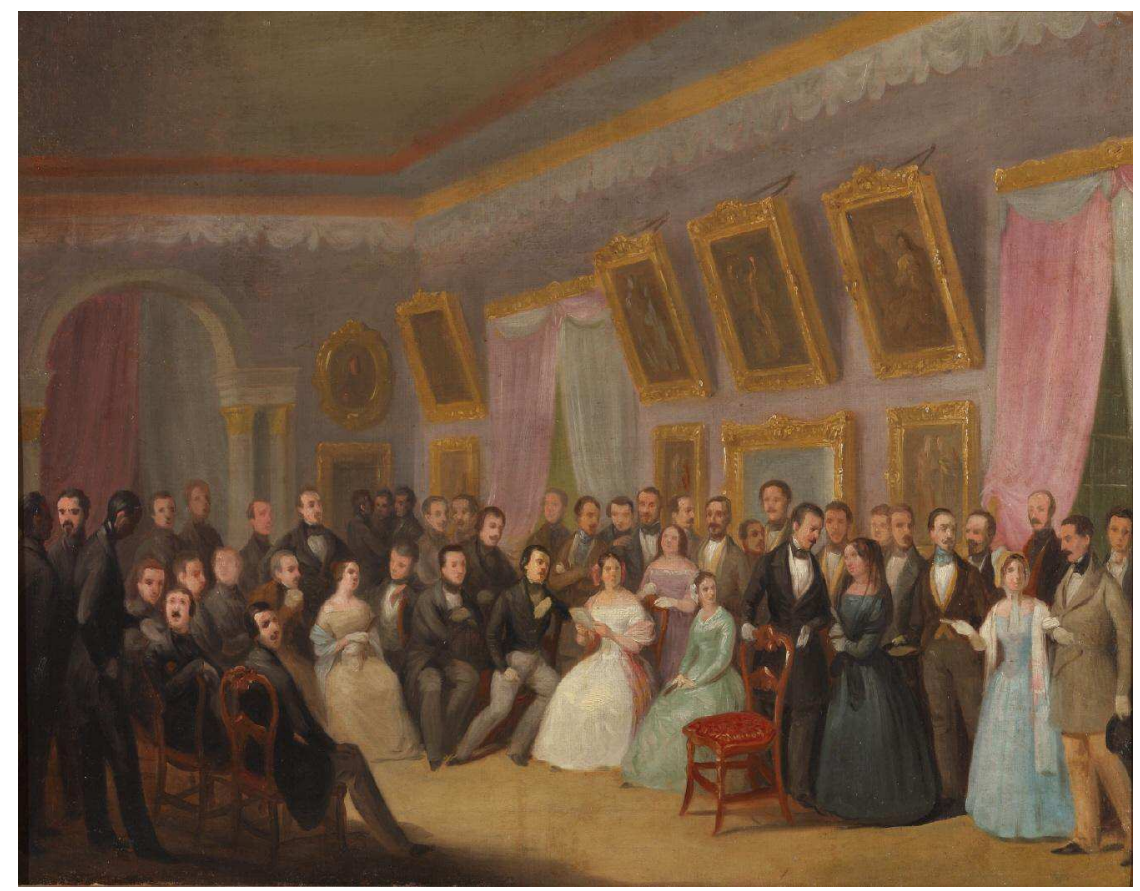

Fig. 180. Antonio María Esquivel, Reunión literaria: reparto de premios en el Liceo, 1846. Museo Nacional del Romanticismo.

A pesar de que la escena no parece corresponder con la solemnidad de las entregas de premios, que en el momento de realización de la obra estaban limitadas a los Juegos Florales anuales, podría tratarse de la representación de un momento concreto en la historia del Liceo. Queda constancia de un premio literario convocado en 1845 y patrocinado por el liceísta Vicente Bertrán de Lis, cuyo el objeto era conmemorar la amnistía concedida por la reina a varios presos políticos. Algunas peculiaridades de la obra mueven a pensar que podría tratarse de una representación de la tertulia previa a la entrega de premios, y a fechar, por lo tanto, la obra en 1845, tal y como apuntaba Carlos Reyero (2015: 540). La premiada en esta ocasión fue la poetisa Gertrudis Gómez de Avellaneda, que obtuvo -con la polémica correspondiente (EZAMA GIL, 2015: 3243)- el primer y segundo premio, y que podría identificarse en la obra en la dama que, vestida de blanco, sostiene en sus manos una publicación: con toda probabilidad se trata de las odas premiadas, que leería Ventura de la Vega después de la ceremonia. A su izquierda, vestida de verde, podría encontrarse su hermana, Josefa de Escalada, quien sabemos la acompañó a la sesión del Liceo (El Heraldo, 1845/20/06: 4; "Liceo", 1845: 4). Cabe pensar en algunas personalidades vinculadas al Liceo que deberían aparecer en la composición, como el propio presidente de la institución, Fernando Álvarez, o los miembros del jurado del certamen, como Juan Nicasio Gallego, Joaquín Francisco Pacheco, Juan de la Pezuela, Ramón Mesonero Romanos o Antonio Segovia. Lo abocetado de las facciones no permite aventurar muchas hipótesis: la figura ubicada en el centro de la composición, destacado sobre una de las colgaduras que ornaron la 
sesión, podría relacionarse con Juan Francisco Pacheco; más clara, sin lugar a dudas, es la identidad del caballero que, en el extremo derecho de la composición, ofrece galantemente un asiento a una dama recién llegada. Se trata, si lo cotejamos con su retrato en Los poetas contemporáneos, del marqués de la Pezuela. Respecto a los cuatro personajes que acaban de hacer su aparición en el salón del Liceo, hecho que confirma el que las dos damas aún lleven cubierta la cabeza con mantilla y sombrero, respectivamente, y que los dos caballeros que las acompañan aún tengan en la mano los sombreros de copa, es especialmente llamativa la atención que suscitan en la tertulia. Cabe la posibilidad de que se trate de las infantas Luisa Teresa y Josefina Fernanda de Borbón, jóvenes hijas de Francisco de Paula de Borbón, encargadas junto a su padre de la representación oficial y de la entrega de los premios.

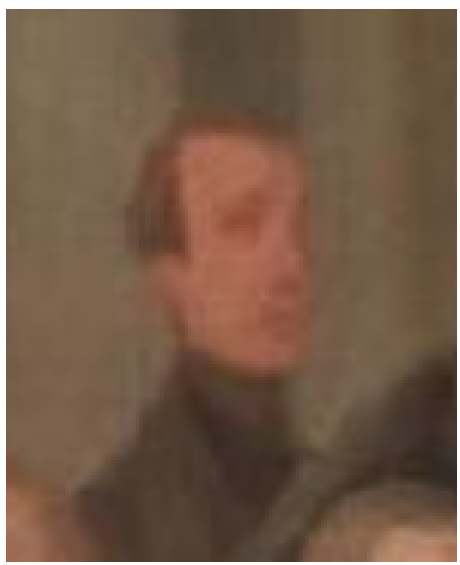

Fig. 181. Antonio María Esquivel. Retrato de Jenaro Pérez Villaamil en Reunión literaria (detalle).

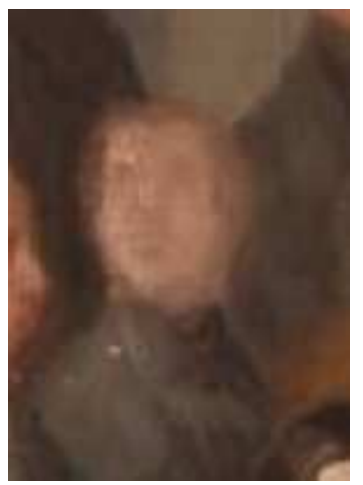

Fig. 183. Antonio María Esquivel. Autorretrato borrado en Reunión literaria (detalle).

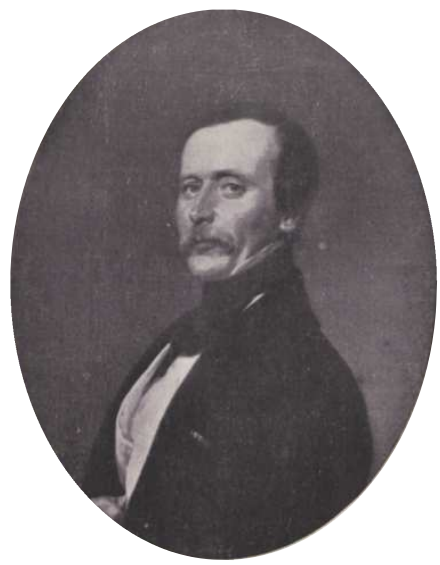

Fig. 182. Federico de Madrazo. Retrato de Jenaro Pérez Villaamil, 1845.

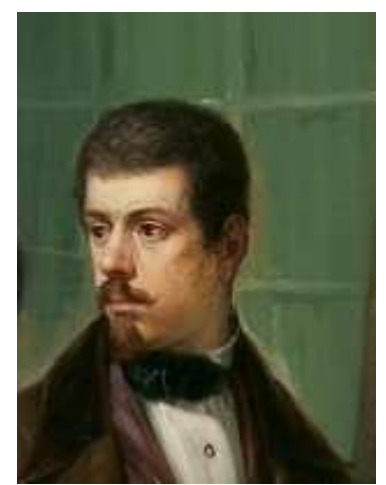

Fig. 184. Antonio María Esquivel. Autorretrato en Los poetas contemporáneos (detalle).

Es interesante también la posible identificación de dos personajes en el grupo de la izquierda, ya que podría tratarse de los retratos de dos pintores en la tertulia. De pie en la fila de atrás, resaltando sobre las columnas pareadas del arco del fondo, un hombre con cabello castaño, bigote rubio y porte altivo evoca la figura del paisajista Jenaro Pérez Villaamil [fig. 181]. En efecto, la semblanza con las efigies conocidas del pintor es notable, especialmente con el retrato realizado por Federico de Madrazo [fig. 182] (realizado también en el año de 1845). La vinculación de Villaamil con el Liceo había sido continua, ya que figura como uno de los miembros fundadores, activo en las 
sesiones de competencia y presente en la mayoría de las exposiciones organizadas por la sociedad. La imagen de Pérez Villaamil se diferencia por la evocada hacia otros artistas en el Liceo en sus primeros años de existencia, esto es, aislados en sus salas de trabajo y entregados a la improvisación pictórica, y se vincula más con el carácter de sociedad, al mismo tiempo culta y amable, en que se había convertido el Liceo en 1845. De este modo, aparece despojado de su identidad profesional -la misma que Esquivel cuida en subrayar en su autorretrato presente en el cuadro de Los poetas contemporáneos-, a favor de una dimensión pública y sociable del hombre de éxito.

Muy cerca de él, sentado y con la cabeza ligeramente vuelta, desconcierta la imagen de un personaje cuyas facciones parecen haber sido deliberadamente borradas [fig. 183]. El dibujo de los rasgos aún es visible bajo el borrón y muestra una cabeza inclinada hacia atrás, como si dirigiese su mirada hacia un punto que escapa de la vista del espectador; tiene este personaje una cabellera castaña que hace juego con un bigote y una larga perilla que corona el mentón; asimismo son perceptibles la nariz y unos labios característicamente carnosos. Unos rasgos, en definitiva, que recuerdan a los del propio Esquivel tal y como los conocemos a través de sus autorretratos, especialmente con el incluido en Los poetas contemporáneos [fig. 184]. La posibilidad de tratarse de un autorretrato es llamativa, ya que en ese caso, Esquivel no se contenta con plasmar la escena desde su puesto de pintor, sino que decide representarla -o recrearlamostrándose como uno de los asistentes a ella. La inclusión del autorretrato parece haber puesto a prueba la habilidad de Esquivel, ya que si bien el resto de retratos podían encajarse con bastante facilidad en la escena, la interpretación de sus facciones sin caer en los convencionalismos del retrato en el espejo, más complicada si cabe al no presentarse pintando, podía hacer fallar la composición. Efectivamente, no parece quedar muy clara la interacción de este personaje con los que le rodean: ¿se encuentra acaso contemplando a los personajes que conversan en el extremo izquierdo de la composición? ¿Tal vez mira por encima del hombro a los personajes que se encuentran tras él? La indecisión sobre la composición, junto con la carga de trabajo que suponía la realización del cuadro de Los poetas y sus compromisos artísticos, pudo haber motivado que esta escena quedase en un esbozo inconcluso.

La historia del Liceo como espacio artístico manifiesta varios cambios que afectan a la percepción masculina del artista. Prueba de ello es que una sociedad inicialmente formada de manera casi exclusiva por una juventud artística, abiertamente militante en lo político, pues el tinte liberal era notorio, y deseosa de encontrar un lugar propio al margen de las restricciones de las instituciones oficiales y su encorsetamiento ideológico, se viese progresivamente convertida en un centro destinado al ocio cultural burgués. Significativo no del espíritu abierto, revolucionario y romántico que se le atribuye, la evolución del Liceo y de los artistas que progresivamente se le vinculan hace que constituya una muestra de las aspiraciones del artista español de los años cuarenta: la de vincularse exitosamente con la élite social y formar parte indispensable de esta. Los efectos de esta inclusión del artista en la normatividad altoburguesa y en unas formas determinadas de sociabilidad inciden, como no podía ser de otro modo, en el tipo de retrato que se practica. Encontramos así que el tipo de retrato directo, fruto de 
la sociabilidad entre liceístas, se produce con más espontaneidad en el primer año de vida de la sociedad, en el que el número aún limitado de socios y los vínculos de amistad entre estos son más fáciles de encontrar. Otros retratos de liceístas fruto también de esta espontaneidad se encuentran en las obras realizadas por Rosario Weiss y por Cosme Algarra, es decir, por una mujer artista y por un artista aún en formación, cuyas obras resultaron invisibilizadas por las producidas por los artistas de la élite (y especialmente por Antonio María Esquivel). Los artistas con una carrera profesional sólida encontraron en el Liceo un espacio en el que constituirse como nuevas personalidades sociales, motivo por el cual sus retratos se vinculan con la identidad profesional y con la vida burguesa, y testimonian que los momentos de ocio del artista buscaron su proyección social como nuevo hombre burgués y como protagonista cultural.

\subsubsection{El Liceo artístico y literario valenciano (1838-1845)}

Al hablar sobre el Liceo valenciano, tanto Francisco Almela (1962), Vicente María Roig (1994), Ester Alba Pagán (2007) y Aránzazu Pérez Sánchez (2005: 261) señalaron, con plena razón, dos de las características fundamentales de este liceo provincial: la primera, más evidente, es la clara influencia de Liceo Artístico y Literario de Madrid, cuyos reglamentos copió al pie de la letra; la segunda, con un carácter peculiar, es la importancia que en él cobró el retrato, debido al hondo calado de la obra de Vicente López en los círculos artísticos valencianos, y también a la actividad que desarrolló en el Liceo su hijo, y heredero en planteamientos pictóricos, Bernardo López.

La sección de Bellas Artes, cuya actividad fue más notable entre 1839 y 1842, pasó posteriormente a una posición relegada en el Liceo, de manera paralela a la situación en Madrid. Contó entre sus socios con algunos de los artistas más destacados en el panorama valenciano (anexo 9), como el citado Bernardo López, Vicente Castelló, vicepresidente de la sección y en cuyo domicilio se realizaron algunas de las sesiones ("Liceo Valenciano", 1838: 4); Teodoro Blasco, Antonio Cavanna, Juan Llácer, Miguel Pou, Miguel Parra, Lorenzo Isern o Rafael Montesinos, y con una amplia lista de pintores aficionados. Además de pintores, también participaron activamente en la sección los grabadores Teodoro Blasco y José Gómez, los arquitectos Joaquín Cabrera, Antonino Sancho, Jorge Gisbert, Manuel María Azofra y Manuel Sorní, y los escultores Blas Gómez y Bernardo Llácer.

Si al hablar del Liceo madrileño mencionábamos algunos de los vínculos familiares existentes entre sus socios, el valenciano no es una excepción, ya que se encuentran en su sección de Bellas Artes relaciones directas de parentesco, como la de los hermanos Llácer y Viana, Juan y Bernardo; además, los hijos de algunos de los pintores anteriormente citados se iniciaron en el ámbito del Liceo en su juventud o niñez, como Vicente López (hijo de Bernardo López), Antonio Castelló o José Felipe Parra. La presencia de mujeres artista parece igualmente limitada, ya que solo constan cuatro como tales o como discípulas de liceístas, y otras cuatro aficionadas, del total de sesenta y ocho socios artistas del Liceo. 


\subsubsection{Noticias de retratos en las exposiciones del Liceo}

No hay noticias que nos permitan hablar de la existencia de una galería de retratos de los miembros de las juntas directivas del Liceo, ni de que llegase a proponerse ninguna iniciativa para su realización, probablemente debido a la corta duración de la sociedad. Gracias al periódico del propio liceo, titulado Liceo valenciano, y publicado únicamente entre 1841 y 1842 , sabemos que las sesiones de competencia del Liceo, en lo tocante a la sección de Bellas Artes, estuvieron casi siempre lideradas por el pintor Juan Llácer y Viana, y que los géneros que solían ocupar a los artistas eran caprichos de pequeño formato (“Salón del Liceo", 1841-1842: 7; D., 1841-1842: 40; A., 1841-1842: 48), tales como escenas bucólicas u otras tomadas de obras literarias ${ }^{504}$. Alguna referencia aislada nos hace pensar que el retrato también pudo ser uno de los temas tratados por los pintores asistentes a estas veladas, quizás debido a una concurrencia entre la que se encontraba lo más selecto de la sociedad valenciana, o tal vez al ambiente propiciado por la sociabilidad artística. Así, en la sesión celebrada el 27 de febrero de 1841, de la que queda una somera noticia, se señala la necesidad de hacer "justicia al Sr. Llácer, infatigable artista, que se ocupó en hacer un retrato perfecto" (D., 1841-1842: 71), sin que conozcamos el modelo que ocupó al pintor en la sesión.

Más conocidos son algunos de los retratos de artista que figuraron en las distintas exposiciones del Liceo, teniendo siempre en cuenta que, a pesar de que el retrato era el género con mayor presencia en estas, rara vez aparecen identificados los retratados en las crónicas o críticas. Sabemos que en la primera exposición del Liceo se presentó un retrato, realizado en litografía, del presidente del Liceo y socio de la sección de Bellas Artes, D. José Juanes, realizado por Miguel Vicente (ROCA DE TOGORES, 1838: 8), del que apenas da noticia Roig Condomina (1994: 27) en su tesis doctoral, pues se centra, al igual que Ester Alba Pagán, en las obras de grabadores de mayor envergadura, como José Gómez o Teodoro Blasco. Al respecto, Mariano Roca de Togores únicamente comentaba: "El señor Vicente ha presentado un retrato del Presidente del Liceo, dibujado sobre piedra litográfica, que nos hacer recordar dolorosamente la falta de buenos prensistas".

En la de 1839, el pintor sordomudo Lorenzo Isern Ricart, académico supernumerario de San Carlos y socio activo del Liceo, que ya había participado en la exposición de 1838, presentó un Autorretrato (ROIG CONDOMINA, 1994: 31; ALBA, 2004: 264), del que Miguel Vicente apenas señaló que era "muy correcto y estudiado" (V., 1839: 1-2), demostrando así su orgullo respecto a su profesión y la voluntad de presentarse, de manera abierta y reconocible, ante sus consocios.

La siguiente exposición, que no se celebró hasta 1841, contó con cuatro retratos vinculados en mayor o menor medida con el propio Liceo: el primero de ellos, presentado por Juan Llácer y Viana, representaba a su propio padre; de los otros tres

\footnotetext{
${ }^{504}$ En la crónica de una sesión del Liceo se da cuenta de la actividad de Juan Llácer, quien "pintó al óleo una de las más interesantes escenas de Don Álvaro o la fuerza del Sino" (A., 1841-1842: 23). También se menciona a Bernardo López, quien realizó en dos sesiones un Eneas (J.A.A., 1841-1842: 91; "Liceo. Sesión Ordinaria ...", 1840: 21).
} 
retratos solo conocemos que habían sido pintados en las sesiones del Liceo (J. A. A., 1841-1842: 92), por lo que cabe suponer que se trataría de socios o socias del propio Liceo, aunque nada permite confirmar que se tratase de retratos de artista. Ester Alba Pagán (2004: 266) interpreta la crítica de Juan Antonio Almela publicada en Liceo valenciano y propone que "Juan Llácer [presentó] cuatro retratos: el de su padre, una copia del retrato de la duquesa de Alba, otra de María Cristina de López" y "una copia de Nuestra Señora de los Dolores de Ribalta y cinco bocetos realizados en las sesiones del Liceo"; no obstante, según se desprende de la crítica en la enumeración de las obras presentadas por Llácer, las copias de los retratos de la duquesa de Alba y de María Cristina no pertenecían a esos tres retratos sin identificar, de los cuales señala que dos fueron realizados en las sesiones del Liceo, tal y como lo interpreta también Roig Condomina (1994: 37).

Rafael Montesinos llamó la atención en la exposición de 1842, en la que no defraudó a un público acostumbrado a las miniaturas de calidad. En este año era vicepresidente de la sección de Bellas Artes y presentó un Retrato en miniatura de Vicente López, que el crítico del Diario mercantil de Valencia consideraba sobresaliente (ROIG CONDOMINA, 1994: 37; "Exposición pública...", 1842: 3; "Crónica del Liceo", 1841-1842: 524-527). Curiosamente, el propio Rafael Montesinos fue retratado por otro miniaturista, obra que también figuró en esa misma exposición de 1842. Se trataba de una pintura realizada por el ya conocido Miguel Vicente y Almazán, autor del retrato del presidente del Liceo. Roig Condomina (1994: 41) creía que la realización de este retrato se debía a que Vicente Almazán podría ser o haber sido discípulo de Rafael Montesinos, aunque la actividad de ambos artistas dentro del Liceo podría también ser un motivo de peso para considerarlo vinculado a la propia sociedad. De la obra solo conocemos la crítica publicada en Liceo valenciano, donde se decía que "el retrato de que hablamos a más del parecido reúne delicadeza y propiedad de colorido, finura de pincel y toques vigorosos y decididos en las ropas" ("Crónica del Liceo", 1841-1842: 526).

En la larga lista de retratos no identificados mencionados en esta reseña, podría aventurarse que el retrato presentado por José Felipe Parra Piquer, hijo de Miguel Parra, pudo haber sido el de su padre, ya que se trataba de la primera participación pública del joven artista en el Liceo; sobre el interés de establecer un vínculo directo entre la obra expuesta, especialmente si se trataba de un joven debutante, y otros familiares artistas, ya se ha visto en otros casos el importante papel del retrato; sin embargo, también fue frecuente el uso de la copia de alguna obra de estos: fue el caso del joven Vicente López, que en la exposición del Liceo de 1845, a los quince años, presentó una copia del San José de su abuelo, Vicente López Portaña (ROIG CONDOMINA, 1994: 49). Aunque sabemos que el Liceo contó con gran número de jóvenes artistas, muchos de los cuales se iniciaron en la actividad -artística y social-a través de sus exposiciones, como el joven Vicente López, José Felipe Parra, Juan de la Cruz Martí o José de Llano y White, con los cuales la crítica siempre se mostraba indulgente con la intención de animarles en el desarrollo de su carrera, su presencia en el Liceo se debía a los vínculos 
establecidos bien con socios liceístas de su misma familia, bien con otros socios artistas de los que eran discípulos.

Con la sección de Bellas Artes en clara decadencia, aún hubo un intento por revivir su actividad con la exposición de 1845. En ella, José Felipe Parra presentó un retrato realizado en tinta china y destinado a ser grabado [fig. 185], del poeta vinculado al Liceo Vicente Boix (GARCÍA CADENA, 1846: 162; ROIG CONDOMINA, 1993: 459).

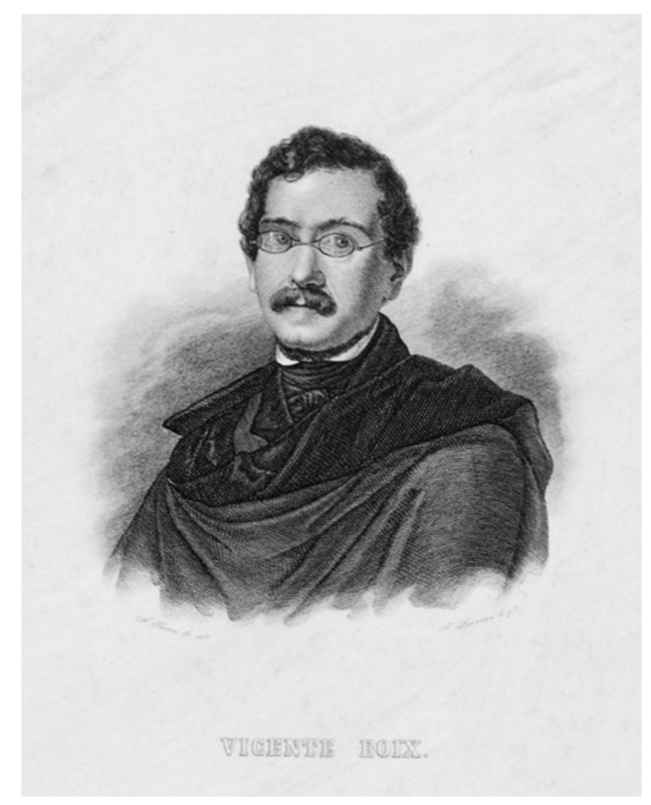

Fig. 185. Felipe Parra (dibujo), Facundo Larrosa (grabado), Retrato de Vicente Boix, 1850. Estampa. Biblioteca Valenciana (Grab/536).

3.1.2.2. Dos retratos de socios fallecidos: los casos de Antonio Cavanna y Luis Laulhé

Además de los que figuraron en las exposiciones del Liceo, tenemos noticia de dos casos singulares en los que la muerte y el carácter conmemorativo centran la producción de dos retratos que fueron especialmente significativos debido, precisamente, a que se trató de iniciativas promovidas en el seno de la sociedad y dedicada a dos de sus socios.

El caso más conocido es el del pintor Antonio Cavanna y Pastor, discípulo aventajado de Vicente López, que fue pensionado en Madrid y falleció de manera prematura en 1840. La vinculación de Antonio Cavanna con el Liceo valenciano se inicia apenas un año antes, en 1839, al participar en las sesiones de competencia realizando apuntes de las funciones teatrales ${ }^{505}$ y mostrar algunas de sus obras en las exposiciones de la sociedad (ALBA PAGÁN, 2003: 90), por lo que fue designado por la sociedad como una joven promesa para el arte valenciano. Su muerte supuso un golpe inesperado y el Liceo Valenciano se movilizó para rendirle tributo, convocando a los socios, y especialmente a los presidentes de las distintas secciones, a concurrir al funeral

\footnotetext{
505 Sabemos de su actividad en algunas sesiones, como en la de febrero de 1840, en la que realizó un boceto al óleo representando dos figuras (“Liceo. Sesión Ordinaria...”, 1840: 21).
} 
que debía celebrarse el 9 de abril de 1840 en la parroquia de los Santos Juanes ("Liceo Valenciano", 1840: 4). Sin embargo, al no haberse podido realizar dicho funeral por motivos desconocidos, el redactor de El Cisne (1840/09/04: 65) informaba de la intención de los socios del Liceo de reunirse para tratar "del último tributo que debe ofrecer a tan digno artista".

Este tributo tuvo finalmente la forma de una función fúnebre, que se celebró el cuatro de julio de 1840, en la que participaron las distintas secciones del Liceo, y en la que se rememoró al artista a través de un retrato póstumo pintado específicamente para la ocasión. La obra fue realizada por el pintor Antonio Gómez Cros, discípulo, al igual de Cavanna, de Vicente López, y compañero del malogrado artista como pensionado en Madrid. Fermín Gonzalo Morón (1840: 1-2) daba cuenta en el Diario Mercantil de Valencia del aspecto del salón de juntas extraordinarias de la sede del Liceo en el antiguo convento del Temple:

La sección de bellas artes diseñó una paleta que circundada de laurel y ejecutada en mármol de Génova, se había fijado en uno de los testeros del salón de juntas extraordinarias con la inscripción siguiente: El Liceo valenciano a la memoria de D. Antonio Cabana. Coronas de laurel se hallaban colocadas en la parte superior de la lápida, y la inferior estaba ocupada por el retrato del malogrado pintor, que el distinguido artista D. Antonio Gómez ha ejecutado con una perfección y delicadeza sorprendentes, sin otra guía que su imaginación, sus recuerdos, su pura y ardiente amistad.

Este retrato pasó a formar parte de la colección del Liceo valenciano y hemos de suponer que adornaría su Sala de Juntas como recuerdo perenne del artista, ya que Antonio Gómez lo regaló al Liceo, como señala el mismo Fermín Gonzalo Morón (1840: 2), por lo cual se hizo "digno con ello de la simpatía y de la gratitud de todos sus individuos que por unanimidad y con aplauso le han nombrado socio del mismo, a propuesta de la sección de Bellas Artes". Efectivamente, Antonio Gómez Cros fue nombrado socio honorífico del Liceo Valenciano por esta obra, además de constar en el momento de la realización del retrato como socio de la sección de Bellas Artes del Liceo Artístico y Literario de Madrid. Vicente María Roig Condomina cita este retrato y señala que fue encargo del Liceo; no obstante, Alba Pagán (2003) no lo menciona en su artículo sobre el pintor Cavanna, ni Gil Salinas (1992: 169-173) lo cita entre la producción de Gómez Cros. Lamentablemente, no ha sido posible localizar esta obra, cuya historia nos es desconocida tras la disolución del Liceo.

Un caso menos conocido es el del retrato de Luis Laulhé, quien fallecía a los 22 años en 1841. Es fácil adivinar los motivos de este olvido, ya que el joven Laulhé, poeta aficionado, pertenecía a la sección de Literatura del Liceo valenciano, y su retrato no figuró en las exposiciones de la sociedad. Juan Llácer fue el autor de una obra realizada, nuevamente, de memoria ${ }^{506}$, y que fue presentada públicamente en una sesión celebrada

506 "Un recuerdo empañaba nuestra alegría, haciendo asomar a nuestros ojos las lágrimas del sentimiento: el retrato en traje de abogado de nuestro consocio y amigo Don Luis Laulhé, pintado de memoria, después de su muerte, por D. Juan Llácer, nos mostraba toda la fría crueldad del destino que cortó a los veintidós años una vida llena de vigor, de talento y de esperanza" (D., 1841-1842: 32). 
en enero del 1841. La noticia sobre la presencia de esta obra fue recogida por el periódico del Liceo, que informaba de que se trataba de un retrato póstumo destinado a ser una efigie para la memoria; en ella aparecía representado en traje de abogado, lo que indicaba los estudios, apenas recién finalizados, del joven poeta, así como una posición social holgada a través de su identidad profesional. No cabe duda de que, además de la vinculación afectiva entre consocios en el Liceo valenciano, Juan Llácer también tuvo en cuenta su relación con el padre del malogrado joven, José María Laulhé, quien había compaginado sus labores políticas y militares con los cursos seguidos en la Real Academia de Bellas Artes de San Carlos.

La breve historia del Liceo Valenciano y la escasez de fuentes gráficas impiden establecer muchas conclusiones; al igual que en la sociedad madrileña, los artistas valencianos vieron en las sesiones del Liceo un escenario en el que dar pie a una forma provechosa de ocio. Sin embargo, no se observa un especial interés por negociar un papel privilegiado de los artistas en el Liceo ni una presencia llamativa de retratos de artista, lo que indica que, al margen de ser una sociedad de recreo, el Liceo no contribuía en exceso a afianzar la identidad profesional del artista. La expresión de los vínculos de amistad se puede observar en los casos de Montesinos y Vicente Miguel Almazán, quienes exhibieron ante sus consocios una muestra de afecto hacia sus maestros. Tan solo dos retratos revisten un matiz de singularidad en la reafirmación de la identidad de Lorenzo Isern y en el homenaje fúnebre a Antonio Cavanna, que manifiestan un menor calado del culto al genio y de la necesidad de reafirmar la identidad masculina del artista por parte de la élite cultural valenciana.

\subsubsection{El Liceo Artístico y Literario de Sevilla (1838)}

Al igual que el Liceo valenciano, la sociedad creada en Sevilla en 1838 copió los objetivos y estatutos del Liceo madrileño. El ideal de crear una comunidad de artistas quedó también reflejado en la prensa, que lo vinculaba en términos análogos con una fraternidad a favor del fomento de las bellas artes ("Liceo en Sevilla", 1838: 144) y con una academia informal (M., 1838: 57-58), lo que se hacía patente en la celebración de sesiones de competencia desde el 9 de abril de 1839 (VELÁZQUEZ Y SÁNCHEZ, 1872: 483) y en sus exposiciones mensuales de pintura (PÉREZ SÁNCHEZ, 2005: 311312). El Sevillano iba incluso un paso más lejos y definía el Liceo como "una reunión donde cada cual da un poco de lo que sabe en cambio de otro poco de lo que ignora, (...) la reunión de todo lo bello, el conjunto de todo lo que la naturaleza ha inspirado a las almas privilegiadas" (“Andalucía”, 1841: 4). Se refería así, en términos similares a los de Fernández de la Vega y Escosura, al nuevo privilegio del genio y la inteligencia, así como a su misión civilizadora, tal como lo recordaba José María Asensio durante la inauguración en 1875 del Nuevo Liceo Sevillano (LICEO SEVILLANO, 1875: 18).

Entre los artistas que se vincularon al Liceo puede mencionarse a Joaquín y José Domínguez Bécquer, Antonio Cabral Bejarano, Manuel Rodríguez Guzmán y Manuel 
Barrón, a los que debe sumarse también la participación de Antonio María Esquivel ${ }^{507}$, cuyas obras figuraron en más de una exposición. Entre otros socios de los que hay noticia en las reseñas de las sesiones y exposiciones, a falta de listas de socios, encontramos a Agustín Mendoza, Castañeda, Santibáñez, y aficionados como Tomás Morales. Respecto a Antonio María Esquivel, sabemos que regresó a Sevilla en 1839 con motivo de su ceguera. Su presencia en las sesiones del Liceo sevillano parece reducirse a la presentación de obras, pero no a la participación directa, al menos hasta la completa restitución de su salud. Así, presentó los retratos de María Cristina e Isabel II, que ocuparon el testero en la celebración que el Liceo realizó con motivo de los días de la Regente, así como varios retratos de personajes desconocidos (LA REDACCIÓN, 1838/29/07: 108). Las sesiones del Liceo, cuyo esplendor variaba en función de la participación de los socios, se vieron también sujetas a los vaivenes políticos, que motivaron al menos en dos ocasiones el cierre temporal de la sociedad.

La escasa actividad de la sección de Pintura fue recogida de manera esporádica por la prensa, ya que privaba a los consocios sevillanos de un bello rato ${ }^{508}$, lo que sin duda indica el carácter de entretenimiento cultural con el que era percibido por la burguesía local. Sin embargo, parece que los artistas gozaron de una buena consideración dentro del Liceo sevillano y que gozaron de un ambiente de cortesía y coqueteo al convertirse en el objeto de la admiración de las damas que concurrían a la sociedad; por su parte, la presencia femenina parece estar justificada, según la prensa, en su papel ornamental y de inspiración para los artistas, al lucir "sus encantos para ostentarlos en nuestro Liceo y para dar inspiraciones al poeta y aplausos y coronas al músico y al pintor" ("Liceo de Sevilla, 1841: 45). Por otra parte, la percepción que se tenía de los artistas en el Liceo era la propia de los caballeros de la mejor sociedad, según El Paraíso, que puntualizaba que el artista de fama, es decir, aquel introducido en el ámbito privilegiado y elitista, debía ser "tan bien mirado como el más opulento señor y aun más” (M., 1838: 37).

Los roces entre el orgullo de algunos pintores y la crítica también estuvieron presentes, como ejemplifica la réplica que Agustín Mendoza hizo públicamente ante la calificación de uno de sus retratos, presentado a la sesión del 8 de mayo de 1841, de "pobre de dibujo". Mendoza hacía notar en sus palabras su opinión de que el nuevo protagonismo social del artista en espacios de ocio, como era el Liceo, hacía que la crítica acre e ignorante estuviese dotada de un escenario para producir el "desconcepto [sic] y la ruina de un artista"; además, buscaba reparar el daño que por ella había sufrido su imagen ante el público, “demasiado apreciable para perderla como quiera, y

\footnotetext{
507 Así, por ejemplo, El Nuevo Paraíso recogía una de las sesiones, en la que "pintaron con la facilidad que le es propia al que posee bien un arte, los Sres. Bejarano, Bécquer don José, Romero, Rodríguez, Barrón, Esquivel, Bécquer don Joaquín, y Roldán. Presentó el célebre artista Esquivel muchos cuadros y muy buenos" ("Liceo", 1839: 72).

${ }^{508}$ De la sesión del ocho de junio de 1838 se decía, por ejemplo, que "disgustó la frialdad que se notaba en la sección de pintura" (L.R., 1838/17/06: 36), y de la del trece del mismo mes que la juventud exitosa permaneciese silenciosa "sin dar muestra de sus talentos; sentimos que aconteciese esto mismo a los Sres. que componen la sección de música y pintura” (La Redacción, 1838/24/06: 48).
} 
más por quien funda en ella su subsistencia ${ }^{509 "}$ (MENDOZA, 1841: 180-181). Mendoza revela de este modo que el prestigio social, real o pretendido, en pequeños círculos de sociabilidad no constituían la realidad profesional del artista, pero da cuenta de cómo al convertirse en un escenario público es también una extensión del mercado de influencias que afecta a reputaciones profesionales ya de por sí vulnerables.

El Liceo sevillano, más vinculado a los temas de costumbres, no presentó entre sus obras grandes composiciones originales de historia o religión, algo que se achacaba al retraso en la apertura de un Museo Provincial de Bellas Artes, pero también a la intención de continuar con la escuela pictórica sevillana; el retrato también fue un género muy practicado, aunque las noticias aparecidas en la prensa no permiten hablar de una gran producción de retratos de artistas o de liceístas. Esta ausencia se explica por las dificultades que atravesó la sociedad sevillana, a raíz por una parte de sus repentinos cierres y por otra de las dificultades para encontrar un local estable en el que asentarse. Las noticas cotejadas a través de la prensa periódica, como El cisne, El paraíso o la Revista andaluza, que en la primera mitad de 1841 fue el órgano del Liceo sevillano, tampoco arrojan datos concisos sobre los retratos ni la identidad de los retratados en las exposiciones, de manera que es posible que el retrato de artista y el derivado de la sociabilidad liceísta tuviesen una mayor presencia de la que conocemos, sin descartar que investigaciones más exhaustivas de las fuentes primarias puedan aportar información más completa al respecto.

Queda constancia de la realización del retrato del compositor Miguel Hilarión Eslava, de la sección de música, con motivo de la sesión de competencia que se realizó en su honor el 3 de julio de 1841:

La sección de pintura contribuyó muy eficazmente también a celebrar las glorias del artista músico. El retrato de este ejecutado por el Sr. Roldán estaba tan bien hecho como bien parecido, y todos los ojos se dirigían a esta obra que mereció la aprobación de los concurrentes. Conocíase sin embargo que había tenido corto plazo para hacerlo ("Variedades", 1841: 271-272).

Según Velázquez y Sánchez, Sevilla ya había honrado a Hilarión y Eslava con una sesión en 1840, en la que otro artista vinculado al Liceo realizó el retrato que se distribuiría. "Estrenada esta obra del maestro de capilla en nuestra catedral la noche del martes, 7 de septiembre, produjo un efecto indescriptible; dando la empresa al favorecido autor un beneficio el sábado, en el cual sus admiradores y amigos hicieron repartir su retrato, dibujo de Rossi” (VELÁZQUEZ Y SÁNCHEZ, 1872: 536). El retrato, realizado por el joven pintor José Roldán, podría haberse realizado en el propio Liceo, del que Hilarión Eslava era presidente de la sección de Música, ya que la iniciativa parece surgida de la propia sociedad; la fama del artista y su reconocimiento por el éxito alcanzado en Cádiz con la ópera El solitario del Monte Salvaje-son en este caso la causa principal de la realización del retrato. La obra debía colocarse en lugar de

\footnotetext{
${ }^{509}$ A este comunicado respondía la redacción de la Revista andaluza en tono cordial, haciendo notar a Mendoza que el juicio del articulista no había sido precipitado, sino que se había formado tras consultar con otros distinguidos pintores del Liceo sevillano.
} 
honor en la exposición y se consideró "digna del artista que lo ha ejecutado", por lo que constituyó el tributo que la sección de Pintura rendía al compositor, al que contribuirían las demás secciones con sus correspondientes obras. Sin embargo, no parece que se realizase ningún acto especial para homenajear a ningún artista pintor dentro del Liceo que pudiese conllevar la realización de sus retratos; ni siquiera en el caso del difunto artista José Domínguez Bécquer, cuyo fallecimiento, acontecido en enero de 1841, no dio pie a ningún tributo en la sociedad. Así lo señala la propia Revista andaluza ${ }^{510}$, donde se indicaba que aun así algunas de sus obras continuaron figurando en las exposiciones del Liceo. Por otra parte, El corresponsal recogía que en la sesión del cinco de marzo, la primera tras ocho meses de inactividad, se pudieron ver los últimos cuadros "que pintó el malogrado D. José Bécquer, el pintor por excelencia de las costumbres anteriores" (“Andalucía”, 1841/14/03: 4), algo que tal vez deba interpretarse como un pequeño homenaje en el que, al parecer, no figuró el retrato del artista.

El autorretrato tuvo escasa proyección en las exposiciones del Liceo sevillano. Tan solo se cuenta con dos noticias al respecto, ambas de 1841. Antonio María Esquivel expuso su propio retrato en la sesión de cinco de marzo ("Andalucía”, 1841/14/03: 4), junto a otras tres obras que remitió (un Retrato de militar, un San Juan y una Vista de la calle de la Amargura). Al parecer, se trató de la última sesión a la que acudió en la sociedad sevillana, ya que días más tarde se recoge su vuelta a Madrid, completamente restablecido (El correo nacional, 1841/18/03: 4). Resulta curiosa la aparición de este autorretrato ya que, de ser verídica la noticia, se trataría del primero que el artista exponía públicamente; sorprende también debido a la escasa relación que el pintor mantenía con la sociedad sevillana, a cuyas exposiciones había enviado obras durante su estancia en Sevilla, sin que quede constancia de su presencia en las sesiones. Podría tratarse de la manera en que Esquivel agradecía al Liceo sevillano el apoyo prestado durante su enfermedad, ya que la sociedad hispalense, siguiendo el ejemplo de Madrid a quien regalaría La caída de Luzbel como agradecimiento-, también realizó una sesión en beneficio del pintor. Sin embargo, el hecho de que solo aparezca recogido en una fuente puede implicar un error de interpretación por parte del autor de la reseña, al tratarse las obras expuestas por Esquivel de retratos de su mano, pero no representando su propia imagen, hipótesis que nos parece la más acertada.

Frente a este retrato de un artista reconocido, la segunda noticia corresponde por el contrario a un artista aficionado perteneciente a la sección de Pintura, Tomás Morales. Se trataba de "un cuadro de familia, perfectamente hecho y en el cual, más que la composición brilla la ejecución en general, pues los retratos están muy bien imitados y con especialidad el del mismo Sr. Morales, que parecía querer hablar y salirse del cuadro" ("Liceo de Sevilla", 1841: 312). Mediante este retrato familiar, en el que Morales se incluía, el liceísta no buscaba únicamente un reconocimiento de su faceta de pintor -algo que, desconociendo la iconografía de la obra, no puede descartarse-, sino

510 "Del difunto Bécquer había dos cuadros, que nos trajeron vivamente a la memoria su prematura muerte, uno de ellos era un retrato de señora, bien ejecutado y otro de costumbres, sobresaliente, en cuyo género era inimitable. Sentimos que el Liceo no haya hecho algunas demostraciones por su pérdida, y aconsejamos a sus individuos se sirvan tomar en cuenta esta indicación" ("Liceo de Sevilla", 1841: 312). 
más en concreto una proyección de sí mismo, y de su estatus social. Parte de esta voluntad de ostentación se desprende del hecho de que Morales eligiese la exposición en honor a Hilarión Eslava para presentar su obra.

\subsubsection{El Liceo Granadino frente a otras sociedades recreativas: el caso de La Cuerda.}

Si los casos provinciales anteriormente estudiados evidencian la asimilación de las modas procedentes de Madrid y unas formas de sociabilidad vinculadas a la alta burguesía, el caso granadino llama la atención por el desarrollo que el retrato cobra dentro de su Liceo, así como por la pluralidad de sociedades contemporáneas a él que revelan otras prácticas sociales de carácter recreativo, con un despliegue masculino atípico y un curioso uso del retrato.

Granada acogió, entre 1839 y 1842, su correspondiente Liceo Artístico y Literario como asociación vinculada a la cultura burguesa y a la buena educación, en la que se celebraban sesiones de competencia y exposiciones. A ellas concurrieron artistas como Cecilio Corro, Luis Frasquero, Andrés Giuliani, Manuel Noguera, los arquitectos Juan Pugnaire y Francisco Enríquez, y los escultores Manuel González, José Vilches y Manuel de Salas, además de numerosos pintores aficionados de ambos sexos ${ }^{511}$. Respecto a los retratos de socios o socios artistas en el Liceo de Granada, contamos con algunas noticias procedentes del que fue el órgano de difusión del mismo, el periódico La Alhambra. Al parecer, el retrato fue el género por excelencia en la exposición inaugural, especialmente al lápiz o en miniatura, entre las que destacaban cinco presentadas por Cecilio Corro. Luis Fernández-Guerra y Orbe, pintor aficionado pero uno de los más activos en las sesiones del Liceo, presentó un retrato a la acuarela del tenor Manuel Ojeda Manti, en el que se alabaron "la pureza del dibujo, la delicadeza del pincel, la suavidad de las tintas, y la elegante y poética posición que le ha dado al cuerpo", así como "aquella cabeza llena de vida y expresión y aquella mirada arrebatadora" ("Solemne apertura del Liceo...", 1839: 282); el pintor escenógrafo José Llop contribuyó con un autorretrato al óleo ("Solemne apertura...", 1839: 282) del que no se ofrecen más noticias y que Caparrós Masegosa (1992: 430-431) no menciona entre las obras de esta exposición. El autor de la reseña de esta primera exposición echaba en falta entre las obras de esta exposición un retrato realizado por el pintor sevillano Antonio Cortés del arquitecto Salvador Amador ${ }^{512}$, y señalaba respecto a otras obras que muchas de ellas fueron legadas de manera desinteresada al Liceo, por lo que es de suponer que formaron parte de la decoración del local.

\footnotetext{
${ }^{511}$ Los estatutos del Liceo señalaban tres clases de socios (profesores, socios y corresponsales), lo que incluye a las señoras, que podían pertenecer a cualquiera de las tres. Sin embargo, mientras los sociosprofesores tenían la obligación de contribuir con sus conocimientos en las tareas del Liceo, ninguna obligación recaía en las socias, aunque perteneciesen a la misma clase de profesoras ("Liceo de Granada", 1839: 129-130; SANTOS MORENO, 1997: 172; PÉREZ SÁNCHEZ, 2005: 315-317).

512 "Extrañamos no ver el retrato que hizo [D. Antonio Cortés] de nuestro amigo D. Salvador Amador, que es muy bueno; pero nos figuramos que la modestia de este no le permitiría exponerlo" ( "Solemne apertura del Liceo", 1839: 279).
} 
En la segunda sesión de competencia, en la que se realizó también un pequeño homenaje a Antonio María Esquivel mediante la exposición de tres de sus retratos y la lectura de algunos versos en su honor, tuvo lugar una exhibición de obras de algunos liceístas, entre los que destacaba un retrato al lápiz de Dolores Gómez de Cádiz de Velasco, joven malagueña y socia de la sección de literatura, realizado por Luis Fernández-Guerra y Orbe. Esta obra "de un exacto parecido y del mayor mérito" (“Segunda sesión de competencia...”, 1840: 351-352) fue regalada al Liceo, por lo que cabe imaginar también que permanecería en sus colecciones hasta su disolución.

Durante la segunda exposición del Liceo se pudieron observar al menos dos retratos de liceístas: uno de ellos era el realizado al óleo por el italiano Andrés Giuliani del director de la sección de música, Juan Bautista Salazar ("Exposición del día 23...", 1840: 506), y de su esposa, del que se señalaba positivamente el efecto de claroscuro, el uso de las tintas y la franqueza del estilo. Luis Fernández-Guerra y Orbe expuso un retrato del actor Julián Romea ("Exposición del día 23...", 1840: 506), quien figura documentado en el Liceo de Granada desde su inauguración hasta su partida de la ciudad en marzo de 1840; la pintura se alabó por su parecido y por la elección de la postura. Por el contrario, la identidad de los dos retratos al óleo que se exhibieron en el salón del Renacimiento del Liceo en la sesión de competencia del 13 de junio de ese mismo año es desconocida, aunque sí consta que sus autores fueron Francisco Enríquez y José Bordonava ("Sexta sesión mensual...", 1840: 144), al igual que sucedió con el retrato presentado por Luis Fernández-Guerra y Orbe a la exposición de la sesión de competencia de 24 de julio. De la última muestra de 1840, celebrada el 9 de diciembre, formaron parte los retratos, pintados por Antonio María Esquivel, del liceísta Francisco Castillejo y su esposa, realizados probablemente por encargo de esta pareja al margen del Liceo, así como la acuarela, obra de Luis Fernández-Guerra y Orbe, de Salvador Andreo (AMADOR, 1840: 444), personaje del que únicamente conocemos su profesión en el ámbito de las leyes, y al que encontramos reiteradamente en las reseñas de las sesiones del Liceo participando como tenor.

Es posible que la actividad de bellas artes decayese notablemente a partir de 1841, como recoge con cierto tono humorístico una composición poética publicada en $L a$ Alhambra $^{513}$ en agosto de ese año. La sección, presidida por Juan de Herrasti, y que contaba con José Llop y José O'Laulor como consiliarios y Vicente Sánchez Flores y Manuel González como secretarios (La Alhambra, 1841/10/01: 24), espacia cada vez más las exposiciones y toma la resolución de realizar únicamente tres anuales para que las obras presentadas fuesen más acabadas ("Sesión de competencia...", 1841: 49) y, aunque el retrato es en ellas el género más abundante, lo más habitual es que se oculte la identidad de los efigiados. Entre ellos destaca uno realizado por el ya conocido Luis

\footnotetext{
513 "En la segunda [sección] noto / pocos progresos / y es sección numerosa / según entiendo. / Los mismos nombres / se ven siempre en sus cortas / exposiciones" (SALAZAR, 1841: 369). Más rotundo, aunque seguramente irónico, se mostraba Nicolás de Roda en noviembre de ese año, cuando hablando de la sección de artes decía que "hace mucho tiempo que ni aun se ha abierto la habitación donde debían hacer sus ensayos" (RODA, 1841: 58).
} 
Fernández-Guerra, representando a otro liceísta: el poeta y redactor principal de $L a$ Alhambra, Manuel Cañete (E. R., 1841: 156).

Es interesante respecto a estos retratos que la mayoría de ellos fueron realizados en las propias sesiones del Liceo, de modo que la práctica artística animaba ese espíritu de sociabilidad. Surge la duda sobre si fue el carácter de la sociedad, mucho más modesta que la de los grandes Liceos de Madrid, Valencia y Sevilla, lo que propició este acercamiento entre los socios mediante el retrato. En el caso del que representaba a Dolores Gómez de Cádiz de Velasco, es muy probable que fuese realizado en la propia inauguración del Liceo, ya que esta participó en la sesión de apertura declamando sentidos versos ("Segunda sesión...", 1840: 353); en el del poeta Cañete queda claramente de manifiesto, como testimonia la crónica de la sesión semanal del Liceo, donde se describe cómo "en la sección de artes, en fin, trabajando diversos objetos unos de capricho, y otros copiados del yeso, señalándose muy particularmente nuestro amigo el señor Fernández Guerra, que durante la sesión hizo el retrato al lápiz de nuestro fecundo poeta el señor Cañete, admirablemente" (L. R., 1841: 156). El retrato del tenor Manuel Ojeda se obtuvo, muy probablemente, durante la visita de este a Granada el 30 de julio de 1839, tal y como recoge la propia revista La Alhambra, en una crónica de teatros firmada por Salvador Andreo (1839: 95-96); este posado previo a la instauración oficial del Liceo, así como su temática cultural, justifica su presencia en la exposición inaugural del Liceo y lo excluye como fruto de las sesiones de esta sociedad. Además de estas obras, se tiene noticia también del dibujo al lápiz del marquesito de Caicedo por Leopoldo López, en la sesión de competencia del 29 de marzo, "exactamente parecido" ("Sesión semanal...", 1841: 186), presentado a la exposición de la sesión del 13 de julio de 1841 (“Sesión general...", 1841: 347-348), donde figuraba con el nombre del marqués, Alonso Mesía.

Las relaciones fluidas de amistad y fraternidad entre los socios se ponen continuamente de manifiesto en las páginas de La Alhambra, donde encontramos a miembros de las distintas secciones trabajando en común, como ocurrió con el homenaje al presidente de la sección de Literatura, José Valero, obsequiado con una obra de Vicente Sánchez Flores ("Una ofrenda concedida...", 1841: 179), así como en los trabajos de construcción del teatro para las representaciones de la sección de declamación, cuyas decoraciones fueron realizadas por los socios de la sección de $\operatorname{artes}^{514}$. Esta amistad se observa también en las dedicatorias de poemas, como hacía Manuel Cañete (1841: 372) al pintor Leopoldo López.

La temprana desaparición del Liceo en 1843 daría pie al nacimiento de otras sociedades de índole similar, la primera de las cuales sería la Sociedad Literaria y Artística de Granada (RODRÍGUEZ BAILÓN, 2006: 143-166), cuya corta vida solamente duraría entre 1846 y 1849. Contó, al igual que el Liceo, con una sección de artes integrada por hombres y mujeres, y realizó al menos dos exposiciones públicas. El

\footnotetext{
${ }^{514}$ Entre ellas se mencionan los retratos de Calderón y Lope de Vega, realizados en yeso por Luis Fernández-Guerra, o los decorados dirigidos por José Llop ("Primera representación dramática ...", 1841: 248-252).
} 
hecho de que muchos de sus socios procediesen del desaparecido Liceo, así como el alto número de retratos que constan en las reseñas de las exposiciones podría indicarnos nuevamente que surgieron como fruto de esa sociabilidad; no obstante, la mayor parte de estas obras no fueron identificadas en las reseñas. El único retrato que podemos confirmar como de un miembro de la sociedad es el autorretrato de José Aguilera, en el que se presentaba con los atributos de pintor ante un piano, como recoge María Dolores Caparrós (1992: 434) a partir de la crónica aparecida en El álbum granadino ("Bellas Artes. Exposición...", 1849: 30-31). A pesar de que la sociedad perviviría hasta 1880 bajo el nombre de Nuevo Liceo, su sección de Bellas Artes entraró rápidamente en clara decadencia.

Frente al espíritu claramente burgués y oficial de esta sociedad, algunos de los propios liceístas y de los miembros de la Sociedad Literaria y Artística formaron otra sociedad $^{515}$, más próxima por su carácter bromista a una tertulia informal que a la rigurosa etiqueta de otras asociaciones; formada por escritores, músicos, escultores y pintores -profesionales o aficionados-, fue una sociedad de carácter masculino, si bien a algunas de sus tertulias también acudían mujeres, lo que dio pie a que sus miembros explotaran un tipo de masculinidad vinculada con la excentricidad, el ruido y el humor con que se venía vinculando el ingenio artístico, tal y como había sido frecuente entre los tertulianos del Parnasillo.

Un rasgo definitorio de esta sociedad es que sus miembros se trataban unos a otros mediante apodos y que, al carecer de sede fija, se reunían en cafés o en la casa de los hermanos José y Mariano Vázquez Gómez. Entre los artistas que frecuentaron esta tertulia-sociedad se cuentan los arquitectos Julio Dutel, francés de origen y conocido como Agosto, y el ruso Pablo Notbeck, a quien dieron el nombre de Brique; entre los pintores se encontraban José González Bande (El Pintaor), Eduardo García Guerra (Barcas), Gaspar Méndez (Ocasión), el dibujante Miguel Pineda Montón (Vílchez), Eduardo Sorokin, de nacionalidad rusa y cariñosamente denominado Qué Importa, y José Vázquez Gómez (Sidonia), además del aficionado José Fernández Jiménez (Ivón). La historia de esta sociedad-tertulia (VARGAS LIÑÁN, 2015; GALLEGO ROCA, 1991; LEÓN y CASCARES, 1928), rescatada en buena medida a través de las memorias de algunos de sus miembros (especialmente Miguel del Palacio), parece una imagen algo deformada en la que, como señala Vargas Liñán (2015: 58), sus protagonistas se autorrepresentan como jóvenes excéntricos, ruidosos y fuera de la norma, con la manifiesta voluntad de destacar mediante su carácter virilizado y provocador respecto a la seriedad y civilidad de otros círculos sociales y del ideal masculino del caballero burgués; se emplearon para ello tertulias disparatadas, en las que el humor jugaba un papel importante, y donde también eran recurrentes las actitudes galantes hacia las mujeres, de las que se conocen ejemplos, como el del ruso Sorokin, o las frecuentes serenatas con las que algunos "nudos"

\footnotetext{
${ }^{515}$ La Cuerda granadina adoptó algunos recursos propios de las sociedades, como la elaboración de un libro de actas que registrase, de manera claramente informal y humorística, la actividad de la misma.

${ }^{516}$ Con este nombre se conocía a los miembros de La Cuerda.
} 
De especial interés para nuestro estudio son los dos álbumes manuscritos que se conservan en el Museo-Hemeroteca de la Casa de los Tiros en Granada, realizados en 1853 y 1854 a modo de actas por los propios "nudos", ya que son un testimonio de la actividad creativa de La Cuerda. En sus hojas se reunieron composiciones poéticas, musicales, chistes y, especialmente, numerosos dibujos entre los que se encuentran caricaturas y retratos, compuestos todos ellos durante los encuentros de la tertulia, aunque también se incorporaron algunas aportaciones enviadas por los nudos instalados en Madrid.

Uno de los dibujos incluidos en este álbum, realizado a plumilla por Vilchez (Miguel Pineda Montón), nos presenta un curioso retrato de grupo [fig. 186] ${ }^{517}$. La escena parece representar a los "nudos" retratándose entre ellos: sentados ante una mesa se encuentran cuatro personajes, uno de los cuales ha sido tachado; en la figura de la izquierda, vestida con sotana y en alusión, por tanto, a su formación en teología, se puede reconocer a Ivón (José Fernández Jiménez), y frente a él, en el otro extremo de la mesa, un hombre ataviado con sombrero de copa, que podría ser Vilchez (Miguel Pineda Montón). Tanto Ivón como Vílchez aparecen entregados en una tarea afanosa, ya que se encuentran retratando a algunos de sus compañeros. Así, en la mesa descansan algunos pliegos con retratos ya realizados, como el de Puertas (Mariano Vázquez), mientras que Vílchez se encuentra rematando el de Malipieri (Francisco Rodríguez Murciano). Alrededor de los dos improvisados dibujantes se encuentran ocho personajes que, de pie, contemplan la labor o posan para sus compañeros, entre los que se puede reconocer al propio Puertas, Malipieri y Ramón Entrala, así como a otros cuya identidad es dudosa, como podría ocurrir con el personaje situado en el extremo derecho, que tal vez sea Malatesta (Leandro Pérez Cossío). Por encima de sus cabezas, colgando de las paredes, se encuentran los retratos ya realizados, sin que esto impida que se repitan las identidades de algunos de los representados: comprobamos cómo, en efecto, en esta serie de dibujos Malipieri aparece hasta tres veces en la composición, al igual que Puertas, mientras que otros, como Sidonia (representado en el centro y mirando al frente) solo se presentan una vez, ya que no son incluido entre los asistentes a la tertulia.

El carácter espontáneo de este dibujo, en el que algunas figuras se repiten y donde, sin duda, no están todos los "nudos" de La Cuerda, es un testimonio especialmente interesante de la actividad artística de esta tertulia. Al mismo tiempo revela cómo en sus últimos años el dibujo cobra un valor cada vez más importante; las caricaturas de sus miembros son frecuentes a lo largo de las páginas de los dos álbumes, siendo esta imagen de los "nudos" retratándose entre ellos una pequeña galería a medio camino entre el humor de la caricatura y la seriedad de un retrato de grupo.

\footnotetext{
517 Álbum de La cuerda, tomo II (1854), fol. 59 ro. Museo-Hemeroteca Casa de los Tiros de Granada. Vargas Liñán (2015: 325) lo recoge en su inventario como "Nudos retratándose a sí mismos".
} 


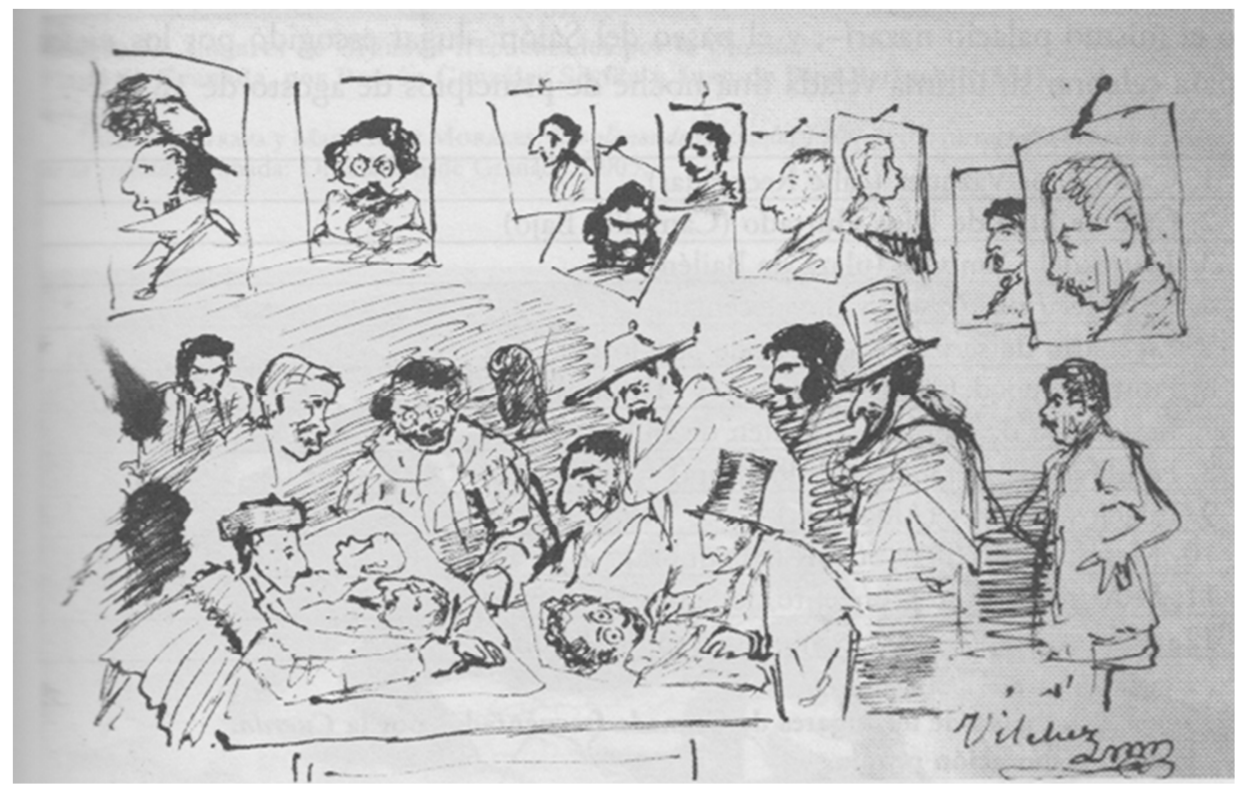

Fig. 186. Miguel Pineda Montón (Vílchez), Nudos retratándose a sí mismos, Álbum de La Cuerda, tomo II, fol. 59r. Museo-Hemeroteca Casa de los Tiros (Granada).

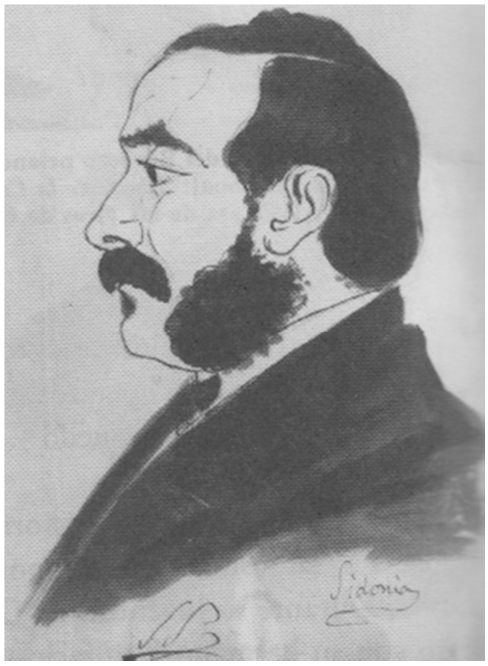

Fig. 187. J. Vázquez, Autorretrato. Álbum de La Cuerda, tomo I. Museo-Hemeroteca Casa de los Tiros.

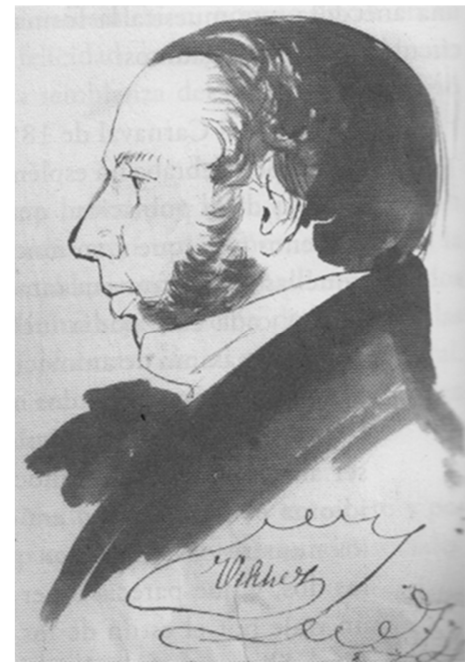

Fig. 188. Miguel Pineda, Autorretrato. Álbum de La Cuerda, tomo I. Museo-Hemeroteca Casa de los Tiros

No es la única representación de los "nudos" como grupo de amigos, ya que un dibujo de Palissade (José Salvador de Salvador) fechado el 25 de octubre de $1853^{518}$ presenta ya a doce nudos -entre los que se puede distinguir a Ocasión (Gaspar Méndez) y al Abate (José Joaquín Soler de la Fuente)- dispuestos en círculo y sosteniendo en sus manos una cuerda. Incluso en fecha anterior ( 7 de junio de 1853) Sidonia realiza un dibujo a la acuarela ${ }^{519}$, insertado posteriormente en el álbum de 1854, en el que presenta a los miembros de La Cuerda dormitando alrededor de una mesa, tal vez exhaustos, mientras descansa abierto sobre la mesa el propio álbum de 1853.

\footnotetext{
${ }^{518}$ Álbum de la Cuerda, tomo I, fol. 66 ro.

519 Álbum de la Cuerda, tomo II, fol. 24 ro.
} 
Por otra parte, conocemos también los retratos de buena parte de los "nudos", lo cual constituye un importante documento gráfico que nos ha permitido identificar a algunos de los representados en el retrato de grupo. De este modo, al final del álbum de 1853 se incluyen en hojas sueltas los de José Salvador de Salvador ${ }^{520}$ y Juan Facundo Riaño ${ }^{521}$ y Montero por Pablo Notbeck, varios retratos sin identificar, como los dos realizados por Miguel Pineda ${ }^{522}$ y los otros dos pintados por Sorokin ${ }^{523}$, los autorretratos de José Vázquez Gómez ${ }^{524}$ [fig. 187], Miguel Pineda ${ }^{525}$ [fig. 188] y Eduardo García Guerra $^{526}$. Además de estos retratos, de los que apenas hemos señalado unos pocos, en el álbum de 1854 se incluyó uno de Pablo Notbeck ${ }^{527}$ por Eduardo García Guerra bajo el título jocoso "El idalgo [sic] castellano. Maestro Yeso". Son retratos de busto, de perfil y en actitud seria, realizados a tinta china con mayor cuidado y esmero en el depurado de las líneas y las manchas que configuran cabellos y levitas.

También son testimonios interesantes del espíritu de fraternidad de la tertulia, aunque con un carácter quizás más anecdótico, los dibujos del álbum en los que se representan las despedidas a algunos de los "nudos" a su partida de la ciudad. Permanecer en Granada o marchar a Madrid en busca de mayor reconocimiento fue la duda constante entre los jóvenes artistas y escritores de provincias. Fue precisamente la segunda opción la preferida por numerosos "nudos", lo que acabó poniendo fin en 1854 a la tertulia granadina. A la partida de Sidonia a Madrid ${ }^{528}$ corresponde un dibujo del álbum de 1853, fechado el 16 de abril, en el que se muestra una diligencia por cuya ventana asoma, autorrepresentado, el emocionado joven, de cuyos ojos caen sendas cataratas hasta el suelo. Por encima de la ciudad de Granada, entre las nubes, sobrevuelan los compañeros de La Cuerda, entonando una despedida mientras dos de ellos sostienen el propio álbum. También a la partida de José González Bande se realizó una velada que pareció acabar como las demás incluidas en el álbum, a pesar de no quedar testimonio gráfico: con el pintor subido en el techo de la diligencia, llorando y saludando a los compañeros que lo despedían (VARGAS LIÑÁN, 2015: 132). De este mismo modo se representó Sorokin en el dibujo que figura su despedida ${ }^{529}$, montado en lo alto de la diligencia y saludando con el sombrero a la procesión de "nudos" que, tras ella, improvisa un concierto callejero.

\subsection{Ateneos Científicos y Literarios}

La instauración de los Ateneos, vinculada al espíritu de regeneración política y cultural, así como a un espíritu de sociabilidad basado en el civismo y el bien común, tiene su punto de partida en 1835 tras el fallido intento del Ateneo madrileño existente

\footnotetext{
${ }^{520}$ Álbum de la Cuerda, tomo I, fol. 249 ro.

${ }^{521}$ Álbum de la Cuerda, tomo I, fol. $250 \mathrm{r}^{\mathrm{o}}$.

522 Álbum de la Cuerda, tomo I, fol. $251 \mathrm{r}^{\mathrm{o}}$ y $252 \mathrm{r}^{\mathrm{o}}$.

523 Álbum de la Cuerda, tomo I, fol. 258 r $^{\mathrm{o}}$ y $259 \mathrm{r}^{\mathrm{o}}$.

${ }^{524}$ Álbum de la Cuerda, tomo I, fol. $253^{\circ}$.

${ }^{525}$ Álbum de la Cuerda, tomo I, fol. $254^{\circ}$.

${ }^{526}$ Álbum de la Cuerda, tomo I, fol. 255 ro.

527 Álbum de la Cuerda, tomo II, fol. $90 \mathrm{r}^{\mathrm{o}}$.

${ }_{528}$ Álbum de la Cuerda, tomo I, fol. $106 \mathrm{r}^{\mathrm{o}}$.

${ }^{529}$ Álbum de la Cuerda, tomo II, fol. $124 \mathrm{r}^{\mathrm{o}}$.
} 
durante el Trienio Liberal. Los Ateneos se constituyeron rápidamente como centros de sociabilidad masculina y culta, lugares propicios para el intercambio intelectual, y también como organismos destinados a la educación e ilustración pública (RUIZ SALVADOR, 1971; VILLACORTA BAÑOS, 1980; ZOZAYA, 2010). Francisco Villacorta (1980: 38) destaca que los Ateneos constituyeron el escenario fundamental en que ideología política y cultura se unieron para manifestar el nuevo poder alcanzado por la burguesía; la exportación del modelo ateneísta desde el núcleo madrileño a las sociedades provinciales seguirá unas pautas similares a las ocurridas con otras instituciones de índole similar, como los Liceos Artísticos y Literarios. No obstante, y debido probablemente a su labor educativa, de un mayor calado social, los ateneos suelen consolidarse como sociedades de vida mucho más duradera que los Liceos, algo que también se puede comprobar en los ateneos provinciales. La faceta que más interesa aquí, ya que el análisis de los ateneos como centros de la sociabilidad culta masculina trasciende el tema de nuestro estudio, es el más estrechamente relacionado con el panorama artístico; los artistas que se vincularon a los ateneos lo hicieron por la existencia en ellos de unas secciones artísticas, pero también, y fundamentalmente, para participar de la vida intelectual, las tertulias cultas y el contacto social que proporcionaban. Es preciso señalar que el papel de los ateneos respecto al arte fue no solo secundario, ya que estos prestaron mayor atención a las ciencias útiles y al progreso en materias jurídicas, filosóficas e industriales, sino también muy desigual en función de las ciudades, por lo que pasó desapercibido en algunos de los núcleos más potentes que contaban con otras sociedades especializadas, sobre todo a partir de los años sesenta del siglo XIX, si bien es cierto que contribuyeron articular en ciertos en otros casos la vida artística de la ciudad mediante la convocatoria de clases, concursos y exposiciones.

\subsubsection{El Ateneo Científico, Literario y Artístico de Madrid}

Desde su fundación en 1835, el Ateneo madrileño contaba con una sección destinada a la Literatura y Bellas Artes, que se desglosó en dos secciones diferenciadas en 1884, momento en que lo artístico cobró autonomía respecto al monopolio ejercido por lo literario hasta 1868. Las noticias respecto a la actividad de la sección no son muy abundantes, con la excepción de los debates que, centrados en el teatro y la literatura, articularon la vida cultural del Ateneo. Podría plantearse cuál fue la presencia efectiva de los artistas en ella ya que, aunque sabemos que algunos artistas frecuentaron el Ateneo, como Jenaro Pérez Villaamil y Federico de Madrazo ${ }^{530}$, no queda constancia de que la sección de Literatura y Bellas Artes proporcionase a los profesores de estas últimas un marco en el que debatir sobre pintura. La fundación del Liceo en 1837, que concentraba la mayor actividad literaria, musical y pictórica, facilitó, como señala Rafael María Labra (1878: 110), el que el Ateneo se dedicase durante las dos décadas

\footnotetext{
${ }^{530}$ La lista de socios de 1836 presenta entre los miembros del Ateneo a los pintores Valentín Carderera, Federico de Madrazo, José de Madrazo y Jenaro Pérez Villaamil (ATENEO DE MADRID, 1836: s.p.); Ruiz Salvador (1971: 67) señala acertadamente a Federico de Madrazo como vicesecretario de la sección, aunque debido a su marcha a París se dio de baja, no constando ni él ni José de Madrazo en la lista de socios de 1837, en la que solo figuran Carderera, Antonio Rotondo y Villaamil (ATENEO DE MADRID, 1837: s.p.).
} 
siguientes al estudio científico y a cuestiones políticas, desvinculándose los artistas de esta sociedad $^{531}$. Quedó así el Ateneo convertido en un espacio intelectual y ameno, en el que buena parte de la sociedad madrileña daba sus primeros pasos profesionales en lo relativo a política, literatura y enseñanza, y pasó a ser el centro en el que se desarrollaba y ponía a prueba la valía de los futuros hombres públicos. Sin embargo, la profunda crisis -especialmente económica- que sobrevino en el Ateneo por culpa de la inestabilidad política, unida a las facilidades que la institución ofrecía (gabinete de lectura, punto de reunión), propiciaron que en 1868 varios artistas pasasen a engrosar la lista de miembros de la sociedad, a la que únicamente pertenecían Enrique Mélida (desde 1863), Carlos de Haes (desde 1864), y Aureliano de Beruete (desde 1866). Así, se incorporaron los pintores Dionisio Fierros, Germán Hernández Amores, Gabriel Maureta, Francisco Mendoza, Vicente Palmaroli y Dióscoro Puebla, que tenían en común una carrera pictórica relativamente consolidada, tras haber pasado por París e incluso por Roma. Serían numerosos los pintores que seguirían su iniciativa, registrándose entre 1869 y 1876 un importante ingreso de artistas en el Ateneo, debido a los privilegios -esencialmente la exención del pago de cuotas mensuales- que conseguían aquellos que realizasen obras para la recién inaugurada galería de retratos. En 1870 ingresaron Cosme Algarra y Vicente Esquivel; en 1872 Ceferino Araujo, Francisco Díaz Carreño, Cristóbal Férriz y Francisco Marchesi; en 1874 Eduardo Balaca, Jacinto Laberón, Federico de Madrazo, Bartolomé Maura, Rafael Monleón, Ramón Mosquera, Miguel Pineda y Luis Taberner; en 1875 Miguel Aguirre, Francisco Aznar, Francisco Jiménez, Agustín Lhardy y Ramón García Espínola; y en 1876 Antonio Hoffmeyer, Vicente Poleró, Manuel Ojeda y José Gonzálvez. El aumento de artistas entre los denominados socios de mérito pudo haber causado malestar entre otros socios; Rafael María de Labra aseguraba que la exención de cuota se había extendido no solo a los 28 profesores que desempeñaban las cátedras del Ateneo, sino también a 43 pintores, expresándose contrario a esta costumbre que había derivado en la existencia de obras de baja calidad en la sociedad y en desigualdades entre los socios:

Tampoco estimo acertada la costumbre introducida por la Directiva de favorecer con aquella exención a los pintores que donan un cuadro. Que con un Suárez Llanos, por ejemplo, se haga después de haber donado cuatro buenos retratos, corriente; pero que esta medida tome el carácter de general me parece un profundo error. Y no quiero decir más. A mi juicio esto debía de reformarse de suerte que obtuviesen la exención, no el pintor que enviara un cuadro o el profesor que desempeñara una cátedra, sí que éste después de cuatro o cinco años de trabajos y aquél después de haber enriquecido la casa con varias muestras de su talento (LABRA, 1878: 196).

La medida dejó de aplicarse en 1876 al reformarse el reglamento ${ }^{532}$, para ser retomada en 1884 con la nueva reforma de este (ATENEO DE MADRID, 1884: 5 y 6). En este período de tiempo entre 1877 y 1884 son escasos los ingresos de artistas en la

\footnotetext{
${ }^{531}$ Así, en el año 1838 cursó baja Jenaro Pérez Villaamil, que no volvería a aparecer como miembro hasta 1847; Carderera y Rotondo dejan de figurar en el mismo año de las listas de socios.

${ }_{532}$ Establecía de este modo que no se podía exceptuar a más de tres socios en un mismo año (ATENEO DE MADRID, 1876: 12).
} 
sociedad; por el contrario, 1884 supone un momento de efervescencia artística debido, por una parte, al cambio de sede del Ateneo al lujoso edificio de la calle del Prado y, por otra, a la pujanza económica y aumento del número de socios, siendo muy numerosos los pintores que figuraban como socios de mérito en 1903. En 1877 habían ingresado el arquitecto y escultor Arturo Mélida, y el pintor Manuel Domínguez; en 1880 Francisco Pradilla y Augusto Comas, y en 1883 Francisco Jover. Se incorporaron en 1884 Tomás Campuzano, en 1885 Juan Espina y Capó, José Grajera, y Juan Luna; en la lista de socios de 1891 figuran ya nuevos artistas, como Eugenio Álvarez Dumont, Luis Álvarez, Ricardo Arredondo, José Benlliure, José Echena, Manuel García Hispaleto, Luis Llanos, José Parada y Santín, Antonio Reina, Manuel Ruiz Morales, Agustín Salinas, Constantino Gómez, Antonio Graner, Enrique Simonet, Silvio Fernández, José Uría, Ricardo Villegas Cordero, Vicente March, José Recio Gil, Francisco Reguera, Pablo Salinas, Francisco Peralta, Juan José Puerto, Justo Millán y Espinosa, Ulpiano Checa, Joaquín Sorolla y Ricardo Villodas ${ }^{533}$. Otros artistas, cuyos nombres curiosamente no hemos encontrado en las listas de socios, colaboraron en las labores artísticas del Ateneo, como Joaquín Espalter, Antonio Gisbert o Isidoro Lozano (OLMOS, 2015).

Las actividades en la práctica artística dentro del Ateneo se dedicaron fundamentalmente a la organización de exposiciones, la formación de la galería de retratos y la decoración de la sociedad. Respecto a las primeras, solo tenemos constancia de la organizada en el año 1879-1880, de carácter benéfico, para ayudar a los afectados por las inundaciones (RUIZ SALVADOR, 1971: 146; "Por caridad", 1879: 3). La noticia recogida por El Globo (“Ateneo", 1879: 3) afirmaba que las obras destinadas a la exposición serían donadas exclusivamente por los pintores socios del Ateneo; una consulta de los artistas que participaron en ella corrobora, en efecto, que no se trató de una convocatoria abierta. Los artistas participantes fueron Enrique Mélida, Bartolomé Maura, Carlos de Haes, José Vallejo, Federico de Madrazo, Ceferino Araujo, Dionisio Fierros, Francisco Mendoza, Vicente Esquivel, Pablo Gonzalvo, Manuel Ojeda, Rafael Monleón, Mosquera, Joaquín Espalter, Carmona, Benicio Navarro, Ignacio Suárez Llanos, Eduardo y Ricardo Balaca, Hoffmeyer, Teófilo Dióscoro Puebla, Gonzálvez, Francisco Díaz Carreño, Aureliano Beruete, Cosme Algarra, Sánchez Blanco y Vicente Poleró. Las obras se instalaron en la Sala de Retratos del Ateneo, como incentivo añadido para que el público decidiese visitar la exposición ("Exposición de cuadros...", 1879: 176; "El salón de la caridad...", 1879: 1). Respecto a la decoración de la nueva sede (inaugurada en 1884 en la calle del Prado), fueron numerosos los artistas que participaron en ella de manera desinteresada, como Mélida, Maureta, Monleón, Beruete, Lhardy, Férriz, Dióscoro Puebla, Laverón y Balaca (GARCÍA MARTÍ, 1948: 166; "Nuevo Ateneo", 1884: 1). El primero llevço a cabo las pinturas de la cátedra, incluido el techo del salón; Maureta decoró la galería; las pinturas

${ }^{533}$ Entre los pintores se encontraban Federico Amutio, José maría Angolotí, Pío Ardanaz, José Arpa, Rafael Arroyo, Juan Antonio Benlliure, Juan Cohiba, Hermenegildo Esteban, Manuel Fernández de Carpio, Juan Francés, Ubaldo Fuentes, José Garnelo, Rafael Hidalgo de Caviedes, Ricardo de Madrazo, Maximino Peña, Vicente Poveda, Julio Rodríguez, Emilio Sala, Lorenzo Vallés y Salvador Sánchez Barbudo. 
de Lhardy, Beruete, Monleón y Férriz decoraban el llamado "salón de los paisajistas", mientras que en el Salón Central se colgaron seis lienzos, obra de Puebla, Laverón y Balaca. Además, Gomar se encargó de las pinturas del techo, y de Francisco Jiménez se ubicaron dos cuadros en la escalera de los socios. También las cátedras se abrieron al tema artístico de la mano de Ceferino Araújo y Luis Alfonso en el curso de 1883-1884, algo que tal vez motivó el que en el reglamento de 1884 se aprobase la desvinculación de la sección de Bellas Artes de la de Literatura, incorporando a otros oradores sobre arte, como Cossío, José Fernández Jiménez, Vicente Lampérez o José Parada Santín (GARCÍA MARTÍN, 1948: 196). Otro distinguido artista que formó parte del Ateneo fue Francisco Pradilla, según consta en una carta que le remitió el vicepresidente de la sociedad ${ }^{534}$.

\subsubsection{La galería de retratos del Ateneo Científico, Literario y Artístico de Madrid}

La presencia de los artistas en el Ateneo fue, como se ha podido comprobar, mucho más numerosa y fructífera de lo que Ruiz Salvador transmitía en su estudio sobre el Ateneo, lo que se debió en gran medida al desarrollo de la galería de retratos. Según recogen las fuentes, fue en 1869 , tras el importante giro político que había sacudido la nación el año anterior, cuando se comienza a configurar una galería de retratos dentro del propio Ateneo, una iniciativa que partía del secretario Gómez Molinero, quien ostentó el cargo entre 1867 y 1870 . Este había propuesto la conveniencia de que se realizasen los retratos de los presidentes de la sociedad, desde el duque de Bailén hasta Alcalá Galiano (GARCÍA MARTÍ, 1948: 139 ${ }^{535}$ ), lo que posteriormente se hizo extensivo al retrato de todos los ateneístas ilustres.

La iniciativa constituyó en gran medida una manera eficaz de paliar la escasa presencia de las artes en el Ateneo, siendo un poderoso aliciente la exención de cuota, tal y como expone José de Castro y Serrano en las páginas de la Ilustración Española y Americana:

Porque el Ateneo, según sus antiguos Estatutos, releva de cotización mensual a los socios que han ocupado sus cátedras; y asimismo, por disposición novísima, a los pintores que retratan sus celebridades. Esta última idea ha proporcionado a la Sociedad el concurso y amalgama del elemento artístico, que solo por analogía entraba, y rara vez, en su seno. Hoy los jóvenes pintores que regeneran el bello arte de nuestra patria, ejercen su pincel perpetuando las figuras de los que fueron presidentes o miembros notables del Ateneo, con gloria para sí y regocijo para las ciencias y las letras; pues ya penden de las paredes de la casa los retratos del duque de Bailén, marqués de Valdegamas, Pacheco, Martínez de la Rosa, duque de Gor, marqués de Pidal, Méndez Núñez, Posada Herrera, Gallardo y Mesonero, pintados

\footnotetext{
${ }^{534}$ Carta de Manuel Antón Ferrándiz, vicepresidente del Ateneo de Madrid, a Francisco Pradilla. Archivo del Museo del Prado, caja 268, leg. 12.01, exp. 2, doc. 20.

${ }^{535}$ Recoge, a su vez, el testimonio de R. M. de Labra, que afirma que "diose un gran impulso a la obra de los retratos, que al principio (en 1869), y por iniciativa del Secretario Gómez Molinero, que lo fue desde 1867 a 1870, debieron reducirse solo a los presidentes, desde el duque de Bailén hasta Alcalá Galiano, pero que después se extendió a todos los ateneístas ilustres, cuya reproducción pictórica vino en voluntad a los muchos y afamados artistas que se cuentan en el seno de la casa" (LABRA, 1879: 139).
} 
por Dióscoro Puebla, Germán Hernández, Mélida, Maureta, Mendoza, Fierros, Suárez Llanos y Casado; y dentro de poco lucirán también obras de Gisbert, Rosales, Díaz Carreño, y de cuantos con entusiasmo y gloria se dedican al noble arte de la pintura (CASTRO Y SERRANO, 1870: 375).

Esto permitía al artista obtener el mismo estatus que los profesores de las cátedras, es decir, de socios de mérito -algo aparentemente irrelevante, pero un mérito, no obstante, que figuraba en las listas de socios que se colocaban a la vista de todos los miembros del Ateneo ${ }^{536}$. En el breve interludio de un año desde el nacimiento de la propuesta hasta la redacción de este artículo se habían realizado ya diez retratos a cargo de los socios-artistas mencionados. Víctor Olmos (2015) recoge la comunicación de Eusebio Gómez Molinero en la memoria anual de 1868 de esa iniciativa de crear una galería de retratos, de la que se desprende una idea interesante: mientras la sociedad buscaba realizar una galería de los presidentes de la institución, es decir, de carácter exclusivamente corporativo, fueron los artistas consultados los que propusieron ampliarla, "viendo que a nuestra sociedad han pertenecido y pertenecen muchos de los hombres que han honrado y honran España con sus virtudes, sus talentos y sus hechos", a una "galería de socios ilustres". La colección se inició en marzo de 1869, con la presentación del retrato de Francisco Javier Castaños realizado por Dióscoro Puebla (LABRA, 1878: 97).

La llegada masiva de artistas entre 1870 y 1876 contribuyó a un aumento notable de la galería, de manera que en 1876 el número de retratos ascendía a 48, tal y como recoge la relación de retratos de la galería incluida en la memoria anual (GONZÁLEZ BURGOS, 1876: 103-106): 13 de presidentes y los 35 restantes de socios notables, constituyendo, en palabras de Labra (1878: 17-18), "una de las curiosidades más estimables de Madrid, toda vez que solo en el Ateneo y en el Salón de conferencias del Congreso es dado a conocer de vista a los hombres que mayor influencia y más cumplida fama han disfrutado en la política y en la ciencia española en estos últimos cincuenta años". El secretario Luis González Burgos, al comunicar las últimas obras incorporadas a la galería, debidas a los pinceles de José Gonzálvez, Vicente Poleró, Isidoro Rosell y Manuel Ojeda, reservaba palabras especialmente calurosas de agradecimiento al pintor Ignacio Suárez Llanos, que se disponía en aquel momento a llevar a cabo el del presidente José Moreno Nieto, quinto retrato de su mano que saldría para la colección del Ateneo ${ }^{537}$.

\footnotetext{
536 “Art. 13. La lista general de socios de número y de mérito permanecerá expuesta constantemente en el cuadro de anuncios del Ateneo, haciéndose en ella mensualmente las adiciones o supresiones que exija el movimiento de socios" (ATENEO DE MADRID, 1884: 8).

537 "La galería de retratos se ha enriquecido con los de los señores: Julián Romea, pintado por D. José Gonzálvez; D. Joaquín Aguirre, por D. Vicente Poleró; D. José Zorrilla, por D. Isidoro Rosell, y el del Sr. vizconde del Pontón, por D. Manuel Ojeda. El Ateneo posee hoy una galería de 47 retratos, la más notable de las colecciones de esta clase. Los Presidentes se hallan retratados los trece primeros que ocuparon este puesto. El decimocuarto lo estará muy en breve, pues el distinguido artista D. Ignacio Suárez Llanos, no contento con haber hecho a esta sociedad el importante donativo de cuatro retratos originales, que todos admiramos, se ha ofrecido generosamente a pintar el de nuestro querido amigo y presidente, Ilmo. Sr. D. José Moreno Nieto" (GONZÁLEZ BURGOS, 1876: 18).
} 
Los retratos pintados en esta fecha fueron ubicados en el edificio del Ateneo, que en el momento tenía su sede en la calle de la Montera, distribuyéndose según se iban realizando en las distintas dependencias. Las descripciones que nos han llegado de estas permiten saber que en el wagón, lugar de encuentro de pintores, escritores y de la alegre juventud ${ }^{538}$, se colocaron, entre las fotografías de ruinas artísticas, los retratos "de Barzanallana, Benavides, Corradi y Alonso Martínez, todos cruzados de Carlos III" (MARTÍN GARCÍA, 1948: 130), a los que se añadieron los de Nicolás Rivero, Claudio Moyano y Juan Valera (LABRA, 1878: 97).En la cacharrería, otro espacio emblemático del Ateneo, se fueron colgando los de Nicomedes Pastor Díaz, Luzurriaga, Argüelles, Sanz del Río, Aguirre y Julián Romea (MARTÍN GARCÍA, 1948: 131).

El carácter peculiar de la galería, así como la continua incorporación de retratos, hizo que en el diseño del nuevo edificio de la calle del Prado se destinase un espacio propio a la galería de retratos. Edificado en 1884 a cargo de los arquitectos y socios del Ateneo Luis Landecho y Enrique Fort, el nuevo edificio pretendía dar una nueva imagen del estatus alcanzado por la sociedad y por la distinción de sus socios, visibilizado a través de la construcción de nueva obra de la sede -cuyo coste llegó a dos millones de reales- y de la elegancia de su decoración. En un artículo publicado en La librería se detallaba la iniciativa de este programa decorativo, afirmando que

\begin{abstract}
habiendo surgido (...) una verdadera competencia de generosidad y buen deseo por parte, si no de todos, al menos de la mayoría de los artistas - pintores y escultoresque son socios del centro, para embellecer y adornar el nuevo local, aprovechó la celosa Junta tan valiosos elementos y pudo ofrecer al Instituto que preside una casa propia, no ya pobre y sencilla, sino elegante y hasta fastuosa ("Ateneo científico... II", 1884: 19).
\end{abstract}

Los socios artistas que participaron desinteresadamente en las tareas decorativas del Ateneo $^{539}$ fueron Ferrant, Araujo, Díaz Carreño, Mosquera, Taberner, Laveron, Jover, Algarra, Balaca, Dióscoro Puebla, Gomar, Beruete, Lhardy, Monleón, Férriz, Federico Jiménez y Domínguez. Otros artistas estuvieron más o menos vinculados con el Ateneo, como José Luna Novicio -algunas de cuyas cartas están redactadas en hojas con el membrete del Ateneo ${ }^{540}$, y José Benlliure, a quien el Ateneo nombró socio de mérito

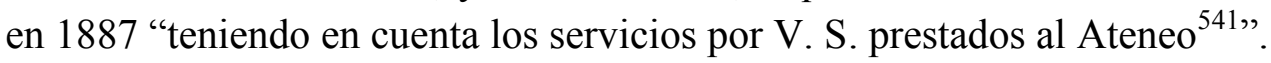

Por lo que respecta a la distribución de los retratos en la nueva sede del Ateneo, sabemos que los de los presidentes fueron destinados al salón de cátedras o de sesiones; colocados en las paredes de la sala elíptica aparecían en 1884 los de Alcalá Galiano, Castaños, Pacheco, Pidal, el marqués de Molins, Martínez de la Rosa, Donoso Cortés, Posada Herrera, Cánovas, Olózaga, el Duque de Gor, Figuerola, el duque de Rivas y

\footnotetext{
${ }^{538}$ Allí acudía, entre otros, Ceferino Araujo tras las conferencias a reunirse y conversar en el círculo de los estamperos, que Mélida recuerda como antítesis del bullicio de la cacharrería (MÉLIDA, 1897: 130).

539 "(...) Los artistas trabajan de balde, sin retribución ninguna, y han llevado su esfuerzo y su ingenio para crear el que será como hogar de literatos y artistas (...)" ("Nuevo Ateneo", 1884: 1).

${ }_{540}$ Carta de José Luna Novicio a José Benlliure, 27 de junio de 1884. Archivo Casa-Museo Benlliure, C10Lun001.

${ }^{541}$ Carta del Ateneo de Madrid a José Benlliure, 14 de junio de 1887. Archivo Casa-Museo Benlliure, C20Ate001.
} 


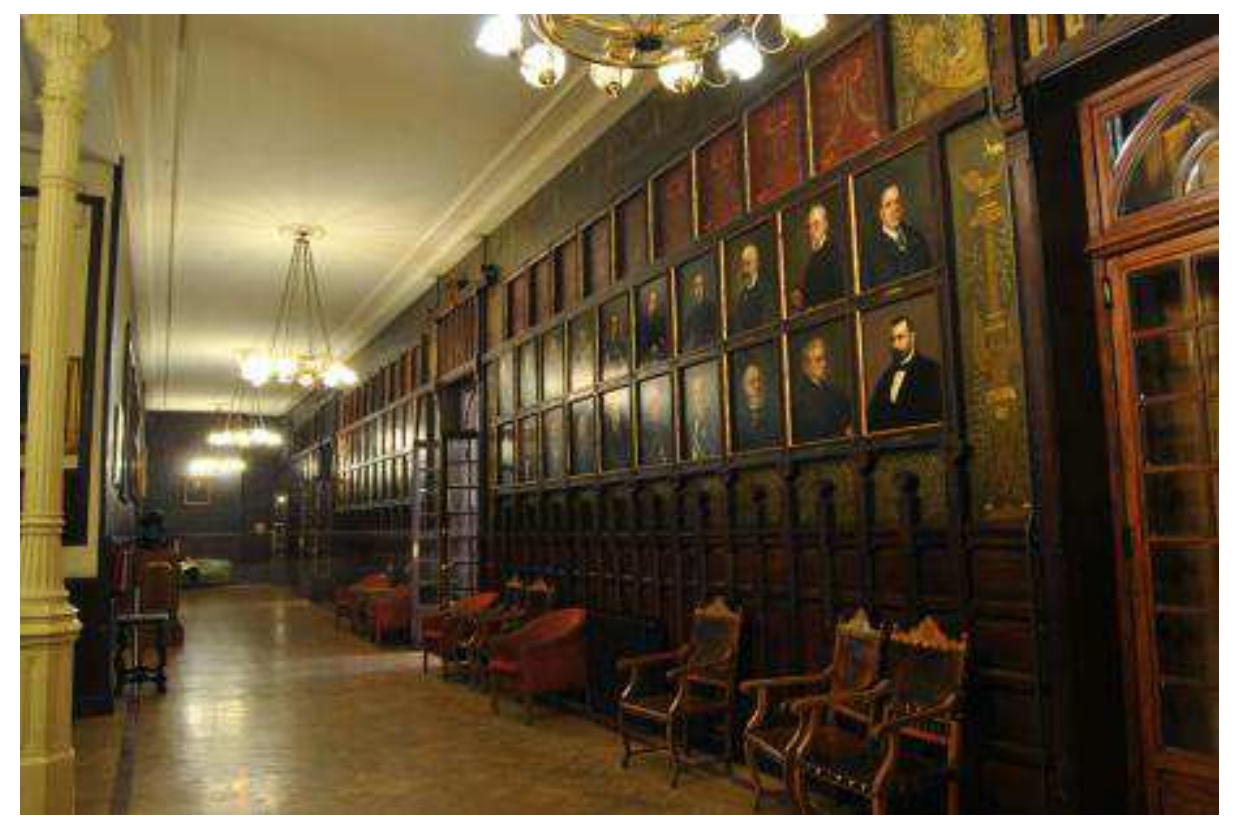

Fig. 189. Galería de retratos del Ateneo de Madrid.

Moreno Nieto, ofreciendo un aspecto solemne e institucional. La galería de retratos de ateneístas ilustres fue ubicada en la antesala de este [fig. 189], o galería de paseo, sirviendo como una historia del éxito de la institución y como un medio de estimular a la juventud ${ }^{542}$.

El nuevo edificio no solo visibilizaba su poder económico, social y cultural a través del lujo y confort de sus salones ${ }^{543}$, sino que también buscaba exteriorizarlo aglutinando en un solo espacio una galería de retratos caracterizada porque sus personalidades destacadas no solo eran relevantes para la institución, sino también y especialmente por su condición de ser glorias nacionales, pues figuraban entre ellos Alberto Lista, Ríos Rosas, Mesonero Romanos, escritores como Hartzenbusch, Bretón de los Herreros, Zorrilla, Valera y Ventura de la Vega, y políticos como Salmerón, Castelar, Moyano, Alonso Martínez o Argüelles. Si bien en algunos casos, y especialmente en los comienzos de la galería, los retratos se debieron a copias o a retratos póstumos, el retrato directo y en vida de numerosos compañeros del Ateneo sirvió como experiencia

\footnotetext{
542 "Espaciosa galería sirve como de antesala al salón de sesiones y a los de conversación. La adornan, formando museo de notabilidades, los retratos de los socios de mérito. Aquellos bustos que el pincel ha animado, son como la historia de la tribuna, de la política, de las letras y de las artes españolas; aquellas cabezas de hombres ilustres han guardado profundos o brillantes pensamientos. Algunos de esos hombres viven todavía, la mayor parte han muerto, y todos forman una galería de retratos que no puede verse sin emoción profunda. (...) ¡Oh joven que llegas de provincias, pobre, oscuro y desconocido! Ahí tienes a tus antepasados en las rudas luchas de la vida; si tienes como ellos fe y aliento, tu retrato de viejo figurará en esa galería, donde está la aristocracia del talento (...)" ("Nuevo Ateneo", 1884: 1).

${ }^{543}$ Hacia 1906, Rafael María Labra (1906: 69-70) afirmaba que "la nueva casa contribuyó grandemente al brillo y la resonancia del Instituto, y sirvió asimismo para el aumento de socios, que pronto pasaron de mil. Nadie puede hoy desconocer que el Ateneo es un círculo de superior distinción y mucho confort". El Ateneo se sumaba así al interés de visibilizar su poder y las clases sociales a que estaba dirigido a través del lujo, manifestado entre otras cosas en el personal de servicio (a los que Labra describe con "azules casacones con botón de plata y deslumbrador chalecón grana" [LABRA,1878: 17]), o en su sede, como ya había ocurrido con el Liceo y su traslado al Palacio de Villahermosa, o con el edificio del Casino (ZOZAYA, 2015: 135).
} 
social para los artistas encargados de realizar las obras, debido fundamentalmente a dos motivos. En primer lugar, porque la elección de los retratados no era arbitraria sino que correspondía a una decisión tomada por la Junta Gubernativa; el artista, sometido de este modo al encargo de la Junta, recibía este no solo como un trabajo a realizar, sino como la posibilidad de obtener un reconocimiento dentro de la institución, sumándose un cierto valor de rito iniciático a la valoración de su trabajo profesional, dos factores importantes para la consolidación de una identidad masculina basada en el intercambio social y en el ejercicio laboral. Por otra parte, la realización del retrato suponía también un momento de encuentro entre pintor y la persona designada ${ }^{544}$, cuyos méritos políticos, literarios o artísticos bien podían suponer una fuente de emulación para el artista que tal vez anhelase ver su efigie situada algún día en la galería.

Debido al carácter y al estatus de los efigiados, los retratos respondían a un formato concreto, se trataba de obras de busto prolongado, generalmente de tres cuartos, adaptadas a las rigideces y exigencias de la imagen oficial. Los personajes, todos ellos masculinos salvo las excepciones de Concepción Arenal y de Emilia Pardo Bazán, pueden dividirse de manera general en dos formas de representación. Por una parte, más vinculada al retrato oficial y a la plasmación de las dignidades, méritos y prestigio social y cultural, aquellos que presentan, sobre elegante traje, bandas de órdenes civiles, así como sus respectivas cruces y placas, y medallas de corporaciones, entre las que destaca la de la Real Academia de la Historia; por otra, relacionada con el ideal de hombre burgués e intelectual, los de aquellos que aparecen vestidos con traje sencillo, ostentando como mucho la distinción de la Legión de Honor francesa, que fue la forma de representación más frecuente entre artistas, escritores y políticos.

\subsubsection{Retratos de artista en la galería del Ateneo}

A pesar de que fueron numerosos los artistas que participaron en la configuración de la galería de retratos ${ }^{545}$, actualmente tan solo queda constancia de cinco retratos de

\footnotetext{
${ }^{544}$ En el archivo del Ateneo queda constancia de este proceso en la comunicación que la Junta hace a Arturo Mélida de la decisión de colocar su retrato en la galería, participándole que para su ejecución había sido designado Salvador Martínez Cubells.

${ }^{545}$ Según el apéndice dedicado a la galería de retratos del Ateneo incluido en el estudio de GARCÍA MARTÍ, Manuel Benso realizó el retrato del duque de Rivas; Eduardo Rosales el de Antonio Ríos y Rosas; Ricardo Balaca el de Severo Catalina; Eduardo Balaca el de Antonio Benavides; B. Maura el del marqués de Barzanallana; Vicente Palmaroli el de Juan Eugenio Hartzenbusch; F. Aznar el de Ventura de la Vega; Francisco Díaz Carreño el de Manuel Bretón de los Herreros; José Casado del Alisal el de Mesonero Romanos; Joaquín Espalter el de Ramón Campoamor; Francisco de Paula Mendoza los de Manuel Alonso Martínez y Juan Valera; Ceferino Araujo el de Antonio R. Zarco del Valle; Federico Jiménez el de Agustín Argüelles; Rafael Monleón el de Luis González Bravo; José Parada y Santín el de Antonio Cánovas; Ignacio Suárez Llanos los de Manuel G. Gallardo, Emilio Castelar y Casto Méndez Núñez; Vicente Esquivel el de Alcalá Galiano; Dióscoro de la Puebla el de Francisco Javier Castaños; Germán Hernández Amores el de Juan Donoso Cortés; Enrique Mélida el de Cayetano Rossel; Dionisio Fierros el de José Pidal; Miguel Pineda el de Nicolás Salmerón; Gabriel Maureta los de Francisco Martínez de la Rosa y Eduardo Saavedra; Federico de Madrazo el de Segismundo Moret; Serafín Martínez del Rincón los de Cristino Martos, Manuel Fernández González y Santiago González Encias; Manuel Yus el de Manuel Pedregal; Jacinto Laverón el de Juan Nicasio Gallego; Mosquera el de Evaristo San Miguel; Juan Luna el de Rafael María de Labra; Rouzé los de Augusto Charro-Hidalgo, Miguel Sánchez, José Echegaray y Francisco Cardenas; Antonio Hoffmeyer el de José de Carvajal; Manuel Arroyo y Lorenzo los de Juan Palarea, Adelardo López de Ayala y José de Esproceda; Manuel García Hispaleto el de Benito Pérez Galdós; Maximino Peña el de Pedro de la Llave; Miguel Aguirre los de Juan
} 
artista en la galería. En las listas de socios es frecuente encontrar a muchos de los artistas pertenecientes al Ateneo afincados en Roma o París; se ha podido observar que su relación con la institución, aunque fuese solamente temporal, resultó fructuosa en términos artísticos. Llama la atención, sin embargo, que entre los retratos de artista de la galería no figuren los de aquellos que más estrechamente vinculados estuvieron con ella, como es el caso de Ignacio Suárez Llanos, Dionisio Fierros, Dióscoro Puebla, Joaquín Espalter o Germán Hernández Amores, personajes que además de su significativa relación con la institución y la configuración de la galería tuvieron trayectorias artísticas lo suficientemente meritorias y reconocidas en el panorama español como para ser incluidos entre las demás celebridades ateneístas.

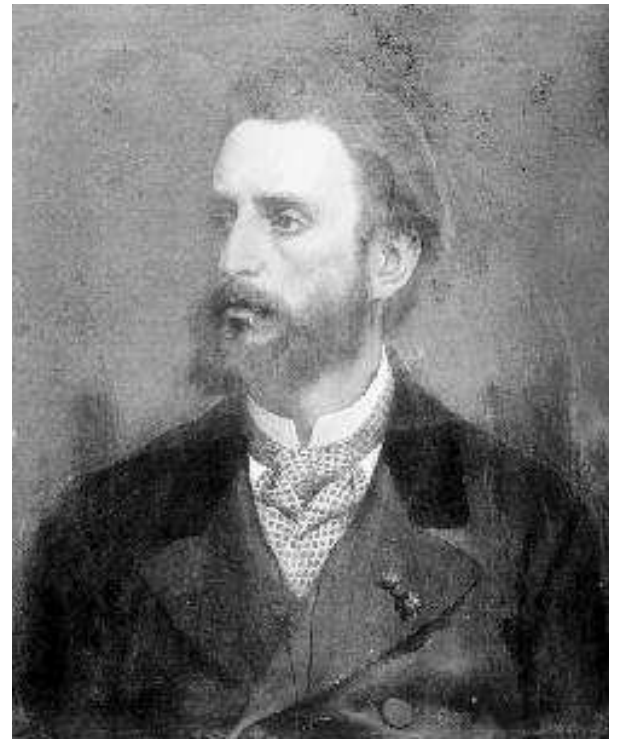

Fig. 190. Francisco Sans, Retrato de Eduardo Rosales. Ateneo de Madrid. Fotografía del Archivo Moreno $\left(\mathrm{n}^{\mathrm{o}}\right.$ inv. 208B).

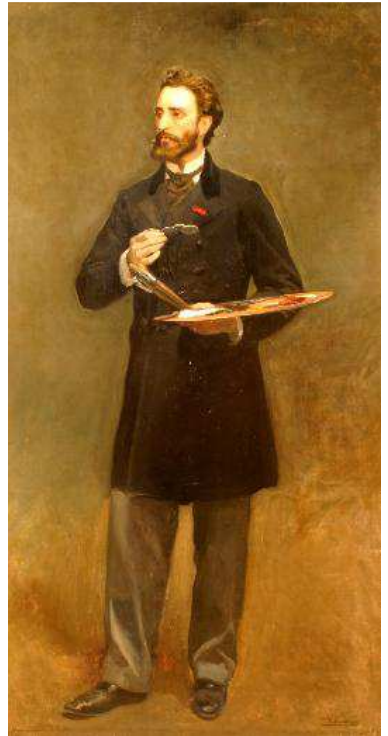

Fig. 191. Joaquín Sorolla, Retrato de Eduardo Rosales. Ateneo de Madrid.

El primer retrato de un artista del que tenemos constancia documental es el de Eduardo Rosales [fig. 190], que figuraba ya colgado entre otros socios notables en fecha tan temprana como 1876, constando en la lista de retratos facilitada en la memoria anual con el número 26, como obra original realizada por Francisco Sans (ATENEO DE MADRID, 1876: 105). La noticia de la próxima realización del retrato de Rosales aparecía ya en prensa en enero de 1874 (La correspondencia de España, 1874: 3), apenas algunos meses después del fallecimiento del pintor, lo que cabe entender como un homenaje póstumo de la institución. La ejecución de la obra corrió a cargo del pintor y director del Museo del Prado Francisco Sans Cabot, cuya relación con el Ateneo no parece haber sido demasiado intensa tras esta puntual colaboración. La personalidad de

Vilanova y Félix Márquez; Manuel Fernández Carpio el de José Velarde; César Álvarez Dumont el de Alejandro Pidal; Carlos Lezcano el de Joaquín María Sanromá; Ricardo de Madrazo los de Federico de Madrazo y Francisco de Cortejarena; Rafael Arroyo el de Pascial Gayangos; Juan Comba el del conde de Morphy; Ubaldo Fuentes el de Luis Álvarez; Juan Francés el de Federico Botella; Emilio Sala el de Jacinto Octavio Picón; Salvador Martínez Cubells el de Arturo Mélida; Vicente Poleró el de Joaquín Aguirre; Francisco Sans el de Eduardo Rosales y Marceliano Santamaría el de Francisco Navarro Ledesma. Para un análisis directo de los retratos ver también el catálogo editado sobre la galería: ATENEO DE MADRID, 2004. 
Eduardo Rosales, que tan solo había pintado para la galería del Ateneo un retrato, el de Antonio de los Ríos y Rosas - una obra que la sociedad madrileña atesoraba como muy valiosa, y que cedió para la exposición póstuma del $\operatorname{artista}^{546}$ (La correspondencia de España, 1873: 3)-, ostentaba no obstante otros méritos que lo hacían más merecedor de ser perpetuado en la institución al encarnar el nuevo ideal de celebridad artística como artífice de un estilo moderno y original. De este modo, honores ajenos a la sociedad del Ateneo como su título de director de la recién inaugurada Academia Española en Roma, la Legión de Honor francesa o la cruz de comendador de la Orden de Isabel la Católica, legitimaban más su exitosa trayectoria artística. La colocación del retrato de Rosales, aparte de celebrar la personalidad del pintor como héroe cultural -acontecimiento al que se sumaron numerosas instituciones y sociedades de índole artística o literaria-, aseguraba ese tinte de modernidad, progreso y eminencia científica y social del propio Ateneo. El retrato, tomado de fotografía ${ }^{547}$, presenta al artista de busto prolongado, con la cabeza ligeramente ladeada, vestido de manera sencilla pero elegante con camisa blanca, corbata de cuadros y chaqueta, en cuya solapa luce la escarapela de la Legión de Honor francesa. Sobre el fondo rojizo, Francisco Sans incluyó una leyenda que identificba al retratado, sin mencionar las fechas de nacimiento y muerte habituales en este tipo de retratos destinados a galerías, sino tan solo un escueto y contundente "el gran pintor Rosales” en el ángulo superior derecho.

Curiosamente, ya en el siglo XX, Joaquín Sorolla realizó otro retrato de Eduardo Rosales para el Ateneo [fig. 191]. Tomó como modelo el retrato realizado por Sans existente en la galería de retratos, aunque decidió dar un mayor protagonismo a la identidad artística pintor y lo presentó de cuerpo entero. El cuerpo imaginario de este retrato de Rosales tenía además la particularidad de interactuar con dos elementos clave para dotar de nuevos significados a la efigie: por una parte, y a pesar de aparecer retratado con traje elegante y con el distintivo de la Legión de Honor, sostiene en su mano izquierda la paleta y los pinceles, encarnando esa imagen del artista trabajador que fascinaba al valenciano. Pero además, Rosales sostiene en su mano derecha unos anteojos que parece acabar de retirar de su rostro, lo que le presenta como trabajador y como intelectual de su tiempo, tal vez en reivindicación ante la sencillez de la caracterización del retrato realizado por Sans, en el que únicamente se tienen en cuenta los honores del artista en relación a su posición social.

Hacia 1885 se aprueba la realización del retrato del arquitecto y pintor Arturo Mélida [fig. 192], quien, al igual que sus hermanos Enrique y José Ramón, había pertenecido al Ateneo y había mantenido una estrecha relación con este. Así, había sido consultado sobre el proyecto de fachada del nuevo edificio del Ateneo y se le invitó a realizar la decoración pictórica del edificio, como efectivamente hizo [fig. 193]. Entre la correspondencia del arquitecto conservada en el Ateneo se encuentra una carta remitida por el secretario José Pérez de Acevedo comunicando la decisión de la Junta de contar

\footnotetext{
${ }^{546}$ Exponiendo el retrato, el Ateneo homenajeaba al pintor y al político retratado, cuyo fallecimiento en noviembre de 1873 fue sentida por la institución cultural madrileña.

${ }^{547}$ La fotografía fue publicada en el catálogo de la exposición celebrada tras la muerte de Rosales en la antigua platería de Martínez (Catálogo de la exposición de pinturas..., 1873).
} 


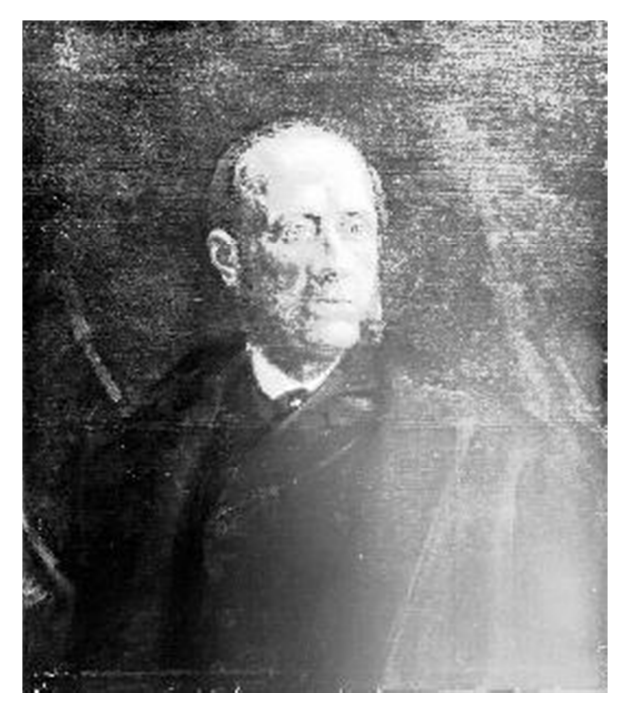

Fig. 192. Salvador Martínez Cubells, Retrato de Arturo Mélida. Ateneo de Madrid. Fotografía del Archivo Moreno ( $\mathrm{n}^{\circ}$ inv. 268B).

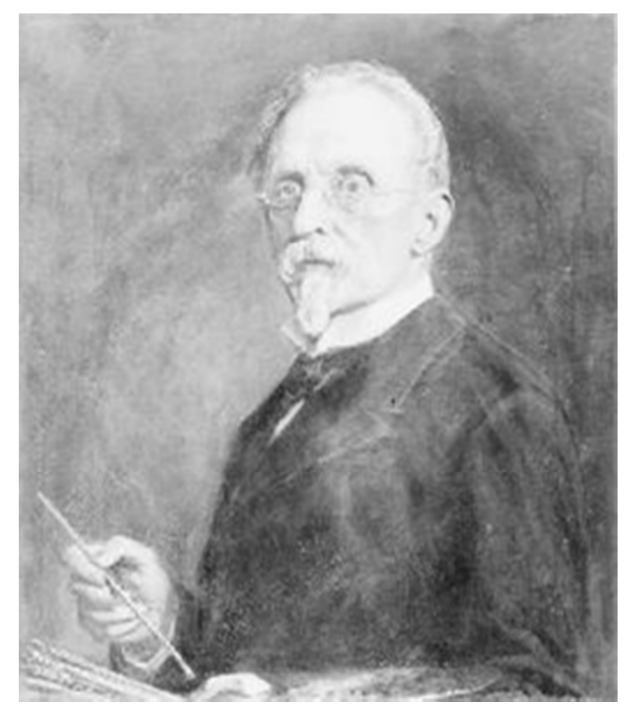

Fig. 194. Ricardo de Madrazo, Retrato de Federico de Madrazo. Ateneo de Madrid. Fotografía del Archivo Moreno ( ${ }^{\circ}$ inv. 205B).

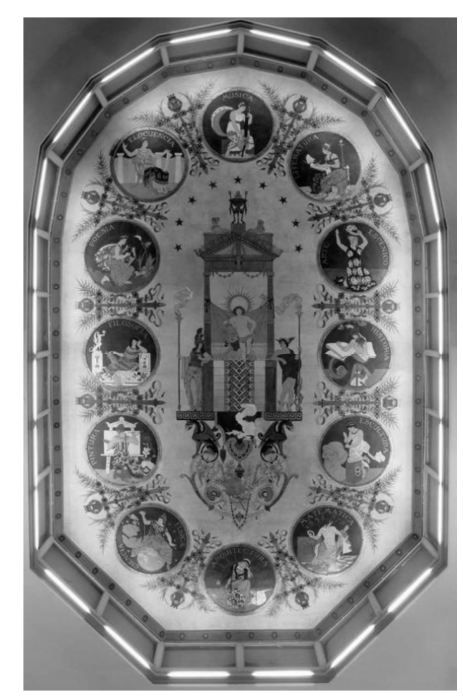

Fig. 193. Arturo Mélida, decoración del techo del Salón de Actos, Ateneo de Madrid.

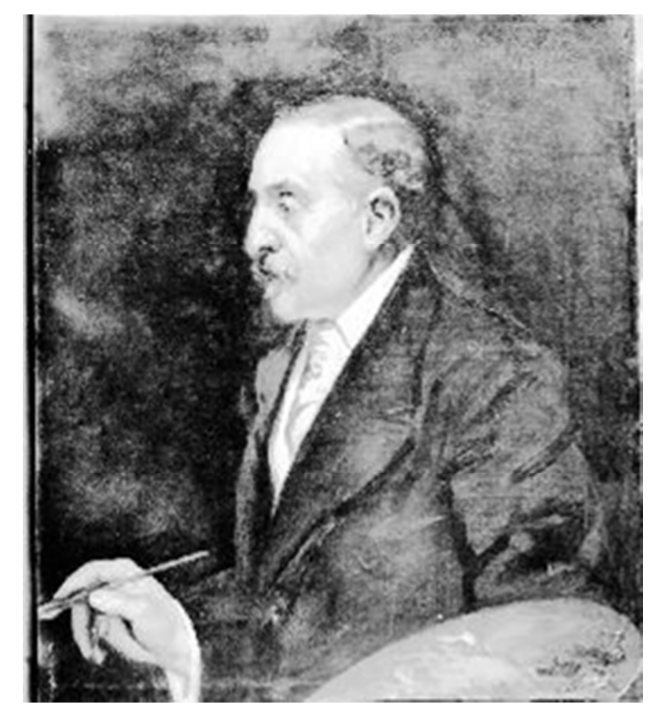

Fig. 195. Ubaldo Fuentes, Retrato de Luis Álvarez Catalá, Ateneo de Madrid. Fotografía del Archivo Moreno ( $\mathrm{n}^{\mathrm{o}}$ inv. 210B).

con su retrato en la galería, cuya tarea se encargó al pintor Salvador Martínez Cubells. Sin embargo, el retrato no se realizaría hasta fecha posterior, como ponen de manifiesto el que aparezca representado con el botón de la legión de honor francesa (condecoración que no obtuvo hasta 1889) y el hecho de que no se incorporase a la galería hasta $1903^{548}$. El retrato, de busto y con la cabeza de tres cuartos, presenta al artista vestido de negro y cubierto con grueso gabán; su fisonomía, caracterizada por las largas y pobladas patillas, permanece ajena a toda expresividad, indicando que probablemente se realizase -bien de memoria o de fotografía- con posterioridad a su muerte, acontecida en 1902.

\footnotetext{
${ }^{548}$ En el apartado destinado a la galería de retratos que se incorporó en la lista de socios de 1903 aún no constaba el retrato de Arturo Mélida; sí que lo hacía en la que se redactó en 1909. Es probable que el retrato se completase en 1903, ya que en la lista de 1909 figura inmediatamente después de los últimos que constaban en la de dicho año (ATENEO DE MADRID, 1903; ATENEO DE MADRID, 1909: 107).
} 
Destacado sobre fondo de cortina roja, la única alusión a su carrera profesional, y como rasgo identificador del éxito y reconocimiento, es precisamente la referida a la Legión de Honor en la solapa de su chaqueta.

Con anterioridad a 1903 se incorporaron los retratos de dos personalidades relacionadas con las artes. Fue uno de ellos el de Federico de Madrazo [fig. 194], socio de mérito del Ateneo desde 1874, fecha en que realiza para la galería el retrato de Segismundo Moret. Lo pintó su hijo Ricardo, socio de mérito del Ateneo que contribuyó además con el retrato de Ramón y Cajal para la misma galería. La obra, en la que deberíamos presuponer una profunda implicación emocional por parte de Ricardo, peca sin embargo de una extraña sobriedad y dista mucho del intimismo que respiraba el retrato del Museo de Bellas Artes de Bilbao realizado por su hermano Raimundo en 1875. No parece haber duda de que el modelo para este retrato lo encontró Ricardo en uno de los últimos autorretratos realizados por Federico de Madrazo. Presenta a su padre de busto prolongado, vestido elegantemente con traje negro, camisa blanca y corbata negra, sin ostentar ninguna distinción; el rostro, ya anciano, evidencia los estragos de la edad en la incipiente calvicie, la canosa perilla y, muy especialmente, en la mirada cansada - muy lejos ya de la perspicaz viveza de su autorretrato juvenil-que se pierde detrás de sus lentes. Significativamente, la imagen del artista transmite una idea constantemente repetida en las biografías de pintores a finales del siglo XIX: se trata de esa vejez que, en lugar de destruir al hombre, le hace mantenerse constante y enérgico; un rasgo que puede observarse en la postura perfectamente erguida de Madrazo, en la seguridad con que su mano diestra sostiene un pincel. La inclusión de la paleta y los pinceles, siendo rasgos propios de la identidad profesional que por lo general no acompañan a otros retratados -la excepción más evidente es, precisamente, otro retrato realizado por Ricardo de Madrazo representando a Ramón y Cajal, además de los retratos en que la representación de uniformes evidencia ocupaciones militares o eclesiásticas-, incide en ese rasgo de actividad artística hasta una edad avanzada.

También fue director del Museo del Prado el siguiente artista retratado, el pintor Luis Álvarez Catalá. Su fallecimiento en 1901 no fue tan mediatizado como el de Madrazo, a pesar de que varios periódicos se encargaron de realizar necrologías del artista. Aunque residió en Roma durante buena parte de su vida, sabemos que tuvo alguna relación con el Ateneo, en el que figuraba como socio de mérito en 1891 (ATENEO DE MADRID, 1891: $\mathrm{n}^{\circ}$ 5241), si bien no queda constancia de las obras que pudiera realizar para la institución. Sin embargo, su retrato fue pintado el mismo año de su muerte, tal y como consta bajo la firma del pintor Ubaldo Fuentes [fig. 195], lo que significa un reconocimiento inmediato de su mérito y prestigio, tanto para la sociedad cultural como para la propia institución. El retrato presenta al artista, como en el caso de Federico de Madrazo, con elegante camisa y chaleco blancos bajo una chaqueta negra, sin lucir ni ostentar medalla ni condecoración alguna; dibujado de riguroso perfil que oculta su expresión, y resaltado sobre un llamativo y elegante fondo rojo, muestra, una vez más, esa identidad indiscutible del artista trabajador al sostener en su mano izquierda una paleta y en la derecha un pincel que, en lugar de retraerse hacia la paleta 
en un acto de descanso, permanece activo trabajando en la obra que, más allá del marco, realiza oculta al espectador.

Finalmente, el último retrato de un artista del siglo XIX existente en el Ateneo, aunque dudosamente con destino a la galería, fue el que Joaquín Sorolla realizase, junto al de Rosales, de Mariano Fortuny. Comparte con este rasgos formales, como el tratarse de un retrato de cuerpo entero; tomando como modelo una fotografía, muestra al pintor sentado sosteniendo de manera distraída un pincel aún cargado de pintura, con una expresión de seria ensoñación en el rostro. A sus pies, y tratadas con la misma pincelada vaporosa que construye la obra, descansa una enorme paleta con su correspondiente corona de laurel.

Se puede observar cómo la presencia del artista en el Ateneo responde a unas formas de sociabilidad generalizada entre los hombres de la mediana y alta burguesía y con inquietudes intelectuales, ya fueran científicas, literarias, políticas o artísticas. Frente al tipo de sociabilidad anclada en el estímulo recreativo del Liceo, el afán progresista y educativo del Ateneo promueve una vinculación colaborativa con los socios artistas, quienes gozan del privilegio de acceder a una esfera cultural de élite a cambio de prestar gratuitamente sus servicios. La imagen que se conserva del artista en la galería de retratos del Ateneo no se vincula con esta realidad social, sino con la exaltación del éxito entendido a través de una trayectoria profesional reconocida, en ocasiones a título póstumo; la galería de españoles ilustres contemporáneos, que supone una fuente de emulación para los ateneístas, reviste en el caso de los artistas una singularidad al plasmar su identidad profesional. De este modo, mientras otros socios ilustres aparecen representados como hombres elegantes, vinculados al poder político o militar, los artistas se vinculan a la práctica pictórica, convirtiéndose esta en un atributo de privilegio al relacionarse con la élite cultural.

\subsubsection{El Ateneo Valenciano}

La constitución del Ateneo de Valencia, tal y como estudió Roig Condomina (1995: 107-114), tuvo como uno de sus objetivos la reanimación del panorama cultural de la ciudad al tomar el relevo de las actividades organizadas por la Sociedad Económica de Amigos del País. Surgido a partir de una tertulia privada y una primitiva sociedad científico-literaria denominada La Antorcha, significativamente en un periodo tan convulso como el abarcado entre 1869 y 1871 en el que otras sociedades de carácter cultural habían decaído o desaparecido, el carácter del Ateneo valenciano se diferenciaba notablemente del de ocio burgués que había marcado los últimos años del Liceo. A pesar de que Roig Condomina equiparaba la labor de ambas sociedades en tanto que promotoras de las artes en la ciudad, es preciso señalar que la relación del Ateneo con las artes y los artistas valencianos fue más efectiva que la que había realizado el Liceo debido al interés de este por constituirse como una sociedad intelectual en busca del progreso sociocultural y científico en el ámbito local. La importancia del Ateneo para el arte en Valencia quedó patente en la organización de sus propias exposiciones con el objetivo de dar visibilidad al trabajo de los jóvenes artistas 
valencianos; el interés de estos por la nueva institución hizo que la sección de Bellas Artes, integrada en la de Literatura, cobrase autonomía en 1875.

El carácter de elitismo cultural del Ateneo valenciano no se diferenciaba, a excepción de la escala provincial, del que ostentaba el Ateneo madrileño, de tal modo que el secretario general del Ateneo, al hacer una breve memoria de los avances obtenidos durante el año 1872, afirmaba ya haber "logrado tener inscritos en su registro de socios más de 200 individuos, entre los cuales bien podemos asegurar que se hallan cuanto de notable encierra Valencia en ciencias, artes y literatura, y cuantos jóvenes han comenzado con éxito supremo esa difícil y angustiosa senda" ("Memoria leída por el secretario...", 1873: 248). Parece que la juventud era un rasgo común entre los artistas que se adhirieron al Ateneo, ya como socios o como participantes en sus exposiciones, puesto que pertenecían a una nueva generación, lejana ya de los antiguos integrantes del Liceo Artístico y Literario, la mayoría de los cuales habían fallecido. La mayor parte de los ateneístas valencianos había nacido entre los años 1850-1855, contando durante el tiempo de actividad del Ateneo con una media de veinticinco o treinta años ${ }^{549}$, con las excepciones de algunos artistas en edad más madura, como Joaquín Agrasot, José Brel, Vicente Borrás o Bernardo Ferrándiz. Además de estos, otros artistas de renombre que se vincularon con el Ateneo fueron Gonzalo Salvá, Ignacio Pinazo, José Nicolau Huguet, Vicente Nicolau Cotanda, Juan Peyró, José Benlliure, Germán Gómez, Luis Franco, Emilio Sala o unos jovencísimos Julio Cebrián y Cecilio Pla. Muy significativo resulta el hecho de que el Ateneo prestase especial atención a la situación de las artes en Valencia; en este sentido destaca la iniciativa de Gonzalo Salvá dentro de la sección de Letras y Bellas Artes de crear una Sociedad Protectora de las Bellas Artes (ROIG CONDOMINA, 1994: 317-322) en 1872, sin duda a imitación de la que florecía en Sevilla. A pesar de que quedó en un intento, es interesante comprobar cómo en el proyecto de reglamento se buscaba una relación entre los socios de la Protectora y del Ateneo, al prever un privilegio en la reducción de las cuotas a los que siendo miembros de una, quisiesen serlo también de la otra. No obstante, el interés por acoger y proteger en cierto modo a los artistas valencianos no fue olvidado por el Ateneo, que se encargó de promover una exposición permanente (Las provincias, 1874/10/03: 2) y realizó varias de carácter temporal.

A través de las noticias que tanto los estudios de Roig Condomina como la prensa periódica valenciana aportan al conocimiento del Ateneo valenciano, parece evidente que los artistas tuvieron una relación mucho más estrecha con esta institución que la que los artistas madrileños mantuvieron con la sociedad de la capital española en las mismas fechas, sin duda porque en el núcleo valenciano la existencia de sociedades artísticas de carácter autónomo estaba más limitada que en Madrid, donde la coexistencia de numerosos artistas con inquietudes variadas daba pie no solo a tertulias privadas, sino también a la progresiva constitución de grupos asociativos vinculados al estudio y a la práctica artística. La élite cultural valenciana que dominaba la actividad ateneísta

\footnotetext{
${ }^{549}$ Son excepciones José Brel, Vicente Borrás y Joaquín Agrasot, nacidos los dos primeros en 1835 y el último en 1836; los más jóvenes fueron, sin lugar a dudas, Cecilio Pla, nacido en 1860, y Mariano Benlliure, nacido dos años después.
} 
extendía también sus inquietudes en otras instituciones, desde la Sociedad Económica hasta la Academia de San Carlos, de lo que sirve como ejemplo más significativo el de Vicente Boix. No obstante, la singularidad del foco valenciano queda puesta de manifiesto en el hecho de que el Ateneo supo examinar y aglutinar las necesidades de la comunidad artística local al contar entre sus socios con varios pintores, a los que dio voz en el Boletín-Revista del Ateneo, un espacio para la discusión en sociedad e incluso para la práctica artística, ya fuesen veladas o estudios ${ }^{550}$; es decir, asumiendo las labores que en otras ciudades realizaron las sociedades protectoras y las de acuarelistas. A cambio, la sociedad se garantizaba la participación de los artistas en la vida de la institución y su contribución con obras pictóricas para amenizar las veladas, para decorar el local o con destino a la galería de retratos.

\subsubsection{La colección pictórica del Ateneo}

Una reconstrucción parcial de la colección pictórica del Ateneo valenciano a través de las noticias ofrecidas por su órgano de prensa, el Boletín-Revista del Ateneo de Valencia, nos muestra que esta fue especialmente heterogénea, debida por lo general a la labor desinteresada de sus socios, que cedían sus obras para ornato de la sede social o para la realización de distintas veladas. En la memoria inaugural del curso 1873 se nos da alguna noticia de las obras que la institución poseía en 1872 ("Memoria leída...", 1873: 242), entre las que se encontraba un retrato de Velázquez por Gonzalo Salvá, tomando seguramente como modelo el existente en la Academia de San Carlos; otro de Fray Luis Vives realizado por Luis Franco y una Santa Teresa de Jesús pintada por Manuel Galmes, quien la donó al Ateneo poco antes de su prematura muerte; poseía también un retrato de Cervantes, a quien se homenajeaba ese mismo año, llevado a cabo por Emilio Sala, y una colección de cabezas pintadas regaladas por el pintor Puerto, que tal vez pudiera tratarse de una pequeña colección de retratos de socios, aunque no conocemos más noticias al respecto.

En 1873 se sumarían a la colección un retrato de Calderón de la Barca, donado por el Sr. Serret, y dos bustos, uno de Bretón de los Herreros y otro de Goethe, realizados por el escultor Emilio Julià ("Memoria leída por D. Emilio Borso...”, 1874: 275). Otros personajes contemporáneos que figuraron en la colección del Ateneo fueron los pintores Rosales y Fortuny, y el poeta valenciano Vicente Boix (ROIG CONDOMINA, 1995: 111 y 114). Además de los retratos de los reyes de Aragón Jaime I, realizado por José Brel, y Alfonso V, por Vicente Borrás, y del rey de Castilla Alfonso X, por Vicente Nicolau Cotanda (ALCAHALÍ, 1897: 228).

También formaron parte de la colección del Ateneo los retratos de Gregorio Mayans y Siscar, el erudito valenciano del siglo XVIII a quien se realizó una sesión conmemorativa, pintado por Germán Gómez Niedertleyner, y de Antonio José de Cavanilles, pintado por Ignacio Pinazo; de los dramaturgos Eugenio Hartzenbusch,

\footnotetext{
${ }^{550}$ Dánvila Jaldero (1888: 71) atribuía al Ateneo no solo la organización de exposiciones, sino también la de una clase nocturna de colorido, "denominada de Acuarela, que ofrece a los artistas un centro de estudio y al propio tiempo agradabilísimas veladas".
} 
pintado por Gonzalo Salvá, y Adelardo López de Ayala, por Antonio Cortina; y de José Moreno Nieto, por José Nicolau Huguet.

\subsubsection{Galería de retratos de presidentes}

Tanto en su tesis doctoral como en el artículo monográfico sobre el Ateneo valenciano, Roig Condomina menciona una colección de retratos de presidentes de la sociedad. Sabemos que en 1877 adornaban el salón de sesiones los retratos de Fernando del Alisal, Joaquín Serrano Cañete, Vicente Wenceslao Querol y Cristóbal Pascual y Genís, según se desprende de las noticias relativas a la velada artística para la instrucción de mujeres, realizados según el anónimo redactor por "cuatro de nuestros mejores pintores" ("Revista de la semana", 1877: 17-18). El del magistrado Fernando del Alisal fue pintado por José Benlliure; el de Joaquín Serrano Cañete por Antonio Cortina; el del poeta Querol por Luis Franco, y el del abogado y periodista Pascual y Genís por Gonzalo Salvá (ROIG CONDOMINA, 1995: 114). Roig Condomina menciona otros tres retratos de presidentes: los de Eduardo Attard y Trinitario Ruiz Capdepón, que habría realizado Joaquín Agrasot, y el de Miguel Velasco y Santos, pintado por José Brel, según las noticias publicadas en la prensa valenciana de los años 1876 y 1877 . No hemos encontrado noticias posteriores de retratos de otros presidentes del Ateneo, como Teodoro Llorente, que fue presidente en 1880, o Francisco de Paula Campá, en 1881. Del mismo modo, la ausencia de noticias al respecto nos hace descartar la hipótesis de que existiese una galería de retratos extensiva a los presidentes de las distintas secciones ${ }^{551}$.

\subsubsection{Las exposiciones del Ateneo}

La importancia del Ateneo para el mundo artístico valenciano residió, fundamentalmente, en el establecimiento de exposiciones de carácter local que animaron el panorama cultural y el mercado del arte. En estas, que comenzaron a celebrarse en 1874, predominaron las escenas de género y los temas costumbristas, además de los paisajes; los retratos, menos frecuentes, no parece que representasen ni a consocios ni a artistas, ya que las vagas alusiones aparecidas en la prensa no permiten identificar las pinturas presentadas en estas exposiciones como retratos de socios artistas. Así, sabemos que en la segunda exposición Francisco Domingo presentó un retrato del que únicamente se señalaba el correcto estudio de Van Dyck y Rembrandt (SERRET, 1874: 238), y tampoco se identificaron los retratos presentados por Daniel Cortina (SERRET, 1874: 240) en la misma exposición, ni el pintado por Luis Franco y presentado en la quinta exposición del Ateneo (SERRET, 1874b: 332), del que solo se especifica que había sido pintado algún año antes.

Cabe pensar que la sociabilidad artística en el Ateneo Valenciano fue especialmente intensa, ya que allí concurrían jóvenes artistas que anteriormente habían sido compañeros en la Academia de San Carlos, y que, en muchos casos, se vincularon

\footnotetext{
${ }^{551}$ Especialmente interesante habría sido la existencia de retratos de los miembros de la sección de Bellas Artes, entre cuyos directores se encontraron Gonzalo Salvá (1875, 1881), Joaquín Agrasot (1880), Antonio Yerro (1882), Nicolau y Huguet (1882) e Ignacio Pinazo (1883).
} 
posteriormente a las actividades artísticas de sociedades como El Iris o el Círculo de Bellas Artes. Fomentando esta sociabilidad, el Ateneo contó desde 1874 y hasta finales de la siguiente década con una clase nocturna de acuarela, en la que se reunían alrededor de una veintena de $\operatorname{artistas}^{552}$; al parecer, se convirtió en punto de reunión de maestros y discípulos, lo que llevó a que la institución les cediese el piso alto para instalar sus talleres (BARRÓN, 2007: 15), uno de los cuales ocupó Ignacio Pinazo ${ }^{53}$. Estos motivos, que parecen sugerir un espacio muy activo a nivel artístico y también como foco de sociabilidad, plantean dudas sobre esta aparente inexistencia de retratos surgidos en esta sociedad como fruto de la relación continua entre artistas.

\subsubsection{Los retratos de Eduardo Rosales y Mariano Fortuny}

Hasta la fecha solo tenemos constancia de dos retratos de artista realizados desde y para el Ateneo de Valencia. Ambos se relacionan con la velada en homenaje de los pintores Eduardo Rosales y Mariano Fortuny que tuvo lugar el 23 de mayo de 1875. Esta quedó convertida en una sesión artística en la que se criticó el realismo, se leyeron pasajes biográficos de ambos artistas por parte de los socios Bernardo Ferrándiz y José Brel, y se expusieron algunas fotografías de cuadros de ambos pintores. Además de un busto escultórico de Fortuny, presidieron la velada dos retratos pintados al óleo de Rosales y Fortuny que ocuparon un lugar de honor bajo dosel.

Son escasas las noticias que hemos podido encontrar al respecto ${ }^{54}$; Vicente Roig afirmaba que el retrato de Rosales fue pintado por Germán Gómez Niederleytner, y que el de Fortuny lo fue por Gonzalo Salvá; ni Vicente Boix ni el barón de Alcahalí dan noticia de estos retratos en las entradas biográficas, pero sí Ossorio y Bernard, quien atribuye a Gómez Niederleytner el retrato de Fortuny, y añade que fue presentado a la exposición valenciana de 1879; a su vez atribuye la autoría del de Rosales a Gonzalo Salvá, del que especifica ser obra destinada al Ateneo de Valencia. Los datos aportados por la prensa, como el artículo publicado en La Renaixença (1875: 34) parecen corroborar las autorías mencionadas por Ossorio y Bernard y seguidas por Roig, además de añadir datos sobre la decoración del local del Ateneo con los elementos propios de las sesiones conmemorativas o fúnebres, como crespones negros.

\subsubsection{El Ateneo Barcelonés}

La importante actividad cultural desempeñada por el Ateneo Barcelonés no ha pasado desapercibida en lo que respecta a las bellas artes, pues ha sido analizada por

\footnotetext{
${ }^{552}$ Roig Condomina (1995: 112) señala como núcleo de la clase de acuarelas a los artistas Joaquín Agrasot, Juan Peyró, José María Fenollera, Germán Gómez, Vicente Borrás Mompó, Ignacio Pinazo, Daniel Cortina, Nicasio Serret, Luis Soria, Jacinto Capuz, Antonio Yerro, Vicente Nicolau Cotanda, José Nicolau Huguet, Luis Ramón Ballester, Pascual Alcaine, Francisco Ballester, Manuel Lluch y José Genovés.

553 “(...) llevándome al Ateneo, donde ya han comenzado sus fructíferas reuniones nocturnas los acuarelistas, hízome subir por empinada y estrecha escalera a los desmantelados desvanes, y allí, en uno de esos espaciosos recintos, vecinos de las nubes, que los pintores aman, encontré a Ignacio Pinazo, pincel y paleta en mano" (VALENTINO, 1880: 28).

${ }_{554}$ El número correspondiente del Boletín-revista del Ateneo de Valencia no ha sido localizado ni en la Hemeroteca Municipal de Valencia ni en la Biblioteca Valenciana Nicolau Primitiu.
} 
Jordi Casassas i Ymbert (1986), Mireia Freixá o, con mayor detenimiento, por María Carmen Riu de Martín (2008: 113-128). Sin embargo, en estos trabajos se señala de manera puntual la participación de algunos artistas dentro de su sección de Bellas Artes, ya fuese mediante las contribuciones en las conferencias sobre materias artísticas o a través de la organización de exposiciones, con lo que pasan por alto la importancia que la institución tuvo como foco de encuentro de artistas con la sociedad intelectual barcelonesa. Este descuido puede deberse, por una parte, al hecho de que el asociacionismo artístico en la capital catalana no había tenido una gran proyección pública durante la primera mitad del siglo XIX; el carácter fundamentalmente musical del Liceo barcelonés, así como las actividades expositivas de la Sociedad Protectora o de Amigos del Arte, llevan a pensar que buena parte del asociacionismo entre artistas se concentraba en torno a la Academia Provincial y a los talleres privados de los artistas. No obstante, y siguiendo las noticias aportadas por Casassas, la actividad artística fue el origen de otras sociedades como la Sociedad Filomática, de carácter literario, artístico y científico, en la que participaron el escultor Antoni Rovira i Trías y el pintor Claudio Lorenzale (CASASSAS I YMBERT, 1986: 30); también tuvo su desarrollo mediante la sección de Bellas Artes del Ateneo Catalán ${ }^{555}$, antecedente directo del Barcelonés, constituido en 1860. No en vano, en el discurso presidencia de la sesión de constitución del Ateneo Catalán Ramón Anglasell apelaba a los distintos profesionales para configurar una nueva asociación de carácter fraternal y enfocada al progreso mediante la cooperación y la puesta en común de los conocimientos de cada uno; prestaba especial atención a los artistas, y atribuyía a la falta de lazos entre las distintas disciplinas el particular aislamiento de los profesores de las bellas artes respecto a la sociedad, y la falta de educación en gusto artístico por parte de esta:

Con respecto a las demás clases de la sociedad se halla el artista todavía en más completo aislamiento: como no conoce más que el arte no puede estar en comunicación con quien no le hable de sus purísimas fruiciones y de sus sublimes encantos: los profanos ni siquiera sospechan su existencia, y llegan muchos hasta el extremo de confundir al artista con el artesano (CASASSAS I YMBERT, 1986: 168).

Lo cierto es que en el Ateneo Barcelonés, constituido oficialmente en 1872, no puede obviarse esta herencia previa de asociaciones, fundamentalmente de carácter económico, de la que proceden buena parte de sus miembros; sin embargo, la inclusión de una sección dedicada de manera exclusiva a las bellas artes ofrece ya cierta información sobre la importancia que estas cobraban dentro de la sociedad intelectual y burguesa barcelonesa. Respecto a los miembros que formaban esta sección, ya que según el reglamento los socios solo podían pertenecer de manera exclusiva a una, Riu de Martín (2008: 117) señala a personajes procedentes del mundo del arte en cualquiera de sus disciplinas, aunque hace constar que las actividades vinculadas a las artes plásticas recibieron menos apoyo que las relacionadas con el ámbito musical.

\footnotetext{
${ }^{555}$ La junta directiva de la sección de Bellas Artes estuvo presidida por Pau Milà i Fontanals, junto a Eusebi Font, Antoni Fargas, Antoni Peyra, Claudio Lorenzale y Elías Rogent (CASASSAS I YMBERT, 1986: 31).
} 
A pesar de no conocerse las listas de socios de la sección de Bellas Artes, los nombres de algunos de los artistas relacionados con las actividades del Ateneo Barcelonés y con la junta directiva de la sección son sumamente reveladores de la importancia de la institución como foco de sociabilidad artística: presidía la sección en 1879 el arquitecto Ignacio Conrado Bartroli, que contaba como secretario con el pintor Modesto Teixidor y como vocal de la directiva con el arquitecto Leandro Serrallach; en 1880 era vicepresidente de la misma el arquitecto José Torres Argullol, con su colega Federico Aymamí como vocal de la directiva; en 1881 dirigía la sección Antonio Gaudí, el pintor Juan Roig y Bofill actuaba como vicepresidente y Antoni de Ferrer y de Corriol como secretario; en 1882 figuraba como presidente el pintor Modesto Urgell, con el arquitecto Buenaventura Pollés como secretario; y en 1883 era vicepresidente el arquitecto Josep Amargós, con el pintor Cayetano Benavent como vicesecretario y Juan Imbert de Janer como revisor de cuentas. Pertenecieron también al Ateneo los arquitectos Luis Domènech i Montaner y Josep Puig i Cadafalch, además de los pintores Martí Alsina, Joan Planella y Santiago Rusiñol.

Respecto a la actividad de los artistas en el Ateneo Barcelonés, se ha subrayado la organización de exposiciones para revitalizar la vida cultural de la ciudad, tal y como contemplaban los estatutos de la sociedad (Boletín del Ateneo Barcelonés, 1880: 127128); no obstante, y en atención al carácter industrial del Ateneo, estas exposiciones no solo contemplaban la exhibición de productos artísticos, sino también productos artesanales, industriales e incluso productos agrícolas, a las que podían concurrir tanto los socios del Ateneo como cualquier persona que no lo fuera (art. 67). Las secciones también podían solicitar permiso a la Junta Directiva para la organización de exposiciones por parte de los socios (art. 68). Tal vez fuese esta carencia de un carácter exclusivamente artístico lo que motivó la iniciativa de Antonio Gaudí de llevar a cabo una exposición artística -según especificaba la prensa, de pintura, escultura, arquitectura, grabado, dibujo, litografía y fotografía (El demócrata, 1881/11/02: 3)destinada a los socios, con motivo de la cual, según recoge Riu de Martín (2008: 116), se haría ingresar en la sección de Bellas Artes a "diversos artistas de renombre de la ciudad para poder aumentar el prestigio de la muestra".

\subsubsection{La galería de retratos de socios ilustres}

Sin embargo, una de las actividades en la que participaron los artistas de la sección de Bellas Artes y que no ha sido recogida por los estudiosos de la institución es la configuración de la galería de retratos del Ateneo Barcelonés, que, al igual que la que estaba constituyendo el Ateneo madrileño, tenía la finalidad de subrayar la identidad de la corporación mediante sus socios ilustres. La galería del Ateneo Barcelonés tuvo un marcado acento de conmemoración póstuma, pues los retratos fueron presentados en las sesiones necrológicas que la institución dedicó a sus distinguidos socios fallecidos. Esta galería quedó inaugurada el 18 de junio de 1878, con la celebración de una sesión en homenaje de Ramón Anglasell y Serrano (ATENEO BARCELONÉS, 1878), quien había sido uno de los fundadores del Ateneo Catalán y miembro muy activo del Barcelonés. El retrato se encargó, cuatro años después de la muerte del ilustre 
economista, al pintor Josep Mirabent i Gatell, asiduo a las tertulias del Ateneo, quien estableció las pautas formales que habría de seguir el resto de la serie, presentando al personaje de medio cuerpo y tomando como modelo una fotografía.

El Boletín del Ateneo Barcelonés ofrece interesantes datos relativos a la participación de otros pintores en la vida del Ateneo y en la configuración de la galería de retratos de socios ilustres. Martí Alsina, que ya se había involucrado activamente en el Ateneo Catalán, también se vinculó al Ateneo Barcelonés -del que fue considerado socio fundador (CHILLÓN DOMÍNGUEZ, 2010: 165)-, y participó en la organización de exposiciones. En 1880, la Junta del Ateneo acordó la necesidad de realizar los retratos de dos socios fallecidos, José Anselmo y Clavé y Francisco Martorell, decidió encomendárselo a Martí Alsina; el encargo, no obstante, tenía sus propios precedentes, ya que en 1877 la Junta escribía una carta al pintor Martí Alsina en la que le comunicaba su interés en que participase en la inauguración de la galería de retratos con la realización del de Ildefonso Cerdá. En esta carta, reproducida por Chillón Domínguez en su tesis doctoral, se subraya el papel del pintor como socio artista del Ateneo:

Muy Sr. mío y estimado amigo y consocio: la actual Junta Directiva del Ateneo Barcelonés con cuya Presidencia me honro, anhelosa de emplear su acción en todo cuanto tienda a levantar y ennoblecer los sentimientos patrióticos del país, $\mathrm{y}$ considerando que uno de los medios más directos para el logro de tal propósito consiste en honrar la memoria de aquellos varones que un día tuvimos a nuestro lado y que al morir nos regalaron obras, ejemplos y virtudes dignos de constante loa, acordó, en una de sus últimas sesiones, inaugurar, durante el presente año académico, una Galería de Socios Ilustres, de los que pertenecieron a nuestra Corporación. (...) En esta confianza, y a nombre y por encargo de la Directiva, me dirijo a V. para manifestarle el vivísimo deseo que tenemos de que V. nos conceda su valiosa cooperación para llevar a efecto el noble intento que nos anima, y de que, en su doble calidad de Socio y pintor peritísimo, se digne encargarse del retrato del Sr. D. Ildefonso Cerdà, uno de los ocho elegidos para comenzar la expresada Galería, en la inteligencia de que dicho retrato debería quedar precisamente terminado para mediados del mes de Marzo próximo venidero ( CHILLÓN DOMÍNGUEZ, 2010: 175).

Martí Alsina aceptó el encargo y realizó en 1878 el retrato de su amigo ${ }^{556}$ de memoria [fig. 196], para lo cual contó con las facilidades que la hija del ingeniero Ildefonso Cerdá ponía a su disposición [fig. 197], según consta en la carta de agradecimiento del presidente del Ateneo al pintor ${ }^{557}$, y entre las que no cabe duda que el retrato fotográfico tuvo una gran importancia. La imagen que este quiso transmitir fue, precisamente, la de un nuevo tipo de artista de la modernidad, comprometido con la sociedad y en busca de su progreso: el ingeniero, autor del proyecto del Ensanche de Barcelona, aparece representado con elementos alusivos a su profesión (y estrechamente vinculados con los atributos propios de la representación tradicional del arquitecto,

\footnotetext{
${ }^{556}$ En los meses de verano, Martí Alsina visitaba la casa de Ildefonso Cerdá, donde realizó algunas pinturas.

${ }_{557}$ Carta del presidente del Ateneo, Sr. Ferrán, a Martí Alsina, 31 de octubre de 1877 (CHILLÓN DOMÍNGUEZ, 2010: 176-177).
} 


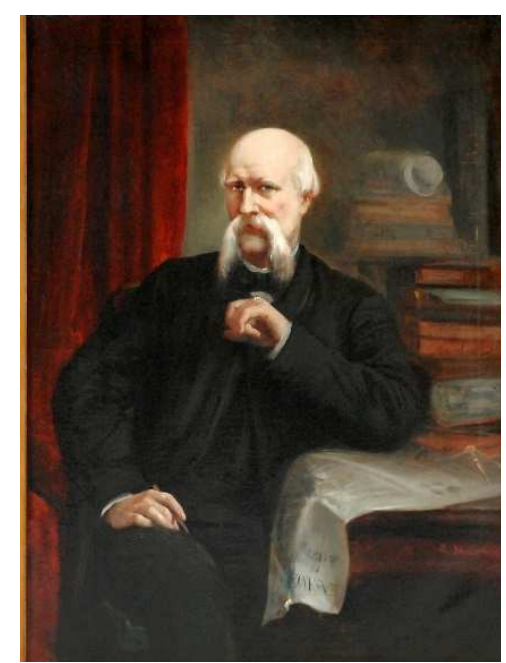

Fig. 196. Martí Alsina, Retrato de Ildefonso Cerdá. Biblioteca del Ateneo de Barcelona.

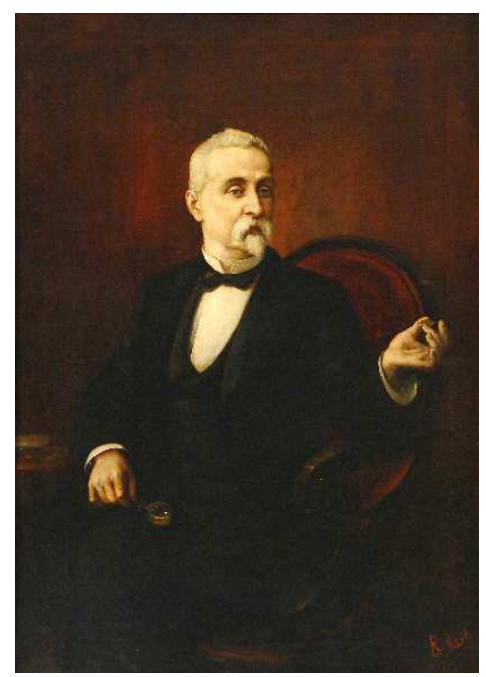

Fig. 198. Martí Alsina, Retrato de Francisco Martorell. Ateneo de Barcelona.

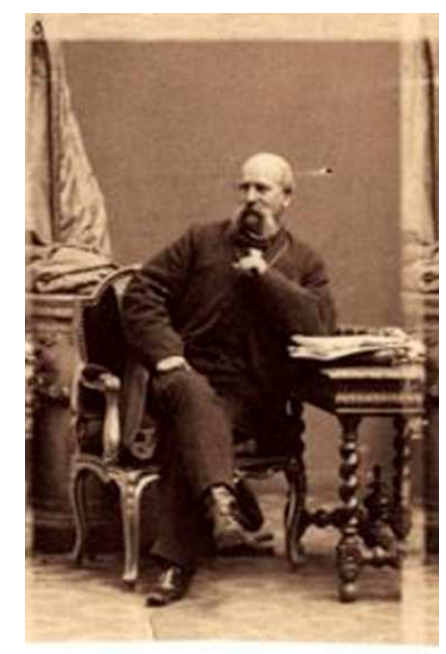

Fig. 197. Eugène Disderi, Retrato de Ildefonso Cerdá. Tarjeta de visita.

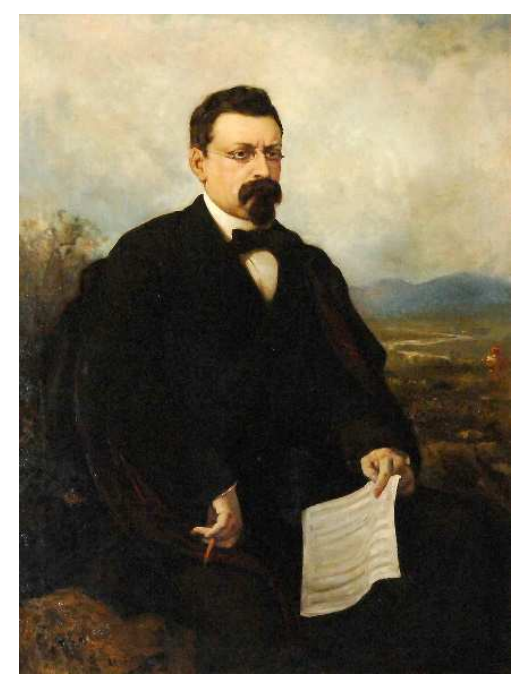

Fig. 199. Martí Alsina, Retrato de José Anselmo Clavé. Ateneo de Barcelona.

como evidencia plástica del conflicto entre ambos sectores profesionales), como eran el propio plano del Ensanche y un compás, además de sostener un lápiz en su mano derecha. Completa la escena una pila de libros y varios planos enrollados, que constituyen el fondo sobre el que se destaca el ingeniero y urbanista, acodado sobre la mesa con un gesto de seguridad que subraya la mirada inteligente y penetrante con que Alsina revitaliza la imagen fotográfica que le sirvió de modelo.

Además del retrato de Ildefonso Cerdá, la vinculación de Martí Alsina con la galería del Ateneo sería más estrecha todavía, ya que al llegar al conocimiento de la Junta que el pintor tenía la intención de realizar el de Francisco Javier Llorens, “del cual no existía más que el nombre en el marco que lo debía contener, por no haber dejado ninguna fotografía a su muerte" (ATENEO BARCELONÉS, 1880: 114), se propuso al pintor que realizase también los de Clavé y Martorell. El Boletín del Ateneo informaba de que "el Sr. Martí y Alsina, con un laudable desprendimiento", se había comprometido a realizar los tres retratos, rebajando el precio de dos de ellos a 560 pesetas en lugar de las 750 habituales, y regalando el tercero a la institución; así, en 
enero de 1880 figuraba ya el del filósofo Francisco Javier Llorens en la sesión necrológica que se le dedicó, y en febrero del mismo año el del compositor -y amigo del pintor- José Anselmo Clavé, en cuyo honor también se realizó una sesión ${ }^{558}$. En los retratos de Martorell [fig. 198] y de Clavé [fig. 199] Martí Alsina vuelve a resaltar, como ya hiciera en el de Ildefonso Cerdá, la identidad profesional de sus consocios. El primero, en calidad de arqueólogo, es presentado en el interior de una estancia, probablemente su gabinete, sujetando en una mano una lupa y en la otra lo que parece ser una moneda antigua, si bien la rigidez del gesto y su expresión evidencian menor compromiso que en otros retratos póstumos. Frente a este retrato que potencia la imagen de Martorell como hombre científico y erudito, Martí Alsina se permite en el de Clavé una mayor libertad a la hora de interpretar la identidad musical de su compañero. Sin faltar a la tradición en la galería de representar al efigiado de medio cuerpo, y por lo general sentado, incluye también los elementos propios de su profesión, ya que sostene en su mano izquierda una hoja de partituras en blanco, y en la derecha un lápiz que mantiene alejado del papel. A pesar del gesto hierático y el incorrecto dibujo anatómico del brazo derecho, el retrato parece estar mostrando a Clavé sumido en plena reflexión artística, evadiéndose su imaginación al paisaje con el que el pintor decidió configurar el fondo. De este modo, la inclusión de Clavé -con su correspondiente silla y los elementos de su arte- en un paisaje perfectamente tratado parece aproximar el retrato al tipo de la fantasía musical, brindando al mismo tiempo a su amigo una prueba más íntima de su talento.

Estrechamente vinculado a Martí Alsina, en cuyo taller se había formado, estuvo otro pintor vinculado al Ateneo Barcelonés que también participó en el primer impulso de la galería de retratos. Francesc Torrescassana fue el encargado de realizar en 1878 el retrato de Juan Güell y Ferrer, según afirma Glòria Escala ${ }^{559}$, aunque en el Boletín del Ateneo no se hace referencia a la autoría de la obra, ni tampoco fue recogida por Elías Molins $^{560}$. En el discurso de Argullol en la sesión necrológica que se le rindió en junio de 1879 se aludía directamente a su efigie, que sin duda presidió el acto, como se deduce de las palabras "vedle ahora en el retrato, cuyo parecido al original es perfecto y

\footnotetext{
${ }^{558}$ La nota aparecida en el Boletín del Ateneo recoge que el retrato de Llorens se expuso por primera vez el 24 de enero, y que había resultado "de admirable parecido a pesar de estar hecho de memoria", aunque actualmente no consta en la colección pictórica del Ateneo Barcelonés. El de Clavé se inauguró el 24 de febrero, y Roca hablaba en nombre de la corporación al afirmar que, debido al mérito personal de Clavé "el Ateneo Barcelonés, celoso de las glorias patrias y de perpetuar el relevante mérito de los socios que lo han ilustrado con sus altas condiciones, agrega hoy el retrato de Clavé a la galería en que figuran filósofos eminentes, sabios jurisconsultos, esclarecidos economistas, ingenieros que fueron honra de su patria y otras notabilidades que han dejado un surco luminoso en el seno de la corporación que tuvo la dicha de contarles en el número de sus asociados" (ROCA ROCA, 1881: 46). El retrato se conserva actualmente en la biblioteca del Ateneo Barcelonés.

${ }^{559}$ ESCALA I ROMEU, G. "Retrat de Joan Güell i Ferrer",

http://testimonisartistics.ateneubcn.cat/personatges-del-vuit-cents/retrat-de-joan-guell-i-ferrer/ (última consulta 28 de febrero de 2017).

${ }^{560}$ En la entrada correspondiente a Juan Güell da noticia de que el Ateneo Barcelonés había acordado colocar su retrato en la galería de socios distinguidos, dando también datos sobre la velada necrológica (ELÍAS MOLÍNS, 1895: 680). En la correspondiente a Francisco Torrescassana, atribuía a su mano el retrato de Juan Güell existente en la Galería de Catalanes Ilustres del Ayuntamiento de Barcelona, sin mencionar la obra del Ateneo Barcelonés (ELÍAS MOLÍNS, 1895: 695).
} 
si es verdad que sea el semblante espejo del alma, bien notaréis en las apacibles líneas de su rostro la expresión de cierta bondad ingénita, inteligencia en su espaciosa frente, firmeza en su mirada, modestia, formalidad, llaneza y seriedad en el conjunto" (ARGULLOL, 1879: 19; ESTASÉN, 1881: 4); las virtudes a que se alude, propias del hombre de bien burgués, constituyen información complementaria al retrato visual ofrecido por Torrescassana, presentando al industrial en su espacio de trabajo, junto a su escritorio, y con una misiva en la mano.

Forman parte también de la galería inicial de retratos del Ateneo Barcelonés el de Francesc Permanyer, que fue encargado en 1878 a Benito Mercadé; y el de Joan Agell, realizado por el pintor Joan Vicens, que llama la atención por el carácter oficial de la representación del científico, vestido con toga y medalla universitaria dentro de su laboratorio. Otros artistas participaron en la galería de retratos, como Joan Planella, que en el mismo año de su ingreso como socio del Ateneo (1885) realizaba el de Manuel Milà i Fontanals, o Manuel Cosí, que en 1895 pintó por encargo del Ateneo el del político Josep Coroleu. Hacia 1895 o 1896 realizaría Luis Graner por encargo de la sociedad el retrato del crítico José Yxert, que ocupó en varias ocasiones cargos en las juntas directivas del Ateneo, incorporándose con posterioridad el del arquitecto Josep Vilaseca, que, legado por sus descendientes, no fue creado con origen a esta galería.

\subsubsection{Dos retratos de pintores en la galería del Ateneo Barcelonés}

Un aspecto interesante que merece la pena destacar dentro de la galería de retratos de socios ilustres del Ateneo Barcelonés es el que alude, precisamente, a aquellos con los que la institución buscó honrar a sus artistas. Destacan dos casos singulares: el de Simón Gómez Polo y el de Ramón Martí Alsina.

En 1880 falleció el pintor Simón Gómez Polo, y el Ateneo acordó celebrar una velada necrológica a modo de homenaje. La reseña de los trabajos realizados durante el año aparecida en el Boletín del Ateneo Barcelonés refería que esta sesión, que tuvo lugar el 21 de abril, fue presidida por Vicente de Romero, y que en ella el pintor José Masriera y el crítico José Ixart leyeron trabajos biográficos sobre el pintor (ATENEO BARCELONÉS, 1880: 115; ELÍAS MOLINS, 1895: 664-666).

Proseguía esta breve nota afirmando que "para dicha velada, D. Juan Brull pintó el retrato del señor Gómez, regalándolo al Ateneo". Llama la atención, pues, que en abril de 1880 el retrato del fallecido figurase en la sesión necrológica, teniendo en cuenta que la obra que se conserva actualmente en el Ateneo Barcelonés [fig. 200] está firmada por Francisco Gómez Soler en 1881, discípulo, al igual que Brull, de Simón Gómez. Cabe la posibilidad de que esta obra, posterior a la que figuró en la velada, fuese legada con una mayor intención conmemorativa; en ella, el joven pintor es presentado de pie y de medio cuerpo, con su brazo derecho apoyado sobre el respaldo de una silla. A su espalda destaca un esbozo de una de sus pinturas más conocidas, "Judas en su desesperación ante los miembros del Sanedrín ${ }^{561 ", ~ q u e ~ c o n s t i t u y o ́ ~ l a ~ p r u e b a ~ d e ~}$

\footnotetext{
${ }^{561}$ La obra debía representar el tema de "Judas ante los miembros del Sanedrín”, con figuras de tamaño natural; no obstante, las incluidas en este retrato no se ajustan a estas dimensiones, y tienen un tratamiento
} 


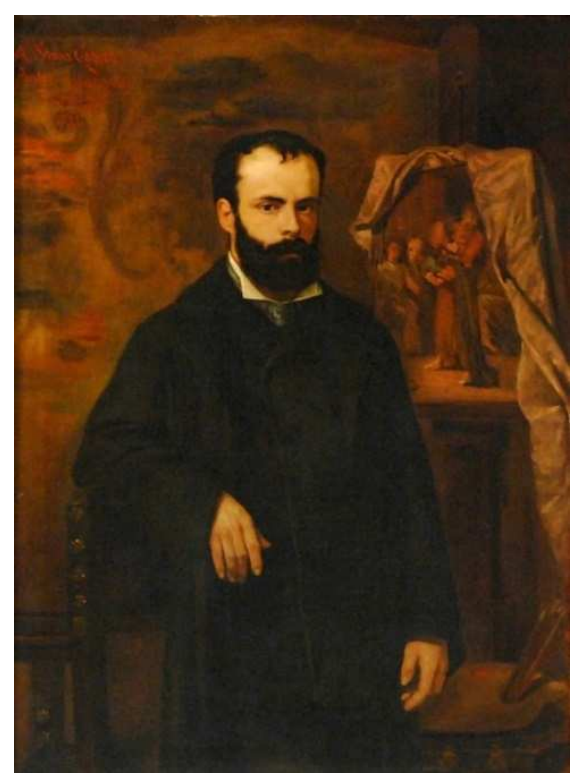

Fig. 200. Francisco Gómez Soler, Retrato del pintor Simón Gómez Polo. Biblioteca del Ateneo Barcelonés.

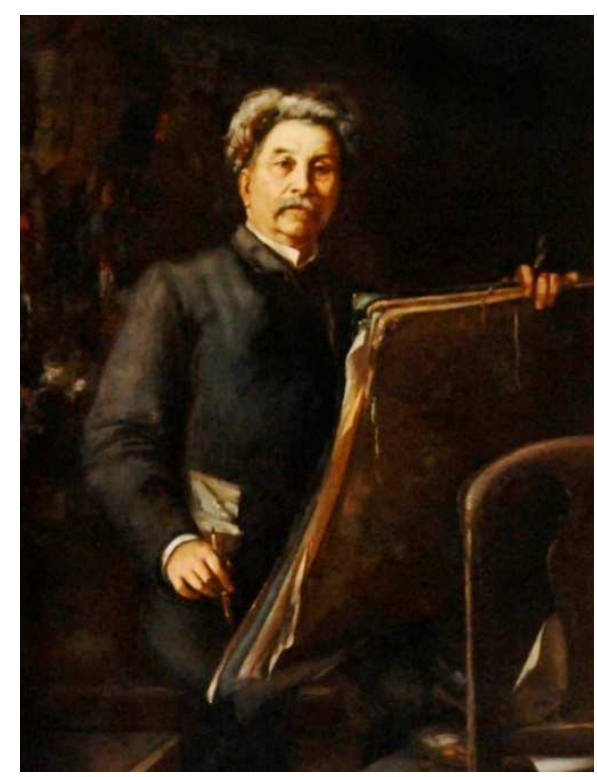

Fig. 201. Ricardo Martí Argullol, Retrato de Ramón Martí Alsina. Biblioteca del Ateneo Barcelonés.

oposición para la cátedra de colorido de la Escuela de Bellas Artes, y que sin embargo obtuvo Caba (ELÍAS, 1913: 52); esta obra, que había obtenido mención honorífica y había sido adquirida por la Diputación Provincial, fue precisamente cedida para la sesión necrológica, figurando en el Salón junto al retrato realizado por Brull y a la obra "Viva la Pepa", cedida por Juan Bofill y Martorell (ATENEO BARCELONÉS, 1880: 115). Reposan junto a su mano izquierda la paleta y los pinceles, que identificaban profesionalmente a Gómez como pintor.

No es muy clara, sin embargo, la relación que Simón Gómez pudo haber tenido con el Ateneo para merecer tal distinción; la sucinta nota del Boletín del Ateneo Barcelonés no ofrece ninguna noticia, si bien siempre se cuidaba de señalar la cualidad de socios de aquellos a los que honraba con una sesión necrológica y con la colocación de su retrato. La personalidad de Simón Gómez no fue desconocida entre los intelectuales barceloneses, ya que su taller fue con frecuencia punto de reunión de poetas, músicos, artistas e incluso políticos. En la biografía que realizó del pintor, Feliu Elías (1913: 80) bosqueja el perfil psicológico de Gómez, con observaciones interesantes sobre su carácter retraído y llegó a afirmar que fue su hermano Enrique el mayor impulsor y eje de la vida social del pintor, ya que "cuando el taller dejó de ser un lugar de cenáculo pictórico-literario-musical, él mantuvo un contacto más estrecho con los cenáculos del Ateneo, del Café Suizo, del Café de las Delicias o bien del Pelayo". Afirma, incluso, que Simón Gómez "tenía aquel temperamento selvático, áspero, insociable, (...) no frecuentaba ni el taller de los artistas, ni los cenáculos, ni se le veía por el Ateneo ${ }^{562}$.

marcadamente abocetado. (ESCALA I ROMEU, G. "Retrat de Simó Gómez i Polo", en testimonisartistics.ateneubcn.cat/personatges-del-vuit-cents/retrat-de-simo-gomez-i-polo/ Última consulta 2 de marzo de 2017).

${ }^{562}$ Y prosigue "Él no frecuentaba cenáculos ni ateneos, pero tenía a su hermano que le aligeraba de esta tarea de ir y venir de los lugares donde se renueva y acrecenta la inteligencia. Enrique era, en este sentido como en tatos otros, el proveedor, el recadero intelectual de Simón. Enrique era el que, de buen grado, 
Sería a través de su hermano Enrique, que frecuentó primero el Ateneo Catalán y posteriormente el Barcelonés, y que, según Feliu Elías (1913: 105) llegó a formar parte de la junta directiva, como Simón Gómez acabó entrando en el Ateneo como socio numerario.

Sin embargo, en lo que respecta a la velada necrológica y el retrato de Simón Gómez, Elías introduce una anécdota inverosímil, según la cual la iniciativa de honrar al artosta se trataría de una peculiar broma ${ }^{563}$. No parecen creíbles los argumentos que exponía, y que tal vez deban interpretarse como un ameno tópico más en la biografía del artista; en primer lugar, por el hecho de que el hermano del fallecido, que se había encargado de construir la reputación de Simón Gómez, era o había sido socio del Ateneo Barcelonés, motivo por el cual la broma habría sido interpretada como una falta de respeto hacia el espíritu de fraternidad que se esperaba reinase en la institución; en segundo lugar, porque la historia del Ateneo, que contaba con la institución previa del Ateneo Catalán, no era lo suficientemente dilatada como para que pudiese haberse pasado por alto el hecho de que Simón Gómez nunca había pertenecido al Ateneo, ni mucho menos lo había presidido; y finalmente porque, según los testimonios de sus contemporáneos, incluso José Masriera en la biografía que leyó del artista, el pintor Simón Gómez era perfectamente conocido por la intelectualidad barcelonesa perteneciente al Ateneo, la cual había acudido a las tertulias realizadas en su taller, y algunos de sus miembros participaron activamente en la sesión necrológica, como es el caso de Yxart o del pianista Vidiella, a quien Simón Gómez había retratado en alguna ocasión.

Sin que quede claro el motivo por el que se le dedicó este homenaje en lo que respecta a su relación con el Ateneo, que fue repetido por otras corporaciones catalanas como la Asociación Catalanista de Excursiones Científicas ("Lo trajiner caralá", 1880: 51), o la exposición monográfica en el Salón Parés ("Secció de bellas artes", 1880: 16) que se le dedicó en el mes de julio, podría sin duda deberse a una iniciativa de su hermano Enrique y de aquellos que habían frecuentado su tertulia en el taller del pintor.

Por el contrario, la existencia de un retrato del pintor Martí Alsina [fig. 201] no ofrece ningún tipo de dudas, ya que, como se ha expuesto anteriormente, la relación de este con el Ateneo y su implicación activa en esta sociedad era ya ampliamente conocida. Además de ser una de las figuras notables de la modernidad artística catalana y de haber contribuido a la creación de la galería de retratos, Martí Alsina también formó parte de la Junta directiva del Ateneo. La velada en su honor se celebró el 25 de

procuraba estar al corriente de todo y el que pasaba por el mundo de la inteligencia y lo llevaba a Poble Sec" (ELIAS, 1913: 97).

${ }^{563}$ Relata, haciendo alusión al hecho de que Simón Gómez nunca pisó el Ateneo y aun así su retrato fue colocado en lugar de honor, que "no fue un error del todo involuntario, sino que también tuvo buena parte de broma, según relata el Sr. Lluis Labarta. El bromista fue Sampere i Miquel, quien montó una zaragata del demonio contra la Junta del Ateneo por la negligencia en honrar la memoria de Simón Gómez, uno de los más prestigiosos presidentes del Ateneo, todo para ver si la Junta se dejaba engañar y solo por el gritería se dejaba convencer. En efecto, la Junta se cuidó de encargar el retrato, organizar la sesión necrológica y colocar la efigie en la Galería de Presidentes Ilustres; así se hizo con el beneplácito de todos los socios (...)" (ELÍAS, 1913: 163). 
junio de 1895, con la intervención de Casellas y de Angel Guimerà, en el salón de cátedras de la sociedad, donde también se instaló una pequeña exposición con las obras del artista (La dinastía, 1895/24/06: 1). El retrato fue encargado al hijo del pintor, Ricardo Martí Aguiló, en $1895^{564}$, aunque no parece que figurase en esa velada de homenaje, ya que Triadó fecha la obra en 1896, año en que el Ateneo perseveró en su recuerdo al difunto artista ofreciendo en los Juegos Florales una medalla de plata a la mejor monografía o estudio de Ramón Martí Alsina y organizando una tómbola artística en beneficio de la viuda e hijos menores del pintor (La dinastía, 1896/20/02: 2). La noticia recogida por La dinastía el 13 de enero de 1896 permite constatar la voluntad del Ateneo por perpetuar la memoria de sus consocios ilustres, ya que ofrecía una medalla de plata "a la mejor monografía o estudio de uno de los siguientes escritores: Don Joseph Ixart, don Joseph Coroleu, don Frederich Soler, y del pintor don Ramón Martí y Alsina, que Cataluña acaba de perder" (La dinastía, 1896/13/01: 1).

La imagen que Ricardo Martí destinó a la galería del Ateneo presenta al artista, de edad avanzada, sentado en lo que parece ser un banco, con una gran carpeta de dibujos apoyada en sus rodillas y firmemente sujeta con la mano izquierda en su parte superior; una representación alejada de la formalidad del retrato de Simón Gómez que plasma una identidad artística más vinculada con la práctica directa de la pintura. Así, sostiene en su mano derecha un lápiz, indicando de manera inequívoca que el retratado se encuentra realizando un esbozo en un papel que, oculto al espectador, se apoya en la carpeta. Un deje de desorden e inmediatez parece emanar de la obra, en los papeles que sobresalen, arrugados y expuestos, por la carpeta, y también en la paleta que reposa en primer plano sobre una silla, con los colores ya dispuestos en ella, como si el esbozo que está realizando al carbón fuese solo un inicio que quedará incompleto sin estos.

\subsection{Sociedades Protectoras de Bellas Artes}

\subsubsection{La Sociedad Protectora de Bellas Artes de Madrid (1856-1861)}

El cierre definitivo del Liceo Artístico y Literario en 1851 y el cese de las exposiciones públicas de la Academia de San Fernando dejaron el panorama artístico sin espacios a propósito para la estimulación de las bellas artes, y a los propios artistas sin un lugar en el que reunirse de manera oficial, o en el que poder exponer y vender sus obras de manera periódica. La constitución en la capital de una Sociedad Protectora de las Bellas Artes a finales de 1855 buscaba, en efecto, responder a estas necesidades con el fin de fomentar y dar prosperidad a las bellas artes, pero también proteger a los propios artistas, tal y como señala el artículo $1^{\circ}$ de su reglamento (“Artistas", 1855: 4). La prensa acogió de manera muy calurosa la propuesta de la Sociedad Protectora debido a su noble objetivo, que planteaba una protección de la práctica profesional de las artes (y por lo tanto con un objetivo implícitamente masculino), como se desprende de la noticia aparecida en La Esperanza, que afirmaba que "el objeto de esa sociedad es la

\footnotetext{
${ }^{564}$ Xavier Triadó no ofrece una fecha precisa, aunque recoge el acuerdo de la Junta de encargar este retrato en el libro de actas del Ateneo correspondiente a 1895.

(http://testimonisartistics.ateneubcn.cat/personatges-del-vuit-cents/retrat-de-ramon-marti-i-alsina/ última consulta: 2 de marzo de 2017).
} 
creación de un centro de acción en que puedan dignamente desarrollarse la emulación noble y la protección verdadera por medio de la discusión, de la realización y publicación de obras y de constantes exposiciones públicas" (La esperanza, 1855/07/12: 4). La iniciativa madrileña contaba con el precedente de las sociedades dramáticas constituidas en 1844 con el fin de promover la música, la literatura dramática y la puesta en escena, que contaron con su propio montepío para socorrer a "los autores desgraciados o a sus familias" (El heraldo, 1844/16/01: 4). Además, Barcelona había instalado en 1846 una primera Sociedad Protectora de Bellas Artes en cuya directiva se encontraban, entre otros, el pintor Claudio Lorenzale, Jaime Batllé y José de Manjarrés y Bofarull (El español, 1846/03/11: 2). La nueva sociedad, a la que se sumaron algunas de las más reputadas personalidades artísticas madrileñas, ya no estaba planteada como un instrumento para la educación y el ameno recreo; en esta ocasión, seguía los ejemplos de las sociedades recreativas y de las de socorros mutuos, buscando poner de relieve y paliar la desprotección oficial a la que se encontraba sujeta la profesión artística. Tras la experiencia liceísta, y conscientes del apoyo económico que iba a requerir la nueva sociedad, los redactores de las constituciones abrieron sus puertas a todos los artistas, pero también a las personas que, sin serlo, deseasen contribuir económicamente (artículo $2^{\circ}$ ), promoviendo además la instalación de un salón de exposición y venta de obras; con el fin de motivar a los socios al pago mensual de las cuotas, se proponía también la celebración de rifas de objetos artísticos, para lo cual los números de participación en el sorteo figuraban en el recibo de pago. Sin embargo, la Sociedad Protectora de Bellas Artes también recuperaba parte del espíritu de sociabilidad del Liceo y de algunas tertulias privadas, con el propósito constituirse como un centro para la conversación y la producción artística.

La aceptación entre sus socios de cualquier persona interesada por las bellas artes suponía nuevamente una búsqueda de miembros procedentes de la buena sociedad, que pudiesen contribuir con su renombre y aportaciones económicas al lustre de la Protectora, tal y como hizo Lord Howden, embajador de Inglaterra ${ }^{565}$. Nuevamente, esto suponía la aspiración del artista de encuadrarse dentro de la élite social en su calidad de productor intelectual. En un ambiente en el que debía primar la protección de la identidad profesional del artista, este negociaba su papel masculino -de evidente vulnerabilidad- configurándose como un personaje indispensable en el consumo burgués como creador de objetos de lujo que, a su vez, determinaban el poder adquisitivo, el gusto y las cualidades intelectuales del cliente. Si bien inicialmente estaba planteada con cuatro secciones (pintura, escultura, arquitectura y grabado), otras disciplinas se abrieron paso, creándose una de literatura en febrero de $1856^{566}$ y otra de música $^{567}$. Sus competencias comenzaron a ampliarse, buscando tener un salón de

\footnotetext{
${ }^{565}$ El interés de Lord Howden por la sociedad creada por Esquivel se tradujo en su inscripción como miembro y la donación de diez mil reales (El clamor público, 1856: 3), algo que le valió el agradecimiento de la Protectora de Bellas Artes y, a juzgar por el mismo periódico, el ser acusado de buscar popularidad con su gesto ("Severidad intempestiva", 1856: 3 ).

${ }^{566}$ La constitución de su junta directiva fue efectiva en febrero de 1856, estando formada por antiguos liceístas como Ventura de la Vega, Joaquín Francisco Pacheco, Juan Antonio Viedma, Manuel Fernández y González y Pedro de Madrazo (La Iberia, 1856/23/02: 4).

${ }^{567}$ Las primeras noticias que tenemos sobre esta sección datan de julio de 1856.
} 
estudio para las diferentes artes ${ }^{568}$, instaurar distintas cátedras que facilitasen instrucción $^{569}$ y también celebrar sesiones de competencia. La sección de pintura comenzó esta última actividad en noviembre de 1856, que tenía lugar los lunes y jueves de ocho a once de la noche, y se cambió a lunes y martes a comienzos de 1857 coincidiendo con el traslado de local; en ellas podían tomar parte todos los socios que así lo deseasen, independientemente de si eran artistas o aficionados (SÁNCHEZ RAMOS, 1856: 3), y al final de la sesión se realizaba la rifa de una o varias de las obras ejecutadas entre los asistentes.

Sabemos que, entre otros, formaron parte de la sociedad los artistas Antonio María Esquivel (fundador y primer presidente), Cecilio Pizarro, Manuel Rodríguez Guzmán, José de Madrazo, Federico de Madrazo (presidente de la sección de pintura en 1856), Ponciano Ponzano, que lo fue el mismo año de la de escultura, Juan Bautista Peyronnet, José Vallejo, Carlos María Esquivel o Luis de Madrazo; artistas, en definitiva, vinculados con la Academia de San Fernando, y, por lo tanto, con la élite artística, algo que no pasó desapercibido cuando los estatutos de la sociedad tuvieron que pasar por la Academia de San Fernando para su aprobación ${ }^{570}$. Efectivamente, en la Junta General de la Academia 9 de noviembre de 1856, a la que acudieron Vicente Peleguer, Bernardo López, Antonio María Esquivel, Carlos Luis de Ribera, Sabino Medina, Joaquín Espalter y Luis Ferrant, entre otros, se dio cuenta de la presentación y aprobación por parte de la Academia de los estatutos de la Sociedad Protectora de Bellas Artes

Analizando y examinando los fines de su institución, que encontraba muy útiles y beneficiosos para la misma, y concluía proponiendo se excitase al Gobierno a proporcionarla [sic] un local espacioso y decente donde pudiese verificar su exposición permanente, el cual podría al mismo tiempo servir para que la Academia celebrase la suya general cada dos años. La Academia se conformó en todo con este dictamen excepto en la última parte, acordando que se propusiese tan solo la conveniencia de facilitarla [sic] un local, pero sin establecer la comunidad de él con la Academia a fin de evitar disgustos que esta circunstancia pudiera acarrear en lo sucesivo ${ }^{571}$.

Esto indica que, a pesar de que algunos académicos tenían relación efectiva con la Sociedad Protectora de Bellas Artes, la Academia pudo llegar a percibirla como potencialmente perjudicial para la institución oficial, siendo posteriormente la relación mucho menor de lo que El clamor público había pretendido.

\footnotetext{
568 Con el fin de recaudar fondos para esta causa, se acordó la realización de catorce cuadros que representarían a las nueve musas, Apolo, la Pintura, Escultura, Arquitectura e Historia, para ser vendidos o rifados, y así poder comprar los modelos y materiales necesarios (El clamor público, 1856/12/07: 3).

${ }^{569}$ La primera instaurada fue de anatomía y perspectiva, para la que se ofreció el propio Antonio María Esquivel; en 1857, siguiendo el ejemplo del Liceo, se estableció una cátedra de dibujo "para la enseñanza gratuita de los socios y sus hijos" ("Bellas Artes", 1857: 4).

${ }^{570}$ El clamor público (1856/30/10: 3) recogía esta noticia, apuntando que "como muchos de los socios de la Academia lo son igualmente de aquella sociedad, creemos que falle favorablemente y con la brevedad que es necesaria".

${ }^{571}$ Acta de la Junta General de 9 de noviembre de 1856, ARABASF (3-92), fol. 200 r. y v.
} 
Otros artistas, como Alfredo Perea, José González Bande, Francisco Díaz Carreño, Manuel Sánchez Ramos, Cecilio Pizarro, Víctor Hernández Amores, Ignacio Suárez Llanos, Manuel García Hispaleto, Antonio Pérez Rubio, Paulino la Linde, Cosme Algarra y Domingo Valdivieso, o pintores aficionados como Ventura Castelaro y José de Toro participaron en las sesiones de competencia (también denominadas sesiones prácticas). Tras el fallecimiento de Antonio María Esquivel, la sociedad dio un nuevo giro: la ampliación del círculo de socios en busca de fondos que respaldasen los múltiples gastos que afrontaba esta y que permitiesen actuar en acciones benéficas dio lugar a invitar a acaudalados amantes de las artes. De esta noticia daba cuenta el Museo universal, afirmando que

la junta directiva deseosa de ensanchar cada vez más el círculo de sus benéficas operaciones, ha dirigido últimamente una comunicación a multitud de personas conocidas por su ilustración y su amor a las artes, invitándolas a inscribirse en la lista de socios, los cuales por la módica cantidad de veinte reales al mes, además de la satisfacción de apoyar tan honroso pensamiento, tendrán derecho a obtener en premio de su desembolso los grabados y objetos de valor artístico que se rifan todos los meses según su reglamento ("Sociedad Protectora de Bellas Artes", 1857: 7).

En este sentido, la misma revista, constituida en órgano de prensa de la sociedad, daba noticia del ingreso de personas muy distinguidas:

A sus constantes esfuerzos, no menos que a la bondad del pensamiento que los guía, se debe que hayan tenido ingreso en la sociedad un gran número de personas de todas clases, y especialmente de la más distinguida por el nacimiento y la riqueza, la cual naturalmente se halla más que ninguna otra en estado de proteger las artes. Entre las personas que se han inscrito últimamente en el catálogo de los socios se encuentran los señores conde de Altamira, marqués de la Isla, duque de Alba, conde de Casa-Bayona, duque de Rivas, marqués de la Cañada, marqués de Villavieja, don Francisco de Paula Retortillo, don Ángel Calderón de la Barca, don Francisco Muños del Monte, don Balbino Cortés, don Nazario Carriquiri y otros muchos ("Sociedad Protectora de Bellas Artes", 1857: 79).

Tal vez por este motivo fue nombrado vicepresidente el acaudalado banquero, también vinculado anteriormente al Liceo, José de Salamanca, lo que transformó progresivamente la sociedad al incluir entre sus actividades otras de carácter lúdico, como la instalación de una mesa de billar (La España, 1847/29/10: 4), la reforma de las bases de las distintas secciones en 1859, la constitución de una sección lírica y dramática ese mismo año (RIVERA, 1859: 4; "Sociedad literaria", 1859: 4) y la celebración de bailes de máscaras en 1860 (GRANDA, 1860: 4).

A pesar del interés que la Sociedad protectora de las Bellas Artes suscita como espacio para la sociabilidad artística, son escasas las noticias que tenemos al respecto para formar una idea clara de cómo influyó en los artistas que la frecuentaron, si bien el hecho de ser considerada sociedad bajo patrocinio regio en 1856 movió a algunos artistas a afianzar su posición dentro de ella con una clara voluntad de proyección 
social $^{572}$. Los datos encontrados hasta la fecha parecen indicar que se trató de una sociedad exclusivamente masculina hasta 1859 , como se desprende de algunos datos, como los nombres de los participantes en las sesiones o de los ganadores en las rifas, entre los que no se encuentra ninguno femenino, o la existencia de juegos como el billar, vinculado con la modernidad y el ocio masculino (ZOZAYA, 2015: 85); respecto a la presencia femenina, queda constancia de que en 1859, con motivo de la formación del Nuevo Liceo a través de las secciones lírica y dramática, la sociedad nombró una comisión, formada por Narciso Serra, Rafael Hernando y Braulio A. Ramírez "para solicitar la concurrencia de las alumnas del Conservatorio y la de todas las señoritas que puedan pertenecer a las secciones lírica y dramática como socias de mérito", aunque no parece que se hiciese extensivo al resto de secciones ("Sociedad literaria", 1859: 4). La actividad de los socios de la sección de pintura puede dividirse en dos períodos: el primero, correspondiente al año de 1856-1857, y vinculado con la intención original de Esquivel de formar una sociedad artística, es del que menos noticias se conservan y, sin embargo, en el que es más probable que el retrato tuviese cierto desarrollo; el segundo corresponde, tras la oscuridad en que las fuentes envuelven el año de 1858, a 1859, en el que las sesiones de pintura vuelven a estar concurridas e integradas por jóvenes pintores ajenos a las antiguas del Liceo, celebrándose también exposiciones. Las sesiones prácticas de pintura fueron, durante 1857, reuniones en las que un número limitado de pintores se dedicaba a realizar obras improvisadas o copias del natural, mientras el resto de socios se dedicaba a la conversación y a observar a los artistas; la amenidad de las reuniones, que propiciaba el encuentro de una sociedad culta, no restaba por el contrario el que algunos concurrentes echasen de menos la participación de las otras secciones "porque de este modo sería aún más amena la distracción, y además lucirían sus talentos

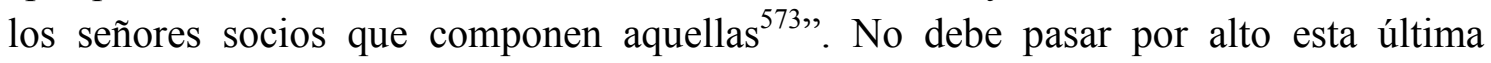
intención, que al parecer era monopolio exclusivo de los artistas en las sesiones, trasladando la sociabilidad culta en el estudio del pintor a las sesiones en las que podían exhibirse varios a la vez. Hasta 1859 no se realizaron sesiones conjuntas de varias secciones, momento en que las de pintura y literatura comparten protagonismo ("Nuevo Liceo", 1859: 3), con participación de la de música (La época, 1859/27/05: 3), aunque en 1860 parece que las sesiones volvieron a ser exclusivamente pictóricas ${ }^{574}$.

El retrato no fue el género más cultivado en la sociedad, algo perfectamente comprensible ya que las obras no rifadas estaban destinadas a la exposición y venta

\footnotetext{
${ }^{572}$ Real Orden de 3 de abril de 1856 por la que Luis Carondelet, duque de Bailén, Mayordomo Mayor de Isabel II, comunica a José de Madrazo que la reina ha aceptado su solicitud de colocar su nombre en la cabeza de los asociados de la Sociedad Protectora de Bellas Artes, Archivo del Museo del Prado, caja 15, exp. 22, doc. 53.

573 "La sociedad protectora de bellas artes celebró en la noche del martes 2 del corriente la sesión de competencia; inútil sería manifestar a nuestros lectores los nombres de las muchas personas de alta clase que concurrieron, baste decir que con la presencia de una reunión tan brillante había grande animación, y todos los señores socios que tomaron parte se esmeraron en ejecutar lindos bocetos, unos a su capricho y otros estudiando el gracioso modelo que con este fin ha adquirido la sociedad" (La esperanza, 1857/06/06: 3).

574 “(...) celebramos el entusiasmo que tienen muchos socios, y particularmente los que pertenecen a la sección de pintura, y desearíamos que los de las demás secciones tomaran, asimismo, parte, amenizando aquellos actos según lo verificaban anteriormente" ("Sociedad protectora de las Bellas Artes", 1860: 3).
} 
dentro de la misma ${ }^{575}$; sin embargo, entre las novedades incluidas en la sección de pintura en noviembre de 1856 se contaban, por una parte, un concurso mensual de una cabeza de expresión, y por otra, sin duda más interesante, el hecho de que algunas de las rifas mensuales correspondiesen a retratos. Así, en la rifa mensual del 30 de noviembre, Antonio María Esquivel se había ofrecido como autor de la obra correspondiente, que sería "un retrato de busto y tamaño natural (...) en obsequio del agraciado ${ }^{576 ", ~}$ (SÁNCHEZ RAMOS, 1856: 3), es decir, de uno de los socios; no obstante, también se daba la posibilidad de que dicho socio designase a otra persona cuyo retrato desease. Para la siguiente rifa se ofreció el pintor José González Bande a realizar el retrato correspondiente, en los mismos términos que el anterior ("Sociedad Protectora...", 1856: 3).

La celebración de exposiciones y certámenes en la Sociedad, al margen de la exposición permanente, se remonta a 1857 , que tuvo lugar en el mes de junio ${ }^{577}$, dándose otra en el mes de enero de $1858^{578}$; la más notable, sin embargo, fue la que organizó la sociedad en 1859 con motivo de la inauguración del Nuevo Liceo, en la que se rindió homenaje al fundador de la Sociedad, Antonio María Esquivel. Se expusieron algunas de sus obras junto a otras composiciones -fundamentalmente paisajes y cuadros de costumbres- realizadas por los socios pintores y aficionados. La única reseña de la exposición (FIDELIO, 1859: 1) demuestra que el retrato no tuvo ninguna importancia en la Sociedad Protectora de Bellas Artes y que, a pesar de que artistas como Carlos María Esquivel, Antonio Rotondo, Eusebio Valdeperas, Cecilio Pizarro, Víctor Manzano, Cosme Algarra o Calixto Ortega ${ }^{579}$ compartieron momentos en las sesiones y clases de la sociedad, no hubo cabida para el retrato de artista.

Con estos datos se puede observar que la Sociedad Protectora, pese a sus fines nobles, sufrió una evolución similar a la del Liceo al adaptarse a los gustos y necesidades de la burguesía, que configuraba la mayor fuente de ingresos para la

\footnotetext{
${ }^{575}$ Las noticias relacionadas con las sesiones prácticas de pintura dejan constancia de que en las primeras celebradas se realizaban bocetos y estudios del natural, para lo cual la sociedad adquirió un modelo ("Sociedad protectora de Bellas Artes", 1857: 3; "Sociedad protectora de Bellas Artes", 1857: 3; La Esperanza, 1857: 3); paisajes y copias ("Rifa", 1857: 4), bocetos inspirados en temas orientales y pintura de género ("Sesión práctica", 1859: 4; "Sociedad protectora de bellas artes", 1859: 4).

576 En esta ocasión, el boleto ganador fue el del director de El criterio, sin que tengamos noticia del retrato que finalmente mandó hacer a Esquivel ("Rifa", 1856: 3).

${ }^{577}$ La prensa madrileña recoge las fechas de celebración, sabiendo que tuvo lugar el día 15 de junio y que el 20 se realizó la adjudicación de premios; sin embargo, no trascendieron las obras presentadas ni los premiados (GARCÍA, 1857: 2).

${ }_{578} \mathrm{Al}$ igual que con el concurso anterior, sabemos que la fecha límite de recepción de obras era el 1 de enero de 1858 ("Recreo", 1857: 4), pero no quedan noticias de su celebración final ni de las obras que pudieron haber participado.

${ }_{579}$ Tan solo Carlos María Esquivel y Cecilio Pizarro formaban parte del núcleo original de la Sociedad; Cosme Algarra se vinculó activamente a ella, actuando en el papel de Apeles en la obra La frutera de Murillo (FIDELIO, 1859: 1) e impartiendo clases de acuarela (REAL ACADEMIA DE BELLAS ARTES DE SAN FERNANDO, 1893: 17); más escasas son las noticias sobre la relación entre los recién regresados a España, Eusebio Valdeperas y Víctor Manzano, con la Sociedad; Valdeperas adquirió algunas de las obras realizadas por sus compañeros en la sesión del 21 de junio de 1859 (La Época, 1859/22/06: 4; "Fomento artístico literario", 1859: 3). Víctor Manzano no aparece mencionado como pintor activo en las sesiones de la Sociedad Protectora, aunque podría haber asistido a ellas como su amigo Ignacio Suárez Llanos.
} 
realización efectiva de exposiciones y actividades. Junto a los artistas que se suscribieron para gozar del amparo que la protectora ofrecía, a similitud de las sociedades de socorros mutuos, es significativo que buena parte de los socios perteneciesen a la élite profesional y estuvieran vinculados a la Academia y a Palacio, lo que manifiesta que se trató de una sociedad fundada desde una perspectiva privilegiada por parte de la élite hacia artistas menos favorecidos. La localización de los libros de actas de la sociedad permitiría rastrear la actividad administrativa y económica, lo que podría ayudar a definir su actividad no solo en la gestión de exposiciones, sino también de los socorros mutuos prestados.

\subsubsection{La Sociedad Protectora de las Bellas Artes de Sevilla (1869-1876)}

En 1869 se constituyó en Sevilla, por iniciativa privada, la Sociedad Protectora de Bellas Artes de esta ciudad, con la finalidad de asegurar a los artistas una institución en la que exponer públicamente sus obras para fomentar de este modo la prosperidad de las artes, tal y como recoge el artículo primero de su reglamento ${ }^{580}$. Compuesta tanto por artistas como por aficionados y notabilidades de la sociedad sevillana, la sociedad protectora se instaló en los salones del Alcázar; los artistas, privilegiados según los estatutos al estar eximidos del pago de las cuotas mensuales si contribuían con sus obras a las exposiciones y entregaban a la sociedad el cinco por ciento del valor de cada obra vendida, tuvieron un papel importante en el desarrollo de las actividades, constituyendo los jurados que examinaban y aprobaban las obras a presentar a las exposiciones ${ }^{581}$. Además, el artículo 19 establecía que la Junta directiva, órgano administrativo de la sociedad, estaría compuesta por doce personas: un presidente, un vicepresidente, siete vocales, un depositario, y dos secretarios; de ellas, al menos cuatro debían ser artistas. Siguiendo esta disposición, la lista de socios incluida en el reglamento recoge en su Junta Directiva a cuatro artistas, los pintores Edmundo Noel, Ignacio Verdejas y Eduardo Cano, y el escultor Gumersindo Jiménez Astorga.

La iniciativa de la fundación de la Sociedad correspondía, según manifestó Gonzalo Segovia y Ardizone (1871: 5), a los propios artistas y a su entusiasmo por revitalizar la vida artística de la ciudad tras un periodo de crisis y postración ${ }^{582}$, buscando dirigirse "a las clases acomodadas" y "pedir protección a los que por sus estudios, por su posición y por su nobleza debía velar por el decoro, por el lustre de la metrópoli andaluza". Se dotaba así de un enfoque basado en el privilegio económico en el que se subraya, frente a lo ocurrido en otras sociedades artísticas previas, la vulnerabilidad en la que se encontraba el artista contemporáneo. De los 178 socios que figuraban en la lista publicada junto al Reglamento (anexo 10), y que debe fecharse hacia 1870 o 1871, se

\footnotetext{
${ }^{580}$ SOCIEDAD PROTECTORA DE LAS BELLAS ARTES, 1871: s.p. El documento consultado se encuentra en la Biblioteca Nacional (VC/4444/8).

${ }^{581}$ Según los artículos 11 y 12 del mismo reglamento, una de las actividades fundamentales de la sociedad era, precisamente, la organización de exposiciones públicas de obras de arte; para asegurar un cierto grado de calidad y decoro entre estas, la Junta directiva delegaba en tres artistas escogidos que practicasen el mismo arte, dependiendo de sus informes para la admisión de obras y para la adquisición de las mismas por parte de la Sociedad.

${ }_{582}$ Puede referirse, como indica Pérez Calero (1998: 277), a la supresión de la Escuela de Bellas Artes en 1869.
} 
puede contar la nada desdeñable cantidad de 50 pintores, 5 escultores y un arquitecto, entre los que se encontraban algunos de los nombres más relevantes del panorama artístico sevillano, como Eduardo Cano, Gumersindo Díaz, Virgilio Mattoni, Manuel Ussel, Manuel Cabral Bejarano, Francisco Cabral Bejarano, Manuel Barrón o Vicente Esquivel.

A pesar de que es escasa la información respecto a la actividad de la Sociedad Protectora sevillana, que celebró de manera regular exposiciones y certámenes a los que no solo concurrieron los artistas locales ${ }^{583}$, se desprende la conclusión de que, más que un foco de sociabilidad artística, fue una respuesta puntual al problema suscitado por el mercado de arte en la ciudad. Apoya esta idea el hecho de que la mayoría de los socios artistas estaban vinculados con la Academia -bien en relación a la formación artística de la Escuela de Bellas Artes o como miembros de esta-, que ya había facilitado una sociabilidad artística previa y de la que consta como testimonio el retrato que de Gumersindo Díaz realizó Valeriano Domínguez Bécquer en 1859 (Museo de Bellas Artes de Sevilla, $\mathrm{n}^{\circ}$ inv. 376P). De los artistas que pertenecieron a la Protectora de Bellas Artes y de los cuales nos ha sido posible recopilar algún dato biográfico, llama la atención que nacieran, en su mayoría, entre 1825 y 1835 , por lo que pertenecían a una generación posterior a la que constituyó el foco de sociabilidad artística del Liceo sevillano $^{584}$; este dato, aparentemente irrelevante, constituye una prueba de que los artistas que formaron parte de la Sociedad Protectora se encontraban en el momento en que pertenecieron a ella en edad madura, y por lo tanto profesionalmente activos y afectados por los vaivenes a los que los gustos de la clientela y la desprotección oficial sometían a su oficio ${ }^{585}$. Parece lógico, por lo tanto, que no se prestase atención al retrato de artista como forma de constituir una identidad corporativa $y$, menos aún, que este tuviese cabida en unas exposiciones destinadas a la venta y la captación de clientes ${ }^{586}$. No es extraño, pues, que no hayamos encontrado referencia alguna que apunte en la dirección de la existencia de retratos generados en el marco de esta Sociedad.

Es preciso tener en cuenta un dato significativo que pudo haber influido en este hecho, como fue la existencia, de manera contemporánea, de un grupo de artistas constituidos como una sociedad de identidad plenamente vinculada con la práctica de las bellas artes: la Academia Libre de Bellas Artes de Sevilla. El hecho de que su

\footnotetext{
${ }^{583}$ El propio reglamento establecía la existencia de dos clases de miembros, residentes y corresponsales, siendo los últimos cualquier persona "con quien la Sociedad juzgue conveniente establecer relaciones" (art. 9). Además del salón de exposición permanente, del que da cuenta Gómez Zarzuela (1872), la Sociedad también fomentó exposiciones con carácter de certamen nacional, como la que tuvo lugar en 1873, concurriendo artistas de toda España (SOCIEDAD PROTECTORA DE BELLAS ARTES DE SEVILLA, 1873; La nación, 1873/01/04: 1).

${ }_{584}$ El pintor Andrés Cortés (1812-1879), inscrito con el número de socio 154, es el único del que tenemos constancia que perteneciese al Liceo.

${ }^{585}$ Los pintores más jóvenes que figuran en la lista de socios son Virgilio Mattoni (1842-1923), Joaquín Turina (1847-1903) y José García Ramos (1842-1912), quienes, a pesar de su edad, debieron compartir la inquietud de otros pintores sevillanos por incorporarse al mercado artístico y darse a conocer en las exposiciones.

${ }^{586}$ Tan solo hemos tenido acceso al catálogo de exposición correspondiente a la inaugural de 1871 mediante el ejemplar conservado en la Biblioteca Nacional, aunque la sociedad permaneció activa hasta, al menos 1876 .
} 
fundación tuviese lugar en 1872 y de que en la iniciativa tomasen parte algunos de los artistas vinculados con la Sociedad Protectora ${ }^{587}$ parece poner de relieve que, en efecto, esta había tenido poca relación con la práctica artística y que los pintores reclamaban un espacio propio.

\subsection{Sociedades de Acuarelistas}

\subsubsection{La Sociedad de Acuarelistas de Madrid (1874-1899)}

Los orígenes de la Sociedad de Acuarelistas son algo confusos. Según manifestaba Ángel Avilés en su discurso de recepción en la Academia de San Fernando, tras la visita de Fortuny a Madrid dos artistas, José Casado del Alisal y Juan Martínez de Espinosa, se asociaron para estudiar la acuarela, concurriendo también algunos alumnos de la Escuela Superior de Pintura:

Su ejemplo y estímulo hizo que en 1869 algunos artistas al frente de los cuales deben figurar los iniciadores de la idea, mi queridísimo amigo D. José Casado del Alisal y mi amigo también el profesorD. Juan Martínez de Espinosa -ambos, desgraciadamente, ya difuntos-, se asociaron para estudiar por la noche la acuarela en el mismo local de la Escuela Superior de Pintura, sita en este mismo edificio. Por entonces juntáronse también con el propio objeto algunos distinguidos alumnos de dicha escuela; y de estos núcleos nacieron otros centros, y en 1874 fundóse la Sociedad de Acuarelistas, y en 1878 el Círculo de Bellas Artes (RABASF, 1893: 19).

Según Cavestany, el núcleo original de la sociedad estuvo vinculado a Martínez de Espinosa, a quien se unieron Palmaroli, Vallejo, Espalter, Ferrant, Megía, Zamacois y Rosales (CAVESTANY, 1946: 11). La iniciativa sufriría varias modificaciones desde 1869, vinculándose con algunos estudiantes de la Escuela de Pintura y de Artes y Oficios, hasta la consolidación definitiva, hacia 1873-1874, de la Sociedad de Acuarelistas. Otros, como Blanco Asenjo (1880/31/05: 3), ubicaban el antecedente más inmediato en el estudio de Díaz Carreño ${ }^{588}$, donde varios jóvenes pintores se reunían para practicar la acuarela. La actividad inicial de la Sociedad de Acuarelistas tuvo poca repercusión hasta la consolidación de sus exposiciones en 1877, bajo la presidencia de Bernardo Rico, momento en que llamó la atención de la prensa al señalar cómo una técnica pictórica tradicionalmente vinculada con el bello sexo había ido ganando cada vez más adeptos en España tras el paso del exitoso Fortuny. La nueva sociedad pasó a ser considerada rápidamente como un círculo fraternal de artistas, constituido como una asociación cooperativa idílica, en que los pintores trabajaban en compañía "con el estímulo de la reunión de amigos y de la economía que resulta (...) del estudio común en que los gastos se hacen a prorrata" (FERNÁNDEZ BREMÓN, 1877: 346). Los matices de este concepto de sociedad son interesantes porque, frente a la imagen del

\footnotetext{
${ }^{587}$ Entre los artistas que figuraron en ambas sociedades se encuentran Gonzalo Álvarez Espino, Joaquín Turina, Federico Eder, José Chaves, Virgilio Mattoni, Manuel Ussel, Antonio María de Vega, José García Ramos, Demetrio de los Ríos, Francisco Peralta, Enrique León, José Ortiz y Pedro de Vega.

${ }_{588}$ Otra noticia establecía el lugar de origen en el estudio de Díaz Carreño, identificando con la iniciativa de asociación a Pradilla y a Alberola (El globo, 1880/07/06: 1).
} 
artista burgués de los Liceos, subraya el nuevo concepto de artista contrario a la institución oficial y de hombre trabajador, al mismo tiempo que el "espíritu de asociación" del que hablaban los románticos se ve asimilado a una imagen del movimiento obrero, apuntando siempre las ventajas del compañerismo. De este modo, La ilustración española y americana (1878/15/02: 107) la describía como

una modesta asociación de la que forman parte distinguidísimos artistas, que ha resuelto dos problemas considerados casi como insolubles entre nosotros: vivir desahogadamente, libre de toda injerencia oficial, y proporcionar a los socios, después del trabajo del día, digno esparcimiento y grato solaz, durante las tres horas que dedican por la noche a nuevo trabajo.

A este concepto de ocio masculino se une la visión del asociacionismo como unión de trabajadores. Un curioso artículo aparecido en la Guía del peluquero y del barbero se abordaba, referente al poder de la asociación de los trabajadores en que se aludía a su papel para elevar el oficio a tener fuerza social, el ejemplo de la propia Sociedad de Acuarelistas:

El artista necesitaba, además de los gastos naturales de sus estudios y trabajos ordinarios, los que acarrea la contratación de modelos a propósito. Luego, una vez terminada su acuarela, tenía que luchar con los inconvenientes que trae consigo el aislamiento para alcanzar la ocasión de una buena venta. Pues ocurrióseles, en buena hora, a los pintores constituir una sociedad de acuarelistas, y el éxito ha sido admirable. Organizado el estudio común en excelentes condiciones, cubiertos los gastos colectivamente, estimulados por otra parte los artistas, en virtud de esas corrientes de emulación noble y levantada que se despierta siempre al contacto de aptitudes diversas, expuestos en lujosa galería los cuadros todos, formalizada, en fin, la idea de asociación que tan ubérrimos frutos produce, llama hoy la atención de toda persona culta ese grupo de artistas distinguidos, y las gentes de posición y dinero se disputan las acuarelas con entusiasmo creciente ("El Ateneo de Madrid y la cuestión social”, 1878: 2).

Se aludía constantemente al espíritu modesto de la sociedad, afirmando de ella ser una reunión de amigos con el único fin de $\operatorname{pintar}^{589}$; Fernández Bremón veía además la necesidad de apuntar que, a pesar de la unión, los estilos personales de los artistas permanecían intactos, como si el trabajo en reunión pudiese implicar desdibujar la individualidad que caracteriza a cada pintor, viendo en esto el éxito de la nueva sociedad artística ${ }^{590}$.

\footnotetext{
589 "La sociedad de acuarelistas, que todos los años expone su pequeña colección de cuadros, no es como esas sociedades extranjeras, una corporación fuerte y rica, que celebra por lujo sus Exposiciones. Es una reunión de amigos, modestos todos, que se han reunido para pintar. El cuadro que cada uno regala a la Sociedad en Mayo es como un recuerdo de los trabajos que han hecho todo el año juntos. Es una Sociedad en la infancia (...)" (ESCOBAR, 1879: 3).

590 “(...) Dudábamos al principio si el trabajo colectivo quitaría al pintor su personalidad, fundiendo su estilo en el de todos; es decir, si tendrían marca social las acuarelas. El examen de las obras expuestas demuestra, por el contrario, independencia y variedad de estilos: parece como que la unión, en vez de borrar las individualidades las acentúa y fortifica..." (FERNÁNDEZ BREMÓN, 1878: 363).
} 


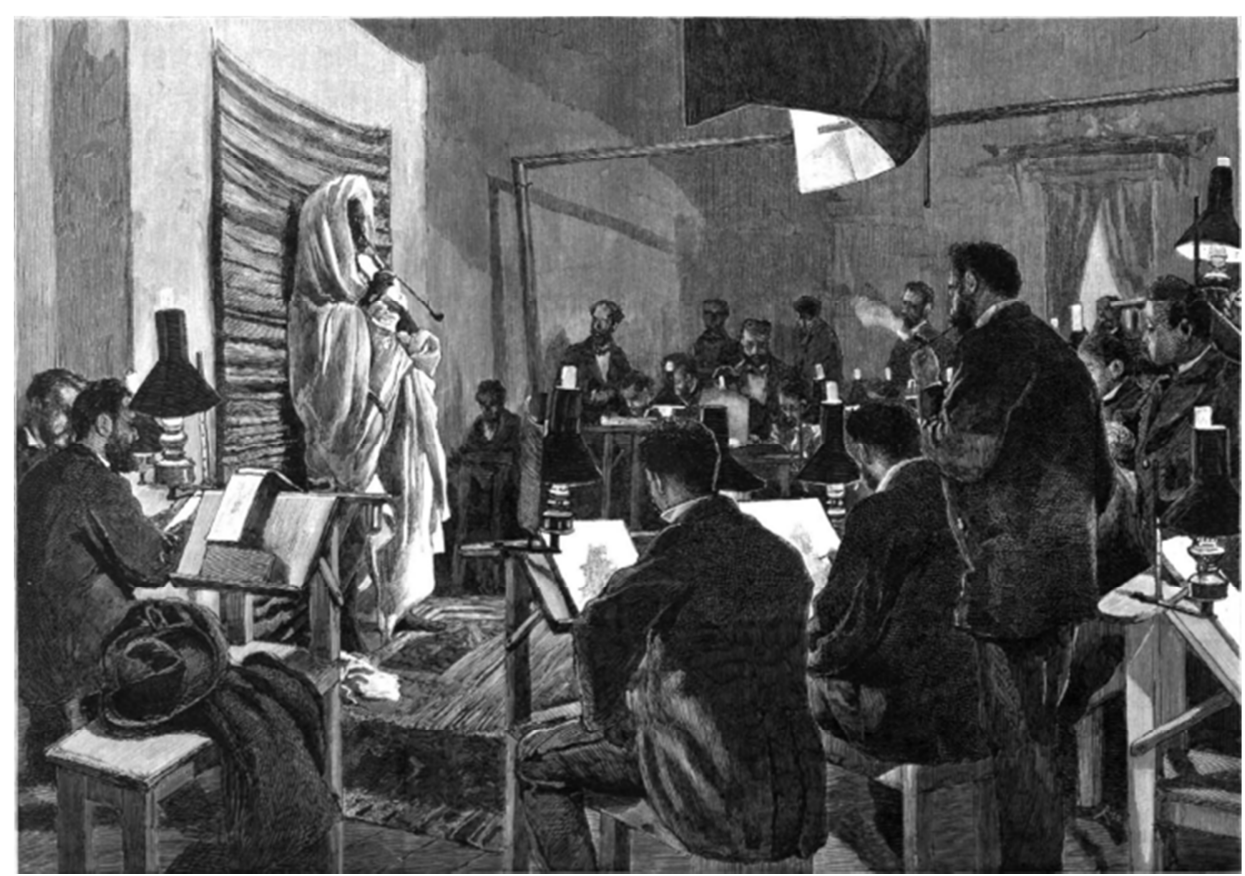

Fig. 202. Pellicer, Una sesión en la Sociedad de Acuarelistas; grabado publicado en La ilustración española y americana (1878/15/02: 112).

Con este afán cooperativo, los acuarelistas instalaron su sede en la calle de la Misericordia, número 2. Todo parece apuntar que, inicialmente, no se contaban entre los socios más que hombres; así parece desprenderse de las descripciones incluidas en $L a$ ilustración española y americana, que vinculaba esta sociedad artística con el esparcimiento masculino posterior y complementario al trabajo. Del mismo modo, un grabado publicado en la misma revista representando una sesión de la sociedad de acuarelistas muestra lo que sin duda es una sesión del natural en la que solo participan hombres artistas. La imagen, tomada de un dibujo realizado in situ por el socio José Pellicer [fig. 202], muestra a los concurrentes, de pobladas barbas, entregados en la tarea de la copia de un modelo oriental; el humo de la pipa que se encuentra fumando uno de los asistentes e incluso el sombrero y chaqueta depositados en el único asiento libre apuntan a una sesión exclusivamente masculina. También se intuye el carácter masculino de la sociedad en las palabras del articulista de El imparcial (1878/10/06: 3), quien se extrañaba, al tratar de la exposición de la sociedad de 1878, de que la acuarela fuese "tan poco cultivada por el bello sexo español". Hasta 1882 no hay noticias de participación femenina en las exposiciones ${ }^{591}$ [tabla 11], algo que tal vez podría deberse no a la ausencia de mujeres artista en las sesiones sino a la invisibilización de su papel por parte de la crítica, aumentando progresivamente -aunque siempre en clara minoríael número de mujeres que participaba en la vida de la sociedad ${ }^{592}$.

\footnotetext{
${ }^{591}$ De las tres expositoras, no deben contarse como asiduas a las sesiones a las infantas doña Paz y doña Eulalia, siendo la otra obra presentada por una mujer, Concepción Soldevilla, una copia de Los borrachos de Velázquez. El crítico de El Día señalaba la acuarela como un medio honrado de ganarse la vida para señoritas de clase media (A., 1882: 6).

${ }^{592}$ En 1883 figuran cuatro mujeres artista (Josefa Serrano, Inés Álvarez, Emilia Menassado y Adela Crooke) frente a un total de treinta y cuatro pintores;
} 


\begin{tabular}{ccccccccc} 
& 1878 & 1879 & 1880 & 1881 & 1882 & 1883 & 1888 & 1889 \\
Hombres & 11 & 17 & 34 & 26 & 30 & 37 & 27 & 25 \\
Mujeres & 0 & 0 & 0 & 0 & 3 & 5 & 3 & 5 \\
\hline
\end{tabular}

Tabla 11. Relación comparativa de los artistas expositores, hombres y mujeres, presentes en las exposiciones de la Sociedad de Acuarelistas (1878-1889).

Respecto a la forma de organización de la sociedad, esta se componía de socios fundadores, profesionales de las bellas artes que abonaban una cuota de entrada de 25 pesetas y una cuota mensual de 15; socios de número, que solo abonaban la mensual al igual que los socios corresponsales, y socios de mérito ("Sociedad de Acuarelistas de Madrid", 1890: 126). Sin embargo, la presencia de artistas consagrados fue reducida en comparación con la afluencia de jóvenes artistas y aficionados, especialmente tras la inauguración del Círculo de Bellas Artes (1878), algo que se hace notar en algunas duras críticas, como la redactada por Luis Alfonso para La época en relación a la exposición de 1882:

La Sociedad de Acuarelistas no se compone de maestros que han llegado a la cima del arte; fórmase más bien de jóvenes alentados y ganosos de aprender, de practicar y de adiestrarse en este linaje de obras. Por otra parte, todos los socios tienen, por serlo, derecho incontestable a exponer tres de aquellas, y no hay en todos ellos bastante cautela ni suficiente respeto al principio de nosce te ipsum para renunciar a este derecho en pro del bien común (L.A., 1882: 3).

En lo que respecta a la sociabilidad entre los artistas y su proyección en las exposiciones, son escasos los datos que se han podido recopilar. Sabemos que Alejandro Ferrant dejó testimonio de su amistad con el pintor Balaca en la exposición de 1888, a la que concurrió con un dibujo representando su entierro, que el crítico de $E l$ país reconocía por haberlo visto en la prensa periódica, tratándose sin duda del publicado en La ilustración española y americana en febrero de 1880 bajo el título Último homenaje al cadáver del pintor Balaca [fig. 203]. En la lúgubre escena, presidida por el ataúd antes de ser tapado, destaca la figura del pintor Aureliano Beruete, autor del croquis en el que posteriormente se basó Ferrant, en el extremo derecho de la composición.

No se recoge en las exposiciones ningún dato referente a retratos entre consocios entre las obras presentadas. Sin embargo, algunos retratos de artistas vinculados a la Sociedad de Acuarelistas podrían haber surgido de las relaciones de amistad establecidas en ella. Entre los retratos existentes en el Museo de Bellas Artes de Córdoba se encuentran dos, debidos a la mano de Nicolás Megía, que podrían responder a estos criterios al presentar a dos personajes vinculados, en cierta medida, con la sociedad. 


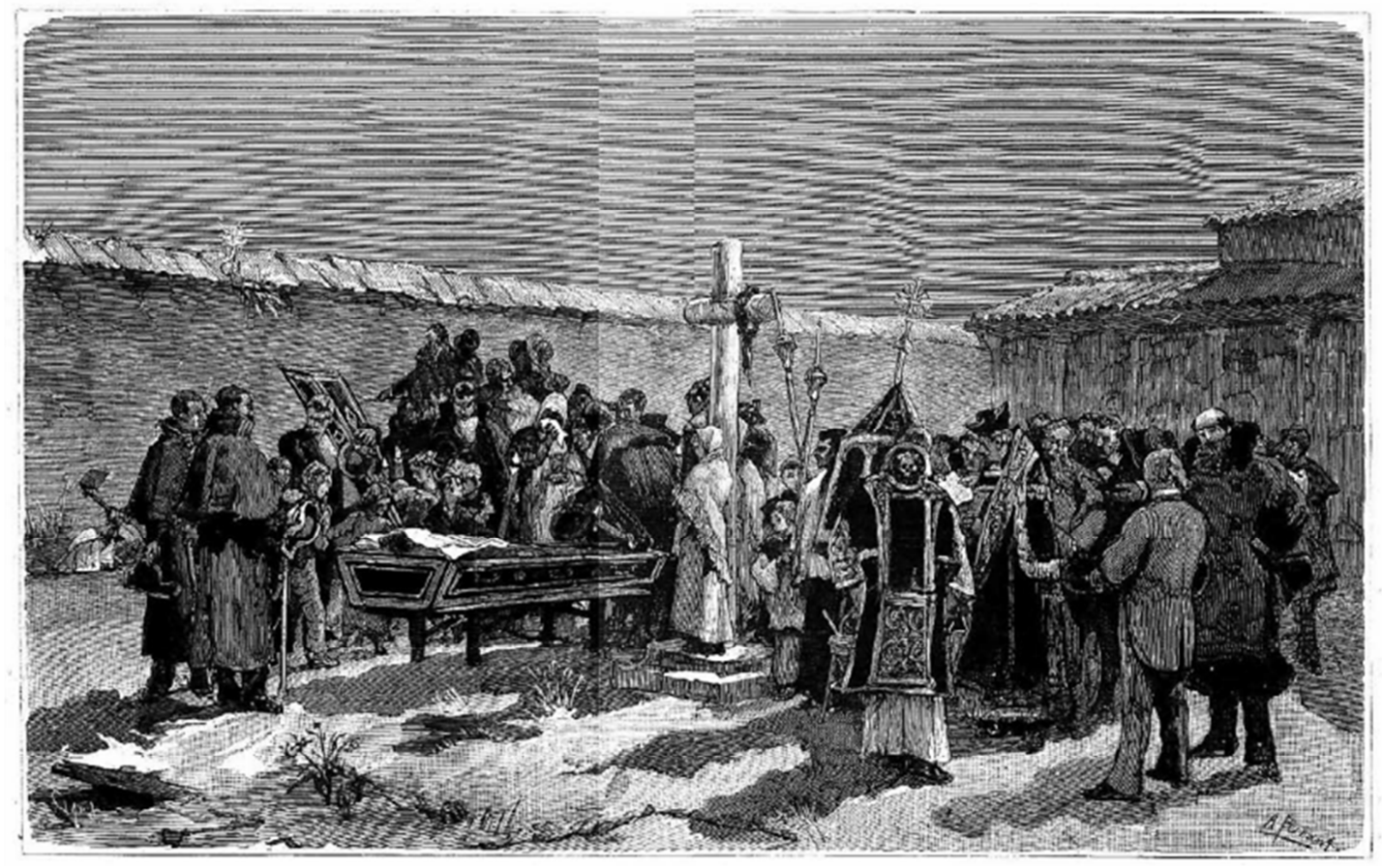

Fig. 203. Alejandro Ferrant, Último homenaje al cadáver del pintor Balaca en el cementerio de Aravaca, publicado en La ilustración española y americana, 29 de febrero de 1880.

Se trata del retrato del pintor Ramón Domec y del acuarelista Ángel Avilés [fig. 205], ambos procedentes de la colección de este último, en la que se encontraban también un retrato a lápiz de Casto Plasencia realizado por José Parcet y acuarelas de sus compañeros Luis Franco, Antonio Gomar, Antonio Maura y Tomás Campuzano. Efectivamente, consta que tanto Domec como Megía pertenecieron a la Sociedad de Acuarelistas, estando documentados en sus exposiciones: Domec en la de 1880 y Megía en la de 1882, si bien este último figura al menos desde 1880 , año en que, tras su regreso de París y Roma, consta en la primera sesión del año copiando del natural una manola (La época, 1880/16/10: 3).

Un dato interesante sobre la sociedad de acuarelistas madrileña es la noticia de la existencia de una colección de retratos de sus miembros, vinculada al nombre de Nicolás Megía. Según recogen El Imparcial y La Ilustración Artística con motivo del fallecimiento de Alfredo Perea, la Sociedad de Acuarelistas poseía un retrato de este, al igual que el Círculo de Bellas Artes, siendo los únicos que habían sido reproducidos en prensa (BALSA DE LA VEGA, 1895: 642) ${ }^{593}$; en efecto, el propio El imparcial (1895/26/08: 1) publicaba acompañando la necrológica el retrato de Perea, señalando al pie del grabado que se trataba de un dibujo realizado por Blanco Coris, "tomado del que existe en la Sociedad de Acuarelistas hecho por D. Nicolás Megía” [fig. 204].

\footnotetext{
${ }^{593}$ La revista barcelonesa señalaba, además, su intención de publicar este retrato, algo que no había sido posible ya que el paquete que lo contenía en el correo se había extraviado.
} 


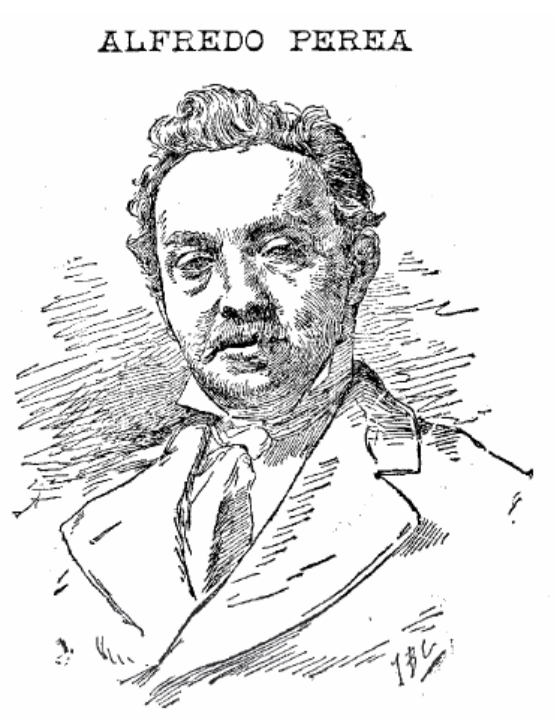

Fig. 204. José Blanco Coris, Retrato de Alfredo Perea, tomado del realizado por Megía. El imparcial (1895/26/08: 1).

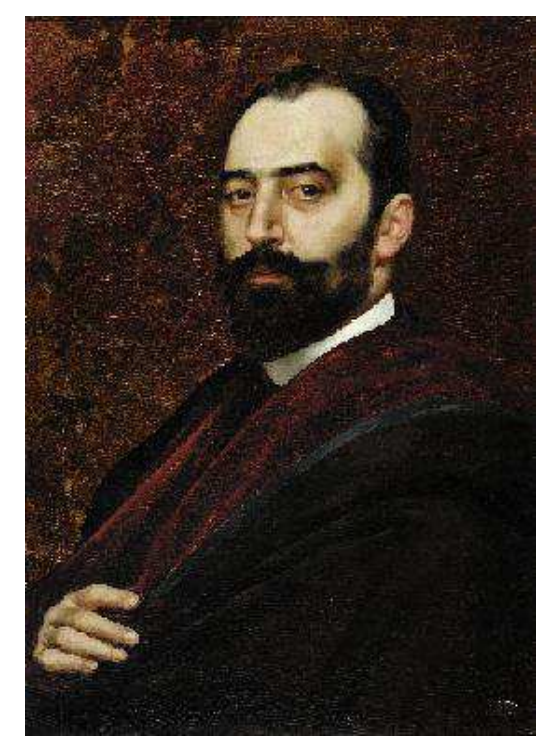

Fig. 205. Nicolás Megía, Retrato de Ángel Avilés, 1887. Museo de Bellas Artes de Córdoba (inv. 1735P).

Aún más sugerente es la noticia transmitida por El Imparcial en 1896, afirmando que en el local de la Sociedad de Acuarelistas en la calle de la Misericordia existía una colección completa de los "retratos de los más insignes cultivadores de la acuarela", de la que Francisco Alcántara (1896: 1) decía ser el único recuerdo, con su correspondiente valor anecdótico, de la vida de la sociedad y el ambiente artístico en los años de sus orígenes. Mientras que la noticia sobre el retrato de Perea ofrecía como datos interesantes el estar realizado al lápiz por otro socio, la de la colección de retratos no especifica si se trataba de una colección fotográfica o gráfica, como podría intuirse del de Perea.

La crisis que sumió a la sociedad en el mismo año de 1896 debido a las tensiones entre artistas, a la competencia existente con el Círculo de Bellas Artes y a la progresiva escasez de fondos hizo que los acuarelistas abandonasen en 1899 su sede anterior en la calle Misericordia para fusionarse, de manera temporal hasta septiembre de 1900, con el Ateneo, disolviéndose de manera definitiva en 1905 tras varios cambios de domicilio ${ }^{594}$. Es probable que la documentación existente en la sociedad, así como su colección de retratos, se perdiese durante esta última etapa, ya que no hemos encontrado referencias posteriores que nos permitan conocer de primera mano la identidad de los presentes en esta peculiar colección y sus características plásticas.

\subsubsection{La Sociedad o Centro de Acuarelistas de Barcelona}

También Barcelona contó con una Sociedad de Acuarelistas activa desde 1885. Joaquín Ciervo, en un breve artículo que publicaba La esfera (1924/18/12: 33), trazaba una sucinta y algo confusa historia de esta institución, afirmando que ya desde la sección de bellas artes del Ateneo barcelonés había existido una iniciativa de formar una

\footnotetext{
${ }^{594}$ En 1900 retorna a la calle Misericordia, número 2 (SAINT-AUBIN, 1900: 1), a la calle Almudena, número 3, bajo (El liberal, 1902/22/09: 3) y finalmente a la calle Chinchilla, número 8 (El heraldo, 1903/16/11:3).
} 
sociedad de acuarelistas, capitaneada por el artista José Luis Pellicer; la existencia del Centro de Acuarelistas, ubicada en la Casa de la Canonja ("Exposición de bellas artes...", 1885/21/06: 395), en las inmediaciones de la Catedral, era entendida por Ciervo como un núcleo "donde se conspiraba con todo el buen sentido y la mayor buena fe en pro del enaltecimiento del Arte”.

Parece, no obstante, que el Centro ya estaba constituido a principios de 1885, como se desprende de la noticia, publicada en enero de ese año en la revista barcelonesa $L a$ ilustración (1885/11/01: 32), en la que se aludía a la renovación de la Junta directiva del mismo, un momento en el que José Luis Pellicer fue elegido vocal junto a Tomás Moragas, José Ferrer y Soler y Ramiro Lorenzale. Sorprende que su primera iniciativa fuese la exposición, de carácter nacional y multidisciplinar, organizada ese mismo mes de mayo en el Museo Martorell ${ }^{595}$, como recoge La ilustración española y americana (1885/22/06: 375). Probablemente la experiencia de Pellicer, colaborador de esta revista y vinculado a la Sociedad de Acuarelistas de Madrid, contribuyese en gran medida a ampliar los objetivos del Centro barcelonés, ya que el dibujante fue el presidente de la comisión organizadora de esta muestra, y en 1886 ya figuraba como presidente de la sociedad $^{596}$.

Entre las actividades realizadas por el Centro de Acuarelistas destacan las clases de dibujo y pintura, a cuyo sostenimiento contribuyó el Ayuntamiento de la ciudad y que motivaron el traslado de la sociedad al segundo piso de la casa Gibert en 1887 ( $L a$ dinastía, 1887/28/04: 2 y 1887/18/09: 3); los fondos del Centro, que al parecer nunca abundaron, hicieron preciso que los acuarelistas apelasen a la colaboración de pintores y escritores para la realización de una exposición en el Salón Parés y la publicación y venta de un álbum con el que cubrir los gastos de mantenimiento del local y de las clases $^{597}$. La publicación de la revista El centro de acuarelistas, del que solo vio la luz un único número el 28 de junio de 1887, incluyó entre sus páginas algunos grabados representando algunos espacios de la sede (MARÍN SILVESTRE, 2006: 19) y los principales entretenimientos que podían encontrar los socios en su interior: tal y como recoge María Isabel Marín en su historia del Círculo Artístico, las clases del natural fueron uno de sus principales alicientes, permitiendo el estudio de figura vestida y desnuda. Pujadas incluyó así una representación del Estudio de modelo desnudo, y Gómez Soler otra titulada La elección de modelo. La creación de una biblioteca o gabinete de lectura también fue uno de los atractivos de la sociedad, y Santiago Rusiñol incluyó una imagen de Hombres leyendo, al igual que Leopoldo Roca, quien optó por presentar El salón de lectura del Centro de Acuarelistas. Además de esta vertiente

\footnotetext{
${ }^{595}$ A comienzos de febrero de 1885 ya se daba noticia de la iniciativa de celebrar "una exposición de acuarelas, dibujos, pinturas al óleo y esculturas, a la cual se trata de invitar a todos los artistas nacionales y extranjeros" ("Barcelona", 1885: 80), a la que concurrieron numerosos artistas nacionales. Para la crítica de la exposición, ver: CAJAL, 1885: 385-387; tanto La ilustración como La ilustración artística publicaron varios grabados de las obras presentadas.

${ }^{596}$ En noviembre de 1886 constituían la junta directiva del Centro de Acuarelistas José Luis Pellicer (Presidente), Leopoldo Roca (vicepresidente), Joaquín Farrán (tesorero), Ramiro Lorenzala, Guillermo Pujadas, Maximino Sala y Luis Buxó (vocales), Francisco Llorens (secretario) y Pablo Bertrán (vicesecretario). La dinastía, 1885/06/11: 3 .

${ }^{597}$ L.A.,1887: 2; La ilustración, 1887/03/07: 431; La dinastía, 1887/04/07: 1.
} 
intelectual, propiciada por la mayor parte de las sociedades decimonónicas, el Centro de Acuarelistas también optó por un componente lúdico más vinculado con el juego; la representación de una partida de cartas, juego más vinculado con el ocio entre los artistas bohemios, podría indicar la voluntad del Centro de no ser exclusivamente una sociedad destinada al estudio artístico, sino a una sociabilidad completamente masculina capaz de cubrir las necesidades profesionales, relacionales y de ocio del artista contemporáneo en la ciudad, uno de los motivos por los que la edad de entrada estaba restringida a los mayores de dieciséis años (MARÍN SILVESTRE, 2006: 15). No consta, sin embargo, que promoviese la creación de una galería de retratos, ni noticias sobre la existencia de estos en la sede de la sociedad.

Es en octubre de 1887, y con motivo del traslado a la Casa Gisbert, en la plaza de Cataluña, cuando el Centro de Acuarelistas, fusionado con los artistas de la sección correspondiente del Ateneo barcelonés, pasa a constituirse en Centro Artístico.

\subsection{Círculos de Bellas Artes}

\section{$\underline{\text { 3.5.1. El Círculo de Bellas Artes de Madrid }}$}

En 1880 Madrid veía nacer una nueva sociedad artística con la intención de desvincularse de la ya existente Sociedad de Acuarelistas; su objetivo principal, el cultivo y difusión de las bellas artes, era una meta común con las demás ya analizadas, al igual que la necesidad de constituir un punto de tertulia para los artistas. Sin embargo, el Círculo de Bellas Artes disfrutó desde sus orígenes de una calurosa acogida por parte de profesionales y de aficionados, como pone de manifiesto el cómputo de socios en ese primer año, que ascendía a 267 personas. Entre las actividades que el Círculo propuso para dar visibilidad a sus socios fueron especialmente atractivas las exposiciones, destinadas a la venta de obra; llamativas también para los artistas y para los amateurs eran las clases de dibujo, fomentando hasta cierto punto de estudio del modelo del natural ya fuese mediante el dibujo o la acuarela ${ }^{598}$. Emulando a otras instituciones, y con la intención de convertirse en una sociedad con todas las implicaciones que esto conllevaba, el Círculo amplió su abanico de propuestas, y se ofertó como centro de reunión, la organización de conciertos, la creación de una biblioteca actualizada o incluso con la cesión sus espacios a los artistas extranjeros que visitasen la ciudad. Martínez Marín (RODRÍGUEZ RUIZ, 2005: 25) señala la proximidad del Círculo de Bellas Artes con algunas instituciones culturales previas, como el Liceo o el Ateneo, y subraya de manera acertada que la actividad artística de este último se encontraba supeditada a las necesidades de una sociedad eminentemente enfocada al debate social y político. No señala, sin embargo, las confluencias y divergencias respecto a la Sociedad de Acuarelistas, que era en aquel momento la única sociedad de carácter exclusivamente artístico en Madrid y que, según recoge la prensa, se planteó la fusión con el Círculo

\footnotetext{
${ }^{598}$ En 1880 se consideraban las bases del Círculo estos cuatro puntos: "1. El establecimiento de un círculo de Bellas Artes donde los socios puedan reunirse. 2. El sostenimiento de una clase de modelo vivo para los socios. 3. La instalación de una exposición permanente de las obras de los socios. 4. La celebración de una gran Exposición anual de obras de los socios en local adecuado al objeto, si no fuese suficiente el Círculo (...)" (La época, 1880/27/01: 4).
} 
(Crónica de la música, 1880/15/07: 6). La peculiaridad del Círculo de Bellas Artes radica, precisamente, en aglutinar las necesidades profesionales e intelectuales de los artistas con las derivadas de una sociabilidad exclusivamente centrada en torno a las bellas artes ${ }^{599}$ : el centro, en definitiva, estaba destinado al artista moderno adaptado al tipo de vida de la burguesía madrileña, tal y como ponía de manifiesto el redactor de una breve reseña sobre el Círculo en Crónica de la música (1880/15/07: 6), al señalar "que, además de presentar los atractivos admitidos en toda sociedad culta" era "la manifestación más genuina del progreso de las bellas artes en nuestro país".

Asentada la sociedad en la calle del Barquillo número 5, fue percibida como un centro de exclusividad artística, donde en principio solo los vinculados con las artes plásticas tenían cabida. Así lo recoge, al menos, La correspondencia de españa (1883/11/06: 3) al dar noticia de una iniciativa del Círculo de transformarse en Liceo y en un lugar donde "estrechen los lazos de amistad, se ilustren mutuamente y auxilien los que cultiven las bellas artes y la literatura" 1883, al considerar probablemente que las actividades de la Sociedad de Escritores y Artistas no encajaban con las que se consideraba que debían realizar los círculos artísticos europeos.

No se trataba de una sociedad masculina, a pesar de que a algunas de sus actividades de ocio -especialmente los juegos- no acudiera público femenino; sin embargo, la presencia de mujeres sí que aparece recogida tanto en las clases de modelo vivo como en las exposiciones; así, las clases de acuarela estaban "dispuestas hasta para señoras, pues en este casino no se excluye, sino que se desea la cooperación del bello sexo" ("Círculo de Bellas Artes", 1883: 3).

Debido a la buena acogida que tuvo el Círculo resulta complicado detallar todos los artistas que pertenecieron a la sociedad ${ }^{600}$ (anexo 12), ya que de los 267 socios iniciales pasó a más de 700 en 1895, entre los cuales se encontraban artistas profesionales, aficionados y amantes de las bellas artes. Entre ellos, se encontraban Casto Plasencia, Miguel Jadraque, Gessa, Mélida, Alfredo Perea, Federico de Madrazo, Carlos Luis Ribera, Carlos de Haes, Bernardo Rico, Suñol, Alejandro Ferrant, Juan Espina y Capó, Agustín Lhardy o Ignacio Zuloaga, algunos de los cuales pertenecieron a las juntas directivas $^{601}$, y también otros pintores como Sorolla, Cecilio Pla o Campuzano, que colaboraron con diversas tareas de decoración de la sede (La ilustración artística,

\footnotetext{
${ }^{599}$ Manuel del Palacio, en un soneto dedicado al Círculo de Bellas Artes decía: “(...) Como él con la justicia y la venganza/ yo con el arte sueño y la poesía/ y en Edén este asilo trocaría/ de perpetuo deleite y bienandanza. / ¡Feliz entre vosotros me contemplo!/ Y pues triunfando de la ruin materia/ al trabajo y la paz alzáis un templo, /por honra y galardón de nuestra Iberia, a mi voz obedientes y a mi ejemplo/ ¡Dejad, los que aquí entréis, toda miseria!” (PALACIO, 1890: 114).

${ }^{600} \mathrm{La}$ imposibilidad de realizar consultas en el Círculo de Bellas Artes de Madrid no nos ha permitido profundizar en nuestras pesquisas. Probablemente la sociedad conserve en sus archivos listas de socios y documentación relativa a los artistas que formaron parte de ella, siendo nuestra lista una aproximación parcial según las noticias encontradas en prensa.

${ }^{601}$ En 1889, por ejemplo, la Junta directiva estaba compuesta por: Bernardo Rico (presidente), Juan Espina y Capó (secretario), y los señores Isidoro Fernández Flores, Miguel Jadraque, Plácido Francés, Aureliano de Beruete, Agustín Lhardu, Germán Hernández, Alfredo Perea, Eugenio Lemus, Nicolás Megía, Casto Plasencia, Manuel Picolo, Manuel del Palacio, Jerónimo Suñol, Antonio Cordero, Cecilio Pla, Luis Marín, Benito Zozaya, Antonio Montojo, Lorenzo García Vela, José Fernández Bremón, Ángel Avilés, José Suárez y Manuel Arroyo como vocales.
} 
1895/21/01: 86) o con ilustraciones para su boletín ("Reuniones y sociedades...", 1895: $3)$.

La voluntad de no ser una sociedad plegada sobre sí misma, sino abierta a la vida cultural de la ciudad llevó a que el Círculo de Bellas Artes comenzase a realizar festejos a imitación de los que otras sociedades, como la de Escritores y Artistas, venían realizando; se inauguran así en 1891 los bailes de máscaras durante las celebraciones de carnaval, generando una nueva actividad en la que los artistas se involucran activamente. La prensa recoge la animación nocturna en el círculo por parte de los pintores, reunidos para realizar las decoraciones de las panderetas, abanicos, sellos o paletas decoradas que se rifaban o vendían durante estas celebraciones, lo que permite también dar una idea de la proyección social que la institución buscaba tener, aunque también ofrece algunas críticas sobre la deriva hacia lo lúdico y el ocio que hacían de lo artístico un entretenimiento o una excusa para organizar exposiciones de escasa modernidad.

\subsubsection{Retratos de socios en el Círculo de Bellas Artes}

Queda constancia de que la práctica del retrato en el Círculo de Bellas Artes fue habitual, correspondiéndose a la propia sociabilidad entre artistas; no obstante, el hecho de que la institución madrileña no haya facilitado acceso a las colecciones, documentos ni materiales de archivo conservados en ella hace que únicamente contemos con información parcial, derivada del estudio de la prensa periódica. Rodríguez Ruiz menciona, al hablar del primitivo núcleo del Círculo, una colección de dibujos con los retratos de los primeros socios, realizados por Alfredo Perea, conservados aún al parecer en el propio Círculo de Bellas Artes (RODRÍGUEZ RUIZ, 2005: 42). Una fotografía publicada en la revista Nuevo mundo (1897: s.p.) [fig. 206] ofrece la imagen de la junta directiva de la sociedad reunida en la secretaría del Círculo; en sus paredes, junto a otras obras artísticas, se puede apreciar la presencia de varios retratos. Los tres realizados al carbón en formato de busto podrían corresponderse con los que Rodríguez Ruiz atribuye a Perea.

Además de estos retratos, se puede observar también en la misma secretaría un retrato de mayor tamaño, realizado al óleo sobre lienzo, representando al pintor Vicente Palmaroli. Sabemos que el autor del retrato, Emilio Sala, estuvo vinculado al Círculo de Bellas Artes desde sus inicios, participando en la primera exposición en 1880, y remitiendo obras a partir de 1890. Además, sus parientes Plácido Francés y Fernanda Francés también mantuvieron una relación ininterrumpida con la sociedad artística. El retrato de Palmaroli fue donado al Círculo en febrero de 1896, apenas un mes después del fallecimiento del pintor, y figuró en la exposición bienal de ese mismo año. La obra, que había sido realizada por Emilio Sala en Roma, no se corresponde al tipo de obra fruto de la sociabilidad del Círculo, sino al homenaje rendido a la personalidad artística del pintor que ocupó la presidencia de la Academia Española en Roma y del Museo del Prado en sus últimos años de vida. La donación fue realizada por parte de la familia de Palmaroli, tal y como recoge un artículo aparecido en El imparcial (1896/22/02: 2). 
El retrato, realizado en Roma cuando Palmaroli era director de la Academia Española y Sala pensionado de mérito (REYERO, 2014: 138), le presenta en elegante actitud de pintar, aludiendo a su profesión artística.

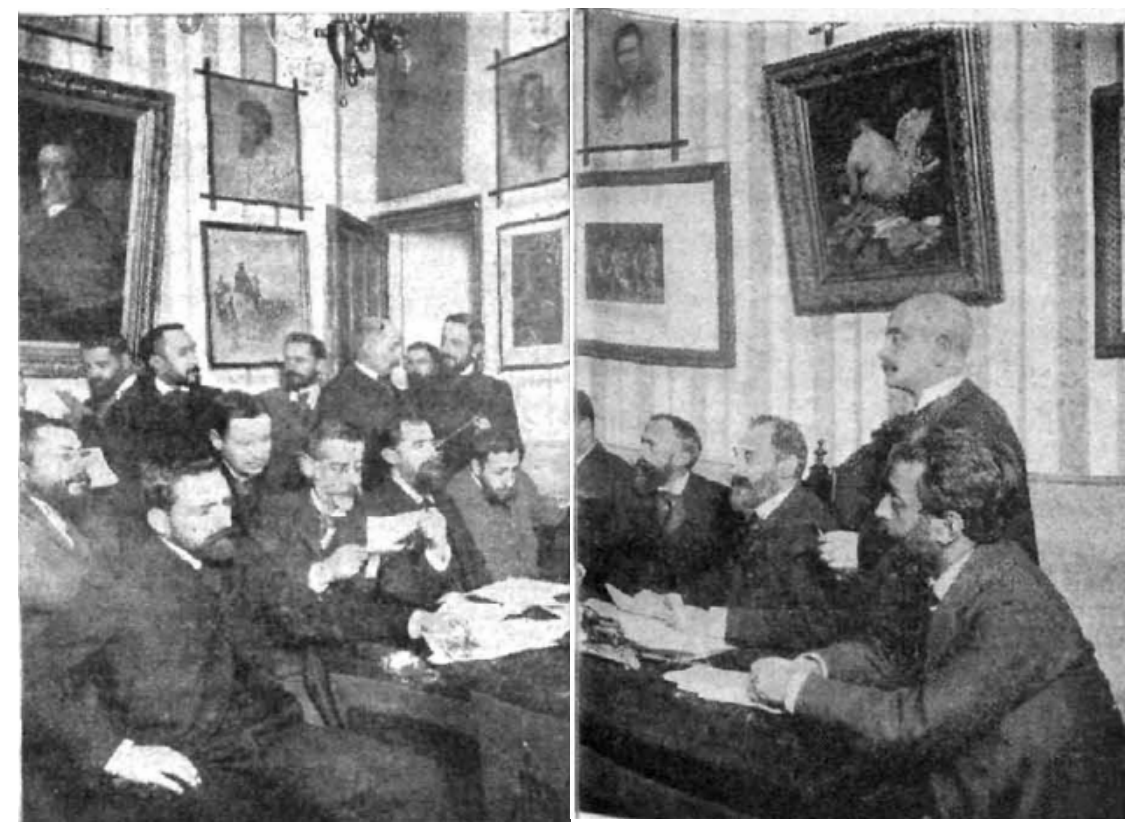

Fig. 206. Secretaría del Círculo de Bellas Artes, fotografía de Compagny publicada en Nuevo mundo (1897/25/02).

\subsubsection{El friso de los retratos del Círculo de Bellas Artes}

Manuel de Mesonero Romanos mencionaba en 1898, al hablar del Círculo de Bellas Artes, una curiosa colección de retratos en esta sociedad, "de figura entera y tamaño poussinesco, especie de historia ilustrada del Círculo", ubicada en las paredes de la sala de billares. Por el interés de la descripción merece la pena reproducir el texto:

La parecidísima Iconografía es una obra bien pintada, seria a ratos, humorística a trozos, y llena siempre de animación, por el contraste de tipos, sexos, trajes y actitudes. En la larga fila se ven ya bastantes artistas que solo viven en el recuerdo, como Martínez Espinosa, Plasencia, Bernardo Rico, Araujo, Germán Hernández, González y Perea; allí otros veteranos como Plácido Francés, mezclados con gente como Cecilio Pla y Manuel Ruiz Guerrero; Campuzano, el marinista eminente; Espina, seno de nuestros mejores cultivadores del paisaje; Ángel Avilés, el académico crítico del arte; Repullés, el arquitecto autor de tantas obras celebradas; Saint-Aubin, cuya personalidad artística crece cada Exposición; Lhardy, Alcázar, Lemus, Arroyo, Comba, Fernández Francés, Rubio, Arbós y otros nombres tan señalados en la pintura, la estatuación, la música y las letras. Quién sabe si esta galería, especie de martirologio ilustrado de soñadores en medio del positivismo al uso, se estudiará algún día con igual afán que las antiguas pinturas, para averiguar los retratos de famosos artistas y peregrinos ingenios. Quizá un Palomino o un Vasari del porvenir descubrirá que aquella testa cuadrada, de barbas rojas, aquella complexión de guerrero medieval, son fiel trasunto del que dio tanta gloria al arte español, del 
malogrado Casto Plasencia; en aquel personaje de rostro melancólico y suave, que contrasta con lo brioso de su pincel, a Alejandro Ferrant; a Manuel Domínguez en el otro no muy medrado de estatura; que el sujeto de descuidado aderezo y cara de soldado de Flandes es el famoso estatuario Jerónimo Suñol; que el calvo caballero, ni mozo ni anciano, de militar bigote, es el predilecto hijo de Apolo, Manuel del Palacio, y que la faz angulosa, invadida por barbas y cabellera, fue la de Bretón, el músico insigne (MESONERO ROMANOS, 1898: $1)$.

Los retratos procedentes de este friso conservados actualmente en el Círculo de Bellas Artes representan a un total a 67 socios [anexo 13] estrechamente vinculados con la vida de la sociedad, con un claro predominio de hombres (63 de 67 retratos son masculinos), y con el evidente protagonismo de los artistas plásticos (fundamentalmente pintores) frente a otras disciplinas:

$\begin{array}{llll}\text { Pintores } & 32 & \text { Dibujantes } & 4 \\ \text { Escultores } & 1 & \text { Músicos } & 4 \\ \text { Grabadores } & 3 & \text { Escritores } & 4 \\ \text { Arquitectos } & 4 & \text { Otros } & 11\end{array}$

Tabla 12. Relación de retratos incluidos en el friso del Círculo de Bellas Artes.

El proceso de realización de estos retratos ha quedado reflejado a través de anécdotas que insinúan que lo habitual era que se produjesen en el propio Círculo y en momentos de encuentro o reunión de socios; cada retrato, de un tercio del tamaño natural y de cuerpo entero, era pintado al óleo sobre una tela y posteriormente recortado para pegarlo "sobre el fondo dorado que a guisa de friso recorría por bajo de la escofia todo el salón principal de la casa donde tenía el Círculo su domicilio" (BALSA DE LA VEGA, 1895: 595). Al analizar las personalidades retratadas llama especialmente la atención el hecho de que prácticamente la mitad de los retratados perteneciesen a la sociedad desde su fundación [figs. 207 a 211]; así sucede con treinta socios, uno más si contamos a Fernanda Francés que, a pesar de no estar incluida en la primera lista, sí que consta participando en la primera exposición del Círculo (ver anexo 13). Junto a este primer dato, también es significativo que, además de concurrir a exposiciones y de participar en las actividades organizadas por la sociedad, la gran mayoría de los retratados perteneciese a la junta directiva, así como el hecho de que se encontrasen artistas laureados en el panorama nacional e internacional (es el caso de Casto Plasencia, Jerónimo Suñol y Eduardo Adaro). 

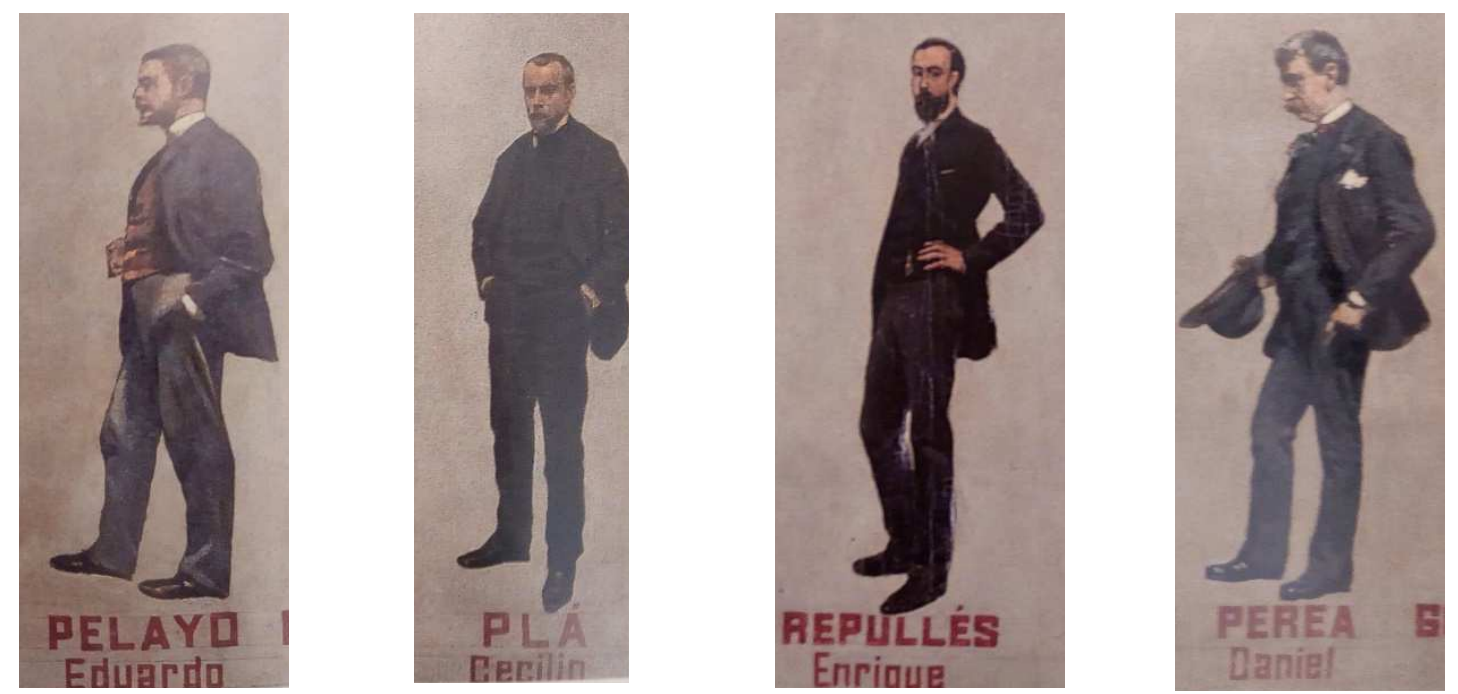

Fig. 207. Retratos de Eduardo Pelayo, Cecilio Pla, Enrique Repullés (detalles del friso, $n^{\circ}$ inv. 01 FA 0426) y Daniel Perea (detalle del friso, $\mathrm{n}^{\circ}$ inv. 01 FA 0471) Círculo de Bellas Artes de Madrid.
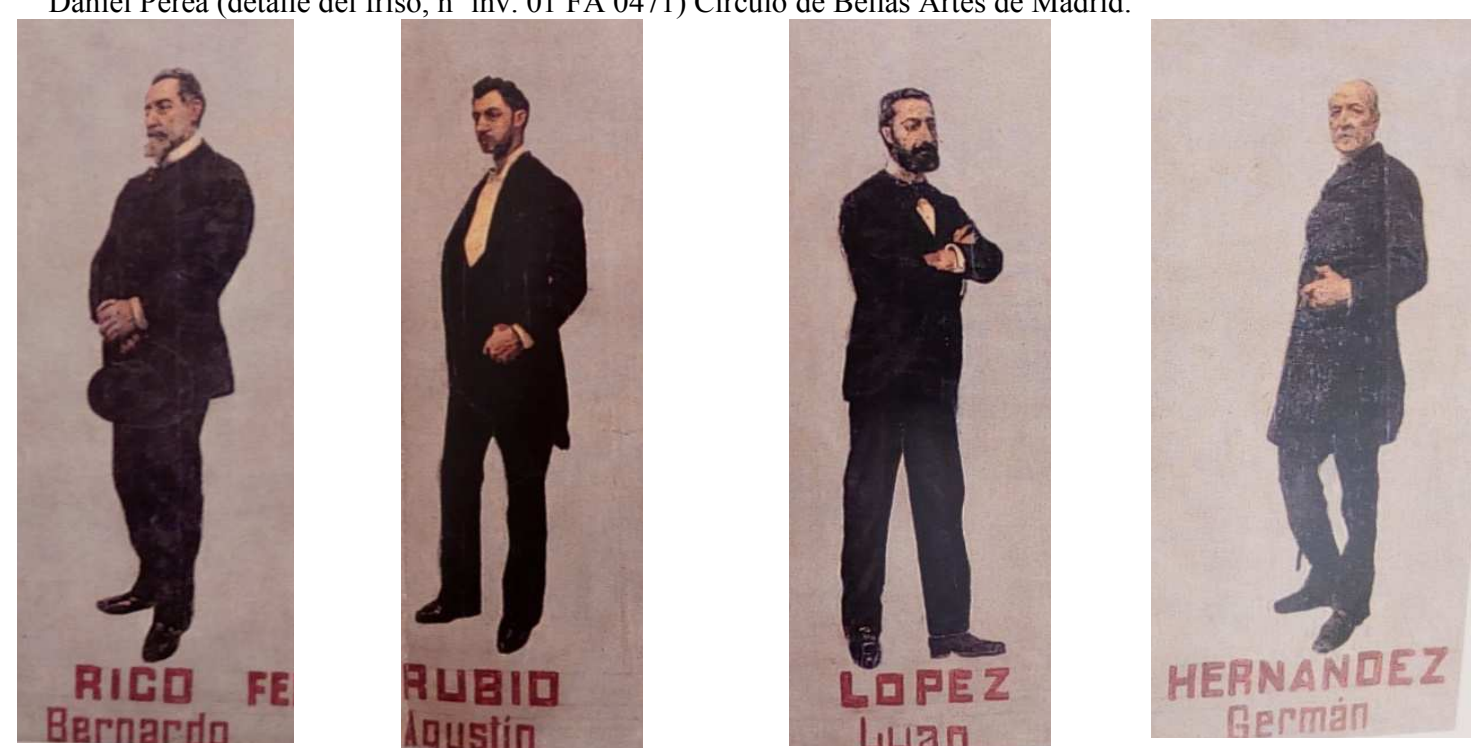

Fig. 208. Retratos de Bernardo Rico, Agustín Rubio, Juan López y Germán Hernández Amores (detalles del friso, $n^{\circ}$ inv. 01 FA 0405). Círculo de Bellas Artes de Madrid.
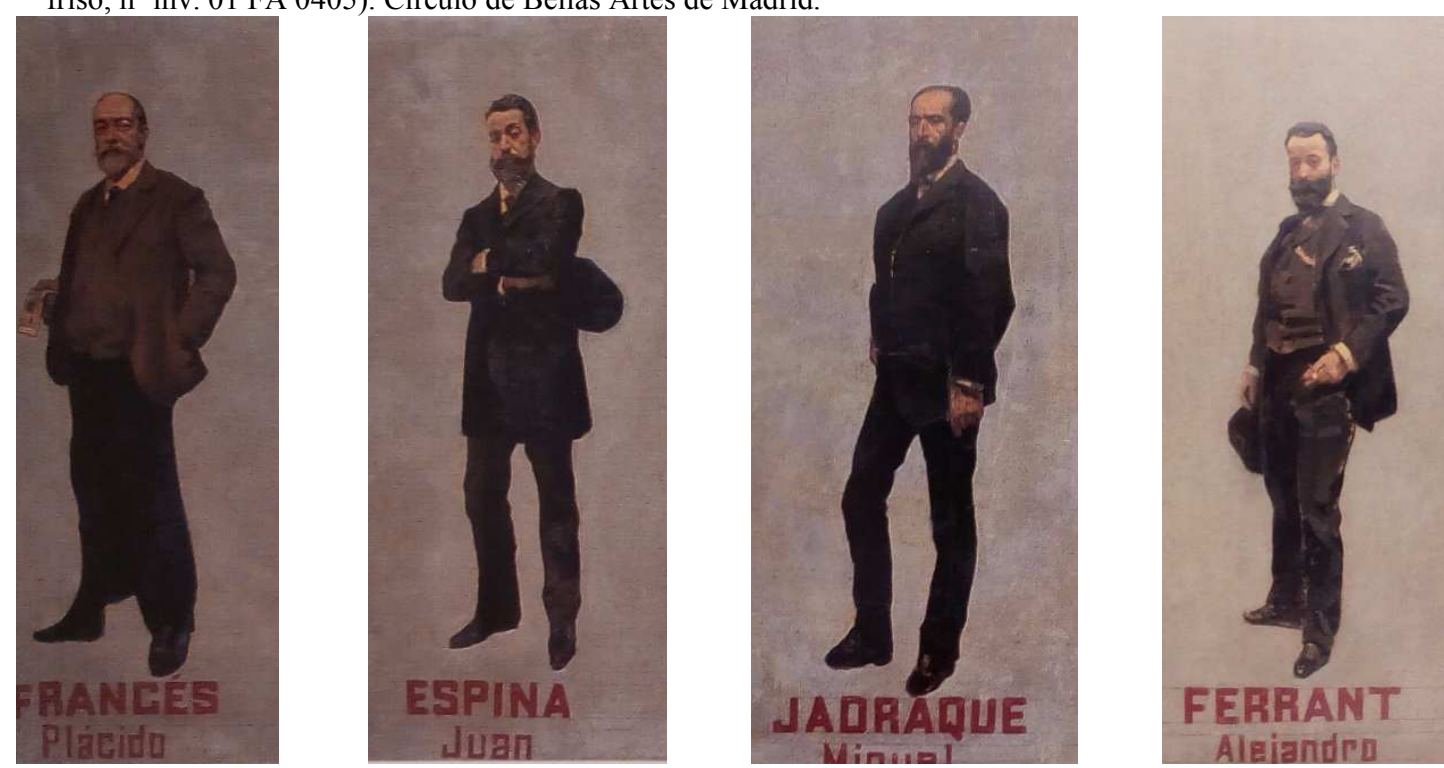

Fig. 209. Retratos de Plácido Francés, Juan Espina y Capó, Miguel Jadraque (detalle del friso, $\mathrm{n}^{\circ}$ inv. $01 \mathrm{FA}$ 0423) y Alejandro Ferrant (detalle del friso, $n^{\circ}$ inv. 01 FA 0473). Círculo de Bellas Artes de Madrid. 
La presencia de cuatro mujeres artista en este friso de retratos llama la atención debido al singular abandono a que su figura es sometida en las galerías de retratos institucionales y en otras sociedades; de este modo, se produce un reconocimiento hacia la actividad de Fernanda Francés, presente en las exposiciones del Círculo desde 1880, en las actividades artístico-recreativas de la sociedad, así como en las exposiciones nacionales de bellas artes; o a Marcelina Poncela, cuya presencia en el panorama expositivo español es anterior a su ingreso en el Círculo de Bellas Artes.

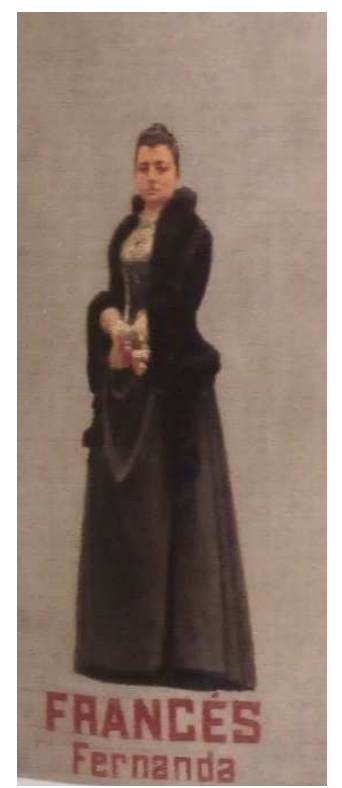

Fig. 210. Retrato de Fernanda Francés (detalle del friso). Círculo de Bellas Artes de Madrid (nº inv. 01 FA 0473).

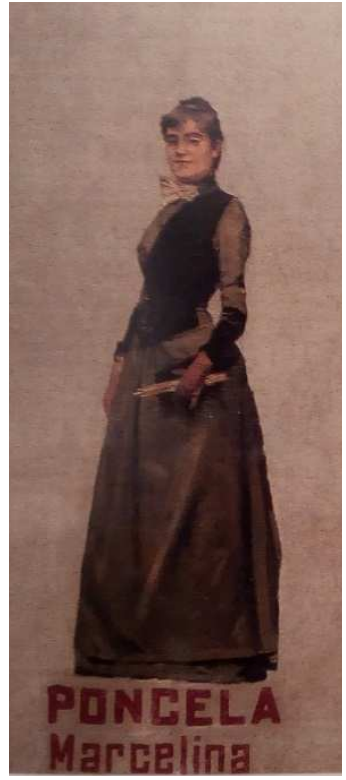

Fig. 211. Retrato de Marcelina Poncela (detalle del friso). Círculo de Bellas Artes de Madrid (nº inv. $01 \mathrm{AF}$ 0467).

A pesar de que Mesonero apuntaba que la secuencia de retratos era seria a veces y a ratos humorística -es el caso de Picolo, que a pesar de su apellido sobresale por encima del resto de retratados-, las representaciones parecen adaptarse a un tipo llamativo: los retratos de cuerpo entero introducen, en la mayoría de los casos, un traje civil y elegante (las excepciones están vinculadas al uso de uniforme militar), incluyendo bastones, sombreros e incluso cigarros en sus manos. Un tipo de imagen burguesa que es respaldada por las posturas de una informalidad poco casual, hasta tal punto de que, según una anécdota recogida por Balsa de la Vega, el pintor Germán Hernández Amores calificó la serie de retratos de colección de figurines de sastrería ${ }^{602}$. En efecto, son pocos, por no decir escasos, los elementos diferenciadores en la forma de representar a los distintos socios: los atributos propios de la profesión artística quedan excluidos por innecesarios, ya que la galería estaba formada por y para una institución en la que las bellas artes constituían el común denominador, y solo fueron empleados en un caso, con especial significado, al tratarse de una mujer artista. Así, Marcelina Poncela es la única que en su retrato se acompaña de un conjunto de pinceles, que sostiene firmemente en su mano; por el contrario, en los retratos de hombres artistas los únicos elementos que

\footnotetext{
602 "Mire usted, no quiero figurar como figurín de sastrería. Porque todos esos son caballeros para láminas de la revista de sastres titulada El español..." BALSA DE LA VEGA, 1895: 595.
} 
se incluyen aluden al éxito mediante la inclusión en su vestimenta del botón rojo de la Legión de Honor en los casos de Casto Plasencia y Alfredo Perea.

El Círculo mantuvo con orgullo esta colección de retratos hasta el traslado de la sociedad a su nueva sede y es significativo que, cuando en 1899 la reina visitó el Círculo de Bellas Artes en 1899, la directiva no dudó en enseñarle las obras que lo decoraban, recogiendo la prensa cómo había llamado la atención "la galería de retratos de los socios más caracterizados como artistas” (“La reina en el Círculo...”, 1899: 3).

\subsubsection{Retratos en las exposiciones del Círculo de Bellas Artes}

A pesar de que el retrato no fue un género especialmente representativo en las exposiciones del Círculo de Bellas Artes, donde prevalecieron la pintura de género y el paisaje, estas se convirtieron en un escenario privilegiado para dar a conocer un aspecto de la sociabilidad entre artistas a través los escasos retratos de consocios que se presentaron. Las exposiciones estuvieron reservadas a los socios entre 1880 y 1893, tal y como recogía el reglamento de exposición de 1886, y se celebraron de manera ininterrumpida con la excepción de los años 1884 y 1885 . No obstante, no todos los socios presentaban sus trabajos ni, como manifestaban los críticos al respecto, eran tan concurridas y exitosas como para estimular la venta y la producción de obras complejas ("Exposición del Círculo...", 1888: 2). El hecho de que a partir de 1893 se abriese la concurrencia a otros artistas sin ser necesariamente socios hace que en las listas de obras presentadas en estas exposiciones se encuentren dos tipos de retrato de artista que merece la pena señalar, no por su calidad técnica, ya que en la mayoría de los casos se trata únicamente de noticias, sino por el tipo de relación entre artistas y con la sociedad que reflejan. Por una parte, aquellos que presentan a un socio retratado por otro socio, sin que esto implique necesariamente que la obra fuese realizada ni en el seno de la sociedad ni como fruto de la relación surgida dentro del Círculo, pero que adquiere esta connotación al presentarse en la exposición de la sociedad. Por otra, están la de los artistas que, aunque socios del Círculo de Bellas Artes, tuvieron poca o nula relación con la sociedad y que, aun así, desearon subrayar el valor de esta como fraternidad artística mediante la presentación de retratos de amistad de otros artistas no relacionados con el Círculo.

Hubo que esperar a la segunda exposición del Círculo, celebrada en 1881, para encontrar el primer retrato de artista; en ella, el pintor aficionado Luis Ducourneau expuso un retrato en cristal de Casto Plasencia (CÍRCULO DE BELLAS ARTES, 1881: 64), que figuró con el número 118 en el catálogo. El retratado no era únicamente uno de los miembros fundadores de la sociedad, sino también el presidente de la misma. Por su parte, Ducourneau aparece como un personaje muy vinculado a la actividad del Círculo de Bellas Artes ${ }^{603}$, puesto que ya figura en la exposición de 1880, a la que concurrió con Una cabeza, y continuó presentando sus obras hasta, al menos, 1883. El retrato de Casto Plasencia volvería a figurar en la exposición de 1882 (El imparcial, 1882/26/03: 2), aunque no ha quedado ninguna descripción ni reproducción de la obra. Un año después

\footnotetext{
${ }^{603}$ De origen francés, Ducourneau llega a España en septiembre de 1874 con veintiún años, según consta en su pasaporte [Archives Departamentales de La Gironde, 4M765/395].
} 
se celebró la tercera exposición del Círculo de Bellas Artes, en la que podría haber figurado un autorretrato femenino de la pintora Clara Lengo, tal y como sugiere Macías Coque (1882: s. p.) en un comentario pretendidamente galante publicado en El día, puesto que habla de una cabeza femenina acompañada de rosas, atribuyéndolo a Clara Lengo, "la bella hija del pintor de los palomos. Ha querido retratarse, sin lograrlo: el original vale infinitamente más". La obra figura en el catálogo bajo el número 61 con el título Una cabeza (retrato). El hecho de que permaneciese en propiedad de la autora puede indicar que, efectivamente, se trataba de un autorretrato. Además de esta obra, según las noticias encontradas en prensa, el pintor y socio Plácido Francés presentó un retrato de una discípula; el escenario era bastante propicio para que se tratase de una imagen de su hija, Fernanda Francés, vinculada como él a la sociedad desde 1880, puesto que a pesar de no constar en la primera lista de socios publicada ese año, sí que participó en la primera exposición del Círculo de Bellas Artes.

La exposición de 1883 tuvo lugar en el Ministerio de Ultramar y a ella solo se envió un retrato de artista $^{604}$, cuya vinculación con Círculo era muy limitada. Se trataba del Retrato del grabador Sensi, realizado por Federico de Madrazo (presidente honorario del Círculo) en 1873, que el pintor conservaba en su propio estudio; la voluntad de Madrazo al presentar esta obra no radicaba únicamente en exhibir sus habilidades técnicas en el género del retrato, incluso en este caso de particular intimismo y tratamiento como "cabeza de estudio". El hecho de que Sensi hubiese fallecido tres años antes parece indicar que Madrazo también albergaba cierta intención conmemorativa, tanto de la personalidad del grabador como de la amistad que los había vinculado durante la última década. Curiosamente, Madrazo volvería a exponer este retrato en otra exposición del Círculo, la bienal de 1893 (BLANCO ASENJO, 1893: 342). Los años 1884 y 1885 pasaron por el Círculo de Bellas Artes sin que se realizase ninguna exposición propia debido, en primer lugar, a la implicación de muchos de sus socios en la Exposición Nacional, y en segundo a las dificultades económicas en que se encontraba la sociedad, lo que motivó el traslado de su sede. Fue en 1886 cuando se planteó revivir las exposiciones del Círculo, para lo cual se redactó un reglamento en el que se especificaba que los socios (y los que se inscribiesen como tales) serían los que tendrían derecho a concurrir. La exposición, que al parecer iba a tener lugar en el mes de abril en el salón Bosch, no llegó a verificarse al establecerse el propio salón de ventas de la sociedad. Este carácter comercial pudo influir en el espíritu de las exposiciones celebradas en 1887 y 1888 , en las que no se encuentra ningún retrato de artista ni de socios del Círculo.

Sin embargo, es muy evidente el papel del retrato en relación con la vida de la sociedad en la exposición del Círculo de 1889, en la que, según las noticias encontradas en la prensa, habrían figurado al menos un tres retratos de artista. El primero del que tenemos noticia es un "retrato de impresión de compañero en el arte" por parte del catalán Antoni Serra (El imparcial, 1889/31/05: 1), emparentado tal vez con el artista y

\footnotetext{
${ }^{604}$ En la prensa se hace referencia también a un retrato de Mr. Lhardy, debido a la pluma de Ducourneau; por el título empleado, parece referirse al padre del pintor Agustín Lhardy ("Exposición del Círculo de...", 1883/29/05: 3; CÍRCULO DE BELLAS ARTES, 1883).
} 
socio desde 1880 Pedro Serra. Por otra parte, es significativo que en la misma exposición se encontrasen dos retratos de Agustín Lhardy Garrigues, realizados por dos consocios que, como él, estaban vinculados al Círculo desde sus orígenes; el primero estaba realizado por el dibujante y grabador Alfredo Perea, del que consta que era una obra realizada al lápiz, probablemente una de aquellas destinadas a adornar la propia institución; el otro retrato, descrito por la prensa como un estudio a color, era obra de Cecilio Pla y Gallardo. El motivo de este peculiar homenaje, puesto que no se trataba únicamente de una muestra de amistad, se encuentra en el papel que el paisajista Lhardy tuvo en la organización de la exposición, que se celebró en el Palacio de Cristal del Retiro; Pérez Nieva (1889: 1), al igual que Francisco Alcántara, señalaba así que "El Círculo de Bellas Artes ha resucitado en público dignamente, gracias a Agustín Lhardy, el pintor incansable y de gran talento. Parece ser que este, aprovechando sus buenos amigos y su influencia en los teatros oficiales logró el préstamo de un local decoroso, el Palacio de Cristal del Retiro". Sobre ambos retratos, La iberia (1889/31/05: 2) decía del primero ser "de admirable parecido, y apuntado con la gracia, ligereza y distinción que caracterizan las obras del afamado dibujante", y del segundo tratarse de un "hermoso retrato del pintor Lhardy, ejecutado con maestría y soltura, y muy vigoroso de color"; en la crítica aparecida en El imparcial (M. de A., 1889: 5) se señalaba además que "de los tres estudios hechos por Pla el que más gusta a los amateurs es el retrato abocetado de Lhardy; un retrato hecho para un artista por otro artista consumado. A un profano jamás le cabrá en la cabeza que aquella es una obra de notable mérito; para un pintor, aquello es un boceto admirable", subrayando el carácter especial del retrato entre artistas. Respecto al retrato realizado por Perea, únicamente señala que se trataba de una obra notable, aunque prefería el que representaba al violinista, y también socio del Círculo, Enrique Fernández Arbós.

Igualmente correspondió a la mano de Cecilio Pla otro retrato de artista presentado en la exposición de diciembre de 1890, denominada "de acuarelas y pasteles", que pasó desapercibido debido al protagonismo del tributo que el Círculo rindió al fallecido Casto Plasencia ("El Círculo de Bellas Artes. Pasteles...", 1890: 1). Se trataba del retrato del pintor de marinas Tomás Campuzano y Aguirre quien, siendo socio del Círculo desde su creación, también concurría a la exposición con varias obras. Cabe subrayar que, además de esta relación de consocios entre pintor y retratado, ambos formaron parte de la comisión organizadora de la propia exposición ${ }^{605}$, por lo que es de esta manera doblemente significativa la presencia del retrato de Campuzano. Jacinto Octavio Picón (1890: 1) situaba a Pla entre los artistas que habían empleado el pastel para reproducir el natural sin pedir al mate de las barrillas más que lo que por su índole pueden dar", y alababa un uso de la técnica que no era lamido ni pretendía imitar los efectos de la pintura al óleo. El crítico Luis Alfonso (1890: 1) señalaba del retrato que era "un portento de realidad", sin que otras reseñas de la exposición aludiesen abiertamente a esta obra; así, Sánchez Jiménez (1890: 2) únicamente mencionaba un retrato al pastel realizado por Pla y Pedro de Madrazo (1890: 1) se limita a comentar

\footnotetext{
${ }^{605}$ Según recoge Pedro de Madrazo (1890: 1), la comisión organizadora estuvo compuesta por Lhardy, Pla, Pelayo, Espina, Campuzano y Perea.
} 
que "Pla en sus cuatro cuadros, especialmente en el retrato (al pastel) de Campuzano, está a la altura de su reputación".

Entre las obras que el pintor sevillano José Jiménez Aranda, asentado en Madrid desde 1890, remitió a la bienal del Círculo de 1891, se encontraba un retrato de artista, realizado al óleo, representando a Aureliano de Beruete. Este último consta como socio del Círculo desde 1880, y consta expositor en 1891 (PICÓN, 1891: 1). Del retrato señalaba Luis Alfonso (1891/23/05: 1) que estaba “dibujado con la precisión matemática propia de Jiménez Aranda, pero tan seco y aun agrio de entonación que, como habrá que verlo y admirarlo, será en fotografía", juicio que ya anticipaba Catalina Navarro (1891: 1).

El tema de la exposición organizada en octubre de 1892, "de cabezas y vitelas", podría indicar la presencia de varios retratos de artista; sin embargo, solo hemos podido recopilar noticia de dos. Sin lugar a dudas, el que más llamó la atención fue un autorretrato de Casto Plasencia, no solo por la calidad del dibujo, sino también por rememorar el talento del artista, fallecido dos años antes; las críticas son unánimes al tratar este retrato, aludiendo al vigor de su ejecución y a la maestría revelada en su ejecución ("En el Círculo...", 1892/25/10: 2; M. A., 1892: 2; "La exposición del Círculo...", 1892/28/10: 2). La reseña aparecida en El imparcial menciona otro retrato de un importante miembro del Círculo de Bellas Artes: el del grabador Bernardo Rico (Museo del Prado), entonces presidente de la sociedad, realizado dos décadas antes por Raimundo de Madrazo. Ambos retratos, cada uno con sus matices respecto a los vínculos personales subyacentes, mantienen estrecha relación con la vida del Círculo, puesto que ambos artistas, reputados y con trayectorias exitosas, no solo habían pertenecido a él sino que habían ostentado cargos directivos en el mismo, lo que mueve a reflexionar sobre la toma de conciencia de la sociedad respecto a su identidad e historia.

Ya se ha señalado que la exposición de 1893 estuvo abierta a quien quisiese concurrir, fuese o no socio del Círculo de Bellas artes; tuvo lugar durante el mes de mayo, y en ella se recoge la presencia de otros dos retratos de artista. Es el primero un autorretrato del pintor de origen vasco Ignacio Ugarte, que aparece registrado participando en las exposiciones del Círculo desde $1889^{606}$, realizado al óleo, y que solo mereció que Ramón Balsa de la Vega (1893: 3) afirmara que acusaba "grandes progresos en el dibujo y en la ejecución”. Además del retrato de Sensi por Madrazo, que ya había figurado anteriormente, sabemos que Emilio Sala, entonces afincado en París, remitió el retrato de su primo y tutor, el pintor Plácido Francés (BALSA DE LA VEGA, 1893: 410), del que es notorio su estrecho vínculo con el Círculo de Bellas Artes (DEL CAMPO PÉREZ DE CAMINO, 1986: 3-10).

Joaquín Sorolla, conocido ya por sus retratos, llamó la atención en la exposición del Círculo de 1894 precisamente por el retrato de un pintor, Luis Sáinz. El retratado figura

\footnotetext{
${ }^{606}$ Queda constancia de que en 1880 era socio del Círculo don Mariano de Ugarte y González, pero no se han encontrado referencias a posibles obras suyas. La presencia de "Ugarte" en las críticas de exposiciones se recoge a partir de 1889 , vinculada a Ignacio Ugarte.
} 
como vinculado al Círculo de Bellas Artes desde 1880, donde consta en la lista de socios, y al menos desde 1889 concurriendo a las exposiciones organizadas por la sociedad; Sorolla, por su parte, figura en las exposiciones del Círculo desde su instalación en Madrid en 1890, y consta entre el grupo de artistas que en 1907 rompieron relación con la institución madrileña. A la obra le dedicó Ribalta (1894: 179189) un largo comentario en la crítica publicada en la Revista contemporánea:

Esta gran tela llama, desde luego, la atención por la firmeza y por la sobriedad con que está tratada. La extraña aunque naturalísima postura del modelo, perfectamente movido; la triste armonía de los tonos fríos del traje y el fondo, el reposo de la figura toda, el enérgico modelado de la cabeza y de las manos, estudiadísimo, sobrio y sincero, son las cualidades que desde luego atraen al público, haciéndole detenerse ante esta severa tela, a la cual el autor supo dar un carácter y una elegancia poco comunes. (...) Al mismo tiempo, la ausencia de utensilios decorativos y la actitud de noble abandono del modelo, actitud que aleja toda idea de presentación escénica, hacen brillar en el cuadro la nota de la espontaneidad simpática.

Esta es la descripción más completa de la obra que hemos podido rastrear en las fuentes, puesto que otras reseñas, como la redactada por Enrique Sepúlveda (1894/13/05: 1-2; 1894/21/05: 322), apenas la mencionaban de pasada entre las presentadas por Sorolla. Así pues, llamaba la atención la actitud desenfadada del modelo, quien lejos de aparecer representado en la habitual escenificación del artista trabajador transmitía la cercanía y confianza propia de un retrato de amigo. Bernardino de Pantorba (1970: 201) catalogó este retrato de Luis Sáinz entre los que se encontraban en paradero desconocido o perdidos y señalaba que en el momento de su exposición en el Círculo de Bellas Artes se encontraba en poder del retratado.

Son interesantes también dos retratos de artista que figuraron en la exposición del Círculo de 1896, presentados por un mismo pintor. Vicente Cutanda optó por presentar su Autorretrato al mismo tiempo que un retrato de su amigo, el pintor Ricardo Arredondo, quien también enviaba obras a esa exposición. Una vez más, ambos pintores tenían relación con el Círculo de Bellas Artes; Ricardo Arredondo figura entre los artistas que expusieron en la sociedad desde 1889, mientras que de Cutanda solo se tiene noticia a partir de 1891, con motivo de la exposición benéfica a favor de las víctimas de las inundaciones ${ }^{607}$.

En el retrato de Arredondo [fig. 212] se pone de manifiesto una voluntad más trascendental que el mero hecho de efigiar a un consocio, como ocurre en algunos de los retratos presentados a las primeras exposiciones de la sociedad; este retrato de amistad corresponde a un vínculo más personal que el ofrecido por el Círculo de Bellas Artes, ya que ambos artistas tuvieron estrecho contacto en Toledo (DÍEZ, 1997: 164). La forma en que Arredondo aparece plasmado se puede vincular con otros retratos fruto de la sociabilidad artística y del plenairismo realizados por pintores españoles a finales del

607 "Para las víctimas de las inundaciones", 1892: 2. En 1894 ya figura como expositor reconocido en la exposición del Cïrculo de Bellas Artes "con sus escenas de obreros tiznados y forzudos" (RIBALTA, 1894/04: 395-399). 
siglo; de pie en mitad del paisaje, la figura del pintor se ubica junto a un caballete, distrayendo su atención de la obra que pinta para mirar al retratista. La indumentaria y actitud del pintor se relacionan precisamente con el momento del trabajo, un rasgo que parece reflejarse en la metáfora empleada por Balsa de la Vega (1896: 3) al hablar tanto de este retrato como del autorretrato de Cutanda [fig. 213]: "supo Cutanda retratar dos temperamentos tan distintos como el de su amigo y el suyo, pero esbozándolos a martillazos como forjan y moldean el hierro los obreros que pinta (...)". Algo similar parecía querer decir Pérez Nieva (1896: 1) al hablar de los dos "juiciosos retratos" presentados por Cutanda, "en los que se ve la influencia del medio ambiente en que el autor se desarrolla ${ }^{608}$,.

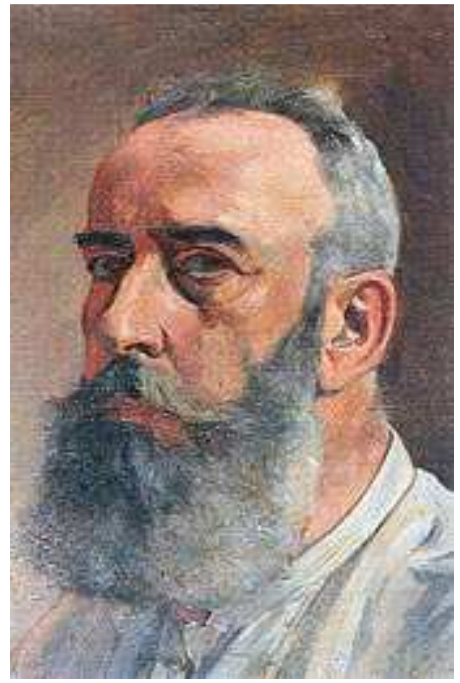

Fig. 212. Vicente Cutanda, Autorretrato (CUTANDA, 2004: 502).

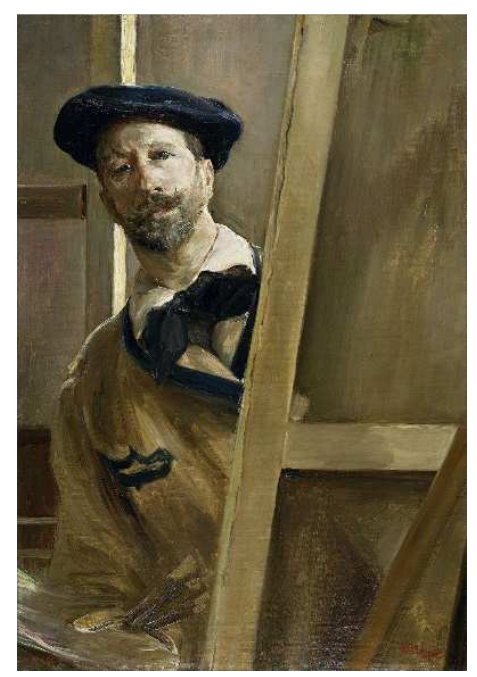

Fig. 214. José Villegas, Autorretrato. Museo Nacional del Prado ( $\mathrm{n}^{\circ}$ inv. P05689).

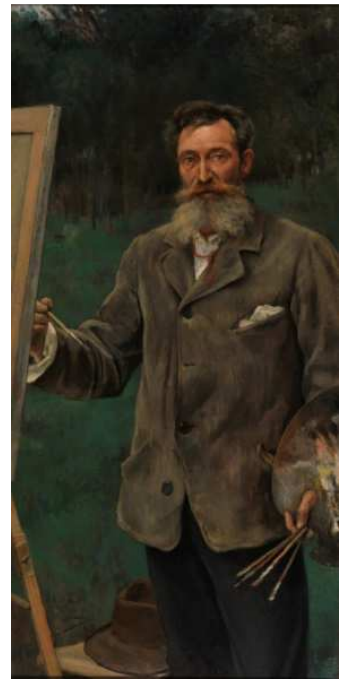

Fig. 213. Vicente Cutanda, El pintor Ricardo Arredondo. Museo Nacional del Prado ( $\mathrm{n}^{\circ}$ inv. P04221).

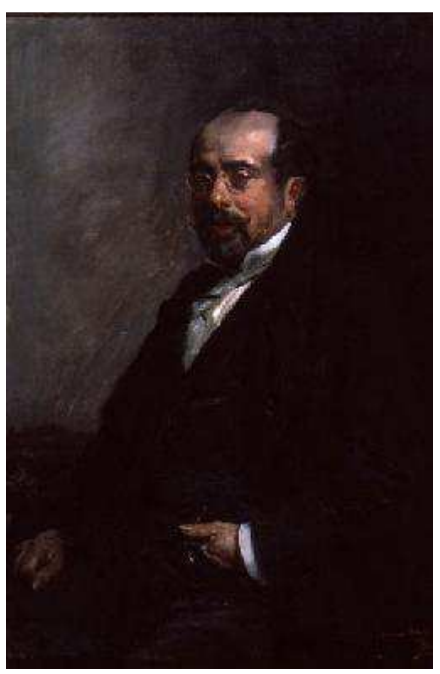

Fig. 215. Joaquín Sorolla, Retrato de Muñoz Degrain. Museo de Málaga ( $\mathrm{n}^{\circ}$ inv. BA/421).

Ningún retrato de artista figuró en la exposición de 1897, destinada a recaudar fondos para los heridos en Cuba y Filipinas, y tan solo se remitió uno a la bienal de 1898; José Villegas envió desde Roma, junto a otras obras, un autorretrato [fig. 214]

${ }^{608}$ También se recogen algunos comentarios sobre ambos retratos en ROVIRA, 1896: 1. 
que llamó la atención por su colorido, ambientación y originalidad (SORIANO, 1898: 2; MISS-TERIOSA, 1898/22/05: 2; PARDO BAZÁN, 1898: 378). En él se presentaba en actitud de pintar, asomándose por detrás del lienzo que le ocupa y escrutando con intensa mirada el sujeto de su pintura; sin embargo, lejos de la imagen que ofrecía Arredondo en el retrato realizado por Cutanda, José Villegas aparece como un artista que, a la par que reflexivo, manifiesta a través de su actitud y su vestimenta (una pulcra bata clara ribeteada de azul, por la que asoma una gran pajarita, o la boina azul de textura aterciopelada) el estatus alcanzado a través de su arte. Del retrato decía Pérez Nieva (1898/02/06: 2):

es un retrato suyo de gran novedad. Diríase que ha querido retratar en él no al hombre sino al artista, reproduciendo antes que la fisonomía el momento psicológico de la inspiración. Así se presenta de frente casi, ante el caballete, viendo el espectador el revés del lienzo en que trabaja. Huelga decir, tratándose de Villegas, hasta que punto habrá acertado con la expresión de su rostro meditativo. El numen baja a aquella cara, la idea se forma, el efecto resulta. Por lo que toca a la factura es de una suavidad infinita, con esa suavidad que no excluye el rigor de la pincelada, característica de Villegas.

El uso de un punto de vista bajo permitía también establecer esa dicotomía entre el artista como hombre trabajador, tal y como indica su atuendo, y la labor de observación e inspiración (DÍEZ, 1997: 160) que se mueve más entre lo intelectual y lo espiritual. No parece posible una relación directa de Villegas con el Círculo de Bellas Artes, ya que había permanecido desde 1868 en Roma y no consta que hubiese participado anteriormente enviando obras ${ }^{609}$. Probablemente la intención del artista al presentar la obra se corresponde con su nombramiento como director de la Academia Española en Roma, deseando así incluirse entre los artistas de mérito.

Siguiendo los límites cronológicos de nuestro estudio, la exposición del Círculo de 1900 constituye el final de esta revisión por las exposiciones de la sociedad. Joaquín Sorolla presentó un retrato del pintor Muñoz Degrain [fig. 215], del que la Ilustración española y americana (1900/22/04: 234) publicaba una reproducción y alababa la obra por su carácter doblemente artístico, aunque solo se precisaba de ella que era "de mucho carácter y en general acertado, así en el movimiento como en la disposición de la figura" (BALSA DE LA VEGA, 1900: 258). No parece que este retrato llamase excesivamente la atención, algo perfectamente comprensible si se compara esta obra, actualmente conservada en el Museo de Málaga ( $\mathrm{n}^{\mathrm{o}}$ inv. BA/421), con la descripción que se hacía del retrato de Luis Sáinz seis años antes; frente a la languidez y postura desenvuelta de este último, la imagen que Sorolla transmite de Muñoz Degrain es de rigidez y convencionalismo oficial. pues aparece representado de medio cuerpo, sentado, elegantemente vestido y con una mirada penetrante tras sus lentes. La entonación y colorido de la obra, en que priman los tonos grises y negros, contribuye a

\footnotetext{
${ }^{609}$ En la exposición de apuntes de viaje celebrada en 1893 se prometía la participación de Villegas $(E l$ Día, 1893/07/12); mientras que Tiépolo (1893: 2) ubicaba efectivamente a un pintor apellidado Villegas entre los expositores, en El liberal ("Exposición del Círculo...", 1893/26/12: 2) se aclaraba que se trataba del pintor Manuel Villegas Brieva, que anteriormente había pertenecido al Círculo de Bellas Artes y a su junta directiva.
} 
recrear una atmósfera plomiza en torno al pintor. Tan solo la dedicatoria, que reza "a mi amigo Muñoz Degrain suyo / J. Sorolla / 1898", señala ese carácter de obra de amistad. Por otra parte, la vinculación de Muñoz Degrain con el Círculo de Bellas Artes es manifiesta, ya que no solo participó en sus exposiciones, sino también en sus reuniones, en actividades decorativas y en su junta directiva ${ }^{610}$.

\subsubsection{Retratos conmemorativos y homenajes fúnebres}

Además de configurarse como un centro para la tertulia artística, la enseñanza noctura y la celebración de exposiciones, uno de los objetivos del Círculo era constituirse como un lugar de encuentro donde los artistas, además de estimularse mutuamente, pudiesen establecer vínculos fraternales. Es en los homenajes fúnebres realizados por el Círculo a algunos de sus consocios donde se observa la importancia y trascendencia de los vínculos creados o fomentados en el seno de la sociedad artística, en algunos de los cuales el retrato fue recuperado como homenaje póstumo y como imagen para la memoria del genio ausente. Son escasos los homenajes que se celebraron en el siglo XIX y aún más difíciles de rastrear son aquellos en los que el retrato del artista tuvo un papel protagonista; de escasa relevancia es el dibujo alegórico en memoria de Rosales presentado por el socio Ángel en la exposición de 1881 (L. A., 1881: 2), al igual que los homenajes realizados a los artistas del pasado en la celebrada en 1883, ya que esta conistió únicamente en la colocación de coronas de laurel con sus nombres sobre los paneles en que se ubicarían los cuadros en el Ministerio de Ultramar (La ilustración española y americana, 1883/15/06: 364). En algunos casos, la manera de honrar a artistas fallecidos recientemente se formalizó mediante la incorporación de algunas de sus obras en la exposición, como sucedió en la de "blanco y n"egro de 1890 con las obras de Valeriano Domínguez Bécquer (L. A., 1890/07/02: 2; "El Círculo de...", 1890/15/02: 91), o en el de Antonio Cortina en la exposición de 1891. En otros casos se encargó de reunir la obra del artista con el fin de organizar una venta o rifa para aliviar la situación económica de la familia, como ocurrió en la "Exposición Gonzalvo" en enero de 1897 (El día, 1897/08/01: 2).

\subsection{Casto Plasencia}

A pesar de que en la exposición de "blanco y negro" de 1890 se rendía un pequeño tributo a Casto Plasencia mediante la incorporación de una figura de mujer que este había realizado, en la muestra de acuarelas y pasteles celebrada en diciembre de ese mismo año el Círculo consagró un tributo de amistad a su consocio fallecido. El periódico El día (1890/20/12: 1) recogía esta iniciativa señalando cómo "el Círculo ha querido rendir un cariñoso tributo a la memoria de Casto Plasencia, y en lugar preferente y rodeada de negros crespones ha expuesto una acuarela del inolvidable artista que, como todas sus obras, revela su genio". Además, indicaba que junto a esta obra se había colocado su paleta envuelta en gasas negras. Dos años después el Círculo

\footnotetext{
${ }^{610}$ Muñoz Degrain aparece recogido entre los artistas que realizaron pinturas en espejos y panderetas para el baile de 1899 ("El baile del Círculo de Bellas Artes", 1899/09/02: 3), así como entre los que cedieron obras para la rifa para recaudar fondos para la estatua de Velázquez ("La Estatua de Velázquez", 1899/03/05: 2). Además, ya en 1897 formaba parte de la junta del Círculo (C., 1897/25/02: 7).
} 
volvía a rendir homenaje a Plasencia destinando a la exposición de cabezas y abanicos el Autorretrato del artista.

\subsection{Julio Gros}

La repentina muerte del pintor y dibujante Julio Gros en diciembre de 1893 causó especial impacto al haberle sorprendido a una edad temprana (ÁLVAREZ SERBIX, 1893: 2); algunos de sus más íntimos amigos, socios del Círculo de Bellas Artes, promovieron la idea de homenajearle dedicándole un espacio a sus obras en la exposición de "Impresiones de viaje", inaugurada a finales del mismo mes. Esta "instalación especial" no pasó desapercibida a los críticos que dieron noticia de ello ${ }^{611}$; sus obras fueron destinadas a un gabinete, con su correspondiente ornamentación fúnebre, y muchas de ellas puestas a la venta en beneficio de su familia. Este homenaje por parte del Círculo no parece la única memoria que dedicó a Julio Gros, "consocio y asiduo concurrente a las clases de la Sociedad" (El día, 1894/23/01: 2), ya que al parecer la Junta Directiva solicitó a su viuda la última obra que se encontraba realizando el pintor. Además, según Blanco Asenjo (1894: 75), se colocó un retrato de Gros, realizado al carbón por su compañero, el también dibujante Covisa, presidiendo el testero de la sala dedicada al difunto artista. La iniciativa fue percibida como un auténtico símbolo del espíritu fraternal del Círculo que ahondaba en los vínculos de amistad y solidaridad masculinos, así como en el respeto a una profesión compartida, tal y como exponía el crítico de El país (L. y A., 1894: 2): “Aquella delicada muestra de cariño que los vivos dedican al compañero que murió con gloria, pues murió luchando, honra no solo a Gros, sino a los artistas del Círculo de Bellas Artes, que así saben entender la amistad y así saben premiar el mérito".

\subsection{Joaquín Araujo}

La noticia del fallecimiento del pintor Joaquín Araujo Ruano, acontecida en marzo de 1894, venía acompañada de otra sobre la muestra de respeto por los artistas del Círculo de Bellas Artes, que acudieron a su velatorio instalado en su domicilio en la calle de los Reyes. Como socio activo del Círculo, no extraña que este pequeño homenaje por parte de sus amigos y consocios se viese respaldado por un reconocimiento público desde la institución artística (“Joaquín Araujo", 1894/16/03: 2). Ya el día posterior al entierro del artista se empezaba a extender el rumor de que el Círculo de Bellas Artes probablemente realizase una exposición en su honor ("El entierro de Araujo", 1894: 2), lo que se verificó en el mes de mayo en el marco de la exposición bienal del Círculo. La prensa dedicó extensas reseñas y elogios a esta iniciativa y a la instalación y obras de la Sala Araujo (ALCÁNTARA, 1894: 2), especialmente llamativa al trasladar el estudio del artista con su mobiliario a la sala. Pérez Nieva (1894: 1), que realizó la descripción más detallada de la sala, señalaba:

Hoy todo aquel alegre y revuelto estudio, con sus apuntes, con sus fraileros, con sus mesas antiguas, con sus bocetos y únicamente sin las virginidades de la escoba

\footnotetext{
611 “La exposición del Círculo de Bellas Artes”, 1892/27/12: 2-3; N., 1893: 3; La Época, 1894/05/01: 3; LAVERNIA, 1894: 3; L. y A., 1894: 2; "Círculo de Bellas Artes", 1894/14/01: 1; BALSA DE LA VEGA, 1894/22/01: 50-52.
} 
del auténtico encuéntrase en el palacio donde se celebra la actual exposición del Círculo de Bellas Artes constituyendo una de sus salas. Un crespón negro cubriendo el retrato del malogrado pintor y unos paños funerarios de luto dejan adivinar la verdad triste. Esa agrupación de sus muebles ante el público es un piadoso recuerdo de sus camaradas de profesión a la memoria del muerto.

El retrato, según consta en otro artículo sobre la exposición firmado por Ribalta (1894: 188), era una obra realizada al difumino por el íntimo amigo de Araujo, Nicolás Megía, quien a través de una obra surgida del afecto personal rendía así el tributo de amistad y reconocimiento profesional de todo el Círculo de Bellas Artes.

\subsubsection{Epílogo}

La evolución del Círculo de Bellas Artes de Madrid entre 1880 y 1900 pone de relieve la transformación de los usos sociales y profesionales que se dieron a la institución, y fundamentalmente de las aspiraciones de los artistas que se vincularon a ella. Si inicialmente se trató de una tertulia destinada al encuentro amistoso entre artistas, a la práctica en común en sesiones de dibujo al margen de las preocupaciones diarias de la profesión y al fomento de exposiciones que diesen visibilidad y creasen un nuevo foco de mercado, la precariedad económica de la propia sociedad movió a ampliar sus fines, configurándose además como una propuesta de ocio destinada a artistas y escritores. No debe sorprender que Rodrigo Soriano (1898: 1) criticase la situación del Círculo con las siguientes palabras:

Cuando se fundó el Círculo de Bellas Artes creyeron muchos de buena fe que se trataba de crear una sociedad compuesta de artistas jóvenes e independientes que procuraban sustraerse a la influencia letal del arte oficinesco y burocrático, al amodorramiento de la rutina artística creada en España por el exceso de distinciones. Por desgracia, cuantos pensaban así equivocáronse lastimosamente. Salvo excepciones honrosísimas, el Círculo que preside D. Amós Salvador es hoy por hoy una Sociedad compuesta de personas amabilísimas y distinguidas, de amenas tertulias y largas partidas de tresillo. Muy poco se diferencia, a la verdad, de otros círculos cortesanos en que el esparcimiento, el solaz, el buen tono y el amable trato mundano tienen su trono (...) Cierto que lo socios del Círculo son simpáticos artistas que procuran a toda costa distraer las monotonías y tristezas de la vida madrileña con alegres e ingeniosas fiestas y copiosos regalos de dibujos, periódicos, panderetas, etc. Antes y después del carnaval, no cabe duda que los alegres socios del Círculo dan ruidosas y plausibles muestras de su actividad y gusto artístico. Quisiéramos, sin embargo, que dedicaran sus esfuerzos a la regeneración del arte nacional, tan decaído y amanerado por culpa de exposiciones mal dirigidas, y deje ese espíritu panzista [sic] y aburguesado que ahoga, en muy poco tiempo, los alientos de independencia y originalidad con que empiezan la carrera pictórica algunos artistas.

La crítica de Soriano pone de relieve la transformación del Círculo en una sociedad si no exclusivamente masculina, sí vinculada al concepto masculinizado de ocio burgués; en sus palabras subyace, además, una imagen idealizada de la profesión artística ajena a las necesidades y vaivenes del mercado, que traiciona en la figura del "regenerador del arte" una vinculación con el héroe cultural (masculino) de fin de siglo. 
El hecho de que en el Círculo iniciasen su carrera y permaneciesen vinculadas a él algunas mujeres artista como Fernanda Francés y Marcelina Poncela indica los cambios respecto a los estereotipos de género -aún muy lentos y de escasa visibilidad- en la relación entre mercado, profesionalización y sociabilidad artística. No cabe duda de que, a pesar de la presencia femenina en sesiones, clases y exposiciones, el Círculo fue una sociedad de carácter masculino, como indica su progresiva vertiente lúdica y las imágenes que nos han llegado de tertulias y de reuniones de la junta directiva. En este sentido, la acusación de Soriano sobre el aburguesamiento del arte y de los socios del Círculo no hace sino transmitir la asimilación por parte de los hombres artista de la capital de los valores normativos masculinos vinculados a la élite social, especialmente en la última década del siglo. Las tensiones y rivalidades convivieron con el espíritu de fraternidad que se observa en los diferentes retratos realizados entre consocios, de lo que es especialmente significativo que en la pervivencia histórica del Círculo de Bellas Artes se hayan conservado algunos de ellos no solo como testimonio gráfico de sus orígenes, sino también de la identidad comunitaria que se derivaba inicialmente de su coexistencia en espacios significativos para los socios.

\subsubsection{El Círculo Artístico y el Círculo Artístico de San Lucas de Barcelona}

La existencia en Barcelona del Centro de Acuarelistas ya había suscitado la necesidad de constituir una sociedad a modo de centro artístico, "en que tuvieran ingreso todos los artistas en pintura y escultura", tal y como se propuso en el banquete celebrado con motivo del éxito de la exposición en el Museo Martorell organizada por los acuarelistas en 1885 ("Barcelona", 1885/21/06: 400) ${ }^{612}$. Según recoge Mireia Freixa (2010: 172), el Círculo Artístico existió en Barcelona desde 1881, fecha de su primer reglamento, aunque es a partir de su fusión con el grupo de acuarelistas cuando la iniciativa cobró mayor fuerza; las noticias, sin embargo, de la creación definitiva del Centro Artístico de Barcelona solo se encuentran a partir de octubre de 1887 como fusión del Centro de Acuarelistas y la comisión para una Asociación de las Artes aseguraba una mayor estabilidad económica aunando propósitos y proyectos ( $\mathrm{La}$ dinastía, 1887/31/12: 1). La junta directiva quedó constituida con José Luis Pellicer como presidente, Manuel Fuxá como vicepresidente, José María Tamburini como secretario y Manuel Durán como vicesecretario; entre los vocales se encontraban artistas como Arcadio Mas, Santiago Rusiñol, Juan Llimona o Juan Baixés (La dinastía, 1888/01/01: 4). La nueva sede contaba ya con los elementos que una sociedad precisaba, desde los relacionados con la administración y jerarquía interna (salón de sesiones y actos, Sala de Juntas y biblioteca), los vinculados con la práctica artística (una clase de acuarela para el estudio de modelo natural de ambos sexos, vestido y desnudo, con capacidad para cuarenta pintores y una clase para estudio del yeso), así como espacios para el ocio y la recreación (billar y café), relacionándose así con otras formas de sociabilidad masculina propias de la élite. Al igual que otros círculos y centros artísticos, proponía convertirse en un centro de unión y discusión para artistas y

\footnotetext{
${ }^{612}$ Para una historia completa del Círculo Artístico (denominado ya en el siglo XX "Real Círculo Artístico"), ver la monografía de María Isabel Marín Silvestre (2006).
} 
teóricos del arte, como puso de manifiesto con organización de conferencias desde febrero de $1888^{613}$, aunque al mismo tiempo hay constancia, como señala Luis Alfonso (1887: 1), de que la vertiente lúdica ya estaba recogida desde casi los inicios de la sociedad entre los objetivos del Círculo:

Los proyectos para el porvenir del Centro Artístico son, como ya indiqué, muchos y buenos, y las esperanzas no son pocas. Precisamente estas se fundan en aquellos. Espera el Centro adquirir pronto y lozano desarrollo en virtud de la idea que representa y que no puede ser más simpática: unión y comunicación de los artistas de toda especie, activos y pasivos -teóricos y prácticos-, así para instruirse e ilustrarse, como para protegerse y servirse, como para intimar y solazarse. Proyéctase, por lo que atañe a la parte útil de la Sociedad, ampliar cuando sea necesario, las clases; adquirir obras y libros de importancia, formar un álbum fotográfico de modelos, con designación de señas particulares y domicilio para que a él acudan en consulta los artistas (lo cual es práctico sobremanera); instruir lecciones públicas y dar conferencias y lecturas que versen sobre materias artísticas, mediante el concurso de personas entendidas en ellas. Al propio tiempo, para hermanar lo útil con lo agradable, proyecta la rejuvenecida Sociedad celebrar en sitio a propósito -el Teatro Lírico v. gr.- bailes de máscaras, esencialmente artísticos a usanza de Roma o Viena; disponer de alguna cabalgata de igual género para el Carnaval -resucitando aquellas que dieron tanto renombre a Barcelona- y procurar en suma recreo y esparcimiento alegres y a la par cultos, inteligentes y artísticos a los socios del Centro, y por reflejo a las personas amantes de las artes y a Barcelona en general.

Todos estos elementos, tomados de las formas de sociabilidad de la clase alta barcelonesa (a ejemplo, por una parte, del Ateneo y, por otra, de los círculos de recreo) se unieron a un concepto de cosmopolitismo, elegancia y trasgresión que se suponía de la presencia de una plantilla de socios "rejuvenecida", es decir, pertenecientes a la juventud artística y a la cual se atribuía el glamuroso atributo de la bohemia. La voluntad de tener una amplia dimensión en la vida social e intelectual barcelonesa queda reflejada desde la sesión inaugural del segundo ciclo de conferencias del Círculo, presidida por Castelar ("Historia de la semana", 1888: 720). Al mismo tiempo, Asarta se encargó de plasmar gráficamente aquel acontecimiento [fig. 216], lo que pone de manifiesto cómo la sesión fue recibida por un público eminentemente masculino, en que los artistas se unen y fusionan sin problema con la elegante concurrencia ("Sesión inaugural...", 1888). En la mesa presidencial, si seguimos la descripción aparecida en La Dinastía, podemos encontrar al propio Castelar en el sillón presidencial, con José Luis Pellicer, José María Tamburini y Mas y Fondevila a su derecha, mientras a su izquierda aparecen Fuxá, Masriera e Ixart (“La conferencia artística...”, 1888: 3).

\footnotetext{
${ }^{613}$ Entre los conferenciantes se encontraron personalidades como José Ixart o José Lázaro Galdiano ( $L a$ dinastía, 1888/16/02: 2; L.A., 1888/18/02: 1; La dinastía, 1888/17/03: 2.
} 


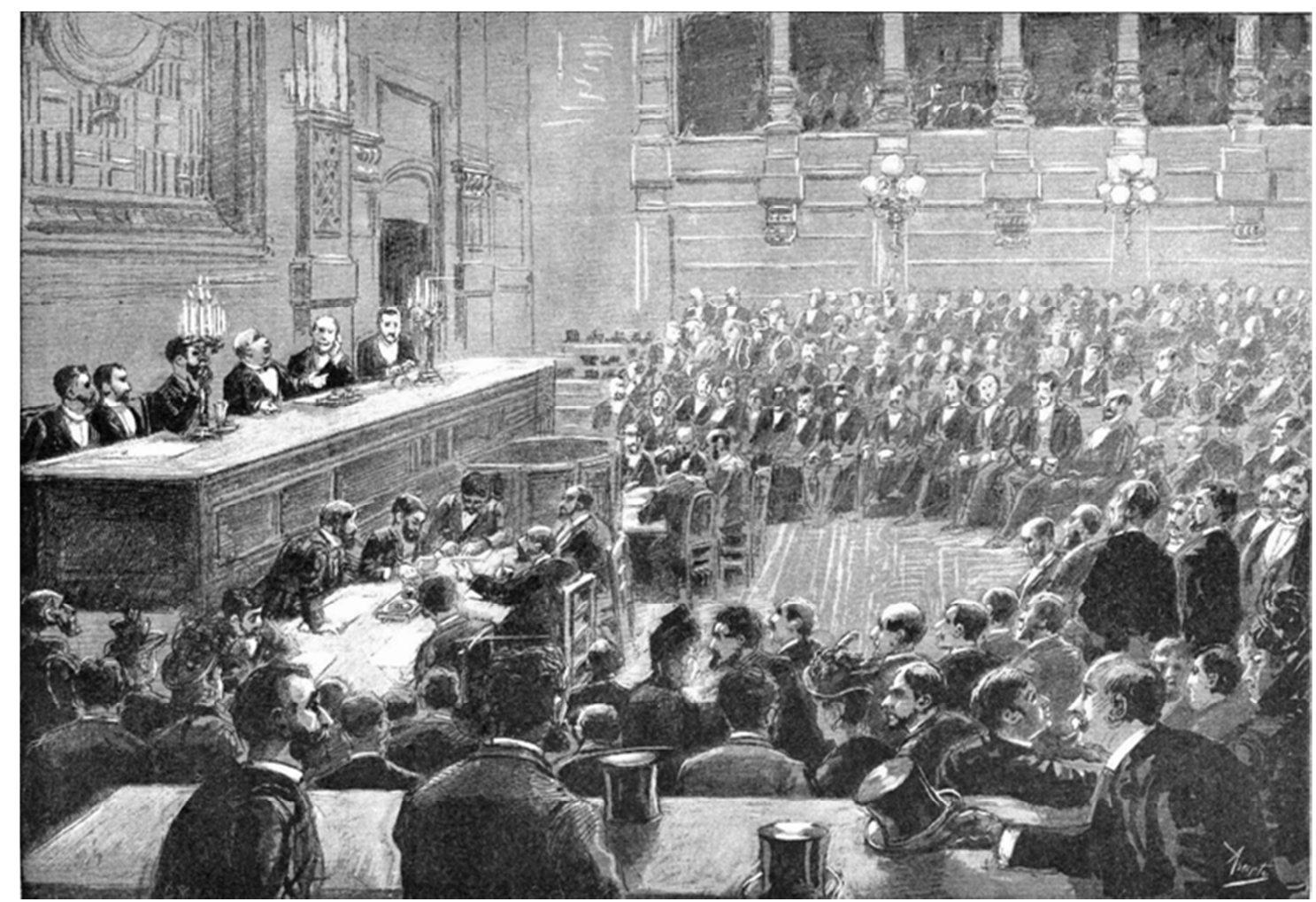

Fig. 216. Sesión inaugural del Centro Artístico, dibujo de Asarta publicado en La ilustración ibérica $(1888 / 10 / 11)$.

Respecto a la actividad plenamente artística de la nueva sociedad queda constancia de la celebración de exposiciones, de cuyo reglamento se extrae la interesante noticia de que la participación estaba restringida a los socios del Círculo. Así, "cada artista podrá presentar un número indeterminado de obras, siempre que la suma total de sus dimensiones, marcos comprendidos, no exceda de la superficie de tres metros de ancho por un metro cincuenta centímetros de alto o viceversa" (La dinastía, 1888/13/02: 1). En las someras reseñas publicadas por Luis Alfonso (1888: 1) se observa que las obras presentadas fueron apuntes y dibujos, sin que conste la presencia de retratos de artista $o$ de consocios.

\subsubsection{Una fallida galería de artistas catalanes}

Uniéndose a la creciente moda de configurar galerías de retratos en las instituciones barcelonesas (sirvan como ejemplo la de Catalanes Ilustres en el Salón de Ciento del Ayuntamiento, o la formada por el Ateneo Barcelonés), el Círculo Artístico manifestó su interés por iniciar lo que denominaba una "galería de artistas catalanes". No debe interpretarse únicamente como una consecuencia del espíritu catalanista, que en plena Renaixença estaba a la orden del día en las sociedades barcelonesas, sino también como un homenaje a la tradición artística regional y a la renovación pictórica de la ciudad en el siglo XIX. Tal es, al menos, la hipótesis que sugiere una iniciativa que, a pesar de la larga historia del Círculo Artístico, no llegó a cuajar.

Su origen radicaba en el fallecimiento, acontecido el 31 de marzo de 1889, de uno de los pintores más notables del Romanticismo catalán, figura clave en la enseñanza artística barcelonesa y artista implicado en los debates sobre el papel del artista en una 
sociedad transformada por el movimiento obrero: Claudio Lorenzale. Para homenajear al pintor, el Círculo organizó una velada necrológica, a similitud de las que se organizaban en el Ateneo, en la que se leyó su biografía, se realizó una pequeña muestra de sus obras y se inauguró el primer retrato de lo que el Círculo Artístico pretendía que fuese una galería de artistas catalanes, tal y como expuso el presidente José Masriera al finalizar el acto (MARÍN SILVESTRE, 2006: 219; La dinastía, 1889/12/05: 2; "En el Círculo", 1889/14/05: 1). Lorenzale, tal y como explicaba Masriera, no perteneció a la corporación por haberse fundado "en la época del retraimiento al que le sujetaba ya su falta de salud" ("En el Círculo", 1889/14/05: 1), por lo que el homenaje no se debía a su vinculación con esta, sino al ejemplo que supuso el pintor para tres generaciones de artistas barceloneses como maestro y como hombre.

Tal y como recoge el artículo publicado por La vanguardia, presidía el salón de conferencias del Círculo el retrato de Claudio Lorenzale, realizado por Antonio Caba (quien, según las noticias lo había regalado a la sociedad), enmarcado por las gasas negras y rama de laurel que indicaban el carácter luctuoso de la ceremonia. Del retrato decía la prensa que era admirable por el parecido y la ejecución, lo que lo convertía en una efigie muy digna de su papel como iniciadora de la galería. La obra presenta al artista de busto prolongado sobre fondo neutro, de edad avanzada, de modo que muestra una imagen contemporánea y alejada del halo místico de sus autorretratos de juventud; vestido sobriamente y con la cabeza de tres cuartos, recuerda mucho al retrato póstumo que el mismo Antonio Caba pintaría en 1891 para la Academia de Bellas Artes de Barcelona, aunque en el ofrecido al Círculo Artístico no aparece alusión alguna a su profesión de pintor.

\subsubsection{Círculo Artístico, arte y sociabilidad artística a favor del ocio}

A pesar de la clara vocación artística de los socios del Círculo Artístico, el ocio y la diversión terminaron acaparando las actividades de la sociedad. Esto fue especialmente fomentado por la prensa, que en su interés por dar trascendencia pública a las actividades barcelonesas dieron mayor cobertura a las noticias de los bailes de máscaras o de trajes que a las exposiciones del centro, de las cuales solo se registra una en el período de 1887 a 1895. Ante este despliegue de lo lúdico preguntarse cómo se visibilizó a los artistas dentro del Círculo, ya que su figura fue rápidamente equiparada con la sociedad elegante gracias a su papel dinamizador. Al igual que había sucedido en instituciones recreativas madrileñas, o como era costumbre entre la alta sociedad, los bailes de carnaval del Círculo Artístico tuvieron una gran acogida por su despliegue artístico y por la equiparación inmediata que estas fiestas, con su halo de modernidad bohemia, establecía con el recuerdo de los carnavales de la colonia artística en Roma, hecho que no pasó desapercibido entre las reseñas que la prensa publicó al respecto ( $\mathrm{La}$ ilustración, 1889/28/04; La ilustración artística, 1889/19/04); por este motivo, el carnaval del Círculo quedó convertido en una fiesta "que no podía ser más simpática para la persona de buen gusto y cultivado entendimiento", ya que su finalidad era "imprimir en una fiesta de sociedad el hermoso sello del arte" (ALGUIEN, 1889: 1). 


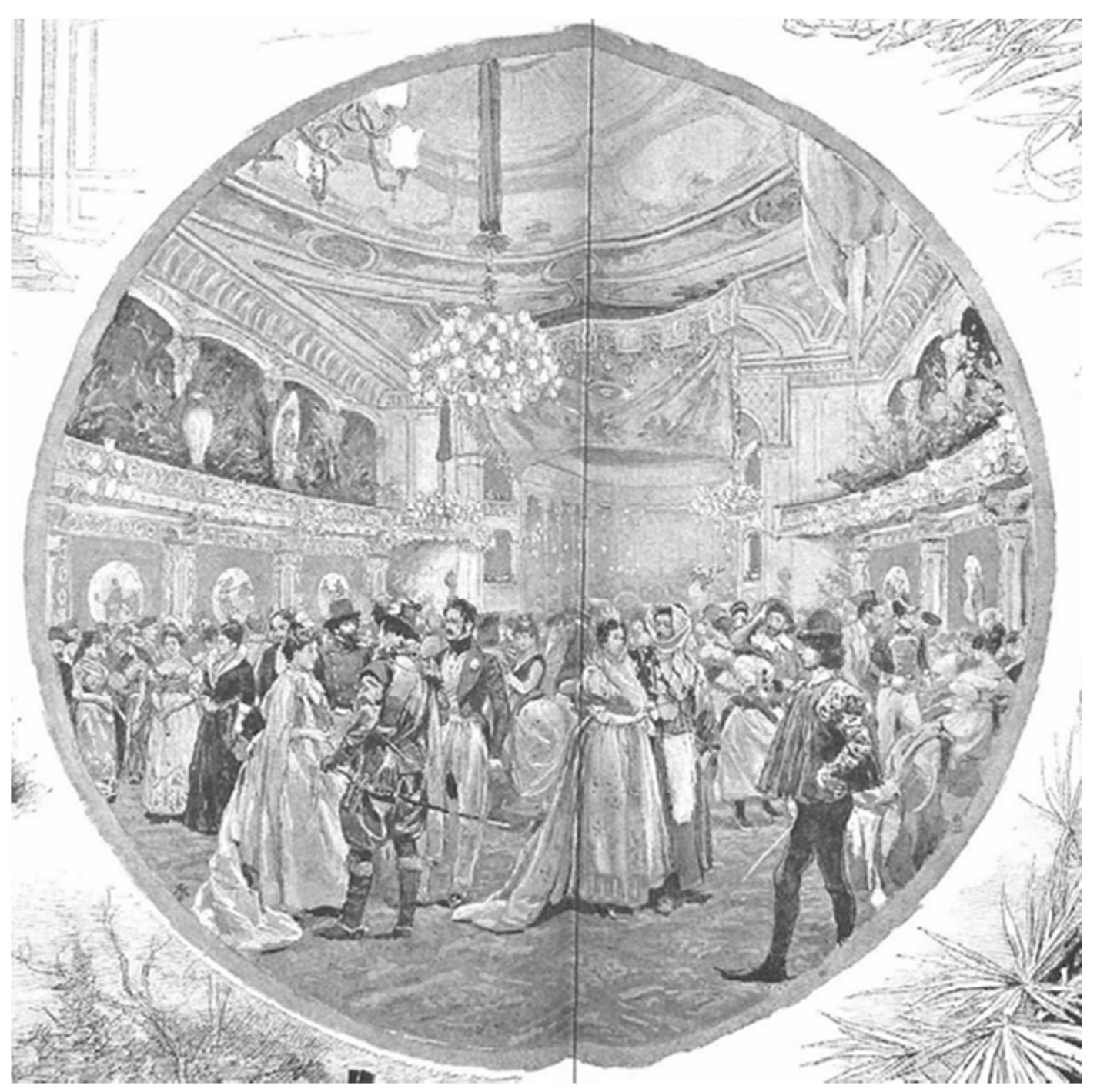

Fig. 217. El baile de trajes del Círculo Artístico celebrado en el Teatro Lírico (detalle). La Ilustración Artística (1889/29/04).

El primero de estos bailes tuvo lugar en marzo de 1889 en el Teatro Lírico, curiosamente pocos meses después de la dimisión del hasta entonces presidente, José Luis Pellicer (La dinastía, 1889/08/01: 2). Pellicer fue sustituido por Masriera, y los artistas del Círculo se volcaron en preparativos, tales como las decoraciones, pero también como parte destacada de la fiesta; La ilustración se recrea en la descripción de los trajes de los artistas por la perfección y detallismo de los atuendos, convirtiéndolos así en los protagonistas de una celebración de exclusivo acento social. Así, por ejemplo, Ramón Casas vistió un traje de época de Pedro IV de Aragón, Santiago Rusiñol de elegante romántico de los años treinta, Manuel Cusí y Tamburini de donceles florentinos, Pellicer de romántico y melenudo artista o José Masriera de albanés, reproduciendo además sus fotografías, realizadas in situ por Napoleón, entre las de lo más selecto de la sociedad barcelonesa (no en vano, las invitaciones eran de pago y estaban destinadas a personas conocidas de los miembros del Círculo y de la comisión 
organizadora $)^{614}$. Sin duda, lo llamativo de los disfraces de muchos artistas se debía, como firmaba Alguien (1889: 1) en La Dinastía, al hecho de destacar entre los muchos hombres que acudieron vestidos de uniforme. La publicación durante los meses siguientes de fotografías de los trajes más vistosos da cuenta de la notoriedad pública alcanzada por el baile. Se publicó además un dibujo a doble página en La ilustración artística, debido a la mano de José Luis Pellicer [fig. 217], que mostraba el aspecto de la fiesta; en el centro de la composición una vista del salón permite distinguir a algunos de los artistas con sus respectivos disfraces. A pesar del éxito de la fiesta, que fue repetido en 1891 en la Casa de la Lonja, sus costes fueron muy elevados para la economía del Círculo, que en 1892 tuvo que suspender con anterioridad el baile correspondiente a ese año por no poder afrontar los gastos (La dinastía, 1892/09/02: 2; La dinastía, 1892/14/02: 1), al tiempo que se vio obligado a realizar una exposición y subasta artística en la Sala Parés para intentar cubrir el déficit producido (La dinastía, 1892/21/02: 2).

Son escasas las noticias del Círculo en los años posteriores, ya que no figuran exposiciones ni nuevas fiestas, con la excepción de colaboraciones puntuales con festejos organizados por el Ayuntamiento de Barcelona. La recuperación de la sociedad se hace efectiva en 1894, cuando celebra una nueva exposición artística con motivo de la inauguración de su nueva sede (La dinastía, 1894/22/05: 3), sin que consten en la prensa las obras presentadas por los socios. El deseado baile de disfraces no volvió a repetirse hasta 1895; en él participaron, entre otros, los artistas Carlos Pellicer, Galofre, Meifrén, Suñer, Moragas, José y Ricardo Masriera y Ricardo Lorenzale, aunque no tuvo tanta repercusión como los anteriores ("Baile del Círculo Artístico", 1895; "Ecos de Barcelona", 1895: 2).

\subsubsection{Masculinidad en conflicto: el Círculo Artístico de San Lucas}

La separación en 1893 de un grupo de artistas del Círculo Artístico, en su momento en franca decadencia, para formar una sociedad propia no se debió únicamente a una diferencia en la forma de entender el arte, sino que tenía unas connotaciones sociales más profundas, ancladas en un sentimiento de desarraigo respecto a la modernidad acorde con el malestar de fin de siglo en Europa ${ }^{615}$. Los fundadores del Círculo Artístico de San Lucas defendían una postura más tradicional que la que preconizaban los jóvenes y bohemios artistas del Círculo Artístico; una moral anclada en los preceptos católicos y un punto de vista peyorativo de compañeros de profesión, que a sus ojos llevaban una vida descarriada y llena de vicios, llevó a Juan Llimona a defender un rol distinto del artista moderno. Junto a su hermano José, Alexandre de Riquer, Dionisio Baixeras, José María Vives, Francisco Amigó, Manuel Urgellés, Joaquín Vancells, Enrique Galwey, Lluis Buxó, Manuel Durán y Antonio Utrillo, algunos de ellos conocidos ya por su papel en el Círculo Artístico, tomó la decisión de crear su propia sociedad artística, caracterizada por su carácter conservador (MARCHI, 2011: 20).

${ }^{614}$ La Ilustración, 12 de mayo de 1889, pp. 292-293; otras descripciones incluyen también a los pintores Cusachs, Luis Pellicer, Antonio Utrillo o Francisco Galofre: "Barcelona: baile de trajes en el Teatro Lírico, dado por el Círculo Artístico", la Ilustración, 12 de mayo de 1889, p. 302.

${ }^{615}$ BEJARANO VEIGA (2015), p. 374. 
La sociedad nacía, según sus estatutos, con los mismos fines que el Círculo del que se habían escindido: promover el estudio y fomento de las artes, y más concretamente del dibujo, y ser un centro para la reunión y relación entre artistas. Sin embargo, frente a los desmanes de los artistas bohemios, se estipularon también algunos llamativos requisitos de acceso, puesto que además de tener dieciséis años cumplidos, los aspirantes a formar parte de la sociedad debían ser de buenas costumbres y profesar la religión católica (MARCHI, 2011: 31). El carácter religioso de la corporación daría lugar a cierto estupor por parte de los artistas más cercanos a la modernidad, puesto que la preocupación por la moralidad de los socios de San Lucas llevó no solo a suprimir los juegos de azar, sino también el estudio del modelo femenino desnudo. El asunto del desnudo femenino, que el Círculo Artístico había tratado con cierta cautela al no permitir acceder a estas sesiones más que a los socios y a las mujeres que deseasen adquirir conocimientos artísticos, ya que estas tenían vedado el acceso al modelo masculino, fue sin duda espinoso; como los críticos de esta prohibición subrayaron, los fundadores del Círculo de San Lucas, al renegar a un aspecto esencial de la modernidad y del progreso artístico, se constituían en los defensores de una espiritualidad oscura y anclada al pasado, de un casticismo anacrónico digno de burla entre los progresistas. No obstante, consiguió la simpatía de varios nuevos socios, e incluso de figuras relevantes en el ámbito artístico como Antonio Caba, que aceptó el nombramiento de socio honorario (La dinastía, 1893/09/03: 3), o de algunos críticos como Bonaventura Bassegoda (1893: 9751), quien felicitaba a estos artistas por "comprometerse tácitamente a desterrar de sus obras el sello de la concupiscencia o de la pornografía”.

La reacción de los artistas en el nuevo Círculo responde a un concepto de masculinidad en conflicto; la búsqueda de un alejamiento del ocio burgués que había reinado en el Círculo Artístico evidencia un rechazo hacia los valores normativos en la sociedad elegante y hacia los artistas que mezclaban sus aspiraciones profesionales y personales con la vinculación con la high class y sus valores hipomasculinos ${ }^{616}$. Cabe preguntarse si en la postura antimaterialista de los miembros del Círculo Artístico de San Lucas existe realmente una renuncia al privilegio masculino basado en el poder económico, o si en el lenguaje modernista de su discurso estético y de su producción plástica se esconde una reivindicación del privilegio intelectual y de una masculinidad artística en la que se observa una tensión continua entre el autodominio y el complejo de castración, que correría paralelo a la crisis masculina existente en el discurso regeneracionista español.

\subsection{Artistas españoles y sociedades artísticas en el extranjero}

La vida cosmopolita, el interés por intercambiar ideas y la necesidad de encontrar un espacio en el que acomodarse al mercado artístico extranjero motivaron el que muchos artistas españoles se vinculasen, durante su estancia en París y Roma, con

\footnotetext{
${ }^{616}$ Martykánová (2017: 32), siguiendo la terminología empleada por Kimmel, define al hombre de la élite española en la última década del siglo XIX a través de una construcción inferior a los valores normativos, por lo tanto "ociosa, corrupta, decadente, llevada por pasiones egoístas, dada a la retórica vacía, inclinada a preferir los intereses familiares frente a los de la Patria", al mismo tiempo que dada al "deseo de competir en lujo y boato" frente a la austeridad del buen caballero español del pasado.
} 
sociedades artísticas, algunas de ellas conocidas por su carácter aristocrático y de buen tono y otras por su objetivo de asegurar una cierta estabilidad al artista contemporáneo. De este modo, sabemos que algunos artistas como Haes y Víctor Manzano entraron en la sociedad parisina de aguafortistas en los años sesenta ${ }^{617}$, y que otros artistas españoles instalados en París formaron parte de algunas sociedades de amigos de las artes, siendo el caso más significativo el de Luis Jiménez Aranda. Sin embargo, en estos últimos casos no queda clara la existencia de un intercambio social entre artistas, limitándose en ocasiones a enviar obras a distintas exposiciones. Por este motivo, hemos elegido dos sociedades artísticas de carácter exclusivamente español en el extranjero: El Quijote, en Roma, y la Sociedad de Artistas Españoles de París, de las cuales hemos conseguido obtener escasas noticias. La primera evidencia las tensiones existentes entre los artistas consagrados y los jóvenes pensionados, donde el intento de crear un foco común se vio rápidamente dificultado por la diversidad de aspiraciones de sus socios; la segunda revela una forma arcaizante de sociedad artística fomentada por la élite española en París, vinculada al fomento de exposiciones y la visibilización de un arte ajeno a los cambios estéticos del nuevo siglo.

\subsubsection{El Círculo Español en Roma: El Quijote (1884-1885)}

José Benlliure da noticia en sus apuntes biográficos de un Círculo Español establecido en Roma, en la Via dei Incurabili (BONET SOLVES, 1994: 193-194), llamado entre sus integrantes Don Quijote y cuya duración fue, al parecer, muy breve, aunque el propio Benlliure no especifica la fecha en que se creó esta sociedad. Según Benlliure, su fundación se produjo cuando ya llevaba muchos años en Roma; su actividad debe acotarse entre los años 1884 y 1885, los únicos en los que se tiene referencia a esta sociedad. En junio de 1884 Juan Luna Novicio ya hace referencia al círculo Don Quijote en una carta remitida a Benlliure desde Madrid en la que menciona la sociedad, permitiendo al lector conocer que los artistas españoles ya se habían reunido en Roma de manera formal, y que allí habían comentado el mérito de algunas obras que se presentarían en la Exposición Nacional de Bellas Artes de ese año ${ }^{618}$. En 1885 es mencionado muy brevemente en la prensa española, en referencia, en primer lugar, a la participación del Círculo Don Quijote en la exposición benéfica y rifa con motivo de las inundaciones de Málaga y Granada (CHACÓN, 1885: 2), junto al Círculo Artístico Internacional. La exposición tuvo lugar en el Palacio de España, y en ella participaron varios artistas españoles, que probablemente tuvieron vinculación con la sociedad que nos ocupa; se trata de Pradilla, Villegas, Palmaroli, Lorenzo Vallés. Álvarez, Galofre, Barbudo, José Arpa, Juan Antonio Benlliure, Poveda, Tusquets y Muñoz, además de los pensionados Ulpiano Checa, Manuel Barrón, Hermenegildo

\footnotetext{
617 "Los conocidos pintores Sres. Haes, Manzano, Llanos y Jiménez han entrado a formar parte de la Sociedad de Aguafuertistas establecida en París y dirigida por el Sr. Cadart" La Gaceta, 24 de diciembre de 1864, p. 4.

${ }^{618}$ Carta de José Luna Novicio a José Benlliure, 27 de junio de 1884. Archivo Casa-Museo Benlliure, C10Lun001.
} 
Esteban y Agustín Querol ${ }^{619}$. Apenas un mes más tarde La Época vuelve a dar noticias de Don Quijote, señalándola como "la sociedad donde se reúnen los artistas españoles en Roma" y aportando información interesante sobre el mantenimiento del círculo al afirmar que los artistas habían procedido a realizar un álbum con pinturas y dibujos originales, cuya venta se destinaba a financiar la sociedad. De este modo, de la venta del álbum producido en marzo de 1885 se habían conseguido recaudar 5000 pesetas ( $L a$ época, 1885/20/04: 2). La noche del 6 de abril se celebró en las dependencias del Círculo una cena presidida por el embajador, marqués de Molins, de la que se conoce la asistencia de algunos pintores españoles que debemos suponer miembros de la sociedad: el pintor Álvarez Catalá, Ignacio Suárez Llanos, Modesto Brocos, Flórez, Aguirre, Reynoso, Pérez Caballero, y el mejicano Pesado.

Los breves apuntes que Benlliure incluye en sus memorias sobre la sociedad dan cuenta de unos recuerdos agridulces al respecto, en que se hacen patentes las rivalidades entre los artistas de más edad y prestigio frente a una juventud que califica como irresponsable, incapaz de pagar las cuotas y deudas, y con un evidente espíritu arrogante al buscar desbancar a los más experimentados de la presidencia. La noticia más interesante, sin embargo, es la relativa a la pintura de un panel con los retratos de los socios ("pintamos un paneaux haciéndonos los retratos"); Benlliure detalla que en una misma sesión ejecutó dos retratos, correspondientes a sus compañeros Lorenzo Vallés y Ricardo Villodas, sin mencionar los otros posibles retratos que se realizasen. Las dos cabezas pintadas, que no duda en afirmar "gustaron por la rapidez en que fueron ejecutadas", no sobrevivieron a la broma de algún compañero, ya que tal y como relata "como no estaba seco el color alguien se divirtió corriendo el color con los dedos hasta quedar tiznados completamente".

\subsubsection{La Asociación de Artistas Españoles de París}

En diciembre de 1901, el Journal Officiel de la République Française daba cuenta de la creación en París de una asociación formada exclusivamente por artistas españoles afincados en la capital francesa. González y Ayxelá citaban como precedente la sociedad fundada en 1892 por Enrique Mélida, el Círculo de la Unión Artística, que tuvo su sede en el número 275 de la rue de Saint-Armand, organizando exposiciones a las que los artistas españoles concurrieron. La existencia, ya en 1860, de un círculo con este mismo nombre, cuyo fin era "establecer una fusión entre los artistas y la gente de mundo" (YRIARTE, 1864), y originado de una sociedad de artistas anterior -en la cual el pintor italiano Galetti realizó el retrato caricaturesco de todos los miembros (YRIARTE, 1864: 252)-, hace cuestionar la iniciativa mencionada por González y Ayxelá y repetida por Fernández Pardo (1998: 34), ya que en los años ochenta y noventa continuaba su actividad realizado exposiciones en la plaza Vendôme; en este Cercle de l'Union Artistique los extranjeros cuya estancia en París fuese temporal no eran admitidos más que por el intervalo de uno a tres meses (CERCLE DE L’UNION

\footnotetext{
${ }^{619}$ Chacón menciona también obras de otros artistas de la colonia española, como Brocos, Carnaro, Echena, Gallegos, Prieto, Gil, Guinea, Jiménez Martín, Muñiz, Olleros, Peralta, Puerto, Robert, Cáceres, Ruiz, Morales, Salinas, Silvela y V. Cordero.
} 
ARTISTIQUE, 1863: 8), en calidad de miembros temporales y bajo el pago de 40 reales mensuales, un estatus previo a ser admitidos miembros permanentes. A pesar de contar con la asistencia de los grandes artistas franceses (Meissonier, Cabannel, Le Poitevin entre otros), la presencia de miembros españoles es escasa, y no consta en la lista de socios de 1863 ningún artista español ${ }^{620}$.

El objetivo de la Asociación de Artistas Españoles en París no era otro que organizar exposiciones de Bellas Artes. Estableció su sede social provisional en el número 235 del Faubourg Saint-Honoré, bajo la presidencia de Raimundo de Madrazo (Journal officiel de la République Française, 1901: 7684). González y Ayxelá (1989: 43) afirman que a ella pertenecieron también Luis Jiménez Aranda, José Llaneces, Ulpiano Checa, Francisco Domingo, Eduardo León Garrido y el supuesto promotor de la sociedad, Mariano Obiols. Sin duda puede sumársele el nombre de Rafael Ochoa, cuya participación consta en 1904. La primera exposición se celebró en 1902, en la galería de Artistas Modernos del número 19 de la calle Caumartin ("Concours et expositions", 1902: 120). Por algunas reseñas conocemos algunos datos más de los que fueron miembros de esta sociedad, como el joven Federico de Madrazo y Ochoa, Martín Rico, Bustos de Lara y Alcalá Galiano (JELOT, 1902: 1). A la exposición de 1903, celebrada en la Sala Durand, concurrieron, además de los citados, Mezquita, Daniel Hernández, Luque, Rogelio Egusquiza, Juan Sala, Isern, Miquel Blay, Joaquín Bilbao y las artistas María Luisa Lariva y la señora Lucville, de la que solo consta el apellido (“El arte español en París...", 1903). La de 1904 tuvo lugar en la galería Durand-Ruel, y en ella participaron un total de veintidós artistas españoles; en las obras presentadas se hizo patente que, frente a la aceptación de un arte más vanguardista, la mayor parte de los miembros de la asociación estaban aún vinculados a una forma de representación académica y lamida - de la cual eran esclavos, según la crítica Juan Sala, León Garrido, Acevedo Bernal, Alonso Pérez o José Garnelo, algo que no debe sorprender teniendo en cuenta que de manera contemporánea a la primera exposición de la asociación se realizaba en la galería Silberberg de París una muestra de obras de Cassals, Darío de Regoyos, Losada y Pablo Uranga-, aunque se sumaron nuevos asociados, como Bustos de Lara, o Arcos (HOLL, 1904: 52-56). Se observa en este momento también que la sociedad había estado presidida ese año por Daniel Vierge, cuyo fallecimiento motivó que se incluyesen en su honor algunas de sus obras ("Artistes espagnols", 1904: 3). Todo parece indicar que la sociedad se extinguió poco después, ya que no se vuelve a tener constancia de ella hasta la fundación de su sucesora, la Asociación de Artistas Españoles Residentes en Francia, en 1925.

Son escasas las noticias sobre la actividad de la sociedad entre 1901 y 1904, aparte de las ya mencionadas exposiciones; cabe suponer que pudo ser un centro de encuentro de ciertos artistas españoles en París, estableciéndose así como un núcleo social basado en la identidad nacional. Dada su corta vida y la ausencia de documentación al respecto, nada señala que la cohesión entre sus miembros diese pie a una actividad retratística en el seno de la asociación.

\footnotetext{
${ }^{620}$ Los únicos miembros españoles son, en calidad de socio permanente, el Marqués de Casa Riera, y en la de socio temporal, Tomás Caro y Álvarez de Toledo, Marqués de la Romana.
} 


\section{CONCLUSIONS}

The constructions of male identity in Spanish nineteenth-century collective imaginary are assembled around two ideals developped in parallel during the century. On the one hand, there we find a masculinity that has inherited Enlightened ideas and whose main values rely upon talent, individual achievements and professional issues such as success; this ideal praises a concept of man able to exert rational power over himself in order to make his own way up society. His way of accepting his fate by the acceptance of reality and the constant overcoming of any obstacle is well reflected in biographical narrations, where the idealized, bourgeois and male expectations find an archetypal character in the figure of the artist. In these artists' biographies, a complex net of sociocultural values overlap the traditional, mythical construction of the genius; during the first half of the century, the creative eccentricities are left behind in order to better highlight the bourgeois way of male life, whose virtues are reflected on the progressive development of a professional career, this one linked (and sometimes burdened with) familial stability, and on the deployment of social skills to successfully cope with the marketplace. On the other hand, we can find another kind of masculinity that takes an elitist aspect, where, in addition to the normative attributes of manliness, the male artist must constantly show the privileges he has been granted with, whether economic, intellectual or political.

The negotiation of the male artist's masculinity oscillates during all century between these two parameters; this evidences the need for conquering privileges, subtle as they may be, that channel the idealized expectations shaping artists' identities. The will of survival in the economic and social marketplace tends to be overshadowed by a will to stand out and to prove one's supremacy over others. In the Ancien Regime Spain, we can prove that the construction of artistic careers in the academic sphere, with their own comprehension of the relation institution/power and of the socioeconomic privilege derivated from it, in the shape of tax or military exemptions, is closely linked to this idea of privilege, which orientates both male expectations and anxieties. The idealized construction of the academic artist constitutes, in the Spanish case, a latecoming demonstration of the professionalization of the arts, by and for the State. Consequently, this highlights an elite-like way of power through the control of knowledge and the monopoly over the ability to judge merit. Once the artist has evolved into a cultural main character with the advenance of Romanticism, he also becomes the representative of contemporary reality, and thus a reflection and a model of normative masculinity.

Both artist's social consideration and his expectations towards the job market and his male identity reflect on the image he wants to leave of himself, depending on the spheres, contexts and sociability networks for which the portrait is painted. We have followed this evolution from Neoclassicism to Fin-de-Siècle painting, and our conclusions redefine the social history of the artist in a gendered way. Allusions regarding the art of drawing in Spanish neoclassical artist's portraits have little or no 
connection with a reliable representation of the job market reality, or put in other words, with the manual activity of art practice. The charcoals and brushes that artists hold in their portraits, or even the busts, are an attribute of a very specific kind of male power, channeled through knowledge; the display of privilege is also evident in the use of the luxurious wardrobe their new economic status grants them, so that they can afford embroidered silk waistcoats, fashionable dress coats and even institutional uniforms with golden trim.

During Isabel II's reign, the proliferation of artists' portraits linked to success take the form of official representations with their due etiquette and decorations; in addition to the idea of professional recognition and the cursus honorum emphasized by Calabrese, this development of portraiture implies another reading: male artists' expectations about success are a product of a relational framework, taking the normative, hierarchical code that affects all society and the notion of courtly elitism as a model. The will of shaping the image of the self regarding the civilian elite of politicians and men of letters reveal how artists' male, professional identity is linked to the expectations and anxieties of high middle-class. Under the need of success visibilization, a new kind of portraiture emerges based on the ideal of the self-made man, where the sitter, invested with an aura of hermetism and superiority, tries to conceal his troubles by a reaffirmation of his own identity in relation to dominant classes, sometimes in spite of the real economic situation of the artist.

It is precisely during Isabel II's reign that a broader variety of connotations of male artist's portraits coexist, thus evidencing a complete assimilation of middle-class normative masculinity. The representation of the artist as intellectual with his working tools remain, especially in those cases when a training relationship exists between the sitter and the painter; the image of the artist as a true professional, that is, highlighting his job as a way of legitimating his social success and economic power, is still linked in the thirties and fourties to a need of reaffirmation emanated from the structured sociocultural marketplace. In opposition to this construction of a triumphal masculinity and its code of appearances, during the fifties and sixties takes place a movement to protect the artist, which evidences his professional vulnerability and, therefore, the instability of artistic practice. The perception of these negotiations of male ideals and the anxieties produced is far more visible in the artist's portraits painted along the seventies and eighties, sometimes by simple emotional depiction or the humbleness of wardrobe, but also by the representation of the artist as a worker or as a man more conscious of his professional abilities than of his intellectual superiority. It is also in these last decades when the versatility of the international artistic market encouraged another relation between the artist and economic capital without the institutional intermediary; this will help to construct a dual image of the artist, whether as the mundane, succesfull man, able to adapt to any inconvenience, or as the victim of the economic market when the purchasing power takes precedence over knowledge or the recognition of creative skills. 
Finally, the two last decades of the nineteenth century are indissolubly connected to a new perception of the artistic elite precisely by the ostentation of purchasing power and wealth; artist's portraits, for instance José Villegas' or Raimundo de Madrazo's, are prone to a depiction of the elegant world as an identity sign of the adquired status. In this moment of sociocultural crisis when a need of regeneration of the patriotic values and masculinity is stated, artist's portraits take a detour towards the image of the cultural hero, able to react and transform the creative sphere, whose role is repeatedly highlighted by critics in their texts. In this sense, Sorolla and Zuloaga are the most representative examples.

Besides the relational construction of male identities by approximation to normativity, we must also point out how importantly the academic institution channeled male artists' expectations. The fact is that Academies and Fine Arts Schools helped not just a centralization of artistic learning, but also the creation of a cohesive social group. Their schoolrooms gathered the creative youth in an age where their identities were being shaped; young artists defined their professional and personal expectations regarding the meritocratic learning system and the male models offered by their progenitors, teachers and schoolmates. The connection of the academic institution with the construction of an artistic, male identity lies, precisely, on the way it channeled young artist's expectations in continous rivalry and in relation to the idea of the own institution as an artistic elite.

This last idea is supported by the hierarchical display produced inside the Academy, and which we have traced through its written records, proving the existence of male anxieties and the progressive definition of the artist's sphere of power. In the portrait galleries created by these corporations the notion of elite adquires a visual body, but each Academy builds their gallery in a different way; the process of progressive incorporations is an epitome of the power structure inside and of the changes in the male perception of artistic profession. Barcelona and Valence reveal a special interest in the presence of the artist in their portrait galleries since the last decade of the eighteenth century, and this initiative prevails until the fourth decade of the nineteenth century; it is no coincidence that during this period both institutions are in active process of privilege vindication, while their artists provide not only cultural recognition, in the case of the teachers, but also economic profit to the cities by their role in the local industry. However, these two portrait galleries also reveal how, despite the artist's constant search of privilege, he is always submitted to the normative male hierarchies and to the power other men exert over them, which can be seen in the relevance of presidents' portraits.

The case of the Academy of San Fernando in Madrid is interesting, as its portrait gallery is built due to several initiatives that hide complex renegotiations of masculinity and power; the gallery is also uncomplete and ecclectic, which clearly differenciates it from other corporations. The first initiative was undertaken in the early years of the Academy, and was meant to include only the portraits of the king and his ministers, who did not belong to the artistic world and yet ruled over the insitution; this first attempt of 
a gallery intended to link the corporation with power as an image of the State, and the arts as a political mission. The second initiative, still in the eighteenth century, sought to soothen the hierarchical tensions among artist and non-artist academicians, as the first ones claimed thus their own role in the Academy. Although the incorporation of portraits was slow and mostly always connected to family gifts, donations or reception paintings to ask for the academician title, this initiative and its debate in 1774 shows the fight between two academician factions: on the one hand, the aristocracy of power who defended their privilege in an obsolete manly status based on their political role; on the other hand, the artists who, coming from middle-class backgrounds, asked for the same privilege on the new parameters of manliness through constant work, merit and skill, in order to form a new aristocracy of culture. The relevance of academicians is rescued in the eighteen-sixties when the enterprise of biographies and portraits is recovered; it then maintains its relationship with the idea of elite, though now tainted with sociability traits and a posthumous feature.

Academic portrait galleries reflect the institution, its history and the concept of manliness sourrounding the artist, but it also sheds some light about the history of the affects and social interplays inside it through donations; this reveals the importance of the artist's self-affirmation by the consolidation of institutional genealogies. Thus, family bonds are more relevant than they first seemed, and this implies that endogamy, which was usual during the eighteenth century, was also inherited by the nineteenthcentury Academy with the creation of new artistic lineages of which the Madrazo and the López families are examples.

The relation of portrait galleries to the notion of elite and private experience is also emphasised when this practice is transferred to the learning sphere, where normative, artistic masculinity and professional practice are taken as a model. In the two specific examples we have found of young artists' portraits in the Academy, though motivated by different aims, both try to extend the privilege of representation from consolidated careers to the promising artistic youth. The Prix de Rome candidates' portraits is an example of emulation, as they were included in the classroom in order to encourage other pupils; the Prix de Rome portrait gallery at the Spanish Academy in Rome has a more institutional role, as it includes a more complex net of male experiences beyond the mere recognition of the pensionate's talent: the inclusion and exclusion of sitters show the frictions among regular and merit pensionates or between different artistic disciplines, and it also is a consequence of the male reality in a foreign country while being subordinated to a regulated behavioural code.

Out of the artistic, institutional sphere, artistic associationism provided a new visibility and protection, but also a new context where the artist must interplay regarding the male habits of a complex group, which includes professionals and middleclass amateurs interested in both artistic practice and its ludic aspect. When we enunciated the objectives of this research, we wondered if the artist's identiy was negotiated according to the sociability contexts where his portraits were created or exhibited; we now conclude by confirming that, indeed, the artist negotiates his identity 
by portraiture as a way of entering the play of male interests and expectations, and that the way he is perceived by other members depends on the kind of association. In massive cultural societies, like Liceos and Atheneums, the presence of artists' portraits is a consequence of their ambition for a greater social consideration. This is evidenced by the kind of portraiture developped inside these institutions, which is linked to the elite representation inside the group, middle-class standards and their principles. In the Atheneum, however, professional identity ends by being an essential attribute of the cultural elite, so that it is an adaptation of the Enlightenment idea of intellectual domination to the new social forms. We must also conclude that there is another difference in the consideration of artists and their portraits in Liceums and Atheneums, as a consequence of the social change produced in the moment of their effective, active presence in these societies, that is, between 1837-1847 in the Liceum and from 1875 in the Atheneum. In the Liceum, the artist is the main character, whether as a cultivated entertainer or as a dignified member, who always looks for attention in order to be a reference model to his middle-class clients. Atheneums, on the other hand, are considered instructive societies focused on progress and knowledge; inside them, artists are set aside as simple contributors who help the association with their artistic skill with the aim of social profit and the privilege of being part of an elitist group.

On the other hand, the associative movement derivated from the artist's professional and economic instability, whose main aim is to cover his most basic needs, is rarely the favorable place for portraiture; this is explained by the evident distance from the ludic aspect of these societies. Even if portraiture is a way of giving visibility to an individual, the proper male image that these societies would offer of the artist would have been that of vulnerability and hypomasculinity, that means, someone unable to cope with the social, economic and professional exigences of the marketplace, but that would undermine artists' need of reaffirmation towards normativity. When the Society for the Protection of the Fine Arts was refocused on entertainement and art exhibitions, artists proved how their goal was not a democracy of the arts, but a society as an extension of the marketplace where they could find potential clients; in this context, the artist renegociated his inferior position, some times by the adoption of compensatory behaviours concealing their real anxieties.

Finally, artistic sociability in the last two decades of the nineteenth century was open to both artists and amateurs, and it allowed attendance to art classes when the learning system made their access requirements stricter, contributed to the market with the organization of exhibitions, and had even a ludic side with masquerades and other parties. The existence of portrait galleries, in the case of the Watercolour Artists' Society a collection of drawings only known by allusions, and in the Fine Arts Center as a painted frieze, shows how both tend to create a collective identity. In these portraits, there is no need for specific representations of the members as artists, as art is what all of them have in common. Besides, the inclusion of women artists in exhibitions and lists of associates is matched with their inclusion among the portraits in the Fine Arts Center. 
Even though group portraits are very rare in the nineteeth century, the bonds between artists were evidenced in other ways; from an affective level, these bonds are reflected in the exchange of portraits and their social experience, in family portraits, donations, homages and commemorative soirees. These last ones are the final recognition that seals the constant renegotiation of social condition, professional reality and male expectations and crisis the artist suffered in his life, which usually implied the exaltation of success and the incorporation of the deceased artist's portrait among the effigies of the non-competitive elite.

We can affirm that the artist was always constrained by his gender, whether consciously or unconsciously; artists found themselves channeling their male expectations with an ideal model in mind, which praised professional success, wealth and middle-class social status. The existence of a structure of goals to achieve also marks artists' male experience from their learning period, focusing on a normative male model with which they wish to identify while they try to negotiate their professional reality. Male crises underlie in the process of construction of a male identity, but they are rare to trace in artists' portraits or self-portraits. The artists tend to prefer a positive identification, whether by the representation of their successes or by the image of social achievements.

There is no doubt that male artists found themselves in a privileged position that women and craftsmen did not share. This is evidenced by the absence of women artists inside the academic institution and its portrait galleries: in the Academy of San Fernando, only two self-portraits painted and donated in the eighteenth century (Faraona Olivieri's and Lucía Gilabert's), and a portrait in the early twentieth century (Madame Anselma's) depict women artists, but none has been found in the other three Academies we have studied, and only two known exceptions have been located in Cádiz. In the same way, artistic associationism was understood as all-male, even if many societies had women artists among their members. In the madrilenian Liceum, the presence of women artists in sessions and exhibitions, for instance Rosario Weiss, did not leave any portrait as testimony. The Atheneum, constituted as a strict all-male society, did not include any female portrait in its gallery until a very late date, and it was not a portrait of an artist.

Further research must be made in order to make a deeper analysis in the construction of male privilege in artistic societies and institutions, so that we could better understand how the expectations and failures inside them shaped artists' male identity. If the academic records have helped us in our analysis of the hierarchical fights between two models of masculinity, they do not give any clue about how artists assimilated this experience. Male and female artists must be individually analysed, in order to have a deeper knowledge about how the social and cultural gender construction has shaped their identities; how they both dealt and negotiated their identities and experiences in a marketplace that has proved to be unstable and male oriented, and how their expectations, realities and crisis found visibility in portraiture. 
Anexo 1. Retratos de artista expuestos en los salones de París (18201879)

\begin{tabular}{|c|c|c|c|c|c|c|c|}
\hline & 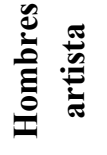 & 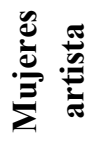 & $\stackrel{0}{\Xi}$ & & & 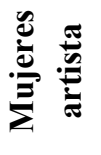 & 葛 \\
\hline $1820^{621}$ & 2 & 0 & 0 & 1850 & 15 & 1 & 0 \\
\hline 1821 & - & - & - & 1851 & - & - & - \\
\hline 1822 & 18 & 2 & 0 & 1852 & 8 & 1 & 0 \\
\hline 1823 & 1 & 0 & 0 & 1853 & 10 & 1 & 0 \\
\hline 1824 & 17 & 1 & 4 & 1854 & - & - & - \\
\hline 1825 & - & - & - & 1855 & 24 & 3 & 0 \\
\hline 1826 & - & - & - & 1856 & - & - & - \\
\hline 1827 & 7 & 0 & 0 & 1857 & 11 & 2 & 1 \\
\hline 1828 & - & - & - & 1858 & - & - & - \\
\hline 1829 & - & - & - & 1859 & 85 & 1 & 2 \\
\hline 1830 & - & - & - & 1860 & - & - & - \\
\hline 1831 & 12 & 7 & 0 & 1861 & 18 & 5 & 0 \\
\hline 1832 & - & - & - & 1862 & - & - & - \\
\hline 1833 & 20 & 2 & 1 & 1863 & - & - & - \\
\hline 1834 & 13 & 0 & 1 & 1864 & 8 & 1 & 1 \\
\hline 1835 & 4 & 4 & 0 & 1865 & - & - & - \\
\hline 1836 & - & - & - & 1866 & 4 & 0 & 0 \\
\hline 1837 & 9 & 9 & 0 & 1867 & 16 & 0 & 1 \\
\hline 1838 & 2 & 2 & 0 & 1868 & - & - & - \\
\hline 1839 & 17 & 1 & 1 & 1869 & 21 & 0 & 0 \\
\hline 1840 & 7 & 0 & 0 & 1870 & 14 & 3 & 2 \\
\hline 1841 & 8 & 2 & 0 & 1871 & - & - & - \\
\hline 1842 & 15 & 1 & 0 & 1872 & 6 & 1 & 0 \\
\hline 1843 & 9 & 0 & 1 & 1873 & 3 & 1 & 3 \\
\hline 1844 & 16 & 1 & 0 & 1874 & - & - & - \\
\hline 1854 & 14 & 1 & 0 & 1875 & 15 & 1 & 1 \\
\hline 1846 & 19 & 1 & 0 & 1876 & 5 & 2 & 0 \\
\hline 1847 & 21 & 2 & 0 & 1877 & 17 & 1 & 0 \\
\hline 1848 & 36 & 3 & 1 & 1878 & 17 & 0 & 0 \\
\hline 1849 & 17 & 2 & 0 & 1879 & 14 & 1 & 0 \\
\hline
\end{tabular}

${ }^{621}$ Datos obtenidos a partir de la consulta de los catálogos oficiales de los salones. 


\section{Anexo 2. Retratos de artista y autorretratos en los salones de París}

\section{(1820-1879)}

\begin{tabular}{|c|c|c|}
\hline Año & Autor & Obra \\
\hline \multirow[t]{20}{*}{1822} & Ansiaux & Retrato de M. C..., escultor, miembro del Instituto. \\
\hline & Mme. Augustin & Retrato de M. Abel de Pujol, pintor de historia \\
\hline & & Retrato de M. Augustin \\
\hline & & Retrato de M. Blondel, pintor de historia \\
\hline & Léon Chéry & Retrato de Mlle. C... de Smirna, artista griega \\
\hline & Cochereau & Retrato del artista en su taller \\
\hline & Dejuinne & Retrato de M. Girodet \\
\hline & Garson & Retrato de M.A.X. Leprince, pintor \\
\hline & Gosse & Retrato de M.J..., grabador \\
\hline & Mlle. Hue de Bréval & Retrato de un artista, media figura \\
\hline & Kiprensky & Retrato del autor \\
\hline & Lafond & Retrato de M.L., pintor \\
\hline & Mlle. Lebrun & Retrato de M. Lebrun en su sala de armas \\
\hline & Leroy de Liancourt & Retrato de un artista \\
\hline & Lesueur & Busto de Eustache Lesueur, pintor \\
\hline & Mme. Renaudin & Retrato de Mme. R..., pintora \\
\hline & Mme. Rouillard & Retrato de M. N., pintor \\
\hline & & Retrato de M. N., artista \\
\hline & Mme. Sem & Retrato de la autora \\
\hline & Serrur & Retrato de M. R..., pintor \\
\hline \multirow[t]{21}{*}{1824} & Blondel & Retrato de M. Hurtault, arquitecto del rey \\
\hline & & Retrato de M..., arquitecto \\
\hline & Bouchot & Retrato de M. C..., grabador \\
\hline & Cogniet & $\begin{array}{l}\text { Retrato del caballero Thévenin, antiguo director de } \\
\text { la Academia de Francia en Roma }\end{array}$ \\
\hline & Delaistre & Busto de Puget, pintor, escultor y arquitecto \\
\hline & Dubois Drahonet & Retrato de M. D..., arquitecto del rey \\
\hline & Duclaux & Alto de artistas a las orillas del Saône \\
\hline & Mme. Dumeray & Retrato de una joven artista \\
\hline & A. Dupuis & $\begin{array}{l}\text { Retrato de M. D..., escultor, pensionado del rey en } \\
\text { Roma }\end{array}$ \\
\hline & Robert Fleury & Retratos de pintores franceses en Francia \\
\hline & Granet & Vista del taller de Granet en Roma \\
\hline & Granger & Retrato de M. Aubry, pintor \\
\hline & Paul Lecarpentier & Retrato de M. M..., grabador \\
\hline & Lecerf & Retrato de M. Urbain Massard, grabador \\
\hline & Maricot & Retrato del autor \\
\hline & Massé & Interior del taller de alumnos de Gros \\
\hline & Millet & Retrato de M. Bouhot, pintor \\
\hline & & Retrato de M. Xavier Leprince, pintor \\
\hline & Plthou & Retrato del autor \\
\hline & Rioult & $\begin{array}{l}\text { Un niño mirando a un joven que dibuja en el taller } \\
\text { del pintor }\end{array}$ \\
\hline & Trezel & Retrato en pie de M. P... en su taller \\
\hline \multirow[t]{4}{*}{1827} & Albrier & Interior del taller del pintor \\
\hline & Bodinier & Retrato de M. Boguet, pintor \\
\hline & Mlle. De Grancière & Retrato de la autora \\
\hline & Lambert & Retrato de Girodet-Trioson \\
\hline
\end{tabular}


L. Langlois

Le Carpentier

Leprince

Menjaud

Noviaire el joven

Rioult

1831

Bougron

Cogniet

Mlle. Cogniet

Collas

Desprez, L.

Dien

Mme. Dumeray

A. Estienne

A. Hugues

Klein

J. Langlois

Lecurieux

Lescorné

J.L. Martin

Achille Meunier

Mlle. Ribault

Rouillard

Scwiter

C. N. Thevenin

J. Vernet

1833

Aiffre

Amaury-Duval

Belnos

Chrétien

Mme. Cousin

De Creuse

De Courcelle

Decamps

Mme. Deherain

Georges Dupré

Egasse

Mlle. Essenar

A. Estienne

J. Franck

Gigoux
Retrato de David

Interior de un taller de pintura

Interior del taller del Sr. Leprince

Los adioses de Girodet a su taller

Retrato del autor

Un joven pintor descansando cerca del hogar

Ch. Dupaty, escultor, maestro del autor

Retrato de M. Pierre Guérin

Interior de taller

Retrato del autor

Busto de Girodet

Retrato de M. Pierre Vignon, arquitecto de la

Madeleine

Retrato de la autora (acuarela)

Joven pintor francés viajando a Bélgica

Retrato del autor

Retrato de M. Achille Meunier, pintor

Retrato de David

Retrato de M. Ducournet de Lille, pintor de retratos y de historia

Busto en yeso de un joven pintor

Retrato del autor

Interior de taller

Clase de pintura de M. Redouté en la sala de

Bouffon

Retrato de M. Jacob, dibujante, profesor en la escuela de Alfort

Retrato de M. Milbert, pintor naturalista

Retrato del autor

Retrato de un joven artista

Retrato del autor

Retrato del autor

Retrato del autor

Retrato del autor

Retrato de Dorlowski, pintor polaco

Interior de taller

Retrato en pie de M.C..., arquitecto

Retrato del autor

Retrato del autor y su familia

Interior de taller

Retrato de M. Antonin Moine, escultor

Retrato del autor

Retrato del autor

Retrato de la autora

Retrato en pie de Mme..., pintando en

Fontainebleau

Retrato del autor

Retrato de M. Johannot (grabador) y M. Moine

(escultor)

Retrato de M. Sigalon

Retrato de mujer pintando un paisaje del natural

Retrato de Delaroche y Delacroix 


\section{J. Guichard}

W. Kingston

Libour

Moench

Phelippes

Mme. Rang

C. Thevenin

1834

Badin

Mlle. Biet

Mme. Bonvoisin

Carpentier

Charon

Desboeufs

Ducastin

Dulac

Gautier

Laguerre

Lépaulle

Libour

Rey-Laurasse

1835

837
Dalleizette

A. Estienne

Mlle. Grandpierre

Louis Hunin

Leclère

Charles Légal

E. Pingret

Roller

Valdahon

Vanderburch

Adolphe Ballot

Carnevali

Desrenaud

Gosse

L. M. D. Guillaume

Hérisson

C. Hugot

Larcher

Larivière

J.P. Lassouquère

Lépaulle

De Malécy

J. Noguès

Noyal

Peyranne

Hyppolite Robillard
Retrato del autor

Retrato del autor

Retrato del autor

Retrato de M. B., escultor

Retrato del autor

Retrato del autor

Retrato de la autora

Retrato de M. Justin-Ouvrié, pintor paisajista

Retrato de M. Raimond Voizel, pintor decorador y marchante de estampas

Interior del taller de alumnos de Léon Cogniet

durante un descanso

Retrato de M. B., pintor

Retrato del autor y su familia

Retrato de M. de Montabert, pinotr

Retrato de M. R... en su taller

Busto en yeso de Henri Scheffer, pintor

Retrato del autor

Retrato de M. Duseigneur, escultor

Retrato del autor

Retrato del autor

Retrato de M. Lemaire, escultor

Retrato de M. Brenet, grabador

Retrato del autor

Retrato de M. J..., con fondo de taller

Retrato en pie de Mme..., artista

Interior del taller de M.A.P..., pintor de historia

El joven dibujante

Retrato de M. E. D..., paisajista

Retrato de M. E. H..., profesor de la academia de dibujo de Rouen

Retrato de M. Delaporte

Retrato del artista

Retrato del autor

Retrato del autor

Retrato del autor

Retrato de M. L..., pintor del rey de España

Retrato del autor

Retrato de M. Jazet, grabador

Retrato del autor

Retrato del autor

Retrato de M. Azemar, arquitecto

Retrato de M. Dufrêne

Retrato del autor

Retrato de M. C., arquitecto

Retrato de M. Chollet

Retrato en busto del autor

Retrato de M. Boulard

Retrato del autor

Retrato de M. Pardinel, grabador

Retrato del autor

Retrato de M. Ducornet 
J. Tosetti

1838

1839

1840

1841

1842

Blondel

C. Eloi

Marcel

Gosse
Elisa Besuchet

Franquelin

Victor de Jonquières

Édouard Pingret

Mme. Félicité Beaudin

Camille Bouchet

Bourgeron

Auguste Charpentier

G.A. Chocarne

Gustave Dauphin

C. Ducornet

Louis Gratia

Mlle. Éugénie Lalouette

J.P. Lassouquère

Lecurieux

H. Lenglet

Émile Loubon

A. Maricot

Édouard Pingret

D.J. Van den Bossche

Calamatta

J. L. Felon

Joseph Hornung

Federico de Madrazo

Guillaume Schlesinger

Thomas Couture

Anatole Dauvergne

Auguste Dehaussy

Alexandre Feulard

Émile Fornerod

Félix Frillié

Charles Landelle

Mme. Céleste Pensotti

Mlle. Ernestine Saint-Yvon

Sébastien Straub

Edmond Bécar

Adolphe Chitier

André Cholet

Alex Clausel

Jean-Edme-Pascal Delacluze

Mlle. Dimier

Ernst-Bénédict Kietz

Pierre-Eugène Lacoste

Isidore Maguès
Retrato del autor

Retrato de la autora

Retrato de M. Vallou de Villeneuve, pintor

Retrato del autor

Retrato de M. Maile, grabador inglés

Retrato de la autora

Retrato de Charles Percier, arquitecto

Retrato de Victor P..., paisajista

Retrato de M. Camel-Pasquet, pintor

Retrato de M. Maurice Dudevant, pintor aficionado

Retrato del autor

Retrato de M. L..., arquitecto

Retrato de M. Charles D..., escultor

Retrato del autor

Retrato del autor (pastel)

Retrato de M. C..., arquitecto en Versalles

Retrato del autor

Retrato de M. Henri de Villeneuve, arquitecto

Retrato en pie del autor

Retrato de M. Ch. Duval, arquitecto

Retrato del autor

Retrato de M..., artista pintor

El mariscal conde de Lobay en el taller de Dantan

el joven

Retrato del autor

Retrato de Ingres

Retrato del autor

Retrato de M. M..., arquitecto

Retrato de M. P..., escultor

Retrato del autor

Retrato de Adrien Dauzats, pintor

Retrato del autor

Retrato de M. Ohnet

Retrato del autor

Retrato de M. Cousin

Retrato del autor

Retrato del autor

Retrato del autor

Retrato del autor

Retrato de la autora

Retrato de la autora

Retrato del autor

Retrato del autor

Retrato del autor

Retrato del autor

Retrato en pie de M. Paillot de Montabert

Retrato de M. Bourgeois, paisajista

Retrato de la autora

Retrato de Paul Delaroche

Retrato de M. L. R..., director de pintura en la

fábrica de vidrio de Sèvres

Retrato del autor 
Jules-Joseph Montjoye

Robert-Eugène Muller

Auguste-Louis-Marie Ottin

Charles Paulus

Édouard Pingret

Gaston de Ségur

Tranquille-Armard de Vastine

1843

1844

1845
Pierre Bisson

H.J. Blondel

Émile Boniface

Victor Darjou

Eugène Durand

J. Léon Dusautoy

E.E. Hillemacher

Pierre Poisson

Jean Roller

Henry Villaine

Frédéric Bernard

Achille Bigot

H.J. Blondel

Ch. Borely

Brun

L. Brunel

Mlle. Chirat

Gustave Courbet

Anatole Dauvergne

Mme. E. Désaugiers

Adolphe-Henri Dubasty

Mme. Dubufe

Eugène Lagier

Mlle. Lepeut

Léon Lyon

Nicolas-Sébastien Maillot

Mélicourt

Benjemin Meyerstein

A. Rève

Charles Rochet

Octave Bézu

Alcide Boichard

Eloi Chapsal

Sébastien Cronu

Pierre Delaval

Adolphe-Henri Dubasty

Gosse

Léon Lyon

Charles Pied

Henri Scheffer

Sophus de Schak

Mlle. Serret

Mlle. Tappes

Auguste Van den Berghe
Retrato del autor

Retrato del autor

Busto de Ingres en bronce

Retrato de M. Henri Porret, grabador

Retrato de M. Brasseux, grabador del rey

Retrato del autor

Retrato del autor

Una comida de artistas

Retrato de M. de Gisors, arquitecto

Retrato del autor

Retrato del autor

El artista amateur, retato de M.F.

Retrato del autor

Retrato del autor

Retrato de M. D..., artista

Retrato de M. Lepère, arquitecto

Retrato de M. P... en el taller

Retrato del autor

Retrato del autor

Retrato de M. H..., rescultor

Retrato de M. Fromentin, pintor

El artista en contemplación

Retrato del autor

Retrato de M. Léon Falconnier, escultor

Retrato del autor

Retrato de M. Vicant Beaucé, pintor

Retrato de M..., artista

Retrato del autor

Busto en mármol de Paul Delaroche

Retrato de M. B..., pintor de marinas

Retrato de la autora

Retrato de M. Ch. Eck, arquitecto

Retrato del autor

Retrato del autor y de su familia

Excursión de artistas

Retrato del autor

Retrato del autor

Retrato de M. Louis Rochet, escultor

Retrato del autor

Retrato en pie de M. L..., escultor

Retrato de M. Jules C..., artista

Retrato de M. Constant Dufeux, arquitecto

Retrato de M. Gelée, grabador

Retrato de M. Charles Fortin, pintor

Retrato de M. A., artista

Retrato en pie de M, P..., arquitecto

Retrato del autor

Retrato de M. Daru, arquitecto

Retrato de Thorvaldsen

Retrato de M. Picard, arquitecto

Retrato de la autora

Retrato de M. B..., arquitecto de la ciudad de París 
Charles Viollemot

1846

1847

1848

Charles Bazin

Clément Bewer

Léon Cogniet

Édouard Dubufe

Falconnier

Alphonse Farcy

Félix Genaille

Gosse

Gabriel Lefébure

Mme. Lehaut

Henry Lehmann

Amédée Pastelot

Charles Shmid

Mme. Sommé

Charles Tillot

Félix Trutat

Génie Vidal

Gustave Aubin

Léonce Biton

André Brossard

Carnevali

André Faure

Gaetan Ferri

Paul Gayrard

Eregott Grünler

Martial Lequeux

Mlle. Loyer

Ulysse Matthey

Hugues Merle

Aimé Millet

Auguste Pidoux

Alexandre Pierret

Constant Tordeux

Charles Vallet

Michel Verwyvel

Charles Bazin
Jean-Carle Elshoëct

Emmanuel-Henry Thomas

Adolphe-André Wacquez

Léonard Belliveaux

François-Théodore Delvaux

Joseph-René Gouézou

Charles Antoine Loyeux

Charles Poterin-Dumotel

Philippe Berger

Émile Berthelemy

Auguste Bonheur

Williams Borione

Hippolyte Caillet

Jean Antoine Caron
Retrato del autor

Retrato de M. S. T..., artista

Retrato de M.A.J..., arquitecto

Retrato de M. Granet, pintor

Retrato de M. Dubufe

Busto de M. N. M..., pintor de historia

Retrato del autor

Retrato de M. A. F..., arquitecto

Retrato del autor

Retrato de M. G..., arquitecto

Retrato del autor

Retrato de M. D. Dupuy, arquitecto

Retrato de Nieuwerkerke

Retrato del autor

Retrato del autor

Retrato del autor

Retrato de M. A. Clesinger, pintor y escultor

Retrato del autor

Retrato del autor

Retrato del autor

Retrato de M. A. C..., grabador

Retrato del autor

Retrato del autor

Retrato del autor

Retrato del autor

Retrato del autor

Retrato de M. Joseph Biès, escultor

Retrato del autor

Retrato del autor

Retrato de Mme. Édouard Dubufe, escultora

Retrato del autor

Retrato de Thorvaldsen

Retrato del autor

Retrato dela autora

Retrato del autor

Retrato del autor

Retrato del autor

Retrato del autor

Retrato del autor

Retrato del autor

Retrato del autor

Retrato del autor

Retrato de M. Charles Duval hijo, arquitecto

Retrato de M. Gustaf Wappers, pintor belga

Retrato de Mme. A. D., pintora

Retrato del autor

Interior de taller, retratos de los señores E.B... y

J.D...

Retrato de Mlle. Rosa Bonheur

Retrato del autor

Retrato del autor

Retrato del autor 
Anatole Dauvergne

Jean de Bay

Sébastien Delarue

Mme. Augustine Despréaux

V. Doutreleau

Louis Douveau

Alphonse Fermepin

J.P. Feulard (padre)

Camille Fontallard

Jean-Marius Fouque

Jules Fressiniat

Émile Giraud

Lucien-Ambroise Hénault

Édouard Hostein

Alexandre Lebour

Hippolyte Mailly

Charles Mondor de l'Aigle

Édouard Moreau

Désiré Philippe

Auguste Pidoux

Clément Pruche

Émile Remy

Henry Scheffer

Léon Suvercaze

Émile Sylva

L. Taillade

Frédéric Tarin

Gabriel Tyr

Tranquille-Armand Vastine

Jean Baptiste Vegeais

1849

Auguste Bonheur

Jean Caron

Paul-Louis Chantrier

Alfred Chenu

Adolphe Delestre

Mme. Eugène Desaugier

Louis Fortuné Ducled

Louis Eustache Lorsay

Louis Frédéric Grosclaude

Charles Muchel Guilbert

Carl Happel

Paul Jourdy

Arnaud Laroche

Lechevalier-Chevignard

Antoine-Jean Michel

Pierre Morain

Mlle. Nolet

Jacques-Étienne Pannier

Marie-Félix Parmentier
Retrato de M. H. D..., arquitecto

Retrato de M. de Bay padre, escultor. Busto en yeso

Busto en yeso de M. Ch. P..., pintor

Retrato de la autora

Retrato de M. Auguste Laloue, pintor

Retrato de M. S..., arquitecto

Retrato del autor

Retrato de M. J. P. Feulard

Retrato de M. Victor Dupré, pintor

Retrato de M. Clesinger, escultor

Retrato de M. Pradier, escultor

Retrato del autor

Retrato del autor

Retrato del autor

Retrato de M. Édouard Hostein

Retrato de M. Jules Lemez, arquitecto

Retrato del autor

Retrato del autor

Retrato del autor

Retrato del autor

Retrato del autor

Retrato de M. E. S..., grabador

Retrato del autor

Retrato de M. Giraud

Retrato de M. de Pommayrac, pintor miniaturista

Retrato del autor

Retrato del autor

Retrato del autor

Retrato del autor

Retrato de M. Vonnet, escultor

Retrato de M. Lemercier, litógrafo

Retrato del autor

Retrato de M. Raymond Bonheyr

Retrato del autor

Retrato del autor

Retrato del autor

Retrato del autor

Retrato de la autora

Retrato de M. A. Vauthier-Galle, escultor

Retrato de M. Flers, artista pintor

Retrato de M. Adam Salomon, escultor

Retrato de M. E. Th..., escultor

Retrato de M. H. Th..., escuotr

Retrato del autor

Retrato del autor

Retrato del autor

Retrato de M. B..., arquitecto

Retrato del autor

Retrato del autor

Interior de uno de los talleres de Léon Cogniet

Retrato del autor

Retrato del autor 
Mme. Léopold Schlezel

P.N. Bergeret

Alphonse Bousseton

Prosper Coronat

Gustave Courbet

Egasse

Léon Goupil

Édouard Hauser

Alexis Mathonat

François Montfallet

Gaspard Mussard

Adolphe Piot

Mlle. Pottier

Quesnel

Florentin Servan

François Verniou

Jules Dehaussy

J.L. Dulong

Aimé Floucaud

Charles Giraud

Charles Lefebvre

Baptiste Martin

J. Planchet

Joseph Richaud

Théodore Aman

Jean Bein

Juliette Bonheur

A. Glaize

Victor Mottez

Léopold de Mouligon

Édouard Moyse

Charles Ronot

Charles Van der Bergh

Mme. Archinard
Henriette Perrard Lebrun

Philippe Hermann Eichens

Mme. Frédérique O'Connell

Joseph Félix Bracquemond

Eugénie-Ernest Hillemacher

Gustave Aubin

David Bles

Joseph-Felix Bracquemond

Gustave Courbet

J. Dehaussy

Édouard Delatour

Gabriel Durand

Mlle. Louisa Durand

Jacques-Joseph Eeckhout

Antonio Manuel de Fonseca

E. Goyet
Retrato de la autora

Retrato del autor

Retrato del autor

Retrato del autor

Retrato del autor

Retrato del autor

Retrato del autor

Retrato de Frédéric Overbeck

Retrato de la autora

Retrato del autor

Retrato del autor

Retrato del autor

Retrato del autor

Retrato de la autora

Retrato del autor

Retrato del autor

Retrato del autor

Retrato del autor

Retrato de M. Laustel-Dulong

Retrato de M. Rauch, escultor del rey

Retrato del autor

Retrato de Niewerkerke

Retrato del barón Taylor

La muerte de Granet, pintor

Retrato de la artista

Retrato del autor

Retrato de M. Chavet, pintor

Retrato del autor

Retrato de Baltard, arquitecto

Mme. Peyrol

Retrato del autor

Retrato del autor

Retrato de M. G..., arquitecto

Retrato de M. Guizot, pintor

Retrato del autor

Retrato del autor

Retrato del autor

Retrato de M. C..., arquitecto

Retrato de la autora y su hijo

Retrato del autor

Retrato de pintor

Retrato del autor

Retrato del autor

Retrato del autor

Retrato del autor

Retrato de M. de Block, pintor belga

Retrato del autor

Retrato de M. Constantin, pintor de esmalte

Retrato del autor

Retrato de un artista y su mujer

Retrato de un artista 
Mlle. Grandpierre Deverzy

François Hayez

Georges Healy

Jules Holtzapffel

Ingres

Frédéric Kaulbach

Édouard-Auguste Melotte

Mme. Frédérique O'Connell

Mlle. Matilde Aita de Peñuela

Joseph Richaud

Henri Rodakowski

Georges Roed

Henri-Auguste Schiott

Joseph Sogni

Vauchelet

1857

1859
Eugène Bataille

Coronat

Dubufe hijo

Amédée Dupuy de Laroche

J.L. Felon

Mlle. Henriquetta Girouard

Adolphe Goupil

Louis Marin Lavigne

Gustave-Lucien Marquerie

Léopold Massard

Jean-Baptiste Poncet

Antony Serres

Charles Steuben

Frédéric-Adolphe Yvon

Léon Brune-Rocque

Léon Erpikum

J.B. Guignet

Mme. Gaggotti-Richards

Louis Garcin

Félix-Henri Giacomotti

Gosse

François Heim

Adolphe Kinderman

Fortuné-Séraphin Layraud

Auguste Lehmann

Victor Mottez

Pasquioux

Isidore Pils

Eugène Pirodon

Louis Roux

Henri Scheffer

Charles Sergent

Charles Suan

F. Tessier

Gabriel Tyr
Interior del taller de M. Abel de Pujol

Retrato del autor

Retrato de M. Thomas Rossiter, pintor

Retrato del artista

Retrato del artista

Retrato de M. Ingres

Retrato de M. G. Kaulbach, président de

l'Académie des Beaux-Arts à Munich

Portrait de M. Eustache Bérat, pintor

Retrato de la artista

Retrato de la artista

Retrato de M. Chavet, pintor

Retrato de M. VIllot

Retrato de un pintor

Retrato de M. Lund, pintor de historia

Retrato del autor

Retrato de L. Visconti, arquitecto

Retrato del autor

Retrato del autor

Retrato de Mlle. Rosa Bonheur

Retrato del autor

Retrato del autor

Retrato de la autora

Retrato del autor

Retrato del autor

Retrato de M. Ad. Brogniart

Retrato de M . Lefuel, arquitecto

Retrato del autor

Reunión de artistas

Retrato del autor

Retrato de Étienne Mélingue, escultor

Retrato del autor

Retrato de Louis Garnerey, pintor

Retrato del autor

Retrato de la autora

Retrato del autor

Retrato de M. Jules David

Retrato de M. G..., arquitecto

64 retratos de miembros del Institut

Retrato del artista

Retrato del autor

Retrato de Michel Grobon, pintor paisajista

Retrato de M. B..., arquitecto

Retrato de la familia del autor

Retrato de M. Lecointe, arquitecto

Retrato de M. G. Jadin

El taller de Paul Delaroche en 1856

Retrato de M. Ary Scheffer

Retrato del autor

Retrato del autor

Retrato del autor

Retrato del autor 
Vauchelet

Eugène Villain

1861

Albert de Balleroy

Erpikum

Jean-Hippolyte Flandrin

Eugène-Antoine Guillon

Jacquand

Mme. Elisabeth Jerichau

Jean Khöler

Louis Matout

Jean Maziés

Adrien Nargeot

Thomas-Casimir Regnault

Achille Sirouy

Winne

1863

Paul Baudry

Ferdinand Birotheau

Auguste Cot

Mlle. Adèle Crauk

Émile Degand

Mme. Dentigny

Charles Doer

Edouard Dubufe

Mme. Eléonore Escallier

Mme. Giard

Jules Goupil

Jean-Jacques Henner

Adolphe Huas

Mlle. Koch

Jean Leloir

Jacques-Edmond Leman

Nanteuil

Amédée-Eugène Oudinot Édouard Pingret

J.B. Poncet

Witkofsky

Matilde Aita de la Peñuela

Auguste Bernard

Jules-Clément Chaplain

Fantin-Latour

Mme. Nadaillac

Jean Poncet

Jules Salet

Charles Serres

Frédéric Yvon

Joseph Bonel
Retrato en pie de M. Visconti, arquitecto

El artista

Retrato de M. Schmitz, pintor

Retrato del autor

Retrato de M. Gateaux, del Institut

Retrato de M. E. A. Guillon

Retrato del autor

Retrato de M. J. A. Jerichau, director de la

Academia de Bellas Artes de Copenague

Retrato del autor

Retrato del autor

Retrato del autor

Retrato de M. Barry, arquitecto

Retrato de M. E. Meissonier

Retrato del autor

Retrato de M. Roeland, arquitecto

Retrato de M. Schuster, arquitecto

Retrato de M. E. Giraud

Retrato del autor

Retrato de M. M..., profesor de escultura en la

Escuela de Bellas Artes de Toulouse

Retrato de la autora

Retrato de M. G. M..., escultor

Retrato de la autora

Retrato de M. Alex Leclerc, escultor

Retrato de M. Robert Fleury

Retrato de la autora

Retrato de la autora

Retrato de M. Aflred le Beau, pintor

Retrato de M. Schnetz, director de la Academia de

Francia en Roma

Retrato del autor

Retrato de la autora

Retrato del escultor Petitot

Retrato de M. Ch. Cordier, escultor

Retratos de amigos

Retrato de F. Halévy

Retrato de M. Nanteuil, escultor

Retrato del autor

Retrato del autor en la llanura de México

Retrato de M. Hippolyte Flandrin

Retrato de Horace Vernet

Retrato de la autora

Retrato del autor

Retrato de M. N. N. L..., escultor

Homenaje a Delacroix

Retrato de M. Paul Baudry

Retrato del autor

M. B. W..., en su taller

Retrato de M. Gilbert

Retrato de M. Couder, pintor

Retrato del autor 
Alexandre Collette

Enault

Fantin Latour

Alexandre Frolof

Mme. Jobard

Alfred Lavidière

Gabriel Lefebure

J.L.E. Meissonier

Vincent-Nicolas Raverat

Raymond Robillard

Ferdinando Robineau

Edmond Toilliez

Jules-Emmanuel Valadon

Jean Végeais

1866 Marie-Alexandre Adolphe

Paul Bellay

Erpikum

Adolphe Lesrel

1867

1868

1869
Édouard Dubufe

Mlle. Duval

Alexandre Grellet

Auguste Hermant

Jean-Adolphe Lafosse

Jean Laurens

Jules Machard

Léon Ottin

Jules Rousset

Pierre Vérussi

Frédéric Astruc

William Borione

Carl Friedrich Bornemann

Alfred Cluysenaar

L.E. Coedès

E. Duval

Pierre Finet

Clément Garnier

Albert Geofroy

Juan Antonio González

Étienne Haro

E.A. Marsal

Gustave Noël

Charles Pamplier

Lucien Przépiorski

Amand Vaché

Régis Vierne

Paul Baudry

Jean Bocquin

Charles Borély

Louis Buchheister

José Calderón

J.B. Danguin
Retrato del autor

Retrato del autor

Le Toast

Retrato del autor

Retrato de la autora

Retrato del autor

Retrato de M. Auguste Hesse

Retrato de M. Charles Meissonier

Retrato de Abel de Pujol

Retrato del autor

Retrato del autor

Interior del taller de M. Journalt

Retrato de M. Bonnet, arquitecto

Retrato del autor

Retrato del autor

Retrato de M. Schnetz

Retrato del autor

Retrato del autor

Retrato de artista

Retrato de M. Gounod

Retrato de M. Ch. Duval, arquitecto

Retrato de M. Vital Dubray, escultor

Retrato del autor

Retrato de M. Picot

Retrato del autor

Retrato de M. Tony Robert-Fleury

Concierto en el taller

Retrato del autor

Retrato del autor

Retrato del autor

Retrato del autor

Retrato de M. Duruy, pintor

Retrato de M. Degroot, escultor

Retrato del autor

Retrato del autor y su hermano

Retrato del autor

Retrato del autor

Retrato del autor

Retrato del autor

Retrato de Ingres

Retrato del autor

Un paisajista

Retrato del autor

Retrato del autor

Retrato del autor

Retrato del autor

Retrato de Charles Garnier

Retrato de M. Gill André, pintor

Retrato del autor

Retrato del autor

Retrato del autor

Retrato del autor 
Adolphe Dervaux

Eugène Duval

G.N. Ginferrer

Henri Grenaud

A.C. Lemoine

Eugène Louchard

Jules Machard

José Cecilio Montes

Louis Puechmagre

Jean Sauvagnac

Achille Sirouy

Edmond Viancin

Alphonse Vien

1870

Hippolyte Aussandon

Jules Balla

Jean Caron

Jean-Louis Charbonnel

Ladislas Ciesielki

Albert Coinchon

Edouard Dubufe

Fantin Latour

Galimard

Félix Jobbé-Duval

René Jouhan

Mlle Julien

Mlle Lafuge

Auguste Laugier

Jean-Adolphe Papin

Théophile Poilpot

Mlle Ponsard

Michel Poussin

Jules Vallent

1872

1873

1875
C.A. Bonnegrace

A.M. Chatinière

Francisque Desportes

Pierre Dupuis

Nils Forsberg

Mlle Gouget

Hippolyte Holfeld

C.A. Bonnegrace

Ernest Duez

Pierre Dupuis

Fantin Latour

Joseph Jouy

Mlle. Kuniska

Jules Bernard

Léon Bonnat

Gustave Courtois

Charles Crès

Jules Faisay

Eugène Decan
Retrato de M. A. Vechte, escultor

Retrato de M. D..., arquitecto

Retrato del autor

Retrato de M. Corot

Retrato de M. Lehmann

Retrato del autor

Retrato de M. C. Lenepveu

Retrato de M. Ramón Rodríguez

Retrato del autor

Retrato del autor

Retrato del autor

Retrato de M. M..., arquitecto

Retrato del autor

Retrato del autor

Retrato del autor

Retrato del autor

Retrato del autor

Retrato del autor

Retrato de M. Coinchon, escultor

Retrato de M. Lefuel

Un taller en les Batignolles

Retrato de Auguste Hesse, pintor de historia

Retrato de M. Parent, arquitecto

Retrato del autor

Retrato de la autora

Retrato de la autora

Retrato de M. Daumas, escultor

Retrato del autor

Retrato del autor

Retrato de la autora

Un viejo pintor, retrato

Retrato del autor

Retrato de M. Desplechin, pintor decorador Retrato de M. A. Chatinière

Mi retrato

Retrato de M. Cavelier, escultor

Retrato del autor

Retrato de la autora

Retrato del autor

Retrato del autor

Comida en el taller

Retrato de M. A. Martinet

Un coin de table

Retrato del autor

Retrato del autor

Retrato del autor

Retrato del autor

Retrato de M. G. Courtois

Retrato del autor

Retrato del autor

Corot 
Jules Dehaussy

Desiré Dubois

Emmanuel Genty

Auguste Georges Sauvage

Eugène Gluck

André Hennebicq

Mlle. Koch

Alfred Lavidière

Émile Nickels

Constant Petit

1876

1877

1878
T.P. Berengier

Louis-Édouard Dubufe

Alfred Lavidière

Mme. Claire Mallon

Mlle Victorine meurent

Hippolyte Planchon

Adhémar Richard

Mlle Rose Marie de Vomane

P.A. Beaufeu

J. B. Blanc

Jerôme Cartellier

Antoine Chalot

Henri Chanet

Louis Dubufe

Louis Gaitet

Henri Gervex

Louis Guédy

Georges Hébert

Frédérick Junker

J.J. Lecomte du Nouy

Mme. Peytel

Jules Rousset

Roch Prosper Rozier

Joseph Valle

Antoine Voltan

Charles Balleroy

André Brossard

Joseph Coomans

Desiré Dubois

H.A. Fauchon

Felix France

Jacques-Louis Gay

Eugène Giraud

Albert-Horace Kossak

Jules Lagger

François-Guillaume Lépaulle

Marcel Mangin

Oscar-Pierre Matthieu

Pierre Pichon

Charles Saunier

Joseph Tourtin
Retrato del autor

Retrato del autor

Retrato del autor

Retrato de M. A. C..., profesor en la Escuela de

Bellas Artes

Retrato de M. C. Gauthier

Retrato de M. N..., arquitecto

Retrato de la autora

Retrato de M. Etex, escultor

Retrato del autor

Retrato del autor

Retrato del autor

Retrato de M. Philippe Rousseau, pintor

Retrato de M. D..., pintor

Retrato de la autora

Retrato del autor

Retrato del autor

Retrato del autor

Retrato de la autora

Retrato del autor

Retrato del autor

Retrato del autor

Retrato de M. E. Bellot, grabador

Retrato del autor

Retrato de M. Harpignies, pintor

Retrato del autor

Retrato de mi amigo Brispot, pintor

Retrato de M. Jouffroy

Retrato del autor

Retrato del autor

Retrato del autor

Retrato de la autora

Retrato del autor

Retrato de M. A. D..., arquitecto

Retrato del autor

Retrato del autor

Retrato del autor

Retrato del autor

Retrato del autor

Retrato de M. E. Breton

Retrato del autor

Retrato de M. Garraud, escultor

Retrato del autor

Retrato de M. C. Giraud, pintor

Retrato del autor

Retrato del autor

Retrato de M. Davioud, arquitecto

Retrato del autor

Retrato del autor

Retrato del autor

Retrato de M. C..., arquitecto

Retrato de M. C. Meunier 
Albert Wolfinger

Mlle Bessey

Charles Blanc

G. Courtois

Diegue Garcie del Mazanarès

Victor favier

Victor Gemito

P.P.L. Glaize

Joseph Granié

Arthur-Thomas Hodgkin

Louis Jubien

J.B. Maléxieux

Pescador y Saldaña

Antoine Plée

Théodore Raillard

Roch-Prosper Rozier

J.S. Sargent
Retrato de M. A. Wolfinger

Retrato de la autora

Retrato del autor

Retrato de M. A. Aublet, pintor

Retrato del autor

Retrato del autor

Retrato de Federico de Madrazo

Retrato de M. Gérôme

Retrato del autor

Retrato del autor

Retrato del escultor Clésinger

Retrato del autor

Retrato de joven

Retrato de M. E. Nickels, pintor

Retrato del autor

Retrato del autor

Retrato de M. Carolus Duran 


\section{Anexo 3. Evolución histórica de la Sala de Retratos de la Academia de San Fernando}

Retratos de la monarquía

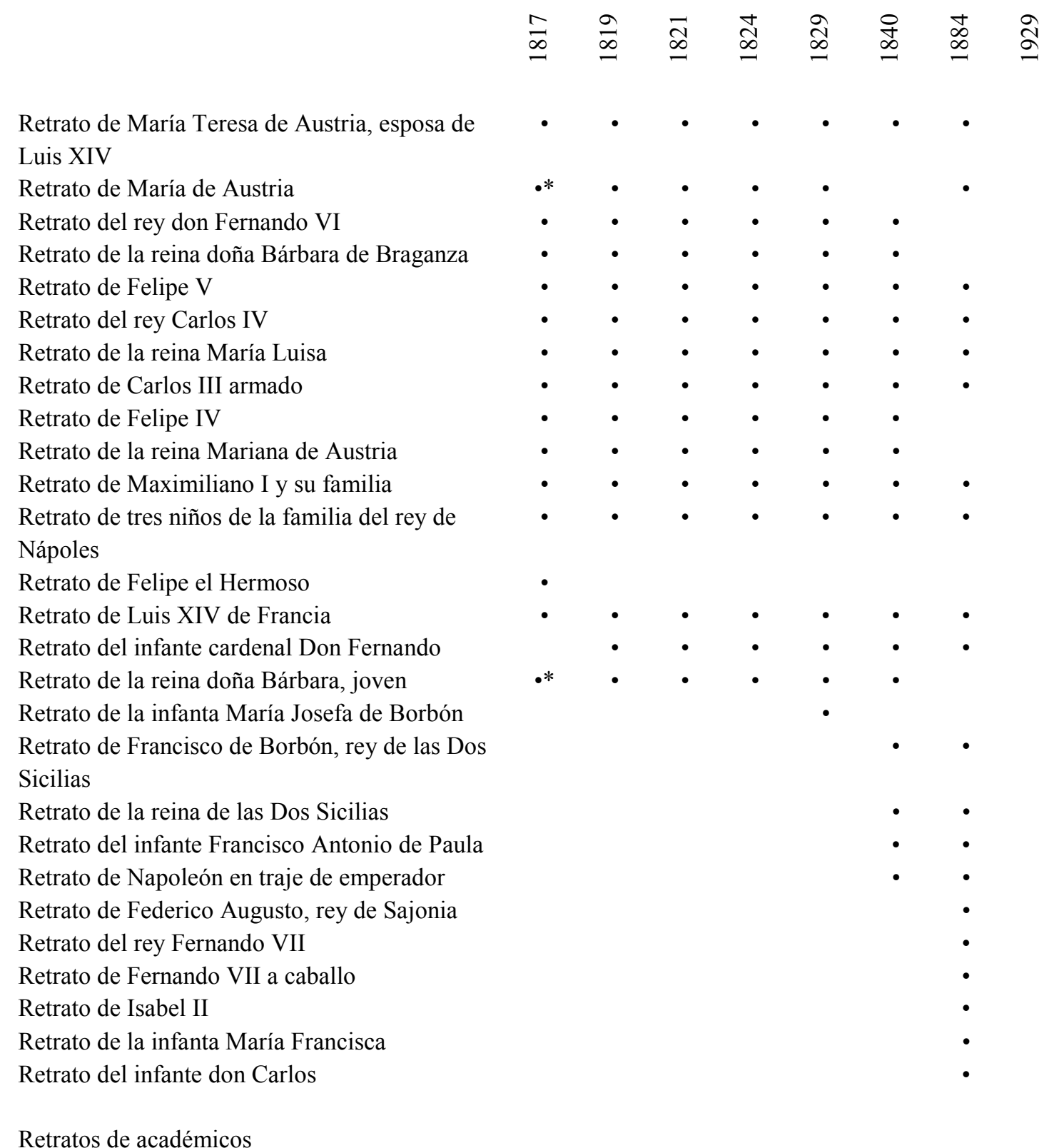

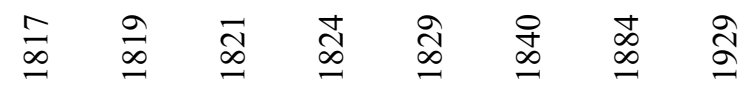

Autorretrato de Faraona Olivieri

Retrato de José de Carvajal

Retrato de Juan Bernabé Palomino

Retrato de Diego Villanueva

Retrato de Manuel de Roda

Retrato de Juan de Villanueva

Retrato de Jaime Marquet 
Retrato de Manuel Salvador Carmona

Retrato de Roberto Michel

Retrato de Ignacio de Hermosilla

Retrato del marqués de Sarria

Retrato de Mengs

Retrato de Filipo Juvara

Retrato de Ventura Rodríguez

Autorretrato de Francisco de Goya

Retrato de Antonio Ponz

Retrato de Manuel Fernández Varela

Retrato de Antonio González Velázquez

Retrato de José Ruiz Munárriz

Autorretrato de Lucía Gilabert

Retrato de Francisco Javier Borrull y Vilanova

Retrato de Antonio González Ruiz

Retrato de Francisco de Goya

Retrato de Vicente López

Retrato de José Amador de los Ríos

Autorretrato de Zacarías González Velázquez

Retrato de Isidro González Velázquez

Autorretrato de Mariano Maella

Retrato de don Pedro Franco

Retrato de don Manuel García de la Prada

Autorretrato de Antonio María Esquivel

$\underline{\text { Retratos de artista }}$

Autorretrato de Faraona Olivieri

Retrato de Juan Bernabé Palomino

Retrato de Juan de Villanueva

Retrato de Jaime Marquet

Retrato de Manuel Salvador Carmona

Retrato de Roberto Michel

Retrato de Mengs

Retrato de Filipo Juvara

Retrato de Ventura Rodríguez

Autorretrato de Francisco de Goya

Retrato de Antonio Ponz

Retrato de Antonio González Velázquez

Autorretrato Lucía Gilabert

Retrato de Antonio González Ruiz

Retrato de Francisco de Goya

Retrato de Vicente López

Autorretrato de Zacarías González Velázquez

Retrato de Isidro González Velázquez

Autorretrato Mariano Maella

Autorretrato Antonio María Esquivel

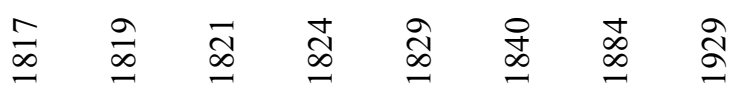

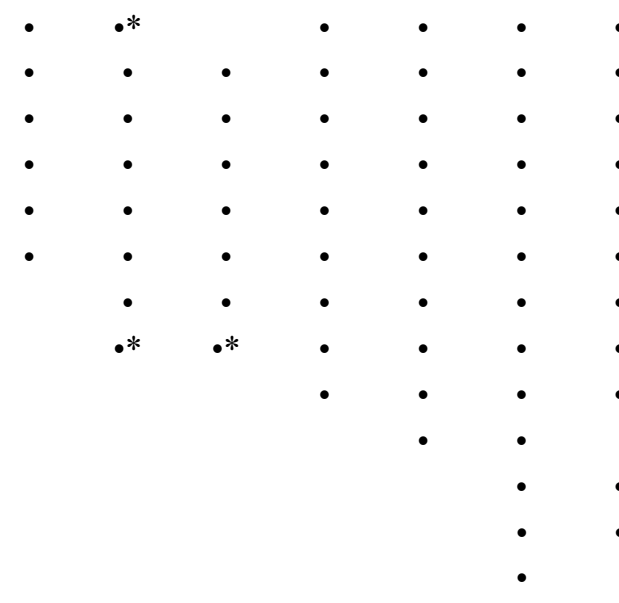


$\underline{\text { Otras obras }}$

Retrato de un joven inglés

El Origen de la Pintura

El Origen de la Pintura

Retrato de un inglés

Retrato de personaje antiguo

Retrato de Hernán Cortés

Retrato de Magallanes

Retrato de Pío VII

Retrato del Papa Inocencio •

Frutero con higos

Dos Floreros

Joven embozado

Retrato desconocido

El célebre jurisconsulto Covarrubias

Retrato de Leandro Fernández de Moratín

Retrato de Pestalozzi

Retrato de Andrés Lacal

Cabeza de anciano

Autorretrato de Luis de Vertucal

Retrato desconocido

Retrato de Cervantes

Retrato desconocido

Retrato de José Canga Argüelles

Retrato de Miguel Francisco Guerrero y

Arteaga

Retrato de Antonio Serbas

Retrato de Manuel Salmón

Tres retratos por Murillo

Retrato de desconocido en miniatura

Retrato de un padre escolapio

Retrato de desconocida en miniatura

San José

Dos retratos de frailes por Zurbarán

Retrato del General Castelldosrius

Retrato de Félix Colón de Larriátegui

Dos retratos desconocidos

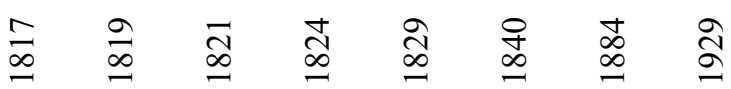

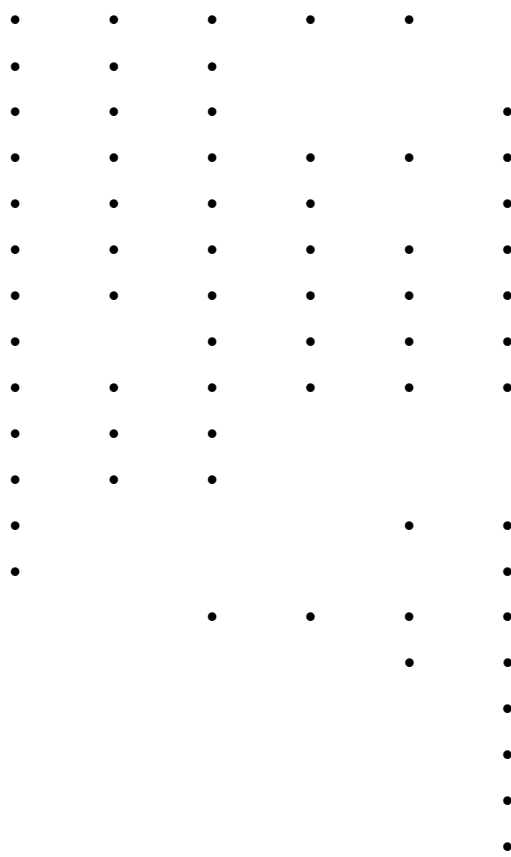




\section{Anexo 5. Evolución histórica de la galería de retratos de la Academia de San Carlos a través de sus inventarios y catálogos}

$\underline{\text { Retratos de presidentes, vicepresidentes y consiliarios }}$

$\begin{array}{cccc}1797- & 1842 & 1867 & 1955 \\ 1849 & & & \end{array}$

Joaquín Pareja y Obregón

Vicente López (1793, académico de mérito)

Francisco Andrés de Azpiroz

José Camarón (1798, académico de mérito)

Antonio Pascual

Luis Planes (1798, académico de mérito)

Manuel Giner

Consiliario

Vicente Velázquez (1798, académico de mérito)

Jorge Palacios

Vicente López

Marqués de la Romana

Académico de honor

Luis Antonio Planes

Conde de Floridablanca

General Elio

Presidente 1815-1822

Ildefonso Díez de Ribera, conde de Almodóvar Presidente 1820-1824

Miguel Parra

Francisco Plasencia

Presidente 1821

Miguel Parra

Felipe de Saint-Marco

Presidente

Miguel Parra

Luis Alejandro de Bassecourt

Presidente 1827

Miguel Parra

José María de Carvajal

Presidente 1826

Miguel Parra

José O'Donell

Presidente 1818

Miguel Parra

Francisco Longa

Presidente 1826

Miguel Parra

Nicolás Maner

Vicepresidente

Miguel Parra

Mariano Liñán

Francisco Javier Borrull

José Zapata

Cayetano de Urbina

Presidente 18-10-1801 
Conde de Almodóvar

José Joaquín Agulló, conde de Ripalda

Presidente 1850-1868

Salustiano Asenjo

Marqués de Montortal

Presidente 1885-1892

Carlos Giner

Vicente Noguera Sotolongo

Presidente 1868

Vicente Borrás Mompó

Vicente Boix

Presidente 1874-1880

José Bergón

Juan Dorda Villarroya

Presidente interino 1868-1874, 1880

Gonzalo Salvá

Marqués de Tremolar

Presidente 1895-1900

Julio Cebrián Mezquita

Eduardo Attard

Joaquín María Belda

Juan Dorda y Morera

José Benlliure

$\underline{\text { Retratos de profesores }}$

Ignacio Vergara

Director general 1-1-1773/31-12-1775

José Vergara

Director general 17-1-1779/31-12-1781

Vicente Gascó

Director general 7-1-1776/31-12-1778

José Esteve

Director general 30-12-1781/31-12-1784

Fernando Selma

Director honorario de grabado desde 1824

Cristóbal Valero

Director general 3-1-1770/31-12-1772

Manuel Monfort

Francisco Alberola

Director general 31-12-1808/30-6-1812

Domingo Olivieri

Luis Antonio Planes

Director general 31-12-1805/31-12-1808

Director general 6-1-1815/31-12-1817

Vicente Marzo

Director general 31-12-1802/31-12-1805

Director general 28-6-1812/31-12-1814

Benito Espinós

Director de Flores y Ornatos

José Zapata

Cristóbal Sales

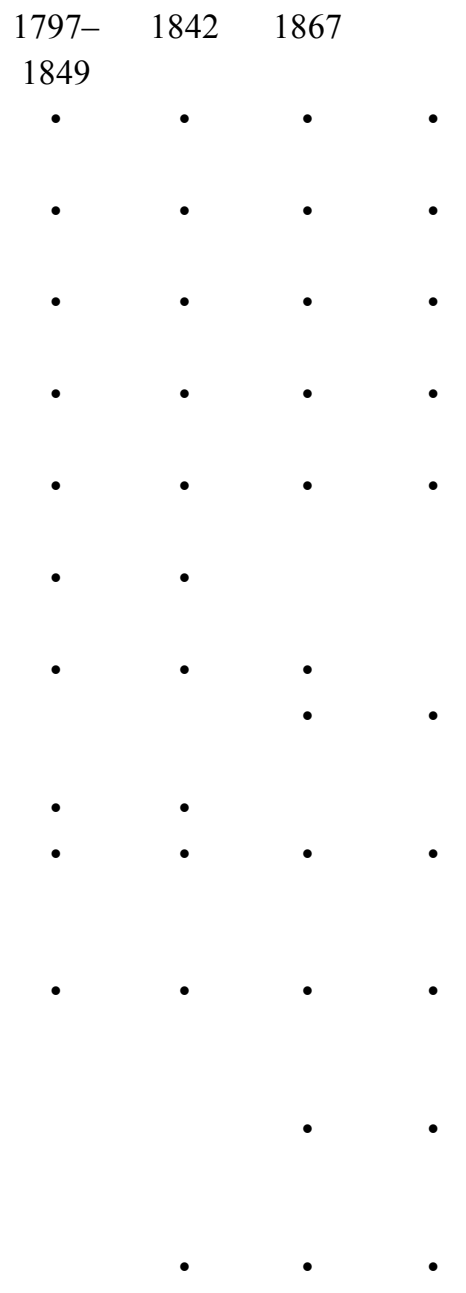


Director general 31-12-1829/31-12-1832

José Cloosterman

Director general 17-1-1836/17-1-1839

José Camarón

Director general 31-12-1796/31-12-1799

Felipe de Castro

Mariano Ferrer

Francisco Bayeu

Rafael Esteve

Juan Plaza

Vicente María Vergara

Académico de mérito y secretario 1809

1830

$\underline{\text { Retratos de artista del pasado }}$

$1797-\quad 1842 \quad 1867$

1849

Retrato grabado de Mengs

Retrato de Velázquez

Retrato de Murillo

Retrato de Sánchez Coello

Realizado por Vicente María

Vergara para académico de mérito

(1802)

Retrato de Rubens

Realizado por Juan Bautista Gil para

académico de mérito (1832)

Retrato de Gregorio Fernández 


\section{Anexo 6. Listado de los retratos existentes en la galería de la Academia de Bellas Artes de Santa Isabel de Hungría}

Retratos de artistas del pasado

Retrato de Pablo de Céspedes

Retrato de Diego de Velázquez

Retrato de Francisco Pacheco

Retrato de Bartolomé Murillo

Retrato de Francisco de Herrera el Viejo

Retrato de Alonso Cano

Retrato de Juan de Valdés Leal

Retrato de Martínez Montañés

Retrato de Zurbarán

Retrato de Roelas

Retrato de Pedro Roldán

$\underline{\text { Retratos de presidentes }}$

\section{$\begin{array}{llll}\text { s. XVIII } & \text { S. XIX } & \text { S. XX } & \text { No }\end{array}$} realizado

Retrato de Francisco de Bruna y Ahumada

Existentes Desaparecidos

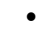

$\cdot$

$\bullet$

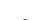

.

Retrato de Manuel López Cepero

Presidente -1858

Retrato de don Manuel Cano Manrique

Presidente 1858-1860

Retrato de don Miguel de Carvajal y Mendieta

Presidente 1860-1882

Retrato de don Andrés Lasso de la Vega

Presidente 1882-1893

José María Asensio

Presidente 1893-1894

Retrato de don Manuel Gómez Imaz

Presidente 1894-1899

$\underline{\text { Retratos de artistas contemporáneos }}$

José Domínguez Bécquer

(Valeriano Domínguez Bécquer)

Antonio Cabral Bejarano

(Manuel Cabral)

Manuel Barrón

(Manuel Cabral)

Eduardo Cano

(José Jiménez Aranda)

José Jiménez Aranda

(Ricardo López Cabrera) 


\section{Anexo 7. Relación de pensionados y de retratos existentes en la Academia Española en Roma (1874-1905)}

Nombre

Alejandro Ferrant

Juan Figueras y Vita

Miguel Aguado de la Sierra

Francisco Pradilla

Casto Plasencia

Jaime Morera

Baldomero Galofre

Ricardo Bellver

Vicente Maurelo

Manuel Aníbal Álvarez

Ramiro Amador de los Ríos

Valentín Zubiaurre

Ruperto Chapí

Manuel Castellanos

Francisco Rabanal y Fariñas

Cleto Zabala y Arambarri

Manuel Zavala y Gallardo

Medardo Sanmartí

Melesio Figueroa

Alejo Vera

Manuel Oms y Canet

Ruperto Chapí

Torcuato Tasso y Nadal

Manuel Ramírez Ibáñez

Juan Montserrat

Eugenio Oliva Rodrigo

Tomás Bretón Hernández

José Moreno Carbonero

Antonio Moltó y Such

Antonio Muñoz Degrain

Felipe Espino e Iglesias

Hermenegildo Esteban

Eduardo Barrón González

Agustín Querol y Subirats

Ulpiano Checa

Francisco Maura

Emilio Sala

Juan Vaucell

Emilio Serrano y Ruiz

Antonio Santamaría

Aquilino Cuervo

Carlota Rosales

Miguel Santonja

José Benlliure
Promoción

:0ี

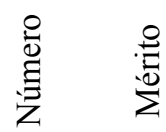

苞

1874

1874

1874

1874

1874

1874

1874

1874

1874

1874

1874

1874

$1874 / 5$

$1874 / 5$

1878

1878

1878

1878

1878

1878

1878

1878

1879

1879

1879

1879

1881

1881

1881

1881

1882

1882

1884

1884

1884

1884

1885

1885

1885

1886

1886

1887

1888

1888

\section{P}

E

A

$\mathrm{P}$

$\mathrm{P}$

E

G

A

M

M

$\mathrm{P}$

A

M

A

E

G

$\mathrm{P}$

E

M

E

P

A

$\mathrm{P}$
$\mathrm{M}$

P

E

P

M

P

E

E

P

P

$\mathrm{P}$

E

M

M

G

P

M 
Enrique Simonet

Antonio Parera

Aniceto Marinas

Joaquín Pavía

Alberto Albiñana

Agustín Querol

Salvador Viniegra

Santiago Regidor

1890

José Sáinz y Basabe

1890

Emilio Tuesta

1895

Fernando Carnicer

Miguel Ángel Trilles

Antonio Alsina

Joaquín Bárbara y Balza

Ezequiel Ruiz y Martínez

César Álvarez Dumont

Ángel Andrade y Blázquez

1895

José Alea y Rodríguez

1899

Manuel Garnelo Alda

Enrique Marín

1899

Eduardo Chicharro

1899

Manuel Benedito y Vives

1899

Fernando Álvarez de Sotomayor

1899

Juan Núñez y Fernández

1899

Vicente Arregui y Garay

1899

Francisco Antonio de San Felipe

1899

Francisco Llorens y Díaz

1902

Antonio Ortiz Echagüe

1904

José Ramón Zaragoza

1904

José Arriero y Moracia

1904

Antonio Flores y Urdapilleta

1904

Francisco Aznar y Sanjurjo

1904

Emilio Cotter Chacer

1904

Eugenio Martín Laurel

1904

Manuel Fernández y Alberdi

1905

\begin{tabular}{|c|c|c|}
\hline $\mathrm{E}$ & & • \\
\hline $\mathrm{P}$ & • & \\
\hline $\mathrm{P}$ & • & \\
\hline $\mathrm{P}$ & • & \\
\hline $\mathrm{E}$ & • & \\
\hline $\mathrm{E}$ & • & \\
\hline A & & • \\
\hline A & • & \\
\hline $\mathrm{E}$ & & • \\
\hline $\mathrm{P}$ & & • \\
\hline $\mathrm{P}$ & • & \\
\hline $\mathrm{M}$ & • & \\
\hline $\mathrm{M}$ & • & \\
\hline $\mathrm{M}$ & • & \\
\hline $\mathrm{E}$ & • & \\
\hline $\mathrm{E}$ & • & \\
\hline $\mathrm{P}$ & • & \\
\hline $\mathrm{G}$ & • & \\
\hline$P$ & • & \\
\hline$P$ & • & \\
\hline $\mathrm{P}$ & • & \\
\hline $\mathrm{E}$ & • & \\
\hline $\mathrm{E}$ & • & \\
\hline $\mathrm{P}$ & • & \\
\hline $\mathrm{P}$ & • & \\
\hline $\mathrm{P}$ & • & \\
\hline $\mathrm{G}$ & • & \\
\hline $\mathrm{M}$ & • & \\
\hline $\mathrm{M}$ & • & \\
\hline$P$ & • & \\
\hline$P$ & • & \\
\hline$P$ & • & \\
\hline $\mathrm{G}$ & • & \\
\hline A & • & \\
\hline A & • & \\
\hline $\mathrm{E}$ & • & \\
\hline $\mathrm{E}$ & • & \\
\hline M & • & \\
\hline
\end{tabular}




\section{Anexo 8. Relación de socios artistas documentados en el Liceo Artístico y}

Literario de Madrid (1837-1849)

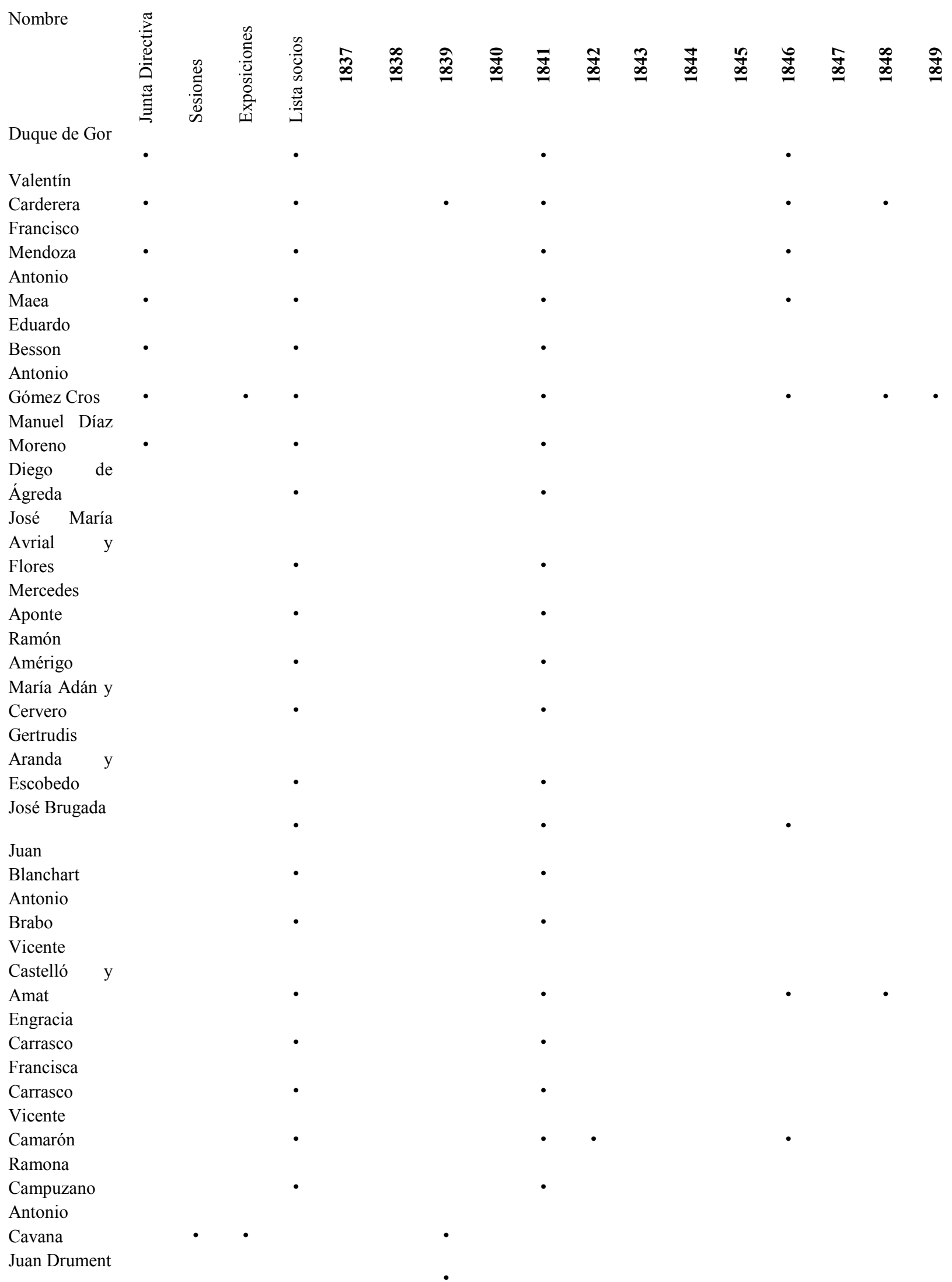




\begin{tabular}{|c|}
\hline José Elbo \\
\hline Francisco \\
\hline Estrado \\
\hline Antonio \\
\hline María \\
\hline Esquivel \\
\hline Rafael Esteve \\
\hline Adriano \\
\hline Ferrán \\
\hline Augusto \\
\hline Ferrán \\
\hline Isabel \\
\hline Fernández de \\
\hline Castro \\
\hline Manuel \\
\hline Fernández y \\
\hline Camaró \\
\hline Ramón Gil \\
\hline Vicente \\
\hline López \\
\hline Francisco \\
\hline Luchini \\
\hline Isabel Larra \\
\hline de Mengs \\
\hline José Martínez \\
\hline Zapata \\
\hline Antonio \\
\hline Maffei \\
\hline Eustasio \\
\hline Medina \\
\hline Federico \\
\hline Madrazo \\
\hline Francisco \\
\hline Mendoza \\
\hline Petronila \\
\hline Menchaca \\
\hline María \\
\hline Concepción \\
\hline Masuti \\
\hline Francisco \\
\hline Morales \\
\hline Castilla \\
\hline Benito \\
\hline Maimó \\
\hline Francisco \\
\hline Manrique \\
\hline José Madrazo \\
\hline Carmen \\
\hline Maroto \\
\hline Francisco \\
\hline Maffei \\
\hline Teresa \\
\hline Obispo \\
\hline Pedro \\
\hline Ortigosa \\
\hline
\end{tabular}


Calixto

Ortega

Adelaida O-

Dena

Manuel

Obispo

Genaro Pérez

Villaaamil

Juan Pérez

Villaamil

Francisco

Prats

Cayetano

Palmaroli

Antonio

Rotondo

María

Ramírez de

Villaurrutia

Francisco

Rosales

Carlos Luis

de Ribera

$D^{\mathrm{a}}$. Ventura

Rubiano

Benito Sáez

Juan Antonio

de la Torre

Rafael Tejeo

Joaquina

Viado

María del

Rosario

Weiss

Francisco

Van Halen

Justo María

Velasco

Luisa Viergol

Andrés de la

Villa

Juan Gálvez

Juan Ribera

Ramona

Zarazaga

Toribio

Areitio

Rafael Amar

Robustiano

Boada

Antonio de

Brugada

Francisco

Cerdá 


Cecilio Corro
Carlos María
de Castro
Vicente de
Escofet
Francisco
Elías
Francisco
Elías Burgos
Joaquín
Ezquerra
Manuel
Fernández
Camaró
José
Fernández
Bernardo
López
Luis Madrazo
Pedro
Miranda
Juan Blas
Molinero
Manuel Mayo
de la Fuente
Francisco de
Sales Mayo
de la Fuente
Enrique Nieto

Vicente
Peleguer
Santiago
Panatty
Francisco
Pérez
José Piquer
Narciso
Pascual
Colomer
Alejandro
Plaza
Patricio
Rodríguez
Ramón Vives
Eusebio
Zarza
Cosme
Algarra
Riguer
Vallespino
Mena


José

Gutiérrez de

la Vega

José

Gutiérrez de

la Vega (hijo)

Manuel Ojeda

Carlos María

Esquivel

Asensio Juliá

José Vilches

Luis Ferrant 
Anexo 9. Listado de socios artistas en el Liceo Valenciano (1838-1845)

\author{
Socios pintores \\ Bernardo López \\ Vicente López [vf] \\ Luis Téllez Girón \\ Vicente Castelló y Amat \\ Antonio Castelló [vf] \\ Antonio Cavanna y Pastor \\ Juan Llácer y Viana \\ Miguel Pou \\ Miguel Parra \\ José Felipe Parra [vf] \\ Lorenzo Isern Ricart \\ José Viló y Rodrigo \\ Joaquín García Barceló \\ José Abella y Garaulet \\ Ramón Amérigo y Morales \\ Manuel Martín Labernia \\ Regina Fernández \\ Amalia López \\ Dolores Caruana y Berard \\ Inés González Valls \\ Socios de mérito \\ Antonio Gómez Cros \\ Socios pintores miniaturistas \\ Rafael Montesinos Ramiro \\ Manuel Argüello \\ Miguel Marco \\ Socios pintores aficionados \\ Miguel Vicente Almazán \\ José María Bonilla \\ Joaquín Mira \\ Fermín Hispano \\ Francisco Sagristá \\ Peregrín García Cadena \\ Antonio Garcés de Marcilla \\ Rufo Gordó \\ Conde de Soto-Ameno \\ José de Llano y White \\ Rafael Marqués \\ Gertrudis Battifora \\ Luisa Dupui \\ Concepción Ruiz \\ Enriqueta Benavides \\ Socios grabadores \\ José Gómez \\ Tomás Rocafort \\ Teodoro Blasco Soler \\ Socios escultores
}

Junta directiva Sesiones Exposiciones Obras 
Blas Gómez

Bernardo Llácer y Viana

Socios arquitectos

Joaquín Cabrera

Antonino Sancho

Jorge Gisbert

Manuel María Azofra

Manuel Sorní

Otros socios artistas

Teodoro Blasco

Mariano Antonio Manglano

Mariano Roca de Togores

N. Cabano

Miguel Marco

Miguel Vicente

José Juanes

Enrique Jiménez

José González

Juan Espinosa

Antonio Sancho

Joaquín Catalá

Juan de la Cruz Martí

José Ángel Laffaya

Antonio Morata

Eduardo Amorós

Vicente Bellmont

Pablo Orellana (fotógrafo)

Adelina Verjes

Catalina Clavel 


\section{Anexo 10. Lista de socios de la Sociedad Protectora de Bellas Artes de Sevilla}

JUNTA DIRECTIVA

Presidente. Sr. D. José María Asensio y Toledo.

Vicepresidente. Sr. D. Jacobo López Cepero. Tesorero. Sr. D. Gonzalo Segovia y Ardizone.

Vocales.

Sr. D. Edmundo Noel.

Sr. D. Manuel de Burgos y Massa.

Sr. D. José de Hoyos y Hurtado.

Sr. D. Ignacio Verdejas.

Sr. D. Eduardo Cano.

Sr. D. Demetrio de los Ríos.

Sr. D. Gumersindo Jiménez Astorga.

Secretarios

$1^{\circ}$. Sr. D. Cayetano de Ester.

$2^{\circ}$. Sr. D. Victorino Urzaz.

\section{SOCIOS FUNDADORES}

1. Sr. D. José María de Álava

2. Sr. D. Francisco de Toledo

3. Sermo. Sr. Duque de Montpensier

4. Sociedad Sevillana de Amigos de los pobres

5. Sr. D. Leandro González de Tejada

6. Sr. D. Jorge Francisco Rossi

7. Sr. D. Carlos Sentiel

8. Sr. D. Francisco Rossi y Agliati

9. Sr. D. Claudio L. Rossi y Agliati

10. Sr. D. Manuel de Burgos y Masa

11. Sr. D. Ignacio Verdejas

12. Sr. D. Gonzalo Álvarez Espino

13. Sr. D. José María Asensio

14. Sr. D. José Sánchez y Marcos

15. Sr. D. Leopoldo Noël

16. Sr. D. Edmundo Noël

17. Sr. D. Gonzalo Segovia y Ardizone

18. Sr. D. Joaquín Turina Areal

19. Sr. D. José de Irureta Goyena

20. Sr. D. Alberto Fernández

21. Sr. D. José María de Vera

22. Sr. D. José María Lagier

23. Sr. D. Francisco de Vargas

24. Sr. D. Fernando Colom

25. Sr. D. A. Rocas

26. Sr. D. Victorino Urzaiz

27. Sr. D. Manuel Pastor y Landero

28. Sr. D. Manuel de Soto y Tello

29. Sr. D. Miguel Muñoz (Escuela Veterinaria)
30. Sr. D. José Montilla

31. Sr. D. Mariano Fernández

32. Sr. D. José Rotenflué

33. Sr. D. Ramón Galcerán

34. Sr. D. José González

35. Sr. D. Julián Rodríguez Serra

36. Sr. D. Diego María Guerrero

37. Sr. D. Tomás Povedano y de Arcos

38. Sr. D. Manuel Pérez Crespo

39. Sr. D. Joaquín Ojeda

40. Sr. D. Joaquín García D. Otero

41. Sr. D. Trinidad Bertendona y Moreno

42. Sr. D. Antonio de Gálvez y Pardal

43. Sr. D. Antonio Megías

44. Sr. D. José García y Rives

45. Sr. D. Joaquín Guzmán

46. Sr. D. Alejandro María Riaño

47. Sr. D. Manuel de Lacambra

48. Sr. D. Francisco García Portillo, Pro.

49. Sr. D. Manuel de Amores

50. Sr. D. Emigdio Serrano Dávila

51. Sr. D. Francisco Collantes

52. Sr. D. Adolfo Rodríguez de Palacios

53. Sr. D. Cayetano de Ester

54. Sr. D. Pedro José Ciaurriz

55. Sr. D. José Álvarez Surga

56. Sr. D. Pedro Huidrobro

57. Sr. D. Ignacio Galindo y Salado

58. Sr. D. Jacobo López Cepero

59. Sr. D. Félix Pérez

60. Sr. D. Juan Escacena [sic. Escazena]

61. Sr. D. Rodulfo Matoní

62. Sr. D. Antonio Pozzi

63. Sr. D. Manuel G. Zarzuela (Periódico Andalucía)

64. Sr. D. José Carrión

65. Sr. D. Manuel Noriega

66. Sr. D. F. Bernis

67. Sr. D. José Vargas Machuca

68. Sr. D. Fernando Santos

69. Sr. D. Antonio Díaz de Cendrera

70. Sr. D. Francisco Mora

71. Sr. D. Pedro González Gutiérrez

72. Sr. D. Domingo Ferreira

73. Sr. D. Cayetano Leigonier (hijo)

74. Sr. D. Antonio Salado

75. Sr. D. Francisco Escudero

76. Sr. D. Antonio Boyer

77. Sr. D. José Pérez Martín 
78. Sr. D. Guillermo Spencer

79. Sr. D. José Cañaveral

80. Sr. D. Manuel Cano y Cueto

81. Sr. D. Agustín de Landa

82. Sr. D. Antonio Freire

83. Sr. D. Antonio María Ariza

84. Sr. D. Antonio de Latour

85. Sr. D. Gregorio Esteban de Elías

86. Sr. D. Luis Montoto

87. Sr. D. Francisco de Borja Palomo

88. Sr. D. Juan Mantilla de los Ríos

89. Sr. D. Fernando de Gabriel y Ruiz de Apodaca

90. Sr. D. Bernardo Toresano

91. Sr. D. Justo de Salinas

92. Sr. D. José María Hoyos

93. Casino sevillano

94. Sr. D. José Eder

95. Sr. D. Manuel de la Vega

96. Sr. D. Pablo Sardá

97. Sr. D. Juan B. Calvi

98. Sr. D. Manuel Barrea

99. Sr. D. Ignacio Vives

100.Sr. D. Exequiel del Campo

101.Sr. D. José Buzón

102.Sr. D. Cándido Viana y Bravo

103.Sr. D. Federico Amérigo y Alcaraz

104.Sr. D. Rafael Álvarez Anitua

105. Revista Sevillana de Filosofía

106. Sr. D. Francisco Vincent

107.Sr. D. Pascual Vincent

108.Sr. D. Vicente Bellóc

109.Sr. D. Manuel Andérica

110.Sr. D. Manuel de la Cámara

111.Sr. D. Manuel Laraña

112.Sr. D. Joaquín Palacios y Rodríguez

113.Sr. D. Miguel Velarde

114.Sr. D. Antonio Colom

115.Sr. D. Juan J. Bueno

116.Sr. D. Joaquín González

117.Sr. D. Eduardo Sánchez

118. Sr. D. Francisco Balza

119.Sr. D. José de la Piña

120.Sr. D. Juan M. de los Santos

121.Sr. D. Gumersindo Díaz

122. Sr. D. Francisco Solano Requena

123.Sr. D. Manuel Barreras

124.Sr. D. Eduardo Cano

125.Sr. D. Federico Eder

126.Sr. D. Manuel Gutiérrez Cano

127.Sr. D. Manuel Arellano

128.Sr. D. José Chaves

129.Sr. D. José Canal
130.Sr. D. Eduardo Montesinos

131.Sr. D. Eduardo Estebaz

132.Sr. D. Virgilio Matoni

133.Sr. D. Manuel Ussel

134.Sr. D. Manuel Lucena

135.Sr. D. Vicente Gutiérrez

136. Sr. D. Manuel de la Portilla

137.Sr. D. Antonio María de Vega

138.Sr. D. Manuel Cabral Bejarano

139.Sr. D. Juan C. Bejarano

140.Sr. D. Antonio de Llamas

141.Sr. D. Eduardo del Castillo

142.Sr. D. José García

143.Sr. D. Antonio Mensaque

144.Sr. D. Nicolás Barrera

145.Sr. D. Rafael de los Reyes

146. Sr. D. Miguel Barragán

147.Sr. D. Manuel Freine Reinoso

148.Sr. D. Francisco Escribano

149.Sr. D. Manuel Gutiérrez Reyes

150.Sr. D. Gumersindo Jiménez Astorga

151.Sr. D. Manuel Barrón

152.Sr. D. Francisco Cabral Bejarano

153. Sr. D. Demetrio de los Ríos

154.Sr. D. Andrés Cortés

155.Sr. D. Francisco Peralta

156.Sr. D. Enrique León

157. Sr. D. Gabriel Astorga y Miranda

158. Sr. D. Rosendo Fernández

159. Sr. D. José Ortiz

160. Sr. D. Miguel López Acuña

161.Sr. D. Rafael Cabral Bejarano

162.Sr. D. Vicente Esquivel

163.Sr. D. Manuel Aragón

164.Sr. D. José Contreras

165.Sr. D. Joaquín Díez

166.Sr. D. José Roldán

167.Sr. D. Manuel Vélez

168.Sr. D. Manuel de la Pela

169.Sr. D. Francisco de Vega

170.Sr. D. Pedro de Vega

171.Sr. D. Antonio Alonso Morgado

172.Sr. D. Leonardo Fernández

173. Sr. D. José S. Martín y Falcón

174.Sr. D. José Pelli

175. Sociedad casino de artistas

176.Sr. D. Napoleón Lionnet

177.Sr. D. Silverio López Uria

178.Sr. D. Manuel Urza 


\section{Anexo 11. Listado de los socios de la Sociedad de Acuarelistas de Madrid, según las noticias recogidas en la prensa periódica}

Socio

Bernardo Rico

Francisco Pradilla

José Luis Pellicer

Alejandro Ferrant

Fischermans

Alfredo Perea

José Cebrián

Francisco de Asís López

Vicente Sabater

Rafael Alberola

Ramón Mosquera

Ángel Rodríguez Tejero

García Hispaleto

Oliva

Daniel Zuloaga

Domingo Muñoz

Miguel Jadraque

García Valladolid

Germán Valdecara (-ava)

Casanova

Merino

Ricardo Madrazo

Casto Plasencia

Jaime Morera

Doucourneau

José Nicolau

Juan Garrido

Muriel

Garnucho/Caruncho

Mariano Urrutia

José María Manresa

Agustín Lhardy

Hermenegildo Esteban

Fernando H. Saavedra

Antonio García López

H. C. Edwards

Acevedo

Galván

Rosadillo

Domec

Sans

Miguel Castaño

Luis Franco

Jorge Laguardia

José Villar Sánchez

Eduardo Senet

Juan [García] Flórez
Exposiciones anuales

$\begin{array}{lllllllll}77 & 78 & 79 & 80 & 81 & 82 & 83 & 88 & 89\end{array}$
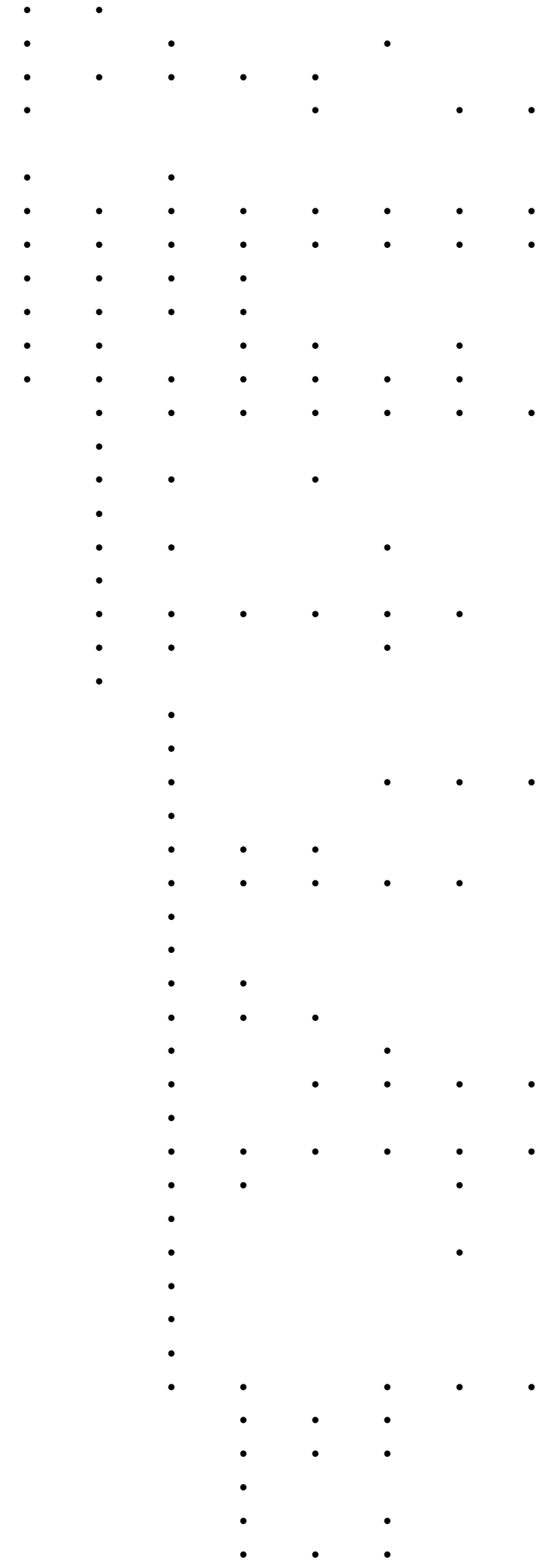
Eduardo Estrada

Antonio Estrada

Ricardo Aramburu

Aníbal Álvarez

Pedro Octavio de Toledo

Jover

Megía

Pelayo

Alcázar (Alcaraz)

Barrau

Cosme Algarra

Benlliure

Laredo

Aguirre

Vallejo

Hoffmeyer

Gomar

Ricardo Bellver

García Ramos

Unceta

Amorós

Villodas

Fabra (Fabrés)

Carreño

Mas i Fondevila

Federico Jiménez

Camaño

Ruiz de Quevedo

Almira

Fierros

Dantin

Casas

Joaquín Sorolla

Caraffa

Graner

Araujo

Herraiz

Tiberio Ávila

Maura

Ezquerra

Urquiola

Yus

Alfredo Souto

Aparici

Caula

López Curet

Román Navarro

Parada y Santín

Cuenca

Ruiz Morales

Domínguez

Tomás Martín 


\section{Socias}

S.A.R. Infanta $\mathrm{D}^{\mathrm{a}} \mathrm{Paz}$

S.A.R. Infanta $D^{a}$ Eulalia

Concepción Soldevilla

Josefa Serrano

Inés Álvarez

Emilia Menassade

Adela Crooke

Srta. Bayo

Isabel Pardo

Ana María Becerra

Carolina Rodríguez Tejero

Inés Flórez

Teresa Vera

Josefa Pardo 


\section{Anexo 12. Listado de artistas vinculados al Círculo de Bellas Artes (1880-1892) y presencia de retratos en las exposiciones}

\begin{tabular}{|c|c|c|c|c|c|c|c|c|c|c|c|c|c|c|c|c|c|c|c|c|}
\hline & $\begin{array}{l}\infty \\
\infty \\
\infty\end{array}$ & $\begin{array}{l}\infty \\
\infty\end{array}$ & $\begin{array}{l}\infty \\
\infty \\
\infty\end{array}$ & $\begin{array}{l}\infty \\
\infty \\
\infty\end{array}$ & $\begin{array}{l}+ \\
\infty \\
\infty \\
-\end{array}$ & $\begin{array}{l}\infty \\
\infty \\
\infty\end{array}$ & $\begin{array}{l}\infty \\
\infty \\
\infty\end{array}$ & $\underset{\infty}{\infty}$ & $\begin{array}{l}\infty \\
\infty \\
\infty \\
\infty\end{array}$ & $\begin{array}{l}\infty \\
\infty \\
\infty\end{array}$ & $\stackrel{\infty}{\infty}$ & $\vec{\infty}$ & ๙ั & $\stackrel{2}{\infty}$ & $\stackrel{\Xi}{\infty}$ & $\stackrel{n}{\propto}$ & $\stackrel{\circ}{\infty}$ & $\hat{\infty}$ & $\stackrel{\infty}{\infty}$ & $\stackrel{\infty}{\infty}$ \\
\hline \multicolumn{21}{|l|}{ Valdivia } \\
\hline H. Esteban & • & • & • & • & & & & $\cdot$ & & & • & & & & & & & & & \\
\hline $\begin{array}{l}\text { Enrique } \\
\text { Esteban }\end{array}$ & $\cdot$ & $\bullet$ & & & & & $\cdot$ & $\bullet$ & $\cdot$ & & $\bullet$ & $\cdot$ & & & & & & & & \\
\hline \multicolumn{21}{|l|}{ Domec } \\
\hline $\begin{array}{l}\text { Antonio } \\
\text { Pérez Rubio }\end{array}$ & $\bullet$ & $\cdot$ & $\cdot$ & $\bullet$ & & & $\bullet$ & $\cdot$ & & & & & & & & & & & & \\
\hline $\begin{array}{l}\text { Eugenio } \\
\text { Duque }\end{array}$ & $\cdot$ & & & - & & & & & & & & & & & & & & & & \\
\hline $\begin{array}{l}\text { Casto } \\
\text { Plasencia }\end{array}$ & $\bullet$ & $\bullet$ & $\cdot$ & $\bullet$ & & & & & $\cdot$ & $\bullet$ & $\bullet$ & & $\cdot$ & & & & & & & \\
\hline $\begin{array}{l}\text { Miguel } \\
\text { Jadraque }\end{array}$ & $\cdot$ & & & & & & & $\cdot$ & & $\cdot$ & $\bullet$ & & & & & & & & & \\
\hline $\begin{array}{l}\text { Sebastián } \\
\text { Gessa }\end{array}$ & $\cdot$ & $\cdot$ & $\bullet$ & & & & & & & & & $\bullet$ & & & & & & & & \\
\hline $\begin{array}{l}\text { Enrique } \\
\text { Mélida }\end{array}$ & $\cdot$ & $\cdot$ & $\cdot$ & & & & & & & & & & $\bullet$ & & & & & & & \\
\hline $\begin{array}{l}\text { Francisco } \\
\text { Jover }\end{array}$ & $\cdot$ & & & & & & & & & & & & & & & & & & & \\
\hline $\begin{array}{l}\text { José } \\
\text { Larrocha }\end{array}$ & $\cdot$ & $\bullet$ & & & & & & & & & & & & & & & & & & \\
\hline $\begin{array}{l}\text { Alfredo } \\
\text { Perea }\end{array}$ & $\cdot$ & $\cdot$ & $\cdot$ & & & & & & & $\cdot$ & $\bullet$ & $\bullet$ & $\cdot$ & & & & & & & \\
\hline Daniel Perea & $\cdot$ & $\cdot$ & $\cdot$ & & & & & & & & & $\bullet$ & & & & & & & & \\
\hline $\begin{array}{l}\text { Federico } \\
\text { Madrazo }\end{array}$ & $\bullet$ & $\cdot$ & $\cdot$ & - & & & & & & & & & - & & & & & & & \\
\hline \multicolumn{21}{|l|}{$\begin{array}{l}\text { Carlos L. } \\
\text { Ribera }\end{array}$} \\
\hline Carlos Haes & & & $\bullet$ & & & & & & & & & & & & & & & & & \\
\hline $\begin{array}{l}\text { Dióscoro } \\
\text { Puebla }\end{array}$ & $\cdot$ & & & & & & & & & & & & & & & & & & & \\
\hline $\begin{array}{l}\text { Rafael } \\
\text { Ruscon }\end{array}$ & $\cdot$ & & & & & & & & & & & & & & & & & & & \\
\hline José Nicolau & $\cdot$ & & & & & & & & & & & & & & & & & & & \\
\hline \multicolumn{21}{|l|}{$\begin{array}{l}\text { Isidoro } \\
\text { Fernández } \\
\text { Flores }\end{array}$} \\
\hline $\begin{array}{l}\text { Bernardo } \\
\text { Rico }\end{array}$ & & $\cdot$ & & & & & & & & & & & & & & & & & & \\
\hline Martín Rico & & • & - & & & & & & & & • & - & & & & & & & & \\
\hline Emilio Sala & - & & & & & & & & & & - & - & - & & & & & & & \\
\hline \multicolumn{21}{|l|}{ Cimarro } \\
\hline \multicolumn{21}{|l|}{$\begin{array}{l}\text { Jerónimo } \\
\text { Suñol }\end{array}$} \\
\hline $\begin{array}{l}\text { Alejandro } \\
\text { Ferrant }\end{array}$ & $\bullet$ & & - & - & & & & & & $\bullet$ & $\bullet$ & & $\bullet$ & & & & & & & \\
\hline Fenollera & & & & & & & & & & & & & & & & & & & & \\
\hline
\end{tabular}




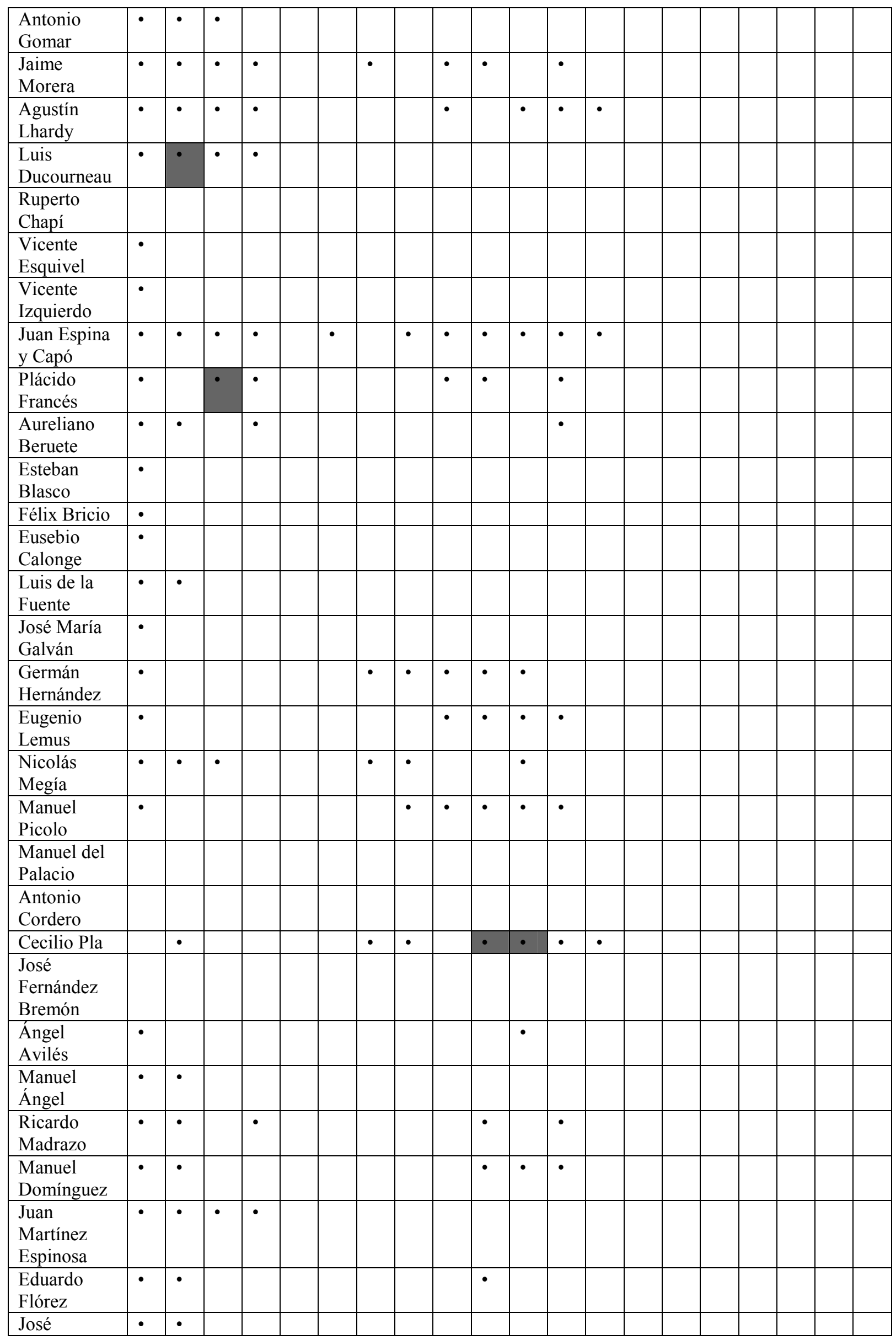




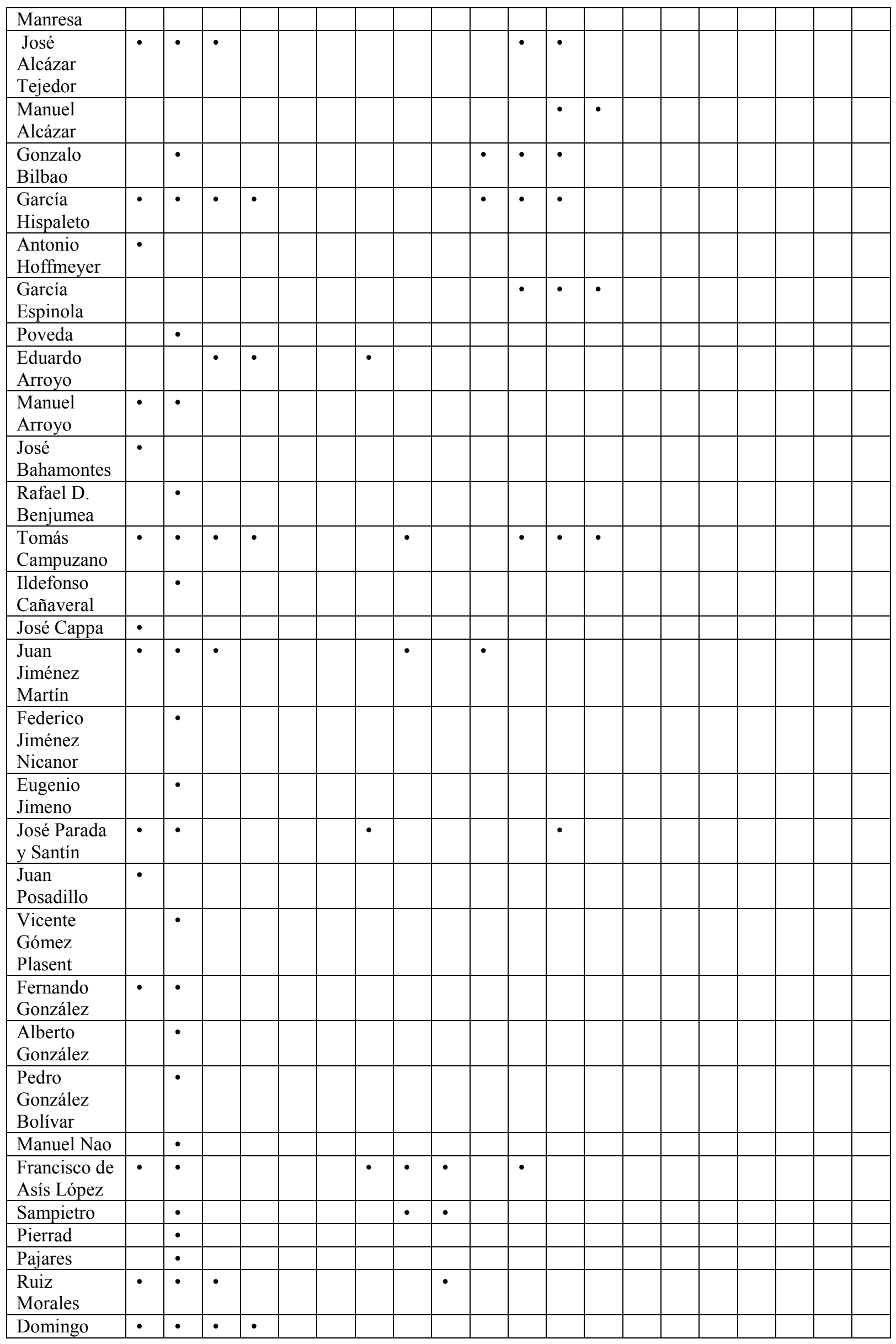




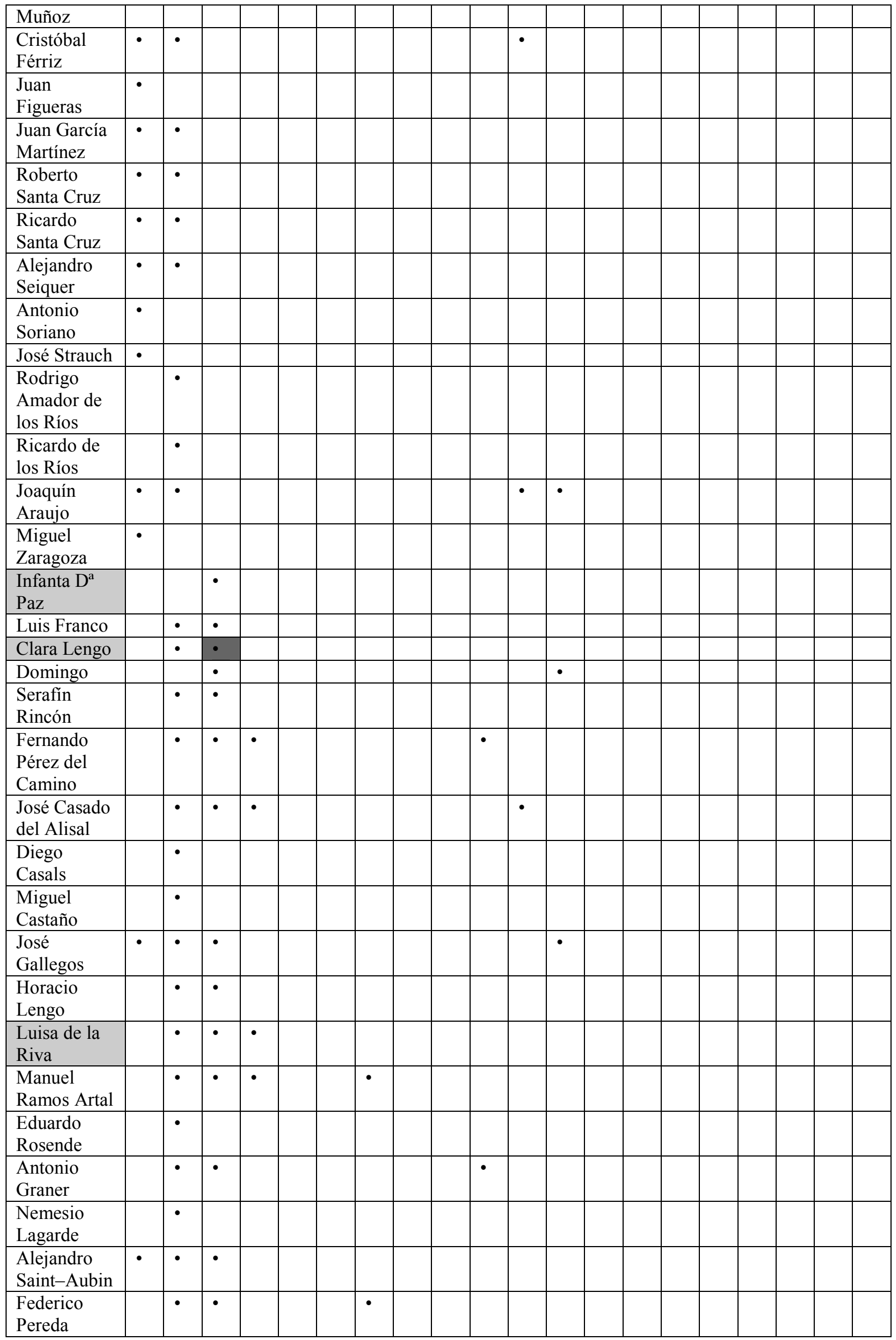




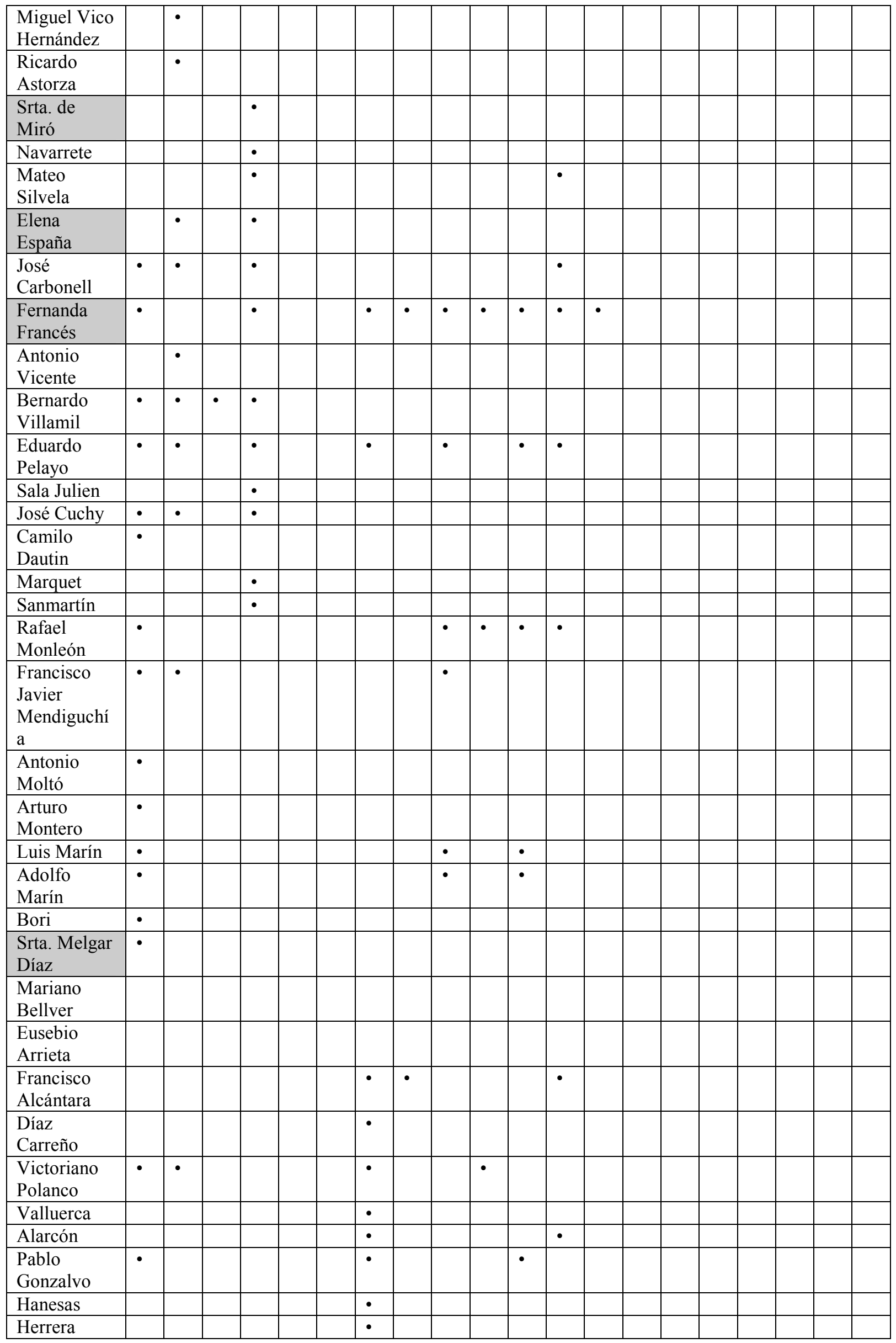




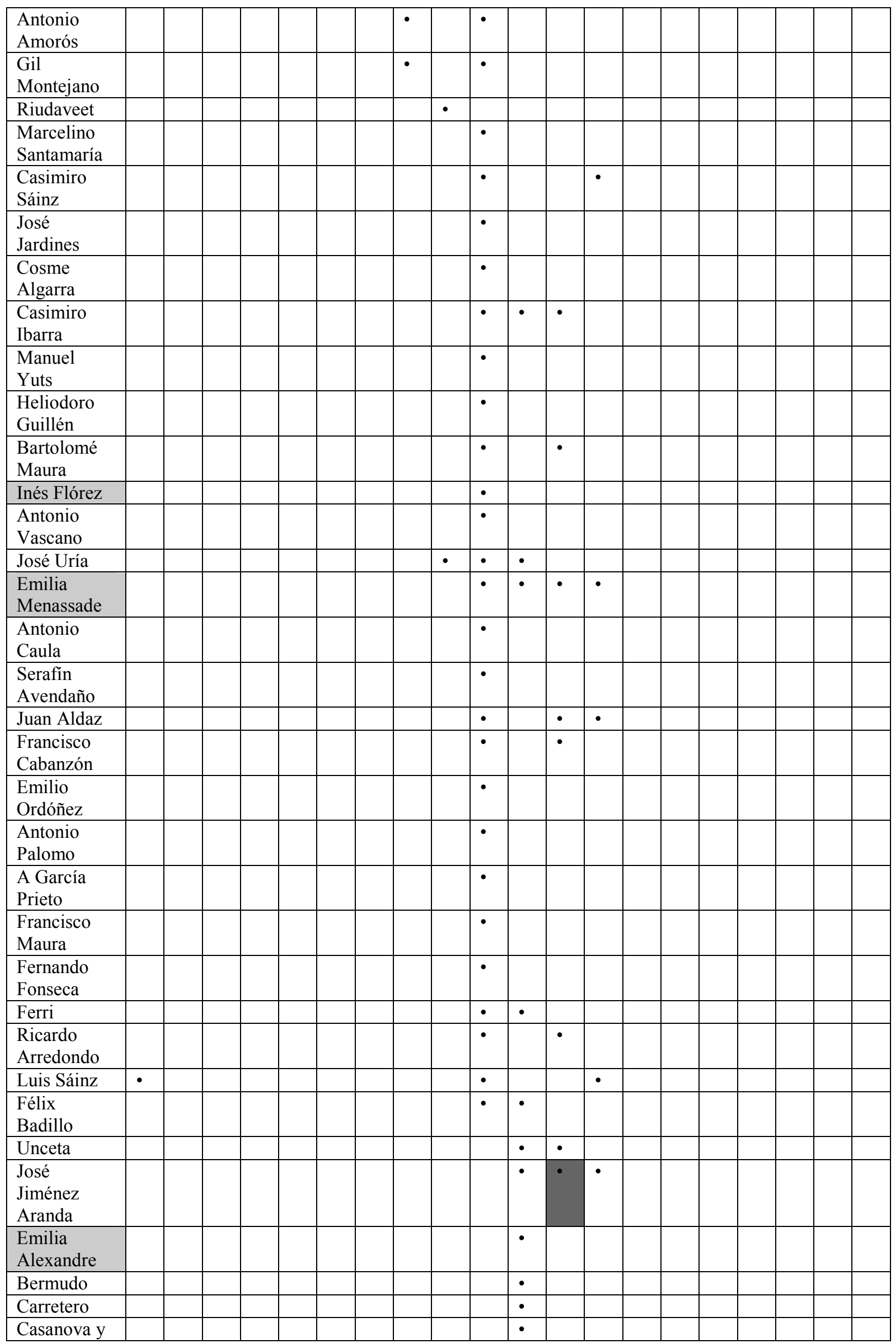




\begin{tabular}{|c|c|c|c|c|c|c|c|c|c|c|c|c|c|c|}
\hline Estorach & & & & & & & & & & & & & & \\
\hline Galofre & & & & & & & & & $\cdot$ & & $\cdot$ & & & \\
\hline Gartner & & & & & & & & & $\cdot$ & $\cdot$ & & & & \\
\hline $\begin{array}{l}\text { Matías } \\
\text { Moreno }\end{array}$ & - & & & & & & & & & & & & & \\
\hline $\begin{array}{l}\text { Moreno } \\
\text { Carbonero }\end{array}$ & & & & & & & & & $\bullet$ & & & & & \\
\hline $\begin{array}{l}\text { Santiago } \\
\text { Regidor }\end{array}$ & & & & & & & & & • & & & & & \\
\hline Heredia & & & & & & & & & $\cdot$ & & & & & \\
\hline $\begin{array}{l}\text { Herreros de } \\
\text { Tejada }\end{array}$ & & & & & & & & & $\bullet$ & & & & & \\
\hline Huertas & & & & & & & & • & $\cdot$ & & & & & \\
\hline Vázquez & & & & & & & & & • & & & & & \\
\hline Pirala & & & & & & & & & $\bullet$ & & & & & \\
\hline Sorolla & & & & & & & & & $\cdot$ & • & $\cdot$ & & & \\
\hline Ruiz Luna & & & & & & & & & - & & & & & \\
\hline Angoloti & & & & & & & & & $\bullet$ & $\cdot$ & & & & \\
\hline Comba & & & & & & & & & $\cdot$ & & & & & \\
\hline $\begin{array}{l}\text { Laura } \\
\text { García }\end{array}$ & & & & & & & & & $\bullet$ & & & & & \\
\hline $\begin{array}{l}\text { García } \\
\text { Rodríguez }\end{array}$ & & & & & & & & & - & & & & & \\
\hline Gartner & & & & & & & & & - & & & & & \\
\hline $\begin{array}{l}\text { Tomás } \\
\text { Muñoz } \\
\text { Lucena }\end{array}$ & $\cdot$ & $\cdot$ & & & & & & & $\cdot$ & $\cdot$ & $\cdot$ & & & \\
\hline José Muriel & $\cdot$ & & & & & & & & & & & & & \\
\hline Luis Ochoa & & - & & & & & & & & & & & & \\
\hline $\begin{array}{l}\text { Mariano } \\
\text { Oliver y } \\
\text { Aznar }\end{array}$ & & $\bullet$ & & & & & & & & & & & & \\
\hline $\begin{array}{l}\text { Marcelina } \\
\text { Poncela }\end{array}$ & & & & & & & & & - & & & & & \\
\hline Sampedro & & & & & & & & & • & & & & & \\
\hline Ugarte & & & & & & & & & $\cdot$ & & & & & \\
\hline $\begin{array}{l}\text { Maximino } \\
\text { Peña }\end{array}$ & & - & & & & & & $\cdot$ & $\cdot$ & - & & & & \\
\hline Mascó & & & & & & & & & $\cdot$ & & & & & \\
\hline $\begin{array}{l}\text { Martínez } \\
\text { Abades }\end{array}$ & & & & & & & & & $\bullet$ & - & & & & \\
\hline Moya & & & & & & & & & - & & & & & \\
\hline Souto & & & & & & & & & $\bullet$ & & & & & \\
\hline $\begin{array}{l}\text { Villapadiern } \\
\text { a }\end{array}$ & & & & & & & & & $\bullet$ & & & & & \\
\hline Llaneces & & & & & & & & & & $\cdot$ & & & & \\
\hline $\begin{array}{l}\text { Manrique de } \\
\text { Lara }\end{array}$ & & & & & & & & & & • & & & & \\
\hline $\begin{array}{l}\text { Tomás } \\
\text { Martín } \\
\end{array}$ & - & • & & & & & & & & $\cdot$ & & & & \\
\hline $\begin{array}{l}\text { Martínez } \\
\text { Cubells }\end{array}$ & & & & & & & & & & • & & & & \\
\hline Morelli & & & & & & & & & & $\cdot$ & & & & \\
\hline Pulido & & & & & & & & & & $\cdot$ & & & & \\
\hline Ramírez & & & & & & & & & & $\cdot$ & & & & \\
\hline Alcoveno & & & & & & & & & & $\bullet$ & & & & \\
\hline $\begin{array}{l}\text { Justo } \\
\text { Gandarias }\end{array}$ & & & & & & & & & & $\bullet$ & $\bullet$ & & & \\
\hline Adela Ginés & & & & & & & & & & • & & & & \\
\hline
\end{tabular}




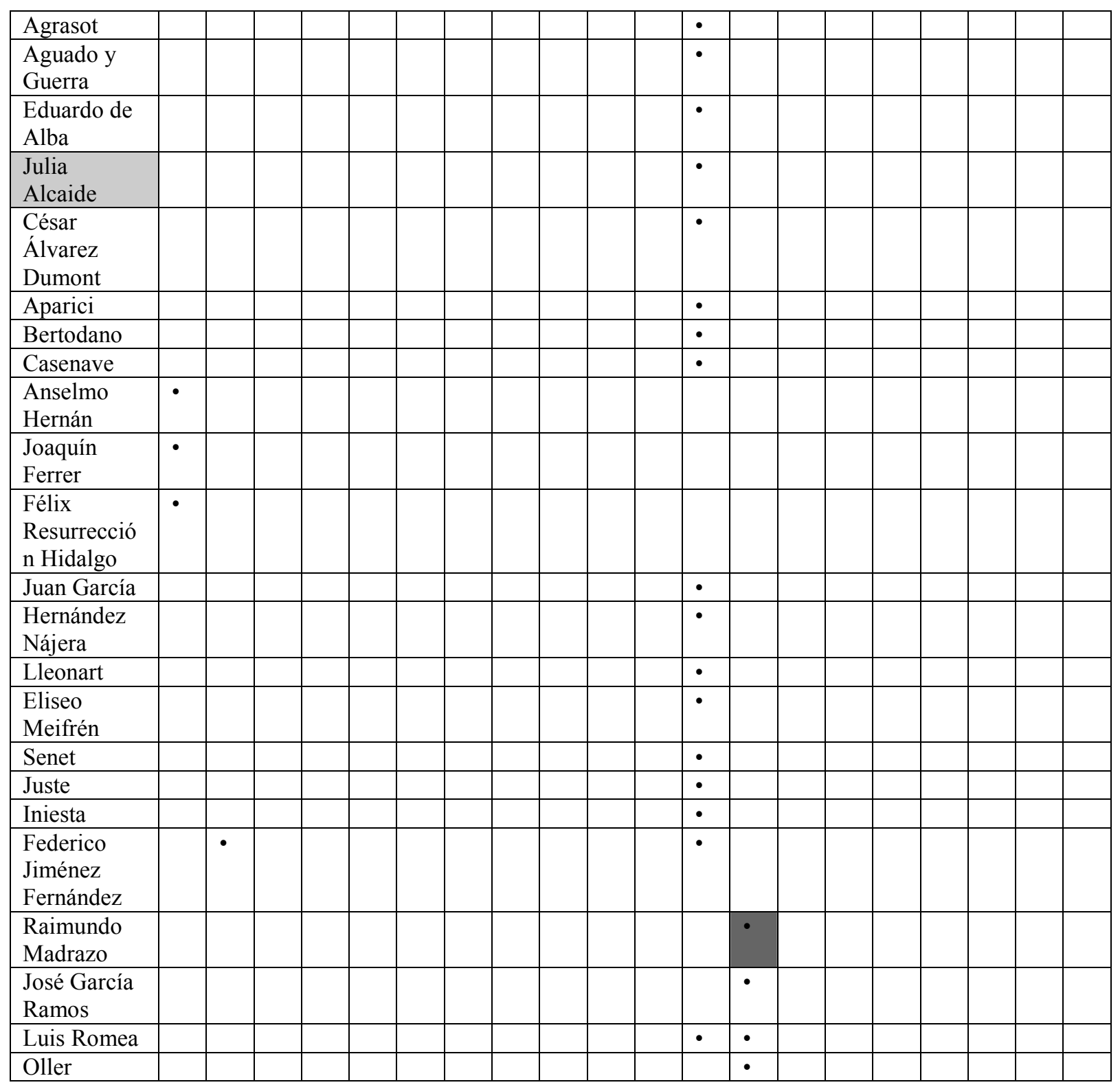




\section{Anexo 13. Retratos del friso del Círculo de Bellas Artes y relación de los retratados con la sociedad}

Eduardo Adaro

Vicesecretario de la Sociedad Central de Arquitectos (1880); medalla de primera clase en la sección de arquitectura en la Exposición Nacional de 1884.

Mariano Adaro

Colaboró como pintor en la preparación del baile de Carnaval del Círculo de Bellas Artes (1892)

Rafael Algueró

Participa en las exposiciones del Círculo (1882)

Manuel Aníbal Álvarez

Socio desde 1880; vocal de la junta (1891)

Vital Anza

colaboró en la preparación del baile de Carnaval del Círculo de Bellas Artes (1892)

Joaquín Araujo

Socio desde 1880;

José Arija

Manuel Arroyo

Socio desde 1880; vocal en la junta directiva $(1889,1890)$;

Ángel Avilés

Socio desde 1880; vocal en la junta directiva (1890); colaboró en la preparación del baile de

Carnaval del Círculo de Bellas Artes (1892)

Tomás Bretón

Colaboró en la preparación del baile de Carnaval del Círculo de Bellas Artes (1892)

José Burgos

Cachavera

Presidente de la Sociedad Central de Arquitectos (1888)

Tomás Campuzano

Socio desde 1880; vocal de la junta (1891); colaboró en la preparación del baile de Carnaval del Círculo de Bellas Artes (1892);

Abelardo José de Carlos

Socio desde 1880; director de La Ilustración Española y Americana. El certamen artístico de dicha revista en 1888 se celebró en el Círculo de Bellas Artes.

Santiago Castellanos

Juan Comba

colaboró en la preparación del baile de Carnaval del Círculo de Bellas Artes (1892)

Antonio Cordero

Socio desde 1880; vocal de la junta (1891);

Joaquín Crámer

Socio de la Central de Arquitectos;

Manuel Domínguez

Socio desde 1880; colaboró en la preparación del baile de Carnaval del Círculo de Bellas Artes (1892)

Manuel Ducasi

Socio desde 1880; colaboró en la preparación del baile de Carnaval del Círculo de Bellas Artes (1892)

Juan Espina

Socio desde 1880; secretario $(1889,1890,1891)$; colaboró en la preparación del baile de

Carnaval del Círculo de Bellas Artes (1892); 
Enrique Fernández Arbós

Alejandro Ferrant

José Fornos

Fernanda Francés

colaboró en la preparación del baile de Carnaval del Círculo de Bellas Artes (1892);

Plácido Francés

Socio desde 1880; vocal de la junta $(1889,1890)$; tesorero $(1891)$, colaboró en la preparación del baile de Carnaval del Círculo de Bellas Artes (1892);

Juan García Martínez

Socio desde 1880;

Tomás Gil y Montijano

Pablo Gonzalvo

Julio Gros

colaboró en la preparación del baile de Carnaval del Círculo de Bellas Artes (1892);

Germán Hernández

Vocal de la junta directiva $(1889,1890)$

Herreros de Tejada

Vicente Ibor

Miguel Jadraque

Socio desde 1880; vocal de la junta $(1889,1890)$; colaboró en la preparación del baile de

Carnaval del Círculo de Bellas Artes (1892);

Manuel Lasa y Nuño

Eugenio Lemus

Socio desde 1880; vocal de la junta $(1889,1890,1891)$; colaboró en la preparación del baile de Carnaval del Círculo de Bellas Artes (1892);

Agustín Lhardy

Socio desde 1880; vocal de la junta $(1889,1890)$; presidente sección de exposiciones (1891)

colaboró en la preparación del baile de Carnaval del Círculo de Bellas Artes (1892);

Manuel Linares Rivas

Juan López

Adolfo Marín

Luis Marín

Socio desde 1880; colaboró en la preparación del baile de Carnaval del Círculo de Bellas Artes (1892);

Serafín Martínez del Rincón

Socio (en calidad de corresponsal) desde 1880;

Nicolás Megía

Socio (en calidad de corresponsal) desde 1880; vocal de la junta $(1889,1890)$

Luis Montojo

Vocal de la junta $(1889,1890)$;

Víctor Morelli

Manuel del Palacio

Socio desde 1880; vocal de la junta $(1889,1890)$; colaboró en la preparación del baile de

Carnaval del Círculo de Bellas Artes (1892);

Eduardo Pelayo

Socio desde 1880; colaboró en la preparación del baile de Carnaval del Círculo de Bellas Artes (1892);

Alfredo Perea

Socio desde 1880; vocal de la junta $(1889,1890,1891)$; colaboró en la preparación del baile de Carnaval del Círculo de Bellas Artes (1892); 


\section{Daniel Perea}

Socio desde 1880; colaboró en la preparación del baile de Carnaval del Círculo de Bellas Artes (1892);

Manuel Picolo

Vocal de la junta $(1889,1890)$;

\section{Cecilio Pla}

Socio desde 1880; vocal de la junta $(1889,1890)$; secretario sección exposiciones $(1891)$; colaboró en la preparación del baile de Carnaval del Círculo de Bellas Artes (1892);

Casto Plasencia

Socio desde 1880; vocal de la junta $(1889,1890)$

Marcelina Poncela

colaboró en la preparación del baile de Carnaval del Círculo de Bellas Artes (1892);

Francisco Pradilla

Enrique Repullés

Bernardo Rico

Socio desde 1880; presidente $(1889,1890,1891)$; colaboró en la preparación del baile de Carnaval del Círculo de Bellas Artes (1892);

Señora de Rico

colaboró en la preparación del baile de Carnaval del Círculo de Bellas Artes (1892);

Francisco Rodríguez

Luis Romea

colaboró en la preparación del baile de Carnaval del Círculo de Bellas Artes (1892);

Agustín Rubio

Alejandro Saint-Aubin

Socio desde 1880;

\section{Clara Salazar}

colaboró en la preparación del baile de Carnaval del Círculo de Bellas Artes (1892);

Amós Salvador

Antonio Santias

Jerónimo Suñol

Socio desde 1880; vocal de la junta $(1889,1890,1891)$

Julián Tordesillas

Benito Zozaya

Socio desde 1880; vocal de la junta $(1889,1890)$ 


\section{Listado de reproducciones}

Fig. 1. José Casado del Alisal. El Museo Universal, 25 de noviembre de 1860, p. 381.

Fig. 2. Federico de Madrazo. El Museo Universal, 29 de julio de 1860, p. 245.

Fig. 3. Eduardo Rosales, La Ilustración Española y Americana, 8 de enero de 1871, p. 1.

Fig. 4. José Casado del Alisal, La Ilustración Española y Americana, 8 de febrero de 1882, p. 83.

Fig. 5. Antonio María Esquivel, Autorretrato con sus hijos Carlos y Vicente (1843). Museo Nacional del Romanticismo (Madrid) [CE7167].

Fig. 6. Antonio María Esquivel, Tertulia en el taller. Museo de Bellas Artes de Sevilla ( $\mathrm{n}^{\circ}$ inv. 0557D).

Fig. 7. Eduardo Zamacois, La distracción. Museo de Bellas Artes de Álava (nº inv. 3043).

Fig. 8. Juan Comba, Idealismo y realidad (detalle). Colección particular.

Fig. 9. Ricardo de Madrazo, Retrato de Marianito Fortuny copiando el retrato de su padre. Imagen procedente del Archivo Ruiz Vernacci (VN-07185).

Fig. 10. Antonio González. Joaquín Sorolla, su mujer y sus hijos, fotografía amtigua. Museo Sorolla $\left(\mathrm{N}^{\circ}\right.$ Inv. 80242).

Fig. 11. Joaquín Sorolla, La familia (1901). Ayuntamiento de Valencia.

Fig. 12. Ana Urrutia y Urmeneta. Semanario Pintoresco Español, 25 enero de 1852.

Fig. 13. José Utrera y Cadenas. Autorretrato. Museo de Cádiz ( $n^{\circ}$ inv. 20433)

Fig. 14. Bouguereau y Toudouze rodeados por sus alumnos (detalle). Fotografía.

Fig. 15. Varios autores. Retrato de los alumnos del taller de Paul Delaroche, 1835-1843. Musée du Petit-Palais, París.

Fig. 16. Federico de Madrazo, Retrato de Carlos Luis de Ribera (detalle). Museo Nacional del Prado ( ${ }^{\circ}$ inv. D05390).

Fig. 17. Retrato de los alumnos del taller de Paul Delaroche (detalle).

Fig. 18. Retrato del escultor Carriès, Manuel González Méndez. 1876. Musée d'Orsay.

Fig. 19. Agustín Esteve, Joven pintor. Fundación Lázaro Galdiano ( $\mathrm{n}^{\mathrm{o}}$ inv. 2001)

Fig. 20. Anónimo. Retrato del pintor Leonardo Alenza. Fundación Lázaro Galdiano ( ${ }^{\circ}$ inv. 07681)

Fig. 21. Antonio Caba, El pintor Francisco Torrescassana, Museo de la Real Academia de San Fernando.

Fig. 22. Antonio Caba. El pintor Francisco Torrescassana, Museo Nacional del Prado.

Fig. 23. Antonio Caba, Retrato del pintor Ramón Padró. MNAC ( $\mathrm{n}^{\mathrm{o}}$ inv 010131)

Fig. 24. Antonio Caba, Retrato del pintor Ramón Padró (detalles).

Fig. 25. José Jiménez Aranda, Retrato de José García Ramos. Museo de Bellas Artes de Sevilla ( $\mathrm{n}^{\circ}$ inv. 0515P).

Fig. 26. José Jiménez Aranda, Autorretrato. Museo de Bellas Artes de Sevilla (nº inv.0516P).

Fig. 27. Inocencio García Asarta, Retrato de un joven artista. Museo de Bellas Artes de Álava ( $\mathrm{n}^{\circ}$ inv. 3290)

Fig. 28. José Aparicio y su hermano en Episodio de la fiebre amarilla en Valencia (detalle).

Fig. 29. José Aparicio, Episodio de la fiebre amarilla en Valencia. Academia Nacional de Medicina de París.

Fig. 30. Manuel Cabral y Aguado Bejarano, Autorretrato. Museo del Romanticismo ( ${ }^{\circ}$ inv. 0053).

Fig. 31. Ignacio Pinazo Camarlench, Autorretrato joven con sombrero. Museo Nacional del Prado $\left(\mathrm{n}^{\circ}\right.$ inv. P04582).

Fig. 32. Antonio María Esquivel. Retrato de Domingo Gallego. BNE (IH/3432)

Fig. 33. José Utrera, Retrato de José Vilches. Museo de Cádiz ( $n^{\circ}$ inv. 434)

Fig. 34. Alfredo Perea, Retrato de Joaquín Sorolla, publicado en La Ilustración Española y Americana, 22 de septiembre de 1895.

Fig. 35. José Jiménez Aranda, Retrato de Joaquín Sorolla. Museo Nacional del Prado (nº inv. P04354).

Fig. 36. Santiago Rusiñol, El escultor Clarasó modelando. Colección particular.

Fig. 37. José Villegas, El escultor Ercole Monti. Museo de Bellas Artes de Sevilla (nº inv. 684P)

Fig. 38. Vicente Palmaroli, Retrato de Ventura Miera. Museo Nacional del Prado ( $\mathrm{n}^{\circ}$ inv. P04534).

Fig. 39. Raimundo de Madrazo, El pintor Benito Soriano Murillo. Museo Nacional del Prado ( ${ }^{\circ}$ inv. P07877).

Fig. 40. Federico de Madrazo. El pintor Eduardo Rosales. Museo Nacional del Prado.

Fig. 41. Federico de Madrazo, Retrato en busto de Mariano Fortuny. Museo Nacional del Prado.

Fig. 42. Federico de Madrazo, El pintor Benito Soriano. Museo Nacional del Prado.

Fig. 43. Federico de Madrazo, El pintor Carlos de Haes. Museo Nacional del Prado.

Fig. 44. Santiago Rusiñol, Retrato de Miguel Utrillo. MNAC ( $\mathrm{n}^{\circ}$ inv. 011383). 
Fig. 45. Santiago Rusiñol, Retrato de Miguel Utrillo. MNAC ( $\mathrm{n}^{\mathrm{o}}$ inv. 011384).

Fig. 46. Dionisio Fierros, Autorretrato del pitillo. Colección particular.

Fig. 47. Gustavo Bacarisas, Autorretrato, Museo de Bellas Artes de Sevilla.

Fig. 48. José Ramón Zaragoza, Retrato de D. José Benlliure. Casa-Museo Benlliure, Valencia.

Fig. 49. José Villegas Cordero, Autorretrato. Museo de Bellas Artes de Sevilla

Fig. 50. Miguel Oslé de Medrano, Autorretrato. Exposición de Autorretratos (1907).

Fig. 51. José Benlliure Ortiz, Autorretrato en traje de esgrima. Casa Museo Benlliure, Valencia.

Fig. 52. Ramón Llissas, Autorretrato. Exposición de Autorretratos (1907).

Fig. 53. Antonio María Esquivel, Esquivel en Palacio retrata a Isabel II. Museo de Bellas Artes de Sevilla.

Fig. 54. Federico de Madrazo, Retrato de José de Madrazo. Destruido en 1935. Archivo Moreno ( $\mathrm{n}^{\circ}$ inv. 06401C).

Fig. 55. Bernardo López, Copia del autorretrato de Vicente López, Academia de San Fernando.

Fig. 56. Federico de Madrazo, Retrato de Jenaro Pérez Villaamil. (MNAM, 1943: $\mathrm{n}^{\circ}$ 256).

Fig. 57. Federico de Madrazo, Retrato de Jenaro Pérez Villaamil (ARIAS ANGLÉS 1986: 166).

Fig. 58. Louis Ghémar, Retrato de Jenaro Pérez Villaamil, Biblioteca Real de Bélgica.

Fig. 59. Raimundo de Madrazo, Federico de Madrazo pintando. Museo de Bellas Artes de Bilbao.

Fig. 60. Raimundo de Madrazo, Autorretrato. Meadows Museum, Dallas.

Fig. 61. Joaquín Sorolla, Autorretrato (detalle). Museo Nacional del Prado.

Fig. 62. Joaquín Sorolla, El pintor Aureliano Beruete (detalle). Museo Nacional del Prado.

Fig. 63. Antonio M. Esquivel, Autorretrato con su esposa (detalle). Paradero desconocido.

Fig. 64. José González Bande. El camino de la gloria artística (boceto). Museo Nacional del Prado.

Fig. 65. Joaquín Sorolla, Escena hogareña. Museo Sorolla (nº inv. 191)

Fig. 66. Manuel Montano, Autorretrato. Museo de Cádiz.

Fig. 67. Juan Rodríguez Jiménez, Retrato de Torcuato José Benjumea. Museo de Cádiz.

Fig. 68. Joaquín Manuel Fernández Cruzado, Autorretrato. Museo Nacional del Romanticismo.

Fig. 69. Vicente Castelló, Autorretrato. Museo Lázaro Galdiano.

Fig. 70. Luis de la Cruz y Ríos, Autorretrato. Colección particular.

Fig. 71. Luis de la Cruz y Ríos, Autorretrato. Museo Nacional del Prado.

Fig. 72. Juan Nepomuceno Magán, Autorretrato. Museo de la Academia de San Fernando ( $n^{\circ}$ inv. 331).

Fig. 73. Antonio María Esquivel, Autorretrato (copia). Museo de Bellas Artes de Córdoba.

Fig. 74. Ignacio León y Escosura, La calle Rivoli la mañana del 25 de mayo de 1871. Paradero desconocido (ALZAGA, 2011: 371).

Fig. 75. Federico de Madrazo. Retrato de José Siro. Museo del Prado.

Fig. 76. Federico de Madrazo. Retrato de Calixto Ortega. Museo del Prado.

Fig. 77. Raimundo de Madrazo. Retrato de Francisco Lameyer (MARTÍNEZ RODRÍGUEZ, 2007:113).

Fig. 78. Raimundo de Madrazo. Retrato de Martín Rico. Museo de Bellas Artes de la Habana.

Fig. 79. Raimundo de Madrazo, Retrato de Eduardo Zamacois. Museo Nacional del Prado.

Fig. 80. Henri Pille. Retrato de Eduardo Zamacois. Musée du Petit-Palais, París.

Fig. 81. J.E. Blanche, Retrato de Rafael de Ochoa, Museo de Bellas Artes de Rouen.

Fig. 82. J.E. Blanche, Retrato de Ignacio Zuloaga, Musée du Petit-Palais, París.

Fig. 83. Daniel Urrabieta, Autorretrato. Musée du Petit Palais, París.

Fig. 84. Paul Renouard, Retrato de Urrabieta Vierge, Le Monde Illustré.

Fig. 85. Luis Ricardo Falero, Autorretrato (BÉLINA, 1883).

Fig. 86. Antonio Casanova, Autorretrato (BÉLINA, 1883).

Fig. 87. Antonio Casanova, Retrato de Claudio Lorenzale (BÉLINA, 1883).

Fig. 88. Antonio María Esquivel, Autorretrato. Museo Nacional del Prado.

Fig. 89. Carlos María Esquivel, Autorretrato. Museo Nacional del Prado.

Fig. 90. Joaquín Sorolla. Retrato de Agustín Otermín. Colección Banco Santander.

Fig. 91. José Díaz Molina, Autorretrato. Museo Nacional del Prado.

Fig. 92. Manuel Salvador Carmona, Retrato de Hyacinthe Colin de Vermont, 1761. Museo Magnin, Dijon.

Fig. 93. Alexandre Roslin, Retrato de Hyacinthe Colin de Vermont, 1753. Museo Nacional de Versalles. Fig. 94. Anton von Maron, Retrato de Francisco Preciado de la Vega, 1767. Academia de San Lucas (inv. 451)

Fig. 95. Anónimo. Retrato de Francisco Vergara, 1761. Academia de San Lucas (inv. 463)

Fig. 96. Copia del retrato de Filippo Juvarra, Academia de San Fernando ( $n^{\circ}$ inv. 0566).

Fig. 97. Agostino Masucci (atrib.), Retrato de Filippo Juvarra, Academia de San Lucas (inv. 452). 
Fig. 98. Andrés de la Calleja, Retrato de Don José de Carvajal y Lancaster. Academia de San Fernando (inv. 0722).

Fig. 99. Antonio González Ruiz, Fernando VI como protector de las artes y las ciencias. Academia de San Fernando (inv. 0683).

Fig. 100. Francisco Muntaner, Retrato de Antonio González Ruiz. BNE (IH/4009G).

Fig. 101. Francisco Ribelles, Retrato de Felipe de Castro. BNE (IH/1959/1)

Fig. 102. José Ramos, Retrato de Roberto Michel, 1808. BNE (IH/5893/1).

Fig. 103. Retrato de Roberto Michel, s. XVIII. Museo Academia de San Fernando ( $\mathrm{n}^{\circ}$ inv. 0715).

Fig. 104. Zacarías González Velázquez, Retrato de Ventura Rodríguez (copia del original de Goya). Museo de la Academia de San Fernando ( $n^{\circ}$ inv. 0539).

Fig. 105. Zacarías González Velázquez, Retrato de Antonio González Velázquez. Museo de la Academia de San Fernando ( $n^{\circ}$ inv. 0694).

Fig. 106. Eduardo Fernández Pescador, Medalla retrato de José de Madrazo. Museo Lázaro Galdiano (n inv. 6906).

Fig. 107. Inventario manuscrito de 1867. Ordenación y numeración de las obras conservadas en la Sala de Retratos. ARABASF, leg4-90-1.

Fig. 109. Zacarías González Velázquez, Autorretrato. Museo de la Academia de San Fernando ( $\mathrm{n}^{\circ}$ inv. 0042).

Fig. 110. Carlos Gato de Lema, Retrato de Antonio María Esquivel. Museo de la Academia de San Fernando ( $n^{\circ}$ inv. 0763).

Fig. 111. Alejandro Ferrant, Valentín Carderera. Museo de la Academia de San Fernando ( $\mathrm{n}^{\mathrm{o}}$ inv. 0567).

Fig. 112. Alejandro Ferrant, Retrato de Luis Ferrant. Museo de la Academia de San Fernando ( $\mathrm{n}^{\mathrm{o}}$ inv. 0561).

Fig. 113. Salvador Martínez Cubells, Don Federico de Madrazo. Museo de la Academia de San Fernando ( $\mathrm{n}^{\mathrm{o}}$ inv. 0564).

Fig. 114. Henriette Brown, Retrato de Alejandrina Gressler (Madame Anselma). Museo de la Academia de San Fernando ( $n^{\circ}$ inv. 0220).

Fig. 115. Ubicación en plano de los espacios dignificados, según el plano del edificio de la Academia proyectado por Villanueva (MARTÍN GONZÁLEZ, 1991).

Fig. 116. Agustín Esteve, El escultor José Esteve. Museo de Bellas Artes de Valencia (nº inv. 1003).

Fig. 117. Agustín Esteve, Retrato de Fernando Selma. Museo de Bellas Artes de Valencia (no inv. 1001).

Fig. 118. Miguel Parra, Retrato del Conde de Almodóvar. Academia de San Carlos.

Fig. 119. Miguel Parra, Retrato de Francisco Longa y Anchía. Academia de San Carlos.

Fig. 120. Miguel Parra, El pintor Luis Antonio Planes. Museo de Bellas Artes de Valencia (no inv. 1012).

Fig. 121. Mguel Parra, El arquitecto Vicente Marzo. Museo de Bellas Artes de Valencia (no inv. 1013).

Fig. 122. José Romá, Retrato de Benito Espinós. Museo de Bellas Artes de Valencia (nº inv. 1014).

Fig. 123. José Zapata, El arquitecto Cristóbal Sales. Museo de Bellas Artes de Valencia (nº inv. 1000).

Fig. 124. Vicente Castelló, El escultor José Cloosterman. Museo de Bellas Artes de Valencia (nº inv. 1017).

Fig. 125. Mariano Illa, Retrato del Intendente Juan Felipe de Castaños. Academia Catalana de Bellas Artes de Sant Jordi ( $\mathrm{n}^{\mathrm{o}}$ inv. 228).

Fig. 126. José Rodríguez Pusat, Retrato del Intendente José de Ansa. Academia Catalana de Bellas Artes de Sant Jordi ( $\mathrm{n}^{\circ}$ inv. 233).

Fig. 127. José Rodríguez Pusat, Retrato del Intendente Juan Bautista Erro y Azpiroz. Academia Catalana de Bellas Artes de Sant Jordi ( $\mathrm{n}^{\circ}$ inv. 232).

Fig. 128. Vicente Rodes, Retrato del Intendente Antonio Barata. Academia Catalana de Bellas Artes de Sant Jordi ( ${ }^{\circ}$ inv. 237).

Fig. 129. Juan Giralt, Retrato de Pedro Pascual Moles. Academia Catalana de Bellas Artes de Sant Jordi (no inv. 258).

Fig. 130. Vicente López, Retrato de Pedro Pascual Moles. MNAC ( $\mathrm{n}^{\circ}$ inv. 40088).

Fig. 131. Juan Giralt, Retrato de Pedro Pablo Montaña. Academia Catalana de Bellas Artes de Sant Jordi (no inv. 257).

Fig. 132. Ramón Planella, Retrato de Jaime Folch. Academia Catalana de Bellas Artes de Sant Jordi ( $\mathrm{n}^{\mathrm{o}}$ inv. 260).

Fig. 133. Francisco Rodríguez Pusat, Autorretrato. Academia Catalana de Bellas Artes de Sant Jordi ( $n^{\circ}$ inv. 259). 
Fig. 134. Ferrán Ferrant Llausás, Retrato de Antoni Celles. Academia Catalana de Bellas Artes de Sant Jordi ( $n^{\circ}$ inv. 240).

Fig. 135. Vicente Rodés, Retrato de Damián Campeny. Academia Catalana de Bellas Artes de Sant Jordi ( $\mathrm{n}^{\mathrm{o}}$ inv. 222).

Fig. 136. Antonio Caba, Retrato del marqués de Alfarrás, Academia Catalana de Bellas Artes de Sant Jordi ( $\mathrm{n}^{\circ}$ inv. 200).

Fig. 137. Luis Franco Salinas, Retrato del marqués de Sentmenat. Academia Catalana de Bellas Artes de Sant Jordi (nº inv. 186).

Fig. 138. Jaime Batllé, Retrato de Vicente Rodes. Academia Catalana de Bellas Artes de Sant Jordi $\left(\mathrm{n}^{\circ}\right.$ inv. 261).

Fig. 139. Antonio Caba, Retrato de Claudio Lorenzale. Academia Catalana de Bellas Artes de Sant Jordi $\left(n^{\circ}\right.$ inv. 248).

Fig. 140. Eduardo Cano, Retrato de Pablo de Céspedes. Archivo RuizVernacci (n inv. VN-28294).

Fig. 141. José Roldan, Retrato de Velázquez. Archivo Ruiz Vernacci ( $\mathrm{n}^{\circ}$ inv. VN-28299)

Fig. 142. Francisco Cabral, Retrato de Pacheco. Archivo Ruiz Vernacci ( ${ }^{\circ}$ inv. VN-28296).

Fig. 143. Francisco Cabral, Retrato de Murillo. Archivo Ruiz Vernacci ( $\mathrm{n}^{\circ}$ inv. VN-28297).

Fig. 144. José Escacena, Retrato de Alonso Cano. Archivo Ruiz Vernacci (n ${ }^{\circ}$ inv. VN-28292).

Fig. 145. Francisco Cabral, Retrato de Francisco de Herrera el Viejo. Archivo Ruiz Vernacci ( $n^{\circ}$ inv. VN-28293).

Fig. 146. Manuel Cabral, Retrato de Juan de Valdés Leal. Archivo Ruiz Vernacci ( $\mathrm{n}^{\mathrm{o}}$ inv. VN-28300).

Fig. 147. Francisco Cabral, Retrato de Manuel López-Cepero. Archivo Ruiz Vernacci (nº inv. VN28298).

Fig. 148. Anónimo. Retrato de Francisco de Bruna y Ahumada. Archivo Ruiz Vernacci ( ${ }^{\circ}$ inv. VN28295)

Fig. 149. Joaquín Domínguez, Retrato de Miguel de Carvajal. Archivo Ruiz Vernacci (n1 inv. VN28290)

Fig. 150. Valeriano Domínguez, Retrato de José Domínguez Bécquer. Archivo Ruiz Vernacci (nº inv. VN-28304).

Fig. 151. Joaquín Domínguez, Retrato de Martínez Montañés. Archivo Ruiz Vernacci (nº inv. VN28303).

Fig. 152. Manuel Cabral, Retrato de Antonio Cabral Bejarano. Archivo Ruiz Vernacci (nº inv. VN28301).

Fig. 153. Antonio Cabral Bejarano, Autorretrato. Archivo Moreno (n inv. 08195B).

Fig. 154. Manuel Cabral, Retrato de Manuel Barrón. Archivo Ruiz Vernacci (VN-28302).

Fig. 155. José Jiménez Aranda, Retrato de Eduardo Cano. Archivo Ruiz Vernacci (VN-28291).

Fig. 156. Ricardo López, Retrato de José Jiménez Aranda. Archivo Ruiz Vernacci (VN-28288).

Fig. 157. Retrato de Juan Miguel de Inclán. Archivo Moreno ( $\mathrm{n}^{\circ}$ inv. 04487B).

Fig. 158. Zacarías González Velázquez, Retrato del escultor Francisco Elías. Museo de la Academia de San Fernando ( $\mathrm{n}^{\mathrm{o}}$ inv. 0560).

Fig. 159. Carlos Luis de Ribera, Retrato de Federico de Madrazo. Hispanic Society.

Fig. 160. Federico de Madrazo, El pintor Carlos Luis de Ribera. Museo Nacional del Prado (n inv. P007799).

Fig. 161. Federico de Madrazo, El Gran Capitán recorriendo el campo de la batalla de Ceriñola. Museo Nacional del Prado ( ${ }^{\circ}$ inv. P008706).

Fig. 162. Federico de Madrazo. El Gran Capitán recorriendo el campo de la batalla de Ceriñola. Museo Nacional del Prado (detalle).

Fig. 163. Antonio María Esquivel, Los poetas contemporáneos. Una lectura de Zorrilla en el estudio del pintor. Museo Nacional del Prado ( $\mathrm{n}^{\circ}$ inv. P004299).

Fig. 164. Antonio María Esquivel, Los poetas contemporáneos Una lectura de Zorrilla en el estudio del pintor. Museo Nacional del Prado (detalle).

Fig. 165. Antonio María Esquivel, Autorretrato. Museo Lázaro Galdiano (nº inv. 07983).

Fig. 166. Federico de Madrazo, Retrato de Luis de Madrazo (detalle). Colección Madrazo ( $\mathrm{n}^{\mathrm{o}}$ inv. Madrazo-12).

Fig. 167. William Bouguereau, Retrato del grabador Tourny. Villa Médici.

Fig. 168. William Bouguereau, Autorretrato, 1854. Villa Médici.

Fig. 169. Achille Bénouville, Retrato de Léon Bénouville, Villa Médici.

Fig. 170. Léon Bénouville, Retrato de Achille Bénouville, Villa Médici.

Fig. 171. Luis de la Cruz, Autorretrato. Museo Nacional del Prado.

Fig. 172. Luis de Madrazo, Retrato del pintor Francisco Sáinz. Museo Nacional del Prado. 
Fig. 173. Antonio María Esquivel, Retrato de José Fernández de la Vega, 1833. Archivo Moreno (inv. 02664B).

Fig. 174. Antonio María Esquivel, Retrato de José Fernández de la Vega, 1836. Archivo Moreno (inv. 09374B).

Fig. 175. Carlos María Esquivel, Retrato de José Gutiérrez de la Vega, 1848. Museo Lázaro Galdiano (inv. 09399).

Fig. 176. Cosme Algarra, Retrato de Lázaro Puig, 1844. Iconografía Hispana, 7504-1.

Fig. 177. Rosario Weiss, Retrato de Manuela Oreiro, 1841. Iconografía Hispana, 6668.

Fig. 178. Antonio María Esquivel, Retrato de Rubini, 1841. Archivo Moreno (inv. 0761B).

Fig. 179. Antonio María Esquivel, Retrato de Manuela Oreiro, 1841. Archivo Moreno (inv. 0760B).

Fig. 180. Antonio María Esquivel, Reunión literaria: reparto de premios en el Liceo, 1846. Museo

Nacional del Romanticismo.

Fig. 181. Antonio María Esquivel. Retrato de Jenaro Pérez Villaamil en Reunión literaria (detalle).

Fig. 182. Federico de Madrazo. Retrato de Jenaro Pérez Villaamil, 1845.

Fig. 183. Antonio María Esquivel. Autorretrato borrado en Reunión literaria (detalle).

Fig. 184. Antonio María Esquivel. Autorretrato en Los poetas contemporáneos (detalle).

Fig. 185. Felipe Parra (dibujo), Facundo Larrosa (grabado), Retrato de Vicente Boix, 1850. Estampa. Biblioteca Valenciana (Grab/536).

Fig. 186. Miguel Pineda Montón (Vílchez), Nudos retratándose a sí mismos, Álbum de La Cuerda, tomo II, fol. 59r. Museo-Hemeroteca Casa de los Tiros (Granada).

Fig. 187. J. Vázquez, Autorretrato. Álbum de La Cuerda, tomo I. Museo-Hemeroteca Casa de los Tiros. Fig. 188. Miguel Pineda, Autorretrato. Álbum de La Cuerda, tomo I. Museo-Hemeroteca Casa de los Tiros.

Fig. 189. Galería de retratos del Ateneo de Madrid.

Fig. 190. Francisco Sans, Retrato de Eduardo Rosales. Ateneo de Madrid. Fotografía del Archivo Moreno ( $\mathrm{n}^{\mathrm{o}}$ inv. 208B).

Fig. 191. Joaquín Sorolla, Retrato de Eduardo Rosales. Ateneo de Madrid.

Fig. 192. Salvador Martínez Cubells, Retrato de Arturo Mélida. Ateneo de Madrid. Fotografía del Archivo Moreno ( $\mathrm{n}^{\mathrm{o}}$ inv. 268B).

Fig. 193. Arturo Mélida, decoración del techo del Salón de Actos, Ateneo de Madrid.

Fig. 194. Ricardo de Madrazo, Retrato de Federico de Madrazo. Ateneo de Madrid. Fotografía del Archivo Moreno ( $\mathrm{n}^{\mathrm{o}}$ inv. 205B).

Fig. 195. Ubaldo Fuentes, Retrato de Luis Álvarez Catalá, Ateneo de Madrid. Fotografía del Archivo Moreno ( $\mathrm{n}^{\mathrm{o}}$ inv. 210B).

Fig. 196. Martí Alsina, Retrato de Ildefonso Cerdá. Biblioteca del Ateneo de Barcelona.

Fig. 197. Eugène Disderi, Retrato de Ildefonso Cerdá. Tarjeta de visita.

Fig. 198. Martí Alsina, Retrato de Francisco Martorell. Ateneo de Barcelona.

Fig. 199. Martí Alsina, Retrato de José Anselmo Clavé. Ateneo de Barcelona.

Fig. 200. Francisco Gómez Soler, Retrato del pintor Simón Gómez Polo. Biblioteca del Ateneo Barcelonés.

Fig. 201. Ricardo Martí Argullol, Retrato de Ramón Martí Alsina. Biblioteca del Ateneo Barcelonés.

Fig. 202. Pellicer, Una sesión en la Sociedad de Acuarelistas; grabado publicado en La ilustración española y americana (1878/15/02: 112).

Fig. 203. Alejandro Ferrant, Último homenaje al cadáver del pintor Balaca en el cementerio de Aravaca, publicado en La ilustración española y americana, 29 de febrero de 1880.

Fig. 204. José Blanco Coris, Retrato de Alfredo Perea, tomado del realizado por Megía. El imparcial (1895/26/08: 1).

Fig. 205. Nicolás Megía, Retrato de Ángel Avilés, 1887. Museo de Bellas Artes de Córdoba (inv. 1735P).

Fig. 206. Secretaría del Círculo de Bellas Artes, fotografía de Compagny publicada en Nuevo mundo $(1897 / 25 / 02)$.

Fig. 207. Retratos de Eduardo Pelayo, Cecilio Pla, Enrique Repullés (detalles del friso, no inv. $01 \mathrm{FA}$ 0426) y Daniel Perea (detalle del friso, $n^{\circ}$ inv. 01 FA 0471) Círculo de Bellas Artes de Madrid.

Fig. 208. Retratos de Bernardo Rico, Agustín Rubio, Juan López y Germán Hernández Amores (detalles del friso, $n^{\circ}$ inv. 01 FA 0405). Círculo de Bellas Artes de Madrid.

Fig. 209. Retratos de Plácido Francés, Juan Espina y Capó, Miguel Jadraque (detalle del friso, $\mathrm{n}^{\circ}$ inv. 01 FA 0423) y Alejandro Ferrant (detalle del friso, $n^{\circ}$ inv. 01 FA 0473). Círculo de Bellas Artes de Madrid. Fig. 210. Retrato de Fernanda Francés (detalle del friso). Círculo de Bellas Artes de Madrid (nº inv. 01 FA 0473).

Fig. 211. Retrato de Marcelina Poncela (detalle del friso). Círculo de Bellas Artes de Madrid (nº inv. 01 AF 0467). 
Fig. 212. Vicente Cutanda, Autorretrato (CUTANDA, 2004: 502).

Fig. 213. Vicente Cutanda, El pintor Ricardo Arredondo. Museo Nacional del Prado (nº inv. P04221).

Fig. 214. José Villegas, Autorretrato. Museo Nacional del Prado ( $\mathrm{n}^{\circ}$ inv. P05689).

Fig. 215. Joaquín Sorolla, Retrato de Muñoz Degrain. Museo de Málaga (nº inv. BA/421).

Fig. 216. Sesión inaugural del Centro Artístico, dibujo de Asarta publicado en La ilustración ibérica $(1888 / 10 / 11)$.

Fig. 217. El baile de trajes del Círculo Artístico celebrado en el Teatro Lírico (detalle). La Ilustración Artística $(1889 / 29 / 04)$.

\section{Gráficos:}

Tabla 1. Rango de edad de los copistas españoles en el Louvre (1834-1870)

Tabla 2. Evolución de la presencia de retratos de artista en los salones parisinos (1820-1879)

Tabla 3. Relación de las obras existentes en la Sala de Retratos según los inventarios de la Academia

Tabla 4. Número de retratos (en pintura) de artista y académicos en el Catálogo de 1929 por distribución

Tabla 5. Comparativa del número de retratos de académicos en relación al espacio en el que fueron distribuidos históricamente.

Tabla 6. Relación de directores generales entre 1770 y 1840

Tabla 7. Artistas retratados por autores pertenecientes a promociones posteriores (1812-1830)

Tabla 8. Artistas retratados por compañeros de pensión de la misma promoción (1812-1830).

Tabla 9. Autorretratos en la galería de la Academia de Francia en Roma

Tabla 10. Comparativa del número de retratos realizados en la Academia Española en Roma frente al número total de pensionados por disciplina y categoría (1874-1905).

Tabla 11. Relación comparativa de los artistas expositores, hombres y mujeres, presentes en las exposiciones de la Sociedad de Acuarelistas (1878-1889).

Tabla 12. Relación de retratos incluidos en el friso del Círculo de Bellas Artes. 


\section{BIBLIOGRAFÍA}

ACADEMIA DEL ARTE DE SEVILLA (1807), Estatutos para el gobierno de la Real Escuela del Diseño de Sevilla y para el estudio de las tres Bellas Artes en ella, Sevilla

ACADÉMIE DES BEAUX ARTS (1933), Règlement de l'Académie de France à Rome, Paris: Firmin Didot

— (1854), Règlements pour les concours aux Grand-Prix de l'Académie des Beaux-Arts, Paris: Firmin Didot Frères

ALBA PAGÁN, E. (2007) Pintura y crítica de arte en Valencia (1790-1868), Valencia:

Universidad de Valencia

(2004) La pintura y los pintores valencianos durante la Guerra de la Independencia y el reinado de Fernando VII (1808-1833), tesis doctoral, Universidad de Valencia

- (2003) “Antonio Cavanna y Pastor (Valencia 1815-1840), una promesa frustrada”, en Archivo de Arte Valenciano, ${ }^{\circ}$ LXXXIV, 2003, pp. 89-96.

ALCAHALÍ, B. de (1897), Diccionario biográfico de artistas valencianos, Valencia: Imprenta de Domenech

ALDANA FERNÁNDEZ, S. (2001 [1998]) La Real Academia de Bellas Artes de San Carlos de Valencia: historia de una institución, Valencia: Real Academia de San Carlos

_ (1960) “El pintor académico José Antonio Zapata” en Archivo de Arte Valenciano, 1960, pp. $69-83$

ALEXANDRE, A. (1895) Jean Carriès, imagier et potier: étude d'une oeuvre et d'une vie, Paris: Librairies-Imprimeries Réunies

ALMELA I VIVES, F. (1962) El Liceo Valenciano: sus figuras y sus actividades, Castellón: Sociedad Castellonense de Cultura

ÁLVAREZ LOPERA, J. “1842: Esquivel contra los Nazarenos. La polémica y su trasfondo”, en Anales de historia del arte, $\mathrm{n}^{\circ}$ 6, 1996, pp. 285-316.

ALZAGA RUIZ, A. (2011) “Ignacio León y Escosura: París, Londres y el mercado artístico norteamericano" en ALZAGA RUIZ, A. [coord.], Colecciones, expolio, museos y mercado artístico en España en los siglos XVIII y XIX, Madrid: Ramón Areces

AMPUDIA DE HARO, F. (2004) La civilización del comportamiento: urbanidad y buenas maneras en España desde la Baja Edad Media hasta nuestros días, tesis doctoral inédita, Universidad Complutense de Madrid

ANGLASELL, R. (1860) "Discurso escrito para el acto de la constitución del Ateneo Catalán por D. Ramón Anglasell”, en Acta de la sesión celebrada para la constitución del Ateneo Catalán, Barcelona: Imprenta del Diario de Barcelona

ANTIGÜEDAD DEL CASTILLO-OLIVARES, M.D. (2004) "La mirada interior: autorretratos en la España del siglo XIX", en Trocadero: revista de historia moderna y contemporánea, $\mathrm{n}^{0}$ 16 , pp. $65-80$.

ARAUJO SÁNCHEZ, C. Goya y su época. Las artes al principiar el siglo XIX, Santander: Servicio de publicaciones de la Universidad de Cantabria 
ARESTI, N. (2014), "A la nación por la masculinidad: una mirada de género a la crisis del 98", en NASH, M. [coord.] Feminidades y masculinidades: arquetipos y prácticas de género, Madrid: Alianza, pp. 47-74;

- (2010), Masculinidades en tela de juicio. Hombres y género en el primer tercio del siglo $X X$, Madrid: Cátedra

(2001), Médicos, donjuanes y mujeres modernas: los ideales de feminidad y masculinidad en el primer tercio del siglo XX, Bilbao: Universidad del País Vasco

(2000) "El ángel del hogar y sus demonios: ciencia, religión y género en la España del siglo XIX”, en Historia contemporánea, n 21, pp. 363-394

ARESTI, N. y PETERS, K. [coord.] (2016), ¿La España invertebrada? Masculinidad y nación a comienzos del siglo XX, España: Comares

ARGULLOL, R. (2004) “Autorretrato: refléjate a ti mismo”, en VV.AA. El retrato, Madrid: Galaxia Gutenberg, pp. 43-54.

ARIAS ANGLÉS, E. (1986), El paisajista romántico Jenaro Pérez Villaamil, Madrid: CSIC

ARTEAGA, A. (2014) The male nude: dimensions of masculinity from the 19th century and beyond, México D.F.: Instituto Nacional de Bellas Artes

ASENSIO, J.M. (1886), Francisco Pacheco: sus obras artísticas y literarias. Introducción e historia del Libro de descripción de verdaderos retratos de ilustres y memorables varones que dejó inédito, Sevilla

ATENEO BARCELONÉS (1878), Inauguración de la galería de retratos: acta de la sesión solemne para honrar la memoria de D. Ramón Anglasell celebrada en el Salón de Cátedras el día 16 de junio de 1878, Barcelona: Establecimiento Tipográfico de la Renaixensa

ATENEO DE MADRID (2004), Galería de retratos, Madrid: Ateneo Científico, Literario y Artístico de Madrid

— (1909), Lista de señores socios. Abril de 1909, Madrid: Establecimiento Tipográfico Sucesores de Rivadeneyra

— (1903), Lista de señores socios. Marzo de 1903, Madrid: Establecimiento Tipográfico Viuda e Hijos de Tello

- (1884), Reglamento del Ateneo Científico, Literario y Artístico de Madrid, Madrid: Imprenta Central

(1876) Reglamento del Ateneo Cientifico, Literario y Artístico de Madrid, Madrid: Imprenta de Víctor Sáiz

- (1837), Lista alfabética de los individuos del Ateneo Científico, Literario y Artístico de Madrid existentes en $1^{\circ}$ de marzo de 1837, Madrid: Imprenta del Colegio de Sordomudos

(1836), Lista alfabética de los individuos del Ateneo Cientifico, Literario y Artístico existentes en $1^{\circ}$ de marzo de 1836, Madrid: Imprenta del Colegio de Sordomudos

AUGÉ, J.L. (2007) "Les élèves espagnols de David. Mythe ou réalité et état présent des ouvres dans les collections françaises", Boletín del Museo del Prado, tomo XXV, n 43, pp. 161-165 
AZCUE BREA, L. (1994), La escultura en la Real Academia de Bellas Artes de San Fernando, catálogo y estudio, Madrid: Real Academia de Bellas Artes de San Fernando.

BADINTER, E. (2012), La ressemblance des sexes. De L'Amour en plus au Conflit, París: Le Livre de Poche.

— (1993) XY. La identidad masculina, Madrid: Alianza Editorial.

BANDA Y VARGAS, A. de la (2002), Antonio María Esquivel, Sevilla: Diputación de Sevilla (1983), Estudios sobre el pintor Joaquín Manuel Fernández Cruzado, Cádiz: Museo de Cádiz

BARON, A. (2006) "Masculinity, the embodied male worker, and the Historian's gaze", en International Labor and Working-Class History, $\mathrm{n}^{\circ}$ 69, pp. 143-160

BARRELL, HALLET y MONKS (eds.) (2013) Living with the Royal Academy: artistic ideals and experiences in England 1768-1848, London: Ashgate

BARRÓN, S. (2007) "La colección artística del Círculo de Bellas Artes de Valencia” en Cercle de belles Arts de València, col·lecció artística, catálogo de exposición, Círculo de Bellas Artes de Valencia, mayo-junio 2007

BASSEGODA I NONELL, J. (1999) "Vida y obra del arquitecto Antonio Celles de Azcona (1775-1835)", en Boletín de la Academia de Bellas Artes de San Fernando, nº 88, pp. 19-30

BEAUVOIR, R. de (1844), La Porte du Soleil, Paris: Dumont

BÉDAT, C. (1989), Real Academia de Bellas Artes de San Fernando: 1744-1808, Madrid: Fundación Universitaria Española

----- (1979), El escultor Felipe de Castro, Santiago de Compostela: CSIC

BECKER, J.R. (1999) "Nothing like a rival to spur one on. Marie Bashkirsteff and Louise Breslau at the Académie Julien”, en WEISBERG, G.P. y BECKER, J.R. (1999), Overcoming all obstacles. The women of the Académie Julien, New York: The Dahesh Museum, pp. 69-107

BÉLINA, A.M. (1883), Nos peintres dessinés par eux-mêmes: notes humoristiques et esquisses biographiques, Paris: E. Bernard

BELLAMY-BROWN, S. (2008). Procès verbaux de l'Académie des Beaux-Arts, t. VIII, 18451849, Paris: École des Chartes

BERGERAC, E. (1911), Souvenirs d'un enfant de Paris, Paris, p. 119

BESNUS, A. (1898) “L'atelier Cogniet”, Mes relations d'artiste, Paris: Paul Ollendorff Ed

BHABBA, H.K. (1995) “Are you a mouse or a man?" en BERGER, M., WALLIS, B. y

WATSON, S. [eds.], Constructing masculinity, Nueva York: Routledge, pp. 57-65

BLANCO MOZO, J.L. (1997) "La otra cara de la Ilustración. La formación artística y la cultura del grabador Manuel Salvador Carmona a través del inventario de sus bienes", Anuario del Departamento de Historia y Teoría del Arte, vol. IX-X, 1997-1998, pp. 277-312.

BOEHN, M. (1929) La moda. Historia del traje en Europa desde los orígenes del cristianismo hasta nuestros dias, Barcelona: Salvat 
BOIME, A. (1995) Art and the French Cojmmune. Imagining Paris after War and Revolution, USA: Princeton University Press

(1986) The Academy and French painting in the Nineteenth Century, New Haven: Yale University

BOIX, V. (1877), Noticia de los artistas valencianos, Valencia: Imprenta de Manuel Alufre

BOLAÑOS, M. (1996), Pasajes de la melancolía. Arte y bilis negra a comienzos del siglo XX, Gijón: Trea.

BONET CORREA, A. (2012), Los cafés históricos, Madrid: Cátedra.

BONET SOLVES, V. (1998) José Benlliure: el oficio del pintor, Valencia: Ayuntamiento de Valencia

BONNET, A. (2006), L'enseignement des arts au XIXe siècle: la réforme de l'École des beauxarts de 1863 et la fin du modèle académique, Presses Universitaires de Rennes,

BONNET, A., JAGOT, H. (2013), L'artiste en représentation. Images de l'artiste dans l'art du XIX siècle, catálogo de exposición, Musée de La Roche-sur-Yon, 14 diciembre 2012 a 23 marzo 2013

BORDO, S. (1999), The male body: a new look at men in private and public, USA: Farror, Strauss and Giroux

BOURDIEU, P. (2001), Las estructuras sociales de la economía, Argentina: Manantial (1998), La dominación masculina, Barcelona: Anagrama (1998b), La distinción. Criterio y bases sociales del gusto, Madrid: Taurus

BOUVIER, B. y MASSOUNIE, D. (2003), Procès-verbaux de l'Académie des Beaux-arts, tome sixième (1835-1839), Paris: École des chartes

BRAY, X. (2004) De Ingres a Cezanne: el siglo XIX en la colección del Petit Palais, catálogo de exposición [Museo de Bellas Artes de Bilbao], 28 de junio-1 de septiembre de 2004

BROD, H. (1995) "Masculinity as masquerade" en PERCHUK, A. y POSNER, H. [eds.], The masculine masquerade. Masculinity and representation, Cambridge: The MIT Press, p. 17

(1987a) "The new Men's Studies: from feminist theory to gender scholarship", Hypatia, vol. 2 , n 1 , pp. 179-196

(1987b) “Does manning Men's Studies emasculate Women's Studies?”, Hypatia, vol. 2 , $\mathrm{n}^{\mathrm{o}} 2$, pp. $153-156$

BRU ROMO, M. (1971), La Academia Española de Bellas Artes en Roma (1873-1914), Madrid: Ministerio de Asuntos Exteriores

BRUNEL, G. (1979) Correspondance des directeurs de l'Académie de France à Rome, vol. I, Répertoires, Roma: Edizioni dell'Elefante

CACHO CASAL, M.P. (2011) Francisco Pacheco y su Libro de retratos, Sevilla: Fundación Focus-Abengoa

CALVO SERRALLER, F. (1990), La novela del artista. Imágenes de ficción y realidad social en la formación de la identidad artística contemporánea (1830-1850), Madrid: Mondadori 
CASADO ALCALDE, E. (1987), La Academia Española en Roma y los pintores de la primera promoción, Madrid: Universidad Complutense

CASASSAS I YMBERT, J. (1986), L'Ateneu Barcelonès. Dels seus orígens als nostres diez, Barcelona: Edicions de la Magrana

CATALÁ-GORGUES, M.A. (1990) "La ciudad de Valencia, patrona y mecenas de la Real Academia de San Carlos", Archivo de Arte Valenciano, n 71, pp. 3-17.

Catálogo de exposición Masculin/Masculin: l'homme un dans l'art de 1800 à nos jours, (2013) Paris: Musée d'Orsay, Flammarion

Catálogo de las obras en pintura que existen en el Museo de la Junta de Comercio de Cataluña, (1847) Imprenta de Fernando Roca

Catálogo de las obras de pintura, escultura, arquitectura, grabado y litografía: presentadas en la Exposición General de Bellas Artes, verificada en las galerías del Ministerio de Fomento desde el 20 de mayo de 1856, formado por el jurado de admisión de obras, (1856) Madrid: Imprenta Nacional

Catálogo de la exposición de pinturas de D. Eduardo Rosales dispuesta por la testamentaría del mismo en los salones del Sr. Bosch, Madrid: Imprenta de la Biblioteca de Instrucción y Recreo, 1873

Catálogo de la Exposición General de Bellas Artes de 1858, verificada en el Ministerio de Fomento, (1858), Madrid: Imprenta Nacional

Catálogo de las obras que componen la Exposición Nacional de Bellas Artes de 1860, abierta en el Ministerio de Fomento, Madrid: Imprenta de Rivadeneyra

Catálogo de las obras que componen la Exposición Nacional de Bellas Artes de 1862, abierta en la nueva casa de la moneda (1862), Madrid: Imprenta de Manuel Galiano

Catálogo de la Exposición Nacional de Bellas Artes de 1866 (1867), Madrid: Imprenta del Colegio de sordo-mudos y de ciegos

Catálogo de la Exposición General de Bellas Artes de 1876, (1876) Madrid: Imprenta y Fundición de M. Tello

Catálogo de la exposición nacional de bellas artes de 1884, (1884) Madrid: Imprenta y Fundición de M. Tello

Catalogue des tableaux modernes dépendant de la succession de M. P.-L. Everard, vente 31 mars-1 avril 1881, Durand-Ruel, 1881, p. 35

CALABRESE, O. (2006), L'art de l'autoportrait, Paris: Citadelles et Mazenod.

CAPARRÓS MASEGOSA, M.D. "Las exposiciones de bellas artes celebradas en Granada y la prensa local (1839-1883)", en Cuadernos de arte de la Universidad de Granada, n 23, 1992, pp. $423-450$.

CARRIGAN, T., CONNELL, R. y LEE, J. (1987) “Toward a new Sociology of Masculinity", en Theory and society, vol. 14, $\mathrm{n}^{\mathrm{o}} 5$, pp. 551-60

CATANO, J.V. (1990) "The rhetoric of masculinity: Origins, Institutions, and the Myth of the self-made man", College English, vol. 52, n 4, pp. 421-436 
CAVEDA, J. (1867) Memorias para la Historia de la Real Academia de San Fernando y de las Bellas Artes en España, desde el advenimiento al trono de Felipe $V$ hasta nuestros días, Madrid: Imprenta de Manuel Tello

CEÁN BERMÚDEZ, J.A. (2001), Diccionario histórico de los más ilustres profesores de las bellas artes en España, Tres Cantos: Akal

CERRILlO RUBIO, L. (1993), Maximino Peña. Vida y obra, Soria: Excmo. Ayuntamiento de Soria

CHENNEVIÈRES-POINTEL, C.P. (18XX), Portraits inédits d'artistes français, Paris:

Viguier, Rapilly

(1883), Souvenirs d'un directeur des Beaux-Arts, Paris

CHILLÓN DOMÍNGUEZ, M.C. (2010). El pintor Ramón Martí Alsina (1826-1894):

contrastos de la seva vida a partir d'una documentació inèdita, i proposta d'un primer catàleg, tesis doctoral inédita, Universidad Autónoma de Barcelona.

CHOCARRO BUJANDA, C. "Docencia y coleccionismo en la Real Academia de Bellas Artes de San Fernando", en BSAA, no LXXII-LXXIII, 2006-2007, pp. 251-268.

CID PRIEGO, C. (1985) "Algunas reflexiones sobre el autorretrato", Liño: revista anual de historia del arte, $\mathrm{n}^{\mathrm{0}} 5$, pp. 177-204.

CÍRCULO ARTÍSTICO DE BARCELONA (1907), Exposición de autorretratos de artistas españoles, Barcelona

CÍRCULO DE BELLAS ARTES DE MADRID (1883), Nota de las obras presentadas en la tercera exposición general celebrada en 1883, Madrid: Est. Tip. de Manuel Minuesa

(1881), Apuntes de la segunda exposición del círculo de Bellas Artes con dibujos originales de los autores, Madrid

Colección de los decretos y órdenes generales expedidos por las cortes extraordinarias, que comprende desde 22 de septiembre de 1821 hasta 14 de febrero de 1822, tomo VIII, Cortes Extraordinarias

COLES, T. (2009), "Negociating the field of masculinity: the production and reproduction of multiple dominant masculinities", en Men and Masculinities, $\mathrm{n}^{\circ}$ 12, pp. 30-44

COMAS Y BLANCO, A. (1890), La Exposición Nacional de Bellas Artes de Madrid, Madrid: Establecimiento tipográfico "Sucesores de Rivadeneyra"

CONNELL, R.W. (2005 [1995]) Masculinities, United Kingdom: Polity Press

CONNELL, R. y MESSERSCHMIDT, J.W. (2005) "Hegemonic masculinity. Rethinking the concept", Gender and Society, vol. 19, nº 6, pp. 829-859

CORBIN, A. (1986), "Commercial sexuality in Nineteenth-Century France: a system of images and regulations", en Representations, n' 14, pp. 209-219

CORBIN, A. y PERROT, M. (2002), "Des femmes, des hommes et des genres", en Vingtième siècle, revue d'histoire, $\mathrm{n}^{\circ} 75$, pp. 167-176

CORBIN, A., COURTINE, J.J. y VIGARELLO, G. (2011), Histoire de la virilité, 3 vols., Paris: Éditions du Seuil 
CROW, T. (1995) Emulation: making artists for Revolutionary France, New Haven: Yale University Press

(1994) "A male republic: bonds between men in the art and life of Jacques-Louis David" en PERRY, G. y ROSSINGTON, M. [eds.] Feminity and masculinity in eighteenth century art and culture, London: Ashgate, pp. 204-218

CUTANDA, M. L. (2004), "Vicente Cutanda (1850-1925): un pintor realista y social", Ondare, $\mathrm{n}^{\mathrm{o}} 23,501-512$.

DARAGON, H. (1909), Ingres d'après une correspondance inédite, Paris

DE GIROLAMI CHENEY, L., CRAIG FAXON, A. y RUSSO, K. (2000) Self-portraits by woman painters, London: Ashgate

DEBANS, C. (1889) “L’Académie Julien”, Les plaisirs et les curiosités de Paris, Paris: Kolb

DEL CAMPO PÉREZ DE CAMINO, M.T. (1986), "El pintor Plácido Francés, fundador del Círculo de Bellas Artes de Madrid”, en Villa de Madrid, no 88, pp. 3-10

DELABORDE, H. (1891), L'Académie des Beaux-Arts depuis la fondation de l'Institut de France, Paris: Librairie Plon, Nourrit et Cie

(1865), Lettres et pensées d'Hippolyte Flandrin, accompagnées de notes et précédées d'une notice biographique et d'un catalogue des oeuvres du maître, Paris: Henri Plon Impr.

DERRIDA, J. (1990), Mémoires d'aveugle: l'autoportrait et autres ruines, Paris: Réunion des Musées Nationaux

DÉZALLIER D'ARGENVILLE, A.N. (1781) Description somaire des ouvrages de peinture, sculpture et gravure exposés dans les salles de l'Académie Royale, Paris

DÍAZ PENA, R. (2011), Sorolla y la fotografia, Tesis doctoral inédita: Universidad Rey Juan Carlos.

DIEGO, E. (2010) "Espejos sin alinde”, FONTCUBERTA, J. y GALLEGO, J. [ed.] A través del espejo, Madrid: La Oficina

DÍEZ, J.L. (2009), Joaquín Sorolla: 1863-1923, Madrid: Museo Nacional del Prado (1999), Vicente López (1772-1850), vida y obra, vol. I, Madrid: Fundación de Apoyo a la Historia del Arte Hispánico

—_ (1998a), José de Madrazo (1781-1859), Santander: Fundación Marcelino Botín —_ (1998b), José de Madrazo. Epistolario, Santander: Fundación Marcelino Botín _ (1997), Artistas pintados. Retratos de pintores y escultores del siglo XIX en el Museo del Prado, catálogo de exposición, Madrid: Museo Nacional del Prado

_ (1994a) Federico de Madrazo. Epistolario, vol. 1, Madrid: Museo del Prado, p. 648

(1994b), "Los poetas contemporáneos. Una lectura de Zorrilla en el estudio del pintor", en El mundo literario en la pintura del siglo XIX del Museo del Prado, Madrid: Ministerio de Cultura

DOLIVET, C. (1872) Histoire de la garde nationale et des bataillons mobilisés du IX arrondissement avant et pendant le siège de la capitale, Paris 
DONALDSON, M. (1993) "What is hegemonic masculinity?", en Theory and Society, vol. 22, $\mathrm{n}^{\mathrm{o}} 5$, pp. 643-657

DU GUÉ TRAPIER, E. (1932), Catalogue of paintings (19th and 20th centuries) in the collection of the Hispanic Society of America, Nueva York: The Trustees

DUPARC, A. [ed.] (1872), Correspondence de Henri Regnault annotée et recueillie par Arthur Duparc: suivie du catalogue complet de l'oeuvre de H. Regnault et ornée d'un portrait gravé à l'eau-forte par M. Laguillermie d'après une photographie de M. Berthaud, Paris: Charpentier

MIGUEL EGEA, P. de (2007), "Dos colecciones inéditas de dibujos de Carlos Luis de Ribera" en VV.AA. In Sapientia Libertas: estudios en homenaje al profesor Alfonso E. Pérez Sánchez, Madrid: Museo del Prado, Fundación Focus Abengoa, pp. 677-685

_ (1983) Carlos Luis de Ribera: pintor romántico madrileño, Madrid: Patronato Nacional de Museos

EGEA GARCÍA, M. (2013), Los espacios de creación: la representación de talleres de artista desde el Romanticismo hasta las primeras vanguardias, tesis doctoral inédita, Universidad de Granada

El món de Goya i López en el Museu Sant Pius V de Valencia, catálogo de exposición, Museo de Bellas Artes de Valencia, marzo-mayo 1992

ELIAS, F. (1913), Simò Gómez: historia verídica d'un pintor del Poble Sec, Barcelona: Edicions de la Junta Municipal

ELÍAS MOLÍNS, A. de. (1895) Diccionario biográfico y bibliográfico de escritores y artistas catalanes del siglo XIX, vol. 1, Barcelona: Imprenta de Fidel Giró

ÉNAULT, L. (1878) Les beaux-arts à l'Exposition Universelle de 1878, Paris: E. Gros

ESCOIQUIZ, J. (1828) Tratado de las obligaciones del hombre, Barcelona: Imprenta de los hermanos Torras

ESPINÓS DÍAZ, A. (2009), "La enseñanza del arte del grabado en “, en DE LA CALLE, R. [ed.], La Real Academia de Bellas Artes de San Carlos en la Valencia ilustrada, Valencia: Publicaciones de la Universidad de Valencia, pp. 159-184.

EXPOSICIÓN NACIONAL DE RETRATOS (1902), Catálogo de la exposición nacional de retratos, Madrid: Mateu

EZAMA GIL, A. (2015) "La presencia de las señoras en los Liceos: el caso de Gertrudis Gómez de Avellaneda", en Romance Studies, vol. 33, issue 1, pp. 32-43

FEHRER, C. (1994) "Women at the Académie Julien in Paris", The Burlington Magazine, vol. $136, n^{\circ} 1100$, p. 756

FENTON, J. (2006) School of Genius: a history of the Royal Academy of Arts, London: Royal Academy of Arts

FERNÁNDEZ PARDO, F. (2000) Real Academia Catalana de Bellas Artes de Sant Jordi. Exposición antológica de pintura, Madrid: Real Academia de Bellas Artes de San Fernando FERRÁN SALVADOR, V. (1963) "Iconografía presidencial valenciana”, en Archivo de Arte Valenciano, $\mathrm{n}^{\mathrm{o}} 34$, pp. $45-63$ 
FERRERO MERINO, V.J. (2015), La persistencia de la hegemonía masculina en la cultura occidental ante la necesidad de un nuevo modelo de identidad. El soldado como arquetipo de la masculinidad hegemónica en las prácticas artísticas del siglo XXI, tesis doctoral inédita, Universidad Miguel Hernández de Elche

[http://dspace.umh.es/bitstream/11000/2419/1/TD\%20Ferrero\%20Merino\%2c\%20Valent\%c3\% adn\%20Jos\%c3\%a9.pdf última consulta: 6 de noviembre de 2017]

FONTBONA, F. (1993) "El Museu de la Reial Academia Catalana de les Belles Arts de Sant Jordi (1775), primer museu d'art de Catalunya”, en Butlletí de la Reial Acadèmia Catalana de Belles Arts de Sant Jordi, vol. 7-8, pp. 167-186.

FOnTBONA, F. y DURÁ, V. (1999), Catàleg de la Reial Acadèmia Catalana de Belles Arts de Sant Jordi, I. Pintura, Barcelona: Reial Acadèmia Catalana de Belles Arts de Sant Jordi.

FOSSIER, F. [ed.] (2006), Correspondance des directeurs de l'Académie de France à Rome, $t$. VIII: Directorat de Jean Alaux (1847-1852), http://www.bibliotheque-

Institutdefrance.fr/sites/default/files/04._tome_viii_allaux.pdf [última consulta 30 ene. 18]

FREIXA, M. (2010) "Pensament estètic, gust i consum de les arts", Barcelona Quaderns d'història, $\mathrm{n}^{\circ} 16$, pp. 163-190.

GACTO SÁNCHEZ, M. (2012), “", Mirando a Clío. El arte español espejo de su historia. Actas del XVIII Congreso CEHA, Santiago de Compostela, 20-24 septiembre 2010, pp. 11511158 .

GÁlLEGO, J. (1978) Autorretratos de Goya, Zaragoza: Caja de Ahorros de Zaragoza.

GALLEGO ROCA, M. (1991) La Cuerda Granadina. Una sociedad literaria del postromanticismo, Granada: Comares

GALOFRE, J. (1851) El artista en Italia y demás países de Europa, atendido el estado actual de las bellas artes, Madrid

GARB, T. (1997) "Masculinity, muscularity and modernity in Caillebotte's male figures", en SMITH, T. [ed.] Invisible touch: modernism and masculinity, Chicago: University of Chicago Press, pp. 53-74

GARCÍA ÁLVAREZ, L.B. (2017) "Moda masculina y distinción social. El ejemplo de Asturias desde la Restauración hasta la Segunda República”, en Vínculos de Historia, nº 6, pp. 153-170

GARCÍA CORTÉS, J.M. (2004) Hombres de mármol. Códigos de representación y estrategias de poder de la masculinidad, Barcelona: Egales

(2003) "Masculinidad y representación” en HERNÁNDEZ SÁNCHEZ, D. [coord.] Arte, cuerpo, tecnología, Salamanca: Ediciones Universidad de Salamanca, pp. 223-242

_ [com.] (2002), Héroes caídos, masculinidad y representación, Espai d'Art Contemporani de Castellón

GARCÍA MARTÍ, V. (1948), El Ateneo de Madrid, Madrid: Dossat

GARÍN ORTIZ DE TARANCO (1955) Catálogo-guía del Museo Provincial de Bellas Artes de San Carlos, Valencia: Institución Alfonso el Magnánimo

(1945), La Academia valenciana de Bellas Artes. El movimiento academicista europeo y su proyección en Valencia, Valencia: F. Domenech 
GESTOSO Y PÉREZ, J. (1912) Catálogo de las pinturas y esculturas del museo provincial de Sevilla, Madrid: Imprenta de J. Lacoste

GIL SALINAS, R. (1992) "Un discípulo valenciano de Vicente López en Madrid: Antonio Gómez Cros”, en Saitabi, n 42, 1992, pp. 169-173.

(1991) “Nuevas aportaciones sobre el pintor Asensio Juliá Alvarrachi”, en Archivo de arte valenciano, $\mathrm{n}^{\circ} 72$, pp. $59-61$

— (1986) “Asensio Juliá (1748-1832): Rasgos biográficos”, en Archivo de arte valenciano, $\mathrm{n}^{\mathrm{o}} 67$, pp. $79-82$

GILMORE, D.D. (1994) Hacerse hombre. Concepciones culturales de la masculinidad, Barcelona: Paidós

GIMILIO SANZ, D. (2005) José Vergara 1726-1799. Del tardobarroco al clasicismo dieciochesco, catálogo de exposición, Museo de Bellas Artes de Valencia, 6 abril-29 mayo 2005

(2003) “José Vergara Gimeno y la retratística valenciana en el siglo XVIII", en Ars Longa: cuadernos de arte, $\mathrm{n}^{\circ} 12$, pp. $75-82$

GÓMEZ ZARZUELA, M. (1872, 1874, 1875, 1877) Guía de Sevilla, su provincia, etc., Sevilla: La Andalucía

GONZÁLEZ BURGOS, L. (1876) "Galería de retratos", Memoria leída en el Ateneo Científico, Literario y Artístico de Madrid en la Junta General de 30 de diciembre de 1876 por D. Luis González Burgos, Madrid: Imprenta de la Revista Contemporánea

GONZÁLEZ LÓPEZ, C. y MARTí AYXELÁ, M. (1994), Federico de Madrazo (1815-1894), Madrid: Museo Romántico

— (1989), Pintores españoles en París: 1850-1900, Barcelona: Tusquets

GONZÁLEZ LÓPEZ, C. (2007) El mundo de los Madrazo: colección de la Comunidad de Madrid, catálogo de exposición, Madrid: Consejería de Cultura y Deportes

GONZÁLEZ ZYMLA, H. (2003), Catálogo de pinturas de la Real Academia de la Historia, Madrid: Real Academia de la Historia

GONZÁLEZ ZYMLA, H. y DE FRUTOS SASTRE, L.M. (2002), Archivo de la colección de pintura y escultura de la Real Academia de la Historia. Catálogo e índices, Madrid: Real Academia de la Historia

GRACIA, C. (1986) El Tribunal de las Aguas. Ferrándiz ante la Modernidad, Valencia: Institució Alfons el Magnànim, p. 123

GRÉARD, M.O. (1897) Jean Louis Ernest Meissonier. Ses souvenirs, ses entretiens, Paris: Hachette

GRONKOWSKI, C. (1927), Palais des Beaux-Arts de la ville de Paris: catalogue sommaire des collections municipales, Paris: Creté

GUEREÑA, J.L. (2013) "Disciplinar el cuerpo: los manuales de urbanidad en España (17501950)", en ESTEBAN ORTEGA, J. [ed.] Marcas del cuerpo en educación: imaginarios simbólicos y materiales, Valladolid: Universidad Europea Miguel de Cervantes, pp. 17-38 
(2001) "El espíritu de asociación. Nuevos espacios y formas de sociabilidad en la España decimonónica”, en ROURA, L. y FUENTES ARAGONÉS, J.F. [coord.], Sociabilidady liberalismo en la España del siglo XIX: homenaje al profesor Alberto Gil Novales, Lleida: Milenio, pp. 225-238

(1997) “Los manuales de urbanidad”, en ESCOLANO BENITO, A. [coord.] Historia ilustrada del libro escolar en España: del Antiguo Régimen a la Segunda República, Madrid: Fundación Germán Sánchez Ruipérez, pp. 467-500

(1990) "Les antécédents du Fomento de las Artes: la Velada de artistas, jornaleros y labradores (1847-1858”, Bulletin Hispanique, vol. 92, nº 2, pp. 761-787

GUERRERO LOVILLO, J. (1957), Antonio María Esquivel, Madrid: Instituto Diego Velázquez GUILLÉN, E. (2007). Retratos del genio. El culto a la personalidad artística en el siglo XIX, Madrid: Cátedra

GUTIÉRREZ BURÓN, J. (1987), Exposiciones Nacionales de Pintura en España en el siglo XIX, 2 vols., Madrid: Universidad Complutense de Madrid.

GUTIÉRREZ MÁRQUEZ, A. y MARTÓNEZ PLAZA, P. J. (2017), Epistolario del Archivo Madrazo en el Museo del Prado (1). Cartas de Mariano Fortuny, Cecilia, Ricardo, Raimundo e Isabel de Madrazo, Madrid: Museo Nacional del Prado.

HADAS, M. (2016) "The tricky true object: Bourdieu's masculine domination and historicity" en Masculinidades y cambio social, vol. 5, nº 6, pp. 210-240.

HALBERSTAM, J. (2008) Masculinidad femenina, Madrid: Egales

HARVEY, K. y SHEPARD, A. (2005) "What have historians done with masculinity?

Reflections on five centuries of British History, circa 1500-1950", en Journal of British Studies, $n^{\circ} 44$, pp. $274-280$

HAUPTMAN, W. (1985), "Delaroche's and Gleyre's teaching ateliers and their group portraits", Studies on the History of Art, $\mathrm{n}^{\circ}$ 18, pp. 79-119

HERNÁNDEZ DÍAZ, J. (1967) Museo provincial de Bellas Artes. Sevilla, Madrid,

HERNÁNDEZ LATAS, J. (1994), “Correspondencia entre los Madrazo y Bernardino Montañés”, Goya, n² 239, pp. 270-281.

HOFFMANN, K. (1996), Concepts of identity: historical and contemporary images and portraits of self and family, New York: Harper Collins

HOWARD, S. "Jacob Merz's portraits of the Vienna Academy Faculty", en Master Drawings, vol. $22, \mathrm{n}^{\circ} 1,1884$, pp. $47-55$

IBÁÑEZ PÉREZ, A.C. (1982), Historia de la Academia de dibujo de Burgos, Burgos, pp. 131138

INCISA DELLA ROCCHETTA, G. (1979) La collezione dei ritratti dell'Accademia di San Lucas, Roma: Accademia Nationale di San Lucas

JENSEN, H. B. (2011) "Picturing paternity: the artist and father-daughter portraiture in PostRevolutionary France", en BALDUCCI, T., JENSEN, H. B. y WARNER, P.J. [ed.] Interior portraiture and masculine identity in France, 1789-1914, UK: Ashgate 
JONES, A. (1995) "Clothes make the man: the male artist as a performative function", en Oxford Art Journal, vol. 18, n², pp. 18-32

JORDÁN DE URRÍES, J. (2012) "Crear artífizes yluminados en el buen camino de el Arte: los últimos discípulos españoles de Mengs”, Goya, n³40, julio-septiembre 2012, pp. 210-235.

JOUIN, H. (1894) Salle des Portraits. Professeurs de l'École Académique..., Paris: Imprimerie Nationale

- (1893) Salles des Portraits: directores, professeurs, membres du Conseil Supérieur d'Enseignement. Notice sur cette collection et son developpement du $1^{\text {er }}$ janvier au 31 décembre 1892, Paris: Imprimerie Nationale

_ (1891) “Elie Delaunay”, L'artiste, 1891, pp. 241-243

— (1884), “Les portraits d'artistes français à la Villa Médicis”, Nouvelles archives de l'art français,

JUNTA DE ICONOGRAFÍA NACIONAL (1930), Retratos del Museo de la Real Academia de Bellas Artes de San Fernando, Madrid: Aldecoa.

KESTNER, J.A. (1995) Masculinities in Victorian Painting, Aldershot: Scholar Press

KIMMEL, M.S. (2001) "Masculinidades globales: restauración y resistencia”, en SÁNCHEZ-

PALENCIA, C. e HIDALGO, J.C., Masculino plural: construcciones de la masculinidad, Lleida: Edicions de la Universitat de Lleida

(1993) “Invisible masculinity”, Society, no 9, pp. 28-35

(1987) "Men's responses to feminism at the turn of the century", en Gender and Society, vol. $1, \mathrm{n}^{\circ} 3$, pp. $261-283$

KOSOVKSY-SEDGWICK, E. (1993), Between Men: English literature and male homosocial desire, New York: University of Columbia Press

KRIS, E. y KURZ, O. (1995 [1979]), La leyenda del artista, Madrid: Cátedra

LABRA, R.M. (1906) El Ateneo de Madrid (1835-1905). Notas históricas, Madrid: Tipografía de Alfredo Alonso

(1878) El Ateneo de Madrid. Sus orígenes, desenvolvimiento, representación y porvenir, Madrid: Imprenta de Aurelio J. Alaria

LACROIX, O. (1872), Expositions internationales. Londres, 1872. Beaux-arts et beaux-arts appliqués à l'industrie,, s.d.

LAFENESTRE, G. (1888) Notice des portraits d'artistes exposés dans la Salle Denon du Musée du Louvre, Paris: Librairie des Imprimeries Réunies

LAFFON, J. (1981), Catalogue sommaire illustré des peintures, Paris: Musée du Petit Palais

LAGUNA ENRIQUE, M.E. (2013) El Museo Nacional de Bellas Artes de la Habana y la colección de retratos de la pintura española del siglo XIX, Salamanca: Ediciones Universidad de Salamanca

LAPAUZE, H. (1924) Histoire de l'Académie de France en Rome (1802-1910), París: PlonNourrit 
LAUGÉE, T. (2011), "Le génie créateur enfant. Théories et iconographie de la faculté d'invention dans la première moitié du XIXe siècle français", en Révue des Sciences Humaines, $n^{\circ} 303,2011$

LEMAISTRE, A. (1889), L'École des Beaux-Arts dessinée et racontée par un élève, Paris: Firmin Didot

LEÓN, M. y CASCALES, J. (1928). Antología de la Cuerda Granadina, México: Imprenta de Manuel León Sánchez

LETHÈVE, J. (1968), La vie quotidienne des artistes français au XIXe siècle, Paris: Hachette

LICEO ARTÍSTICO Y LITERARIO (1841), Catálogo de los socios del Liceo artístico y literario de Madrid, Madrid: Establecimiento Tipográfico.

(1840 [1838]), Constituciones del Liceo artístico y literario de Madrid con arreglo a las modificaciones hechas por las juntas general y delegada hasta el 25 de noviembre de 1840, Madrid: Establecimiento tipográfico

LICEO SEVILLANO (1875), Discurso leído por el vicepresidente honorario Sr. D. José María Asensio en la sesión inaugural el día 31 de enero de 1875, Sevilla

LICEO VALENCIANO (1838), Liceo valenciano. Colección de producciones artísticas y literarias, Valencia: Imprenta de Cabrerizo.

LLORENS, T. (2006) Sargent/Sorolla, catálogo de exposición, Madrid: Fundación Colección Thyssen-Bornemisza

LORENTE LORENTE, J.P. (1991) "La Academia de Bellas Artes de San Luis y los pintores de Zaragoza en el siglo XIX, Artigrama, nº 8-9, 1991-1992, pp. 405-434.

(1988), "Goya, Pradilla y la Academia Española de Roma”, en Seminario de Arte Aragonés, XLII-XLIII, 1888-1889

LUNA, J.J. (1981) Miguel-Ángel Houasse, 1600-1730, pintor de la corte de Felipe V, Madrid: Ayuntamiento de Madrid

MADRAZO, P. (1843) Catálogo de los cuadros del Real Museo de Pintura y Escultura de S.M., Madrid: Oficina de Aguado

MANET, E. (1996) Lettres du siège de Paris, Parais: Éditions de l'Amateur

MARCHI, M.B. (2011), Cercle artistic de Sant Lluc 1893-2009: historia d'una institució referent per a la cultura barcelonina, tesis doctoral inédita, Universidad de Barcelona, p. 30. [www.tesisenred.net/handle/10803/22653 Última consulta: 3 de marzo de 2017]

MARÍN SILVESTRE, M.I. (2006), Cercle Artistic de Barcelona. Primera aproximació a 125 anys d'història, Barcelona: Reial Cercle Artistic de Barcelona

MARTHOLD, J. (1906), Daniel Vierge: sa vie, son oeuvre, Paris: H. Floury

MARTYKÁNOVÁ, D. (2017) “Los pueblos virtiles y el yugop del caballero español. La virilidad como problema nacional en el regeneracionismo español (1890-1910)", Cuadernos de Historia Contemporánea, no 39, pp. 19-37.

MARTÍN, S. (2007) "Los estudios de la masculinidad. Una nueva mirada al hombre a partir del feminismo", en TORRAS, M. Cuerpo e identidad I, Barcelona: Edicions UAB 
MARTÍN GONZÁLEZ, J.J. (1992), "La distribución del espacio en el edificio de la antigua Academia", Academia: Boletín de la Real Academia de Bellas Artes de San Fernando, nº 75, pp. $165-210$

(1991) "La escultura de la Real Academia de Bellas Artes de San Fernando a través de los inventarios y catálogos”, BSAA: Boletín del Seminario de Arte y Arqueología, no LVII, pp. $517-532$

(1991), La situación social del artista, Madrid: Mondadori

MARTÍNEZ GINESTA, M. "El arquitecto D. Jerónimo de la Gándara, fundador del arte moderno en España", La Época, 10 de mayo de 1877, p. 4

MARTÍNEZ OLIVA, J. (2008) “Apuntes sobre algunas imágenes de la masculinidad en el arte español de los años setenta" en ALIAGA, J.V. (2008), A voz e a palabra: coloquio sobre A batalla dos xéneros, CGAC, pp. 194-202

(2005) El desaliento del guerrero. Representaciones de la masculinidad en el arte de las décadas de los 80 y 90, Murcia: Cendeac

MARTÍNEZ RODRÍGUEZ, F.J. (2007), Francisco Lameyer y Berenguer: pintor, militar y viajero (1824-1877), tesis doctoral inédita, Universidad Complutense de Madrid, http://biblioteca.ucm.es/tesis/bba/ucm-t29744.pdf [últ. cons. 21/08/2017],

MASSOUNIE, D. (2007), Procès-verbaux de l'Académie des Beaux-arts, tome septième (1840-1844), Paris: École des chartes

MAYORDOMO, A. (1983) "Bases para el estudio de la formación moral y de la civilidad a través de los textos escolares en la primera mitad del siglo XIX", Historia de la educación, $\mathrm{n}^{\circ} 2$, pp. 55-66

MAZA ZORRILLA, E. (2002) Sociabilidad en la España contemporánea: historiografía y problemas metodológicos, Valladolid: Instituto de Historia Simancas

(2008) “Élites y asociacionismo en España (1850-1923)”, en ZURITA ALDEGUER, R.

y CAMURRI, R. [coord.], Las élites en Italia y España (1850-1922), Valencia: Universidad de Valencia, pp. 179-194

MESONERO ROMANOS, R. de (1994), Memorias de un setentón, Madrid: Castalia

MESSNER, M.A. (2004) “On patriarchs and losers: rethinking men's interests”, Berkeley Journal of Sociology, $\mathrm{n}^{\circ}$ 48, pp. 74-88

MIALARET, M. "La vie artistique parisienne (1860-1870) : vue par le peintre espagnol Raimundo de Madrazo, d'après des documents inedits", Bulletin de la Société de l'Histoire de l'Art Français, 1975, pp. 303-313.

MILNER, J. (2000), Art, war and revolution in France, 1870-1871: myth, reportage and reality, New Haven: Yale University Press

Mobilier artistique et atelier J.G. Vibert. Vente par suite de divorce et de liquidation de la communauté, Paris: Imprimerie de l'Art (1887)

MOLINA, A. (2016) "Retratos de españoles ilustres con un epítome de sus vidas. Orígenes y gestación de una empresa ilustrada”, en Archivo Español de Arte, vol. 89, n 353 
_ (2013), Mujeres y hombres en la España Ilustrada, Madrid: Cátedra

(2012), "Visualizando el género en la Historia del Arte. El siglo XVIII español como caso de estudio", en Anuario del Departamento de Historia y Teoría del Arte, vol. 24, 79-92.

MONLAU, P.F. (1858) Higiene del matrimonio o el libro de los casados, en el cual se dan las reglas e instrucciones necesarias para conservar la salud de los esposos, asegurar la paz conyugal y educar bien a la familia, Madrid: Imprenta de Rivadeneyra

MOREAU-VAUTHIER, C. (1906), Gérôme, peintre et sculpteur: l'homme et l'artiste, d'après sa correspondance, ses notes, les souvenirs de ses élèves et de ses amis, Paris: Hachette

MOROWITZ, L. y VAUGHAN, W. [eds.] (2000), Artistic Brotherhoods in the nineteenth century, London: Ashgate

MURO OREJÓN, A. (1961) Apuntes para la historia de la Academia de Bellas Artes de Sevilla, Sevilla: Imprenta provincial

MUSÉE D'ORSAY (1989), Portraits d'artistes, catálogo de exposición [Musée d'Orsay, 1-121987 a 1-3-1987), Paris: Éditions de la Réunion des Musées Nationaux

MUSEO DE BELLAS ARTES DE ÁLAVA (2013), Retratos y autorretratos de artistas en el museo de Bellas Artes de Álava, catálogo de exposición, Vitoria: Museo de Bellas Artes de Álava.

MUSEO NACIONAL DE ARTE MODERNO (1943) Exposición de autorretratos de pintores españoles (1800-1943), Madrid

N.M.C. (2004) L'Acadèmia de Santa Bàrbara i la Reial de las Tres Nobles Arts de San Carles. Cent anys de enseyament de l'art (1754-1854), catálogo de exposición, Universidad de Valencia, 22 junio-19 septiembre 2004

NAVARRETE, E. (1999), La Academia de Bellas Artes de San Fernando y la pintura española en la primera mitad del siglo XIX, Madrid: Fundación Universitaria Española

NOCHLIN, L. (1988), Women, Art and Power and Other Essays, Westview Press

Notes et souvenirs du peintre Joseph de Nittis, Paris: Libreries et Imprimeries Réunies (1897)

Nuevo reglamento para la Academia de Bellas Artes de la ciudad de Vitoria, dispuesto por su Junta Directiva y aprobado por el Ilustre Ayuntamiento en su sesión de 21 de febrero de 1855, Vitoria: Imprenta de la Viuda de Manteli e Hijos

NÚÑEZ J. PEÑASCO, E. (1958) "Roberto Domingo, maestro de la luz y el movimiento", Revista geográfica española, Madrid, pp. 10-11

NÚÑEZ VERNIS, B. (2000) Zacarías González Velázquez (1763-1834). Vida y obra, Madrid: Fundación de Apoyo a la Historia del Arte Hispánico

_ (1998) “En torno a la obra pictórica de Zacarías González Velázquez”, en Goya, n 262, 1998, pp. 37-51

OLMOS, V. (2015) Ágora de la Libertad: Historia del Ateneo de Madrid, Madrid: La esfera de los libros 
PALOMINO, A. (1724) El Parnaso español pintoresco laureado. Tomo tercero con las vidas de los pintores y estatuarios eminentes españoles, que con sus heroicas obras han ilustrado la nación, y de aquellos extranjeros ilustres que han concurrido en estas provincias..., Madrid.

PARDO CANALÍS, E. (1991) "Los benefactores de la Academia”, en PITA ANDRADE, J.M. [coord.], El libro de la Academia, Madrid: Real Academia de Bellas Artes de San Fernando, pp. 273-296

(1975) “La Exposición de la Academia de San Fernando de 1841", Revista de ideas estéticas, $\mathrm{n}^{\circ} 129,1975$, pp. 71-92

_ (1974) "Papeles y retratos de Rosales", Anales del Instituto de estudios madrileños, $\mathrm{n}^{\circ}$ 10, 1974, pp. 347-362

(1971) "En el estudio de Esquivel. Una imaginaria reunión que ha pasado a la historia", en Anales del Instituto de Estudios Madrileños, tomo VII, pp. 357-381

PAREDES GIRALDO, M.C., “Antonio González Ruiz (1711-1788). Introducción al conocimiento de sus dibujos", Príncipe de Viana, n 196, 1992, pp. 299-336

PASCUAL GARNEIRA, S. (1995) "Miguel Parra: los retratos valencianos", Archivo de Arte Valenciano, $\mathrm{n}^{\circ} 76$, pp. 77-85.

PEMAN Y PEMARTín, C. (1964), Catálogo del Museo Provincial de Bellas Artes de Cádiz, Madrid

PEREZ CALERO, G. (2013) "Semblanza del pintor sevillano Miguel Ángel del Pino y Sardá (1890-1973)", Laboratorio de Arte, n 25, 2013

(2006), “Un álbum juvenil de dibujos del pintor José Jiménez Aranda", Laboratorio de arte, $\mathrm{n}^{\mathrm{o}} 19$, pp. $349-368$

(1998), "La Academia Libre de Bellas Artes de Sevilla (1872-1888)", Laboratorio de arte, $\mathrm{n}^{\mathrm{o}} 11$, pp. $275-300$

(1994) "El autorretrato como expresión de la personalidad del artista", en BARGALLÓ CARRATÉ, J. [coord.] Identidad y alteridad: aproximación al tema del doble, Sevilla: Alfar, pp. 289-293

(1982) José Jiménez Aranda (1837-1903), Sevilla: Publicaciones de la Excma. Diputación Provincial de Sevilla

(1979) El pintor Eduardo Cano de la Peña (1823-1897), Sevilla: Publicaciones de la Universidad de Sevilla

PÉREZ GARZÓN, J.S. (1978) Milicia Nacional y revolución burguesa, Madrid: CSIC

PÉREZ ROJAS, F.J. (2000) "La imagen mundana y aristocrática del artista" en El retrato elegante, cat. de exposición (diciembre de 2000 a enero de 2001), Madrid: Museo Municipal de Madrid

PÉREZ SÁNCHEZ, A. (2005), El Liceo artístico y literario de Madrid (1837-1851), Madrid: Fundación Universitaria Española

PÉREZ SÁNCHEZ, A. (1990) "La personalidad artística de Vicente Castelló y Amat”, en Ars Longa, 1990, pp. 9-25. 
(1977) Museo del Prado. Catálogo de Dibujos III. Dibujos españoles S. XVIII, Madrid: Museo Nacional del Prado

PETIT (1872) Catalogue des tableaux, études et aquarelles de feu Zamacoïs, tableaux et aquarelles par divers artistes, costumes, armes, meubles et curiosités qui composaient son atelier, dont la vente aura lieu Hotel Drouot lundi 15 et mercredi 17 Avril 1872, Paris

PEVSNER, N. (1982) Academias de arte: pasado y presente, Madrid: Cátedra

POINTON, M. (1986) "Interior portraits: women, physiology and the male artist", en Feminist review, $\mathrm{n}^{\mathrm{0}} 22$, pp. 5-22

PORTÚS PÉREZ, J. [ed.] (2004), El retrato español. Del Greco a Picasso, catálogo de exposición, Museo Nacional del Prado (20 de octubre de 2004 a 6 de febrero de 2005).

PRAZ, M. (1971), Conversation pieces: a survey of the informal group portrait in Europe and America, Italia: Pennsylvania State University Press

PUY MORENO, M.V. (1983) “Ángel María Cortellini”, en Archivo Español de Arte, vol. 56, nº 222, pp. $123-142$

QUINTERO ATAURI (1919), Cádiz pintoresco. Colección de retratos del museo de Bellas Artes de Cádiz, Cádiz: M. Álvarez

(1910) "Noticias referentes a un cuadro patriótico y a un pintor hispano-americano", Revista de la Real Academia Hispano-Americana de Ciencias y Artes, ${ }^{\circ}{ }^{1}$, febrero de 1910,

RAMOS SANTANA, A. [ed.] La identidad masculina en los siglos XVIII y XIX. VIII Encuentro "De la Ilustración al Romanticismo (1750-1850)", Cádiz: Servicio de Publicaciones de la Universidad de Cádiz

REAL ACADEMIA DE BELLAS ARTES DE SAN CARLOS (1805) Continuación de las Actas de la Real Academia de las Nobles Artes establecida en Valencia con el titulo de San Carlos y relación de los premios que distribuyó en su Junta Pública de 4 de noviembre de 1804, Valencia: Imprenta de Benito Monfort

- (1828), Estatutos de la Real Academia de San Carlos, Valencia: Imprenta de Benito Monfort

(1867), Catálogo de los cuadros que existen en el Museo de Pinturas de esta capital, Valencia: Imprenta de Domenech

REAL ACADEMIA DE BELLAS ARTES DE SAN FERNANDO (1929) Catálogo del Museo de la Real Academia de Bellas Artes de San Fernando, Madrid: Real Academia de Bellas Artes de San Fernando

(1893), Discursos leídos ante la Real Academia de Bellas Artes en la recepción pública del Exmo. e Ilmo. Sr. D. Ángel Avilés el día 5 de febrero de 1893, Madrid: Establecimiento tipográfico "Sucesores de Rivadeneyra"

(1884), Catálogo de las obras pictóricas que constituyen la Galería de la Real Academia de Bellas Artes de San Fernando,

http://www.realacademiabellasartessanfernando.com/assets/docs/catalogos_historicos/1884_tra nscripcion.pdf [última consulta 30 ene. 18] 
(1845), Real decreto, órdenes y reglamento para la organización y régimen de la Escuela de Nobles Artes de la Academia de San Fernando, Madrid

- (1840), Nota o razón general de los cuadros, estatuas, bustos y demás efectos que se hallan colocados en las dos galerías de la Academia de Nobles Artes de San Fernando para la exposición pública de San Fernando,

http://www.realacademiabellasartessanfernando.com/assets/docs/catalogos historicos/1840 tra nscripcion.pdf [última consulta 30 ene. 18]

(1829), Catálogo de las pinturas y estatuas que se conservan en la Real Academia de San Fernando, Madrid: Ibarra.

http://www.realacademiabellasartessanfernando.com/assets/docs/catalogos_historicos/1829 tra nscripcion.pdf [última consulta 30 ene. 18]

- (1824), Catálogo de las pinturas y esculturas que se conservan en la Real Academia de San Fernando, Madrid: Ibarra

http://www.realacademiabellasartessanfernando.com/assets/docs/catalogos_historicos/1824 tra nscripcion_1.pdf [última consulta 30 ene. 18]

- (1821), Catálogo de los cuadros, estatuas y bustos que existen en la Academia Nacional de San Fernando en este año de 1821, Madrid: Ibarra.

http://www.realacademiabellasartessanfernando.com/assets/docs/catalogos_historicos/1821 tra nscripci\%C3\%B3n.pdf [última consulta 30 ene. 18

- (1819), Catálogo de los cuadros, estatuas y bustos que existen en la Real Academia de San Fernando en este año de 1819, Madrid: Imprenta Real

http:/www.realacademiabellasartessanfernando.com/assets/docs/catalogos_historicos/1819 tra nscripcion.pdf [última consulta 30 ene. 18]

- (1817), Catálogo de los cuadros, estatuas y bustos que existen en la Real Academia de San Fernando en este año de 1817, Madrid: Fuentenebro

http://www.realacademiabellasartessanfernando.com/assets/docs/catalogos_historicos/1817 tra nscripcion.pdf [última consulta 30 ene. 18]

(1817), Inventario de los cuadros que existen en las salas de la Real Academia de San Fernando en el año de 1817,

http://www.realacademiabellasartessanfernando.com/assets/docs/catalogos_historicos/1817 tra nscripcion_1.pdf [última consulta 30 ene. 18]

- (1804), Inventario de las obras de las tres nobles artes y de los muebles que posee la Real Academia de San Fernando,

http://www.realacademiabellasartessanfernando.com/assets/docs/catalogos_historicos/1804_tra nscripcion.pdf [última consulta 30 ene. 18]

_-(1796-1805), Noticia de las pinturas que pose la Real Academia de San Fernando según el orden de su numeración

http://www.realacademiabellasartessanfernando.com/assets/docs/catalogos_historicos/17961805 transcripcion.pdf?PHPSESSID=391d315f079764901edaf05cee7840dd [última consulta 30 ene. 18$]$

(1757), Estatutos de la Real Academia de San Fernando, Madrid: Gabriel Ramírez Impresor 
REAL ACADEMIA DE BELLAS ARTES DE SAN LUIS (1801), Actas de la Real Academia de las Nobles Artes, establecida en Zaragoza con el título de San Luis, y relación de los premios que distribuyó el 25 de agosto de 1801, Zaragoza: Oficina de Medardo y Heras

REAL ACADEMIA DE BELLAS ARTES DE SANTA ISABEL (1853), Junta general pública que para adjudicar premios a los alumnos que más se habian distinguido en el curso de 1852 a 1853 celebró el día 12 de junio de 1853 la Academia de Bellas Artes de primera clase de esta ciudad, Sevilla: Francisco Álvarez y $\mathrm{C}^{\text {ía }}$

(1858), Junta General pública que para adjudicar premios a los alumnos que más se habían distinguido en el último curso celebró el día 3 de octubre de 1858 la Academia de Bellas Artes de primera clase de esta ciudad, Sevilla: Francisco Álvarez y Cía

REAL SOCIEDAD ECONÓMICA DE AMIGOS DEL PAÍS DE MURCIA (1832), Reglamento que debe observarse en la Academia de Bellas Artes establecida en esta capital del Reino de Murcia, bajo la protección de la Real Sociedad de Amigos del País, acordado en junta celebrada en 8 de noviembre de 1832, Murcia: Imprenta de Mariano Bellido

REAL SOCIEDAD ECONÓMICA DE AMIGOS DEL PAÍS DE MURCIA (1844), Reglamento que deberá observarse en las enseñanzas de la Academia de Nobles Artes costeadas por la Sociedad Económica de Amigos del País de esta ciudad de Murcia, Murcia: Imprenta de Pablo Nogués

\section{REAL SOCIEDAD ECONÓMICA DE AMIGOS DEL PAÍS DE LA CIUDAD DE}

SANTIAGO (1837), Reglamento para la escuela de dibujo establecida por la Sociedad Económica de Amigos del País de la Ciudad de Santiago, Santiago de Compostela: Imprenta de la viuda e hijos de Compañel

Reglamento para la escuela de dibujo establecida por la Sociedad Económica de Amigos del País de la ciudad de Santiago, 1838, Santiago: Imprenta de la viuda e hijos de Compañel

Reglamento para la Academia de Dibujo de la ciudad de Vitoria, dispuesto por la Junta Directiva de ella y aprobado por su Ilustre Ayuntamiento en el celebrado en día 26 de febrero de 1830, Vitoria: Imprenta de la Viuda e Hijos de Agapito Manteli

REICH, A. (2010) "Can Bourdieu help us understand masculinity, and can masculinity help us understand Bourdieu?", recogido en PASCOE, C.J. y BRIDGES, T. (2016), Exploring masculinities. Identity, inequality, continuity and change, N.Y. y Oxford: Oxford University Press, pp. 291-300

REMENTERÍA Y FICA, M. (1837) El hombre fino al gusto del día, manual completo de urbanidad, cortesía y buen tono, Madrid: Imprenta del colegio de sordomudos

REYERO, C. (2015) "Amor fraterno y familia real: Luisa Fernanda de Borbón y la visualización de un oxímoron”, en LAHOZ, L. y PÉREZ, M. [coord.], Lienzos del recuerdo. Estudios en homenaje a José Martínez Frías, Salamanca: Ediciones Universidad de Salamanca, pp. 537-544

(2014) "Ideología e imagen del artista español del siglo XIX entre París y Roma", en SAZATORNIL, L. y JIMÉNO, F. [eds.] El arte español entre Roma y París, siglos XVIII y XIX. Intercambios artísticos y circulación de modelos, Madrid: Casa de Velázquez, pp. 129-144 
(2010) "La revolución de las apariencias. Contrastes visuales circa 1800", en RAMOS SANTANA, A. y ROMERO FERRER, A. [coord.] Liberty, liberté, libertad: el mundo hispánico en la era de las revoluciones, Cádiz: Universidad de Cádiz, pp. 495-520

(2008), “Arte y compromiso: los artistas y las imágenes en la lucha política a comienzos del siglo XIX”, en RAMOS SANTANA, A. y ROMERO FERRER, A. [eds.], Cambio político y cultura en la España de entresiglos, Cádiz: Universidad de Cádiz

_ (1996) Apariencia e identidad masculina. De la Ilustración al decadentismo, Madrid: Cátedra

(1992) [com.] Roma y el ideal académico. La pintura en la Academia Española de Roma 1873-1903, Madrid: Consejería de Cultura de la Comunidad de Madrid

(1991), "Pintores españoles del siglo XIX en la Escuela de Bellas Artes de París: entre el aprendizaje cosmopolita y el mérito curricular", Academia, nº 72, pp. 377-396

(1990) “Eduardo Zamacois en el Salón de París y la crítica de arte", Boletín de Arte, $\mathrm{n}^{\circ}$ 11, pp. 219-230

RICO, M. (1906), Recuerdos de mi vida, Madrid: Cultura Hispánica

RINCÓN GARCÍA, W. y QUINTO Y DE LOS RÍOS, J.P. de, (1992), La Real Academia de San Luis y la escultura en Zaragoza durante la primera mitad del siglo XIX, Zaragoza: Real Academia de Bellas y Nobles Artes de San Luis

RINCÓN, W. (2016) "Los autorretratos de Francisco Pradilla”, en AGUILERA ARAGÓN, I. et al. De las ánforas al museo: estudios dedicados a Miguel Beltrán Lloris, Zaragoza: Institución Cultural Fernando el Católico

(1991) El autorretrato en la pintura española: de Goya a Picasso, catálogo de exposición, Madrid: Fundación Mapfre

(1987) Francisco Pradilla (1848-1921), Madrid: Antiquaria

RIU DE MARTÍN, C. (2009) "Les exposicions d'art a Barcelona durant el Sexenni (18681870)", Barcelona. Quaderns d'història, $\mathrm{n}^{\mathrm{o}}$ 15, pp. 171-182

(2008) "La contribució de l'Ateneu Barcelonès al desenvolupament de les arts plastiques durant la Restauració", en Ex Novo: revista d'història i humanitats, n 5, pp. 113-128

ROBINS PENNELL, E. (1920) "My two impressions of Vierge", The American Magazine of Art, vol. 11, no 6, p. 199

RODRÍGUEZ, A. (1801) Colección general de los trages que en la actualidad se usan en España principiada en el año 1801 en Madrid, en BOZAL, V. [ed.] (1982), Colección general..., Madrid: Visor

RODRÍGUEZ BAILÓN, J.D. (2006) "La sociedad Literaria y Artística de Granada (18461849”, en Revista del Centro de Estudios Históricos de Granada y su Reino, n 18, 2006, pp. $143-166$.

RODRÍGUEZ MOYA, I. (2013) “La Junta de Iconografía Nacional (1876-1961) y el retrato del poder", en MÍNGUEZ, V. [ed.] Las artes y la arquitectura del poder, Castellón: Publicaciones de la Universitat Jaume I, pp. 271-296 
RODRÍGUEZ RODRÍGUEZ, M.M. (2014) “El pintor Manuel Rodríguez Ibáñez pensionado en la Academia Española de Bellas Artes en Roma", Atrio: Revista de Historia del Arte, $\mathrm{n}^{\circ} 20$, 2014, pp. 84-97.

RODRÍGUEZ RUIZ, D. (2005), El Círculo de Bellas Artes de Madrid. 125 años de historia (1880-2005), Madrid: Círculo de Bellas Artes.

ROIG CONDOMINA, V.M. (1995), "El Ateneo Científico, Literario y Artístico de Valencia y su aportación a las artes en el último tercio del siglo XIX", en Ars Longa, n 6, pp. 107-114

(1994), Las exposiciones de bellas artes en la Valencia del siglo XIX, tesis doctoral inédita, Universidad de Valencia

(1993) "El Liceo valenciano y su aportación a las artes durante el segundo tercio del siglo XIX", en Actas del Primer Congreso de Historia del Arte Valenciano, Valencia, 1993, pp. 457465.

ROS, C. (2015) "Así me pinto: el autorretrato femenino a principios de la Edad Moderna", en PÉREZ OCHANDO, L. y ALBA PAGÁN, E. [ed.] Me veo luego existo: mujeres que representan, mujeres representadas, Madrid: CSIC, pp. 539-552.

RUIZ DE AEL, M.J. (1992), "Las Bellas Artes en la Real Sociedad Bascongada de Amigos del País. Sus escuelas de dibujo", Boletín de la Real Sociedad Bascongada de Amigos del País, ${ }^{\circ}$ 5, pp. 143-169

RUIZ ORTEGA, M. (1999) La Escuela gratuita de diseño de Barcelona. 1775-1808, Barcelona: Biblioteca de Catalunya

RUIZ SALVADOR, A. (1971) El Ateneo Científico, Literario y Artístico de Madrid (18351885), Tamesis: Londres

SACCHETTI, E. (2012) “Andreia y sus contrarios: Masculinidades plurales a través del arte”, en AIBR: revista de antropología iberoamericana, vol. 7, n 3, pp. 361-394

SALON DES ARTISTES FRANÇAIS (1888), Explication des ouvrages de peinture et dessins, sculpture, architecture et gravure des artistes vivants, París: Imp. $\mathrm{V}^{\mathrm{e}}$ Herissant

SAMBADE, I. (2011), "Honor, control y violencia: una mirada sobre la socialización patriarcal de los varones occidentales", en Clepsydra, $\mathrm{n}^{\circ}$ 11, pp. 149-165

SANTOS MORENO, M.D. (1997) Pintura del siglo XIX en Granada. Arte y sociedad, tesis doctoral, Universidad de Granada, 1997

SANZ CASTAÑO, H. (2017) "Masculinidad y prácticas queer en el audiovisual en España", en MARTÍNEZ-COLLADO, A. y PANEA FERNÁNDEZ, L. [coord.], Secuencias de la experiencia, estados de lo visible: aproximaciones al videoarte español, Brumaria, pp. 273-294

(2010), Imagen artística e identidad masculina en España del franquismo tardío a la era del sida, tesis doctoral inédita, Universidad Autónoma de Madrid

SEGOVIA Y ARDIZONE, G. (1871) Sesión de apertura de la exposición de la Sociedad Protectora de Bellas Artes, Sevilla

SEGRÉ, M. (1998) L'École des Beaux-Arts. XIX $-X X^{e}$ siècles, Paris: LHarmattan 
(1949), "The sociology of sociability", en American Journal of Sociology, vol. 55, pp. $254-261$

SIMMEL, G. (1986 [1929]) Estudios sobre las formas de socialización I, Madrid: Alianza

SIMÓN PALMER, M.C. (1974) "Intelectuales y artistas en la Milicia Nacional de Madrid, Anales del Instituto de estudios madrileños, $\mathrm{n}^{\circ}$ 10, 1974, pp. 319-339

SMITH, T.A. (2006), The emerging female citizen: gender and Enlightenment in Spain, University of California Press

SOCIEDAD ESPAÑOLA DE AMIGOS DEL ARTE (1946), Exposición de acuarelas y aguadas españolas, Madrid

SOCIEDAD PROTECTORA DE LAS BELLAS ARTES DE SEVILLA, (s.a.) Reglamento de la sociedad protectora de las bellas artes, Sevilla

(1873) Acta de la sesión extraordinaria para la adjudicación de los premios concedidos por el jurado en el certamen de 1873, Sevilla: Imprenta de Rafael Tarascó y Lassa

SOHN, A.M. (2009), Sois un homme! La construction de la masculinité au XIX $X^{e}$ siècle, Paris: Éditions du Seuil

SOHM, P. (2007) The artist grows old: the aging of art and artists in Italy, 1500-1800, USA: Yale University Press

SOLACHE VILLELA, G. (2007) "José de Madrazo y la práctica del aguafuerte durante su estancia en Roma (1810-1813). Estampas inéditas y su proceso creativo", Boletín del Museo del Prado, vol. 25, no 43, pp. 84-96

SOLOMON-GODEAU, A. (1997), Male Trouble: a crisis in representation, London: Thames and Hudson

76

(1995) "Male Trouble”, en BERGER, M., WALLIS, B. y WATSON, S. (1995), pp. 69

SUSSMAN, H. (1995) Victorian masculinities: manhood and the masculine poetics in early Victorian literature and art, Cambridge: Cambridge University Press

(1992) "Robert Browning's Fra Lippo Lippi and the problematic of a male poetic", en Victorian Studies, vol. 35, $\mathrm{n}^{\mathrm{o}}$ 2, pp. 185-200

TOSH, J. (1999), A man's place. Masculinity and the middle-class home in Victorian England, New Haven and London: Yale University Press

(1994) "What should historians do with masculinity? Reflections on Nineteenth-Century Britain”, en History Workshop Journal, n ${ }^{\circ}$ 38, pp. 179-202

URREA, J. (1998) Real Academia de Bellas Artes de la Purísima Concepción. Pinturas y esculturas, Valladolid: Diputación de Valladolid

VALVERDE MADRID, J. (1997) "El cuadro de Esquivel de los románticos", en Anales del Instituto de Estudios Madrileños, n 37, 1997, pp. 407-432.

(1979) “Tres documentos sobre el pintor Antonio María Esquivel”, Boletín de Bellas Artes, $\mathrm{n}^{\mathrm{o}} 7$, pp. 235-240. 
VARGAS LIÑÁN, M.B. (2015), La música en la guasona Cuerda granadina: una singular tertulia de mediados del XIX, Granada: Universidad de Granada

VELASCO DUEÑAS, J. (1843) Colección de cruces y medallas de distinción de España, Madrid: Imprenta de Yenes

VELASCO MORENO, E. (2000) "Nuevas instituciones de sociabilidad: las academias de finales del siglo XVII y comienzos del XVIII", Cuadernos dieciochistas, ${ }^{\circ}{ }^{\circ}$, pp. 39-55

VELÁZQUEZ Y SÁNCHEZ, J. (1872) Anales de Sevilla de 1800 a 1850, Sevilla: Hijos de Fe VIBERT, J.G. (1902) La Comédie en peinture, Paris: A. Tooth and sons, vol. 2,

VILLACORTA BAÑOS, F. (1980) Burguesía y cultura. Los intelectuales españoles en la sociedad liberal 1808-1931, Madrid: Siglo XXI

VV.AA (2006) Sorolla y la otra imagen en la colección de fotografia antigua del Museo Sorolla, catálogo de exposición, Valencia: Centro del Carmen, octubre-noviembre 2006

- (2004), El retrato, Madrid: Fundación de Amigos del Museo del Prado

WALDMANN, S. (2007), El artista y su retrato en la España del siglo XVII, Madrid: Alianza

WALLER, S. (2010) "Fin de partie: a group of self-portraits by Jean-Léon Gérôme", Nineteenth-Century Art Worldwide, vol. 9, $\mathrm{n}^{\mathrm{o}} 1$ [http://www.19thc-

artworldwide.org/spring10/group-of-self-portraits-by-gerome última consulta: 11 de octubre de 2016]

(2002) "Professional Posseurs: the male model in the École des Beaux Arts and the popular imagination", Oxford Art Journal, vol. 25, n 2, pp. 43-64

WAYNE, J. (1973) "The male artist as a stereotypical female", en Art Journal, vol. 32, n 4, pp. 414-416

WELLS, E.C. (1904) “The passing of Daniel Vierge, master illustrator”, Brush and Pencil, vol. $14, n^{\circ} 3$, p. 209

WEY, F. (1871) Chronique du Siège de Paris, 1870-1871, Paris: Hachette

WILLIAMS, H. (2015), Académie Royale. A History in Portraits, London: Ashgate

WITTKOWER, R. y M. (1982 [1963]), Nacidos bajo el signo de Saturno. El carácter y la conducta de los artistas, Madrid: Cátedra.

YRIARTE, Ch. (1864) “Le Cercle de l'Union Artistique”, Les cercles de Paris (1828-1864), Paris

ZOZAYA MONTES, M. (2016), Identidades en juego. Formas de representación social del poder de la elite en un espacio de sociabilidad masculino, 1836-1936, Madrid: Akal

- (2014), "Mujer y familia en un club privado masculino. La sombra del Casino de Madrid, 1836-1923”, Historia contemporánea, no 49, pp. 499-536

(2010), "Sociabilidad y fraternidad. Influencias masónicas en la creación de círculos asociativos", en FERRER BENIMELI, J.A. [coord.] La masonería española. Represión y exilios, Zaragoza: Gobierno de Aragón, pp. 1373-1385 


\section{PRENSA PERIÓDICA}

Boletín del Ateneo Barcelonés, $\mathrm{n}^{\circ}$ 5, julio-septiembre 1880, pp. 127-128

Courrier de l'art, 11 de mayo de 1882, p. 220

Crónica de la música, 15 de julio de 1880, p. 6.

Diario de Valencia, 29 de julio de 1833, p. 165

Diario oficial de avisos de Madrid, 21 de abril de 1877, p. 3

El Cisne, 9 de abril de 1840, p. 65

El Clamor público, 11 de enero de 1856, p. 3

El Clamor Público, 12 de julio de 1856, p. 3

El Clamor público, 30 de octubre de 1856, p. 3

El Correo, 19 de octubre de 1829, p. 1

El Correo Nacional, 16 de diciembre de 1840, p. 4

El Correo Nacional, 18 de marzo de 1841, p. 4.

El Demócrata, 11 de febrero de 1881, p. 3.

El Día, 7 de diciembre de 1893

El Día, 8 de enero de 1897, p. 2.

El Duende de los cafés, 17 de octubre de 1813, p. 352

El eco del comercio, 17 de diciembre de 1839, p. 4

El Español, 14 de enero de 1846, p. 4

El Español, 3 de noviembre de 1846, p. 2.

El Globo, 7 de junio de 1880, p. 1

El Heraldo, 20 de junio de 1845, p. 4

El Heraldo, 16 de enero de 1844, p. 4.

El Heraldo, 16 de noviembre de 1903, p. 3

El Imparcial, 10 de junio de 1878, p. 3.

El Imparcial, 26 de marzo de 1882, p. 2.

El Imparcial, 31 de mayo de 1889, p. 1.

El Laberinto, 23 de diciembre de 1843

El Liberal, 10 de julio de 1881, p. 3

El Liberal, 22 de septiembre de 1902, p. 3

El Nacional, 9 de junio de 1836, p. 543

El País, 15 de marzo de 1901, p. 3 
El Tiempo, 20 de junio de 1845, p. 4

El Tiempo, 14 de noviembre de 1845, pp. 3-4

El Tiempo, 24 de septiembre de 1846

Gaceta de Madrid, 12 de septiembre de 1815

Gaceta de Madrid, 2 de enero de 1838, p. 2

Gaceta de Madrid, 27 de abril de 1842, p. 4

Gaceta de Madrid, 23 de junio de 1851, p. 1

Gaceta de Madrid, 12 de febrero de 1870, p. 1

Gaceta de Madrid, 30 de marzo de 1870, p. 1

Gaceta de Madrid, 23 de marzo de 1872, p. 868

Gaceta de Madrid, 18 de mayo de 1872, p. 484

Gaceta de Madrid, 25 de mayo de 1872, p. 563

Gaceta de Madrid, 29 de enero de 1873, p. 327

Gaceta de Madrid, 15 de agosto de 1876, p. 445

Gaceta de Madrid, 10 de septiembre de 1878, p. 720

Gaceta de Madrid, 12 de enero de 1882, p. 175

Gaceta de Madrid, 13 de julio de 1885, p. 122

Gedeón diputado a Cortes por Madrid en la Exposición de Bellas Artes, número extraordinario, 15 de junio de 1897 , p. 1

La Alhambra, 10 de enero de 1841, p. 24.

La Correspondencia de España, 9 de octubre de 1864, p. 3

La Correspondencia de España, 5 de noviembre de 1873, p. 3

La Correspondencia de España, 16 de enero de 1874, p. 3

La Correspondencia de España, 25 de febrero de 1878, p. 2

La Correspondencia de España, 11 de junio de 1883, p. 3.

La Dinastía, 6 de noviembre de 1885, p. 3

La Dinastía, 1 de enero de 1888, p. 4.

La Dinastía, 28 de abril de 1887, p. 2

La Dinastía, 18 de septiembre de 1887, p. 3.

La Dinastía, 31 de octubre de 1887, p. 1.

La Dinastía, 16 de febrero de 1888, p. 2

La Dinastía, 17 de marzo de 1888, p. 2 
La Dinastía, 24 de junio de 1895, p. 1.

La Época, 27 de mayo de 1859, p. 3.

La Época, 22 de junio de 1859, p. 4

La Época, 27 de enero de 1880, p. 4.

La Época, 16 de octubre de 1880, p. 3.

La España, 29 de octubre de 1857, p. 4

La Esperanza, 7 de diciembre de 1855, p. 4.

La Esperanza, 6 de junio de 1857, p. 3.

La Iberia, 23 de febrero de 1856, p. 4.

La Iberia, 10 de octubre de 1877, p. 3

La Iberia, 21 de noviembre de 1879, p. 3.

La Iberia, 24 de octubre de 1877, p. 2

La Iberia, 31 de mayo de 1889, p. 2.

La Ilustración Artística, 10 de febrero de 1890, p. 1

La Ilustración artística, 21 de enero de 1895, p. 86.

La ilustració catalana, 30 de abril de 1891, p. 114

La Ilustración Española y Americana, 15 de febrero de 1878, p. 107.

La Ilustración Española y Americana, 15 de junio de 1883, p. 364

La Ilustración española y americana, 22 de septiembre de 1895, pp. 162-163

La Nación, 1 de abril de 1873, p. 1

La Renaixensa, 31 de mayo de 1875, p. 34.

Las Provincias, 10 de marzo de 1874, p. 2

Le Monde Illustré, 1 de abril de 1871, p. 196

Le Monde Illustré, 3 de junio de 1871, p. 340

Le Monde Illustré, 4 de febrero de 1871, p. 73

Le Monde Illustré, 6 de mayo de 1871, p. 294

Le monde illustré, 14 de diciembre de 1889, p. 1

Les Annales politiques et littéraires, 27 de marzo de 1904, p. 199

Liceo valenciano. Periódico mensual de literatura, ciencias y bellas-artes, Valencia: Imprenta de López y Compañía, 1841-1842

Los Lunes del Imparcial, 26 de agosto de 1895, p. 1.

Revista cómica de la exposición de Bellas Artes de 1897, mayo-junio de 1987, p. 4 
Revue Universelle, julio de 1902, p. 39

\section{ANÓNIMO}

"A los electores", El universal observador español, 19 de mayo de 1820, p. 4

“Ana Urrutia de Urmeneta", Semanario Pintoresco Español, 25 de enero de 1852, p. 30

“Andalucía”, El Corresponsal, 14 de marzo de 1841, p. 4.

"Artistas", La Iberia, 3 de diciembre de 1855.

“Artistes espagnols", Le Petit Journal, 11 de junio de 1904, p. 3

“Ateneo", El Globo, 26 de octubre de 1879, p. 3.

"Ayuntamiento constitucional de Madrid. Comisión de Milicia Nacional", Diario Oficial de Avisos de Madrid, 1 de abril de 1855, p. 1

“Ayuntamiento constitucional de Madrid. Comisión de Milicia Nacional”, Diario Oficial de Avisos de Madrid, 15 de mayo de 1855, p. 1

"Ayuntamiento constitucional de Madrid. Comisión de Milicia Nacional", Diario Oficial de Avisos de Madrid, 29 de mayo de 1855, p. 1

"Baile del Círculo Artístico", La Dinastía, 27 de febrero de 1895; "Ecos de Barcelona", La Dinastía, 3 de marzo de 1895, p. 2.

"Barcelona", La Ilustración, 11 de enero de 1885, p. 32.

"Barcelona", La Ilustración, 1 de febrero de 1885, p. 80

"Barcelona", La Ilustración, 21 de junio de 1885, p. 400.

"Barcelona”, La Ilustración, 3 de julio de 1887, p. 431

"Barcelona: baile de trajes en el Teatro Lírico, dado por el Círculo Artístico", la Ilustración, 12 de mayo de 1889, p. 302

“Bartolomé Esteban Murillo”, El Porvenir (Sevilla), 4 de abril de 1882, pp. 1 y 2

"Bellas Artes”, La España, 22 de julio de 1857, p. 4

“Bellas Artes”, La Ilustración española y americana, 8 de septiembre de 1891, p. 131

"Bellas artes. Exposición de pinturas", El álbum granadino, 24 de mayo de 1849, pp. 30-31

“Cartas madrileñas”, La Época, 1 de diciembre de 1855, p. 4

"Catálogo de los señores socios del Liceo, hoy día de la fecha", Boletín del Liceo, 3 de febrero de 1846, s.p.

“Círculo de Bellas Artes”, El Liberal, 15 de junio de 1883, p. 3.

“Círculo de Bellas Artes”, El Día, 14 de enero de 1894, p. 1

"Concours et expositions", La Chronique des arts et de la curiosité, 12 de abril de 1902, p. 120.

“Crónica de arte”, La Ilustración Artística, 21 de mayo de 1894, p. 322 
“Crónica general”, La Ilustración Española y Americana, 22 de septiembre de 1877, p. 186

“Crónica local”, La Convicción, 28/11/1871, p. 7379

“Crónica nacional”, El Anfión matritense, 11 de junio de 1843, p. 181

“D. Federico de Madrazo”, El Museo Universal, 29 de julio de 1860, p. 245

"D. Raimundo de Madrazo y D. Martín Rico, pintores españoles premiados en la Exposición de París”, La Ilustración española y americana, 8 de noviembre de 1878, pp. 261 y 263

"Decreto creando la orden civil de María Victoria", Gaceta de Madrid, 12 de julio de 1871, p. 133

"Dirección general de Instrucción pública. Bellas Artes", Gaceta de Madrid, 14 de febrero de 1881, p. 434

“Dirección general de Instrucción pública", Gaceta de Madrid, 17 de diciembre de 1886, p. 845

"Distrito de Quintas de la Aduana. Lista de los mozos declarados soldados por este distrito en la quinta correspondiente al año de 1844", Diario de Avisos de Madrid, 22 de septiembre de 1845

"Documento parlamentario. Proyecto de ley presentado por el Sr. Ministro de la Guerra sobre organización y reemplazo del ejército", Gaceta de Madrid, 12 de febrero de 1870, p. 1

“Don Antonio María Esquivel”, El Museo Universal, 14 de abril de 1857, pp. 54-55

"Don Francisco Pradilla, laureado autor del cuadro Doña Juana la Loca", en La Ilustración española y americana, 8 de mayo de 1878, p. 298

“Don Isidro Velázquez”, El Artista (1836(, vol. III, pp. 2-5.

“Don Joaquín Domínguez Bécquer”, La Ilustración española y americana, 30 de enero de 1880 , p. 61

"Don José Villegas y Cordero, autor del cuadro Un bautismo en Sevilla, adquirido en 150000 pesetas", La Ilustración española y americana, 15 de agosto de 1880, p. 83.

“Don Manuel Vilar y Roca, escultor español”, El Museo Universal, 2 de marzo de 1862, pp. 6769

“Don Ricardo Balaca y Canseco", La Ilustración española y americana, 29 de febrero de 1880, p. 181

“Don Víctor Manzano”, El Museo Universal, 12 de noviembre de 1865, pp. 362-363

“El arte en sus relaciones con la política y la administración”, Revista de España, enero de 1874, pp. 474-495

"El arte español en París. Exposición de pinturas”, La Época, 19 de marzo de 1903

"El Ateneo científico, literario y artístico de Madrid (II)", La Librería, febrero de 1884, p. 19

“El Ateneo de Madrid y la cuestión social. II", Guía del peluquero y barbero, 1 de agosto de 1878 , p. 2.

"El baile del Círculo de Bellas Artes”, El Liberal, 9 de febrero de 1899, p. 3 
"El Círculo de Bellas Artes de Madrid", La Ilustración Española y Americana, 15 de febrero de 1890, p. 91.

“El Círculo de Bellas Artes. Pasteles y acuarelas”, El Día, 20 de diciembre de 1890, p. 1.

"El entierro de Araujo", El Imparcial, 17 de marzo de 1894, p. 2

"El Liceo", El Liceo Artístico y Literario, I, 1838, p. 58

"El pintor D. Luis Jiménez, premiado con medalla de honor en la Exposición Universal de París”, La Ilustración española y americana, 15 de diciembre de 1889, p. 354

“El pintor José Benlliure”, La Ilustración española y americana, 30 de marzo de 1893, p. 217

"El pintor José Benlliure y su cuadro San Francisco de Asís", La Ilustración española y americana, 30 de marzo de 1893, p. 203

“El pintor Luis Ruipérez”, El Museo Universal, 16 de noviembre de 1867, p. 366

"El pintor Plasencia y la restauración de San Fernando el Grande", La Ilustración Española y Americana, 30 de noviembre de 1876, p. 307

“El salón de la caridad en el Ateneo", La Época, 21 de noviembre de 1879.

"En el Círculo", La Vanguardia, 14 de mayo de 1889, p. 1

“En el Círculo de Bellas Artes”, El País, 20 de diciembre de 1890, p. 1.

“En el Círculo de Bellas Artes", La Época, 25 de octubre de 1892, p. 2

“España en la Exposición Universal de París", La Ilustración española y americana, 30 de septiembre de 1889 , p. 179

“Esposición de bellas artes de 1856. Artículo II", La España, 29 de mayo de 1856, p. 2

“Esposición de bellas artes", La Esperanza, 3 de junio de 1856, p. 4

“Esposición de bellas artes de 1856. Artículo II”, La España, 29 de mayo de 1856, p. 2

"Esposición de cuadros de la Real Academia de San Fernando", El Eco del Comercio, 17 de octubre de 1835 , p. 2

“Esposición de nobles artes. Artículo tercero”, El Clamor Público, 27 de octubre de 1860, p. 4.

“Esposición de pinturas”, El Español, 23 de octubre de 1846, pp. 3-4

"Exposición del Liceo", El Heraldo, 1 de julio de 1846

"Esposicion pública de pintura en la Real Academia de San Fernando", El Artista, vol. I, 1835, p. 155

“Estudios filarmónicos. Rubini”, Seminario Pintoresco Español, 1841, pp. 395-396

"Excmo. Sr. D. Francisco Sans y Cabot", La Ilustración española y americana, 15 de mayo de 1881, p. 299

"Excmo. Sr. D. Manuel Domínguez, presidente de la sección española de Bellas Artes en la Exposición de París", La Ilustración española y americana, 22 de octubre de 1889, p. 226

“Exposición de Bellas Artes", El Museo Universal, 16/12/1860, p. 402 
"Exposición de Bellas Artes organizada por el Centro de Acuarelistas", La Ilustración, 21 de junio de 1885 , p. 395

"Exposición de cuadros en el Ateneo", La Guirnalda, 20 de noviembre de 1879, p. 176

"Exposición del Círculo de Bellas Artes", La Época, 8 de mayo de 1888, p. 2.

“Exposición del Círculo de Bellas Artes”, El Liberal, 26 de diciembre de 1893, p. 2.

“Exposición del Círculo de Bellas Artes. Visita de SS. MM.”, La Iberia, 29 de mayo de 1883, p. 3 ;

"Exposición de la Academia de Nobles Artes de San Fernando", en Revista de Teatros, 1 de octubre de 1843, p. 2

"Exposición de obras de pintura y escultura en el Liceo", El Heraldo, 1 de julio de 1846, p. 3

"Exposición del día 23 de marzo", La Alhambra, 29 de marzo de 1840, p. 506.

“Exposición del Liceo", El Clamor Público, 27 de enero de 1849, p. 3.

"Exposición regional valenciana. Sección bellas artes", Revista de Bellas Artes, 30 de junio de 1867 , p. 319

“Exposition de 1839”, Journal des artistes, 7 de abril de 1839, p. 210

"Esposición de Bellas Artes”, El Mundo Pintoresco, 7 de noviembre de 1858, p. 243

“Exposición Nacional de Bellas Artes de 1897”, La Correspondencia de España, 7 de mayo de 1897, p. 1.

"Exposición pública del Liceo Valenciano", en Diario Mercantil de Valencia, 11 de diciembre de 1842 , p. 3

"Fallecimiento", La Nación, 8 de junio de 1854, p. 3

“Fiesta artística. La Exposición Jiménez Aranda", La Época, 08/06/1903, p. 2

"Fomento artístico literario", La España, 22 de junio de 1859, p. 3

"Instituciones artísticas. La primera exposición del Centro de Acuarelistas de Barcelona", La Ilustración Española y Americana, 22 de junio de 1885, p. 375

“Joaquín Araujo", El Imparcial, 16 de marzo de 1894, p. 2

Joaquín Araujo", El Día, 16 de marzo de 1894, p. 1

“Jochs Florals de Barcelona”, La Dinastía, 13 de enero de 1896, p. 1.

“Jóvenes aprovechados”, El Clamor público, 6 de octubre de 1860, p. 3

"Julio Gros", El Imparcial, 6 de diciembre de 1893, p. 2

"Junta provisional de gobierno de la provincia de Madrid", La gaceta, 19 de octubre de 1840, p. 1

"Historia de la semana", La Ilustración, 4 de noviembre de 1888, p. 720

"La conferencia artística de anoche", La Dinastía, 28 de octubre de 1888, p. 3

“La Estatua de Velázquez”, El País, 3 de mayo de 1899, p. 2 
“La exposición del Círculo de Bellas Artes”, La Iberia, 28 de octubre de 1892, p. 2.

“La exposición del Círculo de Bellas Artes”, La Época, 27 de diciembre de 1892, pp. 2-3

"La leyenda del rey monje, cuadro del Sr. Casado del Alisal", La Ilustración española y americana, 8 de febrero de 1882, pp. 83 y 85

"La Reina en el Círculo de Bellas Artes de Madrid", Diario Oficial de Avisos de Madrid, 11 de enero de 1899 , p. 3.

"Le futur reglèment de la Villa Medicis", La Comoedia, 27 de junio de 1928, p. 1

“Le Salon”, L'Écho des Beaux-Arts, 20 de mayo de 1870, p. 4

"Les on-dit du rempart", Le Rappel, 9 de febrero de 1871, p. 2

“Liceo", El Nuevo Paraíso, 1839, p. 72

“Liceo Artístico y Literario", Siglo XIX, 1 de enero de 1838, p. 80.

"Liceo artístico y literario", El Corresponsal, 19 de diciembre de 1842, p. 4

"Liceo Artístico y Literario", El Cisne, 29 de julio de 1838, p. 108.

"Liceo artístico y literario de Madrid", Diario de Avisos de Madrid, 3 de diciembre de 1841, p. 2

"Liceo Artístico y Literario. Noche del 3 de enero", Seminario Pintoresco Español, 6 de enero de 1839 , p. 7

"Liceo de Granada", La Alhambra, 25 de agosto de 1839, pp. 129-130

"Liceo de Madrid", El Corresponsal, 6 de diciembre de 1841, p. 4.

"Liceo de Sevilla", Revista Andaluza y periódico del Liceo de Sevilla, t. II. 1841, p. 45.

"Liceo de Sevilla", Revista Andaluza y periódico del Liceo de Sevilla, t. II, 1841, p. 312.

"Liceo en Sevilla", Siglo XIX, 1 de enero de 1838, p. 144.

“Liceo. Sesión ordinaria en la noche del sábado 22 del actual”, El Cisne, no 3, 27 de febrero de 1840, p. 21.

"Liceo valenciano", Diario de Valencia, 7 de diciembre de 1838, p. 4

“Liceo valenciano", en Diario Mercantil de Valencia, 8 de abril de 1840, p. 4

"Lista de los cuadros presentados", La Esperanza, 14 de diciembre de 1864, p. 3.

“Lo trajiner catalá", La Ilustració Catalana, 10 de septiembre de 1880, p. 51.

"Los artistas valencianos", Las Provincias, 25 de agosto de 1868, p. 3

"Loterie Nationale", Journal Officiel de la République Française, 25 de noviembre de 1870, p. 2

“M. Vicente Urrabieta", Le Monde Illustré, 3 de enero de 1880, p. 16

"Memoria leída por D. Emilio Borso en la sesión inaugural celebrada la noche del 31 de octubre de 1874", en Boletín-Revista del Ateneo de Valencia, tomo IX, 1874, p. 275. 
"Memoria leída por el Secretario General del Ateneo, Sr. D. Carlos Testor, en la sesión inaugural del curso de 1873 a 1874", en Boletín-revista del Ateneo de Valencia, tomo VII, Valencia: Imprenta de José Rius, 1873, p. 248.

“Milicia urbana de Madrid”, La Revista española, 9 de marzo de 1834, p. 284

"Ministerio de Fomento", Gaceta de Madrid, 15 de septiembre de 1855, p. 1

"Nécrologie", L'Aurore, 7 de septiembre de1898, p. 3.

"Nuevo Ateneo", El Día, 25 de enero de 1884, p. 1

"Nuevo Liceo", El Clamor público, 20 de abril de 1859, p. 3.

"Para las víctimas de las inundaciones", Diario oficial de Avisos de Madrid, 13 de diciembre de 1892 , p. 2

“Pensionados españoles en Roma", El Heraldo, 1 de septiembre de 1852, p. 1

"Por caridad", El Globo, 25 de octubre de 1879, p. 3

"Primera representación dramática ejecutada en la noche del 18 de actual en el Liceo Artístico y Literario", La Alhambra, 23 de mayo de 1841, pp. 248-252.

"Próxima esposición de pinturas", La Época, 3 de mayo de 1856, p. 3

“Quintas”, La Iberia, 16 de febrero de 1870, p. 1

"R. D. de 26 de diciembre de 1893, Reglamento de la Escuela Especial de Pintura, Escultura y Grabado", Gaceta de Madrid, 27 de diciembre de 1893, p. 939

"Real Decreto", El Renacimiento, 6 de junio de 1847, p. 102

"Recreo", La España, 29 de octubre de 1857, p. 4

"Reglamento Provisional de la Escuela Superior de Pintura, Escultura y Grabado, Gaceta de Madrid, 8 de octubre de 1857, p. 1

"Reglamento de la Escuela Especial de Pintura, Escultura y Grabado", Boletín de la Revista General de legislación y jurisprudencia, vol. 36, 1871, p. 606

"Reglamento de la Escuela Especial de Pintura, Escultura y Grabado", Gaceta de Madrid, 27 de diciembre de 1893, p. 939

"Reglamento de la orden civil de María Victoria", Gaceta de Madrid, 22 de julio de 1871, p. 253

“Reglamento para la próxima exposición nacional de Bellas Artes”, El pensamiento español, 5 de julio de 1860 , p. 3

"Reglamento para la Exposición Nacional de Bellas Artes”, El arte en España, 1862, p. 168

“Retrato de D. Ricardo Bellver”, La Ilustración española y americana, 8 de marzo de 1890, p. 147.

"Retrato de Jerónimo Suñol, escultor", La Ilustración española y americana, 22 de junio de 1882 , p. 385 
"Retrato de D. Joaquín Sorolla y Bastida", La Ilustración española y americana, 15 de enero de 1893 , p. 27

"Reuniones y sociedades. El Círculo de Bellas Artes", El Imparcial, 2 de febrero de 1895, p. 3.

"Revista de Academias", Las Bellas Artes, 10 de octubre de 1854, p. 98

"Revista de la semana", Valencia ilustrada, no 3, 20 de mayo de 1877, p. 17-18.

"Revista política", El siglo futuro, 14 de agosto de 1876, p. 2

"Rifa", El Clamor Público, 3 de diciembre de 1856, p. 3

"Rifa", La España, 3 de mayo de 1857, p. 4

“Salon de 1840", Journal des artistes, 8 de marzo de 1840, p. 152

"Salon de 1841", Journal des artistes, p. 181

“Salon de 1845", Journal des artistes, pp. 95 y 188

“Secció de bellas artes”, La Ilustració Catalana, 20 de julio de 1880, p. 16.

"Segunda sesión de competencia en el Liceo Artístico y Literario de Granada”, La Alhambra, 12 de enero de 1840, pp. 351-354.

"Sería un escándalo", El Clamor público, 18 de marzo de 1855, p. 3

“Sesión de competencia del Liceo artístico y literario", La Alhambra, 31 de enero de 1841, p. 49.

"Sesión general de competencia celebrada en el Liceo Artístico y Literario la noche del 13 del actual", La Alhambra, 18 de julio de 1841, pp. 347-348.

"Sesión inaugural del Centro Artístico, presidida por el Sr. Castelar, en el Palacio de la Ciencias", La Ilustración ibérica, 10 de noviembre de 1888

“Sesión necrológica”, La Dinastía, 14 de abril de 1891, p. 2

"Sesión práctica", La España, 20 de julio de 1859, p.4

“Sesión semanal de competencia del Liceo”, La Alhambra, 4 de abril de 1841, p. 168.

“Severidad intempestiva”, El Clamor público, 15 de enero de 1856, p. 3

"Sexta sesión mensual de competencia del Liceo artístico y literario de Granada celebrada en la noche del 13 de este mes", La Alhambra, 21 de junio de 1840, p. 144.

“Situación de los artistas españoles en Roma”, Gaceta de Madrid, 7 de abril de 1842, pp. 1 y 2

"Sociedad de Acuarelistas de Madrid", Anuario literario y artístico, 1890, p. 126.

"Sociedad literaria", La Discusión, 25 de febrero de 1859, p. 4

“Sociedad protectora de las bellas artes”, El Clamor Público, 24 de diciembre de 1856, p. 3.

"Sociedad protectora de las bellas artes", El Museo Universal, 15 de abril de 1857, p. 7.

"Sociedad protectora de Bellas Artes", El Clamor público, 23 de abril de 1857, p. 3

“Sociedad protectora de Bellas Artes”, El Clamor público, 10 de mayo de 1857, p. 3 
"Sociedad protectora de bellas artes", El Museo Universal, 30 de mayo de 1857, p. 79.

“Sociedad protectora de bellas artes", La España, 20 de octubre de 1859, p. 4

"Sociedad protectora de las Bellas Artes", La Iberia, 7 de junio de 1860, p. 3

"Solemne apertura del Liceo Artístico y Literario de Granada, en la noche del 19 de noviembre de 1839”, La Alhambra, 24 de noviembre de 1839, p. 282

"The exhibition of the Palette Club", The New York Times, 15 de marzo de 1874

“Triste realidad", La Discusión, 15 de febrero de 1870, p. 1

"Un retrato de Palmaroli", El Imparcial, 22 de febrero de 1896, p. 2.

"Una ofrenda concedida al mérito", La Alhambra, 11 de abril de 1841, p. 179

"Valencia", Diario Mercantil de Valencia, 19 de noviembre de 1850, p. 2

"Variedades", El Artista, vol. I, p. 132

"Variedades", Revista Andaluza y periódico del Liceo de Sevilla, t. II. 1841, pp. 271-272 y 312

“Virilidad, vejez”, El amigo de la niñez, 1 de mayo de 1841, pp. 76 y 77

A. "Exposición de la Sociedad de Acuarelistas", El Día, 22 de mayo de 1882, p. 6

A.M. de (1887) "El arte religioso", La Ilustración católica, 5 de julio de 1887, p. 227

A.P. "École Espéciale de Dessin”, Le Gaulois, 9 de agosto de 1872, p. 2

AGÜEROS, V. "El artista mexicano Don Félix Parra", La Ilustración española y americana, 30 de junio de 1884, pp. 402 y 405

ALARCÓN, P.A. "Esposición de bellas artes”, La Época, 20 de octubre de 1858, p. 3

ALCÁNTARA, F. “Exposición de los Acuarelistas”, El Imparcial, 13/1/1896, p. 1.

"Exposición del Círculo de Bellas Artes. Sala de Araujo", El Imparcial, 19 de mayo de 1894, p. 2

ALFONSO, J. “Comunicado”, La España, 18 de abril de 1855, p. 4

ALFONSO, L. (1890), "En el Círculo de Bellas Artes. La Exposición de pasteles y acuarelas", La Época, 21 de diciembre de 1890, p. 1.

(1891), "La exposición del Círculo de Bellas Artes. III y último", La Época, 23 de mayo de 1891, p. 1

ALGUIEN (1889), "El baile de trajes del Círculo Artístico", La Dinastía, 6 de marzo de 1889, p. 1

ÁLVAREZ SERBIX, R. “Julio Gros”, Revista contemporánea, diciembre de 1893, pp. 545-546

AMADOR, S. "Exposición de Bellas Artes de la noche del 9 de diciembre de 1840", $L a$

Alhambra, 13 de diciembre de 1840, p. 444.

ANDREO DAMPIERRE, Salvador; "Teatro", en La Alhambra, 4 de agosto de 1839, pp. 95-96.

ARAUJO, C. (1897), "Palmaroli y su tiempo", Revista contemporánea, septiembre de 1897, p. 
ARGULLOL, J. de (1879), "Sesión necrológica del día 22 de junio de 1879”, Boletín del Ateneo Barcelonés, $\mathrm{n}^{\mathrm{o}}$ 1, p. 19

ARNAO, A. "Don Domingo Valdivieso (recuerdos)", La Ilustración española y americana, 8 de diciembre de 1872, pp. 734-735

B., J.M. "Pintura. Esposición pública de la Academia de San Fernando", El Espectador, 18 de octubre de 1846, p. 2

BALBY, L. “Mariez donc...”, L'Intransigeant, 13 de noviembre de 1913, p. 1

BALSA DE LA VEGA, R. "Círculo de Bellas Artes. Primera exposición de pasteles y acuarelas", El Liberal, 20 de diciembre de 1890, p. 2

__ “Crónica artística”, La Ilustración Artística, 23/9/1895, p. 642

—_Crónica de arte”, La Ilustración Ibérica, 26 de junio de 1893, p. 410

—_Crónica de arte”, La Ilustración Artística, 22 de enero de 1894, pp. 50-52

—_Exposición del Círculo de Bellas Artes”, El Liberal, 3 de junio de 1896, p. 3

___Exposición del Círculo de Bellas Artes”, El Liberal, 17 de mayo de 1893, p. 3.

—_ “Hernández Amores”, La Ilustración Artística, 2 de septiembre de 1895, p. 595.

“La exposición del Círculo de Bellas Artes", La Ilustración Española y Americana, 30 de abril de 1900, p. 258

"Siluetas de artistas. Ferrant", El Liberal, 10 de septiembre de 1890, p. 1

BASSEGODA, B. "Circul Artistic de Sant Lluc. Exposició de Bellas Arts", La Renaixença, 10 de diciembre de 1893, p. 9751

BASSEGODA I NONELL, J. (1973) "El rostro de los neoclásicos", La Vanguardia española, 21 de diciembre de 1973, p. 59

BAYARD, E. (1898) “Daniel Vierge”, L'Illustration et les illustrateurs, pp. 299-307

BLANCO ASENJO "Exposición bienal del Círculo de Bellas Artes", La Ilustración Ibérica, 26 de junio de 1893, p. 342.

"Exposición de impresiones de viaje en el Círculo de Bellas Artes de Madrid (diciembre, 1893 - enero, 1894)", La Ilustración Ibérica, 3 de febrero de 1894, p. 75

"La pintura a la acuarela en España”, El Imparcial, 31 de mayo de 1880, p. 3

BECERRO DE BENGOA, R. "Casado", La Ilustración española y americana, 15 de octubre de 1886, p. 215

BERGERAC, E. “Un grand artiste”, Le Journal, 26 de abril de 1898, pp. 1 y 2

C., E. "El Círculo de Bellas Artes”, Nuevo Mundo, 25 de febrero de 1897, p. 7

C.H., "Las bellas artes en España. Esposición general de 1856. Artículo 30”, El clamor público, 29 de junio de 1856 , p. 3

CAJAL, F. (1885) “Bellas Artes”, La Ilustración, 21 de junio de 1885, pp. 385-387

CAÑETE, M. “A mi amigo D. Leopoldo López”, La Alhambra, 1 de agosto de 1841, p. 372. 
"Exposición de pinturas y esculturas en el Liceo Artístico y Literario", El Heraldo, 15 de julio de 1848, pp. 1 y 2

CARDERERA, V. (1836) “Don José de Madrazo", El Artista, vol. III, pp. 306-310

CASTELAR, E. “Cartas literarias”, El Globo, 13 de julio de 1875, p. 1

CASTRO Y SERRANO, J. de. (1870), "El refugio de las letras", La Ilustración Española y Americana, 25 de octubre de 1870, p. 375

CATALINA NAVARRO, E. (1891), "Exposición del Círculo de Bellas Artes”, La Iberia, 22 de mayo de 1891, p. 1.

CHACÓN, R. (1885) “Los artistas españoles en Roma”, La Época, 8 de marzo de 1885, p. 2.

CIERVO, J. (1924) "La agrupación de acuarelistas de Cataluña", La Esfera, 18 de octubre de 1924, p. 33.

CORRO, C. (1842) “Comunicado", en El Corresponsal, 19 de octubre de 1842, p. 3

D., "Esposición pública de nobles artes en la Academia de San Fernando", El Correo Nacional, 5 de noviembre de 1839 , p. 4

DÁNVILA JALDERO, A. (1888) “El arte en Valencia”, Almanaque de las provincias, p. 71.

DOMENECH, J.M. "Esposición nacional de bellas artes del año 1864. VI", La Esperanza, 10 de enero de 1865 , p. 3

E.R. "Sesión semanal del Liceo", La Alhambra, 28 de marzo de 1841, p. 156.

EL CURIOSO PARLANTE (1839) "Costumbres. El espíritu de asociacion", Seminario

Pintoresco Español, n ${ }^{\circ}$ 52, 29 de diciembre de 1839, pp. 411-413

EL DÓMINE LUCAS, "Esposición general de 1856. Artículo VI”, La Época, 18 de junio de 1856, p. 4

ESCOBAR, A. "Crónica del lunes", La Época, 26 de mayo de 1879, p. 3

ESCOSURA, P. de la (1838), “Introducción”, Liceo Artístico y Literario, I, pp. 6-11

ESQUIVEL, A.M. "Exposición de pinturas” en El Eco del Comercio, 25 de octubre de 1841, pp. $1-2$

"Peligros y perjuicios que resultan de las preocupaciones en materia de Pintura", Liceo Artístico y Literario, I, pp. 139-143

ESTASÉN, P. (1881), “El economista D. Juan Güell y Ferrer”, Boletín del Ateneo Barcelonés, $\mathrm{n}^{\circ} 9$, p. 4.

FERRÁN, A. [Sin título], Observatorio Pintoresco, 5 de septiembre de 1837, p.6

FERRER DEL RÍO, A. (1859) “Necrología. Excmo. Sr. D. José de Madrazo”, La América, crónica hispanoamericana, 24 de mayo de 1859, pp. 13-14

FERNÁNDEZ BREMÓN, J. La Ilustración Española y Americana, 30 de mayo de 1877, p. 346.

La Ilustración Española y Americana, 8 de junio de 1878, p. 363. 
“Bernardo Rico”, La Ilustración española y americana, 15 de diciembre de 1894, p. 354

“Crónica general”, La Ilustración española y americana, 22 de agosto de 1895, p. 98

FERNÁNDEZ DE LA VEGA, J. “Al público y a mis amigos”, Liceo Artístico y Literario, I, pp. 3-5

“A S. M. la Reina Gobernadora”, Liceo Artístico y literario, recogido en SIMÓN DÍAZ (1947), Liceo Artístico y Literario (1838), Madrid: Instituto Nicolás Antonio.

FERNÁNDEZ Y GONZÁLEZ, M. (1857). “Folletín. Revista de Madrid”, La Discusión, 12 de abril de 1857 , p. 1

FIDELIO, “Conversación”, Suplemento del Mundo Pintoresco, 8 de mayo de 1859, p. 1

—CConversación”, Suplemento del Mundo Pintoresco, 15 de mayo de 1859, p. 1.

FIGUERAS, E. "Decreto suprimiendo la orden civil de María Victoria”, Gaceta de Madrid, 8 de mayo de 1873 , p. 347

FLAVIO, "Don José Piquer (apuntes biográficos)", La Ilustración española y americana, 15 de septiembre de 1871, p. 453

G., J.M. "Esposición de bellas artes", La España, 19 de octubre de 1860, p. 1

G. de G., J.H., “Exposición del Liceo”, El Tiempo, 27 de junio de 1846, p. 4

G.L., S. (1831) “De l'avenir des arts”, L'artiste, vol. 2, p. 233

GALLEGO, J.N. (1836) “Don Vicente López”, El Artista, vol. II, p. 280

GALOFRE, J. "Nobles Artes. Del protectorado a favor de las mismas", La Nación, 16 de junio de 1853 , p. 3

GANTE, N. "Esposición de bellas artes de 1856. Artículo III”, La Zarzuela, 9 de junio de 1856, p. 148

GARCÍA, J. "Sociedad protectora de bellas artes", Diario oficial de avisos de Madrid, 8 de junio de 1857, p. 2

GARCÍA CADENA, P. (1846) “Liceo valenciano. Exposición pública de 1845”, en El Fénix, 4 de enero de 1846, p. 162.

GARCÍA DE QUEVEDO, J.H., "Esposición de la Academia de Bellas Artes”, El Clamor público, 6 de octubre de 1848, pp. 3-4

GAUTIER, T. "Victor Giraud”, Journal Officiel de la Republique Française, 27 de febrero de 1871, p. 124.

GONZÁLEZ BRABO, L. “Crónica artística y literaria. Exposición de objetos artísticos verificada en los salines del Liceo", Liceo artístico y literario, I, pp. 94-98

GONZALO MORÓN, F. (1840) "Función fúnebre dada por el Liceo valenciano en la noche del 4 actual en memoria del malogrado joven pintor D. Antonio Cavana”, en Diario Mercantil de Valencia, 8 de julio de 1840, pp. 1-2

GRANDA, J. de, "Bailes", El Clamor público, 20 de enero de 1860, p. 4. 
J.L. "Esposicion de Bellas Artes en la Real Academia de San Fernando", La Ilustración, 11 de octubre de 1851, p. 7

JELOT, E. "Chez les artistes", Le XIX ${ }^{e}$ siècle, 11 de abril de 1902, p. 1.

H. de V., C. (1832) “Paul Delaroche”, L'Artiste, vol. 4, pp. 301-302

HOLL, J.C. "Troisième exposisition de l'Association des Artistes Espagnols", Signification de l'art, pp. 52-56

IBÁÑEZ MARTÍN, J. “El escultor Benlliure”, La Ilustración española y americana, 22 de diciembre de 1891, p. 402.

L.A. "Barcelona artística", La Dinastía, 16 de noviembre de 1887, p. 1

"Barcelona artística. El centro de acuarelistas", La Dinastía, 29 de junio de 1887, p. 2

—_Barcelona artística. La primera conferencia del Círculo Artístico", La Dinastía, 18 de febrero de 1888 , p. 1

__ "Exposición de acuarelas", La Época, 20 de octubre de 1881, p. 2.

__Los pensionados por la diputación”, El Solfeo, 12 de diciembre de 1877, p. 2

"La exposición de blanco y negro en el Círculo de Bellas Artes. II", La Época, 7 de febrero de 1890, p. 2

—_La exposición del Círculo Artístico", La Dinastía, 10 de abril de 1888, p. 1

“La exposición de la Sociedad de Acuarelistas”, La Época, 18 de mayo de 1882, p. 3.

L. y A., J., "En el Círculo de Bellas Artes”, El País, 7 de enero de 1894, p. 2

L.R., "Liceo Artístico y Literario", El Cisne, 17 de junio de 1838, p. 36

L.Z., "La Exposición Jiménez Aranda", La Correspondencia de España, 08/06/1903, p. 3

La Redacción, "Liceo Artístico y Literario", El Cisne, 24 de junio de 1838, p. 48

LAVERNIA, "Visita al Círculo de Bellas Artes", Diario oficial de avisos de Madrid, 6 de enero de 1894 , p. 3

LEPORELLO, "Revista de Madrid”, La Ilustración, 3 de julio de 1854, p. 4

M., "La esposición de 1845", en El Español, 7 de octubre de 1845, pp. 1-3

M. (Sin título), El Paraíso, 4 de noviembre de 1838, pp. 57-58.

M.A. "Velada y exposición. Círculo de Bellas Artes", El Imparcial, 25 de octubre de 1892, p. 2

M. de A. (1889), "La exposición del Círculo de Bellas Artes. Segundo y último artículo", El Imparcial, 12 de junio de 1889, p. 5.

M., P. (1890) “En el Círculo de Bellas Artes”, El País, 28 de diciembre de 1890, p. 1.

M.V. (1839) "Exposición pública de pinturas del Liceo Valenciano", en Diario Mercantil de Valencia, 29 de noviembre de 1839, pp. 1-2.

MACÍAS COQUE (1882), "Una visita de confianza”, Suplemento Literario de El Día, 20 de marzo de 1882, s.p. 
MADRAZO, F.“Comunicado”, El Heraldo, 19 de julio de 1848, p. 4

“Don Juan Antonio Ribera", El Artista, vol. III, p. 25

MARTÍNEZ VILLERGAS, J. "Esposición de pinturas. Cuadro de pandilla", suplemento de $E l$ Espectador, 27 de septiembre de 1846, p. 1

MÉLIDA, J.R. (1897), “Don Ceferino Araujo Sánchez”, La España Moderna, diciembre de 1897, p. 130.

MENDOZA, A. "Remitido", Revista Andaluza y periódico del Liceo de Sevilla, t. II. 1841, pp. $180-181$

MESONERO ROMANOS, M. "El Círculo de Bellas Artes", El Globo, 26 de mayo de 1898, p. 1.

MILANÉS, J.S. (1857) “Don Juan Antonio Ribera. Pintor de historia, contemporáneo”, El Museo Universal, 28 de febrero de 1857, p. 30

MISS-TERIOSA, "Exposición de bellas artes III”, El Globo, 22 de mayo de 1898, p. 2

MONTEJO Y ROBLEDO, “Orden disponiendo que los expositores que merecen recompensa y no han sido incluidos en la propuesta (...) sean propuestos para la cruz sencilla de María Victoria", Gaceta de Madrid, 29 de noviembre de 1871, p. 701

MORA, J. de D. (1860), "Esposicion de Bellas Artes (V)”, La Discusión, 8 de noviembre de 1860 , p. 3

MORIN, L. "Daniel Vierge", L'artiste, febrero de 1894, p. 96

MOUREY, G. “Daniel Vierge", L'art et les artistes, octubre de 1911, p. 161

N., "Excmo. Sr. D. Valentín Carderera", La Ilustración española y americana, 30 de mayo de 1880, p. 350

N., "Exposición de impresiones de viaje", La Época, 31 de diciembre de 1893, p. 3

NOMBELA, J. (1871) "Eduardo Zamacois", La Ilustración española y americana, 25 de enero de 1871 , p. 56

OCHOA, E. de, (1836a) “D. José Álvarez”, El Artista, vol. I, p. 122

__ (1867) “El gobierno y las bellas artes”, La España, 13 de marzo de 1867, pp. 3 y 4

_ (1836c) “Los pensionados en Roma”, El Artista, vol. I, pp. 181-183

—— (1836b), "Velázquez”, El Artista, vol. I, pp. 6 y 7.

PALACIO, M. del (1890), “Al Círculo de Bellas Artes”, Revista de España, diciembre de 1890, p. 114.

"Eduardo Zamacois (apuntes biográficos)", La Ilustración de Madrid, 30 de enero de 1871 , p. 30

PALET Y VILLAVA, J. “Bellas Artes. Exposición de 1860”, La Iberia, 02/11/1860, p. 3

"Bellas Artes. Esposición de 1860. Artículo tercero y último", La Iberia, 2 de noviembre de 1860 , p. 3 . 
PARADA Y SANTÍN, J. "Don Luis de Madrazo. Impresiones", La Ilustración española y americana, 8 de marzo de 1897, pp. 147-148

PARDO BAZÁN, E. "La vida contemporánea. Impresiones de Arte", La ilustración artística, 13 de junio de 1898 , p. 378

PASQUINO, "Nuestros artistas en Roma", El Día, 6 de diciembre de 1882, p. 1

PÉREZ NIEVA, A. "Cuarta exposición bienal del Círculo de Bellas Artes. Sala Araujo”, La Dinastía, 30 de junio de 1894, p. 1.

“Desde Madrid. Nuestro Salón”, La Dinastía, 21 de junio de 1889, p. 1.

—_ "Quinta exposición bienal del Círculo de Bellas Artes. Los cuadros al óleo", La Dinastía, 26 de mayo de 1896, p. 1

"Sexta exposición bienal del Círculo de Bellas Artes (III)", La Dinastía, 2 de junio de 1898, p. 2.

PICÓN, J.O. "Exposición del Círculo de Bellas Artes”, El Imparcial, 23 de diciembre de 1890, p. 1.

“Exposición del Círculo de Bellas Artes II”, El Imparcial, 15 de mayo de 1891, p. 1

PICTOR, “Georges Vibert”, Revue Illustrée, 15 de junio de 1894, p. 128

PLANCHE, G. (1832) “École de Rome. Première partie”, L'Artiste, vol. 4, p. 61

PLANCHE, G. (1832) “La quatrième classe de l'Institut”, L'Artiste, vol. 4, p. 117

POMPEY, F. "La Academia de Bellas Artes en Roma. La inmoralidad del reglamento por el que se rigen los pensionados en Roma", El Parlamentario, 2 de septiembre de 1917

PUIGGARÍ, J. (1870) “Exposición de bellas artes en Barcelona”, en La Ilustración española y americana, 13 de julio de 1870, p. 222

R. "Sobre la Real Orden de 24 de mayo último", El Renacimiento, 13 de junio de 1847, pp. 107-109, 20 de junio de 1847, pp. 115-116 y 27 de junio de 1847, pp. 123-125

RIBALTA, A. "La exposición del Círculo de Bellas Artes. Artículo primero", Revista contemporánea, abril de 1894, pp. 395-399.

"La exposición del Círculo de Bellas Artes. Artículo cuarto y último", Revista contemporánea, julio 1894, pp. 179-189.

RIBEYRE, F. (1883), "Cham, sa vie, son oeuvre. Chapitre II: un aspirant à caricaturiste”, Le Figaro, 27 de junio de 1883, p. 3

RICO, M. (1890) “Daniel Urrabieta Vierge”, La ilustración española y americana, 8 de junio de 1890 , p. 355.

RIVERA, L. "Sociedad protectora de las Bellas Artes", La Discusión, 14 de enero de 1859, p. 4

ROCA ROCA, J. (1881) “José Anselmo Clavé”, Boletín del Ateneo Barcelonés, nº 9 (julioseptiembre 1881), p. 46

RODA, N. de. "No leo", La Alhambra, 28 de noviembre de 1841, p. 58. 
ROMERO, M. del, "Esposición pública de pinturas en la Academia Nacional de San Fernando", La Ibera musical y Literaria, 30 de octubre de 1842

ROMILLY, P. y G. "Chez les artistes. Un peintre espagnol: Manuel G. Méndez”, Revue des arts et de la vie, noviembre de 1904, pp. 8-14.

ROVIRA, P. "En el Palacio de Cristal”, La Correspondencia de España, 29 de mayo de 1896, p. 1.

RUIZ ZORRILLA, M. “Ministerio de Fomento. Exposición”, Gaceta de Madrid, 12 de julio de 1871, p. 133

S.N., R. (1868) “D. Antonio María Esquivel”, n 7, p. 40

SAINT-AUBIN, “¿Qué sucede?”, Heraldo de Madrid, 8 de septiembre de 1900, p. 1

SAINT-C. (1832) "De la position sociale des artistes", L'Artiste, vol. 4, p. 51

SALAZAR, J.B. "El ejercicio hace maestro", La Alhambra, 1 de agosto de 1841, p. 369.

SÁNCHEZ JIMÉNEZ, E. (1890) "Exposición de acuarelas y pasteles en el Círculo de Bellas Artes”, La Iberia, 24 de diciembre de 1890, p. 2.

SÁNCHEZ RAMOS, M. "Sociedad protectora de bellas artes”, El Clamor público, 7 de noviembre de 1856, p. 3.

SEPÚLVEDA, E. “La Exposición del Círculo de Bellas Artes”, El Día, 13 de mayo de 1894, pp. $1-2$

SERRET, N. (1874) "Exposiciones en el Ateneo de Valencia. Segunda exposición”, en Boletínrevista del Ateneo de Valencia, p. 238.

(1874b), "Exposición de bellas artes en el Ateneo. Pintura", en Boletín-revista del Ateneo de Valencia, p. 332.

SCHOELCHER, V. (1831) "MM. Delaroche, Scheffer, Grenier, Robert, Isabey, Gudin, Camille Roqueplan, Schnetz, Granet, Forbin”, L'Artiste, vol. 1, p. 281

SORIANO, R. “Exposición del Círculo”, La Época, 23 de mayo de 1898, p. 1.

“La Exposición del Círculo de Bellas Artes”, La Época, 19 de mayo de 1898, p. 2

TIÉPOLO (1893) “Círculo de Bellas Artes. Exposición de impresiones de viaje”, La Justicia, 26 de diciembre de 1893, p. 2

TUBINO, J.M. (1866), "Bartolomé Esteban Murillo. II", Revista de Bellas Artes, 27 de octubre de 1866

"La reforma artística", Revista de España, marzo de 1873

U. y R., L. (1836) “Don José Rivelles y Helip”, El Artista, vol. III, p. 38

UN ESPAÑOL EN ROMA, "Inauguración de la Academia Española en Roma (conclusión)", La Ilustración Española y Americana, 15 de febrero de 1881, pp. 95-98

VALENTINO, “Artistas valencianos. Un pintor, un escultor y un arquitecto", Revista de Valencia, 1 de noviembre de 1880, p. 28. 
VAN-HALEN, F. "Sres. Redactores de El Correo Nacional", El Correo Nacional, 2 de junio de 1842, p. 4

VELAZ DE MEDRANO, E., "Exposición de bellas artes en la Academia de San Fernando (artículo II)", La España, 13 de octubre de 1848a, p. 4

-b "Exposición de bellas artes en la Academia de San Fernando (artículo III)", en La España, 14 de octubre de 1848b, p. 3

c "Exposición del Liceo. Artículo I", La España, 4 de julio de 1848c, p. 4.

d "Exposición del Liceo. Artículo II", La España, 4 de julio de 1848, p. 4

1846a_——Exposición del Liceo", El Español, 19 de julio de 1846, p. 3

1846b_ “Exposición del Liceo. Tercero y último artículo", El Español, 24 de julio de 1846, p. 3

“Revista de Nobles Artes", El Español, 11 de junio de 1847, p. 3

VILLALBA, J., El Correo Nacional, 16 de diciembre de 1840, p. 4.

VILLANUEVA, L. "Don Antonio María Esquivel”, Museo de las Familias, 25 de abril de 1844, p. 92

WOLFF, A. "Courier de Paris", Le Figaro, 13 de junio de 1880, p. 1

YXART, J. (1891), "La exposición general de Bellas Artes", La ilustración artística, 4 de mayo de 1891 , p. 274 